\title{
The Lino Site: A Stratified Late Archaic Campsite in a Terrace of the San Idelfonzo Creek, Webb County, Southern Texas
}

\author{
J. Michael Quigg \\ Chris Lintz \\ Texas State University \\ Grant Smith \\ Scott Wilcox
}

Follow this and additional works at: https://scholarworks.sfasu.edu/ita

Part of the American Material Culture Commons, Archaeological Anthropology Commons, Environmental Studies Commons, Other American Studies Commons, Other Arts and Humanities Commons, Other History of Art, Architecture, and Archaeology Commons, and the United States History Commons

Tell us how this article helped you.

This Article is brought to you for free and open access by the Center for Regional Heritage Research at SFA ScholarWorks. It has been accepted for inclusion in Index of Texas Archaeology: Open Access Gray Literature from the Lone Star State by an authorized editor of SFA ScholarWorks. For more information, please contact cdsscholarworks@sfasu.edu. 


\section{The Lino Site: A Stratified Late Archaic Campsite in a Terrace of the San Idelfonzo Creek, Webb County, Southern Texas}

\section{Licensing Statement}

This is a work produced for the Texas Department of Transportation (TxDOT) by the report producer. TxDOT and the report producer jointly own all rights, title, and interest in and to all intellectual property developed under TXDOT's contract with the report producer. The report may be cited and brief passages from this publication may be reproduced without permission provided that credit is given to both TXDOT and the report producer. Permission to reprint an entire chapter, section, figures or tables must be obtained in advance from either the Supervisor of the Archeological Studies Branch, Environmental Affairs Division, Texas Department of Transportation, 125 East 11th Street, Austin, Texas, 78701 or from the report producer. 


\section{TRC}

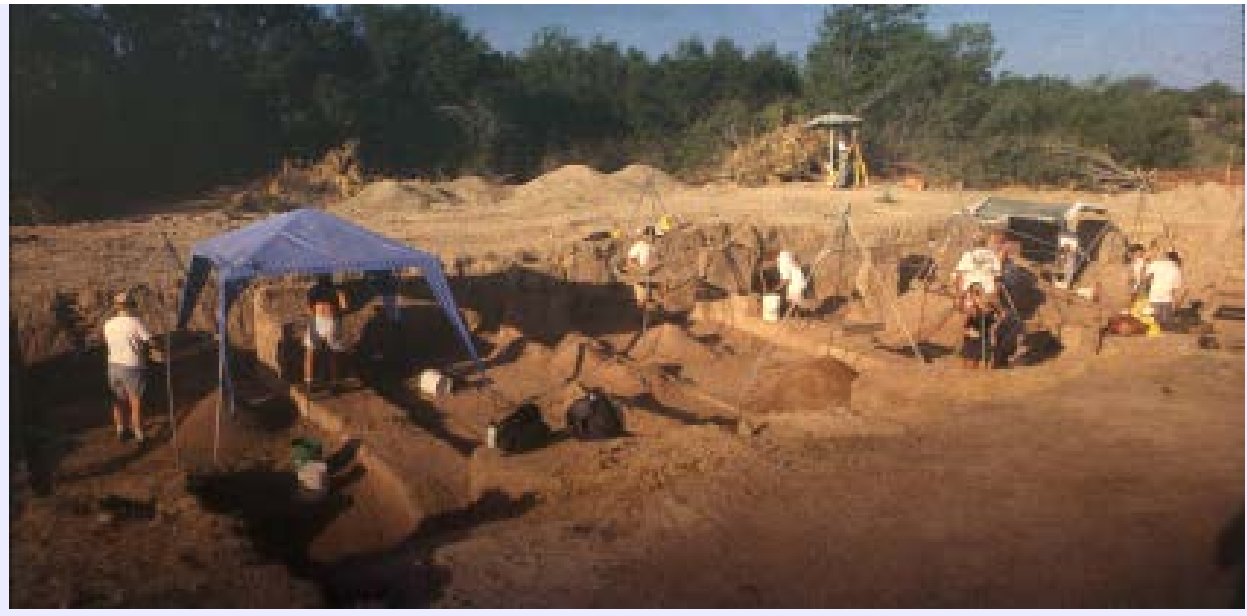

\section{The Lino Site:}

A Stratified Late Archaic Campsite in a Terrace of the San Idelfonzo Creek, Webb County, Southern Texas

by J. Michael Quigg

with contributions from

Chris Lintz, Grant Smith, and Scott Wilcox

Technical Report No. 23756

TRC Mariah Associates Inc.

Austin, Texas

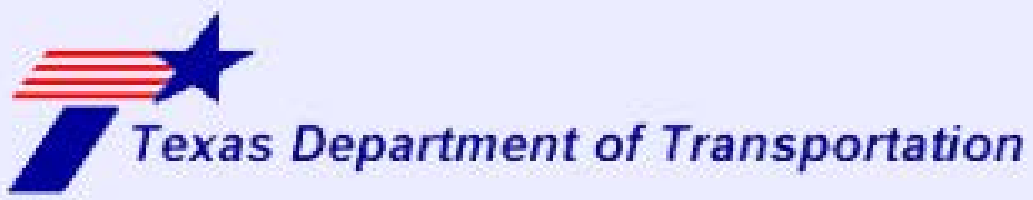

Environmental Affairs Division

Archeological Studies Program, Report No.20

Principal Investigator

Chris Lintz, Ph.D.

Texas Antiquities Permit No. 1996

February 2000 


\author{
The Lino Site: \\ A Stratified Late Archaic Campsite in a Terrace \\ of the San Idelfonzo Creek, Webb County, Southern Texas \\ by J. Michael Quigg \\ with contributions from \\ Chris Lintz, Grant Smith, and Scott Wilcox
}

Technical Report No. 23756

TRC Mariah Associates Inc.

Austin, Texas

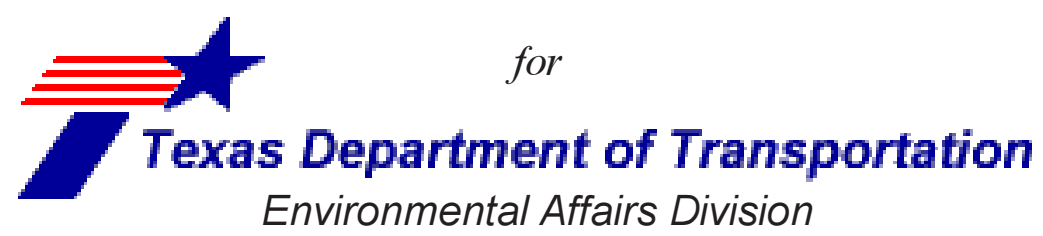

Archeological Studies Program, Report No. 20

\author{
Principal Investigator \\ Chris Lintz, Ph.D.
}

Texas Antiquities Permit No. 1996

February 2000 


\section{EXECUTIVE SUMMARY}

Archeologists from TRC Mariah Associates Inc. of Austin conducted mitigation excavations at the Lino site (41WB437) during a six-week period in April and May 1998 under contract with the Texas Department of Transportation, Environmental Affairs Division. The prehistoric archeological site was within the right-of-way of the planned expansion of Highway 83, south of Laredo. A single $196 \mathrm{~m}^{2}$ block measuring 7 $\mathrm{m}$ north-south by $28 \mathrm{~m}$ east-west was investigated following requirements of a contract that stipulated a three-pronged approach to data recovery. First, a Gradall ${ }^{\mathrm{TM}}$ was employed to carefully strip 2 to $4 \mathrm{~cm}$ thick layers in eight 3 $\mathrm{m}$ wide areas within the block. Balks measuring $80 \mathrm{~cm}$ wide by $120 \mathrm{~cm}$ tall were left standing between each $3 \mathrm{~m}$ wide Gradall ${ }^{\mathrm{TM}}$-stripped area. The material discovered in situ during the Gradall ${ }^{\mathrm{TM}}$ stripping was plotted using a total data station. When clusters of cultural materials were encountered during the GradallTM stripping, these were designated as features, and a series of manual excavations in 1 by $1 \mathrm{~m}$ units were dug around each feature. The matrix surrounding these features was screened and in situ data recorded with the total data station. Feature matrix was collected and floated in the laboratory. A total of $124 \mathrm{~m}^{2}$ were hand excavated around 24 recognized features discovered during Gradall ${ }^{\mathrm{TM}}$ stripping. Upon reaching the target depth of $120 \mathrm{~cm}$ below the surface, the Gradall ${ }^{\mathrm{TM}}$ stripping ceased, having mechanically removed $187 \mathrm{~m}^{3}$ of deposits.

The second field approach was the hand excavation and screening of matrix from the 80 $\mathrm{cm}$ wide by $7 \mathrm{~m}$ long standing balks. The total data station was used to plot most in situ material greater than $5 \mathrm{~cm}$ in diameter from the $48 \mathrm{~m}^{3}$ hand-excavated balks. In conjunction with the hand excavations of the linear balks, the third field approach involved the collection of 348 four-liter flotation samples from 29 vertical columns systematically spaced every $2 \mathrm{~m}$ across the excavation balks. These float samples were collected from the northwest corner of every other hand excavation unit. Flotation results from eight analyzed columns of samples were the basis for assessing the recovery rate from hand excavated units immediately adjacent to the selected columns.

The $235 \mathrm{~m}^{3}$ block investigation yielded quantities of cultural materials relatively well stratified throughout the $120+\mathrm{cm}$ deposits. At least five and possibly six cultural occupation zones were more or less horizontally distributed across the excavation block. Based on three wood charcoal dates from the testing phase and nine radiometric dates from the mitigation phase, all occupations occurred during a 1,400-year period between ca. 2000 and 3400 B.P. The occupations yielded quantities of scattered burned sandstone, 22 burned rock dumps, three burned rock-filled pits, one charcoal stained hearth, two mussel shell concentrations, and one mano cluster. Also recovered were quantities of lithic debitage, a few mussel shells, and sparse formal stone tools including fewer than a dozen ground stone implements. Virtually no bone or burned subsistence remains, and relatively few Rabdotus shells were recovered. Chipped stone tools included 24 whole and fragmented projectile points, 46 bifaces, 18 scrapers, two drills, three hammerstones, and at least 202 edgemodified flakes. The ground stone tools included five manos and eight abraders. One mussel shell pendant with a single drilled hole and notched edges was also recovered. The occupation zones yielded sparse diagnostics in the form of 11 Tortugas projectile points, one Matamoros point, and five Refugio points. Occupations 2 and 6 did not yield diagnostic projectiles, and the latter may not represent a 
discrete occupation. Occupation 5 was related to the Refugio points and dated to about 3200 B.P. Occupations 1, 3, and 4 were related to the Tortugas and Matamoros points and dated to between 2000 and 3000 B.P.

Thirty-six features ( 8 through 43) were recognized during the mitigation investigations. These included 22 burned rock clusters, three rock filled basins, three occupation lenses, two fresh water mussel shell clusters, one flake concentration, one mano cluster, one charcoal stained basin hearth, and at least one burned root.
The burned rock clusters dominate the features (67 percent) and contained from four to 80 burned sandstone rocks. These loosely clustered but unpatterned rocks were associated with sparse wood charcoal chunks and mostly sparse chert debitage. All four basin features yielded quantities of charcoal, and three of these were deeper basins filled with burned rocks. Formal stone tools were rarely found immediately adjacent to the burned rock pit features. The mitigation results contribute significant information about the nature and diversity of Late Archaic adaptations in extreme south Texas. 


\section{ACKNOWLEDGEMENTS}

The 1998 data recovery investigations at the Lino site by staff from TRC Mariah Associates Inc. of Austin and sponsored by the Texas Department of Transportation, Environmental Affairs Division, were facilitated by the hard work and various contributions of many individuals, organizations, and companies. Briefly, I want to thank all those who contributed to help preserve a small part of Texas prehistory through this investigation, even though their collective contributions appeared to be disjointed.

I thank the Texas Department of Transportation personnel in the Environmental Affairs Division, especially Dr. Nancy Kenmotsu, Dr. Jim Abbott, and $\mathrm{Al} \mathrm{McGraw,} \mathrm{who} \mathrm{worked} \mathrm{closely} \mathrm{with} \mathrm{TRC}$ personnel to facilitate the completion of the field investigations on time and provided directions to the analysis and reporting of the recovered data. Members of the Environmental Affairs Division conducted a number of field visits to lay out the excavation block, clear trees and brush from the block, excavate backhoe trenches and Ditch Witch ${ }^{\mathrm{TM}}$ trenches, and put up safety fences. Other Texas Department of Transportation personnel at the Laredo District Office are also thanked, especially Melissa Montemayor (Laredo District environmental specialist), who made a number of trips to the site and facilitated the local arrangements. Jose Delapaza and Simon Aguirre (Laredo District maintenance) helped in digging the Ditch Witch $^{\mathrm{TM}}$ trenches, fencing, and other tasks.

I want to recognize and thank Mr. Lino Lara of Zumwalt Construction in San Antonio for his precise Gradallтм work. Not only did he demonstrate considerable expertise with the machine, he continuously helped out with the actual hand excavating and screening during down time for the Gradallтм. His friendly and positive attitude helped to accomplish the work on time and in a professional manner.

The Texas Historical Commission staff members are thanked, especially Myles Miller for his comments into the planning and oversight of the project. Bill Martin made a brief visit to the site during the period of the hand excavations.

The field crew persevered through one of the hottest field periods on record. Despite windy conditions and an atmosphere filled with smoke from the Central American fires, they were able to complete the excavations on time and in a professional manner. Scott Wilcox provided his expertise with the total data station equipment and was responsible for all the recordings and the instrument care. He was assisted by Mindy Bonine, who was the rod person and in charge of the various computer aspects, including nightly checks of the collected total data station data, entry corrections, and downloading the data.

Shane Pritchard preformed admirably throughout the 30 days and was a terrific worker. Other dedicated crew members consisted of Greg Sullivan, Bradford Heasley, Dennis Glinn, Tiffany Terneny, Don Badon, Frank Mitchell, Alan O'Farrell, Margaret Enrile, Stephanie Lopez, Craig Weaver, Billy Turner, Matt Twomey, Jennifer Giesecke, Ernest Wingate, Dawn Ramsey, and Gregg Harmon. All are thanked for their hard work under difficult working conditions and tight time restraints.

Grant Smith spent two days on site and conducted the geomorphic field documentation of the exposed sediments. He also wrote the section on the site geomorphology. Paul Lehman performed the matrix analyses derived from soil 
columns, provided general observations of the analytical results, and performed the removal of calcium carbonates from the burned rock matrix samples prior to isotope analyses. Thank you, gentlemen, for your varied expertise.

In the Austin laboratory, Don Badon spent two months floating the 360 column and feature samples, and he completed the extensive burned rock analyses. Shane Pritchard washed and catalogued the artifacts, conducted the lithic debitage and stone tool analyses, picked and sorted float sample results, did most of the data entry, conducted considerable quality control and assurance tasks, performed the computer mapping of the features and most line drawings for the report, and completed most of the sorting and packaging artifacts for curation. Scott Wilcox wrote the method section on the use of the total data station and the specific record procedures that were used in the field during raw data collection. Carol Hepp Mills drew all the artifact illustrations. Bill Hudspeth created the initial draft of the site map, which was later finalized by Shane Pritchard. Marybeth Tomka oversaw all the laboratory and curation procedures, created the many tables using Microsoft Excel ${ }^{\circledR}$, continually provided constructive comments and direction on the database, provided detail and insights concerning the use of the total data station data, finalized the material for curation, and prepared the database for use in the creation of the CDROM, including the Readme file for the disk.
I would also like to acknowledge and thank the various individuals, laboratories, and organizations that contributed their professional expertise in conducting the numerous outside technical data analyses. These people provided their scientific knowledge and interpretations of the various data sets in attempts to gain more understanding from the fragments of the past. Their individual contributions are presented as separate appendices in the back of this report.

Management oversight was conducted by Dr. Jim States, who also helped considerably in structuring the cost parameters for this project, participated in the contract discussions with the Texas Department of Transportation, and added significant comments, contributions, and suggestions for the assessment section. Dr. Chris Lintz wrote the research design issues, made numerous constructive comments on analytical direction, performed the major task of editing this document to make it more readable, and provided input and suggestions on the assessment section. Chris also drew the sketch of the individual performing stone boiling with hot rocks. Thank you Jim and Chris. Gabriela Estrada controlled all the administrative paper work including the crew paychecks, forms, expense sheets, and the general accounting flow throughout this project. Sue Carlson admirably completed a draft edit and the final document production, including the integration of all the data tables and figures with the text. I thank all for their contributions to the completion of this investigation. 


\section{Table of Contents}

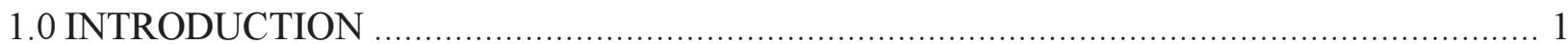

1.1 PROJECT LOCATION AND DEVELOPMENT ….......................................... 1

1.2 PREVIOUS CULTURAL RESOURCE INVESTIGATIONS ................................... 1

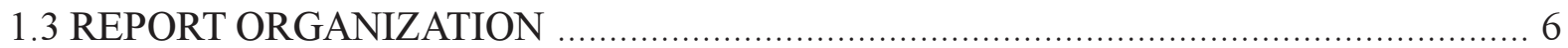

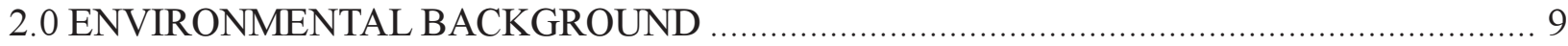

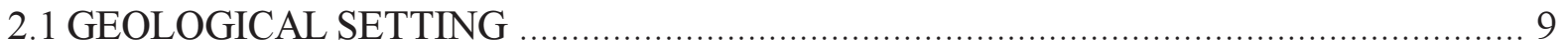

2.2 PHYSIOGRAPHIC AND GEOMORPHIC SETTING …....................................... 9

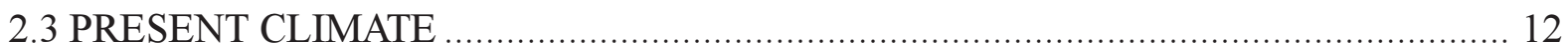

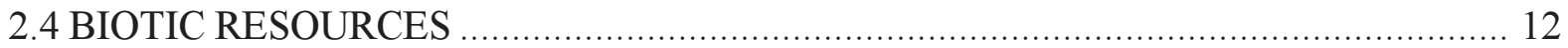

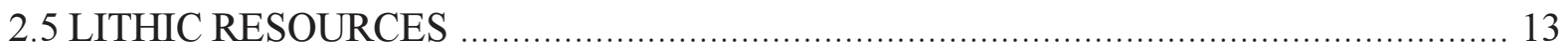

3.0 CULTURAL BACKGROUND AND RESEARCH ISSUES …................................... 15

3.1 ARCHAEOLOGICAL BACKGROUND IN EXTREME SOUTH TEXAS …............ 15

3.2 THE ARCHAIC PERIOD IN SOUTH TEXAS ….................................................. 18

3.3 PALOENVIRONMENTAL RECONSTRUCTION FROM 4500 TO 1500 B.P. ........... 22

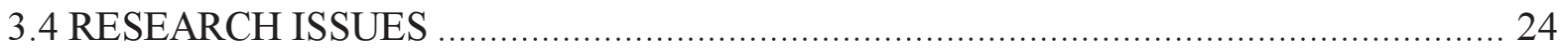

3.4.1 Site Formation Processes Contextual Framework ............................................... 24

3.4.2 Chronology and Cultural Affiliation Contextual Framework .............................. 25

3.4.3. Subsistence Contextual Framework ................................................................ 27

3.4.4 Paleoenvironmental Studies Contextual Framework .......................................... 28

3.4.5 Burned Rock Technology and Data Content Contextual Framework ..................... 29

3.4.6 Site Structure and Organization Contextual Framework .................................... 30

3.4.7 Lithic Resource Procurement and Technology Contextual Framework ................ 32

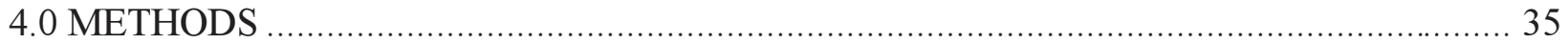

4.1 ARCHAEOLOGICAL FIELD PROCEDURES …................................................ 35

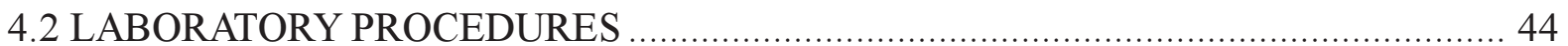

4.2.1 Stone Tool Analyses ...................................................................................... 44

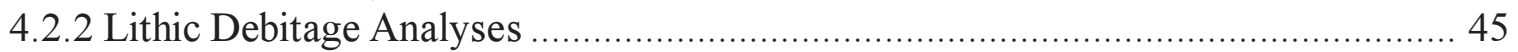

4.2.3 Microwear Analysis .................................................................................... 46

4.2.4 Burned Rock Analyses .............................................................................. 46

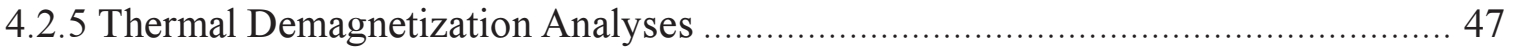

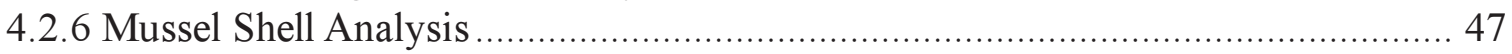

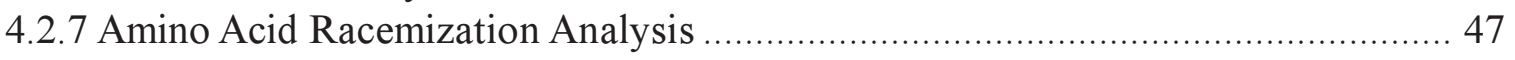

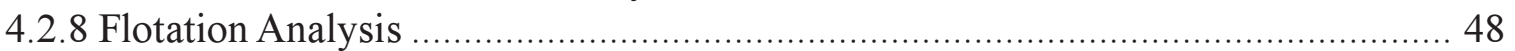

4.2.9 Charcoal Analyses ................................................................................... 48

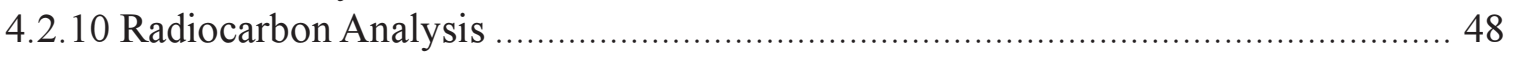

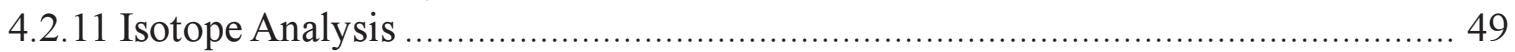

4.2.12 Lipid Residue Analysis ............................................................................. 49

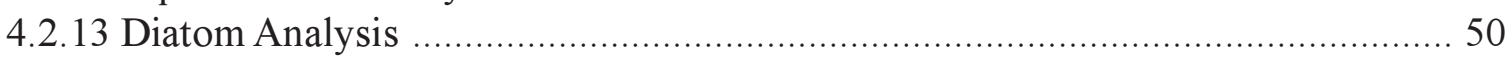

4.2.14 Phytolith Analysis ...................................................................................... 50 
5.0 INTRODUCTION TO LINO SITE 41WB437 _....................................................... 51

5.1 GEOMORPHOLOGY AND GEOARCHAEOLOGY …........................................ 51

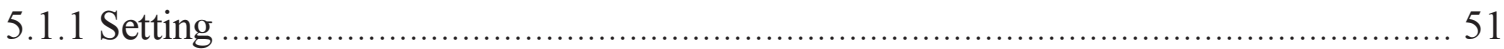

5.1.2 Previous Studies ......................................................................................... 51

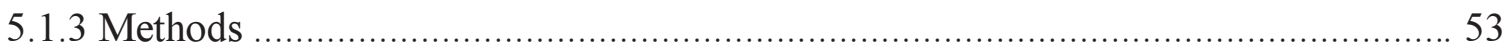

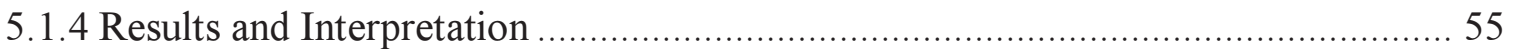

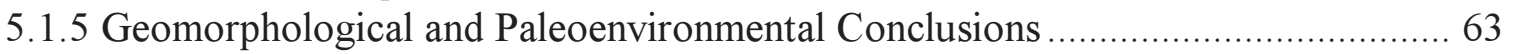

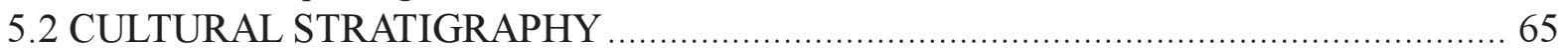

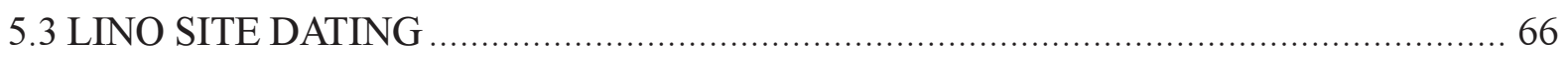

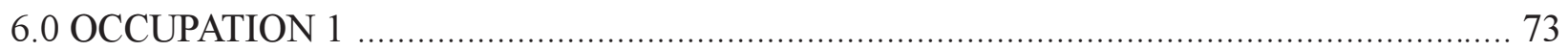

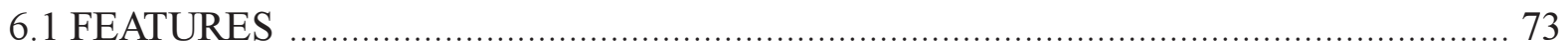

6.2 CHIPPED LITHIC ASSEMBLAGE …............................................................ 93

6.3 CHIPPED STONE TOOLS …......................................................................... 94

6.4 GROUND STONE TOOLS ........................................................................... 100

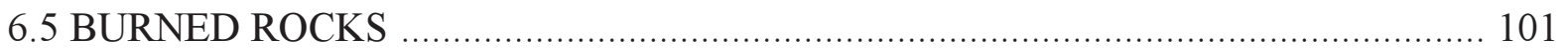

6.6 MUSSEL SHELLS _................................................................................... 103

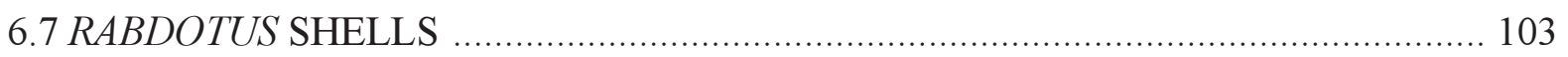

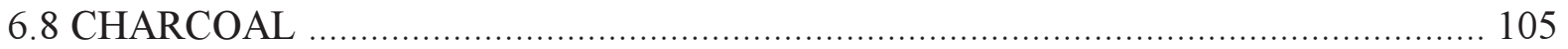

6.9 OTHER MATERIALS ........................................................................................ 105

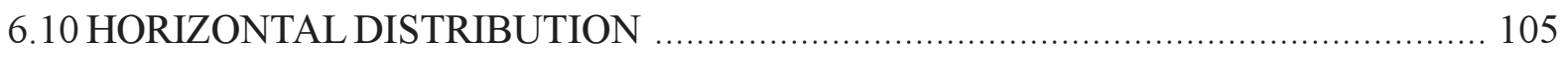

6.11 SUMMARY AND INTERPRETATIONS .......................................................... 109

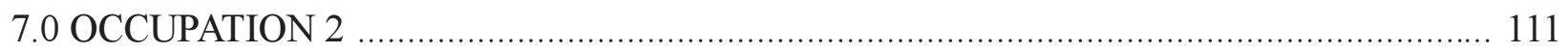

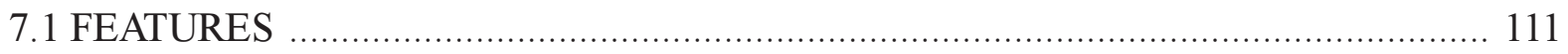

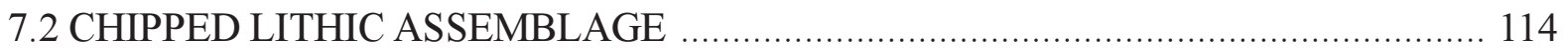

7.3 CHIPPED STONE TOOLS …......................................................................... 116

7.4 BURNED ROCKS _..................................................................................... 119

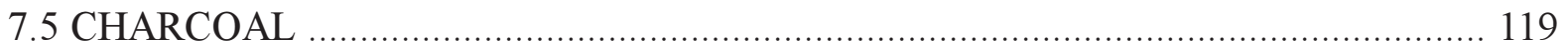

7.6 OTHER MATERIAL ...................................................................................... 119

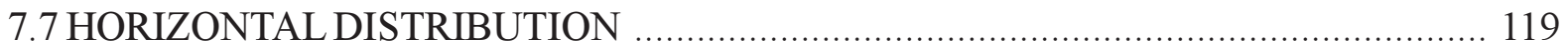

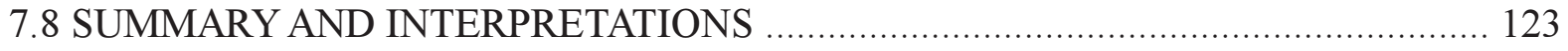

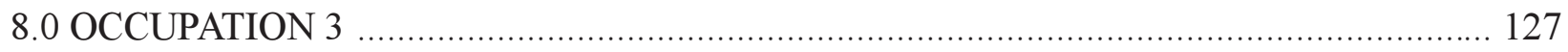

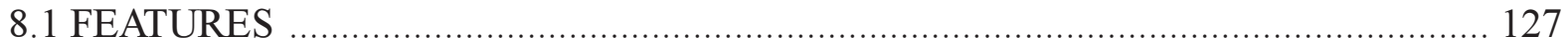

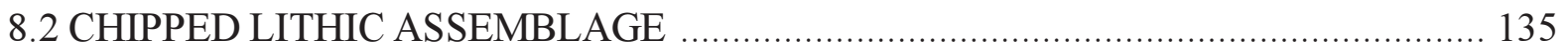

8.3 CHIPPED STONE TOOLS ......................................................................... 136

8.4 GROUND STONE TOOLS …............................................................................ 142

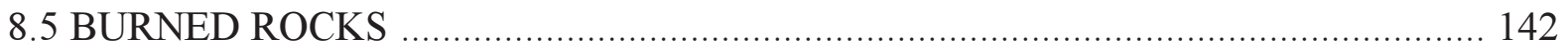

8.6 MUSSEL SHELLS …...................................................................................... 143

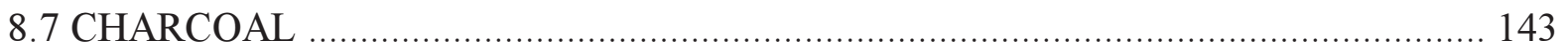

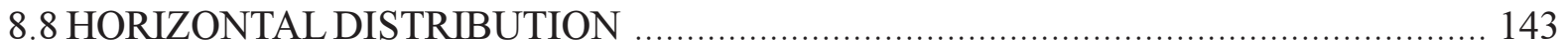

8.9 SUMMARY AND INTERPRETATIONS ...................................................... 148

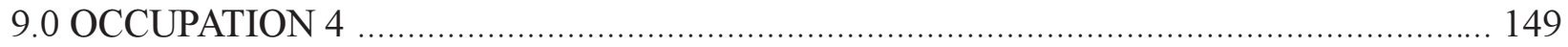


9.1 FEATURES

9.2 CHIPPED LITHIC ASSEMBLAGE

9.3 CHIPPED STONE TOOLS

9.4 GROUND STONE TOOLS

9.5 BURNED ROCKS

9.6 MUSSEL SHELLS 172

9.7 CHARCOAL 172

9.8 HORIZONTAL DISTRIBUTION

9.9 SUMMARY AND CONCLUSIONS

10.0 OCCUPATION 5

10.1 FEATURES

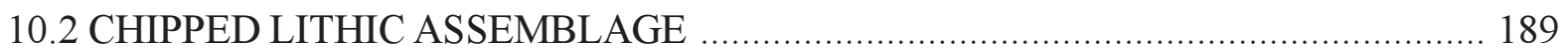

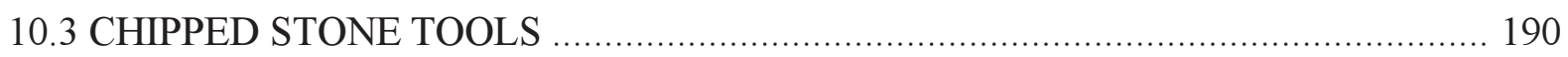

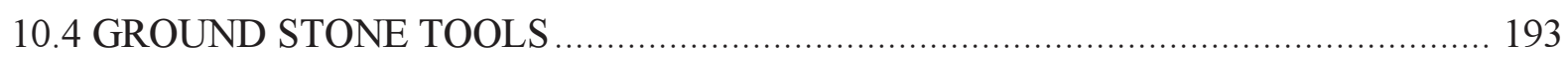

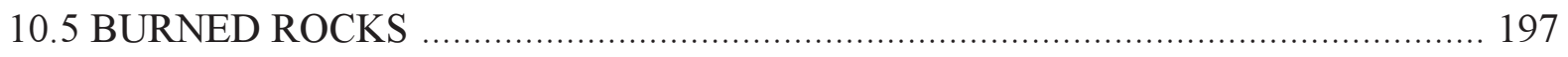

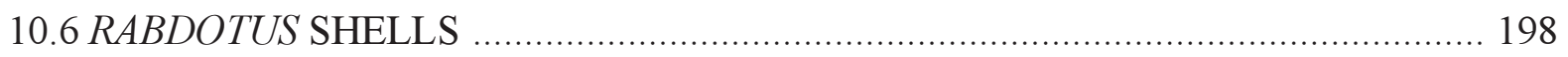

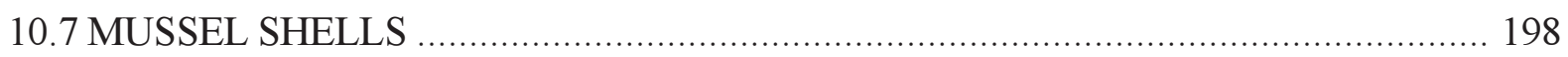

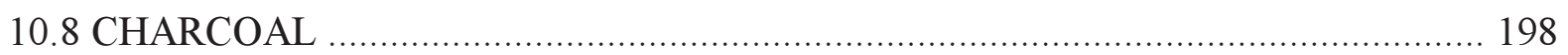

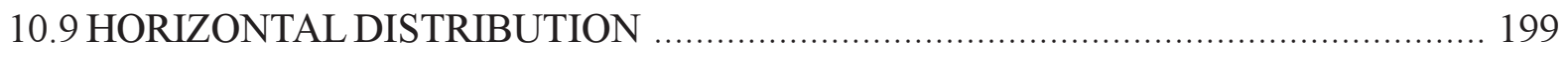

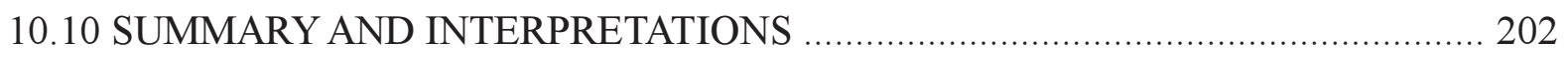

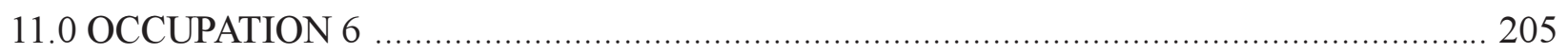

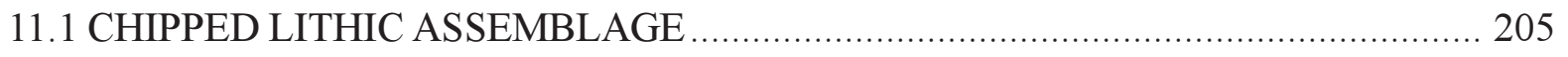

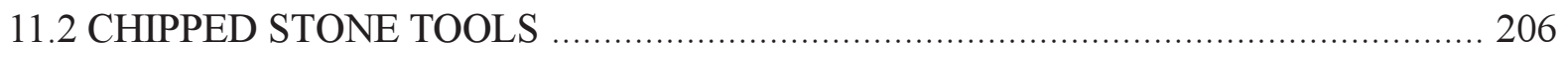

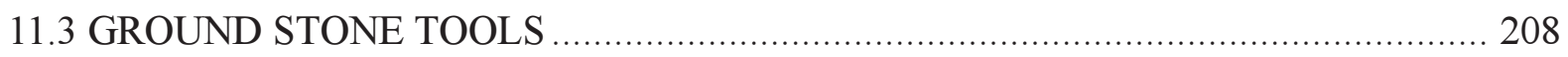

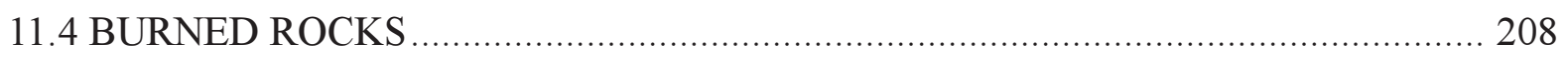

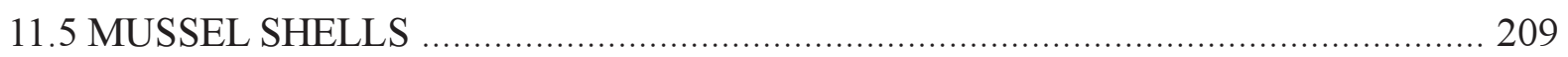

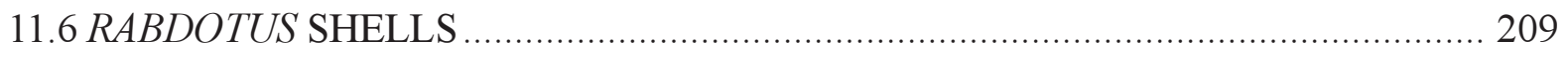

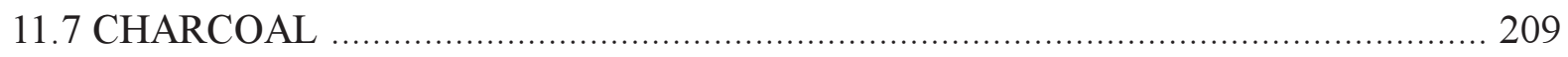

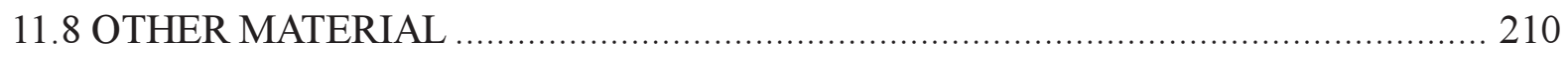

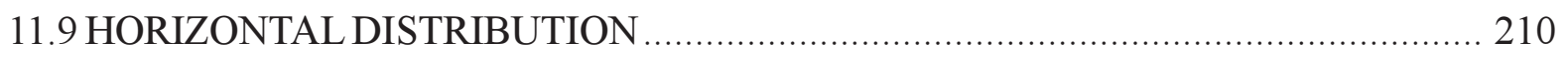

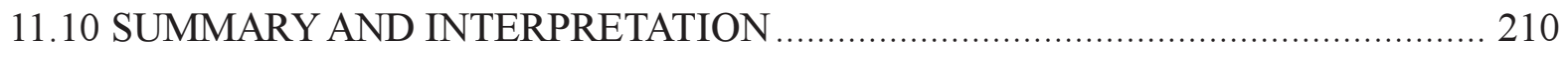

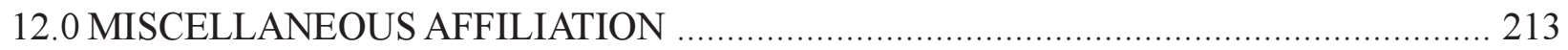

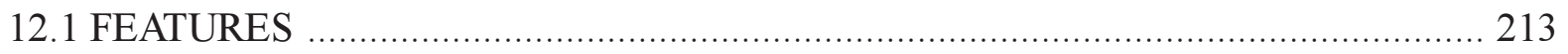

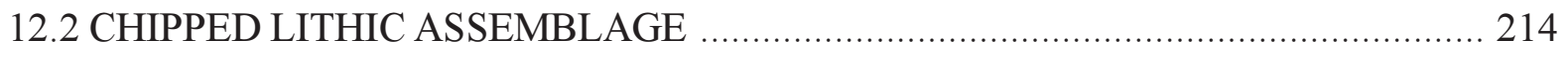

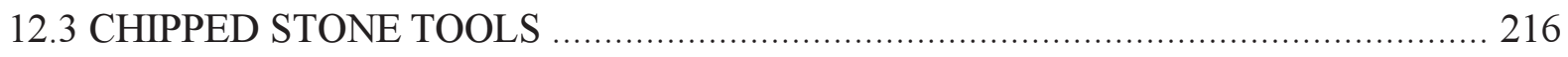

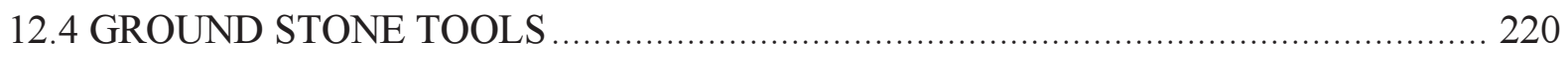

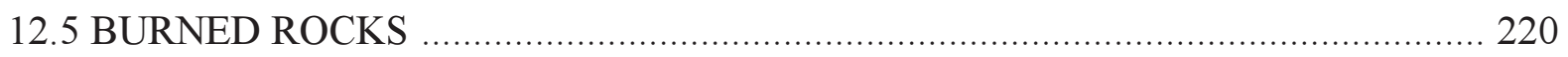

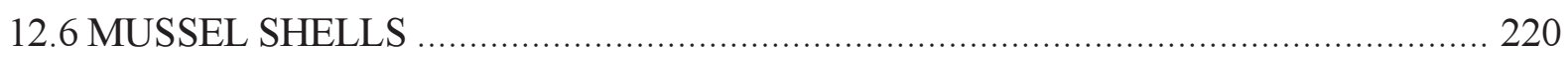

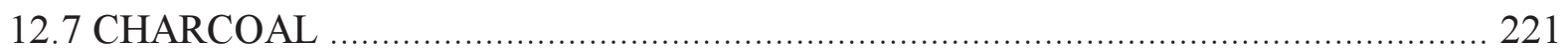

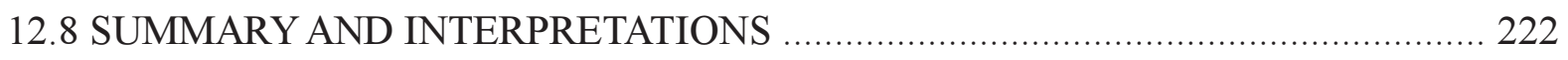

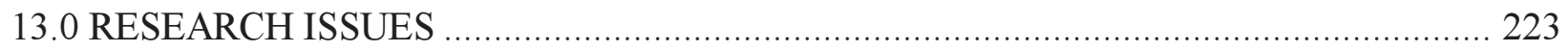




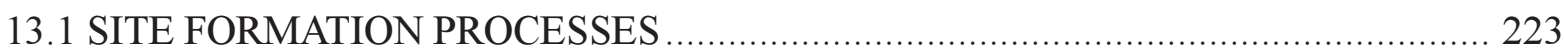

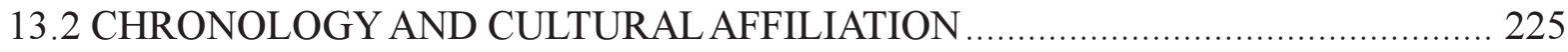

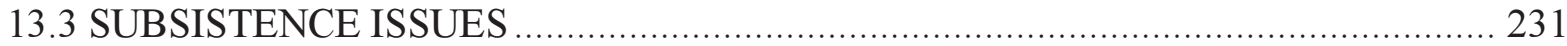

13.3.1 C3 Plants and Herbivores That Primarily Consume C3 Plants ........................ 232

13.3.2 C4 Plants and Herbivores That Primarily Consume C4 Plants ........................ 236

13.3.3 The Lino Site Carbon and Nitrogen Isotope Results ………........................... 238

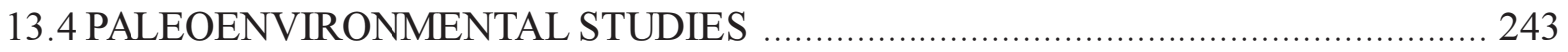

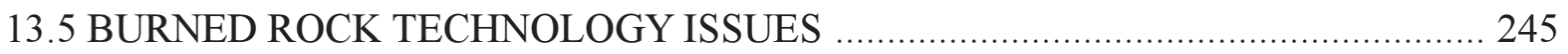

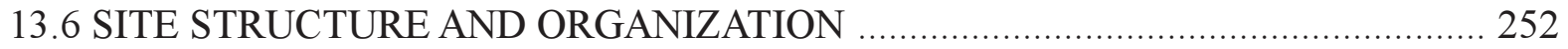

13.7 LITHIC RESOURCE PROCUREMENT AND TECHNOLOGY …....................... 259

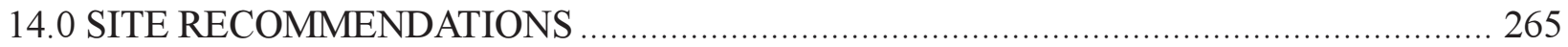

15.0 ASSESSMENT OF FIELD EXCAVATION STRATEGIES AND

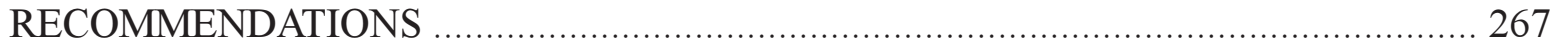

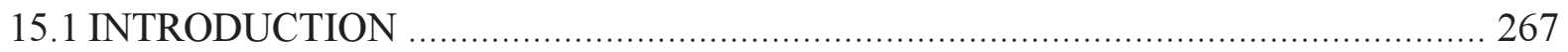

15.2 THE HIGGINS EXPERIMENT EXCAVATION STRATEGIES _............................. 269

15.2.1 Use of the TDS on the Higgins Experiment ………………………............. 270

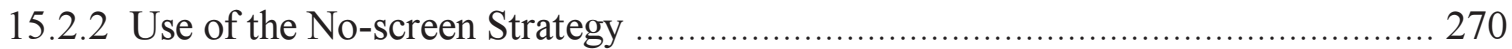

15.2.3 Acknowledged Problems from the Higgins Experiment …………………...... 270

15.3 THE LINO SITE EXCAVATION STRATEGIES …………................................... 271

15.3.1 Testing Phase Assumptions ………………….......................................... 271

15.3.2 Field Methods: Opportunities and Constraints ………………..................... 273

15.4 EVALUATION OF THE SUCCESS OF THE LINO SITE MIXED APPROACHES ...... 284

15.4.1 Was mechanical excavation of large areas cost effective? ............................... 285

15.4.2 How much information was lost using mechanical excavation with a

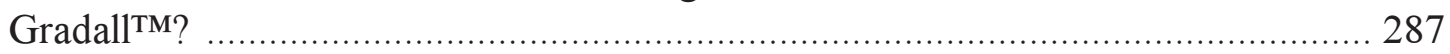

15.4.3 Did the hand excavations of seven narrow balks spaced about $3 \mathrm{~m}$ apart and the 1

$\mathrm{m}$ units around discovered features provide sufficient data to interpret activities and

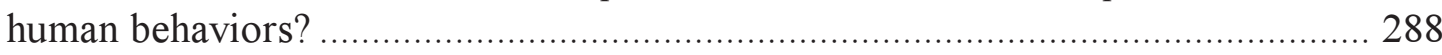

15.4.4 Were the fine screen results from column samples useful for interpreting human

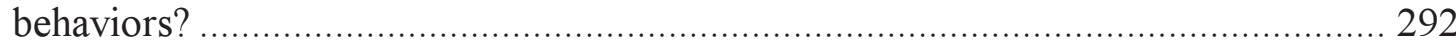

15.4.5 Did the field approach combining traditional and alternative methods affect the ability to address research design issues? ……………...................................... 294

15.4.6 Evaluative Summary of the Lino Site Field Tactics ........................................ 296

15.5 SUGGESTIONS AND RECOMMENDATIONS FOR FUTURE PROJECTS .......... 296

15.5.1 Planning and Remedial Investigations ...................................................... 296

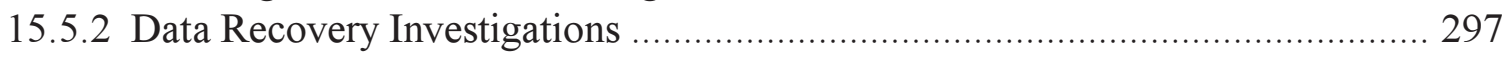

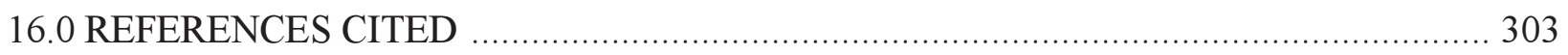

17.0 GLOSSARY ……………… 317

APPENDIX A: Radiocarbon Analyses by Beta Analytic Inc. ............................................. 323 
APPENDIX B: Macrobotanical Analyses by J. Philip Dering 347

APPENDIX C: Use Wear Studies by Caryn M. Berg. 363

APPENDIX D: Carbon and Nitrogen Isotopic Laboratory Results ..... 381

APPENDIX E: Demagnetization Analysis by Wulf A. Gose 387

APPENDIX F: Rabdotus Shell A/I Ratios by Glenn A. Goodfriend 403

APPENDIX G: Lipid Residue Analyses by Mary Malainey . 407

APPENDIX H: Phytolith Analysis by John G. Jones

APPENDIX I: Diatom Assessment by Barbara Winsborough 441

\section{LIST OF FIGURES}

Figure 1.1 Archaeological Site 41WB437 Located South of Laredo, Texas.

Figure 1.2 Archaeological Site 41WB437 Immediately West of U.S. Highway 83 with Private Access Road Cutting Site in Half and Vegetation Bordering San Idelfonzo Creek. ............... 3

Figure 1.3 Exposed Burned Rock Feature 3, $40 \mathrm{Cmbs}$ in Backhoe Trench 2 on South Side of Private Access Road at 41WB437.

Figure 2.1 Geological Map of the Vicinity around 41WB437 (Barnes 1976). 10

Figure 2.2 Topographic Setting around 41WB437.

Figure 2.3 Looking South. Site Vicinity with Low Rolling Hills Dissected by San Idelfonzo Creek in Middle of Picture.

Figure 2.4 Upland Gravels Capping Older Eocene Deposits West of 41WB437.

Figure 2.5 Closeup of Siliceous Cobbles in Upland Gravels, which Reveals Size Variations and Density. 14

Figure 3.1 Generalized Physiographic Regions of Texas. Adapted from Erwin Raisz 1954 .... 16

Figure 3.2 Map of South Texas with Selected Archeological Sites. 16

Figure 4.1 Excavation Localities at the Lino Site (41WB437), 1997 Testing and 1998 Excavation Block. 36 
Figure 4.2 General Layout of $3 \mathrm{~m}$ Wide Gradall ${ }^{\text {TM }}$ Areas (Areas A through $\mathrm{H}$ ) and $80 \mathrm{~cm}$ Wide Hand Excavation Balks (Balks A through $\mathrm{H}$ ), with Backhoe Trenches along West and South Sides.

Figure 4.3 Shane Pritchard Monitoring Gradall ${ }^{\mathrm{TM}}$ Stripping of Thin Layers in Area B 37

Figure 4.4 View West across Excavation Block Following Completion of Gradall ${ }^{\mathrm{TM}}$ Stripping. 38

Figure 4.5 Hand Excavation of Units at a Feature Discovered during Gradall ${ }^{\mathrm{TM}}$ Stripping. ...... 39

Figure 4.6 Hand Excavation of Balks Following Gradall ${ }^{\text {TM }}$ Stripping. View Northwest with H7 in Right Foreground.

Figure 4.7 A Cleaned Part of the East Side of Balk F Showing Natural Stratigraphy of $120 \mathrm{~cm}$ Thick Profile. General Zone Designations Used during Gradall ${ }^{\mathrm{TM}}$ Stripping.

Figure 4.8 Scott Wilcox Using a Sokkia SET5A Total Data Station Surveying Instrument with a Sokkia SDRSS Electronic Field Book to Document Artifact Provenience.

Figure 5.1 Geomorphic Sketch Map of the Vicinity of 41WB437 and 41WB438 Prepared from Aerial Stereopair Photographs.

Figure 5.2 Overall Excavation Block Plan Showing Locations of Seven Documented Geomorphic Profiles (W1, W2, S1, S2, S3, S4, E1).

Figure 5.3 Profile of South Trench Wall at S-2 Showing Sample Column and Intervals Sampled

for Texture Analysis.

Figure 5.4 Profile of South Trench Wall at S4

Figure 5.5 Stratigraphic and Pedologic Relationships on the South Wall of Excavations at Site 41WB437.

Figure 5.6 Organic Matter and Calcium Carbonate Equivalency at Profile S-2. 59

Figure 5.7 Lino Site (41WB437) South Trench without Gravel. 60

Figure 5.8 Profile of West Trench Wall at W-2.

Figure 5.9 Vertical Back Plotted Profiles of $80 \mathrm{~cm}$ Wide Balks A-F through the $7 \mathrm{~m}$ Long Axis.

Figure 5.10 Vertical Back Plotted Profiles of $7 \mathrm{~m}$ Long Balks A-G through the $80 \mathrm{~cm}$

Wide Axis. 
Figure 5.11 Composite through the West Encompassing the Entire $28 \mathrm{~m}$ Long Excavation Block.

Figure 5.12 Composite through the North Encompassing the Entire $28 \mathrm{~m}$ Long Excavation Block.

Figure 6.1 Plan View of Burned Rock-Filled Pit Feature 14 and Profile. 77

Figure 6.2 Profile and South Half of Rock Filled Pit Prior to Excavation. 78

Figure 6.3 Closeup of Charcoal Sticks on Northern Edge of Feature 14. 78

Figure 6.4 Exposed Burned Rocks in South Half of Pit Feature 14. 78

Figure 6.5 Plan View of Feature 36 Mussel Shell Cluster. 81

Figure 6.6 Mussell Shell Cluster in Feature 36, Balk A5. 81

Figure 6.7 Plan View of Feature 41, Balk A7, Mussel Shell Cluster. 81

Figure 6.8 Plan View of Feature 8 Burned Rock Cluster. 82

Figure 6.9 Plan View of Feature 9 Burned Rock Cluster. 83

Figure 6.10 Plan View of Feature 10 Burned Rock Cluster. 84

Figure 6.11 Plan View of Feature 11 Burned Rock Cluster. 85

Figure 6.12 Plan View of Feature 12 Burned Rock Cluster. 86

Figure 6.13 Plan View of Feature 13 Burned Rock Cluster. 87

Figure 6.14 Plan View of Feature 15 Burned Rock Cluster. 88

Figure 6.15 Plan View of Feature 19 Burned Rock Cluster. 89

Figure 6.16 Plan View of Feature 35 Burned Rock Cluster. 90

Figure 6.17 (Part 1) Selected Stone Tools from Occupation 1 (Actual Size). 96

Figure 6.17 (Part 2) Selected Stone Tools from Occupation 1 (Actual Size). 97

Figure 6.18 Ground Stone Tools from Occupation 1 (Actual Size). 102

Figure 6.19 Sandstone Abrader \#300 from Occupation 1 (Actual Size). 103 
Figure 6.20 Rabdotus Shell A/I Ratios and Vertical Proveniences. 104

Figure 6.21 Mussel Shell Pendant from Occupation 1 (Actual Size). 106

Figure 6.22 Horizontal Distribution of Occupation 1 Material. 107

Figure 6.23 All TDS Shot In Material for Occupation 1.

Figure 6.24 Lithic Debitage, Mussel Shells, and Tools Shot In with the TDS for Occupation 1.

Figure 7.1 Plan View of Burned Rock-Filled Pit Feature 16.

Figure 7.2 Plan View of Burned Rocks in Feature 33.

Figure 7.3 Plan View of Burned Rocks in Feature 34.

Figure 7.4 Selected Stone Tools from Occupation 2 (Actual Size).

Figure 7.5 Horizontal Distribution of Occupation 2 Material.

Figure 7.6 All TDS Shot In Material for Oddupation 2.

Figure 7.7 Lithic Debitage, Mussel Shells, and Stone Tools Shot In with the TDS for Occupation 2.

Figure 8.1 Plan View of Feature 18.

Figure 8.2 Plan View of Feature 20 Prior to Excavation.

Figure 8.3 Plan View of Feature 20 during Excavation.

Figure 8.4 Profile View of Feature 20 Prior to Excavation.

Figure 8.5 Plan View of Feature 20 and Profile. 132

Figure 8.6 Plan View of Feature 23. 134

Figure 8.7 Plan View of Feature 32. 135

Figure 8.8 Overview of Feature 32 with Associated Tortugas Point. 135

Figure 8.9 Selected Stone Tools from Occupation 3 (Actual Size). 140

Figure 8.10 Edge Modified Flakes and Mano (4325) from Occupation 3 (Actual Size). 141 
Figure 8.11 Horizontal Distribution of Occupation 3 Material.

Figure 8.12 All TDS Shot In Material for Occupation 3.

Figure 8.13 Lithic Debitage, Mussel Shells, and Stone Tools Shot In with the TDS for Occupation 3.

Figure 9.1 Plan View of Feature 27 and Profile.

Figure 9.2 Oblique View of Burned Rock Pit Feature 27.

Figure 9.3 Plan View of Feature 27 with Edge of Gradall ${ }^{\mathrm{TM}}$ on Left (West) Margin. 152

Figure 9.4 Plan View of Feature 37 and Profile. 156

Figure 9.5 Closeup of Large Charcoal Branch (\#5741 ) underlying Large Burned Rock in Feature 37.

Figure 9.6 Plan View of Feature 22.

Figure 9.7 Plan View of Feature 26.

Figure 9.8 Plan View of Feature 28.

Figure 9.9 Plan View of Feature 32.

Figure 9.10 Plan View of Feature 42.

Figure 9.11 Plan View of Feature 25.

Figure 9.12 Selected Stone Tools, Projectile Points, Bifaces, and Scrapers from Occupation 4 (Actual Size).

Figure 9.13 Selected Scrapers and Edge Modified Flakes from Occupation 4 (Actual Size)... 169

Figure 9.14 Sandstone Abraders from Occupation 4.

Figure 9.15 Mano (\#1998) from Occupation 4.

Figure 9.16 Horizontal Distribution of Occupation 4 Material.

Figure 9.17 All TDS Piece Plotted Material from Occupation 4.

Figure 9.18 Horizontal Distribution of TDS Plotted Material in Occupation 4. 
Figure 10.1 Plan View of Burned Rocks in Feature 21.

Figure 10.2 A Pair of Manos from Feature 38 in Profile.

Figure 10.3 Plan View of Manos from Feature 38.

Figure 10.4 Plan View of Burned Rocks in Feature 24.

Figure 10.5 Plan View of Burned Rocks in Feature 29.

Figure 10.6 Plan View of Burned Rocks in Feature 30.

Figure 10.7 Plan View of Feature 40. 188

Figure 10.8 Linear Patterning of Cultural Material in Feature 40.

Figure 10.9 Selected Artifacts from Occupation 5 (Actual Size).

Figure 10.10 Manos from Feature 38 in Occupation 5. 196

Figure 10.11 Mano \#4725 from Feature 38.

Figure 10.12 Mano \#4726 from Feature 38.

Figure 10.13 Sandstone Abrader \#4692 from Occupation 4.

Figure 10.14 Horizontal Distribution of Occupation 5 Material.

Figure 10.15 All TDS Shot In Material for Occupation 5.

Figure 10.16 Lithic Debitage, Mussel Shells, and Stone Tools Shot In with the TDS for Occupation 5.

Figure 11.1 Edge Modified Flake (\#5512-4) from Occupation 6. 209

Figure 11.2 Horizontal Distribution of Occupation 6 Material. 211

Figure 11.3 All TDS Shot In Material for Occupation 6.

Figure 12.1 Plan View of Feature 17.

Figure 12.2 Plan View of Feature 43. 216

Figure 12.3 Selected Artifacts from Assigned Proveniences (Actual Size) 220 
Figure 13.1 Cultural Stratigraphy (Shown by Vertical TDS Shots in a Selected Part of the Site), Associated Projectile Point Types, and Ages of Occupation Zones 1-6 at Lino Site (41WB437).

Figure 13.2 Stable Isotope Summaries from Modern Edible Plant Parts and Lino Site 41WB437

Burned Rock Results.

Figure 13.3 Plot of Modern Plant Isotope Values and Generalized Plant Categories. 235

Figure 13.4 Prehistoric Burned Rock Isotope Results from the Lino Site (41WB437). 239

Figure 13.5 Average Rock Weight per Burned Rock Feature at Lino Site 41WB437. 249

Figure 13.6 Schematic of One Possible Stone Boiling Process. 250

Figure 13.7 Occupation 1, Pit Feature 14 and Associated Material in the Immediate Vicinity $(30-40 \mathrm{cmbs})$. 255

Figure 13.8 Occupation 3, Pit Feature 20 and Associated Material in the Immediate Vicinity $(65-75 \mathrm{cmbs})$ 256

Figure 13.9 Occupation 4, Pit Features 27, 42, and 26 and Associated Materials. 257

Figure 13.10 Projectile Point Width vs. Thickness, Lino Site (41WB437)...... 263

Figure 15.1 Graphic Presentation of Float Data Compared to Corresponding Unit Data in Units $\mathrm{E} 5, \mathrm{C} 3$, and $\mathrm{C} 5$. 281

Figure 15.2 Graphic Presentation of Float Data Compared to Corresponding Unit Data in Units A3, D5 and F3. 282

Figure 15.3 Graphic Presentation of Float Data Compared to Corresponding Unit Data in Units F3 and F5. 283

Figure 15.4 A Projected $60 \mathrm{~m} 2$ Block Excavation Was Used to Calculate the Possible Encounters with Three Unusual Feature Types at the Lino Site (41WB437). 286

Figure 15.5 Material Distribution around Pit Feature 37, Occupation 4 (80 to $90 \mathrm{cmbs}$ )........ 290 


\section{LIST OF TABLES}

Table 1.1 List of Excavation Units and Associated Cultural Features, Testing Phase at 41WB437 (Abbott 1997).

Table 1.2 Selected Feature Attributes from Testing Phase at 41WB437.

Table 3.1 Cultural Periods and Age Estimates for Archaeological Materials in Choke Canyon Reservoir (after Hall et al. 1986).

Table 4.1 Artifact Label Designations.

Table 4.2 List of Codes Used with Data Collector.

Table 5.1 Correlation, Ages, and General Description of Stratigraphic Units at the Lino Site (41WB437).

Table 5.2 Representative Sediment Analyses from the Lino Site 41WB437 and Nearby Localities.

Table 5.3 Radiometric Data Obtained on Dated Materials at the Lino Site (41WB437). 71

Table 6.1 Attributes of Features from Occupation 1 74

Table 6.2 Occupation 1 Burned Rock Data. 75

Table 6.3 Float Results from Occupation 1 Features. 80

Table 6.4 Occupation 1 Lithic Debitage Analysis. 94

Table 6.5 Point and Biface Attributes for Occupation 1. 95

Table 6.6 Scrapers and Edge Modified Tool Attributes for Occupation 1. 99

Table 6.7 Ground Stone Attributes for Occupation 1. 101

Table 7.1 Attributes of Features from Occupation 2. 111

Table 7.2 Occupation 2 Lithic Debitage Analysis.

Table 7.3 Point and Biface Attributes for Occupation 2.

Table 7.4 Scraper and Edge Modified Tool Attributes for Occupation 2. 
Table 7.5 Burned Rock Data for Occupation 2.

Table 8.1 Attributes of Features from Occupation 2.

Table 8.2 Occupation 3 Burned Rock Data.

Table 8.3 Occupation 3 Lithic Debitage Analysis.

Table 8.4 Point and Biface Tool Attributes for Occupation 3.

Table 8.5 Scraper and Edge Modified Tool Attributes for Occupation 3.

Table 9.1 Feature Attributes for Occupation 4.

Table 9.2 Occupation 4 Burned Rock Data.

Table 9.3 Occupation 4 Lithic Debitage Analysis.

Table 9.4 Point and Biface Tool Attributes for Occupation 4. 164

Table 9.5 Scraper and Edge Modified Tool Attributes for Occupation 4. 167

Table 9.6 Ground Stone Attributes for Occupation 4. 170

Table 10.1 Attributes of Features from Occupation 5.

Table 10.2 Occupation 5 Burned Rock Data.

Table 10.3 Occupation 5 Lithic Debitage Analysis.

Table 10.4 Point and Biface Tool Attributes for Occupation 5. 191

Table 10.5 Scraper and Edge Modified Tool Attributes from Occupation 5. 194

Table 10.6 Ground Stone Attributes from Occupation 5. 195

Table 11.1 Occupation 6 Lithic Debitage Analysis. 206

Table 11.2 Point and Biface Tool Attributes from Occupation 6. 207

Table 11.3 Scraper and Edge Modified Tool Attributes from Occupation 6. 207

Table 11.4 Occupation 6 Burned Rock Data. 208

Table 12.1 List of Proveniences for Miscellaneous Material. 214 
Table 12.2 Miscellaneous Lithic Debitage Analysis. 217

Table 12.3 Point and Biface Attributes of Miscellaneous Tools. 218

Table 12.4 Attributes of Miscellaneous Scraper and Edge Modified Tools. 219

Table 12.5 Miscellaneous Burned Rock Data 221

Table 13.1 Stable Carbon and Nitrogen Isotope Values on Modern Plant Parts from South Texas. 233

Table 13.2 Summary of Material Classes per Lino Site (41WB437) Occupation Zone. 253

Table 13.3 Selected Data from a Sample of Tool Stone Material from the Uplands Adjacent to Lino Site 41WB437. 260

Table 13.4 Percentage of Flake Types per Occupation Zone at Lino Site 41WB437 262

Table 15.1 Overview of Comparison of Higgins and Lino Site Investigations. 274

Table 15.2 Material Classes Recovered and Plotted by the TDS 276

Table 15.3 Comparison of Classes of Artifacts Recovered by Four Different Recovery

Techniques.

Table 15.4 Flotation Results on Eight Columns across the Lino Site. 280

\section{LIST OF ACRONYMS}

\begin{tabular}{|c|c|c|c|}
\hline AMS & accelerator mass spectrometry & NRHP & National Register of Historic \\
\hline BT & backhoe trench & & Places \\
\hline amsl & above mean sea level & ROW & right of way \\
\hline $\mathrm{cmbs}$ & centimeters below surface & ST & shovel test \\
\hline CAD & computer-aided drafting & TARL & Texas Archeological Research \\
\hline EDXA & $\begin{array}{l}\text { ecologically diagnostic xylem } \\
\text { analysis }\end{array}$ & TDS & $\begin{array}{l}\text { Laboratory } \\
\text { total data station }\end{array}$ \\
\hline EAD & Environmental Affairs Division & $\mathrm{THC}$ & Texas Historical Commission \\
\hline & of the Texas Department of & TRC & TRC Mariah Associates Inc. \\
\hline EDM & $\begin{array}{l}\text { Transportation } \\
\text { electronic distance }\end{array}$ & TxDOT & $\begin{array}{l}\text { Texas Department of } \\
\text { Transportation }\end{array}$ \\
\hline IRn & $\begin{array}{l}\text { measurement } \\
\text { invitation for bids }\end{array}$ & UV & ultraviolet light \\
\hline
\end{tabular}




\subsection{INTRODUCTION}

TRC Mariah Associates Inc. (TRC) of Austin was awarded a service contract on April 1, 1998, to perform specific excavations, conduct analyses, and write a technical report on data recovered during mitigation at archaeological site 41WB437 in Webb County, Texas, for the Texas Department of Transportation (TxDOT), Environmental Affairs Division (EAD). A prefield meeting was held with TxDOT personnel to establish final procedures. After receiving a Texas Historical Commission (THC) antiquity permit (No. 1996), field investigations were conducted between April 27 and June 3, 1998, under the field direction of Mike Quigg.

\subsection{PROJECT LOCATION AND DEVELOPMENT}

The mitigation of 41WB437 in Webb County, in the far south Texas region, occurred just 7.5 $\mathrm{km}$ (4.7 miles) south of Laredo, Texas (Figure 1.1). This prehistoric campsite is on a low terrace on the north side (right bank) of San Idelfonzo Creek where it is crossed by U.S. Highway 83. This is about $0.5 \mathrm{~km}$ east of the confluence of the creek with the Rio Grande River. Site 41WB437 is about $115 \mathrm{~m}$ (377 feet) above mean sea level (amsl). The existing terrace surface has been extensively modified by tree and brush clearing, grading, construction of an old, elevated road grade for U.S. Highway 83 , the building of an east-west road grade across the site for access to private land, and recent dumping of historic garbage. Mesquite trees (Prosopis glandulosa) are prominent along the margins of the two channels of San Idelfonzo Creek (Figure 1.2).

TxDOT plans call for expanding a $4.7 \mathrm{~km}(2.9$ mile) segment of U.S. Highway 83 south of Laredo, Texas, from a two lane to a four lane divided highway. The new $11.6 \mathrm{~m}(38 \mathrm{ft}$.) wide roadway will include two $3.7 \mathrm{~m}(12 \mathrm{ft}$.) lanes, one $1.2 \mathrm{~m}$ ( $4 \mathrm{ft}$.) shoulder, and one $3.0 \mathrm{~m}(10 \mathrm{ft})$ shoulder. All construction activities will be completed within the existing right of way (ROW).

\subsection{PREVIOUS CULTURAL RESOURCE INVESTIGATIONS}

In May 1996, the TxDOT Laredo District submitted plans to the EAD in Austin (Abbott 1997). TxDOT conducted a site file search at the Texas Archeological Research Laboratory (TARL) and a search of the records of the National Register of Historic Places (NRHP) at THC to comply with Section 106 of the National Historic Preservation Act of 1966 (P.L. 94-422, P.L. 94-458 and P.L. 96-515). Between August 20 and August 23, 1996, Jerry Henderson of the EAD conducted a pedestrian survey and shovel testing program of the $4.7 \mathrm{~km}$ long development segment that resulted in the discovery and recording of four prehistoric archaeological sites: 41WB435, 41WB436, 41WB437, and 41WB438. A single shovel test (ST-2), which was $60 \mathrm{~cm}$ in diameter and $100 \mathrm{~cm}$ deep, was excavated into the terrace deposits at 41WB437. The material was screened, and nine flakes were recovered randomly throughout the shovel test hole (Henderson 1997). Sites 41WB437 and 41WB438 on the north and south sides of San Idelfonzo Creek, respectively, were thought to have some potential for listing on the NRHP based on the presence of deep deposits with the potential to contain stratified cultural materials. These two buried sites were recommended for site significance testing (Henderson 1997). Sites 41WB435 and 41WB436 were judged ineligible for listing on the NRHP (Abbott 1997). The THC concurred with the survey 


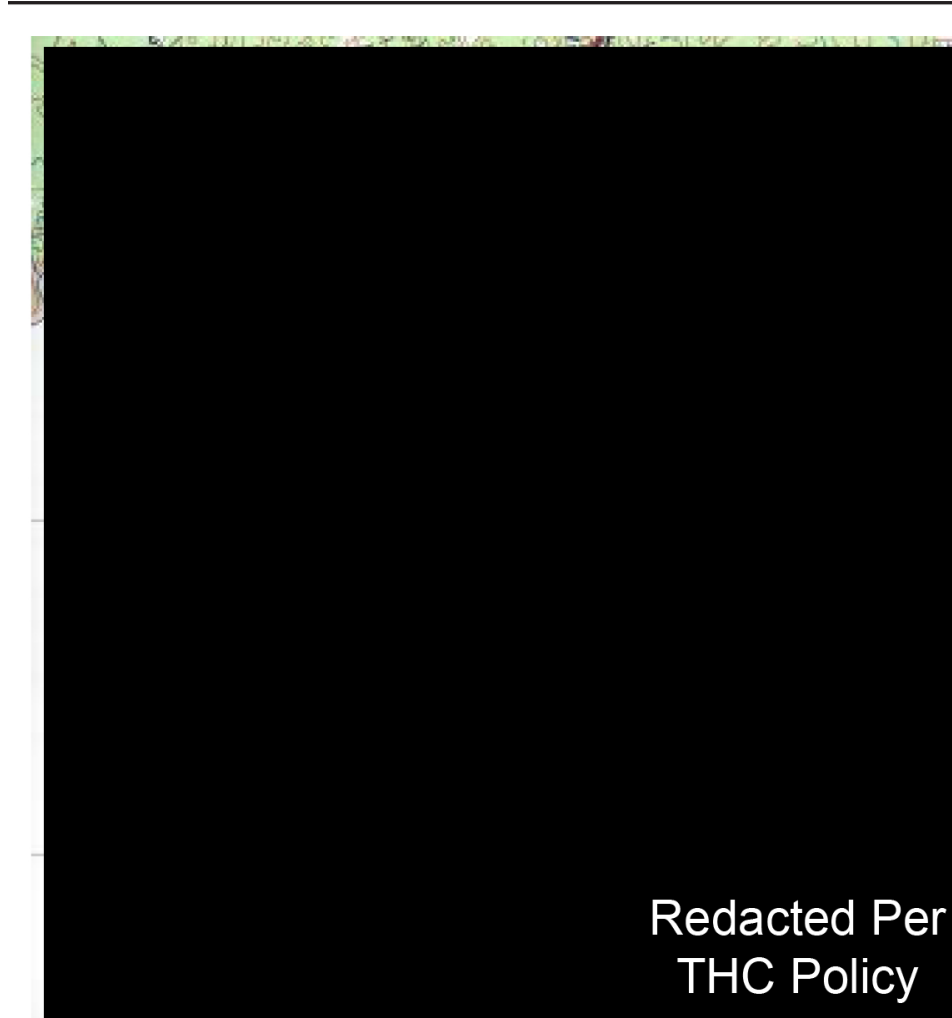

Redacted Per

THC Policy

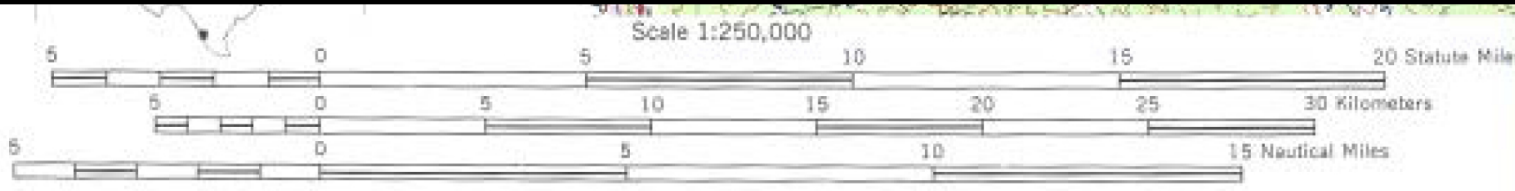

CONTOUR INTERVAL 50 FEET

WITH SUPPLEMENTARY CONTOURS AT 25 FOOT INTERVALS

Figure 1.1 Archaeological Site 41WB437 Located South of Laredo, Texas. 


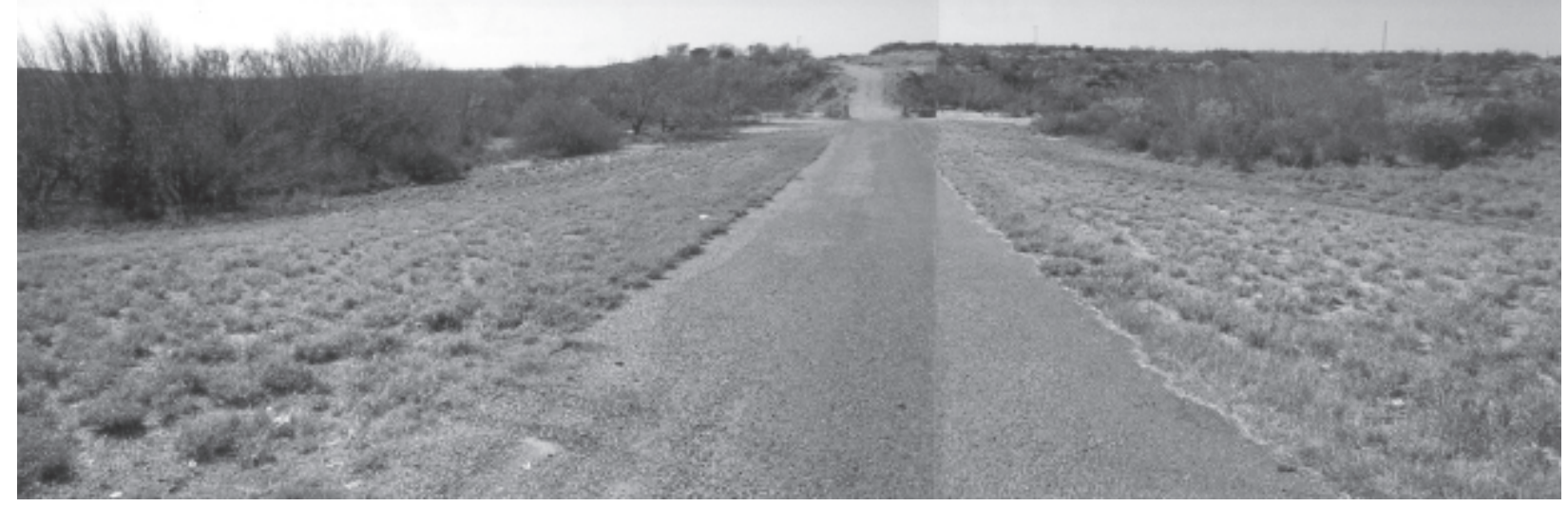

Figure 1.2 Archaeological Site 41WB437 Immediately West of U.S. Highway 83 with Private Access Road Cutting Site in Half and Vegetation Bordering San Idelfonzo Creek.

recommendations and TxDOT's proposed testing scope to determine eligibility for inclusion in the NRHP (Bruseth 1997).

The eligibility testing of archaeological sites $41 \mathrm{WB} 437$ and 41WB4438 was investigated by personnel from the TxDOT EAD from March 18 through March 28, 1997 (Abbott 1997). Testing of $41 \mathrm{WB} 437$ was conducted by mechanical trenching and hand excavations of 1 by $1 \mathrm{~m}$ units. Seven hand units and four trenches varying from 5.0 to $10.2 \mathrm{~m}$ long by 1.3 $\mathrm{m}$ wide were excavated to various depths (Table 1.1). Four test units (\#1 through \#4) were clustered around Feature 3, which was discovered in backhoe trench (BT) 2 and dug to $40 \mathrm{~cm}$ below surface (cmbs) (Figure 1.3). Three test units (\#5 through \#7) were clustered around Feature 5 and dug to depths of $60 \mathrm{cmbs}$. The maximum depth of the manually dug tests was $60 \mathrm{cmbs}$, with the emphasis focused on exposing burned rock features. The seven test units encompassed $2.95 \mathrm{~m}^{3}$ and recovered three cores/ early stage bifaces, one expedient lithic tool, 138 pieces of lithic debris, 20 bone and shell items, two historic items, six cultural features and one natural feature (Table 1.2). The block of four test units (\#1 through \#4) at Feature 3 yielded

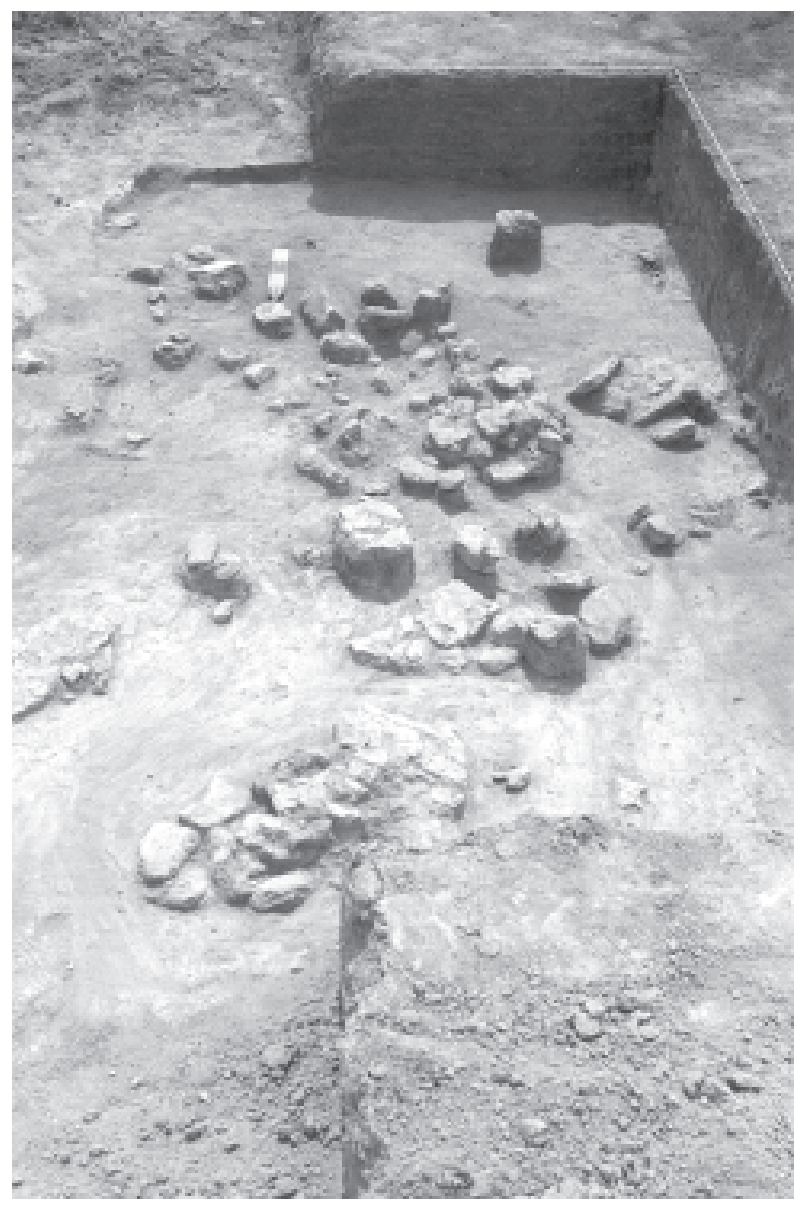

Figure 1.3 Exposed Burned Rock Feature 3, 40 Cmbs in Backhoe Trench 2 on South Side of Private Access Road at $41 \mathrm{WB} 437$. 
Table 1.1 List of Excavation Units and Associated Cultural Features, Testing Phase at 41WB437 (Abbott 1997).

\begin{tabular}{|c|c|c|c|c|c|}
\hline TU & BT & Size (m) & Depth (cm) & Feature & Comments \\
\hline 1 & - & $1 \times 1$ & $0-40$ & 3 & Adjacent to BT2 \\
\hline 2 & - & $1 \times 1$ & $0-40$ & 3,4 & Adjacent to BT2 \\
\hline 3 & - & $1 \times 1$ & $0-40$ & 3 & Adjacent to BT2 \\
\hline 4 & - & $1 \times 1$ & $0-40$ & 3 & Adjacent to BT2 \\
\hline 5 & - & $1 \times 1$ & $0-60$ & 5 & \\
\hline 6 & - & $1 \times 1$ & $0-60$ & 5 & \\
\hline 7 & - & $0.5 \times 0.5$ & $0-60$ & 5 & \\
\hline- & 1 & $10.2 \times 6.1$ & $0-330$ & 1,6 & $\begin{array}{l}\text { Sparse burned sandstone throughout; Feature } 1 \text { at } 180 \mathrm{~cm} \text {; } \\
\text { Feature } 6 \text { at } 80 \mathrm{~cm} \text { (noted in wall after excavation) }\end{array}$ \\
\hline- & 2 & $5.0 \times 1.3$ & $0-25$ & 3 & Trench halted to investigate and record Feature $3(25 \mathrm{~cm})$ \\
\hline- & 3 & $6.3 \times 1.3$ & $0-106$ & 2 & $\begin{array}{c}\text { Sparse burned sandstone feature (Feature 2) at } 25 \mathrm{~cm} \text { bgs } \\
\text { briefly recorded, exhumed with machine; Feature } 7 \text { noted in } \\
\text { east wall after excavation }\end{array}$ \\
\hline- & 4 & $8.1 \times 1.3$ & $0-290$ & - & No significant cultural material noted \\
\hline
\end{tabular}

60 items for a density of $37.5 / \mathrm{m}^{3}$, excluding the burned rocks. The block of three test units (\#5 through \#7) around Feature 5 yielded 74 pieces of lithic debitage for a density of $164 / \mathrm{m}^{3}$, excluding the burned rock (Abbott 1997). No counts on the burned rocks were presented.

Formal lithic artifacts consisted of one ground/ pecked stone from the surface, two late-stage bifaces in association with Features 1 and 3, one tested cobble from Feature 1, and one edgemodified flake from Unit 6 . Two historic items, a short piece of coiled steel wire, and a 0.32 caliber handgun cartridge were recovered from Units 1 and 3, respectively (Abbott 1997).

In conjunction with the backhoe trenching, $\mathrm{J}$. Abbott of TxDOT EAD conducted geomorphological interpretations. Two principal allostratigraphic units (Strat Units 1 and 2) were defined along San Idelfonzo Creek. Only Strat Unit 2 existed at 41WB437 on the north side of the creek (Abbott 1997). Strat Unit 2 consists of silty to silty loam that ranged from dark brown and brown (10YR 3/3-4/3) in the A horizon to brown, pale brown, very pale brown, yellowish brown, and light yellow brown (10YR 5/3-5/4, 10YR 6/3-6/4, 10YR 7/3) in the B and $C$ horizons. This is a very thick stratigraphic unitat least $3.3 \mathrm{~m}$ at BT 1 -with sediments clearly stratified in somewhat structured packets of silty loams alternating with massive silts. The loamier strata exhibit a relatively weak structure labeled subangular blocky (Abbott 1997). The most recognizable element of the structure consists of small $(0.1$ to $1.0 \mathrm{~cm})$, irregular, randomly oriented blocks resulting from the desiccation cracking and subsequent disruption of thin flood drapes. A swale observed across the main terrace was regarded as an erosional feature (Abbott 1997).

Strat Unit 2 contains cultural bearing deposits that are mostly restricted to the loamier facies, which suggests that the massive, silty beds may represent individual large flood deposits. The loamier facies may represent more gradual aggradation of the point bar surface arising from many lower magnitude events (Abbott 1997). The findings at 41WB437 appeared to represent the remains of a number of relatively short-term activity surfaces dating to the Archaic period, 


\begin{tabular}{|c|c|c|c|c|c|c|c|c|}
\hline $\begin{array}{ll}\text { Fea. } \\
\text { No. }\end{array}$ & Location & Units & $\begin{array}{l}\text { Depth } \\
\text { (cmbs) }\end{array}$ & $\begin{array}{c}\begin{array}{c}\text { Diameter } \\
(\mathbf{c m})\end{array} \\
\end{array}$ & $\begin{array}{c}\text { Thickness } \\
(\mathbf{c m})\end{array}$ & Description & Associated Artifacts & Age \\
\hline 1 & BT1, wall & NA & 185 & 80 & $1-2$ & Fired shallow basin & $\begin{array}{l}\text { Burned sandstone }(\mathrm{n}=27) \text {, mussel } \\
\text { shells }(\mathrm{n}=2) \text {, debitage }(\mathrm{n}=10) \\
\text { bifaces }(\mathrm{n}=2) \text {, snail shells, charcoal }\end{array}$ & $\begin{array}{r}\text { Charcoal date } 3240= \\
\text { Beta } 10632 \xi\end{array}$ \\
\hline 2 & BT3 & NA & 25 & $90 \times 160$ & 20 & Probable natural burn & $\begin{array}{l}\text { Burned sandstone (few), charcoal } \\
\text { fleck stain }\end{array}$ & \\
\hline 3 & $\mathrm{BT} 2$ & $1-4$ & $30-40$ & 270 & NA & Burned rock cluster & $\begin{array}{c}\text { Burned sandstone }(\mathrm{n}=140) \\
\text { debitage }(\mathrm{n}=12) \text {, charcoal, burned } \\
\text { earth, biface }(\mathrm{n}=1), \text { fractured bone, } \\
\text { shell }\end{array}$ & $\begin{array}{r}\text { Charcoal date } 2060= \\
\text { Beta } 106326\end{array}$ \\
\hline 4 & BT2 & 2,3 & $13-20$ & 30 & $1-2$ & Burned rock cluster & Burned sandstone $(\mathrm{n}=5)$ & \\
\hline 5 & & $5,6,7$ & $50-60$ & $100 \times 20$ & NA & Burned rock cluster & $\begin{array}{l}\text { Burned sandstone }(\mathrm{n}=11) \text {, debitage } \\
\qquad(\mathrm{n}=10)\end{array}$ & \\
\hline 6 & BT1, wall & NA & 80 & 60 & 10 & Burned rock cluster & Burned sandstone & $\begin{array}{r}\text { Charcoal date } 2130= \\
\text { Beta } 10632 ;\end{array}$ \\
\hline 7 & BT3, wall & NA & NA & 60 & 20 & Shallow, basin stain & $\begin{array}{l}\text { A few burned rocks, charcoal } \\
\text { flecks }\end{array}$ & \\
\hline
\end{tabular}


then sealed by flood deposits of San Idelfonzo Creek (Abbott 1997). The thick Strat Unit 2 deposit contained buried burned rock features with considerable charcoal and isolated burned rocks. The latter were thought to indicate archaeological strata that were disrupted and strewn across the point bar surface by high magnitude floods. Features were buried at depths of 13 to $20,30,50$ to 60,80 , and 185 cmbs across the site. In addition to the burned rock clusters, two features (Features 1 and 7) were basin-shaped stains 80 and $60 \mathrm{~cm}$ in diameter and 2 and $20 \mathrm{~cm}$ thick, respectively. However, the individual occupations were believed to be relatively ephemeral and exhibited a paucity of associated remains (Abbott 1997).

Following the presentation of the testing data and interpretations, Abbott (1997:42-44) presented many research questions as well as a methodology to recover the field data necessary to address the stated research questions. These questions centered on major research issues, including subsistence, lithic resource procurement and technology, burned rock technology and data context, site structure and organization, chronology and cultural affiliation, paleoenvironmental studies, and site formation processes.

The field method presented to address research questions was derived from logistical and budgetary constraints. A modification of the excavation techniques pioneered at the Wurzback site and refined at site 41BX996 (Black et al. 1997) was to be used to mitigate 41WB437 (Abbott 1997). Excavations were to focus on one excavation block of about $200 \mathrm{~m}^{2}$ from the surface to a depth of $120 \mathrm{cmbs}$. The principal excavation was to be accomplished by removing thin (1 to $2 \mathrm{~cm}$ thick) slices of sediment with a Gradall in long, narrow bucketwide strips. Matrix balks left between the strips would be hand excavated. The idea was to open and expose broad paleosurfaces and determine the relationship between artifacts. When features were encountered during machine stripping, the sediments within a $1 \mathrm{~m}$ radius would be hand excavated and screened. The feature fill would be collected and floated to maximize recovery of small, fragile remains. Following machine excavations, the balks left standing between the Gradall stripped areas would be hand excavated in natural levels and screened through $6.4 \mathrm{~mm}$ (1/4 inch) screens. Column samples would be collected at $2 \mathrm{~m}$ intervals along each balk for flotation. These excavations were designed to have discovered artifacts point-plotted with a total data station (TDS) instrument. The total projected volume to be excavated would be about $220 \mathrm{~m}^{3}$. At least $4.8 \mathrm{~m}^{3}$ would consist of column flotation samples, while $43.2 \mathrm{~m}^{3}$ would be hand dug and screened in the field. This three-part field approach to sampling allows a high degree of confidence in the evaluation of recovery rates from each method and simultaneously facilitate rapid, efficient excavation (Abbott 1997).

TRC's mitigation followed Abbott's proposed and THC's approved field approach with some limited, agreed-upon alterations. The Gradall stripping was a significant aspect of the investigations. Due to the precision, dedication, and enthusiasm shown by the GradallTM operator, Mr. Lino Lara of San Antonio, we have named 41WB437 the Lino site in his honor.

\subsection{REPORT ORGANIZATION}

The following mitigation site report is divided into 17 sections and nine appendices. The first four sections provide general background information. Section 1.0 is the introduction to the project location and description. Section 2.0 provides a brief environmental background. Section 3.0 provides an overview of some the important aspects of the cultural background and the seven general research issues to be addressed. Section 4.0 discusses the field methods and the 
laboratory procedures and analyses employed to extract the data. Section 5.0 is the introduction to site 41WB437 with its natural and cultural stratigraphy and the dating of those deposits. This is followed by seven sections, 6.0 through 12.0, that describe the materials from each of the identified cultural occupations plus the miscellaneous material not assigned to a particular occupation. Section 13.0 combines all the discovered data and uses it to address the seven research issues in a summary format. Section 14.0 provides the site-specific recommendations. Section 15.0 assesses the field methodology employed during site mitigation. Section 16.0 shows the references listed in the text. A glossary is presented in Section 17.0.

The nine appendices are individually authored and provide technical information and data from various analyses completed to derive specific information from different data sets. Appendix A contains the results performed by Beta
Analytic Inc. laboratory. Appendix B is a detailed identification of some of the charcoal samples and an examination of specific growth structures of mesquite wood to address possible paleoenvironmental conditions during the period of occupation. Appendix $\mathrm{C}$ provides a highpowered microwear study of selected stone assemblages from the various occupations. Appendix D contains the raw laboratory data on the stable carbon and nitrogen isotope data from various organic residues extracted from inside burned rocks. Appendix E contains thermodemagnetization analyses of burned rock. Appendix F contains the laboratory data concerning the amino acid racemization of the Rabdotus land snails collected from the deposits. Appendix $G$ is the laboratory analyses of the lipid residue investigations of the organic residues extracted from the interiors of burned rocks. Appendix $\mathrm{H}$ is an assessment of the phytolith preservation from a variety of contexts at the Lino site. Finally, Appendix I provides the diatom results for various issues. 
Intentionally Left Blank 


\subsection{ENVIRONMENTAL BACKGROUND}

\subsection{GEOLOGICAL SETTING}

The area generally conforms to the underlying Laredo Formation of the Eocene Epoch (Barnes 1976). Water laid alluvial deposits are along the margins of the streams and rivers and are mostly Holocene in age (Figure 2.1). In places, the uplands are capped by a thin lag of diverse fluvial gravels deposited by the ancestral Rio Grande. The Laredo Formation is characterized by thick upper and lower sandstone members that tend to be very fine to fine grained as well as glauconitic, micaceous, ferruginous, crossbedded, and dominated by the colors red and brown (Barnes 1976). Farther east about $5 \mathrm{~km}$ is the Yegua formation, which is also of Eocene age and which may contribute matrix to the San Idelfonzo Creek drainage. It consists of clay and sandstone that is lignitic, sandy, bentonitic, silty, mostly well laminated, and chocolate brown to reddish brown. The sandstones are mostly quartz with some chert grain inclusions (Barnes 1976).

\subsection{PHYSIOGRAPHIC AND GEOMORPHIC SETTING}

The Laredo area is part of the West Gulf Coastal Plain section of the Coastal Plains physiographic province (Fenneman 1938). The large, deeply incised Rio Grande valley lies about $0.5 \mathrm{~km}$ west of the archeological site and flows in a southerly direction through Eocene deposits. The river is a major geographic feature and forms the border of southern Texas. Near Laredo, the Rio Grande has a relatively narrow valley with as many as three alluvial terraces preserved along the valley margins. High cliffs are present in some areas, and the river is actively incising (Gustavson and Collins 1998). The channel reflects numerous flooding and down-cutting events whereas the adjacent terraces continue to aggrade. In the
Laredo area historic floods have exceeded $16 \mathrm{~m}$ above the modern flood plain but have not topped the highest prehistoric terraces (Gustavson and Collins 1998). Just north of Laredo the lower terrace is roughly $120 \mathrm{~m}$ amsl whereas the upper terrace is about $128 \mathrm{~m}$ amsl and the river is at an elevation of $110 \mathrm{~m}$ (Gustavson and Collins 1998). Overbank deposits consisting mostly of fine silts and sands of the Rio Grande terraces are those sediments that are apt to preserve cultural materials in stratified context. Post-depositional bioturbation and pedoturbation have the potential to disrupt the stratified deposits (Gustavson and Collins 1998). No evidence of synchronous, basin-wide cycles of alluviation and down cutting were observed by Gustavson and Collins (1998).

The area surrounding the site exhibits low rolling hills dissected by small creek valleys that drain about a 5 to $10 \mathrm{~km}$ wide strip along the Rio Grande valley (Figures 2.2 and 2.3). The Lino site lies in a narrow (300 to $500 \mathrm{~m}$ wide) stream valley of San Idelfonzo Creek, a small ephemeral tributary of the Rio Grande. This creek has incised 8 to 12 $\mathrm{m}$ below the surrounding uplands. It has a restricted catchment area of about $25 \mathrm{sq} \mathrm{km}$, mostly located northwest of the site (Abbott 1997). The catchment is sufficiently large to have sizeable stream flows that move fine sediments down the valley, but the volume of water may not be sufficient to move and deposit large gravels. The relatively small terraces bordering the creek testify to the past alluvial deposits. The terrace treads are about 5 to $6 \mathrm{~m}$ above the bottom of the stream channel at about $117 \mathrm{~m}$ amsl. These terraces are about 15 to $17 \mathrm{~m}$ above the modern low-water level of the Rio Grande (Gustavson and Collins 1998). The terraces continue upstream for about $0.5 \mathrm{~km}$ and down to the Rio Grande valley. The San Idelfonzo Creek terraces are at the same elevation as those on the Rio 


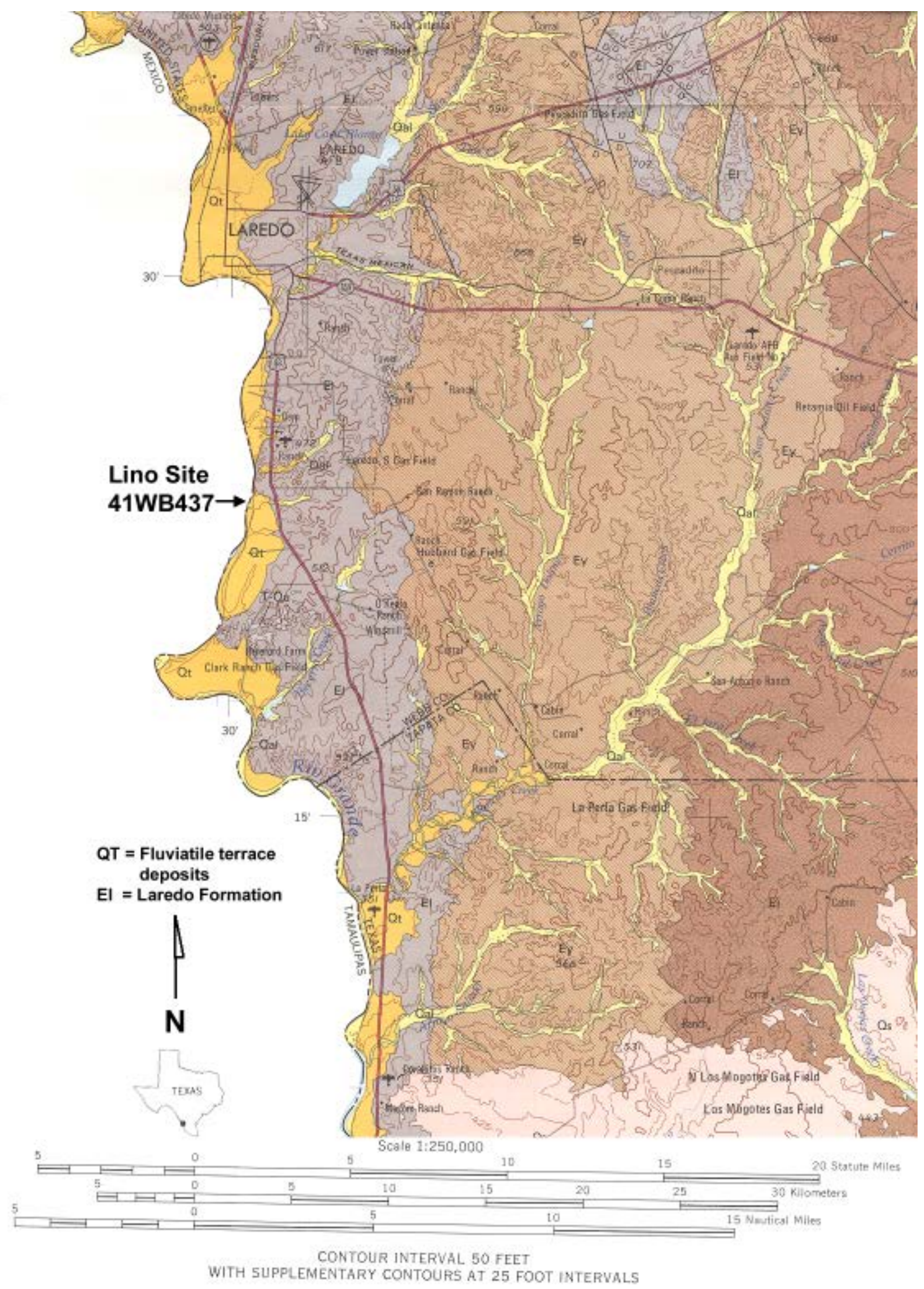

Figure 2.1 Geological Map of the Vicinity around 41WB437 (Barnes 1976). 


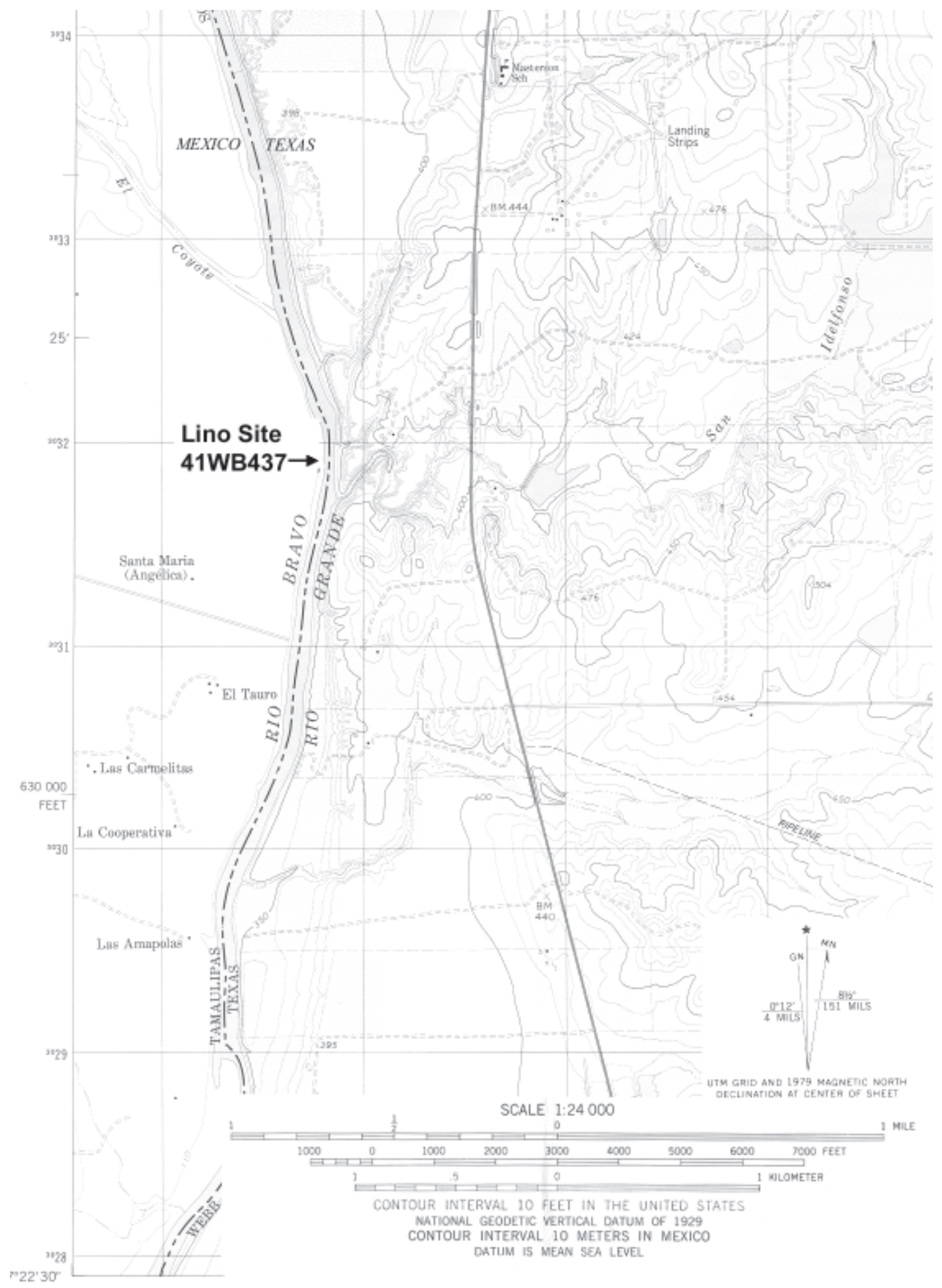

Figure 2.2 Topographic Setting around 41WB437. 


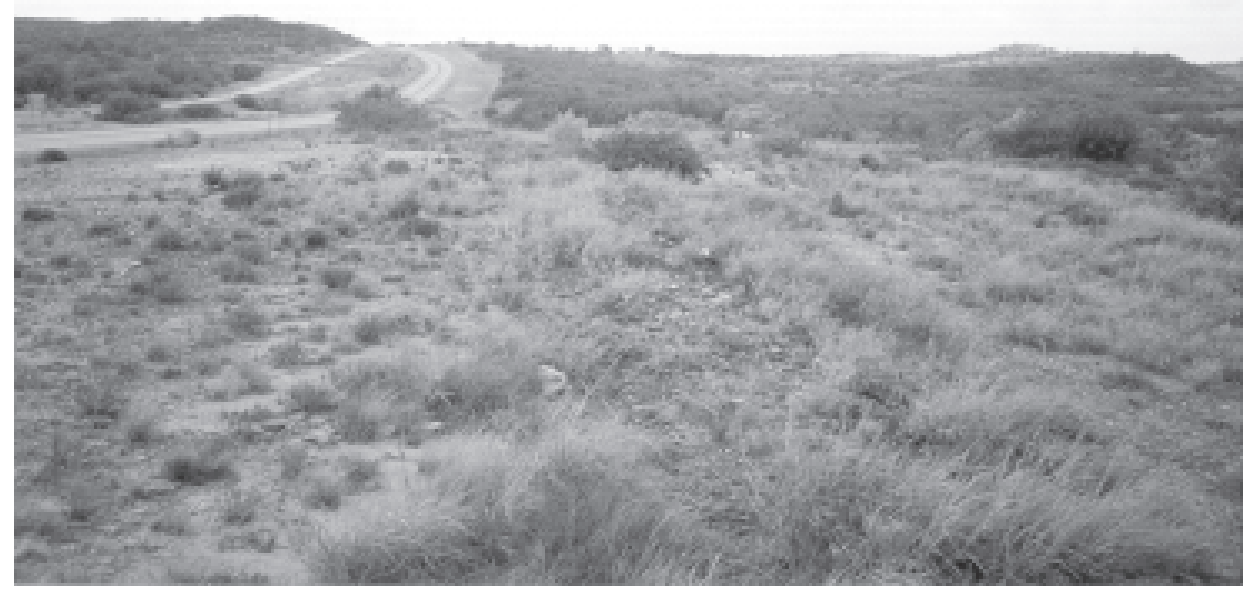

Figure 2.3 Looking South. Site Vicinity with Low Rolling Hills Dissected by San Idelfonzo Creek in Middle of Picture.

Grande, and thus some sediments may have been derived from flood events on the larger Rio Grande (Gustavson and Collins 1998).

The soil in the lower San Idelfonzo Creek valley was mapped as the Verick series and consist of shallow, fine, sandy loam soils (Sanders and Gabriel 1985). The soils that developed in the alluvial terrace deposits are most likely part of the Tela silty clay loam series. These Mollisols (Typic Argiustolls) are the soils that form in calcareous loamy alluvium on flat surfaces. The adjacent uplands are a combination of the Nidorock outcrop complex and the Verick series. The Verick soils are Aridisols (Ustollic Hapalargids) and occur on gently slopes or hills. The Nidorock soils are Entisols (Ustic Torriorthents) and occur on summits and side slopes where sandstone bedrock and lag gravel are exposed.

\subsection{PRESENT CLIMATE}

The climate of the Laredo region is classified as semi-arid subtropical. Characteristically, the winters are fairly warm with rare cold spells. The average winter temperature is 14 degrees $\mathrm{C}$ (58 degrees F) with the lowest recorded temperature being 8.8 degrees $\mathrm{C}$ ( 16 degrees $\mathrm{F}$ ). Snowfall and cold spells are rare. In summer, the average daily maximum temperature is 36 degrees $\mathrm{C}$ ( 97 degrees $\mathrm{F}$ ). The average annual precipitation is $50.3 \mathrm{~cm}$ (19.8 inches), with nearly 70 percent occurring in April through September; however, yearly precipitation varies greatly from year to year. Rains are most often associated with tropical storms (Sanders and Gabriel 1985). Significant rainfall from Pacific storms happens once in three to five years (Bomar 1983). Atlantic hurricanes have also produced significant flooding along the lower Rio Grande valley. They occur about once in seven years (Bomar 1983). Humidity is about 60 percent at mid-afternoon and increases at night to become about 80 percent at dawn. The prevailing winds are from the southeast and average about 11 miles per hour.

\subsection{BIOTIC RESOURCES}

The Laredo area is within the western Tamaulipan biotic province and it extends for hundreds of kilometers in all directions (Blair 1950). In general, the Tamaulipan province is characterized by thorny brush including: mesquite (Prosopis glandulosa), various species 
of acacia and Minosa, granjeno (Celtis pallida), lignum vitea (Porliera angustifolia), cenizo (Leucophyllum texanum), white brush (Aloysia texana), prickly pear (Opuntia lindbeimeri), tasajillo Opuntia leptocaulis), and Condalia and Castela. The brush on the sandy soils differs in species and aspect from that of clay soils.

It is not clear how long the thorny brush vegetation community has been in place. Some cite observations made by early explorers through this region to claim that the thorny brush developed only a short while ago. Sanchez, who accompanied Berlandier on his expedition into south Texas in A.D. 1828, describes the vicinity of Laredo as follows: "A desolate air envelops the entire city and there is not a single tree to gladden the eye as the vegetation of this arid land consists of small mesquites and huisache with cactus scattered here and there" (Inglis 1964:77). In A.D. 1842, Hendricks traveled down the Rio Grande from Laredo to near Falcon Reservoir and reported that "the whole county where we now were, was a wilderness, covered thick with chaparral.... [T] he only timber of any size was mesquite" (Inglis 1964:78). Overall, the early historic observations provide a general impression that the Rio Grande valley had riparian woods of willow, cottonwood, and other species alternating with areas where the bank was bare of trees (Inglis 1964:98).

The vertebrate fauna of the Tamaulipan province is considerable and includes at least 61 species of mammal, 36 species of snakes, 19 lizards, two land turtles, three urodels, and 19 anurans (Blair 1950:103).
Non-vertebrate species include freshwater bivalves in the streams and rivers. Little information is present for most of the Rio Grande. Neck and Metcalf (1988) list 12 species occurring in several habitats in the lower Rio Grande downstream from Falcon Reservoir. These species include Anodonta imbecilis, Anodonta grandis, Megalonaias gigantea, Quadrula apiculata, Popenaias popei, Crytonaias tampicoensis, Potamilus salinasensis, Lampsilis teres, Toxolasma pavus, and introduced species Corbicula fluminea, Sphaeium partumeium, and Sphaerium transversum (Neck and Metcalf 1988). Some or many of these species may have been present farther upstream in the Laredo area in prehistoric times.

\subsection{LITHIC RESOURCES}

Sandstones are quite abundant in a number of the formations within the Eocene deposits. This rock resource could have been used to retain and transfer heat in various cooking techniques and for ground stone tools such as manos, metates, and abraders. Fossil woods, quartzites, and cherts are also part of the Eocene deposits in the Jackson, Yegua, and Laredo formations (Barnes 1976). Gravel caps on many upland divides provided abundant stones for use (Figures 2.4 and 2.5). The origins of these gravels are not weIl understood. In the alluvium deposits along the Rio Grande there are a wide variety of tool stones available that could have been utilized prehistorically, including cherts, agates, and basalts, and that washed into the valley from the Trans-Pecos region (Barnes 1976). 


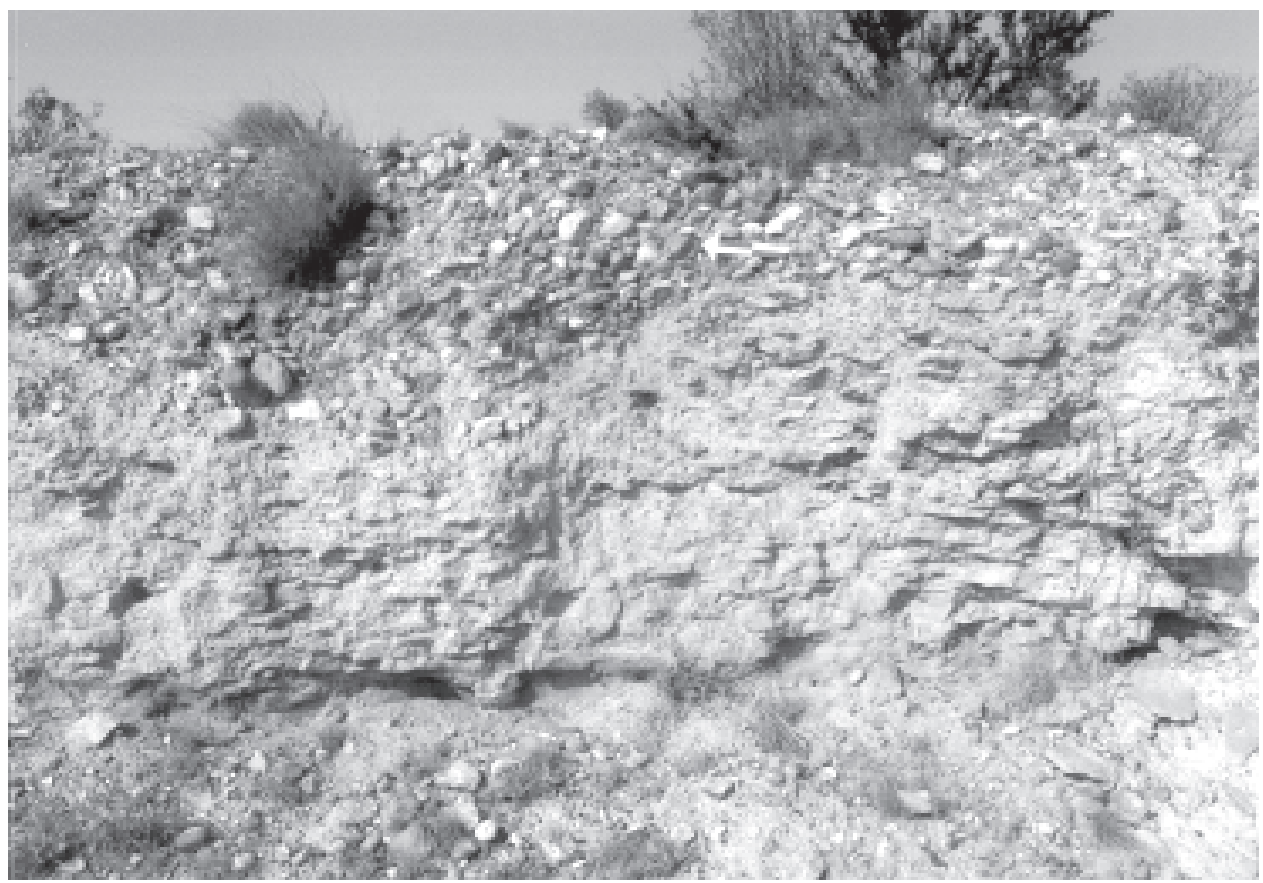

Figure 2.4 Upland Gravels Capping Older Eocene Deposits West of 41WB437.

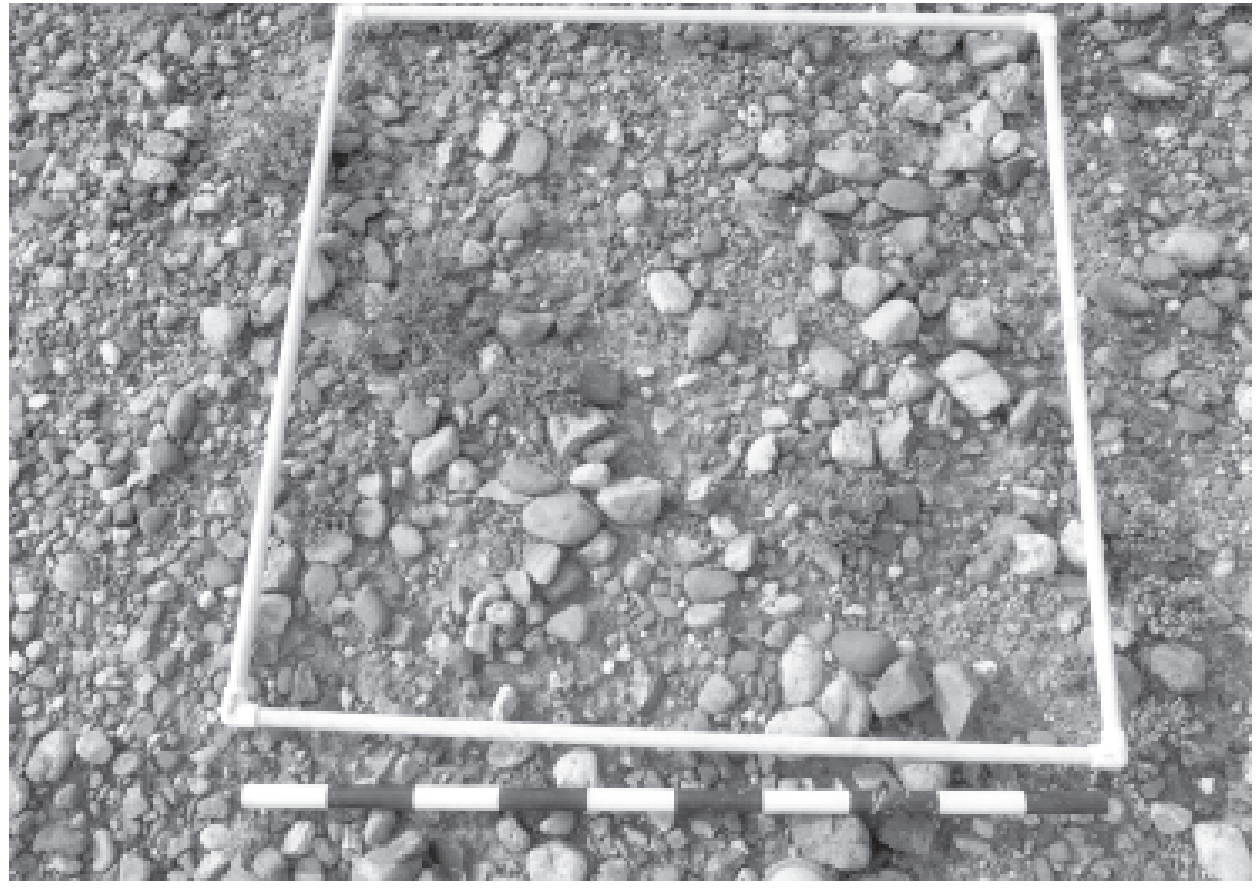

Figure 2.5 Closeup of Siliceous Cobbles in Upland Gravels, which Reveals Size Variations and Density. 


\subsection{CULTURAL BACKGROUND AND RESEARCH ISSUES}

This section provides a brief overview of what is generally known about the cultural background of the south Texas region. The discussion then focuses on the general archaic period that encompasses the cultural materials encountered at the Lino site. A broad-spectrum view of the paleoenvironmental conditions is then presented. Finally, the research issues that guided the Lino site investigations are presented.

\subsection{ARCHAEOLOGICAL BACKGROUND IN EXTREME SOUTH TEXAS}

The south Texas archaeological region (Hester 1980) is a broad, triangular area of mostly flat topography dissected by a number of southeastern flowing rivers, each with their headwaters in the Edwards Plateau (Figure 3.1). The Edwards Plateau lies along the northern border topographically defined by the Balcones Escarpment. The Coastal Bend region paralleling the Gulf of Mexico forms the eastern boundary, and the Rio Grande valley separating Texas from Mexico forms the western border (Figure 3.2). This arbitrary region does not represent the homeland of any one specific cultural group or reflect a single cultural lifeway throughout time.

Adaptations along the coast differ from those in the interior savanna and from those along the Rio Grande valley (Hester 1981). These differences have allowed subdivision of this broad region into smaller biotic-geographical units to compare and contrast cultural adaptations (Black 1989:39). The differences have lead to the THC providing completely separate planning documents, such as the Southern Coastal Corridor Archeological Region (Mercado-Allinger et al. 1996) from the Rio Grande Plains Archeological Region. Since the regional topography and resources north and south of the Rio Grande are similar, the cultural adaptations in south Texas may have many similarities to and much continuity with those in northern Mexico (Hester 1980). It is through careful archaeological investigations that the similarities and differences will come to light.

Hester (1980) provided a general archaeological overview for south Texas that summarizes information as understood ca. A.D. 1980. Black (1989) provided an in-depth summary of south Texas with detail on the area, history of previous investigations, various site types, and a culturalhistorical synthesis. More recently, Hester (1995) and Black (1995a) have synthesized and updated the south Texas archaeological overview. Much of the following brief review was extracted from these documents.

Prior to A.D. 1950, the south Texas literature was restricted to comments on artifact distributions (Black 1995b:31). The first professional archaeological surveys and site testing programs occurred between A.D. 1950 and 1970. Most published reports through this period again focused on describing artifacts collected from the surface. Major surveys included one in Dimmit County (Nunley and Hester 1966) and another in McMullen and Live Oak counties prior to construction of the Choke Canyon Reservoir (Wakefield 1968).

The only major project that occurred during this period was the investigations for the development of Falcon Reservoir (Figure 3.2; Krieger and Hughes 1950; Hartle and Stephenson 1951; Cason 1952). The Falcon Reservoir investigations involved intensive excavations at two prehistoric campsites: 41SR42 (originally 41-78-B9-4) and the Royer site 41ZP50 (Hartle and Stephenson 1951). The first one, 41SR42, is a deeply stratified site that 


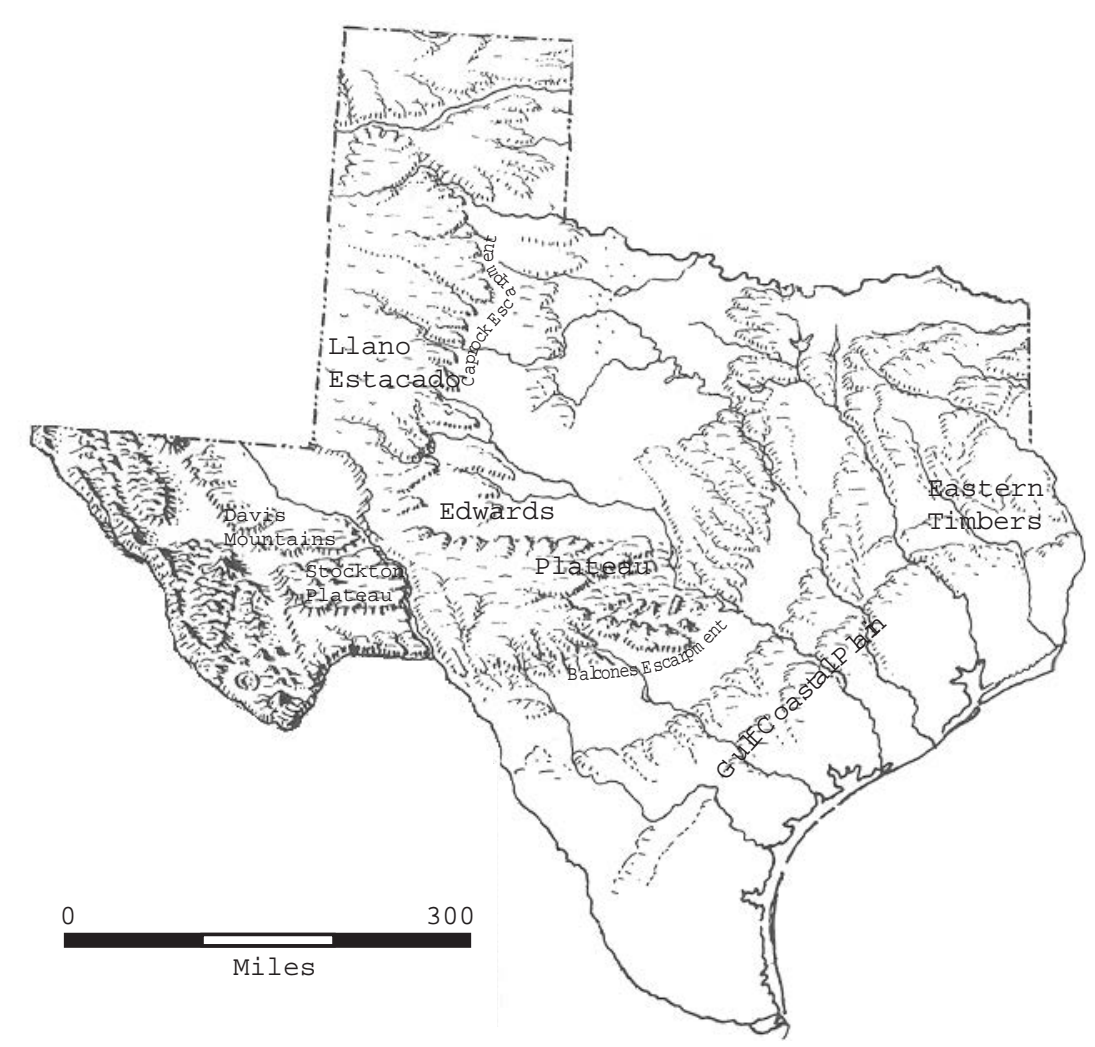

Figure 3.1 Generalized Physiographic Regions of Texas. Adapted from Erwin Raisz 1954.

$1=$ Falcon Reservoir Area

$2=41 Z$ P39, 176, 364 Sites

$3=41$ ZP50, Royer Site (78-B9-17)

$4=41$ SR42 Site (78-B9-4)

$5=41$ WB437, Lino Site

$6=41$ WB73 Site

$7=41$ LK28, Loma Sandia Site

$8=41 \mathrm{LK} 67$, Choke Canyon Reservoir Site

$9=41 \mathrm{LK} 31 / 32,41 \mathrm{LK} 201$, Choke Canyon Reservoir Site

$10=41$ MC222, Choke Canyon Reservoir Site

$11=41$ WN73, Shrew Site

$12=41$ ZV10, Chaparrasa Ranch Site

$13=41 \mathrm{VV} 218$, Bonfire Shelter Site

$14=41$ AS16, Swan Lake Site

Figure 3.2 Map of South Texas with Selected Archeological Sites. 
contained at least four thin bands of cultural material, the lowest of which occurred at 275 cmbs (110 inches) and was targeted for excavation. The overlying sediments included three cultural zones within a 6.1 by $15.3 \mathrm{~m} \mathrm{(20}$ by $50 \mathrm{ft}$.) area that were mechanically removed to a point just above the 10 to $17.5 \mathrm{~cm}$ (4 to 7 inch) thick target occupation. Hand excavations and screening of sediments encompassing the target occupation yielded chert flakes, snail shells, some mussel shells, many stone tools, charcoal, and intact hearth features. Included were lenses of charcoal and burned earth. Only four partially burned pieces of bone were recovered; these consisted of a distal end of a deer or antelope phalange and three small, unidentifiable slivers. Stone tools included 28 Tortugas points, 59 bifaces, two end scrapers, nine side scrapers, eight core scrapers, 43 flake scrapers, 11 gouges, 18 miscellaneous worked pieces, and one possible sandstone slab/abrader (Hartle and Stephenson 1951). A single charcoal sample yielded an uncorrected, uncalibrated date of 2700 B.C. $(4650 \pm 300$ B.P., lab and number unknown) (Suhm et al. 1954:565). This provides one of the few absolute dates for an isolated occupation containing Tortugas points (and possibly Matamoros points) in south Texas.

A second excavated site near Falcon Dam was the Royer site, 41ZP50 (originally 78-B9-17), which also yielded a discrete occupation with Tortugas points, but it was never dated (Cason 1952). This cultural zone was about $15 \mathrm{~cm}(6$ inches) thick and was buried $70 \mathrm{cmbs}(2.3 \mathrm{ft}$.) within the Zapata Terrace (Evans 1962). This zone yielded a heavy concentration of chert flakes, several hearths, and many chipped stone tools. All projectile points were triangular Tortugas types with slight variations in overall form. The tool inventory included about nine points, 17 blades (bifaces), two scrapers, three choppers, a pendant, a shell bead, a shark tooth, a piece of ochre, three mussel shells, some debitage, a painted shell, and quantities of charcoal.
After A.D. 1970, interest continued to increase, and many articles on various aspects of south Texas were written, especially after the formation of the South Texas Archeological Society in 1973. Many small surveys and some site-specific testing programs have contributed information to the region, but most investigations lack radiocarbon dates to place cultural events in a temporal context. The first broad-scale and in-depth archaeological project involving considerable excavations was the Choke Canyon Reservoir project on the Frio River in Live Oak and McMullen counties. This intensive investigation was near the center of the broad south Texas archaeological region. That project occurred over some 16 years and has provided a critical 12volume report series published between A.D. 1981 and 1986 . Volume 10 presents a summary of the Choke Canyon Reservoir area prehistory, which provides a best-guess chronological sequence supported by 30 radiocarbon dates from the testing phase archaeological investigations (Hall et al. 1986; Table 3.1).

Table 3.1 Cultural Periods and Age Estimates for Archaeological Materials in Choke Canyon Reservoir (after Hall et al. 1986).

\begin{tabular}{ll}
\hline Cultural Period & Age Range (B.C./A.D.) \\
\hline Paleoindian & $9200-6000$ B.C. \\
Early Archaic & $6000-2500$ B.C. \\
Middle Archaic & $2500-400$ B.C. \\
Late Archaic & 400 B.C. - A.D. $200-900$ \\
Hiatus (?) & A.D. $200-900$ \\
Late Prehistoric (early)A.D. $900-1400$ \\
Late Prehistoric (late) & A.D. $1400-1650$ \\
\hline
\end{tabular}

Although the entire cultural sequence is provided in the Choke Canyon summary, many cultural periods have not been firmly established by new radiocarbon dates from the project area. Much of the chronological sequence was extrapolated from the adjacent Central Texas and Lower Pecos regions where more excavations and radiocarbon dates have been obtained with associated artifact 
assemblages. Although the number of archaeological projects in south Texas continues to increase along with the number of prehistoric sites, more broad-scale site excavations with radiocarbon dates associated with diagnostic artifacts are needed to establish the contextual framework for this broad region. Until that is accomplished, extrapolations of cultural material and ages from better-known adjacent regions will continue to suffice.

Limited testing at sites 41ZP39 and 41ZP176 plus small scale data recovery at site 41ZP364 at Falcon Reservoir have recently added new data to the Archaic and our understanding of prehistoric upland use in that region (Quigg and Cordova 1999a, 1999b; Quigg 1999). The assemblages and radiocarbon dates from these few excavated sites provide supporting information from well-dated contexts about the south Texas Archaic period. The following discussion focuses on the Archaic of south Texas as represented from dated assemblages.

\subsection{THE ARCHAIC PERIOD IN SOUTH TEXAS}

Since the Lino site cultural material is part of the broad Archaic period (ca. 6000 B.C. to A.D. 600/ 700; Hester 1995), the following discussions focus on what is known for this long period. Many of the radiocarbon dates presented in this background section are those reported from the Choke Canyon Reservoir investigations and are presented in the literature as MASCA corrected ages (after Ralph, Michael, and Han 1973). As far I can tell, these ages are not $\delta^{13} \mathrm{C}$ corrected and are uncalibrated. Caution is required when comparing these reported ages to B.P. ages. At Choke Canyon, two excavated prehistoric sites41LK31/32 (Scott 1982) and 41LK51 (Hall et al. 1986) - fall within the Early Archaic period, whereas two excavated sites - 41LK201 (Hall et al. 1982) and 41LK67 (Brown et al. 1982) — had occupations during the Late Archaic period. Other information on the Archaic is derived from the Archaic cemetery at the Loma Sandia site (Taylor and Highly 1995) and sites 41ZP364, 41ZP39, and 41ZP176 at Falcon Reservoir (Quigg and Cordova 1999a, 1999b; Quigg 1999).

Investigations at Choke Canyon yielded a few artifacts believed to be representative of the Early Archaic period. These include the Guadalupe tool and Bell and Bandy dart points. Unfortunately, all the Guadalupe tools were from surface context, and only one generic "Early Expanding Stem" dart point that is similar to the Bandy type was recovered from subsurface context. That broken point came from $20 \mathrm{~cm}$ below a charcoal sample that yielded two uncorrected radiocarbon dates of $5860 \pm 80$ B.P. (TX-4691; MASCA 4450 B.C.) and $6360 \pm 90$ B.P. (TX-4690; MASCA corrected to 5130-5110 B.C.). This charcoal came from lot 248 in Unit N998 E982, level 15 at 41LK51.

At 41LK31/32, five stratified cultural zones were identified between 140 to $255 \mathrm{~cm}$ below datum over an excavated area of $80 \mathrm{~m}^{2}$ (Scott 1982). The $2+m$ thick alluvial deposits yielded nearly a $1 \mathrm{~m}$ thick zone of Archaic cultural deposits divided into five cultural zones that were designated Zones 2-6 from the bottom up. These zones contained 20 cultural features but only three diagnostic projectile points. Three radiocarbon dates from Features 1, 3, and 6 within Zones 2 and 5 yielded uncorrected charcoal dates of 4710, 4690, and 3970 B.P. respectively (Hall et al. 1982). The occupations in Zone 6 and above are thus younger than the 3970 B.P. date. A few Clear Fork tools (gouges), a Nolan, a Travis, a Lange point, and at least three Tortugas-like unstemmed triangular bifaces were part of the stone tool assemblage recovered from these dated zones. Tortugas-like points were associated with Feature 17, along with diverse occupational material in Zone 2 dating 4690 to 4710 B.P. The 20 cultural features were dominated by small burned-rock clusters 
associated with mussel and Rabdotus shells and lithic debitage. Features 6 and 11 in Zone 5, dating to 3970 B.P., were carefully constructed circular concentrations of burned chert cobbles with charcoal near the base of the rocks that measured ca. $110 \mathrm{~cm}$ in diameter. Feature 6 had a slight basin whereas Feature 11 was flat. The artifact associations are difficult to reconstruct because the material is presented by artifact class rather than occupational zones.

At 41LK51, 211 by $1 \mathrm{~m}$ test pits were excavated to depths reaching $200 \mathrm{cmbs}$ across five areas over a $120 \mathrm{~m}$ long section of a broad terrace (Hall et al. 1986). Cultural materials were analyzed in broad cultural horizons, each varying between 30 and $40 \mathrm{~cm}$ thick. Horizon 4 in Area A yielded materials from a $6 \mathrm{~m}^{2}$ area and roughly $150 \mathrm{cmbs}$. A charcoal sample from Feature 6 yielded two dates of $5860 \pm 80(\mathrm{TX}-4691)$ and $6360 \pm 90$ (TX-4690). Associated in Horizon 4 were 10 thin bifaces including some Tortugas-like points and one expanding stem projectile resembling a "Bandy" point. Horizons 2 and 3 in Area A of 41LK51 contain Middle and Late Archaic cultural materials as based on stratigraphic position. Unfortunately, these materials lacked supporting chronometric dates (Hall et al. 1986). The bulk of Archaic cultural material from these deposits included quantities of burned rocks, mussel shells, Rabdotus snail shells, lithic debitage, ground stone tools, bifaces, Clear Fork Tools, and identifiable cultural features. The presence of mussel shells and Rabdotus shells is thought to reflect subsistence remains (Hall et al. 1986). Two Fairland points and one distally beveled tool were recovered from mixed context in Area C.

For the Choke Canyon project, the temporal division between the Early and Middle Archaic periods was arbitrarily established at 2500 B.C. (4500 B.P.; Hall et al. 1986:398). The Middle Archaic was recognized by the occurrence of Pedernales, Langtry, and Morhiss projectile points. These points are demonstrated Middle
Archaic types in adjacent archaeological regions of Central Texas, Texas Coastal Plain, and Lower Pecos. Many thin bifaces assigned to Groups 2, 3,4 , and 5 in the Choke Canyon reports could be referred to as triangular Tortugas points. Distally beveled tools (gouges) were also part of the cultural assemblages found at Choke Canyon. These tool types are believed to represent the Middle Archaic cultures that are associated with radiocarbon dates from 2360 to 660 B.C. (ca. 4400 to 2500 B.P.).

In the Choke Canyon documents, some conflicting ages are reported for the Middle and Late Archaic periods. In the site-specific discussion on 41LK67, the Late Archaic dates are 1590 to 660 B.C. (Brown et al. 1982), but the summary volume dates the Late Archaic at 400 B.C. to A.D. 900 (Hall et al. 1986:401).

At site 41LK67, a valley margin-upland site with roughly $40 \mathrm{~cm}$ of deposition, two cultural zones were recognized with the lower and more widely distributed zone being assigned to the Late Archaic period. Nearly $195 \mathrm{~m}^{2}$ were excavated primarily from three blocks across this broad upland setting. Four radiocarbon dates on charcoal and one date on mussel shell from three separate features (Features 5, 8, and 25) yielded uncorrected ages ranging between 2200 and 3300 B.P. (400 to 1500 B.C.; Brown et al. 1982:167). The Late Archaic zone contained more than one occupation event and possibly had some materials from other periods mixed together. The Late Archaic zone in Area A encompassed a $120 \mathrm{~m}^{2}$ block area that yielded an Ensor, a Tortugas, a Fairland/Ensor, two distally beveled bifaces (gouges), a metate and metate fragment, quantities of burned rocks, mussel shells, and 11 features. This diverse assemblage is believed to be associated with a charcoal date of $780 \pm 70$ B.C. (TX-2902) from Feature 5. A $64 \mathrm{~m}^{2}$ block in Area $\mathrm{C}$ yielded a Late Archaic zone below a Late Prehistoric zone in the top $20 \mathrm{cmbs}$. Five burnedrock features and quantities of lithic debitage and 
mussels shells were present. Both Blocks A and $\mathrm{C}$ also yielded a few fish otoliths, but no other bone was preserved.

At site 41LK201, the Phase II investigations yielded a Late Prehistoric occupation overlying multiple Middle and Late Archaic occupations. Radiocarbon dates of 1300 B.C. and 840 to 820 B.C. (Hall et al. 1986:398-402) indicate the presence of Middle Archaic occupation events. Horizon 4 in Area A yielded one large hearth (Feature 2) but no diagnostic projectiles. In Area $\mathrm{B}$, one Pedernales point, one distally beveled biface (gouge), and three features (Features 7, 8, and 9) were associated with a charcoal date of 840 to 820 B.C. Just below that was a Kinneylike or possibly a Tortugas point. Horizon 3 yielded a cultural assemblage indicative of Archaic events, but it is unclear if they are Middle Archaic or Late Archaic or a combination of both (Brown et al. 1982). Area A yielded an Ensorlike point, a thin triangular biface (Tortugas), a large stemmed biface, one distally beveled Nueces scraper, and a burned rock (Feature 5). Feature 5 consisted of a 60 by $35 \mathrm{~cm}$ oval of tightly clustered burned rocks with some charcoal, chunks and sticks, and ashy matrix with some oxidation/ backed clay that yielded charcoal dated to 480 B.C. Although it is difficult to tell from the description, it seems that this was a shallow basin filled with burned rocks and was an in situ feature. Area B yielded four distally beveled tools (gouges). A Morhiss point from Horizon 2 of Area B appeared to be out of context.

Of the seven burned rock features in these Middle to Late Archaic deposits, only Feature 2 is considered a pit (Brown et al. 1982). Charcoal from Features 5 and 7 contained wood identified as Acacia or Prosopis whereas charcoal from Feature 2 was identified as Quercus and Prosopis sp. Faunal remains from the Archaic horizons include a vast array of resources including fish, bird, turtle, snake, deer, mussel and Rabdotus shells, bison, bobcat, badger, rabbit, and rodents. These same food resources were also present in the upper Late Prehistoric horizons. It is not clear which of these resources were part of the Archaic subsistence base since some turbation was present in these shallow deposits. The single distal bison phalanx in Archaic Horizon 4 that dates to about 480 B.C. could have been displaced from the Late Prehistoric Horizon 1 that contained numerous bison remains dating from about A.D. 1500.

In general, the presence of stemmed dart points including Ensor, Frio, Ellis, Marcos, and Fairland types at Choke Canyon were used to identify Late Archaic period occupations. Distally beveled tools (gouges) were recovered from 13 sites that yielded Late Archaic point types, and therefore seem to be associated. Also associated with the identified Late Archaic point types were nondiagnostic cultural materials including quantities of burned rock, lithic debitage, mussel and Rabdotus shells, grinding stones (manos and metates), modified and trimmed flakes, and bifaces.

The Loma Sandia cemetery site (41LK28), located about $8 \mathrm{~km}$ east of Choke Canyon Reservoir, has added a great deal to our knowledge of the late Middle Archaic period. The tentative time period for the Middle Archaic was placed between ca. 2500 and 400 B.C. (ca. 4500 to 2500 B.P.). Although projectile points representative of the entire cultural continuum were represented at Loma Sandia, only the late Middle Archaic is represented in unmixed contexts (Highley 1995:649). This stratum contained some 205 human burials directly associated with many diagnostic artifacts and provides an inventory of tool forms, ornaments, and other material remains for a very limited time period between roughly 450 and 850 B.C. (2400 and 2800 B.P. uncorrected and uncalibrated ages [Taylor 1995:842]). At least two Early Archaic (Andice and Lange) and one Middle Archaic (Pedernales) projectile points 
were in context, indicating that these diagnostic projectiles were collected and curated by later groups.

Considering only the cultural materials from the cemetery context, the diagnostic points include 122 Tortugas, 22 Lange, eight Abasolo, three Morhiss, one Carrizo, one Palmillas, one Refugio, and 10 unclassifiable straight stemmed and expanding stemmed points. Other material remains include two clusters of rounded and smoothed flakes interpreted as contents of perished rattles, cores, thick and thin bifaces, small distally beveled tools, a perforator/drill, unifaces, trimmed flakes, hammerstones, manos, metates, stone pipes, deer antlers, and modified marine shells. The dominant Tortugas point co-occurred with Abasolo, Lange, Morhiss, and Refugio point types. The Tortugas points occurred in a wide range of sizes with beveled and unbeveled blade edges, and some occurred with straight sides and others with convex edges. The range of blade lengths encompassed what have previously been classified as Tortugas dart and Matamoros arrow points. Analysis of the Loma Sandia triangular points indicates that the smaller Matamoros forms are reworked and smaller versions of the Tortugas, and they thus represent part of one broad continuum in size (Highley 1995).

The six separate charcoal dates from the cemetery context, ca. 850 to 550 B.C. (2400 to 2800 B.P.), definitely place the Tortugas and the Matamoros points into the latter part of the Middle Archaic period.

Some 205 human burials were excavated, and although many were directly associated with utilitarian tools, many items such as the tubular pipes, marine shell ornaments, unmodified marine shells, incised bone tools, deer antlers, kaolin, ocher, and shark and stingray teeth probably reflect personal wealth or status symbols. Since almost all the utilitarian and ornamental items were equally divided between males and females, status differentiation did not occur along gender lines.

Upland campsite 41ZP364 at Falcon Reservoir also contains stratified Archaic deposits (Quigg and Cordova 1999B). Tortugas points were found in well-defined occupation zones and were associated with multiple radiocarbon dates. In the area of BT 11, a Tortugas point was associated with two charcoal dates of 4620 and 4820 B.P. (Beta-112422 and 110798). Twenty centimeters above this occupation zone was another occupation that yielded a Matamoros point associated with a charcoal date of 2630 B.P. (Beta110797). Some $20 \mathrm{~cm}$ below the well defined Tortugas occupation was a distally beveled tool that was generally associated with two dates on Rabdotus shell, which, when adjusted for modern age anomaly, yielded dates of 7846 and 8226 B.P. (Beta-107643 and 111646). High-powered microwear analysis on Tortugas points showed many were multi-functional tools used in a range of cutting and scraping activities (Church 1999). A distally beveled tool (gouge) was determined to have been used on wood (Church 1999).

In the area of BT 25 at 41ZP364, an adjusted Rabdotus shell date of 3060 B.P. (Beta-112322) was associated with two Tortugas points. A burned-rock cooking apparatus on a flat surface stratigraphically below the later date was determined to be about 6900 B.P. based on three organic residue dates (Beta-116147, Beta-123597, and Beta-123598). This feature indicates Early Archaic use of burned-rock cooking features along the Rio Grande. Wood from Prosopis sp. is present by at least 4800 B.P. (Dering 1999). Although pollen was not preserved, phytoliths were recovered, and two column assemblages show that the Falcon Reservoir region was dominated by short grasses spanning at least the last 8,000 years (Jones 1999). A slight but noticeable shift toward more-moist conditions occurred at about 4000 B.P (Jones 1999). Fatty 
acid analysis on organic residues extracted from the interior portions of burned rock indicates that plant materials were mostly being cooked (Malainey 1999).

Upland sites 41ZP39 and 41ZP176, which are also in the Falcon reservoir area, yielded a number of small burned-rock clusters stratified in 70 to $80 \mathrm{~cm}$ thick Holocene eolian deposits (Quigg and Cordova 1999a; Quigg 1999). Based on one wood charcoal, 12 Rabdotus shells, and three organic residue dates, these small burned-rock features were apparently in use from about 5000 B.P. No projectile points or distally beveled tools were directly associated with these burned-rock features to contribute to the building of the chronological framework of diagnostic tool forms.

A framework of an environmental/culturalecological approach to the archeological record incorporates the environment, the archeological record, and a theoretical framework to view and discern changes in basic patterns of huntergatherer strategies and mobility through time. Unfortunately, the Rio Grande Plains region has been subjected to limited in-depth excavations, which have yet to produce specific aged assemblages, and to limited in-depth analyses. Therefore, inferences concerning site-specific functions, behaviors, and activities have been limited to the more obvious patterns. It is hoped that more in-depth excavations and analyses will contribute more data to the investigation of broad-based behavioral patterns.

\subsection{PALOENVIRONMENTAL RECONSTRUCTION FROM 4500 TO 1500 B.P.}

Spotty and diverse regional paleoenvironmental data are available for south Texas and northern Mexico. In the Lower Rio Grande Valley delta region of south Texas, archaeological investigations utilized stable carbon and oxygen isotope data extracted from carbonates and soil humates to provide interpretable information (Bousman 1990). Those results indicate that the plant communities in the Rio Grande delta region were dramatically different in the late Pleistocene/ early Holocene (C4 and/or CAM plants comprised roughly 60 percent of the vegetation) compared to the late Holocene period (when C3 plants dominated 65 to 85 percent of the communities). Extrapolation of Bousman's data (Figure 41:1990) indirectly implies an increase in the frequency of $\mathrm{C} 3$ plants from a low of 40 percent at roughly 10,000 B.P. to nearly 85 percent by 2700 B.P. The plant communities during the late Holocene have not been stable; C4/CAM plants apparently have increased rapidly over the last 2,000 years (Bousman 1990).

The modern mean annual temperature in the Lower Rio Grande Valley is 22.8 degrees C (73 degrees F), whereas the mean annual temperature estimated for 17,350 B.P. was 17.2 degrees C (63 degrees F) based on oxygen and carbon stable isotopes. Bousman (1990) sees that by 15,000 B.P. the plant communities were dominated by $\mathrm{C} 4$ and CAM species. This represents an increase in the average temperature of about 5.6 degrees $\mathrm{C}$ ( 10 degrees F) since the last glacial maximum to the present day (Bousman 1990:97).

In the Coastal Bend region of Aransas County, the Swan Lake site yielded evidence that the sea level was about 90 to $120 \mathrm{~cm}$ higher than present from about 4500 B.P. to about 2500 B.P. (Prewitt and Paine 1988). What effects the higher sea level would have had on the plant community composition of the interior are not known. The higher sea level would relate to smaller ice caps that would have resulted from a general warming period.

A nearly 8,200-year-old phytolith record from upland site 41ZP364 at Falcon Reservoir reflects a dominance of $\mathrm{C} 4$ grasses (Quigg and Cordova 
1999b). An increase in calcium oxalate crystals sometime prior to about 4000 B.P. may indicate the abundance of various cactus species. The decreases in calcium oxalate crystals in the upper parts of two profiles sometime after about 4000 B.P. coincide with increases in Panicoid biobate grass and cross-shaped phytoliths, which may reflect slight increases in moisture after 4000 B.P. This general age and apparent shift to slightly more-moist climatic conditions generally coincides with the termination of the general Altithermal/Hypsithermal period documented farther north.

In general, beginning very early in the regional Holocene environment, south Texas apparently had xeric conditions dominated by $\mathrm{C} 4$ grasses. Fossil pollen records from Cueva de la Zona de Derrumbes cave site, located several hundred kilometers south of the Rio Grande in Nuevo Leon, reflect a stable vegetation record over the last 5,000 years (Bryant and Riskind 1980).

Stable carbon and nitrogen isotope analyses of matrix from an $80 \mathrm{~cm}$ thick natural column at upland site 41ZP364, BT 22, revealed a general trend beginning 8200 B.P. (Quigg and Cordova 1999b). That evidence was similar to a modern upland grassland community in south Texas that reflects a $\mathrm{C} 4$-dominated mixture of $\mathrm{C} 3$ forbs and C4 grasses (Boutton et al. 1998:17). From about 5600 B.P. to recent historical times, the $\delta^{13} \mathrm{C}$ isotope results documented a 2.1 parts per thousand (\%o) increase from $-19.7 \%$ toward a more positive value of $-17.6 \%$. This gradual increase in the $\delta^{13} \mathrm{C}$ values may reflect a gradual drying/warming trend dominated by $\mathrm{C} 4$ grasses. The more positive $\delta^{13} \mathrm{C}$ value from the surface context reflects about a 15 percent increase in C4 grasses throughout this nearly 8,200-year period. The isotopic trend does not reflect any major vegetation shifts in the kinds of plants, just subtle changes in the frequency and composition of the community. Climatic shifts may have occurred during this period, but they may not have lasted long enough to change the vegetation pattern sufficiently to alter the isotope signature.

The $\delta^{15} \mathrm{~N}$ isotope data from the column at 41ZP364 revealed major shifts from $80 \mathrm{cmbs}$ to the surface. Prior to about 5756 B.P. and below $70 \mathrm{cmbs}$, a major increase of $2.5 \% \delta^{15} \mathrm{~N}$ occurred that may reflect an increase towards a more grassland-dominated community. For the next few thousand years to about 1000 B.P., the vegetation appeared to be stable with $\delta^{15} \mathrm{~N}$ values that varied between about 7.4 and $8.1 \%$ o between 70 to $30 \mathrm{cmbs}$. After about 1000 B.P. at a depth of $20 \mathrm{cmbs}$, a dramatic decrease of $2.5 \%$ occurred in the values of $\delta^{15} \mathrm{~N}$. This latter dramatic decrease in the $\delta^{15} \mathrm{~N}$ values may reflect a decrease in the grassland community and the advancement of more mesquite trees and legume plants that yield a decrease in $\delta^{15} \mathrm{~N}$ values. Modern south Texas C4 grassland communities typically yield $\delta^{15} \mathrm{~N}$ values of $7.9 \pm 0.7 \%$, whereas modern sediment from under a mesquite tree cluster yielded a more negative value of about $6.2 \pm 0.7 \%$ (Boutton et al. 1992). Based on this modern isotopic data a change of $1.7 \%$ o documents the difference from a recent mesquite tree invasion to previously open grassland. The isotopic data from 41ZP364 at Falcon Reservoir (Quigg and Cordova 1999b) do not parallel Bousman's (1990) findings in Williams and Hildago counties, where C3 vegetation dramatically increased to dominate the vegetation by 2700 B.P.

About $600 \mathrm{~km}$ south of Laredo, at a cave called Cueva de La Zona de Derrumbes in the Rio Santa Rosa Valley of southeastern Nuevo Leon, pollen records from about 5000 B.P. and about 3000 B.P. indicate some general changes in the environment. During that period, grass, mesquite, sotol, and cactus pollen all increased about five percent, agave increased nearly 55 percent, and pine decreased about 18 percent (Bryant and Riskind 1980). Insects and/or humans transported many of the pollen grains 
to this cave, thereby adding a cultural bias to the samples over that from normal wind-derived pollen rains.

Roughly $50 \mathrm{~km}$ south of Laredo at Boca de Potrerillos in the eastern margin of the Sierra Madre Oriental, massive erosion documented a period of regional environmental stress around 4800 to 5600 B.P. (Turpin et al. 1994). The Coconos subarea of the Boca de Potrerillos site yielded pollen data from two alluvial contexts and one cultural hearth feature. This intermontane desert was formerly a grassland and wetland region, and it reflects a decrease in moisture over the last 1,400 years (Turpin et al. 1993).

In the Lower Pecos region of Texas, Bryant (1966) recognized that xeric conditions existed up until about 3000 B.P. Before 3000 B.P. saw increases in percentages of Cheno-ams and other xerophytic herb pollen. Between about 3000 and 2300 B.P. the pollen columns at Bonfire Shelter and Devil's Mouth site show a resurgence in percentages of grass, pine, and sedge pollen and decreases in Ephedra and Chenoam pollen types that are characteristic of cooler, more mesic conditions (Bryant 1969).

In the El Paso, Texas, region, paleoclimatic studies using stable carbon and oxygen isotopes extracted from pedogenic carbonates showed a similar shift from xeric $\mathrm{C} 4$ grassland to more mesic C3 desert scrub around 8000 B.P. (Monger 1993). This change was accompanied by increased erosion, development of alluvial fans in the mountains, and desert conditions to the basin floors. Other evidence for a vegetation change at 8000 B.P. was documented in packrat middens in the Hueco Mountains near El Paso (Van Devender 1990). However, $\delta^{18} \mathrm{O}$ values in alluvial fan soils suggest late Pleistocene temperatures were not drastically cooler than Holocene temperatures (Monger 1993:139). North of El Paso, in the Fort Bliss region, three prehistoric eolian deposits on the basin floor have been identified with tentatively assigned ages of 100 to 1100 B.P. for Organ I deposition, 1100 to 2100 B.P. for Organ II deposits, and 2100 to 7000 B.P. for Organ III deposition (Monger 1993:134).

A short mesic period is thought to have occurred throughout much of Texas at roughly 2500 B.P. (Bryant 1969; Bryant and Shafer 1977; Bryant and Holloway 1985; Collins et al. 1993). But in Central Texas, carbon isotope data on organic matter from alluvial settings at Fort Hood reveal an increase in C4 plants around 2000 B.P. that may be indicative of a brief drying and a slight warming episode (Nordt 1993). Furthermore, Central Texas bog pollen does not reveal any evidence to support a brief mesic period about 2500 B.P. (Bryant and Holloway 1985:62). It is unclear if the conflicting data are a regional difference or a variation in results from using different data sets.

\subsection{RESEARCH ISSUES}

\section{Chris Lintz}

This section discusses the theoretical issues that focused field and analytical methods for data recovery at the Lino site $41 \mathrm{WB} 437$. It was written as the pre-field research design in response to the TxDOT Invitation for Bids (IFB), which stipulated the general research domains. Many new approaches have been developed within the past five years, and some approaches were adapted into the research design.

\subsubsection{Site Formation Processes Contextual Framework}

The site formation processes pertain to the geomorphological development of the alluvial terrace formation within the San Idelfonzo Creek basin and its relationship with the Rio Grande floodplain. The issues relate to the periodicity 
of sediment deposition, the genesis of sediment packages, the pedogenic processes that have modified the sediments containing the archaeological remains, and the degree of integrity remaining for the archaeological components that were developed on floodplain settings. The geomorphology of the terraces along San Idelfonzo Creek is critical for providing the context for interpreting how the site formed and perhaps the way it was used.

\section{Site Formation Processes Methods}

Most salient data to address this issue relate to geomorphic observations on the deposits present in the walls of the excavation block and cut bank that provide information on the formation of geomorphic units, the presence of erosional nonconformaties, abruptness of sediment boundaries, and the visual impression of soil developments. These results need to be supported by various laboratory studies of the sediments. Particle-size analysis helps delineate the sources of the sediments (alluvial vs. colluvial vs. eolian) by defining the depositional environment. Percent organic and carbonate contents provide information on the presence of soil development and the locations of stable land surfaces suitable for human occupation. In addition, the A/I ratios for snail shell epimerization results provide information about the integrity of the deposits and the rapidity of occupation surface burial.

Information about the agents and severity of occupation surface disturbance can be gained from the close study of the horizontal distribution of burned rocks and artifacts of various size and shape classifications. Since periodic flooding along the creek is the main natural force to move artifacts, the artifacts most apt to be displaced are the smaller items with spherical or tabular shapes before the heavier and more blocky artifact forms. If considerable quantities of materials have been translocated, then the epimerization $\mathrm{A} / \mathrm{I}$ ratios from a series of land snail shells should show a heterogeneous and non-consistent patterning. Many other agents can also move small artifacts, such as termites, ants, and roots.

\subsubsection{Chronology and Cultural Affiliation Contextual Framework}

The antiquity of the multiple components is critical for comparing the different assemblages to other assemblages found beyond the immediate site area and for evaluating the rate of culture change at the Lino site. The age of the occupation can be derived from several chronometric procedures. Charcoal, which is usually rare in south Texas burned-feature contexts, was surprisingly present in five of the seven features $(1,2,3,6$, and 7$)$ encountered during the testing phase at 41WB437. Although the frequency of charcoal was not documented, it is advantageous to stipulate the routine use of the more-expensive accelerator mass spectrometry (AMS) carbondating method to obtain reliable results from small organic samples and to date single minute chunks of identified wood for increased provenience and interpretative precision. Recently, AMS dates on organic residues extracted from the interiors of sandstone feature rocks occur in general agreement with dates of associated charcoal flecks from the same features (Quigg 1999; Quigg and Cordova 1999b). Thus, in situations where charcoal has been removed by water or wind, it is now possible to date specific feature events when sandstone is utilized. The antiquity of occupation zones can also be derived from radiocarbon dating of bones, snail shells, and mussel shells that may be debris from the occupation found directly on the buried occupation surfaces. A considerable body of data is emerging from numerous chronometric studies conducted in Texas on cross-dated materials including charcoal, bone, shell, mussels. (Quigg and Peck 1995; Collins 1994; Quigg and Cordova 1999b). These studies yield correction factors 
that must be applied to obtain accurate ages when radiocarbon dating has involved various kinds of substances.

The cultural affiliation of specific components is usually defined on the basis of associated "diagnostic" tool forms, usually projectile points/knives. Although there is no necessary correlation between a single diagnostic tool form and a single cultural group, the occurrence of a simple form (e.g., unnotched point tradition) generally denotes a relative degree of contemporaneity and shared cultural interactions. The distribution of diagnostic points allows archaeologists to draw comparisons between diverse site assemblages so that a range of behaviors and regional settlement-subsistence patterns can be delineated. The inference about interaction is strengthened if the multiple assemblages date to the same time periods and utilize the same lithic and mineralogical resources.

On the other hand, the occurrence of substantially diverse diagnostic tool forms on a single occupation surface might represent contemporaneous or near-contemporaneous use of the site by groups participating in different manufacturing traditions, trade/exchange, artifact recycling or reuse from older occupations. Their occurrence perhaps might also represent diversity in technological strategies by a single group to produce functionally different implements. Some of these possibilities can be sorted out provided that different raw-material patterns are present and manufacturing debris is recovered. For example, recycled and traded/exchanged artifacts are not apt to leave manufacture debris at the site. Recognition of the raw-materials source areas for distinctive stones, pottery, or marine shells provides useful clues to the direction of interaction and/or movement of groups. Functional differences between the unnotched and stemmed point traditions may be discerned from high-resolution use-wear analysis on a series of implements.

\section{Chronology and Cultural Affiliation Methods}

The absolute age of the various occupation surfaces/zones is ascertained primarily from the AMS dating of macrobotanically identified charcoal or organic residues in burned sandstone, mostly from feature-based contexts or in occupation zones. Data on stable carbon isotopes are sought to provide the necessary calendrical correction factors for radiocarbon dates. AMS dating may also be conducted on recovered bone, freshwater mussels, and Rabdotus shells. The relative dating of snail shells in the deposits by amino acid epimerization methods are to be used when more conventional dating methods are not available to derive the ages of critical components.

After discrete occupation surfaces/zones have been identified, the occurrence and association of diagnostic tool forms are to be checked to assess the homogeneity of the assemblage to ascertain whether the unnotched point tradition co-occurs with the stemmed point tradition. If multiple technological patterns are present on the same assemblage, a comparison of assumed ages of "diagnostic tools" would be made to determine whether some tools were recycled from older occupations. The color, texture, and kinds of lithic material types of "diagnostic" implements can be assessed and compared to manufacturing debris stages on the occupation surface and/or recognized sources of tool stones to assess the indigenous occurrence of implements. Exotic materials (marine shell, obsidian, turquoise, pottery, etc.) can be sought and the sources and direction of cultural interaction examined based on the location of known source areas for these materials. Tools, debitage, macrobotanical and faunal remains, and residue results provide data for interpreting activities. High-power magnification use-wear 
analysis can be preformed on a series of implements to determine whether diagnostic implements were used in specialized or generalized functions.

\subsubsection{Subsistence Contextual Framework}

Even though the prehistory and cultural sequence of the south Texas archaeological region is in the early stages of delineation, there is general agreement that most groups throughout prehistory in this area were hunter-gatherers (Hester et al. 1989; Hester 1995). From a cultural-ecological perspective (cf. Steward 1973), it is reasonable to infer that the core cultural elements are most directly affected by subsistence needs, including the scheduling and duration of occupation, the frequency of group movements, and the technologies necessary to procure and process resources into products useful for human consumption. The development of data on subsistence practices is one of the more important research issues in the region. The debate regarding conceptually defining logistical collectors vs. gatherers may work well on a synchronous, regional level involving multiple site locations, but it is not relevant to the diachronic investigations of stratified deposits at a single site. The diachronic investigations of remains from a single location are ideal for examining culture change, since many environmental variables are held constant for a specific place. Differences in subsistence remains, residues, and implements evident between separate occupations at a specific location may be attributed to variations in group size, duration of occupation, season of usage, size and configuration of resource catchment area, and the focal (specialized) or diffuse (generalized) resource exploitation strategy used by people.

Several constraints operate on subsistence studies in south Texas. Foremost is the poor preservation of faunal remains (except shells) and the lack of marked seasonal differentiation based on temperature variability. Open sites in south Texas are renowned for their generally poor preservation of floral and faunal remains. During the testing phase at the Lino site, charcoal appeared to be associated with five of seven feature contexts (Abbott 1997). Small quantities of unidentifiable fragments of a thick bone recovered from Feature 3, and the small quantities of freshwater shell fragments associated with Features 1 and 3, in Test Units $1,3,5$, and 6 , and in backhoe trench walls, are more typical of the poor preservation of faunal remains in the region (Abbott 1997).

The recovery of robust data on site subsistence must rely on both direct and indirect data. Seasonal differences in plant availability/ production in Webb County relate more to precipitation variability than to temperature difference. The lack of severe summer-winter seasonality differentiation in temperature means that traditional methods used to discern seasonality in the northern latitudes (dental annuli on deer/bison, growth bands on fish otoliths and mussels, etc.) may not be reliable indicators of summer or winter months in south Texas (c.f. Clark 1987: 40). The applicability of deer/bison tooth eruption and wear pattern studies, which is predicated on a relatively brief yearly calving season necessitated by short growing periods, also needs to be assessed for south Texas. The general birthing period may not be so narrowly defined as that of the cooler latitudes. Some biotic resources (including cactus pads and tunas as well as mesquite and Texas ebony legumes) ripen or stay edible primarily in response to rainfall availability rather than temperature changes.

Tactics for collecting data for reconstructing subsistence patterns must employ a combination of direct and indirect physical evidence of the floral/faunal remains, complemented by usewear evidence on the prehistoric implements. 
Ideally, the data sets should be from unambiguous archaeological contexts, preferably features matrices or defined and traceable occupation surfaces. Critical data needs for addressing this research issue include: 1) identified floral remains, 2) identified terrestrial and aquatic faunal remains, 3) phytoliths from feature context matrices, 4) stable carbon and nitrogen isotopes from residues on/in burned rock, 5) lipid residues on burned rock and stone tools, and 6) high powered use-wear analyses of stone tools to ascertain the relative frequency of tools used on wood, bone, hides, etc. Finally, data obtained from the growth structure of fish otoliths, ungulate teeth, and mussel shells along with wear patterns on ungulate teeth provide less reliable indications of seasonal delineation.

\section{Subsistence Analysis}

All aquatic and terrestrial faunal remains from feature and column flotation samples, general excavation units, and graded strips can be identified wherever possible. Charred plant remains from flotation samples of feature contexts can be submitted for identification. Phytolith samples from feature matrices at 41ZP39 and 41ZP364 have yielded nonindigenous remains of gourds from hearth features in Zapata County (Quigg and Cordova 1999a, 1999b), and comparable approaches may yield useful data at 41WB437. Stable carbon and nitrogen analysis of residues from burnedrock features provide information on the use of legumes (C3 plants high in nitrogen) and the photosynthetic grouping of general plants cooked in the rock features. Lipid residue data from burned-rock features provide direct subsistence evidence and corroborate the stable isotope data. High-powered use-wear analysis of stone tools also provides indirect inferences about the kinds of resources present, and in conjunction with physical and chemical results, provides information on the resource diversity at 41WB437. Comparison of data sets from multiple occupations can yield information trends useful to ascertain subsistence changes through time. Seasonality data focus on deer/ bison tooth eruption/wear, fish otoliths, and recovered floral remains. Species identifications of mussel shells may indicate whether the resources were obtained from the immediate creek or the more distant Rio Grande habitats.

\subsubsection{Paleoenvironmental Studies Contextual Framework}

While it is widely accepted that the modern plant communities of south Texas have been severely altered from overgrazing of historically introduced livestock, there is little consensus about whether the prehistoric environmental conditions have changed. If environmental change has occurred, the timing and integrity of the change is also not well understood. Empirical data about past conditions are critical for understanding human responses and adaptations. The sources of environmental indicators are from cultural refuse/residues and from non-cultural indicators.

Comparable to packrat behaviors, humans tend to harvest plant and animal indicators of the environment from their surroundings and concentrate them at residential and campsites. These culturally selected materials, along with the naturally occurring components in the sediments, form a rich data field that can be used to derive inferences about past environmental conditions. Identification of macrobotanical remains (seeds, charcoal, etc.) and the recovery of animal remains (bones, shells, etc.) provide insights into the biotic communities near the site. Whereas the catchment models have generally assumed a human procurement radius of about $10 \mathrm{~km}$ for hunter-gatherers, the geometry of resource procurement is apt to be distorted in various selected directions in response to resource preferences. The degree of biotic 
reconstructions based on environmental indicators that have been manipulated by humans undoubtedly yields a distorted reconstruction. Nevertheless, the comparison of floral and faunal remains from multiple occupations at the same location can useful for documenting gross biotic changes in the region.

The kinds of remains less apt to be biased by human behavior involve stable isotopes from plant and pedogenic development and microbiotic remains that tend to be too small to be of concern to people. Stable carbon and nitrogen isotope data and phytoliths from soil horizons should provide data about the relative proportions of $\mathrm{C} 3$ and $\mathrm{C} 4$ varieties of plants as well as the relative occurrence of legumes (such as mesquite) present in the region. Diatoms and ostracods could also provide information on the regional water quality.

\section{Paleoenvironmental Studies Methods}

To reconstruct the paleoenvironmental conditions, stable isotope studies and identification of macrobotanical remains (seeds and charcoal samples) are needed from each of the occupation zones. The identification of animal remains can also be routinely used to infer conditions. In conjunction with the site formation studies, sediment particle size analysis can be performed. In addition, a column of sediment samples spanning all the excavation surfaces in the target zones can be split into four parts and processed for carbon and nitrogen isotopes, phytoliths, and pollen. The identical context for these samples provides the opportunity for a powerful correlation of environmental factors especially in the context of the geomorphic descriptions of the sediments. Finally, diatoms can be extracted from sediment samples to provide information about water quality. Pollen analysis is usually regarded as another approach to reconstructing environmental conditions; but recent studies conducted in Zapata County have yielded negative or statistically inadequate results for meaningful interpretations (Quigg and Cordova 1999a). This poor pollen preservation pattern generally holds throughout the region (Phil Dering, personal communication 1998). Although the author is not recommending the use of pollen studies, pollen samples are to be collected from the vertical sediment column samples in the block. If mussel shells are found in stratified features, oxygen isotope data can be conducted to reconstruct paleotemperatures.

\subsubsection{Burned Rock Technology and Data Content Contextual Framework}

Burned rocks are the most easily recognized expression of cultural activities and probably represent the most abundant material in huntergatherer sites. The rocks are nearly indestructible, and the degree of dispersal/ clustering, size, and position relative to the occupation surface is informative about various food-processing activities and discard patterns of the prehistoric occupants. Associated rocks constitute features, which are the archaeological focus for identifying behaviors relating to heating, cooking, or otherwise converting through heat other resources into useful products. Geometry of the rocks on/in the living surface, degree of clustering, association with charred/ash materials, and oxidization surfaces are attributes helpful in distinguishing how the burned-rock features were constructed as well as distinguishing in situ burned-rock features from secondary dumps.

A major theoretical and interpretative shift has occurred in the past decade away from the gross morphological form of generalized features toward the detailed study of the physical/ chemical properties of burned rocks and the residues on these rocks (Collins 1991; Black et al. 1997). Considerable progress has occurred in compiling the ethnological record on the use 
of burned rocks and the alterations occurring to hot rocks that allow archaeologists to make more powerful observations on the use/reuse of burned rock features (Ellis 1997).

The re-firing of rocks generally results in reducing heated cobbles to smaller pieces. Usually rock fragments in the 2 to $3 \mathrm{~cm}$ size range are regarded as too small for reuse. Thus, the average burned rock weight is a useful measure of size, potential re-firing, and perhaps of heat-use intensity. Different kinds of rocks also obtain, retain, and disperse heat differently. The thermal conductivity of rocks was undoubtedly an important consideration in the selection of the kinds of materials to be used in cooking. Recent claims that differences in the shape of the fractures and form of broken cobbles relates to roasting in air (slow cooling) vs. boiling liquids (quick cooling) have not been statistically verified. Nevertheless, the rock cooling rate does affect the magnetic properties of rocks, and it is possible to separate stone boiling cobbles from roasting pit rocks on the basis of magnetic properties (Takac 1999). The thermal demagnetization of burned rocks also provides information on the temperature gradients of the features as well as whether the rocks are in situ or have been moved since they were last heated to the Curie temperature. The heating also resets the charged particles trapped in the quartz lattice structure of sandstone so that, theoretically, burned sandstone rocks are suited for thermoluminescence dating.

\section{Burned Rock Technology and Data Content Methods}

Documentation of the basal elevations of rocks relative to the living surface using the TDS plottings, coupled with field observations of context and associations with oxidized surfaces and degree of clustering, provide preliminary data about the nature of feature construction and rock disposal. Burned-rock features can be mapped, and both plan and profile observations can be made on the context, integrity, and associations of burned rocks, artifacts, and samples in the feature contexts. Rock density and angularity studies and archaeomagnetic thermal demagnetization data from in situ rocks provide information to ascertain the extent of rock re-use in thermal features, the cooling histories, and whether the rocks were used in roasting or boiling activities. The homogeneity of rock densities within a feature should provide information about the reuse of features. Macrobotanical identification of charcoal from the feature's flotation samples provides data on the type and diversity of fuels used in the hearths. The stable isotope data from residues in burned rocks also provide important data on the use of the features.

\subsubsection{Site Structure and Organization Contextual Framework}

Site structure and organization relates to both the synchronous patterning of activities as represented by artifacts, debitage and features on a single living surface (component), and the diachronic changes in organization of space through time as represented on multiple living surfaces. Subsumed in this latter aspect is the ability to identify the number of occupations present in the upper $120 \mathrm{~cm}$ of the terrace fill and to recognize the geometry of each living surface. The number of occupations can be independently verified through magnetic susceptibility studies of a column of sediment. The structure apparent in the archaeological record is also a function of the duration of surface utilization and the degree of activity overprinting occurring on each surface. Short-term occupations have the clearest expressions, while those with longer duration are apt to have overlapping and smearing of activity remains. Critical for the interpretation of the prehistoric behaviors is the ability to recognize primary contexts or usage abandonment areas from 
evidence of site maintenance as reflected by secondary dumping events (Quigg and Peck 1995; Quigg 1997; Quigg and Cordova 1999b). Dump episodes are apt to be mounded residues (mussel shells/bone, fire cracked rock, etc.) on and above the occupation surface or consist of materials devoid of logical correlates such as the clustering of fire cracked rock that lacks the associated oxidized surface of in situ firing. In contrast, most kinds of in situ features are recognized on or extending into the occupation surface.

Post-depositional factors must also be considered in analyzing and interpreting the pattern of cultural remains. Translocation of artifacts after site abandonment by the processes of wind, rains, flooding, and plant/animal displacements must be evaluated from the context and associated patterns of materials on the occupation surfaces. The sediment texture can be used to help distinguish contexts of redeposition from those of site abandonment.

\section{Site Structure and Organization Methods}

The most common method for identifying the number of occupations and the geometry of the various living surfaces involves "back plotting" artifacts, features elements, and debitage elevations from the TDS and adjacent profiles of the excavation block. Magnetic susceptibility studies of the sediment profile may help isolate the locations and frequency of occupations. After the number and geometry of the living surfaces have been identified, then plan maps for each component can be developed using the same elevation data sets to discern the segregation of activity areas. The horizontal patterns of artifacts, debitage and feature elements provide the spatial patterning needed to assess the association of related materials and the discreteness of activity areas for each occupation zone. In addition, epimerization (A/
I ratio) results from processing multiple Rabdotus shell samples from a cultural surface provide information about the contemporaneity and integrity/duration of surface exposure.

Occupation zones that have a ubiquitous densitydistribution occurrence of tools, debris, and feature elements are apt to reflect a long-term use duration or substantial modification of artifact patterns from post-abandonment processes. Supplemental data from particle-size analyses and soil matrices may help resolve the occurrence of zones of eolian and colluvial sediments. The occurrence of artifact clarity and heterogeneous material distributions provide primary evidence of short-term occupations and rapid abandonments. The clarity of distribution patterns and geomorphic contexts are more important for defining the duration of occupations than recovering diverse forms of "temporally sensitive" diagnostic artifacts from a single context, since many prehistoric groups tended to collect and reuse older tool forms.

The identification of the nature of activity areas depends upon the recovery of logically consistent artifact materials (e.g., debitage, preforms, and stone tool manufacturing debris) and relatively discrete limitations to the artifact distributions. This is most easily accomplished in de facto abandonment situations involving briefly used activity areas. The limits of various activity areas are sometimes detectable from refit analysis of implements or broken bones, or at least the delineation of debitage reduced from a few distinctive kinds/colors of cobbles. The size of individual components can be addressed by the areal extent of artifacts and features back plotted using the TDS on the geometry of the living surfaces within the excavation block limits. The spatial patterning of activity areas and their densities and redundancies can also be defined from the repetitive kinds and densities of artifacts and debris plotted by the TDS. 
3.4.7 Lithic Resource Procurement and Technology Contextual Framework

Stone tools and manufacturing debris are among the best-preserved artifacts in the archaeological record and the least susceptible to weathering deterioration. Due to differential preservation, the importance of stone tool manufacture relative to other activities involving less permanent materials may be difficult to assess. Huntergatherer groups carried finished implements and sometimes implements in need of repair to sites, and they spent considerable amounts of time resharpening, and replacing existing tools. They also may have engaged in "gearing-up" activities involving the manufacture of other tool forms for either the anticipated tasks/resources available at subsequent camping locales or the caching of implements for use on subsequent returns to the site.

The lithic resource issue assumes that recognizable differences in material type, color, texture, or inclusions exist within raw tool stones of the region and an adequate sample of activity areas has been obtained. If consistent material variability is present, then comparisons of raw material debitage and complete/broken tool material can provide insights into which kinds of tools were manufactured on site for replacement (e.g., proximal broken points/ knives), which kinds of tools were manufactured and abandoned on site, and to some extent, which stages and forms of implements were removed from the site manufacturing areas. Critical to conducting these studies is familiarity with stone tool production processes as well as observations on the nature of stone tool breakage patterns.

\section{Lithic Resource Procurement and Technology Methods}

All lithic debris can be analyzed for material/ color types (both natural and ultraviolet/ florescent bands), size grades, cobble cortical presence, and core/biface technical attributes emphasizing flake platform and form. The relative abundance of early cobble reduction debris, tool manufacturing failures, and heat treatment should indicate the importance of tool production activities. Since every flake removed during a tool's production preserves attributes of the technology of stone tool manufacture, attribute analysis of flake platforms and dorsal and ventral surfaces can be used to reconstruct the strategies and stages of converting cobbles into tools. Technological analysis of debris from activity areas will provide information about the discreteness of assemblages between the stratified occupations. Broken and complete chipped-stone tools will also be subjected to analysis of material/color types, stage of completeness, and extent of resharpening as indicated by morphological changes in blade edges. These attributes and the nature of the break characteristics can discern whether the implement broke during manufacture or from snap/bending breaks during usage. The duration of occupation may be inferred from the diversity of cobbles reduced in an area, the volume of debris recovered, the robustness of the cobble reduction stages represented in the tool assemblage, and the diversity of implements.

Heat treatment of lithic materials improves knappability and was often done in south Texas. The treatment is denoted by luster and color changes on the inside of the heated cobble so that flakes with high luster on the ventral surface relative to dorsal surface are from the exterior of the heated prepared cores. Crazed flakes and potlids have been through fires, but their occurrence generally reflects excessive accidental burning rather than intentional heat treatment. Rock features containing flakes with potlids and heat spalls thus reflect either lithic debris on the occupation surfaces that predate the cooking or items discarded into the fire. The recognition of lithic heat treatment features is 
very tenuous, especially if the treated cobbles have been removed for reduction. Thermally altered rocks employed for lithic reduction are apt to be siliceous materials that do not have food residues.

A sample of Pleistocene cobbles from upland areas near the site can be collected and analyzed for material variability, color, and texture as a basis for comparison to the locally available resources. The assemblage can be examined for the occurrence of distinctive resources that typically occur outside the Rio Grande drainage and may be evidence for foreign or trade materials. If the regional tool stone sources are sufficiently distinct, then the frequency of implements and the degree of tool resharpening can provide data on the geographical coverage of the group. With a sufficiently broad pattern, the general directions of group circulation within territorial regions can be described. Caution is required, since some lithic resources are truly exotic goods that are apt to be traded between groups. Usually, these trade items are recognized by their low frequency in the assemblage and their tremendous distances from the source areas. 
Intentionally Left Blank 


\subsection{METHODS}

This section discusses the archaeological field methods, laboratory procedures, and analyses employed for the 1998 mitigation investigations at the Lino site 41WB437. The laboratory analyses and procedures used to process the various samples and material definitions are presented. Various laboratory procedures were implemented to extract site and specific artifact data to address the research questions and issues presented in Section 3.0.

\subsection{ARCHAEOLOGICAL FIELD PROCEDURES}

The archaeological field procedures for the data recovery followed the strategies outlined by Abbott (1997) and called for in the IFB with minor field modifications agreed upon prior to the fieldwork. The THC reviewed and approved the field approaches before they were implemented.

A three-pronged approach consisting of 1) Gradall ${ }^{\mathrm{TM}}$ stripping, 2) hand excavations, and 3) column sampling for data recovery. The mitigation target was a single block area about $200 \mathrm{~m}^{2}$ beginning from the ground surface to a depth of $120 \mathrm{cmbs}$. Although cultural features were demonstrated to occur to depths of at least $185 \mathrm{cmbs}$ during the testing phase, TxDOT required excavations to the area of potential effect restricted to only $120 \mathrm{cmbs}$. The specific block location was determined in consultation with TxDOT personnel just prior initiating fieldwork and was heavily influenced by the need to provide easy access and minimal maneuverability restrictions for the Gradall ${ }^{\mathrm{TM}}$. The rectangular block, 7 by $29 \mathrm{~m}$, was established about $2 \mathrm{~m}$ south of the paved access road that crossed east-west through the site and about 9 m east of the western ROW fence (Figure 3.2). This mitigation block was placed just north of BTs 2 and 3 and hand-dug test Units 1 through 4 around Feature 3 that were dug during the testing phase (Figure 4.1).

The excavated block encompassed $196 \mathrm{~m}^{2}$ and measured $7 \mathrm{~m}$ north-south by $28 \mathrm{~m}$ east-west. An $80 \mathrm{~cm}$ wide backhoe trench was excavated along the southern and western margins of the block (Figure 4.2). These two bordering trenches provided visual guides to the natural and cultural stratigraphy, facilitated the maneuverability of the Gradall ${ }^{\mathrm{TM}}$ bucket along the southern boundary, and provided a drainage system for rain water. TxDOT personnel had staked out the boundaries of the block, mechanically dug the two adjacent backhoe trenches to depths of 60 to $90 \mathrm{cmbs}$, and mechanically dug $10 \mathrm{~cm}$ wide Ditch Witch ${ }^{\mathrm{TM}}$ trenches every $4 \mathrm{~m}$ across the north-south axis to depths between 60 and 90 $\mathrm{cm}$ to sever horizontally extending roots near the surface, which could be caught by the Gradall $^{\mathrm{TM}}$ when scraping the thin layers.

The initial tactic for the mitigation effort was to employ the Gradall ${ }^{\mathrm{TM}}$ to excavate the majority of the block. Upon initiation of the Gradall ${ }^{\mathrm{TM}}$ stripping it was discovered that the block was covered in a layer of fill that was about $20 \mathrm{~cm}$ thick in the southwestern corner and nearly 80 $\mathrm{cm}$ thick in the northeastern corner. The fill, which consisted of a different texture and color from the alluvial deposits, was carefully removed down to the original ground surface. Then the Gradall ${ }^{\mathrm{TM}}$ was employed to carefully strip 3- to 4-cm thick layers in eight $3 \mathrm{~m}$ wide by $7 \mathrm{~m}$ long north-south strips, leaving $80 \mathrm{~cm}$ wide balks between the Gradall ${ }^{\mathrm{TM}}$ strips (Figure 4.3). The $3 \mathrm{~m}$ width was about the width of two Gradall ${ }^{\mathrm{TM}}$ buckets. Letters A through $\mathrm{H}$ designated the eight Gradall ${ }^{\mathrm{TM}}$ stripped areas, starting from the western end. A three-person crew that consisted of the TDS operator, the rod 

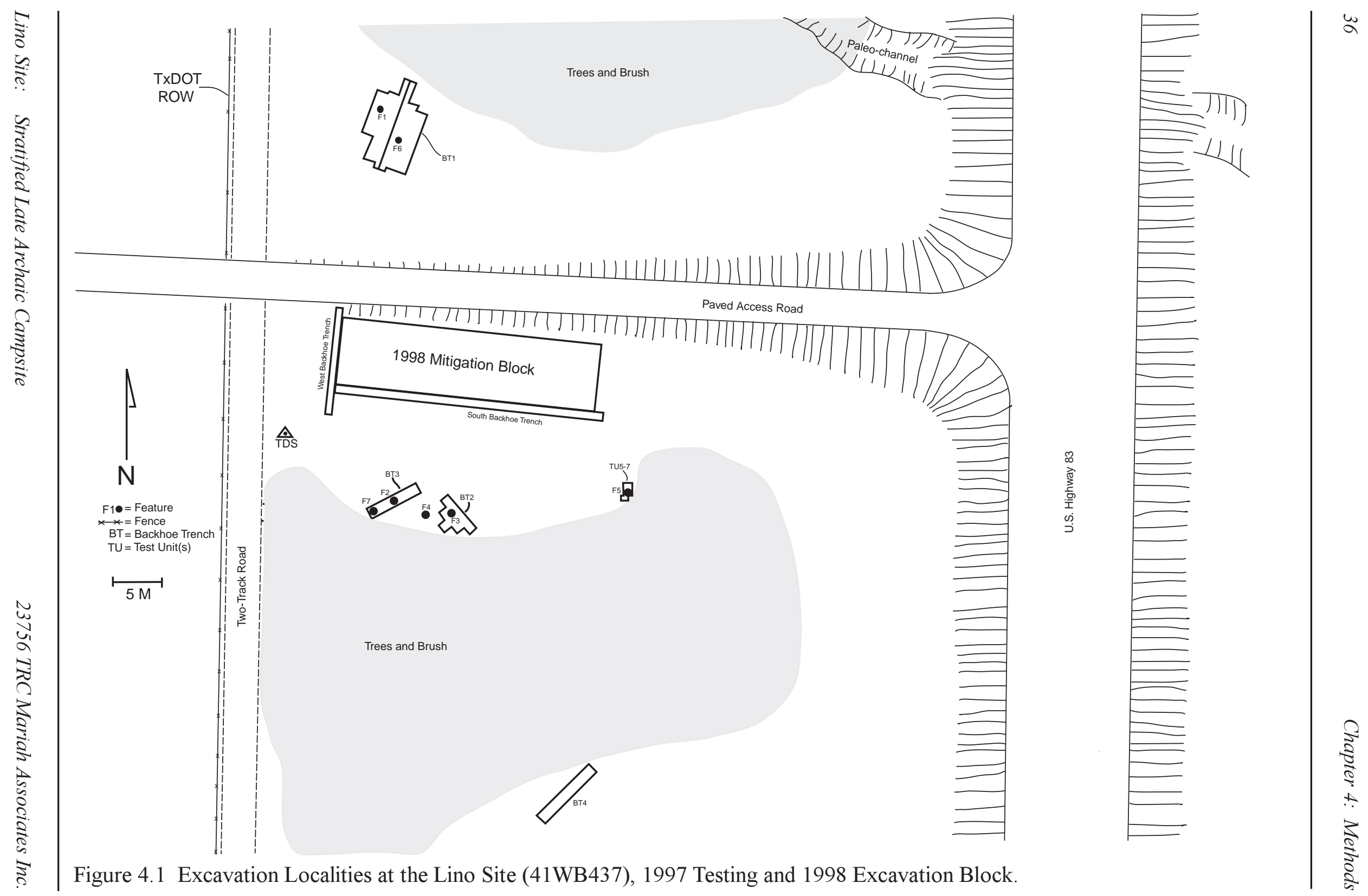


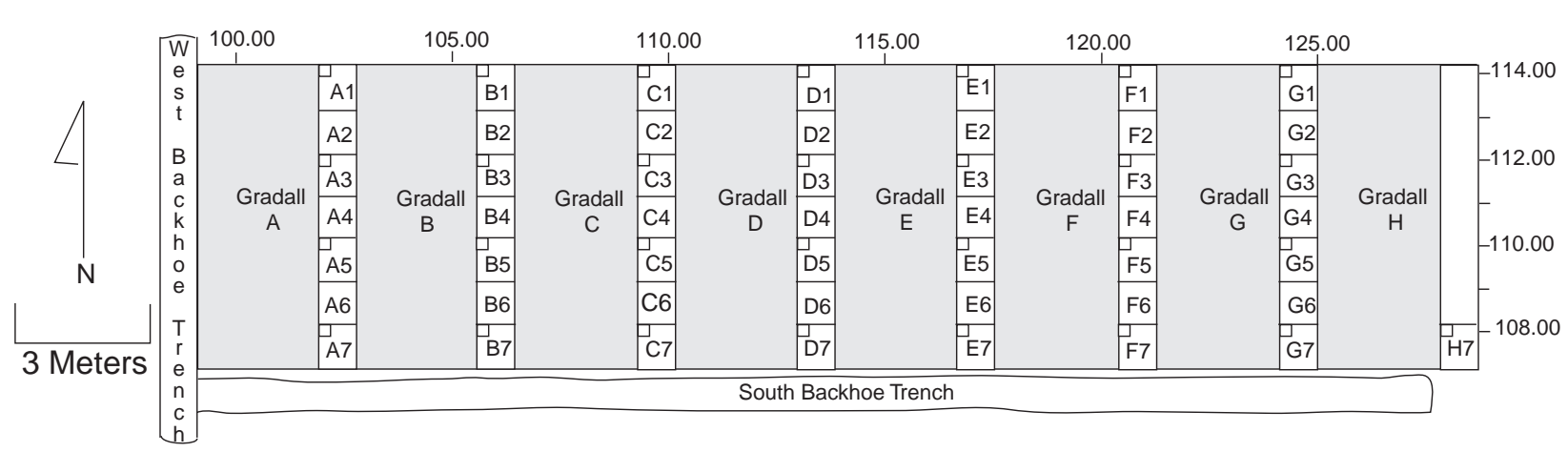

Figure 4.2 General Layout of $3 \mathrm{~m}$ Wide Gradall ${ }^{\mathrm{TM}}$ Areas (Areas A through $\mathrm{H}$ ) and $80 \mathrm{~cm}$ Wide Hand Excavation Balks (Balks A through $\mathrm{H}$ ), with Backhoe Trenches along West and South Sides.

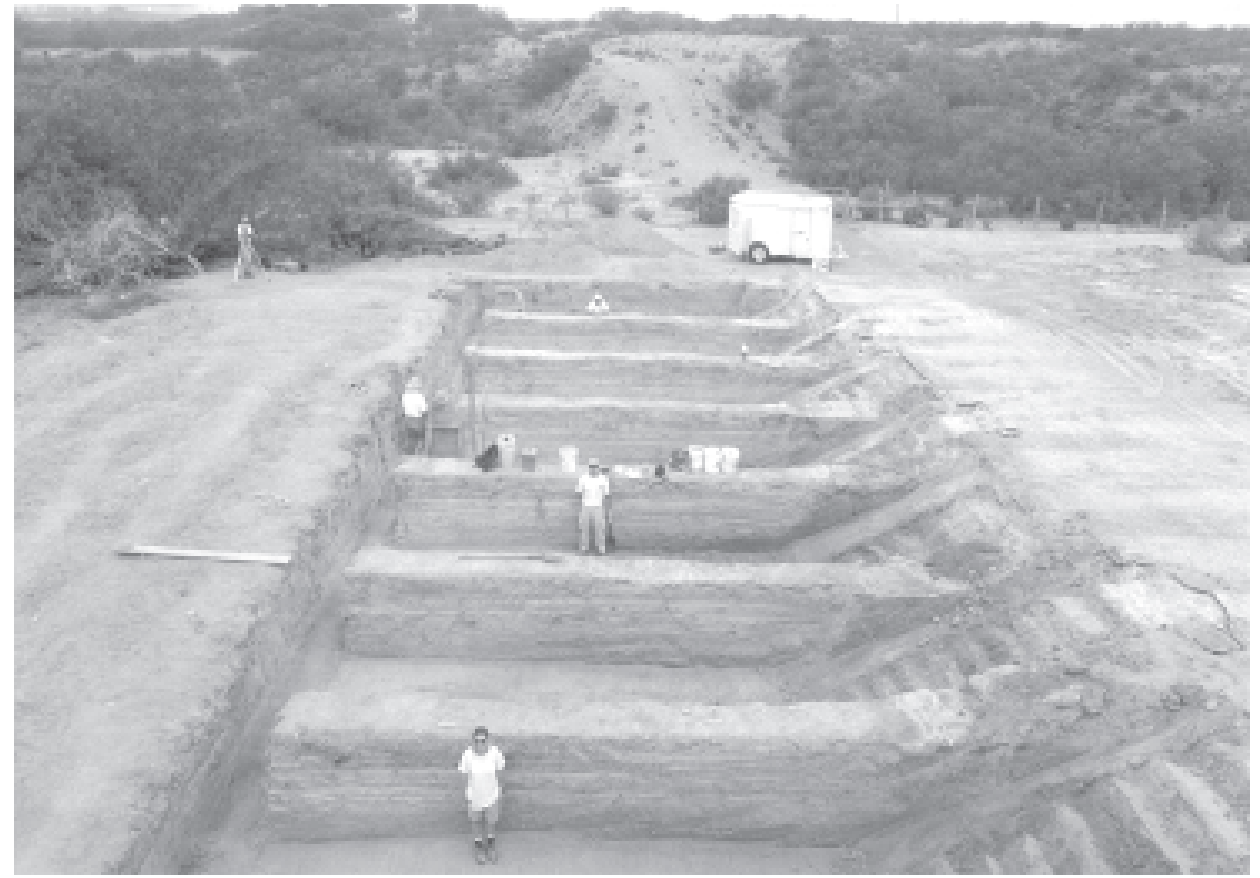

Figure 4.3 Shane Pritchard Monitoring Gradall ${ }^{\mathrm{TM}}$ Stripping of Thin Layers in Area B.

person, and an archaeological technician closely monitored the shallow and slow scraping activity. Each person played a vital role in documenting the provenience of the materials discovered in the stripping. Each time an item was exposed in situ during the Gradall ${ }^{\mathrm{TM}}$ scraping it was plotted using the TDS. Isolated burned rocks were not collected, but all lithic debitage, stone tools, and identifiable mussel shells were bagged and labeled. Nearly $235 \mathrm{~m}^{3}$ of deposits were mechanically removed from the upper $120 \mathrm{~cm}$ using this Gradall ${ }^{\mathrm{TM}}$ stripping procedure (Figure 4.4).

Clustered cultural materials (mostly burned rocks or charcoal stains) exposed during Gradall $^{\mathrm{TM}}$ stripping were designated as features. Specific methods were then employed to excavate the feature and at least a $1 \mathrm{~m}$ area surrounding the designated feature to recover associated materials. One-by-one-meter excavation units were established over each 


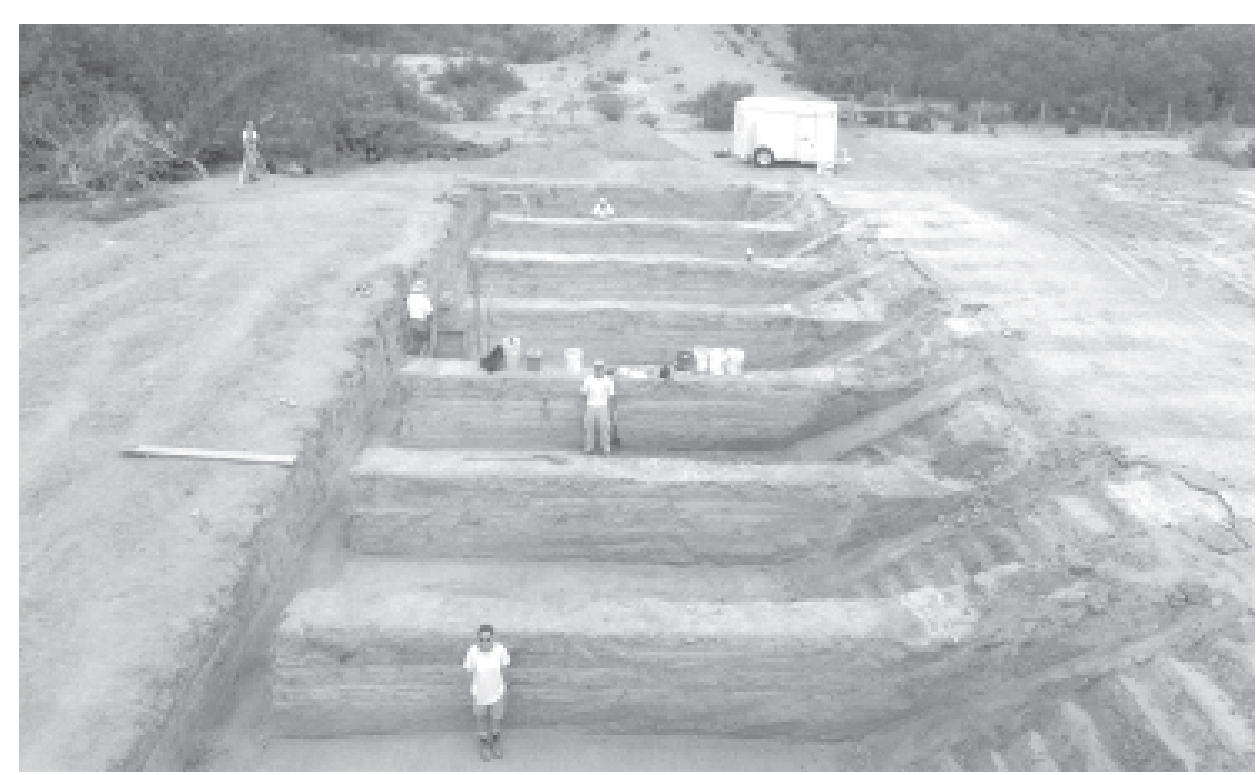

Figure 4.4 View West across Excavation Block Following Completion of Gradall ${ }^{\mathrm{TM}}$ Stripping.

material cluster and the surrounding area. These excavation units were always established inside the Gradall ${ }^{\mathrm{TM}}$ stripped areas without excavating into the adjacent balks. The units were hand excavated, and the matrix was screened through $6.4 \mathrm{~mm}$ (1/4 inch) screen. In situ materials were hand drawn on plan maps and then plotted with the TDS (Figure 4.5). The 1 by $1 \mathrm{~m}$ unit excavated in and around each feature was sequentially numbered following the designation of the feature number. For example, the nine units dug at Feature 20 were designated as 20-1 through 20-9. The number of hand dug units at a feature varied from two to 10 depending on the size of the clustered material. In some instances the boundaries of features were not obvious or well defined because broad scatters of burned rock were encountered. The field director used his professional judgment to decide on the limits of the hand excavation, which sediments were screened, and what was collected for flotation. Most features were crosssectioned to investigate the presence of basins or pits. Only those with detectable staining beneath the rocks were actually profiled. All matrixes within the feature boundary were collected for flotation. If the feature consisted of burned rocks, then all the rocks were collected as well. The matrix outside the feature was screened in the field, and cultural materials were bagged according to material type. A total 123 hand excavation units $\left(123 \mathrm{~m}^{2}\right)$ were dug around 24 features (designated Features 8 through 32) discovered during the Gradall ${ }^{\mathrm{TM}}$ stripping. The hand excavations around the features continued simultaneously with the Gradall ${ }^{\mathrm{TM}}$ stripping. A two-person crew completed the investigation at each of the identified features. The hand excavation boundaries were plotted with the TDS.

The second field tactic was the hand excavation of seven $80 \mathrm{~cm}$ wide by $7 \mathrm{~m}$ long balks standing between the Gradall ${ }^{\mathrm{TM}}$ strips (Figure 4.6). These balks were $3 \mathrm{~m}$ apart and $120 \mathrm{~cm}$ tall. The balks were assigned letter designations A through $\mathrm{G}$, starting from the west end. Each $80 \mathrm{~cm}$ side balk was subdivided into $1 \mathrm{~m}$ long units. The individual units were designated by balk letter and unit number (A1, A2, A3, etc.) starting from the north end of each balk. Hand excavations proceeded in arbitrary $10 \mathrm{~cm}$ thick levels leaving the majority of encountered material in situ for mapping. In the eastern most balks, only Unit 


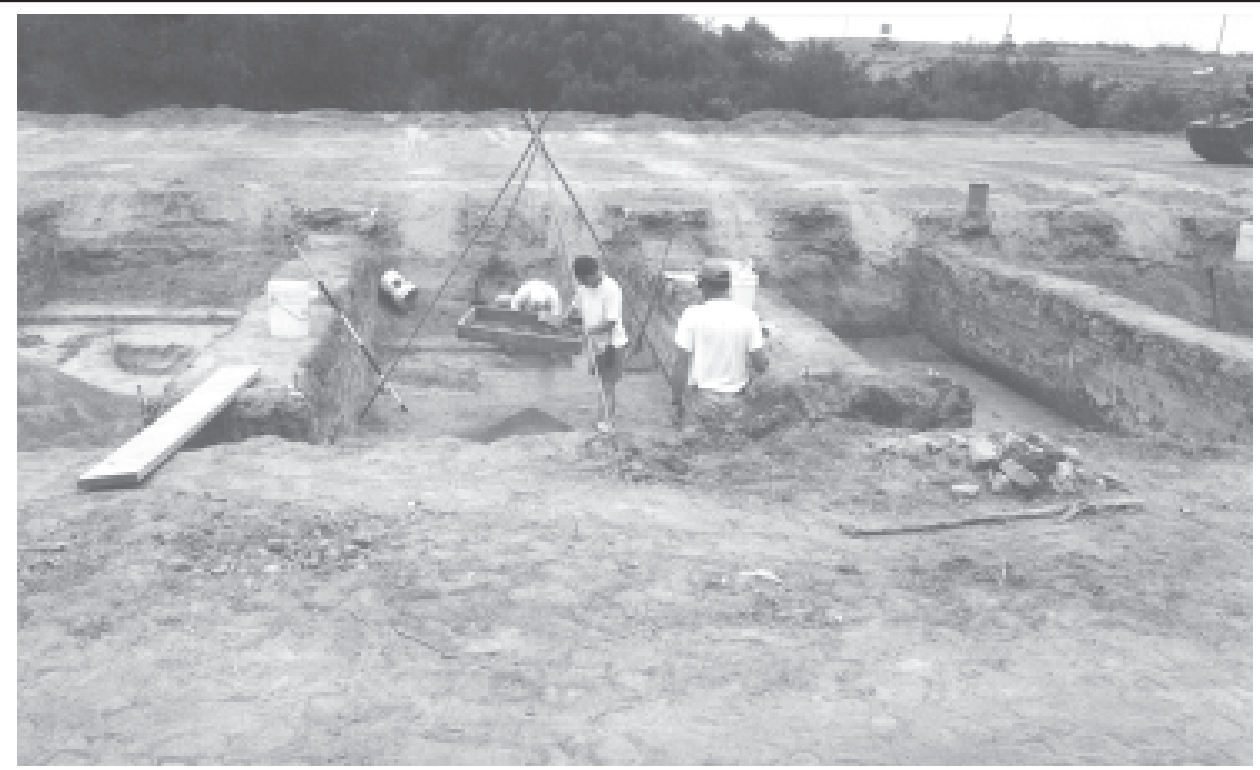

Figure 4.5 Hand Excavation of Units at a Feature Discovered during Gradall ${ }^{\mathrm{TM}}$ Stripping.

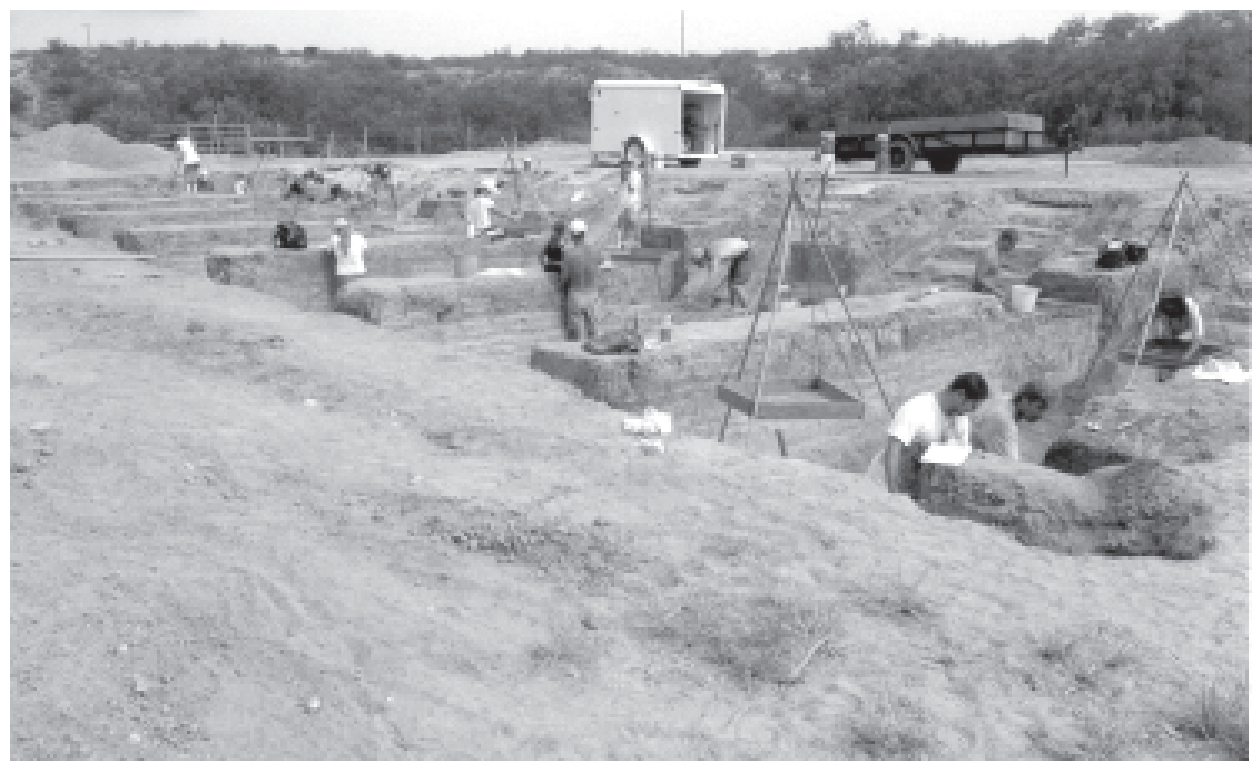

Figure 4.6 Hand Excavation of Balks Following Gradall ${ }^{\mathrm{TM}}$ Stripping. View Northwest with H7 in Right Foreground.

$\mathrm{H} 7$ was hand excavated to meet the volumetric amount of fill required by the contract. Excavated sediments were screened through 6.4 $\mathrm{mm}(1 / 4$ inch) hardware cloth. The in situ cultural materials from the $48.24 \mathrm{~m}^{3}$ handexcavated balks were drawn on level records and plotted with the TDS. Features 33 through 43 were discovered during the hand excavation of the balks and were documented the same way as those previously encountered. As before, the matrix from within each feature was bagged without screening to be floated in the laboratory. Feature forms were completed, feature maps were drawn, associated in situ artifacts were point plotted, most features were crosssectioned, and if necessary, profiles were drawn. 
The third tactic was the collection of matrix from vertical columns during the hand excavation of the balks. Matrix columns were systematically collected from the northwest corner of every other hand-dug unit across the entire block (units $1,3,5$, and 7 in each balk), for a total of 29 matrix columns. Each sample was about four liters ( 20 by $20 \mathrm{~cm}$ square by $10 \mathrm{~cm}$ thick) and collected from the original ground surface to a depth of $120 \mathrm{cmbs}$. These samples were bagged and labeled and returned to the laboratory for floating. The planned size of each float sample was to be 20 by $80 \mathrm{~cm}$ by $10 \mathrm{~cm}$ thick, but extensive turbation of the deposits observed during the Gradall ${ }^{\mathrm{TM}}$ stripping and the hand excavation of the features significantly diminished the anticipated effectiveness of the results. In consultation with TxDOT personnel and with THC approval, the size of the matrix sample was reduced.

Level records were completed for each hand excavated arbitrary $10 \mathrm{~cm}$ level. All cultural materials, including burned rocks and Rabdotus snail shells, were collected and bagged according to the specific $1 \mathrm{~m}$ proveniences. When tools were recognized, they were wrapped in protective tissue without handling to facilitate potential residue analysis. The tool locations were recorded, and they were bagged separately.

When a feature was encountered, the original exposed material was photographed with black and white and color slide film. The feature was re-photographed from a vertical position following careful exposure of attributes of the feature by hand troweling. The in situ material was drawn on plan maps. Feature components and sample localities were plotted with the TDS. The recovered material was bagged and labeled by material type such as lithic debitage, burned rocks, mussel shells, etc. Feature fill was collected, bagged, and labeled. Other matrix samples were collected for stable carbon and nitrogen isotope and phytoliths.
Following the mechanical stripping to a depth $120 \mathrm{cmbs}$, selected portions of the vertical balks were troweled and inspected in order to try to identify natural stratigraphic layers (Figure 4.7). The planned level of effort for profiling was substantially reduced because of the extensive turbation and the lack of visually distinct natural stratigraphic layers. The project geomorphologist recorded and documented six profiles from the eastern, southern, and western sides of the opened block. His field interpretations on the stratigraphic profiles and anomalies aided the hand excavations and sampling strategies of the $80 \mathrm{~cm}$ wide balks. The lack of visual distinctions and clarity of the 120 $\mathrm{cm}$ thick profiles across the block necessitated the use of arbitrary $10 \mathrm{~cm}$ levels during hand excavations. Selected profiles were photographed and six selected locations became reference columns for detailed stratigraphic recording by the geomorphologist.

Because of the extensive turbation only reference column 2 was intensively sampled for matrix analysis. Stable carbon and nitrogen-isotope, sediment-texture, phytolith, and magneticsusceptibility samples were carefully collected from the southeastern wall of the south trench. These samples were extracted in 2 to $3 \mathrm{~cm}$ thick layers spaced $10 \mathrm{~cm}$ apart from the top to the bottom of the trench wall. The magnetic susceptibility samples were $1 \mathrm{~cm}^{3}$ in size and collected in $5 \mathrm{~cm}$ intervals from the column. All reference samples were from the exact same spot in the vertically stratified profile.

The TDS has not become standard equipment on most archaeological projects. For this reason, TRC is providing a detailed discussion of the use of this recording device to facilitate an understanding of it's use and TRC's procedures.

A Sokkia SET5A total data station surveying instrument, in combination with a Sokkia SDR33 electronic field book (data collector), 


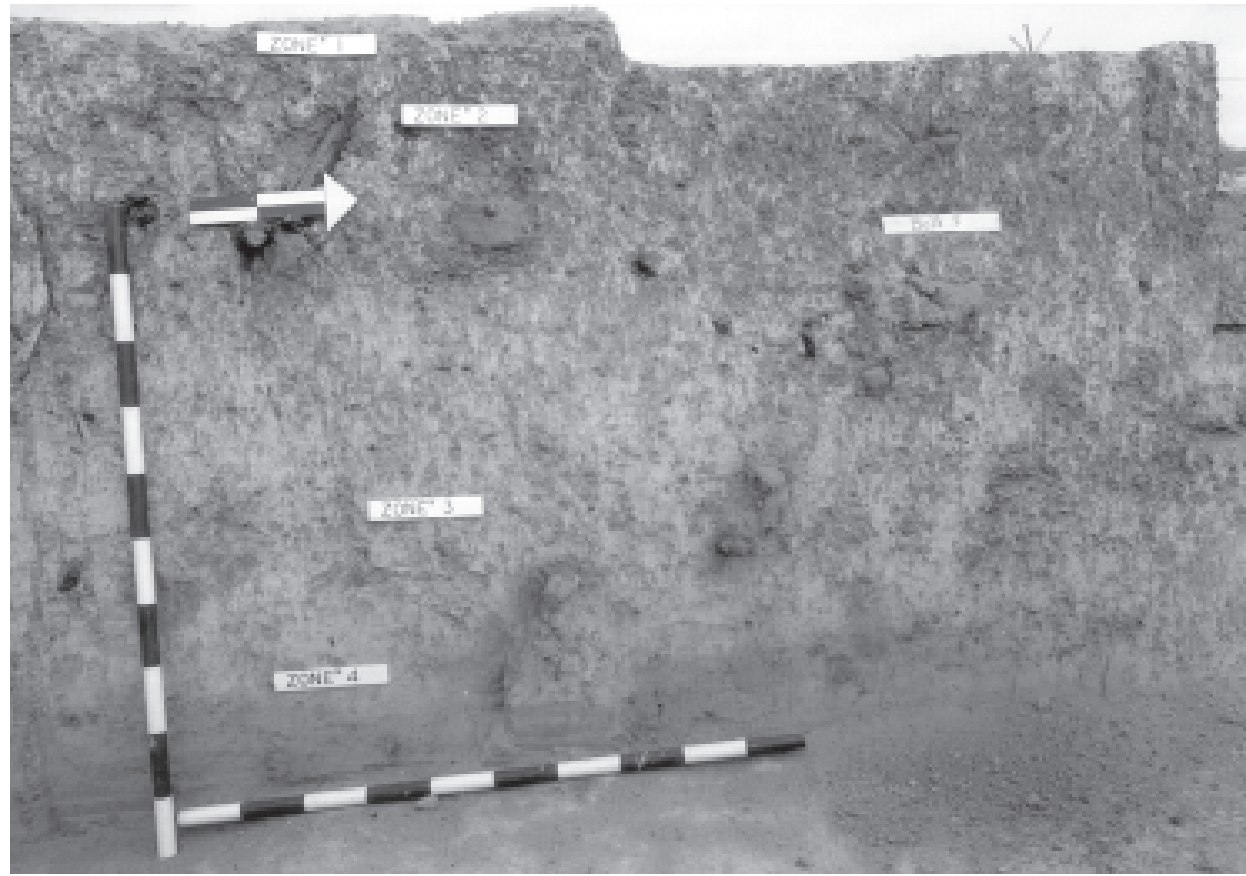

Figure 4.7 A Cleaned Part of the East Side of Balk F Showing Natural Stratigraphy of $120 \mathrm{~cm}$ Thick Profile. General Zone Designations Used during Gradall ${ }^{\mathrm{TM}}$ Stripping.

was employed to provide horizontal and vertical provenience for artifacts, features, and excavation units (Figure 4.8). The SET5A TDS is an electronic theodolite with electronic distance measurement (EDM) integrated into the telescope. The EDM transmits a modulated infrared light, which is reflected from a prism back to the EDM for distance calculation. The unit records the horizontal angle (azimuth), vertical angle (dip), and the slope distance of any given point to derive both the horizontal and vertical position of that point relative to an arbitrary datum. The prism is mounted atop a rod, which is adjustable from 3.5 to $275 \mathrm{~cm}$ in height.

The SDR33 data collector is an electronic calculator housed in a dust- and water-resistant latex-covered case. It has a "flash" EPROM memory and uses the DR-DOS operating system. It is connected via cable to the TDS and transmits commands to and receives data from the instrument. Data can be entered, viewed, or modified through a 56-key keyboard and is displayed on an LCD screen. Upon setup, information about the position of the instrument is entered, and all subsequent measurements are based on that reference information. The height of the rod is entered into the data collector to compensate for the vertical distance between the ground and the prism; likewise, the height of the tripod-mounted TDS is entered into the data collector's program to generate accurate vertical measurements.

All data are stored in the data collector as raw data, or observations, and are converted to horizontal and vertical coordinates for use with computer-aided drafting (CAD) and other computer mapping programs. Raw data include the coordinates of the instrument's position, instrument height, rod height, date and time of day, slope distance, azimuth, and dip. The raw data are converted by the data collector and 


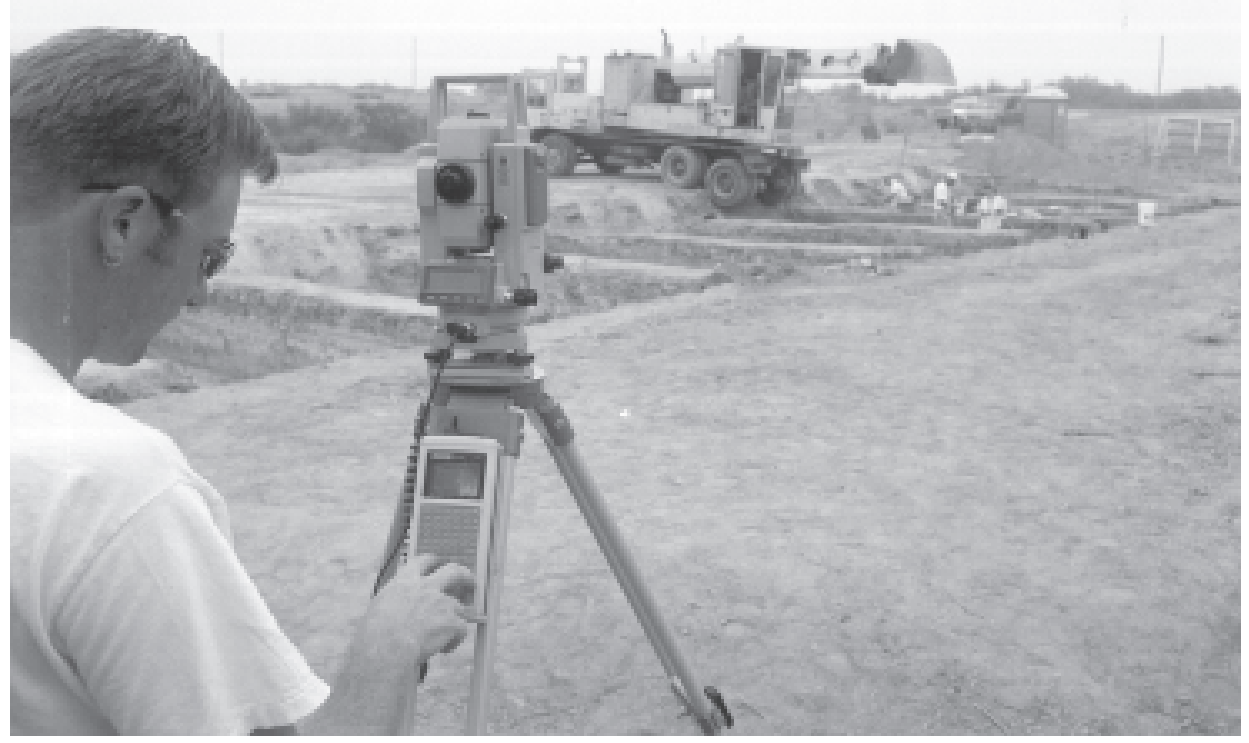

Figure 4.8 Scott Wilcox Using a Sokkia SET5A Total Data Station Surveying Instrument with a Sokkia SDRSS Electronic Field Book to Document Artifact Provenience.

stored as position data, including the observation number, description, and $\mathrm{x} / \mathrm{y} / \mathrm{z}$ (easting/northing/ elevation) coordinates of each point.

The data collector is connected to a computer by means of a serial cable for downloading. Using proprietary software developed by TARL and provided by TxDOT, information from the data collector was downloaded daily to a Dell Latitude laptop computer. With each download, two files were created: a raw data file and a coordinate file. Raw data files were stored for archival purposes, and the coordinate files were used by the CAD operators to produce topographic and other maps.

Prior to mapping work at site 41WB437, a datum was established in a location from which the entire excavation area was visible. The mapping datum was assigned the arbitrary coordinates 100 $\mathrm{m}$ North and $100 \mathrm{~m}$ East with an arbitrary elevation of $100 \mathrm{~m}$, and it served as the sole mapping datum throughout the course of the field work. Three small holes (ca. $15 \mathrm{~cm}$ in diameter) were dug around the datum and filled with concrete to mark the locations and standardize the height of the TDS tripod feet.

A backsight location was selected $30 \mathrm{~m}$ to the magnetic east of the datum, and a second tripod was set up in the same manner as the first. An Ibis tripod held a prism, which was used each morning to calibrate the horizontal angle of the TDS and to check for instrument accuracy during the course of the workday. A nail was also placed on the trunk of a large mesquite tree $44 \mathrm{~m}$ magnetic north of datum and served as a secondary check for the TDS orientation. Each morning after the TDS was set up, readings on the backsight and the north reference point were taken and recorded. These points were checked periodically throughout the day to ensure accuracy.

The data collector automatically assigned each measurement, or "shot," a sequential number beginning at 1000 . In addition to the automated numbering, an identifying label for each record was entered into the data collector. The labels varied according to the type of information being 
collected. Typical artifact labels consisted of four parts separated by periods using the designations "unit, class, size, and material type" as defined in Table 4.1.

The period separating each of these attributes serves as a delimiter to easily transfer this information into separate columns for each of the recorded artifact attributes in a Microsoft Access $97^{\circledR}$ database. Other types of information (e.g., topographic mapping shots, excavation unit boundaries, roads, etc.) were assigned unique, one-part codes. All codes used during the project are listed in Table 4.2.

Five by 12 centimeter ( 2 by 5 inch) tags with pre-printed numbers corresponding to the shot numbers in the data collector were also used to record the information. These tags were placed in bags with collected artifacts, when appropriate, or kept separate for filing purposes.

At the end of each workday, data from the data collector was downloaded and the digital

Table 4.1 Artifact Label Designations.

\begin{tabular}{ll}
\hline Unit & The type of excavation unit identifying either a stratigraphic zone, feature, or excavation unit. \\
Class & A two-letter code identifying the type of artifact being recorded (e.g., burned rock, flake, biface, etc.). \\
Size & The measurement of the long axis of the artifact (in cm). \\
Material Type & A two-letter code identifying the material type of the artifact (e.g., chert, sandstone, quartzite, etc.). \\
\hline
\end{tabular}

Table 4.2 List of Codes Used with Data Collector.

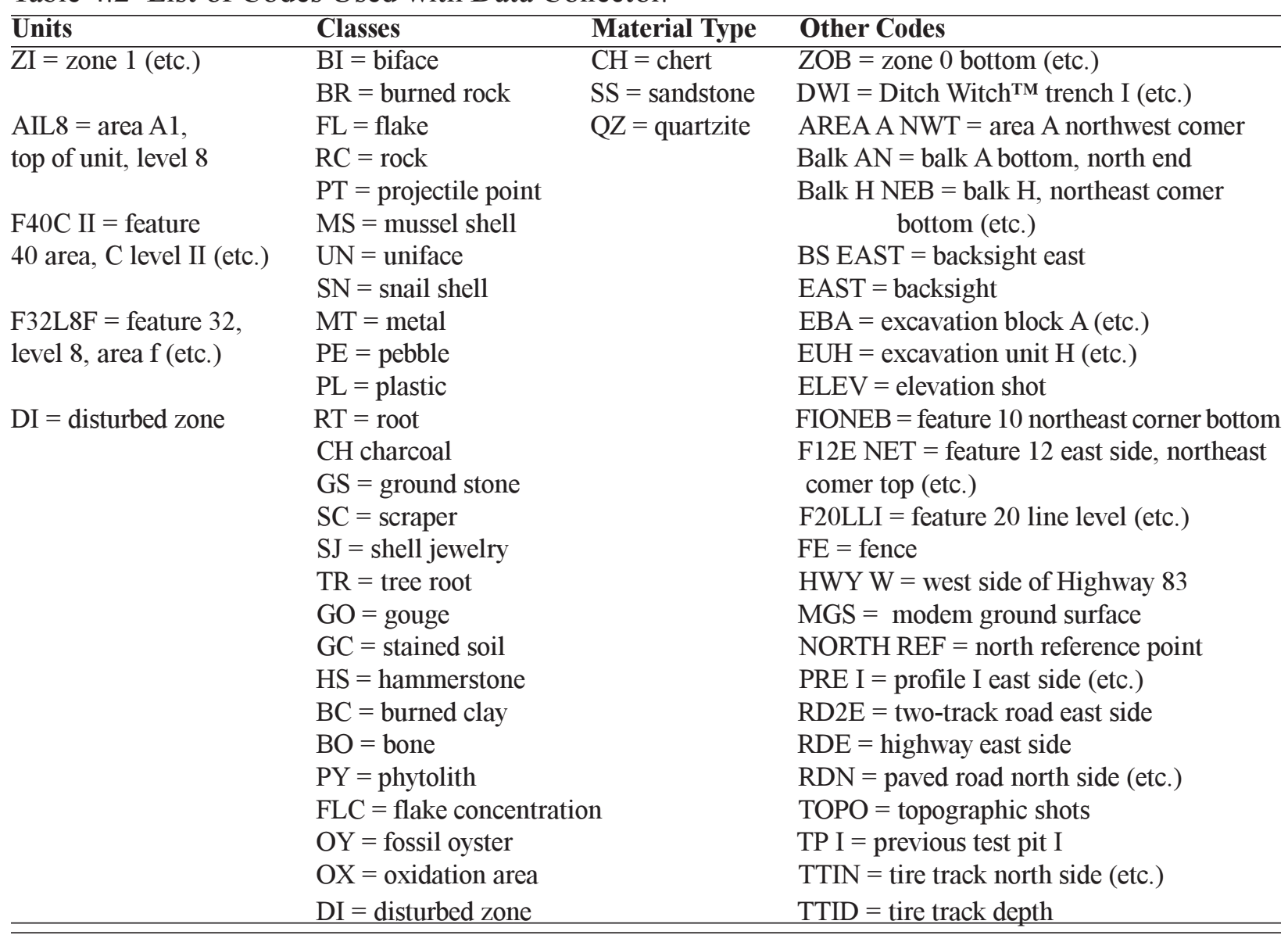


information was cross-checked against the cards for accuracy. The files of coordinates (in ASCII format) created by the data collector download program were subsequently imported to a Microsoft Access $97^{\circledR}$ database. The data, after having been checked for accuracy, was purged from the data collector at the end of each 10day work session. Purging was necessary because the memory limitation of the data collector holds only approximately 3,000 shots.

The mapping crew consisted of the TDS operator, one crew member holding the rod and prism, and another crew member recording the information on preprinted paper tags and bagging the artifacts. Communication between the TDS operator and rod person was accomplished using hand-held two-way radios.

\subsection{LABORATORY PROCEDURES}

In general, artifact processing entailed washing and cataloging lithic debitage and stone tools. Lithic debitage, stone tools, burned rocks, and mussel shells were assigned unique provenience numbers by level and unit in conjunction with the site number. After being catalogued, the specimens were grouped by artifact class. A set of pre-selected attributes for each material class was encoded on paper and then entered into Microsoft Access $97^{\circledR}$. The custom database used a pick list approach for previously selected attributes. Attributes utilized for each class of artifact are presented below.

\subsubsection{Stone Tool Analyses}

The edges and surfaces of each piece of chert debitage were macroscopically examined for signs of use as a tool. If worked areas were identified, the artifact was assigned to a specialized morphological/technological category based on general form and inferred function. The following provides definitions of the tool classes.
Projectile points are a functional subset of the biface class designed to be hafted to the distal end of a shaft for penetrating animal hides and flesh. Specific point types may have various proximal-end modifications for hafting, which consist of side, corner, or basal notches. The points are normally referred to by their defined morphological type of hafting modification and are correlated to named types (Turner and Hester 1993). Point forms are considered diagnostic of general time periods, technological complexes, and/or cultural groups.

Bifaces are predominately a morphological biface class, but they also have functional implications (i.e., cutting tasks). Bifacial specimens exhibit purposeful flake scars across most or all of both faces, but in some instances one face is completely modified whereas the opposite face is only partially worked. Generally, bifaces lack any macro-evidence/ modification for hafting. If only the margin of a specimen is modified and not the entire face, then the tool is classified as an edge-modified tool.

Scrapers are unifacial tools with at least one edge steeply modified. In many instances, both the end and lateral edges are steeply modified. Based upon the location of the primary working edge, scrapers are subdivided into end, side, or combination types.

Gouges (Clear Fork or distally modified tools) can be unifacially or bifacially flaked and are roughly triangular in outline, with the wide end considered the working edge/bit. The wide distal end is usually steeply beveled, and its edges may be convex, straight, or slightly concave. The edge angle of the bit end and lateral edges are relatively steep. These tools are generally associated with woodworking tasks (as scrapers or adzes), rather than true gouges (Turner and Hester 1993:246). 
Edge modified flakes, or "expedient tools," are flakes or flake parts that have at least one or more edges with random and/or patterned flake scars along their margins. The 1 to $2 \mathrm{~mm}$ long flake scars along the edges have not significantly altered the original flake form. These flake tools may have retouch modifications along single or multiple edges, which may occur on each side, either face, or form a bifacial edge.

Cores are masses of raw lithic material selected for the production of flakes and/or bifaces. Negative flake scars originating from one or more platforms characterize cores. Various types of cores are classified according to the degree of knapping and the flake removal strategy. The most common are unprepared cores, which exhibit one or more striking platforms along one or more edges with flake scars occurring in various directions. A tested core has one or two flake scars and may or may not exhibit a standard platform. During the early stages of reduction, the core's exterior exhibits a weathered rind or cortex. A smooth rounded cortex indicates a river-worn cobble origin, whereas a rough, pitted rind reflects a bedrock source. Latter stages of core reduction may remove all signs of cortex. Other observed attributes recorded include heat treating, crazing, heat spalling, and the number of platform facets.

Ground stone tools were identified by the observation of non-natural abrasions, grooves, etc. Once identified as a culturally altered piece, it was placed into a specific ground stone category based on the type of modification exhibited. Based on the modification types, selected characteristics and attributes were analyzed and recorded. Each class of artifacts had a specific set of attributes recorded.

A miscellaneous category was used for items that appeared to be cultural but general and specific uses are unknown at this time. Only a very few specimens are included in this catchall category.

\subsubsection{Lithic Debitage Analyses}

Chipped stone debitage lacks any macroscopic indication of use and represents a byproduct of the manufacturing and maintenance of chipped stone tools. All pieces that exhibited any sign of human-use wear or subsequent modification were excluded from the lithic debitage class. Debitage was classified into four groups based on a combination of attributes that indicate their origin from cores or bifaces and, in some instances, categories of detachment included potlids, over-shot flakes, and shatter. The following definitions were used.

Core flakes are generally a thick flake with a broad single/cortical and most often unground platform, irregular cross sections, large pronounced bulbs of percussion, often evidence of dorsal or platform cortex, obtuse platform angle, and random orientation to the dorsal flakes scar patterns.

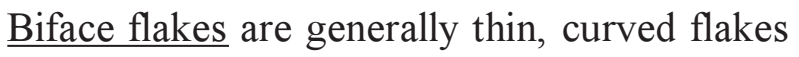
with striking-platform preparation on thin, small, multifaceted platforms with acute angles and convergent dorsal surface flake scars. The bulb of percussion is generally thin and broad. The dorsal surface near the platform exhibits two or more flake scars removed in the same direction as the flake. Multiple hinge fractures or light grinding at the proximal end relates to either trimming or crushing to prepare the platform. Normally, the platform's dorsal surface angle is acute. The longitudinal cross section sometimes displays a curved profile, but less curvature generally reflects the latter stage of biface thinning.

Uniface flakes are defined by platforms that are single faceted, unprepared, flat, and relatively thin and long. The dorsal surface exhibits two or more flake scars removed in the same direction as the flake. Multiple hinge fractures 
exist at the proximal end and relate to either platform trimming, edge stabilization, or a crushed platform. Normally, the dorsal surface dramatically changes angle direction at the distal end. The distal end of the flake's dorsal surface may reflect the dorsal surface of a primary scraper or gouge. In cross section the flake displays a convex profile. The bulb is generally thin and broad. Flake length is generally fewer than $3 \mathrm{~cm}$ with roughly parallel sides. These flakes are assumed to have been removed during manufacture or resharpening of steep sided unifaces.

Heat spalls/potlids were created by differential expansion of lithic material under exposure to extreme heat. These items represent parts of flakes, cores, or tools popped from the artifact's surface during excessive heating. Potlids exhibit one flat and one convex surface. These items have no platforms, bulbs of percussion, or other attributes of knapped flakes. They are attributable to unintentional or accidental heating.

Chunks/shatter are lithic pieces that lack the distinctive flake characteristics of platforms, bulb of percussions, and attributes necessary to discern ventral and dorsal flake surfaces.

Indeterminate flakes are not precisely identified as belonging to one of the preceding categories. It is the intention of this analysis not to force questionable or unknown pieces into a defined category. If a piece did not exhibit the principal attributes of any of the other described categories, then it was placed in this catchall category.

Observations for heat alteration were made in the hope of identifying the knapper's intentional heating of chert to improve its workability. Two characteristics were used: luster and color change. Mnay cherts experience increased luster with heat treatment, and some materials experience color changes, especially to reddish hues. If one of these two attributes was present, then a specimen was assumed to have been intentionally heat altered.

\section{$\underline{\text { 4.2.3 Microwear Analysis }}$}

Ninety-nine chipped stone and five ground stone artifacts from all identified cultural occupations were selected and sent to Caryn Berg at the University of Colorado in Boulder for highpowered microscopic use-wear analysis. Her detailed procedures, results, and interpretations are presented in Appendix C. All the chipped stone lithic types were apparently derived from the Rio Grande gravel sources.

The high powered microwear analysis was refined from methods developed by L.H. Keeley (1980) and involved the identification of distinctive polishes, striations, and damage scars that occur on the edges of chipped stone tools from utilization (Yerkes 1987; Nass 1987). Patterns of use-wear can be differentiated by activity preformed and material worked. Keeley's identifications of micro-polishes have been "verified, extended, and adjusted" by many researchers since 1980 (Yerkes 1989, quoting J. Jenson 1988:54) and have been used in the analysis of chipped stone assemblages that span 1.5 million years (J. Jenson 1988; Owen et al. 1984).

\subsubsection{Burned Rock Analyses}

This category represents natural rocks that have been heated and cooled, thus causing some to crack, discolor, craze, or fragment. In the field, potential burned rocks were treated as other artifacts and were collected, bagged, and returned to the laboratory for analyses. The rocks were identified by material type (i.e., sandstone, chert, etc.). The rock fragments were sorted by size categories ( 0 to $4 \mathrm{~cm}, 4.1$ to $9 \mathrm{~cm}, 9.1$ to 15 $\mathrm{cm}$, and greater than $15 \mathrm{~cm}$ ), counted, and 
weighed by size class. The edge conditions were recorded as rounded, tabular, or angular. Fiftyeight individual burned rocks were selected and sampled for stable carbon and nitrogen isotope residue analysis. The exterior calcium carbonate on the burned rock was ground off using a Dremel tool to remove the post burning deposits. The dark colored organic residues near the outer edge of the burned rock were the target residues for other types of analysis. These targeted residues were ground off with a Dremel tool. Most burned rocks were discarded upon completion of the analyses, but a few samples from a variety of contexts (features) were curated for potential future analysis.

\subsubsection{Thermal Demagnetization Analyses}

Twelve sandstone burned rocks from 12 different burned-rock features encompassing the top five cultural occupations were submitted to Dr. Wolf Gose at the Texas Archeological Research Laboratory in Austin for thermal demagnetization analyses. This process demagnetizes each burned rock at 50 degrees $\mathrm{C}$ temperature intervals to investigate the temperature history of rock heating and cooling during the latter stages of use. Changes in the magnetic properties of the rock at various temperatures may also yield information on how individual rocks were utilized in the cooking processes. Dr. Gose's detailed procedures, results, and interpretations are presented in Appendix E.

\subsubsection{Mussel Shell Analysis}

Fresh water mussel shell fragments and land snail shells were recovered. The larger and more complete mussel shells were identified to species, if possible, using in-house comparative samples. Valves were counted, identified as to side, and examined for signs of human modifications.
The collected Rabdotus land snail shells were not analyzed. A selected number of Rabdotus shells were sent to Dr. Glenn Goodfriend at the Geophysical Laboratory at the Carnegie Institution of Washington for identification and for amino acid racemization analysis. The racemization results were used to determine sediment integrity and help identify snail specimens suitable for AMS radiocarbon dating. Dr. Goodfriend's analytical results are presented in Appendix F.

\subsubsection{Amino Acid Racemization Analysis}

This technique was employed to address the question of stratigraphic integrity or context of buried materials. It also provides a means of assigning relative ages to specific locations. Sixteen unwashed, nearly complete adult Rabdotus alternatus snail shells were submitted to Dr. Glenn Goodfriend for racemization studies. An amino acid analyzer was used to determine the D-alloisolucine/L-isoleucine or A/ I ratio of the shells, and the results were calibrated against the laboratory standard STD0.30 (see Ellis et al. 1996). The rate of conversion from L-isoleucine to Dalloisoleucine varies with temperature but is consistent enough that the $\mathrm{A} / \mathrm{I}$ ratio can be used as a proxy measure of relative age. Heat governs the rate of conversion, and regional environments will produce different rates of racemization. The effects of heating vary with temperature and duration. Little or no significant change occurs over short periods with low temperatures. For example, racemization induced by hydrolysis at 100 degrees $\mathrm{C}$ for 20 hours is only about 0.01 (Abbott et al. 1996:619). Longer periods spanning years of snail exposure to sunlight may indeed influence the rate of the reaction. Shells subjected directly to fire for short periods of time appear to rapidly racemize during heating and result in ratios that resemble much older shells. 
The 16 shells submitted for racemization came from four different proveniences. Four shells each were submitted from Unit A5 (\#5160) between 30-40 cmbs, Unit A5 (\#5167) between 110-120 cmbs, Unit D1 (\#5377) between 20-30 cmbs, and Unit D1 (\#5386) between 110-120 cmbs. The first and third samples were from Occupation 1 while the second and forth were from Occupation 5. Parts of two shells from Occupation 1 with different $\mathrm{A} / \mathrm{I}$ ratios were also sent to Beta Analytic Inc. for AMS radiocarbon dating.

Tightly clustered A/I values can be used to provide a reliable argument for high integrity of deposits and their corresponding artifacts assemblages (Ellis et al. 1996; Abbott et al. 1996). However, dispersed A/I ratios do not automatically signify a low confidence of integrity (Ellis et al. 1996). When A/I ratios from a single provenience are loosely clustered, the reasons behind such clustering will be largely interpretive and dependent on numerous factors, including snail proximity to hearth features, etc. (Ellis et al. 1996).

\subsubsection{Flotation Analysis}

Three hundred and thirty-six samples from columns and 34 feature-specific matrix samples were floated. These matrix samples were processed using a Dousman flotation system at TRC's Austin office. The recovered light and heavy fractions were dried, then materials were sorted into flakes, shell, burned rock, and macrobotanical remains. Results were incorporated into each of the feature discussions. A section concerning the column recovery is also presented. Nine float results were selected for analysis to identify the light fraction materials and sent to Dr. Phil Dering at the Center for Environmental Archeology at Texas A\&M University in College Station. Five samples were from Features 9, 12, 13, 19, and 36 in Occupation 1 with another four samples from
Occupations 2, 4, and 5. Dr. Dering's procedures, results, and interpretations are presented in Appendix B, Table B1.

\subsubsection{Charcoal Analyses}

Eight-one charcoal pieces from mostly feature context and some from general occupational proveniences were selected and submitted to Dr. Phil Dering for identification. The details of his analysis and proveniences are provided in Appendix B. Beyond the identification, Dering explored the density and diameter of the plant cell vessels present in the 20 wood charcoal pieces (10 each from Occupations 1 and 5) to examine possible changes in the xylem tissue that may reflect differences in climatic conditions between 2000 to 3200 B.P. in south Texas.

\subsubsection{Radiocarbon Analysis}

Since charcoal was encountered in many of the identified features and scattered in the cultural occupation zones, this preferred material was the focus of the chronometric dating of the natural and cultural strata. Prior to its destruction in the dating procedure, Dr. Dering analyzed each piece for species identification. Charcoal samples for dating were selected from the features where context was more obvious and unquestioned. Wood charcoal chunks identified as mesquite root were not selected for dating because these roots were probably intrusive and more recent than the occupations from which they came.

Alternate datable material types such as Rabdotus shells and organic residues from the interiors of burned sandstone have been used recently to obtain acceptable dates (Ellis and Goodfriend 1994; Quigg and Ellis 1994; Abbott et al. 1995; Abbott et al. 1996; Quigg et al. 1996; Quigg 1999; Quigg and Cordova 1999a, 1999b). Samples from these materials were again dated 
from the same context as charcoal dates to verify the potential chronometric reliability in other sites when charcoal is unavailable.

The lip portion of two individual Rabdotus alternatus snail shells were carefully removed from nearly complete shells and sent to Beta Analytic, Inc., for pretreatment and then forwarded to one of six collaborating laboratories for AMS measurements. The carbon isotope $\mathrm{C}^{13} / \mathrm{C}^{12}$ ratio was individually determined for each shell, and the measured value was used to correct and establish the "Conventional $\mathrm{C}^{14}$ Age." Beta's laboratory reports and procedures for dating the snail shells are presented in Appendix A.

The use of organic residues extracted from the interior of burned rocks has just recently been investigated (Quigg and Cordova 1999a, 1999b; Quigg 1999). A selected burned sandstone was broken open, and the interior was carefully ground with a Dremel tool to obtain a few grams of residue. This organic residue provides the material for a radiocarbon date using the AMS dating technique.

\subsubsection{Isotope Analysis}

Organic residue samples were extracted from the interiors of selected sandstone burned rocks and submitted to the University of California at Davis, Stable Isotope Facility, for stable carbon and nitrogen isotope analyses. A few modern plant and animal samples were also analyzed for comparisons. These modern data supplement and support the recent stable isotope data gathered on modern edible plants, animals, and nuts from the central and south Texas regions (Quigg and Cordova 1999b).

The selected burned rocks submitted for isotope study came from recognizable cultural features in defined occupation zones. The sandstone burned rocks were broken and the dark interiors were ground out using a Dremel tool with a variety of metal bits. The ground rock matrix was placed in a plastic vial and sent to a geological laboratory for calcium carbonate removal. The laboratory processing to remove the calcium carbonate from the extracted residues involved: 1) wetting each sample with a few $\mathrm{ml}$ of distilled water, 2) adding $20 \mathrm{ml}$ of 20 percent HCL and stirring, 3) stirring in additional HCL gradually to samples still effervescing until all visible reaction ceased and then adding approximately $10 \mathrm{ml}$ more of 20 percent HCL, 4) leaving samples to stand overnight and settle out of suspension, 5) decanting the rock matrix and washing with distilled water three times, 6) drying the rock matrix in a drying oven, and 7) disaggregating, weighing, and repackaging. A tiny amount of each sample was then sent to the University of California at Davis, Stable Isotope Facility, for stable isotope analyses. The specific stable isotope data results are presented in Appendix D, Table D1.

Carbon isotope results are used to assess the relative proportion of $\mathrm{C} 3$ or $\mathrm{C} 4$ photosynthetic pathway of the plant residues or animals that ate these plants, and hence the relative abundance of each photosynthetic community. The stable nitrogen isotope results are believed to be informative for the identification of legume verses non-legume plants. In combination with the phytolith and geomorphological results, the stable isotope results from the soil matrix provide useful data for interpreting potential subsistence resources cooked by the burned rock.

\subsubsection{Lipid Residue Analysis}

Fifty burned rock residue samples were selected and sent to Dr. Mary Malainey in Winnipeg, Manitoba, for lipid residue analysis. Forty-eight samples were from 41WB437, and two were experimental burned rock residues with known south Texas plant residues. The samples were 
extracted using the same grinding procedures used to obtain isotope samples from the burned rocks. The burned rocks came from various burned-rock features encompassing all six identified occupations. The chemical analyses identified the lipids within the organic residues, which may indicate the kinds of foods that were cooked and possible cooking changes over time. The detailed procedures, results, and interpretations are presented in Appendix G.

\subsubsection{Diatom Analysis}

Four matrix samples were submitted to Dr. Barbara Winsborough in Austin for determining the presence or absence of diatoms. Matrix sample (\#5719-2, $17 \mathrm{~g})$ was from beneath a mussel shell, and the others were from Features 13 (\#769a), 14 (\#844a), and 15 (\#914a). The lack of good diatom preservation negated a further in-depth study. Dr. Winsborough's procedures, observations, and results are presented in Appendix I.

\subsubsection{Phytolith Analysis}

Phytolith analysis was conduced on three test matrix samples in order to assess their potential for addressing paleovegetation changes over time and to identify potential plant classes used by the site occupants. Test samples were submitted to Dr. John Jones at the Palynology Laboratory, Department of Anthropology, Texas A\&M University in College Station. Bulk matrix samples were collected from one vertical column in the southern backhoe trench and from specific cultural features for possible analysis. Poor preservation of phytoliths in the test samples negated expansion of this analysis. Dr. Jones's detailed phytolith report is presented as Appendix $\mathrm{H}$. 


\subsection{INTRODUCTION TO LINO SITE 41WB437}

The Lino site is a reasonably well-stratified, Late Archaic site dominated by scattered burned rocks, burned rock features, and lithic debitage in the top $120 \mathrm{~cm}$ of terrace deposits along San Idelfonzo Creek. The following section first discusses the natural deposits that contained the cultural materials. Then the vertical distribution of the cultural remains as documented by the TDS data is presented, and the number of occupations is defined. The radiocarbon dating results are then discussed in order to provide a chronological framework for the cultural materials. Next, the six individual occupation zones and their associated cultural assemblages are described by component in six sections. In Section 13.0, the seven research issues are addressed, and a summary of what was learned from the mitigation investigations is presented.

\subsection{GEOMORPHOLOGY AND GEOARCHAEOLOGY}

\section{Grant Smith}

\subsubsection{Setting}

Archaeological site 41WB437 occurs on the T1 terrace of San Idelfonzo Creek, an ephemeral tributary of the Rio Grande (Figure 5.1). The confluence of this creek with the Rio Grande is approximately $0.5 \mathrm{~km}$ to the west. The terrace is approximately five to six meters above the adjacent dry channel. Abbott (1997) determined that the Lino site terrace was about 15 to 17 meters above the low-water level of the modern Rio Grande and that this elevation approximates that of terraces at the mouth of San Idelfonzo Creek and other tributaries in the area.

It appears that San Idelfonzo Creek was modified to accommodate the Highway 83 bridge that spans the creek. The current channel, which is south of the site, is fairly straight and constrained so as to limit the length of the bridge (after Abbott 1997). The original channel of San Idelfonzo Creek lies to the north of site 41WB437 and takes a much more meandering course. The original channel is lined with yellowish red sands and gravels that appear similar to bedrock outcrops to the north of the creek. Bedrock in the immediate vicinity consists of yellowish red sandstone of the Eocene aged Laredo Formation that is capped by ancestral Rio Grande gravels (Figure 2.4). In contrast, the sediments that comprise the $\mathrm{T} 1$ terrace tend to be silty in texture and not as red as the sandstone bedrock.

\subsubsection{Previous Studies}

Abbott (1997) and Gustavson and Collins (1998) conducted previous geomorphological studies within the San Idelfonzo Creek drainage prior to our site-specific investigation. The first of these (Abbott 1997) investigated archaeological sites $41 \mathrm{WB} 437$ and 41WB438 on either side of San Idelfonzo Creek where Highway 83 crosses it. Abbott's report concluded that two principal allostratigraphic units (Units 1 and 2) occur above the Laredo Formation. Unit 1 the older, was characterized as loamy sand to sandy loam with a Stage II calcic horizon. This unit was only observed on the south side of San Idelfonzo Creek at 41WB438. Unit 2 was present at both archaeological sites but thickened significantly to the north. Unit 2 was determined to be at least 2.5 meters thick at 41WB437. Abbott (1997) identified several stratigraphic zones (Zones 1 through 5) within Unit 2 that varied in texture between silty loam to massive silt. The silts are representative of massive flood deposits while the silty loams are considered to be representative of overbank aggradation. All cultural materials observed at 41WB437 and 


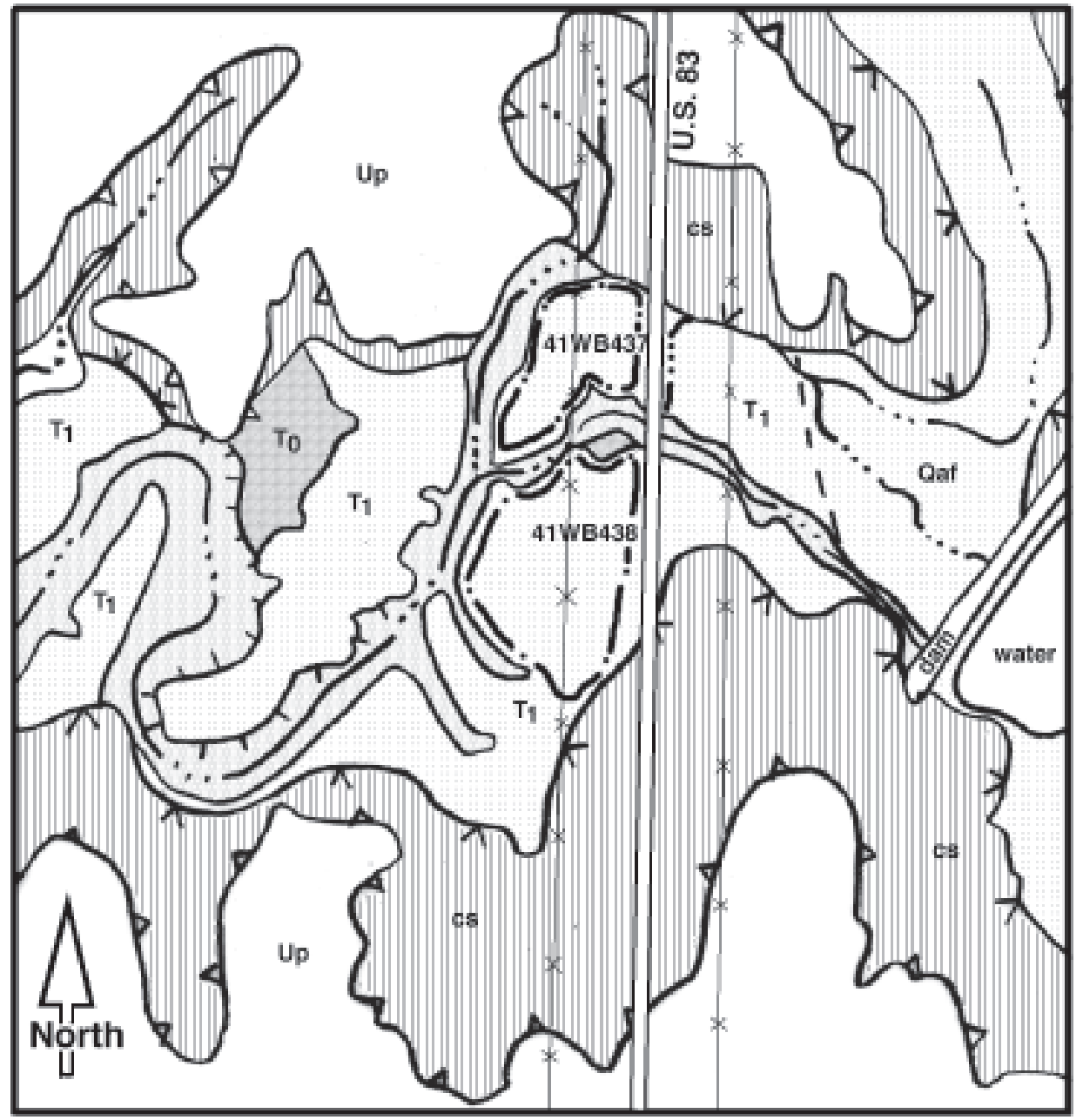

Figure 5.1 Geomorphic Sketch Map of the Vicinity of 41WB437 and 41WB438 Prepared from Aerial Stereopair Photographs. (Areas outside the highway right of way were not examined except by peering over the fence, and the site boundaries are therefore approximate. (Abbott 1997). (Up $=$ Uplands. $\mathrm{T}_{0}=$ Modern Floodplain. $\mathrm{T}_{1}=$ Lowest Terrace. CS = Colluvial Slope. Qaf = Holocene Alluvium.)

41WB438 were within the fine-grained Unit 2 sediments. Archaeological stratigraphy at $41 \mathrm{WB} 437$ and radiocarbon dates of cultural features there suggested that Unit 2 aggraded between about 4000 to 5000 B.P. and 1500 to 2000 B.P.

The second geomorphological study within the San Idelfonzo Creek drainage was conducted by Gustavson and Collins (1998). The San Idelfonzo Creek investigations were part of a larger study that investigated Rio Grande terraces and tributaries from Amistad Dam to the Gulf of Mexico. These investigators relied on radiocarbon dates collected during Abbott's study but developed their own stratigraphic profiles from backhoe trenches. They delineated three primary stratigraphic units (Units 1 through 3 ). The oldest of these, Unit 1, was a cemented and iron-stained gravel stratum. The age of this stratum was not determined, but it may correlate to the Eocene Laredo Formation that Abbott identified at the base of his excavations, or it may be Pleistocene lag gravel. Unit 2 consisted 
of gravels, very fine sands, and silts that exhibited a Stage II pedogenic carbonate accumulation. Based on the carbonates and sediment descriptions, Unit 2 from the Gustavson and Collins report correlates to Unit 1 in Abbott's report. The youngest unit identified by Gustavson and Collins, Unit 3, consists of interbedded silt, mud, silty loam, and sandy loam and can be correlated to Abbott's Unit 2 . Cultural materials were limited to this upper unit. A key difference in the Gustavson and Collins report and this one is that they focused primarily on depositional strata and did not delineate soil horizons. As a result, their profiles and the profiles from TRC's study often appear quite different. While they only discuss geological deposits, TRC also looked at soil development because it indicates periods of landscape stability that may have been suitable for human occupation and utilization of this T1 terrace.

In addition to the San Idelfonzo Creek studies, other regional geomorphological investigations along the Rio Grande and its tributaries include those by Bunker (1978) and Vierra et al. (1997). One important contribution from the Vierra et al. report is a proposed record for climatic change during the Holocene. They propose four major climatic intervals during the Holocene. During the first interval-from 10,000+ years to ca. 7,500 years - the climate was relatively cool. The second interval from 7500 to 4000 B.P. appears to be a warm period. From ca. 4000 to 2200 B.P. is considered to be a cool interval. Finally, they propose two brief warm intervals between 2200 and 1200 B.P. and at sometime after 1000 B.P.

TRC's study concentrates on the silty upper unit of the T1 terrace of San Idelfonzo Creek (Abbott's Unit 2, Gustavson and Collins' Unit 3 ). The previous studies determined that cultural materials were limited to this upper unit and, thus, focused our investigation. A summary correlation of our strata to the two previous reports is made in Table 5.1.

\section{$\underline{\text { 5.1.3 Methods }}$}

The geomorphic/geoarchaeologic investigation of the study area consisted of examination of vertical balk walls (Figure 5.2), trench profiles, and pedestrian examination of the surrounding terrain. Field descriptions follow standard sedimentologic and pedogenic procedures established by the Soil Survey Staff (1962, 1975), Krumbein and Sloss (1963), Gile et al. (1966), Reineck and Singh (1980), Birkeland (1984), Birkeland et al. (1991), and Waters (1992). Field investigations were recorded in a field book and on profile exposure forms.

Bulk matrix samples were collected from the south trench wall (S-2) at $41 \mathrm{WB} 437$ for laboratory testing (Figure 5.3). Matrix samples

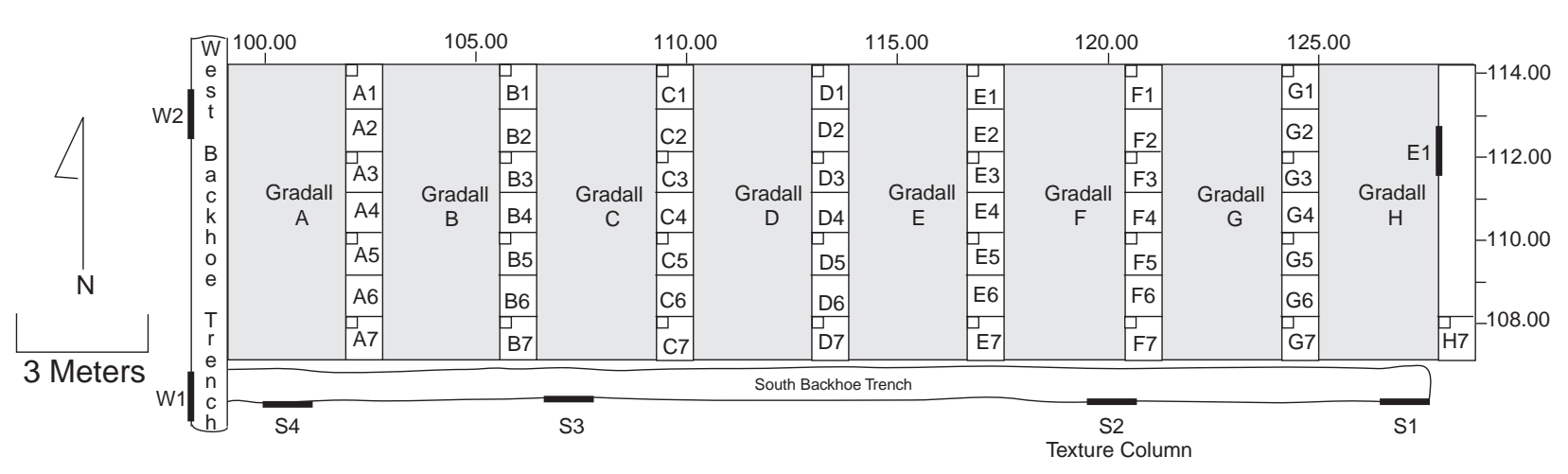

Figure 5.2 Overall Excavation Block Plan Showing Locations of Seven Documented Geomorphic Profiles (W1, W2, S1, S2, S3, S4, E1). 


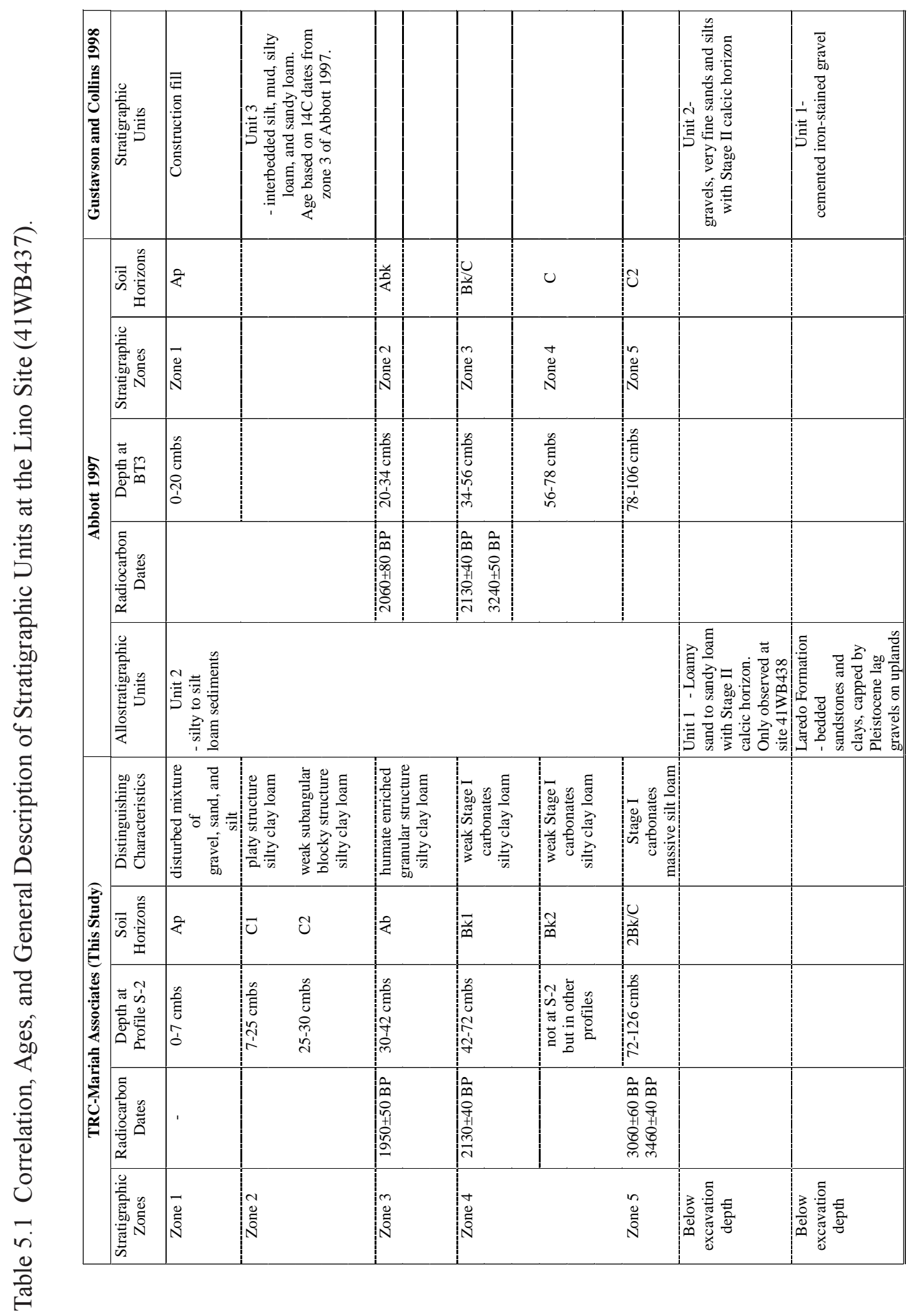




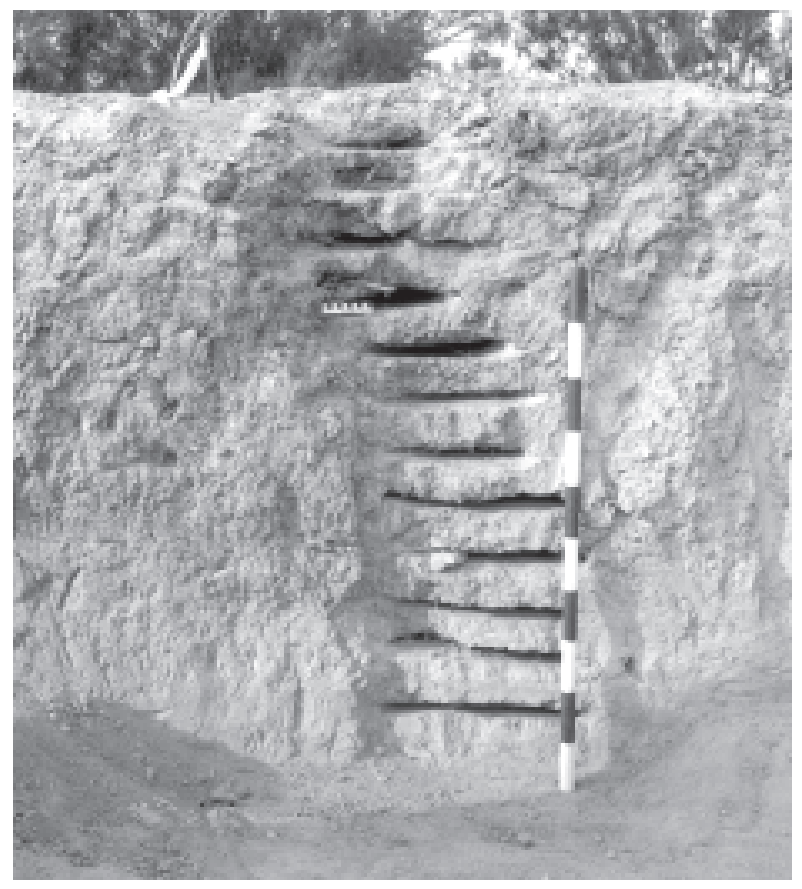

Figure 5.3 Profile of South Trench Wall at S-2 Showing Sample Column and Intervals Sampled for Texture Analysis.

were collected from 2- to $3-\mathrm{cm}$ thick layers spaced at $10 \mathrm{~cm}$ intervals. To help assess the origins of the silty materials that comprise the cultural levels on the terrace, two other bulk matrix samples were collected from areas outside the Lino site. A sample of Rio Grande silt was collected from a low alluvial terrace about $2.0 \mathrm{~km}$ upstream from the confluence of the Rio Grande and San Idelfonzo Creek. The second off-site sample was taken from approximately $1 \mathrm{~km}$ up the San Idelfonzo Creek valley from the sloping margin of the dry channel.

Paul Lehman of the Geology Department at the University of Texas - Austin conducted several laboratory analyses on the samples. Hydrometer analyses (Gee and Bauder 1986) were used to determine the percentages of sand, silt, and clay within the samples. These percentages were used to check and, in some cases, correct the field texture estimates. Sieve analyses were conducted on the sand-sized fraction to characterize the sand distribution. The distribution of the sand-sized fraction helped in the assessment of the origins of the sediments at 41WB437. Organic matter was determined by the loss-on-ignition (LOI) method (Berglund and Ralska-Jasiewiczowa 1986), which was used to help detect and quantify the presence of buried organic materials. A relatively high percentage of organic matter could indicate a buried soil A horizon and thus a hiatus in overbank deposition. A Chittick device was used to determine carbonate equivalency by measuring the volumetric production of $\mathrm{CO}_{2}$ when a calcareouis sample was dissolved in $\mathrm{HCl}$. Finally, calcium carbonate equivalency analyses (Dreimanis 1962) were conducted to quantify the amount of carbonate in the sediments and evaluate whether pedogenic carbonate had accumulated.

\subsubsection{Results and Interpretation}

Examination of the standing balks remaining from Gradall ${ }^{\mathrm{TM}}$ stripping revealed five major depositional zones, although soil formation typically resulted in the delineation of four to six horizons (Figure 5.4). All of the zones dip gently (ca. three degrees) to the west, although the basal unit dips at a steeper angle (ca. 20 degrees) on the very southeastern margin of the excavation block. The upper 7 to $20 \mathrm{~cm}$ consist of a mixture of sediments from recent road construction and site excavation (Zone 1). Of the naturally deposited strata, the uppermost is Zone 2 (between about 7 to $30 \mathrm{cmbs}$ ), which is classified as a $\mathrm{C}$ horizon and consists of overbank sediments that lack significant soil formation. Zone 3 (between 30 to $45 \mathrm{cmbs}$ ) is a buried soil A horizon within the overbank sediments. Zone 4 (between 45 and $70+$ cmbs) is a $\mathrm{Bk}$ horizon. The lowest deposit, Zone 5 (below about $75 \mathrm{cmbs}$ ) consists of massive silts. 


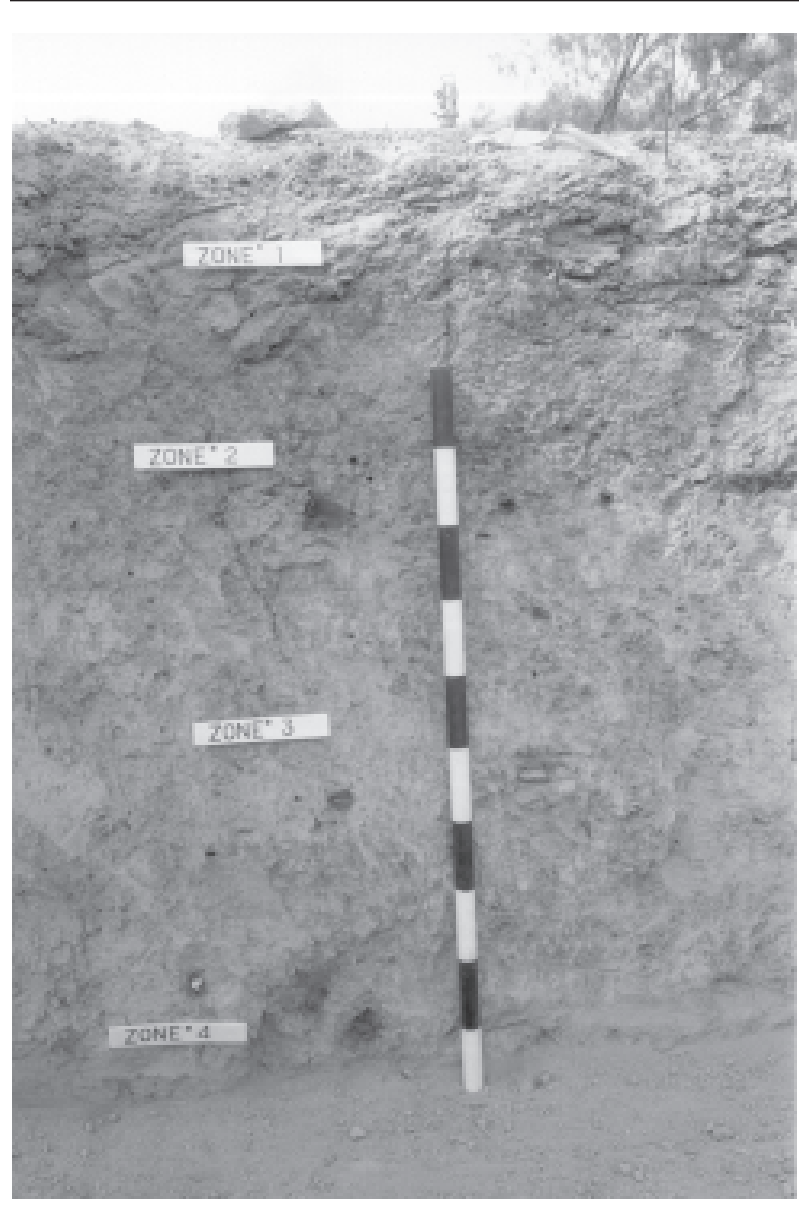

Figure 5.4 Profile of South Trench Wall at S4.

Each of the five zones is described and interpreted below.

\section{Zone 1 (Disturbed Zone)}

The upper 7 to $20 \mathrm{~cm}$ are capped by a mixture of silty, sandy, and clay-rich sediments. These sediments probably result from road construction across the site, from building the present Highway 83, and from previous site testing excavations. In some areas the sediments resemble the underlying horizons (i.e., silty clay loam). In a least one case the material does not resemble any other sediments observed; it is a clay-rich deposit with pedogenic clay-skins and a Stage II carbonate accumulation. These sediments must have been brought in during road construction and do not have potential to yield intact cultural deposits.
In the previous study by Abbott (1997), the upper ca. $20 \mathrm{~cm}$ of sediments is listed as an Ap horizon, a designation used to indicate plowed or otherwise disturbed sediments. This horizon designation is also used here, but as seen in Figure 5.5, the thickness of Zone 1 is variable across the site. In addition, Abbott's Zone 1 may also include the deposits TRC designates as Zone 2 (horizons $\mathrm{C} 1$ and $\mathrm{C} 2$ ). The most likely explanation for this apparent discrepancy is that the disturbance was greater where Abbott did his profiles, a factor that would result in more sediment being designated as a disturbed Ap horizon. In the Gustavson and Collins study (1998), several profiles show "construction fill" that probably correlates to our Zone 1. These correlations are summarized in Table 5.1.

\section{Zone 2 (Upper C1 and C2 Horizons/Silty Clay Loams)}

Below the disturbed sediments is approximately $20 \mathrm{~cm}$ of relatively undisturbed sediments that exhibit a silty clay loam texture. No evidence of soil formation was observed in this zone. At most locales around the margins of the excavation block, two distinct deposits (horizons $\mathrm{C} 1$ and $\mathrm{C} 2$ ) represent this zone. These horizons are grayish brown to brown in color (10YR5/2 to $10 \mathrm{YR} 5 / 3$ ). The upper $\mathrm{C} 1$ horizon is ca. 15 $\mathrm{cm}$ thick and was observed throughout the block. A coarse blocky to platy structure is present within the $\mathrm{C} 1$ horizon but is probably due to compaction by heavy machinery as opposed to pedogenic processes. The lower $\mathrm{C} 2$ horizon tends to be the thinner $(\mathrm{ca} .5 \mathrm{~cm})$ and most ephemeral. Both the $\mathrm{C} 1$ and $\mathrm{C} 2$ horizons exhibit an abundance of roots and insect burrows, and as a result, Zone 2 is highly bioturbated. No datable organic matter or cultural materials were observed within Zone 2. These deposits have a soil texture similar to that described in Zones 3 and 4 (i.e., silty clay loam) and are considered to be deposits resulting from overbank aggradation. Without specific age controls, these 

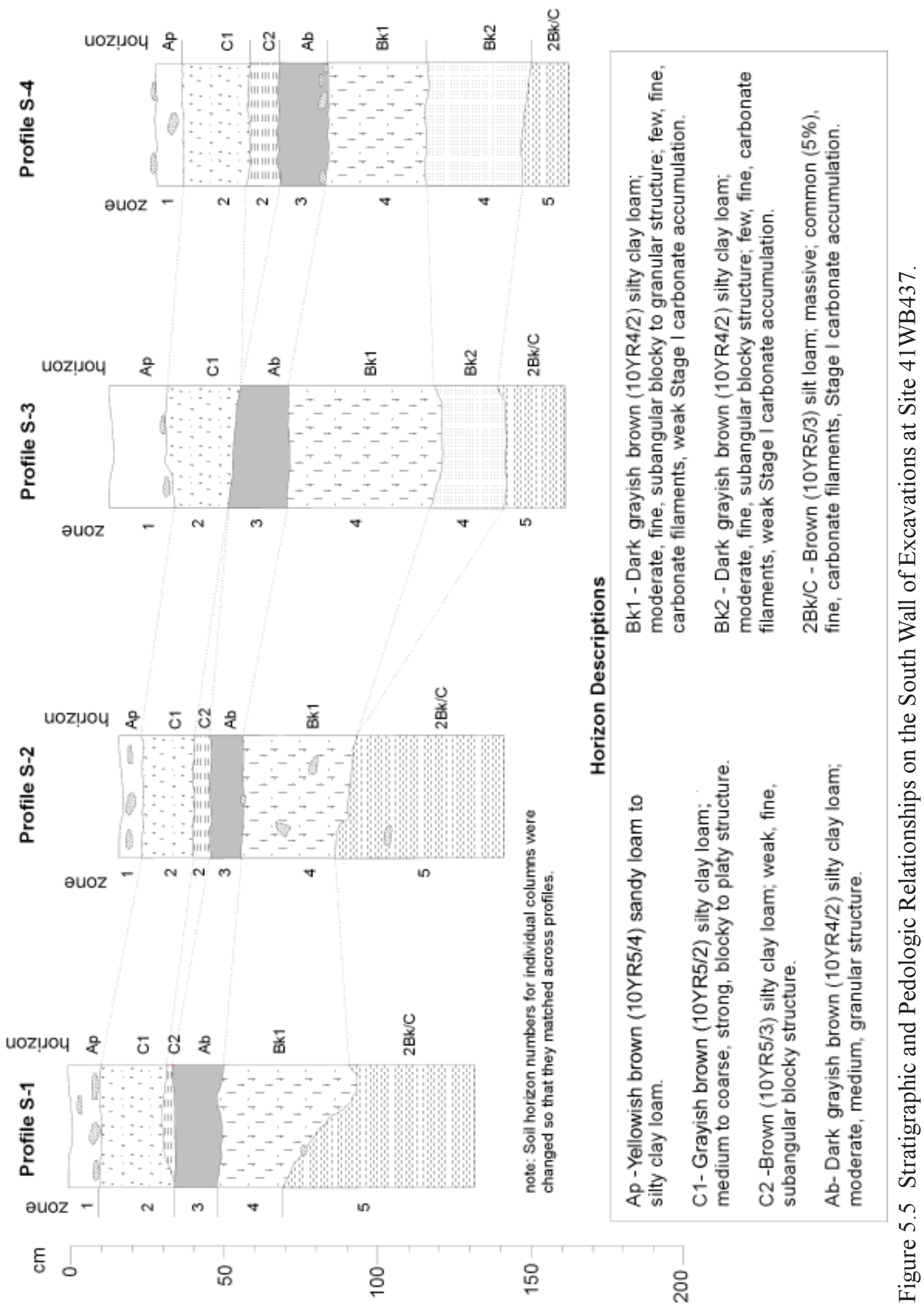
sediments could have been deposited at any time during the past 2,000 years.

\section{Zone 3 (Ab Horizon/Intermediate Silty Clay Loam)}

Underlying the C2 horizon is Zone 3, which consists of 15 to $20 \mathrm{~cm}$ of humate-enriched, silty clay loam. The boundary between Zone 2 and Zone 3 is abrupt and wavy. In comparison to the underlying Zone 4, the humate enrichment in Zone 3 results in a slightly darker gray appearance, though not sufficiently enough to result in a different Munsell color reading of the dark gray brown (10YR 4/2) color. The humate enrichment is evident, however, in the percentage of organic matter in this horizon (40 $\mathrm{cm}$ level in Table 5.2 and Figure 5.6). In addition, this horizon has a moderate granular structure, which is often typical of soil A horizon. This granular structure also appears to display hints of subangular blocky structure, which may be a result of its burial and subsequent pedogenesis. Based on the color and structure, Zone 3 is classified as a buried A horizon. As is typical of A horizons, it lacks the carbonate filaments of the underlying Bk horizon. The unit was in place by $1950 \pm 50$ B.P. (Beta-121730) as indicated by a $\delta^{13} \mathrm{C}$ corrected radiocarbon date on wood charcoal sample from Feature 14.

Another attribute of this stratum is that an ephemeral stone line is often observed at the contact between Zones 3 and 4. This stone line often contained water-worn cobbles up to $10 \mathrm{~cm}$ in diameter but consists of only one to three such cobbles in each meter-wide profile. The stone line illustrated the episodic nature of the overbank deposition associated with Zones 3 and 4. It is probable that the gravels and cobbles deposited on this contact were brought in by slope wash during a hiatus in overbank deposition. It is highly unlikely that the gravels and cobbles were deposited by the same aggradational event responsible for the thin, overbank deposits that comprise Zones 3 and 4. Overbank flows generally lack the competence to carry cobbles and when they are capable of such transport and deposition; the surrounding matrix would be more poorly sorted than the silty

Table 5.2 Representative Sediment Analyses from the Lino Site 41WB437 and Nearby Localities.

\begin{tabular}{ccccccc}
\hline Unit Association & $\begin{array}{c}\text { Depth } \\
(\mathrm{mbs})\end{array}$ & \% Sand & \% Silt & \% Clay & Texture & $\begin{array}{c}\text { \% Organic } \\
\text { Matter }\end{array}$ \\
\hline Rio Grande Silt & - & 12.0 & 75.6 & 12.4 & SiL & 2.84 \\
Upstream Soil Sample & - & 44.2 & 30.7 & 25.1 & $\mathrm{~L}$ & 1.62 \\
S2 Profile - C1 & 0.1 & 17.7 & 51.9 & 30.4 & SiCL & 1.37 \\
S2 Profile - C1 & 0.2 & 19.8 & 50.9 & 29.3 & SiCL & 2.93 \\
S2 Profile - C2 & 0.3 & 13.8 & 51.9 & 34.3 & SiCL & 2.79 \\
S2 Profile - Ab & 0.4 & 9.2 & 51.4 & 39.4 & SiCL & 3.24 \\
S2 Profile - Bk1 & 0.5 & 4.8 & 57.9 & 37.4 & SiCL & 2.71 \\
S2 Profile - Bk1 & 0.6 & 4.2 & 56.8 & 39.0 & SiCL & 2.98 \\
S2 Profile - Bk1 & 0.7 & 6.8 & 58.1 & 35.1 & SiCL & 2.16 \\
S2 Profile - Bk2 & 0.8 & 7.8 & 57.2 & 35.0 & SiCL & 1.90 \\
S2 Profile - Bk2 & 0.9 & 5.9 & 60.6 & 33.5 & SiCL & 1.79 \\
S2 Profile - Bk2 & 1.0 & 2.1 & 71.8 & 26.2 & SiL & 1.52 \\
S2 Profile - Bk2 & 1.1 & 2.5 & 72.6 & 25.0 & SiL & 1.56 \\
S2 Profile - Bk2 & 1.2 & 1.3 & 77.1 & 21.6 & SiL & 1.40 \\
\hline \hline
\end{tabular}

Note: Percentages are based on analyses without gravel. The highest gravel percentage $(1.0 \%)$ was in the "Upstream Soil Sample". Samples at the site were never greater than $0.2 \%$ gravel.

$\mathrm{L}=$ loam $\quad \mathrm{SiL}=$ silt loam $\quad \mathrm{SiCL}=$ silty clay loam 


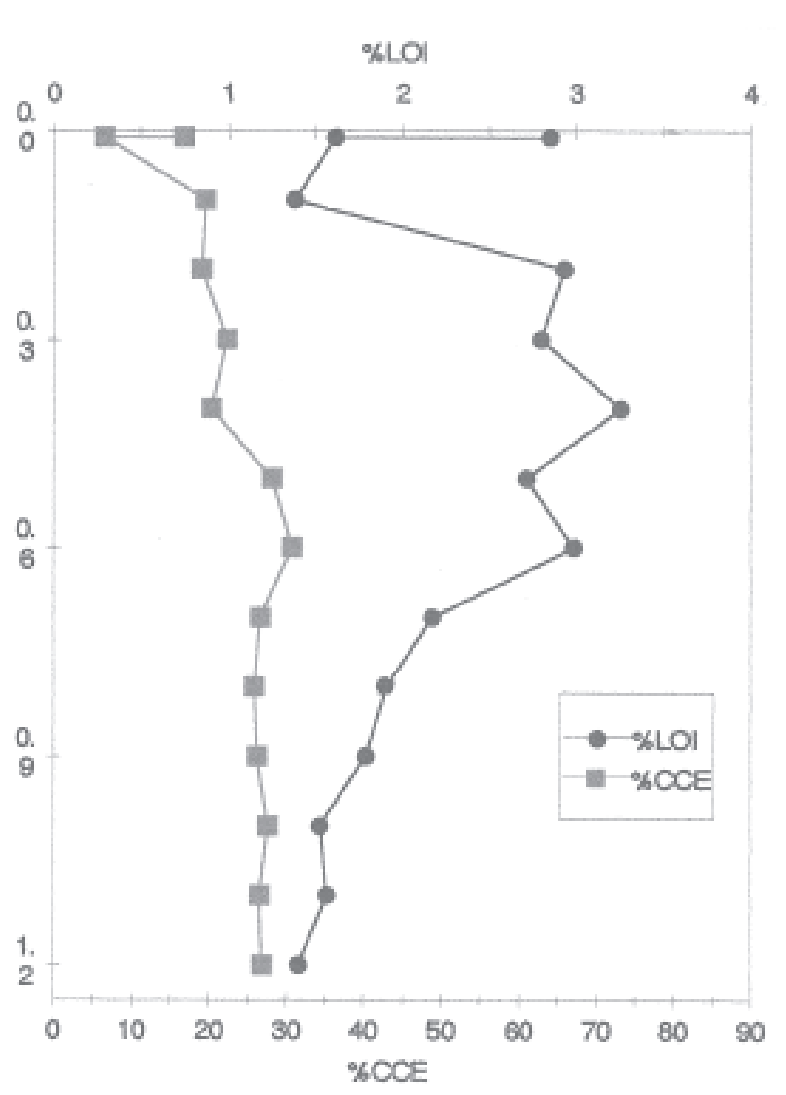

Figure 5.6 Organic Matter and Calcium Carbonate Equivalency at Profile S-2.

clay loam observed in Zones 3 and 4. Although it is also possible that the gravels are manuports, their dispersed nature and lack of any architectural shape makes this possibility remote. The amount of bioturbation could explain the dispersal of manuports.

With respect to cultural materials, the relatively gentle nature of overbank deposition provides favorable circumstances for their preservation. Since the fine sediments accumulated gradually, cultural materials from multiple occupations could have been vertically dispersed throughout this unit. Bioturbation probably has affected the original integrity of some cultural materials, but how much the cultural materials may have been displaced is difficult to assess. In addition, the amount of bioturbation suggests that charcoal staining around hearths would be diffuse, if noticeable at all.

This zone correlates to Abbott's Zone 2 which, depending upon location, he classified as an $\mathrm{AB}$, Abk, or $2 \mathrm{~A}$ horizon. With respect to the calcareous Abk designation, TRC did not observe visible carbonates in our profiles of the $\mathrm{Ab}$ horizon, but given the calcareous nature of the sediments at the site (Table 5.2, Figure 5.7), such an occurrence is not surprising. The AB designation reflects the transitional characteristics of the A horizon being converted to a B-horizon. The 2A designation was used by Abbott in his BT 4, where a change in parent material to a fine sandy loam necessitated adding the prefix of the number two to the horizon name. Such a change in parent material was not observed in our profiles.

\section{Zone 4 (Bk1 and Bk2 Horizons/Intermediate Silty Clay Loam)}

Zone 4 is genetically related to Zone 3 but lacks the humate accumulations observed in the $A b$ horizon. The boundary between Zones 3 and 4 is clear and wavy. Zone 4 increases from a thickness of $20 \mathrm{~cm}$ on the southeastern corner of the excavation block (profile S-1) to $70 \mathrm{~cm}$ thick on the western margin of the excavation block (profile $\mathrm{S}-4$ ). In addition, the western profiles of this unit exhibit two Bk horizons (Bk1 and $\mathrm{Bk} 2$ ) while the eastern portions exhibit only a single $\mathrm{Bk}$ horizon. Where present, the $\mathrm{Bk} 1$ and $\mathrm{Bk} 2$ horizons are both approximately 30 to $35 \mathrm{~cm}$ thick. The characteristic that distinguishes between the $\mathrm{Bk} 1$ and $\mathrm{Bk} 2$ horizons is texture. The Bk2 unit has a slightly higher silt content (ca. three to five percent from field estimates) but is otherwise identical to the Bk1. The slight difference in texture between $\mathrm{Bk} 1$ and $\mathrm{Bk} 2$ is probably due to a slight change in overbank deposition instead of pedogenic development. In terms of deposition and soil formation, these 


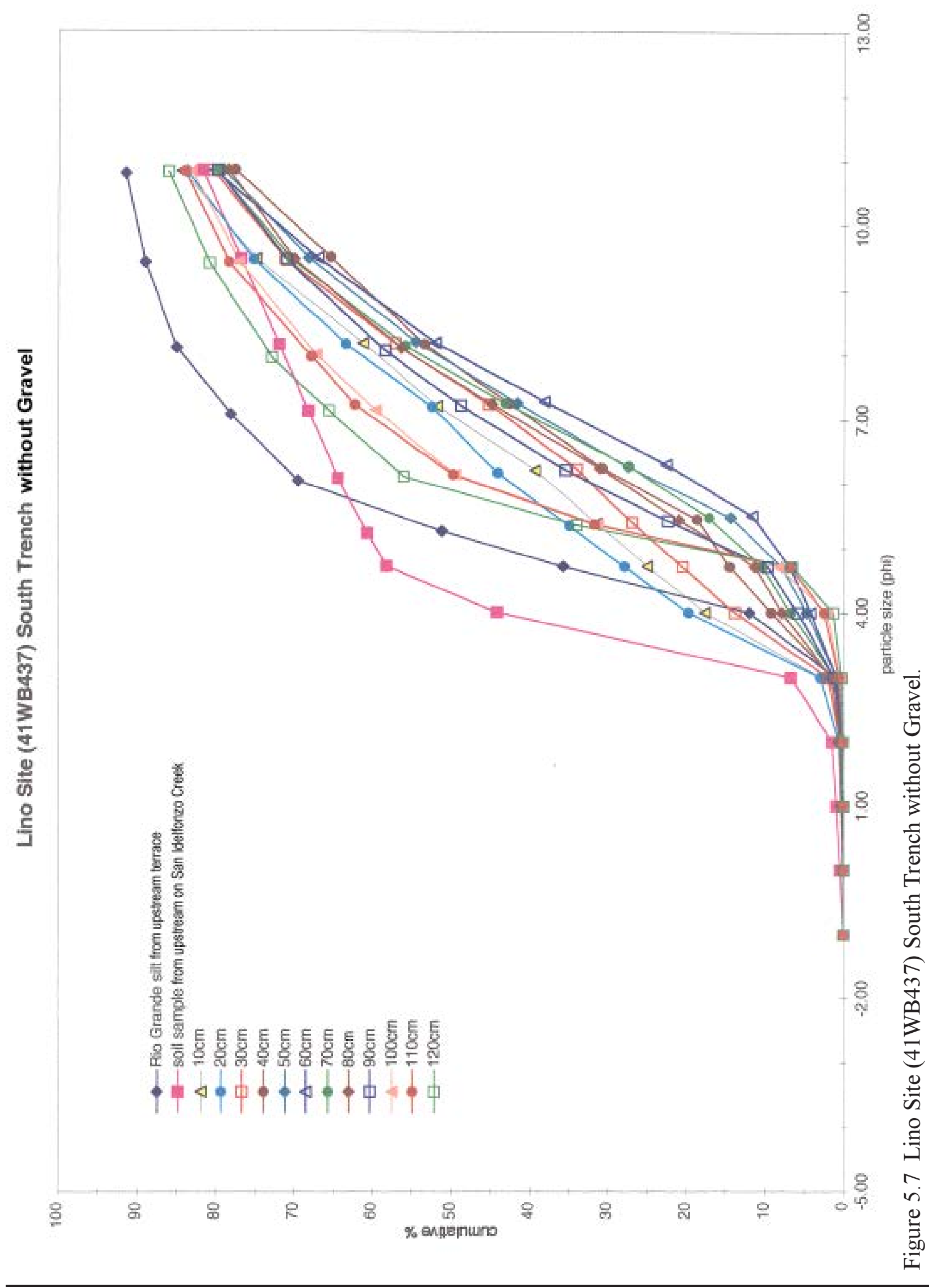


horizons appear very similar and are thus still considered to be part of Zone 4 .

In general, the Zone 4 sediments are a dark grayish brown (10YR 4/2), silty clay loam that exhibit pedogenic carbonates. In contrast to the overlying $\mathrm{Ab}$ horizon, the $\mathrm{Bk} 1$ and $\mathrm{Bk} 2$ horizons have a moderate, fine, subangular blocky structure that differentiates them from the granular Ab horizon (Zone 3) and the massive basal unit (Unit 5). However, the presence of granular structure is gradational from the $\mathrm{Ab}$ horizon into the $\mathrm{Bk} 1$ horizon. Additional evidence of soil formation is provided by the presence of a few, fine carbonate filaments dispersed throughout the zone (weak Stage I accumulation). Bioturbation is very evident within Zone 4. Various small to large krotovina as well as mesquite roots intrude into the Bk1 and $\mathrm{Bk} 2$ horizons. Though the krotovina are often filled with a material similar to the surrounding unit, close examination and weathering help reveal subtle differences in compaction between natural deposits and disturbance. Cultural materials were commonly observed within this unit, and a $\delta^{13} \mathrm{C}$ corrected radiocarbon date of $3040 \pm 40$ B.P. (Beta124391) was obtained from wood charcoal associated with these sediments.

Compared to the massive silt deposits in Zone 5 , the silty clay loam deposits observed within Zones 2, 3, and 4 appear to mark a significant shift in deposition on the T1 terrace of San Idelfonzo Creek. The massive basal silt loam was probably deposited during only a few flood events, while the silty clay loam appears to be a result of incremental overbank aggradation during several floods. The hints of granular structure that increase upward in the profile (and are prominent in the $\mathrm{Ab}$ horizon) suggest that soil formation was cumulic in nature. That is, vegetation and soil formation were able to keep pace with the accumulation of overbank sediments instead of being smothered and forced to reinitiate on a new surface. As a result, the A horizon of this soil started out much lower in the profile but migrated upward with the addition of new sediment. The percentage of organic matter appears to confirm this scenario. Though the final A horizon of Zone 3 has the highest percentage of organic matter, the $\mathrm{Bk} 1$ horizon has nearly the same amount, especially in its upper $10 \mathrm{~cm}$. The increase in organic matter in the upper portions of the $\mathrm{Bk} 1$ horizon could be due to their dispersal by bioturbation. It is doubtful, however, that the granular structure within the $\mathrm{Bk} 1$ horizon could be a result of bioturbation.

This zone probably correlates to the Abbott's Zones 3 and 4. He classifies Zone 3 as a Bk/C horizon or $2 \mathrm{Bk}$ horizon. Abbott's $\mathrm{Bk} / \mathrm{C}$ designation reflects that carbonate development within this unit is weak and that it decreases with depth to the point that this is essentially unaltered parent material. His Zone 4 consists of sediments that lack pedogenic carbonate or any other significant soil formation. The author observed carbonates throughout these sediments (even extending into the basal silt loam) and thus includes no $\mathrm{C}$ designations. This is a subtle difference, however, and should not be viewed as a major discrepancy. It may reflect differences in where the profiles were described. The $2 \mathrm{Bk}$ horizon, as was explained in our Zone 3 discussion, reflects a change in parent material not observed in our profiles.

\section{Zone 5 (2Bk/C Horizon/Basal Silt Loam)}

The basal unit consists of over a meter of brown (10YR 5/3), massive, silt loam. A deep test at the western edge of the excavation block in western BT 2 revealed over $2 \mathrm{~m}$ of this silt loam without encountering its base (Figure 5.8). This zone dips at a steeper angle than the overlying sediments. As a result, on the southeastern, higher-elevation portion of the site the basal silt loam is approximately $80 \mathrm{cmbs}$ while it is 


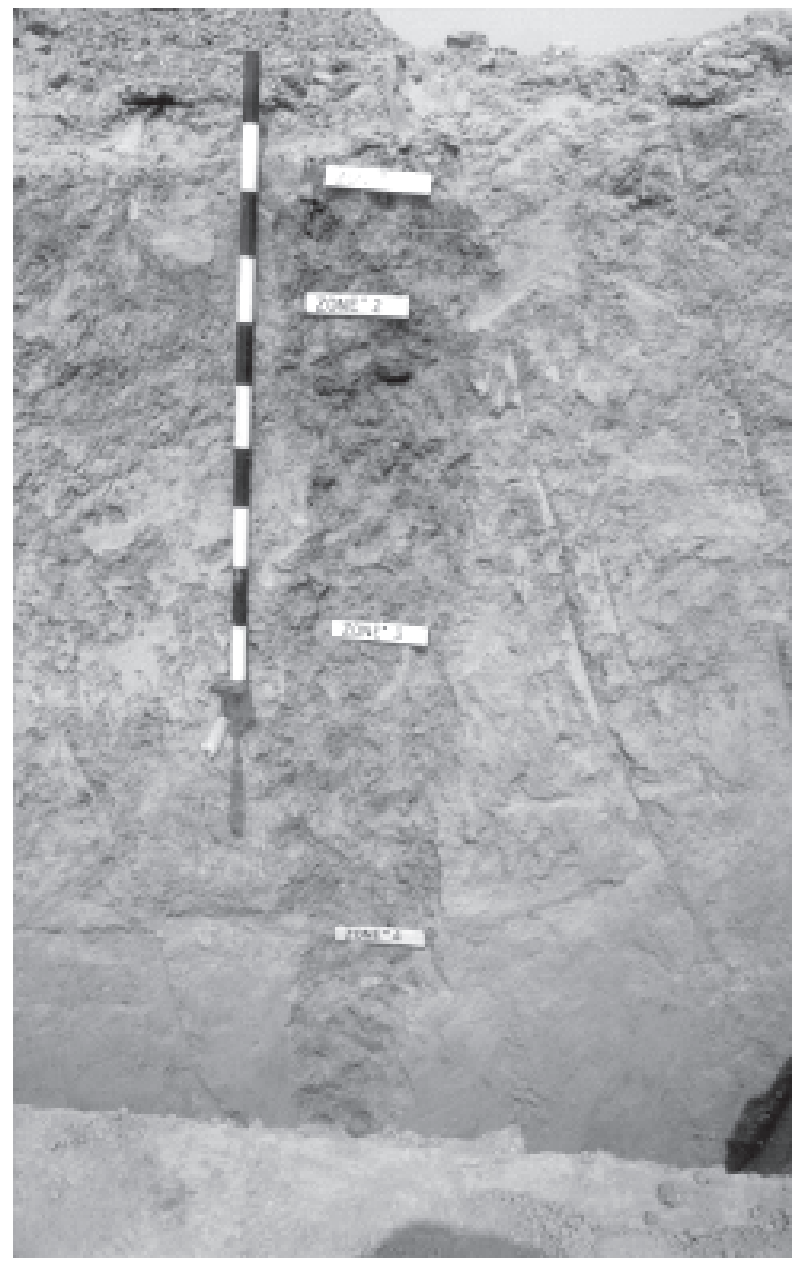

Figure 5.8 Profile of West Trench Wall at $\mathrm{W}-2$.

approximately $140 \mathrm{cmbs}$ at the west-central portion of the excavations. The presence of common (five percent) calcium-carbonate filaments (Stage I accumulation, after Birkeland 1984) and shift in parent material result in its classification as a $2 \mathrm{Bk} / \mathrm{C}$ horizon. The carbonates slightly increase in abundance in the upper ca. $20 \mathrm{~cm}$ of this horizon and are traceable downslope between profiles. Within individual profiles, however, the amount of carbonate decreases with depth until this unit becomes essentially unaltered parent material. The lack of soil structure in this horizon suggests that, although carbonates have accumulated, other soil modifications have been minimal. Though the carbonates in this unit appear slightly more abundant than those observed in the overlying $\mathrm{Bk}$ horizon, this may be due to the change in parent material instead of a different soilforming interval. That is, the carbonates may be more visible in the silt than in the silty clay loam. Bioturbation, although not as abundant as in overlying units, is apparent throughout the basal silt loam. Termite burrows, larger krotovina, and mesquite roots are readily noticeable, especially in the upper $30 \mathrm{~cm}$ of this horizon. This disturbance appears to have been sufficient enough to destroy small-scale stratification in all but a few locales.

The Stage I carbonates within this unit give some indication of its age, but radiocarbon dates from cultural features provide a more precise age. In many areas of the western United States, a soil's age can be estimated based on the degree of carbonate accumulation (e.g., Gile et al. 1966; Machette 1985; Karlstrom 1988). Typically, Stage I carbonates are thought to take at least 1,000 years to develop. This is only a relative age estimate, however, and a consistent chronology based on carbonate development has not been proposed for the south Texas region. A more accurate age is provided by corrected radiocarbon dates on charcoal within this unit of $3060 \pm 60$ B.P. (Beta-124391) and $3460 \pm 40$ B.P. (Beta-121861).

Several paleoenvironmental and site formation interpretations can be made about the basal silt loam. The massive thickness of this silt loam suggests that these sediments were deposited during a few flood events over a short temporal span. Bioturbation has destroyed the small-scale strata to the point that the number of flood events cannot be determined. In addition, the soil formation within this unit (i.e., pedogenic carbonates) appears to be the result of the same soil-forming event as the overlying Bk horizons. If there was a significant hiatus in deposition between Zones 4 and 5, evidence of that hiatus is no longer preserved. 
If Zone 5 resulted from multiple floods in a short period of time, it is possible that cultural occupations occurring over that short time would have been sealed in situ. Since the silt loam would probably have been deposited in a slackwater or overbank setting, deposition would have occurred in a relatively low energy environment. Such low energy deposition is favorable for the in situ burial of cultural materials. Evidence of bioturbation suggests that some displacement of cultural materials may have occurred, but in comparison with overlying units, integrity is greater. In short, materials from cultural occupations that occurred between flood events may be sealed within these sediments and, if present, are probably buried in situ.

\subsubsection{Geomorphological and Paleoenvironmental Conclusions}

Since this T1 terrace is close (about $0.5 \mathrm{~km}$ ) to the Rio Grande floodplain, consideration was given to the possibility that the massive sediments observed in Zone 5 were deposited during a flood event that caused the Rio Grande to back up into this drainage. As a result, large amounts of Rio Grande silt would have been deposited in the area. Review of the site's geomorphic position and laboratory data, however, suggests that the basal silt loam or other overlying zones did not originate from the Rio Grande. First, the position of the terrace at ca. 15 to $17 \mathrm{~m}$ in elevation above the Rio Grande seems an excessive height for a flood event. To reach such a height, hundreds of square kilometers of land would have to be deeply flooded on the south side of the river. The volume of water to accomplish such a task would seem prohibitive. Even if the Rio Grande has incised a few meters during the past 2,000 to 3,000 years, which would have been a very major event for a primary drainage, even a $10 \mathrm{~m}$ deep flood event seems unlikely given the large floodplain to the south of the river.
Sediment analysis also makes such a scenario unlikely. Both the comparative matrix sample from upstream on the San Idelfonzo Creek and from the Rio Grande are coarser than those within the T1 terrace (Figure 5.7). While the sample of the Rio Grande sediment matches the silt loam texture of the basal unit, the color of the two samples is very different. The Rio Grande sediments are gray to grayish tan in appearance while the sediments from San Idelfonzo Creek are yellowish tan in color. The basal silt loam is much more similar in color to the Rio Grande sample taken from about $2 \mathrm{~km}$ upstream from the Lino site. Though the upstream sample has a loam texture, the finergrained nature of the sediments at 41WB437 can be explained by size sorting during a flood event. The sandier sediments would tend to be concentrated within the channel while silts and clays would overflow into the overbank areas. It is also possible, since the Eocene Laredo Formation contains everything from sandstone to claystone, that variations in grain size reflect the variability of local bedrock sources.

Gustavson and Collins (1998) indicate that there are high terraces along the Rio Grande at 18 to $20 \mathrm{~m}$ above it, which is close to the elevation of the T1 terrace of San Idelfonzo Creek. It is very unlikely that the high terraces correlate to the T1 terrace in San Idelfonzo Creek for several reasons. First, the elevations of terraces in tributaries generally do not match those of terraces of the main drainage because of the higher gradients in tributaries. Second, the channel of San Idelfonzo Creek occurs on local bedrock; thus, changes in the level of the Rio Grande River would not significantly influence or incise the San Idelfonzo stream bed. Third, based on their position, the high terraces along the Rio Grande, are the oldest terraces in the area and are probably Pleistocene in age, though no datable materials were recovered by Gustavson and Collins (1998). In contrast, the 
T1 terrace of San Idelfonzo Creek is fairly young (in geologic terms) and appears to have developed entirely during the Holocene.

Why deposition on the terrace switched from massive flood deposits to overbank deposition is unclear. Alluvial deposits often display an upward sequence of fining-from channel gravels to overbank sediments-but that does not necessarily explain the sudden shift in deposition. It is possible that hydrologic factors changed, such as channel migration. Another possibility is that a natural dam, such as an encroaching alluvial fan or even a fallen tree, was present during the deposition of the basal silt loam and caused slack-water conditions. With the eventual removal of this blockage, deposition could have shifted to "regular" overbank deposition. Finally, climatic conditions may have been involved. Some researchers in the region (e.g., Vierra et al. 1997) propose that at ca. 4000 B.P. conditions along this portion of the Rio Grande valley may have favored widespread valley erosion. They further suggest that erosion had terminated by 2000 B.P. Such conditions could explain the depositional sequence at 41WB437. The massive silt loam at the terrace base may have resulted from widespread erosion farther up in the drainage. With large amounts of sediment being flushed down the channel, hydrologic conditions at the Lino site may have caused a significant quantity of this sediment to be deposited. As the climate changed and upstream erosion abated and the sediment supply decreased, more typical overbank deposition may have ensued.

The rate of sediment accumulation during different periods of time may be roughly estimated from the radiocarbon dates acquired from the cultural features. Assuming that the youngest date acquired from Zone 5 (3060 \pm 60 B.P.) approximates the end of deposition for this unit, and assuming that the $2130 \pm 40$ B.P. date approximates the end of deposition of Zone 4, the accumulation rate between ca. 3000 to 2100 B.P. is $0.070 \mathrm{~cm} /$ year. If a similar assumption is made about the $1950 \pm 50$ B.P. date in Zone 3, the sediments that contain the Ab horizon accumulated at a rate of $0.077 \mathrm{~cm} / \mathrm{yr}$. Zone 2, though it may be missing some sediments due to construction activities, accumulated at a rate of ca. $0.017 \mathrm{~cm} / \mathrm{yr}$. It should be stated that these estimates only apply to profile S-4. Upslope and to the east, where the deposits are thinner, the accumulation rate would be lower. These estimates of accumulation rates are culturally significant because they suggest that overbank aggradation was relatively rapid during the prehistoric time period when the terrace was being occupied. The accumulation rate for the sediments in the $\mathrm{Bk} 1$ and $\mathrm{Bk} 2$ horizons is nearly the same as that estimated for the sediments in the Ab horizon. The accumulation estimates also indicate that sedimentation has not been nearly as active in the past 2,000 years.

In contrast, Abbott proposes that from ca. 3200 to 2100 B.P. the accumulation rate was slightly higher than our estimate $(0.094 \mathrm{~cm} / \mathrm{yr}$ vs. 0.070 $\mathrm{cm} / \mathrm{yr}$ ). This is a minor deviation, however, and may reflect differences in the thicknesses of the sampled columns. His data were derived from BT 1, which is northwest and downslope from the excavation block. These are rough age estimates based on cultural features that do not exactly pinpoint the end of deposition for a particular zone. The biggest difference between the present study and Abbott's is the time period at ca. 2000 B.P. Based on stratigraphically separated cultural features, Abbott estimates a high rate of deposition $(0.57 \mathrm{~cm} / \mathrm{yr})$ for a brief period. Our data do not suggest a significant change in deposition during this time frame $(0.077 \mathrm{~cm} / \mathrm{yr})$. This is not meant to suggest that the high deposition rate is wrong, just that the deposits and cultural features observed during this study do not indicate this high deposition 
rate. The two studies do, however, have similarly low estimates for accumulation during the past 2,000 years $(0.019 \mathrm{~cm} / \mathrm{yr}$ vs. $0.017 \mathrm{~cm} / \mathrm{yr})$.

With respect to the climatic intervals proposed by Vierra et al. (1997), Bryant and Holloway (1985), and Toomey et al. (1993), the massive basal silt appears to have been deposited during a warm/dry interval, and the overlying overbank sediments coincide with a cool/moist interval. Interestingly, the cultural occupations coincide with periods of climatic transition. Vierra et al., whose study north of Eagle Pass, Texas, along Elm Creek, which is another low-order tributary to the Rio Grande about $220 \mathrm{~km}$ upstream, propose a cool interval from 4000 to 2200 B.P. A fossil pollen study in southwest Texas by Bryant and Holloway (1985) indicates a mesic interval from 3000 to 2500 B.P. In addition, Toomey et al. suggest that the 7000-to-3000 B.P. interval was relatively dry and the 3000-to-1000 B.P. interval was relatively moist. If a consensus of these studies is taken, deposition of the massive, basal silt (Zone 5) appears to coincide with a warm, dry interval. In such a setting it is possible that the massive silts were deposited during infrequent but high-intensity flood events that caused temporary slack-water conditions away from the channel. Near the end of this interval (ca. 3260 B.P.), when regional climate conditions may have already started to switch to cooler and more moist conditions, Occupation 5 occurred on these silt deposits. It is during the following cool/moist interval that the majority of overbank deposits appear to have been deposited at the Lino site.

In such an environment, San Idelfonzo Creek may have been a more significant hydrologic resource than it is today. Flooding along the creek and sedimentation on the T1 terrace, as is supported by the estimates of sediment deposition, would have been more frequent. This could have resulted in an increase in vegetative resources on the terrace, which probably was an important factor when considering human use of this landform. Throughout much of this cool/moist interval, it appears that the terrace was not occupied. It is possible that flooding was frequent enough to discourage human occupation on the terrace. By the end of this proposed cool/moist interval, however, occupation did occur on the terrace. Occupation 1 roughly occurs after the end of the cool/moist interval proposed by Bryant and Holloway but before the end of similar conditions proposed by Toomey et al. Finally, after ca. 2000 to 1900 B.P., overbank accretion appears to have slowed considerably. This change in deposition may reflect a change in climate at roughly 2000 B.P. that may have made the T1 terrace at 41WB437 less favorable for human occupation.

\subsection{CULTURAL STRATIGRAPHY}

Cultural materials were encountered throughout much of the Gradall ${ }^{\mathrm{TM}}$ stripping and from many hand-excavated levels. Nearly every artifact greater than $5 \mathrm{~cm}$ in diameter was plotted with the TDS. Although many larger materials were discovered during the Gradall ${ }^{\mathrm{TM}}$ stripping, it is unknown how many pieces were missed. During hand excavations, many in situ pieces were shot in with the TDS, but most smaller materials were recovered during the screening efforts using dry $6.4 \mathrm{~mm}$ mesh. Thus, only a small percentage of the collected data was plotted with the TDS.

The TDS recording procedure provided an excellent record of the burned-rock proveniences and associations. Because of the mass of each burned rock, these artifacts probably suffered the least from post-depositional displacement, and therefore they most likely retained their original location. Consequently, the burned rock provenience data was used in various graphics programs to vertically plot the distribution of cultural materials in profile. The profile plots were created for the eight hand-excavated Balks A through $\mathrm{H}$. Each depicts the density of materials back plotted against the north wall 
within an $80 \mathrm{~cm}$ wide balk and across the $7 \mathrm{~m}$ long excavation block (Figure 5.9). A second set of profile plots was developed using a west back plot across the $7 \mathrm{~m}$ wide Balks A though $\mathrm{G}$ (Figure 5.10). A third back plot set involves composites through the west and north that encompass the entire $28 \mathrm{~m}$ long excavation block (Figures 5.11 and 5.12). These profile plots of larger materials were used to identify artifact zones in the $1.2 \mathrm{~m}$ excavation area that were regarded as distinct occupational zones.

The density of materials across the block was sufficient to define a series of 10 to $20 \mathrm{~cm}$ thick zones of material. In viewing the back plotted vertical profiles, some material distribution is attributed to bioturbation and other to the natural western and northern slope of the deposits. Since cultural materials from a single occupation surface at one end of the excavation block may be higher or lower than objects at the other end of the block, the occupation zones appear to be thicker on the back plotted profile. Several vertical back plots from different directions were used to isolate the geometry of the occupational zones. The absence of the distinct color and texture guides within separate depositional units forced the use of arbitrary excavation levels. Occasionally the arbitrary levels cross cut multiple sloping occupations and resulted in some mixing of materials from separate cultural occupations.

Six zones of cultural materials were recognized and designated as Occupations 1 through 6 from the top to the bottom. Clear separation between occupations was not always observed, but material segregation was consistent enough to allow these divisions to be made. After the six occupational zones were identified, the handexcavated levels around features and balks were correlated to the identified occupation zones.

Occupation 1 appeared to contain the highest density of cultural materials. Occupations 2 and
3 were very sporadic but generally well defined. Occupation 6 was the most questionable and poorly defined. The latter's position at the bottom of the excavation block coupled with the sloping deposits made its designation as a discrete occupation questionable. Consequently, Occupation 6 may represent scattered materials from Occupation 5, or a portion of a still deeper occupation, or merely the limited remains of a sloping and very brief camping episode. The six defined occupations and their associated cultural assemblages are described separately in Sections 6.0 through 11.0. Following the discussion of Occupation 6, the scattered materials that were not assigned to a particular occupation are dealt with in general terms by material category. These unassigned recovered items are nevertheless representative of the site's general period of occupation.

Because of the lack of visual natural stratigraphy and the numerous stratified occupations in the $120 \mathrm{~cm}$ thick deposits within this $196 \mathrm{~m}^{2}$ mitigation block, it was not possible to correlate all the cultural materials from the previous testing phase (Abbott 1997) to these recognized occupations. In some instances the cultural materials recovered from the testing phase closest to the surface were probably parts of Occupation 1. Since the deposits slope across the site, the correlation of the deeper material became less certain.

\subsection{LINO SITE DATING}

Sixteen radiometric assays were obtained from three different kinds of materials: wood charcoal, organic residues extracted from burned rocks, and Rabdotus snail shells. Three wood charcoal assays were obtained during the 1997 testing phase and 13 were from the 1998 mitigation phase investigations (Table 5.3). Although the cultural materials from the testing phase were not directly assigned to any of the occupations in the mitigation block, the radiocarbon dates 

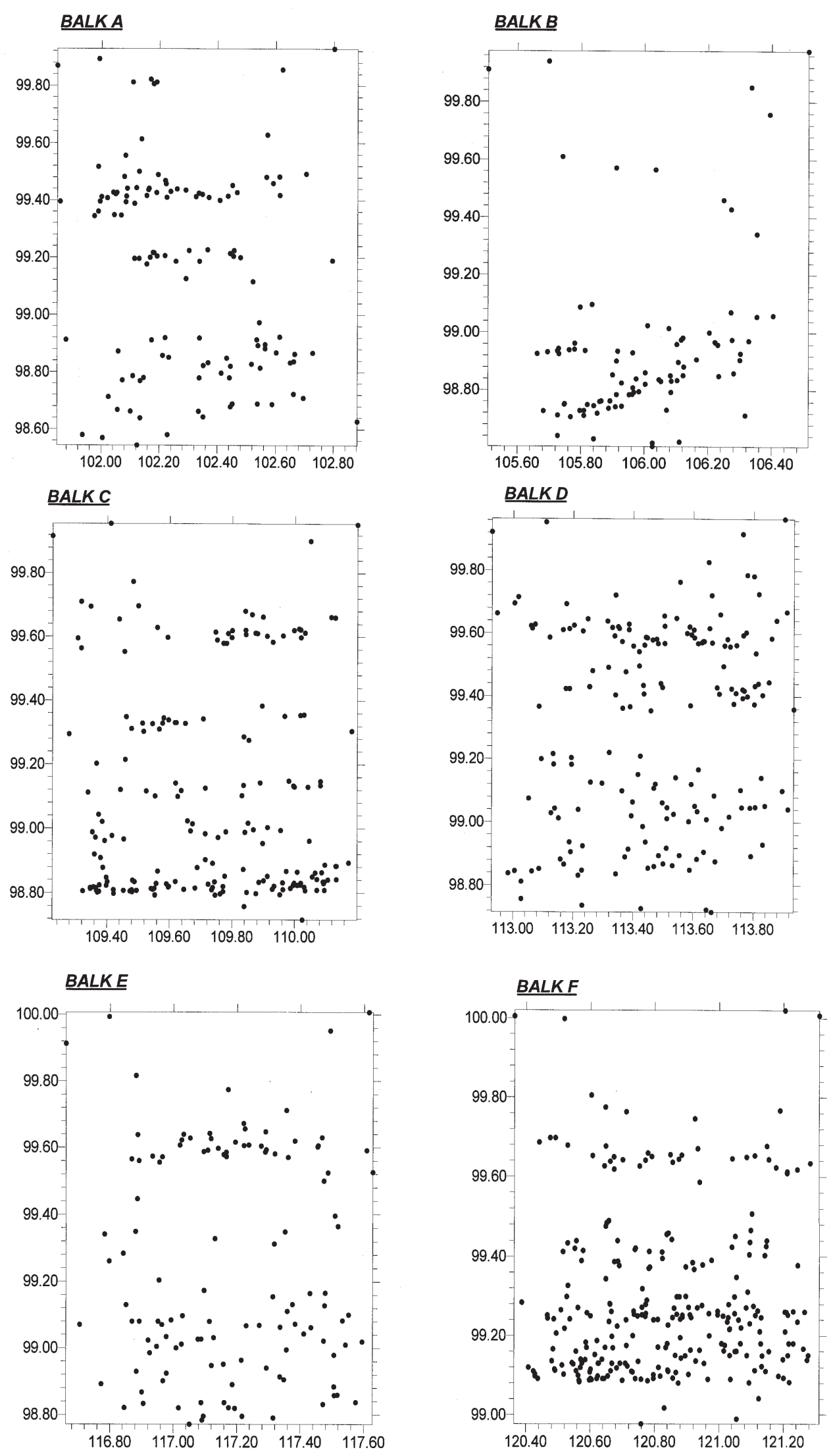

Figure 5.9 Vertical Back Plotted Profiles of $80 \mathrm{~cm}$ Wide Balks A-F through the $7 \mathrm{~m}$ Long Axis. 

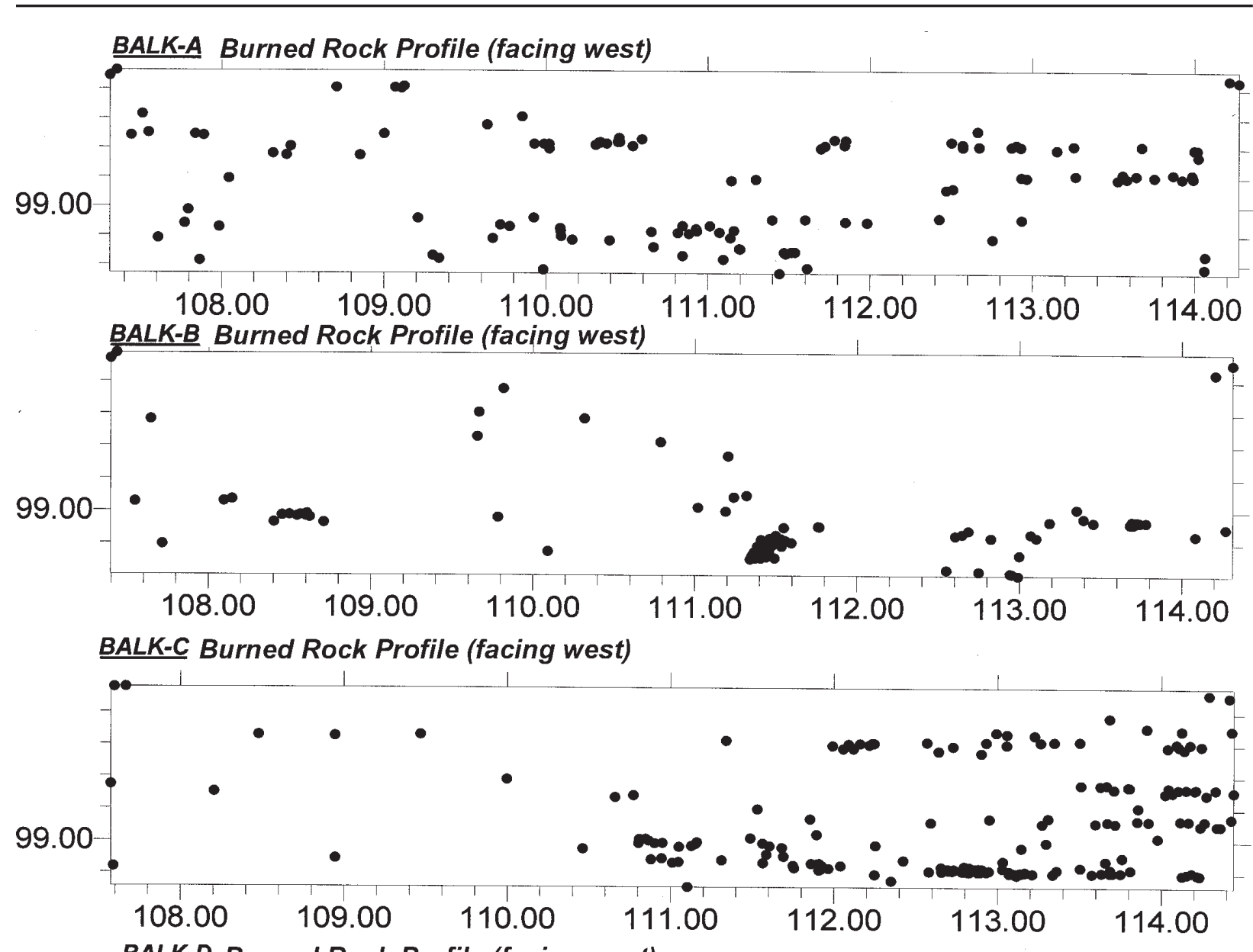

BALK-D Burned Rock Profile (facing west)

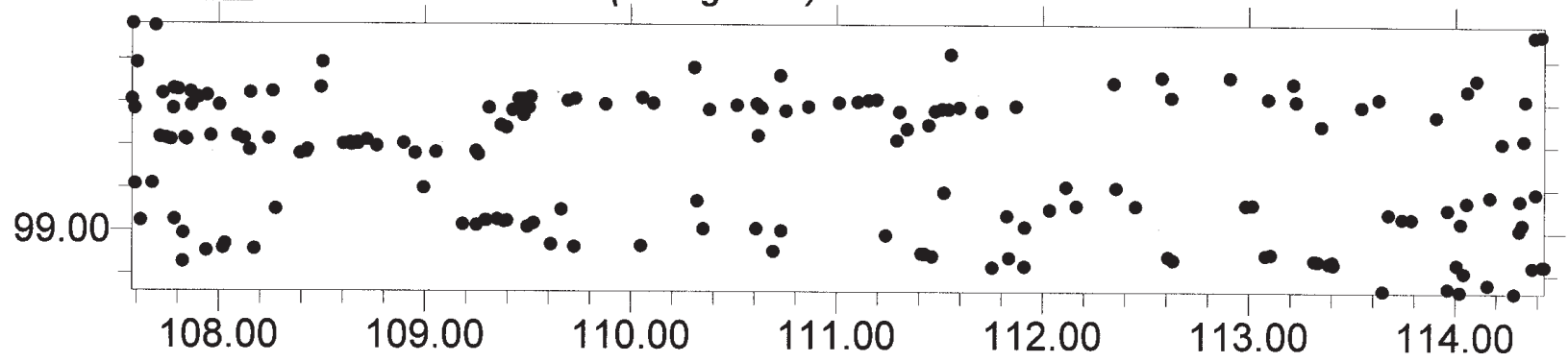

Figure 5.10 Vertical Back Plotted Profiles of $7 \mathrm{~m}$ Long Balks A-G through the $80 \mathrm{~cm}$ Wide Axis. (Balks E-G next page).

from three features excavated during the testing phase helped establish when the occupations occurred in the upper $120 \mathrm{~cm}$ of deposits. The chronometric ages determined from the testing phase reflect a temporal span of about 1,200 years that occurred between ca. 2000 and 3200 B.P. (Abbott 1997). The deposits in the block excavations were believed to have about the same time span. Considering the slope of deposits and the non-continuous excavation units of the testing and mitigation phases, it was not known if the lowest $(185 \mathrm{cmbs})$ and earliest date of ca. 3200 B.P. from the testing phase (Abbott 1997) correlates with Occupation 6 from the mitigation investigations. 

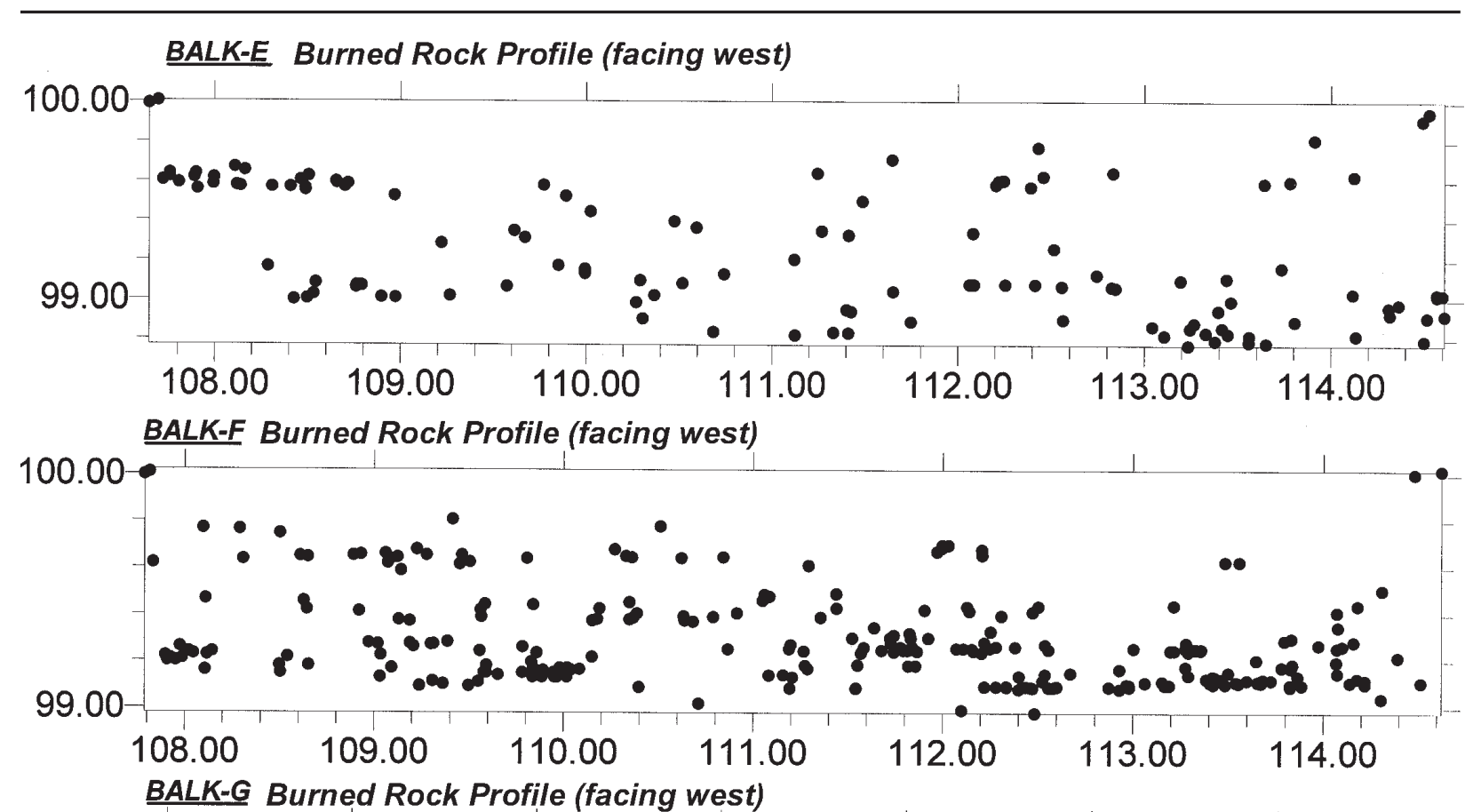

$100.00-$

BALK Burned Rock Profile (facing west)

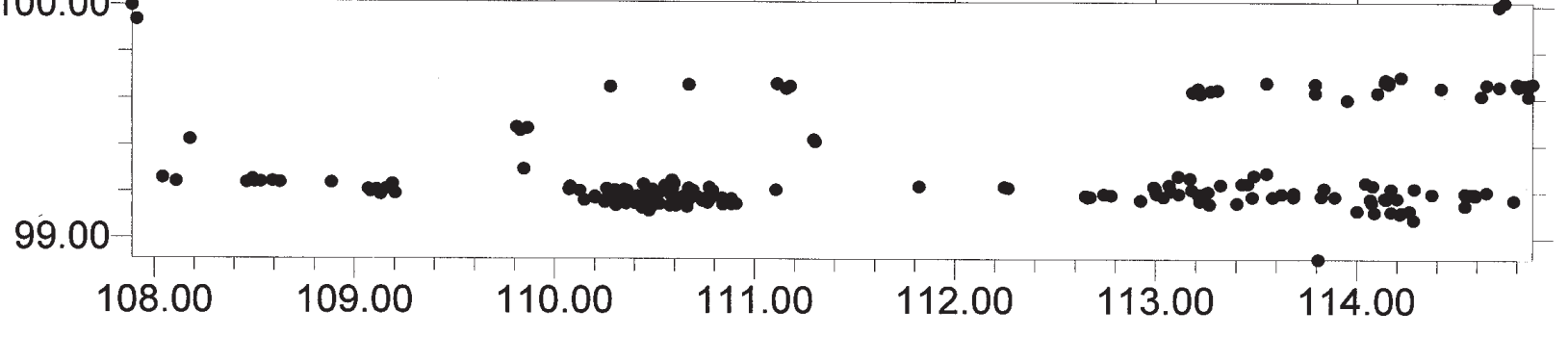

Figure 5.10 continued.

Not all six occupations were directly dated. Samples selected for absolute dating focused on Occupation 1 at the top and Occupations 5 and 6 at the bottom of the $120 \mathrm{~cm}$ deep block to bracket all the ages of all zones. The age of the intervening occupations between the dated occupations can be estimated to within a few hundred years of the event. Charcoal is the preferred and most accepted material for radiometric dating. However, turbation processes potentially could have displaced the small charcoal pieces. Wood charcoal samples for dating were most often selected from recognized features where context was more obvious and controlled. Three wood charcoal dates from Occupation 1 came from Features 3 , 10 , and 14 and yielded $\delta^{13} \mathrm{C}$ adjusted ages of 2060, 2130, and 1950 B.P., respectively. All three wood charcoal dates are accepted and provide an average age for Occupation 1 of 2047 \pm 100 B.P. Based on the wood charcoal date of 2130 B.P. from Feature 6 at $80 \mathrm{cmbs}$ in BT1 (Abbott 1997), it appears that Feature 6 occurred at about this same time and may be linked to Occupation 1.

The four wood charcoal assays from Occupations 5 and 6 yielded $\delta^{13} \mathrm{C}$ adjusted ages of $900,2740,3060$, and 3460 B.P. (Table 5.3). The 900 B.P. date from a wood charcoal chunk in Occupation 5 is obviously too young and is out of context; it is not consistent with the age of the other wood charcoal dates. Even the 2740 B.P. age is possibly too young for Occupation 6, and it may represent a date for another displaced piece of wood charcoal. If it is rejected, then 


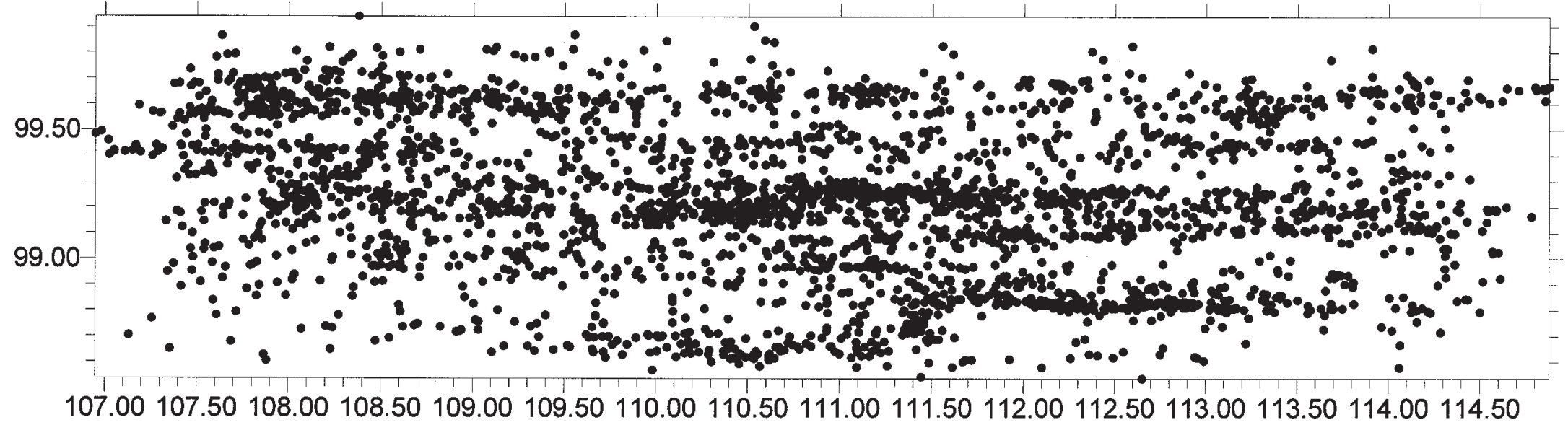

Figure 5.11 Composite through the West Encompassing the Entire $28 \mathrm{~m}$ Long Excavation Block.

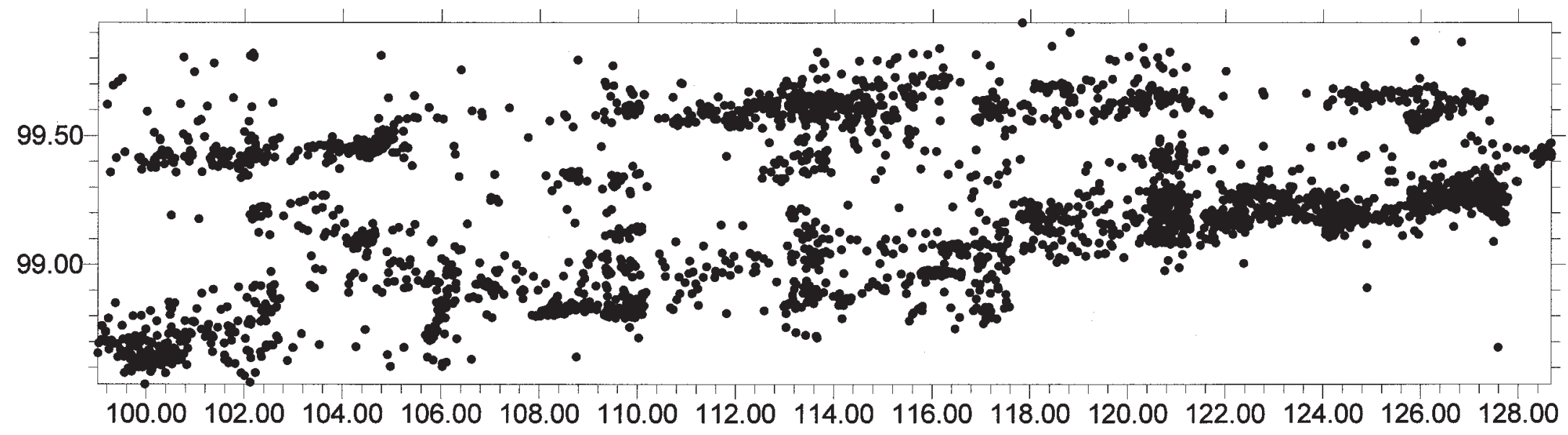

Figure 5.12 Composite through the North Encompassing the Entire $28 \mathrm{~m}$ Long Excavation Block. 
Table 5.3 Radiometric Data Obtained on Dated Materials at the Lino Site (41WB437).

\begin{tabular}{|c|c|c|c|c|c|c|c|c|c|c|}
\hline \multirow[b]{2}{*}{ Cat. No. } & \multirow[b]{2}{*}{ Unit } & \multirow[b]{2}{*}{$\begin{array}{l}\text { Depth } \\
\text { (cmbs) }\end{array}$} & \multirow[b]{2}{*}{$\begin{array}{l}\text { Fea. } \\
\text { No. }\end{array}$} & \multirow[b]{2}{*}{$\begin{array}{l}\text { Occu- } \\
\text { pation }\end{array}$} & \multirow[b]{2}{*}{$\begin{array}{l}\text { Material } \\
\text { (weight) }\end{array}$} & \multirow[b]{2}{*}{$\begin{array}{c}\text { Lab No. } \\
\text { (Beta) }\end{array}$} & \multicolumn{3}{|c|}{ C12/C13 } & \multirow[b]{2}{*}{$\begin{array}{c}\text { Calibrated Age, } \\
1 \text { sigma }\end{array}$} \\
\hline & & & & & & & $\begin{array}{l}\text { Measured } \\
\text { Date B.P. }\end{array}$ & $\begin{array}{l}\text { Value } \\
\text { o/oo }\end{array}$ & $\begin{array}{l}\text { Adjusted } \\
\text { Date B.P. }\end{array}$ & \\
\hline 37 & BT 1 & 35 & 1 & $?, 5$ or 6 & al & 5 & $3220+50$ & -23.3 & $40+50$ & $1530-1435 \mathrm{BC}$ \\
\hline$?$ & BT 1 & 80 & 6 & $?$ & al & 7 & $2110+40$ & -23.6 & $30+40$ & 190 \\
\hline $43+44$ & BT2 & 30 & 3 & 1 & charcoal & 106326 & $2060+80$ & -25 & $2060+80$ & $195 \mathrm{BC}-\mathrm{AD} 47$ \\
\hline $586 \mathrm{a}$ & $10-2$ & $40-50$ & 10 & 1 & organic residue & 121727 & $2100+40$ & -23.6 & $2120+40$ & $185-60 \mathrm{BC}$ \\
\hline $1781-4 a$ & $10-2$ & $40-50$ & 10 & 1 & charcoal (huisache) & 121729 & $2130+40$ & -25 & $2130+40$ & $201-93 \mathrm{BC}$ \\
\hline $769 a$ & $14-3$ & $40-50$ & 14 & 1 & organic residue & 121728 & $2420+50$ & -21.9 & $2470+50$ & $770-415 \mathrm{BC}$ \\
\hline $1847-1 \mathrm{a}$ & $14-3$ & $40-50$ & 14 & 1 & charcoal (hackberry) & 121730 & $1920+50$ & -23 & $1950+50$ & AD $2-87$ \\
\hline $703 a$ & $14--3$ & $40-50$ & 14 & 1 & organic residue & 124388 & $3200+50$ & -25.7 & $3190+50$ & $1505-1410 \mathrm{BC}$ \\
\hline $705 a$ & $14-3$ & $40-50$ & 14 & 1 & organic residue & 124389 & $2220+60$ & -20.5 & $2290+60$ & $290-355 \mathrm{BC}$ \\
\hline $5377-2 \mathrm{c}$ & D1 & $20-30$ & & 1 & Rabdotus (CF-214) & 122719 & $1590+50$ & 2.3 & $2040+50$ & AD $290-420$ \\
\hline $5377-2 d$ & D1 & $20-30$ & & 1 & Rabdotus & 122720 & $1350+40$ & -1.1 & $1740+40$ & AD $650-695$ \\
\hline $3604-4 a$ & $29-6$ & $100-110$ & 29 & 5 & charcoal (mesquite) & 121861 & $3450+40$ & -24.4 & $3460+40$ & $1860-1705 \mathrm{BC}$ \\
\hline $3605-5 a$ & $29-5$ & $100-110$ & 29 & 5 & organic residue & 121862 & $4920+50$ & -24.9 & $4920+50$ & $3760-3655 \mathrm{BC}$ \\
\hline $5455-5 \mathrm{a}$ & D7 & $100-110$ & & 5 & charcoal (mesquite) & 124390 & $840+50$ & -21.2 & $900+50$ & AD $1040-1215$ \\
\hline $5167-4$ & A5 & $110-120$ & & 5 & charcoal (huisache) & 124391 & $3040+60$ & -23.7 & $3060+60$ & $1400-1250 \mathrm{BC}$ \\
\hline $5478-4$ & E2 & $110-120$ & & 6 & charcoal (inderter) & 121863 & $2740+50$ & -24.9 & $2740+50$ & $915-825 \mathrm{BC}$ \\
\hline
\end{tabular}

the age of Occupation 5 is best defined by the average of the remaining two wood charcoal dates at ca. 3260 B.P. Feature 1 that was found at $185 \mathrm{cmbs}$ in BT 1 during the testing phase yielded a $\delta^{13} \mathrm{C}$ adjusted wood charcoal date of 3240 B.P. (Abbott 1997) and fits within this time frame. BT 1 was about $16 \mathrm{~m}$ north of the northwest corner of the mitigation block. Since Occupation 6 is deeper, it must be older than the 3,260 year old Occupation 5. Based on the rate of deposition for geomorphic Zone 5, it is conservatively estimated that Occupation 6 can only be a few hundred years older and probably dates to about 3400 B.P. In general, the six stratified occupational zones identified from the mitigation block probably range in age from about 3400 to 2000 B.P.

An attempt was made to compare radiocarbon dates from two other commonly available organic materials to the dates from wood charcoal. This comparison was undertaken, since many south Texas sites lack well preserved charcoal or have mixed deposits, and the delineation of temporal correction factors would open up the use of these alternate organic materials to providing acceptable means of dating deposits. Alternate datable material such as Rabdotus shells have recently been employed, and they provided acceptable chronometric dates (Ellis and Goodfriend 1994; Quigg and Ellis 1994; Abbott et al 1995; Abbott et al 1996; Quigg et al. 1996; Quigg and Cordova 1999a, 1999b).

At the Lino site, amino acid racemization (A/I ratios) results were obtained on 16 Rabdotus shells in order to investigate the amount of disturbance and vertical displacement that occurred in many small, light objects. The A/I results revealed a relatively small range of variations of only 0.076 (ratio values ranging from 0.096 [CF-204] to 0.172 [CF-208]). However, the $16 \mathrm{~A} / \mathrm{I}$ ratios appear to form two ratio clusters of data around 0.107 and 0.147 . A shell from each cluster with ratios near the cluster's midpoint (0.106 [CF-214] and 0.144 [CF-215]) were selected for radiocarbon dating. Both came from Occupation 1 in Unit D1 (between 20 and $30 \mathrm{cmbs}$ ). The two AMS, $\delta^{13} \mathrm{C}$ adjusted assays were $2040 \pm 50$ B.P. (Beta122719) and $1740 \pm 40$ B.P. (Beta-122720), respectively. Although these shell dates appear 
to be reversed relative to their $\mathrm{A} / \mathrm{I}$ ratios, the dates are similar to the average wood charcoal date from Occupation 1. In fact, the date of 2040 B.P. on shell \#5377-2c appears identical to the average wood charcoal results from Occupation 1 of $2047 \pm 100$ B.P. The age of 1740 B.P., based on a possible aberrant $\delta^{13} \mathrm{C}$ value of $-1.1 \%$ o (\#5377-2d; CF-219), may indicate some problem with the carbon in the shell being dated.

Organic residues extracted from the interior of sandstone burned rocks were chosen as alternate datable material. This material has been investigated from other south Texas sites and has yielded promising results (Quigg 1999; Quigg and Cordova 1999a, 1999b). The advantages of dating this material are that the concentration of large feature rocks is more useful in assessing contextual integrity than integrity on isolated flecks of charcoal, and residues inside burned rocks can survive where charcoal may not. Since the methods of organic material extraction and identification are still being developed, a larger sample of dates is needed to ascertain the accuracy of these radiocarbon assays. Accordingly, a series of residues from burned rocks from two welldefined burned sandstone features (Features 10 and 14) were dated to compare with dates derived from wood charcoal from those same two features. From Feature 10, the wood charcoal and the organic residue from inside the burned rock yielded statistically identical AMS dates of $2130 \pm 40$ B.P. and $2120 \pm 40$ respectively (Table 5.3). Based on the wood charcoal results from other features in Occupation 1, it appears that the organic residues derived from a burned rock date to this same cultural event. The dating of paired samples provides another positive example that organic residues from inside burned sandstone provide an acceptable age for cultural events.

From pit Feature 14, the AMS wood charcoal date of 1950 B.P. appears to be about 100 years younger that the average of three other wood charcoal dates of 2047 B.P. for Occupation 1. The three organic residue samples extracted from three different burned rocks from pit Feature 14 yielded AMS ages of 2290, 2470, and 3190 B.P., which are older than the associated wood charcoal date by 340,520 , and 1240 years (Table 5.3). Since the older organic residue ages are all within the time frame of earlier cultural occupations identified at the Lino site, it is possible that the burned rocks from Feature 14 were re-used from earlier occupations and retained organic residues from earlier cooking events. It is not clear how the older organic residues would have survived the temperatures obtained during later reheating, but at present this seems to be a plausible explanation for the discrepancy in the ages. More investigations are required to fully define variables underlying some inconsistencies that are apparent in the carbon dating of organic residues from inside burned rocks. As an alternative material for dating, the recognition of organic residues inside sandstone burned rocks is an advancement, especially if charcoal is not preserved. Presently, the results must be used with caution. 


\subsection{OCCUPATION 1}

This occupation zone consisted of dense and diverse cultural materials horizontally distributed between 20 and $40 \mathrm{cmbs}$. Some cultural materials encountered above the zone may have once been part of Occupation 1, but their dispersed and scattered nature did not allow their assignment to this occupation. The $20 \mathrm{~cm}$ thick occupation zone dips between 30 to $40 \mathrm{~cm}$ towards the west over the $28 \mathrm{~m}$ block span and some $10 \mathrm{~cm}$ to the north over the $7 \mathrm{~m}$ span. Back plots of in situ material indicate that turbation and root activity have dispersed some materials vertically. Occupation 1 is the best defined, densest, and most consistent occupation identified. This cultural zone yielded numerous burned-rock features, quantities of scattered burned rocks and lithic debitage, a few formal chipped and ground stone tools, mussel shells, and scattered Rabdotus shells. Bone was not present except for one $0.2 \mathrm{~g}$ unburned fragment of cancellous tissue from Unit 9-3. It is believed that bone was once present throughout the occupation but has been destroyed over time. The single bone fragment may be an intrusive modern piece that became displaced through turbation. As discussed above, the chronometric age of Occupation 1 is based on three woodcharcoal dates, one each from Features 3, 10, and 14. These yielded $\delta^{13} \mathrm{C}$ adjusted ages of 2060, 2130, and 1950 B.P., respectively (Table 5.3). The average age of Occupation 1 is about 2050 B.P. Typically these ages suggest a Late Archaic affiliation.

The cultural materials recovered from the $40 \mathrm{~m}^{2}$ hand excavated balks and the $47 \mathrm{~m}^{2}$ hand excavated units around identified features in the Gradall ${ }^{\mathrm{TM}}$ strips from this occupation are presented by material class below. This is followed by a discussion of the horizontal distribution of the major material categories. A summary and interpretation of activities is presented for Occupation 1 at the end.

\subsection{FEATURES}

Twelve features were recognized from Occupation 1. Nine were in the Gradall ${ }^{\mathrm{TM}_{-}}$ stripped areas and three were in the handexcavated balks (Table 6.1). These consisted of two mussel shell concentrations (Features 36 and 41), nine concentrations of burned rocks (Features 8, 9, 10, 11, 12, 13, 15, 19, and 35), and one well-defined, rock-filled basin (Feature 14). Feature 14 is individually described in detail; the two mussel shells features are discussed as a group, as are the nine burned rock concentrations.

Feature 14 measured 60 by $70 \mathrm{~cm}$ across and was a $15 \mathrm{~cm}$ deep basin filled with burned sandstone rocks and quantities of charcoal that occurred in Gradall ${ }^{\mathrm{TM}}$ area H (Figures 6.1, 6.2, 6.3 , and 6.4). The pit boundaries were very faint, but the feature was deepest near the middle with an irregular boundary at the upper edge. The sides sloped up at relatively low angle (Figure 6.1). No ash or oxidation was observed in or along the bottom of the pit, although a few tiny pieces of oxidized earth were in the matrix. The burned rocks did not form a completely circular outline. Although almost circular, the northeastern side of the feature lacked rocks. Four interior rocks were angled at about 45 degrees and provide corroborative evidence of a pit feature. The 47 rocks in the pit weighed a total of 29,758 $\mathrm{g}$ (Table 6.2) and varied from 2 to $17 \mathrm{~cm}$ long. Nearly 16 percent measured fewer than $4 \mathrm{~cm}$ in diameter. Another 49 percent were greater than $9 \mathrm{~cm}$ in diameter, and 34 percent were between 4 and $9 \mathrm{~cm}$ in size. The average weight of the rocks was $633 \mathrm{~g}$. Some 
Table 6.1 Attributes of Features from Occupation 1.

\begin{tabular}{|c|c|c|c|c|c|c|c|c|c|}
\hline $\begin{array}{l}\text { Fea. } \\
\text { No. }\end{array}$ & Unit & $\begin{array}{l}\text { No. of } \\
\text { Units } \\
\text { Exc. } \\
\end{array}$ & $\begin{array}{l}\text { Depth } \\
\text { (cmbs) }\end{array}$ & $\begin{array}{l}\text { Size } \\
(\mathrm{cm})\end{array}$ & Thickness & Description & Interpret. & $\begin{array}{l}\text { Associated } \\
\text { Artifacts }\end{array}$ & $\begin{array}{c}\text { Chrono. } \\
\text { Age } \\
\text { (B.P.) }\end{array}$ \\
\hline 8 & Area E & 4 & $30-40$ & $55 \times 45$ & 1 rock & $\begin{array}{l}\text { BR scatter, ill } \\
\text { defined }\end{array}$ & BR dump & $7 \mathrm{BR}$ & \\
\hline 9 & Area $\mathrm{H}$ & 4 & $30-40$ & $45 \times 35$ & 1 rock & BR cluster & BR dump & $18 \mathrm{BR}$ & \\
\hline 10 & Area A & 2 & $40-50$ & $60 \times 40$ & 1 rock & BR cluster & BR dump & $\begin{array}{l}13 \text { BR, limited } \\
\text { charcoal }\end{array}$ & $\begin{array}{l}2120 \\
2130\end{array}$ \\
\hline 11 & Area B & 6 & $35-45$ & $125 \times 55$ & 1 rock & BR scatter & BR dump & $\begin{array}{l}4 \mathrm{BR}, 2 \text { chert } \\
\text { cores, } 3 \text { flakes }\end{array}$ & \\
\hline 12 & Areas D, E & 9 & $30-40$ & $140 \times 50$ & 1 rock & BR scatter & BR dump & $\begin{array}{c}153 \mathrm{BR} \text {, lots of } \\
\text { charcoal outside }\end{array}$ & \\
\hline 13 & Area F & 4 & $30-40$ & $60 \times 30$ & 1 rock & BR cluster & BR dump & $\begin{array}{c}10 \mathrm{BR} \text {, moderate } \\
\text { charcoal }\end{array}$ & \\
\hline 14 & Area $\mathrm{H}$ & 9 & $40-50$ & $70 \times 60$ & $15 \mathrm{~cm}$ & Rock filled basin & Heating & $\begin{array}{l}49 \mathrm{BR} \text {, lots of } \\
\text { charcoal inside }\end{array}$ & $\begin{array}{l}1950- \\
2470\end{array}$ \\
\hline 15 & Area B & 5 & $40-50$ & $75 \times 80$ & 1 rock & BR cluster & BR dump & $\begin{array}{c}12 \mathrm{BR}, \text { few } \\
\text { chunks of } \\
\text { charcoal }\end{array}$ & \\
\hline 19 & Area F & 4 & $30-40$ & $120 \times 80$ & 1 rock & BR scatter & BR dump & $\begin{array}{l}7 \mathrm{BR} \text {, moderate } \\
\text { charcoal,1 flake }\end{array}$ & \\
\hline 35 & D4, D5 & 2 & $20-30$ & $75 \times 80$ & 1 rock & BR cluster & BR dump & $3 \mathrm{BR}$ & \\
\hline 36 & A5 & 1 & $35-40$ & $60 \times 60$ & 1 rock & $\begin{array}{l}\text { Mussel shell } \\
\text { scatter }\end{array}$ & Shell dump & 15 mussel shells & \\
\hline 41 & A7 & 1 & $30-40$ & $40 \times 50$ & 1 rock & $\begin{array}{l}\text { Mussel shell } \\
\text { scatter }\end{array}$ & Shell dump & $\begin{array}{c}1 \mathrm{BR}, 14 \text { mussel } \\
\text { shells }\end{array}$ & \\
\hline
\end{tabular}

$\mathrm{BR}=$ burned rock $\quad$ Exc. $=$ excavated $\quad$ Fea. $=$ feature $\quad$ Chrono. $=$ chronological

47 percent showed internal cracks. All 47 pieces were sandstone, with 87 percent exhibiting angular shapes.

Three burned sandstone rocks (\#703a, \#705a, and \#769a) from inside the pit were selected for a variety of analyses on the residues from inside the rock, including AMS dating, stable carbon and nitrogen analyses, and lipid residue identification. Organic residues were extracted from the rocks' interiors and analyzed. The three samples yielded $\delta^{13} \mathrm{C}$ adjusted AMS dates of $3190 \pm 50$ B.P. (Beta-124388), $2290 \pm 60$ B.P. (Beta-124389), and $2470 \pm 50$ B.P. (Beta121728), respectively. These three samples yielded $\delta^{13} \mathrm{C}$ values ranging between -20.5 and $-25.7 \%$ in conjunction with the AMS carbon dating (Table 5.3). However, direct isotopic analyses on the same samples yielded $\delta^{13} \mathrm{C}$ values between -18.5 and $-20.9 \%$ (Appendix D). The latter values are thought to be more accurate and indicate that the burned rock organic residues are comprised of a nearly equal mixture of $\mathrm{C} 3$ and $\mathrm{C} 4 / \mathrm{CAM}$ plants or animals that ate these plants. One $\delta^{15} \mathrm{~N}$ value is quite low at 0.11 and probably reflects use of legumes or nuts whereas two values of $6.7 \%$ probably reflect a mixture of various resources. The lipid analyses on the residues from these three burned rocks yielded evidence of, respectively, large herbivore, probable plant, and probable plant (Appendix G). Apparently, the residues in these burned rocks reflect the preparation of a variety of plants and animals. The analyses indicated that two rocks (\#705 and \#769) were quite similar, whereas rock \#703 reflected the processing of totally different resources. Since the latter rock was also much older than the other two, the large herbivore resources reflected by its residues may be remnant residues from an earlier activity rather than not be part of this current occupation. 
Table 6.2 Occupation 1 Burned Rock Data.

\begin{tabular}{|c|c|c|c|c|c|c|c|c|c|c|c|c|c|c|c|c|c|}
\hline \multicolumn{18}{|c|}{ Non Feature Contexts } \\
\hline \multirow[b]{2}{*}{ Unit } & \multirow[b]{2}{*}{ Level } & \multirow[b]{2}{*}{ Fea No } & \multicolumn{4}{|c|}{ Size $(\mathrm{cm})$} & \multicolumn{4}{|c|}{ Material Type* } & \multicolumn{3}{|c|}{ Fracture Type** } & $\mathrm{Cr}$ & & & \\
\hline & & & $0-4$ & $4-9$ & $9-15$ & $>15$ & $\mathrm{CC}$ & Ch & O Qtz & SS & Ang. & Rnd. & Tab. & $\mathbf{Y}$ & $\mathbf{N}$ & Total & Wt $(\mathrm{g})$ \\
\hline $8-1$ & & & 18 & 4 & 3 & & & & 1 & 24 & 21 & 1 & 3 & 2 & 23 & 25 & $1,499.8$ \\
\hline $8-2$ & & & 36 & 2 & & 1 & & & & 39 & 28 & 1 & 10 & 1 & 38 & 39 & 978.3 \\
\hline $8-3$ & & & 31 & 4 & 1 & & 2 & & & 34 & 30 & & 6 & 3 & 33 & 36 & 2,891 . \\
\hline $8-4$ & & & 24 & 5 & 2 & & & & & 31 & 27 & 1 & 3 & & 31 & 31 & $1,711$. \\
\hline $9-1$ & & & 29 & 5 & 2 & & & & & 36 & 33 & 2 & 1 & 3 & 33 & 36 & 978.3 \\
\hline $9-2$ & & & 19 & 6 & & & & 1 & & 24 & 21 & & 4 & 1 & 24 & 25 & 718.6 \\
\hline $9-3$ & & & 13 & 2 & & & & 1 & & 14 & 15 & & & 1 & 14 & 15 & 102.1 \\
\hline $9-4$ & & & 21 & 5 & & & & 3 & & 23 & 21 & & 5 & 1 & 25 & 26 & 423.5 \\
\hline $10-1$ & 5 & & 105 & 14 & 2 & & & 1 & & 120 & 104 & 6 & 11 & 5 & 116 & 121 & $1,475.9$ \\
\hline $10-2$ & 5 & & 62 & 8 & & & & & & 70 & 55 & 6 & 9 & 9 & 61 & 70 & 759. \\
\hline $11-1$ & 4 & & 2 & & & & & & & 2 & 1 & 1 & & & 2 & 2 & 3. \\
\hline $11-2$ & & & 19 & 9 & & & & & & 28 & 27 & 1 & & 5 & 23 & 28 & 638. \\
\hline $11-3$ & 4 & & 26 & 4 & & & & & & 30 & 28 & & 2 & 3 & 27 & 30 & 214. \\
\hline $11-4$ & & & 17 & 3 & & & & & & 20 & 17 & 3 & & 3 & 17 & 20 & 246.0 \\
\hline $11-5$ & & & 18 & 2 & & & & & & 20 & 15 & & 5 & & 20 & 20 & 220. \\
\hline $11-6$ & 4 & & 47 & 1 & & & & & & 48 & 40 & 3 & 5 & & 48 & 48 & 1,824 \\
\hline $12-1$ & 4 & & 38 & 1 & & & & & & 39 & 36 & & 3 & 4 & 35 & 39 & 184.0 \\
\hline $12-2$ & 4 & & 37 & 2 & 1 & & & 1 & & 39 & 33 & 1 & 6 & 15 & 25 & 40 & $1,009$. \\
\hline $12-3$ & 4 & & 8 & 3 & 1 & & & & & 12 & 8 & 1 & 3 & & 12 & 12 & 930.9 \\
\hline $12-4$ & 4 & & 3 & & & & & & & 3 & 3 & & & & 3 & 3 & 140.1 \\
\hline $12-5$ & 4 & & 26 & 4 & & & & & & 30 & 29 & & 1 & 2 & 28 & 30 & 408.3 \\
\hline $12-6$ & 4 & & 49 & 13 & & & & & & 62 & 54 & 2 & 6 & 3 & 59 & 62 & $1,071$. \\
\hline $12-7$ & 4 & & 9 & 1 & & & & & & 10 & 9 & & 1 & & 10 & 10 & 93. \\
\hline $12-8$ & 4 & & 38 & 5 & & & & & & 43 & 40 & & 3 & 3 & 40 & 43 & 544.8 \\
\hline $12-9$ & 4 & & 55 & 3 & 1 & & & & & 59 & 55 & & 4 & 3 & 56 & 59 & $1,870.8$ \\
\hline $12-10$ & 4 & & 16 & & & & & & & 16 & 15 & & 1 & 1 & 15 & 16 & 69.8 \\
\hline $12-12$ & 4 & & 28 & & & & & & & 28 & 28 & & & 3 & 25 & 28 & 40.9 \\
\hline $12-13$ & 4 & & 9 & 1 & & & & & & 10 & 9 & & 1 & 3 & 7 & 10 & 106.9 \\
\hline $12-14$ & 4 & & 21 & & & & & & & 21 & 21 & & & 2 & 19 & 21 & 275.4 \\
\hline $12-15$ & 4 & & 26 & 4 & & & & 1 & & 29 & 25 & & 5 & 6 & 24 & 30 & 369.3 \\
\hline $13-1$ & 4 & & 26 & 2 & & & & & & 28 & 27 & 1 & & 1 & 27 & 28 & 218.9 \\
\hline $13-2$ & 4 & & 21 & 2 & & & & 1 & & 22 & 21 & & 2 & 1 & 22 & 23 & 351.7 \\
\hline $13-3$ & 4 & & 26 & 9 & & & & 2 & & 33 & 35 & & & 2 & 33 & 35 & 671.3 \\
\hline $13-4$ & 4 & & 16 & 8 & 1 & & & 3 & & 22 & 25 & & & 4 & 21 & 25 & $1,456$. \\
\hline $14-1$ & 5 & & 29 & 8 & & & & & & 37 & 37 & & & 2 & 35 & 37 & 445.5 \\
\hline $14-2$ & 5 & & 16 & 3 & & & & & & 19 & 18 & & 1 & 1 & 18 & 19 & 206. \\
\hline $14-3$ & 5 & & 7 & & & & & & & 7 & 7 & & & & 7 & 7 & 48. \\
\hline $14-4$ & 5 & & 85 & 6 & & & & & & 91 & 80 & 11 & & & 91 & 91 & $\mathbf{5 9 7 . 5}$ \\
\hline $14-5$ & 5 & & 46 & 3 & 1 & & & & & 50 & 50 & & & 5 & 45 & 50 & 1,508 \\
\hline $14-6$ & 5 & & 25 & & & & & & & 25 & 25 & & & & 25 & 25 & 82.7 \\
\hline $14-7$ & 5 & & 6 & & & & & & & 6 & 6 & & & & 6 & 6 & 16.2 \\
\hline $14-8$ & 5 & & 5 & & & & & & & 5 & 5 & & & & 5 & 5 & 10.0 \\
\hline $14-9$ & 5 & & 2 & & & & & & & 2 & 2 & & & & 2 & 2 & 2.9 \\
\hline $15-2$ & 5 & & 51 & 15 & & & & & & 66 & 58 & 6 & 2 & 5 & 61 & 66 & $1,492$. \\
\hline $15-3$ & 5 & & 9 & 2 & & & & & & 11 & 10 & 1 & & & 11 & 11 & 115. \\
\hline $15-4$ & 5 & & 73 & 23 & 7 & & & & 1 & 102 & 68 & 15 & 20 & 9 & 94 & 103 & $13,544.0$ \\
\hline $15-5$ & 5 & & 18 & 6 & & & & & & 24 & 20 & & 4 & 2 & 22 & 24 & $1,013$. \\
\hline $19-1$ & & & 73 & 4 & & & & 5 & & 72 & 70 & 4 & 3 & 3 & 74 & 77 & $1,021.8$ \\
\hline $19-2$ & 4 & & 24 & 3 & 1 & & & & & 28 & 26 & & 2 & 4 & 24 & 28 & 972.9 \\
\hline $19-3$ & & & 55 & 21 & & & & & & 76 & 63 & & 13 & 3 & 73 & 76 & 3,305 \\
\hline $19-4$ & & & 59 & 3 & & & 1 & 1 & & 60 & 58 & & 4 & 4 & 58 & 62 & 371. \\
\hline $\mathrm{A} 1$ & $4 \& 5$ & & 46 & 4 & & & & & & 50 & 42 & 5 & 3 & 5 & 45 & 50 & 1,811 \\
\hline A2 & $4 \& 5$ & & 41 & 10 & & & & & & 51 & 41 & 6 & 4 & 4 & 47 & 51 & 712. \\
\hline A3 & $4 \& 5$ & & 19 & 2 & & & & 4 & & 17 & 14 & 7 & & 1 & 20 & 21 & $1,249.8$ \\
\hline A4 & $4 \& 5$ & & 15 & 6 & & & & & & 21 & 15 & 6 & & 4 & 17 & 21 & 3,330 \\
\hline A5 & $4 \& 5$ & & 43 & 6 & & & & & & 49 & 39 & 9 & 1 & 3 & 46 & 49 & 2,984 \\
\hline A6 & $4 \& 5$ & & 7 & 5 & 2 & & & & & 14 & 10 & 3 & 1 & 5 & 9 & 14 & $1,181$. \\
\hline A7 & $4 \& 5$ & & 7 & 5 & & & & & & 12 & 8 & & 4 & 2 & 10 & 12 & 508.7 \\
\hline B1 & 4 & & & & 1 & & & & & 1 & 1 & & & 1 & & 1 & 179.3 \\
\hline B2 & $3 \& 4$ & & 9 & 1 & & & & 1 & & 9 & 8 & 2 & & & 10 & 10 & 151.9 \\
\hline B3 & $3 \& 4$ & & 5 & 1 & & & & & & 6 & 4 & 1 & 1 & & 6 & 6 & 61.0 \\
\hline B4 & 4 & & 4 & & & & & & & 4 & 1 & 1 & 2 & & 4 & 4 & 7.9 \\
\hline B5 & $3 \& 4$ & & 3 & 1 & 2 & & & 1 & & 5 & 4 & 1 & 1 & 1 & 5 & 6 & $4,666.8$ \\
\hline B6 & $3 \& 4$ & & 11 & & & & & & & 11 & 4 & 5 & 2 & & 11 & 11 & 43.2 \\
\hline
\end{tabular}


Table 6.2 continued.

\begin{tabular}{|c|c|c|c|c|c|c|c|c|c|c|c|c|c|c|c|c|c|c|}
\hline \multicolumn{19}{|c|}{ Non Feature Contexts } \\
\hline \multirow[b]{2}{*}{ Unit } & \multirow[b]{2}{*}{ Level } & \multirow[b]{2}{*}{ Fea No } & \multicolumn{4}{|c|}{ Size $(\mathrm{cm})$} & \multicolumn{5}{|c|}{ Material Type* } & \multicolumn{3}{|c|}{ Fracture Type** } & \multicolumn{2}{|c|}{ Cracks } & \multirow[b]{2}{*}{ Total } & \multirow[b]{2}{*}{ Wt (g) } \\
\hline & & & $0-4$ & $4-9$ & $9-15$ & $>15$ & $\mathbf{C C}$ & Ch & $\mathbf{O}$ & Qtz & $\overline{\text { SS }}$ & Ang. & Rnd. & Tab. & $\mathbf{Y}$ & $\bar{N}$ & & \\
\hline B7 & $3 \& 4$ & & 9 & 2 & & & & & & & 11 & 5 & 6 & 0 & 1 & 10 & 11 & $\mathbf{1 7 3 . 2}$ \\
\hline $\mathrm{C} 1$ & $3 \& 4$ & & 38 & 8 & 2 & & & 1 & & & 47 & 27 & 11 & 10 & 1 & 47 & 48 & $8,002.2$ \\
\hline $\mathrm{C} 2$ & $3 \& 4$ & & 36 & 16 & 2 & & 1 & 2 & & & 51 & 31 & 16 & 7 & 5 & 49 & 54 & $2,707.1$ \\
\hline $\mathrm{C} 3$ & $3 \& 4$ & & 10 & 9 & 3 & & & & & & 22 & 13 & 6 & 3 & 3 & 19 & 22 & $1,542.0$ \\
\hline $\mathrm{C} 4$ & 3 & & 5 & & & & & & & & 5 & 5 & & & & 5 & 5 & 98.0 \\
\hline C5 & $3 \& 4$ & & 7 & 10 & & & & 6 & & & 11 & 5 & 12 & & 1 & 16 & 17 & 261.0 \\
\hline C6 & $3 \& 4$ & & 7 & 1 & 1 & & & & & & 9 & 6 & 3 & & 1 & 8 & 9 & 356.5 \\
\hline $\mathrm{C} 7$ & $3 \& 4$ & & 7 & 5 & & & & & & & 12 & 10 & 2 & & 3 & 9 & 12 & 268.9 \\
\hline D1 & 3 & & 16 & 7 & & & & & & & 23 & 15 & 8 & & & 23 & 23 & 406.7 \\
\hline D2 & $3 \& 4$ & & 29 & 5 & & & & 1 & & & 33 & 18 & 16 & & & 34 & 34 & $1,139.0$ \\
\hline D3 & $3 \& 4$ & & 92 & 8 & 1 & & 2 & 2 & & & 99 & 57 & 40 & 4 & 2 & 99 & 101 & $2,225.5$ \\
\hline D4 & $3 \& 4$ & & 116 & 19 & 1 & & & 1 & & & 135 & 88 & 29 & 19 & 2 & 134 & 136 & $1,612.5$ \\
\hline D5 & $3 \& 4$ & & 45 & 5 & 3 & & & 3 & & & 50 & 31 & 12 & 10 & & 53 & 53 & $2,414.7$ \\
\hline D6 & $3 \& 4$ & & 34 & 19 & 5 & 2 & & & & & 60 & 36 & 9 & 15 & 4 & 56 & 60 & $22,064.3$ \\
\hline D7 & $3 \& 4$ & & 37 & 15 & 6 & 1 & 1 & & & & 58 & 30 & 6 & 23 & 2 & 57 & 59 & $5,306.0$ \\
\hline E1 & $3 \& 4$ & & 4 & 3 & & & & & 2 & & 5 & 7 & & & & 7 & 7 & 499.7 \\
\hline E2 & $3 \& 4$ & & 7 & & 1 & & & 1 & & & 7 & 5 & & 3 & 2 & 6 & 8 & 385.9 \\
\hline E3 & $3 \& 4$ & & 3 & 3 & 1 & & & & & & 7 & 6 & 1 & & & 7 & 7 & 543.2 \\
\hline E4 & 4 & & 6 & 4 & 1 & & 1 & & & & 10 & 7 & 2 & 2 & & 11 & 11 & 395.3 \\
\hline E5 & 4 & & & 1 & & & & & & & 1 & & & 1 & 1 & & 1 & 127.6 \\
\hline E6 & 4 & & 20 & 2 & & & & 1 & & & 21 & 10 & 6 & 6 & 4 & 18 & 22 & 848.6 \\
\hline E7 & 4 & & 36 & 17 & 4 & 5 & & 2 & 1 & & 59 & 36 & 24 & 2 & 7 & 55 & 62 & $18,712.8$ \\
\hline F1 & 4 & & 5 & & & & & & & & 5 & 2 & 3 & & & 5 & 5 & 43.6 \\
\hline F2 & 4 & & 1 & 4 & & & & & & & 5 & 2 & 1 & 2 & 2 & 3 & 5 & 161.1 \\
\hline F3 & 4 & & 2 & 1 & & & & & & & 3 & 3 & & & 1 & 2 & 3 & 263.8 \\
\hline F4 & 4 & & 4 & 2 & 1 & & & & & & 7 & 3 & 4 & & 1 & 6 & 7 & 894.2 \\
\hline F5 & 4 & & 15 & 7 & & & & & & & 22 & 5 & 11 & 6 & & 22 & 22 & 811.9 \\
\hline F6 & 4 & & 24 & 12 & 3 & & & & & & 39 & 27 & 12 & & 2 & 37 & 39 & $2,607.1$ \\
\hline F7 & 4 & & 20 & 8 & 1 & & & & 1 & & 28 & 18 & 9 & 2 & 6 & 23 & 29 & $2,669.5$ \\
\hline G1 & $3 \& 4$ & & 79 & 19 & 1 & & & 2 & 2 & & 95 & 77 & 19 & 3 & 8 & 91 & 99 & $2,875.5$ \\
\hline G2 & $3 \& 4$ & & 98 & 7 & & & & & 2 & & 103 & 69 & 27 & 9 & 2 & 103 & 105 & $1,287.3$ \\
\hline G3 & 4 & & 5 & 2 & 1 & & & & & & 8 & 6 & & 2 & & 8 & 8 & 533.0 \\
\hline G4 & $3 \& 4$ & & 19 & 2 & 2 & & & & 2 & & 21 & 15 & 7 & 1 & 2 & 21 & 23 & $7,990.6$ \\
\hline G5 & $3 \& 4$ & & 20 & 4 & & & & 1 & & & 23 & 12 & 7 & 5 & 1 & 23 & 24 & 238.8 \\
\hline G6 & $3 \& 4$ & & 37 & 5 & & & & 4 & & & 38 & 25 & 10 & 7 & 8 & 34 & 42 & 598.1 \\
\hline G7 & 3 & & 2 & & & & & & & & 2 & & 1 & 1 & & 2 & 2 & 9.9 \\
\hline H7 & $3 \& 4$ & & 4 & & & & & & & & 4 & 1 & 2 & 1 & 1 & 3 & 4 & 8.0 \\
\hline Subtotal & & & 899 & 232 & 40 & 8 & 5 & 25 & 10 & 0 & 1,139 & 713 & 322 & 144 & 73 & 1,106 & 1,179 & $91,083.1$ \\
\hline
\end{tabular}

\begin{tabular}{|c|c|c|c|c|c|c|c|c|c|c|c|c|c|c|c|c|c|c|}
\hline \multicolumn{19}{|c|}{ Feature Contexts } \\
\hline \multirow[b]{2}{*}{ Unit } & \multirow[b]{2}{*}{ Level } & \multirow[b]{2}{*}{ Fea No } & \multicolumn{4}{|c|}{ Size (cm) } & \multicolumn{5}{|c|}{ Material Type* } & \multicolumn{3}{|c|}{ Fracture Type*** } & \multicolumn{2}{|c|}{ Cracks } & \multirow[b]{2}{*}{ Total } & \multirow[b]{2}{*}{ Wt (g) } \\
\hline & & & $0-4$ & $4-9$ & $9-15$ & $>15$ & $\mathrm{CC}$ & Ch & $\mathbf{O}$ & $\overline{Q t z}$ & SS & Ang. & Rnd. & Tab. & $\mathbf{Y}$ & $\mathbf{N}$ & & \\
\hline $8-1 \& 8-2$ & 4 & 8 & & 1 & 4 & 2 & & & & & 7 & 6 & & 1 & 3 & 4 & 7 & $4,500.1$ \\
\hline $9-1 \& 9-4$ & 4 & 9 & & & 4 & 1 & & & 2 & & 3 & 4 & & 1 & 3 & 2 & 5 & $4,357.6$ \\
\hline $10-2$ & 5 & 10 & 2 & 10 & 1 & & & & & & 13 & 12 & & 1 & 4 & 9 & 13 & $2,460.2$ \\
\hline $11-2$ & & 11 & & 4 & & & & & & & 4 & 4 & & & 2 & 2 & 4 & 712.3 \\
\hline \multicolumn{19}{|l|}{$12-3,12-4,12$} \\
\hline $9 \& 12-10$ & & 12 & 96 & 31 & 26 & & & & 2 & & 151 & 127 & & 26 & 7 & 146 & 153 & 23,646 . \\
\hline $13-1 \& 13-2$ & & 13 & & 11 & & & & & & & 11 & 10 & 1 & 0 & 7 & 4 & 11 & $2,026.8$ \\
\hline $14-2$ & 5 & 14 & 8 & 16 & 21 & 2 & & & & & 47 & 41 & 2 & 4 & 22 & 25 & 47 & $29,758.8$ \\
\hline $15-2 \& 15-4$ & & 15 & & 8 & 4 & & & & & & 12 & 8 & 1 & 3 & 3 & 9 & 12 & $4,158.7$ \\
\hline \multirow[t]{2}{*}{ 19-4 } & & 19 & & 6 & 1 & & & & 1 & & 6 & 6 & 1 & & 1 & 6 & 7 & $2,395.9$ \\
\hline & 3 & 35 & & 2 & & & & & & & 2 & 2 & & & & 2 & 2 & 192.1 \\
\hline A7 & 4 & 41 & & 1 & & & & & & & 1 & & & 1 & & 1 & 1 & 205.9 \\
\hline Subtotal & & & 106 & 90 & 61 & 5 & 0 & 0 & 5 & 0 & 257 & 220 & 5 & 37 & 52 & 210 & 262 & $74,414.9$ \\
\hline Total & & & 1,005 & 322 & 101 & 13 & 5 & 25 & 15 & 0 & 1,396 & 933 & 327 & 181 & 125 & 1,316 & 1,441 & $165,498.0$ \\
\hline
\end{tabular}

*CC= Calcium Carbonate, $\mathrm{Ch}=$ Chert, $\mathrm{O}=\mathrm{O}$ ther, $\mathrm{Qtz}=\mathrm{Quartzite}$, and $\mathrm{SS}=\mathrm{Sandstone}$

**Ang.=Angular, Rnd.=Round, Tab.=Tabular

Fea $=$ Feature 


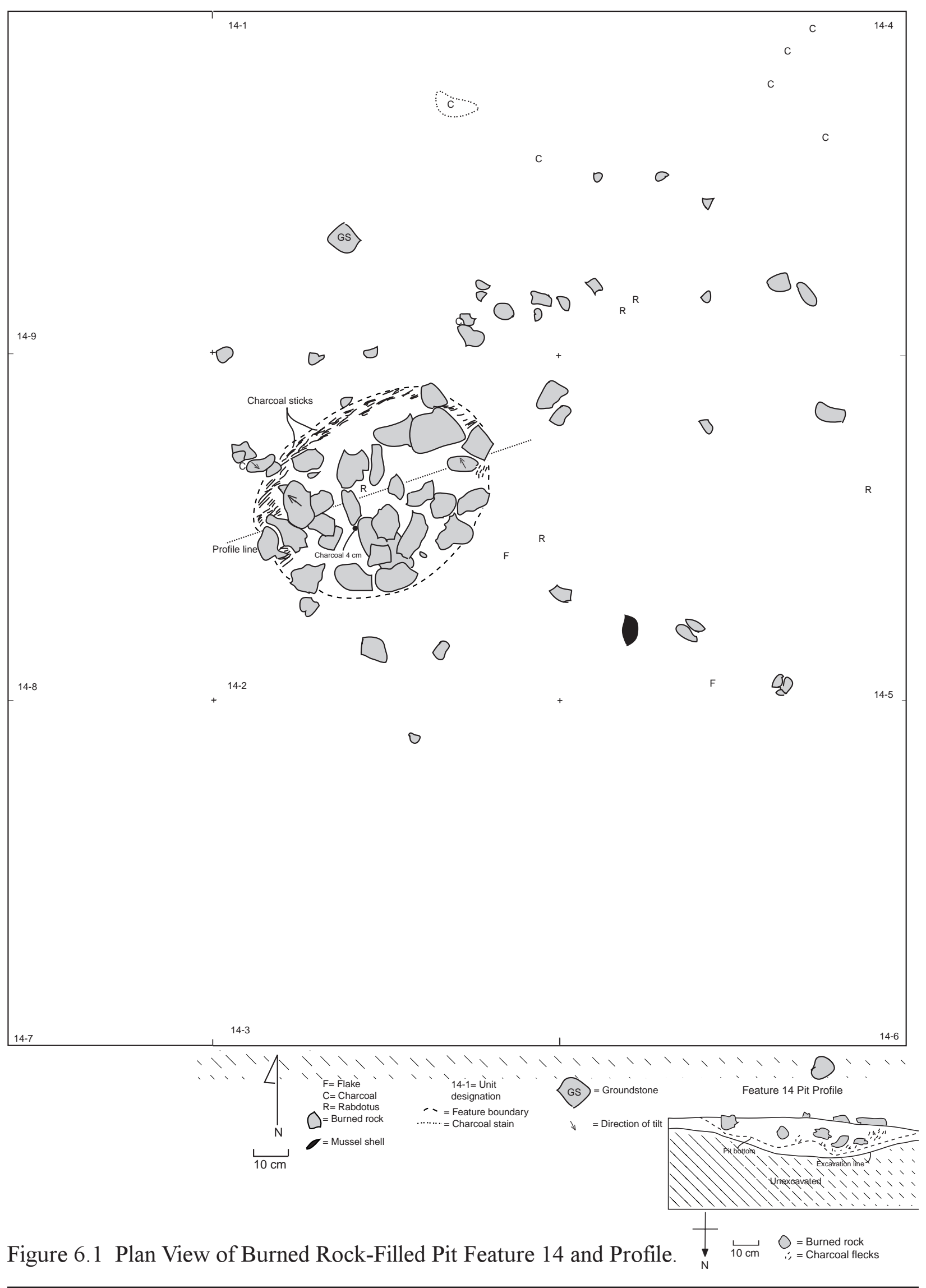




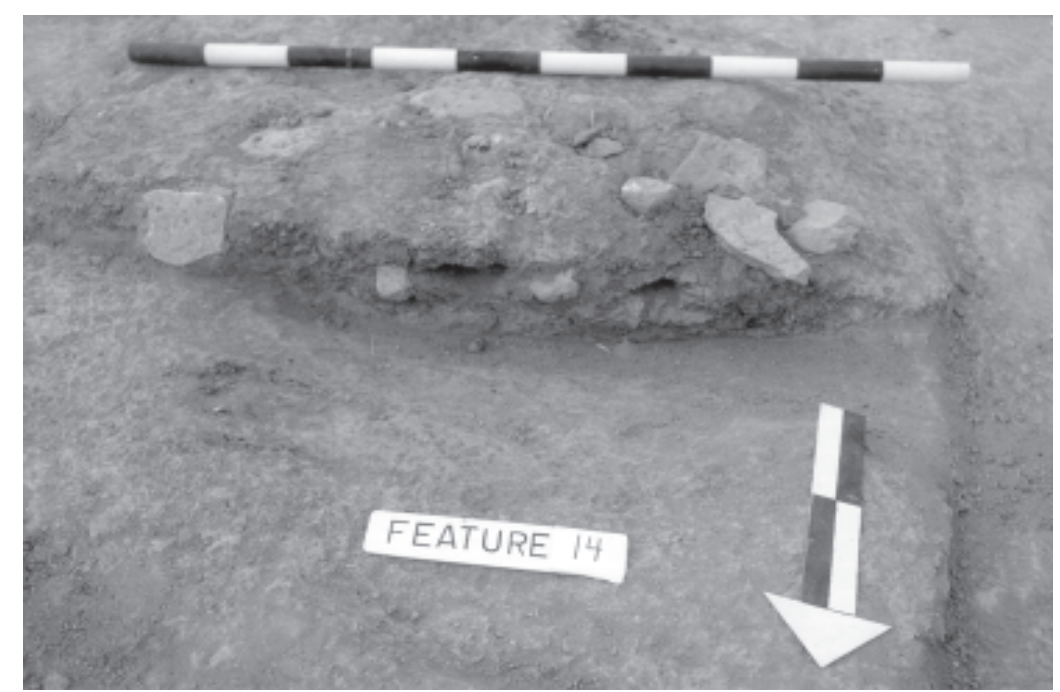

Figure 6.2 Profile and South Half of Rock Filled Pit Prior to Excavation.

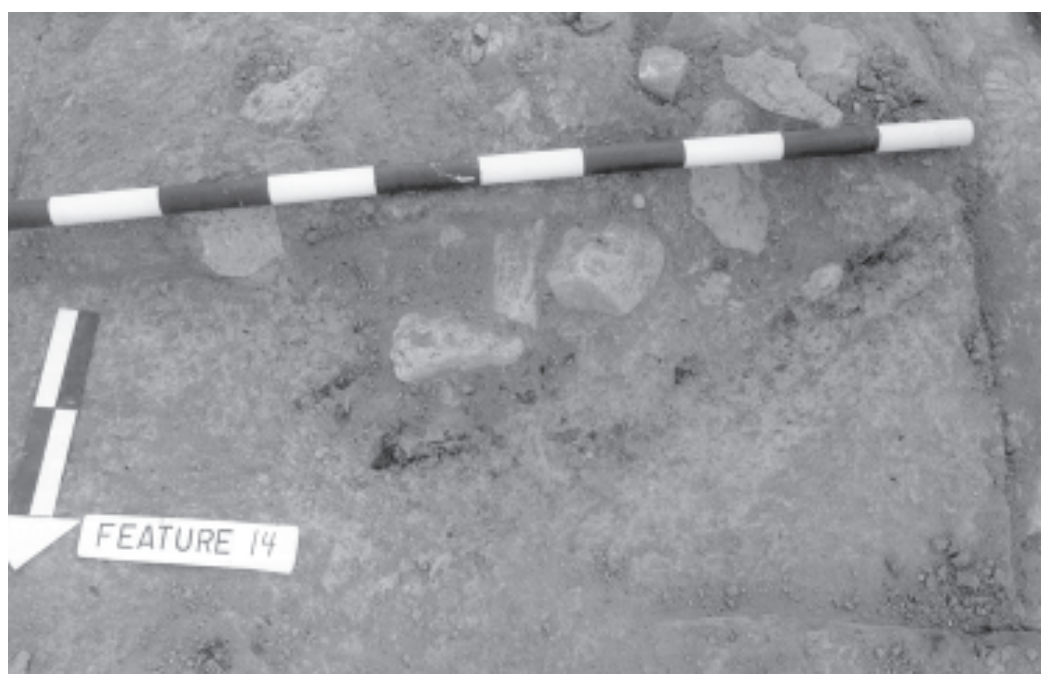

Figure 6.3 Closeup of Charcoal Sticks on Northern Edge of Feature 14.

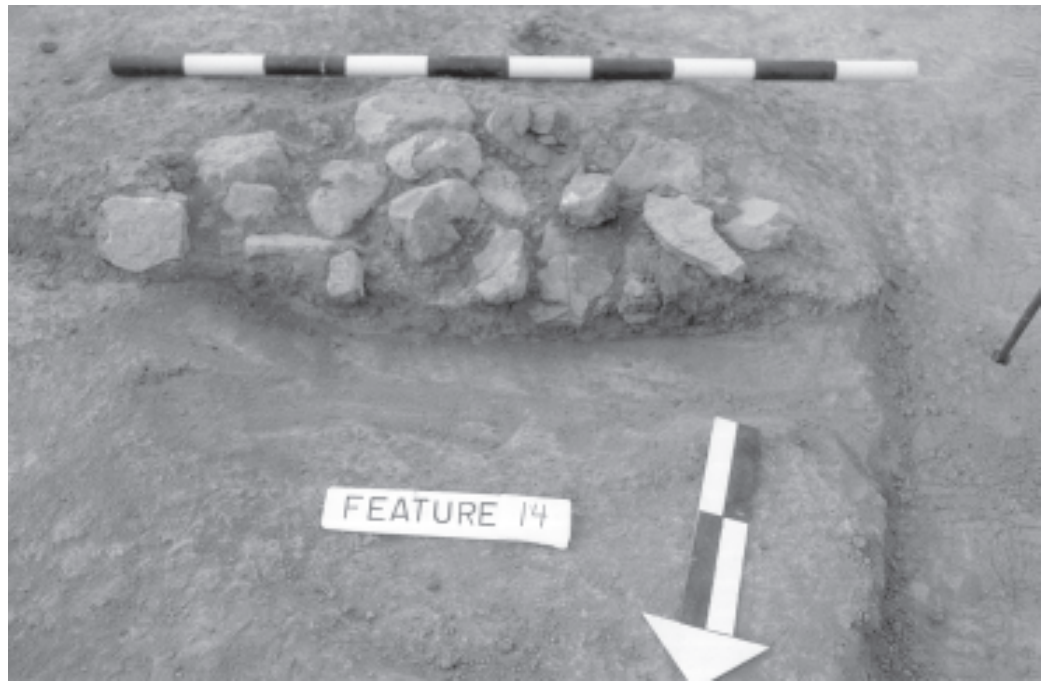

Figure 6.4 Exposed Burned Rocks in South Half of Pit Feature 14. 
Burned rock \#705 was subjected to thermal demagnetization. Analysis revealed two magnetic components (Appendix E). Although no definitive magnetic signature has been recognized for this pattern as yet, the two components could represent rapid cooling associated with stone boiling process.

Most charcoal in the pit feature was on the northeastern side along the outer margins of the rocks on that side. The charcoal pieces appeared to be in situ in long, linear patterns that reflected the use of long sticks, many of which were 2 to $3 \mathrm{~cm}$ wide with at least one piece being $4 \mathrm{~cm}$ in diameter. These sticks appeared to have been placed along the one edge and then covered by some burned rocks, but the sticks did not occur under all the rocks. Three charcoal samples from within Feature 14 were identified as mesquite root (\#1811-5a), acacia (\#1813-4a), and hackberry (\#1847-1a). The hackberry specimen, which was recovered from the central-pit matrix float sample, was dated. It yielded a $\delta^{13} \mathrm{C}$ adjusted date of $1950 \pm 50$ B.P. (Beta-121730) (Table 5.3). This date is accepted for Occupation 1 , although it is the youngest of the three charcoal and the three rock-residue dates from this occupation. Old wood does not appear to be a factor in the fuel used for these fires. This woodcharcoal date is also some 340, 520, and 1,240 years younger than the AMS dates on the burned rock residues.

The well-defined pit yielded about 24 liters of matrix, which was floated. This yielded abundant charcoal (101 g) and burned rock fragments (203 g) (Table 6.3). In addition to the burned rocks and charcoal in the pit, a single Rabdotus snail shell was near the top of the rocks. This feature is interpreted as representing an in situ rock heating apparatus. Apparently the some rocks retained organic residues from earlier events, as is evident from older radiocarbon dates. These results suggest the reuse of thermal cobbles in this feature.
Hand excavations were conducted around a $1 \mathrm{~m}$ radius from this intact pit feature near the center of Gradall ${ }^{\mathrm{TM}}$ area $\mathrm{H}$. The nine hand excavated units surrounding Feature 14 yielded relatively few scattered burned rocks, a few charcoal chunks, a few Rabdotus shells, a couple of mussel shells, a few pieces of lithic debitage, one edge modified flake, one sandstone abrader (\#711), and one large ( $6 \mathrm{~cm}$ wide by $13 \mathrm{~cm}$ long) charred piece of huisache (\#662b ). This large charcoal piece was $40 \mathrm{~cm}$ north of the basin. Except for the possible abrading of some unknown material, no specific activity appeared to have been conducted within $1 \mathrm{~m}$ of this heating element. Nearly $2 \mathrm{~m}$ southwest of Feature 14 was Feature 9, a burned rock cluster with five quite large rocks. These may have been piled nearby for use in the Feature 14 pit.

The two mussel shell clusters (Features 36 and 41) were both found in the $80 \mathrm{~cm}$ wide Balk A. Thus, the size, horizontal patterning, and artifact associations of these features are only partially revealed in the narrow balks (Figures 6.5, 6.6, and 6.7). The two shell clusters were quite similar in that they both consisted of loose clusters of more or less complete mussel shell valves that lacked obvious pattern, boundary, stacking, or pit to restrict their location. Feature 36 contained 16 relatively complete valves. These were identified as two valves of an indeterminate species and 14 valves of Cyrtonaias sp., which are nearly equal in left and right valves. No obvious burning or cultural modification was observed on any of the shells. A single burned rock (\#4183) from among the shells was analyzed for stable carbon and nitrogen isotopes and lipid residues. It yielded only a trace of lipids (Appendix G). The $\delta^{13} \mathrm{C}$ isotope value of $-18.9 \%$ and the $\delta^{15} \mathrm{~N}$ value of 7.7\% (Appendix D) are believed to reflect a mixture of $\mathrm{C} 3$ and $\mathrm{C} 4$ plant materials or animals that ate these plants. 
Table 6.3 Float Results from Occupation 1 Features.

\begin{tabular}{|c|c|c|c|c|c|c|c|c|c|c|c|c|c|c|c|c|c|c|}
\hline \multirow[b]{4}{*}{ Cat. No* } & \multirow{4}{*}{$\begin{array}{c}\text { Fea } \\
\text { No }\end{array}$} & & & \multirow{2}{*}{\multicolumn{2}{|c|}{$\begin{array}{c}\text { Burned } \\
\text { Clay } \\
\text { Sample }\end{array}$}} & \multirow{4}{*}{$\begin{array}{c}\begin{array}{c}\text { Burned } \\
\text { Rock }\end{array} \\
\text { Wt (g) }\end{array}$} & \multirow{4}{*}{$\begin{array}{c}\begin{array}{c}\text { Charcoal } \\
\text { Sample }\end{array} \\
\text { Wt (g) }\end{array}$} & & & & & & & & & Class & & \multirow[b]{4}{*}{ Wt $(\mathrm{g}$} \\
\hline & & & one & & & & & \multicolumn{2}{|c|}{$\begin{array}{c}\text { Lithic } \\
\text { Debitage }\end{array}$} & \multicolumn{2}{|c|}{$\begin{array}{c}\text { Macro- } \\
\text { botanical }\end{array}$} & \multicolumn{2}{|c|}{$\begin{array}{c}\text { Mussel } \\
\text { Shell }\end{array}$} & \multicolumn{2}{|c|}{$\begin{array}{l}\text { Other } \\
\text { Rock }\end{array}$} & $\begin{array}{l}\text { Snail } \\
\text { Shell }\end{array}$ & \multirow[b]{3}{*}{ Total } & \\
\hline & & & Wt & & & & & & Wt & & $\mathbf{W t}$ & & Wt & & $\mathbf{W t}$ & & & \\
\hline & & $\mathbf{N}$ & (g) & $\mathbf{N}$ & Wt (g) & & & $\mathbf{N}$ & (g) & $\mathbf{N}$ & (g) & $\mathbf{N}$ & (g) & $\mathbf{N}$ & (g) & Wt (g) & & \\
\hline $1840-2 \& 18$ & & & & & & & & & & & & & & & & & & \\
\hline 2 & 8 & & & & & 99.4 & & & & & & & & & & 2.2 & 12 & 101.7 \\
\hline $1843-2$ & 10 & 1 & 0.1 & & & 34.9 & 0.1 & & & & & & & & & 10.1 & 2 & 45.2 \\
\hline $1844-2$ & 11 & & & & & 11.8 & 0.2 & 32 & 0.8 & 5 & 0.1 & & & & & 2.2 & 6 & 15.1 \\
\hline $1845-2$ & 12 & 1 & 0.1 & & & 71.5 & 1.5 & 15 & 0.4 & & & 1 & 0.2 & & & 11 & 3 & 84.7 \\
\hline $1849-2$ & 15 & 1 & 0.1 & & & 25.4 & 2.2 & 1 & 0.1 & & & & & & & 30.1 & 3 & 57.9 \\
\hline $1850-2$ & 16 & 1 & 0.1 & & & 31.4 & 0.5 & 1 & 0.1 & & & & & & & 3.5 & 3 & 35.6 \\
\hline $1851-2$ & 18 & & & & & & & 9 & 0.1 & & & & & & & 0.8 & 10 & 0.9 \\
\hline $1852-2$ & 19 & & & & & & 0.9 & 8 & 0.2 & & & & & & & 4.3 & 1 & 5.4 \\
\hline $3563-2$ & 20 & & & 1 & 17.5 & 64.4 & 2.4 & 17 & 0.9 & & & & & 1 & 5.8 & 6.2 & 20 & 97.2 \\
\hline $3567-2$ & 22 & & & & & 6 & 0.1 & 27 & 0.4 & & & 1 & 1.4 & & & 0.6 & 29 & 8.5 \\
\hline $3581-5$ & 24 & & & & & 38.2 & 0.1 & 54 & 1.6 & & & 1 & 0.4 & & & 2.4 & 56 & 42.7 \\
\hline $5718-1 \& 57$ & & & & & & & & & & & & & & & & & & \\
\hline 2 & 27 & 1 & 0.1 & & & 124.7 & 6.4 & 96 & 2.5 & 1 & 0.1 & & & & & 11.8 & 100 & 145.6 \\
\hline $3607-1 \& 36$ & & & & & & & & & & & & & & & & & & \\
\hline 2 & 28 & & & & & 40.2 & 0.2 & 29 & 0.6 & & & & & & & 2 & 30 & 43 \\
\hline $3607-2 \& 36$ & & & & & & & & & & & & & & & & & & \\
\hline 2 & 29 & & & & & 33.2 & 0.1 & 99 & 2.6 & & & & & & & 4.8 & 100 & 40.7 \\
\hline $3618-2 \& 36$ & & & & & & & & & & & & & & & & & & \\
\hline 5 & 30 & 2 & 0.2 & & & 60.9 & 0.3 & 31 & 1.1 & & & & & & & 4.3 & 35 & 66.8 \\
\hline $3623-2$ & 31 & & & & & 7.8 & 31.6 & 114 & 40.1 & & & & & & & 2.4 & 115 & 81.9 \\
\hline $5715-1$ & 32 & 1 & 0.1 & & & 17.2 & & 4 & 0.1 & & & 1 & 0.1 & & & 1.2 & 7 & 18.7 \\
\hline $5279-6$ & 34 & & & & & 6.3 & 0.1 & 2 & 0.1 & & & & & & & 2 & 3 & 8.5 \\
\hline $5714-1$ & 35 & & & & & 310.1 & & 11 & 0.3 & 1 & 0.2 & 1 & 0.3 & & & 3.7 & 14 & 314.6 \\
\hline $5712-1$ & 36 & & & & & 310.1 & & 3 & 0.1 & & & 1 & 8.3 & & & 3.7 & 2 & 322.2 \\
\hline $5716-1$ & 39 & & & & & 15.3 & & 10 & 0.3 & & & & & & & 10.1 & 11 & 25.7 \\
\hline $5717-1$ & 42 & & & & & 3.4 & 0.4 & 11 & 0.1 & & & & & & & 0.2 & 13 & 4.1 \\
\hline 5713-1 & 43 & 1 & 2.4 & & & 41.5 & 0.3 & 50 & 1.4 & 1 & 0.1 & 1 & 0.4 & & & & 54 & 46.1 \\
\hline Total & & 9 & 3.2 & 1 & 17.5 & $1,254.3$ & 47.4 & 624 & 53.9 & 8 & 0.5 & $\begin{array}{lll}7 & \end{array}$ & 11.1 & 1 & 5.8 & 117.4 & 617 & $1,511.1$ \\
\hline
\end{tabular}

* Note: All catalogue numbers from hand excavated proveniences have been formed by adding a dash and appear in the database with leading zeros. These leading zeros have been omitted to conserve space.

Feature 41 yielded 14 valves that varied from small fragments to nearly 90 percent of the valve. Six valves were identified as Cyrtonaias sp. The sides were nearly equally represented by five lefts, four rights, and four indeterminates. No obvious signs of burning or cultural modifications were observed. A single $205 \mathrm{~g}$ sandstone burned rock (\#5183) from among the shells was analyzed for stable carbon and nitrogen isotopes and lipid residues. It yielded a combination of lipids that is similar to prickly pear pads and other plants (Appendix G). The $\delta^{13} \mathrm{C}$ isotope value of $-21.9 \%$ and the $\delta^{15} \mathrm{~N}$ value of 8.0\% (Appendix D) are believed to reflect a mixture of $\mathrm{C} 3$ and $\mathrm{C} 4$ plant materials. Thermal demagnetization conducted on burned rock \#5183-3 yielded two magnetic components (Appendix E) that could represent rapid cooling from stone boiling process.

Scattered burned sandstone rocks were in the general area of Features 36 and 41 but were relatively sparse. No stone tools and only a few pieces of lithic debitage were scattered in the vicinity of the shells. No charcoal, ash, burned bones, or oxidation was apparent around the cluster of mussel shells. Floated matrix samples (9.0 and 4.75 liters) did not yield charcoal or burned macrobotanical remains (Appendix B) but contained mostly tiny snail shell and burned 


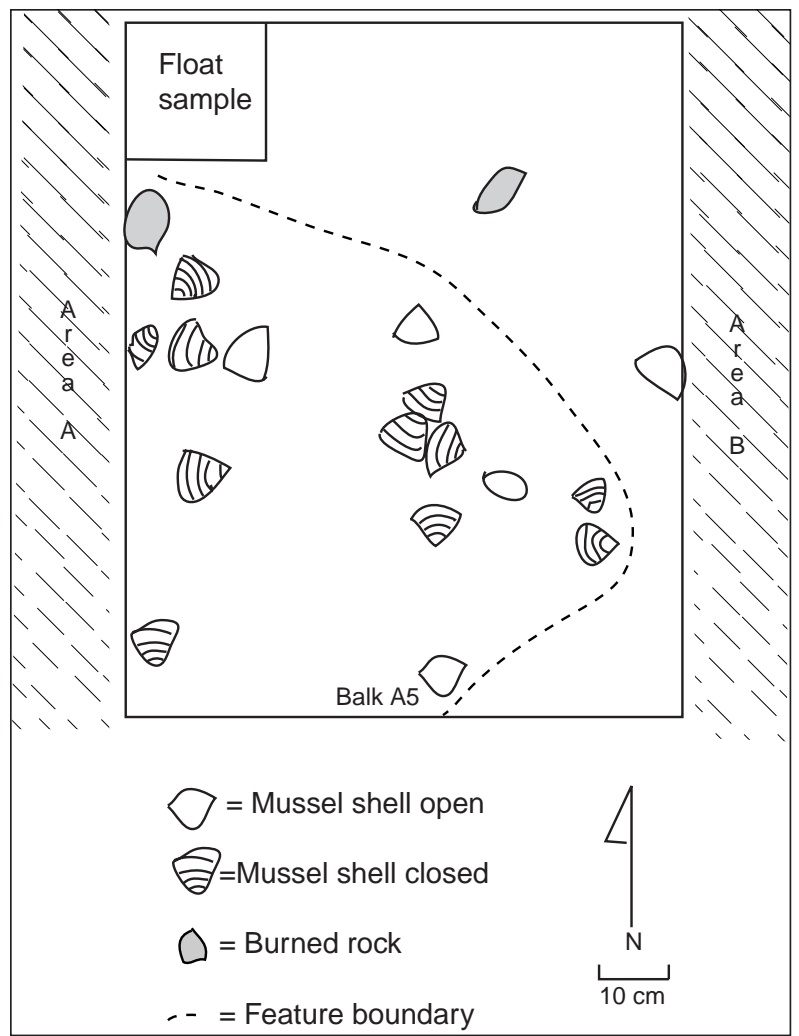

Figure 6.5 Plan View of Feature 36 Mussel Shell Cluster.

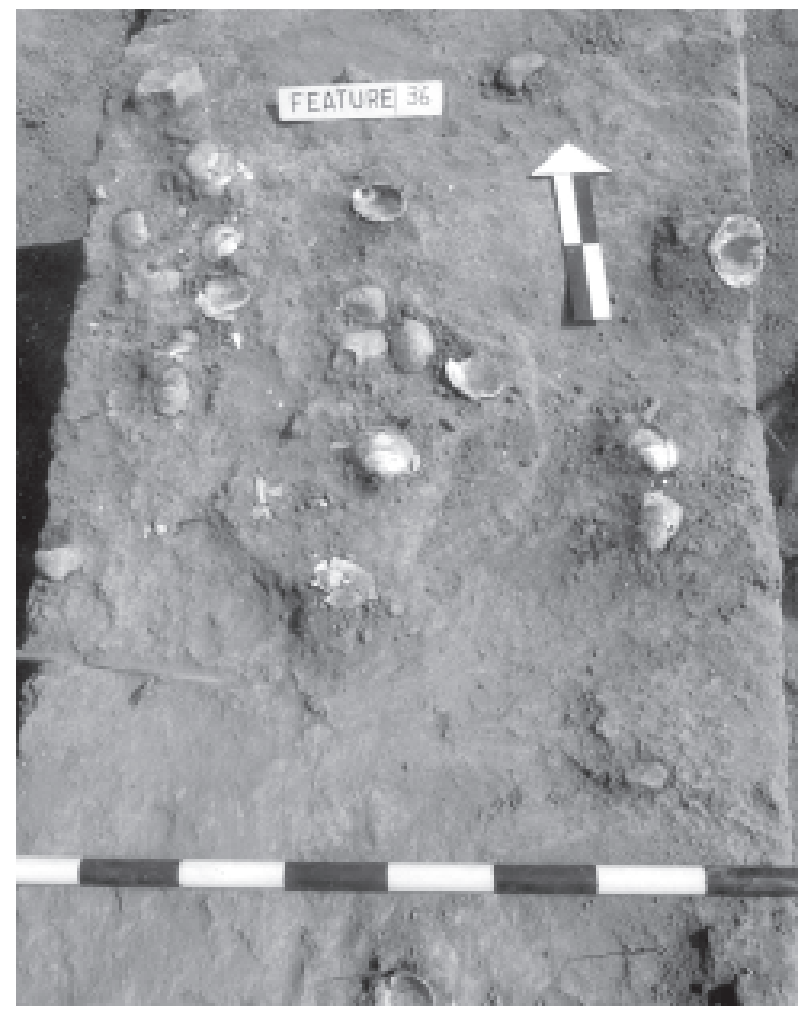

Figure 6.6 Mussell Shell Cluster in Feature 36, Balk A5.

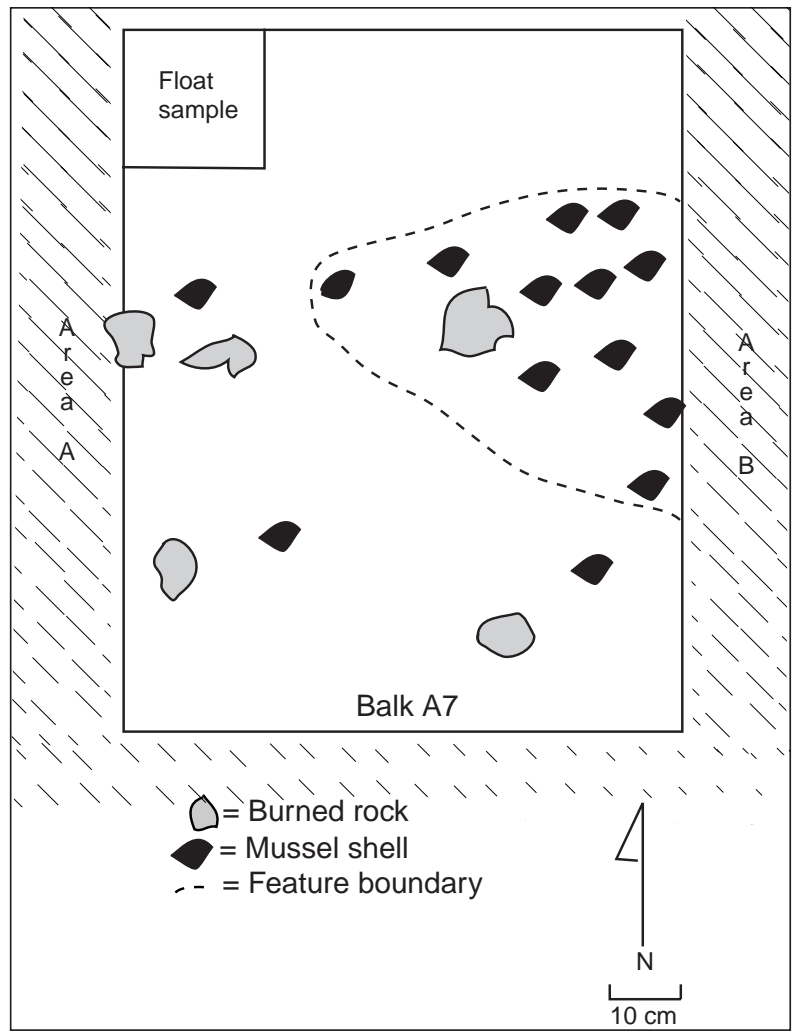

Figure 6.7 Plan View of Feature 41, Balk A7, Mussel Shell Cluster.

rock fragments (Table 6.3). The two clusters appear to represent general locations of discarded mussel shells following the removal of their meat. Features 36 and 41 were only 150 $\mathrm{cm}$ apart in Balk A near the western end of the excavation block. Other scattered mussel shells were documented in GradallTM Area A immediately west of these two features.

Nine burned rock clusters (Features 8, 9, 10, 11, $12,13,15,19$, and 35$)$ were quite similar to one another (Figures 6.8, 6.9, 6.10, 6.11, 6.12, 6.13, $6.14,6.15$, and 6.16). They all contained a single layer of burned rocks in non-recognizable horizontal patterns, all more or less lying on flat surfaces. No obvious pit constrained their distributions. Ash and oxidized soil was not observed at any of these features. Features 10, $12,13,15$, and 19 were associated with sparseto-moderate quantities of charcoal. The number of burned rocks was quite variable and ranged 


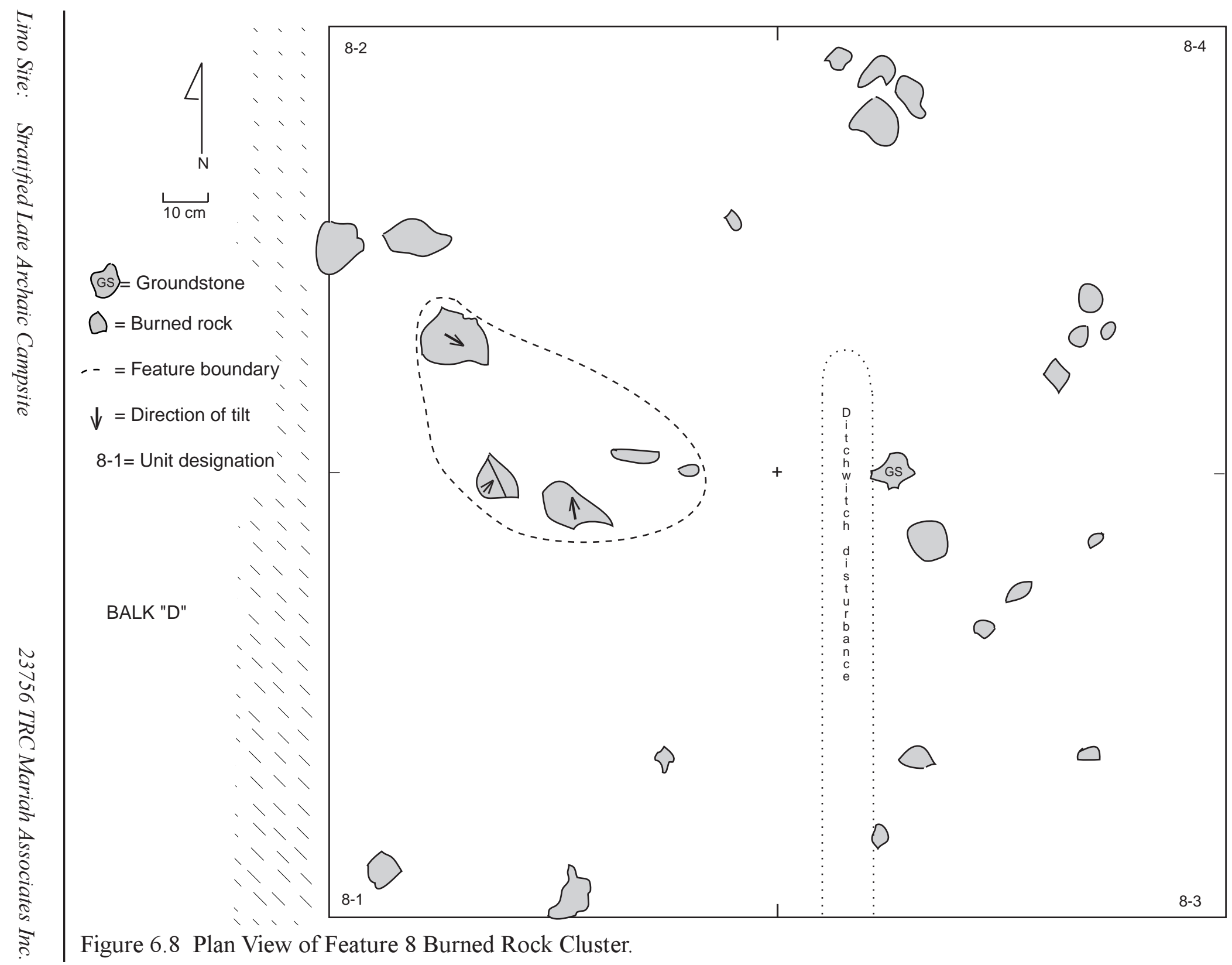




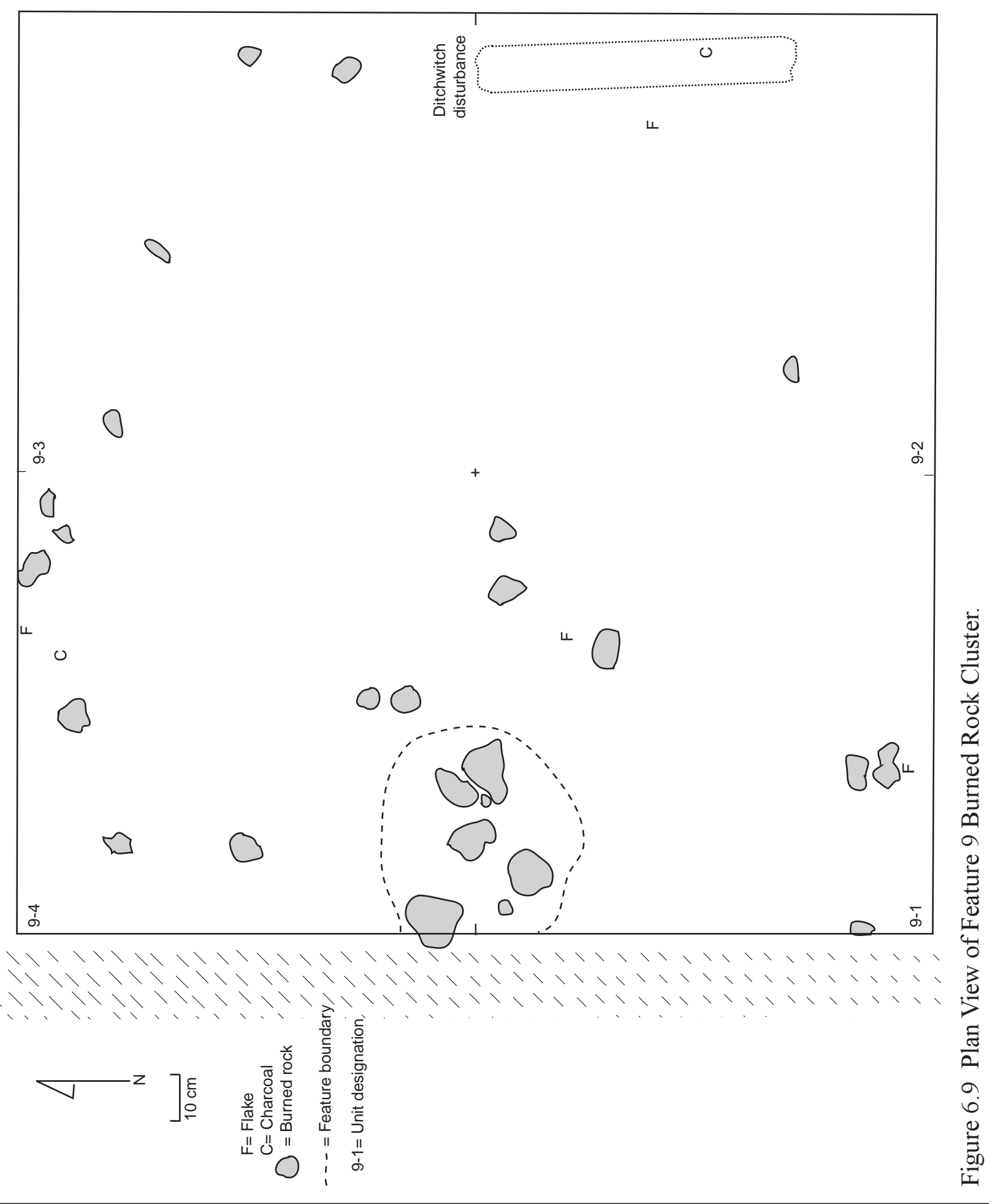




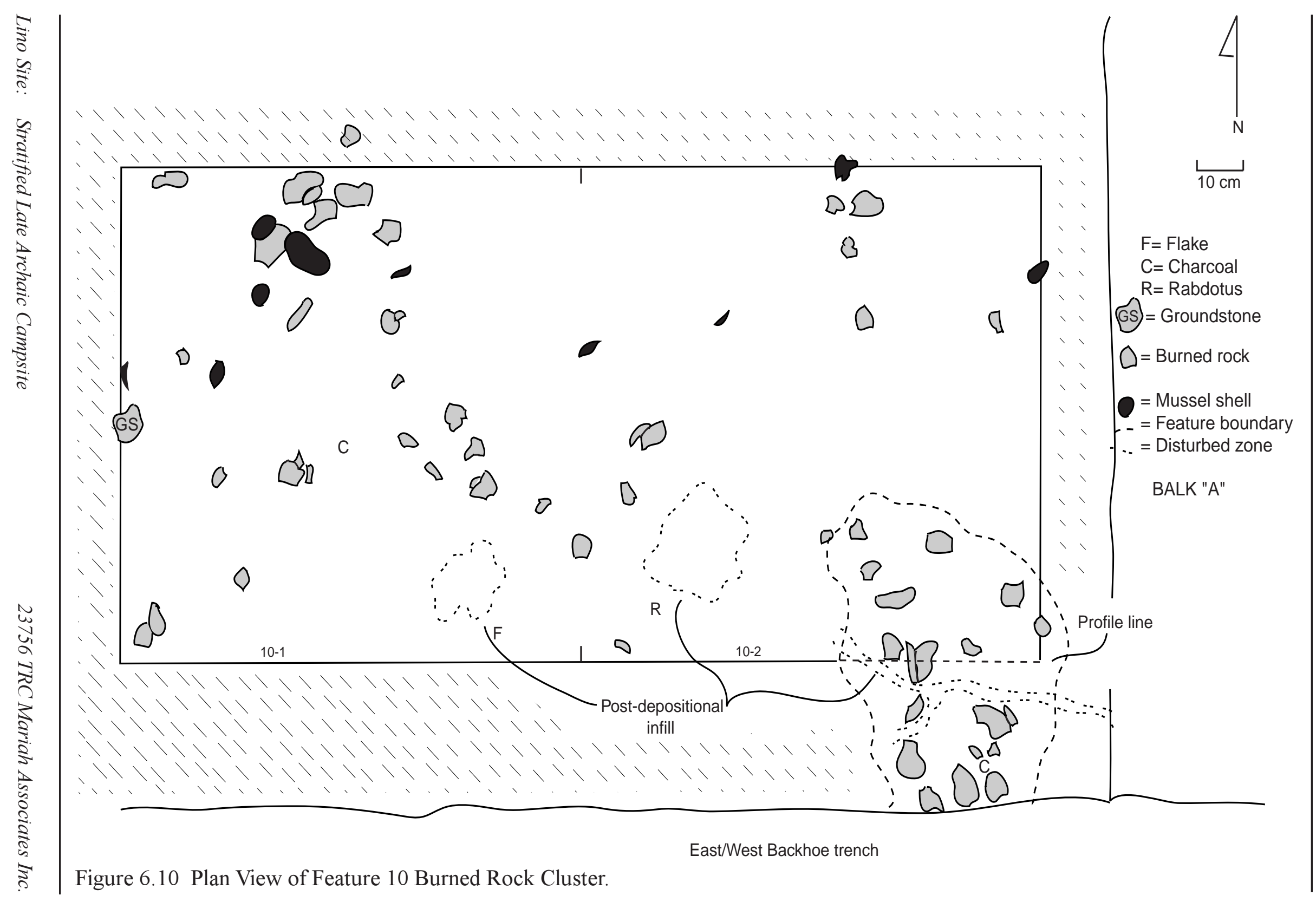




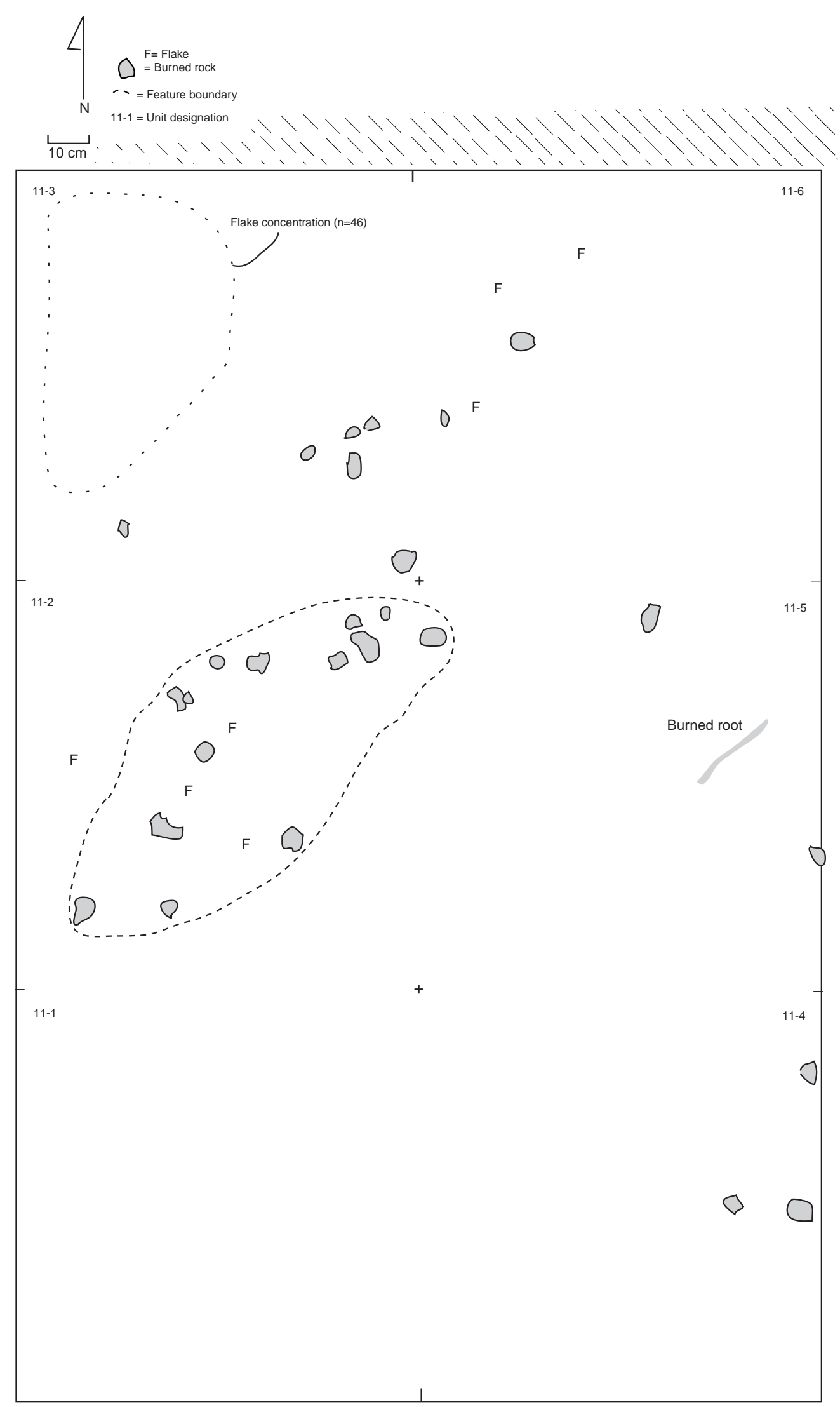

Figure 6.11 Plan View of Feature 11 Burned Rock Cluster. 


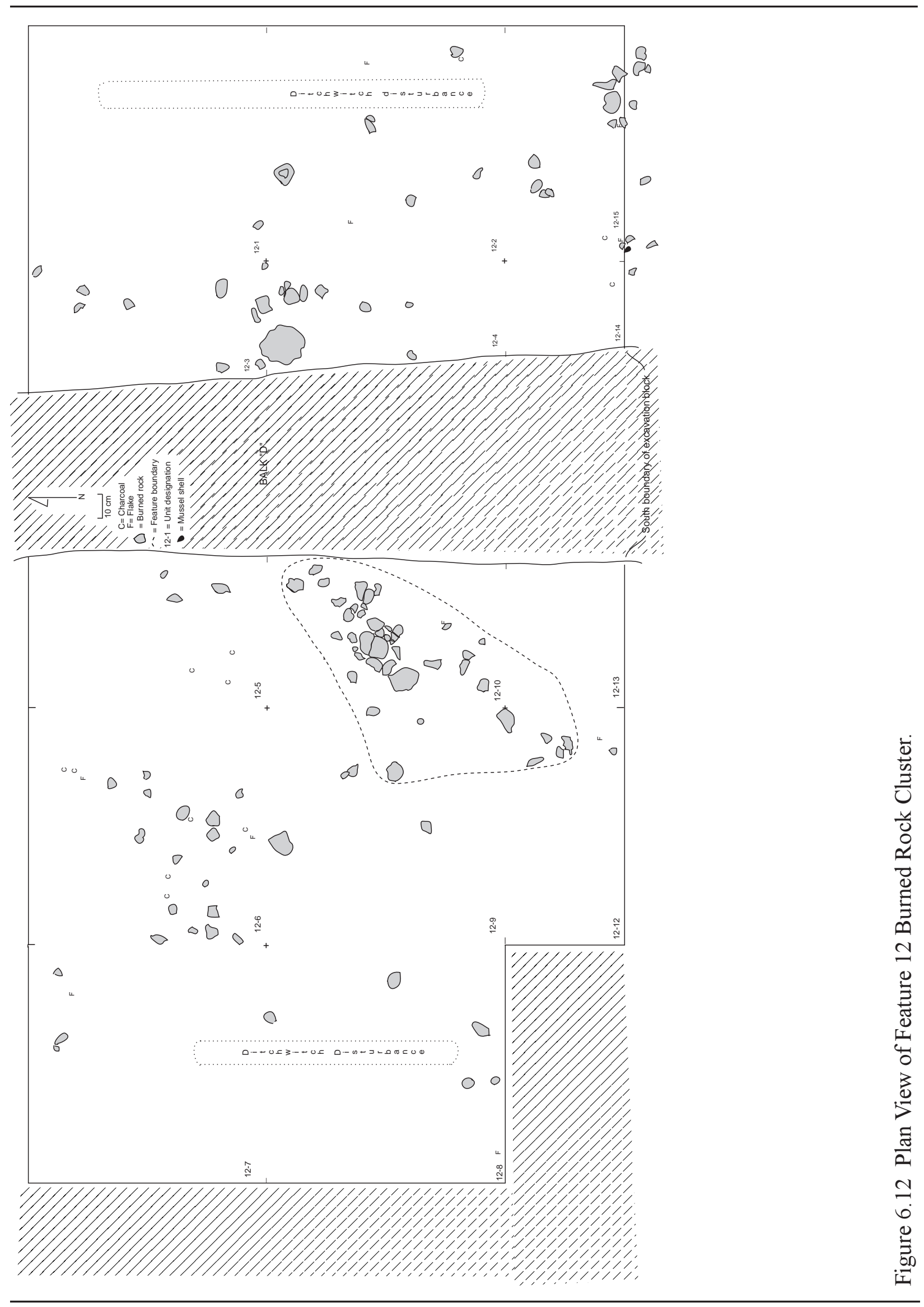




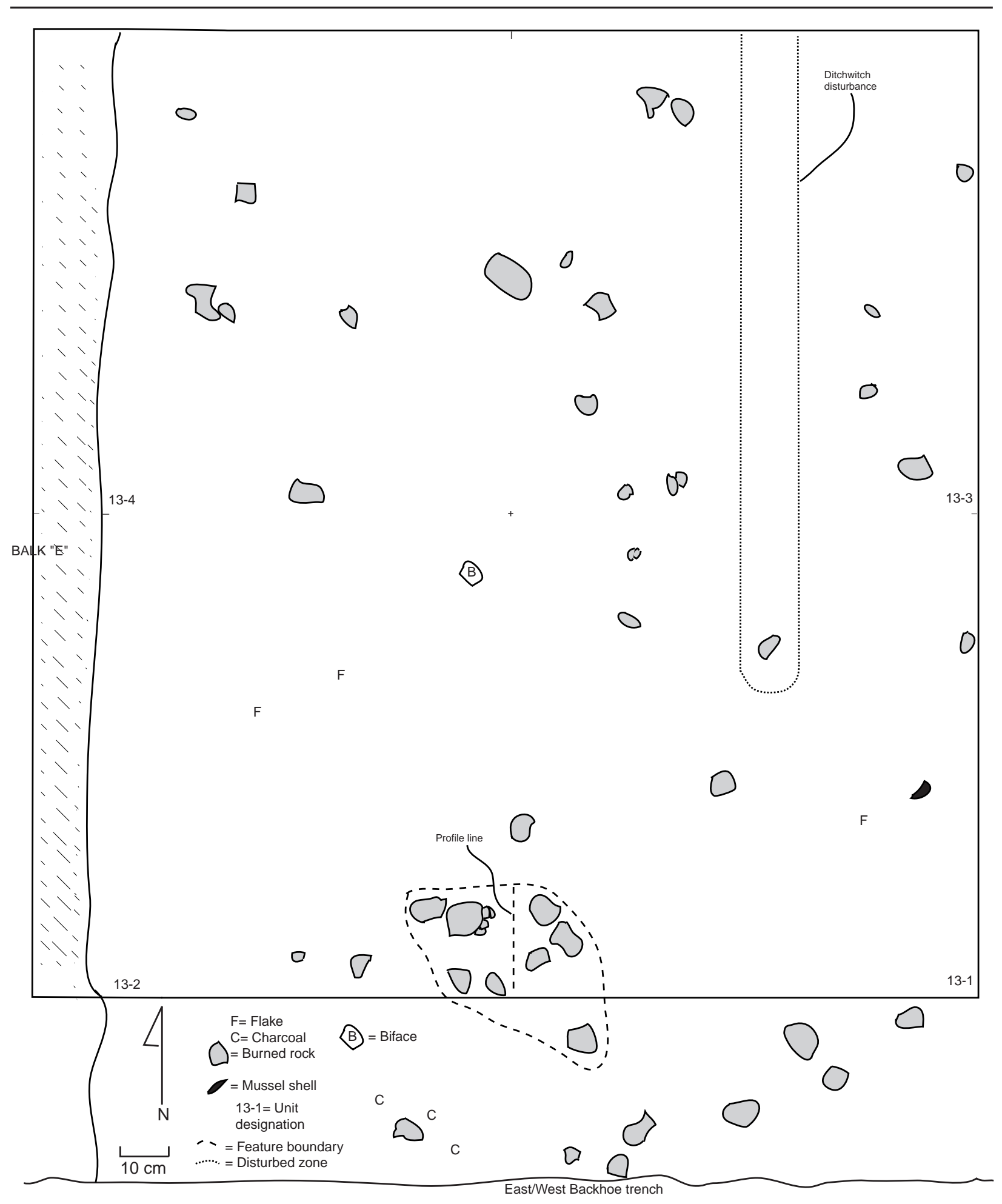

Figure 6.13 Plan View of Feature 13 Burned Rock Cluster. 


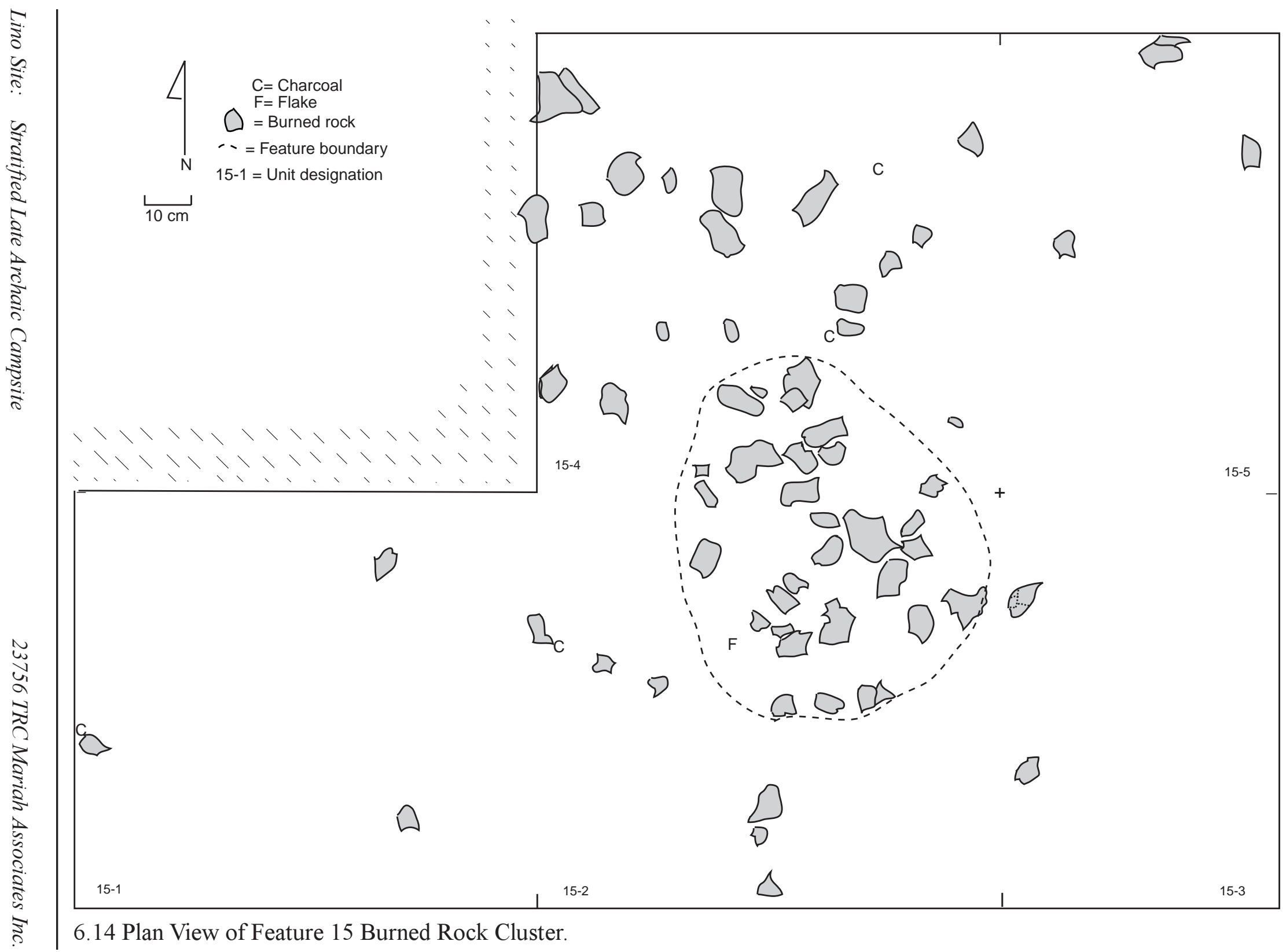

$\infty$
$\vdots$
$\vdots$
$\vdots$
$\vdots$
$\vdots$
$\vdots$
$\vdots$
$\vdots$
$\vdots$
$\vdots$
0 

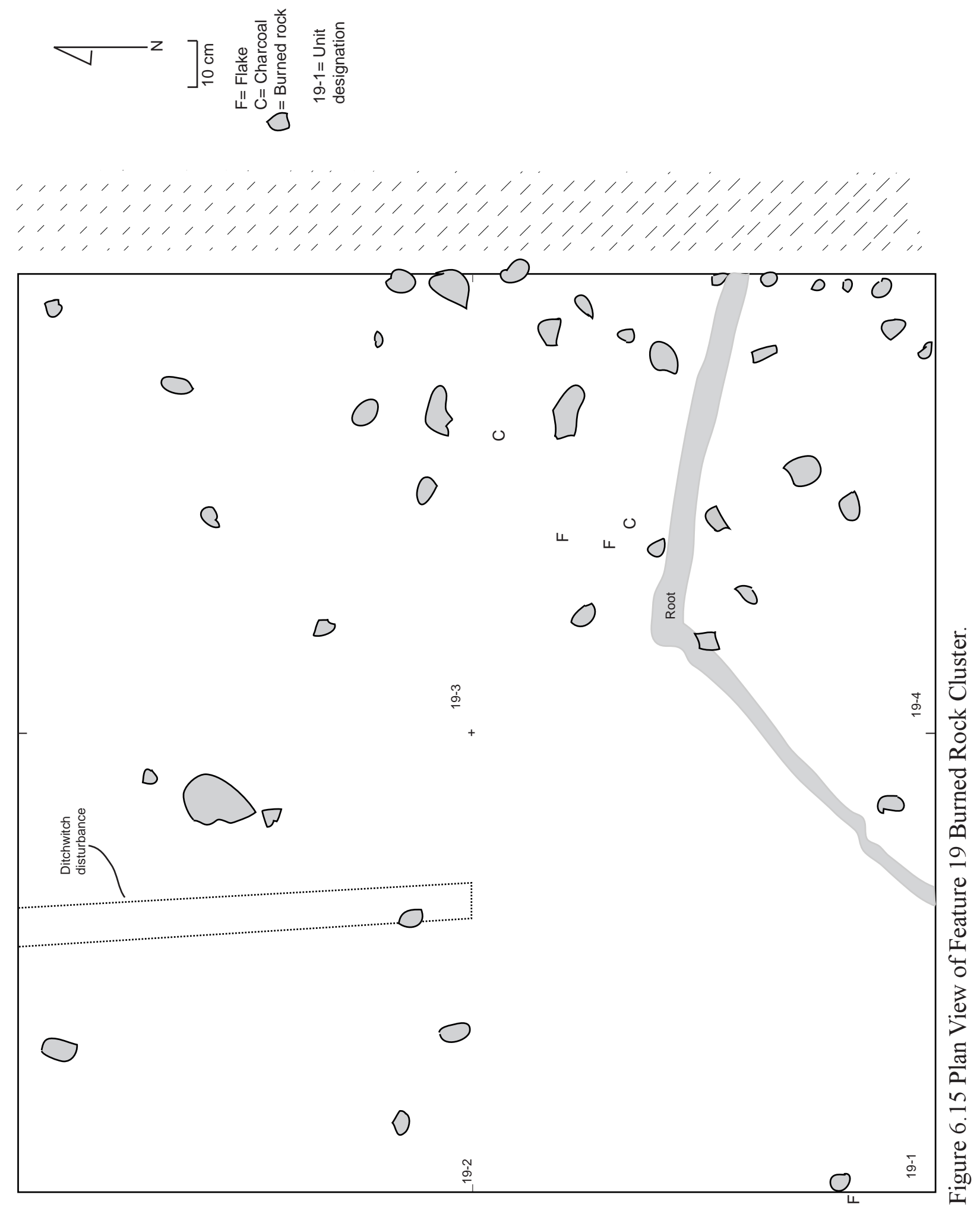


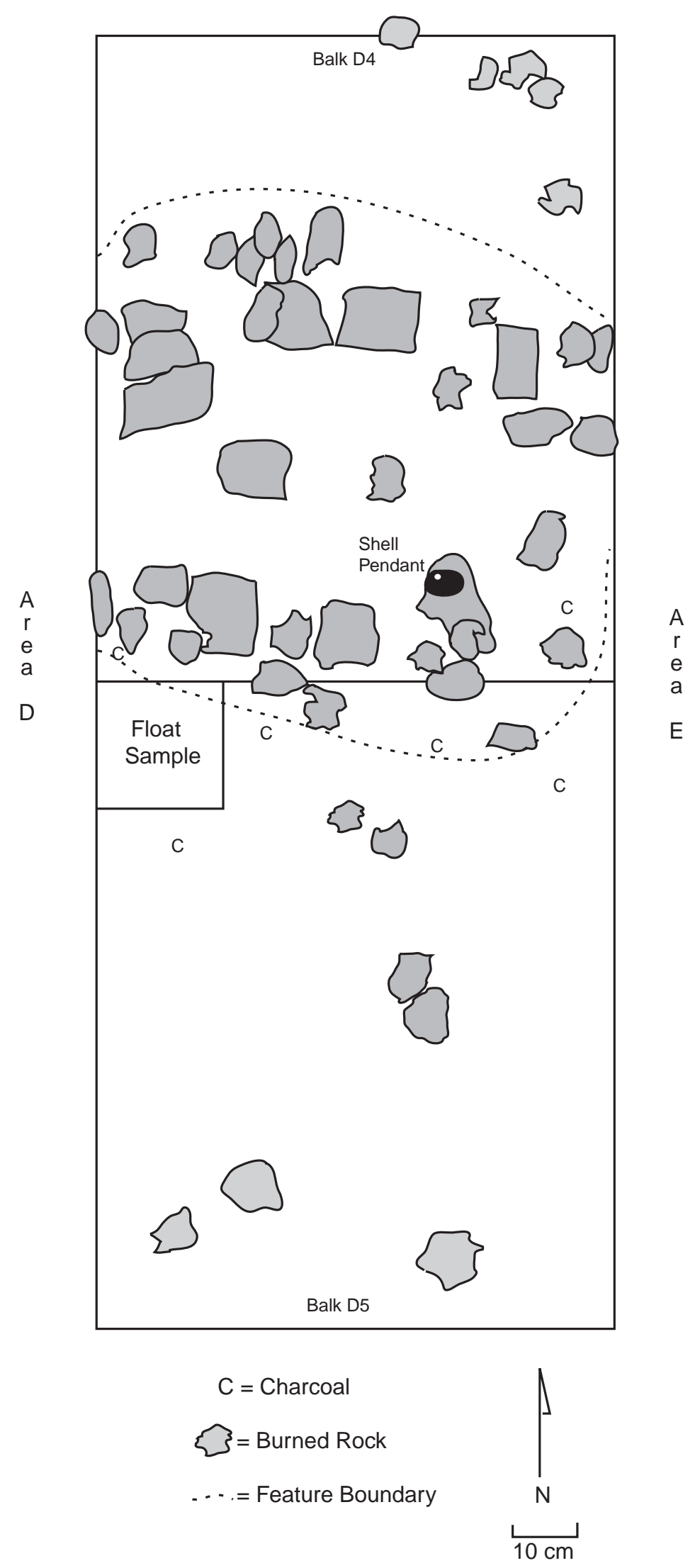

Figure 6.16 Plan View of Feature 35 Burned Rock Cluster. 
from seven to 153 pieces (Table 6.2). Feature 12 contained the greatest number (153 pieces) with an average rock weight of about $155 \mathrm{~g}$. Features 12 was dominated by pieces measuring between 0 and $4 \mathrm{~cm}$ in diameter, whereas Features 8 and 9 were dominated by pieces greater than $9 \mathrm{~cm}$. Rocks between 4 and $9 \mathrm{~cm}$ in diameter (Table 6.2) dominated Features 10, $11,13,15,19$, and 35 . The 214 burned rocks in these nine features that appeared to represent similar activities yielded an average rock weight of $255 \mathrm{~g}$. The burned rocks were nearly all sandstone with a few miscellaneous types and no chert or quartzite (Table 6.2). Since the latter two material types are available in the immediate region, it appears that sandstone was being selected for use.

Residues from burned rocks \#579 and \#586 out of Feature 10 were subjected to stable carbon and nitrogen isotope analyses and lipid analysis. The $\delta^{13} \mathrm{C}$ value of \#579 was -26.5\% (Appendix D) and indicates the presence of a $\mathrm{C} 3$ seed or nut. The $\delta^{15} \mathrm{~N}$ value from the same rock was $-1.0 \%$, which reflects a legume bean or nut. The lipid analysis indicated the residue was from plants (Appendix G), which supports the isotopic analyses. The $\delta^{13} \mathrm{C}$ value of $\# 586$ was $-21.8 \%$ (Appendix D) and could reflect a mixture of $\mathrm{C} 3$ and $\mathrm{C} 4 / \mathrm{CAM}$ plants or animals that ate these kinds of resources. The $\delta^{15} \mathrm{~N}$ value from the same rock was $4.1 \%$, which reflects a mixture of $\mathrm{C} 3$ and $\mathrm{C} 4 / \mathrm{CAM}$ resources. The lipid analysis reflects the presence of residues from large herbivore (Appendix G), which is one of the possibilities from the isotope data. The isotope and lipids from these two burned rocks indicate that at least two resources - plants (possible mesquite beans or nuts) and large herbivores (probably deer)—were thermally processed using these rocks.

From Feature 12, two burned rocks (\#1133 and $\# 1155)$ had internal residues extracted and analyzed. Burned rock \#1133 yielded $\delta^{13} \mathrm{C}$ values of $-20.6 \%$ that could be a mixture of $\mathrm{C} 3$ and $\mathrm{C} 4$ plant resources (Appendix D). The $\delta^{15} \mathrm{~N}$ value of $3.5 \%$ may also reflect a mixture of $\mathrm{C} 3$ and $\mathrm{C} 4$ resources. These same residues (sample Lino 3) had fatty acids that resemble the signature for large herbivore (Appendix G). The isotope results would indicate that the heated rocks were used to process a deer that had eaten various legume beans and/or possibly nuts. Burned rock \#1155 yielded $\delta^{13} \mathrm{C}$ values of $-21.9 \%$ that could reflect a mixture of $\mathrm{C} 3$ and $\mathrm{C} 4$ resources (Appendix D). The $\delta^{15} \mathrm{~N}$ value of $6.9 \%$ may also reflect a mixture of resources. The fatty acids from the same rocks (sample Lino 4) correspond to the pattern of a large herbivore (Appendix G). Again, the isotopic and lipid results would indicate the processing of a deer that had eaten various legume beans and/or possibly nuts. The burned rocks from Feature 12 appear to have been used to cook deer meat.

Feature 15 had one burned rock (\#914) sampled for lipids and isotopes. The $\delta^{13} \mathrm{C}$ isotope value of $-21.8 \%$ indicates a possible mixture of $\mathrm{C} 3$ and $\mathrm{C} 4$ resources (Appendix D). The $\delta^{15} \mathrm{~N}$ value of $7.5 \%$ may also reflect a mixture of resources. The residues from that same rock (\#914; Lino 4) had fatty acids that correspond to plants (Appendix G). Due to the inconsistent patterns between the isotope and lipid analyses, it is not clear what resources were cooked by this rock.

Two Feature 12 rocks and one rock each from Features 10 and 14 revealed only the presence of residues from large herbivores along with the supporting data from the isotopes studies. The results indicate that deer were most likely the resources processed in these burned rock features. In contrast, Features 10, 14, and 15 contained burned rocks that had plant residues, which appear to have included a mixture of C3 and $\mathrm{C} 4 / \mathrm{CAM}$ plants. This indicates that multiple kinds of resources were cooked by these rocks. 
Archaeomagnetic analysis using thermal demagnetization was conducted on one rock from each of Features 10 (\#575), 12 (\#1133), 14 (\#705), and 41 (\#5183). All four burned rock samples lose all or nearly all of their magnetic intensity at about 600 degrees $\mathrm{C}$. Three burned rocks (\#705, \#1133, and \#5183) exhibit two magnetic components upon thermal demagnetization, whereas rock \#575 exhibited three magnetic components (Appendix E). The magnetic vector components changed in rock $\# 705$ at about 400 degrees $C$, in rock \#1133 at about 150 degrees $C$, in rock \#5183 at about 200 degrees C, and in rock \#575 at 200 degrees C and at 450 degrees $C$ (Appendix E). The three rocks in Features 12, 41, and 10 may have all had a similar heating and cooling patterns. Although no definitive magnetic signature has been recognized by Dr. Gose, the magnetic data could be interpreted as reflecting stone boiling (Appendix E). Since recent replication of stone boiling experimental data using sandstone from the area has yielded the same two magnetic vector components (Takac 1999), it is the author's contention that stone boiling is the activity responsible for the magnetic patterns in Features 12, 14, and 10. The abrupt change in the magnetic components indicates that the rocks went through a heating episode and then were cooled very quickly when placed in water.

Floated matrix collected from around the burned rocks yielded similar types of cultural materials that included snail shell fragments, tiny chert flakes, burned rock crumbs, and an occasional unburned seed (Table 6.3).

Wood charcoal from Feature10 and identified as huisache yielded an $\delta^{13} \mathrm{C}$ adjusted AMS date of $2130 \pm 40$ B.P. (Beta-121729), and organic residues extracted from burned rock $\# 586 \mathrm{a}$ yielded an $\delta^{13} \mathrm{C}$ adjusted AMS date of $2120 \pm$ 40 B.P. (Beta-121729) (Table 5.3). These two dates established the age of this feature and the associated Occupation 1 material. The dates also provide data to evaluate the validity of organic residue dates from burned rocks. The extracted organic residues from a burned rock have yielded a statistically acceptable age for this feature from Occupation 1. The organic residue also provided a $\delta^{13} \mathrm{C}$ value of $-21.8 \%$ and a $\delta^{15} \mathrm{~N}$ value of $4.1 \%$ (Appendix D) that may represent a mixture of $\mathrm{C} 3$ and C4/CAM materials. The lipid analysis yielded evidence for the processing of a large herbivore (Appendix G).

Selected wood charcoal chunks from Features $10,12,13,14,15$, and 19 were identified as huisache, mesquite, acacia, hackberry, and mesquite root (Appendix B). The mesquite root could have been derived from a recent tree and thus was not considered to be cultural or originally associated with Occupation 1. A single wood fragment of the holly family, agarita (Berberis trifoliata), was from Feature 9 (Appendix B). Four fragments of Condalia wood were from Feature 12, as were modern seeds of bristlegrass (Setaria sp.) (Appendix B). An unburned poaceae (grass family) stalk/culm was in Feature 13. At least these species were used for fuel wood in these six features.

In general, these nine burned rock clusters are interpreted as the remains of burned rocks used in some type of cooking activities involving plants and/or large ungulates, probably deer. Following their cooking use, they were then discarded away from the primary use area. Feature 14, the rock filled basin, may have been the type of feature used to heat the rocks prior to their use in the cooking process. Since flat rock griddles or roasting type cooking pits were not identified within this $203 \mathrm{~m}^{2}$ area, then some other form of cooking apparatus was employed. It is postulated that most rocks were used in a stone boiling process in an above-ground hide/ basket apparatus since no pits were recognized that might have served as boiling features. Although it might be possible that Feature 14 could have served as a boiling pit because it was 
filled with rocks, the extensive charcoal on the one open side and under many of the rocks would imply that the pit was not lined with a hide full of water, which would have functioned as a primary boiling feature. The archaeological remains detected with the occupation surface are those of the primary rock heating apparatus (Feature 14) and the secondary or discarded scatters of burned rocks following their use in the stone boiling process.

Small matrix samples of sediments from Features 13, 14, 15, and 36 were submitted for diatom analysis. The matrix sample from Feature 36 came from directly under a mussel valve, which might have provided a better chance of preserving diatoms associated with the shells. No diatoms were present. Present, however, were five-micrometer size clusters of spheres that are too large for the one-micron or less spheres for bacteria associated with the breakdown of organic matter (Appendix I). A relatively substantial amount of what appeared to be ash was also present. The three matrix samples from Features 13, 14, and 15 were actually the decomposed interiors of burned sandstone. This form of analysis was an exploration into what kinds of substances might be detected under high-powered microscopic examination of sediments (Appendix I). No diatoms or other recognizable material were detected within these samples.

\subsection{CHIPPED LITHIC ASSEMBLAGE}

The lithic assemblage from the hand excavated balks $\left(40 \mathrm{~m}^{2}\right)$ and the hand-excavated units around the various features $\left(47 \mathrm{~m}^{2}\right)$ yielded 667 pieces of unmodified chipped stone debitage. This occupation yielded about eight pieces of lithic debitage per square meter. The raw material represented was all chert except for five pieces of grayish quartzite. All lithic debitage was probably derived from local gravel sources. Color differences exist in the cherts. In very general terms, most cherts are light and dark tans and grays, with some examples of brown, white, light blue with dark blue specks, and dark red hues.

The debitage was classified into five types. Three principal attributes were recorded per type (Table 6.4). Core (28 percent) and late stage biface (30 percent) flakes are dominant. Angular debris (three percent) and uniface flakes (two percent) are the least commonly represented types. In general terms, the represented flake types indicate some gross types of cobble reduction and tool maintenance strategies. Unifacial tools appear to have been resharpened but not to a great extent. Their low frequency may be misleading because small unifacial resharpening flakes may not have been recovered from the $6.4 \mathrm{~mm}$ screen. In one instance, in Unit 11-3 in Area B outside burned rock Feature 11, nine unifacial flakes from one tool were recovered. The tool was a dark brown chert with a light gray exterior cortex. These nine unifacial flakes appear to have been systematically removed during the production of a unifacial tool. No chipped stone tool with this specific color was recovered (see below). Biface and core reduction occurred quite frequently in comparison to other strategies. The slight percentage differences in the early and late stage biface reduction flakes suggest that both stages of tool manufacture were nearly equally undertaken.

The condition of the flake debris (complete or distal, medial, and proximal fragments) is relatively equally represented and ranges between 20 and 27 percent (Table 6.4). Angular debris is infrequent and represents three percent of the flakes. The higher frequency of complete pieces associated with core flakes may simply reflect stability from their greater thickness over that from biface reduction flakes. Experimental knapping has also documented that multidirectional core reduction yields fewer 
Table 6.4 Occupation 1 Lithic Debitage Analysis.

\begin{tabular}{|c|c|c|c|c|c|c|c|}
\hline \multirow[b]{2}{*}{ Condition } & \multicolumn{6}{|c|}{ Flake Type } & \multirow[b]{2}{*}{ Total } \\
\hline & $\begin{array}{c}\text { angular } \\
\text { debris }\end{array}$ & core & $\begin{array}{c}\text { early } \\
\text { biface }\end{array}$ & Indet. & $\begin{array}{c}\text { late } \\
\text { biface }\end{array}$ & uniface & \\
\hline \multirow[t]{2}{*}{ complete } & 1 & 67 & 20 & 20 & 54 & 11 & 173 \\
\hline & $6 \%$ & $35 \%$ & $22 \%$ & $13 \%$ & $27 \%$ & $85 \%$ & $26 \%$ \\
\hline \multirow[t]{2}{*}{ distal } & & 34 & 21 & 28 & 53 & & 136 \\
\hline & - & $18 \%$ & $11 \%$ & $15 \%$ & $28 \%$ & - & $20 \%$ \\
\hline \multirow{2}{*}{ fragment } & 17 & & & 11 & & & 28 \\
\hline & $94 \%$ & - & - & $7 \%$ & - & - & $4 \%$ \\
\hline \multirow[t]{2}{*}{ medial } & & 22 & 21 & 76 & 34 & & 153 \\
\hline & - & $12 \%$ & $23 \%$ & $50 \%$ & $17 \%$ & - & $23 \%$ \\
\hline \multirow[t]{2}{*}{ proximal } & & 67 & 28 & 18 & 62 & 2 & 177 \\
\hline & - & $35 \%$ & $31 \%$ & $12 \%$ & $31 \%$ & $15 \%$ & $27 \%$ \\
\hline \multirow{2}{*}{ Total } & 18 & 190 & 90 & 153 & 203 & 13 & 667 \\
\hline & 3\% & $28 \%$ & $13 \%$ & $23 \%$ & 30\% & $2 \%$ & $100 \%$ \\
\hline \multirow{4}{*}{$\frac{\text { Cortex }}{\text { primary }}$} & \multicolumn{6}{|c|}{ Flake Type } & \\
\hline & $\begin{array}{c}\text { angular } \\
\text { debris }\end{array}$ & core & $\begin{array}{c}\text { early } \\
\text { biface }\end{array}$ & Indet. & $\begin{array}{c}\text { late } \\
\text { biface }\end{array}$ & uniface & Total \\
\hline & & 7 & & 1 & & & 8 \\
\hline & - & $4 \%$ & - & $1 \%$ & - & - & $1 \%$ \\
\hline \multirow{2}{*}{ secondary } & 6 & 112 & 19 & 29 & 4 & 10 & 180 \\
\hline & $33 \%$ & $59 \%$ & $21 \%$ & $19 \%$ & $2 \%$ & $77 \%$ & $27 \%$ \\
\hline \multirow[t]{2}{*}{ tertiary } & 12 & 71 & 71 & 123 & 199 & 3 & 479 \\
\hline & $67 \%$ & $37 \%$ & $79 \%$ & $80 \%$ & $98 \%$ & $23 \%$ & $72 \%$ \\
\hline \multirow[t]{2}{*}{ Total } & 18 & 190 & 90 & 153 & 203 & 13 & 667 \\
\hline & 3\% & $28 \%$ & $13 \%$ & $23 \%$ & 30\% & $2 \%$ & $100 \%$ \\
\hline \multirow{4}{*}{$\begin{array}{c}\text { Heating } \\
\text { crazed }\end{array}$} & \multicolumn{6}{|c|}{ Flake Type } & \\
\hline & $\begin{array}{c}\text { angular } \\
\text { debris }\end{array}$ & core & $\begin{array}{c}\text { early } \\
\text { biface }\end{array}$ & Indet. & $\begin{array}{c}\text { late } \\
\text { biface }\end{array}$ & uniface & Total \\
\hline & & 9 & 2 & 6 & & & 17 \\
\hline & - & $50 \%$ & $11 \%$ & $33 \%$ & - & - & $3 \%$ \\
\hline \multirow[t]{2}{*}{ indeterminate } & 14 & 45 & 20 & 30 & 53 & 1 & 163 \\
\hline & $78 \%$ & $24 \%$ & $22 \%$ & $20 \%$ & $26 \%$ & $8 \%$ & $24 \%$ \\
\hline \multirow{2}{*}{ none } & 1 & 123 & 64 & 95 & 143 & 11 & 437 \\
\hline & $6 \%$ & $65 \%$ & $71 \%$ & $62 \%$ & $70 \%$ & $85 \%$ & $66 \%$ \\
\hline \multirow[t]{2}{*}{ spall } & 2 & 11 & 4 & 21 & 6 & 1 & 45 \\
\hline & $11 \%$ & $6 \%$ & $4 \%$ & $14 \%$ & $3 \%$ & $8 \%$ & $7 \%$ \\
\hline \multirow[t]{2}{*}{ treatment } & 1 & 2 & & 1 & 1 & & 5 \\
\hline & $6 \%$ & $1 \%$ & - & $1 \%$ & $0 \%$ & - & $1 \%$ \\
\hline Total & $\begin{array}{r}18 \\
3 \%\end{array}$ & $\begin{array}{r}190 \\
28 \%\end{array}$ & $\begin{array}{c}90 \\
13 \%\end{array}$ & $\begin{array}{r}153 \\
23 \%\end{array}$ & $\begin{array}{r}203 \\
30 \%\end{array}$ & $\begin{array}{r}13 \\
2 \%\end{array}$ & $\begin{array}{c}667 \\
100 \%\end{array}$ \\
\hline
\end{tabular}

broken flakes (Tomka and Fields 1990). The high frequency of uniface resharpening flakes reflects the care and control needed to shape and manufacture tools using that particular process.

Cortex remains on about 28 percent of the debitage. The majority of cortical pieces are from core reduction flakes that exhibit partial cortex (Table 6.4). Pieces with one surface nearly covered in cortex are quite infrequent. Cortex-covered cobbles appear to have been the parent nodule commonly used at this site for reduction. Apparently, some early stage bifaces retained some cortex, whereas late stage biface had very minimal cortex. Many unifacial tools retained a considerable amount of cortex, which suggests that the prehistoric people selected large decortification flakes for the manufacture of unifacial tools. The angular debris with cortex comprise about 33 percent of this flake class; thus these pieces are more likely to have been derived from core or early biface reduction processes.

Heat alterations (crazing and spalls) were recognized on 10 percent of the debris (Table 6.4). Nearly 73 percent of the heat altered pieces are represented by heat spalls. These probably resulted from the accidental or incidental exposure to direct fires. Less than one percent of the pieces appeared to have been heat-treated to improve knappability. Heat treating was not regarded as a standard practice used by these occupants.

\subsection{CHIPPED STONE TOOLS}

The recognized chipped-stone tool assemblage was classified into five form/functional classes. These consist of three projectile points, four bifaces, one drill, 10 scrapers, and 21 edgemodified tools (Figure 6.17). As a group, these 39 tools account for about 0.8 percent of the total material recovered from Occupation 1 encompassed by excavations of an $87 \mathrm{~m}^{2}$ area.

The three projectile points were base portions of chert Tortugas points (Table 6.5, Figure 6.17). The midsection breaks could not be identified. The metric measurements reveal some size differences with \#3733 being quite long. Specimen \#3733 was manufactured from a dark gray chert with much white mottling. Point base \#3733 has a straight basal edge, but the corners are slightly rounded with one face having flake scars on the basal edge parallel to the long axis. This specimen differs from most other Tortugas points in that it is not well thinned, the basal corners are rounded, and the length is proportionately longer than the width. A second 


\begin{tabular}{|c|c|c|c|c|c|c|c|c|c|c|c|c|c|c|c|c|c|c|c|c|c|c|c|}
\hline \multirow[b]{2}{*}{ Cat. \# } & \multirow[b]{2}{*}{ Unit } & \multirow[b]{2}{*}{$\mathrm{F} \#$} & \multirow[b]{2}{*}{ Lvl } & \multirow[b]{2}{*}{ Depth } & \multirow[b]{2}{*}{$\mathrm{N}$} & \multirow[b]{2}{*}{$E$} & \multirow[b]{2}{*}{ Elev } & \multirow[b]{2}{*}{ Pt/Tool } & \multirow[b]{2}{*}{ Brk } & \multirow[b]{2}{*}{ Con. } & \multirow[b]{2}{*}{ Sh } & \multirow[b]{2}{*}{ Stg } & \multirow[b]{2}{*}{ Cort. } & \multicolumn{3}{|c|}{ Color } & \multirow[b]{2}{*}{$\begin{array}{l}\text { Bas } \\
\text { Edg }\end{array}$} & \multirow[b]{2}{*}{$\begin{array}{l}\text { Bas } \\
\text { Thin }\end{array}$} & \multirow[b]{2}{*}{ Bvl } & \multicolumn{3}{|c|}{ Size $(\mathrm{mm})$} & \multirow[b]{2}{*}{ Wt $(g)$} \\
\hline & & & & & & & & & & & & & & Mat'l & SW & LW & & & & L & W & Th & \\
\hline 3437 & A2 & & 3 & $20-30$ & & & & $T$ & Uk & $P$ & & & & $\mathrm{Br} / \mathrm{Gry}$ & Or & Or & $C x$ & $P$ & $\mathrm{~N}$ & & 37.7 & 11.7 & 19.5 \\
\hline 3733 & $\mathrm{~B} 1$ & & 4 & & & & & $\mathrm{~T}$ & & $P$ & & & & $\begin{array}{c}\text { Spk Dk. } \\
\text { Gry }\end{array}$ & $\begin{array}{l}\text { Dk. } \\
\text { Or }\end{array}$ & Dk. Red & $C x$ & $P$ & $\mathrm{~N}$ & & 29.9 & 9.1 & 18.0 \\
\hline 3783 & $\mathrm{C} 2$ & & 3 & $20-30$ & & & & T & Uk & $P$ & & & & $\begin{array}{l}\text { Red/ } \\
\text { Pink }\end{array}$ & Prp & Prp & Cc & $P$ & $\mathrm{~N}$ & & 33.5 & 8.0 & 110.1 \\
\hline $5539-3^{*}$ & $\mathrm{~F} 1$ & & 4 & $30-40$ & & & & & & & & & & & & & & & & & & & \\
\hline $5469-5$ & E2 & & 3 & $20-30$ & & & & B & $\mathrm{M}$ & $P$ & $\mathrm{~L}$ & $L$ & & & Or & Or & & & & & 25.0 & 6.7 & 5.3 \\
\hline 840 & & & & & 108.598 & 118.444 & 99.651 & B & Uk & $P$ & 0 & $\mathrm{~L}$ & & & Or & Or & & & & & 40.0 & 11.9 & 25.6 \\
\hline $5229-5$ & B4 & & 4 & $30-40$ & & & & B & Uk & D & $\mathrm{T}$ & $\mathrm{L}$ & & & & & & & & & & 6.4 & 1.5 \\
\hline $5216-5$ & B3 & & 3 & $20-30$ & & & & B & Us & $P$ & 0 & M & & & Or & Yw/Or & & & & & & 9.9 & 7.2 \\
\hline $5329-1$ & G5 & & 3 & $20-30$ & & & & D & & C & $\mathrm{T}$ & L & & & Or & Or & & & & 40.8 & 18.0 & 6.1 & 3.3 \\
\hline
\end{tabular}

Pt/Tool: B=biface, $D=$ drill, $T=$ Tortugas

Brk: M=manufacture, Us=use, Uk=unknown

Condition (Con.): $C=$ complete, $P=$ proximal, $M=$ medial, $D=$ distal

Shape (Sh), Basal Edge (Bas Edge), \& Basal Thinning (Bas Thin): P=Parallel, Sn=sinuous, St=straight, Cc=concave, Cx=convex, L=lanceolate, $\mathrm{O}=0 \mathrm{val}, \mathrm{R}=\mathrm{rectangular}, \mathrm{T}=\mathrm{trian}$ gular, l=irregular, Ot=other

Man. Stage (Stg): L=late, M=middle

Cortex (Cort.): $P=$ primary, $S=$ secondary, T=tertiary

Color: Or=orange, $\mathrm{Y}_{W}=y e$ ellow, $\mathrm{Prp}=$ purple, $\mathrm{Spk}=$ speckled, $\mathrm{Br}=$ brown, Gry=Gray; $\mathrm{SW}=$ short wave $\& \mathrm{LW}=$ long wave

Bevel (Bv): $N=$ none

$\mathrm{L}=$ length, $\mathrm{W}=$ width, $\mathrm{Th}=$ thickness, $\mathrm{Wt}=$ weight

Note: All catalogue numbers from hand excavated proveniences have been formed by adding a dash and appear in the database with leading zeros. These leading zeros have been omitted to conserve space. 

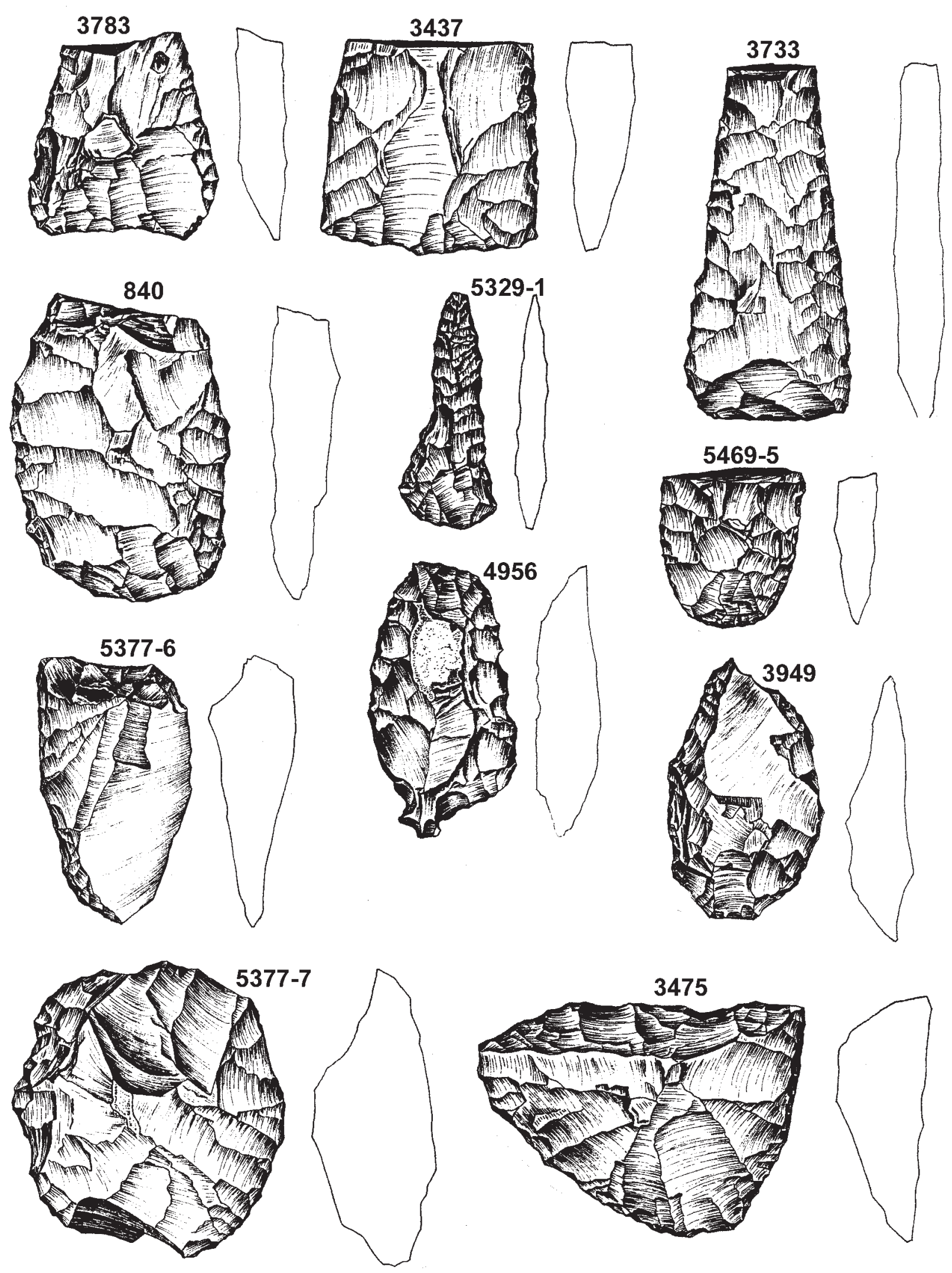

Figure 6.17 (Part 1) Selected Stone Tools from Occupation 1 (Actual Size). $\frac{0}{\mathrm{~cm}-3}$ 

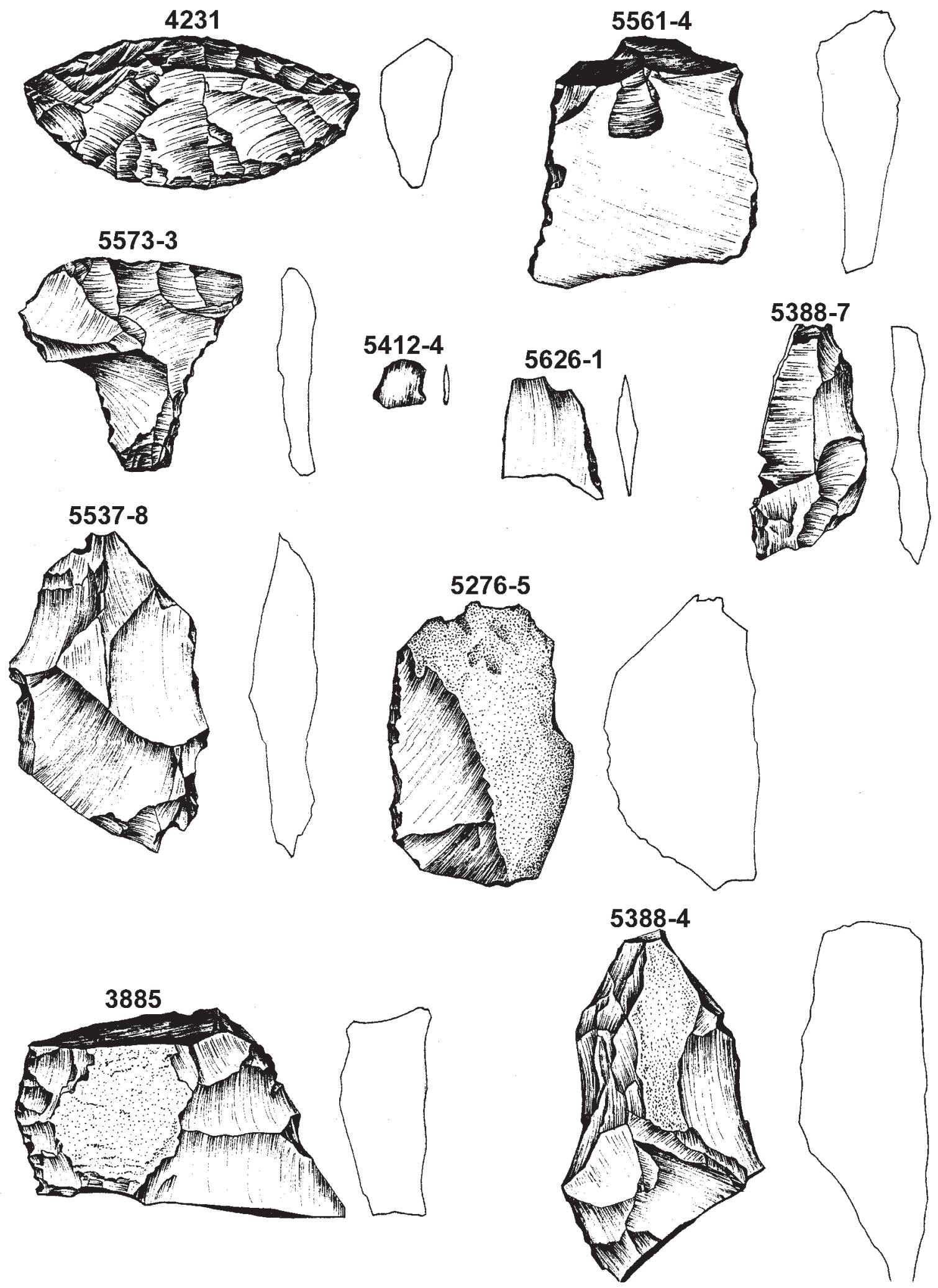

Figure 6.17 (Part 2) Selected Stone Tools from Occupation 1 (Actual Size). $\frac{0}{\mathrm{~cm}}-3$ 
base (\#3437) is quite broad and thick, but the overall shape and basal modifications appear identical to the smaller Tortugas points.

The four bifaces included three proximal ends and one distal end fragment. One proximal end had a use break and appeared to have failed during the middle stage of manufacture. The other three are in the late stage of reduction into various shapes (Table 6.6). One lanceolate piece was broken during manufacturing (\#5469-5). The complete chert drill (\#5329) has an elongated triangular outline with a slightly constricted neck near the middle and only a slightly expanded base that lacks hafting modifications (Figure 6.17). The flake scars along the bit are parallel to each other at an oblique angle to the lateral edge. Tiny hinge scars are nearly absent along either lateral edge.

The 10 scrapers consist of three side scrapers, four end scrapers, two Nueces tools, and one Clear Fork tool (\#3475). The Clear Fork tool was manufactured from a very light-gray, coarsegrained chert. It has an asymmetrical triangular outline with the dorsal surface completely worked but only one or two flake scars on the ventral surface (Figure 6.17). The lateral edges had tiny hinge scars whereas the distal working end has tiny hinges along the very margin. The thick working edge angle is quite steep at 62 degrees (Table 6.6).

One Nueces tool (\#3949) was made from a mottled gray chert. It exhibits an oval outline with a partial break on one end. The ventral surface is flat with a couple of flake scars along the margins whereas the dorsal surface is slightly domed with one long edge containing most of the flake scars (Figure 6.17). The $9.7 \mathrm{~mm}$ thick working edge appears crushed as indicated by the presence of many tiny hinge fractures concentrated along about a $30 \mathrm{~mm}$ long section. The other Nueces tool (\#4231) was manufactured on a light gray chert with darker mottles. It has a crescent outline with a flat ventral surface and small flake scars along the thin margin. The dorsal surface is completed modified, with the one working edge having a 64 degree edge angle that is opposite a tapered edge (Figure 6.17). Numerous tiny hinge fractures are all along the working edge, which is about $7.3 \mathrm{~mm}$ thick.

Scraper \#4956 was manufactured from a light gray-striped chert. It has an oval outline with a relatively flat ventral surface and flake scars along the non-scraping edge. The dorsal surface is dome shaped with both lateral edges worked, although cortex remains on one spot near the middle (Figure 6.17). One broken end appears to have been altered through heat spalling. One lateral edge exhibits many tiny hinge scars along a 62 degree edge angle. The opposite edge is about 57 degrees but lacks the tiny hinge fractures. This tool may be classified as a side scraper.

Side scraper \#5377-6 was a complete flake from a very fine-grained, light-gray chert. The thick platform is still present with some crystal pockets present on the dorsal surface. The contracting lateral edges taper to a point, with an arris present. The right lateral edge is flaked with many tiny hinge scars along the very margin (Figure 6.17). The left lateral edge is unworked. The ventral surface is flat and unmodified except for the extensive margin of the left lateral edge and distal end.

Scraper \#5377-7 is somewhat unusual because it is circular in outline and bifacially worked (Figure 6.17). It exhibits one large flake scar across one-third of the ventral surface that is similar to a bit facet on a Guadalupe biface. Its point of origin is uncertain because it lacks a bulb of percussion and other knapping attributes. On the dorsal surface, opposite this broad, deep flake scar, is an intentionally retouched edge with tiny flakes and hinge scars along the very margin 


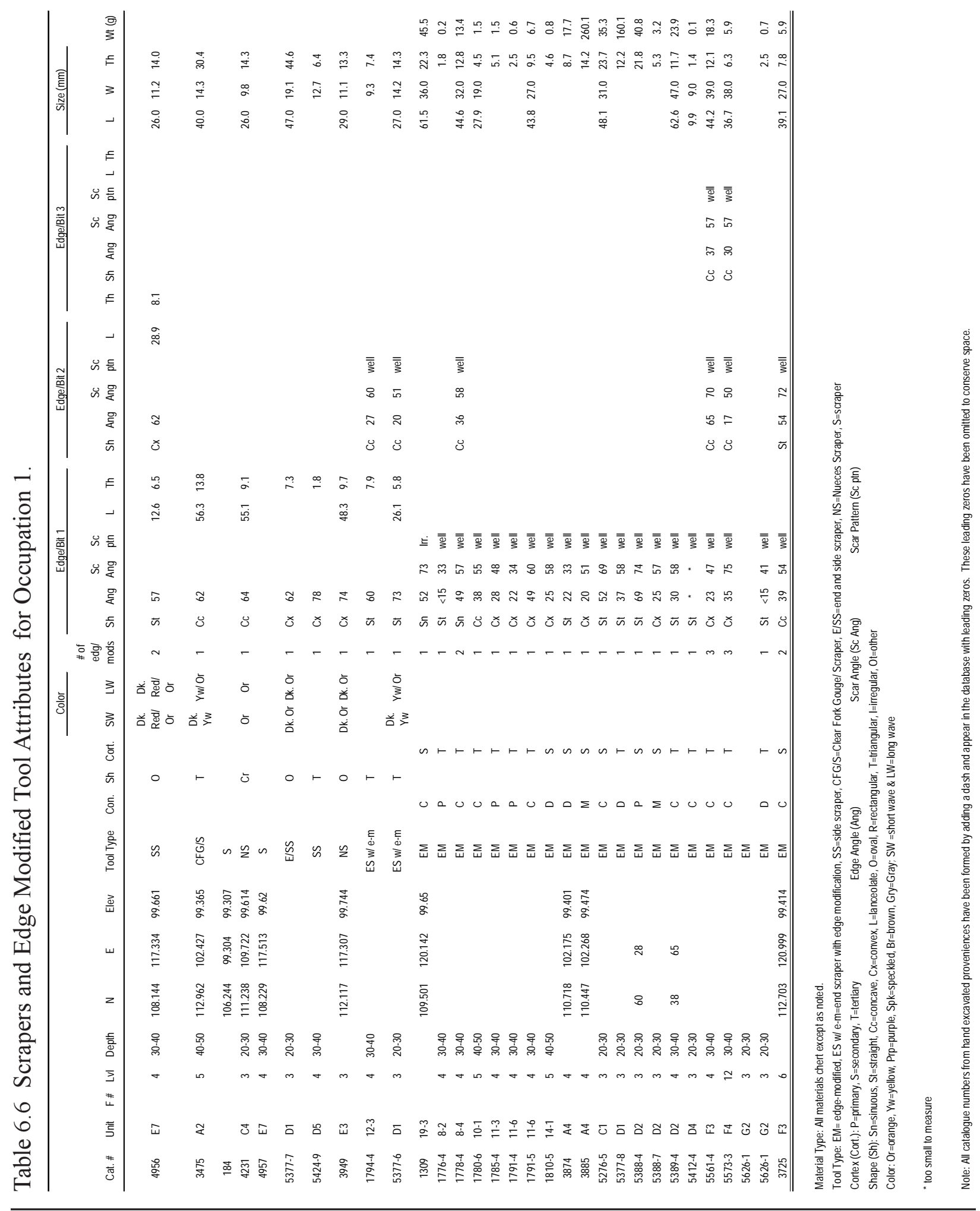


that represents the scraping edge. Although not as elongated as a Guadalupe biface, this tool may have functioned much the same as one.

The 20 edge-modified pieces are all chert and show considerable variation in form and size (Table 6.6, Figure 6.17). Half are complete, and the others consist of parts of flakes. All but one have well-patterned use scars, which are most often associated with scraping tasks. The shape of the working edges is quite variable. Forty percent exhibit convex edges and 40 percent have straight edges. Four pieces have more than one modified edge (Table 6.6). Specimen \#3885 is the medial section of a thick secondary flake with one lateral edge having steep retouch and tiny hinge fractures that could permit classification as a side scraper (Figure 6.17). Specimen \#5412-4 is a tiny chert heat spall with one edge of the flat dorsal surface containing four or five tiny scars along a slightly convex edge. How this small worked edge would have functioned is unknown. The well-patterned and relatively steep scar angles indicate that most of these edge-modified flakes were employed in some form of scraping activity.

The high-powered microwear analyses on two Tortugas points (\#3733, \#3783), a drill (\#53291), two scrapers (\#4231, 3949), and seven edgemodified flakes (\#3885, 5276-5, 5377-8, 53887, 5412-4, 5561-4, 5573-3) revealed minimal overall use-wear on these tools. Only two edgemodified tools (\#5276-5 and \#5388-7) had usewear, and both relate to scraping (the latter tool on dry hide). Specimen \#5276-5 exhibited a well-rounded edge with weak polish, which generally occurs with hide working.

\subsection{GROUND STONE TOOLS}

The recognized ground-stone tool assemblage consisted of five abraders and one mano. All abraders were made of sandstone; the mano is a coarse-grained igneous rock similar to a gabbro.
The fragmented mano is a rectangular midsection with one questionable worked surface. It has a trapezoid cross section with possible use on the slightly convex and largest side (Figure 6.18). The use surface has a few scattered pits similar to peck marks made to refurbish the grinding surface along with a small fractured scar on one edge. It is a pinkish-gray color with the color possibly resulting from exposure to heat. This may have also been used as a cooking rock or gone through some other heating process. Metric attributes are presented in Table 6.7.

The four sandstone abraders have two to four grooves across one relatively flat surface (Figure 6.18 ). These pieces varied in overall shape. The individual pieces range from 74 to $123 \mathrm{~mm}$ long and are between 31 and $48 \mathrm{~mm}$ thick. Of the 12 grooves present on the four stones, eight are " $U$ " shaped and two are "V" shaped. Groove lengths varied from 28.9 to $89.6 \mathrm{~mm}$, widths varied from 2.0 to $11.9 \mathrm{~mm}$, and the depths varied from 0.8 to $4.4 \mathrm{~mm}$.

Abrader \#3717 (specimen Lino 49) had residues extracted from its interior that were quite close to mesquite beans and prickly pear (Appendix G). This residue may have been from the subsequent use of this sandstone piece as a burned rock and not specifically from its use as an abrader.

Abrader \#300 is quite large, measuring about $12 \mathrm{~cm}$ long, and has a light calcium carbon layer over the entire specimen (Figure 6.19). One irregular surface has three grooves that are generally orientated parallel to each other but are different in shape and size. The largest and most pronounced groove (measuring $89.6 \mathrm{~mm}$ long, $11.9 \mathrm{~mm}$ wide, $4.4 \mathrm{~mm}$ deep) is " $U$ " shaped and goes across the entire surface. A second groove is narrow and "V" shaped (54.6 mm long, $5.5 \mathrm{~mm}$ wide, and $2.6 \mathrm{~mm}$ deep) (Table 6.7). 


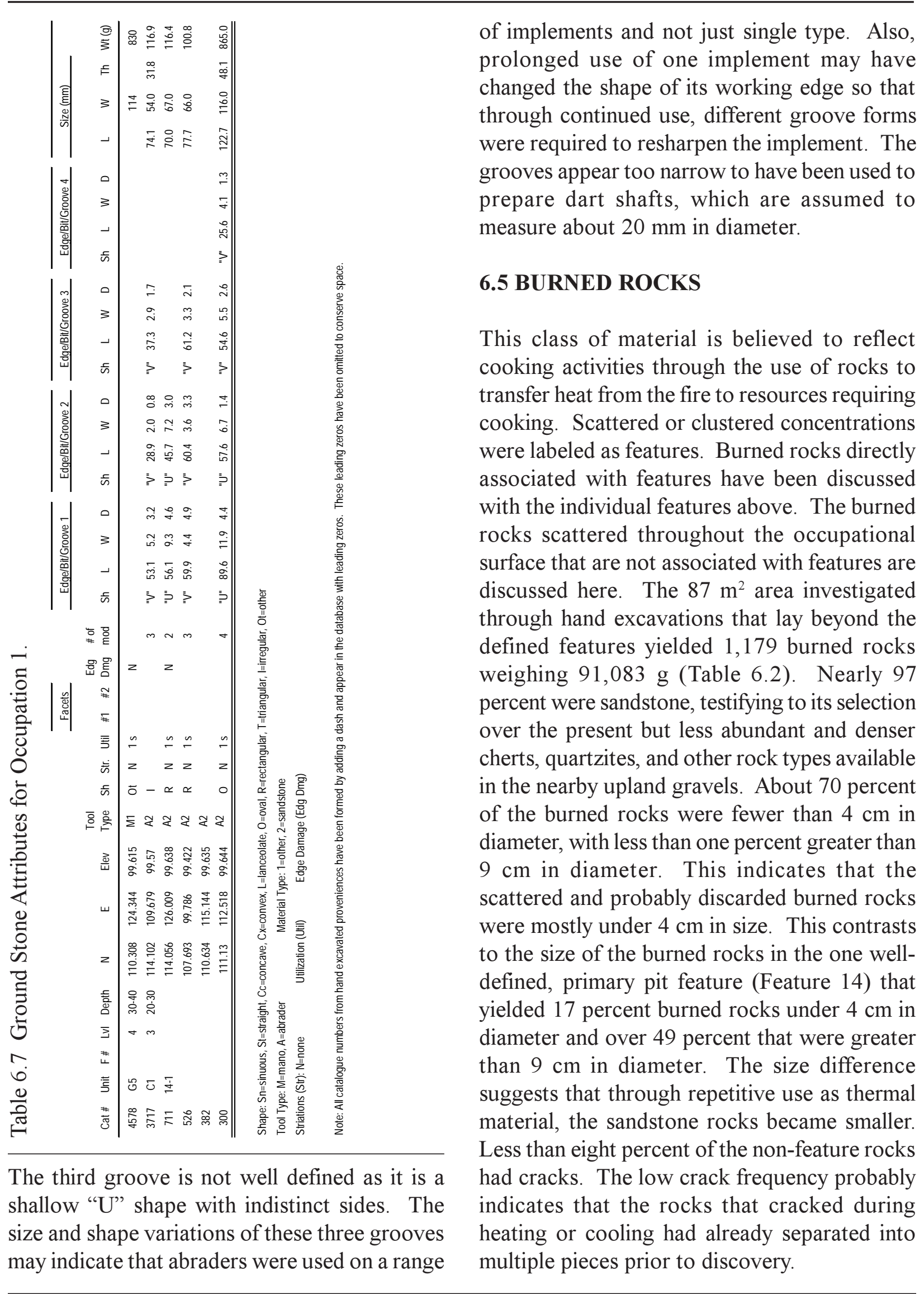



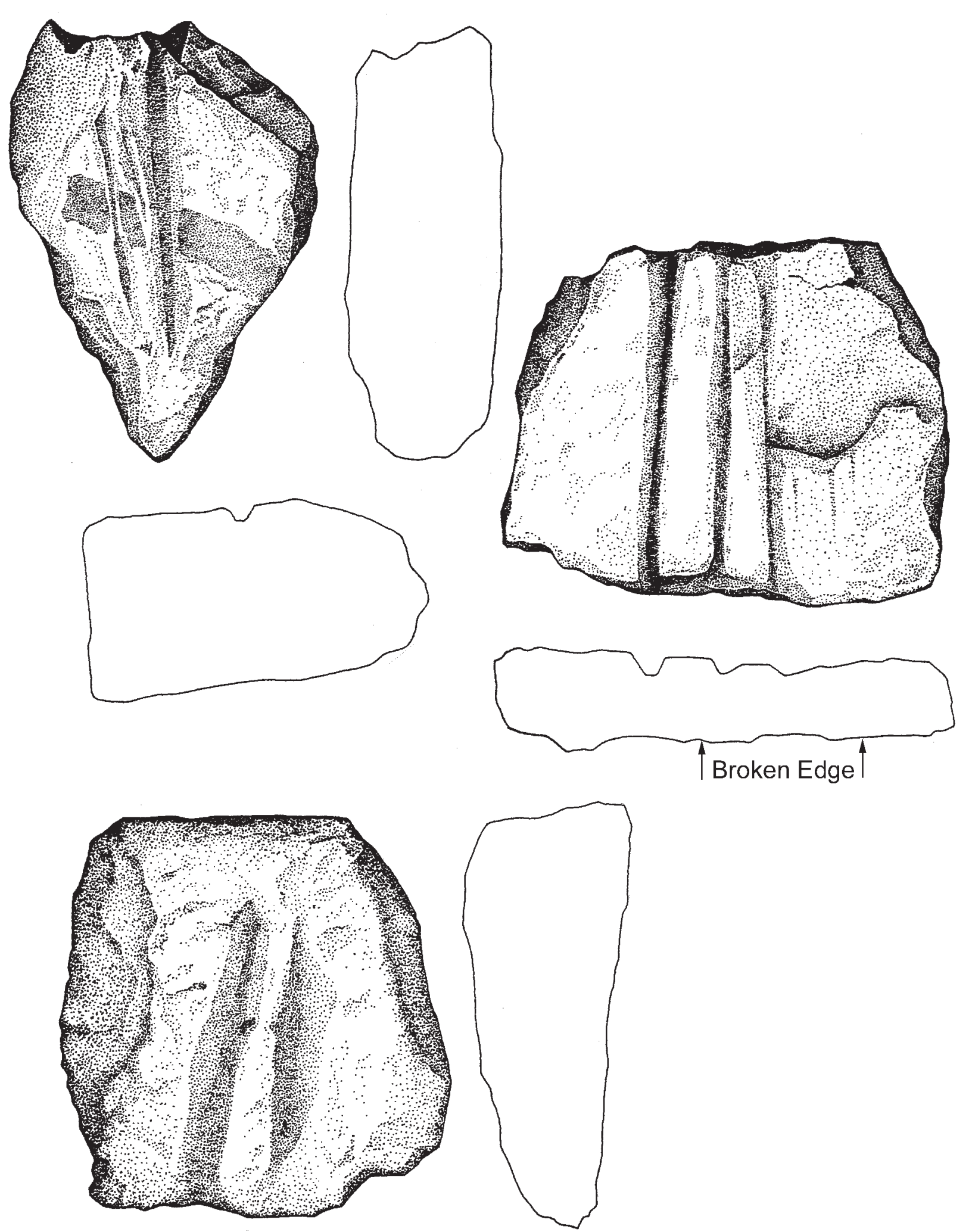

Figure 6.18 Ground Stone Tools from Occupation 1 (Actual Size).

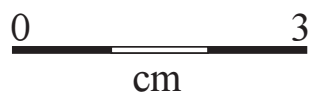




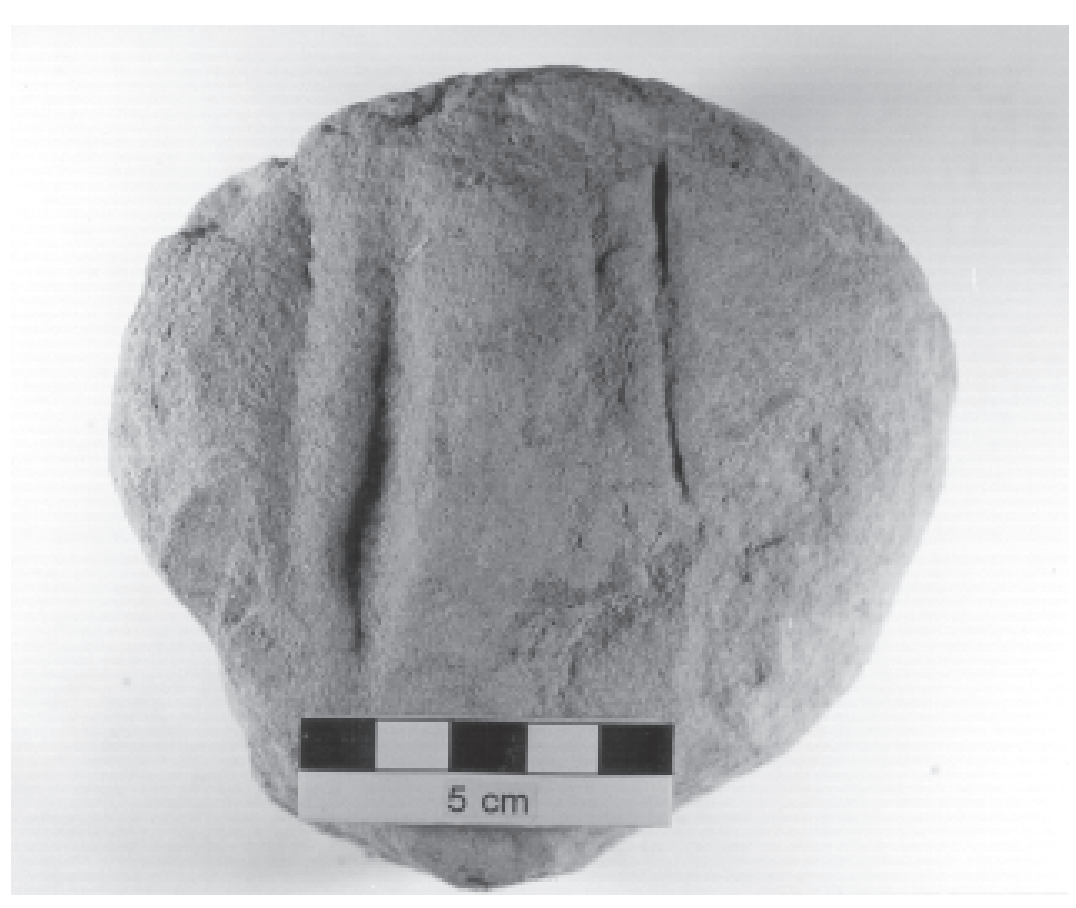

Figure 6.19 Sandstone Abrader \#300 from Occupation 1 (Actual Size).

The burned rocks from the 11 identified features (262 pieces weighing 84,558 $\mathrm{g}$ for an average weight of $322 \mathrm{~g}$ ) coupled with those scattered across the hand excavated area in Occupation 1 total 1,441 pieces weighing 175,641 g (Table 6.2). This represents nearly 44 pieces per square meter from hand excavated units. Each piece weighed an average of $122 \mathrm{~g}$.

\subsection{MUSSEL SHELLS}

Features 36 and 41 were labeled as mussel shell dumps and are discussed above. Both features contained only a single species of mussels, Cyrtonaias sp. About 27 valves and valve fragments were scattered over the rest of the block providing a low density of about one shell for every $4 \mathrm{~m}^{2}$. It is the scattered mussels shells that are discussed here. Valves varied from 100 percent complete to about 20 percent complete, with the latter mostly representing unidentifiable fragments. Species identified as isolated valves include eight Cyrtonaias sp., one Potamilus purpuratus, and 18 unidentifiable fragments.
Left and right halves are roughly equally represented.

Including shell Features 36 and 41, with 14 valves each, the total for Occupation 1 is 55 valves. Cyrtonaias sp. accounts for nearly all the identifiable pieces.

\subsection{RABDOTUS SHELLS}

Four shells from Unit D1 between 20 and 30 cmbs and four shells from Unit A5 between 30 and $40 \mathrm{cmbs}$ - all believed to be part of Occupation 1 -were selected for A/I ratio analysis. These eight shells from the upper component yielded A/I ratios between 0.096 and 0.154 (Appendix F). When the $\mathrm{A} / \mathrm{I}$ ratios that form the upper component (20 to $40 \mathrm{cmbs}$ ) are combined with eight other $\mathrm{A} / \mathrm{I}$ ratios from 110 to $120 \mathrm{cmbs}$, they form two clusters from snail ratios (Figure 6.20).

One shell from each of the two clusters was selected for AMS dating. Both shells were from 


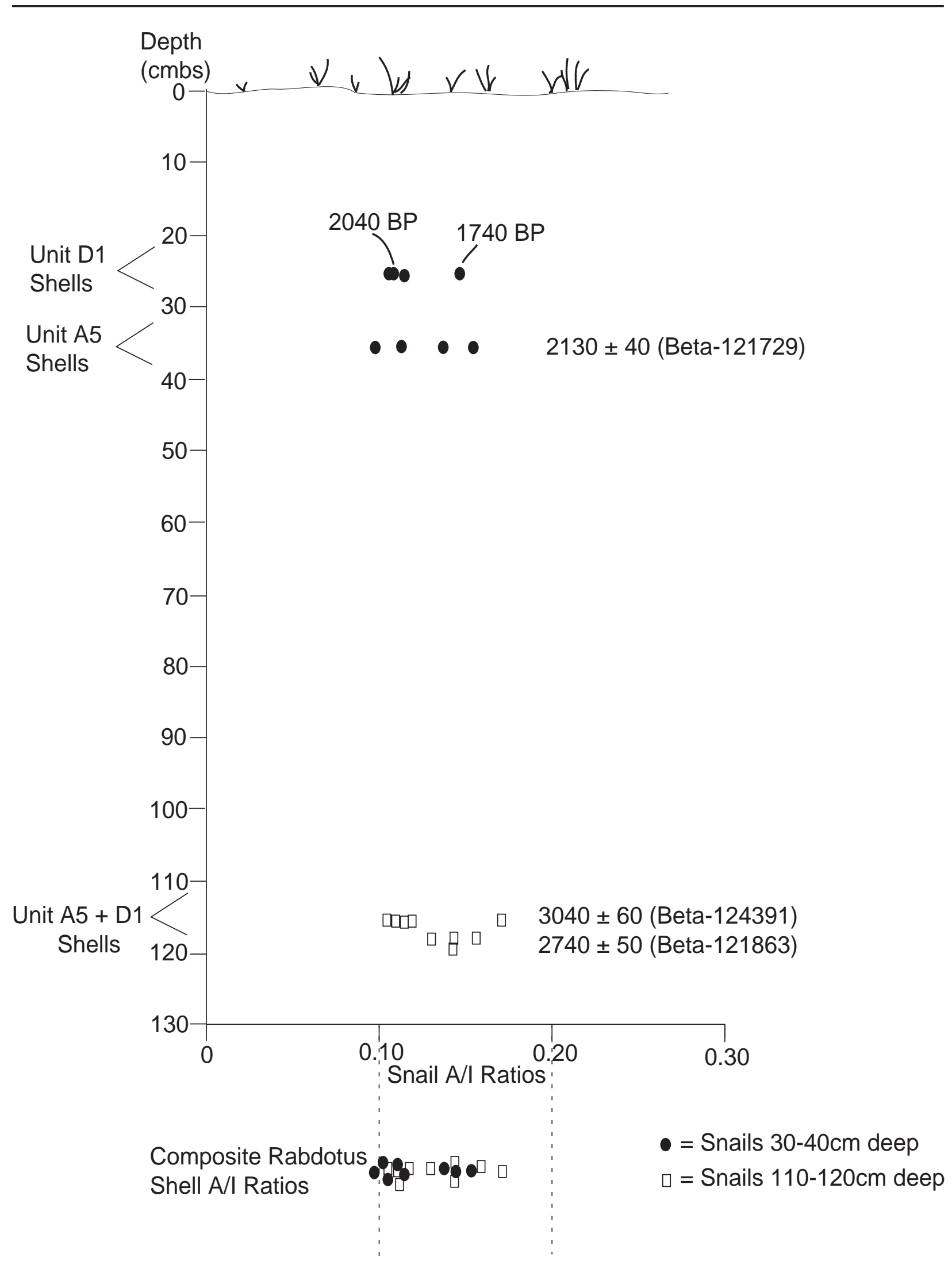

Figure 6.20 Rabdotus Shell A/I Ratios and Vertical Proveniences. 
Unit D1 between 20 and $30 \mathrm{cmbs}$ and had A/I ratios of 0.106 and 0.144 . The shell with the smaller ratio $(0.106)$ yielded a $\delta^{13} \mathrm{C}$ adjusted (2.3\%) age of $2040 \pm 50$ B.P. (Beta-122719) (Table 5.3). The shell with the larger ratio of 0.144 yielded a $\delta^{13} \mathrm{C}$ adjusted $(-1.1 \%$ ) age of $1740 \pm 40$ B.P. (Beta-122719). Since the $C^{12} /$ $\mathrm{C}^{13}$ ratio of $-1.1 \%$ is unexpectedly low, the younger date on the shell with the larger ratio of 0.144 is not acceptable. The date of 2040 B.P. appears to be in line with the three charcoal dates that average about 2050 B.P. from three features from Occupation 1. This latter shell date is acceptable.

The three shells that are part of the older cluster of shells based on their $\mathrm{A} / \mathrm{I}$ ratios are thought to be displaced from lower deposits in the profile. These snails were apparently displaced upward through rodent or other turbation activity. Turbation was observed throughout the vertical profiles. The A/I ratios suggest that these snail shells were vertically displaced upward by some $80 \mathrm{~cm}$.

\subsection{CHARCOAL}

Some 68 wood charcoal chunks weighing about 2,598.2 g were recovered outside features and float samples. Features 8, 10, 11, and 19 all yielded only traces of charcoal flecking in the floated matrix, with Features 12, 14, and 15 yielding charcoal weighing $1.5 \mathrm{~g}, 4.0 \mathrm{~g}$, and 4.1 $\mathrm{g}$ respectively. One $12 \mathrm{~cm}$ long wood charcoal chunk (\#662) that weighs in excess of $300 \mathrm{~g}$ was recovered outside Feature 14 and identified as huisache (Appendix B).

From the abundant charcoal chunks recovered from Occupation 1, 11 chunks were selected for wood identification. The results are presented in Appendix B. Species identified include mesquite, huisache, acacia, hackberry, and some pieces of indeterminate species. These four different species represent fuel wood used for fires. One sample (\#1811-5a) from Feature 14 and one (\#1839-4a) from Feature 19 were identified as mesquite root and therefore were not considered cultural and not dated. One hackberry sample (\#1847-1a) from Feature 14 yielded an acceptable AMS radiocarbon date of $1950 \pm 50$ B.P. (Beta-121730).

\subsection{OTHER MATERIALS}

Most of a mussel shell pendant was found in Unit D4, between 30 and $40 \mathrm{cmbs}$. Since the distal edge is broken, the original length is unknown. It measures $43 \mathrm{~mm}$ wide and about 3 $\mathrm{mm}$ thick with the outer shell mostly present on one surface and a shiny inner surface on the other side. The interior surface has an area of about $15 \mathrm{~mm}$ long by $11 \mathrm{~mm}$ wide that contains what appear to be multiple tiny scratches (Figure 6.21). Also near the edge, on a high linear ridge, the white shiny shell has been worn away, revealing a linear section of the cream-colored inner shell. The intact lateral edges are decorated by a series of incisions/notches orientated perpendicular to the edge and spaced between 2.6 and $6 \mathrm{~mm}$ apart. The incisions are visible on both sides and are "V" shaped. The edge had been rounded prior to the placement of the notches. A $4 \mathrm{~mm}$ diameter drilled hole is present $3 \mathrm{~mm}$ from the proximal edge. The hole was drilled from both sides, as indicated by a slight ridge near the center of the hole.

A small, smoothed, natural chert pebble came from Units A7 between 30 to $40 \mathrm{cmbs}$. It was oval, measured about 39.01 by $26.3 \mathrm{~mm}$, and weighed $43.2 \mathrm{~g}$. No peck or scratch marks were observed. It is unclear how this natural pebble was deposited, but it appears too large for low energy overbank deposits to have transported it.

\subsection{HORIZONTAL DISTRIBUTION}

Occupation 1 yielded moderate to high quantities of burned rocks $\left(37 / \mathrm{m}^{2}\right)$ outside the identified 


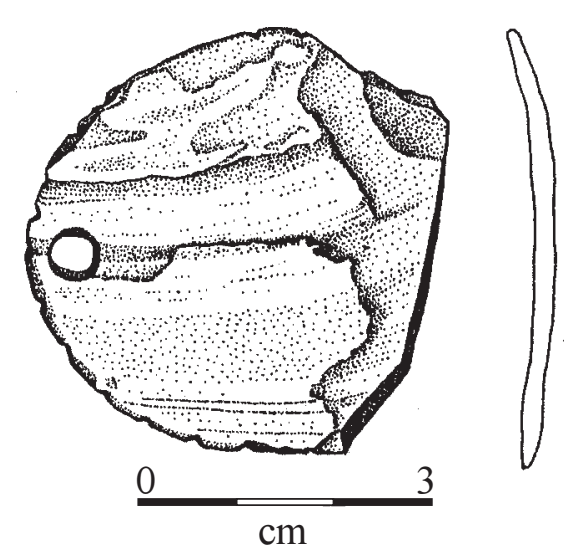

Figure 6.21 Mussel Shell Pendant from Occupation 1 (Actual Size).

features, limited frequencies of lithic debitage $\left(8 / \mathrm{m}^{2}\right)$, extremely low frequencies of mussel shells $\left(0.6 / \mathrm{m}^{2}\right)$, and a low frequency of stone tools $\left(0.5 / \mathrm{m}^{2}\right)$, for an overall material density of 53 items $/ \mathrm{m}^{2}$. Cultural materials were nonrandomly distributed across the entire excavation block and appeared to continue beyond the block margins in all directions (Figure 6.22). The cultural deposits dipped towards the west and less so to the north.

High, moderate, and low frequencies of artifacts were identified from the hand excavation units across the block (Figure 6.22). The highest concentrations were widely scattered across 24 units that clustered in 1 to $4 \mathrm{~m}^{2}$ areas. Some 34 units yielded moderate burned rock frequencies, and these were generally distributed adjacent to the high-density units. An area at the north end of Balks B, E, and F yielded relatively sparse quantities of burned rocks. This burned rock patterning implies specific activity and/or use areas over a more homogenous scatter. This nonrandom distribution probably reflects some behavioral consequence.

The 667 pieces of lithic debitage were also nonrandomly distributed across the block but in less obvious patterns (Figure 6.22). Only seven units (eight percent) yielded high concentration and another 16 units (18 percent) yielded moderate frequencies. These relatively highly concentrated frequencies were generally clustered towards the northern half of the block, specifically in Balks B, C, and D. In three or four instances the concentrations were about 1 $\mathrm{m}$ from a burned rock feature. For example, Unit 11-3, immediately north of burned rock Feature 11, yielded a high lithic debitage frequency of 42 pieces, which represented at least five different parent materials along with a moderate frequency of burned rocks $(n=30)$. The lithic debitage included nine unifacial flakes from the same dark gray unifacial tool. Sufficient evidence is not available to state confidently that this is a primary or in situ knapping location but it may be. However, the association of these two classes of material, burned rocks and lithic debitage, along with multiple chert flakes representing different reduction stages of different tools, may indicate that the pieces of lithic debris may not be in their primary use locations. This general but complex association may indicate that some lithic debris was also thrown away near the discarded burned rocks. It indicates that this specific area was used for discarding unwanted materials.

Based on material-type observations and stage of manufacturing represented by these different materials, one gets the impression that there were areas representing specific activities. Even though nine unifacial-resharpening flakes from one tool may be from the same unit it does not necessarily mean that tool was resharpened in that spot. Based on the association with numerous burned rocks or other types of data, the similar flakes may represent the place that they were dumped/discarded. Material types could provide some clues that certain tools were either manufactured or resharpened on site and that the tool was curated. This appears to be what often happened, although specific material types were not a recorded attribute in all cases. 


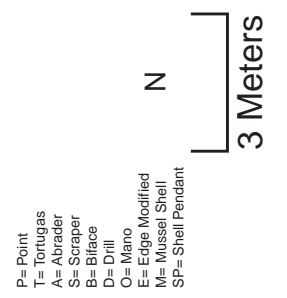

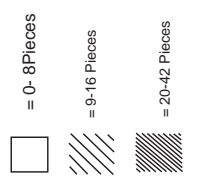

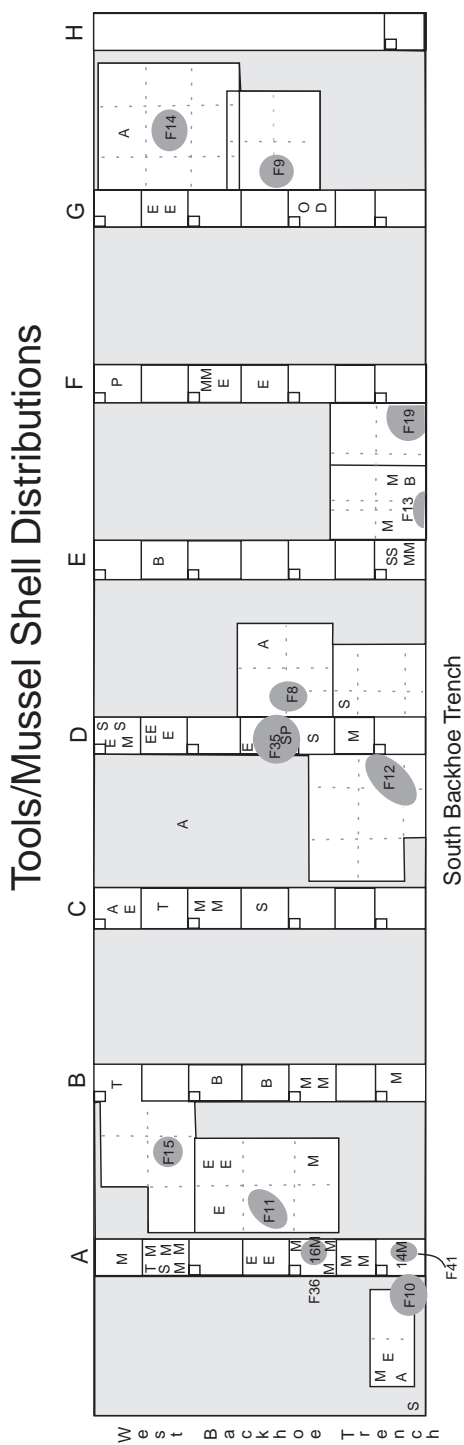

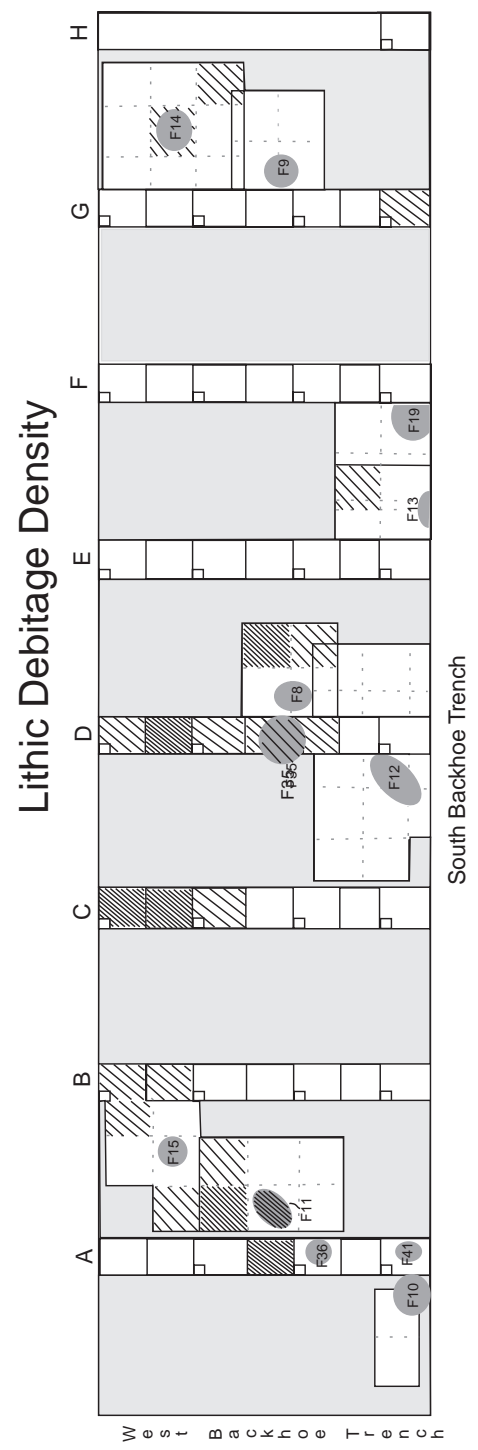

Figure 6.22 Horizontal Distribution of Occupation 1 Material.

A high instance of documented features $(n=12)$ occurred in Occupation 1, with all but three (Features 35, 36, and 41) discovered in the Gradall $^{\mathrm{TM}}$ stripped areas. Feature 14, a burned rock filled pit located in the extreme northeastern end of the block, may represent the only in situ burning event. The closest burned rock concentration to that burned rock filled pit was Feature 9, only $2 \mathrm{~m}$ to southwest. The five rocks of Feature 9 were all quite large and may have been concentrated there for subsequent use in the heating pit of Feature 14. The two mussel 
shell concentrations (Features 36 and 41) and the nine burned rock concentrations represent discards and materials that were no longer unusable. The two mussel shell clusters were at the western end, opposite the in situ pit Feature 14. These shell clusters were only $1.5 \mathrm{~m}$ apart in Balk A, and they occurred in the immediate vicinity of discarded burned rocks Features 10 and 11 on the north and south sides of the mussel shells. A high frequency of scattered burned rocks occurred between the two mussel shell clusters with very few associated pieces of lithic debris in or around these features.

It is difficult to envision that all the recovered burned rocks were used in a single heating pit (Feature 14), but no other in situ fires/hearths were detected. If these features are correctly interpreted as discard features, it does not appear that any single area was selected for dumping. Alternatively, the two mussel-shell and two burned-rock features concentrated in a limited area of the southwestern corner of the block is clearly a dump area. Five other discard features were near the south edge of the block. No burned rock dumps appear to be immediately associated with the intact pit Feature 14.

Although minimal cultural materials were found immediately south of in situ Feature 14, scattered charcoal chunks, a distal fragment of an edge modified flake (\#1810-5), a $12 \mathrm{~cm}$ long woodcharcoal chunk, and an abrading stone (\#711) were on the north side of the pit (Figure 6.22). This area may have been the up-wind side of the hearth, where some activities may have occurred around this feature. In general, the higher frequencies of formal stone tools were towards the western end of the excavation block (Figure 6.22). Abrading stones were also associated with two other burned rock features, one west of Feature 10 and the other east of Feature 8. Thus, in three of four instances abrading stones were associated with discarded clusters of burned rock. In four of the five instances, the abraders were also associated with edge modified flakes. However, few other formal tools were in close proximity to these features.

Most hand dug units (81 percent) yielded no formal tools, whereas a few units (four percent) yielded two or three formal tools. This nonrandom distribution of formal tools may reflect the use of some areas for specific processing activities (Figure 6.22). Scrapers were found in or adjacent to units with two or three mussel shells in four areas of the block, but no functional or behavioral link is suggested by their proximity. The few Tortugas projectile points were widely scattered and were not associated with dense accumulations of burned rocks. In one of four instances (Unit A2), a Tortugas base was in a unit with another tool, a Clear Fork scraper. The four bifaces were from units that did not contain any other formal tools. A single mano came from the same unit as a complete chert drill along with scattered burned rocks (Unit G5), which were less than $1 \mathrm{~m}$ southwest of burned rock Feature 9 (Figure 6.22). The significance of these associations is unclear.

In general, the 21 edge-modified flakes were distributed across the entire block in 12 percent of the hand dug units. In six instances, multiple edge-modified tools were within $1 \mathrm{~m}$ of each other. This may indicate a pattern of discard over a specific use area, assuming that it would not have taken more than one tool to conduct a limited task in a particular area. Unit $\mathrm{C} 1$ yielded an abrading stone (\#3717) and a weakly polished edge modified tool with a rounded edge (\#52765). The observed use polish is associated with scraping. Again, this combination of tools associated with high frequencies of burned rocks and lithic debitage all in one unit suggest that this location served as a discard area.

The shell pendant was found among the burned rocks of Feature 35 that was interpreted as a 
discard pile. The pendant was recovered slightly below the main rock concentration. The lack of burning on the shell and its association with burned rocks and lithic debitage may indicate that this area functioned as a discard location.

The horizontal plotting of only the proveniences of materials recorded by the TDS in Figures 6.23 and 6.24 reveal a similar distribution pattern of the burned rocks and mussel shells. There are many areas in the horizontal patterning that lack many plotted materials, but since the Gradall ${ }^{\mathrm{TM}}$ stripped areas were not screened it is uncertain how much was missed in those areas. The TDS plotted materials form a general arc-shaped pattern between 112 and $122 \mathrm{~m}$ east with the open area of low shell/rock frequency to the north. Since the data recovery techniques documented primarily the larger sizes of materials, the TDS pattern can produce misleading and spurious patterns. It is unclear what this patterning represents. Within this general arc, five burned rock discard features were recognized. The north side of the arc had limited materials yielded even from the handexcavated units in Balks $\mathrm{E}$ and $\mathrm{F}$.

\subsection{SUMMARY AND INTERPRETATIONS}

This dense $\left(53 / \mathrm{m}^{2}\right)$, well-defined occupation was horizontally distributed between about 20 and $40 \mathrm{cmbs}$. The nearly $20 \mathrm{~cm}$ thick zone dips down towards the west and slightly to the north and

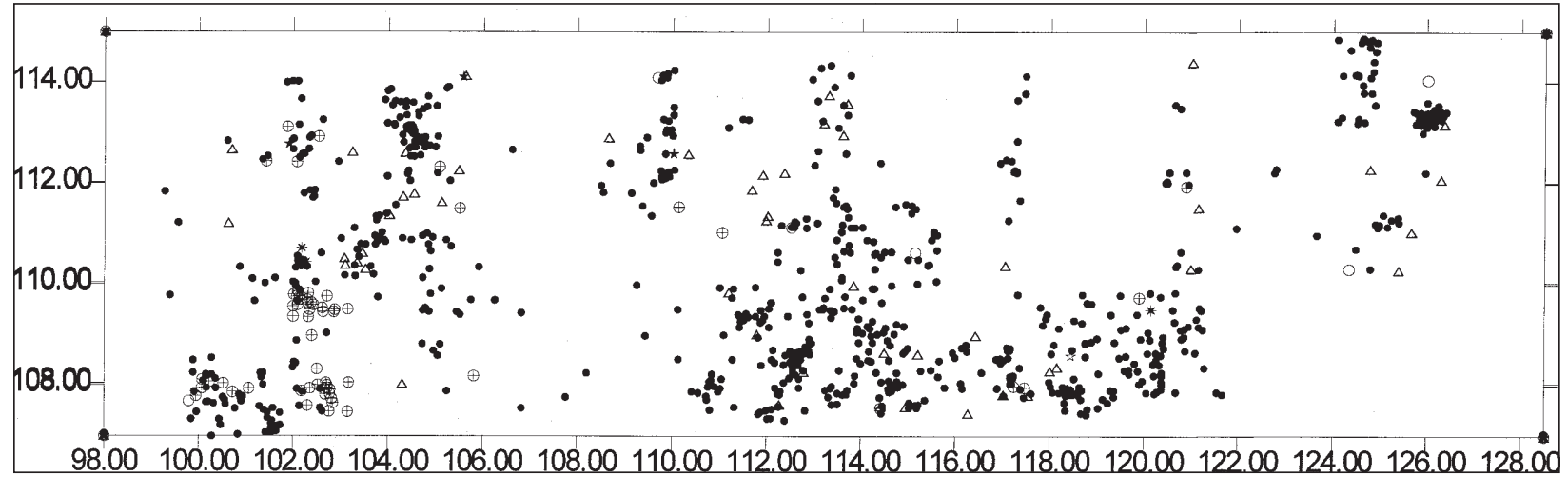

$\bullet=$ burned rock $\oplus=$ mussel shell $\triangle$ = lithic debitage $\star$ = points $\mathrm{O}=$ ground stone tool $*=$ tools Figure 6.23 All TDS Shot In Material for Occupation 1.

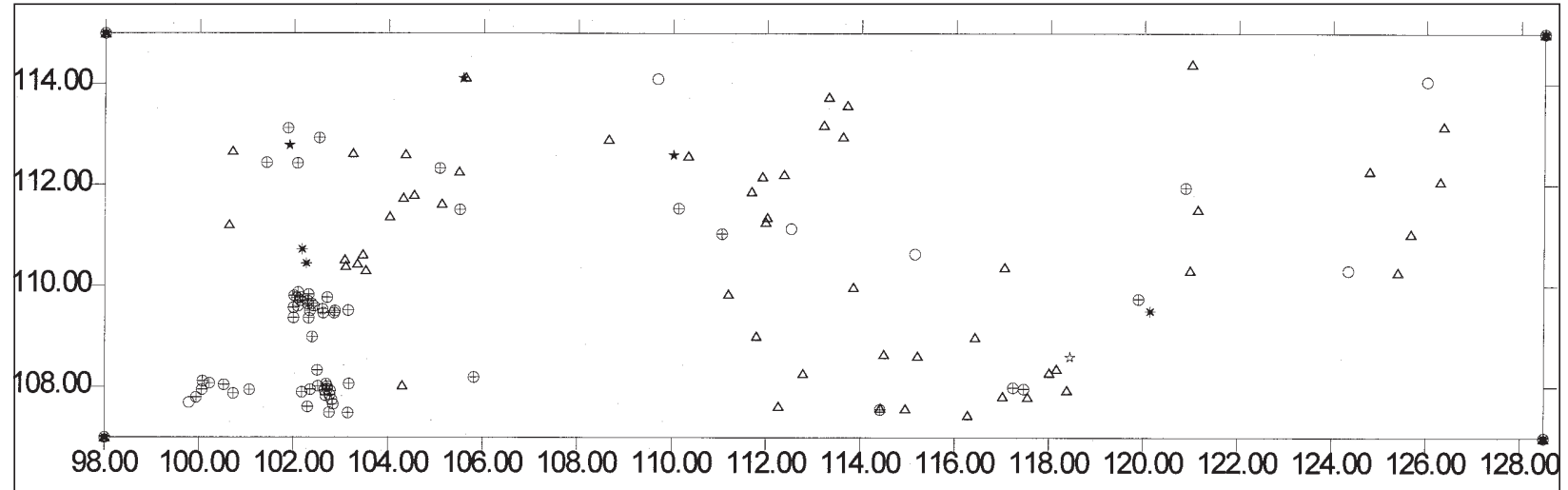

Figure 6.24 Lithic Debitage $(\triangle)$, Mussel Shells $(\oplus$ ), and Tools ( $\star$ O*) Shot In with the TDS for Occupation 1. 
reflects some vertical displacement of cultural objects, which probably resulted from various turbation and tree root activity. Although some displacement is recognized, the zone is sufficiently distinct from Occupation 2 to have been analyzed separately. The chronometric age is based on three wood charcoal dates from Features 3, 10, and 14. The average age of Occupation 1 is about 2050 B.P.

Occupation 1 yielded 10 burned rock features encompassing 261 burned rocks, 1,179 scattered burned rocks, 667 pieces of lithic debitage, 39 chipped tools, six ground stone tools, 55 scattered mussel shells, one shell pendant, and scattered Rabdotus shells. Although animal bones were not preserved, the lipid residues extracted from the interiors of burned rocks indicate that large herbivore food resources (probably deer) and various but unidentified plants were processed and eaten. Of the eight burned rock residue samples analyzed, the results were equally divided between plant and animal resources. At least some $\delta^{15} \mathrm{~N}$ values reflect use of legumes such mesquite beans or possibly nuts. One of 12 tools analyzed exhibited microscopic use-wear, and this edgemodified tool reflected the scraping of hides that supports the procurement of large game resources and the processing of hides. The two mussel shell clusters (Features 36 and 41) and other scattered shell valves indicate that river resources were also part of the diet. In addition to consuming the meat of mussels, one shell valve was manufactured into a pendant.

The size of the encampment and the number of people present in Occupation 1 are unknown. However, the presence of numerous burned rock dumps and the discard of shells and other unwanted materials from the primary processing spots suggest that the site must have been occupied for more than a couple of days. The extrapolation of hunting, butchering, hide working, and cooking activities reflects a diversity that generally is associated with people of both genders. This may indicate the presence of family units. In light of the amount of material recovered and accounting for the quantity of materials not preserved, a multifamily group was probably present. 


\subsection{OCCUPATION 2}

This occupation zone consisted of a broad but uneven horizontal distribution of diverse cultural remains concentrated between 55 and $67 \mathrm{cmbs}$ at the eastern end and 60 to $70 \mathrm{cmbs}$ at the western end. The ca. $10 \mathrm{~cm}$ thick zone dips some 8 to $10 \mathrm{~cm}$ towards the west and slightly to the north. It is best defined across Balk F and occurs some 15 to $18 \mathrm{~cm}$ below Occupation 1 and 10 to $12 \mathrm{~cm}$ above Occupation 3 . Turbation and root activity has slightly and vertically dispersed some cultural materials from this thin occupation zone. The cultural zone yielded a few burned rock features, low quantities of scattered burned rocks, sparse lithic debitage, a few chipped and ground stone tools, and scattered Rabdotus shells. Bone was again absent except for a $0.4 \mathrm{~g}$ unburned cortical fragment (\#5507-4) from Unit E5.

The absolute chronometric age of Occupation 2 was not directly established from dated organic materials. The age was extrapolated from three wood charcoal dates from Occupation 1, $15 \mathrm{~cm}$ above, and two accepted wood charcoal dates from Occupation 5, some $60 \mathrm{~cm}$ below (Table 5.3). The average radiometric age from three wood charcoal samples from Occupation 1 is about 2050 B.P. The average radiometric age from two acceptable wood charcoal dates from Occupation 5 is 3260 B.P. Therefore, assuming a standard rate of deposition between
Occupations 5 and 1, Occupation 2 is estimated to be 2300 B.P.

The cultural materials recovered from the $40 \mathrm{~m}^{2}$ hand excavated balks and the $4 \mathrm{~m}^{2}$ hand excavated units around Feature 16 discovered during Gradual stripping within this occupation are presented by material class below. This is followed by a discussion of the horizontal distribution of the occupational materials. Summary and interpretation sections are presented at the end.

\subsection{FEATURES}

Three features were recognized. One occurred in Gradall ${ }^{\mathrm{TM}}$ stripped Area C (Feature 16), and two were in hand-excavated Balks $\mathrm{H}$ and $\mathrm{C}$ (Features 33 and 34) respectively (Table 7.1). All three features were similar and consisted of burned rock concentrations that lacked horizontal patterning.

Feature 16 consisted of 12 angular, burned sandstone cobbles that weighed 2,466 $\mathrm{g}$ and ranged from $6.3 \mathrm{~g}$ to $286 \mathrm{~g}$. About 50 percent were between 4 and $9 \mathrm{~cm}$ in diameter with the remainder split nearly equally between the size classes of 0 to $4 \mathrm{~cm}$ in diameter and 9 to $15 \mathrm{~cm}$ diameter. Two burned rocks had tiny cracks. The burned rocks were in two small clusters and

Table 7.1 Attributes of Features from Occupation 2.

\begin{tabular}{|c|c|c|c|c|c|c|c|c|c|}
\hline $\begin{array}{l}\text { Fea. } \\
\text { No. }\end{array}$ & Unit & $\begin{array}{l}\text { No. of } \\
\text { Units } \\
\text { Exc. }\end{array}$ & $\begin{array}{l}\text { Depth } \\
(\mathrm{cmbs})\end{array}$ & $\begin{array}{l}\text { Size } \\
(\mathbf{c m})\end{array}$ & Thickness & Description & Interpret. & $\begin{array}{c}\text { Associated } \\
\text { Artifacts }\end{array}$ & $\begin{array}{l}\text { Chrono. } \\
\text { Age (B.P.) }\end{array}$ \\
\hline 16 & Area $\mathrm{C}$ & 4 & $60-70$ & $\begin{array}{c}60 x \\
35\end{array}$ & 1 rock & BR cluster & Unclear & $\begin{array}{l}12 \mathrm{BR}, \\
\text { charcoal }\end{array}$ & Est 2200 \\
\hline 33 & H7 & 1 & $40-50$ & $\begin{array}{c}80 \times \\
?\end{array}$ & 1 rock & BR cluster & BR Dump & $\begin{array}{c}31 \mathrm{BR}, \\
\text { scattered } \\
\text { BR }\end{array}$ & Est 2200 \\
\hline 34 & $\mathrm{C} 1$ & 1 & $50-60$ & $\begin{array}{c}70 x \\
30\end{array}$ & 1 rock & BR cluster & BR Dump & $\begin{array}{l}52 \mathrm{BR} \text {, } \\
\text { charcoal }\end{array}$ & Est 2200 \\
\hline
\end{tabular}

\begin{tabular}{lll}
\hline $\mathrm{BR}=$ burned rock & Fea. $=$ feature & Exc. $=$ excavated
\end{tabular}


formed no apparent pattern over an area measuring about $65 \mathrm{~cm}$ north-south by $25 \mathrm{~cm}$ east-west (Figure 7.1). An oval stained area was around the burned rocks that, in profile, revealed a 2 to $3 \mathrm{~cm}$ thick stained lens that continued under the rocks. A few charcoal chunks were present in the stained area, but no ash or oxidized matrix was observed. Many tiny insect holes were observed throughout the stained area, and a hard silty disturbance was on the western edge of the feature. Fifteen liters of the dark stained matrix were floated and yielded one tiny piece of debitage, nearly $125 \mathrm{~g}$ of fragmented burned rock, less than $0.1 \mathrm{~g}$ of bone, $3.5 \mathrm{~g}$ of crushed snail shells, and $0.5 \mathrm{~g}$ of charcoal (Table 6.3). A moderate frequency of burned rock was scattered to the west, and decayed roots were in the immediate vicinity.

Two burned rocks (\#1167 and \#1176) from Feature 16 had some interior matrix extracted and chemically analyzed. The stable carbon analyses on burned rock $\# 1167$ yielded a $\delta^{13} \mathrm{C}$ value of $-21.6 \%$, which reflects a possible mixture of $\mathrm{C} 3$ and $\mathrm{C} 4 / \mathrm{CAM}$ residues (Appendix D). The $\delta^{15} \mathrm{~N}$ value was $1.8 \%$, which reflects possible legume beans or nuts. Burned rock \#1176 yielded a $\delta^{13} \mathrm{C}$ value of $-21.8 \%$ and again may be a mixture of various $\mathrm{C} 3$ and $\mathrm{C} 4 / \mathrm{CAM}$ plant and animal resources. The $\delta^{15} \mathrm{~N}$ value of $4.8 \%$ is an intermediate value for a variety of plants and may also reflect a mixture of resources.

Fatty acid analysis indicates that burned rock \#1167 (sample Lino 9) residue was mostly derived from plants (Appendix G). Burned rock \#1176 (sample Lino 10) yielded fatty acids similar to those from large herbivore (Appendix $\mathrm{G})$. The $\delta^{13} \mathrm{C}$ value of $-21.8 \%$ indicates that the large herbivore was more likely deer as opposed to bison. These chemical analyses show that a mixture of plant and probably deer resources were processed using these burned rocks.
The appearance of a 2 to $3 \mathrm{~cm}$ thick organic stain under or around the burned rocks that lacks many actual charcoal pieces is intriguing. The two analyzed burned rocks from this cluster yielded organic residues that are assumed to have been derived from some cooking activity, probably through stone boiling. However, the stained area may indicate more than just discarded rock. The lack of any quantity of charcoal chunks, the absence of any sign of soil oxidation, or the absence of a pit could indicate that this feature is not an in situ heating element or hearth. The float results do not provide any significant clues as to this feature's possible function. Thus, it is unclear what these few loosely clustered cooking rocks and associated stain represent.

Feature 33 consisted of 31 burned pieces of siliceous rock that weighed $1,611 \mathrm{~g}$. Nearly 55 percent were 0 to $4 \mathrm{~cm}$ in diameter; the rest measured 4 to $9 \mathrm{~cm}$ in diameter. Comparable percentages were observed in the overall shape of cobbles, with slightly more angular than rounded pieces present. Many pieces were part of the same cobble, with at least six cobbles represented. The lack of sandstone is peculiar in comparison to other features. Only one piece had cracks. The 31 burned rocks were scattered over an area $80 \mathrm{~cm}$ north-south by $40 \mathrm{~cm}$ eastwest, although the entire feature was not excavated since it extended east into unexcavated areas (Figure 7.2). At least one chert flake was with the burned rocks. No chunks of charcoal, ash, or oxidized matrix were observed with the rocks. No float sample was collected from around the burned rocks. A chert core, four mussel shell fragments, and quantities of chert flakes were found immediately west of the burned rocks.

Feature 34 consisted of 52 burned sandstone rocks that weighed $3,415 \mathrm{~g}$. About 58 percent measured 0 to $4 \mathrm{~cm}$ in size whereas 37 percent were 4 to $9 \mathrm{~cm}$ in diameter. More than 84 percent 


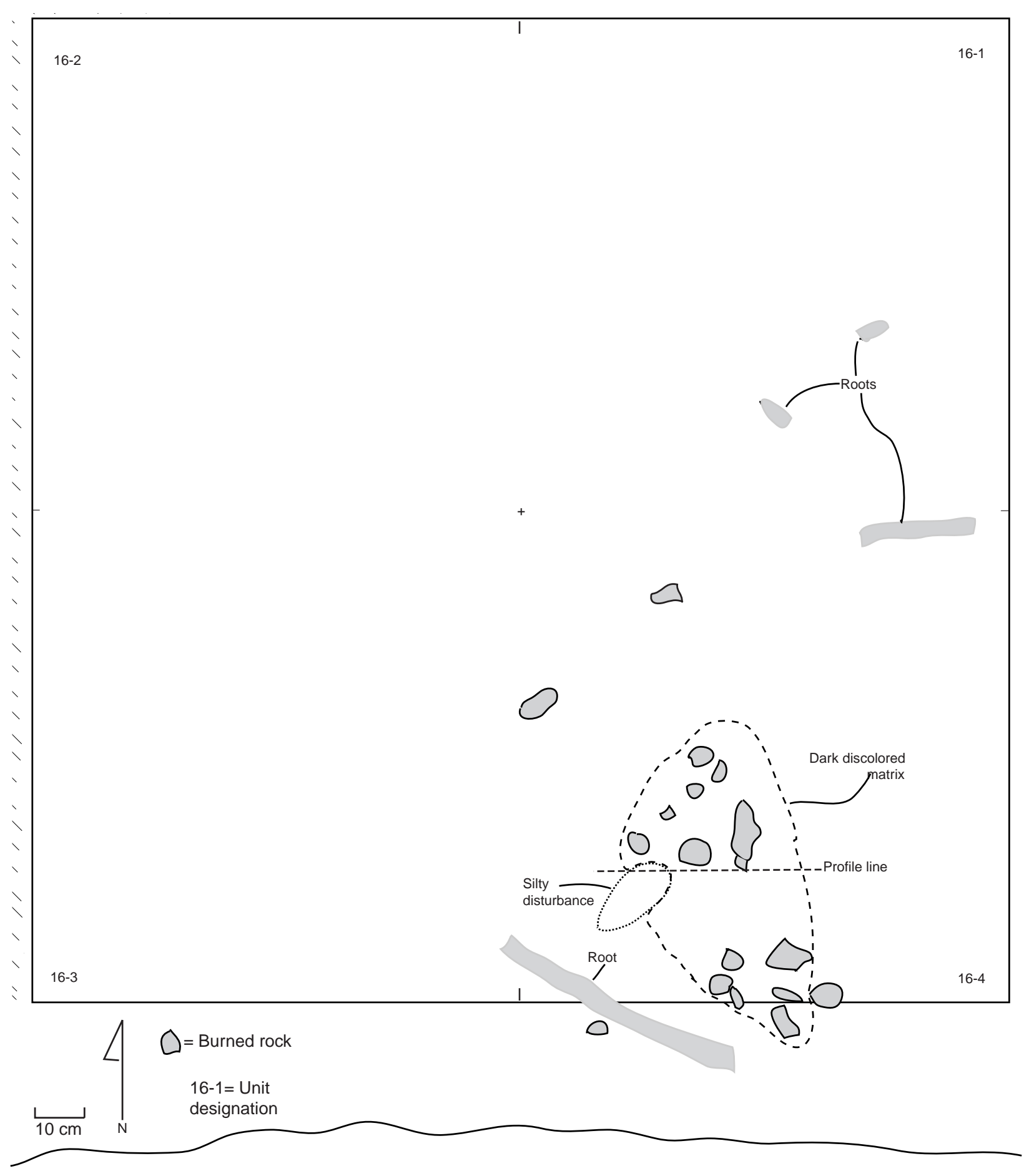

East/West Backhoe trench

Figure 7.1 Plan View of Burned Rock-Filled Pit Feature 16. 


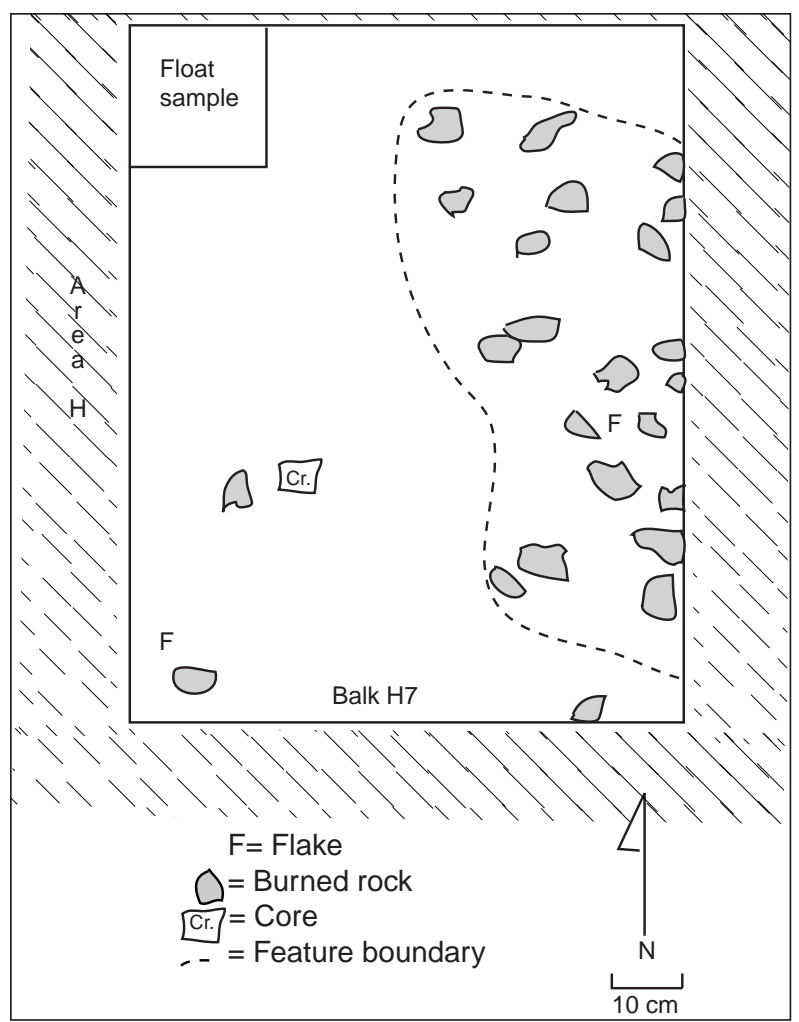

Figure 7.2 Plan View of Burned Rocks in Feature 33.

appeared angular in shape, 13 percent were tabular, and six percent were rounded. Nearly 12 percent had tiny cracks still visible. The burned rocks were irregularly distributed in an elongated pattern about $80 \mathrm{~cm}$ north-south by $30 \mathrm{~cm}$ east-west (Figure 7.3). No ash or oxidized matrix was observed. A three-liter float sample from beneath the rocks yielded two tiny chert flakes, nearly $25 \mathrm{~g}$ of burned rock fragments, a trace of charcoal, and $2 \mathrm{~g}$ of crushed snail shells (Table 6.3). A few burned rocks were in the immediate vicinity of the feature cluster.

Two burned rocks (\#5279-4-2 and \#5279-4-1) from Feature 34 had some interior matrix extracted for chemical analysis. The stable carbon isotope analysis on residue from rock $\# 5279-4-2$ yielded a $\delta^{13} \mathrm{C}$ value of $-19.4 \%$, which may reflect a mixture of isotopes from different resources. The $\delta^{15} \mathrm{~N}$ value from that

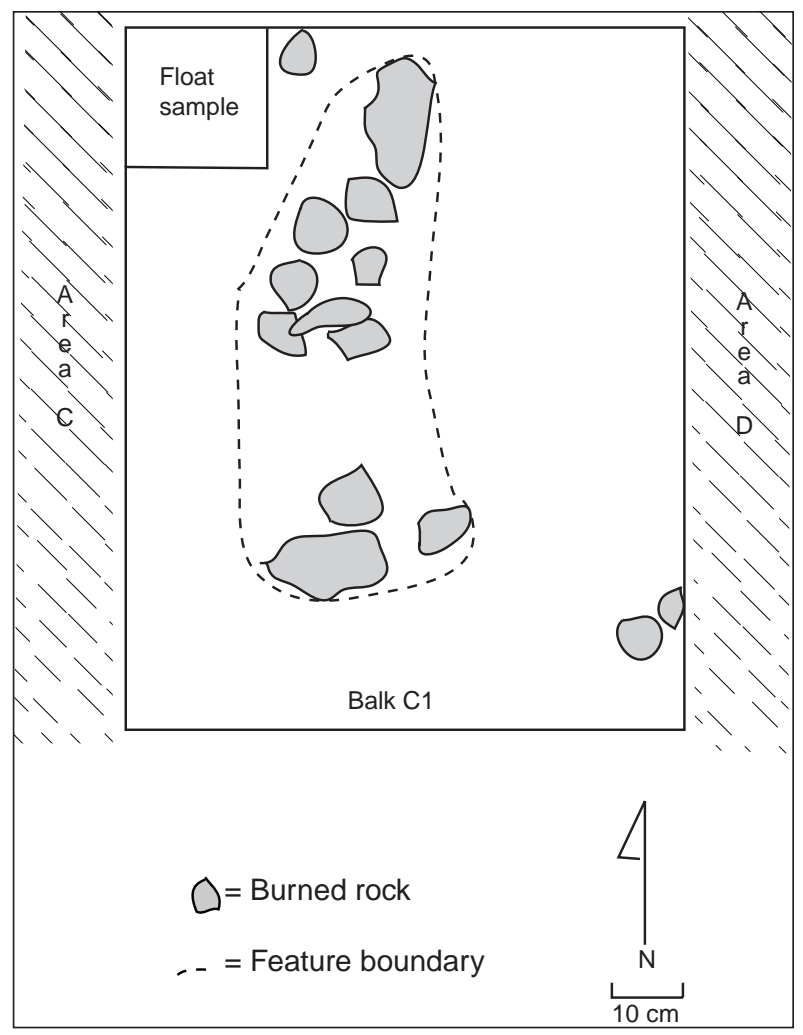

Figure 7.3 Plan View of Burned Rocks in Feature 34.

same sample was $6.6 \%$ and also reflects a possible mixture of resources. Residue from rock \#5279-4-1 (sample Lino 34) yielded only a trace of lipids that could not be interpreted (Appendix G). Rock \#5279-4-2 (sample Lino 33 ) yielded fatty acids that reflect a value closely resembling that of Texas ebony seeds (Appendix $\mathrm{G})$. The $\delta^{15} \mathrm{~N}$ isotope result of $6.6 \%$ from this rock residue is similar that of modern Texas ebony seeds at $5.4 \%$.

\subsection{CHIPPED LITHIC ASSEMBLAGE}

The lithic assemblage from the $40 \mathrm{~m}^{2}$ hand excavated balks and the $4 \mathrm{~m}^{2}$ hand-excavated units around Feature 16 yielded 378 pieces of unmodified chipped stone debitage (Table 7.2). This represents nearly nine pieces per square meter. The raw material was all chert and appears to have been procured from local gravel 
Table 7.2 Occupation 2 Lithic Debitage Analysis.

\begin{tabular}{|c|c|c|c|c|c|c|}
\hline \multirow[b]{2}{*}{ Condition } & \multicolumn{6}{|c|}{ Flake Type } \\
\hline & $\begin{array}{l}\text { angular } \\
\text { debris }\end{array}$ & core & $\begin{array}{c}\text { early } \\
\text { biface }\end{array}$ & \multicolumn{2}{|c|}{$\begin{array}{cc}\text { late } \\
\text { Indet. } & \text { biface }\end{array}$} & Total \\
\hline \multirow[t]{2}{*}{ complete } & & 45 & 12 & 21 & 19 & 97 \\
\hline & - & $30 \%$ & $22 \%$ & $22 \%$ & $25 \%$ & $26 \%$ \\
\hline \multirow[t]{2}{*}{ distal } & & 25 & 9 & 8 & 18 & 60 \\
\hline & - & $17 \%$ & $16 \%$ & $9 \%$ & $23 \%$ & $16 \%$ \\
\hline \multirow[t]{2}{*}{ fragment } & 4 & & & 1 & & 5 \\
\hline & $100 \%$ & - & - & $1 \%$ & - & $1 \%$ \\
\hline \multirow[t]{2}{*}{ medial } & & 26 & 10 & 61 & 19 & 116 \\
\hline & - & $18 \%$ & $18 \%$ & $65 \%$ & $25 \%$ & $31 \%$ \\
\hline \multirow[t]{2}{*}{ proximal } & & 52 & 24 & 3 & 21 & 100 \\
\hline & - & $35 \%$ & $44 \%$ & $3 \%$ & $27 \%$ & $26 \%$ \\
\hline \multirow[t]{2}{*}{ Total } & 4 & 148 & 55 & 94 & 77 & 378 \\
\hline & $1 \%$ & $39 \%$ & $15 \%$ & $25 \%$ & $20 \%$ & $100 \%$ \\
\hline \multirow{4}{*}{$\frac{\text { Cortex }}{\text { primary }}$} & \multicolumn{6}{|c|}{ Flake Type } \\
\hline & $\begin{array}{c}\text { angular } \\
\text { debris }\end{array}$ & core & $\begin{array}{c}\text { early } \\
\text { biface }\end{array}$ & Indet. & $\begin{array}{c}\text { late } \\
\text { biface }\end{array}$ & Total \\
\hline & & 10 & & & & 10 \\
\hline & - & $7 \%$ & - & - & - & $3 \%$ \\
\hline \multirow[t]{2}{*}{ secondary } & 3 & 96 & 10 & 20 & 2 & 131 \\
\hline & $75 \%$ & $65 \%$ & $18 \%$ & $21 \%$ & $3 \%$ & $35 \%$ \\
\hline \multirow[t]{2}{*}{ tertiary } & 1 & 42 & 45 & 74 & 75 & 237 \\
\hline & $25 \%$ & $28 \%$ & $82 \%$ & $79 \%$ & $97 \%$ & $63 \%$ \\
\hline \multirow[t]{2}{*}{ Total } & 4 & 148 & 55 & 94 & 77 & 378 \\
\hline & $1 \%$ & $39 \%$ & $15 \%$ & $25 \%$ & $20 \%$ & $100 \%$ \\
\hline \multirow[b]{2}{*}{ Heating } & \multicolumn{6}{|c|}{ Flake Type } \\
\hline & $\begin{array}{c}\text { angular } \\
\text { debris }\end{array}$ & core & $\begin{array}{c}\text { early } \\
\text { biface }\end{array}$ & Indet. & $\begin{array}{c}\text { late } \\
\text { biface }\end{array}$ & Total \\
\hline \multirow[t]{2}{*}{ crazed } & & 3 & & 1 & & 4 \\
\hline & - & $2 \%$ & - & $1 \%$ & - & $1 \%$ \\
\hline \multirow[t]{2}{*}{ indeterminate } & & 19 & 4 & 16 & 3 & 42 \\
\hline & - & $13 \%$ & $7 \%$ & $17 \%$ & $4 \%$ & $11 \%$ \\
\hline \multirow[t]{2}{*}{ none } & 4 & 124 & 49 & 75 & 74 & 326 \\
\hline & $100 \%$ & $84 \%$ & $89 \%$ & $80 \%$ & $96 \%$ & $86 \%$ \\
\hline \multirow[t]{2}{*}{ spall } & & 2 & 1 & 2 & & 5 \\
\hline & - & $1 \%$ & - & - & - & $1 \%$ \\
\hline \multirow[t]{2}{*}{ treatment } & & & 1 & & & 1 \\
\hline & - & - & $2 \%$ & - & - & $0 \%$ \\
\hline \multirow[t]{2}{*}{ Total } & 4 & 148 & 55 & 94 & 77 & 378 \\
\hline & $1 \%$ & $39 \%$ & $15 \%$ & $25 \%$ & $20 \%$ & $100 \%$ \\
\hline
\end{tabular}

sources. Color differences exist, but in very general terms, most are tans and grays with some brown, white, and dark red hues represented.

The debitage was classified into five recognizable types: angular debris, core flakes, early and late stage biface flakes, and uniface flakes based on platform and dorsal face attributes. Other observations include condition, amount of cortex, and the presence of heating as recorded per debitage type (Table 7.2). Core flakes (39 percent) dominate, followed by indeterminate pieces (25 percent), late stage biface ( 21 percent), early stage biface flakes (15 percent), and angular debris (one percent). These flake types indicate that core and biface reduction occurred most frequently, with no significant occurrence of uniface manufacturing or uniface maintenance activities. The absence of uniface flakes may be misleading because small resharpening flakes may not have been retained in the $6.4 \mathrm{~mm}$ screen used to sift the matrix. Nevertheless, some uniface flakes were recovered using the same screen size from Occupation 1.

The conditions of debitage (complete, medial, and proximal portions) range between 25 and 31 percent and are relatively equally represented (Table 7.2). Distal fragments appear underrepresented at 16 percent. The slightly higher frequency of complete pieces associated with core flakes may be due to their thicker and more durable shape compared to the thinner biface flakes. The low thickness variable may also underlie the higher frequency of distal and medial pieces in the late stage biface debris relative to that of the core flakes. Experimental knapping has also documented that multidirectional core reduction strategy yielded fewer broken flakes (Tomka and Fields 1990).

Cortex remains on about 38 percent of all debitage classes and 72 percent of the core flakes (Table 7.2). The high frequency of cortex in the core flakes (72 percent) reflects the decortification process of the rounded, waterworn cobbles during the early stages in the reduction strategy. Some cortex remained on the early stage biface flakes (18 percent) and in the indeterminate pieces ( 21 percent), but little or no cortex was still present on late stage bifaces (three percent). The occurrences of cortext on angular debris probably reflect their being derived from core reduction. 
Heat alterations (crazing and spalls) account for two percent of the debitage, with spalls being most dominant (Table 7.2). These flakes were probably damaged during direct exposure to fires and probably reflect thermal exposure of waste material where the debitage was discarded. Less than one percent of the pieces appeared to have been heat treated. This occurrence is similar to that found in Occupation 1. It reflects that inventional heat treating was not a standard practice.

\subsection{CHIPPED STONE TOOLS}

The recognized chipped-stone tool assemblage was classified into four standard form/functional classes and consists of three bifaces, 15 edgemodified flakes, three cores, and one hammerstone. As a group, these 22 tools account for nearly two percent of the total material recovered from the $44 \mathrm{~m}^{2}$ hand excavated area in Occupation 2.

All but the hammerstone were manufactured from chert. The three bifaces were all broken and include two distal and one proximal piece.
Two biface fragments are from late reduction stages and one is from a middle reduction stage. The specimens represent oval, triangular, and lanceolate forms (Table 7.3, Figure 7.4). Two have break characteristics of manufacture failures and one has an unknown break type. The two late-stage pieces were relatively narrow with widths of 29 and $32 \mathrm{~mm}$, whereas the middle stage piece was nearly $68 \mathrm{~mm}$ wide.

The 15 edge-modified pieces were all manufactured from chert, with fewer than half (47 percent) represented by complete flakes. Most (66 percent) were secondary decortification flakes with the rest tertiary pieces (Table 7.4). All the modified edges had regular patterned flake scars along straight $(n=6)$, concave $(n=5)$, sinuous $(n=2)$, or convex $(n=2)$ lateral edges. Six specimens (40 percent) had two or more modified edges. The modification appears related to scraping activities, with the angles of the original flake edges measuring between 15 and 63 degrees. The retouched scar angles are generally steeper and range between 47 and 75 degrees.

Table 7.3 Point and Biface Attributes for Occupation 2.

\begin{tabular}{|c|c|c|c|c|c|c|c|c|c|c|c|c|c|c|c|c|c|}
\hline \multirow[b]{2}{*}{ Cat.\# } & \multirow[b]{2}{*}{ Unit } & \multirow[b]{2}{*}{ Lvl } & \multirow[b]{2}{*}{ Depth } & \multirow[b]{2}{*}{$\mathrm{N}$} & \multirow[b]{2}{*}{$E$} & \multirow[b]{2}{*}{ Elev } & \multirow[b]{2}{*}{ Tool } & \multirow[b]{2}{*}{ Brk } & \multirow[b]{2}{*}{ Con. } & \multirow[b]{2}{*}{ Sh } & \multirow[b]{2}{*}{ Stg } & \multicolumn{2}{|c|}{ Color } & \multicolumn{3}{|c|}{ Size $(\mathrm{mm})$} & \multirow[b]{2}{*}{ Wt $(G)$} \\
\hline & & & & & & & & & & & & sW & LW & $L$ & W & Th & \\
\hline 4210 & D4 & 5 & & 111.388 & 113.599 & 99.461 & B & $M$ & D & 0 & M & Yw/Or & $\mathrm{Yw} / \mathrm{Or}$ & & 67.7 & 14.7 & 53.9 \\
\hline $5575-005$ & F4 & 6 & $50-60$ & & & & B & M & D & $\mathrm{T}$ & $\mathrm{L}$ & Or & Red/Or & & 29.3 & 6.7 & 6.8 \\
\hline 5495-004 & E4 & 7 & $60-70$ & & & & B & M & $P$ & L & $\mathrm{L}$ & Yw/Or & $\mathrm{Yw} / \mathrm{Or}$ & & 31.5 & 8.3 & 16.6 \\
\hline
\end{tabular}

Tool Type: B=biface

Brk: $\mathrm{M}=$ manufacture, Us=use, UK=unknown

Condition (Cond.): $\mathrm{C}=$ complete, $\mathrm{P}=$ proximal, $\mathrm{M}=$ medial, $\mathrm{D}=$ distal

Shape (Sh): $\mathrm{P}=$ Parallel, $\mathrm{Sn}=$ sinuous, $\mathrm{St}=$ straight, $\mathrm{C}=$ =concave, $\mathrm{Cx}=$ convex, $\mathrm{L}=$ lanceolate, $\mathrm{O}=\mathrm{oval}$, $\mathrm{R}=$ rectangular, $\mathrm{T}=$ triangular, l=irregular, Ot=other Manufacture Stage (Stg): L=late, M=middle

Color: Or=orange, $\mathrm{Y} W=y e l l o w, P r p=p u r p l e, S p k=s p e c k l e d, B r=b r o w n, G r y=G r a y ; S W=$ short wave \& LW=long wave

Note: All catalogue numbers from hand excavated proveniences have been formed by adding a dash and appear in the database with leading zeros. These leading zeros have been omitted to conserve space. 


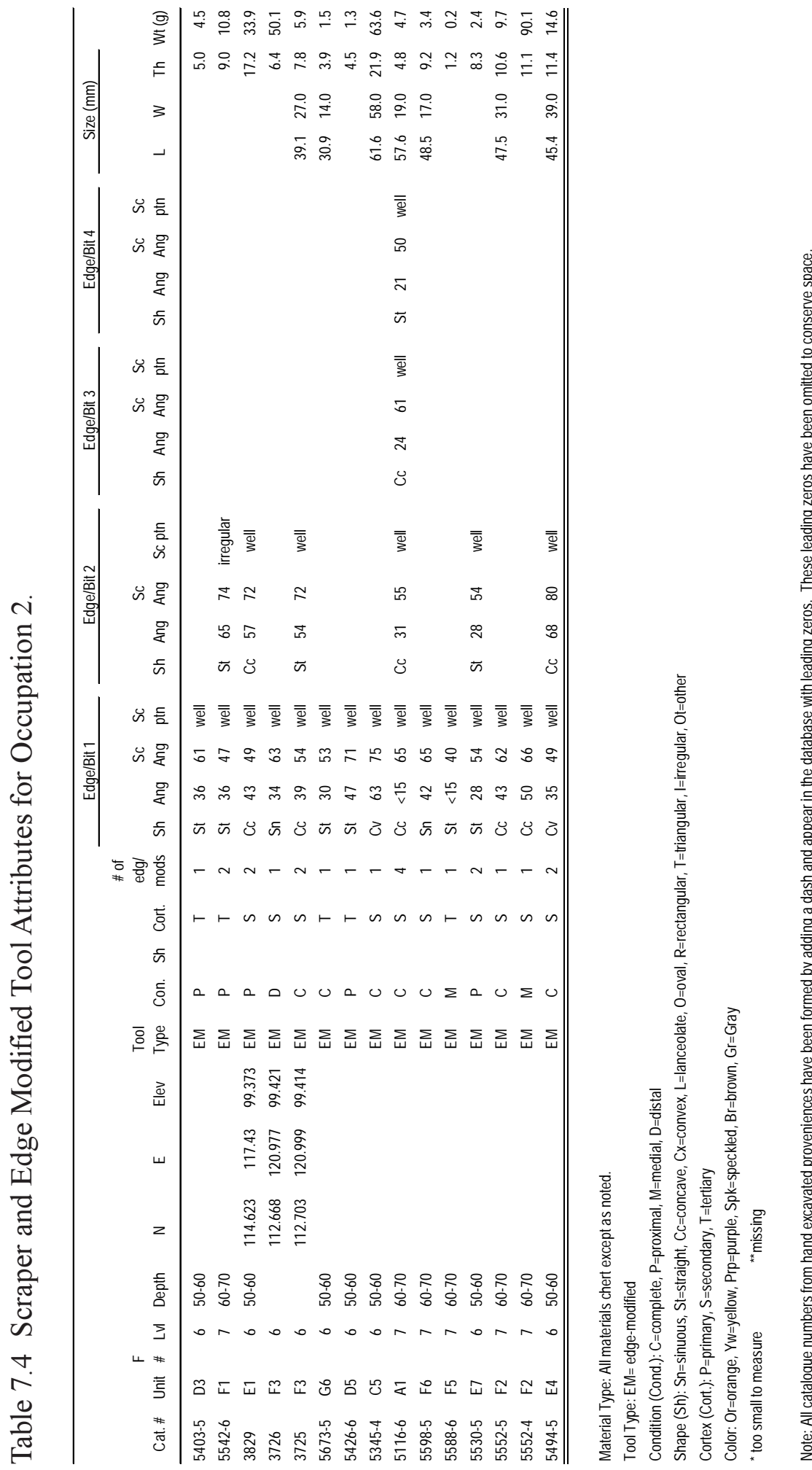



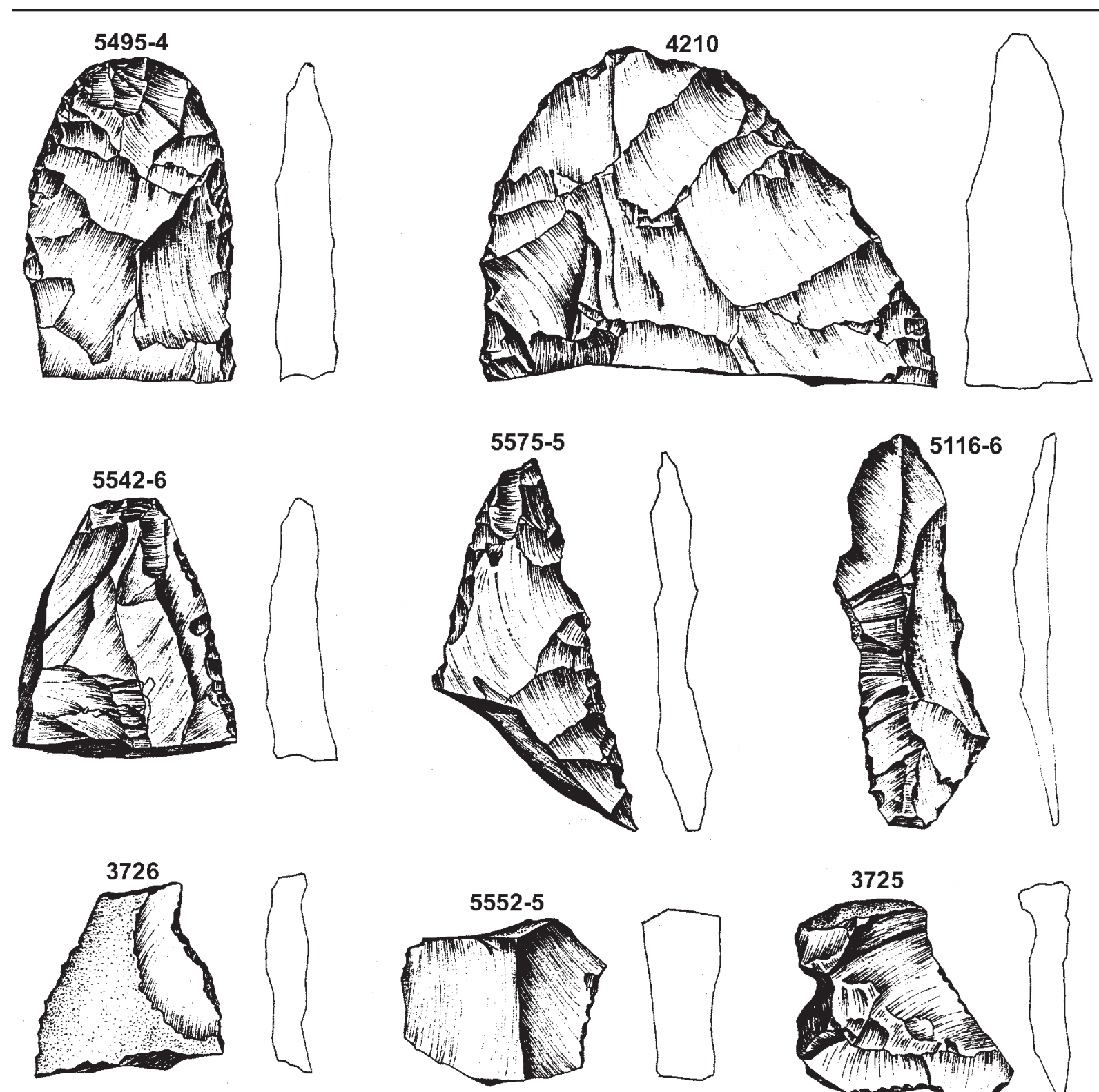

Figure 7.4 Selected Stone Tools from Occupation 2 (Actual Size).

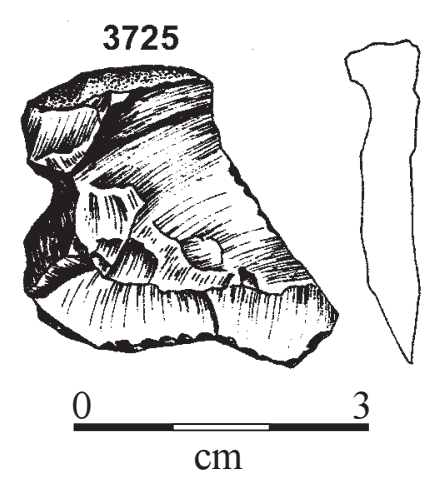

Specimen \#5542-6 is the proximal end of a relatively thick, well executed flake. The platform is well prepared with a number of small hinge fractures on the dorsal surface and light grinding on the platform edge. Both lateral edges reveal tiny flake scars along the very margins. The proximal end of this tool may have been part of a uniface, such as an end scraper.
Of the three chert cores found, two are complete (\#3434 and \#3769) and one is fragmentary (\#4221). The complete specimens are bifacial cores with 15 to 80 percent of their surfaces still covered in cortex. These two are nearly $90 \mathrm{~cm}$ long and weigh 164 and $310 \mathrm{~g}$. The fragment is a unifacial core with only 15 percent cortex covering the cobble. 
The oval hammerstone (\#4123) was made of quartzite with limited crushed and flaked scars on one end and crushed spots on the other. The crushed spots resemble impacts from striking hard objects. One end is bifacial, with the resulting ridge revealing minimal crushing. This nearly $9 \mathrm{~cm}$ wide cobble weighs nearly $600 \mathrm{~g}$.

The high-powered microwear analyses on three bifaces (\#4210, \#5495-4, and \#5575-5) and five edge-modified flakes (\#3725, \#3726, \#5116-6, \#5542-6, and \#5552-4) revealed minimal usewear. Only one edge-modified tool (\#3726, a distal flake fragment) revealed use-polish along one lateral edge, and that relates to scraping fresh hides (Appendix C).

\subsection{BURNED ROCKS}

The burned rocks scattered throughout Occupational 2 and outside the defined features are discussed here. The $44 \mathrm{~m}^{2}$ investigated by hand excavations yielded 740 burned rocks that weighed 39,992 g (Table 7.5). Nearly 90 percent were sandstone followed with nearly eight percent chert pieces, testifying to the selection of sandstone over other available materials. About 68 percent were smaller than $4 \mathrm{~cm}$ in diameter, 28 percent measured between 4 and 9 $\mathrm{cm}$, and only four percent were greater than 9 $\mathrm{cm}$ in diameter. The average scattered burned rock weighed $54 \mathrm{~g}$. This indicates that the scattered burned rocks were mostly smaller than $4 \mathrm{~cm}$. Eight percent of the scattered burned rocks had tiny, hairline cracks. The low percentage probably reflects that most rocks cracked during heating or cooling and had already separated into multiple pieces by the time they became scattered. The small size of most rocks and their dispersal distribution suggest that these burned rocks were probably discarded during hearth maintenance activities.

The average weight of the scattered burned rocks was $54 \mathrm{~g}$, whereas those burned rocks from feature discard piles averaged $79 \mathrm{~g}$. This indicates that those burned rocks in defined features were 56 percent heavier than those scattered about the occupation.

The burned rock from the three identified features and those scattered across the handexcavated area in Occupation 2 totaled 835 pieces and weighed 47,483 g (Table 7.5 ). This represents nearly $19 / \mathrm{m}^{2}$ from hand excavated units. The overall average weight of each burned rock was $57 \mathrm{~g}$.

\subsection{CHARCOAL}

Nineteen charcoal pieces from non-feature contexts weighed about 348 g, with nearly 60 percent derived from one large sample (\#4757) from Unit E6 and a second sample from that same unit accounting for another 26 percent of the charcoal wood weight. Wood charcoal was very limited from Occupation 2 , even in the burned rock features. The 18 liters of matrix that encompassed these burned rock clusters was floated and yielded only $0.5,0.1$, and $0.1 \mathrm{~g}$ of charcoal from Features 16, 33, and 34, respectively. A single piece (\#5297-4a) from Feature 34 was submitted for identification. However, it was too small for specific wood identification (Appendix B).

\subsection{OTHER MATERIAL}

A $1 \mathrm{~cm}$ rounded sandstone sphere (\#5426-7) came from Unit D5. No obvious human alterations are apparent. Its presence in the occupation may indicate that it had been collected and carried in. It is unclear if this sphere had a particular cultural function or was a natural occurrence.

\subsection{HORIZONTAL DISTRIBUTION}

Occupation 2 yielded moderate quantities of burned rocks $\left(17 / \mathrm{m}^{2}\right)$ outside burned rock 
Table 7.5 Burned Rock Data for Occupation 2.

\begin{tabular}{|c|c|c|c|c|c|c|c|c|c|c|c|c|c|c|c|c|}
\hline \multicolumn{17}{|c|}{ Non Feature Contexts } \\
\hline \multirow[b]{2}{*}{ Unit } & \multirow[b]{2}{*}{ Level } & \multirow[b]{2}{*}{ Fea } & \multicolumn{3}{|c|}{ Size $(\mathrm{cm})$} & \multicolumn{4}{|c|}{ Material Type* } & \multicolumn{3}{|c|}{ Fracture Type** } & \multicolumn{2}{|c|}{ Cracks } & \multirow[b]{2}{*}{ Total } & \multirow[b]{2}{*}{ Wt (g) } \\
\hline & & & $0-4$ & $4-9$ & $9-15$ & $\mathbf{C C}$ & Ch & O & SS & Ang. & Rnd. & Tab. & $\mathbf{Y}$ & $\mathbf{N}$ & & \\
\hline $16-1$ & 7 & & 2 & & & & & & 2 & 1 & 1 & & & 2 & 2 & 4.5 \\
\hline $16-2$ & 7 & & 7 & 1 & & & 1 & & 7 & 6 & & 2 & & 8 & 8 & 81.5 \\
\hline $16-3$ & 7 & & 18 & 5 & & & 2 & & 21 & 15 & 4 & 4 & 2 & 21 & 23 & 942.3 \\
\hline $16-4$ & 7 & & 4 & & & & & & 4 & 3 & 1 & & 1 & 3 & 4 & 18.5 \\
\hline A1 & 6 & & 21 & 12 & 1 & & & 3 & 31 & 27 & 7 & & 6 & 28 & 34 & $4,460.9$ \\
\hline $\mathrm{A} 2$ & $6 \& 7$ & & 20 & 6 & & & 1 & & 25 & 14 & 8 & 4 & 1 & 25 & 26 & $1,291.0$ \\
\hline A3 & $6 \& 7$ & & 2 & 1 & & & & & 3 & 3 & & & & 3 & 3 & 56.4 \\
\hline A5 & 6 & & 3 & & & & & 1 & 2 & 2 & 1 & & & 3 & 3 & 16.6 \\
\hline A6 & 6 & & 1 & & & & & & 1 & 1 & & & & 1 & 1 & 1.6 \\
\hline A7 & 7 & & & 1 & & & & & 1 & & & 1 & & 1 & 1 & 52.9 \\
\hline $\mathrm{C} 1$ & 6 & & 29 & 2 & & & & & 31 & 29 & 2 & & 2 & 29 & 31 & 177.6 \\
\hline $\mathrm{C} 2$ & 6 & & 1 & 2 & & & & & 3 & 2 & 1 & & & 3 & 3 & 40.1 \\
\hline $\mathrm{C} 4$ & 6 & & 3 & 2 & & & & & 5 & 3 & & 2 & 1 & 4 & 5 & 462.6 \\
\hline C5 & 6 & & & & 1 & & & & 1 & & & 1 & & 1 & 1 & 238.7 \\
\hline C6 & 6 & & 3 & & & & & & 3 & 3 & & & 2 & 1 & 3 & 26.0 \\
\hline $\mathrm{C} 7$ & $6 \& 7$ & & 7 & 3 & 1 & & & 1 & 10 & 8 & 2 & 1 & 3 & 8 & 11 & $1,178.9$ \\
\hline D1 & $5 \& 6$ & & 5 & 2 & & & & & 7 & 3 & 3 & 1 & & 7 & 7 & $1,083.9$ \\
\hline D3 & $5 \& 6$ & & 11 & & & & 1 & & 10 & 5 & 4 & 2 & 2 & 9 & 11 & 88.8 \\
\hline D4 & $5 \& 6$ & & 10 & 5 & 1 & 1 & 1 & & 14 & 7 & 6 & 3 & 1 & 15 & 16 & $2,176.6$ \\
\hline D5 & $5 \& 6$ & & 12 & 2 & & & & 1 & 13 & 10 & 3 & 1 & 1 & 13 & 14 & 133.8 \\
\hline D6 & $5 \& 6$ & & 31 & 18 & & & & & 49 & 23 & 13 & 13 & 3 & 46 & 49 & $1,228.9$ \\
\hline D7 & $5 \& 6$ & & 18 & 24 & 2 & & & 2 & 42 & 34 & 7 & 3 & 8 & 36 & 44 & $2,365.0$ \\
\hline E1 & 7 & & 2 & & & & & & 2 & 2 & & & & 2 & 2 & 13.7 \\
\hline E2 & 7 & & 1 & & & & & & 1 & 1 & & & & 1 & 1 & 8.5 \\
\hline E3 & $6 \& 7$ & & 5 & 8 & & & 2 & & 11 & 3 & 4 & 6 & & 13 & 13 & 536.3 \\
\hline E4 & $6 \& 7$ & & 10 & 8 & & 1 & & 2 & 15 & 10 & 7 & 1 & 1 & 17 & 18 & 934.3 \\
\hline E5 & $6 \& 7$ & & 19 & 9 & & & & 1 & 27 & 19 & 7 & 2 & 1 & 27 & 28 & $1,961.8$ \\
\hline E6 & $6 \& 7$ & & 11 & 8 & & & 1 & 2 & 16 & 10 & 4 & 5 & 4 & 15 & 19 & 761.5 \\
\hline E7 & 6 & & 1 & 1 & & & & & 2 & 1 & & 1 & 1 & 1 & 2 & 59.9 \\
\hline $\mathrm{F} 1$ & $6 \& 7$ & & 10 & 4 & 2 & & 1 & & 15 & 9 & 5 & 2 & 1 & 15 & 16 & $2,413.2$ \\
\hline $\mathrm{F} 2$ & $6 \& 7$ & & 2 & 2 & & & & & 4 & 1 & 2 & 1 & & 4 & 4 & 238.7 \\
\hline F3 & $6 \& 7$ & & 26 & 15 & 12 & & 2 & & 51 & 21 & 12 & 20 & 3 & 50 & 53 & $7,241.3$ \\
\hline $\mathrm{F} 4$ & 6 & & 21 & 7 & & & & & 28 & 17 & 4 & 7 & & 28 & 28 & 369.5 \\
\hline F5 & $6 \& 7$ & & 31 & 14 & 1 & & & & 46 & 24 & 11 & 11 & 4 & 42 & 46 & $1,454.0$ \\
\hline F6 & $6 \& 7$ & & 34 & 1 & 5 & & 1 & & 39 & 22 & 6 & 12 & 1 & 39 & 40 & $2,271.9$ \\
\hline F7 & $6 \& 7$ & & 14 & 4 & & & & & 18 & 8 & 7 & 3 & 1 & 17 & 18 & 473.2 \\
\hline G1 & $5 \& 6$ & & 24 & 4 & & & & & 28 & 21 & 3 & 4 & 2 & 26 & 28 & 998.4 \\
\hline $\mathrm{G} 2$ & $5 \& 6$ & & 7 & & & & & & 7 & 5 & 2 & & & 7 & 7 & 22.5 \\
\hline G3 & 5 & & 7 & 2 & & & & & 9 & 9 & & & & 9 & 9 & 74.7 \\
\hline G4 & $5 \& 6$ & & 6 & 4 & & & & 2 & 8 & 4 & 2 & 4 & & 10 & 10 & 147.1 \\
\hline G5 & $5 \& 6$ & & 13 & 11 & & & 1 & & 23 & 18 & 1 & 5 & 7 & 17 & 24 & $1,014.0$ \\
\hline G6 & 5 & & 9 & 7 & & & 3 & & 13 & 13 & 2 & 1 & 2 & 14 & 16 & 417.7 \\
\hline $\mathrm{H} 7$ & $5 \& 6$ & & 44 & 14 & & & 40 & 3 & 15 & 44 & 12 & 2 & & 58 & 58 & $2,452.5$ \\
\hline Subtotal & & & 505 & 209 & 26 & 2 & 57 & 18 & 663 & 461 & 154 & 125 & 61 & 679 & 740 & $39,991.8$ \\
\hline
\end{tabular}

\begin{tabular}{|c|c|c|c|c|c|c|c|c|c|c|c|c|c|c|c|c|}
\hline \multicolumn{17}{|c|}{ Feature Contexts } \\
\hline \multirow[b]{2}{*}{ Unit } & \multirow[b]{2}{*}{ Level } & \multirow[b]{2}{*}{ Fea No } & \multicolumn{3}{|c|}{ Size $(\mathrm{cm})$} & \multicolumn{4}{|c|}{ Material Type* } & \multicolumn{3}{|c|}{ Fracture Type** } & \multicolumn{2}{|c|}{ Cracks } & \multirow[b]{2}{*}{ Total } & \multirow[b]{2}{*}{ Wt (g) } \\
\hline & & & $0-4$ & $4-9$ & $9-15$ & $\mathrm{CC}$ & Ch & $\mathbf{O}$ & SS & Ang. & Rnd. & Tab. & $\mathbf{Y}$ & $\mathbf{N}$ & & \\
\hline $16-4$ & & 16 & 3 & 7 & 2 & & & & 12 & 11 & & 1 & 2 & 10 & 12 & $2,465.9$ \\
\hline $\mathrm{H} 7$ & 5 & 33 & 17 & 14 & & & 31 & & & 16 & 14 & 1 & 1 & 30 & 31 & $1,610.5$ \\
\hline $\mathrm{C} 1$ & 6 & 34 & 30 & 19 & 3 & & & & 52 & 42 & 3 & 7 & 6 & 46 & 52 & $3,415.1$ \\
\hline Subtotal & & & 50 & 40 & 5 & 0 & 31 & 0 & 64 & 69 & 17 & 9 & 9 & 86 & 95 & $7,491.5$ \\
\hline Total & & & 555 & 249 & 31 & $\mathbf{0}$ & 88 & 18 & 727 & 530 & 171 & 134 & $\begin{array}{ll}0 & 70 \\
\end{array}$ & 765 & 835 & $47,483.3$ \\
\hline
\end{tabular}

${ }^{*} \mathrm{CC}=$ Calcium Carbonate, $\mathrm{Ch}=$ Chert, $\mathrm{O}=$ Other, $\mathrm{Qtz}=$ Quartzite, and $\mathrm{SS}=$ Sandstone

**Ang.=Angular, Rnd.=Round, Tab.=Tabular 
features and limited frequencies of lithic debitage $\left(9 / \mathrm{m}^{2}\right)$ that were non-randomly distributed across the investigated block. Most cultural materials were in the eastern half, with those from the western half concentrated along the northern margin. The exception was burned rock Feature 16, located near the southern boundary. The distribution indicates that materials extended north, south, and east but not west of the excavation block limits. The slight westward dip in the natural deposits may have contributed to the apparent decrease of material remains in that direction.

The 378 pieces of lithic debitage were widely scattered from one end of the block to the other. About 73 percent were concentrated in nine moderate and five high-density units (Figure 7.5). The four eastern balks contained the vast majority, with the four densest units occurring in Balk F and another dense unit in Unit H7. The nine units that yielded moderate densities were primarily in Balks D, E, and F. These concentrations may reflect specific activity areas. Debitage in unit $\mathrm{H} 7$ reflects primarily core reduction with limited evidence of early and late stage biface reduction. This high frequency was mixed with dense burned rock from Feature 33, and the association with burned rocks appears to represent discarded debitage. Debitage was also associated with similar burned rock concentrations at Features 16 and 34. Most of the 14 units with high to moderate debitage concentrations were associated with high to moderate frequencies of burned rocks. This pattern at feature and non-feature areas with high quantities of burned rock and debitage implies a repetitive pattern of discard.

The horizontal distribution of the 740 nonfeature burned rocks was definitely non-random across the excavation block (Figure 7.5). Areas of high, moderate, and low frequencies of burned rock were identified. The units with the highest concentrations were widely distributed across seven units dispersed from one end of the block to the other. Two high-density units, $\mathrm{C} 1$ and $\mathrm{H} 7$, were immediately adjacent to dense burned rock Features 34 and 33, respectively. Both units had highly concentrated burned rocks and numerous scattered rocks. Unit $\mathrm{H} 7$ also contained high frequencies of lithic debitage. The other five high frequency units were adjacent to units that yielded moderate burned rock frequencies, indicating broad areas of scattered burned rocks. Moderate frequencies of burned rock occurred across the middle of Balk E, and along with the frequencies in Balks $\mathrm{D}$ and $\mathrm{F}$, appeared to be the most intensive areas for the burned rocks. These moderate and high frequency units were probably general discard areas. Most burned rock concentrations and associations reflect general discard, but the primary use areas and hearths or pit features were not apparent within the confines of the block excavations. The lack of burned rock in Balks $\mathrm{A}$ and $\mathrm{B}$ may indicate either that some other activity was present along the western part of the excavation block or that area was not utilized.

The 22 stone tools were broadly scattered with Balk $\mathrm{F}$ yielding 41 percent of the implements (Figure 7.5). Balks A and B at the western end of the excavation block lacked formal tools. This pattern further supports that the western margin of Occupation 2 activities and discard may have been near Balk C. Twenty-seven percent of the formal tools were east of the middle of the block, although Balk G lacked formal tools. All three bifaces were recovered near the middle of the Balks D, E, and F and were associated with moderate frequencies of burned rocks. At least one edge-modified flake also occurred within about $1 \mathrm{~m}$ of each biface (Figure 7.5).

A chert core (\#3769) was associated with burned rock Feature 33, which consists of a discard pile and a high frequency of lithic debitage. The associated core may strengthen the interpretation that this area functioned as a discard area and 


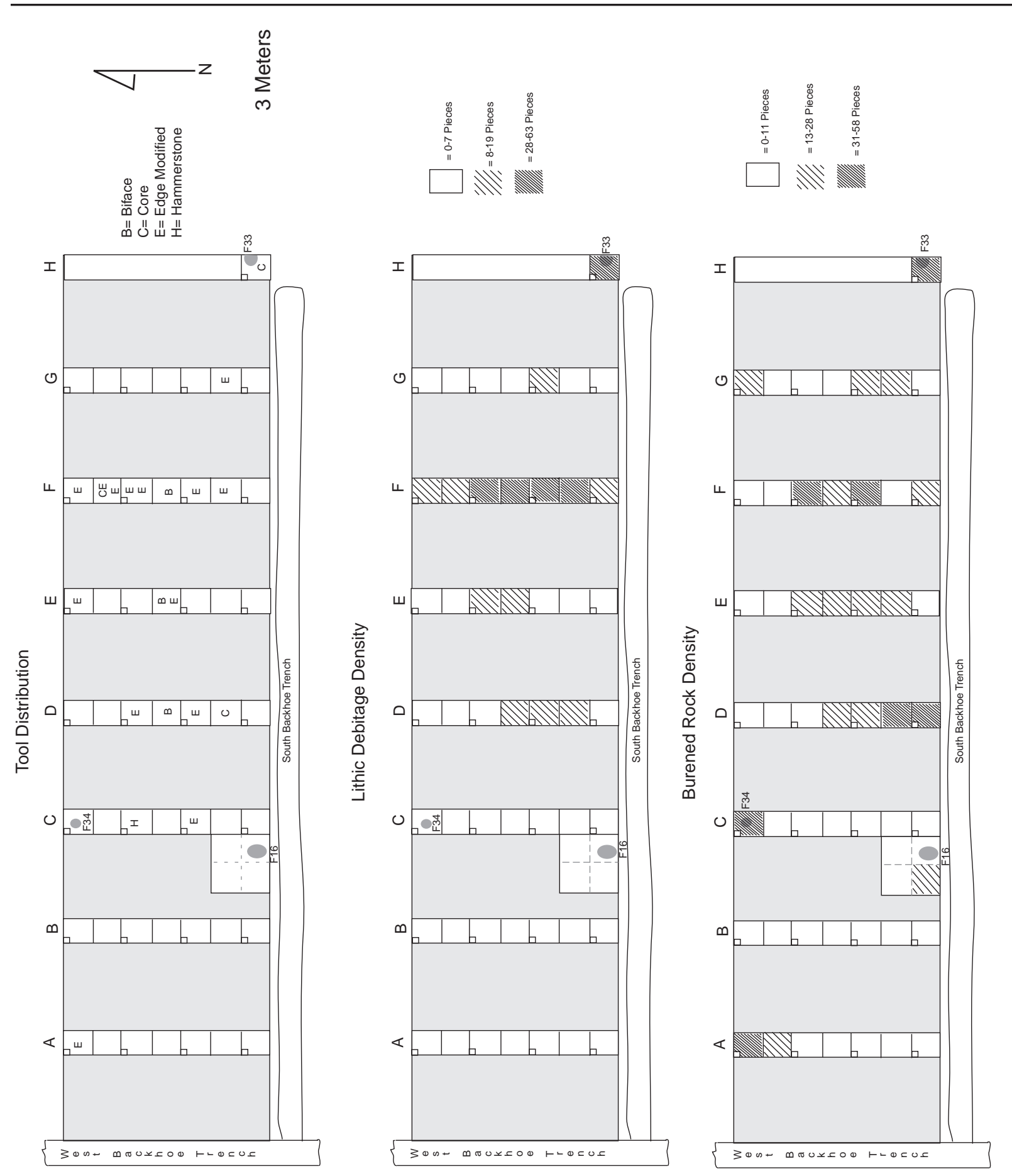

Figure 7.5 Horizontal Distribution of Occupation 2 Material.

not a primary knapping area. Two other cores (\#3434 and \#4221) were associated with moderate frequencies of lithic debitage and moderate to high frequencies of burned rocks in Units D6 and F2. Again, the association of multiple types of unrelated material remains may represent discarded material and not primary intact work areas.

The one hammerstone (\#4123) was associated with only three flakes in an area of very sparse lithic debitage and almost no burned rocks. This 
association also implies a discard area over a knapping area. One third $(n=5)$ of the edgemodified flakes were in units associated with very limited flakes or burned rocks. Their limited occurrence with associated other materials may reflect specific activity areas where these tools were used. Alternatively, they may have been tossed to their final positions.

No tools were recovered from the immediate vicinity of the three identified burned rocks concentrations, implying that the distribution reflects selective discard of certain types of material.

The horizontal plotting of only the specifically provenienced materials recorded by the TDS is presented in Figures 7.6 and 7.7. The overall horizontal pattern of all the different types of material remains displayed in Figure 7.6 does indicate that the materials were widely distributed, but they are concentrated more towards the eastern half of the excavation block. This overall horizontal pattern is skewed since not all the material was piece plotted using the TDS. The distribution patterns documented by the various excavated units in Figure 7.5 are more realistic because it accounts for all materials. Based on the piece plotting of burned rocks, Balk $\mathrm{F}$ and Balk $\mathrm{H} 7$ revealed a very high density of the larger burned rocks. The H7 burned rocks were part of Feature 33, but those burned rocks in Balk F were more scattered and not considered a feature. With under 10 percent of the lithic debitage individually plotted by the TDS, the overall horizontal representation of the lithic debitage in Figure 7.7 is significantly skewed and therefore misleading. In very gross terms, the general horizontal pattern of distribution reflects a concentration towards the eastern half. However, the more realistic horizontal distribution of lithic debitage is visible in Figure 7.5.

\subsection{SUMMARY AND INTERPRETATIONS}

This vertically well-defined occupation contained relatively sparse cultural material. Nearly 26 items $/ \mathrm{m}^{2}$ occurred non-randomly distributed across $44 \mathrm{~m}^{2}$ of hand-excavated area at depths between 55 and $70 \mathrm{cmbs}$. The roughly $10 \mathrm{~cm}$ thick occupation zone dips slightly to the west and north. It is about 15 to $18 \mathrm{~cm}$ below Occupation 1.

The chronometric age for Occupation 2 is extrapolated from a combination of wood charcoal dates from Occupations 1 and 5. Occupation 1 dated to about 2000 B.P. and Occupation 2 is estimated at a few hundred years earlier, at about 2300 B.P. The lack of diagnostic artifacts does not allow identification of specific cultural association. Since Tortugas points were recovered from Occupations 1 and 3, it is likely that cultural groups using that particular projectile point type may have been responsible for this occupation event.

Three features were identified. All were nonpatterned concentrations of burned rocks interpreted as being discarded rocks from cooking tasks. These three features contained 95 burned rocks that weighed 7,492 g, an average of $79 \mathrm{~g} /$ rock. The 740 scattered burned rocks weighed $39,992 \mathrm{~g}$, an average of about $54 \mathrm{~g} /$ rock. The burned rocks in the three features were some $25 \mathrm{~g}$ heavier than the scattered burned rocks on the occupation surface.

The lithic debitage averaged about $9 / \mathrm{m}^{2}$, but about 73 percent was concentrated in nine moderate and five high-frequency units, and it nearly always was associated with moderate to high frequencies of burned rocks. This association is interpreted as reflecting a discard pattern and not intact, in situ knapping localities. 


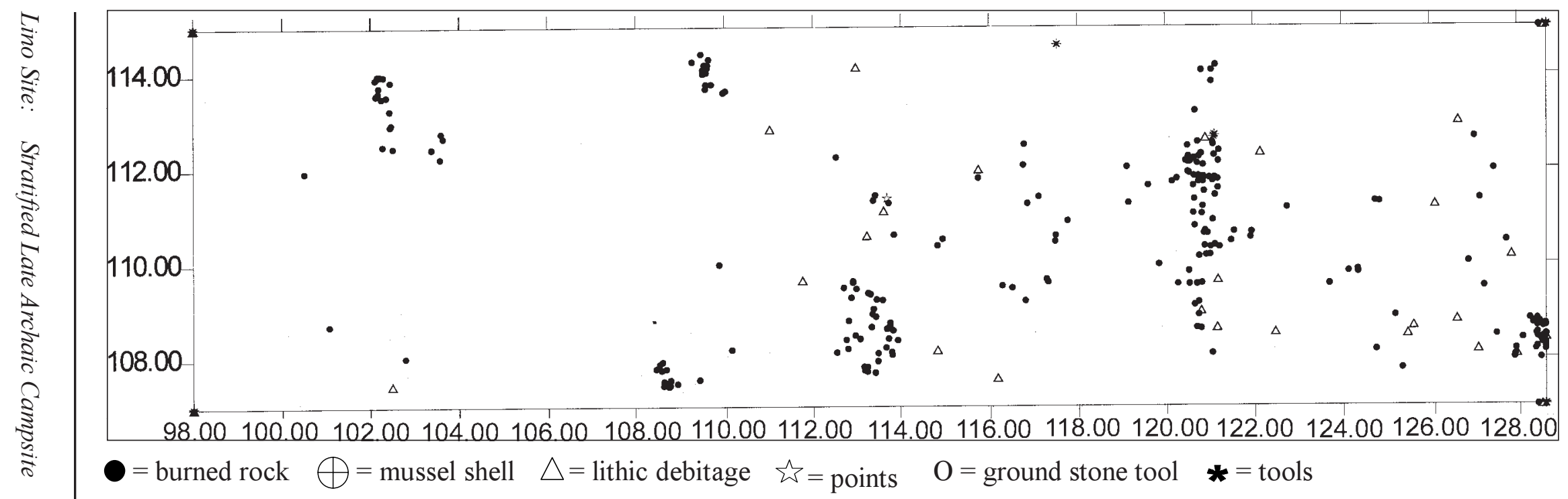

Figure 7.6 All TDS Shot In Material for Occupation 2.

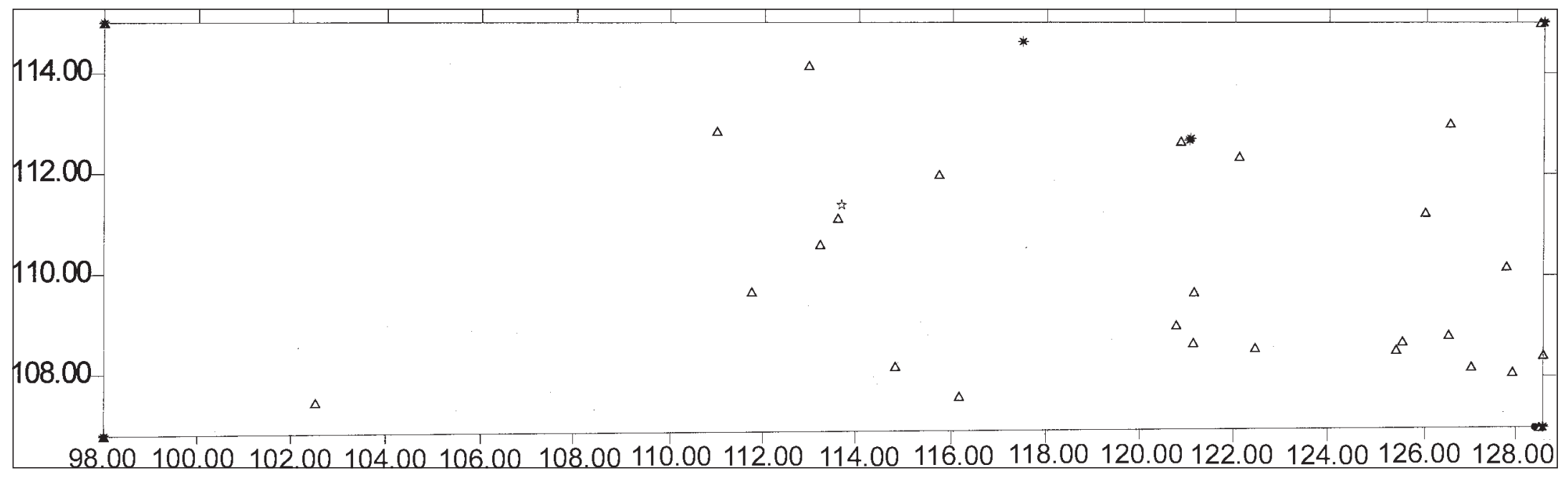

Figure 7.7 Lithic Debitage $(\triangle)$, Mussel Shells $(\oplus)$ and Stone Tools $(*)$ Shot In with the TDS for Occupation 2. 
The debitage was dominated by core reduction and late stage biface production; with uniface preparation apparently absent.

The stone tool assemblage was limited to 22 items representing less than two percent of the material recovered. These tools include three bifaces, three cores, a hammerstone, and 15 edge-modified flakes. All appeared to be manufactured from local cherts. This tool assemblage reflects a limited number of tasks that focused on flake and biface production, cutting, and light scraping tasks. A marble-size sandstone sphere from this occupation has an unknown function and may be a natural occurrence in the alluvial sediment.

The absence of bone reflects a preservation problem. The absence of mussel shells, which were present in Occupation 1, may be attributed to sampling error or change in subsistence. The scraping of hides as evident from use-wear on one edge-modified flake plus fatty acid and stable isotope residues from a large herbivore (probably a deer/antelope) and from plants that include Texas ebony beans provide hints of the subsistence resources used at this occupation.

The recovered 1,235 cultural items represent part of a broad occupation that apparently continued east, south, and possibly north. The reduction stages evident in the debitage assemblage and scattered and clustered burned rocks reflect general camp debris from a short-term huntergatherer site. The near absence of use-wear on the eight analyzed stone tools (three bifaces and five edge modified) support the contention for a short-term duration of tool use. The horizontal material patterning generally reflects discard over in situ series of events. 
Intentionally Left Blank 


\subsection{OCCUPATION 3}

This occupation zone consisted of widely scattered but diverse cultural remains concentrated between 70 and $80 \mathrm{cmbs}$. The ca. $10 \mathrm{~cm}$ thick zone dips some 5 to $10 \mathrm{~cm}$ towards the west and slightly to the north. The TDSplotted data reveal that this zone pinches out towards the east, just prior to reaching Balk G. The occupation area was not represented in Balks $A$ and $G$ on either end and is minimally represented in Gradall ${ }^{\mathrm{TM}}$ Area B. The area of Balk $\mathrm{F}$ best defined the vertical distribution of Occupation 3 materials between the other occupations by the presence of well-stratified concentrations of cultural materials. This cultural zone yielded burned rock and lithic debitage features, relatively limited quantities of scattered burned rocks and lithic debitage, a few chipped and ground stone tools, very sparse amounts of mussel shells, and a few scattered Rabdotus shells. Bone was again absent. The chronometric age of Occupation 3 was not directly established from dated organic materials extracted from this occupation. An estimated age was extrapolated from wood charcoal dates out of Occupations 1 and 5. Those two occupation zones yielded average radiometric ages of 2050 B.P and 3400 B.P., respectively (Table 5.3). Occupation 3 is estimated to date about 2700 B.P.
The cultural materials recovered from the $40 \mathrm{~m}^{2}$ of hand excavated balks and the $19 \mathrm{~m}^{2}$ of hand excavated units around three identified features discovered during Gradall ${ }^{\mathrm{TM}}$ stripping are presented by material class below. This is followed by a discussion of the horizontal distribution of the various occupational materials and then a summary and interpretation of events at Occupation 3.

\subsection{FEATURES}

Four features were recognized. Three were in Gradall ${ }^{\mathrm{TM}}$ stripped Areas B, F and G and one was in hand excavated Balk F (Table 8.1). These consisted of one burned rock concentration (Feature 32), one flake concentration (Feature 23), one well defined burned rock-filled basin (Feature 20), and one feature that represents dense occupational material (Feature 18). Feature 18 material (Figure 8.1) is discussed in the various material categories below and is not treated as a specific feature. The other three features are described individually below (Table 8.1).

Rock filled basin Feature 20 was in Gradall ${ }^{\mathrm{TM}}$ Area B toward the western end of the excavation block at about 70 to $80 \mathrm{cmbs}$ (Table 8.1, Figures

Table 8.1 Attributes of Features from Occupation 2.

\begin{tabular}{|c|c|c|c|c|c|c|c|c|c|}
\hline $\begin{array}{l}\text { Fea. } \\
\text { No. }\end{array}$ & Unit & $\begin{array}{l}\text { No. of } \\
\text { Units } \\
\text { Exc. }\end{array}$ & $\begin{array}{l}\text { Depth } \\
\text { (cmbs) }\end{array}$ & $\begin{array}{l}\text { Size } \\
(\mathbf{c m})\end{array}$ & Thickness & Description & Interpret. & $\begin{array}{c}\text { Associated } \\
\text { Artifacts }\end{array}$ & $\begin{array}{c}\text { Chrono. } \\
\text { Age } \\
\text { (B.P.) }\end{array}$ \\
\hline 18 & Area $G$ & 4 & $70-80$ & $\begin{array}{c}200 x \\
200\end{array}$ & 1 rock & $\begin{array}{c}\text { Occupational } \\
\text { debris }\end{array}$ & $\begin{array}{l}\text { Occupation } \\
\text { zone }\end{array}$ & $\begin{array}{l}1 \text { biface, much } \\
\text { BR, many flakes }\end{array}$ & \\
\hline 20 & Area B & 9 & $75-80$ & $\begin{array}{c}70 x \\
60\end{array}$ & 2 rocks & BR filled pit & $\begin{array}{l}\text { Heating } \\
\text { element }\end{array}$ & $\begin{array}{l}38 \mathrm{BR} \text {, burned } \\
\text { clay, charcoal }\end{array}$ & \\
\hline 23 & Area F & 6 & $65-76$ & $\begin{array}{c}15 \mathrm{x} \\
10\end{array}$ & 1 rock & Flake cluster & $\begin{array}{l}\text { Lithic } \\
\text { dump }\end{array}$ & $\begin{array}{c}16 \text { clustered } \\
\text { flakes, scattered } \\
\text { BR }\end{array}$ & \\
\hline 32 & $\mathrm{~F} 2$ & 1 & $70-80$ & $\begin{array}{c}30 x \\
40\end{array}$ & 1 rock & BR cluster & BR Dump & $\begin{array}{c}19 \text { BR, Tortugas } \\
\text { point }\end{array}$ & \\
\hline
\end{tabular}

$\mathrm{BR}=$ burned rock 
8.2, 8.3 and 8.4). The burned rock cluster measured 70 by $60 \mathrm{~cm}$ across and was about 12 $\mathrm{cm}$ deep in the middle of the basin (Figure 8.5). The charcoal-stained basin was faint but relatively well defined, with gradual sloping sides and quantities of charcoal occurring under the rocks. A slight color change from light oxidation of the surrounding sandy matrix was barely detected. Insect holes less than $1 \mathrm{~cm}$ in diameter were numerous below the basin and were filled with dark stained matrix. Charcoal chunks were present, and some $2 \mathrm{~cm}$ wide and 8 to $9 \mathrm{~cm}$ long pieces appeared to represent burned remnants of in situ sticks. Some charcoal chunks were individually collected from different areas of the feature. Wood charcoal was concentrated on the southwestern side of the basin just beyond the rocks and below the rocks on that side. Three separate wood charcoal chunks (\#3558-5a, $\# 3558-3 \mathrm{a}$, and \#3558-4a) were identified as mesquite (Appendix B).

The burned rocks were throughout the basin except along the southwestern side (Figure 8.5). At least six rocks along the outer margin were angled; some sloped inward and others sloped outward. Feature 20 contained 38 burned rocks that weighed $24,138 \mathrm{~g}$. Thirty-four pieces were sandstone (Table 8.2). Fewer than three percent were fewer than $4 \mathrm{~cm}$ in diameter, 34 percent were between 4 and $9 \mathrm{~cm}, 50$ percent were between 9 and $15 \mathrm{~cm}$, and 13 percent were greater than $15 \mathrm{~cm}$ in diameter. Seventy-four percent were angular in shape with another 24 percent being rounded. More than 60 percent had hairline cracks (Table 8.2). The average rock weight was $635 \mathrm{~g}$.

Four burned rocks (\#2065, \#2076, \#2090, and \#2092) had some of their interior matrix extracted and analyzed for isotopes and lipid residues. The stable carbon isotope analyses yielded $\delta^{13} \mathrm{C}$ values ranging between $-20.1 \%$ o and $-22.7 \%$, which appears to reflect a mixture of $\mathrm{C} 3$ and $\mathrm{C} 4 / \mathrm{CAM}$ resources (Appendix G).
The $\delta^{15} \mathrm{~N}$ values from those same rocks yielded values between $1.1 \%$ and $5.1 \%$. These values are sufficiently low so as to exclude prickly pear, but the results are not sufficiently definitive to identify what groups of plants or animals they represent. The fatty acid analyses on three of the same four burned rock residues yielded different results (Appendix G). Residue samples \#2090 (sample Lino 13) and \#2092 (sample Lino 15) reveal lipids from large herbivores. The associated stable isotope results from these rocks with $\delta^{13} \mathrm{C}$ values between $-20.2 \%$ o to $-22.7 \%$ o and the $\delta^{15} \mathrm{~N}$ values between $2.0 \%$ and 5.1\%o indicate that the herbivore was probably deer/ antelope. Sample \#2065 (sample Lino 14) yielded fatty acids very similar to mesquite and prickly pear (Appendix G). The isotope values would indicate the presence of mesquite over prickly pear. Since these three rocks were from what is interpreted as a heating element, and the rocks contained diverse organic residues, it is likely that the residues were in these rocks prior to their heating in pit Feature 20. If this is correct, then these burned rocks may have been reused and the residues were acquired in a previous cooking events. It is possible that the food residues were absorbed into the rocks while this feature was being used as a cooking element.

Thermal demagnetization was conducted on burned rock \#2090 from pit Feature 20. This rock apparently was heated to about 550 degrees $\mathrm{C}$ and had two magnetic components with the change occurring at about 200 degrees C. The change of the two components may reflect the use of this burned rock in stone boiling cooking. Although heated to this temperature, the interior matrix still yielded interpretable organic residues that were attributed to a large herbivore. Interestingly, the heating did not destroy all those residues. If this was only a heating element and not a cooking feature, then the residues were introduced to the burned rock during a previous event. This would support an interpretation of re-use of certain burned rocks. 
Table 8.2 Occupation 3 Burned Rock Data.

\begin{tabular}{|c|c|c|c|c|c|c|c|c|c|c|c|c|c|c|c|c|c|c|}
\hline \multicolumn{19}{|c|}{ Non Feature Contexts } \\
\hline \multirow[b]{2}{*}{ Unit } & \multirow[b]{2}{*}{ Level } & \multirow[b]{2}{*}{ Fea No } & \multicolumn{4}{|c|}{ Size $(\mathrm{cm})$} & \multicolumn{5}{|c|}{ Material Type* } & \multicolumn{3}{|c|}{ Fracture Type** } & \multicolumn{2}{|c|}{ Cracks } & \multirow[b]{2}{*}{ Total } & \multirow[b]{2}{*}{ Wt (g) } \\
\hline & & & $0-4$ & $4-9$ & $9-15$ & $>15$ & $\mathbf{C C}$ & Ch & $\mathbf{O}$ & Qtz & $\overline{\text { SS }}$ & Ang. & Rnd. & Tab. & $\mathbf{Y}$ & $\mathbf{N}$ & & \\
\hline $18-1$ & 7 & & 95 & 32 & 5 & & & 3 & 6 & 2 & 121 & 105 & 11 & 16 & 8 & 124 & 132 & $6,869.6$ \\
\hline $18-2$ & 7 & & 44 & 7 & 2 & & & & 1 & & 52 & 28 & 3 & 22 & 2 & 51 & 53 & $1,299.6$ \\
\hline $18-3$ & 7 & & 19 & 3 & & & & & & & 22 & 14 & 4 & 4 & 1 & 21 & 22 & 196.9 \\
\hline $18-4$ & 7 & & 38 & 20 & 2 & & & 8 & 3 & & 49 & 44 & 6 & 10 & 2 & 58 & 60 & $3,665.8$ \\
\hline $20-1$ & & & 7 & 1 & & & & & & & 8 & 8 & & & 1 & 7 & 8 & 87.3 \\
\hline $20-2$ & & & 3 & & & & & & & & 3 & 1 & 1 & 1 & 1 & 2 & 3 & 5.5 \\
\hline $20-3$ & & & 11 & 2 & 2 & & & 1 & & & 14 & 6 & & 9 & 1 & 14 & 15 & 732.0 \\
\hline $20-5$ & & & 4 & 2 & & & & & & & 6 & 4 & & 2 & & 6 & 6 & 41.7 \\
\hline $20-6$ & & & 2 & & & & & 1 & 3 & & 34 & 28 & 9 & 1 & 23 & 15 & 2 & 3.5 \\
\hline $20-7$ & & & 3 & 4 & 1 & & & & & & 2 & 2 & & & & 2 & 8 & 369.2 \\
\hline $20-8$ & & & & & 1 & & & & & & 8 & 3 & 3 & 2 & 2 & 6 & 1 & 123.3 \\
\hline $20-9$ & & & 15 & 2 & & & & & & & 1 & 1 & & & & 1 & 17 & 161.8 \\
\hline $23-1$ & & & 9 & 3 & & & & 1 & & & 16 & 10 & 5 & 2 & & 17 & 12 & 293.6 \\
\hline $23-2$ & & & 6 & 11 & 3 & & & 1 & & & 11 & 10 & 2 & & 2 & 10 & 20 & $6,791.8$ \\
\hline $23-3$ & & & 21 & 3 & & & & 4 & 1 & & 19 & 18 & 6 & & 1 & 23 & 24 & 294.0 \\
\hline $23-4$ & & & 9 & 2 & 1 & & & & & & 12 & 8 & 3 & 1 & & 12 & 12 & 632.6 \\
\hline B1 & 8 & & 2 & & & & & & & & 2 & & 2 & & & 2 & 2 & 6.2 \\
\hline B2 & 8 & & & 1 & & & & & & & 1 & 1 & & & & 1 & 1 & 105.8 \\
\hline B4 & 8 & & 18 & 5 & & & & & & & 23 & 12 & 4 & 7 & 3 & 20 & 23 & 562.9 \\
\hline B5 & 8 & & & 2 & & & & & & & 2 & & 2 & & & 2 & 2 & 620.1 \\
\hline B6 & 8 & & 2 & 1 & & & & & & & 3 & 2 & 1 & & 1 & 2 & 3 & 32.8 \\
\hline B7 & 8 & & 20 & 13 & & & & 4 & 2 & & 27 & 20 & 10 & 3 & 1 & 32 & 33 & 995.1 \\
\hline $\mathrm{C} 1$ & 8 & & 8 & 11 & 3 & & & & & & 22 & 16 & 4 & 2 & 3 & 19 & 22 & $5,621.2$ \\
\hline $\mathrm{C} 2$ & 8 & & 4 & 1 & 1 & & & & & & 6 & 5 & & 1 & 1 & 5 & 6 & 516.6 \\
\hline $\mathrm{C} 3$ & 8 & & 4 & & 1 & & & & & & 5 & & 3 & 2 & 1 & 4 & 5 & 803.0 \\
\hline $\mathrm{C} 4$ & 8 & & & 1 & & & & & & & 1 & & 1 & & & 1 & 1 & 50.0 \\
\hline C5 & 8 & & 3 & 1 & & & & & & & 4 & 3 & & 1 & & 4 & 4 & 702.4 \\
\hline C6 & 8 & & 1 & 3 & & & & 1 & & & 3 & 1 & 3 & & 2 & 2 & 4 & 136.3 \\
\hline C7 & 8 & & 1 & & & & & & & & 1 & & 1 & & & 1 & 1 & 5.9 \\
\hline D1 & 8 & & 16 & 5 & 1 & & & & 1 & & 21 & 14 & 7 & 1 & 3 & 19 & 22 & 733.2 \\
\hline D2 & 8 & & 24 & 3 & & & & & & & 27 & 16 & 8 & 3 & 3 & 24 & 27 & 350.9 \\
\hline D3 & 8 & & 3 & 1 & & & & & & & 4 & 1 & 2 & 1 & & 4 & 4 & 49.5 \\
\hline D4 & 8 & & & 1 & & & & & & & 1 & 1 & & & & 1 & 1 & 255.6 \\
\hline D5 & 8 & & 1 & 1 & 1 & & & 1 & & & 2 & 1 & 2 & & & 3 & 3 & 736.2 \\
\hline D6 & 8 & & 8 & 2 & & & & 1 & & & 9 & 5 & 2 & 3 & & 10 & 10 & 181.7 \\
\hline D7 & 8 & & 1 & 1 & 1 & & & & & & 3 & & & 3 & & 3 & 3 & 406.9 \\
\hline E1 & 8 & & 2 & 1 & & & & & & & 3 & 2 & & 1 & & 3 & 3 & 84.2 \\
\hline E2 & $8 \& 9$ & & 16 & 2 & & & 1 & 2 & 2 & & 13 & 11 & 6 & 1 & & 18 & 18 & 731.8 \\
\hline E3 & $8 \& 9$ & & 12 & 4 & & & & & 1 & & 15 & 11 & 3 & 2 & 1 & 15 & 16 & 598.7 \\
\hline E4 & $8 \& 9$ & & 7 & 6 & & & & 1 & 7 & & 5 & 6 & 4 & 3 & 4 & 9 & 13 & 787.0 \\
\hline E5 & $8 \& 9$ & & 13 & 5 & 2 & & & & & & 20 & 9 & 8 & 3 & 2 & 18 & 20 & $2,303.1$ \\
\hline E6 & $8 \& 9$ & & 24 & 9 & & & & 3 & & & 30 & 19 & 6 & 8 & 4 & 29 & 33 & 955.7 \\
\hline E7 & $8 \& 9$ & & 11 & 2 & & & & 2 & & & 11 & 10 & 2 & 1 & & 13 & 13 & 696.9 \\
\hline $\mathrm{F} 1$ & 8 & & 26 & 12 & 1 & & & 8 & & & 31 & 24 & 13 & 2 & 2 & 37 & 39 & $10,838.8$ \\
\hline $\mathrm{F} 2$ & 8 & & 20 & 8 & & & & 1 & & & 27 & 19 & 3 & 6 & 2 & 26 & 28 & 449.8 \\
\hline F3 & 8 & & 16 & 9 & & & & & & & 25 & 17 & 5 & 3 & 1 & 24 & 25 & $1,721.4$ \\
\hline $\mathrm{F} 4$ & 8 & & 17 & 5 & & & & & & & 22 & 14 & 6 & 2 & 2 & 20 & 22 & $2,190.2$ \\
\hline F5 & 8 & & 6 & 2 & & & & & & & 8 & 5 & 2 & 1 & & 8 & 8 & 217.2 \\
\hline F6 & 8 & & 15 & 13 & & & & 1 & 5 & & 22 & 13 & 7 & 8 & 1 & 27 & 28 & $10,513.2$ \\
\hline F7 & 8 & & 18 & 9 & & & & & 2 & & 25 & 18 & 3 & 6 & 5 & 22 & 27 & 793.5 \\
\hline ubtotal & & & 605 & 232 & 28 & 0 & 1 & 44 & 34 & 2 & 802 & 566 & 173 & 144 & 86 & 797 & 865 & $67,322.0$ \\
\hline
\end{tabular}

\begin{tabular}{|c|c|c|c|c|c|c|c|c|c|c|c|c|c|c|c|c|c|c|}
\hline \multicolumn{19}{|c|}{ Feature Contexts } \\
\hline \multirow[b]{2}{*}{ Unit } & \multirow[b]{2}{*}{ Level } & \multirow[b]{2}{*}{ Fea No } & \multicolumn{4}{|c|}{ Size $(\mathrm{cm})$} & \multicolumn{5}{|c|}{ Material Type* } & \multicolumn{3}{|c|}{ Fracture Type** } & \multicolumn{2}{|c|}{ Cracks } & \multirow[b]{2}{*}{ Total } & \multirow[b]{2}{*}{ Wt (g) } \\
\hline & & & 0-4 & $4-9$ & $9-15$ & $>15$ & $\overline{\mathrm{CC}}$ & Ch & $\mathbf{O}$ & Qtz & SS & Ang. & Rnd. & Tab. & $\mathbf{Y}$ & $\overline{\mathbf{N}}$ & & \\
\hline $20-5$ & & 20 & 1 & 13 & 19 & 5 & & 1 & 3 & & 34 & 28 & 9 & 1 & 23 & 15 & 38 & $24,138.1$ \\
\hline $23-1$ & & 23 & & 2 & 1 & & & 3 & & & & 2 & 1 & & & 3 & 3 & 414.1 \\
\hline F2 & & 32 & 7 & 9 & 3 & & & & & & 19 & 16 & & 3 & & 19 & 19 & $3,013.2$ \\
\hline Subtotal & & & 8 & 24 & 23 & 5 & 0 & 4 & 3 & 0 & 53 & 46 & 10 & 4 & 23 & 37 & 60 & $27,565.4$ \\
\hline Total & & & 613 & 256 & 51 & 5 & 1 & 48 & 37 & 2 & 855 & 612 & 183 & 148 & 109 & 834 & 925 & $94,887.4$ \\
\hline
\end{tabular}

${ }^{*} \mathrm{CC}=$ Calcium Carbonate, $\mathrm{Ch}=$ Chert, $\mathrm{O}=$ Other, $\mathrm{Qtz}=$ Quartzite, and $\mathrm{SS}=$ Sandstone

**Ang.=Angular, Rnd.=Round, Tab.=Tabular 


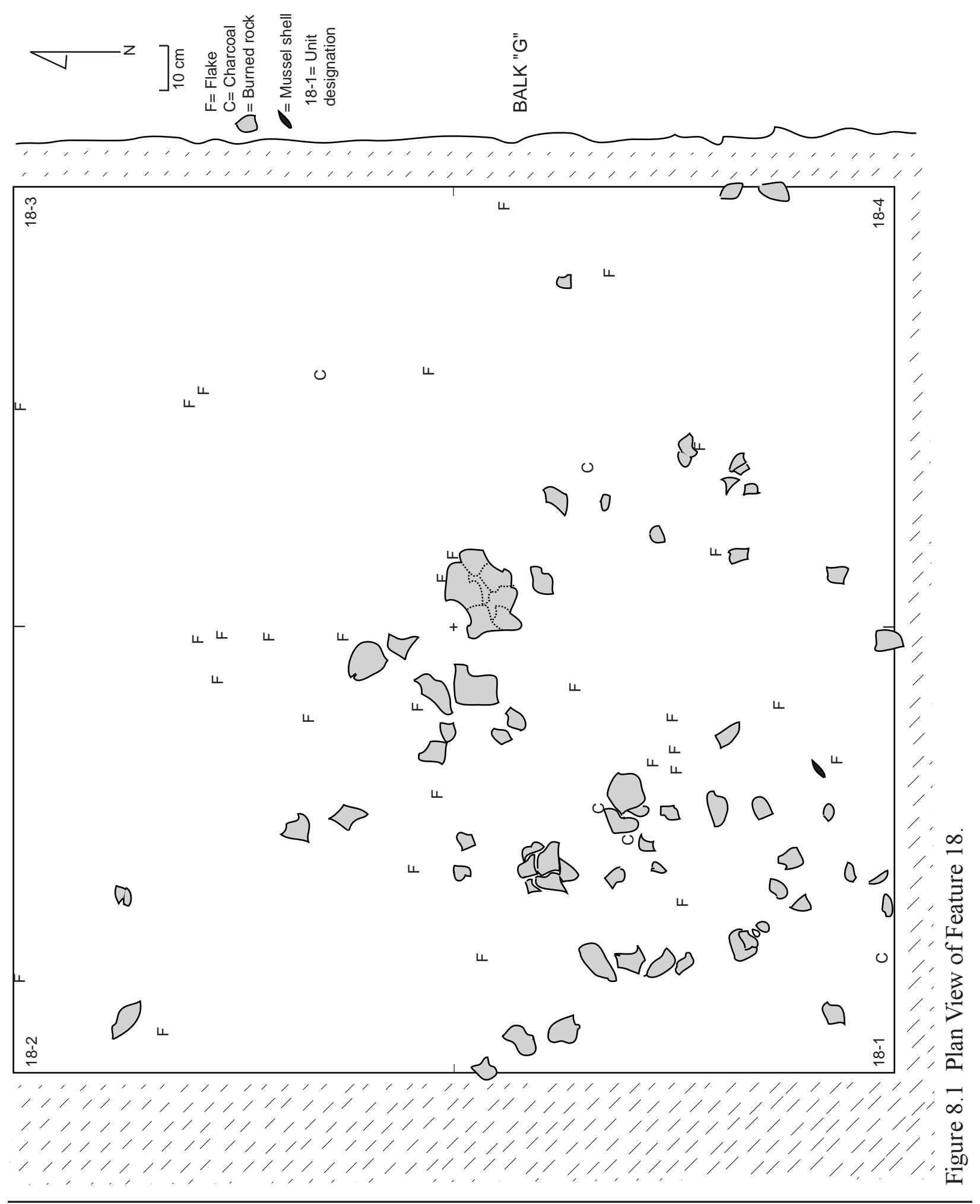




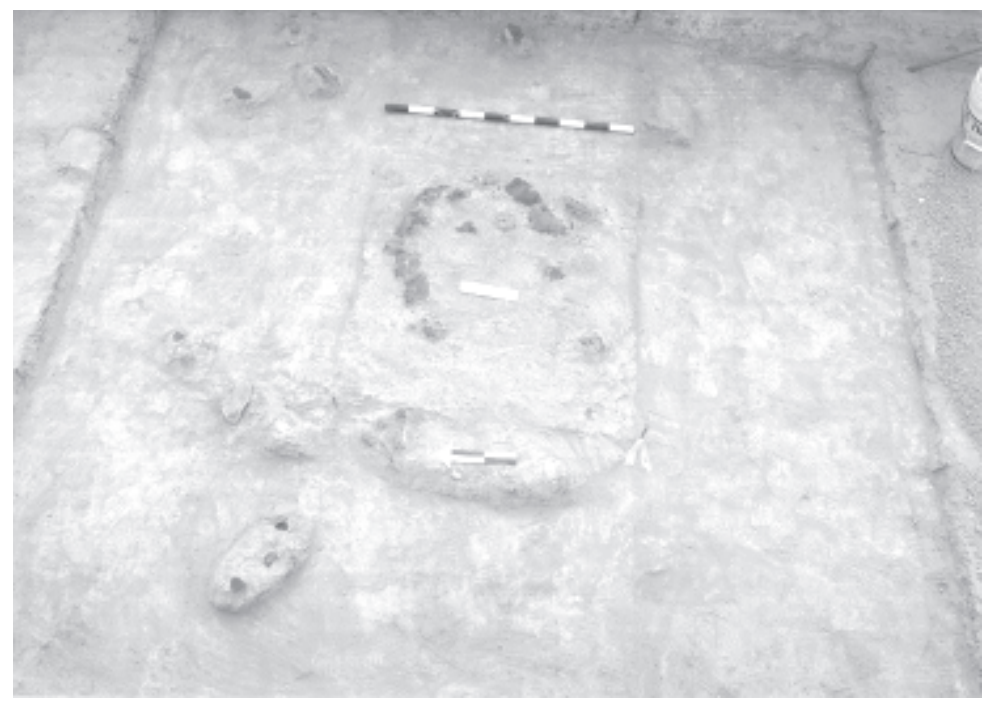

Figure 8.2 Plan View of Feature 20 Prior to Excavation.

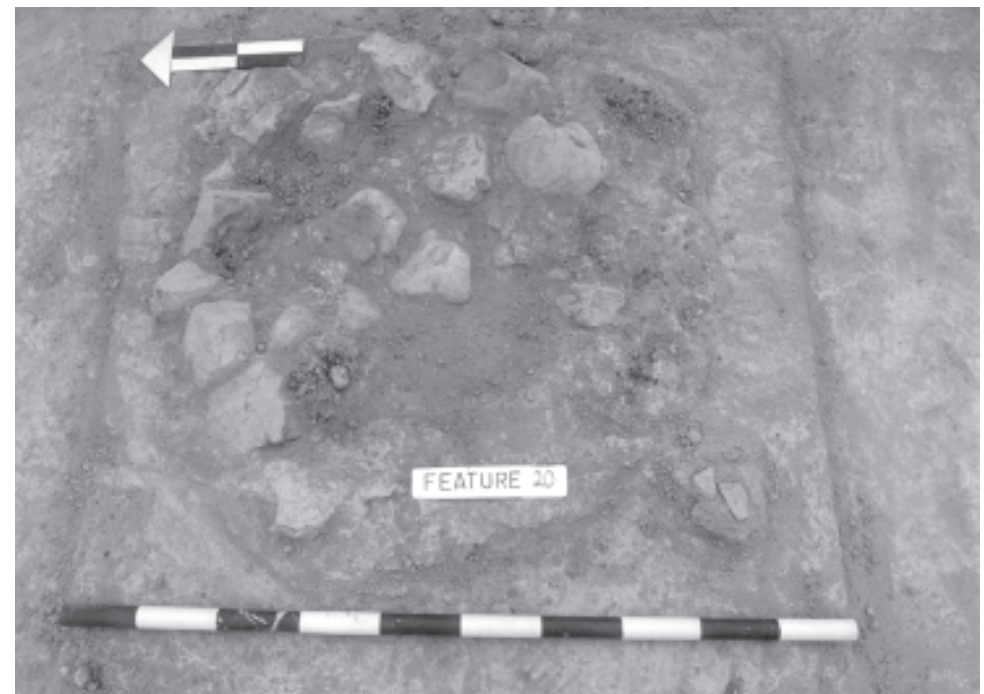

Figure 8.3 Plan View of Feature 20 during Excavation.

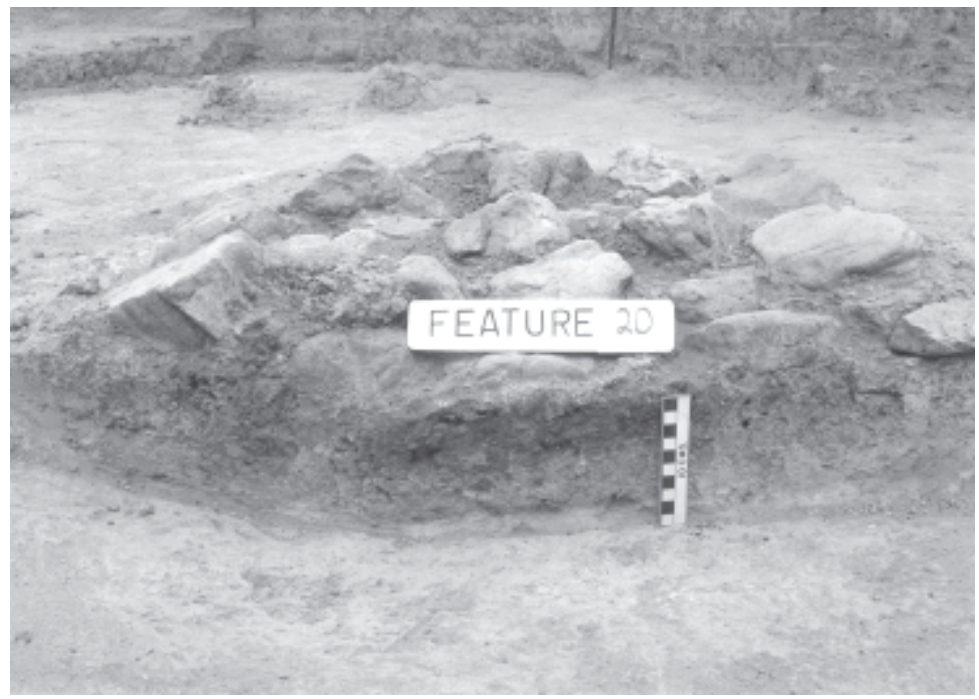

Figure 8.4 Profile View of Feature 20 Prior to Excavation. 


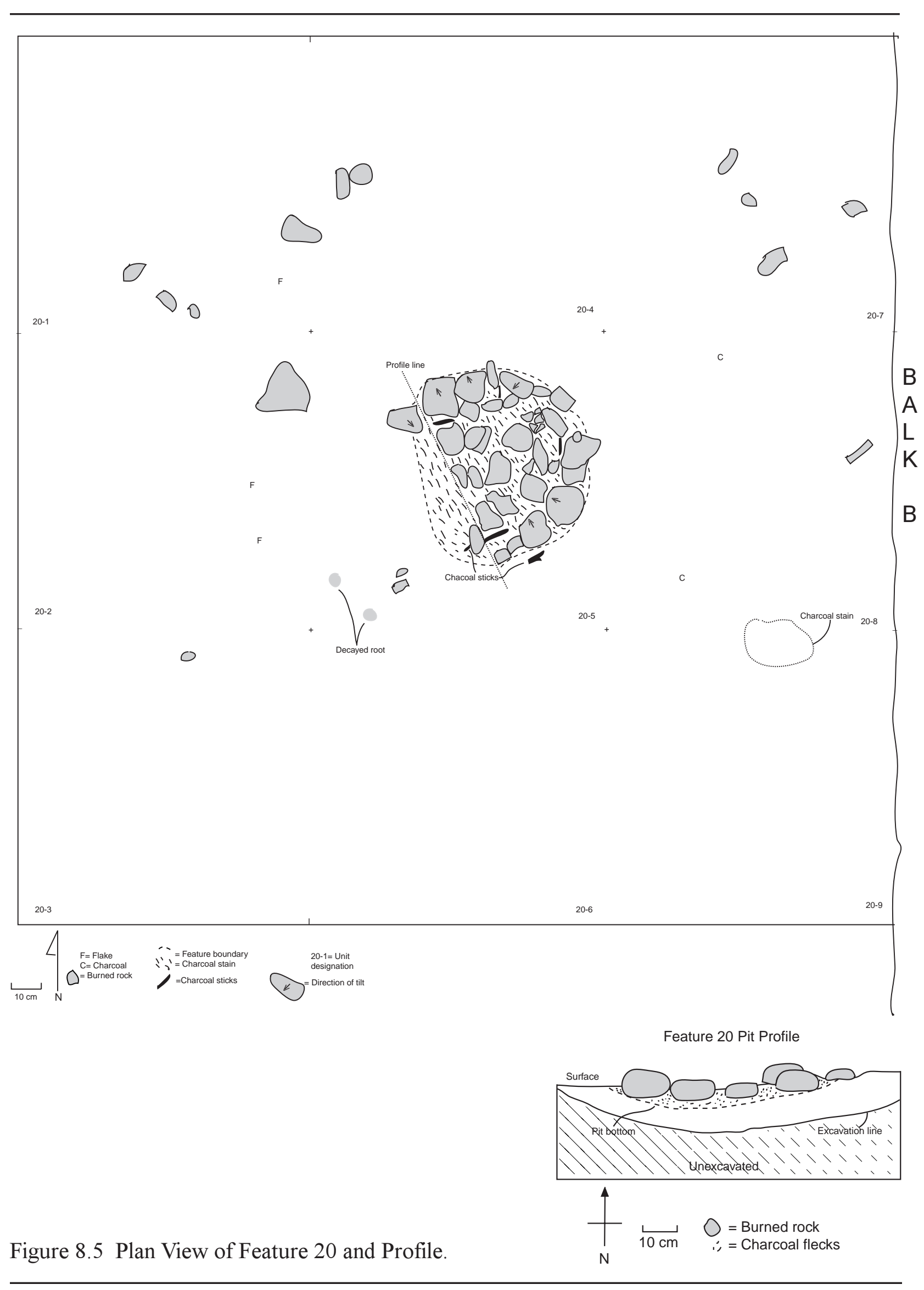


No ash, flakes over $6.4 \mathrm{~mm}$, or major parts of mussel shells were in this well-defined rock filled basin. Thirty-five liters of basin matrix were floated and yielded abundant charcoal (2.4 g), 17 tiny flakes that weighed a total of $0.9 \mathrm{~g}$, fragmented snail shells (6.2 g), $17.5 \mathrm{~g}$ of burned clay lumps, and $484 \mathrm{~g}$ of burned rock fragments (Table 6.3). The largest burned clay lump was about $1.5 \mathrm{~cm}$ in diameter, but most pieces were between 2 and $4 \mathrm{~mm}$. Most of the 17 tiny flakes were heat shatter from burned chert; only about five were actually flakes. This rock filled basin with quantities of charcoal under the rocks and along the southwestern edge is interpreted as an in situ rock-heating pit. Feature 20 is nearly identical in shape, size, and basin thickness to Feature 14 in Occupation 1, which is thought to have served the same purpose.

Features 20's discovery near the center of Gradall $^{\mathrm{TM}}$ Area B promoted the use of and excavations to occur completely around this intact feature. The eight hand excavated units that surrounded Feature 20 yielded a few scattered burned rocks, an occasional chunk of charcoal, and a few pieces of lithic debitage (Figure 8.5). The charcoal chunks were more frequent on the eastern side of the feature, whereas the chert flakes were more abundant on the western side. The flake types were nearly equally divided between core and late-stage biface flakes. One relatively large sandstone burned rock was found about $30 \mathrm{~cm}$ west of the basin. This rock may have had a specific function, such as a weight, a support, or platform for an unspecified activity.

Feature 23 consisted of 20 chert flakes clustered in an area $16 \mathrm{~cm}$ in diameter (Figure 8.6). All 20 pieces are a light gray in color, some with tiny dark gray specks and others without the specks. Even though slight differences in the gray color exist they could have been derived from the same cobble. Twelve are late stage biface reduction flakes; another two are core flakes based on the thickness. Three are platform preparation flakes, and three are indeterminate pieces. All but one complete core flake lacked cortex. None of these flakes revealed evidence of any type of heat alteration. Four late stage biface flakes were complete while others represented proximal, medial, and distal fragments. This cluster appears to reflect at least two stages of cobble reduction. In conjunction with the very tight spatial clustering, Feature 23 is interpreted as a dump of knapping debris.

The six hand dug units around Feature 23 recovered occupational material that included scattered burned rocks, numerous chert flakes, a mussel shell valve, and charcoal chunks. These were found east of the flake concentration and represent numerous tasks from the occupation. The unit immediately southeast yielded a high density of flakes and a distal biface (\#2139) of brown chert, which may have represented an in situ knapping area.

Feature 32 consisted of a tight cluster of 19 burned rocks near the middle of Unit F2 at depths between 78 to $80 \mathrm{cmbs}$. The burned rocks were clustered in an area about 45 by $40 \mathrm{~cm}$ in diameter and in no discernible pattern (Figures 8.7 and 8.8). Three chert flakes were associated. The north-south cross section failed to disclose any type of pit, charcoal, or ash staining. About 37 percent of the burned rocks were fewer than $4 \mathrm{~cm}$ in size, 47 percent were in the 4 to $9 \mathrm{~cm}$ size group, another 16 percent were greater than $9 \mathrm{~cm}$ in size. All burned rocks were sandstone; 84 percent were angular, and none had cracks. The 19 pieces weighed 3,013 g, for an average of about $159 \mathrm{~g} /$ rock.

Burned rocks \#3498 and \#3624 from Feature 32 had interior matrix extracted and analyzed for lipid and isotopes. The stable carbon and nitrogen isotope analyses yielded $\delta^{13} \mathrm{C}$ values of $-19.8 \%$ and $-21.4 \%$ (Appendix D). These appear to represent a mixture of $\mathrm{C} 3$ and $\mathrm{C} 4 / \mathrm{CAM}$ 


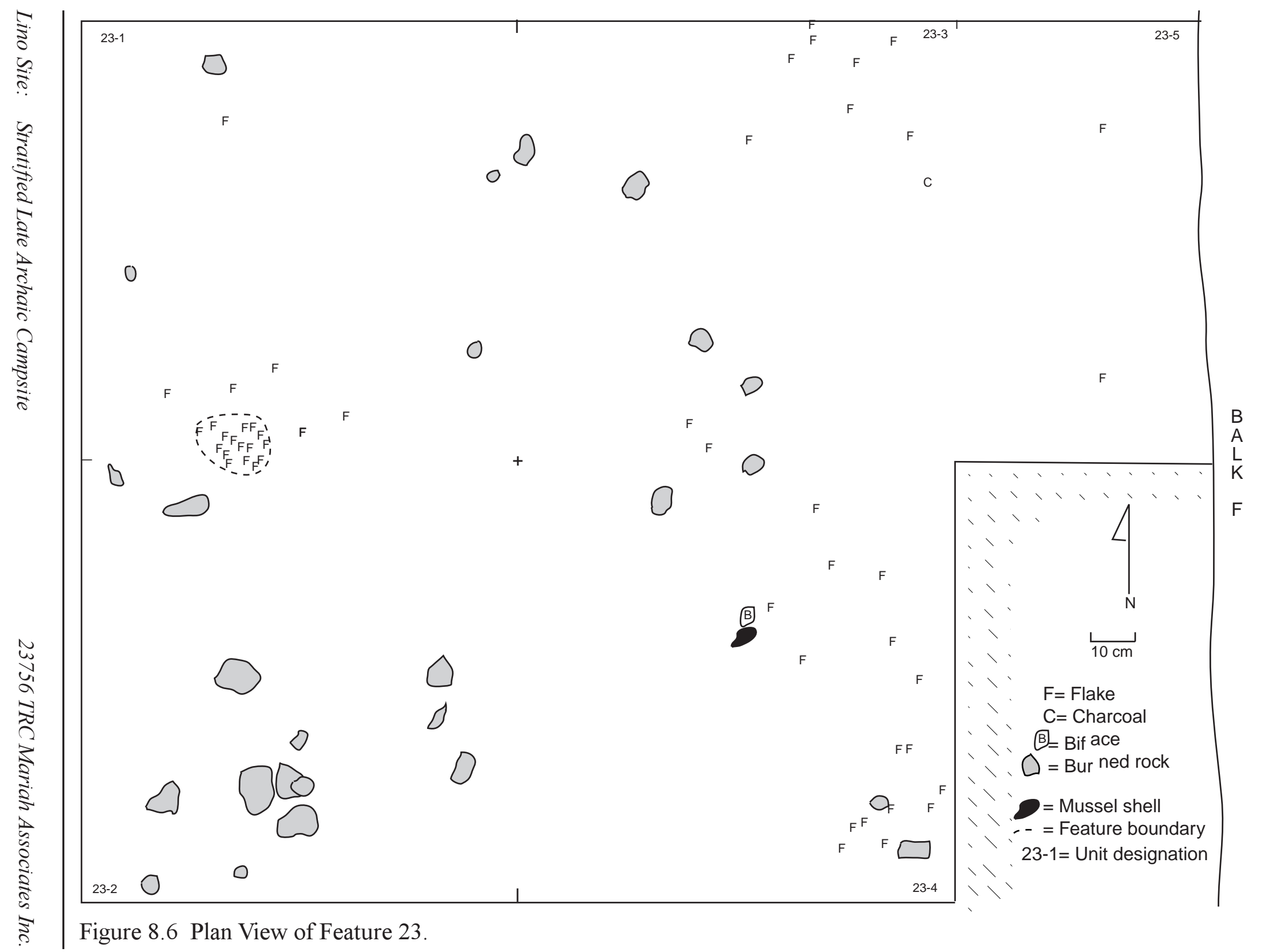




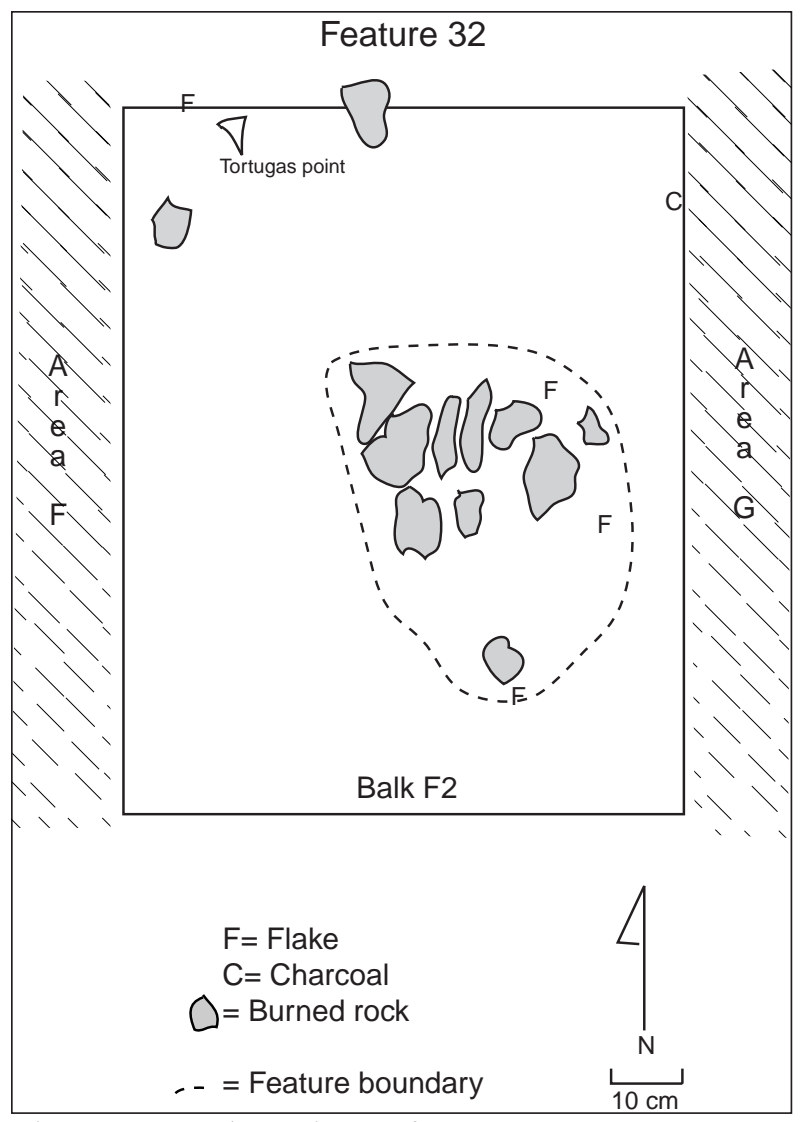

Figure 8.7 Plan View of Feature 32.

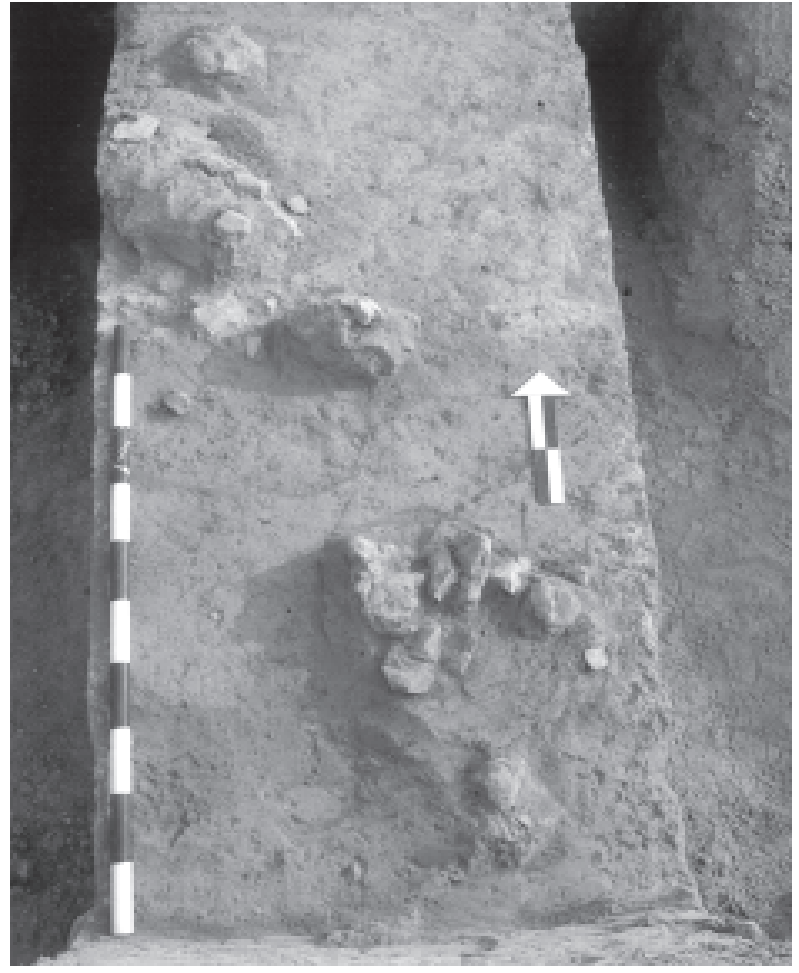

Figure 8.8 Overview of Feature 32 with Associated Tortugas Point. plant and animal resources. The $\delta^{15} \mathrm{~N}$ values were 5.9\%o and 4.2\%o for rocks \#3498 and \#3624-2, respectively (Appendix D). These are also thought to represent a mixture of resources. The lipid analyses on these same two residue samples were inconclusive (Appendix G). Neither \#3624-2 (sample Lino 31) nor \#3498 (sample Lino 32) yielded sufficient fatty acids to be interpretable.

A sample of 7.5 liters of floated matrix from around the burned rocks yielded $1.2 \mathrm{~g}$ of snail shell fragments, four tiny chert flakes, $124 \mathrm{~g}$ of burned rock crumbs, seven chert flakes greater than $6.3 \mathrm{~mm}$, and an occasional unburned seed (Table 6.3).

This same level in Unit F2 also yielded a complete chert Tortugas point (\#3491) from 30 $\mathrm{cm}$ to the northwest of Feature 32, a chunk of charcoal about $20 \mathrm{~cm}$ to the northeast, about 10 chert flakes, and a couple of scattered burned rocks that extend north about $50 \mathrm{~cm}$. The tightly clustered burned rocks with associated chert flakes are interpreted as a secondary dump in an occupational zone.

\subsection{CHIPPED LITHIC ASSEMBLAGE}

The lithic assemblage from the hand excavated balks $\left(40 \mathrm{~m}^{2}\right)$ and the hand-excavated units around the three features $\left(19 \mathrm{~m}^{2}\right)$ yielded 666 pieces of unmodified chipped stone debitage. This occupation yielded about 11 pieces of lithic debitage per square meter. The raw material was all chert except for three pieces of quartzite. All raw materials could have been procured from local gravel sources. Color differences exist in the chert debitage, but in very general terms, most are tans, grays, and browns, with some occurrences of white and dark red hues.

The debitage was classified into six recognizable types (Table 8.3). Core (33 percent) and latestage (30 percent) biface flakes dominated the 
Table 8.3 Occupation 3 Lithic Debitage Analysis.

\begin{tabular}{|c|c|c|c|c|c|c|c|}
\hline \multirow[b]{2}{*}{ Condition } & \multicolumn{6}{|c|}{ Flake Type } & \multirow[b]{2}{*}{ Total } \\
\hline & $\begin{array}{c}\text { angular } \\
\text { debris }\end{array}$ & core & $\begin{array}{c}\text { early } \\
\text { biface }\end{array}$ & Indet. & $\begin{array}{c}\text { late } \\
\text { biface }\end{array}$ & uniface & \\
\hline \multirow[t]{2}{*}{ complete } & & 80 & 15 & 40 & 41 & 1 & 177 \\
\hline & - & $36 \%$ & $14 \%$ & $32 \%$ & $21 \%$ & $100 \%$ & $27 \%$ \\
\hline \multirow[t]{2}{*}{ distal } & & 34 & 18 & 16 & 43 & & 111 \\
\hline & - & $15 \%$ & $17 \%$ & $13 \%$ & $22 \%$ & - & $17 \%$ \\
\hline \multirow[t]{2}{*}{ fragment } & 11 & & & & & & 11 \\
\hline & $100 \%$ & - & - & - & - & - & $2 \%$ \\
\hline \multirow[t]{2}{*}{ medial } & & 38 & 29 & 62 & 49 & & 178 \\
\hline & - & $17 \%$ & $27 \%$ & $50 \%$ & $25 \%$ & - & $27 \%$ \\
\hline \multirow[t]{2}{*}{ proximal } & & 71 & 46 & 7 & 65 & & 189 \\
\hline & - & $32 \%$ & $43 \%$ & $6 \%$ & $33 \%$ & - & $28 \%$ \\
\hline \multirow{2}{*}{ Total } & 11 & 223 & 108 & 125 & 198 & 1 & 666 \\
\hline & $2 \%$ & 33\% & $16 \%$ & $19 \%$ & $30 \%$ & $\mathbf{0} \%$ & $100 \%$ \\
\hline \multirow[b]{2}{*}{ Cortex } & \multicolumn{6}{|c|}{ Flake Type } & \\
\hline & $\begin{array}{c}\text { angular } \\
\text { debris }\end{array}$ & core & $\begin{array}{c}\text { early } \\
\text { biface }\end{array}$ & Indet. & $\begin{array}{c}\text { late } \\
\text { biface }\end{array}$ & uniface & Total \\
\hline \multirow[t]{2}{*}{ primary } & & 13 & & & & & 13 \\
\hline & - & $6 \%$ & - & - & - & - & $2 \%$ \\
\hline \multirow[t]{2}{*}{ secondary } & 4 & 141 & 14 & 23 & 3 & 1 & 186 \\
\hline & $36 \%$ & $63 \%$ & $13 \%$ & $18 \%$ & $2 \%$ & $100 \%$ & $28 \%$ \\
\hline \multirow[t]{2}{*}{ tertiary } & 7 & 69 & 94 & 102 & 195 & & 467 \\
\hline & $64 \%$ & $31 \%$ & $87 \%$ & $82 \%$ & $98 \%$ & - & $70 \%$ \\
\hline \multirow[t]{2}{*}{ Total } & 11 & 223 & 108 & 125 & 198 & 1 & \multirow{2}{*}{$\begin{array}{l}666 \\
100 \%\end{array}$} \\
\hline & $2 \%$ & 33\% & $16 \%$ & $19 \%$ & $30 \%$ & $\mathbf{0} \%$ & \\
\hline \multirow{4}{*}{$\frac{\text { Heating }}{\text { crazed }}$} & \multicolumn{6}{|c|}{ Flake Type } & \\
\hline & $\begin{array}{c}\text { angular } \\
\text { debris }\end{array}$ & core & $\begin{array}{c}\text { early } \\
\text { biface }\end{array}$ & Indet. & $\begin{array}{c}\text { late } \\
\text { biface }\end{array}$ & uniface & Total \\
\hline & & 1 & 1 & 4 & & & 6 \\
\hline & - & $0 \%$ & $1 \%$ & $3 \%$ & - & - & $1 \%$ \\
\hline \multirow[t]{2}{*}{ indet. } & 1 & 34 & 5 & 16 & 5 & & 61 \\
\hline & $9 \%$ & $15 \%$ & $5 \%$ & $13 \%$ & $3 \%$ & - & $9 \%$ \\
\hline \multirow[t]{2}{*}{ none } & 10 & 181 & 95 & 100 & 192 & 1 & 579 \\
\hline & $91 \%$ & $81 \%$ & $88 \%$ & $80 \%$ & $97 \%$ & $100 \%$ & $87 \%$ \\
\hline \multirow[t]{2}{*}{ spall } & & 6 & 3 & 5 & 1 & & 15 \\
\hline & - & $3 \%$ & $3 \%$ & $4 \%$ & $1 \%$ & - & $2 \%$ \\
\hline \multirow[t]{2}{*}{ treatment } & & 1 & 4 & & & & 5 \\
\hline & - & $0 \%$ & $4 \%$ & - & - & - & $1 \%$ \\
\hline \multirow[t]{2}{*}{ Total } & 11 & 223 & 108 & 125 & 198 & 1 & 666 \\
\hline & $2 \%$ & $33 \%$ & $16 \%$ & $19 \%$ & $30 \%$ & $0 \%$ & $100 \%$ \\
\hline
\end{tabular}

assemblage, followed by indeterminate (19 percent) and early-stage (16 percent) biface flakes. These flake frequencies reflect that most knapping activity related to core and biface reduction. Almost no uniface maintenance was conducted unless the screen size used was insufficient to capture these flake types. Biface reduction occurred, but the early stages of production were not as common as later stage production. However, some core flakes may have come from early stages of bifaces.

The complete, medial, and proximal condition of the individual pieces are relatively equally represented and range between 27 percent and 28 percent (Table 8.3). Distal fragments appear underrepresented at only 17 percent. Angular debris is quite infrequent at two percent. These frequencies are nearly identical to those identified from Occupation 2. The higher frequency of complete pieces associated with core flakes could be due to their thickness and strength relative to biface reduction flakes. Experimental knapping has also documented that multidirectional core reduction yielded more complete flakes (Tomka and Fields 1990).

Cortex remains on 30 percent of the debitage, with 69 percent of core flakes exhibiting cortex (Table 8.3). The high frequency of cortex on the core flakes reflects the decortification of the original nodule early on in the reduction strategy. Some cortex remains on the early stage bifaces, but little or no cortex is present on late stage biface flakes. The presence of cortex on angular pieces of debris probably reflects their origin in the core reduction process.

Heat alterations (crazing and spalls) account for three percent. Heat spalls account for about two-thirds of the total (Table 8.3). These heat alterations probably resulted from direct exposure of chert debris to fires, which probably reflects where this waste material was discarded. Less than one percent appeared to have been heat treated. This is similar to the proportion of heated materials that was observed in Occupation 1. Intentional heat treating of chert to improve knapping qualities was not a standard practice.

\subsection{CHIPPED STONE TOOLS}

The recognized chipped-stone tool assemblage was classified into five form/functional classes and consists of eight projectile points, eight bifaces, two scrapers, 29 edge-modified flakes, and one core. As a group, these 54 tools account for three percent of the total material recovered 
from Occupation 3 encompassed by the hand excavations of $59 \mathrm{~m}^{2}$.

The eight projectile points included five Tortugas points, two unknown points, and one complete Refugio point (Table 8.4, Figure 8.9). Two of the five Tortugas points are complete. Three have straight bases, one has a concave base, and one complete specimen has a convex base. All five specimens have parallel basal thinning scars, but only one has a beveled blade edge. One specimen untyped specimen is a distal fragment with one beveled edge. One of the unknown point types has a use break. Based on color and form, specimen \#5072 appears to be the distal tip of specimen \#2652 with a missing middle section. They are the same dark, fine grained quartzite with similar workmanship. The breaks represent a manufacture shock, possibly from removing a large basal flake that hinged. The Refugio is nearly complete and lacks only the very tip (Figure 8.9). It appears to have been manufactured from yellowish fine-grained quartzite. It has a rounded base with convex lateral edges tapering into the tip. Both faces are completely modified with tiny, wellcontrolled pressure flakes along the very margins. The lateral edges appear to have been dulled through use. All are chert except for one Tortugas base and one Refugio, which are finegrained quartzites.

The eight bifaces included two complete specimens, three proximal ends, two medial fragments, and one distal fragment. The two complete bifaces represent early and late stages of manufacture (Figure 8.9). The late stage biface (\#2671) is triangular in outline and has the general form of a large Tortugas, but this piece is asymmetrical and relatively thicker than expected for most Tortugas points and thus is classified as a biface. The early stage specimen is oval. At least three have manufacture breaks. One proximal end has a use break and appears to be from a middle stage of biface manufacture.
Two specimens are in the late stage and one in the middle stage of the reduction sequence. The late stage bifaces vary in shapes and include rectangular, lanceolate, and triangular forms (Table 8.5).

The two scrapers included one complete, oval end scraper (\#1228) and one complete crescent Clear Fork tool (\#5532-6) (Figure 8.9). The Clear Fork specimen was made from a light gray chert with white cortex on the dorsal surface and a white patina on the ventral surface. It appears to have been made on a broken distal flake with a slightly curved and unworked ventral surface. All the lateral margins have been worked and have relatively low angles. The worked distal end is very steep with numerous hinge scars.

The 29 edge-modified pieces are mostly (65 percent) broken flake fragments of chert. About 55 percent were tertiary flakes while the rest are secondary pieces (Table 8.5, Figure 8.10). Modifications are nearly all regularly patterned, with two having irregularly scarred edges. About 21 percent have multiple worked edges. Nearly 39 percent have straight modified edges, and 25 percent exhibit convex edges. Another 23 percent have concave edges, and seven percent have sinuous edges. The regularly patterned scars and relatively steep scar angles indicate that most of these were associated with scraping activities. Specimen \#562 has one regularly modified edge that has created a small prominent spur or beak in the middle and resembles an engraving tip (Figure 8.10). Tiny hinge scars on either side of the spur indicate that the original tip may have been removed. Specimen \#18354 is dark chert with tiny scars on one lateral edge, although rounding and polish are evident on most of the non-broken edges (Figure 8.8). This rounding may be associated with hide scraping. Specimen \#1836-6 is a very thin, complete flake with regularly patterned, tiny flake scars near the middle of the right lateral edge (Figure 8.10). Farther along this same side, the lateral edge has 
Table 8.4 Point and Biface Tool Attributes for Occupation 3.

\begin{tabular}{|c|c|c|c|c|c|c|c|c|c|c|c|c|c|c|c|c|c|c|c|c|c|c|}
\hline \multirow[b]{2}{*}{ Cat.\# } & \multirow[b]{2}{*}{ Unit } & \multirow{2}{*}{\multicolumn{2}{|c|}{ F\# LV }} & \multirow[b]{2}{*}{ I Depth } & \multirow[b]{2}{*}{ N } & \multirow[b]{2}{*}{ E } & \multirow[b]{2}{*}{ Elev } & \multirow[b]{2}{*}{$\begin{array}{l}\text { PtTool } \\
\text { Type }\end{array}$} & \multirow[b]{2}{*}{ Brk } & \multirow[b]{2}{*}{ Con. } & \multirow[b]{2}{*}{ Sh } & \multirow[b]{2}{*}{ Stg } & \multirow[b]{2}{*}{ Cort. } & \multicolumn{2}{|c|}{ Color } & \multirow[b]{2}{*}{$\begin{array}{l}\text { Bas } \\
\text { Edg }\end{array}$} & \multirow[b]{2}{*}{$\begin{array}{l}\text { Bas } \\
\text { Thin }\end{array}$} & \multirow[b]{2}{*}{ Bvl } & \multicolumn{3}{|c|}{ Size (mm) } & \multirow[b]{2}{*}{ Wt (g) } \\
\hline & & & & & & & & & & & & & & SW & LW & & & & $\mathrm{L}$ & w & Th & \\
\hline $2650^{*}$ & & & & & & & & $T$ & & $D$ & & & & & & $\mathrm{Cc}$ & $P$ & 2 edg & & 27.0 & 8.2 & 7.3 \\
\hline 2139 & 23-4 & 23 & & $65-75$ & & & & U & Uk & $\mathrm{D}$ & & & & Prp & Prp & $\mathrm{Br}$ & & $\mathrm{N}$ & & 26.0 & 9.5 & 8.8 \\
\hline 2641 & & & & & & & & T & $\mathrm{N}$ & C & & & & $\mathrm{Yw} / \mathrm{Or}$ & $\mathrm{Yw} / \mathrm{Or}$ & St & $P$ & $\mathrm{~N}$ & 64.1 & 24.2 & 7.6 & 9.3 \\
\hline 2652 & & & & & & & & $T^{3}$ & Us & $\mathrm{P}$ & & & & Prp & Prp & $\mathrm{St}$ & $\mathrm{P}$ & $\mathrm{N}$ & & 26.6 & 8.0 & \\
\hline 2688 & & & & & & & & T & Us & $P$ & & & & Dk. Red & Dk. Red/ Prp & St & $P$ & $\mathrm{~N}$ & & 37.2 & 9.9 & 15.4 \\
\hline 3491 & F2 & & 8 & $70-80$ & & & & T & N & $c$ & & & & Prp & Dk. Red/ Prp & $C x$ & $P$ & $\mathrm{~N}$ & 49.8 & 26.1 & 6.6 & 7.6 \\
\hline $5072^{*}$ & E7 & & 9 & $80-90$ & & & & $U^{3}$ & Us & D & & & & Prp & Prp & $\mathrm{Br}$ & & 1 edg & & 19.6 & 6.5 & 3.3 \\
\hline $5474-3$ & E2 & & 8 & $70-80$ & & & & $\mathrm{R}^{3}$ & N & c & & & & Prp & Dk. Red/Prp & $C x$ & $P$ & N & 53.8 & 21.0 & 6.7 & 8.2 \\
\hline 5060 & E7 & & 8 & $70-80$ & 108.616 & 117.566 & 99.26 & B & M & $D$ & $\mathrm{~T}$ & M & & Prp & Prp & & & & & 35.4 & 10.0 & 7.8 \\
\hline 5393-4 & D2 & & 8 & $70-80$ & & & & B & M & M & $\mathrm{R}$ & M & & Prp & Prp & & & & & & 5.9 & 1.2 \\
\hline $5269-5$ & B7 & & 8 & $70-80$ & & & & B & $u$ & M & $\mathrm{R}$ & $\mathrm{L}$ & & Prp & Dk Red/ Prp & & & & & & 6.6 & 3.8 \\
\hline 2671 & & & & & 108.008 & 118.46 & 99.179 & B & & c & $T$ & $\mathrm{~L}$ & & $\mathrm{YW} / \mathrm{Or}$ & $\mathrm{Yw} / \mathrm{Or}$ & & & & 70.5 & 39.4 & 10.6 & 27.3 \\
\hline 2633 & & & & & 107.984 & 118.351 & 99.203 & B & $U$ & $P$ & $\mathrm{~L}$ & $\mathrm{~L}$ & & Prp & Prp & & & & & 37.9 & 11.8 & 13 \\
\hline 2678 & & & & & 109.257 & 118.367 & 99.174 & B & & $C$ & 0 & E & & Dk Red/ Or & DkRed/ Or & & & & 52.1 & 47.0 & 19.2 & 34 \\
\hline $5532-4$ & E7 & & 9 & $80-90$ & & & & B & M & $\mathrm{P}$ & L & $\mathrm{L}$ & & Dk Yw/ Or & Or & & & & & 45.5 & 11.5 & 220.1 \\
\hline $1837-6$ & $18-4$ & & 7 & $60-70$ & & & & $B$ & M & $P$ & $\mathrm{~L}$ & L & & Or & Or & & & & & 25.3 & 7.0 & 5.3 \\
\hline
\end{tabular}

Point/Tool Type (Pt/Tool Type): B=biface, D=drill, and T=Tortugas, U=Unknown, R=Refugio. All materials chert except as noted: 1=other, 2=sandstone, 3=quartzite Brk: $M=$ manufacture, Us=use, UK=unknown

Condition (Con.): $\mathrm{C}=$ complete, $\mathrm{P}=$ proximal, $\mathrm{M}=$ medial, $\mathrm{D}=$ Distal

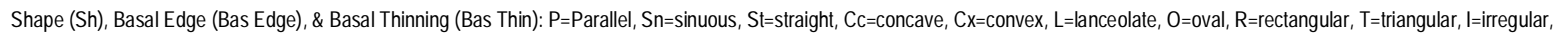
Ot=other

Manufacture Stage (Stg): L=late, M=middle

Cortex (Cort.): $P=$ primary, $S=$ secondary, T=tertiary

Color: Or=orange, $\mathrm{Y}_{\mathrm{w}}=\mathrm{yellow}, \mathrm{Prp}=$ purple, Spk=speckled, Br=brown, Gry=Gray

Beveling $(\mathrm{Bvl}): \mathrm{N}=\mathrm{N}$

Note: All catalogue numbers from hand excavated proveniences have been formed by adding a dash and appear in the database with leading zeros. These leading zeros have been omitted to conserve space.

intense rounding. The opposite lateral also reveals rounding on the protruding feathered edge. The rounded edges are generally associated with hide working activities. The regularly patterned flake scars along a convex edge of specimen \#5565-6 produce a spoke shave that is about $16 \mathrm{~mm}$ wide. At least two of the edge-modified flakes are massive pieces (\#3896 and \#3921) with weights ranging from 126 to $169 \mathrm{~g}$. At the opposite end of the size range is a tiny flake fragment fewer than $10 \mathrm{~mm}$ $(0.2 \mathrm{~g})$, which exhibits attributes of a miniature end scraper (Figure 8.10).
The high-powered microwear analyses on 19 tools, including four Tortugas points (\#2641, \#2652, \#2688, and \#3491), one unknown point type fragment (\#5072), a Refugio point ( $\# 5474-$ 3 ), three bifaces (\#1837-6, \#2671, and \#52695), a scraper (\#5532-6), and nine edge modified flakes (\#1835-4, \#1836-6, \#3896, \#3921, \#52694, \#5509-5, \#5543-6, \#5565-5, \#5589-4) revealed minimal use-wear (Appendix C). Only a complete Tortugas point (\#2641) had polish of undetermined origin along one lateral edge, but the wear was undetermined as to its use (Appendix C). One analyzed edge modified 


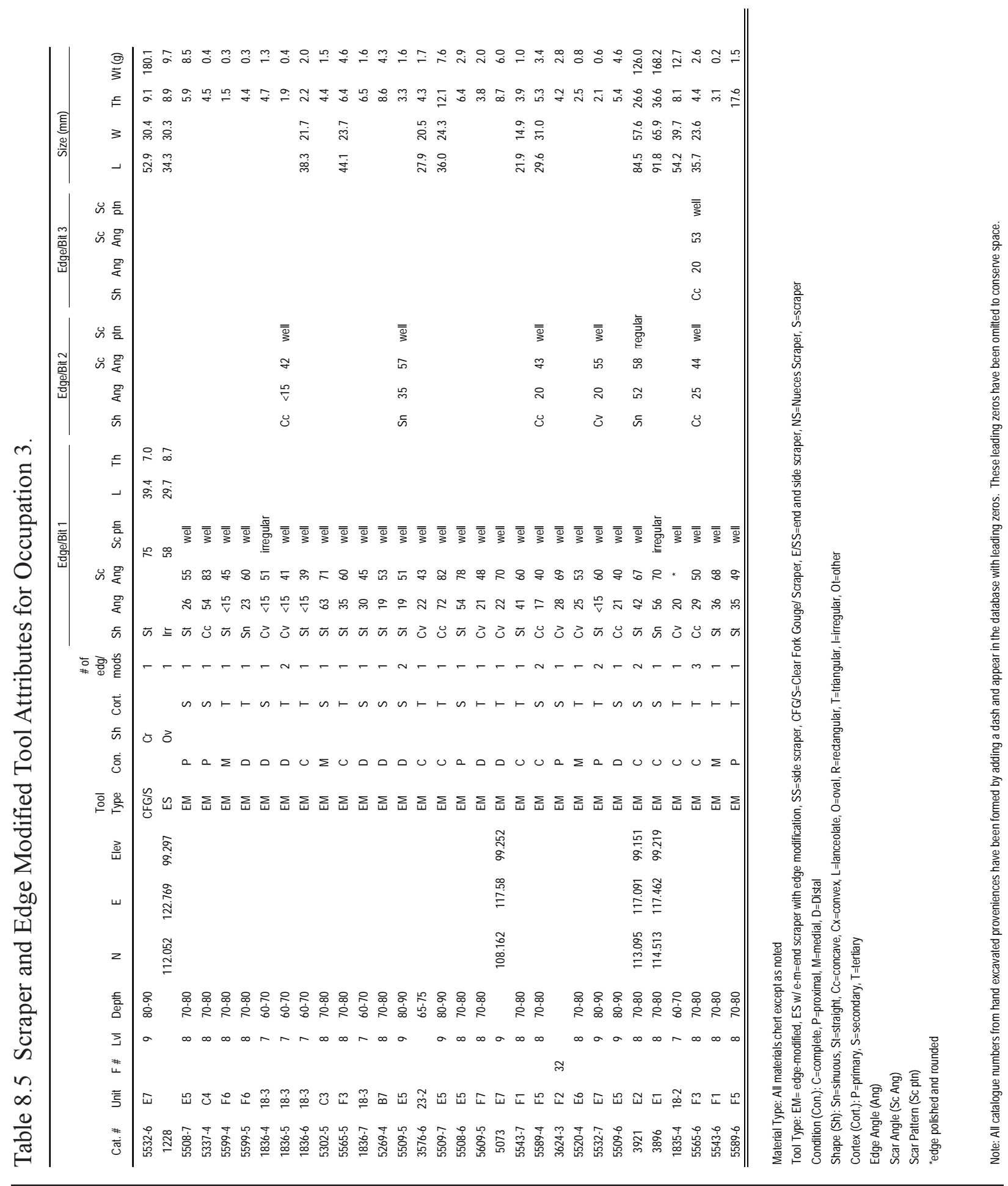




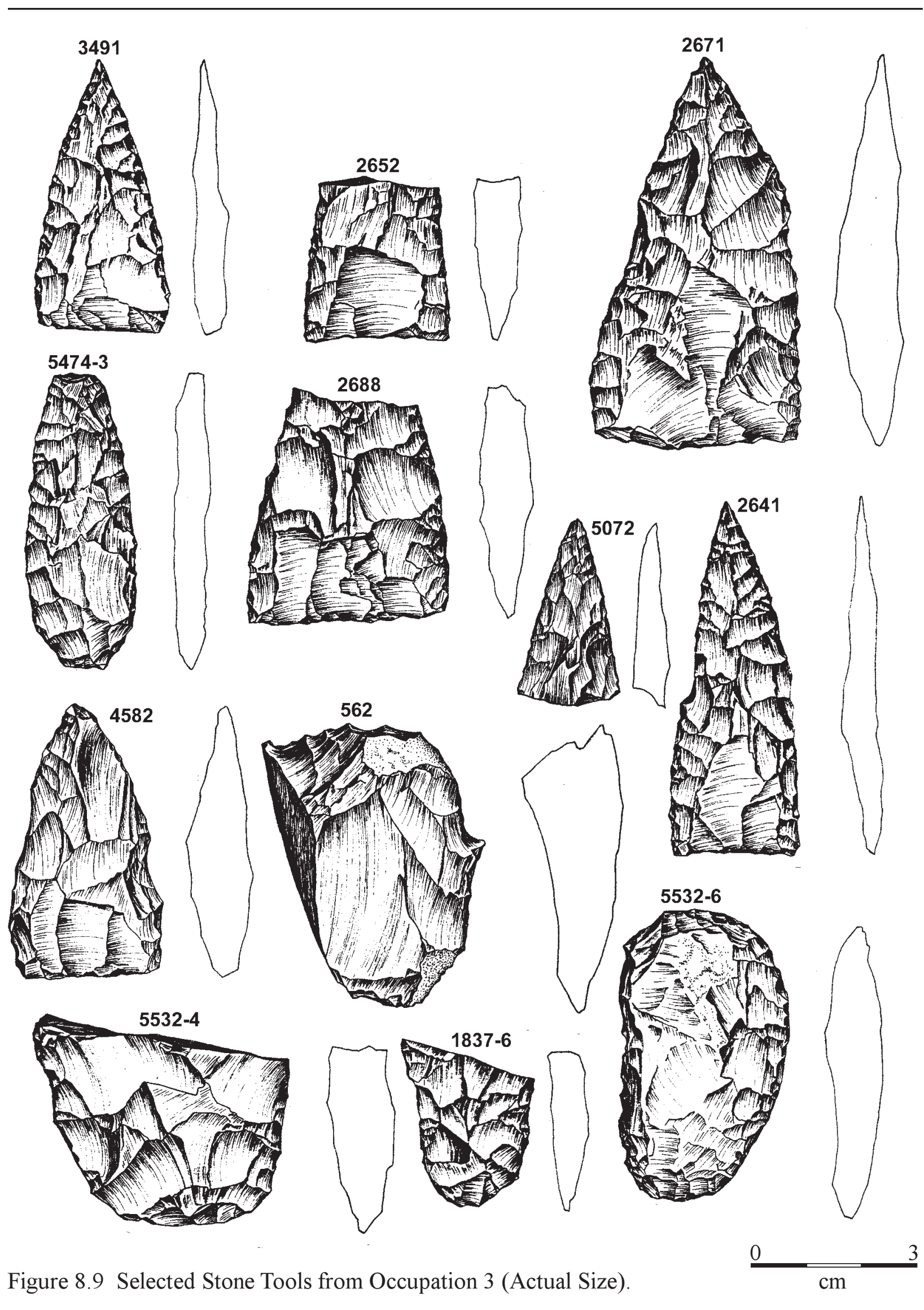

Lino Site: $\quad$ Stratified Late Archaic Campsite 


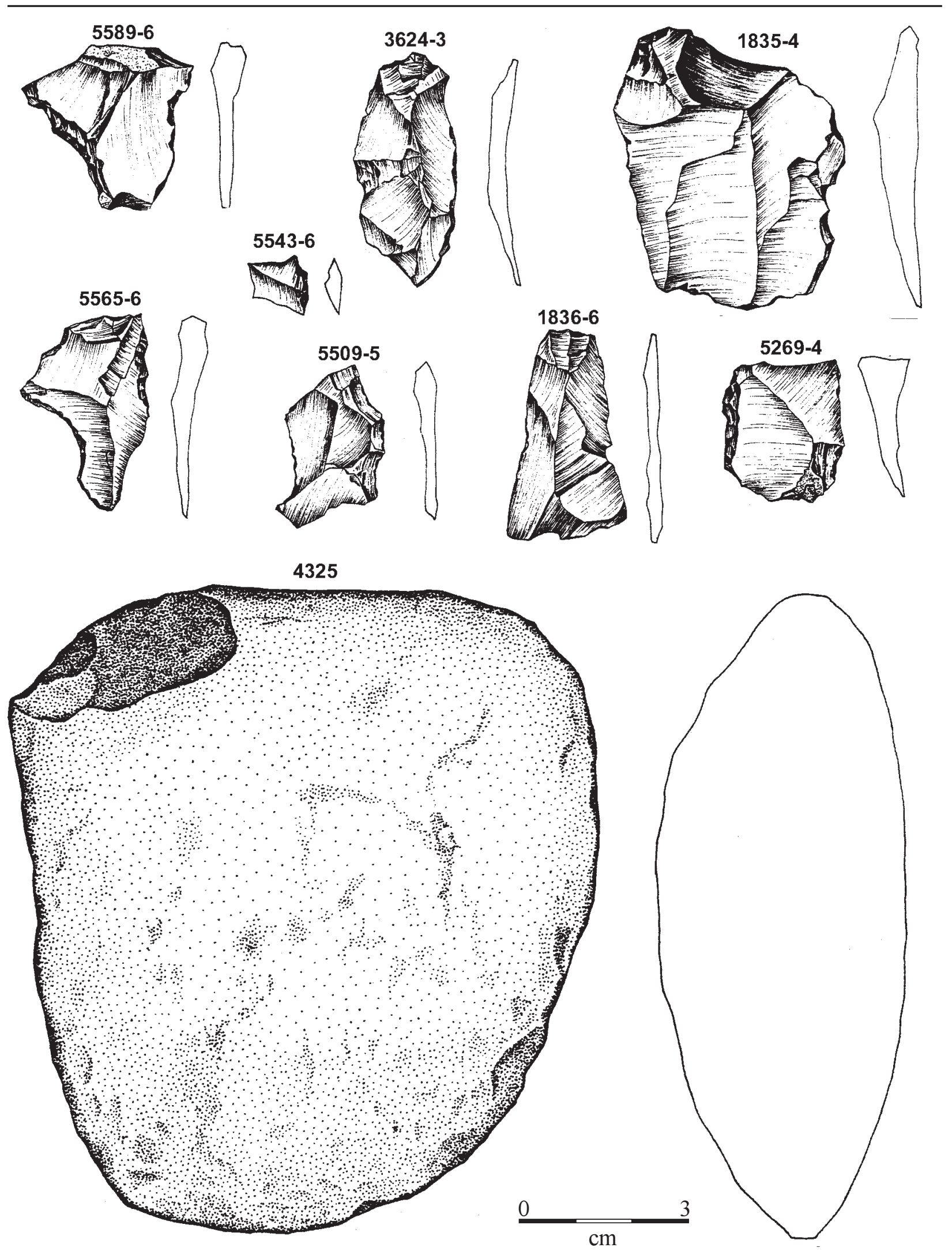

Figure 8.10 Edge Modified Flakes and Mano (4325) from Occupation 3 (Actual Size). 
flake (\#1835-4) revealed intense edge polish and rounding macroscopically, but no microscopic use-wear. The macroscopic rounding observed on specimen \#1836-6 was not considered usewear by Berg (Appendix C).

A single chert core was present. It was a unifacial fragment and quite small, with about 45 percent cortex still remaining. This was recovered from Unit E7 and found with a number of other tools. This group of items may be part of a discard pile.

\subsection{GROUND STONE TOOLS}

A single ground stone artifact-a one-sided mano (\#4325) - came from E4 at 70 to $80 \mathrm{cmbs}$ (99.18 elevation). This oval, orthoquartzite specimen measures $115.6 \mathrm{~mm}$ long, $107 \mathrm{~mm}$ wide, $46.5 \mathrm{~mm}$ thick, and weighs $768 \mathrm{~g}$. One face exhibits a relatively smooth convex surface with numerous tiny pits scattered across an area that measures about 114 by $98 \mathrm{~mm}$ of worked surface (Figure 8.10). The pits appear to be human-induced peck marks. This face was unwashed, and thus detailed examination was not conducted. No striations were obvious. The opposite face has a more rounded convex surface and appears unworn. One or two edges appear relatively smooth and straight, and these edges may have been used, but no obvious striations or polish were detected. At the corner of two adjoining straight edges are two impact scars. The largest scar penetrates $21 \mathrm{~mm}$ into the smoothed worn face. The two striking platforms are crushed with tiny hinges on the inside of the scar, which indicates probable impact with another hard object. These impact scars probably resulted from subsequent use of the mano as a hammerstone. Thus, this may have served as a composite tool for grinding and pounding activities.

\subsection{BURNED ROCKS}

The burned rocks scattered throughout Occupation 3 and outside the three defined features are discussed here. The $59 \mathrm{~m}^{2}$ investigated through hand excavations yielded 865 burned rocks that weighed 67,322 g (Table 8.2). Sandstone accounted for 93 percent followed by five percent chert and four percent other kinds of materials. Sandstone rocks were clearly the preferred material selected. Seventy percent were fewer than $4 \mathrm{~cm}$ in diameter, 27 percent were between 4 and $9 \mathrm{~cm}$, and three percent were greater than $9 \mathrm{~cm}$ in diameter. These frequencies are nearly identical to the frequencies of burned rock scattered in Occupation 2. The average weight of the scattered burned rocks was $78 \mathrm{~g}$ (Table 8.2). The scattered burned rocks were mostly small broken pieces fewer than $4 \mathrm{~cm}$ in diameter but averaging nearly $30 \mathrm{~g}$ heavier than those in Occupation 2. About 65 percent were angular pieces with the rest nearly equally split between rounded and tabular pieces. Cracks appeared in about 10 percent. The low frequency of cracks may reflect that thermally cracked cobbles probably disintegrated into multiple pieces by the time they were scattered.

The 38 burned rocks from in situ rock-filled basin Feature 20 weighed an average of about $635 \mathrm{~g}$. These burned rocks were nearly six times the size of those scattered about the occupation. The much larger burned rocks in Feature 20 probably represented an abandoned heating pit, and the rocks had not been reduced to an unusable size before being discarded. The low frequency (seven percent) of the scattered rocks with cracks contrasted with nearly 61 percent of cracked rocks for Feature 20. This difference in size, weight, and crack proportions reflects the process of disintegration of larger feature rocks into smaller pieces. 
The burned rocks from the two identified burned rock features and those scattered across the 59 $\mathrm{m}^{2}$ hand-excavated area in Occupation 3 total 925 pieces that weighed 94,887 g (Table 8.2). On average then, about 16 burned rocks occurred per square meter for hand excavated units, with the average burned rock weighing $120.5 \mathrm{~g}$.

Two burned rocks from the occupation surface, initially designated Feature 18, had their interior matrix removed and chemically analyzed for isotopes and lipids. The stable isotope values yielded various results. Burned rock \#1283 had a $\delta^{13} \mathrm{C}$ value of $-23.9 \%$ with a $\delta^{15} \mathrm{~N}$ value of $-0.1 \%$ (Appendix D). Burned rock \#1286 had a $\delta^{13} \mathrm{C}$ value of $-21.8 \%$ with a $\delta^{15} \mathrm{~N}$ value of 2.0\%o. Burned rock \#1283d (sample Lino 11) yielded fatty acids quite similar to Spanish dagger or tasajillo fruit. The $\delta^{13} \mathrm{C}$ isotope value does not support this interpretation, as the value is mostly representative of $\mathrm{C} 3$ plants as opposed to the C4 plants Spanish dagger and tasajillo. Burned rock \#1286 (sample Lino 12) yielded fatty acids similar to larger herbivore plus plant or marrow (Appendix G). The isotope values from the same cobble suggest that the large herbivore was a deer/antelope rather than bison.

\subsection{MUSSEL SHELLS}

Only six mussel shell fragments were recovered. One was identified as Cyrtonaias sp. and the other two were unidentifiable as to species. None showed evidence of burning or human modification.

\subsection{CHARCOAL}

Wood charcoal was relatively abundant from this occupation and the three identified features. Some 30 samples outside Feature 20 weigh nearly $94 \mathrm{~g}$. Feature 20 contained very abundant wood charcoal (about $262 \mathrm{~g}$ ), and three individual pieces from this feature were identified as mesquite (Appendix B). Individual charcoal pieces from Features 2 and 23 along with scattered chunks from Units $\mathrm{C} 1$ and D1 were all identified as mesquite. The exceptions were sample \#5281-2a from Unit C1 that was an indeterminate species of wood and sample \#3576-5a from Feature 23, which was identified as hackberry (Appendix B). At least these two species were used as fuel wood.

\subsection{HORIZONTAL DISTRIBUTION}

Occupation 3 yielded limited quantities of burned rocks $\left(15 / \mathrm{m}^{2}\right)$ and lithic debitage $\left(11 / \mathrm{m}^{2}\right)$ non-randomly distributed across the five middle balks (Figure 8.11). Balks A and $\mathrm{G}$ on the eastern and western ends, respectively, lacked cultural materials, and Balk $\mathrm{C}$ yielded only minimal frequencies. Apparently, the primary occupation was linear and restricted primarily north and south between Balks A and G. The natural deposits rise near Balk $\mathrm{G}$, and some undetected paleotopography landform or erosion channel may limit the ability to trace the horizontal distribution.

The horizontal distribution of lithic debitage revealed the highest concentration in Balk F (34 percent of the total) and four hand excavated units in Gradall ${ }^{\mathrm{TM}}$ Area G (Figure 8.11). The four units in Gradall ${ }^{\mathrm{TM}}$ Area $\mathrm{G}$ reflect intense use or massive dumping of lithic debris as they represent 26 percent of the total. Lithic density was generally moderate across Balks D and E but rapidly decrease in Balks B and C. Unit D5 was the exception, with a high frequency $(n=41)$ of debitage. Most of the lithic debris appears to relate to the decortification of at least two cores/ early bifaces, and at least three late stage bifaces. Some 22 chert pieces smaller than $6.4 \mathrm{~mm}$ in size from the float sample in this unit indicate that this may have been the location of an in situ knapping station. The 22 tiny pieces generally would not have been culturally collected and moved, and thus they represent the spot where the knapping occurred. However, these small 


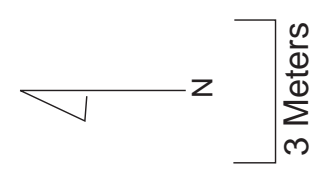

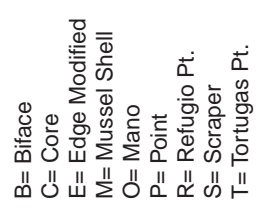

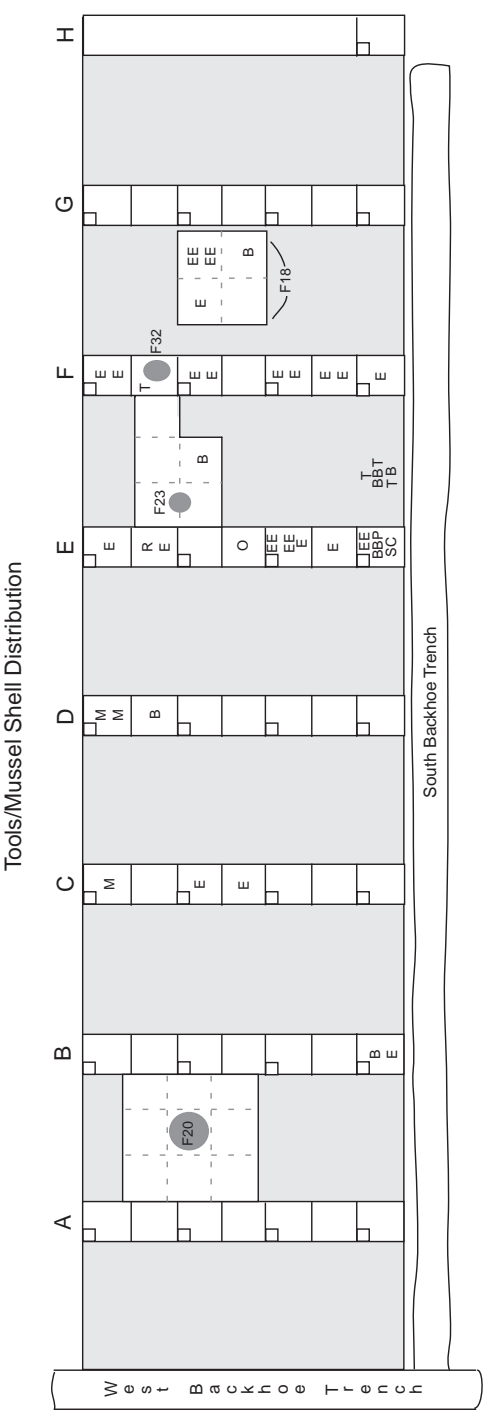

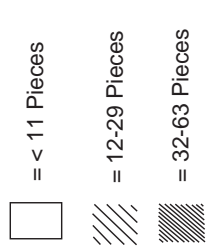

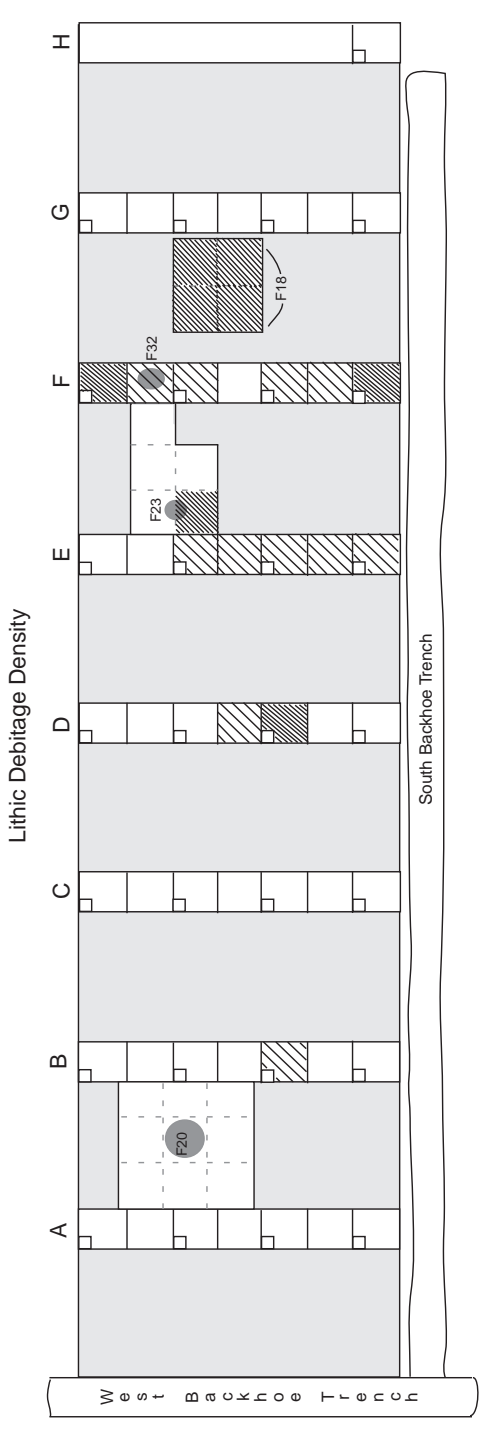

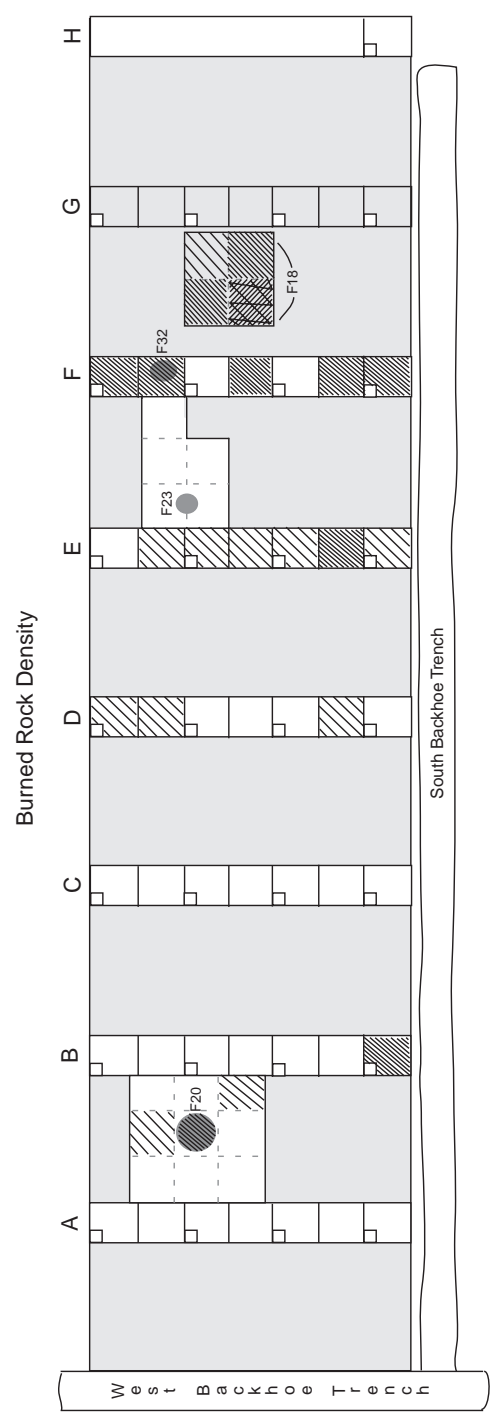

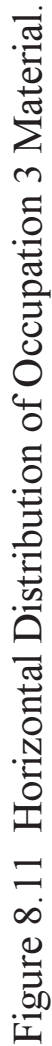


flakes are easily moved by bioturbation, which may have played a role. A high concentration $(n=43)$ came from Unit 23-4 adjacent to the 20 piece cluster designated Feature 23 (Figure 8.11). Unit 23-4 contained core reduction and platform preparation flakes, with some early biface flakes identified. This limited amount of lithic reduction, coupled with sparse burned rocks, indicates a probable in situ knapping area. The 20 flakes constituting Feature 23, which are dominated by late stage biface flakes and a few core reduction flakes, are interpreted as a dump that is probably associated with the knapping area. It may be that the knapper in the adjacent unit dumped debris next to the activity area.

The high lithic density at both ends of Balk F is associated with high frequencies of burned rocks and may reflect lithic dumping, as opposed to in situ work areas. Unit F1 yielded a very high density of flakes $(n=48)$ immediately north of burned rock dump Feature 32. This implies a general area of dumping activity. In contrast to the dumping, very few lithic pieces (fewer than $6 / \mathrm{m}^{2}$ ) occurred within $1 \mathrm{~m}$ of burned rock filled pit Feature 20. The pit fill yielded only one flake greater than $6.4 \mathrm{~mm}$ in size, although the floated matrix yielded 17 tiny pieces of chert. The lack of lithic debitage around this in situ feature indicates that knapping was not conducted on the very margins of this feature.

The horizontal distribution of the nearly 900 burned rocks was patterned across the block (Figure 8.11). In the five middle balks, the highest concentrations of burned rocks and lithic debitage was in Balk $\mathrm{F}$ and in the adjacent $4 \mathrm{~m}^{2}$. Burned rock frequency decreased to the west, with mostly moderate frequencies occurring in Balk E. Since these moderate and high frequencies overlap with moderate and high frequencies of lithic debitage, these are regarded as general areas of discard. The five units with moderate and high frequencies west of Balk $\mathrm{E}$ also probably represent specific locations for discarding burned rocks.

The well defined burned rock-filled basin Feature 20, at the extreme western end of the excavation block, yielded mostly low frequencies of burned rock (fewer than $9 / \mathrm{m}^{2}$ ) scattered within a $1 \mathrm{~m}$ radius. Twenty-five percent of the surrounding units yielded moderate frequencies $\left(10 / \mathrm{m}^{2}\right.$ and $\left.17 / \mathrm{m}^{2}\right)$ of burned pieces, which generally supports the interpretation of a broad scatter around the pit. No recognizable stone tools were in the vicinity of the pit (Figure 8.11). The low frequencies of burned rocks, lithic debitage, and tools coupled with the lack of perishable material presents a relatively clean area surrounding Feature 20. This patterning is unlike the distribution pattern Binford (1978, 1984) described for activities around hearths. Feature 20, the rock filled basin, is interpreted as an in situ heating element for sandstone rocks, which was placed to the side of and distinct from other activities, including general discarded materials. The apparent separation may have been because of the intense heat or smoke produced from the fire or some other unknown factor. The closest high density of burned rock to Feature 20 was in Unit B7 at the south end of Balk B, nearly $4 \mathrm{~m}$ to the south. This unit also contained a biface and an edgemodified flake.

Features 23 and 32 near the middle of the highest density area, along with clustered formal tools, all are interpreted as discard areas. Burned rock cluster Feature 32, a small, tight cluster of 19 burned rocks, was nearly $16 \mathrm{~m}$ east of pit Feature 20 and generally surrounded by areas of moderate to high burned rock densities. This burned rock dump represents discard of thermally reduced burned rock crumbs and chunks. However, primary cooking features are not apparent between the heating element Feature 20 and this final dump area represented 
by Feature 32. A complete Tortugas projectile point (\#3491) was recovered from immediately north of Feature 32, and at least five edgemodified flakes were within $1 \mathrm{~m}$ of this area.

The small flake dump Feature 23 was generally surrounded by moderate frequencies of lithic debitage. At least five tools were within $2 \mathrm{~m}$ of Feature 23. A distal end of a dark gray, finished biface/point (\#2139) was found about $1 \mathrm{~m}$ to the southeast. A mano (\#4325) was about $1.5 \mathrm{~m}$ to the southwest. A Refugio point (\#5474-3) was recovered about $1 \mathrm{~m}$ to the northwest. This latter point may be out of context and displaced upward from a lower occupation. Two edgemodified flakes were located west and northwest of Feature 23. These may or may not represent in situ task areas, since the narrow strip of the excavation units hinders definitions of activity associations.

Five edge-modified flakes and one proximal end of a late stage biface (\#1837-1) were in the four units designated as Feature 18, now considered to be just an occupation surface. The high concentration of burned rocks and lithic debitage found with a series of the tools implies an area of general discard. An apparent tool concentration at the south end of Gradall ${ }^{\mathrm{TM}}$ Area F contained numerous bifaces and points (Figure 8.11). This concentration continued west in Unit E7, where two bifaces (\#5532-4 and \#5060), two edge-modified flakes (\#5532-7 and \#5073), a core (\#5531-5), a Tortugas point (\#2652), and a scraper (\#5532-6) were recovered. The association of so many different tools representing a variety of functions in a restricted area probably represents a discard area or a heavily overprinted work area. The lack of continuous hand excavations limits the interpretation of the range of activities that occurred there.
A single, complete mano (\#4325) came from Unit E4 and was found just north of five edgemodified flakes in E6. The mano was associated with a few scattered burned rock fragments $(n=13)$ and sparse chert flakes $(n=12)$. This specific area may or may not represent an in situ activity area. Insufficient information is available to reliably judge.

Occupation 3 lacked quantities of mussel shells. Only six valve fragments were recovered. These were from the northern edge in Units $\mathrm{C} 1$ and D1. Their location along the northern edge may indicate that the main shell processing and/or discard areas were farther north and that only the southern edge extended into the excavation block. As observed in Occupation 1, the mussel shells appeared to be concentrated to one side and were not evenly scattered over the occupation. Apparently shells were discarded away from primary activity areas.

The horizontal plotting of the TDS-plotted materials is shown in Figures 8.12 and 8.13. Here again, Feature 20 appears to be off to the side or away from the more obvious activities that produced the burned rocks and lithic debitage. The few plotted pieces of lithic debitage on the western side of Feature 20 may indicate the location of a second activity that was carried on immediately adjacent to the heating of the rocks, possibly by the individual tending the fire. The TDS-plotted data also reveals areas of hand excavated balks with linear north-south distribution patterns and at least one very dense lithic activity between Balks E and F. These piece-plotted materials reveal a non-random distribution and not just a broad scatter of material types from overprinting of multiple events. The biased data and observed specific activity areas support the idea that this material represents an occupation. 


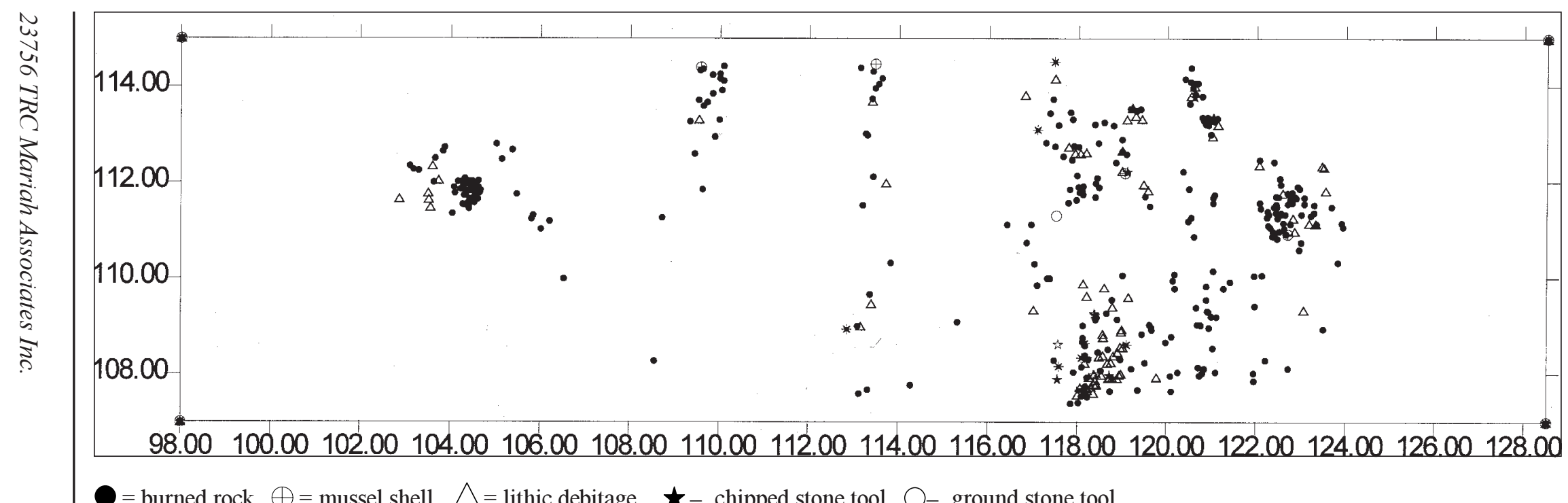

Figure 8.12 All TDS Shot In Material for Occupation 3.

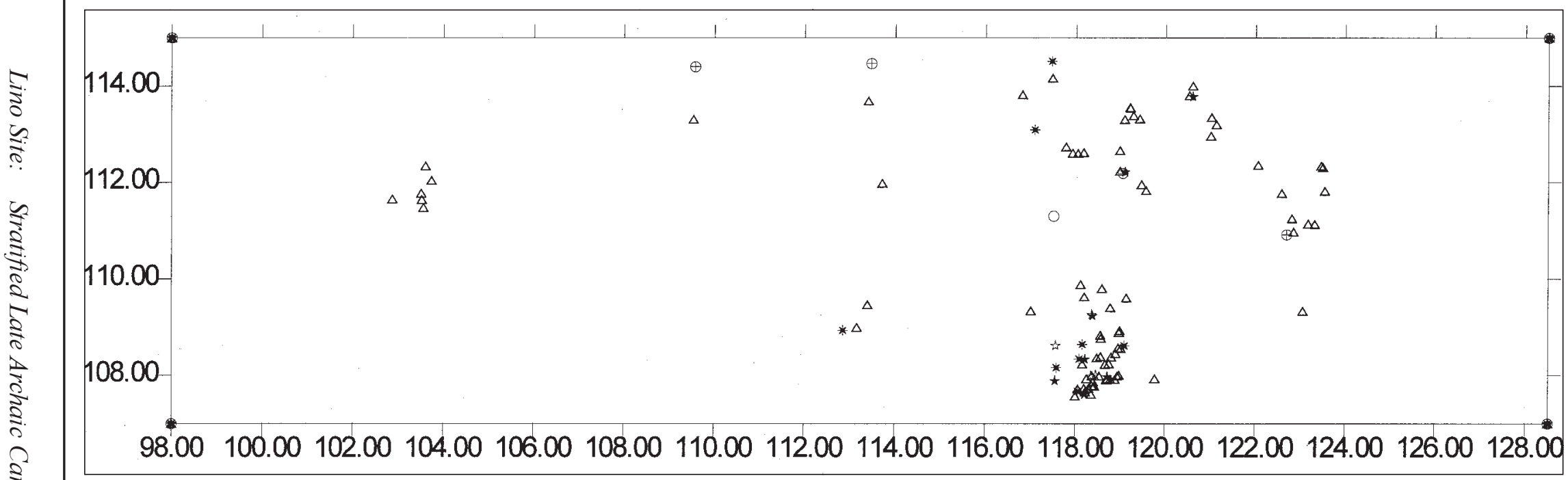

Figure 8.13 Lithic Debitage $(\triangle$ ), Mussel Shells $(\oplus$ ), and Stone Tools ( $\star$ O *) Shot In with the TDS for Occupation 3. 


\subsection{SUMMARY AND INTERPRETATIONS}

This occupation consisted of a moderate amount of cultural remains (28 items per $\mathrm{m}^{2}$ ) concentrated between about 70 and $80 \mathrm{cmbs}$. The $10 \mathrm{~cm}$ thick zone dips towards the west and slightly to the north. Materials mostly occurred towards the middle of the block and were concentrated in Balks E and F. This cultural zone yielded three features: one burned rock cluster (Feature 32), one lithic debitage cluster (Feature 23), and one rock fill pit (Feature 20). It had relatively low quantities of scattered burned rocks $(\mathrm{n}=862)$ and lithic debitage $(\mathrm{n}=666), 54$ chipped and one ground stone tool, six mussel shell fragments, and sparse scatters of Rabdotus shells. Cultural bone was absent.

The chronometric age of Occupation 3 was extrapolated from five wood charcoal dates from Occupations 1 and 5, which were between ca. 2000 B.P. and 3400 B.P., respectively. Occupation 3 is estimated to be about 2700 B.P. The presence of four Tortugas and one Refugio projectile point place these point types into a general time period. Although not directly associated with an absolute age, their presence in these stratified deposits helps confirm their relative age and places these point types into a local/regional chronological framework.

The 865 scattered burned rocks weighed 67,322 $\mathrm{g}$, with an average of about $78 \mathrm{~g} /$ rock. The burned rocks in the pit Feature 20 averaged considerably more at $635 \mathrm{~g}$. The significant rock weight difference between these two distinct contextual types documents that the scattered rocks were much smaller and probably at the end of their use life. Once they were thermally reduced to a point where they could no longer function effectively, they were discarded. The burned rock-filled pit is interpreted to be a heating apparatus in which at least some of the rocks were re-used because they retained organic residues even in this apparent heating element. Alternatively, the interpretation could be that this feature functioned as a cooking apparatus, which thus explains the residues on the rocks.

The 666 pieces of chert debitage averaged about 11 pieces $/ \mathrm{m}^{2}$. Flake types reflect mostly knapping activities focused on core and biface reduction. Early stage biface reduction was not as common or pronounced as later stage manipulation. The limited stone tool assemblage appears to reflect hunting and butchering tasks along with some scraping activities. The one mano implies grinding preparation of some unknown plant resources. As indicated by the stable carbon isotope results, the matrix extracted from the interior of burned rocks indicates that Spanish dagger, tasajillo fruit, mesquite beans, and prickly pear were probably four of the plant resources used along with the cooking of larger herbivore meat that appears most likely to have been deer/antelope.

These 1,683 cultural items represent part of a broad occupation that was partially encountered in the $59 \mathrm{~m}^{2}$ hand excavations. The material remains appear to represent general camping debris from a short-term hunter gatherer site. The absence of microscopic use-wear on 19 analyzed stone tools may support the short-term duration of their use and the non-curation of tools. The overall lithic debitage and stone tool assemblage, along with the presence of burned rocks indicate that tool production activities and cooking tasks were undertaken. The grinding stone indicates that plant processing occurred, but the specific kinds of plant remains unidentified. 


\subsection{OCCUPATION 4}

This occupation zone consisted of a broad horizontal distribution of dense cultural remains concentrated between about 80 and $100 \mathrm{cmbs}$. The 15 to $20 \mathrm{~cm}$ thick zone dips about 30 to 35 $\mathrm{cm}$ towards the west and some 10 to $12 \mathrm{~cm}$ to the north. The cultural materials were vertically dispersed across it from turbation and root activity. Clear and identifiable soil or cultural zone boundaries were not observed or detected during excavation. The vertical proveniences obtained from the TDS were used to define this occupation zone. Vertical plots revealed more vertical displacement towards the western end. The greatest concentration of cultural materials was in Gradall ${ }^{\mathrm{TM}}$ Areas $\mathrm{G}$ and $\mathrm{H}$, which is where all the lower occupations became pinched together and closer to the surface. This cultural zone yielded multiple burned rock features, quantities of scattered burned rocks and lithic debitage, a few chipped and ground stone tools, mussel shells, and scattered Rabdotus shells. Bone, if originally present, was not preserved.

The chronometric age of Occupation 4 was not directly determined through dating wood charcoal from this zone. Its age is extrapolated from three wood charcoal dates from Occupation 1 that average about 2000 B.P. and two accepted wood charcoal dates from Occupation 5 that average about 3400 B.P. (Table 5.3). The estimated age of Occupation 4 is about 3000 B.P.

The cultural materials recovered from the $40 \mathrm{~m}^{2}$ hand excavated balks and the $31 \mathrm{~m}^{2}$ hand excavated units around five identified features discovered during Gradall ${ }^{\mathrm{TM}}$ stripping are presented by material class below. This is followed by a discussion of the horizontal distribution of the occupational materials. Finally, summary and conclusions about Occupation 4 are presented.

\subsection{FEATURES}

Eight features were recognized in Occupation 4. Five were discovered in the Gradall ${ }^{\mathrm{TM}}$ stripped areas and were manually excavated whereas three were found in the hand-excavated balks (Table 9.1). These features consisted of five concentrations of burned rocks (Features 22, 26, 28, 39, and 42), one well-defined rock-filled basin (Feature 27), a small charcoal-stained basin (Feature 37), and part of the broader occupation zone (Feature 25). Each feature is described in conjunction with analyses of specific materials from that particular feature starting with the two pit features and followed by the five burned rock concentrations. The material from Feature 25 is discussed with the other occupational material and is not treated as a separate feature.

Feature 27, which measured 60 by $70 \mathrm{~cm}$ across, was a $17 \mathrm{~cm}$ deep basin filled with burned sandstone and charcoal. About $10 \mathrm{~cm}$ along the western edge of the basin was discovered during Gradall $^{\mathrm{TM}}$ stripping in Area $\mathrm{G}$, and the majority was hand excavated from Balk $\mathrm{G}$ (Figures 9.1, 9.2, and 9.3). The pit boundary was faint, but it demarcated an area about $50 \mathrm{~cm}$ in diameter. It was deepest in the middle with a nearly flat bottom that extended to the steep sloping sides (Figure 9.1). No ash or oxidized matrix was in or along the bottom of the pit, and the burned rocks were not resting on the very bottom.

The 108 burned rocks that filled the pit did not form a circular pattern at the top but formed a slightly elongated oval. Some burned rocks on the outer margins along the northern and southern ends were slightly displaced and lay just outside the pit boundary. Four relatively small burned rocks towards the middle were 
Table 9.1 Feature Attributes for Occupation 4.

\begin{tabular}{|c|c|c|c|c|c|c|c|c|}
\hline $\begin{array}{l}\text { Fea. } \\
\text { No. }\end{array}$ & Unit & $\begin{array}{l}\text { No. of } \\
\text { Units } \\
\text { Exc. }\end{array}$ & $\begin{array}{l}\text { Depth } \\
\text { (cmbs) }\end{array}$ & $\begin{array}{l}\text { Size } \\
(\mathbf{c m})\end{array}$ & Thickness & Description & Interpret. & $\begin{array}{c}\text { Associated } \\
\text { Artifacts }\end{array}$ \\
\hline 22 & Area $\mathrm{C}$ & 6 & $90-100$ & $50 \times 30$ & 1 rock & BR cluster & BR Dump & $\begin{array}{c}11 \mathrm{BR} ; \\
\text { Scattered BR }\end{array}$ \\
\hline 25 & Area $\mathrm{H}$ & 4 & $60-70$ & $\begin{array}{l}200 x \\
200\end{array}$ & 1 rock & $\begin{array}{c}\text { Occupational } \\
\text { debris }\end{array}$ & occupation & $\begin{array}{l}\text { Scattered BR; } \\
\text { few flakes }\end{array}$ \\
\hline 26 & Area G & 4 & $75-85$ & $60 \times 70$ & 1 rock & BR cluster & BR Dump & $\begin{array}{c}20 \\
\text { BR;scattered } \\
\text { BR; flakes }\end{array}$ \\
\hline 27 & $\begin{array}{l}\text { Area G, } \\
\quad \mathrm{G} 5\end{array}$ & 5 & $75-85$ & $60 \times 70$ & 2 rocks & BR filled pit & $\begin{array}{l}\text { Heating } \\
\text { element }\end{array}$ & $\begin{array}{l}108 \text { BR in pit; } \\
\text { charcoal }\end{array}$ \\
\hline 28 & Area E & 6 & $80-90$ & $65 \times 50$ & 1 rock & BR cluster & BR Dump & $\begin{array}{c}23 \mathrm{BR} ; 1 \\
\text { mussel shell }\end{array}$ \\
\hline 37 & F4 & 1 & $80-90$ & $40 \times 40$ & $10 \mathrm{~cm}$ & $\begin{array}{l}\text { Charcoal } \\
\text { stained basin }\end{array}$ & Hearth & $\begin{array}{c}3 \text { BR; large } \\
\text { charred stick in } \\
\text { pit; ash }\end{array}$ \\
\hline 39 & G1 & 1 & $80-90$ & $30 \times 30$ & 1 rock & BR cluster & BR Dump & $\begin{array}{c}4 \mathrm{BR} \text {; scattered } \\
\text { BR }\end{array}$ \\
\hline 42 & G6 & 1 & $70-80$ & $20 \times 30$ & 1 rock & BR cluster & BR Dump & 7 isolated BR \\
\hline
\end{tabular}

$\mathrm{BR}=$ burned rock

oriented vertically (Figure 9.1). Another five rocks near the middle were angled, but not all in the same direction. Two rocks along the margin were angled: one towards the outside and one towards the inside (Figure 9.1). Near the middle of the pit the burned rocks were piled two or more thick but not in well-defined layers or with one cobble on top of another. The 108 burned sandstone pieces weighed a total of $61,320 \mathrm{~g}$ with an average weight of $568 \mathrm{~g} /$ rock. Some six percent were smaller than $4 \mathrm{~cm}, 54$ percent were 4 to $9 \mathrm{~cm}$ in diameter, another 38 percent were 9 to $15 \mathrm{~cm}$, and two percent were greater than $15 \mathrm{~cm}$. Eighty-seven percent were sandstone with a couple chunks of chert and a few other cobbles of unknown material types. In general, their shapes were about 57 percent angular, 32 percent rounded, and 12 percent tabular. Nearly 32 percent had tiny visual cracks.

Organic residues extracted from the interiors of four burned rocks (\#2960, \#2961, 4901-1, \#4901-2) were subjected to various kinds of isotope and fatty acid analyses. Stable carbon isotope analysis yielded $\delta^{13} \mathrm{C}$ values ranging between $-18.6 \%$ to $-22.4 \%$ (Appendix D). These values appear to reflect a mixture of $\mathrm{C} 3$ and $\mathrm{C} 4 / \mathrm{CAM}$ resources. The $\delta^{15} \mathrm{~N}$ values range between $-7.5 \%$ and $9.3 \%$, but the single negative value is in question and is probably contaminated (Appendix D). If this is the case, then the remaining $\delta^{15} \mathrm{~N}$ values range between $1.6 \%$ and $9.3 \%$. These values also appear to represent a mixture of resources. Three of these same four residues were analyzed for their fatty acids. Residues from \#2961 (sample Lino 25) and \#2960 (sample Lino 26) yielded plant results that closely resemble those from mesquite beans or prickly pear. Sample \#4901-2d (sample Lino 24) yielded results very similar to the other fatty acids and could represent the same material (Appendix G). The stable isotope analyses yielded results closer to that from mesquite beans than prickly pear. If Feature 27 was strictly a heating element and not used for cooking, then the presence of organic residues inside the burned rocks may indicate that the burned rocks were previously used, during which time they 


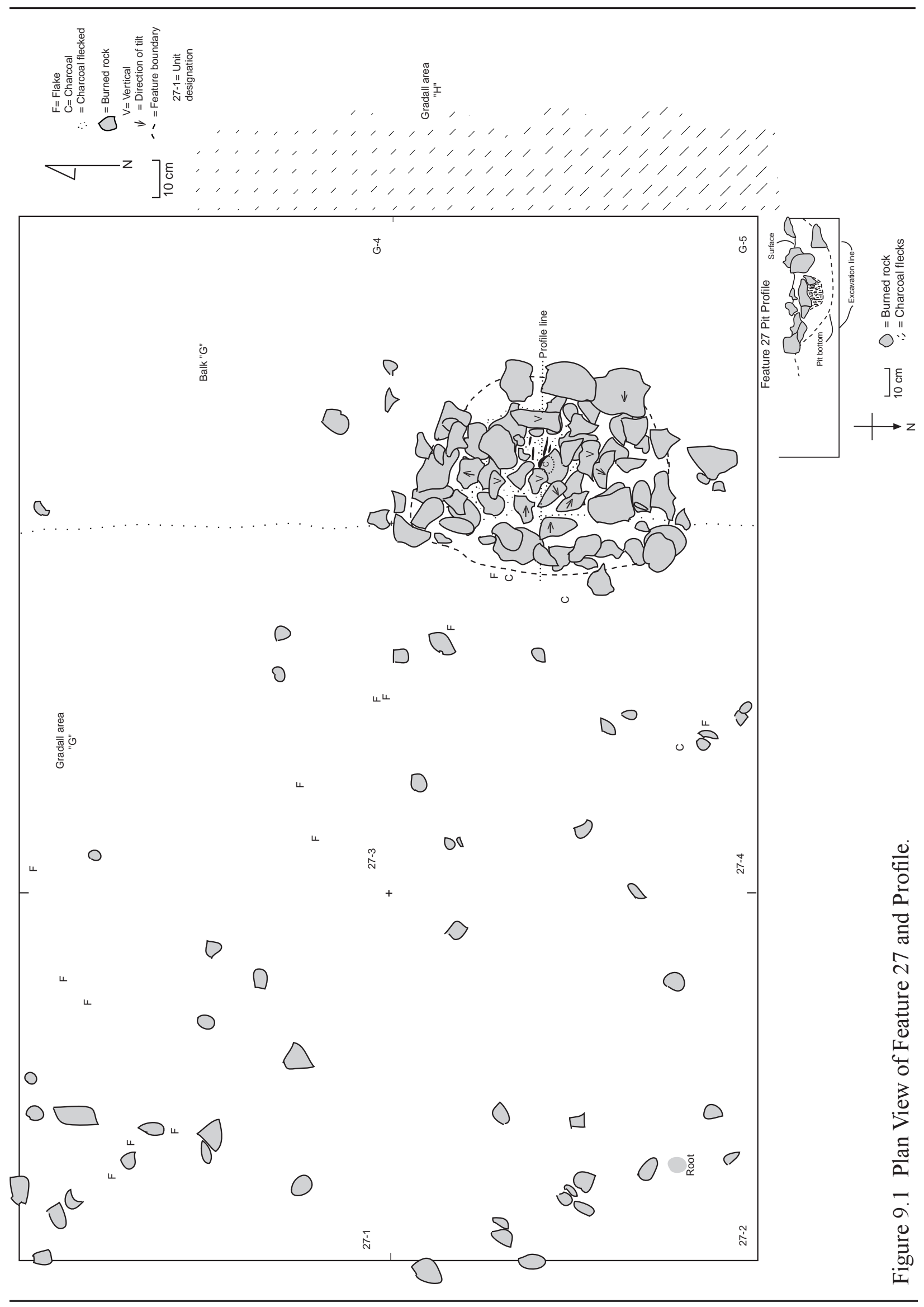




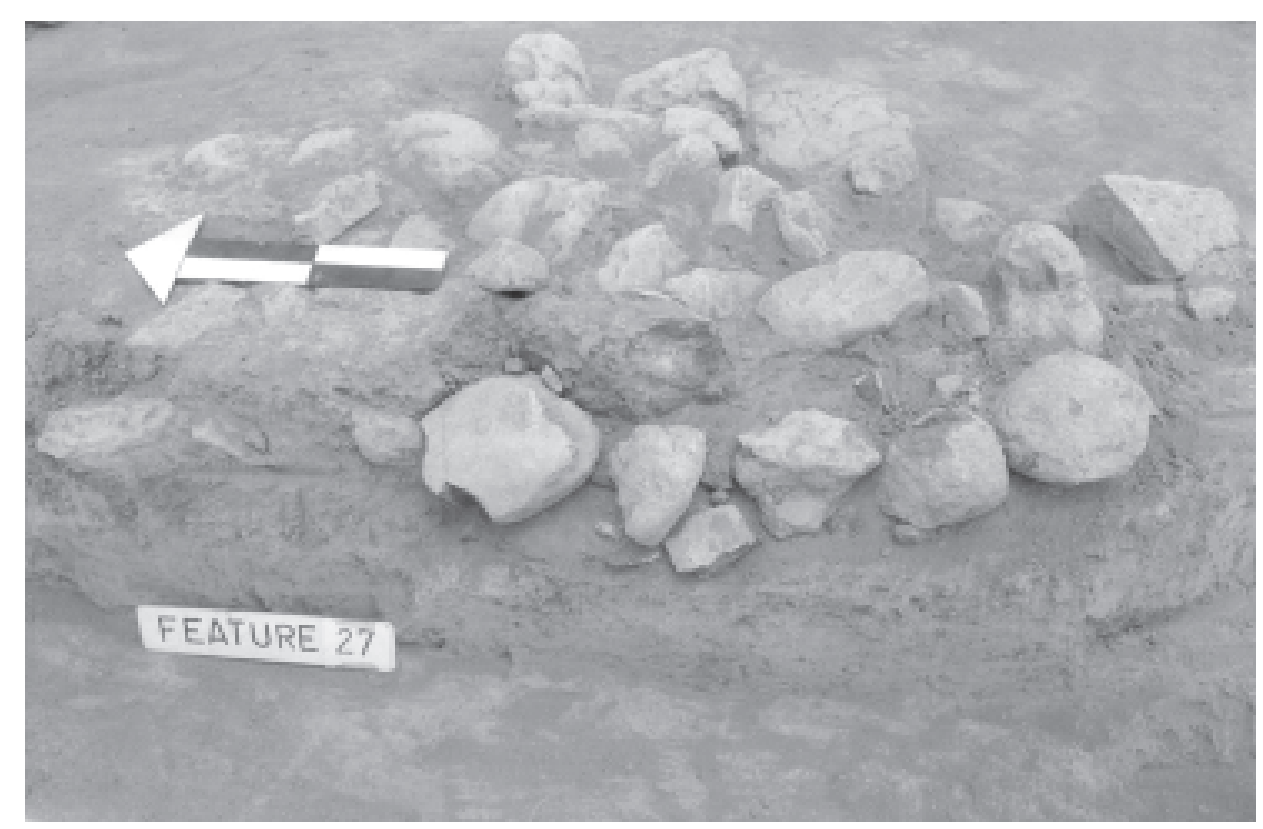

Figure 9.2 Oblique View of Burned Rock Pit Feature 27.

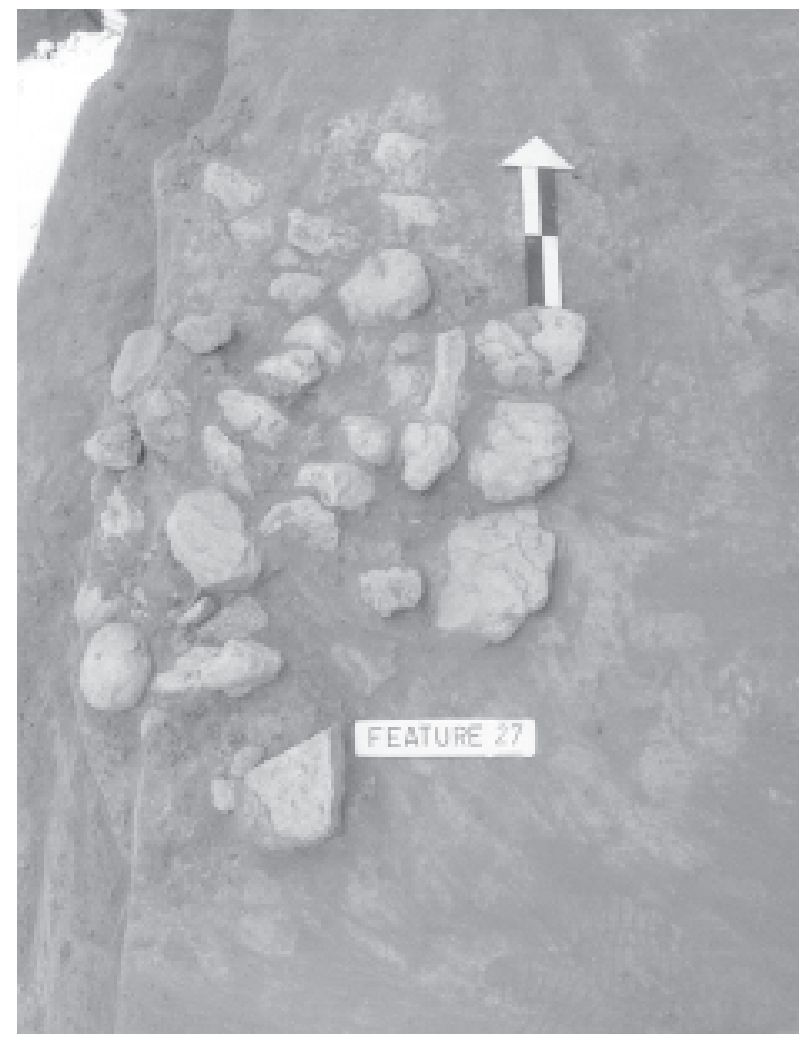

Figure 9.3 Plan View of Feature 27 with Edge of Gradall ${ }^{\mathrm{TM}}$ on Left (West) Margin.

accumulated their organic residues. Alternatively, the rock feature may have been used as a plant cooking apparatus whose heat rocks were also used in stone boiling or other kinds of thermal activities.

Burned rock (\#4901-2) from Feature 27, with an interior color of $10 \mathrm{YR} 3 / 2$, was subjected to thermal demagnetization and exhibited only one temperature component (Appendix E). This rock was probably heated to above 580 degrees $\mathrm{C}$ and cooled in place, although Dr. Gose interprets the rock as never having been heated (Appendix E). The thermal discoloration on the interior of the cobble along with the recovery of organic residues with carbon and nitrogen isotopes and fatty acids from its interior provides irrefutable evidence that this rock was heated and culturally utilized.

Relatively large wood charcoal chunks were recovered near the middle of the charcoal-stained basin, under the upper layer of burned rocks. Two charcoal chunks from within the basin were identified as agarita (Berberis trifoliata) or very similar diffuse porous wood (\#3594-4a) (Appendix B) and an indeterminate hardwood root (\#3594-6a). This latter root is not considered to be of cultural origin in the feature because it could have been a root that was burned 
naturally. Eleven liters of pit matrix were floated and yielded sparse charcoal (1.5 g), crumbs of burned rock fragments $(321.9 \mathrm{~g}), 55$ pieces of lithic debitage $(6.5 \mathrm{~g}), 3.5 \mathrm{~g}$ of snail shell fragments, and one unburned seed (Table 6.3). This feature is interpreted as representing an in situ apparatus for heating the rocks for various cooking procedures. It is quite similar in appearance to Feature 14 in Occupation 1 and Feature 20 in Occupation 3.

The discovery of the edge of Feature 27 along the eastern margin of Gradall ${ }^{\mathrm{TM}}$ Area $\mathrm{G}$ allowed the hand excavations of the majority of the sediments in and around Feature 27 in Balk G. Eight square meters were hand excavated immediately west and southwest of Feature 27 in the Gradall ${ }^{\mathrm{TM}}$ Area $\mathrm{G}$. The good control from these units provided information about the association of materials and hence the activities that may have occurred on the western side. The four units immediately west yielded high densities of scattered burned rocks, and two units yielded moderate densities of chert flakes. Charcoal chunks were occasionally present, but only two edge-modified flakes were within $2 \mathrm{~m}$ of Feature 27.

Feature 37 consisted of a 50 by $40 \mathrm{~cm}$ diameter charcoal stain associated with one large, flat burned sandstone rock (24 cm long by $4 \mathrm{~cm}$ wide) and two smaller burned sandstone rocks near the occupation surface (Figures 9.4 and 9.5). This feature occurred between 80 to $90 \mathrm{cmbs}$ in Unit F4. The eastern half was destroyed during Gradall ${ }^{\mathrm{TM}}$ stripping in Area $\mathrm{G}$, and therefore the precise size and shape of the feature is not known. A shallow 3 to $4 \mathrm{~cm}$ deep basin contained a $2 \mathrm{~cm}$ thick charcoal lens along the bottom (Figure 9.4). Beneath the large, flat burned rock was a limited area that contained a $2 \mathrm{~cm}$ thick ash lens and one $5 \mathrm{~cm}$ diameter chunk of intact burned tree branch (Figure 9.5). No oxidized soil was observed at the base of the basin, but small insect holes were detected along the bottom margins, which may have hindered the detection of oxidation. The two smaller burned sandstone rocks were on the northern edge of the basin and adjacent to the large rock. They may have been pieces broken from the large rock. It appears that this was the location of a small in situ fire, with the most intense heat having occurred directly under the flat rock If so, this rock may have been a griddle that facilitated some type of cooking/warming.

About $130 \mathrm{~cm}$ north of Feature 37 were a complete Matamoros projectile point (\#4478) and a point fragment (\#4528) from Unit F3. Three edge-modified flakes were within $1 \mathrm{~m}$ in Unit F4 whereas one edge-modified flake and a Tortugas point (\#5327-1) were within $1 \mathrm{~m}$ of the charcoal-stained basin on the south side. Other associated materials included a few scattered chert flakes and a couple of small burned pieces of sandstone. Between 70 to $130 \mathrm{~cm}$ directly south of the basin was a small cluster of 10 burned sandstone rocks that were not designated as a feature. The same general area also yielded about 25 chert flakes.

Features 22, 26, 28, 39, and 42 were dominated by clusters of burned rocks in various frequencies that formed no apparent patterns. Feature 22 consisted of 11 burned sandstone rocks and at least one chert flake in a relatively tight cluster that measured about $30 \mathrm{~cm}$ northsouth by $50 \mathrm{~cm}$ east-west (Figure 9.6). No pit, charcoal or ash lens, or oxidized matrix were observed around or below the rocks. The burned rocks weighed a total of $3,143 \mathrm{~g}$ and were mainly 4 to $9 \mathrm{~cm}$ in diameter ( 82 percent). They varied between angular and tabular in general shape (Table 9.2). Ten of the 11 pieces exhibited tiny cracks.

Organic residue extracted from the interior of burned rocks \#2120 and \#2121 from Feature 22 were subjected to isotope and fatty acid analyses. The stable carbon isotope analysis yielded $\delta^{13} \mathrm{C}$ 
Table 9.2 Occupation 4 Burned Rock Data.

\begin{tabular}{|c|c|c|c|c|c|c|c|c|c|c|c|c|c|c|c|c|c|c|}
\hline \multicolumn{19}{|c|}{ Non Feature Contexts } \\
\hline \multirow[b]{2}{*}{ Unit } & \multirow[b]{2}{*}{ Level } & \multirow[b]{2}{*}{ Fea No } & & Size ( & & & & & rial T & Type* & & Fractu & re Type & $\mathrm{e}^{* * *}$ & $\mathrm{Cra}$ & cks & & \\
\hline & & & $0-4$ & $4-9$ & 9-15 & $>15$ & $\mathrm{CC}$ & Ch & $\mathbf{0}$ & Qtz & $\overline{\mathbf{S S}}$ & Ang. & Rnd. & Tab. & $\bar{Y}$ & $\bar{N}$ & Total & Wt $(g)$ \\
\hline $22-1$ & 10 & & 14 & 3 & & & & & & & 17 & 14 & 1 & 2 & 1 & 16 & 17 & 238.4 \\
\hline $22-2$ & 10 & & 7 & 6 & & & & & & & 13 & 6 & 2 & 5 & & 13 & 13 & 504.8 \\
\hline $22-3$ & 10 & & 20 & & & & & 1 & & & 19 & 16 & 4 & 0 & 1 & 19 & 20 & 69.3 \\
\hline $22-4$ & 10 & & 17 & 1 & 1 & & & & & & 19 & 17 & 1 & 1 & 3 & 16 & 19 & 347.2 \\
\hline $22-5$ & 10 & & 13 & 1 & & & & 2 & & & 12 & 10 & 3 & 1 & 2 & 12 & 14 & 255.9 \\
\hline $22-6$ & 10 & & 20 & 1 & & & & 1 & & & 20 & 17 & 2 & 2 & & 21 & 21 & $1,113.3$ \\
\hline $25-1$ & & & 3 & 4 & & & & 7 & & & & 4 & 3 & & & 7 & 7 & $3,534.6$ \\
\hline $25-2$ & 7 & & 19 & 13 & 4 & & & 2 & & & 34 & 25 & 8 & 3 & 1 & 35 & 37 & $12,290.4$ \\
\hline $25-3$ & 7 & & 29 & 9 & & & & 2 & & & 36 & 27 & 7 & 4 & & 38 & 38 & $2,792.9$ \\
\hline $25-4$ & 7 & & 21 & 17 & 3 & & & 11 & & & 30 & 30 & 10 & 1 & 4 & 37 & 41 & $3,479.3$ \\
\hline $25-5$ & 7 & & 5 & 4 & 1 & & & 1 & 1 & & 8 & 9 & & 1 & & 10 & 10 & 567.6 \\
\hline 26-1 & & & 23 & 20 & 1 & & & 4 & & & 40 & 32 & 6 & 6 & 2 & 42 & 44 & $4,759.8$ \\
\hline $26-2$ & & & 52 & 13 & 1 & & & 9 & & & 57 & 49 & 9 & 8 & 6 & 60 & 66 & $1,767.1$ \\
\hline $26-3$ & & & 15 & 5 & 1 & & & 5 & & & 16 & 14 & 4 & 3 & 1 & 20 & 21 & $3,739.7$ \\
\hline $26-4$ & & & 15 & 6 & 7 & & & 2 & 4 & & 22 & 17 & 3 & 8 & 4 & 24 & 28 & $7,160.2$ \\
\hline $27-1$ & & & 17 & 12 & 1 & & & 4 & & 1 & 25 & 19 & 7 & 4 & 5 & 25 & 30 & $2,162.1$ \\
\hline $27-2$ & & & 15 & 16 & & & & & & 2 & 29 & 19 & 6 & 6 & 2 & 29 & 31 & $4,610.5$ \\
\hline $27-3$ & & & 19 & 4 & & & & 2 & & & 21 & 15 & 3 & 5 & & 23 & 23 & 243.8 \\
\hline $27-4$ & & & 28 & 10 & & & & 7 & & 3 & 28 & 30 & 2 & 6 & 2 & 36 & 38 & $2,446.7$ \\
\hline $28-1$ & 9 & & 16 & 2 & 1 & & & 5 & & & 14 & 16 & 1 & 2 & 1 & 18 & 19 & $2,258.3$ \\
\hline $28-2$ & 9 & & 6 & 1 & & & & & & & 7 & 6 & 1 & & & 7 & 7 & 406.5 \\
\hline $28-3$ & 9 & & 4 & & & & & & & & 4 & 2 & 2 & & & 4 & 4 & 21.7 \\
\hline $28-4$ & 9 & & 6 & 1 & & & & & 1 & & 6 & 6 & & 1 & & 7 & 7 & 397.3 \\
\hline $28-5$ & 9 & & 14 & 6 & & & & 1 & 1 & & 18 & 16 & 4 & & & 20 & 21 & 308.5 \\
\hline $28-6$ & 9 & & 42 & 3 & 1 & & & & & & 46 & 36 & 6 & 4 & & 46 & 46 & 697.3 \\
\hline A1 & $10 \& 11$ & & 9 & 2 & & & & & 2 & & 9 & 8 & 3 & & & 11 & 11 & 181.1 \\
\hline A2 & $10 \& 11$ & & 9 & 3 & & & & 1 & 5 & & 6 & 10 & 2 & & 1 & 11 & 12 & $1,512.3$ \\
\hline A3 & $10 \& 11$ & & 13 & 7 & 1 & & & & 1 & & 20 & 11 & 9 & 1 & 1 & 20 & 21 & $3,365.2$ \\
\hline A4 & $10 \& 11$ & & 20 & 6 & 2 & & & 1 & 3 & & 24 & 14 & 9 & 5 & & 28 & 28 & $1,300.0$ \\
\hline A5 & $10 \& 11$ & & 19 & 12 & 1 & & & 2 & 9 & & 21 & 20 & 10 & 2 & 4 & 28 & 32 & $1,540.5$ \\
\hline A6 & $10 \& 11$ & & 11 & 3 & & & & & 3 & & 11 & 11 & & 3 & 1 & 13 & 14 & 215.4 \\
\hline A7 & $10 \& 11$ & & 13 & 3 & & & & 4 & 4 & & 8 & 8 & 7 & 1 & & 16 & 16 & 485.0 \\
\hline B1 & 9 & & 12 & 8 & 2 & & & 1 & 13 & & 8 & 11 & 8 & 3 & 1 & 21 & 22 & $2,243.5$ \\
\hline B2 & 9 & & 2 & 1 & 1 & & & & 2 & & 2 & 3 & 1 & & 2 & 2 & 4 & 644.6 \\
\hline B3 & 9 & & 23 & 6 & 1 & & & & 4 & & 26 & 19 & 8 & 3 & 11 & 19 & 30 & 898.0 \\
\hline B4 & 9 & & 23 & 6 & & & & 3 & 6 & & 20 & 17 & 5 & 7 & 3 & 26 & 29 & 401.2 \\
\hline B5 & 9 & & 5 & 4 & & & & 1 & 3 & & 5 & 7 & 2 & & 1 & 8 & 9 & 511.7 \\
\hline B6 & 9 & & 34 & 13 & 2 & & & 10 & 7 & & 32 & 38 & 6 & 5 & 1 & 48 & 49 & $4,124.9$ \\
\hline B7 & 9 & & 43 & 8 & 1 & & & 3 & 5 & & 44 & 40 & 6 & 6 & 1 & 51 & 52 & $1,285.9$ \\
\hline $\mathrm{C} 1$ & 9 & & 3 & 3 & & & & & & & 6 & 4 & 2 & & 1 & 5 & 6 & 346.8 \\
\hline $\mathrm{C} 2$ & 9 & & 7 & 2 & & & & & 1 & & 8 & 8 & & 1 & & 9 & 9 & 351.5 \\
\hline $\mathrm{C} 3$ & 9 & & 10 & 8 & & & & 5 & 2 & & 11 & 12 & 6 & & & 18 & 18 & $2,328.2$ \\
\hline $\mathrm{C} 4$ & 9 & & 29 & 15 & & & & 4 & 17 & & 23 & 27 & 12 & 5 & 1 & 43 & 44 & $1,402.3$ \\
\hline C5 & 9 & & 11 & 4 & & & & & 4 & & 11 & 10 & 3 & 2 & & 15 & 15 & 274.3 \\
\hline C6 & 9 & & 10 & 3 & & & & 5 & 3 & & 5 & 9 & 4 & & 1 & 12 & 13 & 381.2 \\
\hline C7 & 9 & & 5 & 2 & & & & 1 & 4 & & 2 & 7 & & & 3 & 4 & 7 & $1,415.1$ \\
\hline D1 & 9 & & 8 & 6 & & & & & & & 14 & 4 & 10 & & 1 & 13 & 14 & $3,864.6$ \\
\hline D2 & 9 & & 14 & 2 & & & & 2 & 5 & & 9 & 12 & 2 & 2 & & 16 & 16 & 179.4 \\
\hline D3 & 9 & & 3 & 2 & & & & & 5 & & & 3 & 2 & & & 5 & 5 & 171.3 \\
\hline D4 & 9 & & 14 & 1 & & & 1 & 1 & 3 & & 10 & 10 & 5 & & & 15 & 15 & 122.5 \\
\hline D5 & 9 & & 6 & 3 & 1 & & & & 1 & & 9 & 5 & 3 & 2 & & 10 & 10 & $1,016.1$ \\
\hline D6 & 9 & & 6 & 5 & 1 & & & 2 & 4 & & 6 & 8 & 4 & & & 12 & 12 & $5,700.7$ \\
\hline D7 & 9 & & 5 & 4 & 1 & & & & 4 & & 6 & 4 & 6 & & & 10 & 10 & $2,944.8$ \\
\hline F1 & $9 \& 10$ & & 31 & 22 & 2 & & & 4 & 15 & & 36 & 35 & 15 & 5 & 1 & 54 & 55 & $2,837.9$ \\
\hline F2 & $9 \& 10$ & & 40 & 33 & & & & 1 & 14 & & 58 & 42 & 29 & 2 & 3 & 70 & 73 & $2,488.0$ \\
\hline F3 & $9 \& 10$ & & 32 & 21 & 1 & & & 4 & 19 & & 31 & 36 & 18 & & 4 & 50 & 54 & $5,771.3$ \\
\hline F4 & $9 \& 10$ & & 50 & 11 & 1 & & & & 11 & & 51 & 50 & 5 & 7 & 6 & 56 & 62 & $3,939.6$ \\
\hline F5 & $9 \& 10$ & & 26 & 27 & 4 & & & 3 & 14 & & 40 & 37 & 15 & 5 & 6 & 51 & 57 & $2,923.6$ \\
\hline F6 & $9 \& 10$ & & 22 & 14 & 2 & & & 1 & 12 & & 25 & 23 & 14 & 1 & 2 & 36 & 38 & $1,228.1$ \\
\hline F7 & 9 & & 23 & 4 & 3 & & & & 10 & & 20 & 19 & 6 & 5 & 2 & 28 & 30 & $2,180.7$ \\
\hline G1 & $8 \& 9$ & & 64 & 25 & 2 & & & 12 & 9 & & 70 & 64 & 16 & 11 & 1 & 90 & 91 & $3,423.3$ \\
\hline G2 & $8 \& 9$ & & 117 & 55 & 7 & 1 & & 37 & 55 & & 88 & 118 & 47 & 15 & 1 & 179 & 180 & $9,944.5$ \\
\hline G3 & $8 \& 9$ & & 27 & 10 & & & & 4 & 11 & & 22 & 21 & 16 & 0 & 0 & 37 & 37 & $1,361.9$ \\
\hline G4 & $8 \& 9$ & & 25 & 1 & 2 & & & 7 & 14 & & 7 & 19 & 7 & 2 & 2 & 26 & 28 & $1,907.8$ \\
\hline G5 & $8 \& 9$ & & 25 & 3 & & & & 8 & 11 & & 9 & 17 & 8 & 3 & 4 & 24 & 28 & 366.6 \\
\hline G6 & 8 & & 12 & 12 & & & & 6 & 9 & & 9 & 23 & 1 & & & 24 & 24 & 647.1 \\
\hline G7 & 8 & & 7 & 7 & & & & & 3 & & 11 & 7 & 2 & 5 & & 14 & 14 & $1,090.1$ \\
\hline Subtotal & & & 1,308 & 545 & 60 & 1 & 1 & 199 & 334 & 6 & 1,374 & 1,303 & 429 & 182 & 101 & 1,813 & 1,916 & $135,491.8$ \\
\hline
\end{tabular}


Table 9.2 continued.

\begin{tabular}{|c|c|c|c|c|c|c|c|c|c|c|c|c|c|c|c|c|c|c|}
\hline \multicolumn{19}{|c|}{ Feature Contexts } \\
\hline \multirow[b]{2}{*}{ Unit } & \multirow[b]{2}{*}{ Level } & \multirow[b]{2}{*}{ Fea No } & \multicolumn{4}{|c|}{ Size $(\mathbf{c m})$} & \multicolumn{5}{|c|}{ Material Type* } & \multicolumn{3}{|c|}{ Fracture Type*** } & \multicolumn{2}{|c|}{ Cracks } & \multirow[b]{2}{*}{ Total } & \multirow[b]{2}{*}{$\mathrm{Wt}(\mathrm{g})$} \\
\hline & & & $0-4$ & 4-9 & $9-15$ & $>15$ & $\mathbf{C C}$ & Ch & $\mathbf{O}$ & Qtz & SS & Ang. & Rnd. & Tab. & $\mathbf{Y}$ & $\mathbf{N}$ & & \\
\hline $22-1 \& 22-2$ & & 22 & 2 & 9 & & & & & & & 11 & 6 & & 5 & 1 & 10 & 11 & $3,142.6$ \\
\hline $25-1 \& 25-2$ & 7 & 25 & 31 & 21 & 2 & & & 5 & & & 49 & 42 & 10 & 2 & 4 & 50 & 54 & $2,947.3$ \\
\hline $26-4$ & & 26 & 10 & 9 & 1 & & 1 & 1 & & & 18 & 11 & 3 & 6 & 1 & 19 & 20 & 827.4 \\
\hline $27-4 \&$ G5 & 8 & 27 & 7 & 58 & 41 & 2 & & 2 & 12 & & 94 & 61 & 34 & 13 & 34 & 74 & 108 & $61,319.9$ \\
\hline $28-5$ & 9 & 28 & 15 & 16 & 2 & & 1 & 1 & & & 31 & 22 & 5 & 6 & 4 & 29 & 33 & $1,690.7$ \\
\hline F4 & 9 & 37 & 1 & 1 & & 1 & & & & & 3 & 3 & & & 2 & 1 & 3 & $1,645.2$ \\
\hline G1 & 9 & 39 & & & 4 & & & & & & 4 & 3 & 1 & & 1 & 3 & 4 & 3,193.3. \\
\hline G6 & 8 & 42 & & 6 & 1 & & & 2 & & & 5 & 5 & 1 & 1 & 3 & 4 & 7 & 945.7 \\
\hline Subtotal & & & 66 & 120 & 51 & 3 & 2 & 11 & 12 & 0 & 215 & 153 & 54 & 33 & 50 & 190 & 240 & $75,712.1$ \\
\hline Total & & & 1,374 & 665 & 111 & 4 & 3 & 210 & 346 & 6 & 1,589 & 1,456 & 483 & 215 & 151 & 2,003 & 2,156 & $211,203.9$ \\
\hline
\end{tabular}

values of $-22.2 \%$ and $-23.0 \%$ (Appendix D). These values appear to represent a mixture of $\mathrm{C} 3$ and $\mathrm{C} 4 / \mathrm{CAM}$ resources. The $\delta^{15} \mathrm{~N}$ values were 5.5\%o and 4.9\%o (Appendix D). These values also represent mixtures of various plant and animal resources. These same two samples were examined for fatty acids. Sample \#2120 (sample Lino 17) yielded fatty acids similar to large herbivore whereas \#2121d (sample Lino 16) yielded insufficient fatty acids to allow interpretation (Appendix G). The stable carbon isotopic value from \#2120b is more consistent with that of deer rather than residues from bison.

Thermal demagnetization studies conducted on one burned rock (\#2120) yielded two magnetic components (Appendix E). These two components may represent a stone boiling process, although Dr. Gose has not recognized a magnetic signature for stone boiling.

Eight liters of matrix from under and around the burned rocks in Feature 22 were floated. This matrix yielded six pieces of lithic debitage greater than $6.4 \mathrm{~mm}$, another 27 tiny (fewer than $6.4 \mathrm{~mm}$ ) pieces of debitage, some $26 \mathrm{~g}$ of burned rock crumbs, about $1.4 \mathrm{~g}$ of crushed mussel shell fragments, a trace of snail shell fragments, and a trace of charcoal (Table 6.3). The adjacent hand excavated units yielded a few scattered burned rocks, a charcoal chunk $10 \mathrm{~cm}$ west of
Feature 32, a few pieces of lithic debitage, and four mussel shell fragments.

Feature 26 consisted of 20 burned rocks and at least five flakes in an area measuring about 65 $\mathrm{cm}$ north-south by $30 \mathrm{~cm}$ east-west (Figure 9.7). This cluster was adjacent to the eastern boundary of Gradall ${ }^{\mathrm{TM}}$ strip $\mathrm{G}$ and the south edge of the excavation block. It was unclear how much of this feature concentration was captured in the excavation block. Hand excavation along the adjacent $4 \mathrm{~m}^{2}$ only sampled the western half of the feature. The burned rocks appeared to be on an irregular surface with no obvious sign of a pit, charcoal staining, or oxidized matrix. The 20 burned rocks weighed $827 \mathrm{~g}$ with an average weight of $41 \mathrm{~g} /$ rock (Table 9.2). Fifty percent were fewer than $4 \mathrm{~cm}$ in diameter with another 45 percent between 4 and $9 \mathrm{~cm}$ in diameter. All but two pieces were sandstone; the other pieces were chert and a calcium carbonate chunk. The chert cobble had been shattered into multiple fragments. Fifty-five percent of the rocks were angular, 30 percent were tabular, and 15 percent were rounded. Nineteen exhibited tiny cracks.

Organic residues from the interior portions of four burned rocks (\#2849, \#2876, \#2887, and \#2888) from Feature 26 were subjected to various analyses. The stable carbon isotope analysis yielded $\delta^{13} \mathrm{C}$ values between $-21.0 \%$ o 


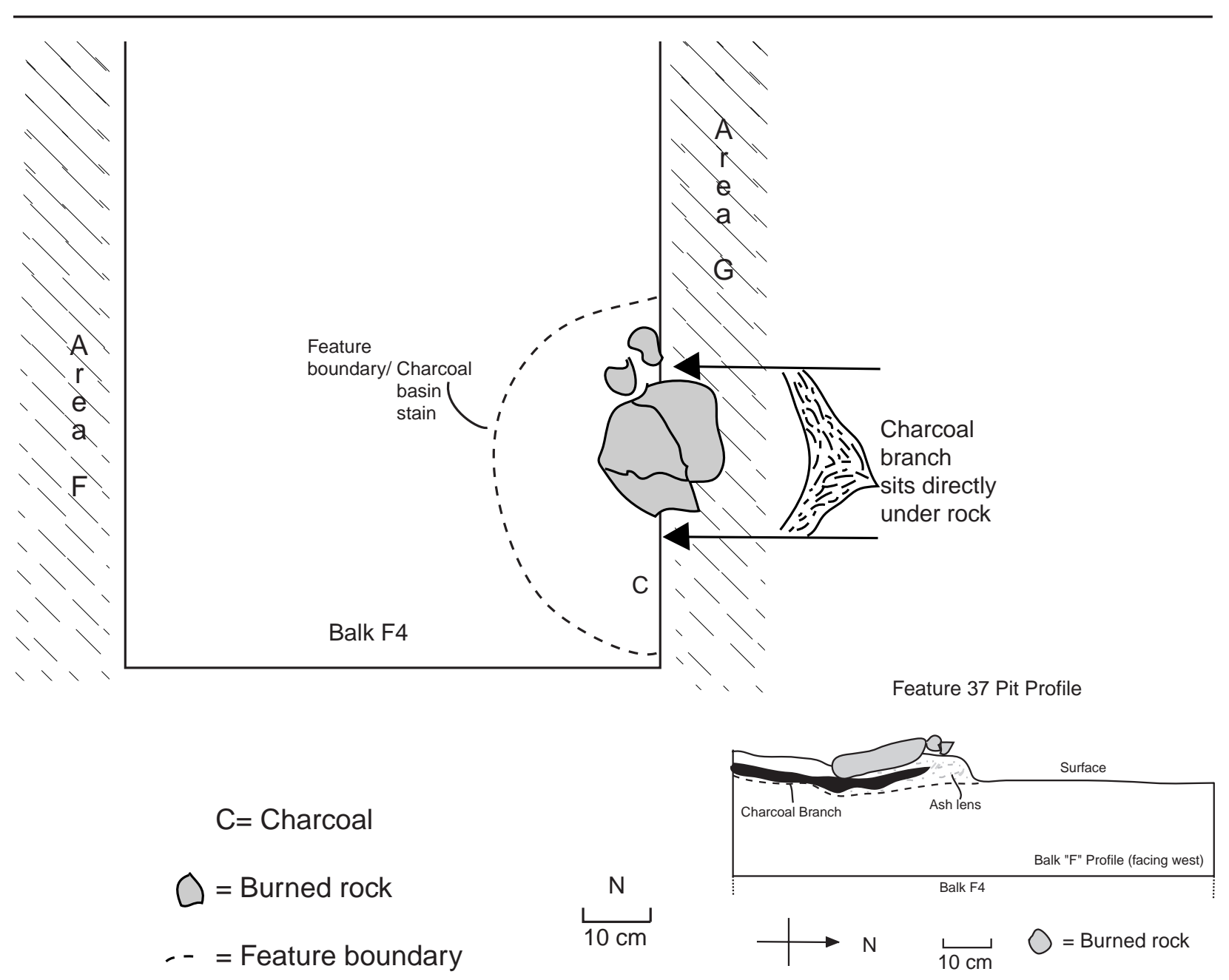

Figure 9.4 Plan View of Feature 37 and Profile.

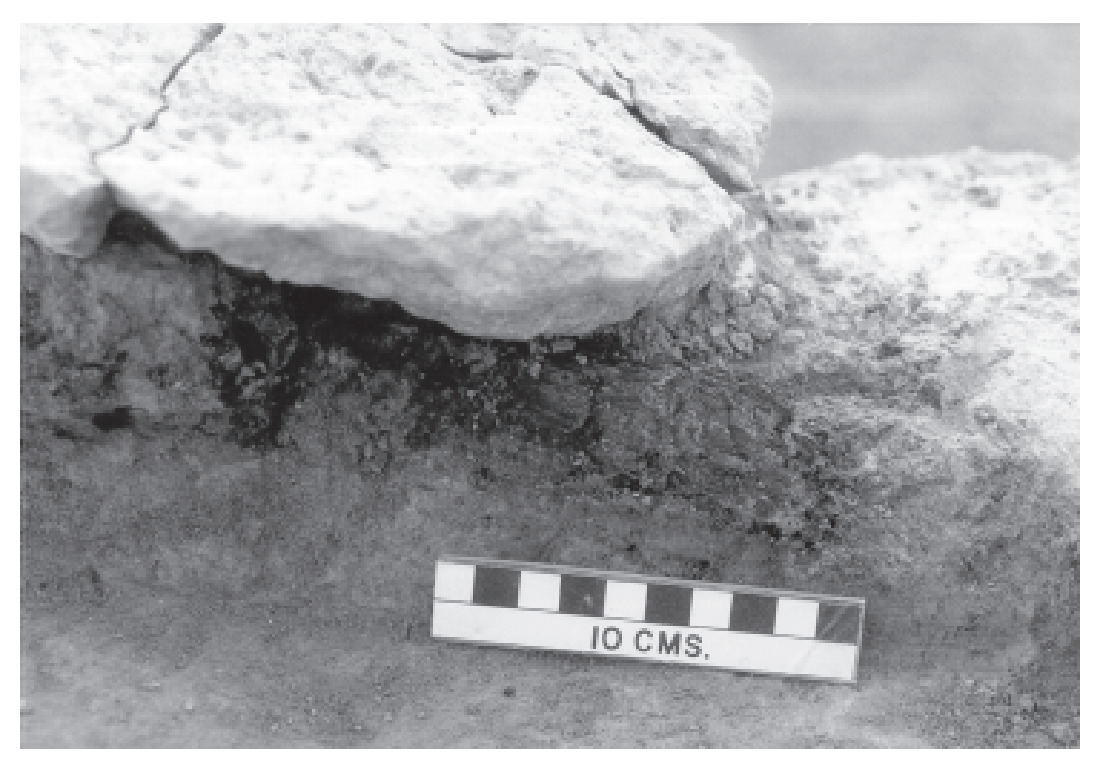

Figure 9.5 Closeup of Large Charcoal Branch (\#5741 ) underlying Large Burned Rock in Feature 37. 


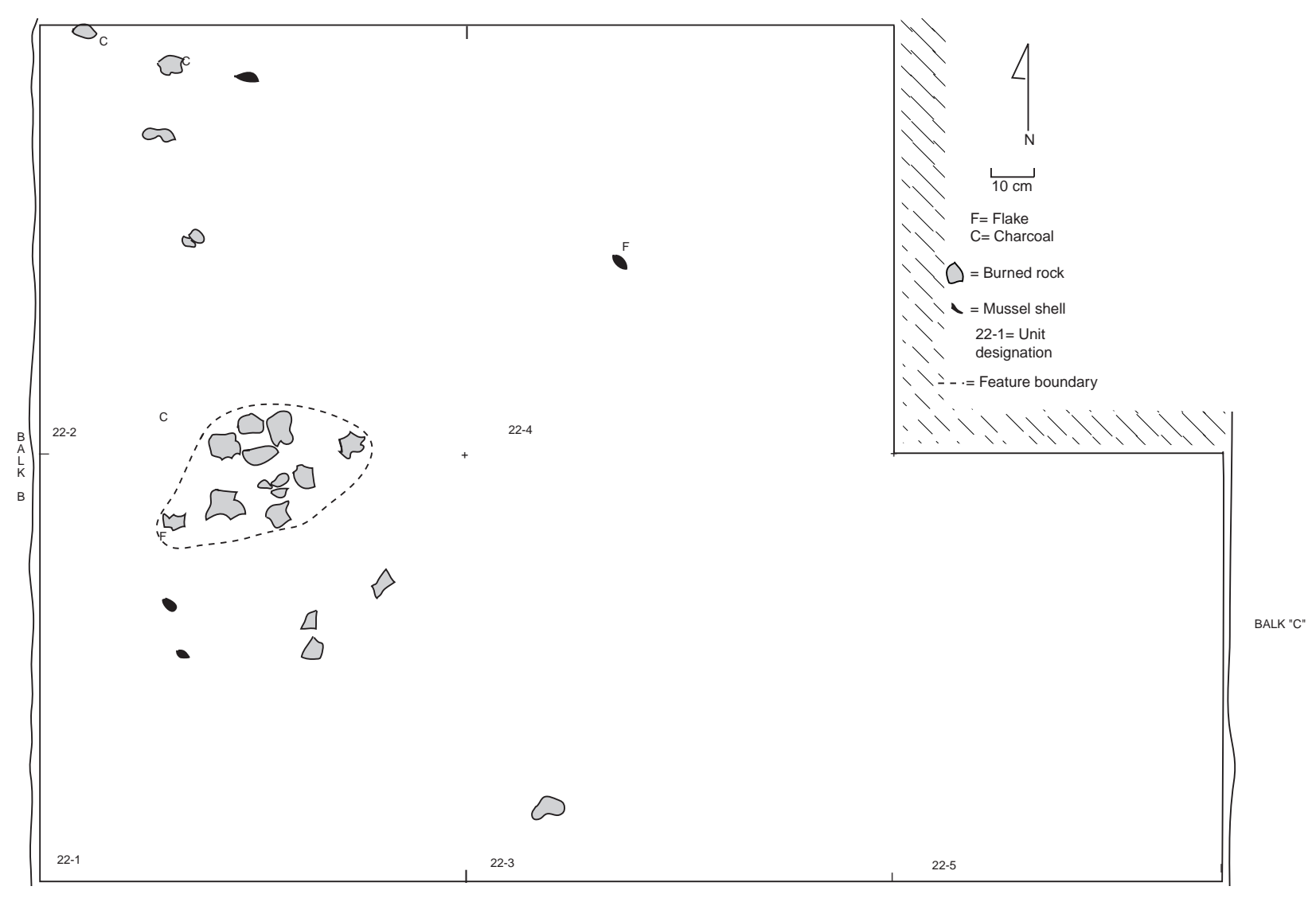

Figure 9.6 Plan View of Feature 22.

and $-24.1 \%$ (Appendix D). These values may represent a mixture of $\mathrm{C} 3$ and $\mathrm{C} 4 / \mathrm{CAM}$ plant or animal resources. The $\delta^{15} \mathrm{~N}$ values range between 4.6\%o and 9.8\%o (Appendix D). These values encompass a wide variety of food resources and probably represent a mixture of C3 and C4/CAM plant and animal resources. Two of the organic residues (\#2849 and \#2888) were also examined for their fatty acid content. The residues extracted from burned rock \#2849d (sample Lino 23) yielded a fatty acid signature of a large herbivore (Appendix G). The stable isotopic analysis from that same rock supports the presence of deer residue for the large herbivore. Residues from \#2888 (sample Lino 22 ) yielded mostly plant fatty acids. Apparently, deer meat and plants were processed using these two burned rocks.
Also from Feature 26, burned rock \#2876 was subjected to thermal demagnetization analysis, and two temperature components were identified (Appendix E). Although Dr. Gose has not recognized a definitive magnetic signature for these patterns, recent stone boiling experiments on sandstone from the area by Quigg (Takac 1999) has yielded a comparable two-component pattern.

The $4 \mathrm{~m}^{2}$ hand excavated area on the northwestern side of Feature 26 yielded a continuation of scattered burned rocks, flakes, an occasional charcoal chunk, a couple of mussel shell fragments, and a light charcoal stain in a 20 by $10 \mathrm{~cm}$ area. The faint stain was about 170 $\mathrm{cm}$ west of the margin of the feature; it was extremely thin and lacked clear boundaries. It is unclear what this stain represents. 


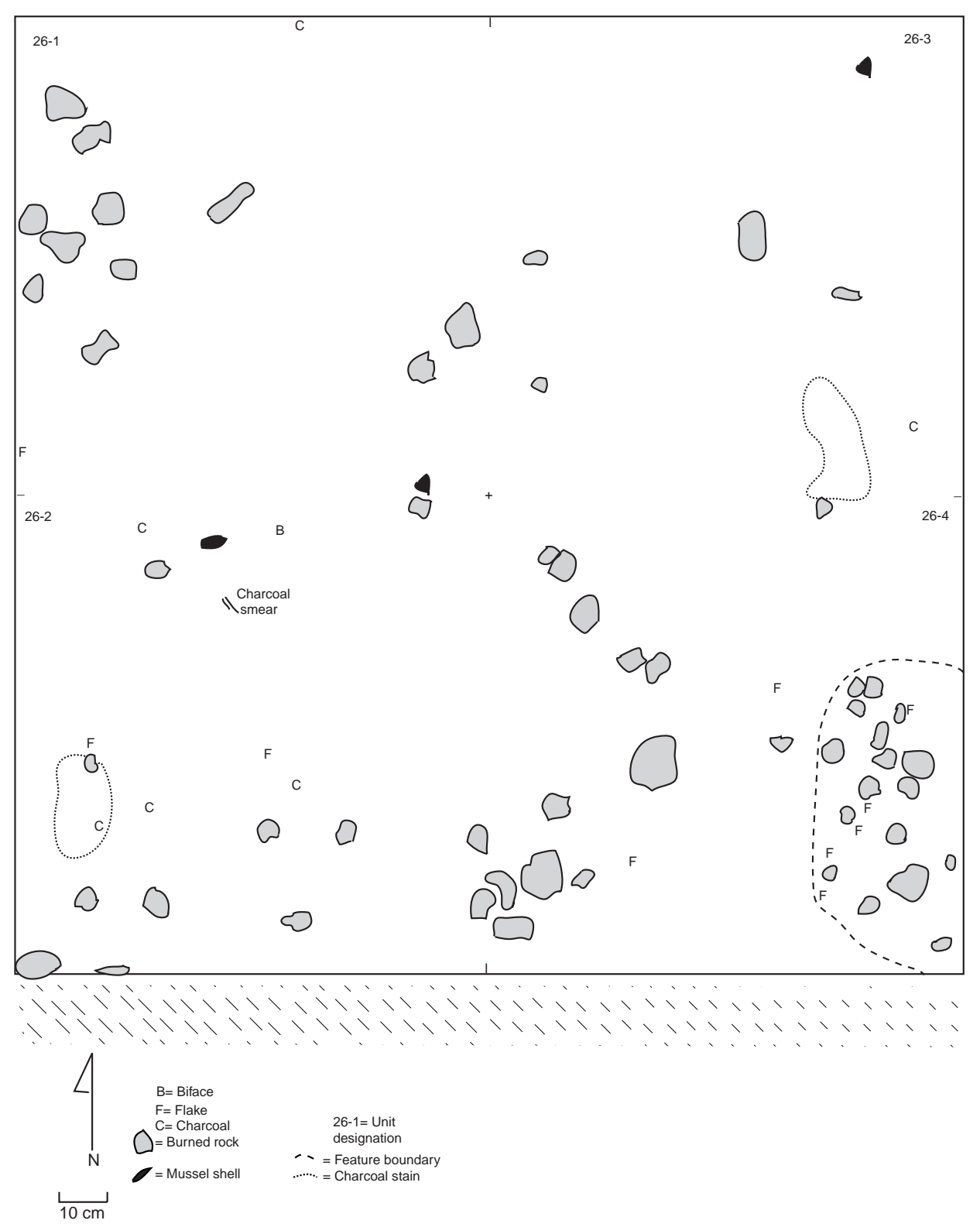

Figure 9.7 Plan View of Feature 26.

Feature 28 consisted of 33 burned rocks, one chunk of charcoal, one mussel shell valve, and at least three flakes all clustered in an area that measured about $70 \mathrm{~cm}$ north-south by $50 \mathrm{~cm}$ east-west (Figure 9.8). A north-south profile revealed no sign of a pit, charcoal staining or oxidation. The 33 rocks weighed a total of 1,691 g. All but two were sandstone, one was chert and the other was a chunk of calcium carbonate (Table 9.2). The rock sizes were almost equally split between the size categories of smaller than
$4 \mathrm{~cm}$ and 4 to $9 \mathrm{~cm}$ in diameter, with two rocks greater than $9 \mathrm{~cm}$. Nearly two-thirds of the stones were angular, with some tabular and some rounded pieces. Only four pieces exhibited tiny cracks. The adjacent five hand-excavated units yielded minimal amounts of lithic debitage, a few scattered burned rocks, a couple of mussel shell valve fragments to the northwest, and a few scattered burned rocks with a moderate number of small burned rocks in the unit to the south. 


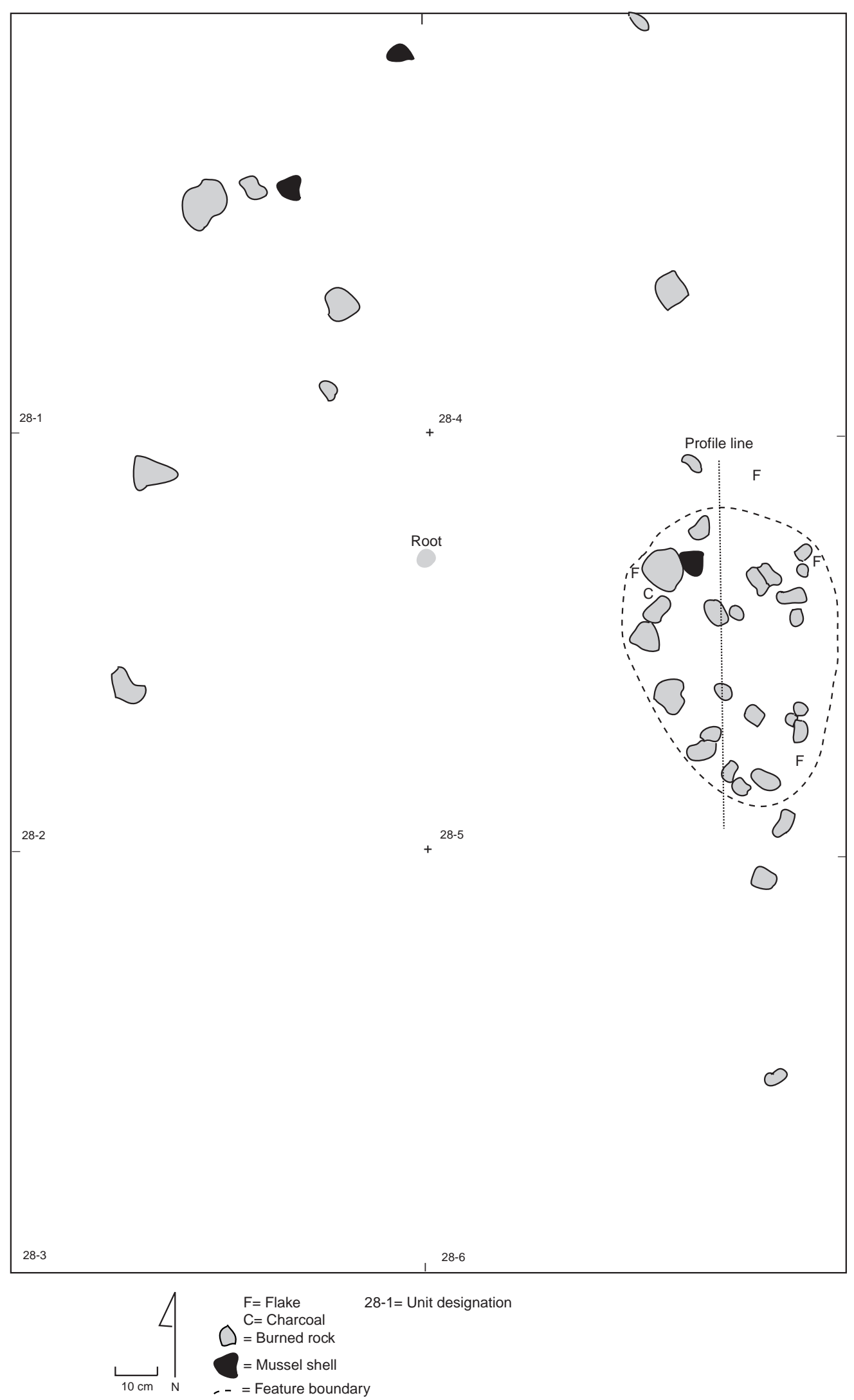

Figure 9.8 Plan View of Feature 28. 
Feature 39 consisted of four burned sandstone rocks clustered in an area that measured $40 \mathrm{~cm}$ by $25 \mathrm{~cm}$ from Unit G1 (Figure 9.9). A profile cut through the cluster did not reveal a basin, ash or charcoal lens. The rocks were on a relatively level surface. The four rocks weighed a total of 3,193 $\mathrm{g}$ and had an average weight of nearly $800 \mathrm{~g}$ (Table 9.2). One of the four rocks that measured 9 to $15 \mathrm{~cm}$ diameters accounted for 40 percent of the total weight. The other three rocks were small and angular. Only one rock exhibited cracks. This small sandstone rock cluster had scattered burned rocks, scattered flecks of charcoal, about 10 chert flakes, and a mussel shell fragment within the same unit, Unit G1.

The internal matrices from two burned rocks (\#4704-1b, \#4704-2b and \#4704-2) were analyzed for organic residues. The stable carbon and nitrogen isotope analyses yielded $\delta^{13} \mathrm{C}$ values of $-18.8 \%$ and $-20 \%$, whereas the $\delta^{15} \mathrm{~N}$ values are $4.5 \%$ and 6.5\% (Appendix C). These isotope values appear to reflect mixed $\mathrm{C} 3$ and C4/CAM plant and animal resources. Fatty acid analysis on the residues from rock \#4704-2d yielded lipid evidence of large herbivore, possibly mixed with some plant lipids (Appendix G). One burned rock (\# 4704-2) was subjected to thermal demagnetization. It yielded four thermal components (Appendix E). Although it is unclear how these four components were created, this signature does fit at least one of the assumed stone boiling signatures.

A 9.25 liter matrix sample from around and under the burned rocks of Feature 39 was floated. It yielded 12 pieces lithic debitage; only two flakes are over $6.4 \mathrm{~mm}$ in size. Other materials include $153 \mathrm{~g}$ of fragmented burned sandstone and a trace of snail shell fragments.

Feature 42 consisted of seven tightly clustered burned rocks scattered over an area of about 25 by $40 \mathrm{~cm}$ within Unit G6 (Figure 9.10). No basin, charcoal or ash lens, or matrix oxidation was observed beneath or around the burned rocks. Seventy-one percent of the burned rocks were sandstone with the rest represented by chert (Table 9.2). The burned sandstone rocks mostly (86 percent) ranged between 4 and $9 \mathrm{~cm}$ in diameter; the other cobbles measured 9 to 15 $\mathrm{cm}$ in diameter. About 71 percent were angular, and one each was rounded and tabular. Fortytwo percent exhibited tiny cracks. The seven burned rocks weighed $945 \mathrm{~g}$, for an average weight of $135 \mathrm{~g} / \mathrm{rock}$.

The interior organic residues from burned rocks \#4842-1 and \#4842-2 were analyzed. The stable carbon and nitrogen isotopes yielded $\delta^{13} \mathrm{C}$ values of $-23.0 \%$ and $-23.1 \%$, whereas the $\delta^{15} \mathrm{~N}$ values were $0.8 \%$ and $1.0 \%$ (Appendix C). These carbon isotope values are slightly above the expected values for legume beans, whereas the nitrogen values are within the range of legumes. However, some kinds of nuts exhibit the same low nitrogen value ranges. These same residues were also analyzed for fatty acids. Rock \#48421d yielded only a trace of lipids and could not be interpreted. Rock \#4842-2d yielded fatty acids indicative of general plants (Appendix G). The lipid results support the isotope findings that plant residues occur inside the rocks.

About three liters of matrix from under and around the burned rocks from Feature 42 were floated. This sample yielded 14 flakes, three of which are over $6.4 \mathrm{~mm}$ in size and the rest in tiny pieces. Also recovered were less than a gram of snail shell fragments and charcoal flecks along with about $9 \mathrm{~g}$ of tiny crumbs of burned sandstone. Hand excavation of this same Unit G1 also yielded 12 chert flakes, small scattered burned rocks, flecks of charcoal, and Rabdotus shell fragments. Rock-filled pit Feature 27 was $1 \mathrm{~m}$ north whereas another small cluster of burned rocks, Feature 26, and was within $1 \mathrm{~m}$ to the southwest. Three adjacent 1 by $1 \mathrm{~m}$ units in 


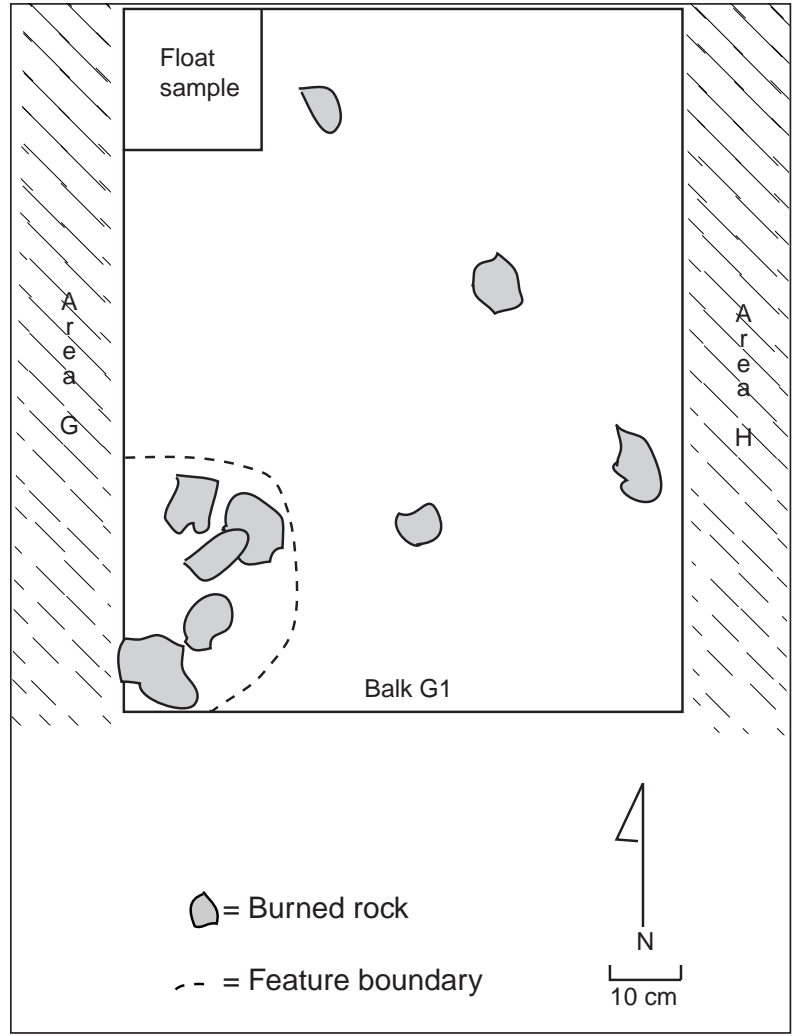

Figure 9.9 Plan View of Feature 32.

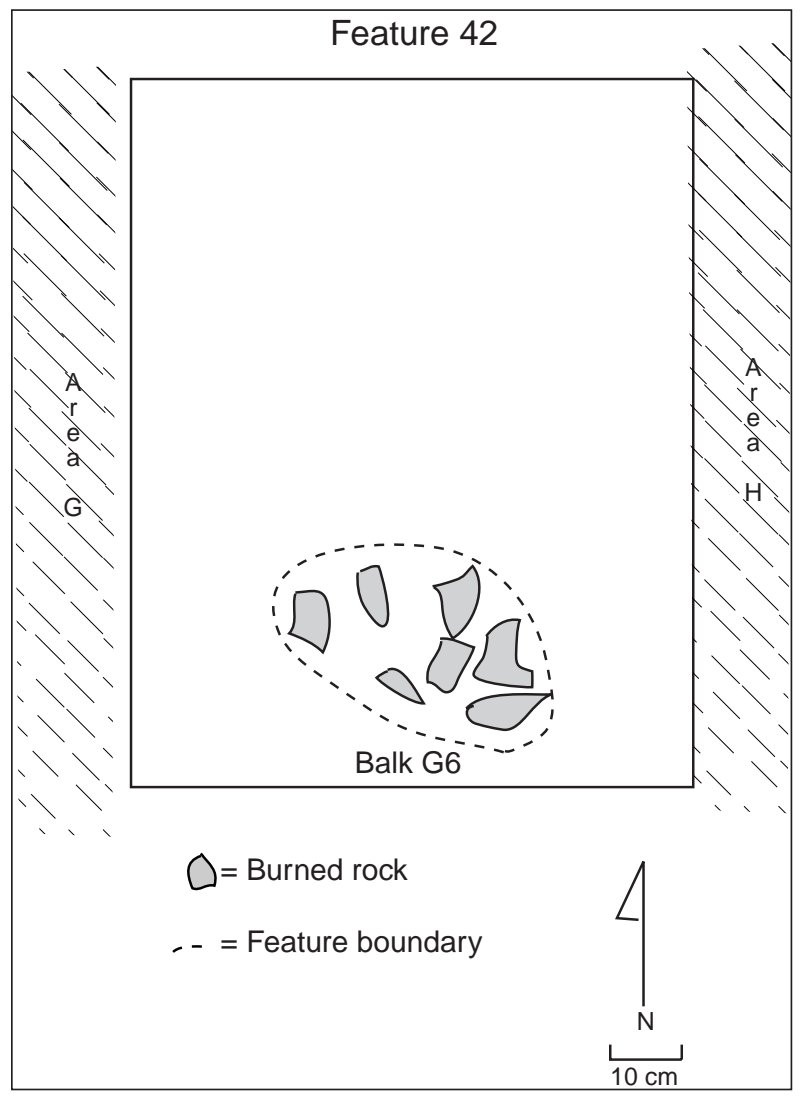

Figure 9.10 Plan View of Feature 42.
Area $\mathrm{G}$ yielded similar low lithic debris density and burned rock frequencies. No tools were found in this or the adjacent three units, although a chert core was recovered from Unit G7.

Feature 25 was initially identified by a small cluster of burned rocks exposed during Gradall $^{\mathrm{TM}}$ stripping. Upon hand excavation of four adjoining 1 by $1 \mathrm{~m}$ units, it became clear that the rocks represented part of a much broader occupation floor and not a specific burned rock feature (Figure 9.11). A small cluster of burned rocks was evident, but this concentration is regarded as a fortuitous group that is quite typical of an occupation surface. Thus, these materials were not analyzed as a separate feature. The cultural materials from these units are analyzed with the material categories below.

\subsection{CHIPPED LITHIC ASSEMBLAGE}

The lithic debitage assemblage from the $40 \mathrm{~m}^{2}$ hand-excavated balks and the $31 \mathrm{~m}^{2}$ handexcavated units around three recognized features yielded 1,760 pieces of unmodified chipped stone debitage. This occupation zone yielded about 25 pieces of lithic debitage per square meter. The raw material was all chert that could have been procured from local gravel sources. Color differences exist in the cherts, and in very general terms most are light and dark tan, gray, and brown, with some white and dark red hues.

The debitage was classified into six types (Table 9.3). Core flakes (32 percent) were the most frequent, followed by nearly equal frequencies of indeterminate flakes ( 25 percent), late stage biface flakes ( 22 percent), and early stage biface flakes (20 percent). The angular debris and uniface flakes were minimally represented by a few pieces. Difficulty exists in that recognizing some uniface flakes is possible, but identification errors are not sufficiently significant to change the overall characterization of the knapping processes. The flake type frequencies 
Table 9.3 Occupation 4 Lithic Debitage Analysis.

\begin{tabular}{|c|c|c|c|c|c|c|c|}
\hline \multirow[b]{2}{*}{ Condition } & \multicolumn{6}{|c|}{ Flake Type } & \multirow[b]{2}{*}{ Total } \\
\hline & $\begin{array}{c}\text { angular } \\
\text { debris }\end{array}$ & core & $\begin{array}{c}\text { early } \\
\text { biface }\end{array}$ & indet. & $\begin{array}{c}\text { late } \\
\text { biface }\end{array}$ & uniface & \\
\hline \multirow[t]{2}{*}{ complete } & - & 142 & 44 & 81 & 67 & 6 & 340 \\
\hline & $0 \%$ & $25 \%$ & $13 \%$ & $19 \%$ & $17 \%$ & $100 \%$ & $19 \%$ \\
\hline \multirow[t]{2}{*}{ distal } & - & 106 & 68 & 42 & 116 & - & 332 \\
\hline & $0 \%$ & $19 \%$ & $20 \%$ & $10 \%$ & $30 \%$ & $0 \%$ & $19 \%$ \\
\hline \multirow[t]{2}{*}{ fragment } & 13 & - & - & - & - & - & 13 \\
\hline & $100 \%$ & $0 \%$ & $0 \%$ & $0 \%$ & $0 \%$ & $0 \%$ & $1 \%$ \\
\hline \multirow[t]{2}{*}{ medial } & - & 87 & 82 & 272 & 91 & - & 532 \\
\hline & $0 \%$ & $15 \%$ & $24 \%$ & $62 \%$ & $24 \%$ & $0 \%$ & $30 \%$ \\
\hline \multirow[t]{2}{*}{ proximal } & - & 236 & 154 & 41 & 112 & - & 543 \\
\hline & $0 \%$ & $41 \%$ & $44 \%$ & $9 \%$ & $29 \%$ & $0 \%$ & $31 \%$ \\
\hline \multirow[t]{2}{*}{ Total } & 13 & 571 & 348 & 436 & 386 & 6 & 1760 \\
\hline & $1 \%$ & $32 \%$ & $20 \%$ & $25 \%$ & $22 \%$ & $0 \%$ & $100 \%$ \\
\hline & \multicolumn{6}{|c|}{ Flake Type } & \\
\hline Cortex & $\begin{array}{c}\text { angular } \\
\text { debris }\end{array}$ & core & $\begin{array}{c}\text { early } \\
\text { biface }\end{array}$ & indet. & $\begin{array}{c}\text { late } \\
\text { biface }\end{array}$ & uniface & Total \\
\hline \multirow[t]{2}{*}{ primary } & - & 46 & - & 3 & - & - & 49 \\
\hline & $0 \%$ & $8 \%$ & $0 \%$ & $1 \%$ & $0 \%$ & $0 \%$ & $3 \%$ \\
\hline \multirow[t]{2}{*}{ secondary } & 5 & 338 & 29 & 62 & 7 & - & 441 \\
\hline & $38 \%$ & $59 \%$ & $8 \%$ & $14 \%$ & $2 \%$ & $0 \%$ & $25 \%$ \\
\hline \multirow[t]{2}{*}{ tertiary } & 8 & 187 & 319 & 371 & 379 & 6 & 1270 \\
\hline & $62 \%$ & $33 \%$ & $92 \%$ & $85 \%$ & $98 \%$ & $100 \%$ & $72 \%$ \\
\hline \multirow[t]{2}{*}{ Total } & 13 & 571 & 348 & 436 & 386 & 6 & 1760 \\
\hline & $1 \%$ & $32 \%$ & $20 \%$ & $25 \%$ & $22 \%$ & $0 \%$ & $100 \%$ \\
\hline \multirow{4}{*}{$\frac{\text { Heating }}{\text { crazed }}$} & \multicolumn{6}{|c|}{ Flake Type } & \\
\hline & $\begin{array}{c}\text { angular } \\
\text { debris }\end{array}$ & core & $\begin{array}{c}\text { early } \\
\text { biface }\end{array}$ & indet. & $\begin{array}{c}\text { late } \\
\text { biface }\end{array}$ & uniface & Total \\
\hline & - & 18 & 4 & 2 & 1 & - & 25 \\
\hline & $0 \%$ & $3 \%$ & $1 \%$ & $0 \%$ & $0 \%$ & $0 \%$ & $1 \%$ \\
\hline \multirow[t]{2}{*}{ indet. } & 3 & 27 & 2 & 21 & 3 & - & 56 \\
\hline & $23 \%$ & $5 \%$ & $1 \%$ & $5 \%$ & $1 \%$ & $0 \%$ & $3 \%$ \\
\hline \multirow[t]{2}{*}{ none } & 10 & 504 & 335 & 388 & 382 & 6 & 1625 \\
\hline & $77 \%$ & $88 \%$ & $96 \%$ & $89 \%$ & $99 \%$ & $100 \%$ & $92 \%$ \\
\hline \multirow[t]{2}{*}{ spall } & - & 22 & 7 & 25 & - & - & 54 \\
\hline & $0 \%$ & $4 \%$ & $2 \%$ & $6 \%$ & $0 \%$ & $0 \%$ & $3 \%$ \\
\hline \multirow[t]{2}{*}{ Total } & 13 & 571 & 348 & 436 & 386 & 6 & 1760 \\
\hline & $1 \%$ & $32 \%$ & $20 \%$ & $25 \%$ & $22 \%$ & $0 \%$ & $100 \%$ \\
\hline
\end{tabular}

recognized here reflect the most dominant knapping activities of core reduction and biface manufacture. Uniface maintenance was conducted on site but at a very low level in comparison to other knapping tasks.

Medial and proximal flake fragments are equally represented by 30 percent each (Table 9.3). Complete flakes and distal fragments are also equally represented with about 19 percent each. Angular debris accounts for less than one percent, which is similar to frequencies found in the previous occupations. Complete core flakes are represented by about six percent fewer flakes than those in previous occupations, whereas broken core flakes are more frequently recovered than in the previous occupations. These differences may denote a change in the core reduction technique, a change in general reduction strategy, or they may reflect an increase in breakage due to more trampling of discarded debitage or other post-depositional processes. Distal debitage fragments appear to be underrepresented compared to the frequency of medial sections present.

Cortex remains on about 28 percent of the debitage assemblage. Some 67 percent of the core flakes and another 39 percent of angular debris had some remaining cortex (Table 9.3). The high cortex frequency on core flakes reflects the decortification process of weathered nodules. The high percentage of cortex on the angular debris links this material to the decortification process. Minor cortex remains on the early stage biface flakes, which reflects the continuation of the nodule process. Little or no cortex occurs on late stage biface flakes.

Heat altered (crazed and spalled) pieces account for four percent of the assemblage, with heat spalls accounting for about two-thirds of that total (Table 9.3). These heat alterations probably resulted from direct exposure of chert debitage to fires, which probably reflects that some waste lithic debris was discarded around areas later used for cooking. Since little or no intentional heat treatment was observed, controlled thermal exposure to enhance knappability was not a standard practice applied to this assemblage.

\subsection{CHIPPED STONE TOOLS}

The recognized chipped-stone tool assemblage was classified into five form/functional classes. They consist of six projectile points, eight bifaces, one end scraper, 68 edge-modified flakes, and seven cores. As a group, these 86 tools account for 0.4 percent of the total material recovered from the $71 \mathrm{~m}^{2}$ hand-excavated material in Occupation 4. The 19 formal tools 


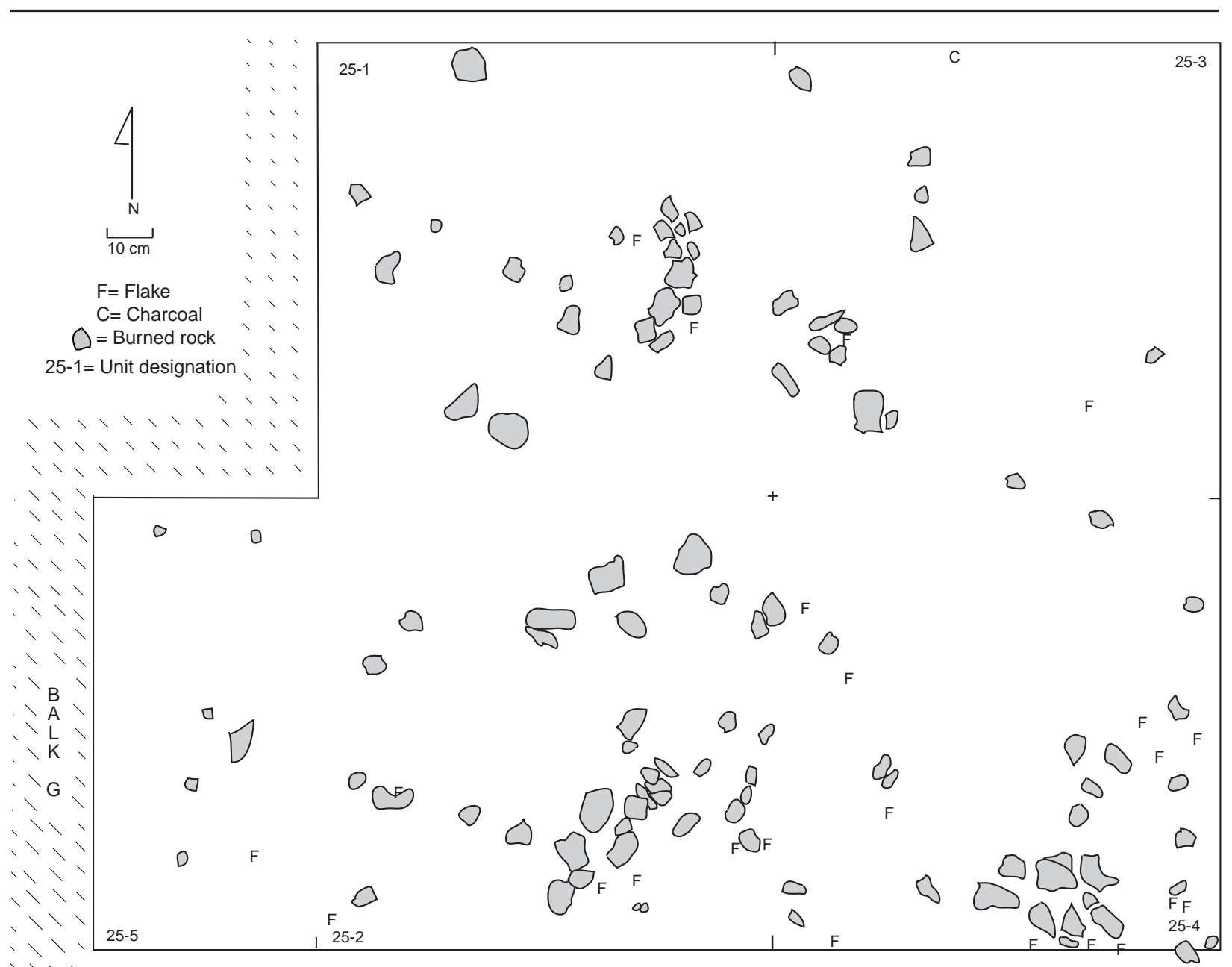

Figure 9.11 Plan View of Feature 25.

account for only 22 percent of the total number of tools.

All tools are made of chert. The six projectile points include five Tortugas, one Matamoros, and one unknown point (Table 9.4). Three Tortugas points are complete whereas two are bases that exhibit use-breaks (Figure 9.12). All five Tortugas points exhibit regularly patterned flake scars thinned along the lateral edges and with parallel basal thinning scars. No grinding is present on the basal edges or the lower margins along the lateral edges. The complete Tortugas point (\#4582) was manufactured from a light brown/gray chert. It does not appear to be as well made as the others and has pronounced scar ridges, a tiny spot of cortex, broad areas without flake scars, an unthinned base, and lateral margins that lack fine finishing pressure flake scars. This point may have been a preform or an unfinished specimen. Another complete Tortugas point (\#5711-1) is well executed with alternately beveled edges and a straight base (Figure 9.12).

Matamoros point (\#4478) is complete with a straight base and slightly convex lateral edges (Figure 9.12). It was manufactured from a high quality, dark gray chert with tiny dark gray and light blue spots. The lateral edges are beveled with well-controlled pressure flakes along the very margins. The unground basal edge reveals parallel thinning scars orientated towards the distal end. Its small size is the only apparent 


\begin{tabular}{|c|c|c|c|c|c|c|c|c|c|c|c|c|c|c|c|c|c|c|c|}
\hline \multirow[b]{2}{*}{ Cat. \# } & \multirow[b]{2}{*}{ Unit $\mathrm{F} \#$} & \multirow[b]{2}{*}{ Lvl } & \multirow[b]{2}{*}{ Depth } & \multirow[b]{2}{*}{$N$} & \multirow[b]{2}{*}{$E$} & \multirow[b]{2}{*}{ Elev } & \multirow[b]{2}{*}{$\mathrm{Pt} / \mathrm{Tool}$} & \multirow[b]{2}{*}{ Brk } & \multirow[b]{2}{*}{ Con. } & \multirow[b]{2}{*}{ Sh } & \multirow[b]{2}{*}{ Stg } & \multicolumn{3}{|c|}{ Color } & \multirow[b]{2}{*}{$\begin{array}{l}\text { Bas } \\
\text { Edg }\end{array}$} & \multirow[b]{2}{*}{$\begin{array}{l}\text { Bas } \\
\text { Thin }\end{array}$} & \multirow[b]{2}{*}{$\mathrm{Bvl}$} & \multicolumn{2}{|c|}{ Size $(\mathrm{mm})$} \\
\hline & & & & & & & & & & & & Mat'l & SW & LW & & & & $\mathrm{L}$ & W \\
\hline 2772 & & & & & & & $\mathrm{~T}$ & Us & $P$ & & & $\mathrm{Br}$ & $Y^{*}$ & $Y^{*}$ & $\mathrm{Br}$ & $P$ & Uk & & \\
\hline 4478 & F3 & 9 & $80-90$ & & & & M & $\mathrm{N}$ & C & & & Gry & Prp & Dk. Red Or & St & $P$ & 2 edg & 39.3 & 25.0 \\
\hline 4528 & F3 & 10 & & & & & Uk & & & & & & & & & & & & \\
\hline $5327-1$ & F5 & 9 & $80-90$ & & & & $\mathrm{~T}$ & Us & $P$ & & & Gry & Dk. Yw & Yw/Or & $\mathrm{Cc}$ & $P$ & $N$ & & 38.5 \\
\hline $5711-1$ & $\mathrm{C} 1$ & 9 & $80-90$ & & & & $\mathrm{~T}$ & $\mathrm{~N}$ & C & & & Lt Pk & Or & Or & $\mathrm{Cc}$ & $P$ & 2 edg & 50.1 & 26.6 \\
\hline 4394 & G3 & 8 & & 112.036 & 124.658 & 99.221 & B & Uk & $P$ & $\mathrm{~L}$ & L & & & & & & & & 34.0 \\
\hline 4614 & F6 & 10 & & 109.814 & 121.236 & 99.031 & B & Uk & D & $\mathrm{T}$ & L & & & & & & & & 16.0 \\
\hline 4638 & D5 & 9 & $80-90$ & 110.389 & 113.868 & 99.033 & B & & C & $\mathrm{T}$ & $\mathrm{M}$ & Prp & Prp & & & & & 71.3 & 45.0 \\
\hline 2750 & & & & 110.522 & 118.352 & 99.064 & B & M & $P$ & 0 & $M$ & Dull Gr & Prp & & & & & & 85.0 \\
\hline $5145-6$ & A3 & 11 & $100-110$ & & & & B & & C & 0 & $\mathrm{~L}$ & Dk. Red/Or & Dk. Red/Or & & & & & 56.0 & 30.0 \\
\hline 4310 & D3 & 9 & $80-90$ & 111.804 & 113.466 & 99.071 & B & Uk & $P$ & & L & Yw/Or & Yw/Or & & & & & & 27.0 \\
\hline 2899 & $26-2$ & & $75-85$ & 108.778 & 122.614 & 99.24 & $B$ & M & $\mathrm{D}$ & $\mathrm{T}$ & $\mathrm{L}$ & Red/Or & Red/Or & & & & & & 25.0 \\
\hline
\end{tabular}

All materials chert unless noted.

Point/Tool Type: B=biface, $D=$ drill, T=Tortugas, Uk=Unknown, M=Matamoros

Break (Brk): $M=$ manufacture, Us=use, Uk=unknown

Condition (Con.): $C=$ complete, $P=$ proximal, $M=$ medial, $D=$ distal

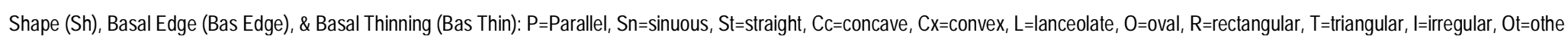
Manufacture Stage (Stg): L=late, M=middle

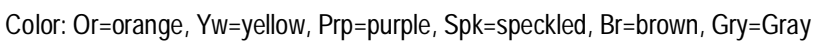

Beveling (Bvl): N=none

Note: All catalogue numbers from hand excavated proveniences have been formed by adding a dash and appear in the database with leading zeros. These leading zeros have been omitted to conserv 


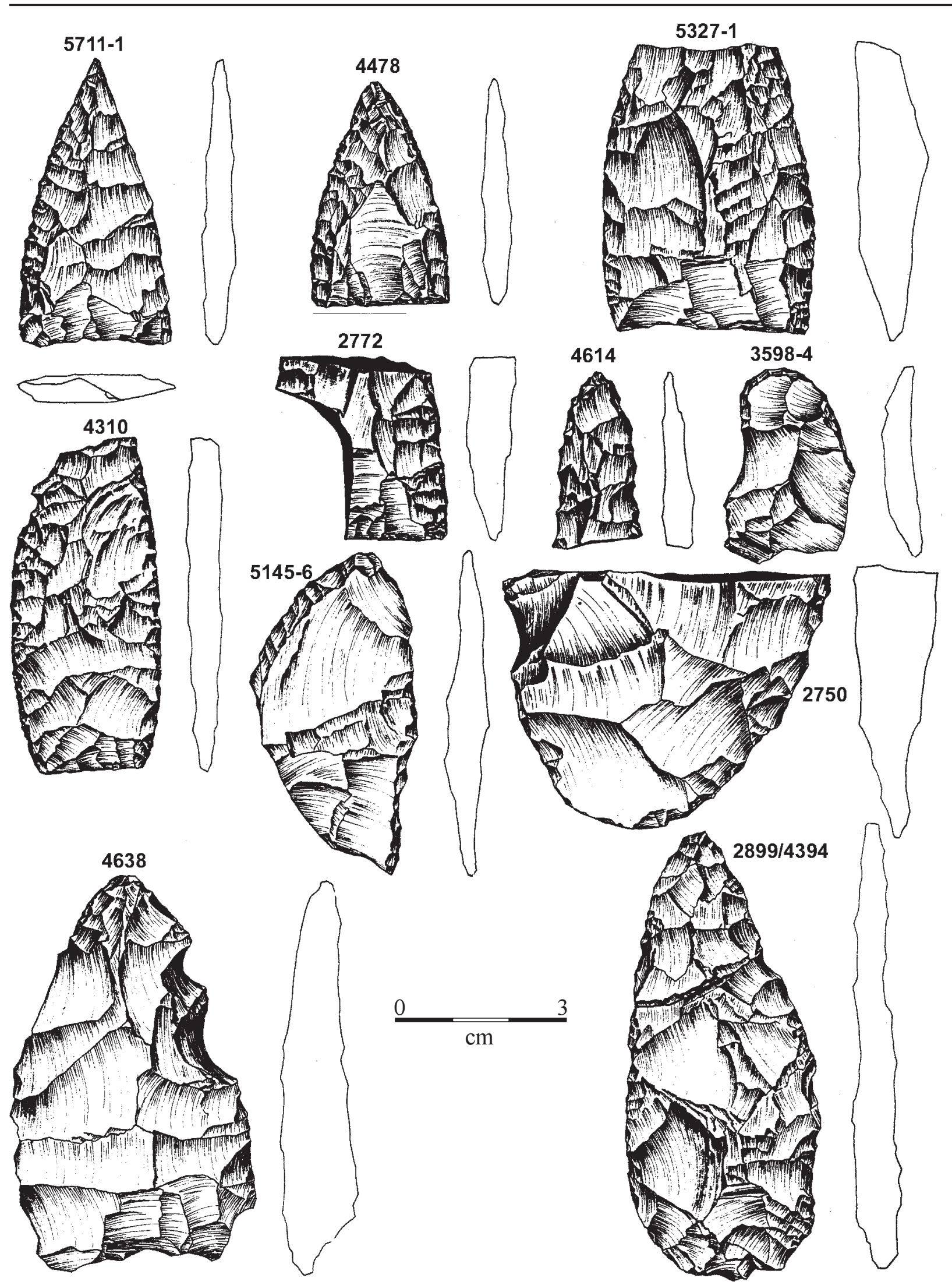

Figure 9.12 Selected Stone Tools, Projectile Points, Bifaces, and Scrapers from Occupation 4 (Actual Size). 
difference from this specimen and the Tortugas points. Technically, the methods of manufacture appear to be the same.

The eight bifaces include two complete specimens, three proximal ends, and three distal end fragments. One complete specimen (\#4638) has a triangular outline whereas the other complete specimen has an oval outline (Figure 9.12). The fragments exhibit triangular (43 percent), oval (14 percent), and lanceolate (14 percent) body outlines. Biface \#4638 appears to represent the middle stage of manufacture and has one relatively large knot near the base. This knot, which was formed by stacked hinge flake terminations, may be the reason this biface was not finished prior to being discarded. The other complete biface is in the late stage of manufacture. Specimen \#4614 is a distal fragment that is relatively long and narrow (16 $\mathrm{mm}$ ) and may have been the stem and distal end of a broad drill (Figure 9.12). However, the lateral edges are not very straight, nor do they exhibit numerous tiny hinge fractures that might be caused from drilling activities. Only 14 percent of the broken bifaces are in the middle stage of reduction, with most reflecting the late stage of tool reduction (Table 9.4). Two bifaces in the middle stage of reduction have more than twice the thickness of those bifaces in the late stage reduction. Thin biface \#4310 is missing just the tip. It is very well manufactured, with tiny pressure flake scars along the convex lateral edges (Figure 9.12). The straight base and slightly convex lateral edges are similar to Tortugas point attributes. One distal tip (\#2899) and the proximal two-thirds (\#4394) of another biface fit together to form a complete biface. These two fragments were found about $4 \mathrm{~m}$ apart and on either side of burned rock pit Feature 27.

A small, crescent shaped flake scraper (\#35984 ) is complete. It is classified as an end scraper manufactured on a thin $(6.1 \mathrm{~mm})$, tertiary flake of high quality, tan chert. The thin $(3 \mathrm{~mm})$ distal end is steeply retouched along the very margin, and tiny hinge fractures occur on the convex edge. The steep distal retouch continues around and covers about one-third of the lateral edges. The right lateral edge exhibits extensive, tiny flake hinge scars. The flake platform is still present on the proximal end.

The 68 edge-modified flakes were all manufactured from chert. About 30 percent are complete flakes, 28 percent are distal fragments, 22 percent are medial segments, and 19 percent are proximal fragments (Table 9.5). Nearly 79 percent are tertiary flakes and the other 21 percent are modifications on secondary flakes. Every specimen has regularly patterned tiny flake scars, with nearly 14 percent exhibiting two worked edges (Figure 9.13). The flake scars are along straight (52 percent), convex (23 percent), concave (20 percent), and sinuous (five percent) edges (Table 9.5). Since the tiny flake scars are well patterned, these tools are believed to have functioned mostly in scraping activities. Specimen \#2880 is quite large (85 mm long) and made of gray mottled limestone. It exhibits numerous pressure flake scars along all the tapered lateral margins and the tapered distal end (Figure 9.13). The proximal end exhibits a 13 $\mathrm{mm}$ wide multifaceted platform with a very diffuse bulb and pronounced lip. Specimen \#4632 is a distal gray chert flake fragment. Intentional edge modification forms a small spur or point along the irregular left lateral edge (Figure 9.13). The spur-like projection may have functioned as a graving tool.

Six of the eight cores are complete, and all are chert. Five are considered to be bifacial, two are unifacial, and one is similar to a unidirectional blade core. They range in length from 84 to $51 \mathrm{~mm}$ and range in weight from 61 $\mathrm{g}$ to $107 \mathrm{~g}$. These relatively small sizes reflect the nature of the original cobbles selected to make their stone implements. 


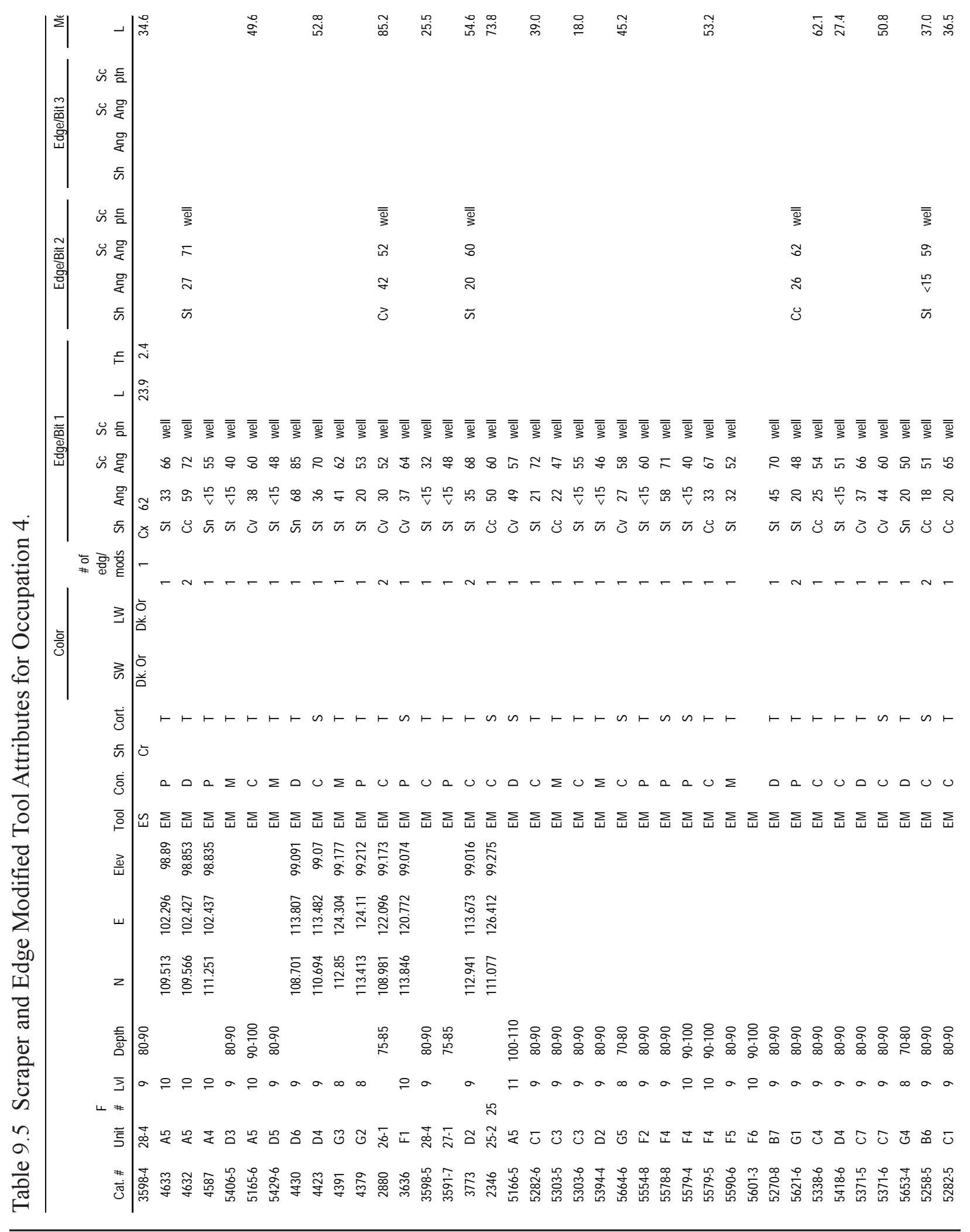




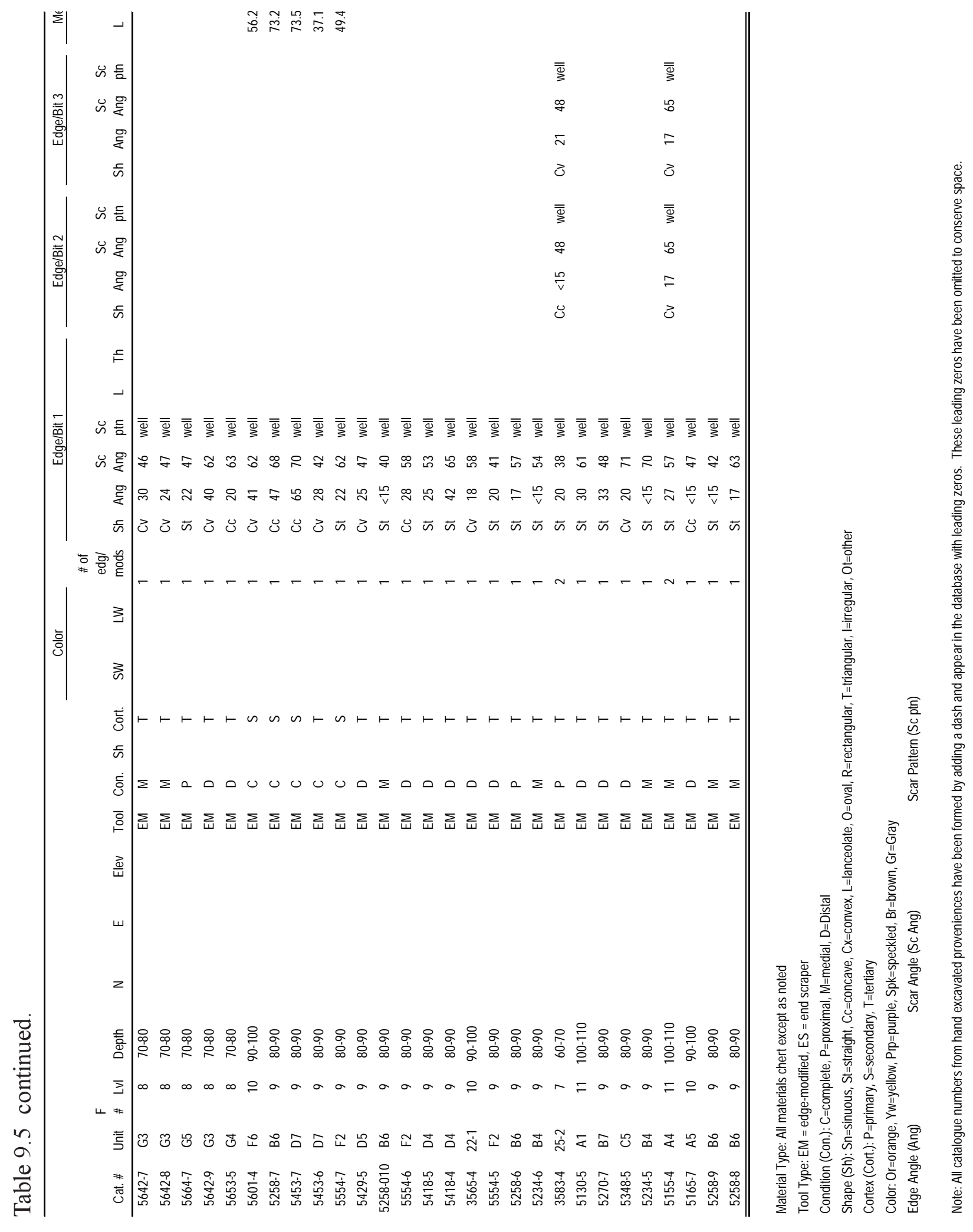




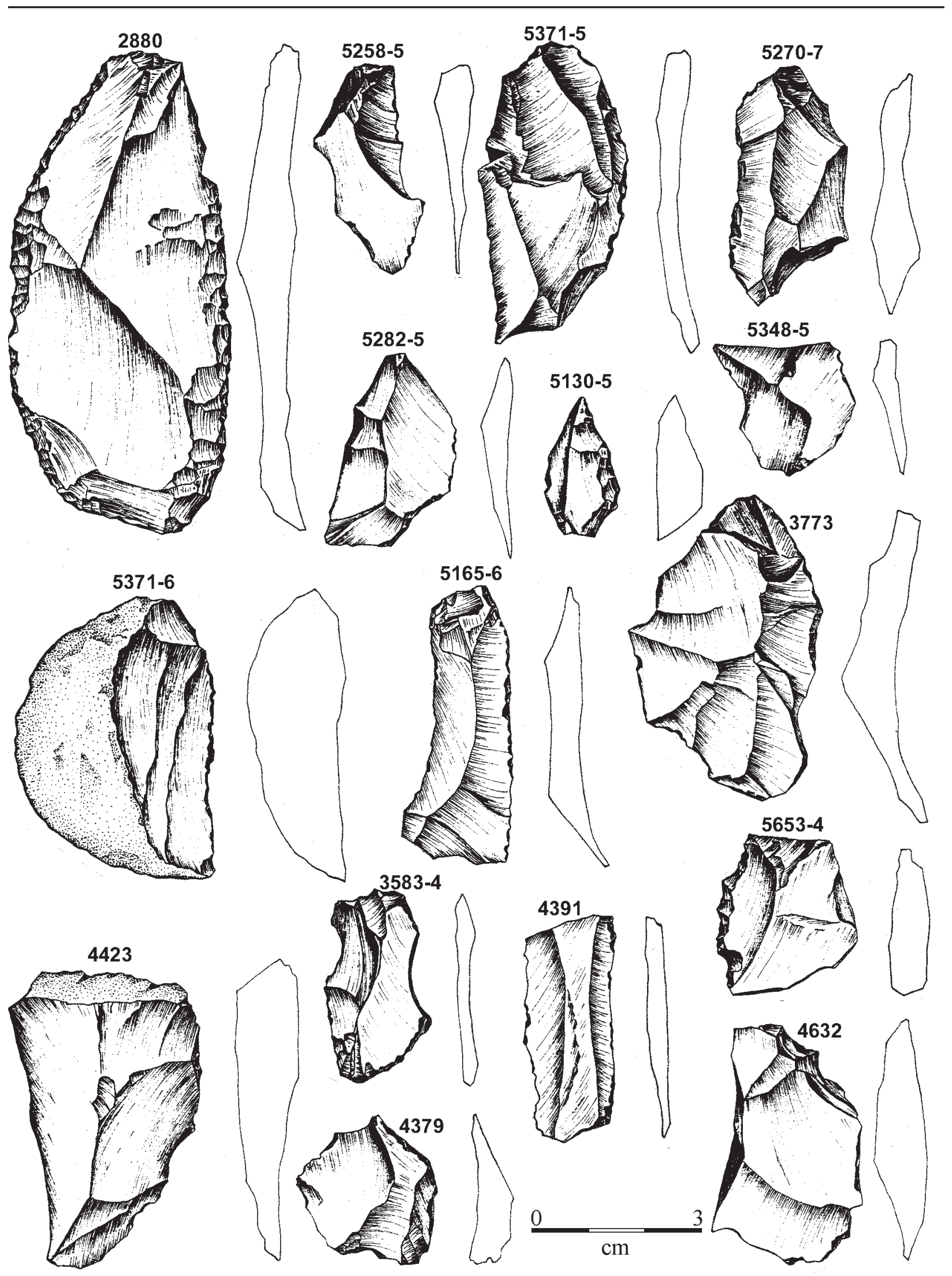

Figure 9.13 Selected Scrapers and Edge Modified Flakes from Occupation 4 (Actual Size). 
The high-powered microwear analyses on three Tortugas points (\#2772, \#5327-1, \#5711-1), two complete bifaces (\#4310 and \#4638), one complete end scraper (\#3598-4), and 11 edge modified flakes (\#2880, \#3773, \#4632, \#4391, \#4379, \#5165-6, \#5258-5, \#5282-5, \#5348-5, $\# 5454-7$, and \#5653-4) failed to reveal any microscopic use-wear (Appendix C). Biface $\# 4638$ is a complete specimen and is in the middle stage of reduction, which might explain its lack of use. Biface \#4310 is well made and finished and appears to have a use-break on the distal end. Two Tortugas points are bases that reflect midsection breaks attributed to use and thus are assumed to have been utilized. The reasons for the lack of observed use-wear on these implements is unknown.

\subsection{GROUND STONE TOOLS}

Two sandstone abraders (\#3599-5 and \#56424) and one mano (\#1998) were recovered. Abrader \#3599-5 came from within burned rock dump Feature 28. It is a small, roundish sandstone piece measuring $39.7 \mathrm{~mm}$ long, 34 $\mathrm{mm}$ wide, and $25.2 \mathrm{~mm}$ thick, and it weighs 30.4 g. It has one "U" shaped groove measuring 21.4 $\mathrm{mm}$ long, $8.9 \mathrm{~mm}$ wide, and $4.8 \mathrm{~mm}$ deep (Table 9.6, Figure 9.14). The groove crosses the entire width of the tool near one edge and does not appear to taper on either end. The size and curvature of the groove would accommodate a stick or bone the size of a pencil. A small section of one end was damaged during evacuation. Abrader \#5642-4 came from G3 (80 to $90 \mathrm{cmbs}$ ). It is rectangular in shape and measures $70.7 \mathrm{~mm}$ long, $66 \mathrm{~mm}$ wide, and $22.8 \mathrm{~mm}$ thick, and it weighs $1,100 \mathrm{~g}$ (Figure 9.14). The single groove is "U" shaped and is $61.6 \mathrm{~mm}$ long, $7.1 \mathrm{~mm}$ wide, and $4.3 \mathrm{~mm}$ deep (Table 9.6). This abrader was subjected to fatty acid analysis and yielded residue quite similar to Texas ebony (Appendix G). It may have been used to shape or smooth a stick of Texas ebony wood in the production of a usable tool.

The mano (\#1998) came from Gradall ${ }^{\mathrm{TM}}$ Area A and was assigned to Occupation 4 based on its depth below surface and continuous debris scattered across this area. It is nearly complete. Both surfaces exhibit smoothing that taper to form a wedge-shaped cross section (Figure 9.15). It appears to be made from hard, non-local sandstone as distinguished by a light gray interior with black specks and fossil shells. One surface is coated with a white calcium carbonate layer. The metric measurements are provided in Table 9.6. The mano was subjected to lipid residue analysis that physically altered small parts of both grinding surfaces to a depth of about 3 to 4 $\mathrm{mm}$ and broke a portion of one end. The small fragment was chemically washed and altered.

Table 9.6 Ground Stone Attributes for Occupation 4.

\begin{tabular}{|c|c|c|c|c|c|c|c|c|c|c|c|c|c|c|c|c|c|c|c|c|c|c|c|}
\hline \multirow[b]{2}{*}{ Cat\# } & \multirow[b]{2}{*}{ Unit } & \multirow[b]{2}{*}{$\mathrm{F} \#$} & \multirow[b]{2}{*}{ Lvl } & \multirow[b]{2}{*}{ Depth } & \multirow[b]{2}{*}{$\mathrm{N}$} & \multirow[b]{2}{*}{$\mathrm{E}$} & \multirow[b]{2}{*}{ Elev } & \multirow[b]{2}{*}{ Tool } & \multirow[b]{2}{*}{ Sh } & \multirow[b]{2}{*}{ Str. } & \multirow[b]{2}{*}{ Util } & \multicolumn{2}{|c|}{ Facets } & \multirow[b]{2}{*}{$\begin{array}{l}\text { Edg } \\
\text { Dmg }\end{array}$} & \multirow[b]{2}{*}{$\begin{array}{l}\text { \# of } \\
\text { mod }\end{array}$} & \multicolumn{4}{|c|}{ Edge/Bit/Groove 1} & \multicolumn{4}{|c|}{ Metrics in $\mathrm{mm}$} \\
\hline & & & & & & & & & & & & $\# 1$ & $\# 2$ & & & Sh & L & W & D & L & W & Th & Wt (g) \\
\hline $3599-5$ & $28-5$ & 28 & 9 & $80-90$ & & & & $A^{2}$ & $\mathrm{Rd}$ & $\mathrm{N}$ & $1 \mathrm{~s}$ & & & & 1 & "U" & 21.4 & 8.9 & 4.8 & 39.7 & 34 & 25.2 & 30.4 \\
\hline $5642-4$ & G3 & & 8 & $70-80$ & & & & $A^{c}$ & $\mathrm{R}$ & & $1 \mathrm{~s}$ & & & & 1 & "U" & 61.6 & 7.1 & 4.3 & 70.7 & 66 & 22.8 & 1100 \\
\hline
\end{tabular}

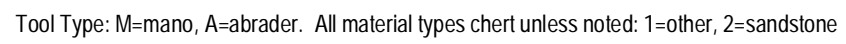

Shape (Sh): $\mathrm{Sn}=$ sinuous, $\mathrm{St}=$ straight, $\mathrm{Cc}=$ concave, $\mathrm{Cx}=$ convex, L=lanceolate, $\mathrm{O}=0 \mathrm{val}, \mathrm{R}=$ rectangular, $\mathrm{T}=$ triangular, $\mathrm{l}=\mathrm{irregular}, \mathrm{Ot=0ther}, \mathrm{Rd}=\mathrm{round}$

Striations (Str.): N=none

Utilization (Util): surf=surface

Edge Damage (Edge Dmg)

Note: All catalogue numbers from hand excavated proveniences have been formed by adding a dash and appear in the database with leading zeros. These leading zeros have been omitted to conserve space. 


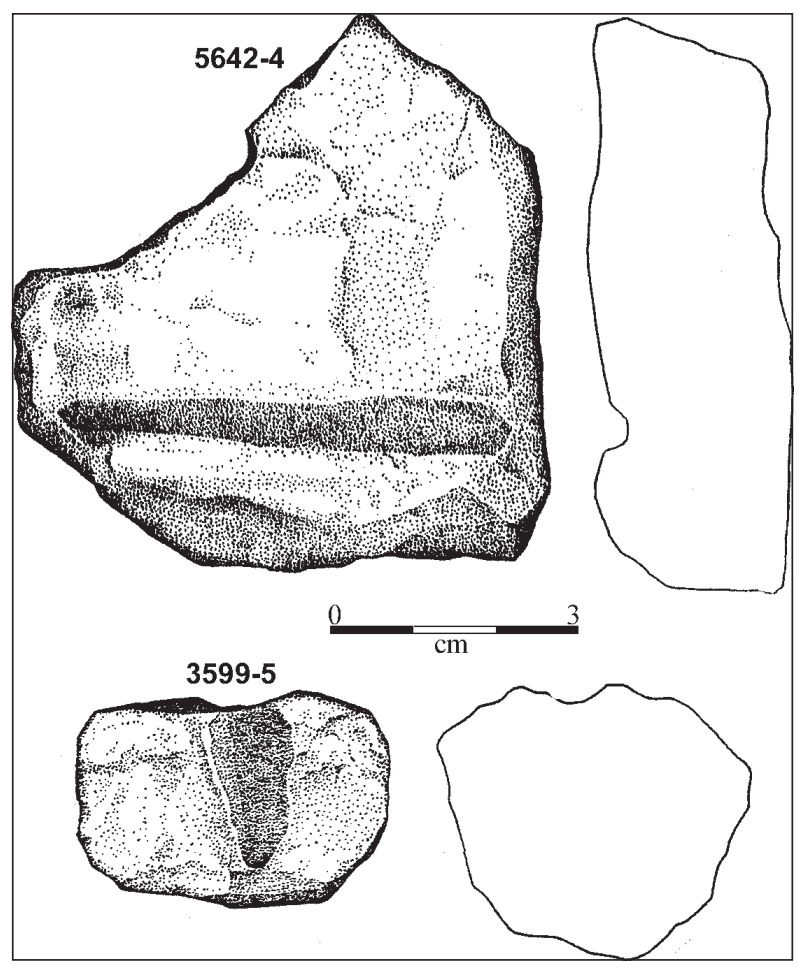

Figure 9.14 Sandstone Abraders from Occupation 4.

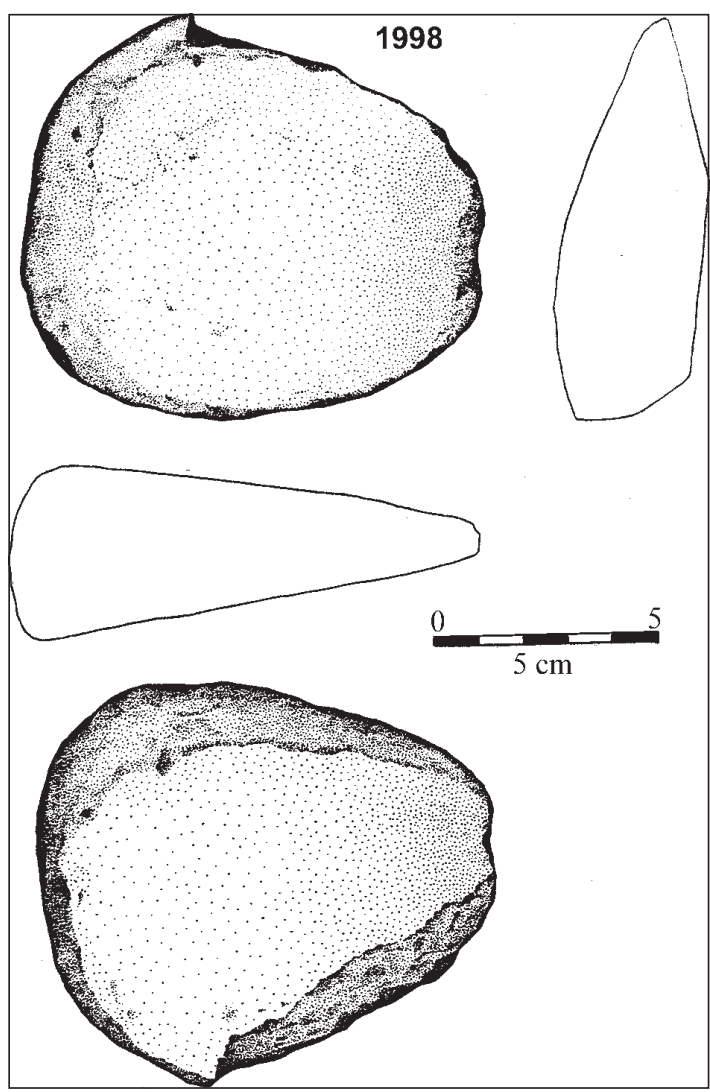

Figure 9.15 Mano (\#1998) from Occupation 4.
Extracted residues (sample Lino 460) yielded insufficient lipids for confident identification (Appendix G).

\subsection{BURNED ROCKS}

The burned rocks scattered throughout Occupation 4 and outside the eight defined features are discussed here. The $71 \mathrm{~m}^{2}$ investigated through hand excavations yielded 1,916 burned rocks that weighed 135,492 g (Table 9.2). Sandstone accounted for 72 percent followed by 17 percent other, 10 percent chert, and less than one percent quartzite. Sandstone was being selected as a preferred heating stone. Sixty-eight percent were fewer than $4 \mathrm{~cm}$ in diameter, 28 percent were between 4 and $9 \mathrm{~cm}$, and only three percent were greater than $9 \mathrm{~cm}$ in diameter. These frequencies are nearly identical to the frequencies of burned rock scattered in Occupations 2 and 3. The average weight of the scattered burned rocks was $71 \mathrm{~g}$ (Table 9.2). These data indicate that the scattered and discarded burned rocks were typically small, broken pieces that measured fewer than $4 \mathrm{~cm}$ in diameter. About 68 percent of the rocks were angular pieces, 22 percent had rounded edges, and nine percent were tabular pieces. Tiny cracks appeared in less than five percent of the cobbles. This low frequency of cracks also contrasts with those rocks from pit Feature 27, which revealed cracks in 31 percent of the burned rocks. If the rocks cracked during heating, then they fell apart during the subsequent use.

The burned rocks from the eight identified features plus those scattered across the handexcavated area in Occupation 4 total 2,156 pieces that weighed 211,204 g, or an average of about $98 \mathrm{~g} /$ rock (Table 9.2). This is in stark contrast to the average rock weight of $568 \mathrm{~g} /$ rock for those pieces from pit Feature 27. The pit feature rocks are nearly eight times the weight of the scattered burned rocks. Together the 
burned rocks average about 31 pieces per square meter across the $71 \mathrm{~m}^{2}$ hand excavated units.

\subsection{MUSSEL SHELLS}

Some 43 fragments of mussel shells were recovered. Only fifteen pieces were identified: eight are Cyrtonaias sp., five Lampsillinae, one Lampsillis teres, and one Potamilus sp. The rest are indeterminate. The pieces ranged in size from about 15 percent to 100 percent of a valve. None were culturally modified or had obvious signs of burning.

\subsection{CHARCOAL}

Wood charcoal chunks were abundant across the occupation zone ( $n=32$, weighing $170 \mathrm{~g}$ ) with additional pieces recovered from floated matrix from Features 22 (163 g), 26 (4.6 g), 27 (156.4 g), 28 (less than $1 \mathrm{~g}$ ), and 42 (less than $1 \mathrm{~g}$ ). The five features yielded a total $325 \mathrm{~g}$ of charcoal for an occupation zone total of nearly $495 \mathrm{~g}$. Two samples from pit Feature 27 were analyzed, and one (\#3594-4a) was identified as agarita (Berberis trifoliata) or a very similar diffuse, porous wood. The second piece (\#3594-6a) was an indeterminate hardwood root (Appendix B). Wood charcoal chunks from Features 22, 26, and 28 were identified as hackberry (\#3566-4), mesquite (\#3590-4), and indeterminate wood species (\#3599-4), respectively. Wood charcoal chunks from Units D6 and F2 were also identified as mesquite (Appendix B). A column float sample collected between 90 to $100 \mathrm{cmbs}$ from Unit A3 (\#5144-4-2a) and yielded 14 mesquite wood fragments (Appendix B). None of the charcoal from this occupation was radiometrically dated. Mesquite wood appears to have been the principal source of the fuel wood and was supplemented by agarita and hackberry.

\subsection{HORIZONTAL DISTRIBUTION}

Occupation 4 yielded high frequencies of burned rocks $\left(28 / \mathrm{m}^{2}\right)$ outside the six identified features, high frequencies of lithic debitage $\left(25 / \mathrm{m}^{2}\right)$, limited stone tools $\left(1.3 / \mathrm{m}^{2}\right)$, and sparse cultural features $\left(0.4 / \mathrm{m}^{2}\right)$ non-randomly distributed across the entire block. The seven hand-dug balks and the manually dug portions of the Gradall ${ }^{\mathrm{TM}}$ strips yielded signs of a continuous occupation that contained considerable cultural debris. The occupation zone appears to continue in all directions except eastward, where it pinches out at Balk H. The natural deposits and cultural occupation dip westward and slightly northward.

In Balk E, the cultural materials were quite sparse and so vertically dispersed that uncertainty arose about which occupation was represented by the cultural material. With cultural material extending laterally on either side of Balk E, the occupation continued through this area, but the low density and scattered nature of the materials prevented assignment of Balk E material to Occupation 4.

The horizontal distribution of the 1,760 pieces of lithic debitage revealed a high concentration across the block expected for the area of Balk $\mathrm{E}$ (Figure 9.16). Twelve units (19 percent of the productive units) yielded high debitage densities, mostly toward either end of the excavation block but with one (unit D4) concentration near the middle. Moderately dense debris units accounted for nearly 29 percent of the total units and were widely distributed, but they often occurred adjacent to the high density units. It is uncertain if these moderate to high density areas represent in situ knapping or discard areas because about half the units with high to moderate flake densities also have high to 
Tools/Mussel Shell Distribution
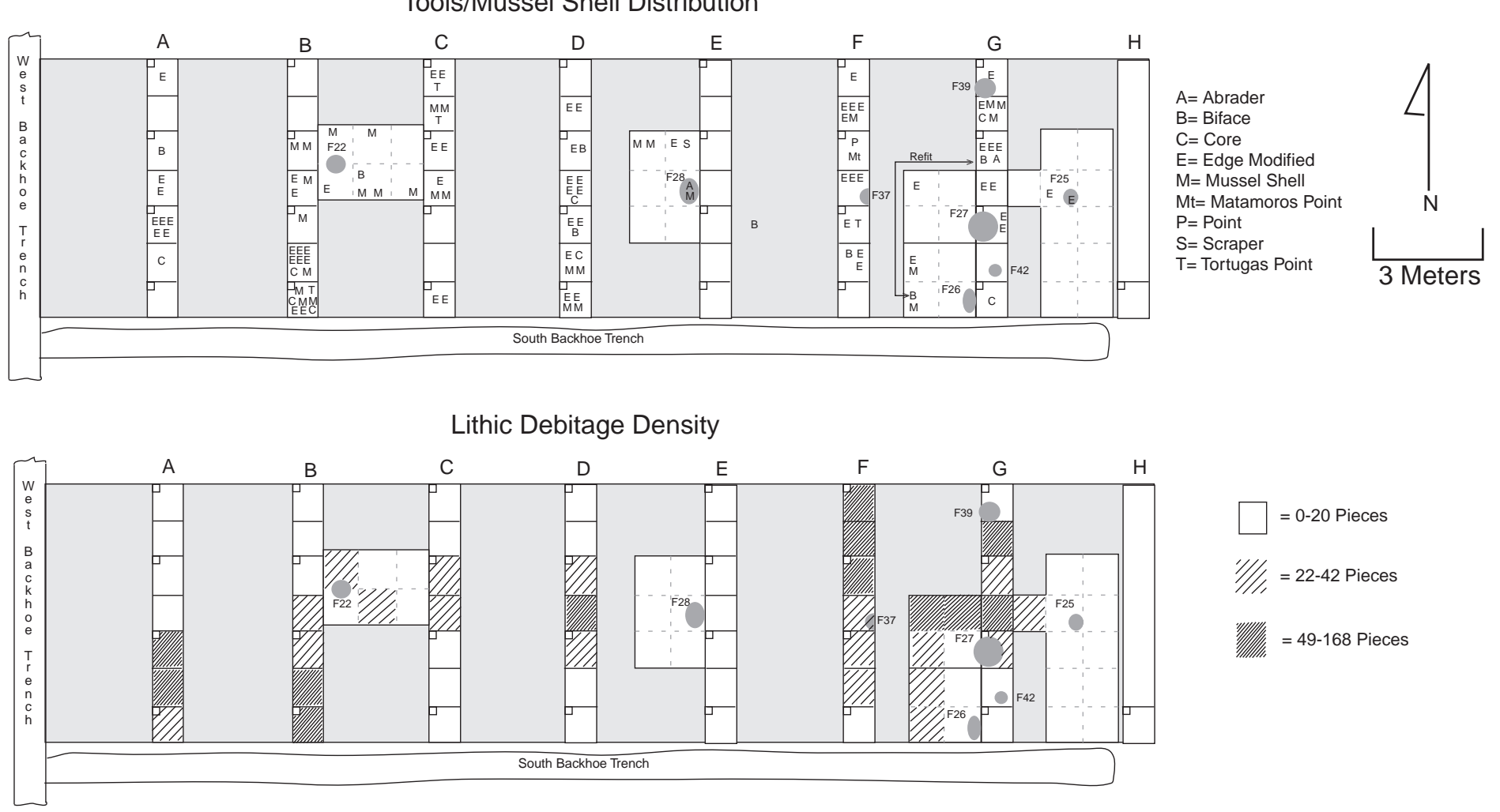

Burned Rock Density

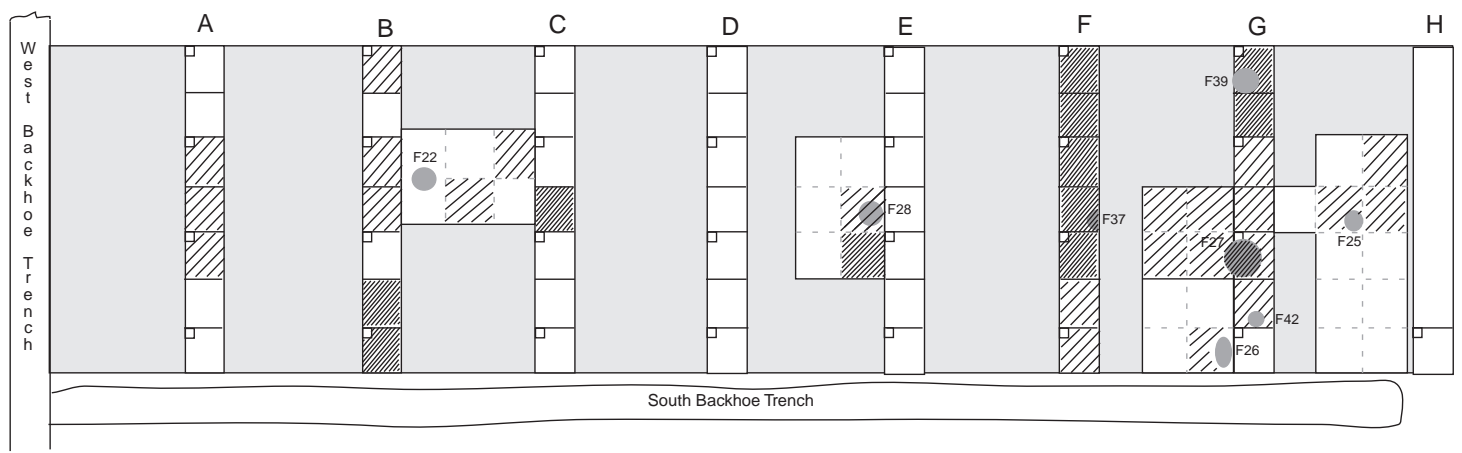

$\square=0-19$ Pieces

$Y_{/ / l,}=21-41$ Pieces

1)

Figure 9.16 Horizontal Distribution of Occupation 4 Material. 
moderate densities of burned rock, which would indicate possible discard localities rather than in situ knapping areas. Where not directly overlapping with quantities of burned rocks, the occurrence of lithic debitage immediately found around burned rock concentrations, such as Feature 11 in Unit 11-1, would also imply a dumping event.

Unit D4 stands out with a very high density $(n=89)$ of debris with moderate densities $(n=25$, and $n=22$ ) occurring immediately north and south, respectively. These three adjoining units yielded two bifaces (\#4310 and \#4638), a core (\#4424), and seven edge-modified flakes. The different types of flakes indicate nearly equal counts of core flakes, early and late stage biface flakes, indeterminate pieces, and limited platform preparation flakes. Nearly half the core flakes exhibit cortex that indicates these may be related to early biface production. The float sample from Unit D5 yielded eight chert pieces fewer than $6.4 \mathrm{~mm}$ at this same level, which suggests that this locale functioned as an in situ knapping area where bifaces were made. Alternatively, the presence of microdebitage may reflect the dumping of knapping debris from a skin or mat that captured the full size range of lithic debris from a knapping event.

The burned rock was also widely distributed across the block (Figure 9.16). Eleven units (18 percent) yielded high densities. Eight of those units were toward the eastern end; one highdensity unit (C4) was near the middle, and three units were toward the western side. Many of these high density units were composed of small to medium pieces of burned rock. High density Units B6 and B7 also yielded high frequencies of lithic debitage and therefore may indicate a dump location. The same may be said of much of the Balk F area, where quantities of lithic debitage and burned rocks were concentrated in nearly all the units. The units that yielded moderate densities of burned rock were often adjacent to those units with high-densities. Units with moderate densities nearly surrounded pitfilled Feature 27 and reflect an area of intense use. Small dumps of burned rocks, such as represented by Features 26, 33, and 42, may have come from thermal apparatus pits similar to Feature 27.

If Features 22, 26, 33, and 42 are interpreted correctly as small discard dumps of burned rocks, then it is apparent that no single area within the excavation block served as a primary dump for discarding waste debris. Since so much burned rock was recovered from around pit Feature 27; it does not appear that the inhabitants of Occupation 4 always maintained their activity area by removing unwanted burned rock to formal dump areas. However, the creation of small dumps across the occupation surface does document at least some maintenance activities.

At Feature 28, a single mussel valve and a small fragment of an abrader were found within a cluster of discarded burned rocks. Chipped stone tools were not associated with any of the identified features, but some were in the surrounding areas. Mussel shell valves and a few edge-modified tools were also found in the immediate vicinity of Features 22, 27, and 28. Adjacent to the small charcoal-stained pit Feature 37 were at least five edge-modified tools and one Tortugas projectile point. Since this was an intact pit, it may have functioned as a focal point for other activities related to the use of the edge-modified flakes. The four units that yielded the Tortugas points also had at least one edgemodified tool and various quantities of scattered burned rocks and flake debris. The association of the different material categories implies that these are discard locales. In only one instance (unit F3) were two formal tools - a Matamoros point and an unclassified point fragment - found in the same excavation unit. This same unit yielded high densities of burned rocks and lithic 
debitage, which reflects a dump locale. The eight bifaces and five cores were broadly scattered across the excavation block. The distal tip (\#2899) and the proximal half (\#4394) of a single biface were recovered about $4 \mathrm{~m}$ apart on the northern and southwestern sides of pit Feature 27. Flake debris and burned rocks were associated with both halves of this biface.

In most instances (at least 18 times), multiple edge-modified flakes came from the same excavation unit. These very abundant tools were widely distributed across Occupation 4. The thin flake scraper (\#3598-4) was about $1 \mathrm{~m}$ north of burned rock dump Feature 28 in Unit 28-4 and associated with an edge-modified flake. Since few burned rocks or flakes were in this unit, this may indicate an in situ work area.

The 43 mussel shell fragments came from 20 widely distributed units. No unit yielded more than two pieces of shell. Mussel shell fragments were associated with burned rocks, edgemodified flakes, and other tools, and one was with burned rock dump Feature 28. Apparently no single area served for discarding or processing mussel shells.

In contrast to the general artifact density maps for Occupation 4 (Figure 9.16), all TDS plotted material from this occupation is provided in Figures 9.17 and 9.18. The all-encompassing data in Figure 9.17 reveals the same general horizontal distribution pattern of material. The TDS data is biased with more of the larger pieces plotted, whereas more of the lithic debitage was recovered from the screen and thus not plotted. It appears that the burned rocks and lithic debitage were most often in the same areas, which could indicate some overprinting of activities or events. The horizontal patterning is not as clear as in some of the other occupations.

\subsection{SUMMARY AND CONCLUSIONS}

Occupation 4 consisted of a broad horizontal distribution of dense cultural debris (58 items per $\mathrm{m}^{2}$ ) concentrated between about 80 and 100 cmbs. This 15 to $20 \mathrm{~cm}$ thick cultural zone dipped towards the west and north. Turbation and root activity has vertically dispersed some materials, thus making zone identification difficult in some areas. Cultural materials include one rock-filled pit, five burned rock dump features that contained 240 burned rocks $(75,712 \mathrm{~g})$, a shallow charcoal-stained pit, 1,914 scattered burned rocks (135,045 g), 1,760 pieces of lithic debitage, 83 chipped stone tools, two sandstone abraders, one mano, 43 mussel shells/ fragments, and scattered Rabdotus shells.

The chronometric age of Occupation 4 is extrapolated from five accepted wood-charcoal dates from Occupations 1 and 5. The age of Occupation 4 is interpreted to be about 3000 B.P. This age estimate also provides some time control for the use of one Matamoros and five Tortugas projectile points recovered from Occupation 4. It adds information to the overall chronological framework for south Texas.

Five burned rock features $(22,26,28,39$, and 42) consisted of clusters of relatively moderately sized burned rocks (average $131 \mathrm{~g} /$ rock), which are thought to represent burned rock dumps. The non-feature burned rock from the occupation zone averages $71 \mathrm{~g}$. Both these average weights contrast with the average weight of $568 \mathrm{~g}$ from in situ pit Feature 27 rocks, which are interpreted as a heating element. The sizes of the burned rocks in pit Feature 27 are significantly larger than those in the discard piles and those scattered across the occupation surface. The apparent size reduction of the burned sandstone undoubtedly occurred through multiple re-uses of the burned rocks. Pit Feature 27 is nearly identical to pit Feature 14 in Occupation 1 and pit Feature 20 


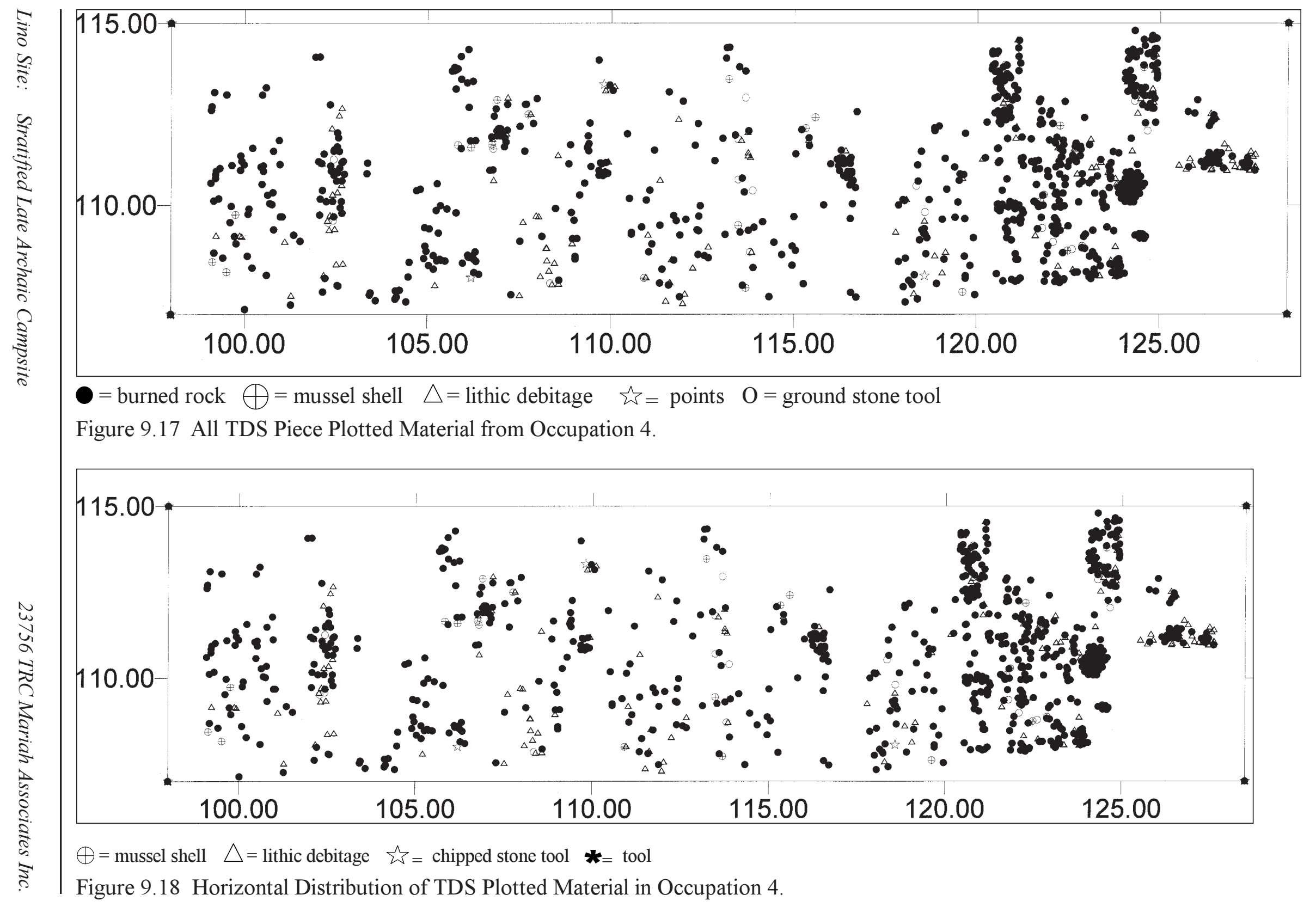


in Occupation 3. Also, the burned rock discard clusters in the previous occupations are very similar to those in Occupation 4. The one relatively small charcoal stained pit (Feature 37), may document a small hearth or warming fire. This was the only one of its kind identified at the Lino site.

The 4,089 artifacts represent part of a broad occupation that was partially exposed in the 71 $\mathrm{m}^{2}$ hand excavations of the excavation block. The recovered materials represent general camping debris from a hunter-gatherer site. The lack of microscopic use-wear on 13 analyzed stone tools indicates a relatively short-term duration of the site use. The overall lithic debitage, the stone tool assemblage, the presence of burned rock heating and discard features, and scattered burned rocks indicate that tool production activities and cooking tasks were undertaken in widely distributed parts of the area studied. Two sandstone abraders document the presence of specific sharpening or grinding tasks, but exactly what materials were abraded remains unknown. Although some general activities are recognized in the artifacts recovered, the discontinuous nature of the excavation within the block area hindered the identification of the precise locations of many activities underling the site structure.

Although prehistoric bone was not preserved to directly indicate subsistence resources used, analyses of residues provide indirect insights into categories of potential resources used. Fatty acid analysis on 14 burned rock residues indicates that large herbivores and various plant resources were processed using the burned sandstone rocks. The $\delta^{13} \mathrm{C}$ values indicate that the large herbivore was probably deer. Some $\delta^{15} \mathrm{~N}$ isotope data derived from the same residues indicate that legumes and/or nuts were probably part of the processed resources. The stone projectile points, bifaces, edge modified flakes, and scrapers also support the killing, butchering, and hide preparation of large herbivores. The abraders may have been used to sharpen digging sticks, and the mano may suggest some plant processing occurred.

The number of people who utilized this occupation, the season of useage, and the duration of residence are all unknown. The numerous burned rock discarded piles and the large quantities of burned rocks and lithic debitage support the presence of hunter-gatherer groups for more than a few nights. The need to maintain areas by discarding materials away from the primary activity areas also supports a stay of more than a few days. The inferences of hunting and butchering, hide working, and cooking activities reflects diverse tasks and activities probably conducted by both genders. This further indicates the presence of family units in a general camp setting as opposed to a task specific activity site. 
Intentionally Left Blank 


\subsection{OCCUPATION 5}

This occupation consisted of diverse cultural remains concentrated between 110 and $120 \mathrm{cmbs}$ across the western end and between 90 to 110 $\mathrm{cmbs}$ at Balk $\mathrm{F}$ towards the eastern side of the excavated block. The 10 to $15 \mathrm{~cm}$ thick cultural zone dips about $20 \mathrm{~cm}$ towards the west and possibly 5 to $10 \mathrm{~cm}$ to the north. Cultural materials were concentrated and best defined near the middle of the excavation block in Balks $\mathrm{C}$ and $\mathrm{D}$. The occupation pinched out towards the east with very sparse materials occurring in and east of Balk F. The dispersed nature of some cultural material is believed to be postdepositional movement due to various turbation activities from roots, insects, and rodents.

This cultural zone yielded multiple burned rock features, quantities of scattered burned rocks and lithic debitage, a few chipped and ground stone tools, sparse mussel shells, and scattered Rabdotus shells. Bone was present in very limited quantities, but it appeared to have been recovered from rodent holes and thus not associated with the prehistoric cultural materials. If bone was present during the original occupation then it has decomposed over time. The bone in the rodent hole was partially weathered and included an unburned medial section of a deer tibia (43.6 g) with rodent gnawing, a newly completed unburned rabbit mandible $(0.5 \mathrm{~g})$, and an unburned turtle scute fragment $(0.5 \mathrm{~g})$.

The chronometric age of Occupation 5 is based on three wood charcoal dates from this occupation. One wood charcoal piece was from Feature 29 (\#3604-4a), one was from Unit A5 (110-120 cmbs) (\#5167-4a), and one was from Unit D7 (100-110 cmbs) (\#5455-4a), which yielded adjusted ages of 3460, 3060, and 900 B.P., respectively (Table 5.3). The latter date is obviously too young for this occupation and reflects a charcoal chunk displaced by turbation activity. The age of $\# 5455-4 a$ is not an accepted age indicator for Occupation 5. The two accepted wood charcoal dates average about 3260 B.P. and thus provide an approximate age of Occupation 5. Organic residues extracted from the interior of burned rock \#3605-5a from Feature 29 yielded a $\delta^{13} \mathrm{C}$ adjusted age of 4920 \pm 50 B.P. (Table 5.3). This date appears to be some 1,660 years older than the average of two accepted wood charcoal ages and is too early for Occupation 5. The dated organic residue may have remained inside the burned rock reused from some previous use episodes of an earlier component.

The cultural materials recovered from the $39 \mathrm{~m}^{2}$ hand excavated balks and the $21 \mathrm{~m}^{2}$ hand excavated units around four identified features discovered during the Gradall ${ }^{\mathrm{TM}}$ stripping are presented by material class below. This is followed by a discussion of the horizontal distribution of the prominent occupational materials. Finally, a summary and interpretation of Occupation 5 is presented.

\subsection{FEATURES}

Six features were recognized: four in the Gradall $^{\mathrm{TM}}$ stripped areas and two in the handexcavated balks. These consisted of four burned rock concentrations (Features 24, 29, 30, and 40 ), a pair of manos (Feature 38), and one general occupation surface (Feature 21). After the hand excavation of Feature 21, the material remains included burned rocks, flakes, charcoal, mussel shells, and Rabdotus shells. They were horizontally dispersed in such a manner as to represent scattered occupational debris that lacked specific patterns or concentration with which to designate as a feature (Figure 10.1). Therefore the cultural materials from what was 


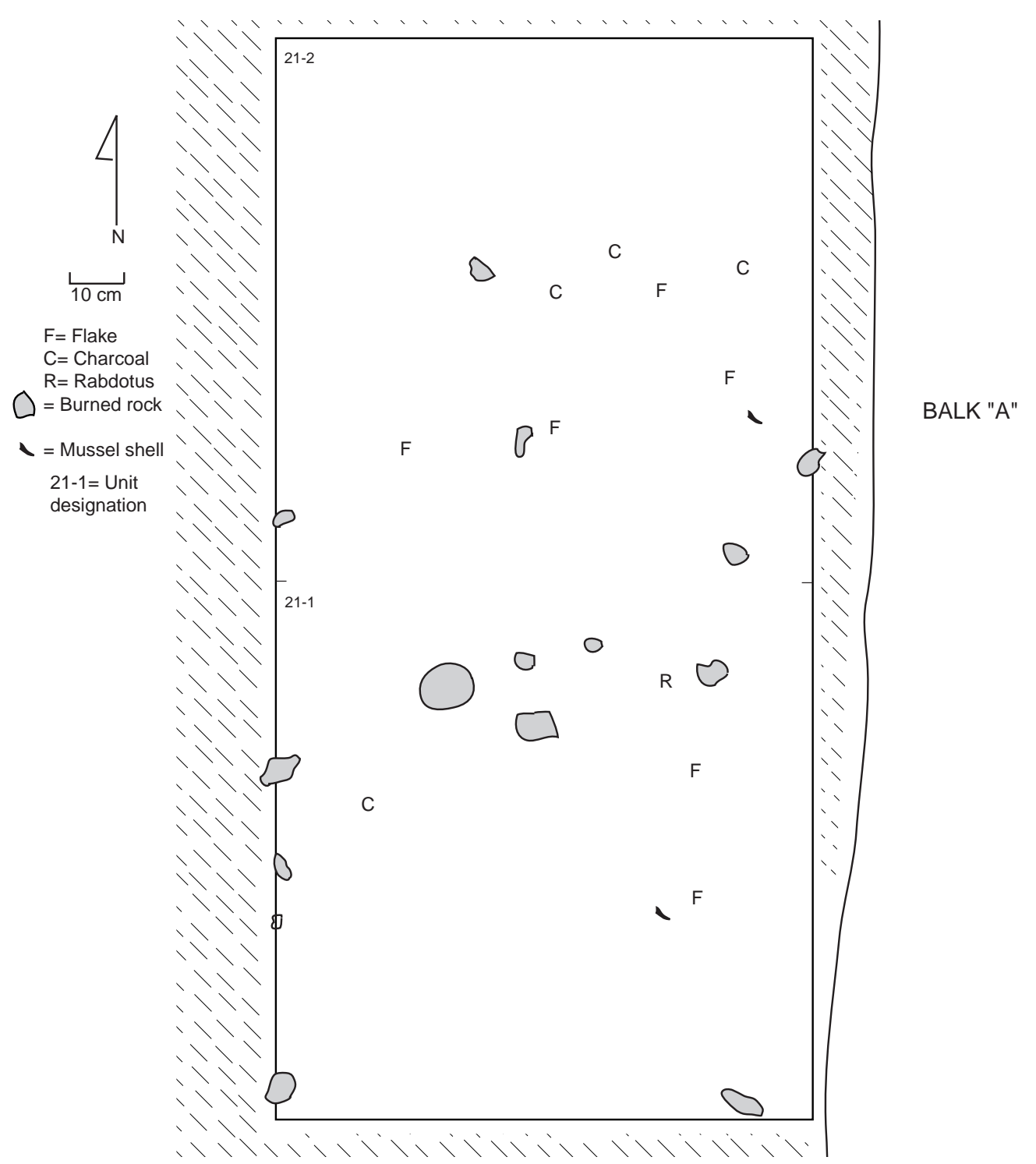

Figure 10.1 Plan View of Burned Rocks in Feature 21.

originally labeled Feature 21 were analyzed as part of the overall occupation zone. The five features are individually described. Selected feature attributes are presented in Table 10.1.

Feature 38 was explored in Unit F4 (100 to 110 cmbs) and consisted of two complete, extensively used sandstone manos (\#4725 and \#4726). Both were vertically and side by side at a slight angle to one another. One mano occurred $2 \mathrm{~cm}$ below the other (Figures 10.2 and 10.3). Careful hand excavation and profiling did not discern a pit or soil color change around the two manos. Their upright orientation would suggest placement in a pit, but no direct sediment color or textural evidence for a pit was observed. The 1 to $3 \mathrm{~cm}$ space between the manos was not sufficient for a vertical support to prop up these two manos. A 80 by $100 \mathrm{~cm}$ hand excavated unit around the manos yielded minimal cultural debris that included four chert flakes and one small burned rock fragment. These manos occurred about $18 \mathrm{~cm}$ below the level of Occupation 4 at a depth that is compatible with 
Table 10.1 Attributes of Features from Occupation 5.

\begin{tabular}{|c|c|c|c|c|c|c|c|c|c|}
\hline $\begin{array}{l}\text { Fea. } \\
\text { No. }\end{array}$ & Unit & $\begin{array}{l}\text { No. of } \\
\text { Units } \\
\text { hand } \\
\text { Exc. }\end{array}$ & $\begin{array}{c}\text { Dep } \\
\text { th } \\
(\mathrm{cm} \\
\text { bs }) \\
\end{array}$ & $\begin{array}{l}\text { Size } \\
(\mathrm{cm})\end{array}$ & Thickness & Description & $\begin{array}{c}\text { Interpre- } \\
\text { tation }\end{array}$ & $\begin{array}{c}\text { Associated } \\
\text { Artifacts within } \\
\text { feature }\end{array}$ & $\begin{array}{c}\text { Chrono. } \\
\text { Age } \\
\text { (B.P.) }\end{array}$ \\
\hline 21 & Area A & 2 & $\begin{array}{c}110 \\
- \\
120\end{array}$ & $\begin{array}{c}200 x \\
100\end{array}$ & 1 rock & $\begin{array}{c}\text { Occupational } \\
\text { debris }\end{array}$ & $\begin{array}{l}\text { Occupatio } \\
\text { n zone }\end{array}$ & $\begin{array}{c}\text { scattered BR, } \\
\text { flakes, charcoal, } \\
\text { mussels }\end{array}$ & \\
\hline 24 & Area C & 4 & $\begin{array}{l}90- \\
100\end{array}$ & $\begin{array}{c}70 x \\
70\end{array}$ & 1 rock & BR cluster & BR Dump & $\begin{array}{l}152 \text { BR, } 29 \\
\text { flakes } \\
\text { concentrated, } \\
\text { biface }\end{array}$ & \\
\hline 29 & Area E & 6 & $\begin{array}{c}100 \\
- \\
110\end{array}$ & $\begin{array}{c}90 x \\
75\end{array}$ & 1 rock & BR cluster & BR Dump & $\begin{array}{c}47 \mathrm{BR}, 20 \\
\text { scattered flakes }\end{array}$ & $\begin{array}{l}\text { Charcoal } \\
=3460\end{array}$ \\
\hline 30 & Area A & 9 & $\begin{array}{c}110 \\
- \\
120\end{array}$ & $\begin{array}{c}160 x \\
60\end{array}$ & 1 rock & BR cluster & BR Dump & $\begin{array}{l}97 \mathrm{BR} \text {, scattered } \\
\text { BR \& flakes }\end{array}$ & \\
\hline 38 & F4 & 1 & $\begin{array}{c}100 \\
- \\
110\end{array}$ & $\begin{array}{c}15 \mathrm{x} \\
15\end{array}$ & 1 rock & Mano cluster & $?$ & $\begin{array}{c}2 \text { complete } \\
\text { manos standing } \\
\text { in pit, }\end{array}$ & \\
\hline 40 & $\mathrm{C} 2$ & 1 & $\begin{array}{c}100 \\
- \\
110\end{array}$ & $\begin{array}{c}40 x \\
90\end{array}$ & 1 rock & BR cluster & BR Dump & $\begin{array}{c}43 \text { BR, } \\
\text { Stemmed biface, } \\
47 \text { flakes }\end{array}$ & \\
\hline
\end{tabular}

$\mathrm{BR}=$ burned rock

Occupation 5. Presuming that the manos were buried, the orifice of the pit might have originated in Occupation 4.

The four burned rock concentrations (Features 24, 29, 30, and 40) contained various amounts of burned rock in no obvious, discernible patterns. Feature 24 consisted of 152 pieces of clustered and dispersed burned rock (Figure 10.4). The burned rocks included 81 percent sandstone and 18 percent chert pieces (Table 10.2). Some 71 percent measured 0 to $4 \mathrm{~cm}$ in size, 27 percent measured 4 to $9 \mathrm{~cm}$, and less than two percent occur larger than $9 \mathrm{~cm}$ in diameter. Nearly 64 percent were angular, 24 percent rounded, and 12 percent were tabular in form. Fewer than two percent showed cracks.

Stable carbon and nitrogen isotope analyses were conducted on burned rock residue samples \#2163, \#2165, \#2173, and \#2177. The four $\delta^{13} \mathrm{C}$ values range between $-21.0 \%$ and $-22.2 \%$, which likely represents a mixture of $\mathrm{C} 3$ and $\mathrm{C} 4 /$ CAM plants and/or animals that ate those plants (Appendix D). C4 plants such as corn, grasses, and prickly pear tunas or animals that ate $\mathrm{C} 4$ plants such as bison are not obvious in the obtained values. The $\delta^{15} \mathrm{~N}$ values varied from 3.7 to $8.3 \%$ o (Appendix D). These values could represent a mixture of plant and animal resources.

The same four burned rock residues (\#2163, \#2165, \#2173, and \#2177) from Feature 24 also were submitted for fatty acid analysis. Burned rocks \#2163d (sample Lino 18) and \#2173d (sample Lino 19) yielded residues linked to plants that closely resemble mesquite beans or prickly pear (Appendix G). Since the corresponding isotope results do not support the presence of prickly pears, it is likely that mesquite beans were processed. Burned rock \#2177d (sample Lino 20) yielded residues from unknown seeds (Appendix G). The stable 
Table 10.2 Occupation 5 Burned Rock Data.

\begin{tabular}{|c|c|c|c|c|c|c|c|c|c|c|c|c|c|c|c|c|c|c|c|}
\hline \multicolumn{20}{|c|}{ Non Feature Contexts } \\
\hline \multirow[b]{2}{*}{ Unit } & \multirow[b]{2}{*}{ Level } & \multirow[b]{2}{*}{ Fea No } & & Size & cm) & & & Mat & rial t & Type* & & & acture & е Type* & & $\mathbf{C r}$ & & & \\
\hline & & & $0-4$ & 4-9 & $9-15$ & $>15$ & $\mathbf{C C}$ & Ch & $\mathbf{O}$ & Qtz & SS & Ang. & Ind. & Rnd. & Tab. & $\mathbf{Y}$ & $\mathbf{N}$ & Total & Wt (g) \\
\hline $21-1$ & & & 1 & 1 & 1 & & & & 1 & & 2 & 3 & & & & 1 & 2 & 3 & $4,329.9$ \\
\hline $21-2$ & & & 2 & 1 & & & & 2 & & & 1 & 3 & & & & 1 & 2 & 3 & 216.6 \\
\hline $24-2$ & 11 & & 17 & 3 & & & & & 1 & & 19 & 10 & & 6 & 4 & & 20 & 20 & 564.0 \\
\hline $24-3$ & 11 & & 42 & 19 & 3 & & & 13 & & & 51 & 29 & & 19 & 16 & 2 & 62 & 64 & $4,906.9$ \\
\hline $24-4$ & 11 & & 4 & 7 & & & & 6 & & & 5 & 4 & & 4 & 3 & 2 & 9 & 11 & 360.6 \\
\hline $28-5$ & & & & & 1 & & & 1 & & & & & & 1 & & & 1 & 1 & $6,510.1$ \\
\hline $29-1$ & 11 & & 12 & 1 & 2 & & & 3 & 1 & & 11 & 11 & 1 & 3 & & 1 & 14 & 15 & $2,658.4$ \\
\hline $29-2$ & 11 & & 19 & 3 & & & & 3 & & & 19 & 16 & & 5 & 1 & 2 & 20 & 22 & 502.5 \\
\hline $29-3$ & 11 & & 5 & 2 & & & & & & & 7 & 6 & & 1 & & 1 & 6 & 7 & 81.2 \\
\hline $29-4$ & 11 & & 13 & 2 & & & & 1 & & & 14 & 10 & & 3 & 2 & & 15 & 15 & 834.3 \\
\hline $29-5$ & 11 & & 44 & 6 & 1 & & & 10 & & & 41 & 42 & & 7 & 2 & 1 & 50 & 51 & $2,070.2$ \\
\hline $30-1$ & & & 9 & 2 & & & & & & & 11 & 8 & & 1 & 2 & 2 & 9 & 11 & 162.3 \\
\hline $30-2$ & & & 6 & 4 & 1 & & & & 2 & & 9 & 9 & & 2 & & 3 & 8 & 11 & $1,704.3$ \\
\hline $30-3$ & & & 11 & 1 & & & & & & & 12 & 10 & & 2 & & & 12 & 12 & 175.9 \\
\hline $30-4$ & & & 8 & 3 & & & & 1 & & & 10 & 7 & & 2 & 2 & 1 & 10 & 11 & 246.6 \\
\hline $30-5$ & & & 39 & & & & & 1 & & & 38 & 28 & & 7 & 4 & 2 & 37 & 39 & 224.7 \\
\hline $30-6$ & & & 19 & 3 & 2 & & & & & & 24 & 17 & & 5 & 2 & 1 & 23 & 24 & $1,019.9$ \\
\hline $30-7 ?$ & & & 8 & & & & & & & & 8 & 3 & & 4 & 1 & & 8 & 8 & 72.5 \\
\hline $30-8$ & 12 & & 7 & & & & & 1 & & & 6 & 2 & & 3 & 2 & & 7 & 7 & 147.7 \\
\hline $30-9$ & 12 & & 17 & 7 & 3 & & & 1 & & & 26 & 19 & & 5 & 3 & 1 & 26 & 27 & $4,175.1$ \\
\hline A1 & 12 & & 5 & 2 & & & & & & & 7 & 6 & & 1 & & 1 & 6 & 7 & 275.2 \\
\hline A2 & 12 & & 14 & 2 & & & & 2 & 4 & & 10 & 12 & & 4 & & 1 & 15 & 16 & 356.3 \\
\hline A3 & 12 & & 6 & 4 & & 1 & & 2 & 2 & & 7 & 5 & & 6 & & 1 & 10 & 11 & $12,165.8$ \\
\hline A4 & 12 & & 6 & 1 & & 1 & & & & & 8 & 6 & & 2 & & 2 & 6 & 8 & $1,741.1$ \\
\hline A5 & 12 & & 3 & 1 & 1 & 4 & & & & & 9 & 5 & & & 4 & 2 & 7 & 9 & $1,454.3$ \\
\hline A6 & 12 & & 2 & 2 & 1 & & & & & & 5 & 5 & & & & 3 & 2 & 5 & 384.4 \\
\hline A7 & 12 & & 9 & 2 & & & & 1 & & & 10 & 9 & & 2 & & 2 & 9 & 11 & 151.8 \\
\hline B1 & $10 \& 11$ & & 6 & & & & & 2 & 1 & & 3 & 5 & & 1 & & 2 & 4 & 6 & 32.0 \\
\hline B2 & $10 \& 11$ & & 19 & 8 & 1 & & & & 7 & & 21 & 23 & & 5 & & 6 & 22 & 28 & $1,192.4$ \\
\hline B3 & $10 \& 11$ & & 20 & 11 & & & 1 & & 2 & & 28 & 17 & & 9 & 5 & 4 & 27 & 31 & 803.7 \\
\hline B4 & 11 & & 13 & 3 & & & & 1 & 3 & & 12 & 9 & & 7 & & 4 & 12 & 16 & 266.2 \\
\hline B5 & 11 & & 5 & 4 & 2 & & & 6 & 1 & & 4 & 5 & & 6 & & & 11 & 11 & $1,028.2$ \\
\hline B6 & 11 & & & 1 & & & 1 & & & & & 1 & & & & & 1 & 1 & 195.7 \\
\hline B7 & 11 & & 2 & 2 & & & & 1 & & & 3 & 4 & & & & 1 & 3 & 4 & 539.4 \\
\hline $\mathrm{C} 1$ & 11 & & 29 & 19 & & 1 & & 3 & 18 & & 28 & 19 & & 20 & 10 & 1 & 48 & 49 & $2,379.3$ \\
\hline C2 & 11 & & 45 & 6 & & & & 4 & & & 47 & 22 & & 17 & 12 & 2 & 49 & 51 & 1,309.6 \\
\hline C3 & 11 & & 18 & 9 & & & 1 & 3 & 4 & & 19 & 17 & & 4 & 6 & & 27 & 27 & $1,798.0$ \\
\hline $\mathrm{C} 4$ & 11 & & 12 & 4 & & & 1 & & 4 & & 11 & 8 & & 4 & 4 & 2 & 14 & 16 & 403.5 \\
\hline C6 & 11 & & 5 & 1 & & & 1 & & 2 & & 3 & 1 & & 5 & & & 6 & 6 & 127.6 \\
\hline C7 & 11 & & & 1 & 1 & & & & & & 2 & 2 & & & & 1 & 1 & 2 & 442.8 \\
\hline D1 & $10 \& 11$ & & 6 & 8 & 2 & & & & 1 & & 15 & 8 & & 5 & 3 & 1 & 15 & 16 & $2,017.1$ \\
\hline D2 & $10 \& 11$ & & 13 & 9 & 1 & & 1 & 3 & 7 & & 12 & 15 & & 7 & 1 & 2 & 21 & 23 & $3,316.6$ \\
\hline D3 & $10 \& 11$ & & 19 & 9 & 1 & & & 4 & 10 & & 15 & 14 & & 12 & 3 & & 29 & 29 & $1,420.7$ \\
\hline D4 & 10 & & 12 & 4 & 2 & & & 1 & 6 & & 11 & 9 & & 7 & 2 & & 18 & 18 & $5,106.0$ \\
\hline D5 & $10 \& 11$ & & 14 & 7 & 2 & & 1 & 1 & 5 & & 16 & 12 & & 8 & 3 & 3 & 20 & 23 & 786.4 \\
\hline D6 & $10 \& 11$ & & 14 & 8 & & & 1 & 2 & 7 & & 12 & 12 & & 9 & 1 & 2 & 20 & 22 & $2,026.9$ \\
\hline D7 & $10 \& 11$ & & 12 & 13 & & & & 6 & 3 & & 16 & 11 & & 13 & 1 & 3 & 22 & 25 & $2,478.1$ \\
\hline E1 & 11 & & 9 & 7 & & & & 1 & 7 & & 8 & 7 & & 9 & & 1 & 15 & 16 & $2,815.0$ \\
\hline E2 & 11 & & 11 & 2 & & & & & & & 13 & 8 & & 3 & 2 & 2 & 11 & 13 & 196.8 \\
\hline E3 & 11 & & 2 & 1 & & & & 1 & 1 & & 1 & 2 & & 1 & & & 3 & 3 & $2,225.4$ \\
\hline E4 & 11 & & 3 & 7 & 1 & & & 2 & 1 & & 8 & 4 & & 4 & 3 & 1 & 10 & 11 & $7,425.9$ \\
\hline E5 & 11 & & 13 & 2 & & & & & & & 15 & 6 & & 6 & 3 & 1 & 14 & 15 & $1,205.1$ \\
\hline E6 & 11 & & 2 & 2 & & & & 1 & 1 & & 2 & 3 & & 1 & & 1 & 3 & 4 & 86.1 \\
\hline F3 & 11 & & 2 & & & & & & 2 & & & 2 & & & & & 2 & 2 & 4.4 \\
\hline F4 & 11 & & 1 & & & & 1 & & & & & 1 & & & & & 1 & 1 & 50.1 \\
\hline Subtotal & & & 635 & 227 & 29 & 7 & 9 & 90 & 104 & 0 & 695 & 532 & 1 & 258 & 107 & 73 & 825 & 898 & $89,171.6$ \\
\hline & & & & & & & & Fea & 0 & Contex & & & & & & & & & \\
\hline & & & & $\mathrm{Si} i$ & & & & Mat & erial ? & Гуре* & & & acture & е Type* & & & cks & & \\
\hline Unit & Level & Fea No & $0-4$ & $4-9$ & $9-15$ & $>15$ & $\mathbf{C C}$ & Ch & O & Qtz & SS & Ang. & Ind. & Rnd. & Tab. & $\mathbf{Y}$ & $\mathbf{N}$ & Total & Wt (g) \\
\hline $21-2$ & 10 & 21 & 16 & 12 & 1 & & & 3 & & & 26 & 18 & & 3 & 8 & 5 & 24 & 29 & $1,111.2$ \\
\hline $24-1,24-2$, & & & & & & & & & & & & & & & & & & & \\
\hline $24-3, \& 24$ & & & & & & & & & & & & & & & & & & & \\
\hline 4 & 11 & 24 & 108 & 41 & 3 & & & 27 & 2 & & 123 & 97 & & 37 & 18 & 3 & 149 & 152 & $4,890.8$ \\
\hline $29-5$ & 11 & 29 & 16 & 29 & 1 & & & 7 & & 1 & 38 & 33 & & 6 & 7 & 1 & 45 & 46 & $1,864.7$ \\
\hline $30-5,30-6$, & & & & & & & & & & & & & & & & & & & \\
\hline$\& 30-8$ & 12 & 30 & 4 & 56 & 31 & 6 & & 2 & & & 95 & 72 & & 14 & 11 & 23 & 74 & 97 & $32,704.6$ \\
\hline $\mathrm{C} 2$ & 11 & 40 & 4 & 34 & 5 & & 1 & 14 & & & 29 & 32 & & 8 & 3 & 1 & 42 & 43 & $5,430.4$ \\
\hline Subtotal & & & 148 & 172 & 41 & 6 & 1 & 53 & 2 & 1 & 311 & 252 & 0 & 68 & 47 & 33 & 334 & 367 & $46,001.7$ \\
\hline
\end{tabular}




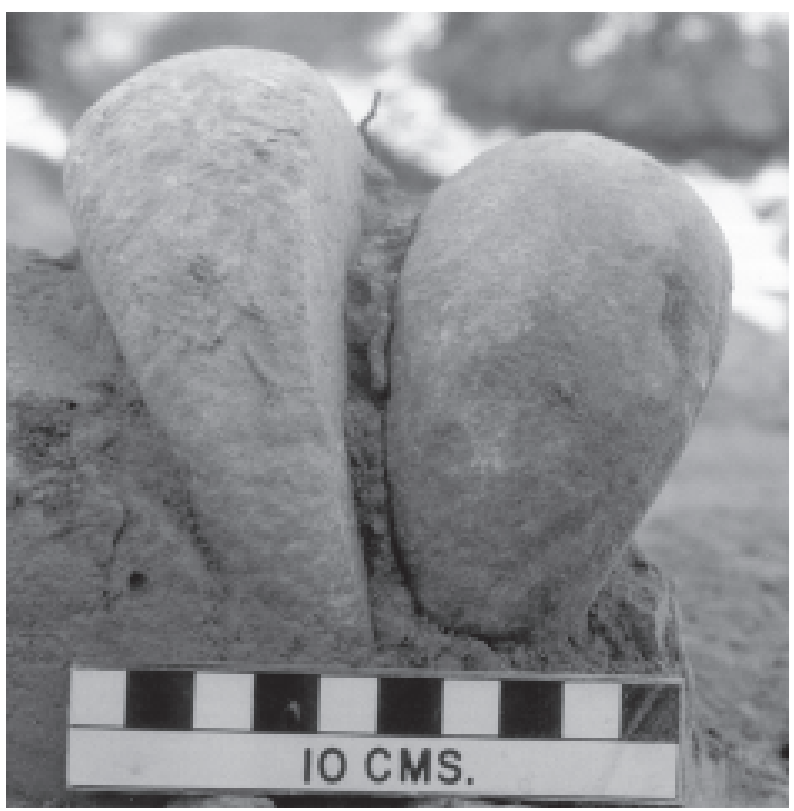

Figure 10.2 A Pair of Manos from Feature 38 in Profile.

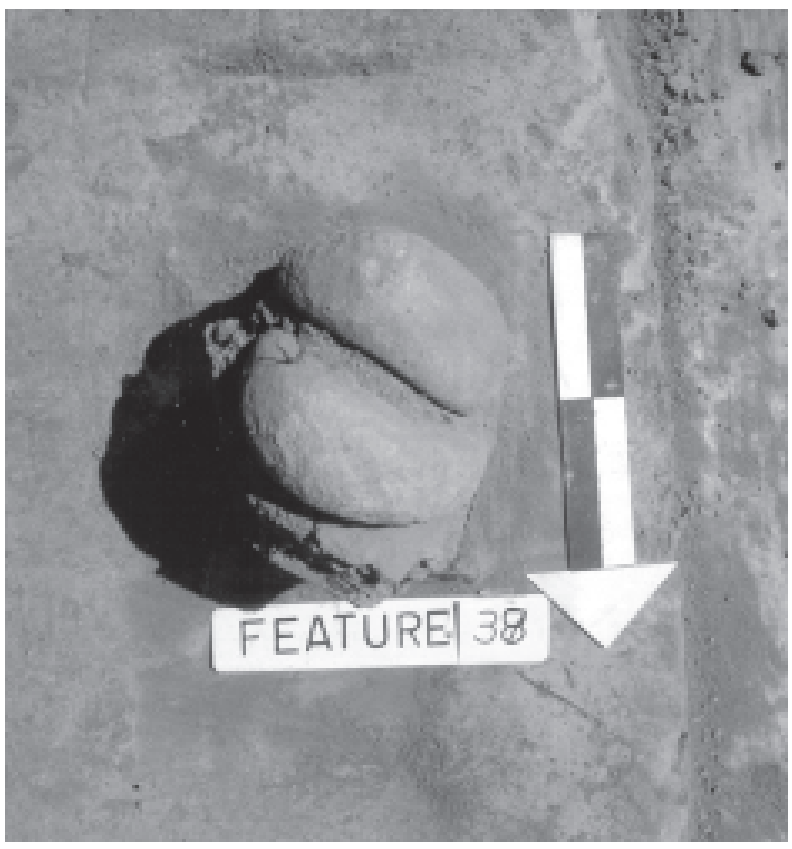

Figure 10.3 Plan View of Manos from Feature 38.

isotope results from this rock residue indicate that the seeds were from some $\mathrm{C} 3$ plants rather than $\mathrm{C} 4$ plants, such as grass seeds, or CAM plant seeds, such as prickly pear tunas. Burned rock \#2165 (sample Lino 21) yielded residue that was from a large herbivore (Appendix G). The corresponding isotopic results would indicate the presence of deer/antelope rather than bison for this large herbivore.

Burned rock \#2168 from Feature 24 was subjected to thermal demagnetization and yielded two definite temperature components (Appendix E). This rock appears to have been heated to about 250 degrees $\mathrm{C}$ as it was used in the cooking process. The detected signature may have resulted from stone boiling activities (Appendix E).

The four 1 by $1 \mathrm{~m}$ hand excavated units surrounding Feature 24 yielded high frequencies of lithic debitage and burned rocks, one mussel shell valve, two edge modified flakes, one core, and one basal section of a Refugio point. The Refugio point was from about $30 \mathrm{~cm}$ south of the burned rock concentration. The bulk of the lithic debitage was concentrated in an ovateshaped area on the northern margin of the burned rock cluster (Figure 10.4).

Nearly 13 liters of matrix from around and below the burned rocks in Feature 24 were floated. This sample yielded 83 flakes (29 of which are greater than $6.4 \mathrm{~mm}$; the other flakes are tiny pieces), about $2.4 \mathrm{~g}$ of snail shell fragments, less than 1 $\mathrm{g}$ of mussel shell, less than $1 \mathrm{~g}$ of charcoal flecks, and $319 \mathrm{~g}$ of burned rock fragments (Table 6.3). These results reflect the co-occurrences of high frequencies of burned rocks and lithic debitage in that area. The concentration of burned rocks and lithic debitage and the nearby tools and shell indicate that this was probably a discard area rather than an in situ activity location. Although the presence of tiny pieces of chert from the float sample might indicate in situ knapping, the dumping of waste knapping debris collected on a skin would create the same pattern in the archaeological record. 


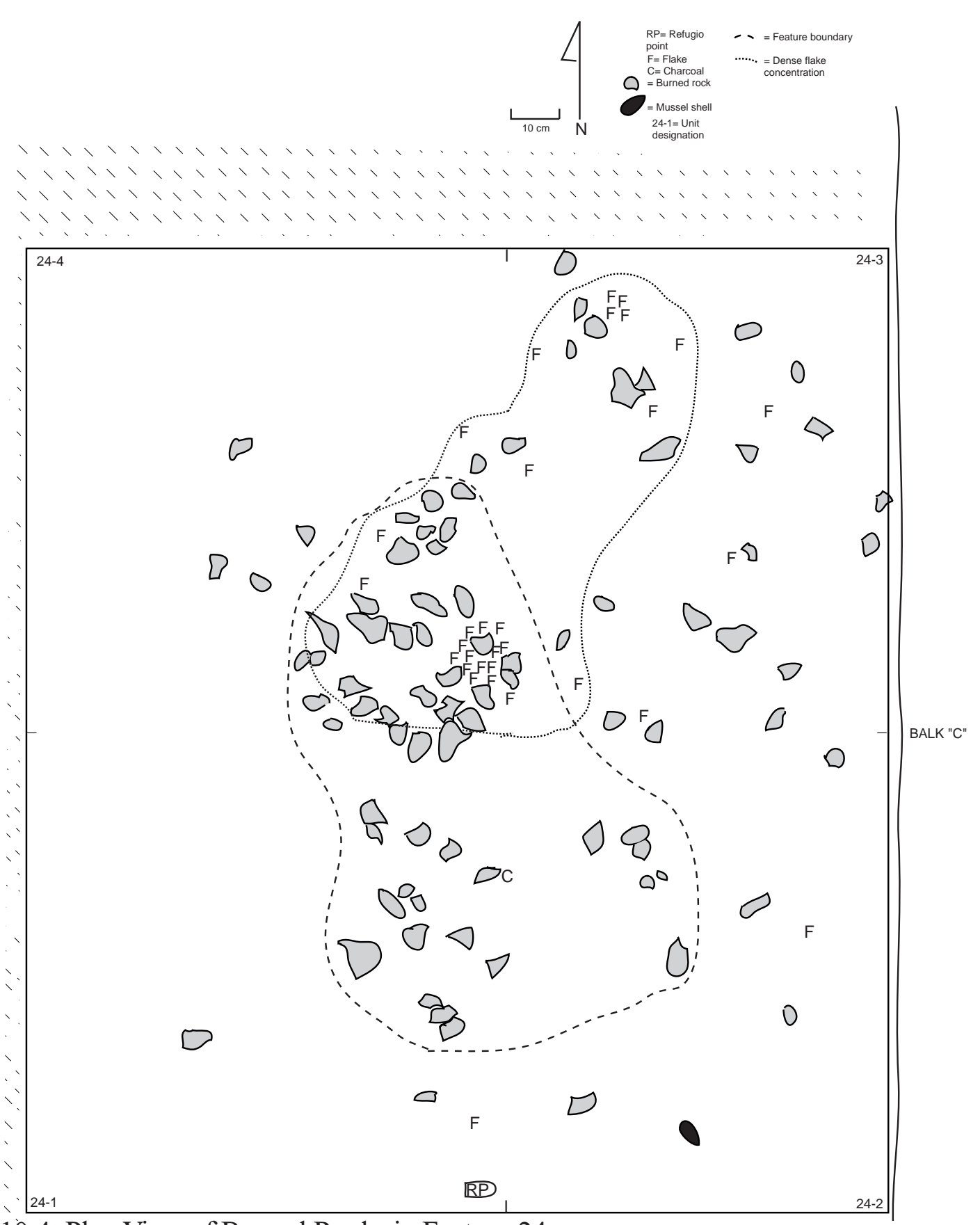

Figure 10.4 Plan View of Burned Rocks in Feature 24.

Feature 29 consisted of 47 burned rocks and at least four chert flakes in a loose cluster that covered an area measuring $100 \mathrm{~cm}$ northwest to southeast and $70 \mathrm{~cm}$ northeast to southwest in Unit 29-5 (Figure 10.5). The area that contained these rocks was bisected, and no pit, ash or charcoal lens, or oxidized matrix was observed in profile. The 46 burned rocks weighed 1,865 $\mathrm{g}$ for an average of $40 \mathrm{~g} /$ rock. Some 36 percent were in the 0 to $4 \mathrm{~cm}$ in size, 62 percent were 4 to $9 \mathrm{~cm}$ in diameter, and one was between 9 and $15 \mathrm{~cm}$ in diameter (Table 10.2). Only one burned rock had tiny cracks.

Organic residues from the interior portions of burned rocks \#3235 and \#3605-5 were analyzed. 


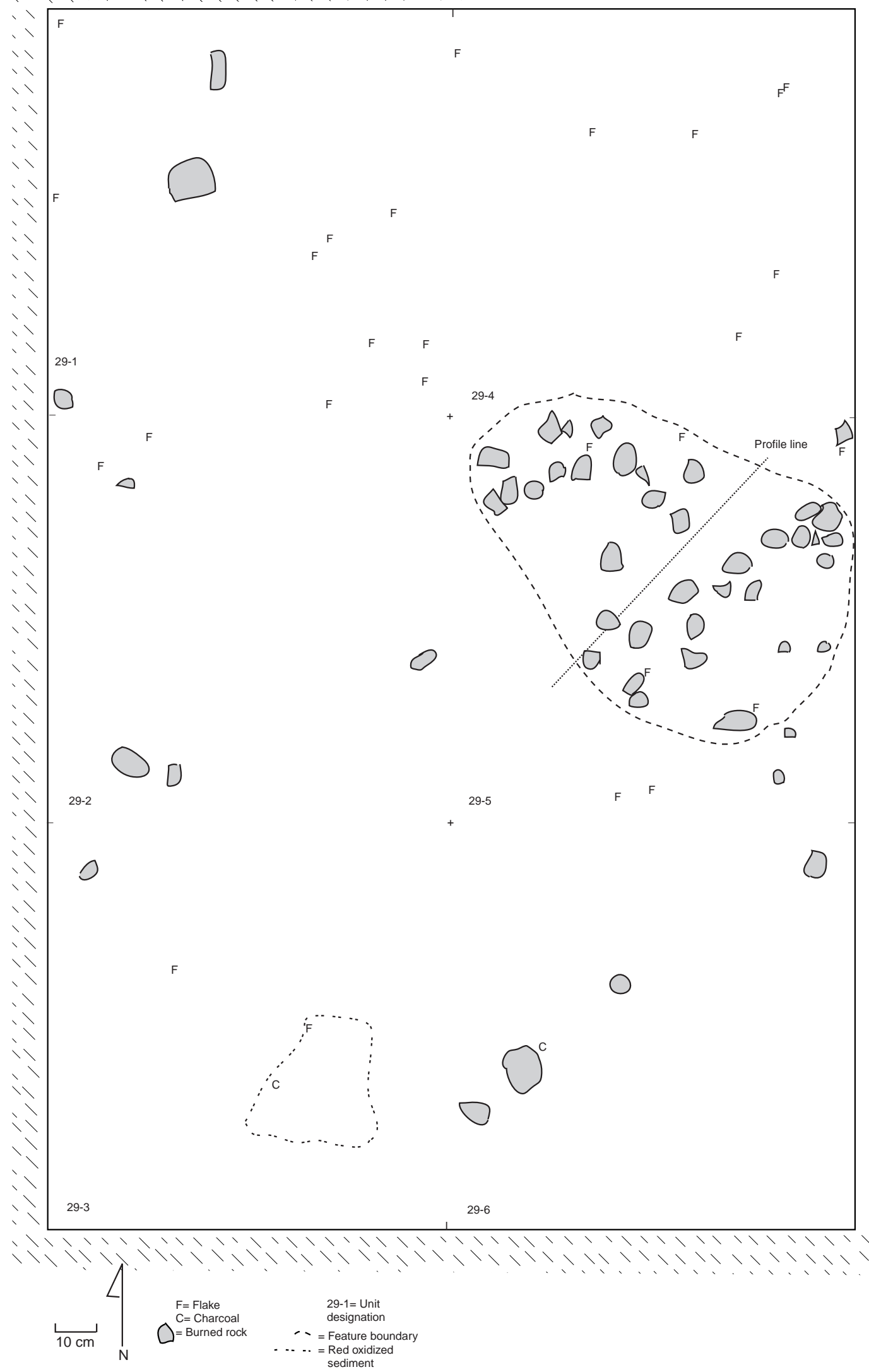

Figure 10.5 Plan View of Burned Rocks in Feature 29. 
The stable carbon and nitrogen isotope analyses provided $\delta^{13} \mathrm{C}$ values of -21.9 and $-22.2 \%$, whereas the $\delta^{15} \mathrm{~N}$ values were $5.3 \%$ and $8.5 \%$, respectively (Appendix D). These isotopic values appear to reflect mixtures of $\mathrm{C} 3$ and $\mathrm{C} 4$ / CAM resources. These same two residues were subjected to fatty acid analyses. Burned rock \#3235d (sample Lino 28) yielded fatty acids similar to that derived from plants (Appendix G). Burned Rock \#3605d (sample Lino 27) was contaminated with modern lipids and yielded no interpretable data (Appendix G).

The five hand excavated units immediately surrounding Feature 29 yielded moderate frequencies of small, scattered burned rocks, moderate frequencies of lithic debitage on the south side, and high lithic frequencies on the west and north sides. About $1 \mathrm{~m}$ to the southwest was an irregular area about $25 \mathrm{~cm}$ in diameter that yielded a chunk of wood charcoal near the edge of a red oxidized area (Figure 10.5). The charcoal chunk appeared to be angled into the ground, but it is unclear if the charcoal had a cultural origin or was part of a burned root.

About 13 liters of matrix from around and beneath the burned rocks was floated. This sediment sample yielded 119 flakes (20 of which were greater than $6.4 \mathrm{~mm}$; the rest were tiny chert pieces), about $4.8 \mathrm{~g}$ of snail shell fragments, 293 $\mathrm{g}$ of burned rock fragments, and a trace of charcoal flecks. No macrobotanical remains were recovered. The presence of unpatterned burned rocks and lithic debitage indicates that this was a dump area.

Feature 30 consisted of a few scattered flakes, a couple of small chunks of charcoal, and 97 burned rocks loosely clustered over an area about $180 \mathrm{~cm}$ north-south by $140 \mathrm{~cm}$ east-west near the western end of the block. In a few instances - primarily near the central and densest area-the burned rocks occurred at different elevations but were not neatly stacked. The rocks in the middle area may have once been piled but subsequently became scattered (Figure 10.6). No basin, ash or charcoal lens, or oxidized soil was observed around or below the rocks. The 97 burned rocks weighed 32,705 g, and yielded an average of about $337 \mathrm{~g} /$ rock. Nearly 58 percent of the burned rocks were 4 to $9 \mathrm{~cm}$ in diameter with another 32 percent being between 9 to $15 \mathrm{~cm}$ in diameter (Table 10.2). One large, $25 \mathrm{~cm}$ diameter rock was near the core of this cluster. Ninety-eight percent of the cobbles were sandstone and two were chert rocks. Some 74 percent were angular, 14 percent were rounded, and 11 percent were tabular. Hairline cracks were detected in about 76 percent of the rocks.

Organic residues extracted from the interior of burned rocks \#3063, \#3064, \#3071, and \#3079 were analyzed. The stable carbon and nitrogen analyses yielded $\delta^{13} \mathrm{C}$ values that varied between $-21.0 \%$ and $-24.1 \%$, and the $\delta^{15} \mathrm{~N}$ values are between 2.1\%o and 6.4\%o (Appendix D). These results indicated a probable mixture of $\mathrm{C} 3$ and C4/CAM resources, with most of the material derived from $\mathrm{C} 3$ plants. The same residues from \#3063 (sample Lino 29) and \#3071 (sample Lino 30) were analyzed for fatty acid content. Burned rock \#3063d yielded fatty acids quite similar to that from Texas ebony seeds (Appendix G). The nitrogen isotopic results support this legume interpretation. Burned rock \#3071d yielded insufficient lipid residue to be interpreted.

Burned rock \#3064 was subjected to thermal demagnetization, which revealed three components, two of which were well-defined and a third was weak (Appendix E). It is possible this burned rock was used in stone boiling activities.

About 20.5 liters of matrix from around and below the burned rocks were floated. This sample yielded 36 chert flakes (five greater than $6.4 \mathrm{~mm}$ and the rest tiny pieces), about $4.3 \mathrm{~g}$ of crushed snail shells, less than $1 \mathrm{~g}$ of charcoal 


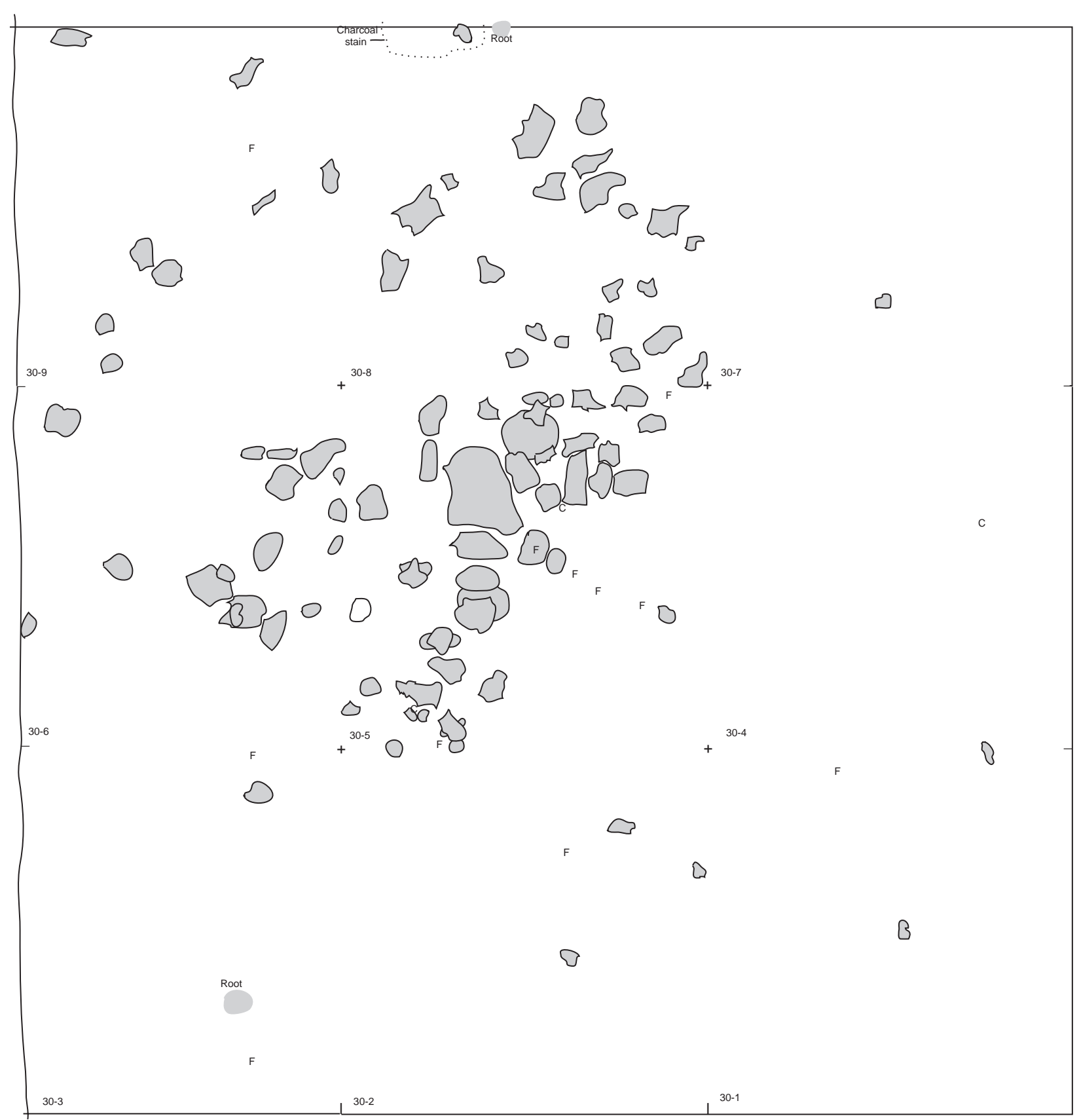

Figure 10.6 Plan View of Burned Rocks in Feature 30.

flecks, a trace of bone, and about $285 \mathrm{~g}$ of granular-size burned rock fragments (Table 6.3).

The seven hand excavated units surrounding Feature 30 yielded relatively sparse lithic debitage, moderate amounts of scattered burned rocks, and the distal end of a late stage biface. About 30 to $40 \mathrm{~cm}$ north of this cluster of burned rocks was an irregular area of light charcoal staining that measured about 10 by $30 \mathrm{~cm}$ in diameter and continued beyond the limits of the excavation unit. Feature 30 is also interpreted as a dump of burned rocks.

Feature 40 consisted of a dense concentration of 43 burned rocks along with numerous flakes, a stemmed biface, two other biface fragments, an edge-modified flake, and charcoal in an area 
that measured at least $90 \mathrm{~cm}$ northwest to southeast by $60 \mathrm{~cm}$ wide in Unit C2 (Figures 10.7 and 10.8). These items were not in a pit or surrounded by charcoal staining. The 43 burned rocks weighed 5,430 $\mathrm{g}$ and yielded an average of about $126 \mathrm{~g} /$ rock (Table 10.2). The burned rocks were of sandstone (67 percent) and chert (33 percent). This is the highest frequency of chert recognized in the burned rock features. The rocks were mostly ( 80 percent) between 4 to 9 $\mathrm{cm}$ in diameter with the rest equally split between 0 to $4 \mathrm{~cm}$ and 9 to $15 \mathrm{~cm}$ in size. Nearly 75 percent were angular in outline with another 19 percent more rounded. Only one rock had hairline cracks.

Organic residues extracted from the interior of three burned rocks (\#5295-4-1, \#5294-4-2, and \#5295-4-3) were analyzed. The stable carbon and nitrogen isotope analyses yielded $\delta^{13} \mathrm{C}$ values between $-21.2 \%$ and $-23.7 \%$, and the $\delta^{15} \mathrm{~N}$ values were between $-15.3 \%$ and $-2.1 \%$ (Appendix D). The carbon isotope values fall into the range of $\mathrm{C} 3$ plants or animals that ate C3 plants. There are no known modern $\delta^{15} \mathrm{~N}$ values even close to the $-15 \%$ value, and therefore this value may be in error. Even the $-4.3 \%$ value is low and could be in error. The negative values reflect either legume beans and/ or nuts. These same three residue samples also yielded traces of fatty acids that could not be interpreted (Appendix G). Only rock \#5294-42 was subjected to thermal demagnetization, and it exhibited one temperature component (Appendix E). This single magnetic component indicates that the rock was heated to above 580 degrees $\mathrm{C}$ and then cooled in place.

Some seven liters of matrix from around and below the rocks were floated and yielded 59 flakes of which 17 are greater than $6.4 \mathrm{~mm}$. The rest are tiny chert pieces, about $2 \mathrm{~g}$ of fragmented snail shells, and $155 \mathrm{~g}$ of burned rock fragments. No charcoal or macrobotanical remains were collected (Table 6.3).

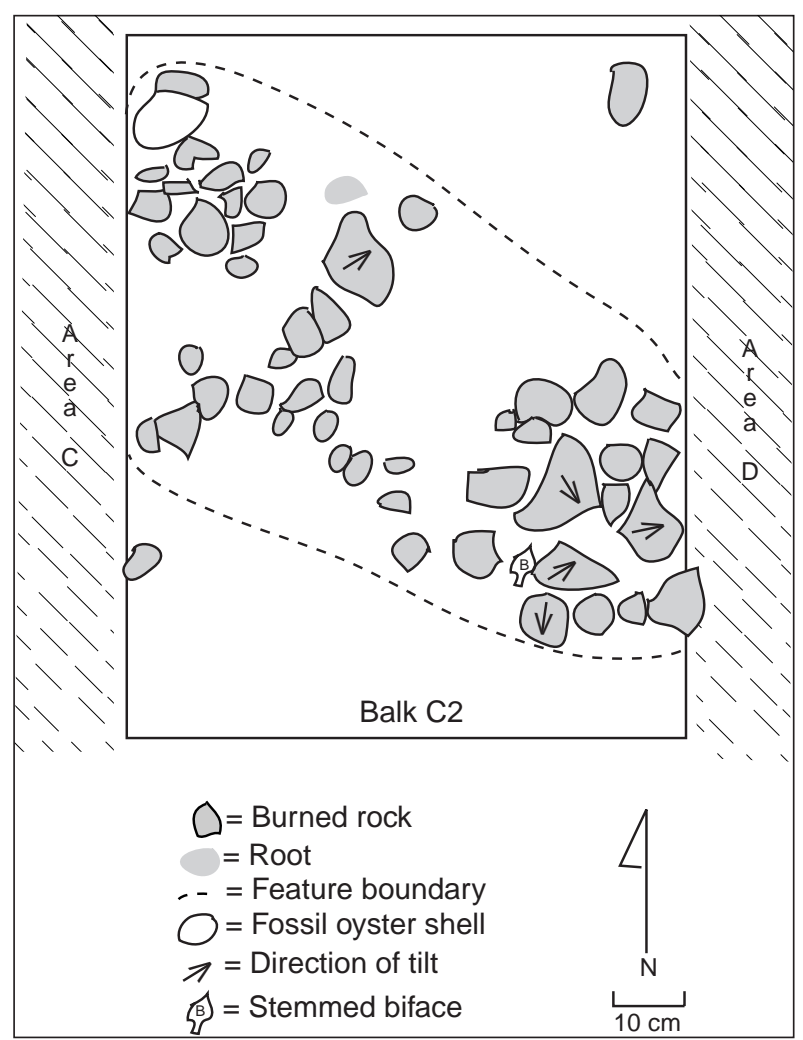

Figure 10.7 Plan View of Feature 40.

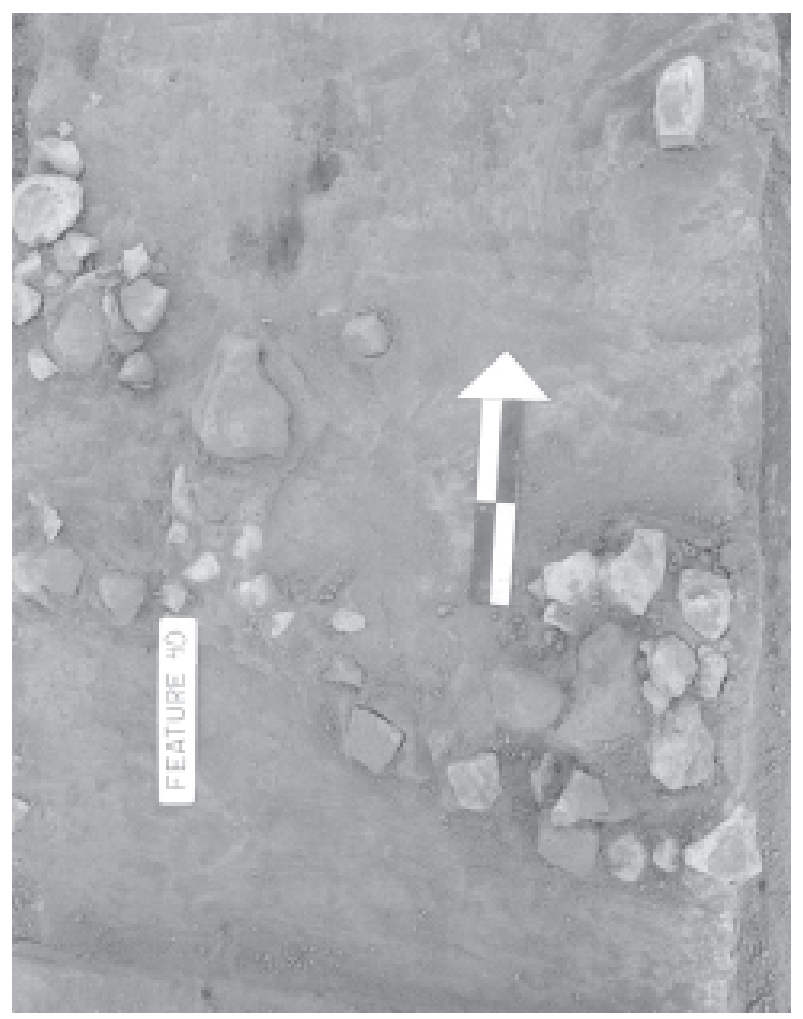

Figure 10.8 Linear Patterning of Cultural Material in Feature 40. 
The hand-excavated unit immediately north of Feature 40 (Unit C1) yielded a high frequency of scattered burned rocks and a moderate frequency of lithic debitage. The handexcavated unit immediately south (Unit C3) yielded high frequencies of lithic debitage and moderate quantities of scattered burned rocks. The accumulation of these different material types, including the tools, would indicate that this area was another dump.

In summary, all four burned rock concentrations (Features 24, 29, 30, and 40) contained between 43 and 152 burned rocks with no obvious sign of in situ burning at any of these locations. Often chert flakes were mixed with or near the burned rock clusters. In some instances broken tools were nearby. A near absence of burned macrobotanical and bone remains occurred, but this may merely reflect poor preservation. Charcoal was generally absent except for a few small chunks. Thus, these clusters of burned rocks are interpreted to be discarded used rocks. The 367 rocks in these four features weighed a total of $46,002 \mathrm{~g}$, or $125 \mathrm{~g} /$ rock on average.

\subsection{CHIPPED LITHIC ASSEMBLAGE}

The lithic assemblage from the hand excavated balks $\left(39 \mathrm{~m}^{2}\right)$ and the hand-excavated units around three features $\left(21 \mathrm{~m}^{2}\right)$ in the Gradall ${ }^{\mathrm{TM}}$ area yielded 1,330 pieces of unmodified chipped stone debitage, or about 22 pieces of lithic debitage per square meter. The raw material was of good-to-high quality chert that could have been procured from local gravel sources. Color differences exist in the cherts; in very general terms most are tans, grays, and browns with some whites and dark reds.

The debitage was classified into six recognizable types (Table 10.3). Core flakes (35 percent) were most frequent, followed by indeterminate flakes (27 percent), late stage biface flakes (18 percent), and early stage biface flakes (18 percent). The
Table 10.3 Occupation 5 Lithic Debitage Analysis.

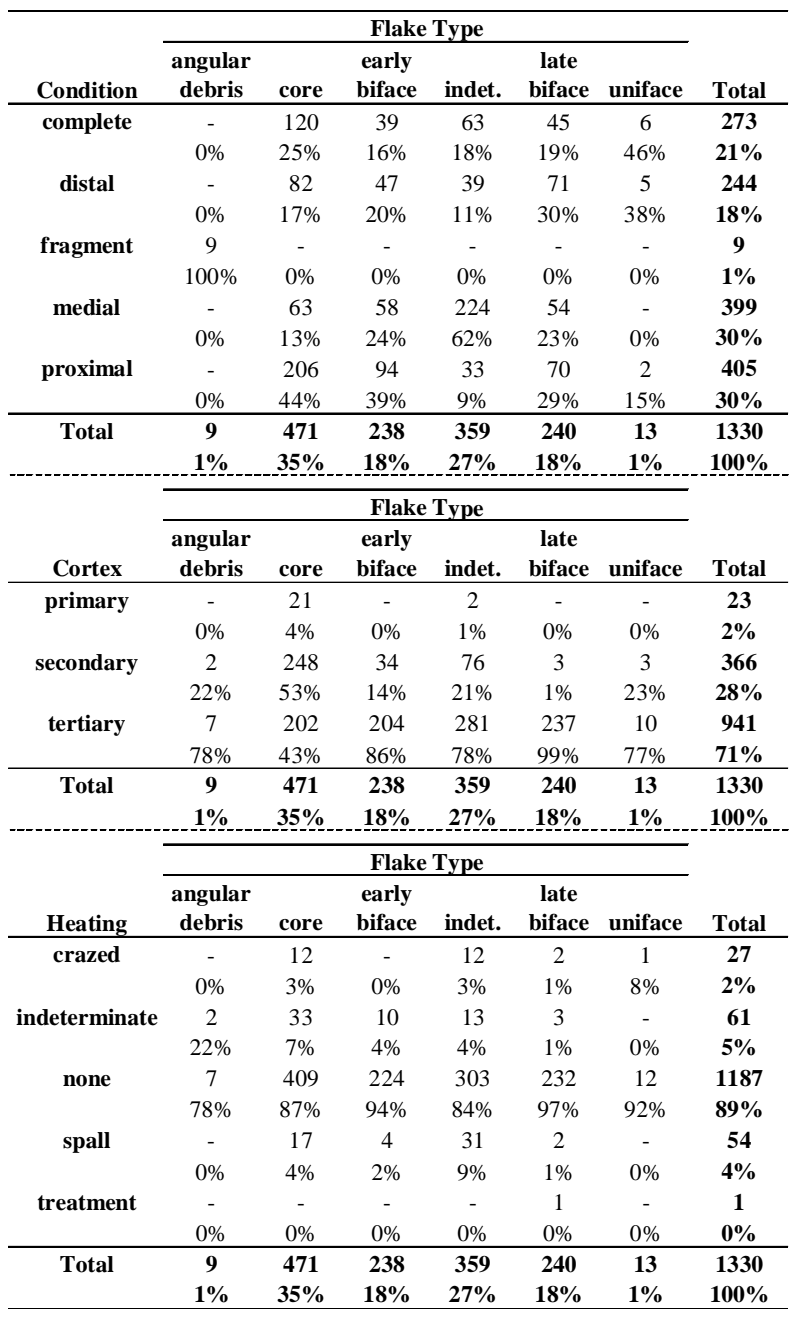

angular debris and uniface flakes were just barely represented (one percent each). The overall flake type frequencies reflect considerable core and biface manipulation. Uniface maintenance was conducted but at a relatively infrequent level in comparison to the core and biface manufacturing activities.

Medial and proximal flake fragments are equally represented by 30 percent each (Table 10.3). Complete flakes and distal fragments are about equally represented with about 20 percent and 18 percent respectively. Angular debris is represented by less than one percent and is similar to frequencies from other occupation zones at this site. Distal fragments appear to be 
underrepresented compared to medial sections. These percentages are nearly identical to those in Occupation 4. Thus, no change is apparent in the behaviors reflecting stone-tool manufacturing and maintenance activities.

Cortex remains on about 28 percent of the debitage. Nearly 53 percent of the core flakes had cortex, followed by 22 percent on angular debris, 21 percent on indeterminate pieces, 14 percent on early stage biface flakes, and only one percent on late stage biface flakes (Table 10.3). This trend reflects progressive decortification of the original cobbles. By the late stage in the biface manufacturing sequence, there is little to no cortex remaining on the objective piece. The relatively high percentage of cortex on the angular debris and indeterminate pieces indicates these relate to the early core reduction stages.

Heat altered (crazed and spalled) pieces account for six percent of the assemblage, with heat spalls representing about two-thirds of the total (Table 10.3). These heat alterations resulted from direct exposure of lithic debris to fires and probably reflect accidental burning of waste material before being discarded. Intentional heat treating of chert to improve its workability does not appear to have been a standard practice.

\subsection{CHIPPED STONE TOOLS}

The chipped-stone tool assemblage was classified into seven form/functional classes and consists of two projectile points, 11 bifaces, one drill, one scraper, 34 edge-modified flakes, two cores, and one hammerstone. As a group, these 52 tools account for 1.9 percent of the total material recovered from the $60 \mathrm{~m}^{2}$ excavation area encompassing Occupation 5.

All tools are made of chert. The two projectile points were both Refugio point types (Table 10.4). One Refugio was nearly complete
(\#4683) with a rounded base with convex lateral edges that converge to form a sharp tip (Figure 10.9). It was manufactured from a mottled cream-to-white chert with dark patches. Both faces are completely modified with very fine finishing scars along the margins. The base exhibited a use-break (Figure 10.9). The second Refugio (\#2244) is the proximal half that was manufactured from a mottled gray chert. It has a rounded base with one straight and one convex lateral edge (Figure 10.9). The straighter edge reveals an area with many tiny hinge fractures indicating an attempt to reduce a raised area on one face. The break appears to indicate failure during use and thus was apparently a finished product. The two points have quite similar metric attributes for the width and thickness, and the workmanship is high quality on both.

The 12 bifaces include three complete, four proximal ends, four distal ends, and one medial fragment. Two complete specimens have rectangular outlines and the third (\#4817) has a stem. This stemmed biface has an extremely thick knot on one face with broad hinge fractures all along its margins, indicating an apparent attempt to remove the knot (Figure 10.9). This fine-grained, gray chert specimen does not have many tiny hinge fractures around the margins to indicate final thinning or use. Because of the knot, this biface may have been discarded prior to use. Another complete biface (\#3605-4) has an asymmetrical triangular outline with sinuous edges (Figure 10.9). Many broad hinge fractures are present on both faces, and it appears that this middle stage biface may have not been finished due to the flaking problems encountered during manufacture. Biface \#5511-6 is a complete, teardrop shaped drill with a broad rounded base that exhibits no hafting element (Figure 10.9). It was made from a gray chert with light colored circular spots. The stem section is quite thick with tiny hinge fractures along the two opposing edges. The stem is thick enough to withstand considerable pressure if used as a punch. Slight 


\begin{tabular}{|c|c|c|c|c|c|c|c|c|c|c|c|c|c|c|c|c|c|c|c|c|c|}
\hline \multirow[b]{2}{*}{ Cat.\# } & \multirow[b]{2}{*}{ Unit } & \multirow[b]{2}{*}{ F\# } & \multirow[b]{2}{*}{ Lvl } & \multirow[b]{2}{*}{ Depth } & \multirow[b]{2}{*}{$\mathrm{N}$} & \multirow[b]{2}{*}{$\mathrm{E}$} & \multirow[b]{2}{*}{ Elev } & \multirow[b]{2}{*}{ PtTool } & \multirow[b]{2}{*}{ Brk } & \multirow[b]{2}{*}{ Con. } & \multirow[b]{2}{*}{ Sh } & \multirow[b]{2}{*}{ Stg } & \multicolumn{3}{|c|}{ Color } & \multirow[b]{2}{*}{$\begin{array}{l}\text { Bas } \\
\text { Edg }\end{array}$} & \multirow{2}{*}{$\begin{array}{l}\text { Bas } \\
\text { Thin }\end{array}$} & \multirow[b]{2}{*}{$\mathrm{Bvl}$} & \multicolumn{3}{|c|}{ Size $(\mathrm{mm})$} \\
\hline & & & & & & & & & & & & & Mat'l & sW & LW & & & & L & W & Th \\
\hline 2244 & & & & $100-110$ & & & & $R$ & U & $P$ & & & Pk/Prp & Prp & Prp & $C x$ & $R$ & $\mathrm{~N}$ & & 23.1 & 7.7 \\
\hline 4683 & D4 & & 11 & $100-110$ & & & & $\mathrm{R}$ & $\mathrm{N}$ & c & & & Tan & $\mathrm{Yw}_{\mathrm{w} / \mathrm{Or}}$ & Yw/ Or & $C x$ & $\mathrm{R}$ & $\mathrm{N}$ & 57.1 & 21.7 & 6.2 \\
\hline 4541 & $\mathrm{D} 7$ & & 10 & $90-100$ & 107.843 & 113.414 & 99.029 & B & & $P$ & 0 & M & & Or & Or & & & & & 54.0 & 10.9 \\
\hline 4817 & $\mathrm{C} 2$ & 40 & 11 & $100-110$ & 112.693 & 109.953 & 98.823 & B & & C & $\mathrm{T}$ & $\mathrm{L}$ & & Dk Yw/ Or & Pale Yw/Or & & & & 55.4 & 33.0 & 16.1 \\
\hline 4695 & $\mathrm{~A} 1$ & & 12 & $110-120$ & 113.809 & 101.807 & 98.622 & B & M & P & 0 & M & & $\mathrm{Yw} / \mathrm{Or}$ & $\mathrm{Yw} / \mathrm{Or}$ & & & & & & 15.2 \\
\hline 4946 & $\mathrm{C} 4$ & & 11 & $100-110$ & 111.091 & 109.905 & 98.812 & B & M & D & $T$ & $\mathrm{~L}$ & & Yw/ Or & Or & & & & & 21.0 & 4.5 \\
\hline $3605-4$ & $29-5$ & & 11 & $100-110$ & & & & B & & c & $T$ & M & & Or & Or & & & & 69.7 & 42.0 & 20.3 \\
\hline $3610-2$ & $30-2$ & & 12 & $110-120$ & & & & B & Uk & $P$ & 0 & $\mathrm{~L}$ & & $\mathrm{Yw}_{\mathrm{w} / \mathrm{Or}}$ & $\mathrm{Yw} / \mathrm{Or}$ & & & & & 34.0 & 8.2 \\
\hline $5295-7$ & $\mathrm{C} 2$ & & 11 & $100-110$ & & & & B & M & D & $T$ & $\mathrm{~L}$ & & Or & Red/Or & & & & & 28.0 & 8.0 \\
\hline $5454-6$ & $\mathrm{D} 7$ & & 10 & $90-100$ & & & & B & M & $P$ & 0 & $\mathrm{~L}$ & & Dull Yw & Dull Yw & & & & & 46.0 & 13.1 \\
\hline $5511-6$ & E5 & & 11 & $100-110$ & & & & B & & C & $\mathrm{T}$ & $\mathrm{L}$ & & Or & Or & & & & 42.5 & 20.0 & 6.8 \\
\hline $5295-11$ & $\mathrm{C} 2$ & & 11 & $100-110$ & & & & B & & M & $\mathrm{T}$ & $\mathrm{L}$ & & Or & $\mathrm{Yw} / \mathrm{Or}$ & & & & & & 4.4 \\
\hline $5580-3$ & $\mathrm{~F} 4$ & & 11 & $100-110$ & & & & B & & D & $T$ & $\mathrm{~L}$ & & Prp/Or & $\mathrm{Yw}_{\mathrm{w} / \mathrm{Gr}}$ & & & & & & 4.5 \\
\hline $3601-4$ & $29-1$ & & 11 & $100-110$ & & & & B & $\mathrm{M}$ & D & $\mathrm{T}$ & L & & Dk Red/ Or & Dk Red/Or & & & & & 29.0 & 9.8 \\
\hline
\end{tabular}

All materials chert unless noted.

Point/Tool Type: B=biface, $D=$ drill, T=Tortugas, Uk=Unknown, M=Matamoros

Break (Brk): M=manufacture, Us=use, Uk=unknown

Condition (Con.): $\mathrm{C}=$ complete, $\mathrm{P}=$ proximal, $\mathrm{M}=$ medial, $\mathrm{D}=$ distal

Shape (Sh), Basal Edge (Bas Edge), \& Basal Thinning (Bas Thin): $P=P$ arallel, $S n=$ sinuous, $S t=s t r a i g h t, C c=$ concave, $C x=$ convex, $L=l a n c e o l a t e, ~ O=0 v a l, R=r e c t a n g u l a r$,

$T=$ triangular, l=irregular, Ot=other

Manufacture Stage $(S t g)$ : L=late, M=middle

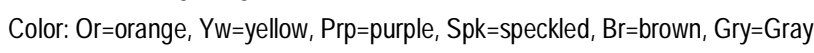

Beveling (Bvl): $\mathrm{N}=$ none

Note: All catalogue numbers from hand excavated proveniences have been formed by adding a dash and appear in the database with leading zeros. These leading zeros

have been omitted to conserve space. 


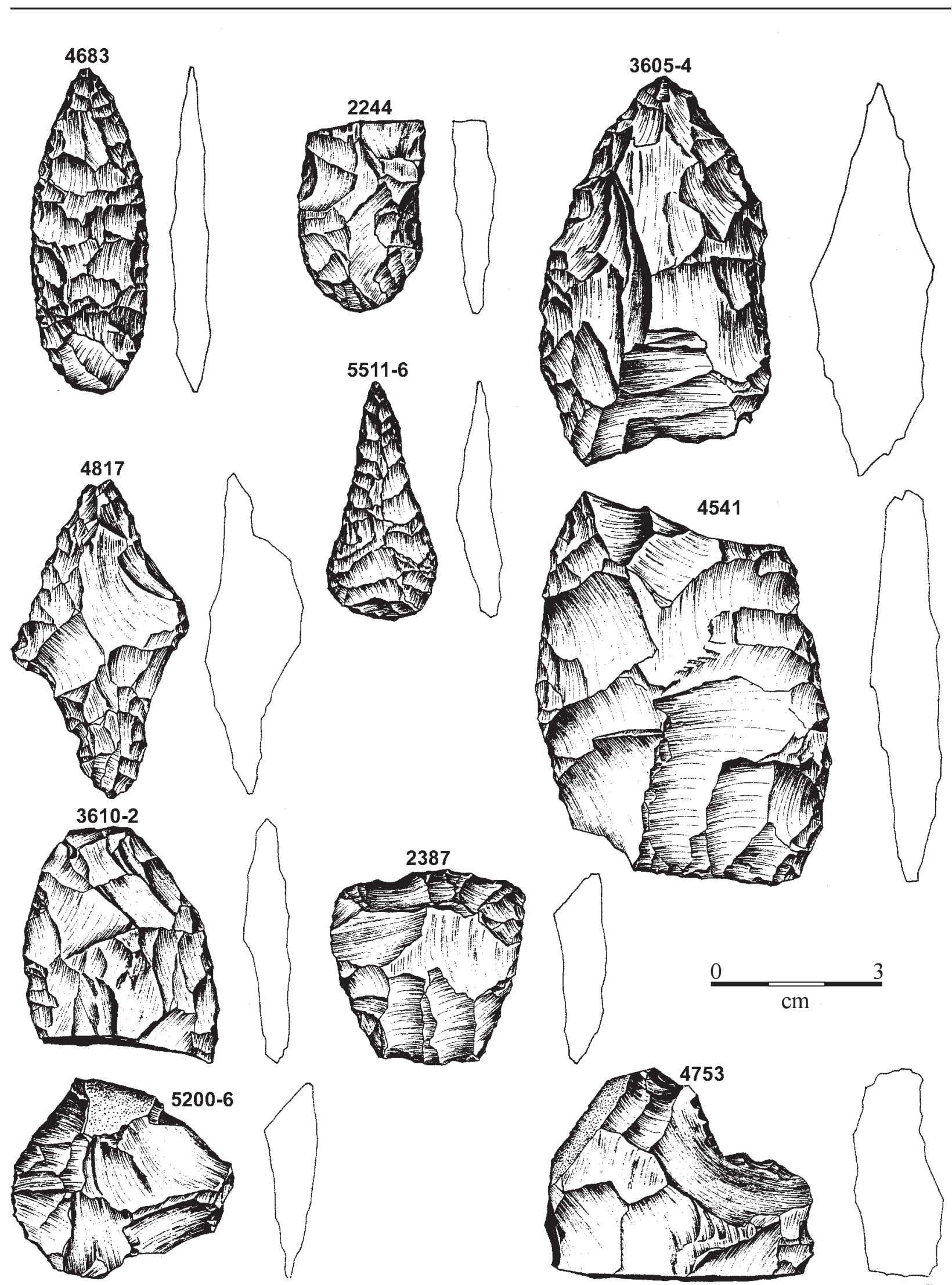

Figure 10.9 Selected Artifacts from Occupation 5 (Actual Size). 
grinding occurs along the lateral edges, and the base shows slightly heavier grinding. The tip is relatively thin and lacks any impact scars or obvious wear. All four broken proximal ends have oval outlines. One proximal fragment has a use-break and reflects attributes to indicate it was in a middle stage of manufacture. The other three proximal ends are in the late stages of reduction and have various shapes (Table 10.4). One lanceolate biface was broken during manufacture.

The complete scraper (\#2387) is classified as a bifacial Nueces tool made from a mottled light and medium gray chert. It has an oval-totrapezoidal outline, a slightly convex working end, and a straight proximal end with slightly convex lateral edges (Figure 10.9). The lateral edges are sinuous with evidence of minor crushing and few hinge fractures. The distal working end resembles a scraper from the Plains region farther north. The distal end has a low 57 degree working edge angle. The lateral edges are quite thin and show minimal edge modifications. The ventral surface is completely worked and is convex. The proximal end has been thinned from both faces with no apparent polish to indicate hafting.

The 33 edge-modified flakes were from 22 tertiary and 12 secondary flakes or flake fragments (Table 10.5, Figure 10.9). All but one had regularly-patterned edges that were along straight (38 percent), convex (26 percent), concave (24 percent), or sinuous (12 percent) lateral edges. Four (12 percent) had two worked edges. Most modified areas are only a few millimeters long and generally not along the entire lateral edge. The tiny size of the flake scars and their regularly patterned nature indicate that most may have been used in scraping activities.

Both chert cores are complete with one unifacially worked piece that has about 50 percent cortex still remaining. The hammerstone was an oval quartzite cobble with a combination of crushing and flaking resulting from impacts. This kind of damage is believed to have developed during flint knapping.

The high-powered microwear analyses on two Refugio points (\#2244 and \#4683), three bifaces (\#3605, \#3610, and \#4541), the complete drill (\#5511), the scraper (\#2387), and seven edgemodified flakes (\#2989, \#4753, \#4796, \#53056, \#5407-5, \#5407-6, \#5454-7) revealed no microscopic use-wear on any of these tools (Appendix C). Two bifaces are proximal fragments from the middle stage of reduction, and their unfinished condition could be why no use-wear was observed on those two specimens. Since the drill exhibits use scars, it is unclear why the microscopic analysis yielded no usewear. Since tools have had to be used for some time to develop use-wear attributes, it is possible that the lack of detected microwear wear may reflect the limited time these items were employed as tools.

\subsection{GROUND STONE TOOLS}

Three ground stones implements came from Occupation 5. These included two manos and one abrader. None of these were washed prior to analysis in the hope of retaining some cultural residues.

The two associated manos from Feature 38 in Unit F4 are characterized as wedge-shaped bifacial one-handed manos. Mano \#4725 is oval and measured nearly $6 \mathrm{~cm}$ thick. Both surfaces showing grinding use with light battering along the edges (Figure 10.10). This sandstone mano shows moderate striations, and both surfaces have small peck marks (Table 10.6, Figure 10.11). Mano \#4726 is round and measured about $5.5 \mathrm{~cm}$ thick with two worked surfaces (Figure 10.10). No battering was detected along the edges, although moderate striations were 


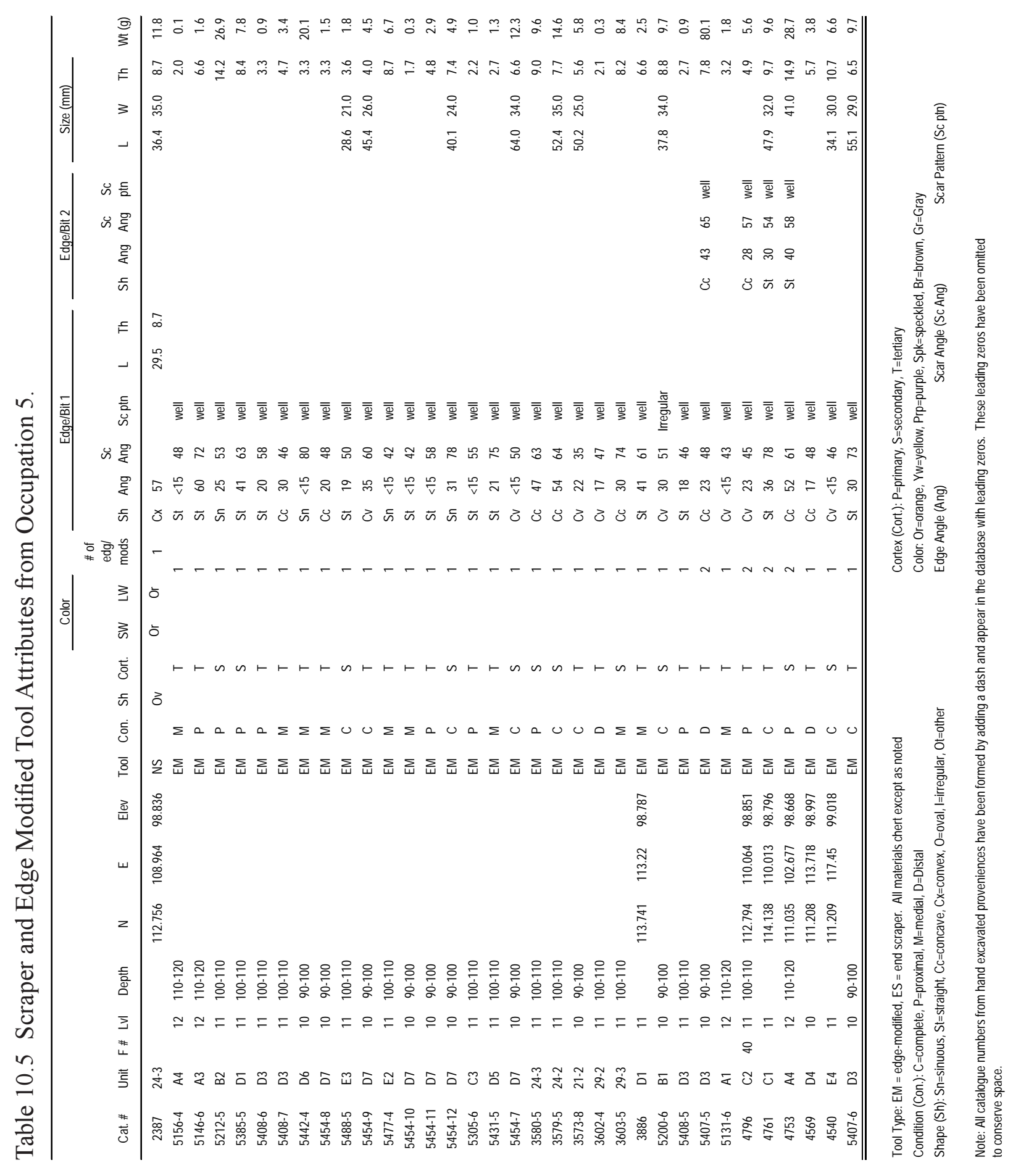


present on the surfaces. The ground and smoothed surfaces exhibit peck marks across them (Figure 10.12). Both manos were subjected to phytolith washes, but no phytoliths were recovered and neither were any pollens (Appendix H). Both were submitted for fatty acid analysis. Mano \#4725b (Lino 47) yielded fatty acids that closely resemble mesquite beans or prickly pear residues (Appendix G). Mano \#4726b (Lino 48) yielded fatty acids that resemble those from Spanish dagger seed pods or tasajillo fruit (Appendix G). It is more likely that the latter were Spanish dagger seedpods because the tasajillo fruit probably did not require grinding or crushing.

The one sandstone abrader (\#4692) came from Unit D3 (110 to $120 \mathrm{cmbs}$ ). This rectangular, wedge shaped piece weighing $168 \mathrm{~g}$ may have been part of a metate because it exhibits one very flat, smooth face with very few tiny pits (Figure 10.13). The obverse face is also flat with numerous deep pits or peck marks towards the thick side of the wedge. Three distinct grooves are on the thick lateral edge and one shallow groove is on one face of this wedged shaped piece. A shallow, slightly curved, expanding " $U$ " shaped groove crosses part of one face (Table 10.6). This groove intersects the thick lateral edge but ceases to exist just before it reaches the edge of the flat surface. It is deepest at the lateral edge and tapers to a non-groove at the opposite end. It is not well defined or well executed and may not have served in the same manner as the other three grooves on the thicker lateral edge. Three well-defined grooves occur on the thick lateral edge opposite the tapered edge (Figure 10.13). One is a distinctive, straight groove that parallels the long axis of the stone; two other grooves are very short and set at a roughly 40 degree angle to the larger groove (Table 10.6). The longer and well-defined groove is "V" shaped with a slightly rounded 1 $\mathrm{mm}$ wide bottom and measures $43 \mathrm{~mm}$ long, 5.7 $\mathrm{mm}$ wide, and $2.8 \mathrm{~mm}$ deep at the deepest point.

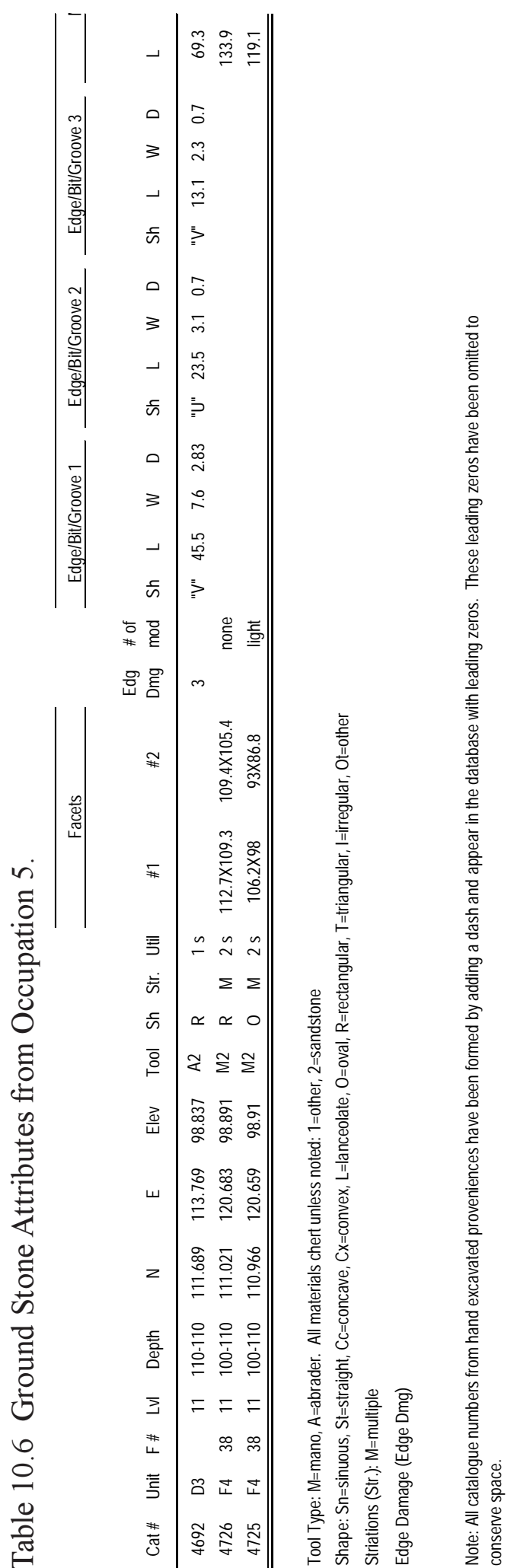



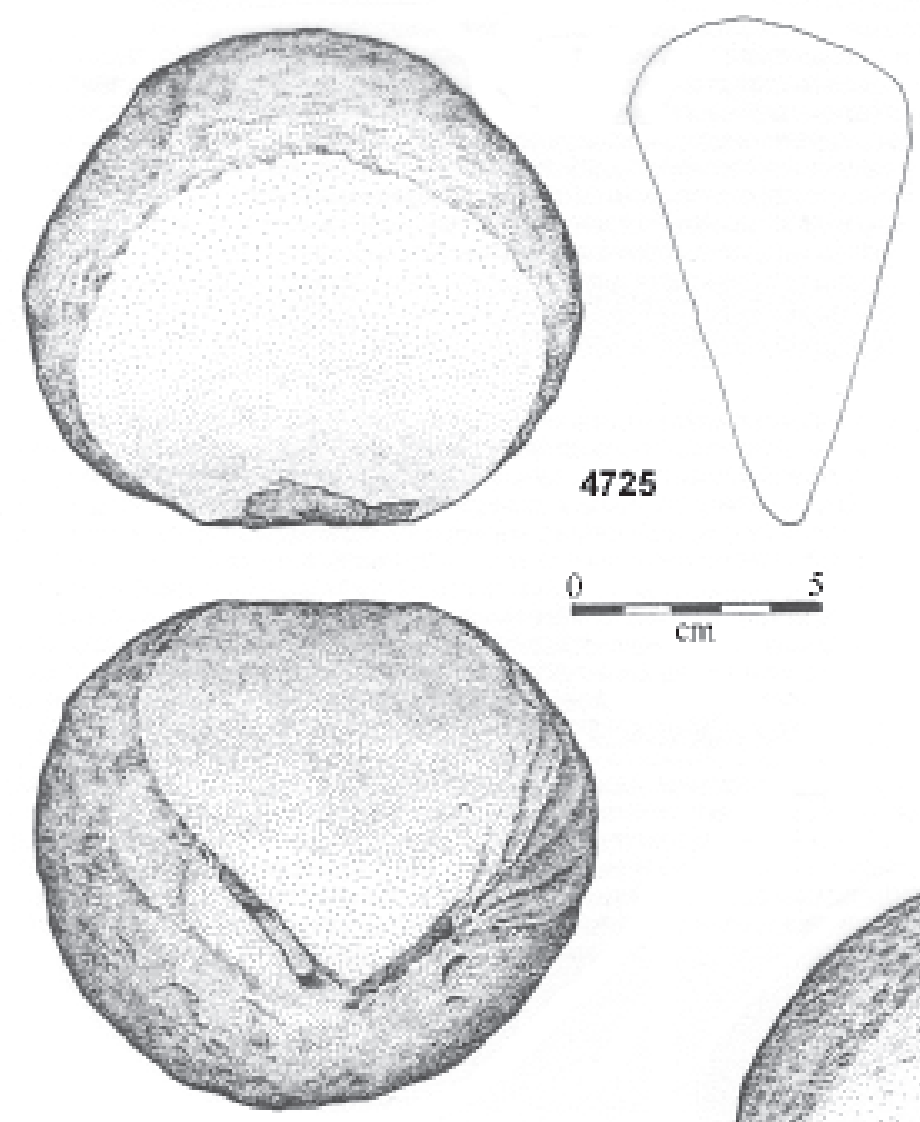

4726

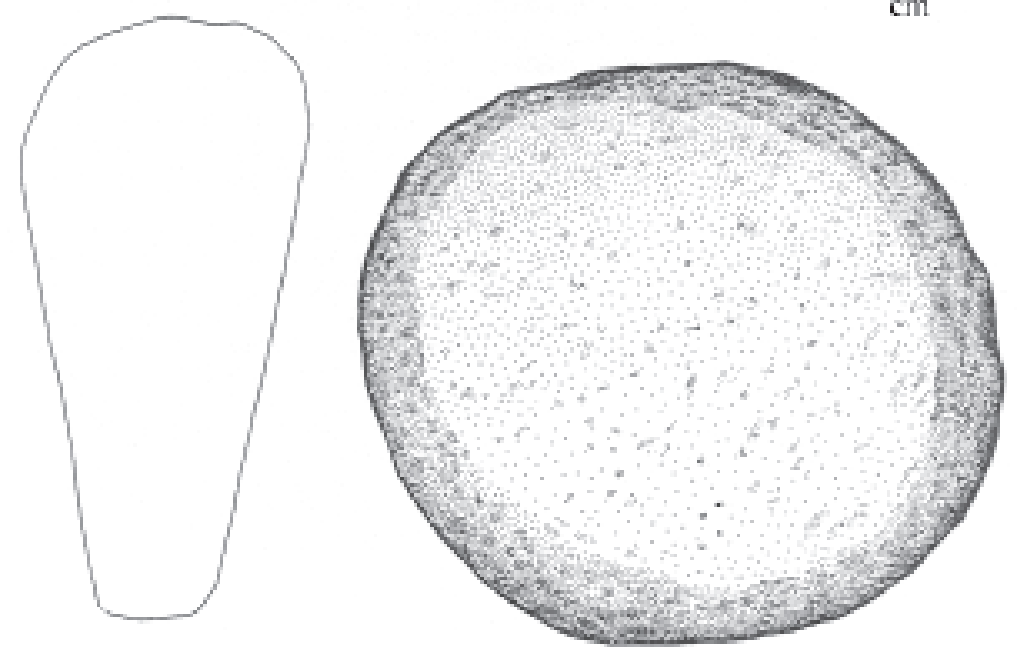

Figure 10.10 Manos from Feature 38 in Occupation 5. 


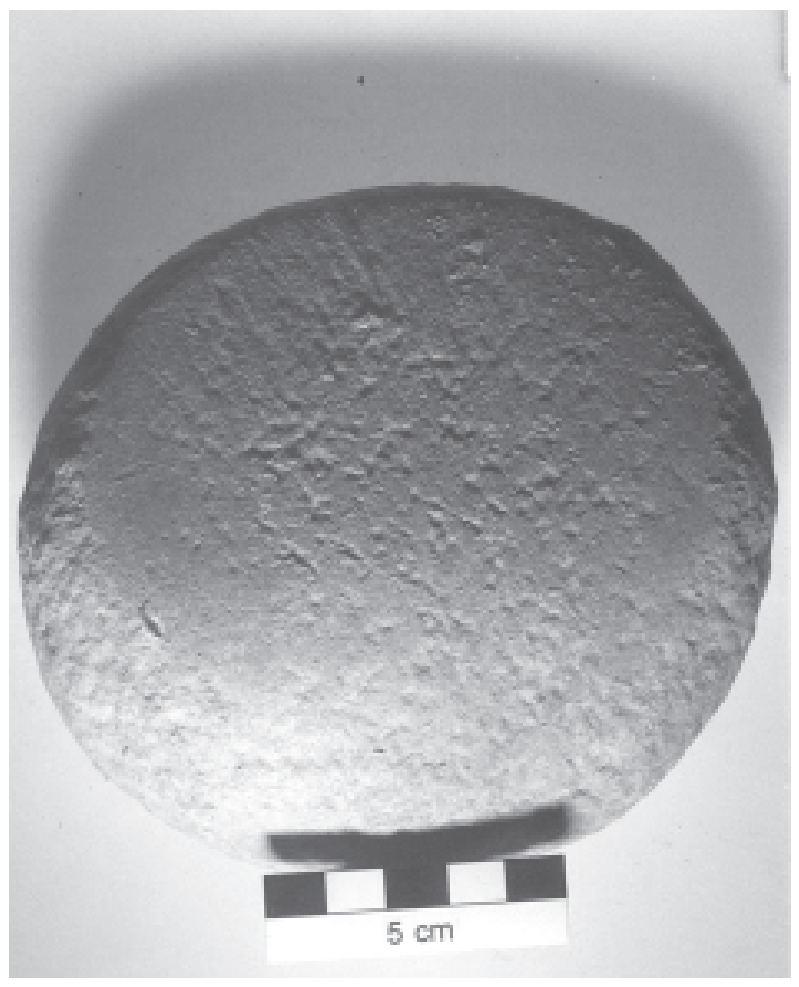

Figure 10.11 Mano \#4725 from Feature 38.

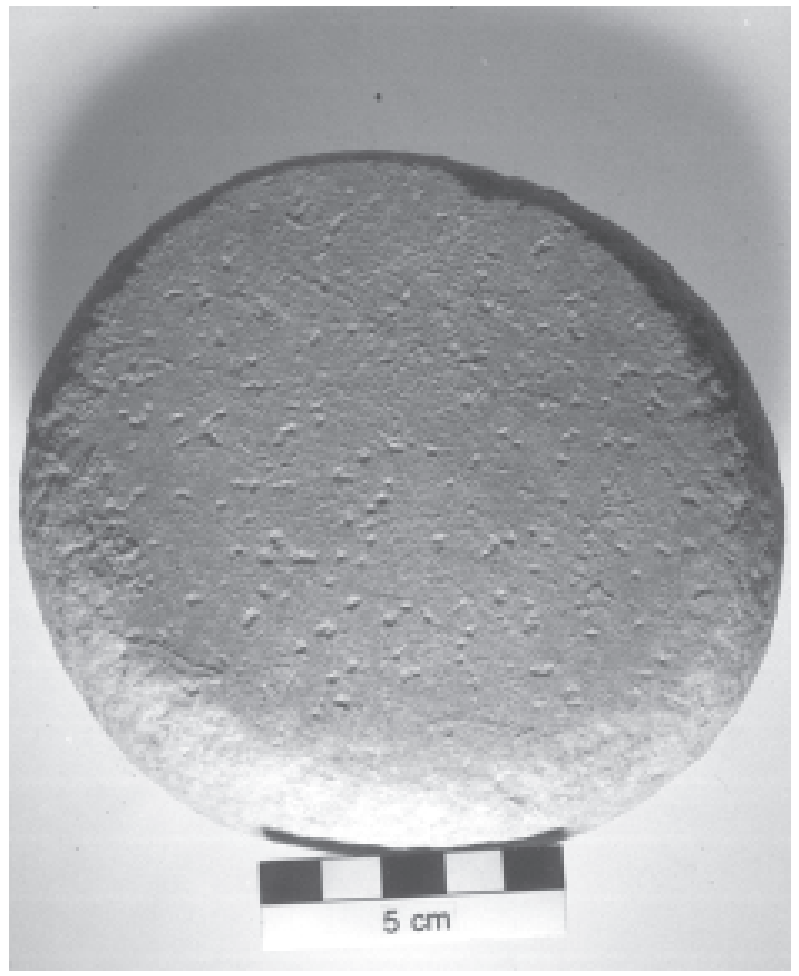

Figure 10.12 Mano \#4726 from Feature 38.

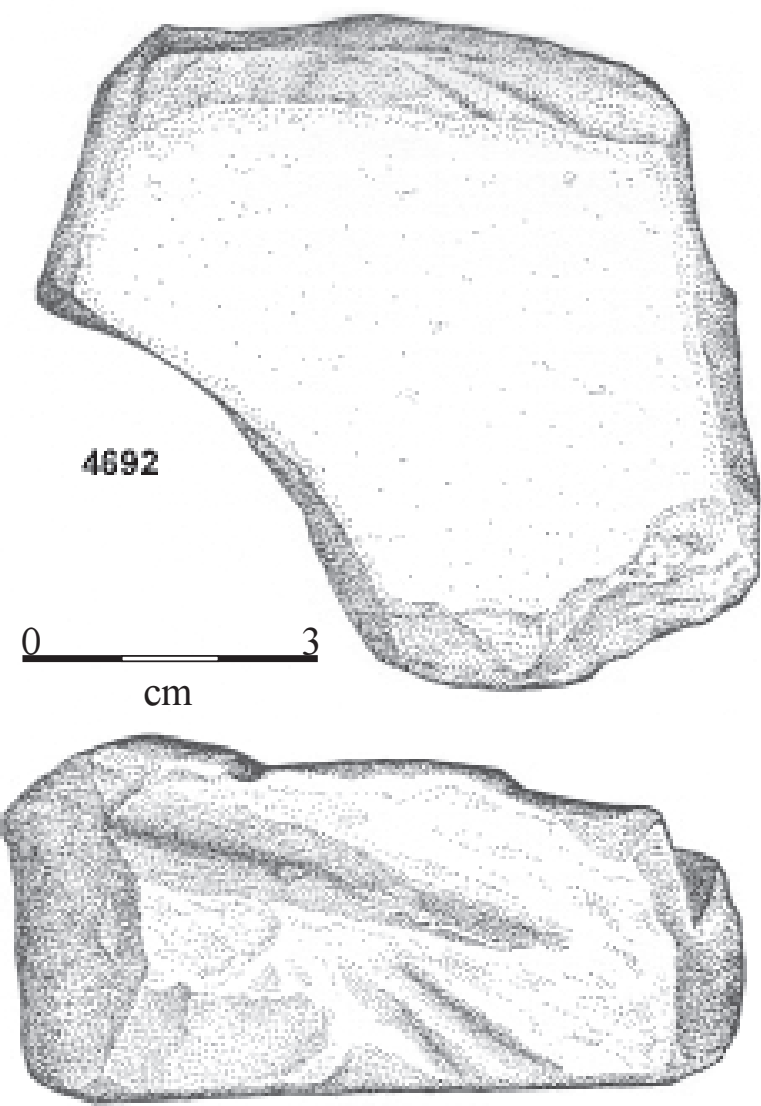

Figure 10.13 Sandstone Abrader \#4692 from Occupation 4.

It exits one edge, becomes shallower and narrower towards the middle, and does not extend to the other end of the rock. The two poorly defined grooves are 23.5 and $13.1 \mathrm{~mm}$ long with shallow "U" to "V" shaped grooves. Since this sandstone abrader is made from a broken piece of metate, it is not clear if the double-sided metate was used at the Lino site before a piece was fashioned into an abrading tool.

\subsection{BURNED ROCKS}

The burned rocks scattered throughout Occupation 5 and outside the four burned rock features are discussed here. The $60 \mathrm{~m}^{2}$ investigated through hand excavations yielded 898 burned rocks that weighed 89,172 g (Table 10.2). Sandstone accounted for 77 percent 
followed by 11 percent other, and nine percent chert. The material type frequencies are similar for the previous occupations with slightly less sandstone. Seventy-one percent were fewer than $4 \mathrm{~cm}$ in diameter, 25 percent measured between 4 and $9 \mathrm{~cm}$, and four percent were greater than 9 $\mathrm{cm}$ in diameter. The proportions of these size classes are quite similar to the burned rock sizes found in previous occupations. The average weight of the scattered burned rocks was $99 \mathrm{~g}$ (Table 10.2), which is nearly twice the average weight of those found scattered in Occupation 4. About 60 percent were angular pieces, 29 percent had rounded edges, and 12 percent were tabular pieces. Similar frequencies of shapes were observed in previous levels. Cracks appeared present in less than eight percent of the burned rocks.

The four burned rock features yielded 367 pieces that weighed 46,002 $\mathrm{g}$ (Table 10.2). The feature rocks average about $125 \mathrm{~g} /$ rock and were about $26 \mathrm{~g}$ heavier than the scattered burned rocks. The larger average rock weight reflects the more numerous rocks in the 4 to $9 \mathrm{~cm}$ (47 percent) and greater than $9 \mathrm{~cm}$ (13 percent) size classes, which account for nearly 60 percent of the total rock from the features. This compares to only 29 percent for these same two size classes in the scattered rocks.

Burned rocks from four discard features and the scattered burned rocks across the handexcavated area in Occupation 5 total 1,258 pieces and weigh 135,173 g (Table 10.2). This reveals an average of about 22 rocks $/ \mathrm{m}^{2}$ of hand excavated units. The average weight for all burned rocks from Occupation 5 was $107 \mathrm{~g}$.

\subsection{RABDOTUS SHELLS}

Four snail shells from Unit A5 (between 110 and $120 \mathrm{cmbs}$ ) were selected for A/I ratio analysis. These Rabdotus shells yielded A/I ratios of $0.105,0.113,0.115$, and 0.172 (CF-208 through
211, Appendix F). The three smaller ratios form part of a cluster of ratios obtained from 16 Rabdotus shells from four proveniences that seem to be younger in age. The largest $\mathrm{A} / \mathrm{I}$ ratio is the extreme value for a second and older cluster of ratios. One shell from Unit D1 (between 20 and $30 \mathrm{cmbs}$ ) with a ratio of 0.106 , which is part of the younger cluster of ratios, was selected for AMS dating. It yielded a $\delta^{13} \mathrm{C}$ (2.3\%o) adjusted date of $2040 \pm 50$ (Beta122719). The age appears to correspond to the ages of three charcoal dates that average about 2050 B.P. from three features in Occupation 1 between 20 and $40 \mathrm{cmbs}$. The derived AMS date of 2040 B.P. is accepted as reliable for the shell ratio of 0.106 and its cluster of comparable $\mathrm{A} / \mathrm{I}$ ratios. However, it seems that bioturbation processes have moved this and at least three other shells from the Occupation 1 to ca. 110 cmbs.

\subsection{MUSSEL SHELLS}

Fourteen mussel shell fragments were assigned to Occupation 5. The valve pieces varied from 10 percent to 60 percent complete. Four fragments were identified as Cyrtonaias sp. and Lampsilis teres. The other pieces were too small for positive identification. Since one tiny fragment has a gray color and is very brittle, it may have been burned. Other intentional modifications by humans were not observed. This low frequency is about 41 percent of that found in Occupation 4. The sampling biases or different emphases on resource exploitations may account for the numerical differences in the assemblage.

\subsection{CHARCOAL}

Wood charcoal chunks ( $\mathrm{n}=27$ weighing roughly $357 \mathrm{~g}$ ) were scattered across the occupation, with another $12.6 \mathrm{~g}$ recovered from four burned rock features. Feature 30 yielded about $10.5 \mathrm{~g}$ of charcoal, and two chunks (\#3080a and 3613-3a) 
were identified as mesquite (Appendix B). One charcoal sample (\#5295-6a) from Feature 40 yielded indeterminate flecks. A sample (3578$5 a)$ from Feature 24 was an indeterminate kind of monocot wood (Appendix B). Charcoal from a column float sample in Unit A5 was identified as huisache (Appendix B). Another 10 wood charcoal chunks were identified as mesquite (Appendix B). At least three different species were used as fuel in the four features. It is not clear if the very small quantities of charcoal in the burned rock features reflect a direct association (trapped among the rocks prior to being buried) or displaced to these locations through turbation.

\subsection{HORIZONTAL DISTRIBUTION}

Occupation 5 yielded 2,700 pieces of cultural material non-randomly distributed across the 60 $\mathrm{m}^{2}$ hand-excavated block. The debris included moderate to high frequencies of burned rocks $\left(21 / \mathrm{m}^{2}\right)$ scattered outside the four identified features, moderate to high frequencies of lithic debitage $\left(22 / \mathrm{m}^{2}\right)$, sparse stone tool frequency $\left(0.9 / \mathrm{m}^{2}\right)$, and a number cultural features $(0.1 /$ $\mathrm{m}^{2}$ ). The western five balks and the GradallTM stripped areas west of Area F yielded cultural evidence for a continuous horizontal occupation that contained considerable cultural debris (Figure 10.14). East of Balk $E$ the occupation appeared to pinch out as it vertically rose and may have become mixed with materials from Occupation 4 near Balk E. Since the occupation area did not appear in the $12 \mathrm{~m}^{2}$ across the eastern end of the excavation block, the densities were recalculated. The $48 \mathrm{~m}^{2}$ of productive area yielded an average high frequency of $27 / \mathrm{m}^{2}$ pieces of lithic debitage. The burned rock yielded an average high density of $28 / \mathrm{m}^{2}$, but the features were sparse $\left(1.1 / \mathrm{m}^{2}\right)$. The productive occupation area yielded an overall very high density of $56 / \mathrm{m}^{2}$. Occupation 5 continued beyond the excavation block towards the north, west, and south. The natural silty loam deposits and occupational materials dip westward and slightly to the north.

The 1,330 pieces of lithic debitage appear to be non-randomly distributed across the western two-thirds of the excavated block (Figure 10.14). About 10 hand excavated units yielded very high frequencies of debitage (between 40 and 144 pieces). Eleven units contained high concentrations and were in the central part of the excavation block. The 24 units that yielded moderate densities mostly surrounded the highdensity units, with another 10 moderate-debris density units occurring toward the western end. The central area of the excavation block appeared to be the primary lithic activity area, which may be a discard area because of the general association of chipped stone debris with moderate frequencies of burned rocks. Three of the four burned rock discard features (Features 24, 29, and 40) appeared to be associated with the high frequencies of lithic debris. The third (Feature 30) had moderate frequencies of lithic debitage around it. The clustered burned rocks tend to confirm that these areas were general discard areas that included lithic debitage. Consequently, most lithic debris was probably discarded and was not found in the primary knapping areas. If this interpretation is correct, then the majority of the hand-excavated areas represent refuse-discard areas.

The concentrated burned rocks were associated with four clusters designated as Features 24, 29 , 30 , and 40 . Scattered burned rocks also occurred outside the four features and in three units with very high frequencies. The three high frequency units were located adjacent to Features 24 and 40 and were surrounded by moderate frequencies of burned rocks, which were much more prevalent $(n=33)$ with a much broader distribution (Figure 10.14). It appears that originally the four burned rock features may have been larger and denser, but prior to their burial and entry into the archaeological record, the piles 

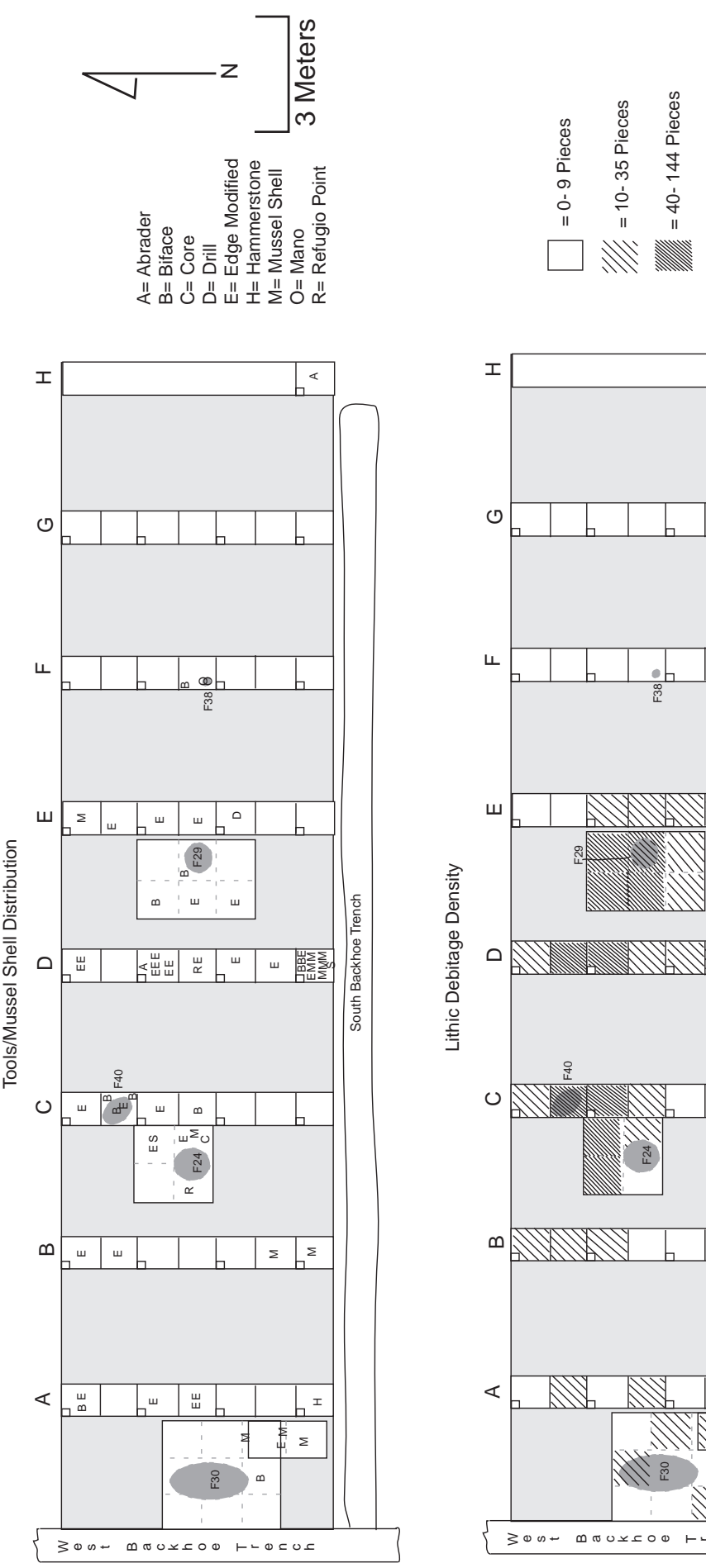
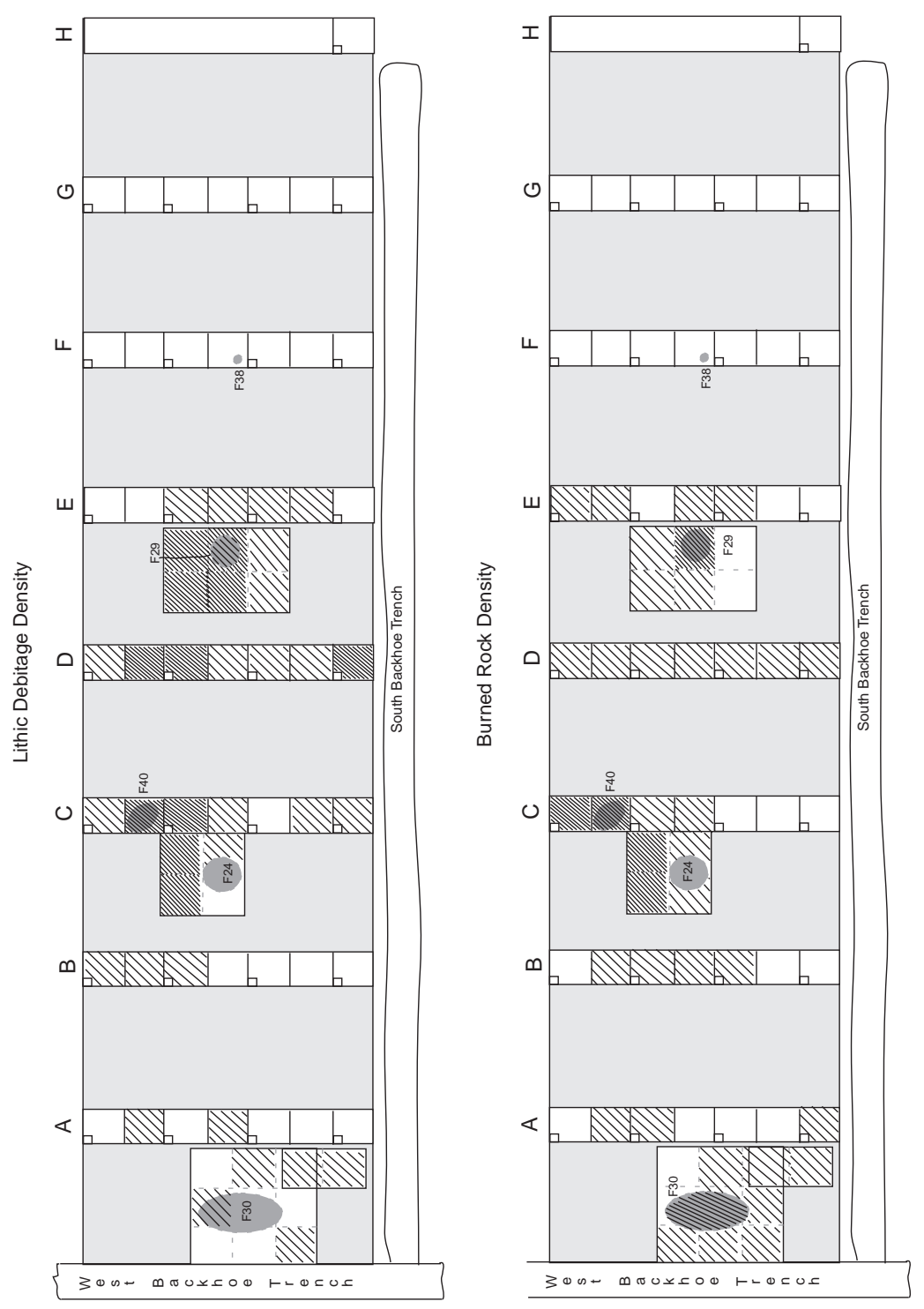

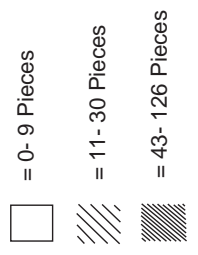

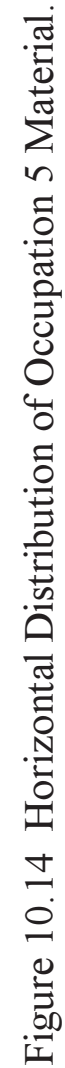


became scattered and more dispersed. In general, less than 30 percent of the productive units yielded low frequencies of burned rock, implying a wide and relatively moderate occurrence of burned rock over most of the investigated occupation area.

The two manos (\#4725 and \#4726) that formed Feature 38 were in Unit F4, east of the dense occupational materials. The two manos were associated with very sparse lithic debitage and sparse burned rock. One distal biface fragment (\#5580-3) was less than $1 \mathrm{~m}$ north. This association may indicate a specific activity where these manos were employed or that they may have been "cached" at the margin of the occupation.

All four burned rock discard features had at least one biface within $1 \mathrm{~m}$ of its margin (Figure 10.14). These bifacial tools may have been discarded or not have been part of any in situ activities. The general discard interpretation is very apparent at Feature 40, where three bifaces (\#4817, \#5295-7, and \#5295-11) were found among the densely clustered burned rocks. The bifaces and burned rocks had different functions but ended up clustered together through a process of refuse discard activity, probably as a result of cleaning up a primary activity area.

The 14 mussel shell valves appeared to be somewhat clustered in two principal areas - one at the southern end of Gradall ${ }^{\mathrm{TM}}$ Area A and the other at southern end of Balk D (Figure 10.14). Only the few fragmented shells at the southern end of Gradall ${ }^{\mathrm{TM}}$ Area A were near burned rocks dump Feature 30. The other shell concentration was associated with moderate frequencies of burned rocks and a high frequency of lithic debitage. The numerous valves clustered in Unit D7 were also associated with two bifaces (\#4541 and 5454-6) and six edge-modified flakes. The clustering of multiple tool types, numerous mussel shell fragments, dense lithic debitage, and moderate quantities of scattered burned rock supports the interpretation that area functioned as a dump or discard area.

The two Refugio points (\#4683 and \#2244) were among high concentrations of diverse debris, one in D4 and the other in Gradall ${ }^{\mathrm{TM}}$ Area C, Unit 24-1 (Figure 10.14). The drill (\#5511-6) was southeast of burned rock Feature 29 and not associated with any other tools, although an edge-modified flake was found within $1 \mathrm{~m}$ to the north. The hammerstone (\#5059) was some 2 to $3 \mathrm{~m}$ southeast of Feature 30 and relatively near some fragmented mussel shell valves. The same unit also contained limited amounts of lithic debitage and moderate frequencies of burned rocks. It does not appear that the hammerstone was recovered from a primary knapping area. The 33 edge-modified flakes were scattered about with higher frequencies occurring in those areas that also contained higher frequencies of lithic debitage. Three units (D3, D7, and A4) contained two or more edgemodified flakes, and all three units also yielded numerous pieces of lithic debitage and moderate frequencies of burned rocks. Unit D3, with five edge modified flakes, also yielded one abrading tool (\#4692). With high frequencies of lithic debris and moderate burned rocks in the same unit, this may have been a refuse discard area and not a primary activity area. The other clusters of edge modified flakes were also probably discard areas.

Some $60 \mathrm{~m}^{2}$ were hand excavated within this block, but cultural debris associated to Occupation 5 only came from the western 48 $\mathrm{m}^{2}$ (Figure 10.14). The four burned rock concentrations and the clustered lithic debris documented over that $48 \mathrm{~m}^{2}$ indicates that most of the area was used for discarding material. Without primary-hearth or other in situ activity areas identified, it is not known which direction and how far refuse was moved or even if any multiple discard areas existed. Intact activity 
areas are difficult to distinguish using this type of excavation, and no specific areas were discerned from the discontinuous excavation block.

Figures 10.15 and 10.16 show all the TDSplotted materials, which represent only about 10 percent of what was recovered from all of Occupation 5. The TDS data reflects the general overall horizontal distribution documented and reveals some areas of high and low density.

\subsection{SUMMARY AND INTERPRETATIONS}

Occupation 5 consisted of a broad horizontal distribution of 2,700 pieces of material concentrated within $48 \mathrm{~m}^{2}$ of the western twothirds of the block. The occupation pinched out east of Balk E. The 10 to $15 \mathrm{~cm}$ thick occupation zone dipped to the west with material on the eastern side occurring between 90 and $100 \mathrm{cmbs}$ and on the western end occurring between 110 to $120 \mathrm{cmbs}$. Turbation and root activities have vertically dispersed some materials from their original context. Cultural materials were concentrated and best defined near the middle of the excavation block near the areas of Balks $\mathrm{C}$ and $\mathrm{D}$. The distribution of occupation debris continued beyond the excavation block limits towards the west, south, and north.

Occupation 5 comprised four burned rock dump features, two carefully placed manos (Feature 38), 1,301 scattered burned rocks, 1,330 pieces of lithic debitage, 55 chipped stone tools, one sandstone abrader, 14 mussel shells, and scattered Rabdotus shells. Bone was present in very limited numbers, but since all of it is thought to have come from rodent holes it is not associated with the prehistoric cultural materials.

The chronometric age of Occupation 5 is based primarily on three wood charcoal dates from this occupation zone. One wood charcoal piece from
Feature 29 (\#3604-4a), one from Unit A5 (110$120 \mathrm{cmbs}$ ) (\#5167-4a), and one from Unit D7 (100-110 cmbs) (\#5455-4a) yielded $\delta^{13} \mathrm{C}$ adjusted ages of 3460, 3060, and 900 B.P., respectively. The latter date is obviously too young for this occupation and reflects of charcoal chunk that was displaced by turbation. The two accepted wood charcoal dates average about 3260 B.P. and thus provide an approximate age of Occupation 5. Organic residues extracted from the interior matrix of burned rock \#3605-5 from Feature 29 yielded a $\delta^{13} \mathrm{C}$ adjusted age of $4920 \pm 50$ B.P. This age is too early in comparison to the two wood charcoal dates and is not accepted. These burned rock residues may have remained inside a burned rock that was reused from a previous occupation episode.

Occupation 5 included four burned rock clusters (Features 24, 29, 30 and 40) that encompassed 338 burned rocks weighing 44,891 g (125 g/ rock) and showed a somewhat larger average size than did the 898 scattered burned rocks outside the features that weighed 89,172 g (99 $\mathrm{g} /$ rock). This size reduction apparently resulted from cobble re-use in thermal features, but the primary hearth/boiling structure/oven apparatus was not detected in the excavation block. An above ground boiling apparatus would be the least likely to be preserved and the most difficult to detect.

The $39 \mathrm{~m}^{2}$ area in the hand-excavated balks and the $21 \mathrm{~m}^{2}$ hand-excavated units around four identified features discovered during the Gradall $^{\mathrm{TM}}$ stripping reveal an overall high density of artifacts $\left(56 / \mathrm{m}^{2}\right)$. The 2,700 cultural items represent general camping debris from a short-term hunter-gatherer campsite. The lack of microscopic use-wear identification on 14 analyzed stone tools supports the short-term duration of tool use-life. The overall lithic debitage and stone tool assemblage along with the presence of at least four burned rock dump features and quantities of scattered burned rocks 


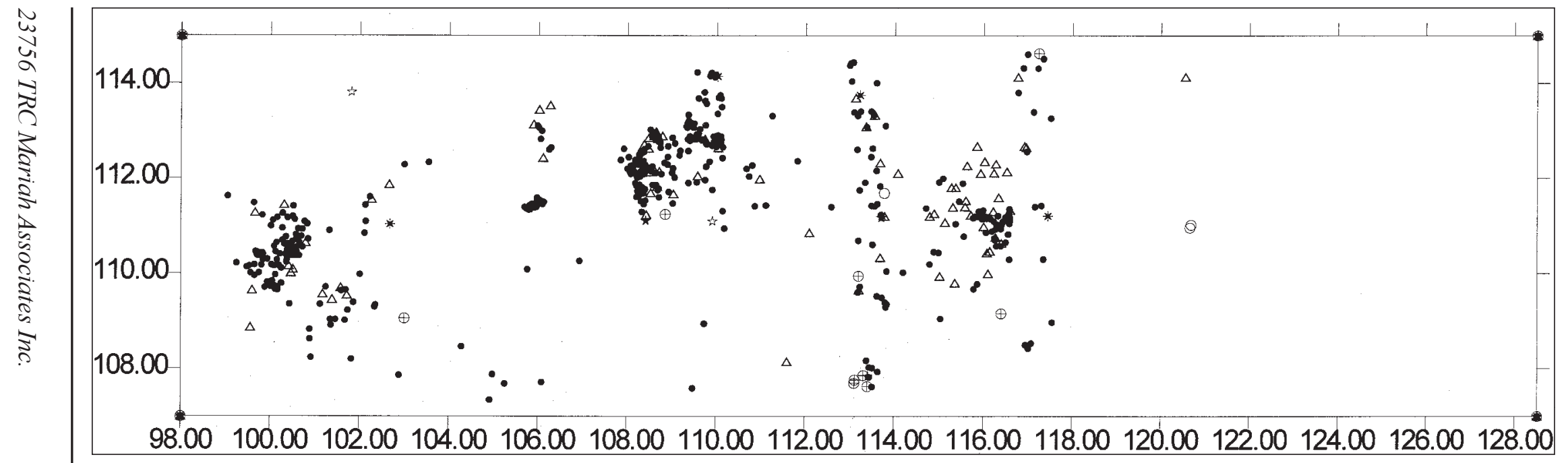

$\boldsymbol{0}$ = burned rock $\bigoplus=$ mussel shell $\triangle=$ lithic debitage $\quad \hat{\tau}=$ points $\mathrm{O}=$ ground stone tool $*=$ tools Figure 10.15 All TDS Shot In Material for Occupation 5.

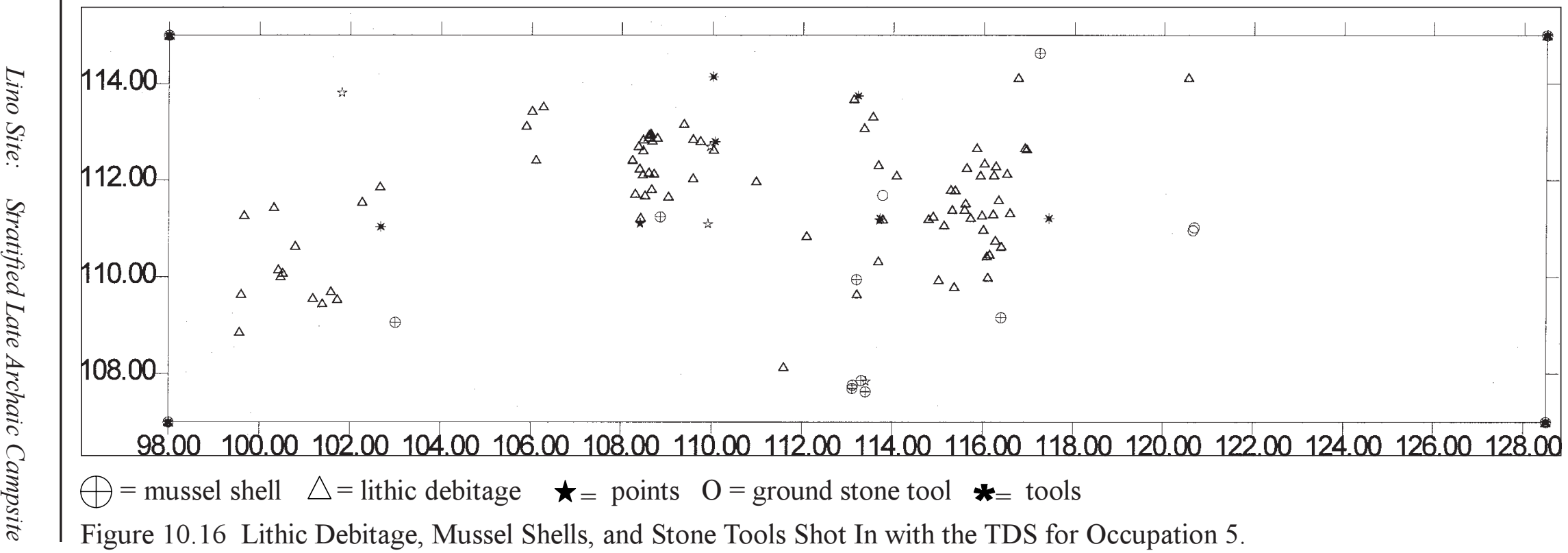


indicate that tool production, cooking tasks, and dumping were principal activities represented in the occupation.

The chemical analyses of residues from eight burned rocks indicate that they were used to process primarily plant resources that included at least Texas ebony seeds, some unknown seeds, and some large herbivore. Some stable nitrogen isotope data from the rock residues support the presence of legumes or nuts as part of the processed resources. The stable carbon isotope data indicates that the large herbivore was probably deer/antelope. The two Refugio projectile points, 11 bifaces, one drill, and one scraper also support the killing, butchering, and hide preparation of large herbivores. The pair of manos may be linked with pounding/grinding of various plant resources. The sandstone abrader may be indirectly linked to the acquisition of food resources or the production of perishable tools. Thus, the overall cultural assemblage reflects a relatively mobile huntergatherer lifeway. 


\subsection{OCCUPATION 6}

This occupation was horizontally restricted and consisted of limited cultural remains between about 110 and $120 \mathrm{cmbs}$. It was best defined in Balks D and E and Gradall ${ }^{\mathrm{TM}}$ Area E. The occupation appears to extend deeper than our excavations west of Gradall ${ }^{\mathrm{TM}}$ Area B and pinch out east of Gradall ${ }^{\mathrm{TM}}$ Area F. Our hand excavations stopped at $120 \mathrm{cmbs}$, but the cultural material continued to go deeper. It is unclear if the sparse and horizontally restricted materials represent a separate occupation, or displaced materials from Occupation 5, or an occupation below $120 \mathrm{cmbs}$. The relatively low frequency, limited diversification and horizontal patterning, and lack of excavations below $120 \mathrm{cmbs}$ all hindered clear interpretations of this zone.

This cultural zone yielded scattered burned rocks, sparse lithic debitage, few chipped stone tools, minimal mussel shells, a few Rabdotus shells, and no recognized features. Cultural bone was absent and is believed to have been destroyed over time. The chronometric age of Occupation 6 is based on a combination of wood charcoal dates from Occupation 5 and 6. One wood charcoal chunk (\#5478-4a) from E2 (110$120 \mathrm{cmbs}$ ) in Occupation 6 yielded a $\delta^{13} \mathrm{C}$ adjusted date of $2740 \pm 50$ B.P. (Beta-121863). Three wood charcoal dates from Occupation 5 , two of which are accepted, yielded an average age of 3260 B.P. (Table 5.3). The younger charcoal date of 2740 B.P. is too young for Occupation 6 and is not accepted. This small charcoal piece must have filtered down through the profile or been disturbed through turbation. The average age of Occupation 6 is estimated to be about 3400 B.P, a few hundred years older than Occupation 5.

The cultural materials recovered from the $26 \mathrm{~m}^{2}$ hand excavated balks that encompassed this occupation are presented by material class below.
This is followed by a discussion of the horizontal distribution of the occupational materials. A summary and interpretation is presented in the end.

\subsection{CHIPPED LITHIC ASSEMBLAGE}

The lithic assemblage from the hand excavated balks $\left(26 \mathrm{~m}^{2}\right)$ yielded 279 pieces of unmodified chipped stone debitage. Overall, this occupation yielded a low frequency of 11 pieces of lithic debitage per square meter. The raw material consisted of good to high quality chert that could have been procured from local gravel sources. Color differences exist and in very general terms are dominated by tan, gray, and brown hues.

The lithic debitage was classified into six recognizable types (Table 11.1). Most frequent were core flakes (51 percent), followed by indeterminate flakes (26 percent), early stage biface flakes (14 percent), and late stage biface flakes (nine percent). Angular debris was minimally represented by one piece, whereas no uniface flakes were recognized. These flaketype frequencies reflect a dominance of core reduction with limited early stage biface manipulation. Late stage biface production occurred but at a relatively low level compared to previous occupations. The absence of uniface flakes indicates the lack of manufacturing or resharpening of unifacial tools such as scrapers and gouges.

Medial (35 percent) and proximal (30 percent) flake fragments are well represented with fewer complete (19 percent) and distal (16 percent) flake fragments (Table 11.1). Distal fragments appear underrepresented compared to medial sections. The near absence of angular debris may indicate that our $6.4 \mathrm{~mm}$ screen size was too large to capture this material. Core 
Table 11.1 Occupation 6 Lithic Debitage Analysis.

\begin{tabular}{|c|c|c|c|c|c|c|}
\hline \multirow[b]{3}{*}{ Condition } & \multicolumn{5}{|c|}{ Flake Type } & \multirow[b]{3}{*}{ Total } \\
\hline & angular & & early & & late & \\
\hline & debris & core & biface & indet. & biface & \\
\hline \multirow[t]{2}{*}{ complete } & - & 35 & 5 & 10 & 3 & 53 \\
\hline & $0 \%$ & $25 \%$ & $13 \%$ & $14 \%$ & $13 \%$ & $19 \%$ \\
\hline \multirow[t]{2}{*}{ distal } & - & 13 & 12 & 10 & 10 & 45 \\
\hline & $0 \%$ & $9 \%$ & $30 \%$ & $14 \%$ & $42 \%$ & $16 \%$ \\
\hline \multirow[t]{2}{*}{ fragment } & 1 & - & - & - & - & 1 \\
\hline & $100 \%$ & $0 \%$ & $0 \%$ & $0 \%$ & $0 \%$ & $0 \%$ \\
\hline \multirow[t]{2}{*}{ medial } & - & 31 & 8 & 53 & 5 & 97 \\
\hline & $0 \%$ & $22 \%$ & $20 \%$ & $73 \%$ & $21 \%$ & $35 \%$ \\
\hline \multirow[t]{2}{*}{ proximal } & - & 62 & 15 & - & 6 & 83 \\
\hline & $0 \%$ & $44 \%$ & $38 \%$ & $0 \%$ & $25 \%$ & $30 \%$ \\
\hline \multirow[t]{2}{*}{ Total } & 1 & 141 & 40 & 73 & 24 & 279 \\
\hline & 0\% & $51 \%$ & $14 \%$ & $26 \%$ & $9 \%$ & $100 \%$ \\
\hline \multirow{4}{*}{$\begin{array}{c}\text { Cortex } \\
\text { primary }\end{array}$} & \multicolumn{5}{|c|}{ Flake Type } & \\
\hline & $\begin{array}{c}\text { angular } \\
\text { debris }\end{array}$ & core & $\begin{array}{c}\text { early } \\
\text { biface }\end{array}$ & indet. & $\begin{array}{c}\text { late } \\
\text { biface }\end{array}$ & Total \\
\hline & - & 9 & - & - & - & 9 \\
\hline & $0 \%$ & $6 \%$ & $0 \%$ & $0 \%$ & $0 \%$ & $3 \%$ \\
\hline \multirow[t]{2}{*}{ secondary } & - & 58 & - & 7 & - & 65 \\
\hline & $0 \%$ & $41 \%$ & $0 \%$ & $10 \%$ & $0 \%$ & $23 \%$ \\
\hline \multirow{2}{*}{ tertiary } & 1 & 74 & 40 & 66 & 24 & 205 \\
\hline & $100 \%$ & $52 \%$ & $100 \%$ & $90 \%$ & $100 \%$ & $73 \%$ \\
\hline \multirow[t]{4}{*}{ Total } & 1 & 141 & 40 & 73 & 24 & 279 \\
\hline & $0 \%$ & $51 \%$ & $14 \%$ & $26 \%$ & $9 \%$ & $100 \%$ \\
\hline & \multicolumn{5}{|c|}{ Flake Type } & \\
\hline & angular & & early & & late & \\
\hline Heating & debris & core & biface & indet. & biface & Total \\
\hline \multirow[t]{2}{*}{ crazed } & - & 2 & - & - & - & 2 \\
\hline & $0 \%$ & $1 \%$ & $0 \%$ & $0 \%$ & $0 \%$ & $1 \%$ \\
\hline \multirow[t]{2}{*}{ indet. } & - & & - & - & 1 & 1 \\
\hline & $0 \%$ & $0 \%$ & $0 \%$ & $0 \%$ & $4 \%$ & $0 \%$ \\
\hline \multirow[t]{2}{*}{ none } & 1 & 136 & 40 & 69 & 23 & 269 \\
\hline & $100 \%$ & $96 \%$ & $100 \%$ & $95 \%$ & $96 \%$ & $96 \%$ \\
\hline \multirow[t]{2}{*}{ spall } & - & 3 & - & 4 & - & 7 \\
\hline & $0 \%$ & $2 \%$ & $0 \%$ & $5 \%$ & $0 \%$ & $3 \%$ \\
\hline \multirow[t]{2}{*}{ Total } & 1 & 141 & 40 & 73 & 24 & 279 \\
\hline & $0 \%$ & $51 \%$ & $14 \%$ & $26 \%$ & $9 \%$ & $100 \%$ \\
\hline
\end{tabular}

manipulation was prominent with relatively minor biface reduction. The thickness of the core flakes may reflect the high percentage of their completeness.

Cortex remains on about 26 percent of the debitage. Nearly 47 percent of the core flakes exhibited some cortex with limited amounts on the indeterminate pieces (Table 11.1). The apparent progression of cobble decortification to bifacial forms is similar to previous occupations.

Heat altered (crazed and spalled) pieces account for 3.2 percent, with heat spalls representing about two-thirds of the total (Table 11.1). The various heat-altered pieces probably resulted from direct exposure to fires and are thought to reflect where waste material was discarded. These types of heat alterations are not generally associated with the heat treating of chert to improve its workability. Heat-treating the chert apparently was not practiced, which is constant with the occupations above.

\subsection{CHIPPED STONE TOOLS}

The recognized chipped-stone tool assemblage was classified into three form/functional classes and consist of one tiny projectile point fragment, one biface fragment, and six edge-modified flakes (Tables 11.2 and 11.3). As a group, these eight tools account for 1.6 percent of the total cultural material recovered from the $26 \mathrm{~m}^{2}$ hand excavated areas in Occupation 6.

All tools were manufactured from chert. The less than $1 \mathrm{~cm}$ long distal point fragment (\#5386$5)$ was unidentifiable as to type. However, the thickness indicates it more closely resembles a Tortugas tip rather than the thinner Refugio point tip. Since the fragment is so small, it could have easily been displaced from its original context and thus not be directly associated with the other materials. The proximal biface (\#4919) is of mottled gray chert in the middle to late stage of manufacturing. Its lanceolate outline is similar to the Refugio point outlines. The break appears to be from an internal crack or a manufacture break. It appears as an unfinished specimen. High-powered microwear analysis on this proximal segment revealed no traces of use-wear (Appendix C). 
Table 11.2 Point and Biface Tool Attributes from Occupation 6

\begin{tabular}{|c|c|c|c|c|c|c|c|c|c|c|c|c|c|c|c|c|c|c|c|c|c|c|}
\hline \multirow[b]{2}{*}{ Cat. \# } & \multirow[b]{2}{*}{ Unit } & \multirow[b]{2}{*}{$\mathrm{F} \#$} & \multirow[b]{2}{*}{ Lvl } & \multirow[b]{2}{*}{ Depth } & \multirow[b]{2}{*}{$\mathrm{N}$} & \multirow[b]{2}{*}{$E$} & \multirow[b]{2}{*}{ Elev } & \multirow[b]{2}{*}{ Pt/Tool } & \multirow[b]{2}{*}{ Brk } & \multirow[b]{2}{*}{ Con. } & \multirow[b]{2}{*}{ Sh } & \multirow[b]{2}{*}{ Stg } & \multicolumn{3}{|c|}{ Color } & \multirow[b]{2}{*}{$\begin{array}{l}\text { Bas } \\
\text { Edg }\end{array}$} & \multirow{2}{*}{$\begin{array}{l}\text { Bas } \\
\text { Thin }\end{array}$} & \multirow[b]{2}{*}{$\mathrm{Bvl}$} & \multicolumn{3}{|c|}{ Size (mm) } & \multirow[b]{2}{*}{ Wt (g) } \\
\hline & & & & & & & & & & & & & Mat'l & SW & LW & & & & $\mathrm{L}$ & W & Th & \\
\hline $5386-5$ & D1 & & 12 & $110-120$ & & & & Uk & Uk & D & $\mathrm{T}$ & & & & & Uk & Uk & Uk & & & & 0.2 \\
\hline 4919 & B2 & & 12 & $110-120$ & 113.108 & 105.686 & 98.666 & B & M & $\mathrm{P}$ & $\mathrm{L}$ & $\mathrm{L}$ & & Yw/Or & Yw/Or & & & & & 23.0 & 10.5 & 7.9 \\
\hline
\end{tabular}

All materials chert unless noted

Point/Tool Type: $B=b i f a c e, D=d r i l l, T=T o r t u g a s, ~ U k=U n k n o w n, M=$ Matamoros

Break (Brk): M=manufacture, Us=use, Uk=unknown

Condition (Con.): $C=$ complete, $P=$ proximal, $M=$ medial, $D=$ distal

Shape (Sh), Basal Edge (Bas Edge), \& Basal Thinning (Bas Thin): P=Parallel, Sn=sinuous, St=straight, Cc=concave, $C x=$ convex, L=anceolate, $O=0$ val, $R=$ rectangular, $T=t$ triangular, l=irregular Ot=othe

Manufacture Stage (Stg): L=late, M=middle

Color: Or=orange, $Y w=y e l l o w$, Prp=purple, Spk=speckled, Br=brown, Gry=Gray

Beveling (Bvl): $\mathrm{N}=$ none

Note: All catalogue numbers from hand excavated proveniences have been formed by adding a dash and appear in the database with leading zeros. These leading zeros have been omitted to conserve space.

Table 11.3 Scraper and Edge Modified Tool Attributes from Occupation 6.

\begin{tabular}{|c|c|c|c|c|c|c|c|c|c|c|c|c|c|c|c|c|c|c|c|c|c|c|c|c|}
\hline \multirow[b]{2}{*}{ Cat. \# } & \multirow[b]{2}{*}{ Unit } & \multirow[b]{2}{*}{$\mathrm{F} \#$} & \multirow[b]{2}{*}{ Lvl } & \multirow[b]{2}{*}{ Depth } & \multirow[b]{2}{*}{ Tool } & \multirow[b]{2}{*}{ Con. } & \multirow[b]{2}{*}{ Sh } & \multirow{2}{*}{$\begin{array}{c}\text { \# of } \\
\text { edg/ } \\
\text { mods }\end{array}$} & \multicolumn{4}{|c|}{ Edge/Bit 1} & \multicolumn{4}{|c|}{ Edge/Bit 2} & \multicolumn{4}{|c|}{ Edge/Bit 3} & \multicolumn{3}{|c|}{ Size $(\mathrm{mm})$} & \multirow[b]{2}{*}{ Wt (g) } \\
\hline & & & & & & & & & Sh & Ang & $\begin{array}{c}\text { Sc } \\
\text { Ang }\end{array}$ & $\begin{array}{l}\text { Sc } \\
\text { ptn }\end{array}$ & Sh & Ang & $\begin{array}{c}\text { Sc } \\
\text { Ang }\end{array}$ & $\begin{array}{l}\text { Sc } \\
\text { ptn }\end{array}$ & Sh & Ang & $\begin{array}{c}\text { Sc } \\
\text { Ang }\end{array}$ & $\begin{array}{l}\text { Sc } \\
\text { ptn }\end{array}$ & L & W & Th & \\
\hline $5535-4$ & E7 & & 12 & $110-120$ & EM & D & $\mathrm{T}$ & 1 & Sn & 24 & 53 & well & & & & & & & & & & & 6.47 & 6.8 \\
\hline $5478-8$ & E2 & & 12 & $110-120$ & EM & M & S & 1 & Cv & 22 & 51 & well & & & & & & & & & & & 4.98 & 20.1 \\
\hline $5478-7$ & E2 & & 12 & $110-120$ & EM & C & $S$ & 1 & $\mathrm{Cc}$ & 37 & 61 & well & & & & & & & & & 45.28 & 31 & 12.86 & 14.9 \\
\hline $5478-6$ & E2 & & 12 & $110-120$ & EM & P & S & 1 & Cc & 61 & 79 & well & & & & & & & & & & & 12.37 & 30.6 \\
\hline
\end{tabular}

Tool Type: $E M=$ edge-modified, ES = end scraper. All materials chert except as noted Condition (Con.): $\mathrm{C}=$ complete, $\mathrm{P}=$ proximal, $\mathrm{M}=$ medial, $\mathrm{D}=$ Distal

Shape (Sh): $\mathrm{Sn}=$ sinuous, $\mathrm{St}=$ straight, $\mathrm{C}=$ =concave, $\mathrm{Cx}=$ convex, $\mathrm{O}=$ oval, l=irregular
Cortex (Cort.): $\mathrm{P}=$ primary, $\mathrm{S}=$ secondary, $\mathrm{T}=$ tertiary

Edge Angle (Ang)

Scar Pattern (Sc ptn)

Note: All catalogue numbers from hand excavated proveniences have been formed by adding a dash and appear in the database with leading zeros. These leading zeros have been omitted to conserve space. 
The six edge-modified chert flakes were evenly divided between secondary and tertiary pieces. Two were complete, two were medial, one was distal, and one was a proximal fragment. All displayed well-patterned flake scars along various lateral edges. The modified edges varied from straight to convex to concave, with one sinuous edge. The scar angles vary from 45 to 79 degrees. These angles plus the well-patterned nature of the tiny scars indicate that these were primarily used in scraping activities. Specimen \#5512-4 had three well-worked edges that encompassed both lateral edges and the distal end, in a continuous modification (Figure 11.1). High-powered microwear on three edgemodified flakes (\#5478-6, \#5478-7, and \#55124) failed to reveal any sign of microscopic usewear (Appendix C).

\subsection{GROUND STONE TOOLS}

No ground stone implements were recovered from this occupation zone.

\subsection{BURNED ROCKS}

The burned rocks scattered throughout this occupation are outside any defined features. The $26 \mathrm{~m}^{2}$ investigated through hand excavations yielded 215 burned rocks that weighed 11,894 g (Table 11.4). Sandstone accounted for 55 percent of the raw material, followed by 28 percent chert and 17 percent other types. This is the highest frequency of chert and other material types in comparison to the five previous occupations, which substantially reduced the frequency of sandstone. Fifty-seven percent exhibited angular edges, 32 percent had rounded edges, and 11 percent were tabular in form. Seventy-seven percent were fewer than $4 \mathrm{~cm}$ in diameter, 19 percent were between 4 and $9 \mathrm{~cm}$,

Table 11.4 Occupation 6 Burned Rock Data.

\begin{tabular}{|c|c|c|c|c|c|c|c|c|c|c|c|c|c|c|c|c|c|}
\hline \multicolumn{18}{|c|}{ Non Feature Contexts } \\
\hline \multirow[b]{2}{*}{ Unit } & \multirow[b]{2}{*}{ Level } & \multirow[b]{2}{*}{ Fea No } & \multicolumn{4}{|c|}{ Size $(\mathbf{c m})$} & \multicolumn{4}{|c|}{ Material Type* } & \multicolumn{3}{|c|}{ Fracture Type** } & \multicolumn{2}{|c|}{ Cracks } & \multirow[b]{2}{*}{ Total } & \multirow[b]{2}{*}{$W t(g)$} \\
\hline & & & $0-4$ & 4-9 & $9-15$ & $>15$ & $\mathrm{CC}$ & $\mathbf{C h}$ & $\mathbf{O}$ & SS & Ang. & Rnd. & Tab. & $\mathbf{Y}$ & $\mathbf{N}$ & & \\
\hline \multicolumn{18}{|c|}{$31-1,31-3$} \\
\hline \& 31-4 & & $31 * * *$ & 0 & 3 & 1 & 1 & 0 & 0 & 0 & 5 & 1 & 1 & 3 & 2 & 3 & 5 & $1,912.9$ \\
\hline B1 & 12 & & 5 & & & & & & 1 & 4 & 2 & 2 & 1 & 2 & 3 & 5 & 94.7 \\
\hline B2 & 12 & & 56 & 11 & & & & 38 & 6 & 23 & 54 & 4 & 9 & 4 & 63 & 67 & 946.2 \\
\hline B3 & 12 & & 7 & 4 & 1 & & & 3 & 2 & 7 & 6 & 4 & 2 & & 12 & 12 & 413.7 \\
\hline B4 & 12 & & 16 & 1 & & & 1 & 5 & 3 & 8 & 12 & 3 & 2 & 1 & 16 & 17 & 185.7 \\
\hline B5 & 12 & & 1 & 3 & & & & 1 & 1 & 2 & 2 & 2 & & 2 & 2 & 4 & 385.2 \\
\hline B6 & 12 & & 6 & 4 & & & & & 6 & 4 & 6 & 3 & 1 & & 10 & 10 & 143.5 \\
\hline B7 & 12 & & 3 & 1 & & & & 1 & & 3 & 2 & 2 & & 2 & 2 & 4 & 185.5 \\
\hline D1 & 12 & & 13 & 1 & 2 & & & 5 & & 11 & 7 & 3 & 6 & & 16 & 16 & 690.1 \\
\hline D2 & 12 & & 10 & & & & & & 4 & 6 & 4 & 5 & 1 & & 10 & 10 & 34.9 \\
\hline D3 & 12 & & 4 & & & & & 1 & & 3 & 1 & 3 & & & 4 & 4 & 33.7 \\
\hline D5 & 12 & & 7 & 1 & & & & 1 & & 7 & 3 & 5 & & 1 & 7 & 8 & 54.2 \\
\hline D6 & 12 & & 4 & 1 & & & & 1 & 1 & 3 & 2 & 3 & & & 5 & 5 & 57 \\
\hline E1 & 12 & & 11 & 1 & & & & 1 & 2 & 9 & 7 & 5 & & 1 & 11 & 12 & 390.2 \\
\hline E2 & 12 & & 7 & 6 & 4 & 1 & & 1 & 7 & 10 & 6 & 10 & 2 & 1 & 17 & 18 & 5383.1 \\
\hline E3 & 12 & & 1 & 1 & & & & & 1 & 1 & & 2 & & 1 & 1 & 2 & 135.7 \\
\hline E4 & 12 & & 8 & 3 & & & & 1 & 2 & 8 & 3 & 8 & & 1 & 10 & 11 & 2518.5 \\
\hline E5 & 12 & & 2 & 2 & & & & 1 & & 3 & & 4 & & 1 & 3 & 4 & 140.1 \\
\hline E7 & 12 & & 5 & 1 & & & & & & 6 & 5 & 1 & & 1 & 5 & 6 & 101.5 \\
\hline Total & & & 166 & 41 & 7 & 1 & 1 & 60 & 36 & 118 & 122 & 69 & 24 & 18 & 197 & 215 & $11,893.5$ \\
\hline \multicolumn{18}{|c|}{${ }^{*} \mathrm{CC}=$ Calcium Carbon ate, $\mathrm{Ch}=$ Chert, $\mathrm{O}=\mathrm{Other}, \mathrm{Qtz}=\mathrm{Quartzite}$, and $\mathrm{SS}=$ Sandstone } \\
\hline \multicolumn{18}{|c|}{$* *$ Ang. $=$ Angular, Rnd. $=$ Round, $\mathrm{T}$ ab. $=\mathrm{T}$ abular } \\
\hline$* * *$ Burned & Root & & & & & & & & & & & & & & & & \\
\hline
\end{tabular}




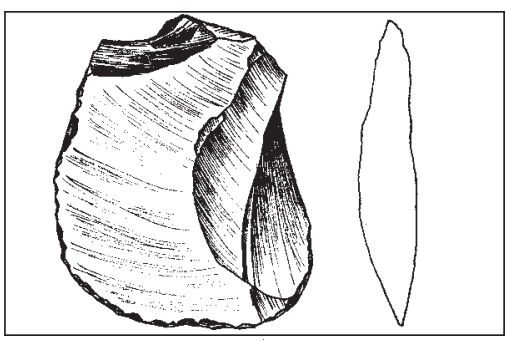

Figure 11.1 Edge Modified Flake (\#5512-4) from Occupation 6.

and four percent were greater than $9 \mathrm{~cm}$ in diameter. These size frequencies are similar to the frequencies of burned rock scattered in Occupations 2 through 4, although the smaller pieces are about 10 percent more abundant here. The average weight of the scattered burned rocks was $55 \mathrm{~g}$ (Table 11.4). The light average weight per rock indicates that the scattered burned rocks were small pieces fewer than $4 \mathrm{~cm}$ in diameter. Internal cracks appeared in slightly more than nine percent which is consistent with scattered rocks from previous occupations.

\subsection{MUSSEL SHELLS}

Only three mussel shell fragments were assigned to this occupation. None were sufficiently complete or diagnostic to be identified as to species. Each fragment represented less than 30 percent of a complete valve. No sign of burning or other human modification was observed. This low frequency is significantly different from the 60 shells in Occupation 1. It is not clear if this difference reflects a change in the availability of mussels in the river, the lack of procurement by the occupants, a change in cultural practices, or a sampling basis.

\subsection{RABDOTUS SHELLS}

Four Rabdotus shells from Unit D1 (between 110 and $120 \mathrm{cmbs}$ ) were selected for $\mathrm{A} / \mathrm{I}$ ratio analysis. These four shells yielded $\mathrm{A} / \mathrm{I}$ ratios of $0.131,0.141,0.141$, and $0.158(\mathrm{CF}-216$ through
219, Appendix F). These four ratios form about half the values within the older cluster of ratios obtained from 16 analyzed Rabdotus shells (Figure 6.18). One shell from Unit D1 (between 20 and $30 \mathrm{cmbs}$ ) with a ratio of 0.144 and part of this older $\mathrm{A} / \mathrm{I}$ ratio cluster was AMS dated. It yielded a $\delta^{13} \mathrm{C}(-1.1 \%$ o $)$ adjusted date of $1740 \pm$ 40 (Beta-122720). Even though this shell A/I ratio is part of the older clusters, the AMS date is younger than a Rabdotus AMS date of $2040 \pm$ 50 (Beta-122719) on a shell from the younger cluster. The low $\delta^{13} \mathrm{C}$ value and the young age of this AMS date create some questions as to the validity of this shell date. Consequently, this Rabdotus shell does not appear appropriate, and the date is not accepted. The variations in the shell ratios and the locations of the shells document the considerable movement that has occurred in these small, light objects.

\subsection{CHARCOAL}

Five wood charcoal samples were recovered from this cultural zone with a total weight of $7.9 \mathrm{~g}$. These were evenly divided between Balks $\mathrm{B}, \mathrm{C}$, and $\mathrm{E}$, which indicates light but constant horizontal dispersal. One large chunk (\#5057a, $4.6 \mathrm{~g}$ ) was identified as mesquite root (Appendix B). Wood charcoal chunk \#5478-4a from E2 (110 to $120 \mathrm{cmbs}$ ) was identified as indeterminate hardwood and yielded $\delta^{13} \mathrm{C}$ adjusted date of $2740 \pm 50$ B.P. (Beta-121863). The hardwood piece was some 300 years younger than AMS dates from Occupation 5, and thus this piece was determined to have been displaced from its original cultural association. Out of the eight vertical columns that were floated, only three columns were in Balks B, C, and $\mathrm{E}$, with the latter, E5 (between 110 and 120 cmbs), yielding a tiny amount ( $0.1 \mathrm{~g})$ of charcoal from this occupation. Since extensive turbation has occurred in this deposit, it is possible that the charcoal in Occupation 6 moved down the profile to appear associated with this occupation. 


\subsection{OTHER MATERIAL}

A small, sandstone, marble-like sphere came from $\mathrm{E} 4$ between 110 and $120 \mathrm{cmbs}$. It has an oval outline, is about 24.1 by $19.8 \mathrm{~mm}$, and weighs $13.7 \mathrm{~g}$. No obvious signs of wear are present, and this is probably a natural object. It is unclear if humans brought it in to this occupation. Other similar objects came from Occupations 1 and 2 with four other spheres recovered from mixed or outside the recognized occupation zones.

\subsection{HORIZONTAL DISTRIBUTION}

This occupation was horizontally limited primarily to Balks B, D and E and the area between with very infrequent materials over the western side and none east of Balk E. The detected occupation dips below our excavations west of Gradall ${ }^{\mathrm{TM}}$ Area B and pinches out in Gradall $^{\mathrm{TM}}$ Area F. The partial presence of this occupation due to the dipping of deposits and the termination of our hand excavations at 120 cmbs skews the horizontal distribution and overall patterning. The following interpretations should be viewed with extreme caution because so little of this occupation is represented in our excavations.

The 279 pieces of lithic debitage were only in Balks B, D, and F (Figure 11.2). Two units on the north edge of Balk D yielded high frequencies. The extremely high density of 120 pieces in Unit D1 is interpreted to reflect a discard area. However, the limited vertical spacing between this and Occupation 5 could have allowed for some downward displacement of materials without our detection. Each of the three productive balks yielded one to three units with moderate frequencies adjacent to one another. This clustering pattern reflects localized or specific activity areas.
The 215 burned rocks were unevenly distributed across three balks (Figure 11.2). One unit had a very dense accumulation of 67 pieces (Unit B2), with moderate frequencies in the two units immediately south. The moderate frequencies in Balk E correlate to moderate frequencies of lithic debitage in those same units. In Balk B the high densities of burned rock were in units with moderate frequencies of lithic debitage. The reverse was true in Balk D, where moderate burned rock frequencies were associated with high densities of lithic debitage. The accumulation of these two dominate debris categories in the same units is interpreted as reflecting dumping or discarding of materials vs. single activities isolated in an area.

The eight stone tools came from the same three balks as did the other cultural debris and were widely distributed (Figure 11.2). The six edgemodified tools were concentrated in Balk E with three in Unit E2. The unidentifiable tiny point tip came from the same unit as a mussel shell fragment, 120 flakes, and 16 scattered burned rocks. The proximal biface was in the same unit as the highest density of burned rocks. The three mussel shell fragments were widely dispersed and varied their association with burned rocks and lithic debitage. The various associations support the interpretation that these areas represent discarded material rather than in situ activity areas.

\subsection{SUMMARY AND INTERPRETATION}

This is a questionable occupation because the cultural remains are sparse $(n=510)$ and limited to only about $26 \mathrm{~m}^{2}$ of hand excavated area between 110 to $120 \mathrm{cmbs}$. This occupation zone appeared to dip below our excavation depth of $120 \mathrm{cmbs}$, and some question arises as to whether this zone could represent disturbed 

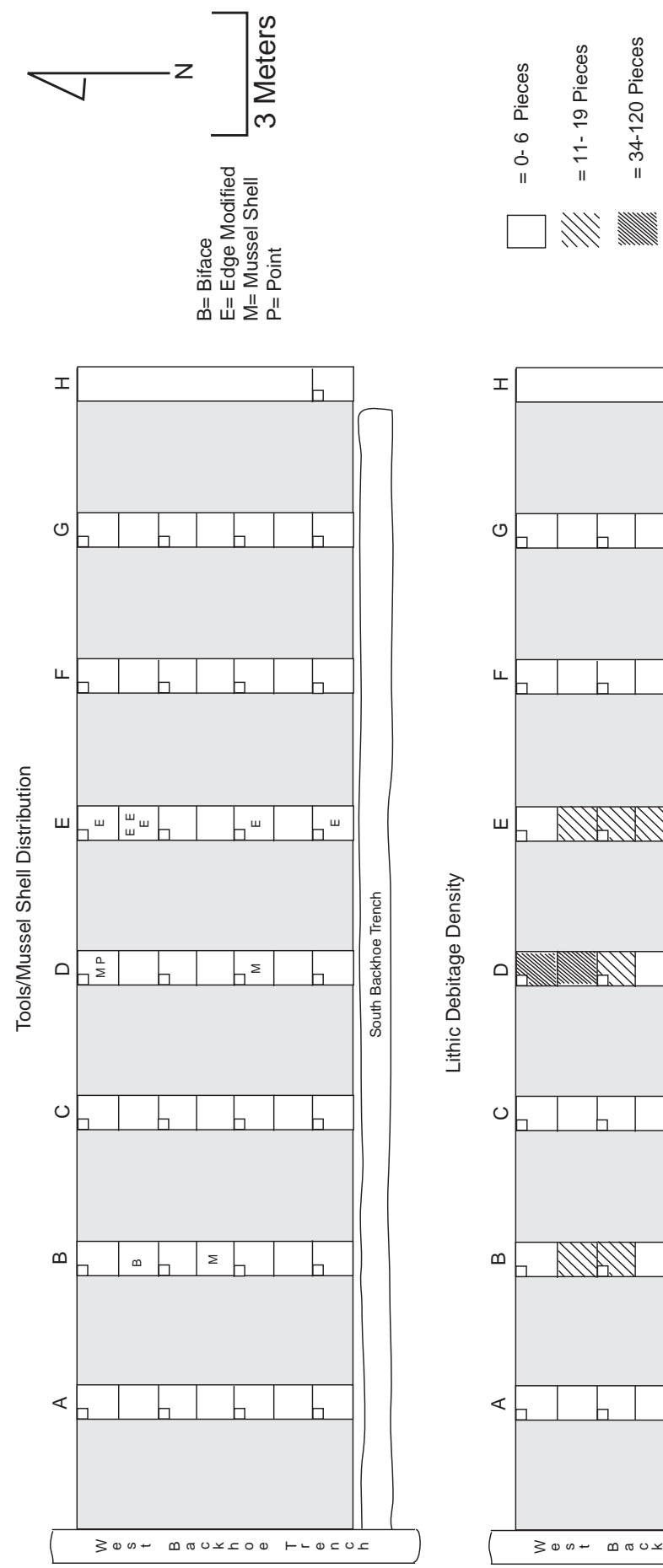
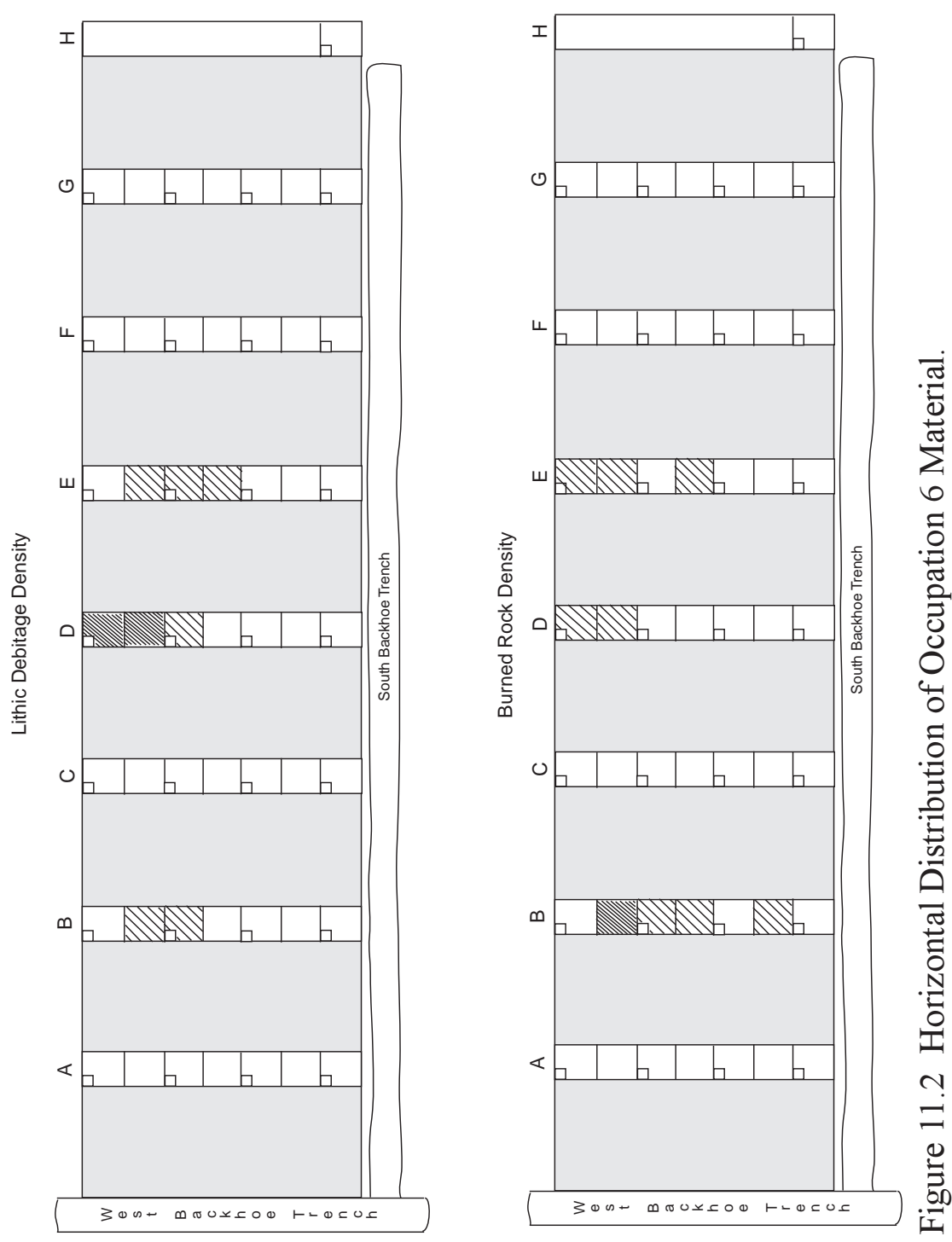
materials from other occupations above and below. Only excavations below 120 could help sort this out.

The chronometric age of Occupation 6 is estimated from a combination of wood charcoal dates from Occupations 5 and 6. One wood charcoal chunk (\#5478-4a) from Occupation 6 yielded and $\delta^{13} \mathrm{C}$ adjusted date of $2740 \pm 50$ B.P. (Beta-121863). Three wood charcoal dates from Occupation 5, two of which are accepted, yielded an average age of 3260 B.P. The younger wood charcoal date of 2740 B.P. from Occupation 6 appears to young compared to the two accepted wood charcoal dates from Occupation 5 and is not accepted. Assuming Occupation 6 is slightly older than Occupation 5, Occupation 6 is estimated to be about 3400 B.P.

No cultural features were recognized and no cultural bones were recovered. Three mussel shell fragments were widely scattered. The 215 scattered burned rocks (43 percent of the total material) weighed 11,894 g and averaged about $55 \mathrm{~g} /$ rock. The 279 pieces of lithic debitage (55 percent of the total) averaged about 11 pieces/ $\mathrm{m}^{2}$. The stone tool assemblage was limited to eight items: a tiny point tip, a distal biface fragment, and six edge-modified flakes. All tools were manufactured from local cherts. One small, sandstone, marble-like object was recovered, but it is unclear if the occupants brought in this natural piece.

These 510 cultural items appear to represent part of a broad occupation that was partially encountered in our hand excavations to 120 cmbs. The material remains appear to represent camping debris from a short-term huntergatherer camp. The absence of microscopic usewear on the six analyzed stone tools may support the short-term duration of their use and the site. The dominance of lithic debitage and burned rocks indicate that cooking and tool production activities occurred at Occupation 6. This cultural event appears to be very similar to the five recognized cultural events above, which were also dominated by these two material categories and similar stone tools.

All the TDS shot-in material reflects the same general overall distribution that the hand excavations and screening revealed (Figure 11.3). Here, the shot-in material represents only about 11 percent of the Occupation 6 material.

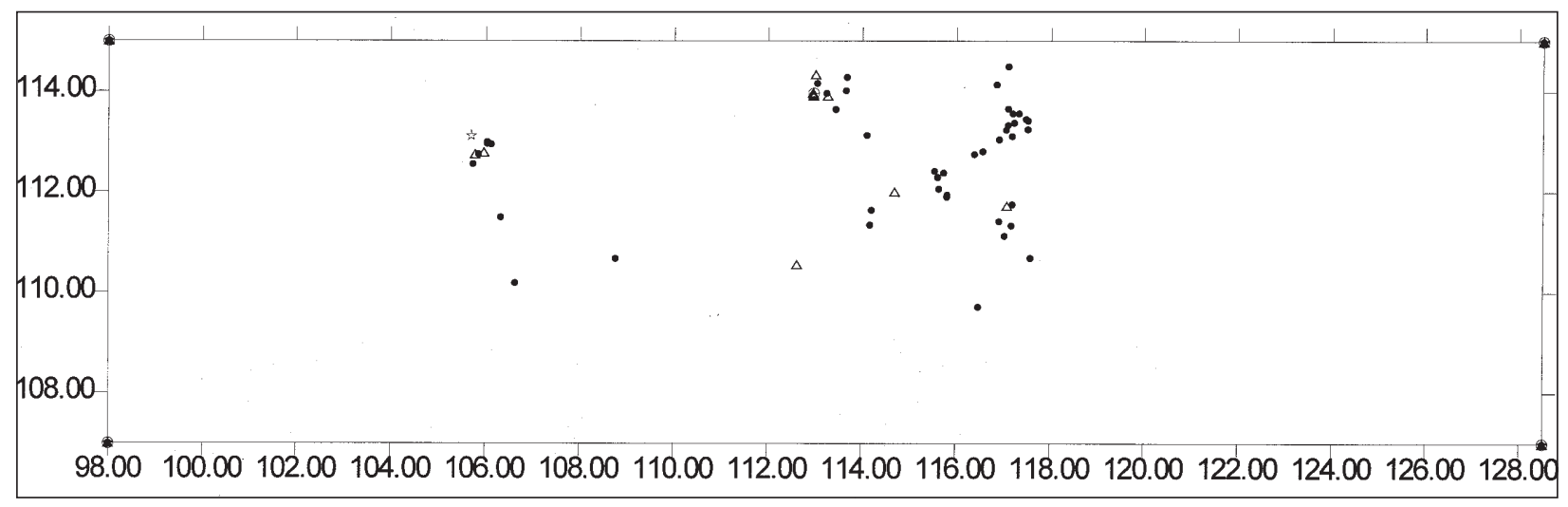

= burned rock $\Delta=$ lithic debitage $\quad \hat{s}=$ biface

Figure 11.3 All TDS Shot In Material for Occupation 6. 


\subsection{MISCELLANEOUS AFFILIATION}

The cultural material discussed below is a catchall group that could not be assigned to any one of the specifically identified cultural occupation zones. In a number instances the closely spaced occupational zone materials had been vertically displaced and could not be confidently assigned to any specific occupation. If artifacts were determined to be of questionable origin or not part of a distinct occupational zone, then it was assigned to the miscellaneous affiliation category. Although this material was not assigned to a specific occupation zone, it does belong to the same general time period as the six dated occupations. Based on the three wood charcoal dates from Occupation 1 with an average age of 2000 B.P., the average of two wood charcoal dates from Occupation 5 at about 3200 B.P., and an estimated age of Occupation 6 of about 3400 B.P., these miscellaneous materials date within this 1400 B.P. time period.

Table 12.1 lists the various proveniences that yielded the following materials assigned to this group. The cultural materials recovered from the hand-excavated balks and the Gradall ${ }^{\mathrm{TM}}$ stripped areas that encompassed this occupation period are presented by material class below. A summary and discussion is also presented at the end.

\subsection{FEATURES}

Three clusters of cultural materials were designated Features 17, 31, and 43 and could not be assigned to any particular occupation zone. Feature 17 was a well-defined occupation surface in Area $\mathrm{H}$ that occurred between 60 to $70 \mathrm{cmbs}$ near the eastern end of the excavation block where the natural and cultural stratigraphy became vertically compressed and closer to the surface (Figure 12.1). Occupations 3 and 4 pinched together across Gradall ${ }^{\mathrm{TM}}$ Area G, and those cultural materials in Gradall ${ }^{\mathrm{TM}}$ Area $\mathrm{H}$ became too compressed to separate into specific occupation zones. Feature 17 may be affiliated with either Occupation 3 or 4 , but because of the compressed stratigraphy, precise assignment was not possible. Materials from Feature 17 came from an area immediately east of pit Feature 27 in Occupation 4. If Feature 17 is from the same component, then its materials could be relevant to the interpretation of activities conducted at pit Feature 27.

The horizontal distribution and density of the larger burned rocks appear to represent what might be expected for a single occupation and not a mixture of multiple events (Figure 12.1). Two Refugio projectile points came from opposite sides of this $6 \mathrm{~m}^{2}$ excavation area. These related point types may link materials from Feature 17 to a single event, or at least to one time period. Specimen \#1523, a Refugio point base, came from Unit 17-6, and a second Refugio point base (\#1829-1) came from Unit 17-2. Two bifaces also came from the area of Feature 17. A complete biface (\#1628) came from 17-4 with a proximal biface fragment from 17-2 (\#1829-6).

Feature 31 was a charcoal chunk associated with some scattered burned rocks in Area E (between 110 to $120 \mathrm{cmbs}$ ). It was designated as a feature upon discovery and then carefully investigated. After hand excavations in the area and especially after cross sectioning the charcoal, it was determined that the burned wood represented part of a burned mesquite root penetrating through scattered cultural material. The associated few scattered burned rocks and lithic debitage was coincidental. No finished tools or other significant materials were found in association. 
Table 12.1 List of Proveniences for Miscellaneous Material.

\begin{tabular}{ccc}
\hline Unit & Level & Fea No \\
\hline- & - & 28 \\
- & - & 31 \\
$17-1$ & 7 & - \\
$17-2$ & 7 & - \\
$17-3$ & 7 & - \\
$17-4$ & 7 & - \\
$17-5$ & 7 & - \\
$17-6$ & 7 & - \\
$31-1$ & - & - \\
$31-2$ & - & - \\
$31-3$ & - & - \\
$31-4$ & - & - \\
A1 & $1-3, \& 8$ & - \\
A2 & $2-3, \& 8-9$ & - \\
A3 & $2 \& 9$ & - \\
A4 & $2 \& 8-9$ & - \\
A5 & $1-2 \& 9$ & - \\
A6 & $1,3, \& 8-9$ & - \\
A7 & $1-3, \& 8-9$ & - \\
B1 & $2 \& 5-6$ & - \\
B2 & $5-6$ & - \\
B3 & $2,5-7, \& 10$ & 43 \\
B4 & $1,2,7, \& 10$ & - \\
B5 & $1,6, \& 10$ & - \\
B6 & $1,2,5-6, \& 10$ & - \\
B7 & $1,5-7, \& 10$ & - \\
C1 & $2,5-7,10 \& 12$ & - \\
C2 & $7,10 \& 12$ & - \\
C3 & $1,5,7,10 \& 12$ & - \\
C4 & $2,5, \& 10$ & - \\
C5 & $5,7,10 \& 12$ & - \\
\hline \hline & & \\
\hline
\end{tabular}

\begin{tabular}{|c|c|c|}
\hline Unit & Level & Fea No \\
\hline C6 & $2,5,7,10 \& 12$ & - \\
\hline $\mathrm{C} 7$ & $1,2,5,10 \& 12$ & - \\
\hline D1 & $1-2, \& 7$ & - \\
\hline D2 & $2 \& 7$ & - \\
\hline D3 & $1-2, \& 7$ & - \\
\hline D4 & $1-2, \& 7$ & - \\
\hline D5 & $1-2, \& 7$ & - \\
\hline D6 & $1-2, \& 7$ & - \\
\hline D7 & $1-2, \& 7$ & - \\
\hline E1 & $1-2, \& 9-10$ & - \\
\hline E2 & $2 \& 10$ & - \\
\hline E3 & $1,5, \& 10$ & - \\
\hline E4 & $1,5, \& 10$ & - \\
\hline E5 & $2-3,5 \& 10$ & - \\
\hline E6 & $1-3,5 \& 10$ & - \\
\hline E7 & $2-3 \& 10-11$ & - \\
\hline F1 & $1-3,5 \& 12$ & - \\
\hline $\mathrm{F} 2$ & $2-3$ & - \\
\hline F3 & $1-3,5 \& 12$ & - \\
\hline F4 & $1-2,5 \& 12$ & - \\
\hline F5 & $1-3, \& 5$ & - \\
\hline F6 & 5 & - \\
\hline F7 & $1-3,5,10 \& 12$ & - \\
\hline G1 & $1,7,10, \& 12$ & - \\
\hline $\mathrm{G} 2$ & $2,7, \& 11-12$ & - \\
\hline G3 & 10 & - \\
\hline G4 & $7, \& 11-12$ & - \\
\hline G5 & $1,7, \& 10$ & - \\
\hline G6 & $1,7, \& 11-12$ & - \\
\hline G7 & $1,4,7,9,11-12$ & - \\
\hline H7 & $1-2,7-8, \& 12$ & - \\
\hline
\end{tabular}

Feature 43 was a concentration of burned rocks in Unit B3 between 90 and $100 \mathrm{cmbs}$. The plan view drawn in the field shows some 20 to 25 burned rocks tightly clustered in an area about 60 by $30 \mathrm{~cm}$ along the south edge Unit B3 (Figure 12.2). Although concentrated, the cross section revealed that at least eight rocks were vertically distributed over nearly a $20 \mathrm{~cm}$ thick zone. Even though a rodent hole was not obvious in the field during excavation, the vertical dispersal and angled nature of the tightly clustered rocks indicate that these pieces might have occurred within a linear rodent burrow. The lack of horizontally associated cultural materials in the immediate area caused further doubt about the concentration representing a cultural event. The distribution of burned rocks is attributed to a fortuitous rodent disturbance and thus was not assigned to a cultural occupation zone.

\subsection{CHIPPED LITHIC ASSEMBLAGE}

Lithic debitage from the various scattered proveniences are represented by 340 pieces. 


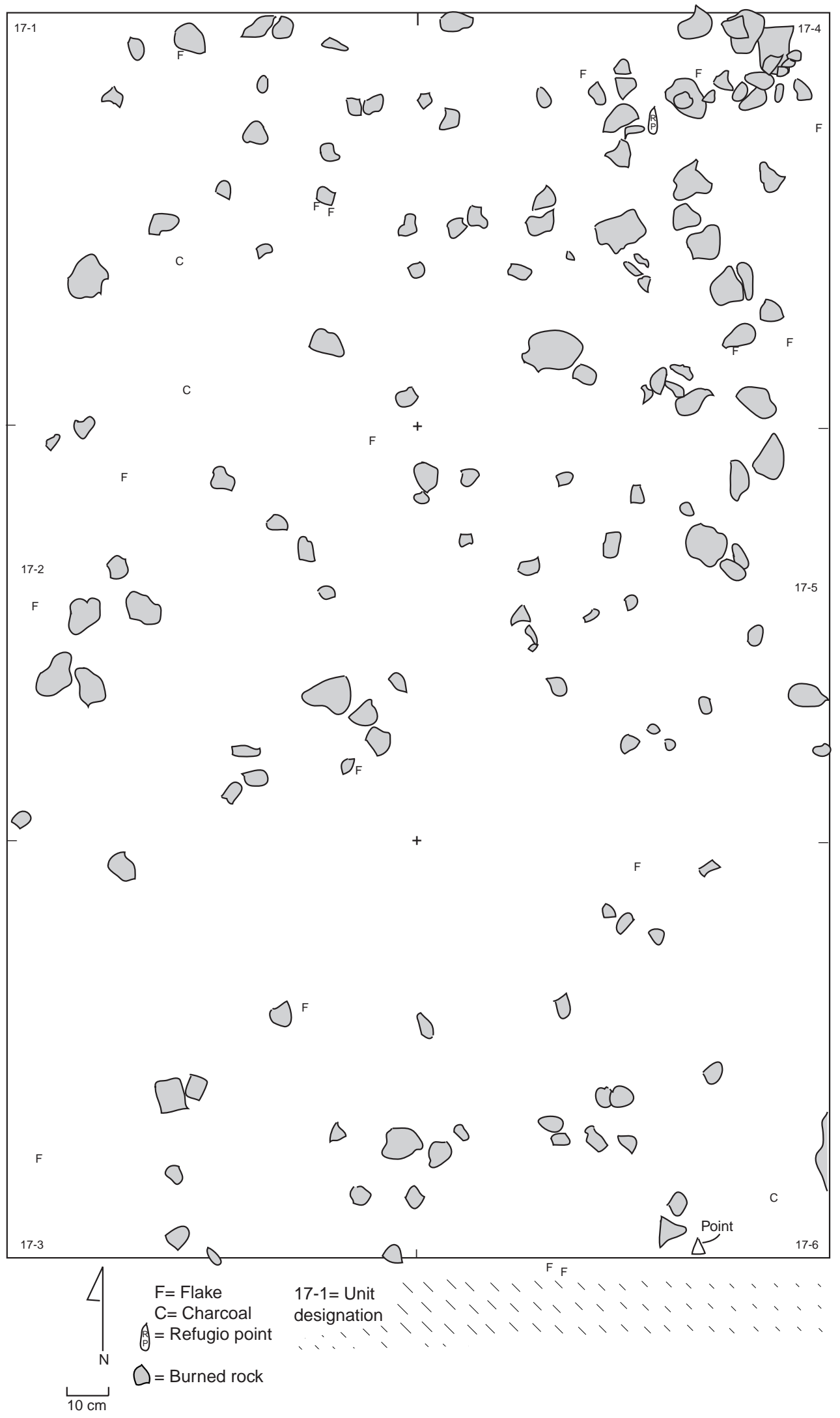

Figure 12.1 Plan View of Feature 17. 


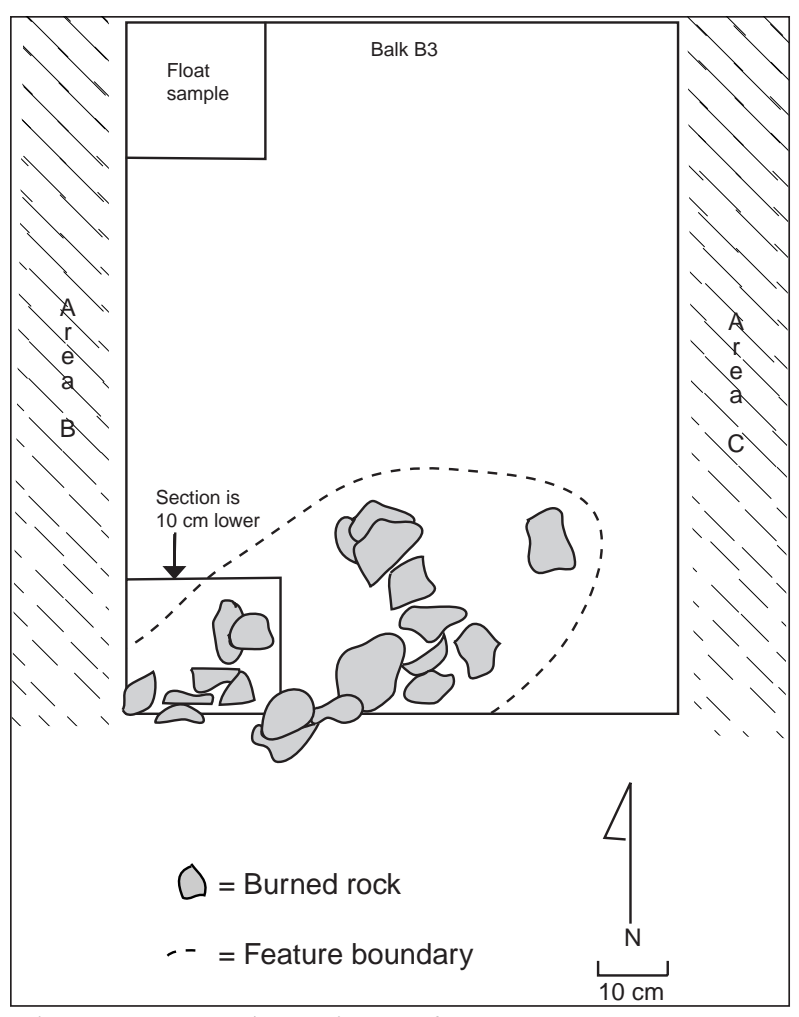

Figure 12.2 Plan View of Feature 43.

Core flakes dominate the group (40 percent) followed by late biface flakes at 27 percent, indeterminate pieces at 17 percent, early biface flakes at 12 percent (Table 12.2). The flake types represented are similar to those detected in most of the cultural occupations. About 31 percent of the pieces have cortex, and cortex is primarily on core flakes and early biface flakes. Less than 10 percent of the total exhibit heat alterations. Since these 340 pieces were from a variety of vertical and horizontal contexts, no conclusions about cultural behaviors are inferred.

\subsection{CHIPPED STONE TOOLS}

The recognized chipped-stone tool assemblage was classified into five form/functional classes. These tools consist of three projectile points, 11 bifaces, one scraper, three cores, and 26 edgemodified flakes. As a group, these 44 chipped stone tools account for less than four percent of the total cultural material recovered from unassigned proveniences.

Two point fragments are classified as Refugio types. One (\#1829-1) is a narrow, thin specimen with a well-formed base (Figure 12.3). It has a very rounded basal edge and nearly straight lateral edges. The break appears to be a snaptype break from being used (Table 12.3). It was manufactured from a light gray chert with tiny light specks. Both faces are completely modified with all margins exhibiting fine pressure retouch. The lateral and basal edges exhibit light wear or grinding. It was from the occupation surface surrounding Feature 17 (Figure 12.1). A somewhat larger base (\#1523) was manufactured from a yellowish chert with dark gray spots. It has a relatively flat, ventral surface that is only modified along the margins, indicating that this was made on a flake preform with the original platform located near the proximal end. The dorsal surface is completely modified with tiny pressure flakes along most margins (Figure 12.3). The lateral edges are straight with a rounded base. Only the right lateral edge exhibits light wear on the tiny projections. The break appears to be a snap type attributed to failure during use. This specimen also came from the Feature 17 occupational surface.

The other probable point is the distal tip of an unknown point type that was recovered from 10 to $20 \mathrm{cmbs}$ in Unit F1. It was manufactured from a gray chert mottled with beige coloring. The fragment is about $7.9 \mathrm{~mm}$ thick with a relatively narrow width of about $17 \mathrm{~mm}$, and it does not resemble the blade form of a Refugio or Tortugas point types. The presence of pot lids indicates that it has gone through extreme heating.

The 11 bifaces include three complete specimens with oval and trapezoidal shapes representing the middle stage of reduction (Table 12.3). 
Table 12.2 Miscellaneous Lithic Debitage Analysis.

\begin{tabular}{|c|c|c|c|c|c|c|c|}
\hline \multirow[b]{2}{*}{ Condition } & \multicolumn{6}{|c|}{ Flake Type } & \multirow[b]{2}{*}{ Total } \\
\hline & $\begin{array}{c}\text { angular } \\
\text { debris }\end{array}$ & core & $\begin{array}{c}\text { early } \\
\text { biface }\end{array}$ & indet. & $\begin{array}{c}\text { late } \\
\text { biface }\end{array}$ & uniface & \\
\hline \multirow[t]{2}{*}{ complete } & - & 48 & 4 & 12 & 22 & 1 & 87 \\
\hline & $0 \%$ & $55 \%$ & $5 \%$ & $14 \%$ & $25 \%$ & $1 \%$ & $26 \%$ \\
\hline \multirow[t]{2}{*}{ distal } & - & 26 & 10 & 8 & 19 & - & 63 \\
\hline & $0 \%$ & $41 \%$ & $16 \%$ & $13 \%$ & $30 \%$ & $0 \%$ & $19 \%$ \\
\hline \multirow[t]{2}{*}{ fragment } & 19 & - & - & - & - & - & 19 \\
\hline & $100 \%$ & $0 \%$ & $0 \%$ & $0 \%$ & $0 \%$ & $0 \%$ & $6 \%$ \\
\hline \multirow[t]{2}{*}{ medial } & - & 16 & 9 & 36 & 16 & - & 77 \\
\hline & $0 \%$ & $21 \%$ & $12 \%$ & $47 \%$ & $21 \%$ & $0 \%$ & $23 \%$ \\
\hline \multirow[t]{2}{*}{ proximal } & - & 45 & 16 & - & 33 & - & 94 \\
\hline & $0 \%$ & $48 \%$ & $17 \%$ & - & $35 \%$ & $0 \%$ & $28 \%$ \\
\hline \multirow[t]{2}{*}{ Total } & 19 & 135 & 39 & 56 & 90 & 1 & 340 \\
\hline & $6 \%$ & $40 \%$ & $11 \%$ & $16 \%$ & $26 \%$ & $0 \%$ & $100 \%$ \\
\hline & \multicolumn{6}{|c|}{ Flake Type } & \\
\hline Cortex & $\begin{array}{c}\text { angular } \\
\text { debris }\end{array}$ & core & $\begin{array}{c}\text { early } \\
\text { biface }\end{array}$ & indet. & $\begin{array}{c}\text { late } \\
\text { biface }\end{array}$ & uniface & Total \\
\hline \multirow[t]{2}{*}{ primary } & - & 16 & - & - & - & - & 16 \\
\hline & $0 \%$ & $100 \%$ & $0 \%$ & $0 \%$ & $0 \%$ & $0 \%$ & $5 \%$ \\
\hline \multirow[t]{2}{*}{ secondary } & 8 & 80 & 6 & 9 & 1 & 1 & 105 \\
\hline & $8 \%$ & $76 \%$ & $6 \%$ & $9 \%$ & $1 \%$ & $1 \%$ & $31 \%$ \\
\hline \multirow[t]{2}{*}{ tertiary } & 11 & 39 & 33 & 47 & 89 & - & 219 \\
\hline & $5 \%$ & $18 \%$ & $15 \%$ & $21 \%$ & $41 \%$ & $0 \%$ & $64 \%$ \\
\hline \multirow[t]{4}{*}{ Total } & 19 & 135 & 39 & 56 & 90 & 1 & 340 \\
\hline & $6 \%$ & $40 \%$ & $11 \%$ & $16 \%$ & $26 \%$ & $0 \%$ & $100 \%$ \\
\hline & \multicolumn{6}{|c|}{ Flake Type } & \\
\hline & angular & & early & & late & & \\
\hline \multirow{3}{*}{$\begin{array}{c}\text { Heating } \\
\text { crazed }\end{array}$} & debris & core & biface & indet. & biface & uniface & Total \\
\hline & - & 2 & 1 & 2 & - & - & 5 \\
\hline & $0 \%$ & $40 \%$ & $20 \%$ & $40 \%$ & $0 \%$ & $0 \%$ & $1 \%$ \\
\hline \multirow[t]{2}{*}{ indet. } & - & 8 & 1 & 1 & - & - & 10 \\
\hline & $0 \%$ & $80 \%$ & $10 \%$ & $10 \%$ & $0 \%$ & $0 \%$ & $3 \%$ \\
\hline \multirow[t]{2}{*}{ none } & 16 & 120 & 35 & 43 & 89 & 1 & 304 \\
\hline & $5 \%$ & $39 \%$ & $12 \%$ & $14 \%$ & $29 \%$ & $0 \%$ & $89 \%$ \\
\hline \multirow[t]{2}{*}{ spall } & 3 & 5 & 2 & 10 & 1 & - & 21 \\
\hline & $14 \%$ & $24 \%$ & $10 \%$ & $48 \%$ & $5 \%$ & $0 \%$ & $6 \%$ \\
\hline \multirow[t]{2}{*}{ Total } & 19 & 135 & 39 & 56 & 90 & 1 & 340 \\
\hline & $6 \%$ & $40 \%$ & $11 \%$ & $16 \%$ & $26 \%$ & $0 \%$ & $100 \%$ \\
\hline
\end{tabular}

Complete biface \#5493-5 is a lanceolate form from a late stage of reduction that is made of light gray chert with light circular spots. It has one relatively thick knot of stacked hinge/step fractures on each face (Figure 12.3). The right lateral edge appears to be unfinished, while the left edge has tiny retouched flake scars and hinges indicating possible use. This edge morphology is similar to that of a scarping edge. At least one biface fragment (\#5349-4) reveals a use break on a late stage reduction piece. Five fragments represent middle stages of reduction whereas the others represent late stages. The late stage biface fragments have either lanceolate or triangular shapes. Bifaces \#4554, \#4555, and \#5349-4 were in Area C from a questionable depth between Occupations 4 and 5 .
One scraper (\#3553-1) was not assignable to any specific occupation zone. This specimen was recovered from an erosional surface along the two-track road paralleling the fence line, toward the southwestern margin of the site. It could have eroded from Occupation 1. Specimen \#3553-1 is classified as a complete Clear Fork tool with an asymmetrical, roughly triangular outline (Figure 12.3). It was manufactured from a dark gray chert with small white inclusions and occasional black spot. It is relatively small measuring $52.4 \mathrm{~mm}$ long, $43.4 \mathrm{~mm}$ wide, and $122.1 \mathrm{~mm}$ thick, and it weighs about $23.6 \mathrm{~g}$ (Table 12.4). The distal primary working edge is slightly concave and is $37.7 \mathrm{~mm}$ long and 8.3 $\mathrm{mm}$ thick with a 50 degree working edge angle. The ventral surface is worked on the proximal two thirds. The part of the right lateral edge reveals heavy crushing and tiny hinge fractures, and it is relatively dull.

The 26 edge-modified flakes show considerable size and shape variations (Table 12.4). Specimen \#5296-4 is about $10 \mathrm{~mm}$ long and is a small gray chert flake with the left lateral edge exhibiting tiny hinge scars, which is possibly indicative of scarping activities. One of the larger specimens (\#5276-5) is a dark gray chert with cortex over half the dorsal surface and a flat ventral surface. One lateral edge exhibits patterned flake scars that also indicate scraping actions. All 26 specimens exhibit tiny, well-patterned flake scars along one or more edges that appear to relate to scraping activities. Nine specimens have two modified edges and one has three modified edges (Table 12.4).

Three cores were identified and all were chert with the exception of one quartzite specimen. These included bifacial and unifacial pieces with multiple platforms. None of these cores appeared to be prepared for the systematic removal of consecutive flakes. Because these 


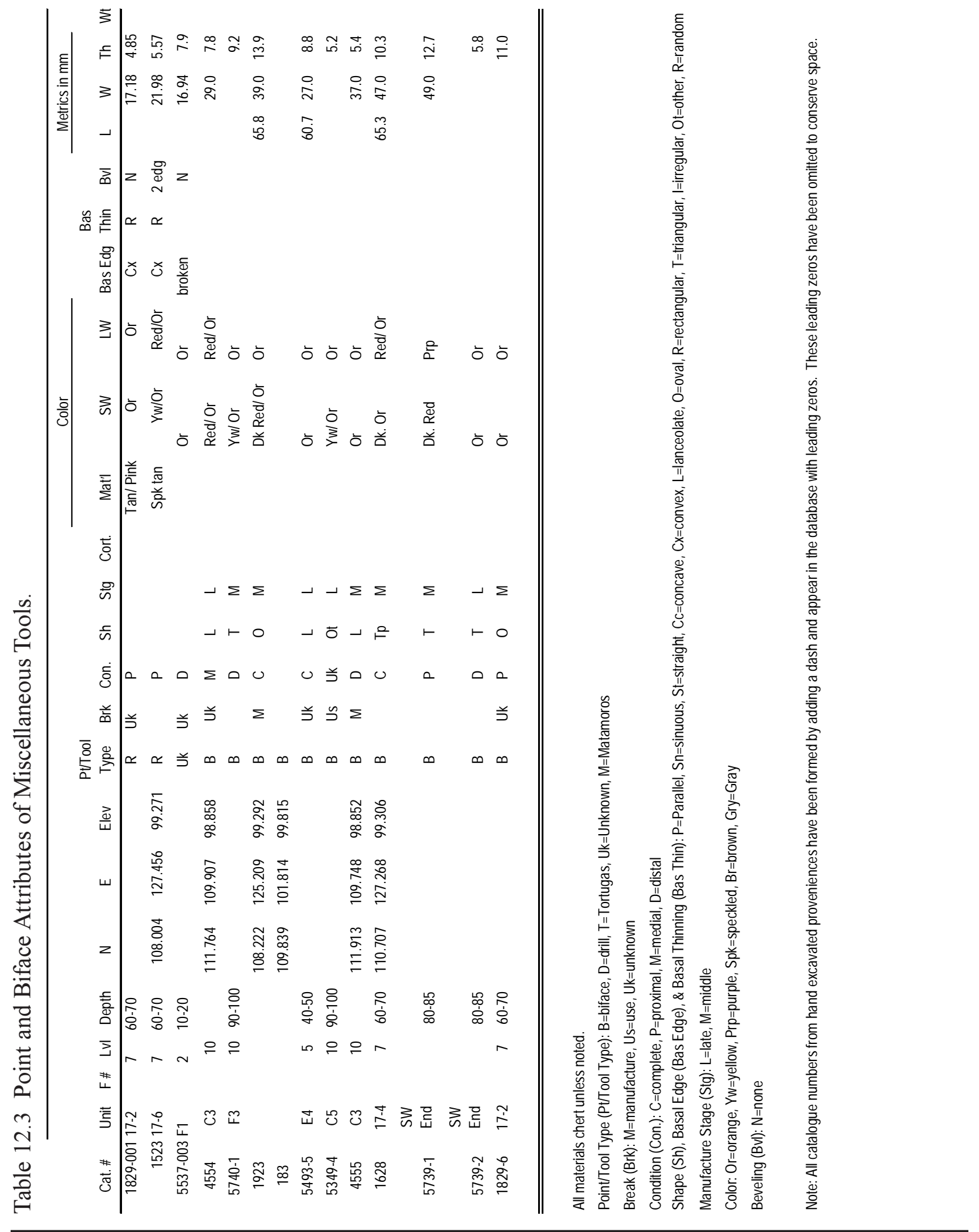



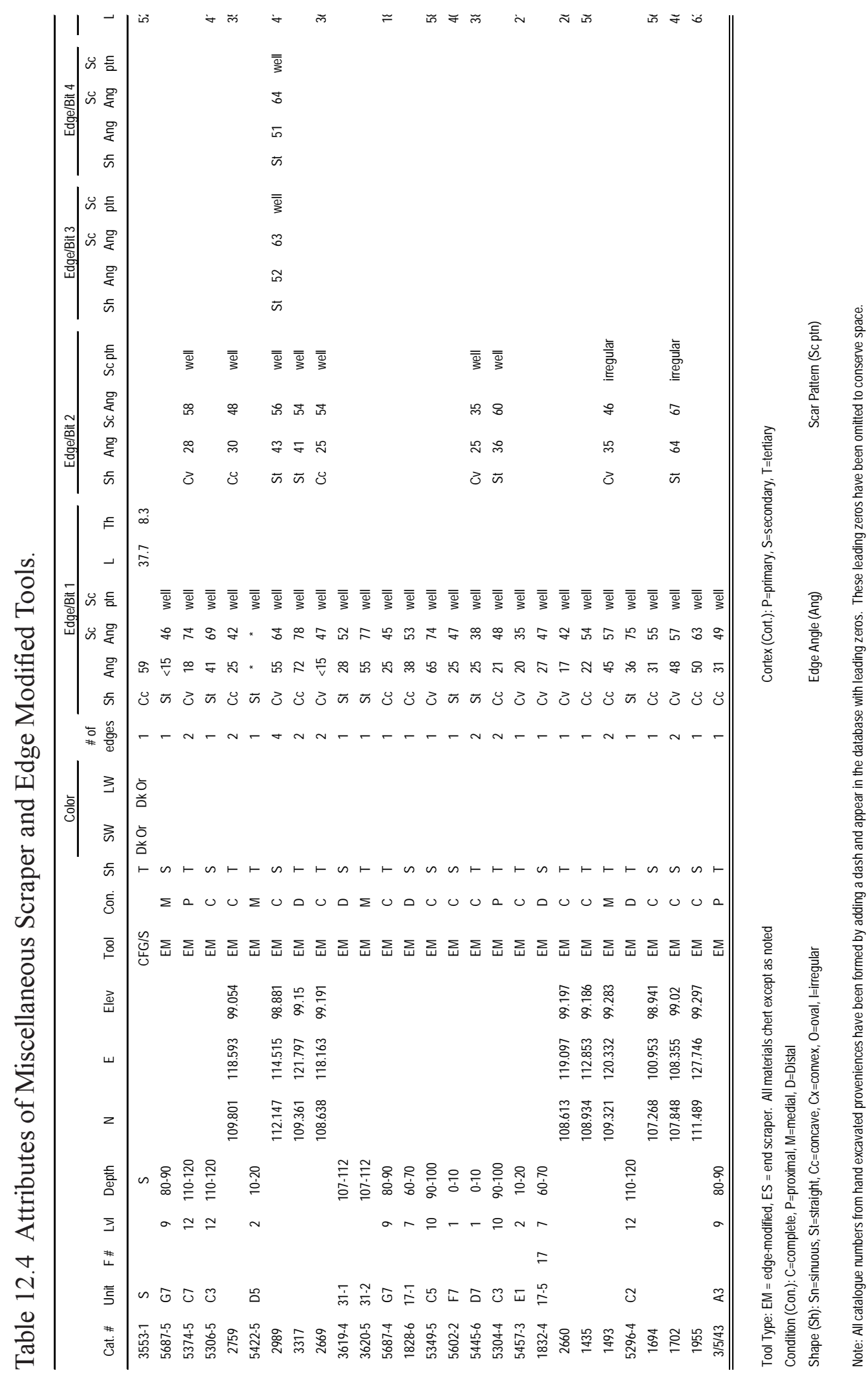


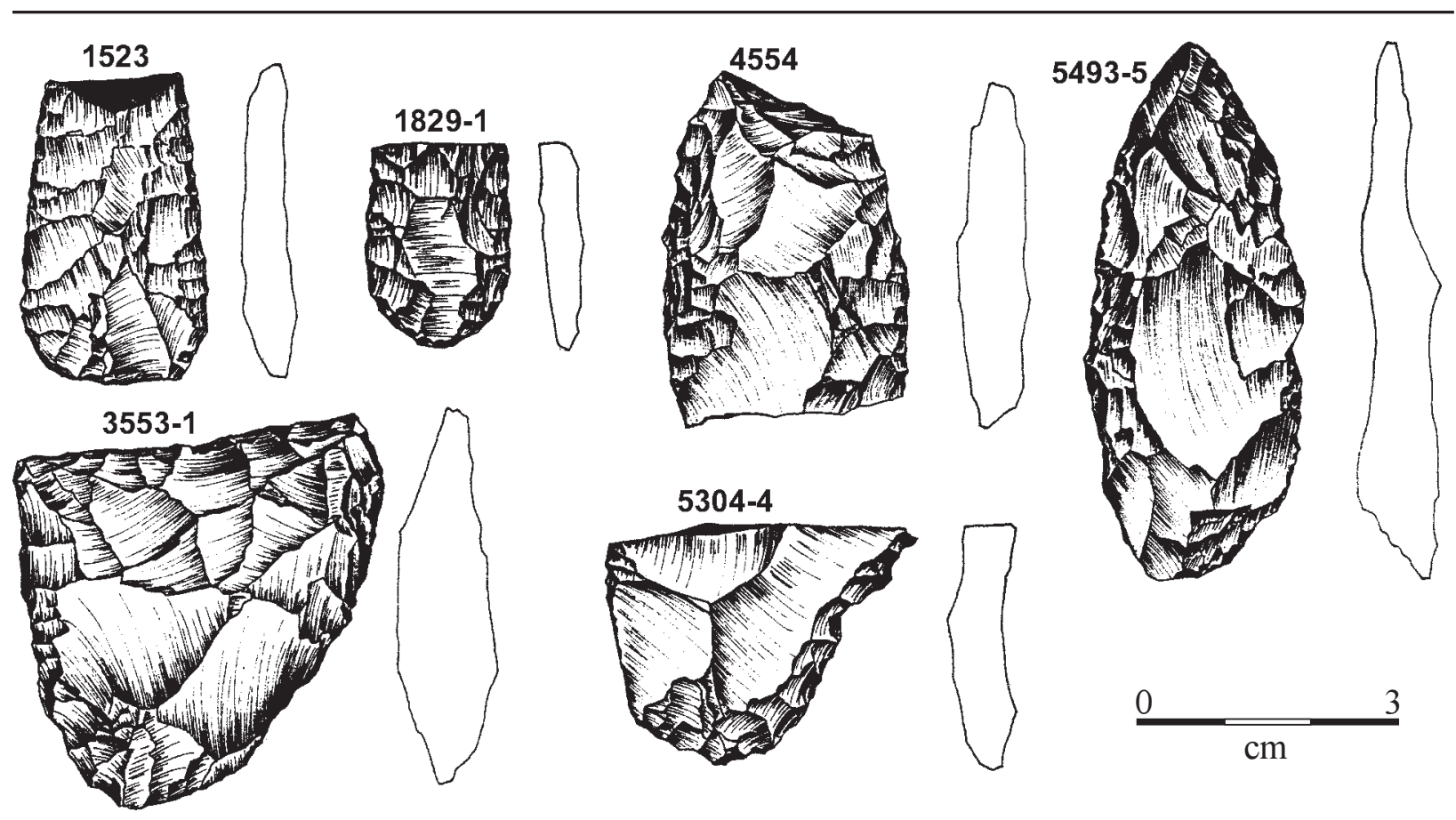

Figure 12.3 Selected Artifacts from Assigned Proveniences (Actual Size).

were from general Gradall ${ }^{\mathrm{TM}}$ areas, these specimens were not analyzed in detail.

High-powered microwear analysis was conducted on 11 specimens, two Refugio points (\#1523 and \#1829-1), three bifaces (\#4554, \#5349-4, and \#5493-5), one Clear Fork tool (\#3553-1), and five edge-modified tools (\#36243, \#5276-5, \#5296-4, \#5374-5, and \#5602-2). Unfortunately, this analysis failed to find any sign of microwear on any of the specimens (Appendix C).

\subsection{GROUND STONE TOOLS}

No ground stone implements were assigned.

\subsection{BURNED ROCKS}

The burned rocks from various unassigned proveniences and outside identified features are represented by 835 pieces that weigh $51,321 \mathrm{~g}$ (Table 12.5). The average size of $61 \mathrm{~g} / \mathrm{rock}$ is similar to the scattered burned rocks from every other occupation zone. Some 1,440 other burned rocks were shot in with the TDS in the field during Gradall ${ }^{\mathrm{TM}}$ stripping and not collected. Data collected in the field included material type and size and are in the database.

Feature 35 yielded some 29 sandstone burned rocks primarily ranging between 1 and $9 \mathrm{~cm}$ in diameter (Table 12.5). Feature 43 yielded another 37 pieces, most of which were sandstone. These pieces were nearly equally divided between 0 to $4 \mathrm{~cm}$ and 4 to $9 \mathrm{~cm}$ size classes.

\subsection{MUSSEL SHELLS}

Some 17 mussel shell fragments are included here. Pieces range from about 15 percent of a valve to about 95 percent of a valve. Eleven specimens are Cyrtonaias sp., three are Lampsillis teres, one is Potamilus purpuratus and six are unidentifiable. About 23 percent were from hand excavated balks; the others were discovered during GradallTM stripping. Two small fragments, each representing less than 10 percent of a valve, came from float samples from 
Table 12.5 Miscellaneous Burned Rock Data.

\begin{tabular}{|c|c|c|c|c|c|c|c|c|c|c|c|c|c|c|c|c|c|c|}
\hline \multicolumn{19}{|c|}{ Non Feature Contexts } \\
\hline \multirow[b]{2}{*}{ Unit } & \multirow[b]{2}{*}{ Level } & \multirow[b]{2}{*}{ Fea No } & \multicolumn{4}{|c|}{ Size $(\mathbf{c m})$} & \multicolumn{4}{|c|}{ Material Type* } & \multicolumn{4}{|c|}{ Fracture Type** } & \multicolumn{2}{|c|}{ Cracks } & \multirow[b]{2}{*}{ Total } & \multirow[b]{2}{*}{ Wt $(\mathrm{g})$} \\
\hline & & & $0-4$ & $4-9$ & $9-15$ & $>15$ & $\mathrm{CC}$ & Ch & $\mathbf{0}$ & $\overline{\text { SS }}$ & Ang. & Ind. & Rnd & Tab. & $\bar{Y}$ & $\overline{\mathbf{N}}$ & & \\
\hline $17-1$ & 7 & & 66 & 20 & 1 & & & 18 & & 69 & 69 & & 13 & 5 & 1 & 86 & 87 & $2,412.9$ \\
\hline $17-2$ & 7 & & 4 & 5 & 2 & & & 1 & & 10 & 4 & & 3 & 4 & 2 & 9 & 11 & $5,160.7$ \\
\hline $17-3$ & 7 & & 88 & 15 & & & & 12 & & 91 & 76 & & 7 & 20 & 2 & 101 & 103 & $1,937.0$ \\
\hline $17-4$ & 7 & & 199 & 85 & 12 & & & 73 & 3 & 220 & 224 & & 36 & 36 & 5 & 291 & 296 & $26,367$. \\
\hline $17-5$ & 7 & & 54 & 15 & 1 & & & 12 & & 58 & 45 & & 13 & 12 & & 70 & 70 & $5,329.2$ \\
\hline $17-6$ & 7 & & 90 & 25 & & & 1 & 6 & 1 & 107 & 74 & & 25 & 16 & 2 & 113 & 115 & $1,527.5$ \\
\hline $22-1$ & & & & 1 & & & & 1 & & & 1 & & & & 1 & & 1 & 79.8 \\
\hline $24-3$ & & & & 1 & & & & & & 1 & 1 & & & & & 1 & 1 & $2,380.1$ \\
\hline $31-1$ & & & 10 & 1 & & & & & & 11 & 9 & & 2 & & & 11 & 11 & 177.7 \\
\hline $31-2$ & & & 3 & & & & & & & 3 & 1 & & 2 & & & 3 & 3 & 6.2 \\
\hline $31-3$ & & & 4 & & & & & 1 & & 3 & 4 & & & & & 4 & 4 & 197.1 \\
\hline $31-4$ & & & 5 & 2 & & & & & & 7 & 6 & & 1 & & & 7 & 7 & 100.6 \\
\hline $\mathrm{C} 1$ & 12 & & 3 & 1 & & & & & & 4 & 3 & & 1 & & & 4 & 4 & 25.4 \\
\hline $\mathrm{C} 2$ & 12 & & & 1 & & & & & & 1 & & & & 1 & & 1 & 1 & 29.0 \\
\hline $\mathrm{C} 3$ & 10 & & 31 & 11 & 3 & & & 2 & 23 & 20 & 25 & & 14 & 6 & 3 & 42 & 45 & $2,255.5$ \\
\hline $\mathrm{C} 3$ & 12 & & 9 & 2 & & & 1 & 2 & & 8 & 4 & & 4 & 3 & & 11 & 11 & 387.0 \\
\hline $\mathrm{C} 6$ & 12 & & 1 & 1 & & & & & & 2 & 1 & & 1 & & 2 & & 2 & 35.3 \\
\hline $\mathrm{C} 7$ & 12 & & 2 & & & & & & 2 & & 2 & & & & & 2 & 2 & 16.0 \\
\hline E4 & & & 2 & 2 & & & & & & 4 & 2 & & & 2 & & 4 & 4 & 208.0 \\
\hline E6 & 1 & & 7 & & & & & 1 & & 6 & 4 & & 1 & 2 & & 7 & 7 & 70.1 \\
\hline E6 & 3 & & 7 & & & & & & & 7 & 4 & & 1 & 2 & & 7 & 7 & 70.1 \\
\hline E7 & 3 & & 7 & 4 & & & & 1 & & 10 & 9 & & 1 & 1 & 3 & 8 & 11 & 524.2 \\
\hline G7 & 7 & & 15 & 16 & 1 & & & 6 & 13 & 13 & 14 & 1 & 12 & 5 & 1 & 31 & 32 & $2,023.2$ \\
\hline Subtotal & & & 607 & 208 & 20 & 0 & 2 & 136 & 42 & 655 & 582 & 1 & 137 & 115 & 22 & 813 & 835 & $51,320.8$ \\
\hline \multicolumn{19}{|c|}{ Feature Contexts } \\
\hline & & & \multicolumn{4}{|c|}{ Size $(\mathrm{cm})$} & \multicolumn{4}{|c|}{ Material Type* } & \multicolumn{4}{|c|}{ Fracture Type** } & \multicolumn{2}{|c|}{ Cracks } & & \\
\hline Unit & Level & Fea No & $0-4$ & 4-9 & $9-15$ & $>15$ & $\mathrm{CC}$ & Ch & 0 & SS & Ang. & Ind. & Rnd & Tab. & $\bar{Y}$ & $\overline{\mathbf{N}}$ & Total & Wt $(\mathrm{g})$ \\
\hline & 3 & 35 & 3 & 17 & 8 & 1 & & & & 29 & 25 & & & 4 & 1 & 28 & 29 & $\mathbf{9 , 8 9 5 .}$ \\
\hline B3 & 10 & 43 & 16 & 21 & & & & 5 & & 32 & 19 & & 14 & 4 & 2 & 35 & 37 & $7,790.3$ \\
\hline Subtotal & & & 19 & 38 & 8 & 1 & 0 & 5 & 0 & 61 & 44 & 0 & 14 & 8 & 3 & 63 & 66 & $17,685.9$ \\
\hline Total & & & 626 & 246 & 28 & 10 & 2 & 141 & 42 & 7160 & 626 & 1 & 151 & 1230 & 25 & 876 & 901 & $69,006.7$ \\
\hline
\end{tabular}

*CC=Calcium Carbonate, $\mathrm{Ch}=\mathrm{Chert}, \mathrm{O}=\mathrm{Other}, \mathrm{Qtz}=\mathrm{Quartzite}$, and $\mathrm{SS}=$ Sandstone

**Ang.=Angular, Rnd. $=$ Round, Tab. $=$ Tabular

Unit B3 (90 to $100 \mathrm{cmbs}$ ) and Unit C5 (90 to $100 \mathrm{cmbs})$. No pieces revealed identifiable human alterations with the possible exception of \#5493-2. This 40 percent fragment of a Cyrtonaias sp. valve has an unusual circular modification to the central part of the shell. These appear as small $4 \mathrm{~mm}$ diameter holes forming a continuous series that created a larger hole about $17.5 \mathrm{~mm}$ in diameter in the central part. The series of possibly five small holes appear to have been drilled from the outside of the shell. Humans may have done this, but animal alterations may be possible as well.

\subsection{CHARCOAL}

About 17 samples yielded nearly $460 \mathrm{~g}$ of charcoal, but nearly 96 percent of the weight is derived from three samples. A $257 \mathrm{~g}$ sample accounts for 56 percent of the total weight, a $150 \mathrm{~g}$ sample represents 33 percent of the weight, and a root segment (Feature 31) accounts for 6.7 percent of the total. Most float samples from the various columns yielded less than $1 \mathrm{~g}$ of charcoal flecks per sample. A wood charcoal chunk from Feature 17, the unassigned occupation surface, was identified as mesquite. 
This wood species was identified in all other occupations.

\subsection{SUMMARY AND INTERPRETATIONS}

The cultural materials from the miscellaneous affiliations are from mixed or unassignable occupation zones and do not represent a single cultural event. The stripping with the Gradall ${ }^{\mathrm{TM}}$ contributed to the location of numerous artifacts, but it did not provide sufficient horizontal continuity with other materials to clarify the affiliation of these materials. The extensive turbation caused by tree roots, rodents, and insects also contributed to the displacement of material, having moved pieces beyond the boundaries of the identified cultural zones. The material remains document the same or similar ranges of events and activities by hunter-gatherer groups as identified in the six identified occupations. These materials date to a general span of time identified by the dated occupations, which encompasses a 1,400-year time range between 2000 and 3400 B.P. 


\subsection{RESEARCH ISSUES}

The research issues presented in Section 3.4 defined the major issues to be addressed by the findings from the upper stratified cultural deposits of the Lino site. The findings resulted from mitigation excavations focused on a 196 $\mathrm{m}^{2}$ block measuring $7 \mathrm{~m}$ wide by $28 \mathrm{~m}$ long and $120 \mathrm{~cm}$ deep. Within that area, $174.6 \mathrm{~m}^{3}$ were dug with a Gradall ${ }^{\mathrm{TM}}, 48 \mathrm{~m}^{3}$ were hand excavated in $80 \mathrm{~cm}$ wide balks spaced about 3 $\mathrm{m}$ apart, and another $124 \mathrm{~m}^{2}\left(12.4 \mathrm{~m}^{3}\right)$ were hand excavated to $10 \mathrm{~cm}$ levels $\left(12.4 \mathrm{~m}^{3}\right)$ around features discovered during Gradall ${ }^{\mathrm{TM}}$ stripping. Since detailed site-specific investigations are rare across much of south Texas, and relatively little is known about specific adaptations to the region, these research issues are general and broad. In some instances, data sets necessary to address these issues were not present or not suitable to permit a comprehensive discussion of a specific issue. In other instances, new approaches were investigated in an attempt to explore whether other lines of data analyses might provide usable information to address a particular issue. The recovered data from the six identified cultural occupation zones at the Lino site are summarized and used to discuss seven broad issues that include: site formation processes, chronology and cultural affiliation, subsistence, paleoenvironment, burned rock technology, site structure and organization, and lithic resource procurement and technology.

\subsection{SITE FORMATION PROCESSES}

The natural deposits within the top $120 \mathrm{cmbs}$ were nearly all alluvial-derived sediment deposits. These deposits were fine overbank sediments as observed and documented in natural Zones 2, 3, and 4 overlying massive silty loam in Zone 5. Zone 1, which is modern fill brought in from elsewhere, tops this alluvial sequence. The alluvial overbank deposits consist of fine-grained sand, silt, or clay-size particles (Appendix J) deposited by slowly moving, very low-energy water from San Idelfonzo Creek. These low-energy sequences would not have moved coarse sediments larger than 3 to $4 \mathrm{~cm}$ in diameter. The one exception to the sequence of alluvial fine sediments at the Lino site is an ephemeral stone line occurring at the base of Zone 3. This dispersed line of relatively small cobbles measuring fewer than $10 \mathrm{~cm}$ in diameter is probably related to slope wash or colluvial redeposits and not alluvial actions.

The silty clay loam overbank deposits within Zones 2, 3, and 4 were laid down along a threedegree slope that dips down towards the west and the Rio Grande. The three zones reflect incremental aggradation to the terrace that happened during several flood episodes. The incremental nature of the deposition is reflected by the pedogenic development of Zone 3, which is a 15 to $20 \mathrm{~cm}$ thick cumulic A horizon that did not terminate or punctuate the soil development but added new sediment so as to slowly aggrade the surface. The sediments thickened over time without totally choking out the growing vegetation responsible for the A horizon development. Zone 5, the lowest natural zone, is a massive silty loam that dips about 20 degrees and also reflects sediment accumulation during a few flood events. The cultural deposits within Zone 5 follow the same general slope as the natural deposits but with shallower and compressed deposits occurring toward the east and thicker deposits occurring toward the west.

The $120 \mathrm{~cm}$ thick natural deposits accumulated over about a 1,400-year period and indicate relatively rapid deposition during which time humans intermittently occupied this terrace. Cultural materials in Zone 5 are estimated to date 3200 to 3400 B.P. based on a number of wood- 
charcoal radiocarbon dates. The cultural materials in Zone 3, near the top of the profile at about $40 \mathrm{cmbs}$, were directly dated by wood charcoal to about 2000 B.P. If the overbank deposits occurred on a periodic basis, and it appears that they did, then they would have buried previous occupational material and provided a relatively clean surface for subsequent occupations. This actually happened on a number of occasions with at least five and possibly six cultural occupation lenses identified within these natural alluvial deposits. The rate of deposition appears to be relatively constant in Zones 3, 4, and 5 with an accumulation rate of about $0.07 \mathrm{~cm} /$ year. The deposition of Zone 2 slowed considerably to a rate of about 0.017 $\mathrm{cm} /$ year. Since about 2000 B.P., the terrace has stopped receiving overbank deposits and was stabilized until the artificially added fill of Zone 1 was introduced in historic times.

Fossil pollen from Southwest Texas indicates a mesic (moist) period interval from 3000 to 2500 B.P. (Bryant and Holloway 1985) whereas data from central Texas reflects a relatively mesic period from 3000 to 1000 B.P. (Toomey et al. 1993). Johnson (1995) has suggested that a relatively dry and probably warm climate existed based on radiocarbon-dated alluvial stratigraphy from central Texas during what he terms the Edwards interval of ca. 4400 to 2700 B.P. If these climatic changes did occur in the area of the Lino site during the time span represented by the investigated natural deposits, then the massive silt of Zone 5 could coincide with the warm, dry interval. The incremental overbank deposits could have developed during the cool/ moist interval. The lowermost two cultural occupations, Occupations 5 and 6, probably occurred within the development of the massive silt zone. Occupation 4 , which is roughly 80 to $90 \mathrm{cmbs}$, is near the base of Zone 4, and it and the upper occupations are projected to have occurred within the overbank deposits, which are possibly related to the cool/moist period. For more discussion on the paleoclimate conditions, see section 13.4 below.

An important aspect to the natural and cultural deposits in the $120 \mathrm{~cm}$ thick targeted excavation zone involves understanding what has happened to the deposits since they formed. Within the last 100 years, the natural terrace deposits were partially covered with clay-rich sediments from some unknown outside source. This overburden added new and different types of material, including the possibility of cultural materials, to the top of the natural terrace. Below the intrusive fill from Zone 1 it was relatively easy to identify large objects within the fine terrace sediments in Zones 2, 3, 4, and 5 as having been brought in during human occupations. It is possible that a few materials were redeposited from other occupation zones by burrowing animals. Since the bulk of the natural sediments were deposited by low-energy waters, it is unlikely that substantial horizontal displacement of artifacts has occurred by the water actions of sheet washing or channel cutting. Nearly all items attributed to an occupation zone were brought to the site by prehistoric people.

During the data-recovery investigations, many large ant nests/colonies, termite trails and nests, tree roots, insect holes, and rodent holes and tunnels were observed. All of these actions may have displaced some natural and cultural deposits. The amount of disturbance from turbation activities is difficult to measure. It is assumed that many larger cultural objects such as the burned rocks over $40 \mathrm{~mm}$ in size would not have moved significantly, whereas tiny chert flakes, snail shells, and plant seeds smaller than $6.4 \mathrm{~mm}$ in size may have been displaced throughout the investigated matrix.

The extent of movement is indicated by a number of specific examples. For instance, a chunk of wood charcoal recovered during hand excavations from between 100 and $110 \mathrm{cmbs}$ in 
Unit D7 was radiocarbon dated to 900 B.P. (Beta124390). This was statistically much younger than the 3200 B.P. cultural deposits encompassing the charred wood chunk. It is believed that this charcoal piece was displaced downward about $100 \mathrm{~cm}$ during the last 2,000 years. If not directly displaced by some type of turbation, then the wood charcoal might represent an in situ burned tree root unaffected by turbation processes. The $\mathrm{A} / \mathrm{I}$ ratio results also indicate that considerable upward and downward movement occurred among the light Rabdotus snail shells. Small, unburned bristlegrass seeds (Setaria sp.) were discovered 50 to $60 \mathrm{cmbs}$. Due to the paucity of bone in the archeological deposits, the unburned condition of these seeds suggests that they are modern. These examples illustrate that some cultural material remains have undoubtedly moved vertically from their place of original deposition. However, it cannot be determined with any degree of certainty which objects moved or how far a single item had been displaced. Nevertheless, even though some vertical displacement of artifacts has occurred, the TDS plotting of artifact proveniences indicates that a fair amount of integrity remains within the discrete occupation zones.

Similar alluvial terrace deposits in south Texas have good potential to yield similarly stratified cultural deposits. These may contain one or two cultural occupation stratigraphically separated by much thicker deposits so that vertical mixing may not be a problem. The preservation of organic remains including bones and charcoal may also be similar and may be partially related to how soon flood deposits covered occupational debris after site abandonment. Other preservation factors are related to postdepositional processes and soil chemistry, which may destroy materials ordinarily preserved by rapid burial. The only way to determine many of these preservation factors is to conduct intensive testing in various site settings. Delineation of the general ages of the different sediment deposition packages within terraces correlated across the region may also permit the determination of the occupation ages within distinctive sediments. Numerous terrace settings will have to be tested to acquire cultural materials associated with wood charcoal to enable development of chrono-stratigraphic correlation on a regional level. The Lino site, with its stratified occupation zones and lack of preserved organic remains, may not be unique in south Texas; these sites are very informative and can contribute to many research issues.

\subsection{CHRONOLOGY AND CULTURAL AFFILIATION}

Wood charcoal was relatively abundant throughout the alluvial deposits and in specific cultural features and scattered across the identified occupational surfaces. The wood charcoal appeared as chunks measuring up to $12 \mathrm{~cm}$ in length, but very few isolated flecks or charcoal stains were recognized. Mesquite trees with deeply penetrating root systems were growing on the site, and burned and decayed mesquite roots were present throughout the 120 $\mathrm{cm}$ of investigated alluvial deposits. Since intense bioturbation caused some doubt in the context of the scattered charcoal pieces, caution was necessary in selecting charcoal samples for radiometric dating. Wood charcoal identification prior to selecting samples for dating often permitted the segregation of burned mesquite roots from probable burred fuel wood in the prehistoric fires. Wood charcoal chunks were selected for dating in preference to small charcoal flecks recovered from the sediment floatation sorts because various bioturbation processes may have contextually moved the smaller flecks. Wood charcoal was the preferred material for radiometric dating. Nine individual wood charcoal pieces were AMS dated to help establish when the six cultural occupations occurred. The associated absolute ages of these stratified cultural events along with some 
diagnostic projectile points contribute to the refinement of the basic south Texas chronological framework.

The uppermost and most recent component, Occupation 1 (located 30 to $50 \mathrm{cmbs}$ ), had wood charcoal dated to about 2050 B.P., which is an average of three wood charcoal dates. Unfortunately, the lowest event, Occupation 6, was only partially represented in the excavation block and did not yield wood charcoal from welldefined contexts of cultural features. Therefore, a wood charcoal chunk from the general occupation zone was dated. It yielded a $\delta^{13} \mathrm{C}$ adjusted age of $2740 \pm 50$ B.P. (Beta-121863), which appears to be too young for Occupation 6 in comparison to the average of three wood charcoal dates from Occupation 5. Occupation 5 , located 5 to $10 \mathrm{~cm}$ above Occupation 6, was wood charcoal dated by three samples to an average age of about 3260 B.P. Consequently, the age of the six occupations identified in the targeted top $120 \mathrm{~cm}$ of silty alluvial deposits falls between roughly 3400 and 2000 B.P. (1450 to 50 B.C.). Since dart points were predominately recovered, this time frame represents the latter part of the broad Archaic period.

Which components are representative of the Late Archaic and/or Middle Archaic is subject to interpretation and debate. As previously indicated, differences exist in the time intervals and artifact remains assigned to the Middle and Late Archaic periods (Hester 1980, 1995; Hall et al. 1986; Black 1989, 1995b). These differences become increasingly important when making inter- and intraregional comparisons of archeological assemblages. No single criterion is consistently used for dividing the Archaic into subperiods comparable to the occurrence of arrow points and pottery in separating the Late Prehistoric from the Late Archaic period. The general consensus of the Middle/Late Archaic transition has an arbitrary chronological dividing line at ca. 2300 B.P. (400 B.C.). Black (1995b:44) indicates that the Late Archaic is also defined by small, corner- or side-notched dart points (Ensor, Frio, Marcos, Fairland, and Ellis) and small, distally beveled tools. Tortugas points have also been found in Late Archaic contexts. However, Tortugas points and distally beveled tools both occur in Middle Archaic contexts (Black 1995b). Using tool forms alone in south Texas to identify time periods is very problematic because these specific forms have been used over a very long time.

The radiocarbon ages obtained from the investigated Lino site occupations represent an important period spanning the arbitrary chronometric boundary between the Middle and Late Archaic periods. Sites in south Texas with similar radiocarbon ages include 41LK201 (Hall et al. 1986), 41MC29 (Hall et al. 1986), 41MC 296 (Hall et al. 1986), 41LK28 (Taylor and Highley 1995), 41ZP364 (Quigg and Cordova 1999b). These five sites have yielded at least 10 wood charcoal dates between ca. 2000 and 2700 B.P. (50 to 750 B.C.).

An important aspect of the Lino site is the stratified nature of the six identified occupations and their association with at least 18 identified projectile points. It is these projectile points that can be used to establish cultural affiliation for the occupations. Twelve Tortugas, five Refugio, and one Matamoros point were identified in the six occupations. No stemmed or notched projectile points or notching flakes were recovered from the $120 \mathrm{~cm}$ thick deposits investigated at the Lino site.

Tortugas points were found in Occupation zones $1(n=3), 3(n=5)$, and $4(n=5)$ of the Lino site (Figure 13.1). The single Matamoros point came from Occupation 4 and thus appears to be directly associated with five Tortugas points. The 12 Tortugas and one Matamoros point were restricted to occupations above Occupation 5. A single Refugio point was the only other point type 


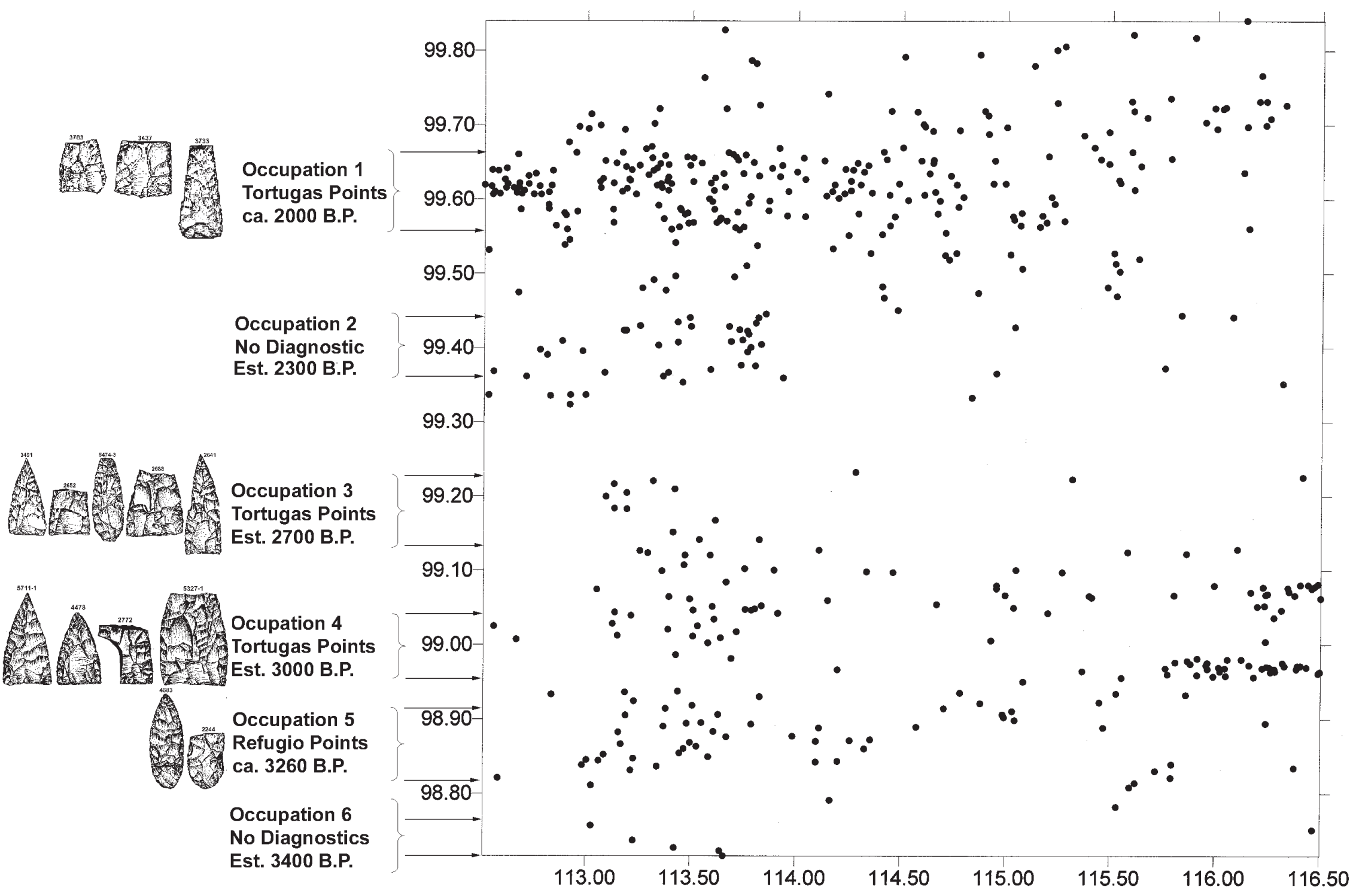

Figure 13.1 Cultural Stratigraphy (Shown by Vertical TDS Shots in a Selected Part of the Site), Associated Projectile Point Types, and Ages of Occupation Zones 1-6 at Lino Site (41WB437). 
recovered from these upper occupations, and it came from Occupation 3. No projectile points were recovered from Occupations 2 or 6 . Based on the wood charcoal dates from Occupations 1 and 5, the sequence of Lino site Tortugas points dates between ca. 3200 to 2000 B.P. This time span probably does not represent the maximum period of Tortugas point style use in south Texas. Since five Tortugas points and one smaller Matamoros point are all similar in form and technology and came from good context in Occupation 4, the morphologically different Refugio point in Occupation 3 might be out of context. In consideration of the turbation detected during excavation, it is possible that the single Refugio point from Occupation 3 was vertically displaced from deeper components, since other Refugios forms came from Occupation 5. Alternatively, the Refugio point type from Occupation 3 represents a later or terminal use of this type.

The two Refugio points from Occupation 5 are the only point type in that component. Occupation 5 was wood-charcoal dated by three samples to about 3200 B.P. Two other Refugio points (\#1523 and \#1829-1) were recovered from questionable or mixed deposits in Area $\mathrm{H}$ and Units 17-1 through 17-6. The occupational material in Units 17-1 through 17-6 could not be assigned to any specific occupation zone. The context was questionable and represented either a mixture with Occupation 4 or, more likely, Occupation 5. Based on the context of these few identifiable specimens, the Refugio points primarily appear to be below the Tortugas and Matamoros points at the Lino site. Two wood charcoal dates from Occupation 5 also place the Refugio points earlier than the Tortugas points at the Lino site.

Refugio points appear to represent a distinguishable point type that possibly represents a separate cultural group in the Lino site stratifiedoccupation sequence. It is possible that the Refugio points continued in use and may co-exist with Tortugas points in some areas of south Texas. The Lino site provides a rare occupation containing only Refugio points that can now be dated to roughly 3400 B.P.

The dated components from the Lino site probably do not span the entire temporal range for Refugio points in south Texas. Although other excavated sites across the region have yielded Refugio points (41WB13 [McGraw 1983] and the Shrew site 41WN73 [Labadie 1988]), neither site yielded absolute dates associated with the Refugio point layers. The Refugio point at 41WB13 was from $32 \mathrm{cmbs}$ and associated with a burned rock-filled basin about $44 \mathrm{~cm}$ in diameter and located less than $1 \mathrm{~km}$ upstream from the Lino site (McGraw 1983). The three Refugio points from 41 WN73 were from mixed contexts with numerous other point types from a hilltop setting in the San Antonio River flood plain (Labadie 1988). At least 12 Refugio specimens were recovered from the Loma Sandia site 41LK28 (Highley 1995:431433). However, only one Refugio point was directly associated with a well-defined and dated cemetery feature (Feature 111), which also contained two Tortugas specimens. The associated wood charcoal dates indicate an age of 2400 to 2800 B.P. (850 to 550 B.C.) (Taylor 1995). Further excavation of other stratified sites with Refugio points associated with radiometric dates will undoubtedly expand the temporal range of the Refugio point type. Prewitt (1995:127) has shown the Refugio point type to be most prevalent in south Texas with some occurring in the central and Trans Pecos regions. The different distribution of this point type may eventually lead to the delineation of core area and peripheral use regions that might be associated with specific cultural groups.

Other excavated and dated sites in south Texas have documented different, broad time ranges for Tortugas points. In the Falcon Reservoir area of far south Texas, a Tortugas occupation that yielded 28 Tortugas points at 41SR42 (originally 41- 
78B9-4) (Hartle and Stephenson 1951) was wood charcoal dated to $4650 \pm 300$ B.P. (lab and number unknown) (Suhm 1954:565). Another welldefined occupation at 41ZP364 with one Tortugas point was dated using two wood charcoal samples to between 4620 and 4820 B.P. (Beta-112422 and Beta-110798) at 41ZP364 (Quigg and Cordova 1999b). In contrast, a Matamoros point and associated occupational debris was wood charcoal dated to 2630 B.P. (Quigg and Cordova 1999b).

Based on the discoveries at sites $41 \mathrm{LK} 31 / 32$, 41LKJ67, and 41LK210 in Choke Canyon Reservoir area, many of the unstemmed, thin bifaces assigned to Groups 2, 3, 4, and 5 were identified as representative of the Middle Archaic period (Hall et al. 1986:399). These groups appear to be minor morphological variations of the Tortugas point type. The Loma Sandia cemetery site 41LK28 located just east of Choke Canyon Reservoir yielded some 122 triangular points representing a Tortugas-Matamoros point size continuum from human burial contexts that dated to between 2400 and 2800 B.P. (850 to 450 B.C.) (Taylor and Highley 1995). The temporal differences in the age of Tortugas points between the Falcon Reservoir and the Choke Canyon area is a fascinating issue that requires further investigation.

The well-stratified and dated occupations at the Lino site have provided new and important data on the age, distribution, and use of the Tortugas points. The Tortugas points do occur as a unique type in some components and do not always cooccur with some other point form. The Lino site provided at least one specific age for the Refugio point that has not been previously dated from good archeological contexts. These projectile point associations and wood charcoal dates have aided in the assignment of times for specific point types and therefore contributed to the overall chronological framework of south Texas.
About $320 \mathrm{~km}$ up the Rio Grande valley in the Lower Pecos region lies Bonfire Shelter, a wellstratified bison kill site containing at least five bison kill events. One of the upper zones, located between about 35 and $55 \mathrm{cmbs}$, yielded a dense bison bone bed (Bone Bed 3) that dates roughly between 2300 and 2800 B.P. as based on two wood charcoal and two burned bone samples (Dibble and Lorrain 1968). This event is roughly contemporaneous with the Lino site occupations. An important aspect at Bonfire Shelter is the recovery of 19 large corner- and basally notched dart points (subdivided into five groups), including three Montell, two sidenotched, and an indented stemmed point associated with the butchered bison bones in Bone Bed 3 (Dibble and Lorrain 1968). No unnotched triangular points were present that might be classified as Tortugas or Matamoros points types. Therefore, it appears that spatially distinct yet contemporaneous groups were employing different projectile point types in various areas of south Texas. The recovery of corner-notched and unnotched triangular points in south Texas therefore may signal either mixed components or some interactions or joint use of areas during the Late Archaic period.

Distally beveled tools have also been linked to the Archaic period. At the Choke Canyon Reservoir area, distally beveled tools occurred during both the Middle and Late Archaic periods and are associated with specific dates of 4310 to 2600 B.P. (236 to 660 B.C.) (Hall et al. 1986:399-401). At the nearby Loma Sandia site, numerous distally beveled tools date between 2400 and 2800 B.P. (850 to 450 B.C.) (Taylor and Highley 1995). Southeast of the Lino site, in the Falcon Reservoir area, the deeply buried site of 41SR42 yielded many Clear Fork tools (Hartle and Stephenson 1951) dated to $4650 \pm$ 300 B.P. on wood charcoal (Shum et al. 1954:565). Furthermore, site 41ZP364 also yielded distally beveled tools in Middle to Late Archaic contexts (Quigg and Cordova 1999b). 
At the Lino site, about seven distally beveled tools were found that date between 3400 and 2000 B.P. (1450 to 50 B.C.). These dates are consistent with the previously obtained radiocarbon dates and occur during the period spanning the Middle and Late Archaic periods. It appears that these distally beveled Clear Fork and Nueces tools are not very time sensitive across south Texas. They may have been utilized for 5,000 to 6,000 years.

It is not clear if burned rock-filled pits with considerable charcoal, like Lino site Features 14, 20 , and 27 , have been previously documented for the Middle/Late Archaic period in south Texas. The extensive work at Choke Canyon Reservoir certainly documented considerable burned rock in the occupations of comparable time periods, and numerous hearth features with burned rocks have been reported from the area. Unfortunately, most lack detailed descriptions, which makes specific comparisons difficult. Feature 5 at 41LK201 appears to be quite similar to the three rock filled pits at the Lino site. In addition to the apparent presence of a rock filled pit with charcoal sticks, Feature 5 also incorporated recycled mano and grooved sandstone abrader fragments as burned rock elements (Highley 1986:22-24). Wood charcoal identified as acacia or Prosopis sp. from Feature 5 was radiocarbon dated to 2450 B.P. (480 B.C., TX-4665) (Highley 1986:199). The available information indicates that at least one other south Texas site, 41LK201, had a similar rock filled pit that dates to the same time period as the Lino site's rock filled pits.

Rock filled pits are not presently linked to a specific cooking procedure or a specific food resource. Since they are interpreted as heating elements at the Lino site they should be expected to occur in most campsites where rocks were used to transfer heat in various cooking events. Their exact form and size may change through time or for various functions.
Since many archeological sites in south Texas have a paucity of preserved of wood charcoal, the Lino site project advanced investigations into finding new means of utilizing burned rock residues for dating cultural events. This approach was pioneered at three Falcon Reservoir sites with promising results (Quigg 1999; Quigg and Cordova 1999a, 1999b).

At Occupation 1 of the Lino site, Features 10 and 14 (both containing wood charcoal and burned rocks) were targeted for comparative dating. Feature 10 yielded a single wood charcoal AMS date and a single organic residue AMS date from the center of a burned rock that were statistically identical at 2120 B.P. (Table 5.3). Feature 14 yielded one wood charcoal date of 1950 B.P. and, from three separate burned rocks, three organic residue AMS dates of 2290 , 2470, and 3190 B.P. (Table 5.3). Compared to the wood charcoal age of 1950 B.P., all three organic residue assays are older by 340,520 , and 1,240 years, respectively. These three differences are moderately to excessively large. It is the author's opinion that the organic residue can be used to obtain acceptable AMS radiocarbon dates, but the accumulated residues within the rocks can be complex. It is quite possible that the age differences between the Feature 14 charcoal and rock residues resulted from the dating of older residues retained in previously used burned rocks that were not completely destroyed during the reuse and reheating of rocks used for cooking.

A third comparative study involves Feature 29 from Occupation 5. The dated wood charcoal chunk from this feature yielded an AMS date of 3460 B.P. whereas the organic residue from one burned rock yielded an AMS date of 4920 B.P. (Table 5.3). This 1,460-year difference is not considered acceptable. The residue date is much older than the documented age for Occupation 5 and is attributed to the dating of older residues retained in previously fired rock. 
It is unclear how older organic residues inside the burned rocks would have survived the subsequent reheating unless the temperatures were insufficient to purge the lipids. Presently, one plausible explanation for the occurrence of older residues than the associated radiocarbon date on wood charcoal involves the presence of residual fatty acids from reused stones. Further investigations are required to define the possible variables that could arise from dating organic residues inside burned rocks. Although problems obviously exist with using these organic residues to date cultural events in some cases, this approach appears to provide an alternative when charcoal is lacking. It is recommended that a number of residue dates be obtained from a single occupation zone to investigate and identify possible reuse of burned rocks and to obtain an average for the date of the occupation. Other studies should also focus on examining the chemical components of fatty acid residues comparable to the collagen studies that Dr. Stafford has conducted on dating bone (Stafford 1984).

\subsection{SUBSISTENCE ISSUES}

Evidence of the subsistence patterns and the kinds and quantities of plant and animals used as food resources at the Lino site is difficult to amass due to the lack of preserved animal bones and scarcity of charred economic plant parts, plant pollen, and phytoliths. The poor preservation is attributed to high $\mathrm{pH}$ and calcium carbonates in the silty sediments on site. Even the extensive efforts to float feature and column matrices failed to yield charred economic botanical remains. Preserved materials include land snail shells and fresh water mussel shells, which are addressed below.

In an effort to overcome the lack of direct physical evidence, indirect chemical proxies for potential food resource categories were sought using stable (nonradioactive) carbon $\left({ }^{13} \mathrm{C}:{ }^{12} \mathrm{C}\right.$ ratio) and nitrogen isotopes and lipid residue analyses of organic residues extracted from the interior of burned rocks. Differences in carbon isotope values reflect the variations in the integration of atmospheric carbon by plants using three photosynthetic processes, which are designated C3, C4, and CAM. The background on stable isotopes is presented, and each of these three photosynthetic pathway groups is discussed below. Within each group, the present biological literature is summarized, followed by presentation of new isotopic data on modern edible plant parts from south Texas specimens. Although much less is known about nitrogen isotopes, they have been shown to be important in distinguishing between $\mathrm{C} 3$ legumes and C3 non-legumes. Consequently, nitrogen isotopes are discussed under the $\mathrm{C} 3$ pathway. The stable carbon and nitrogen isotopic results of prehistoric data from the Lino site are presented next, followed by the lipid residue analysis from the burned rock and ground stone samples. Combined stable carbon and nitrogen isotope results and the lipid residue results are discussed. Finally, the general classes of food resources that probably account for the isotopic and lipid values from for the Lino site are summarized.

The ratio of ${ }^{13} \mathrm{C}:{ }^{12} \mathrm{C}$ used to express differences in stable carbon abundance is expressed as ${ }^{13} \mathrm{C}$ value in units of parts per thousand (\%). The $\delta^{13} \mathrm{C}$ values detected in plants are largely a function of the photosynthetic pathway, and they may be sensitive to some environmental factors (Tieszen 1994). The three different metabolic pathways recognized in plants are the CalvinBenson (CAL or C3) pathway, the Hatch-Slack (HS or C4) pathway, and the crassulacean acid metabolism (CAM) pathway. Slight variations in the carbon isotopic values are a direct result of the ambient $\delta^{13} \mathrm{C}$ value for carbon dioxide $\left(\mathrm{CO}_{2}\right)$ in air, which is normally around $-8 \%$. (O'Leary 1981). Herbivores that eat the plants from the three groups reflect a similar isotopic signature, but as the food nutrients are 
assimilated into the different parts of an animal's system, a fractionation effect takes place that diminishes the values. This trophic depletion level continues as humans or carnivores consume the herbivores. The general $\delta^{13} \mathrm{C}$ values presented below are from the biological literature and are obtained from plant leaves rather than edible plant parts. Different plant parts can have slightly different $\delta^{13} \mathrm{C}$ signals ranging between $1.6 \%$ and $6.0 \%$; the level can also vary for a single plant part depending on seasonality (Warembourg 1993; Tieszen 1994). Seeds are about 5\% more positive than their corresponding leaves (Tieszen 1994).

The ${ }^{15} \mathrm{~N}:{ }^{14} \mathrm{~N}$ ratio is used to express the differences in stable nitrogen abundance and is expressed as $\delta^{15} \mathrm{~N}$ value in units of parts per thousand (\%o). Most plants obtain natural nitrogen from the soil. However, some plants, such as C3 legumes, are capable of obtaining nitrogen from the atmosphere with the aid of microorganisms. Such plants are designated as nitrogen-fixing plants. The plants that dominate the C3 legume group are those that produce beans and include mesquite, Texas ebony, Texas kidneywood, acacias, and cultigen beans. Most of the nitrogen baseline research has been conducted on terrestrial and marine organisms in Africa (Sealy et al. 1987). The different nitrogen levels in legumes and nitrogen-fixing plants and non-fixing plants are close to $2 \%$ (Heaton 1987). Although the $\delta^{15} \mathrm{~N}$ values appear to overlap, plants, which rely on soil nitrogen, may have significantly higher nitrogen values than some nitrogen-fixing plants (Delwiche et al. 1979; Virgina and Delwiche 1982; Shearer et al. 1983; Ambrose 1991).

Nitrogen isotope ratios may not undergo marked fractionation similar to that of carbon isotopes with each different trophic level. Trophic level studies between terrestrial herbivores and carnivores have shown differences in the range of $3.0 \%$ to $3.5 \%$ (Schoeninger and DeNiro
1984) or 5.0\%o to 6.0\% (Ambrose and DeNiro 1986). The nitrogen ratio of terrestrial animals varies widely and generally corresponds to the amount of rainfall; values above $10 \%$ for herbivores occur in areas receiving fewer than $400 \mathrm{~mm}$ of rain per annum (Heaton et al. 1986; Ambrose and DeNiro 1986). Preliminary information indicates that variability in nitrogen isotopes is greatest in areas with lowest rainfall.

In order to gain empirical comparative information on the $\delta^{13} \mathrm{C}$ values for the edible plant parts specifically in south Texas, a series of modern samples were collected and analyzed. Recently acquired stable carbon and nitrogen isotopic signatures from 36 modern edible plant parts from Falcon Reservoir plus six additional samples collected during the A.D. 1930s and 1940s and on file at the University of Texas herbarium were processed for control (Table 13.1; Quigg and Cordova 1999b). These samples were supplemented by 16 more modern plant and animal samples collected and processed during the present project (Figures 13.2 and 13.3; Table D2). These 58 samples provide the initial interpretative baseline for the isotope results from the archeological materials from south Texas. Most modern plants and animals sampled were those mentioned in the ethnographic literature as food resources used by the inhabitants of south Texas (Hodge 1907; Ruecking 1955; Campbell and Campbell 1981; Campbell 1983; Salinas 1990).

Each of the three photosynthetic pathway groups is discussed below, starting with the $\mathrm{C} 3$ material.

\subsubsection{C3 Plants and Herbivores That Primarily Consume C3 Plants}

The C3 plants consist primarily of most trees, flowering shrubs, and cool season grasses. They have a carbon isotopic range between $-22 \%$ to $-32 \%$ with an average value of $-26.5 \%$ based on analysis of leaves (Tieszen 1994). The $\delta^{15} \mathrm{~N}$ 
Table 13.1 Stable Carbon and Nitrogen Isotope Values on Modern Plant Parts from South Texas.

\begin{tabular}{|c|c|c|c|c|c|c|c|}
\hline \multirow[b]{2}{*}{$\begin{array}{c}\text { Sample } \\
\text { Code }\end{array}$} & \multirow[b]{2}{*}{ Material Type } & \multicolumn{3}{|c|}{ Carbon Isotope } & \multicolumn{3}{|c|}{ Nitrogen Isotope } \\
\hline & & $\begin{array}{c}\text { Microgram } \\
\text { Carbon } \\
\end{array}$ & $d^{13} C$ & $\begin{array}{l}\text { Sample } \\
\text { Weight }\end{array}$ & $\begin{array}{c}\text { Microgram } \\
\text { Nitrogen } \\
\end{array}$ & $\mathbf{d}^{15} \mathbf{N}$ & $\begin{array}{l}\text { Sample } \\
\text { Weight }\end{array}$ \\
\hline MQ-ZP-A10 & Acorn nut & 827 & -26.34 & 1.98 & 38.5 & 3.12 & 5.37 \\
\hline MQ-ZP-B7 & Acorn nut & 992 & -24.63 & 1.87 & 32.7 & -0.19 & 6.30 \\
\hline MQ-ZP-A2 & Bean & 1008 & -23.71 & 2.25 & 383.1 & 1.65 & 9.05 \\
\hline MQ-ZP-C10 & Bottle gourd seeds & 744 & -26.79 & 1.93 & 52.6 & 3.87 & 5.62 \\
\hline MQ-ZP-A12 & Bur oak nut & 631 & -25.60 & 1.52 & 30.1 & 0.51 & 6.01 \\
\hline MQ-ZP-C3 & Caesalpinia & 1063 & -23.86 & 2.39 & 298.1 & 2.50 & 7.83 \\
\hline MQ-ZP-A4 & Clammyweed seed & 1350 & -26.41 & 2.58 & 150 & 4.43 & 4.56 \\
\hline MQ-ZP7-C6 & Coyotillo berry & 1041 & -25.13 & 2.29 & 162.7 & 2.61 & 8.27 \\
\hline MQ-ZP-C2 & Crow poison & 927 & -26.35 & 2.35 & 117.8 & 4.43 & 7.84 \\
\hline MQ-ZP-B5 & Guayacan fruit & 938 & -25.94 & 2.01 & 135 & 13.32 & 4.25 \\
\hline MQ-ZP-A3 & Guaycan seed & 973 & -27.04 & 1.96 & 204.7 & 13.42 & 5.98 \\
\hline MQ-ZP-A9 & Huisache bean & 796 & -22.80 & 1.65 & 411.6 & 0.77 & 8.33 \\
\hline MQ-ZP-B3 & Juniper seed & 920 & -26.93 & 1.92 & 86.2 & 2.57 & 5.32 \\
\hline MQ-ZP-C1 & Leather stem seed & 848 & -23.86 & 1.84 & 433.8 & 4.53 & 7.66 \\
\hline MQ-ZP-A8 & Lechuguilla base & 763 & -12.81 & 1.83 & 47.3 & -0.22 & 4.62 \\
\hline MQ-ZP-A5 & Mesquite bean & 805 & -26.78 & 1.90 & 27.9 & -1.77 & 3.83 \\
\hline MQ-ZP-A6 & Mesquite bean & 991 & -25.23 & 2.30 & 144.3 & 9.13 & 2.41 \\
\hline MQ-ZP-A11 & Mesquite sap & 824 & -21.77 & 2.06 & 22.7 & 4.57 & 5.35 \\
\hline MQ-ZP-B6 & Pecan nut & 1344 & -29.24 & 1.95 & 128.1 & 2.57 & 6.45 \\
\hline MQ-ZP-B11 & Pinyon nut & 1274 & -23.30 & 2.06 & 206.2 & 2.06 & 7.84 \\
\hline MQ-ZP-B4 & Prickly pear fruit seed & 1173 & -12.08 & 2.26 & 101.4 & 7.73 & 4.52 \\
\hline MQ-ZP-B1 & Prickly pear pad & 794 & -13.03 & 2.49 & 26.4 & 13.97 & 5.36 \\
\hline MQ-ZP-C7 & Rattlebush seeds & 1030 & -25.25 & 2.24 & 519 & 7.83 & 8.75 \\
\hline MQ-ZP-B12 & Retama seed & 1080 & -24.89 & 2.28 & 431.5 & 4.88 & 5.56 \\
\hline MQ-ZP-A7 & Sotol bulb/base & 855 & -24.20 & 2.04 & 126.6 & -1.22 & 5.56 \\
\hline MQ-ZP-C11 & Sotol bulb- burned & 736 & -23.35 & 1.52 & 45.4 & 1.40 & 8.95 \\
\hline MQ-ZP-C12 & Sotol bulb unburned & 789 & -22.38 & 1.79 & 25.4 & 0.47 & 8.75 \\
\hline MQ-ZP-C4 & Spanish dagger flower seed & 823 & -12.65 & 1.97 & 477.2 & 4.55 & 9.80 \\
\hline MQ-ZP-C9 & Spanish dagger pod & 739 & -13.36 & 2.02 & 25.9 & 2.27 & 6.08 \\
\hline MQ-ZP-C8 & Spanish dagger seeds & 1071 & -13.64 & 1.99 & 110.2 & 5.04 & 5.73 \\
\hline MQ-ZP-C5 & Tasajillo fruit & 556 & -13.25 & 1.83 & 46 & 7.87 & 7.12 \\
\hline MQ-ZP-B2 & Texas ebony seed & 1284 & -24.65 & 2.62 & 190.9 & 5.38 & 6.16 \\
\hline MQ-ZP7-B8 & Texas kidneywood bean & 879 & -27.04 & 1.90 & 153.6 & 0.17 & 1.89 \\
\hline MQ-ZP-B9 & Texas kidneywood seed hull & 961 & -28.96 & 2.37 & 50 & -1.04 & 8.18 \\
\hline MQ-ZP-B10 & Texas mountain laurel seed & 1265 & -27.77 & 2.40 & 227.5 & 3.54 & 8.07 \\
\hline MQ-ZP-A1 & Walnut meat & 1414 & -28.19 & 2.04 & 188.7 & -0.88 & 6.28 \\
\hline
\end{tabular}

Plant parts from the University of Texas Herbarium collected prior to ca. A.D. 1950

\begin{tabular}{|c|c|c|c|c|c|c|}
\hline $22317-5 B$ & Texas ebony bean $(3 / 20 / 1907)$ & Hidalgo Co. & -22.5 & 0.8 & 6.1 & 0.8 \\
\hline 22317-6B & Mesquite bean (6/4/1945) & Webb Co. & -24.7 & 2.1 & 7.1 & 2.1 \\
\hline 22317-7B & Blackbrush acacia bean $(5 / 14 / 1928)$ & Kenny Co. & -24 & 0.1 & 3.2 & 0.1 \\
\hline 22317-8B & Tasajillo fruit $(9 / 19 / 1943)$ & La Salle Co. & -13 & 0.5 & 7.3 & 0.5 \\
\hline 22317-9B & Prickly pear fruit $(5 / 25 / 1946)$ & Hidalgo Co. & -12.3 & 2.3 & 12 & 2.3 \\
\hline $22317-10 \mathrm{~B}$ & Retama bean $(5 / 22 / 1933)$ & Zapata Co. & -25.4 & 0.4 & 9.1 & 0.4 \\
\hline
\end{tabular}

Data from Quigg and Cordova 1999b, funded by TransTexas Gas Corp. 


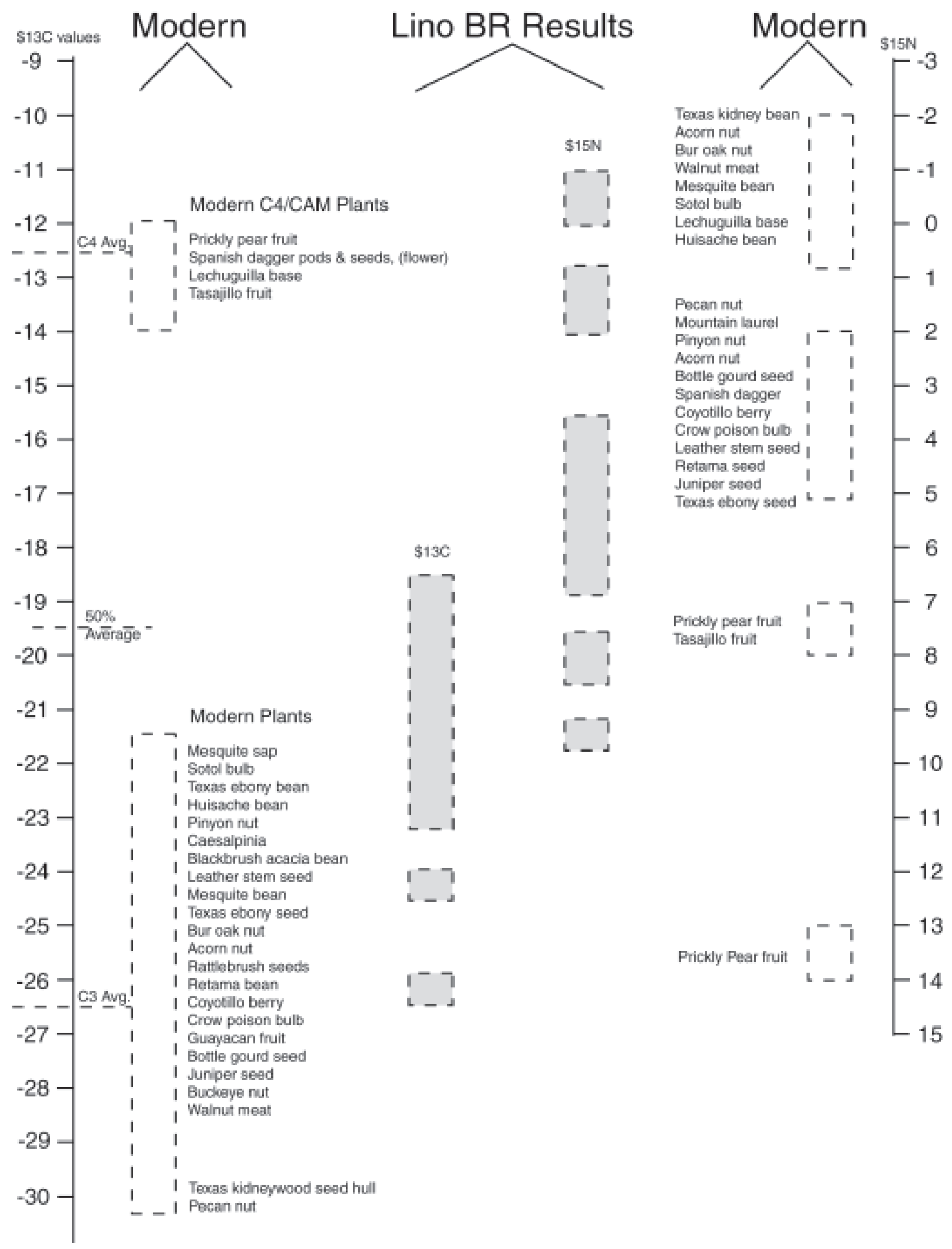

$\$ 15 N$

$\mathrm{I}^{-7}$

$1-4$

-1
1
-1

Pecan nut

Mountain laure

Bottle gourd seed

Spanish dagger

Cros poison butb

Leather stem seed

Retama seed 


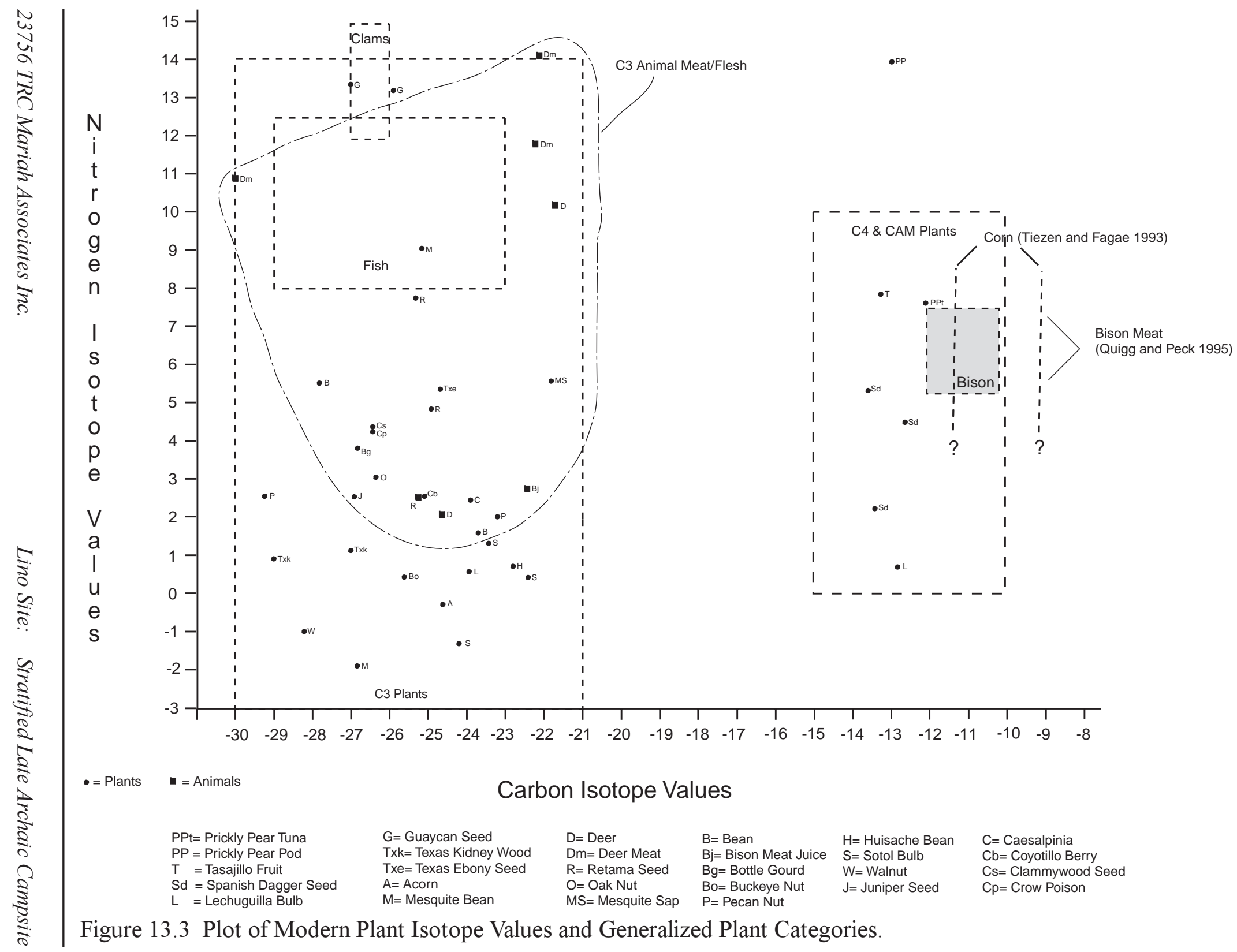


values from terrestrial plants in South Africa typically range from $-1.0 \%$ to $6.0 \%$ with no apparent consistent differences between $\mathrm{C} 3$ plants and C4 grasses or among the various photosynthetic pathway types (Heaton 1987). Eight C3 species of non-legume plants from southern California yielded a $\delta^{15} \mathrm{~N}$ mean of $5.7 \pm$ 0.3\%o (Shearer et al. 1983).

The modern samples of C3 legume plant parts from south Texas included mesquite beans, Texas ebony seeds, Texas kidneywood beans and pods, retama beans, rattlebush beans, caesalpina beans, and huisache beans that yielded $\delta^{13} \mathrm{C}$ values ranging from $-22.4 \%$ o to $-29.0 \%$ (Table 13.1, Figures 13.2 and 13.3; Quigg and Cordova 1999). These C3 legume results provide an average $\delta^{13} \mathrm{C}$ value of $-25.3 \%$ and are very close to the general average value of $\mathrm{C} 3$ plants of $-26.5 \%$. The $\delta^{15} \mathrm{~N}$ values from beans range from $-1.8 \%$ o to $9.1 \%$, with an average of $2.9 \%$ (Table 13.1, Figures 13.2 and 13.3). The $\delta^{15} \mathrm{~N}$ value for the various nuts sampled range between $0.9 \%$ to $3.5 \%$ with an average of $1.8 \%$. Mesquite beans from the Sonoran desert in California yielded a mean of $0.9 \pm 0.3 \%$ o (Shearer et al. 1983). One mesquite bean sample (MQZP-A6) yielded a very high $\delta^{15} \mathrm{~N}$ value of $9.13 \%$, which is beyond the expected range and may be an aberrant or contaminated sample. The leaves of five legumes species encompassing 13 samples had a mean of $4.0 \pm 0.6 \%$. The California mesquite bean values had much lower $\delta^{15} \mathrm{~N}$ values than those values derived for the modern south Texas mesquite beans (Shearer et al. 1983).

Some herbivores, such as deer, that ate these kinds of leaves had isotopic signatures reflecting their predominant C3 plant diet. Deer are nonselective browsers that limit their intake of grasses and feed mostly on leafy foliage from C3 plants. New analysis of modern carbon and nitrogen isotopes on southern Texas deer parts yielded information relating to their feeding habits. Dried modern deer tendons from an individual from Zapata County yielded $\delta^{13} \mathrm{C}$ value of $-21.7 \%$ and $\delta^{15} \mathrm{~N}$ value of $10.2 \%$ (table in Appendix D). A dried skin sample from another modern deer from La Salle County yielded a $\delta^{13} \mathrm{C}$ value of $-22.1 \%$ and a $\delta^{15} \mathrm{~N}$ value of $14.3 \%$. A bone marrow sample yielded a $\delta^{13} \mathrm{C}$ value of $-30.1 \%$ and a $\delta^{15} \mathrm{~N}$ value of $10.9 \%$, and a dried meat sample yielded $\delta^{13} \mathrm{C}$ value of $22.2 \%$ and $\delta^{15} \mathrm{~N}$ value of $11.8 \%$. From the Zapata and La Salle counties individuals, it appears that south Texas deer have an average $\delta^{13} \mathrm{C}$ value of $-22.0 \%$ with an average $\delta^{15} \mathrm{~N}$ value of $11.8 \%$. Since the trophic level typically increases the $\delta^{13} \mathrm{C}$ by as much as $2 \%$ to $4 \%$ o (DeNiro and Epstein 1978), the south Texas deer diet apparently focused on $\mathrm{C} 3$ plants that had average $\delta^{13} \mathrm{C}$ values between $-24.0 \%$ to $-26.0 \%$. The nitrogen isotopes levels of the two deer average about $10.2 \%$ and are considered to reflect the nitrogen levels in plants or some other unknown environmental conditions.

\subsubsection{C4 Plants and Herbivores That Primarily Consume C4 Plants}

The C4 plants include warm-season grasses such as curly mesquite (Hilaria belongeri), buffalo grass (Buchloe dactyloides), blue grama (Bouteloua gracilis), and bermuda grass (Cynodon dactylon) that have $\delta^{13} \mathrm{C}$ values ranging between $-17 \%$ o to $-9 \%$ with an average of $-12.5 \%$. Modern North American corn is a special member of the warm-season grasses that have been analyzed and yielded a $\delta^{13} \mathrm{C}$ value ranging between $-10.8 \%$ and $-11.9 \%$ o (Tieszen and Fagre 1993). Archaeological maize does not change during charring and thus should have the same carbon isotope values as modern samples of C4 plants when adjusted for anthropogenic alteration of atmospheric $\delta^{13} \mathrm{CO}_{2}$ (Tieszen and Fagre 1993).

Generalized consumers of grasses, including bison, would reflect a carbon isotopic signal that 
reflects the vegetation of the region in which they were feeding. Bison grazing in a $\mathrm{C} 4$ grassland as projected for much of this region should yield a $\delta^{13} \mathrm{C}$ values on meat of about $-9.0 \%$. The $\delta^{15} \mathrm{~N}$ values of $5.9 \%$ and $6.6 \%$ on prehistoric bison bones from western and northern Texas, respectively (Quigg and Peck 1995; Quigg 1997), provide a foundation to interpret the prehistoric nitrogen isotope values. The $\delta^{15} \mathrm{~N}$ values derived from bison bones are assumed to be close to the average $\delta^{15} \mathrm{~N}$ values from the grasses that these herbivores consumed.

No modern samples of grasses or corn samples were analyzed for their carbon or nitrogen isotopic values.

The CAM plants can utilize both the $\mathrm{C} 3$ and $\mathrm{C} 4$ photosynthetic pathways depending on temperature and photoperiod. Typical CAM plants include succulents such as cacti, with values that are intermediate to the $\mathrm{C} 3$ and $\mathrm{C} 4$ averages and can range between $-30 \%$ to $-10 \%$ (van der Merwe 1982; DeNiro 1987; Boutton 1991). However, most CAM plants have $\delta^{13} \mathrm{C}$ values within the range of that for C4 plants (e.g., Eickmeier and Bender 1976; Griffiths 1992).

The modern CAM succulent and cactus plants sampled from south Texas include a lechuguilla base, prickly pear pad, prickly pear fruit and seeds, Spanish dagger seeds and pods, Spanish dagger flower seeds, and tasajillo fruit. These samples yielded $\delta^{13} \mathrm{C}$ values that range from $-12.1 \%$ o to $13.7 \%$ with a mean of $-13.0 \%$ (Table 13.1 , Figures13.2 and 13.3). These modern values are statistically identical to the $\delta^{13} \mathrm{C}$ range of $\mathrm{C} 4$ grasses. The $\delta^{15} \mathrm{~N}$ values from CAM succulents range from $-0.2 \%$ o to $14.0 \%$ with an average value of 7.3\%o (Table 13.1, Figures 13.2 and 13.3).

There is a marked contrast between the $\mathrm{C} 3$ and C4/CAM plants. Since the CAM plants and the C4 grasses appear to have very similar carbon isotope values, these are considered as one group designated $\mathrm{CAM} / \mathrm{C} 4$. The $\delta^{13} \mathrm{C}$ value difference of $12.4 \%$ between the modern $\mathrm{C} 3$ plant parts and the modern $\mathrm{CAM} / \mathrm{C} 4$ plant parts provide a statistical and significant numerical spread useful in distinguishing these groups. This $12.4 \%$ o difference empirically derived for south Texas is similar to the $14 \%$ o spread between the C3 and C4/CAM photosynthetic pathway plant groups in the published literature (Boutton 1991). A residue containing an equal mixture of both plant groups would provide an average carbon isotope value of about $-19.5 \%$. The various C3 nuts yielded an $\delta^{13} \mathrm{C}$ average of $-26.4 \%$. This value is nearly identical to the $-25.3 \%$ for the $\mathrm{C} 3$ legumes. Consequently, $\delta^{13} \mathrm{C}$ values alone can not be used to differentiate between the $\mathrm{C} 3$ nuts and the $\mathrm{C} 3$ legumes but are useful only to separate the $\mathrm{C} 3$ from the $\mathrm{CAM} / \mathrm{C} 4$ plants. The $\mathrm{C} 3$ nuts and $\mathrm{C} 3$ legumes must be considered as a single group.

The $\delta^{15} \mathrm{~N}$ values for $\mathrm{C} 4$ grasses are unknown, but the average $\delta^{15} \mathrm{~N}$ values for the modern south Texas CAM plants appear relatively high, with an average of $7.3 \%$. This contrasts significantly from the $\delta^{15} \mathrm{~N}$ average of $1.8 \%$ for the modern C3 nuts and 2.9\%o for the modern C3 legumes (Figure 13.2). The difference in the average $\delta^{15} \mathrm{~N}$ values between CAM and legumes is $4.4 \%$ and may be sufficiently distinct to potentially differentiate CAM plants from C3 legumes on the basis of nitrogen isotopes.

The $\delta^{15} \mathrm{~N}$ data from California indicates that the non-legume plants of that area were only $0.9 \%$ o less positive than the nitrogen isotopes from modern legume beans from south Texas (Shearer et al. 1983). The close agreement between these averages causes considerable difficulty in trying to interpret archeological data using published data from other regions, especially if they are based on non-edible plant parts. Regional factors contributing to different $\delta^{15} \mathrm{~N}$ values may be linked to seasonality, water stress, and latitude (Tieszen 1994:265). 
The $\delta^{13} \mathrm{C}$ values for corn, bison meat, and possibly $\mathrm{C} 4$ grasses are nearly identical. Since these values cannot be separated, they constitute members of the $\mathrm{C} 4$ group.

\subsubsection{The Lino Site Carbon and Nitrogen Isotope Results}

Prehistoric cooking practices are assumed to have involved a mixture of different kinds of plants and animal resources. This combination makes it difficult to identify any specific food resources from residues inside the burned rocks employed in the cooking. Consequently, the burned rock residues are believed to yield isotope values that reflect a mixture of complex signatures from various $\mathrm{C} 3$ and $\mathrm{C} 4 / \mathrm{CAM}$ resources. If the food ingredients were not diversified, the $\delta^{13} \mathrm{C}$ value difference of $12.4 \%$ o between the modern $\mathrm{C} 3$ legume/nuts plant parts and the modern CAM/ C4 cactus parts would provide a statistical and significant numerical spread to isolate either of the two general plant groups.

Stable carbon and nitrogen isotope analyses were conducted on organic residues extracted from the interior matrices of 53 burned rocks (Table 13.1, Figures 13.2 and 13.4, table in Appendix D). The prehistoric $\delta^{13} \mathrm{C}$ values range from $-18.6 \%$ o to $-26.5 \%$, with an average of $-22.0 \%$. This average indicates a probable mixture of $\mathrm{C} 3$ and C4/CAM material with at least 68 percent probably derived from C3 matter. The C3 contribution may have come from a vast array of C3 resources, including legume beans (roughly averaging about $-25.3 \%$ ), nuts (roughly averaging about $-26.4 \%$ ), or deer meat (average value of roughly $-22.0 \%$ ). The potential C4/ CAM contribution could have been derived from such items as prickly pear tunas, tasajillo fruit, and Spanish dagger seed pods (averaging roughly about $-13.0 \%$ ), possibly corn $(-11.2 \%$ ), and potentially even bison meat (estimated about $-9.0 \%$ ). Since none of the prehistoric carbon isotope values were more positive than $-18.0 \%$, it does not appear that significant quantities or, indeed, any $\mathrm{C} 4 / \mathrm{CAM}$ plants or herbivores that ate those plants were processed using the burned rocks at the Lino site.

The $\delta^{15} \mathrm{~N}$ values from the prehistoric samples range from $-15.3 \%$ o to $13.1 \%$ with an overall average of $3.73 \%$. Since these are probably composite values from various kinds of processed resources, it is difficult to interpret this data set as a group. Some isotope groups are distinctive. The eight $\delta^{15} \mathrm{~N}$ values greater than $7.4 \%$ ( 15 percent) may reflect the processing of non-C3 plants, which could include prickly pear parts and tasajillo fruit. The eight values below $0.5 \%$ ( 15 percent) probably relate to $\mathrm{C} 3$ nut/legumes and possibly a sotol or lechuguilla hearth. It is possible that eight other values below $2.5 \%$ ( 15 percent) may also reflect these same $\mathrm{C} 3$ nut/legume resources. The remaining 55 percent of the $\delta^{15} \mathrm{~N}$ values probably reflect some mixture of processed resources and presently do not have a sufficiently distinct signature to allow identification of the specific resources.

In summary, the prehistoric stable carbon and nitrogen isotope results are quite complex. Not all of the influencing factors are presently known. Although the $\delta^{13} \mathrm{C}$ values from $\mathrm{C} 3$ and C4/CAM plants appear to separate into two groups, a broad array of potential food resources occurs within these two groups. The modern stable carbon and nitrogen values have contributed important new data that can be used to identify potential legumes/nuts vs. nonlegume food groups based on preserved residues inside porous burned rocks at archeological sites.

In an attempt to help clarify some of the complexity detected in the prehistoric isotope data and to contribute information from these three major isotope groups, a second chemical approach-lipid analysis on burned rock residue-was also initiated. This chemical 


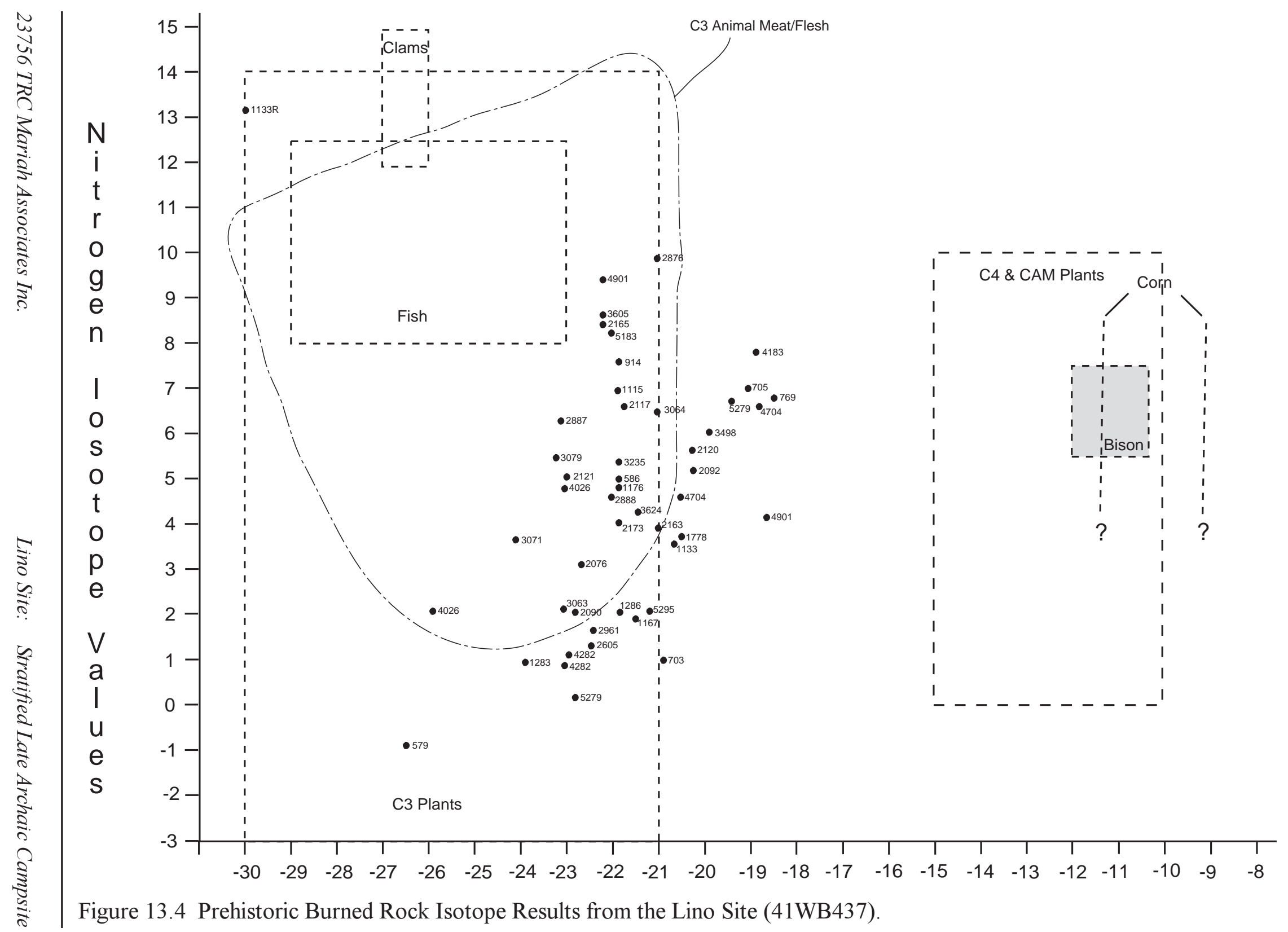


approach was directed at identifying potential food groups, not specific resources that might have been processed by the burned rocks. It was hoped that the stable isotope data would complement the lipid results and contribute further insight into the identification of potential food resource groups being processed.

Gas chromatography analysis was used to identify lipid residues from the interior matrices of 43 burned rocks and five ground stone tools. The details of this method and the individual results are presented in Appendix G. Only a summary of the results is presented here. The 43 burned rock matrix samples were derived from 23 features from Occupations 1 through 5.

Five modern potential food-plant samples from south Texas were analyzed for their fatty acid composition. The modern plants analyzed included two kinds of C3 legumes (mesquite beans and Texas ebony seeds) and three kinds of CAM cactus products (tasajillo berries, prickly pear tunas, and Spanish dagger seed pods). These modern plants provide comparative baseline residue results for interpreting results from the prehistoric samples. The gas chromatography analysis revealed that the artificial degraded fatty acids of modern mesquite beans and prickly pear tunas have similar signatures. Each of the other three plants revealed relatively distinctive fatty acid compositions (Appendix G).

Of the 43 burned rock matrix samples analyzed by the gas chromatography, 32 yielded sufficient fatty acids for interpretation. Only two of the 11 samples lacking sufficient fatty acids actually lacked evidence of any detectable residues (Appendix G). Of the five-ground stone tools analyzed, four yielded sufficient results for interpretation. All gas chromatography results were compared to projected decomposed signatures for modern foods using experimental cooking processes based on the modern plant results, some from south Texas. Ten (31 percent) of the positive samples from eight different cultural features in Occupations 1 through 5 yielded results that resemble fatty acids from large herbivores (Features 10, 12, 14, 16, 20, 22, 24, and 26). Twelve samples (38 percent) from nine features in Occupations 1 through 5 yielded results that had fatty acids representing only plant residues. These consist of residues from Features 10, 14, 15, 16, 24, 25, 26, 29, and 42. Three samples (10 percent) yielded fatty acids that resemble Texas ebony seeds: Features 30 and 34 and abrader \#5642-4. One sample (three percent) represents unknown kinds of seeds from Feature 24 in Occupation 5. Four other samples (12.5 percent) appear to represent a mixture of various plant and animal resources: Features 18, 27, 39, and 41. Mesquite and prickly pear are the strongest candidates for residues from samples derived from Features 20, 27, and 41, mano \#4725, and abrader \#3717. Two samples (six percent) had fatty acids that were close to Spanish dagger or tasajillo fruit: Feature 18 and mano \#4726.

The prehistoric stable isotope results are used in conjunction with the prehistoric lipid results to interpret that the large herbivore identified by the fatty acid results was probably deer, a primarily C3 plant browser. None of the 53 burned rock residue samples yielded $\delta^{13} \mathrm{C}$ values within the range that might reflect the presence of corn, amaranth seeds, C4 plant-consuming bison, or other $\mathrm{C} 4 / \mathrm{CAM}$ resources. Consequently, deer is probably the large herbivore identified by the combined fatty acid analysis and isotopic results. The fatty acid identification of Texas ebony seeds on burned rock \#3071 from Feature 30 is also supported by the $\delta^{13} \mathrm{C}$ isotope value of $-24.1 \%$ extracted from this same rock. This prehistoric value compares quite favorably with a modern Texas ebony seed from south Texas that yielded $\delta^{13} \mathrm{C}$ isotope of $-24.7 \%$. However, the $\delta^{15} \mathrm{~N}$ value on that same prehistoric burned rock sample was 
$3.6 \%$ compared to the modern value of $5.4 \%$ o for the Texas ebony seeds. It is not clear what factors might account for the $\delta^{15} \mathrm{~N}$ value difference of nearly $2.0 \%$ unless a very similar legume such as retama seeds, which has not been experimentally degraded, is represented.

Although the lipid results indicate a very promising approach to identifying subsistence resources, there is considerable need to broaden our understanding of most facets of this analytical approach. Since only five modern edible plant resources from south Texas have been tested for residue decomposition thus far, it is necessary that many more potential food resources be tested in this manner. The present comparisons to western Canadian foods will have to suffice until regionally relevant food sources can be more fully understood. It is also necessary to use a vast array of cooking techniques in order to gain a broader understanding of how and what residues penetrate hot rocks, if specific rock types have different abilities to absorb the residues, which cooking techniques allow for the absorption of the food residues into the cooking rocks, and numerous other factors that may influence the process whereby lipid residues become part of the rock.

One shortcoming in the analyses is that small mammals may be difficult to detect because they may have eaten the same plants that people did, so the residues on the rocks may appear similar to consumable plants. Small carnivores will also prove to be a challenge because they also could have similar residue signatures to other primary consumers or other animals. For more specific identifications of small animals, testing will have to be conducted on multiple samples from specific regions, and their degraded residues will have to be established. Extensive experimenting will be a major factor in promoting better interpretations of the analytical residue results.
The isotope and fatty acid analyses employed to investigate potential food resources yielded positive and corroborative results. They contribute a broad range of data towards advancing the ability to identify general subsistence resources that were processed and consumed by these Late Archaic groups, even in spite of the absence of preserved prehistoric bone and macrobotanical remains. It is important to remember that many kinds of food resources, including prickly pear tunas and nuts, are consumable without cooking. Therefore, the cacti tunas and other similar foods may have been part of the prehistoric diet without leaving a chemical signature in the burned rock residues.

Land snail shells have been recovered in such abundance in some prehistoric south Texas sites that some authors have suggested that they were routinely collected and consumed by prehistoric peoples (Hester 1971:121). Direct evidence for eating land snails has not been confirmed or solidly demonstrated in the archeological record. Tools are not required to collect or process snails, and their meat might have been consumed without visual alteration of the preserved shells. Thus, there is no obvious modification available to distinguish the shells of snails collected for human consumption from those shells of snails that naturally died on the site. As yet, no chemical means is known to identify cooked snails. If snails were boiled, the temperatures were too low to alter the epimerization ratio (Ellis, personal communication 1998).

Snail shells occur literally everywhere in southern Texas. Their presence in high frequencies in archeological deposits is not considered uncommon, and the shells even occur in tight clusters that might indicate they were collected and discarded in heaps. After death, the lightweight snail shells are easily displaced vertically by various bioturbation processes, including root, rodent, and erosional processes. 
Until some direct evidence for human use can be demonstrated, shell abundance is thought to reflect non-cultural occurrences in the site. Meat from a 1998 live-collected Rabdotus snail from Zapata County was dried and submitted for stable carbon and nitrogen isotope analyses. It yielded a $\delta^{13} \mathrm{C}$ value of $-25.2 \%$ and a $\delta^{15} \mathrm{~N}$ value of $-2.6 \%$ (table in Appendix D). Although it is uncertain whether this single sample is representative of the carbon and nitrogen isotopes of snails, it does reflect that this individual was consuming quantities of $\mathrm{C} 3$ plant matter that was very low in nitrogen. Some modern plants, including Texas kidney wood seed hulls, mesquite beans, and possibly some nuts from Zapata County have similar low $\delta^{15} \mathrm{~N}$ values, but none are as depleted of nitrogen as the snail meat sample. Additional data from modern snails is needed to ascertain the range of isotope variations for these animals.

The mussel shells encountered in the various cultural occupations of the Lino site are thought to reflect a prehistoric food resource. Although raccoons and birds are also known to procure mussel shells from creeks and rivers and move them to higher landforms, their shell frequency in direct association with the cultural occupations along with alterations of some shells to make shell pendants are reasons to believe that mussel shells have cultural origins in the Lino site deposits.

Occupation 1 yielded most of the mussel shells $(n=78,48$ percent of all shells from the six occupations), which represents a marked increase over that from the lower occupations (Table 13.2). In Occupation 1, Cyrtonaias sp. comprised some 47 percent of the shells, Potamilus purpuratus represented one percent, and unidentifiable species represented 52 percent. Occupation 4 yielded the second highest frequency of shells $(n=43)$ and represents 30 percent of the total. The identified species were dominated by Cyrtonaias sp. $(\mathrm{n}=10)$ and
Lampsillis teres $(\mathrm{n}=8)$, with one specimen of Potamilus purpuratus. The Cyrtonaias sp. and Lampsillis teres were both present in Occupation 5 but in very limited quantities. Occupation 6 yielded only three shell fragments, none of which were identifiable.

It is possible that the increase in the frequency of mussel shells over time reflects a greater emphasis on aquatic food resources. However, the sample size from most components is so small that the trend may be spurious. It is not clear whether the lack of Lampsillis teres in Occupation 1 compared to the earlier Occupation 4 reflects a habitat exploitation difference or an environmental difference. It is clear that mussels served as a minor food resource for most of the occupations spanning the 1,400-year period of site use.

Although modern mussel meat from the Rio Grande has not been analyzed for stable isotope values, mussels from the Colorado River at $\mathrm{O}$. H. Ivie Reservoir provide general data on the carbon and nitrogen isotope values (Lintz, personal communication 1999). The meat from samples of the central Texas mussels yielded $\delta^{13} \mathrm{C}$ values that range from 12.1 to $15.1 \%$ and average $13.7 \%$. The $\delta^{15} \mathrm{~N}$ values range from -26.9 to $-28.8 \%$ with an average of $-27.6 \%$. These $\delta^{15} \mathrm{~N}$ results are very depleted relative to nitrogen values of all other foods and should be easily distinguished in the archeological results if mussel shell meat was being processed. The isotopic results from the burned rock residues do not appear to represent the sole processing of mussel shell meat and indicate that the mussels were eaten raw or not directly cooked using the burned rocks. Steam from hot rocks may have been used, but this cooking process would not have left a residue in the sandstone cobbles.

In summary, the different Late Archaic groups occupying this alluvial creek terrace during a 
1,400 year interval between about 2000 and 3400 B.P. appear to have eaten some mussel shell meat, deer meat, and a variety of plant foods that most likely included various legumes (i.e., mesquite and Texas ebony beans), possibly nuts, and prickly pear tunas. These resources represent a very diffuse or generalized subsistence base that reflects the exploitation of a broad range of habitats in this region. The generalized resource subsistence pattern does not appear to have changed much over the 1,400year period because each occupation apparently processed a very similar range of food resources. Presently, no data are available to address seasonality. Seasonality would be difficult to interpret from various plant resources that might be encountered because many of the resources could be available in a dried state most of the time. These conclusions must be regarded as tentative, since the excavation area was small and the recovered cultural samples and extracted organic residues were limited. The absence of any single species from one occupation relative to another may simply reflect sampling biases rather than differences in adaptive strategies.

\subsection{PALEOENVIRONMENTAL STUDIES}

The traditional techniques used to reconstruct paleoenvironmental conditions often rely on the analyses of pollen, bone, macrobotanical, phytoliths, and diatom remains from dated geomorphological context. Most of these kinds of analyses of animal and plant resources represent habitats and/or vegetation communities and are proxies for the past environmental conditions.

Pollen preservation has been extremely poor across most of Texas except for bog context, so this analysis was not attempted. Prehistoric bone was not preserved in the Lino site deposits, and macrobotanical remains were not sufficiently abundant to allow interpretations of past plants or environmental conditions. Phytoliths were recently discovered in abundance in upland eolian deposits at 41ZP364 near Falcon Reservoir (Jones 1999) in extreme south Texas and had some potential to be preserved in the terraces near Laredo. Three matrix samples from a variety of carefully selected contexts and two unwashed manos were submitted to evaluate the preservation of phytoliths (Appendix H). Fossil phytoliths were not preserved from any of these samples. Apparently, the oxidizing conditions of the silty deposits completely destroyed the silica bodies.

The presence or absence of diatoms was also investigated by the submission of two sediment samples. Sample \#5719-2 from 30 to $40 \mathrm{cmbs}$ in A5 and an unnumbered sample from beneath an overturned mussel shell in Feature 36 yielded no diatoms, macrophytes, vascular plants, pollen, spores, sponge spicules, or cyanobacterial filaments (Appendix I). Observations under high-power magnification during the diatom investigation revealed tiny clusters of spheres that appear to be similar to iron-reducing bacteria associated with the breakdown of organic material in the soil. These possible bacterial spheres may have consumed the phytoliths, diatoms, and other soil nutrients.

Macrobotanical identification of selected wood charcoal provided a means for characterizing the woody plants in the site vicinity during the various prehistoric occupations. Nearly 50 charcoal chunks were submitted, and most were identified to a specific species (Appendix B). In addition to the identification of wood charcoal, a sample of 10 mesquite charcoal pieces from Occupation 1 and another 10 mesquite charcoal pieces from Occupation 5 were analyzed by ecologically diagnostic xylem analysis (EDXA), which determined the mean vessel diameter and density of wood cells at ca. between 3200 and 2000 B.P. The mean vessel diameters from Occupation 1 (which dates to 2000 B.P.) averaged $0.018 \mathrm{~mm}$ 
greater ( 0.065 to $0.047 \mathrm{~mm})$. Vessel density was $4.01 \mathrm{~mm}$ lower than that of the 3200 B.P. mesquite samples from Occupation 5. Although some overlap exists between the two charcoal sample populations, a change in the mesquite wood anatomy may indicate that effective moisture was much lower around the time of 3200 B.P. The mesquite wood from the 2000 B.P. occupation reflects somewhat more mesic conditions (Appendix B).

The flotation of some 341 column samples (roughly 1,365 liters) plus about 390 liters from feature matrices failed to provide a sizeable or suitable sample of charred macrobotanical plant parts to provide much paleoenvironmental information. Twelve light fraction samples with relatively high seed or wood fragments were submitted for identification (Appendix B). The wood was determined to be mostly mesquite with some pieces from indeterminate species. The seeds present were mostly modern bristlegrass (Setaria sp., Appendix B). This intensive flotation effort also failed to recover micro fauna remains that could have also provided data on the environmental conditions. The fine overbank sediments that created the natural creek terrace at the Lino site represent flood events during this roughly 1,400-year period. The depositional events appear to have stopped around 2000 B.P. with little or no additional natural sediment added to the terrace during the last two millennia. Similar flooding events along the Rio Grande valley have continued into historic times, but the San Idelfonzo Creek terrace has stopped aggrading. Although the lack of terrace aggradation might reflect a major change in the environment, it could just as likely be that the ceasing of terrace building is attributed to the creek channel incision and the occurrence of the terrace surface above most recent flood events.

Fresh water mussel shells were recovered from throughout the top of the $120 \mathrm{~cm}$ thick deposits investigated at the Lino site. The highest mussel shell frequencies came from Occupations 1 $(n=74)$ and $4(n=43)$, with smaller quantities present in other zones. Cyrtonaias sp. was the most common identified species in Occupations 1 and 4 with Potamilus purpuratus also occurring as single examples in both zones. In addition, Occupation zone 4 yielded eight individuals (19 percent) of Lampsillis teres, whereas none were identified in Occupation 1. It is unclear if the identified mussel shell species were obtained from San Idelfonzo Creek or the Rio Grande. The significance of species difference between the various zones is difficult to interpret relative to the environmental conditions because mussel shell frequency is limited and biased by cultural selection during procurement. In general, the relative frequency of Cyrtonaias sp. over time may indicate that little-to-no major change occurred in the water quality or water depths over this roughly $1,400-$ year period.

The presence of Rabdotus shells throughout the deposits indicates that the environment was semiarid and has been relatively constant during the 1,400-year period. Two Rabdotus shells were dated to 2040 and 1740 B.P. (Table 5.3), and their carbon isotope signatures were measured using the AMS process to 2.3 and -1 . $1 \%$ o. These limited isotopic values signal that the shells had incorporated organic plant material that would probably represent plants with a C4 photosynthetic pathway (Goodfriend, personal communication 1998). The C4 plants in south Texas would have been primarily restricted to various grass species. Thus, grasses probably dominated this terrace setting at about the time of the occupations.

The presence of legumes (probably Texas ebony and mesquite beans) and nuts in the organic residues found inside the burned rocks indicates that the vegetation near the site was quite diverse and included $\mathrm{C} 3$ photosynthetic plants along 
with $\mathrm{C} 4$ grasses. Legume plants include trees such as mesquite, Texas ebony, and various acacia plants. Nuts were available from oak trees that probably occurred along the creek and river valley margins. However, the density and diversity of these plants remain unknown.

Although densities and distributions are impossible to discern from the meager available data, the composition of the vegetation communities may be tentatively sketched as follows. The broad flat terraces and adjacent uplands may have been covered in $\mathrm{C} 4$ grasses with the deposits in the lower settings along the Rio Grande and San Idelfonzo Creek margins containing various $\mathrm{C} 3$ shrubs/trees that included mesquite, hackberry, Texas ebony, and low brush such as huisache, agarita, and Condalia that produced legume beans, berries, and possibly oak nuts. Scattered clusters of trees may have dotted the uplands as well. The general landscape topography and the identified floral species are relatively similar to modern vegetation types, although the cactus species are not well represented in the present prehistoric evidence.

Based on mesquite wood analysis of mean vessel diameter, vessel density, and vulnerability index from the 2000 B.P. Occupation 1 and the 3200 B. P. Occupation 5, an increase in effective moisture was detected (Appendix B). The timing and nature of this change between the occupation span is not certain. This change was not sufficient to completely alter the vegetation types or the available food resources in the general area as detected in the archeological record.

From a regional perspective, the Middle Holocene in central Texas is marked by a long dry period that lasted from about either 7500 to 3500 B.P. based on pollen data from bogs (Bousman 1998) or 4400 to 2700 B.P. based on alluvial stratigraphy (Johnson 1995; Toomey et al. 1993). A mesic interval lasting from 3000 to 2500 B.P. was detected in Southwest Texas based on fossil pollen (Bryant and Holloway 1985). Various data sets from central Texas also reflect a relatively moist period from 3000 to 1000 B.P. (Toomey et al. 1993). The mesquite wood charcoal at the Lino site from Occupation 5, dated to 3200 B.P., and the upper Occupation 1, dated to 2000 B.P., documents the shift from a dryer period to a moister period. If the shift from the silty loam deposits in the lower deposits to the sporadic overbank deposits in the upper parts of the profile at the Lino site correlate with the climatic shift from dryer to more mesic conditions, then the date of the climatic change is estimated to be about 2700 B.P. This suggestion must be viewed with caution because variables underlying paleoclimate conditions are complex (Caran 1998). The Lino site data must be used in conjunction with other lines of evidence to refine the paleoenvironmental reconstruction of the region.

\subsection{BURNED ROCK TECHNOLOGY ISSUES}

Nearly 8,000 burned rocks were collected from the six defined occupations at the Lino site, including about 1,000 attributed to 26 discrete features. Other burned rocks were found scattered across the occupation surfaces. The site thus contained a sizable burned rock assemblage useful for examining burned rock technology. The high frequency of burned rocks in the six stratified occupations is a testament to the common use of rocks and indicates that most, if not all, burned rocks were regarded as an appropriate local resource. Their presence also provides a wealth of data to investigate the daily lives of the groups that occupied these sites.

This subsection examines how burned rocks were used at the Lino site. First, it delineates three major types of burned rock features based on morphology and context and discusses the 
results of residue analysis in conjunction with each feature type. Next, it compares the average size of rocks, cracked rock frequency, and residue occurrence to postulate functions for the various features. It appears that the three burned rock features types are related to components of a system of stone boiling activities. Concluding sections examine the utility of residues inside burned rocks as an appropriate medium for dating and the magnetic signatures of rocks.

Burned rock features identified during the mitigation program numbered 30 and consisted of four in situ heating elements (Features 14, 20, 27, and 37), 21 burned rock dumps (Features 8 through $13,15,16,19,22,24,26,28,29,30$, 32 to $35,39,40$, and 42 ), one unclassified rock cluster in Feature 16, and parts of four occupational surfaces (Features 17, 18, 21, and 25). Each category is discussed below, and data to support the interpretation are presented.

At the Lino site, Features 14, 20, 27, and 37 were interpreted as in situ heating elements because they yielded quantities of in situ charcoal and, in three instances, quantities of burned rocks inside recognizable pits. The burned rocks in Features 14, 20, and 27 filled shallow basins or pits but had no apparent internal structure. These features also contained aligned chunks of wood charcoal from individual sticks that had burned in place, but no ash or oxidation was observed. These three relatively small, rock filled pits, all measuring under $1 \mathrm{~m}$ in diameter, could have served as baking, grilling, broiling, parching, frying, steaming, or boiling features. The overall pit size and shape and the presence of charcoal sticks are quite similar to one another as are the average weight of the rocks within the pit (Figure 13.5). The fourth pit (Feature 37) contained only one large, flat burned rock broken into three pieces and overlying a large charred branch. It is interpreted as having a different function from that of the three burned rock filled pits. Possibly it represents a warming hearth.
Eleven burned rocks were selected from the rock filled pit features to have organic residue samples from their interiors analyzed for stable carbon and nitrogen isotopes and lipid residues. The recovery of organic residues from the interior of burned rocks from these four pits indicates that the rocks were involved in cooking foods. The rocks were probably in direct contact with foods during the cooking process; hot liquid residues penetrated into the porous sandstone. Ellis (1997) has identified at least 15 ethnographic uses of burned rocks as a heat convection and conduction apparatus. Many of these cooking techniques could have produced the organic residues found soaked into the rocks. Since these pits lacked any sign of a dirt- or rockcap covering to seal in heat, then their use as baking pits appears to be unlikely. Grilling, roasting, broiling, charring, parching, and frying are also not likely because the individual burned rocks occurred in random and non-structured positions rather than forming a flat heating surface. The pits did not appear to be in-ground, stone-boiling features because quantities of wood charcoal occurred under the rocks, which could not have occurred if the pits were lined with skins or basketry and contained liquid substances. Steaming appears to be unlikely because the rocks would not have directly absorbed organic residues throughout their interiors by this means. Consequently, Features 14, 20, and 27 that contained both fuel wood and randomly patterned heated rocks within pits may have primarily served as apparatus for heating rocks. These hot rocks would have then been used in some other cooking feature. The pits were not the primary cooking features but served to heat the rocks for cooking in other nearby features.

One burned rock from each pit feature was subjected to thermal demagnetization. It was hoped that this would give information allowing inference about heating temperatures and frequency of rock reuse. The analytical results 
on burned rock \#705 from pit Feature 14, burned rock \#2090 from pit Feature 20, and burned rock \#4901-2 from pit Feature 27 indicate, respectively, two thermal components, two thermal components, and one thermal component (Appendix E). The thermal signature of the latter rock reflects a rock that was probably heated and cooled in place and thus compatible with an interpretation that Feature 27 was a heating element. The two thermal components detected for the burned rocks from Features 14 and 20 may have been derived either from multiple use activities or only from stone boiling. The stone boiling technique would have permitted the liquid residues to penetrate the porous sandstone during the cooking process. The occurrence of organic residues within these burned rocks is problematic if these features were strictly heating elements for a single cooking event. However, if the rocks were reused, then the presence of organic residues might be residual residues acquired from previous cooking events that were not burned out during subsequent heating of the rocks in the pit. This concept of rock recycling in cooking features accounts for the two thermal components and the presence of internal residues in rocks found in the pits that functioned as heating elements.

The 21 features interpreted as burned rock dumps contained more or less randomly scattered burned rocks with no observed pattern or organization to their positions within a cluster. The discoloration of the burned rocks coupled with thermal demagnetization signatures indicates that these sandstone rocks were heated. Although scattered charcoal chunks were sometimes present, these rock clusters lacked observable pits, ash lenses, charcoal or oxidation surfaces, and other evidence of in situ fires. The analyses of internal matrix samples from selected burned rocks from these dump features yielded organic residues with specific stable carbon and nitrogen isotopes and fatty acids. The occurrence of organic residues throughout the interiors of the burned rocks documents the use of hot rocks in more than just minor cooking activities confined to surface contact with foods. Apparently, these randomly oriented, clustered burned rocks that contain organic residues were once part of some cooking event, but the lack of ash, charcoal lenses, or oxidation surfaces indicate that these rocks are not in situ cooking features.

The average weight of the burned rocks from each of the 21 burned rock dump features varies considerably. The discard or dump rock features range from a low of $41 \mathrm{~g}$ in Feature 26 to over $870 \mathrm{~g}$ in Feature 9 (Figure 13.5). Four burned rock discard clusters (Features 8, 9, 30, and 39) had moderate to large burned rocks that averaged $663 \mathrm{~g} /$ rock compared to the other 18 small burned rock discard clusters that yielded average rock weights of $103 \mathrm{~g} /$ rock. The 18 discard features with small rocks contain an average weight of only a fraction (1/4.7) of the average weight of elements in the four larger rock discard features. The rapid reduction in the average size of discarded rocks may indicate differences in the stage of use of the burned rocks. The burned rocks in the four pit features (with average weights of $596 \mathrm{~g} /$ rock) were nearly five times larger than those in 80 percent of the dump features, but this is also an average of $67 \mathrm{~g} / \mathrm{rock}$ lighter than 20 percent of the burned rock discard clusters. Burned rocks scattered randomly across the six occupational zones and not assigned to features were even smaller than those in most of the discard features, revealing an average of $75 \mathrm{~g} / \mathrm{rock}$.

Apparently through repeated heating and cooling episodes, the burned rocks broke into smaller pieces to a point were they were considered to be too small to perform the desired function. The smallest burned rocks, weighing an average of $53 \mathrm{~g} / \mathrm{rock}$, are those unaffiliated with features found scattered across the occupation area. They 
appear to represent the general discard after the final stage of use. The burned rocks in the in situ heating pits, with an average rock weight of $596 \mathrm{~g} / \mathrm{rock}$, represent an early stage of being heated for use in cooking. The 18 burned rock dump features with small rocks, weighing an average of $103 \mathrm{~g} / \mathrm{rock}$, have pieces statistically and significantly smaller than those rocks in the four heating element pits. The presence of organic residue on their interiors testifies to their use in cooking.

The pit features yielded high percentages of burned rocks with cracks (32 to 60 percent), which contrasts with those from all other contexts that had very low percentages of cracks (none to 40 percent) with the exception of two instances (Features 13 and 42). If the cracks developed during the heating stage in the pits, then they broke into smaller pieces when cooled rapidly during use. As the rocks became smaller, they were less efficient in transferring heat and, at some point, discarded. The four "dump" features (Features 8, 9, 30, and 39) with large rocks weighing an average of $486 \mathrm{~g} /$ rock (Figure $13.5)$ reflect a possible early stage of rock use or even a pile accumulated for reuse and not final discard. The presence of organic residues inside some of the large rocks in these accumulations indicates that they had experienced some prior use in the cooking process. The burned rocks within these four features were probably collected for re-use because their size still provided an adequate heat reservoir. Once the rocks had been used in a stone boiling process, they required drying prior to their next heating episode, as saturated stones slow the reheating time.

The cooking technique that best fits the types of features discovered and the analytical results is a stone boiling technique. Numerous ethnographic accounts indicate that the rocks first had to be heated (i.e., Hodge 1907:105). This was probably accomplished in apparatus such as pit Features
14,20 , and 27, which yielded quantities of wood charcoal in pits filled with burned rocks. These hot rocks were transported to some above-ground, waterproof cooking apparatus. The latter may have included a stick-supported hide or watertight basket that held water (Figure 13.6). The hot rocks placed into the container would raise the temperature of the water to the boiling point (roughly 100 degrees $\mathrm{C}$ ). This procedure and a slow boil at this temperature would cook foods such as soup, stew, or gruel, or it would extract grease from bone splinters. The rocks would have absorbed organic food residues while they were cooking the stew or soup. Ethnographic accounts suggest that at some point, the larger cooled rocks were either individually removed from the liquid and saved for reuse or discarded; the smaller rock fragments were dumped en masse directly from the container after the foods had been removed. The clustering of rocks in small, irregularly defined and unpatterned discard areas would reflect a rock dump dispersal similar to that of the 21 non-pit burned rock features documented across the six occupations at the Lino site.

In some instances, the analyses documented that rock reheating does not completely destroy organic residues previously absorbed by the cobble. Organic matter generally will begin to ignite at 200 degrees $C$ and finish burning when the temperature reaches 550 degrees C (Stein 1984:241). Organic residues were present in three different burned rocks collected from pit Feature 14 as detected through AMS dating and carbon isotope and fatty acid analyses. Since the dating of extracted organic residues yielded three AMS dates older than the wood charcoal that dates this same occupation zone, the older residue ages must have been derived from organic residues that previously accumulated within the rock.

The cooking apparatus was not detected during the excavations and was probably an ephemeral feature, similar to that represented in Figure 13.6. Excavators may not have observed or recognized 


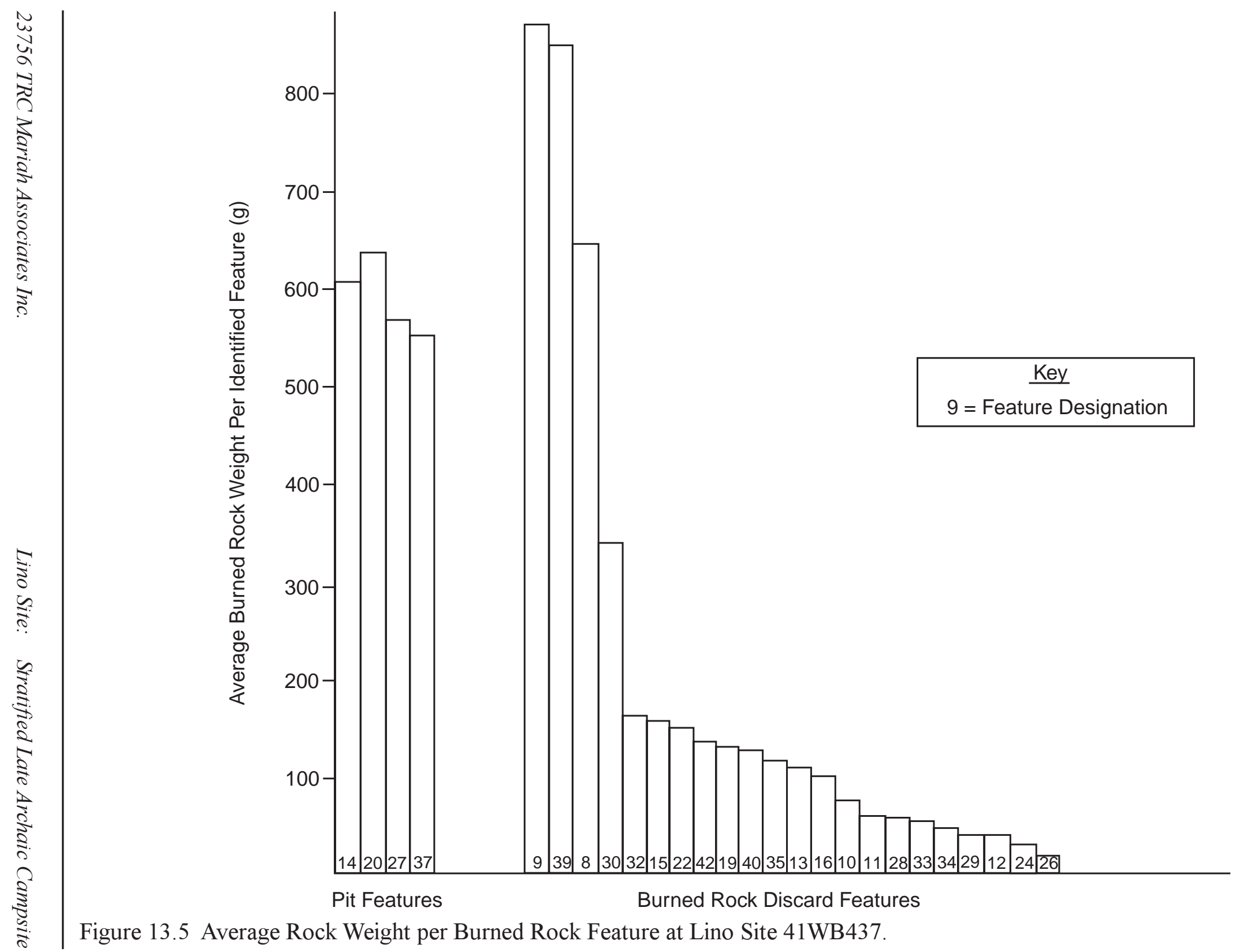




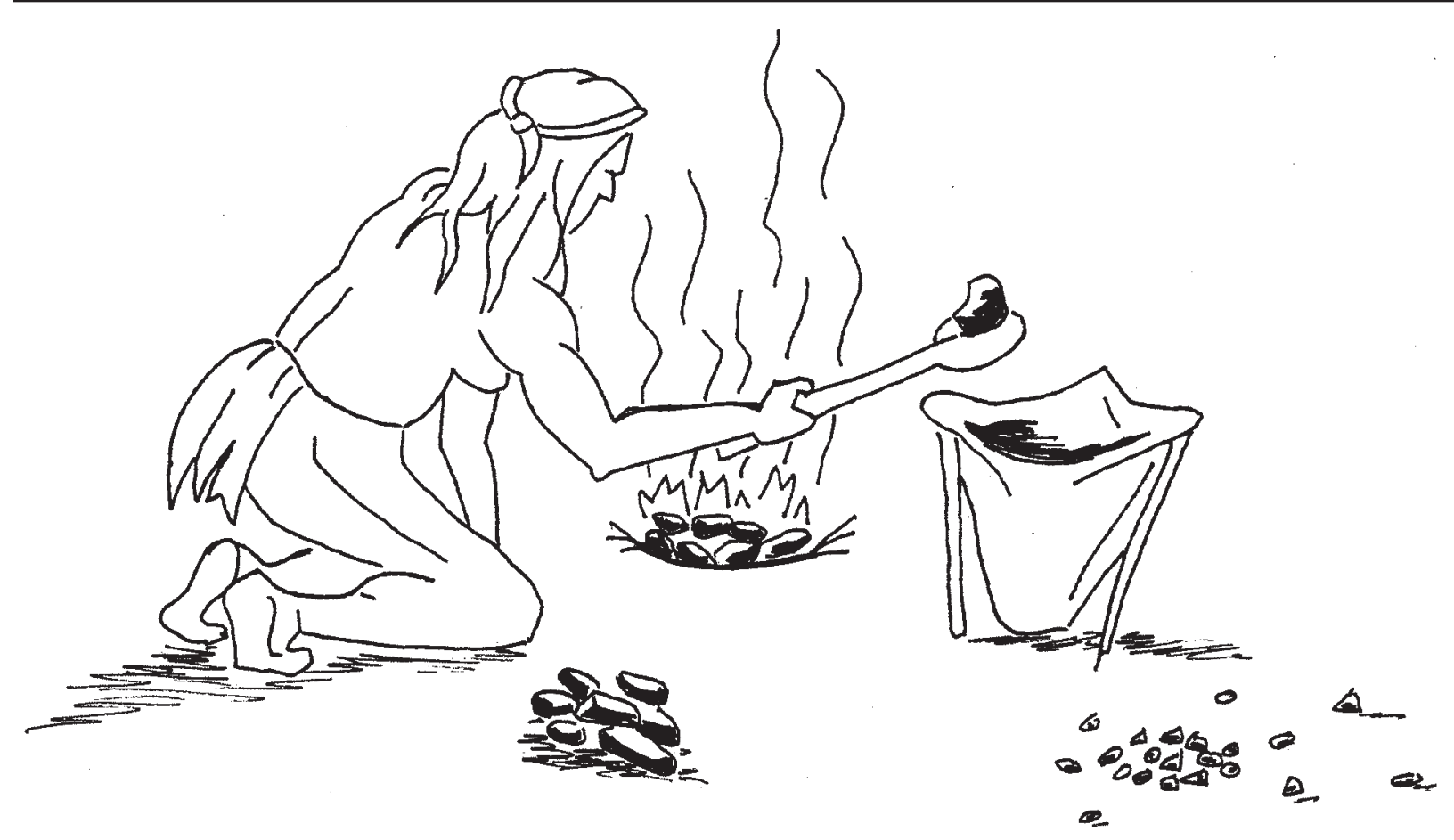

Figure 13.6 Schematic of One Possible Stone Boiling Process.

such a feature, or it may not have been preserved because it was constructed from perishable material or curated for reuse at other sites. The apparatus could have been made of a few sticks that supported a skin that formed an aboveground container holding the liquid and hot rocks (Figure 13.6). This apparatus may have been located beyond the excavation block, or if inside the block, the evidence was too subtle to be identified. It is the author's contention that the stone boiling assemblage best explains the scattered and clustered burned rocks on the occupation surfaces, the burned rock pit features, the organic residues inside the burned rocks that tend to date earlier than the associated living surfaces, and the thermal demagnetization results.

Thus, the nearly 8,000 burned sandstone rocks are interpreted to have been used in stone boiling for food processing. The various kinds of burned rock features reflect components of the cooking activities and various stages of rock use. The stone boiling process should not be unexpected, as Driver and Massey (1957) document stone boiling as the dominant method of food preparation in the Plains and Great Basin regions when they were inhabited by nomadic huntergatherers. The chemical analyses of preserved organic residues inside the rocks have supported or aided in the interpretation and delineate the classes of foods that were being processed. These residues provide organic resources that relate directly to the cultural activities and can be directly dated using the AMS methods. These residues may be preserved long after charcoal has perished. Caution is apparently needed when interpreting dates from these residues because reheating of rocks does not always burn out earlier residues, and the dates may be much older than the last context of the rocks.

Thermal demagnetization analysis of nine burned rocks from features interpreted as burned rock dumps and one mussel shell dump (Feature 41) revealed one rock with one magnetic component (\#5295-4 in Feature 40), six burned rocks with two magnetic components, one with 
three magnetic components (\#3064 in Feature 30 ), and one with four magnetic components (\#4704-2 in Feature 39, Appendix E). It is often assumed that magnetic components reflect the cooling of rocks in situ with each magnetic component representing rock reorientation and a separate firing to a temperature lower than the former heating episode. Although no definitive thermal demagnetization signature for stone boiling has been recognized as yet by Dr. Gose, the experimental results by Quigg on natural sandstone from the region has produced twocomponent signatures very much like those obtained from the Lino site rocks (Takac 1999). If some of the burned rocks were recycled and subjected to multiple heating and cooling events, then it may be possible that some reused rocks would retain three and four magnetic components depending on the magnitude of the refiring temperatures. Since most of the Lino site rocks had maximum temperatures around 600 degrees $\mathrm{C}$, which is what small campfires can generate (Bellomo 1991:77), then the heating can be attributed to human interaction rather than natural causes. Further experimental work is necessary to clarify the meaning of multiple magnetic components and how they may have been derived. Further thermal demagnetization experiments combined with burned rock experiments and observations of thermal weathering such as those conducted by Jackson (1998) and heating experiments conducted by Stark (1997) will undoubtedly further an understanding of the alterations that affect burned rocks. Particularly useful would be to replicate studies of boiling stones because the rocks are moving as they begin to cool upon removal from the fire and then rapidly cool and rotate when dropped into the container of water.

The subsistence technology relating to the frequently used and ultimately massive accumulations of burned rock in middens throughout central Texas persists during the Late Archaic period (Collins 1998:384), but the small hunter-gatherer camps as represented at the Lino site in south Texas do not reflect a contemporaneous cooking technology that formed middens. Possibly the food resources utilized in the central and west Texas middens were not available in the far south Texas region. If the same resources were available, the Late Archaic populations in south Texas may have used a different manner to cook/process those resources. Other sites with better preservation may clarify some of the factors underlying different burned rock features and scattered in the region.

The question of why sandstone was used in the cooking processes arises. This is not an easy question to answer. Since siliceous gravels appear to have been available in the immediate uplands surrounding the site, and sandstone accounted for about 99 percent of the burned rocks identified, it appears that sandstone was preferred. Not only was it preferred by one group of occupants, it was the rock of choice for the entire 1,400 years of occupation represented at the Lino site. Some experimental data has already been accumulated, but the various results are somewhat ambiguous. Lintz (1989) showed that metaquartzite and chert had better heat conductivity than sandstone. Brink et al. (1986) indicated that sandstone was unsatisfactory in experimental stone boiling activities. However, House and Smith (1975) showed that sandstone seemed to maintain the boil longer and fragment less readily than chert or quartzite. Porosity and permeability affect conductivity. Sandstone may have been preferred because its porous structure allows for some expansion and contraction without fracturing as quickly as other material. Slow conductivity means that sandstone may remain hot for a longer time, and if a slow boil is required in the cooking process, then the porous nature of sandstone may again help in the steady release of heat. An often-mentioned drawback to the use of sandstone, especially for stone boiling, is the amount of grit it would 
produce. However, this drawback has not been adequately demonstrated in the stone boiling process because the grit would end up at the bottom of the container, thus not negatively impacting the foods higher in the container. A drawback to chert is that it tends to explode when heated to high temperatures, so it is not safe to stand to close to the heated cherts. The behavior of heated material is another aspect of stone boiling that will require more experimentation to see if sandstone possesses specific attributes that make it preferable for cooking.

\subsection{SITE STRUCTURE AND ORGANIZATION}

The vertical distribution of cultural materials precisely plotted by the TDS revealed at least five, and possibly six, cultural zones within the $120 \mathrm{~cm}$ thick limits of excavation. These were designated as Occupation zones 1 through 6 . The vertical plots also delineated the sloping geometry of the occupation surfaces, their thickness, relative continuity, and the merging of the lower occupation zones toward the eastern end of the excavation block. Cultural remains at the western end were more vertically dispersed compared to those at the eastern end. Although five and possibly six cultural occupation zones were identified, many artifacts were discovered outside the vertical space defining each cultural occupation. Sometimes, items from between two closely spaced occupations could not be assigned with certainty to one specific occupation. The items not assigned to a specific occupation were lumped into a miscellaneous group for general discussion (Table 13.2). Nevertheless, the unassigned pieces still represent materials from a roughly 1,400-year period. This section examines the material artifact similarities and differences, artifact densities, and subsistence and occupation characteristics over time.
In general, the six occupation zones contained similar types of material in their cultural assemblages. They all yielded quantities of burned sandstone rocks, chert debitage, sparse mussel shells, a similar but limited stone tool assemblage, and a limited range of burned rock features (Table 13.2). These multiple, stratified occupations indicate a commonality in the kinds of events that occurred over a roughly 1,400year period that appear to represent a series of short-term camps occupied by bands of generalized hunter-gatherers utilizing the San Idelfonzo Creek terrace as a somewhat protected campsite sheltered by the adjacent upland hills. Besides the more obvious and tangible aspects of the preserved material cultural assemblage, the residues in burned rocks indicate that the subsistence base focused on deer and a variety of plants throughout this 1,400-year period. If the increase detected in effective moisture from 3400 B.P. to 2000 B.P. did occur, then it apparently did not significantly alter the general lifeways of the populations in the region or noticeably change the material assemblages and the apparent subsistence base of the local groups using the Lino site.

The material cultural density per occupation zone within the investigated block reflects how the groups utilized this exact same space through various times during the Late Archaic. Only slight differences are found during each of the recognized occupations. In most cases, the present horizontal distribution pattern does not permit the delineation of precise boundaries between the various inter-site activity areas except near the relatively larger identified cultural features.

If most burned rock features were interpreted correctly as discarded rocks or dumps, then apparently part or most of the surfaces examined across each occupation zone were used for 
Table 13.2 Summary of Material Classes per Lino Site (41WB437) Occupation Zone.

\begin{tabular}{|c|c|c|c|c|c|c|c|c|}
\hline \multirow[b]{2}{*}{ Class } & \multicolumn{7}{|c|}{ Occupation } & \multirow{2}{*}{$\begin{array}{r}\text { Analyzed } \\
\text { Total }\end{array}$} \\
\hline & 1 & 2 & 3 & 4 & 5 & 6 & Misc. & \\
\hline Burned Rock & 1,441 & 835 & 925 & 2,156 & 1,258 & 215 & 901 & 7,731 \\
\hline Charcoal Sample & 68 & 19 & 30 & 32 & 31 & 5 & 17 & 196 \\
\hline Lithic Debitage & 667 & 378 & 666 & 1,760 & 1,330 & 279 & 340 & 5,420 \\
\hline Mussel Shell & 55 & & 6 & 43 & 17 & 3 & 17 & 164 \\
\hline \multicolumn{9}{|c|}{ Formal Tools } \\
\hline Matamoros Point & & & & 1 & & & & 1 \\
\hline Refugio Point & & & 1 & & 2 & & 2 & 5 \\
\hline Tortugas Point & 3 & & 5 & 5 & & & & 13 \\
\hline Unknown Projectile Point & & & 2 & 1 & & 1 & 1 & 5 \\
\hline Abrader & 5 & & & 2 & 1 & & & 8 \\
\hline Mano & 1 & & 1 & 1 & 2 & & & 5 \\
\hline Hammerstone & & 1 & & & 1 & & & 2 \\
\hline Biface & 4 & 3 & 8 & 8 & 11 & 1 & 11 & 46 \\
\hline Drill & 1 & & & & 1 & & & 2 \\
\hline Graver & 1 & & & & & & & 1 \\
\hline Unclassified Scraper & 2 & & & & & & & 2 \\
\hline Clear Fork Gouge/Scraper & 1 & & 1 & & & & 1 & 3 \\
\hline Side Scraper & 2 & & & & & & & 2 \\
\hline End Scraper & 2 & & 1 & 1 & & & & 4 \\
\hline End \& Side Scraper & 1 & & & & & & & 1 \\
\hline Nueces Scraper & 2 & & & & 1 & & & 3 \\
\hline Mussel Shell Pendant & 1 & & & & & & & 1 \\
\hline Edge-Modified Tool & 20 & 15 & 34 & 68 & 34 & 6 & 26 & 203 \\
\hline Lithic Core & & 3 & 1 & 7 & 2 & & 3 & 16 \\
\hline \multicolumn{9}{|c|}{ Features } \\
\hline Burned Rock Discards & 9 & 3 & 1 & 5 & 3 & & & 21 \\
\hline Burned Rock Pits & 1 & & 1 & 1 & & & & 3 \\
\hline Mussel Shell Clusters & 2 & & & & & & & 2 \\
\hline Mano Clusters & & & & & 1 & & & 1 \\
\hline Total & 2,289 & 1,257 & 1,683 & 4,091 & 2,695 & 510 & 1,319 & $\mathbf{1 3 , 8 6 1}$ \\
\hline Hand excavated area $\mathrm{m}^{2}$ & 87 & 44 & 59 & 71 & 60 & 26 & & 347 \\
\hline Density $/ \mathrm{m}^{2}$ & 55 & 28 & 28 & 57 & 44 & 20 & & 232 \\
\hline
\end{tabular}

discarding unwanted burned rocks, mussel shells, and lithic debitage. Only the lowest zone, Occupation 6, did not yield a burned rock dump feature, but in consideration of the small area examined, the lack of a dump is probably a sampling problem and not a cultural use difference. The use of at least part of each occupation surface for discard is supported by the widely scattered distribution of small burned rock fragments. Two mussel shell clusters in
Occupation 1, located only $1.5 \mathrm{~m}$ apart near the western end of the block, document the dumping or discarding of shells along with the discarding of burned rocks. Also in Occupation 1, two dense lithic debris concentrations (neither labeled as features) may have served as locations for discarding lithic debitage. One was north of Feature 11, and a second was mixed in with and adjacent to burned rock Feature 15. The dumping and discarding of lithic debitage, 
mussel shells, and burned rocks, clustered in irregular patterns and in some instances mixed together, indicate the maintenance of primary activity areas.

Three burned rock-filled pits (Features 14, 20, and 27) in Occupations 1, 3, and 4, respectively, are all interpreted as in situ heating elements. The immediate area surrounding these intact primary features is examined to determine what other activities may have been conducted adjacent to them.

Activity areas around primary hearths have been recorded ethnographically by many researchers (e.g., Binford 1978; Yellen 1977; and others). Often high- and low-artifact densities were observed to occur on opposite sides of small hearths. Researchers have interpreted the clustered material as reflecting primary work areas (Yellen 1977) while others have considered them toss zones (Binford 1978). Based on ethnographic observations at a Nunamiut hunting stand, Binford (1978) developed a model of artifact distribution patterns using the spatial distances of people around hearth features seated and the activities preformed. Binford's (1978) drop zone concept is a circular or semi-circular area around a hearth where individuals sat and dropped items. One side is often material free, which reflects the smoky side of the hearth. The drop zone extends about $1 \mathrm{~m}$ from the edge of the hearth. The toss zone is a circular or semi-circular area surrounding the drop zone where the individuals tossed items. An approximately $30 \mathrm{~cm}$ wide unlabeled zone (apparently a material void) lies beyond the drop zone, and from there the toss zone extends another 70 to $80 \mathrm{~cm}$. These activities around a hearth extended about $250 \mathrm{~cm}$ from the hearth.

All three pit features at the Lino site exhibited moderate frequencies of burned rocks in the surrounding area (Figures 13.7, 13.8 and 13.9).
Twenty-five percent of the eight $1 \mathrm{~m}$ by $1 \mathrm{~m}$ units around Feature 20, 50 percent of the eight units around Feature 14, and 80 percent of the 10 units around Feature 27 yielded moderate frequencies of scattered burned rocks. One burned rock cluster (Feature 9) with relatively large burned sandstone pieces was located only $2 \mathrm{~m}$ south of pit Feature 14. South of pit Feature 27 were two clusters of burned sandstone (Features 26 and 42) that were also within the same $2 \mathrm{~m}$ area (Figure 13.9). Pit Feature 20 at the western end of Occupation 3 appears to be isolated from other burned rock features, provided that the GradallTM stripping method has not missed other features.

Sparse lithic debitage as defined by fewer than 10 pieces/ $\mathrm{m}^{2}$ surrounded pit Feature 14, with one unit of moderately dense lithic debris to the southeast corner. Fewer than five pieces of lithic debitage/ $\mathrm{m}^{2}$ also surrounded pit Feature 20. In contrast, 32 percent of the excavated units surrounding pit Feature 27 yielded a high density of lithic debitage (23 to 38 pieces $/ \mathrm{m}^{2}$ ). In general, pit Features 14 and 20 only had sparse lithic debris immediately surrounding them.

Formal tools were quite sparse around all three pit features. A sandstone abrader was recovered about $30 \mathrm{~cm}$ north of pit Feature 14 (Figure 13.7), and another sandstone abrader was also about $150 \mathrm{~cm}$ north of pit Feature 27 (Figure 13.9). Since the sample of two occurrences is small, it is unclear if the abrader association reflects a specific task that occurred near each pit or the association was just coincidence. Since abraders are often used with shaping such perishable items as sticks or bones, it may be that an individual attending the fire pit also had time to shape specific tools. No tools were found within $1 \mathrm{~m}$ of pit Feature 20, and only a few edgemodified flakes occurred around pit Feature 27. In addition to the sandstone abrader, three edgemodified flakes were also on the north side and within $1 \mathrm{~m}$ of pit Feature 14. 


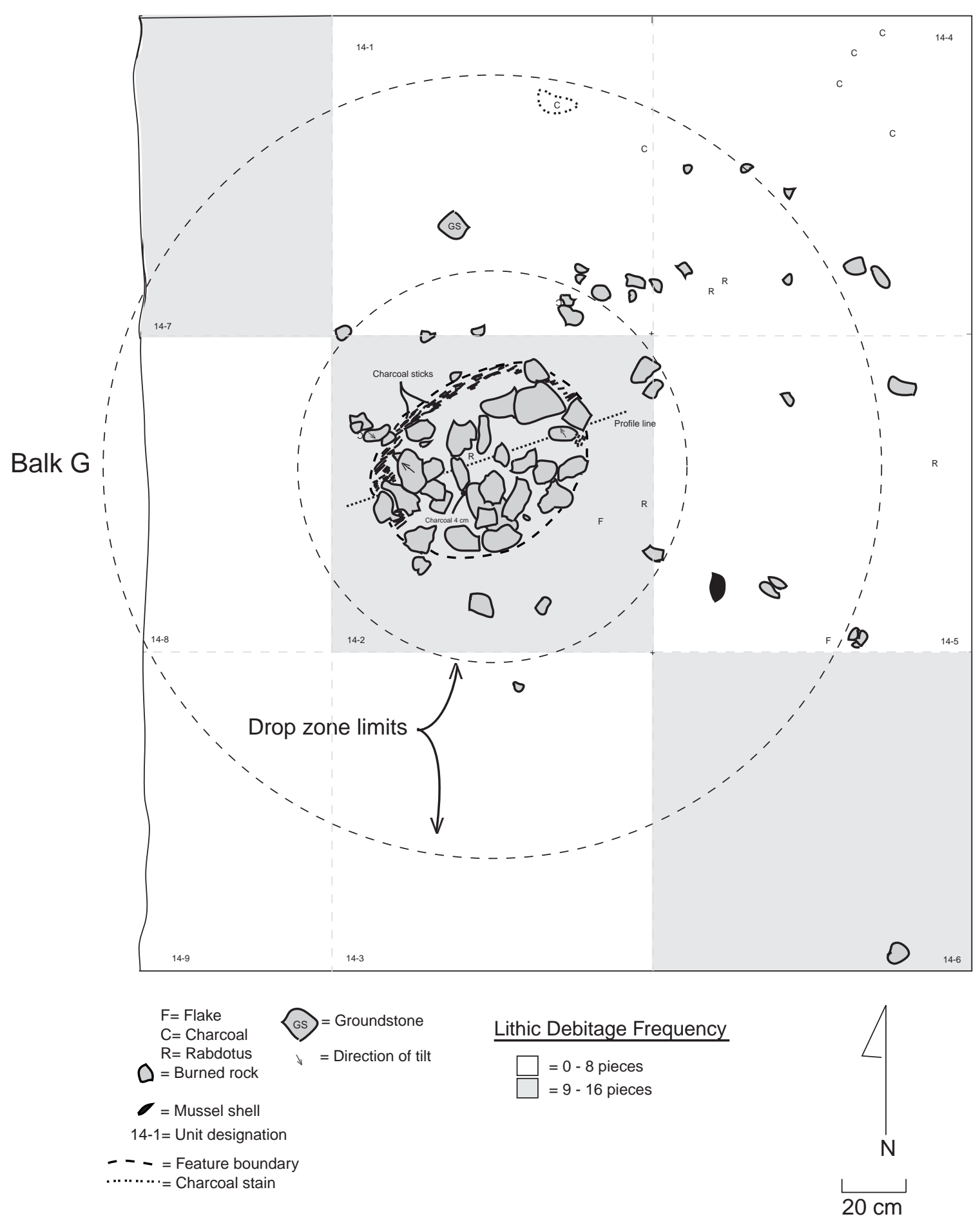

Figure 13.7 Occupation 1, Pit Feature 14 and Associated Material in the Immediate Vicinity (30$40 \mathrm{cmbs})$.

The $1 \mathrm{~m}$ area surrounding the three pit features yielded primarily scattered burned rocks and a few scattered flakes. It is unclear if the sparse amount of burned rock around the pit features was being added to or removed from the pits or if they represented a general scatter from a different nearby activity event. In two instances, minor abrading tasks or scraping tasks appear to have 


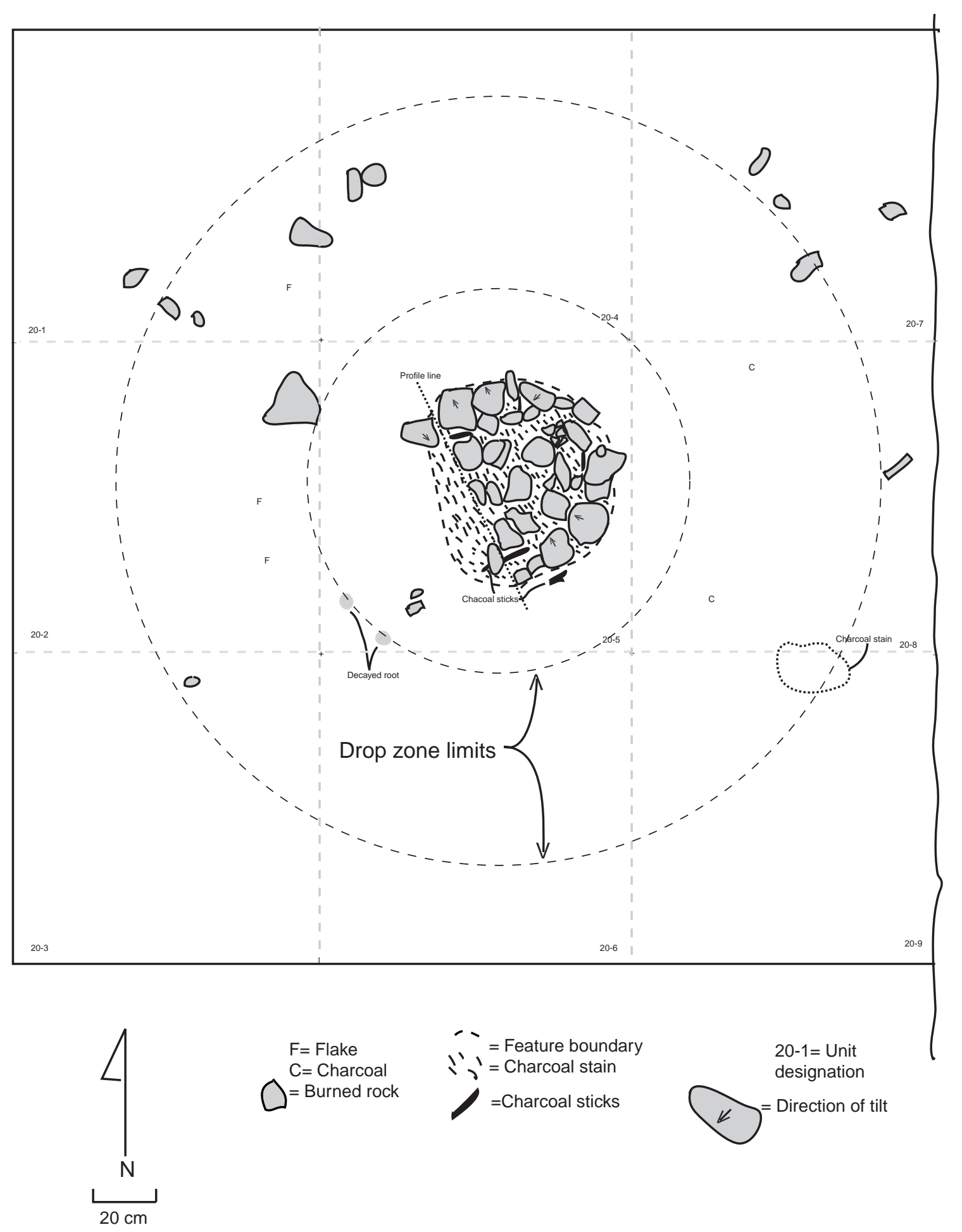

Figure 13.8 Occupation 3, Pit Feature 20 and Associated Material in the Immediate Vicinity (65$75 \mathrm{cmbs})$.

occurred in the immediate vicinity of these heating elements. Pit Feature 27 also had two burned rock dump features located south of the pit, and a small $(30 \mathrm{~cm}$ diameter) charcoal stained pit
(Feature 37) existed about 2 to $3 \mathrm{~m}$ to the west. All three ancillary features that surrounded Feature 27 may have been associated with this heating element and its role in the camp activities. 


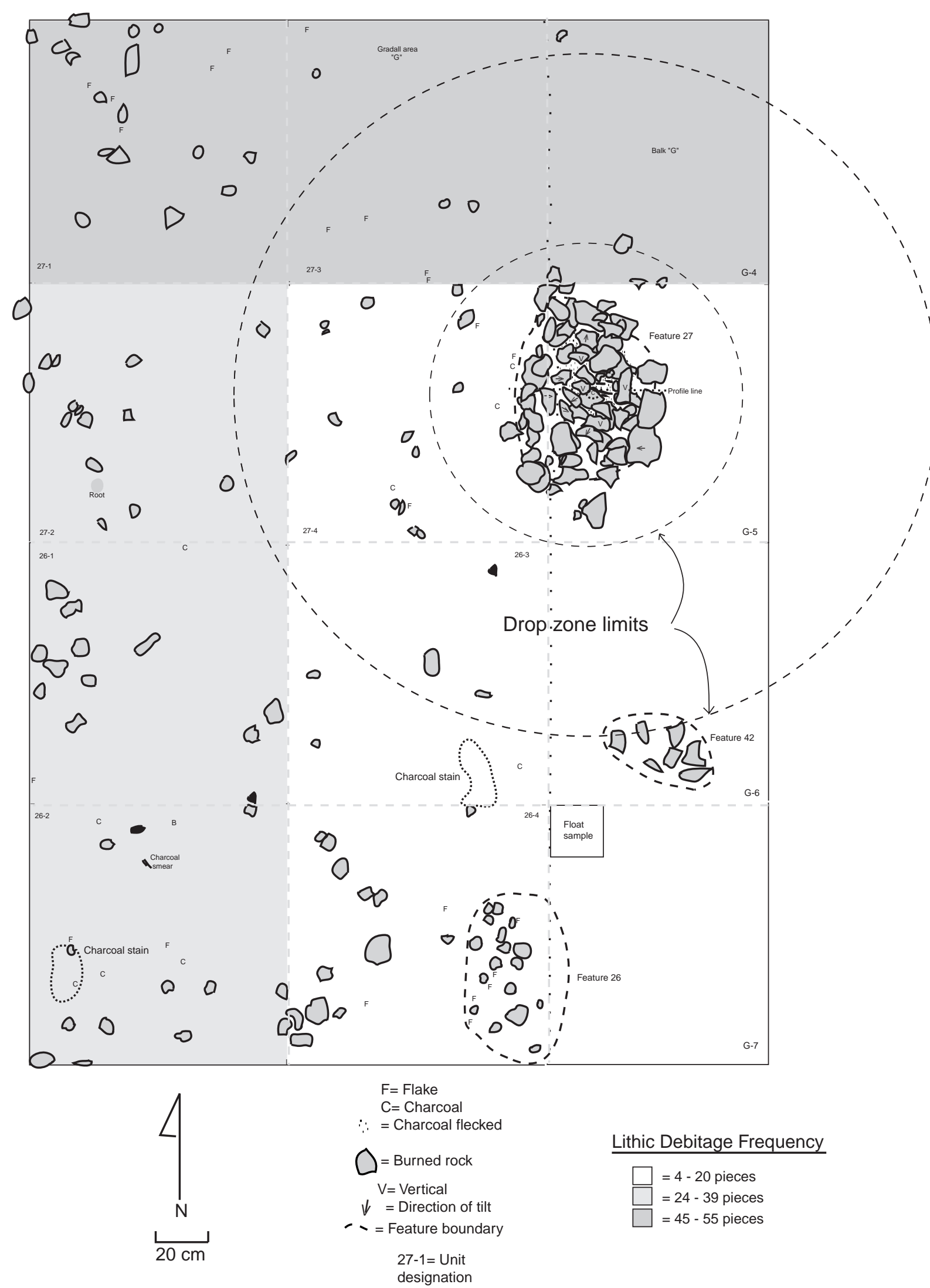

Figure 13.9 Occupation 4, Pit Features 27, 42, and 26 and Associated Materials. 
Although they were sparse, medium- and largesized artifacts were observed within $1 \mathrm{~m}$ radius around each feature. This material patterning does not appear to correspond to Binford's (1978) drop or toss zone model around a hearth. The lack of piece-plotted material remains has, especially regarding the smaller lithic debris, hindered the interpretation of past events. The lack of support for Binford's behavioral model may strengthen the interpretation that these three pit features functioned in a completely different role from Binford's (1978) hearth model, wherein people were projected to have congregated near a hearth to perform various tasks. Either the drop and toss zone model may be too simplistic, or the model does not apply to situations where groups utilized burned rocks in activities involving a sequential series of features, or there could be various other explanations.

The excavation approach that relied on mechanical scraping may have hindered the isolation and recognition of such subtle features and activity areas as habitation structures, stone tool knapping areas, or warming hearths within each occupation and the delineation of boundaries between the different activities. Since burned rocks greater than $5 \mathrm{~cm}$ in size were relatively plentiful, they were most often detected and recorded. Most of the burned rock cluster features are thought to have been discovered by the Gradall ${ }^{\mathrm{TM}}$ stripping method. The smaller pieces of lithic debitage were seldom noticed during Gradall ${ }^{\mathrm{TM}}$ stripping and were not often discovered in situ during the manual excavations. The tiny flakes that reflect various tool manufacturing and resharpening activity areas were not documented to the level of detail necessary for delineation of taskspecific boundaries. These pieces were also more susceptible to considerable displacement by turbation processes. Consequently, evidence relating to non-burned rock activities largely went undetected by the excavation approach used at the Lino site.
The absence of vertebrate faunal remains from these occupations has also hindered the identification of many activity areas because meat and bones must have played an important role in the everyday lives of the inhabitants. The range of other intact primary features such as hearths and activity areas is unknown due to poor preservation conditions and the excavation approach. Without the identification of more primary intact features, it is impossible to reconstruct the range of activities present in each of the occupation zones.

The recognizable material remains and mostidentified features relate to generalized camp maintenance activities as reflected by only three in situ pit heating elements and one in situ hearth from six occupation zones. In Occupations 1 and 3 , the in situ pit heating elements appeared to be isolated from other major material concentrations. The low-density space surrounding these pit features may reflect the need to isolate activities around the heat production features. Much higher concentrations of material remains were found around pit Feature 27 in Occupation 4, which may indicate some completely different activity pattern. It is possible that the pit feature overprinted debris from multiple events that were not archaeologically recognized or segregated. Alternatively, the higher density could also reflect changes in behavior concerning space utilization. Without better provenience control of the artifact and debitage distributions it is difficult to discern the possible activities underlying differences in the material recovered.

The general site structure revealed in each of the six occupation zones at the Lino site is very similar to that observed in other major excavated campsites in south Texas. The major occupation site at 41LK67 in Choke Canyon Reservoir, which dates to about this same period, also had dense clusters of burned rock (tuffa) with 
scattered cultural debris that included considerable amounts of mussel shells, Rabdotus shells, lithic debitage, charcoal, and some chipped stone tools (Brown et al. 1982). The occupation at 41LK67 also yielded Tortugas points and distally beveled tools. The occupations discovered at the Lino site exhibit a similar range of activities and features and indicates that these occupations are representative of one primary kind of site-a general campsite-within the Late Archaic hunter-gatherer settlements and subsistence systems of south Texas.

A functionally different type of site dating to the same period is the Loma Sandia cemetery site. The grave offerings at this mortuary site consisted of chipped stone tools, ground stone, bone, and shell artifacts that reflect complementary parts of the material assemblage containing the tools, jewelry, and perhaps ritual items that are often maintained and curated (Taylor and Highley 1995). Burned rocks were not part of the material goods included with the burials. Their absence undoubtedly reflects the utilitarian nature of burned rock as a common part of the cooking process.

As more excavations are conducted across south Texas, other site types in the settlement and subsistence pattern may be identified. These could include processing sites for animals, plants, or lithic resources. The occurrence or density of burned rocks could play an important role in assigning different functions to the sites encountered.

The material assemblages recovered from the six occupations at the Lino site undoubtedly reflect the dominant material remains left at most huntergatherer campsites. Further data from these kinds of sites can be extracted by focusing on the context and associations between the material classes to the same extent as the amount of attention paid to the artifacts and tools themselves.

\subsection{LITHIC RESOURCE PROCUREMENT AND TECHNOLOGY}

Macroscopic examination of more than 5,000 pieces of lithic debitage and analysis of over 100 formal stone tools from the Lino site assemblage did not identify any lithic material from non-local sources. Less than one percent of the analyzed chipped stone was identified as non-chert material. This included a few pieces of quartzite and unknown material types that could have been derived from local upland or river gravel sources.

An ultraviolet (UV), multiband light source (UV light 254/366 nm Model UVGl-55) was used to attempt to identify possible non-local cherts among some 100+ formal stone tools. Points, bifaces, scrapers, and other formed chippedstone tools were examined under the short- and long-wave fluorescence of the UV light. The UV fluorescence technique is still under development, and not all the known stone sources have had their UV fluorescence signatures identified (see Hofman et al. 1991; Hillsman 1992; and Church et al. 1996:51-58).

To expand the available UV lithic source data, 32 chert, one quartzite, and one igneous cobble from the upland gravels immediately west of the Lino site were also subjected to UV analysis. Each cobble had one or more flakes struck to remove the rounded and weathered cortex and expose a fresh interior surface for UV analysis. Presumably, the upland gravels would have been a potential source for materials available to the inhabitants of the Lino site. Table 13.3 provides material type, color, texture and short- and longwave responses to the UV light on the local gravels. The quartzite specimen had a purple UV response under both long and short wave light, and the igneous rock had a very dark red response under the short wave and purple response under the long wave. Under short wave UV light exposure of freshly exposed surfaces, the chert cobbles yielded UV responses as 


\begin{tabular}{|c|c|c|c|c|c|c|}
\hline \multirow[b]{2}{*}{ Cat. No } & \multirow[b]{2}{*}{ Material Type } & \multirow[b]{2}{*}{ Texture } & \multirow[b]{2}{*}{ Common Color } & \multirow[b]{2}{*}{ Munsell Color } & \multicolumn{2}{|c|}{ Fluorescence Response } \\
\hline & & & & & Short Wave & Long Wave \\
\hline 1 & Quartzite & Medium & Purple & Dusky Red 10R 3/2 & Purple & Purple \\
\hline 2 & Igneous & Coarse & Lt. Purple & Weak Red 10R 5/2 & Very Dark Red & Purple \\
\hline 3 & Chert & Fine & Tan & Lt. Brown 7.5YR6/3 & Purple & Purple \\
\hline 4 & Chert & Fine & Lt. Gray & White 10YR8/1 & Purple & Purple \\
\hline 5 & Chert & Medium & Lt. Gray & Lt. Gray $10 \mathrm{YR} 7 / 2$ & Purple & Purple \\
\hline 6 & Chert & Fine & Brown & Brown $7.5 \mathrm{YR} 4 / 2$ & Yellow & Yellow \\
\hline 7 & Chert & Medium & Gray & Gray 10YR5/1 & Purple & Purple \\
\hline 8 & Chert & Fine & Brown & Yellowish Brown 10YR 5/4 & Purple & Purple \\
\hline 9 & Chert & Fine & Reddish Gray & Reddish Gray 10R6/1 & Lt. Brown & Lt. Brown \\
\hline 10 & Chert & Fine & Gray & Gray $5 Y 5 / 1$ & Purple & Purple \\
\hline 11 & Chert & Fine & Gray Brown & Grayish Brown 10YR 5/2 & Brownish Yellow & Brownish Yellow \\
\hline 12 & Chert & Fine & Gray & Lt. Gray 10YR 7/1 & Purple & Purple \\
\hline 13 & Chert & Fine & Gray Brown & Lt. Brownish Gray 10YR6/2 & Mottled Purple/Lt. Brown & Mottled Purple/Lt. Brown \\
\hline 14 & Chert & Medium & Gray Brown & Grayish Brown 10YR5/2 & Purple & Purple \\
\hline 15 & Chert & Fine & Gray & Gray 10YR 5/1 & Yellow w/ green tint & Yellow \\
\hline 16 & Chert & Medium & Gray & Gray 10YR 6/1 & Brownish Yellow & Brownish Yellow \\
\hline 17 & Chert & Coarse & Lt. Reddish Gray & Reddish Gray 2.5YR 6/1 & Purple & Purple \\
\hline 18 & Igneous & Fine & Lt. Brown & Pale brown 10 YR $6 / 3$ & Yellow & Yellow \\
\hline 19 & Chert & Medium & Lt. Gray & Lt. Gray 7.5YR 7/1 & Purple & Purple \\
\hline 20 & Chert & Fine & Gray & Gray N5/ & Yellow & Yellow \\
\hline 21 & Chert & Fine & Gray Brown & Lt. Brownish Gray 10YR 6/2 & Brownish Purple w. yellow bands & Brownish Purple w. yellow bands \\
\hline 22 & Chert & Fine & Lt. Gray & Lt. Brownish Gray 10YR 6/2 & Grayish Blue & Purple \\
\hline 23 & Chert & Fine & Lt. Brown & Lt. Gray 10YR 7/1 & Yellow w/ Purple blotches & Yellow w/ Purple blotches \\
\hline 24 & Chert & Fine & Lt. Gray & Lt. Gray 10 YR $7 / 1$ & Green/Purple & Purple \\
\hline 25 & Chert & Fine & Gray Brown & Grayish Brown 10YR 5/2 & Yellow & Yellow \\
\hline 26 & Chert & Fine & Gray Brown & Grayish Brown 10YR 5/2 & Greenish Brown w/ Purple & Purple with brownish Purple \\
\hline 27 & Chert & Medium & Green/Gray & Olive Gray $5 Y 4 / 2$ & Purple & Purple \\
\hline 28 & Chert & Fine & Gray Brown & Grayish Brown 10YR 5/2 & Greenish Yellow w/ Purple & Yellow w/ Purple \\
\hline 29 & Chert & Fine & Gray & Gray 10YR 5/1 & Greenish Yellow w/ pale Purple & Greenish Yellow w/ Purple \\
\hline 30 & Chert & Fine & Gray & Gray 10YR 6/1 & Purple & Purple \\
\hline 31 & Chert & Fine & Lt. Gray & Lt. Gray 10 YR $7 / 1$ & Yellow & Yellow w/ Purple \\
\hline 32 & Chert & Fine & Black & Black N2.5/ & Purple & Purple \\
\hline 33 & Chert & Fine & Black & Black N2.5/ & Purple & Purple \\
\hline 34 & Chert & Medium & Dark Gray & Very Dark Gray N3/ & Purple & Purple \\
\hline
\end{tabular}


follows: 49 percent purple or no UV response, 16 percent yellowish, nine percent mottled purple, nine percent yellow greenish, six percent brown and yellow, three percent light brown, three percent mottled colors, and three percent grayish blue. The long wave UV analysis yielded very similar responses with only slight shifts in color variations. Overall, a few of the short wave responses were darker and appeared more purple than the responses under the long wave light. The UV yellow response is similar to, but distinguishable from, the amber-yellow hues that are characteristic of Edwards chert from central Texas. Hand samples of Edwards chert were available for direct comparisons.

The UV light responses on 70 prehistoric formal tools from the Lino site deposits are presented in Table 13.3. In general, the short and long wave UV responses were very similar and are summarized together. Nearly 52 percent of the light responses revealed an orange or dark orange signature, 23 percent had a yellowish or yellowish orange response, 21 percent had a purple response, three percent had a light or dull yellow response, and one percent had a dark red response.

The UV light response from the 70 Late Archaic tools differed from the responses detected on the natural gravels from the upland areas adjacent to the Lino site. The purple response dominant among the natural chert cobbles occurred for only about 21 percent of the Late Archaic tools. The greenish yellow response among 16 percent of the natural chert cobbles was present in a mere three percent of the prehistoric tools in a lighter and duller hue. The dark orange responses in 23 percent of the Late Archaic tools were often recognized in the sample of natural cobbles.

The lack of UV correspondence between the natural and Late Archaic tool chert samples indicates that the Late Archaic chert tools probably came from other sources. Since orange UV responses were observed in natural rocks from the El Paso region, located hundreds of kilometers upstream (Hillsman 1992), it is very likely that the Rio Grande gravels were the source of raw material from which the Late Archaic stone tools were manufactured. This does not necessarily mean that the Rio Grande gravels were non-local sources but that the upland gravels adjacent to the Lino site may have a different origin from the Rio Grand gravels. Although a few formal tools yielded a light yellow UV response, it was not identical to the response from samples of central Edwards chert that show an amber-yellowish UV response. Several tools with the yellow UV responses might represent Cretaceous period cherts that originated along the upper Rio Grande. These locally available Rio Grande chert gravels may have a UV response very similar to the amber-orange-yellow fluorescence response identified central Texas chert.

Lack of correlation between the tools and the sampled gravels from the upland setting adjacent to the Lino site might indicate that the gravels were not accessible when the site was occupied 2,000 to 3,000 years ago. Nevertheless, the macroscopic and UV light analyses did not identify non-local lithic materials among the tool stone used by these groups. The raw material sources appear to have come from watertransported gravels that have UV responses different from those found in the gravels of the immediate uplands. The reliance on local sources may indicate a lack of trade or contact with the populations that had access to different material sources.

Observations concerning the Late Archaic lithic technologies are limited to debitage that was greater than $6.4 \mathrm{~mm}$ in size. The Occupation 6 assemblage is probably not representative because it may not represent a separate or complete occupation. The general analysis indicates that considerable knapping tasks occurred during each occupation. As a collective 
assemblage, the flake types revealed that core reduction focusing on the removal of cortex from the cobbles was the primary knapping activity in each occupation (Table 13.4). Apparently, this decortication led to the production of cobblesized bifaces that were recognizable as early and late stage forms. The early stage biface flakes may slightly overlap with the core reduction stage pieces because the flake characteristics have slightly overlapping attributes. Problems in correctly classifying flakes may account for the low frequency (equal to or lower than 20 percent) of early biface stage pieces recognized in each of the occupation assemblages. Late stage biface flakes were more readily recognized and account for higher percentages that ranged from 18 to 30 percent of the total assemblage (except for the percent of biface flakes from the biased assemblage, Occupation 6). Widespread use of heat treating the raw chert resource is not apparent, although a few pieces from nearly every occupation appear to have been heat treated. As a general observation, most of the pieces of lithic debitage appear to represent byproducts of tool manufacturing that were either curated and removed from the Lino site when the people moved on or reflect the occurrence of finished tools in another, unexcavated part of the site.

Only one very minor trend may be present in the debitage assemblage spanning the roughly 1,400-year period. The two oldest components, Occupations 5 and 6 , have the lowest frequency of late stage biface pieces (18 percent and nine percent, respectively). In contrast, Occupation 1 had the highest frequency (30 percent) of late stage biface flakes. Uniface flakes and angular debris are the two lowest frequency categories. The near absence of unifacial flakes may reflect the very limited nature of unifacial production and/or tool resharpening activities that occurred during these occupations. It could be that unifacial flakes were missed during excavation or the analysis misclassified them because of
Table 13.4 Percentage of Flake Types per Occupation Zone at Lino Site 41WB437.

\begin{tabular}{lccccccc}
\hline & \multicolumn{7}{c}{ Occupations } \\
\cline { 2 - 8 } Flake Type & $\mathbf{1}$ & $\mathbf{2}$ & $\mathbf{3}$ & $\mathbf{4}$ & $\mathbf{5}$ & $\mathbf{6}$ & Miscellaneous \\
\hline Angular & 3 & 1 & 2 & $<1$ & $<1$ & $<1$ & 6 \\
Core & 28 & 39 & 33 & 32 & 35 & 51 & 40 \\
Early biface & 13 & 15 & 16 & 20 & 18 & 14 & 12 \\
Indeterminate & 23 & 25 & 19 & 25 & 27 & 26 & 17 \\
Late biface & 30 & 20 & 30 & 22 & 18 & 9 & 26 \\
Uniface & 2 & 0 & 0 & $<1$ & 1 & 0 & $<1$ \\
\hline Total \%* & $\mathbf{9 9}$ & $\mathbf{1 0 0}$ & $\mathbf{1 0 0}$ & $\mathbf{9 9}$ & $\mathbf{9 9}$ & $\mathbf{1 0 0}$ & $\mathbf{1 0 1}$ \\
\hline * totals may not equal 100\% due to rounding & \\
\hline
\end{tabular}

some unusual attributes associated with distally beveled tool forms compared to the more common shapes of end scrapers.

Little change is apparent in the knapping activities at the campsites spanning this 1,400year period, even though two separate cultural groups are postulated based on the occurrence of Refugio points in Occupation 5 and Tortugas points in Occupations 1 through 4. Minor percentage differences among the lithic debitage assemblages from the various occupations could be attributed to sampling differences within the site area. This broad similarity between components may reflect the overall likeness of the stone tool assemblage (Table 13.2). The dominant use of small, cortex-covered cobbles as a source of raw materials also contributes to assemblage similarity. Production of two kinds of unnotched and unstemmed projectile points by the different occupants could also contribute to the homogenous appearance of the debitage assemblages.

Though both Tortugas and Refugio projectile point types are unnotched forms, their appearance is quite different. Refugio points are leaf shaped whereas the Tortugas points are triangular. Their thicknesses are relatively similar, but the widths show more variability (Figure 13.10). The tremendous variation in the widths of the Tortugas points probably reflects the extent of production and resharpening 


\section{Point Thickness vs. Point Width}

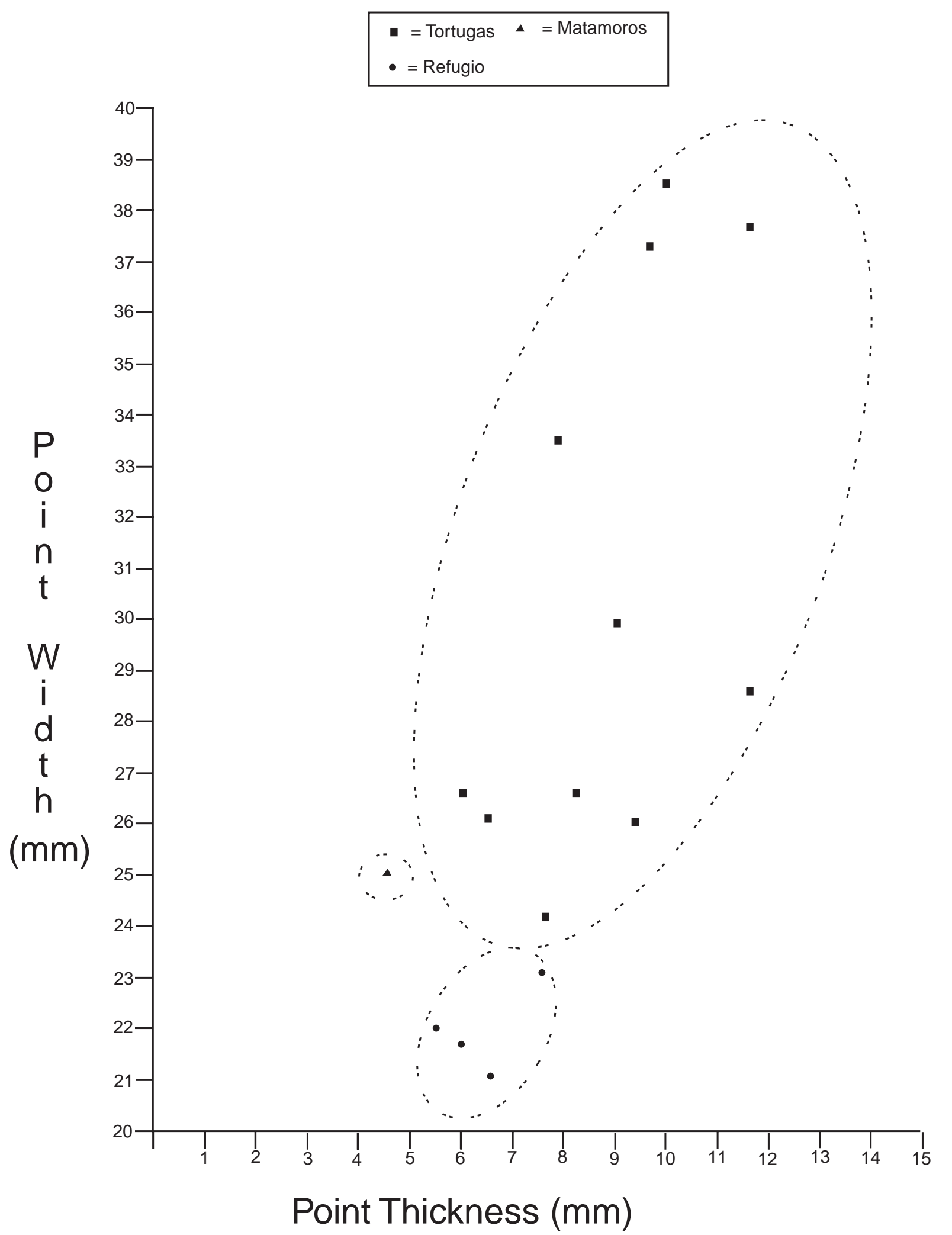

Figure 13.10 Projectile Point Width vs. Thickness, Lino Site (41WB437). 
represented in the larger sample. The single triangular Matamoros point is the thinnest specimen recovered, and it is narrower than 95 percent of the Tortugas point forms. This may reflect a later stage in its life cycle than the Tortugas points. The four Refugio points show remarkable metric similarity with a blade width constantly narrower than the Tortugas and Matamoros points.

The overall lithic assemblages involve the production, use, and resharpening of such stone tools as projectile points, bifaces, drills, scrapers, edge-modified flakes, hammerstones, and ground stones. Although tool type frequencies may vary among the various occupations, the differences primarily represent sampling different parts of each occupation's activity areas (Table 13.2). Although quantities of lithic debitage were recovered that reflect knapping activities, few hammerstones were recovered. This may reflect the retention of the good hammerstones by the knappers. Based on the frequency of quartzite cobbles available in the upland gravels, no shortage of the raw material for a quality hammerstone existed. Interestingly, it appears that little to no debitage was of the same source material as the recovered stone tools. Therefore, the tools that were abandoned, broken, or discarded on site were apparently manufactured elsewhere. The recovery of abraders and manos from both the Refugio occupation zone (5) and the Tortugas occupation zones (1, 3, and 4; Table 13.2) reflects the continuity in the general activities that occurred through time and between the two different groups.

The presence of similarly functioning tools spanning a 1,400-year period indicates similar lifeways and tasks preformed at these six occupation zones, which is that of a generalized Late Archaic hunter-gatherer campsite. The camps appear to have been used for a relatively short duration but possibly reflect stays of more than one or two nights, as based on the density of cultural debris. General site functions reflected by the chipped stone assemblages relate to the retooling of stone implements, the producing of bifaces, the resharpening of tools, the producing of perishable tools through the use of abraders, the grinding of seeds and grains using manos, and the cooking of deer, legumes, and various other plant resources using the stone boiling technique. Related activities also include scraping skins, cutting meat and skins, drilling and punching, and killing and butchering animals. Potentially, many other tasks undertaken left less obvious evidence. Since the general lifeway and non-perishable component of the assemblages are quite similar among the Late Archaic occupations at the Lino site, it would appear that the change from a dry climate at 3400 B.P. to more-moist conditions by 2000 B.P. did not substantially alter the adaptive behavior of these hunter-gatherers. 


\subsection{SITE RECOMMENDATIONS}

Mitigation excavations at the Lino site 41WB437 were required by state and federal laws to minimize the loss of significant cultural resource information anticipated by the direct impact of the expansion of Highway 83 south of Laredo, Texas. Nearly 17,000 pieces of cultural material were recovered from block excavations that encompassed about $235 \mathrm{~m}^{3}$. The alluvial creek terrace deposits contained six stratified components in the top $120 \mathrm{~cm}$ of sediment. The material remains all date to the Late Archaic period and were quite similar in materials and content. They included quantities of burned rocks, burned rock features, quantities of lithic debitage, and sparse stone tools. The remains are interpreted as representing a series of extended family campsites each occupied for more than a few days. Although the component assemblages were limited in terms of formal tools, cultural affiliation was assignable to twothirds of the components based on the presence of diagnostic projectile points. The mitigation efforts at the Lino site have significantly contributed to the information about the Late Archaic period of south Texas by addressing a series of specific research issues.

Highway construction has not destroyed all the site area. Remaining portions of some occupation zones are buried under the elevated roadbed fill and along the edges of the highway right-of-way boundaries. The data recovery program sampled a limited area encompassing $235 \mathrm{~m}^{3}$, but of this area, only $48 \mathrm{~m}^{3}$ represented hand-excavated continuous transects from seven balks and only an additional $12.4 \mathrm{~m}^{3}$ of fill was manually excavated around 24 features. Since only a small area was investigated, it is likely that the data potential of the six stratified components has not been exhausted. To further manage this archeological resource owned by TxDOT, a public entity, we recommend that the Lino site be designated a "State Archeological Landmark" by the Texas Historical Commission because it meets all criteria for qualification. 
Intentionally Left Blank 


\title{
15.0 ASSESSMENT OF FIELD EXCAVATION STRATEGIES AND RECOMMENDATIONS
}

\author{
J. M. Quigg and C. Lintz
}

\subsection{INTRODUCTION}

The Lino site excavation represents an extension of experimental field approaches initiated by an innovative program called the "Higgins Experiment." This experiment was conducted by TARL and sponsored by TxDOT on prehistoric sites along the Wurzbach Parkway in San Antonio in the early 1990s (Potter et al. 1995; Potter and Black 1995; Black et al. 1998). As often happens when new approaches are attempted in highly prescribed scientific disciplines, the "experiment" led to differences of opinion, this time between those who performed the study and those who sponsored it. The differences are summarized at the end of Black et al, 1998, in Appendix L, TxDOT Review Comments and Response. It is important to highlight some of these differences before discussing how insights gained from the Lino site may help us to understand and resolve such differences in the future.

In the view of its TxDOT sponsors, "The revolutionary aspect of Higgins is the abandonment of several deeply entrenched 'traditional' archeological practices, particularly (1) grid-based excavation and (2) routine screening of the matrix." (Ellis et al. 1998:413). And while they commend a number of things about the experiment, they also note there are "some analytical methods, and methodological assumptions that are, in our opinion, implausible." (Ellis et al. 1998:413) For example, the TxDOT sponsors noted that " $[t]$ he decision to abandon grid-based excavation was made possible because (1) the emphasis of the excavation was on the character of 'site structure' as expressed in the distribution of burned rocks, and (2) the technology of the total data station
(TDS) allowed a radically different approach than has been traditionally employed." (Ellis et al. 1998:413)

However, the sponsors go on to point out that

[w] hile use of a TDS circumvents the need for manual recording, transcription, and entry of point-provenience data, it is not incompatible with traditional grid-based excavation. Applying TDS in conjunction with a traditional grid-based strategy would allow for nesting of spatial resolution. Artifacts of "piece-plottable" size could be precisely located in space, while smaller artifacts could be located with unit/level precision. Where different problems can be addressed at different levels of spatial resolution, the wedding of TDS and "traditional" techniques can be used to address problems that require data from artifacts that cannot be recovered effectively using either set of techniques by itself. (Ellis et al. 1998:413)

Further, in their reflections on the no-screen policy followed in the Higgins Experiment, the TxDOT sponsors note that

Black and Jolly argue that the lack of screening was a positive attribute of the study reflecting an enlightened sense of the data potential of lithic debitage.... However, flake analyses need not be the same thing as traditional technological analyses, even if the latter has been what people often have done. Many nontraditional avenues of resource-focused lithic data analysis remain to be explored. In addition, screens may be necessary to acquire samples of "ecofacts" and for finding small formal tools (e.g., thumbnail scrapers and arrow points) and 
small informal tools that cannot be recognized as such while they are still dirty.... Decisions about screening-to screen or not, how much to screen, what to collect from screens-are problem dependent, which in turn determines what balance between Higgins-like and "traditional" techniques is appropriate for any site at hand. (Ellis et al. 1998:414).

An opportunity to resolve some of the controversy from the Higgins Experiment occurred when TxDOT was widening of U.S. Highway 83 at the crossing of San Idelfonzo Creek south of Laredo, Texas, which threatened the integrity of archaeological site 41WB437 (herein referred to as the Lino site). Site testing by TxDOT suggested this as "an ideal site to address specific behavioral questions on the Rio Grande Plain, an area that is poorly understood." (Abbott, 1997) However, the TxDOT report went on to say:

The opportunity for theoretical advancement presented by $41 \mathrm{WB} 437$ is matched by logistical and budgetary disadvantages. Because the individual occupations are relatively ephemeral and exhibit a paucity of associated remains, extensive excavation is required both to understand the spatial structure of the site (and the patterning of activities within that structure) and to recover a sufficient amount of artifactual material for meaningful analysis. Addressing such a problem with traditional, grid-based hand excavation methods is a costly, time-intensive prospect. A viable alternative approach is exemplified by excavations on the Wurzbach Parkway [Higgins Experiment] in San Antonio (Abbott 1997:44).

This brings into consideration another alternative methodology that was utilized but not discussed extensively in the Higgins Experiment report (Black et al. 1998) This was excavation using a Gradall $^{\mathrm{TM}}$ machine. A Gradall ${ }^{\mathrm{TM}}$ can excavate $1.5 \mathrm{~m}$ wide strips with fairly precise depth control and therefore offers a tool to excavate much wider "windows" on the archaeology under investigation. This was important to TxDOT, an agency often required to fund archaeological excavations potentially threatened by its roadworks. In the words of one of the TxDOT sponsors of the Higgins Experiment:

We felt that many of the problems encountered in the Higgins and BX996 excavations were insurmountable because they were a natural consequence of the character of the sites - thousands of years of dense occupational debris compressed into a shallow deposit with no apparent depositional stratigraphy and a strong pedogenic overprint. In short, good idea, wrong site....In our opinion, the Gradall strategy was better suited for addressing sites where occupational debris was relatively sparse and contained in thick deposits with well-expressed stratigraphy and relatively little pedogenic modification. 41WB437 was believed to be such a site.... Granted that the Gradall strategy is better suited for sites like 41WB437 than for sites like Higgins, it is still not as effective as traditional hand excavation for data return because the resolution is poorer and the recovery is more limited. Why, then, would we choose it? The answer is relatively simple. Traditional hand excavation is extremely expensive, and alluvial sites in south Texas are notorious for sparse occupational debris. The Gradall strategy was adopted to make the available funds stretch [further].... The object of the exercise was to assess whether the loss in data resolution resulting from the Gradall technique was counterbalanced by an increase in overall data recovery from the considerably larger excavation.... (Abbott, Personal Communication 1999).

Therefore, to ensure that investigations at site 41WB437 would represent a step forward in the application of alternative methods and resolution of earlier disagreements, TxDOT sought to closely prescribe the methods to be used and purposely 
precluded the usual latitude exercised by project archaeologists in the field. This was made clear in the IFB to perform data recovery at the site. In Exhibit 1 of the IFB, entitled Prescribed Methodology, a primary goal of the investigation is presented in the first paragraph, preceded by the underlying assumption that led to applying the alternative methods at this site:

S-outh Texas archeological sites are difficult to treat in a cost-effective manner because they tend to be sparsely populated with artifacts. Agoal of the proposed investigation is to employ an alternate methodology for excavation of alluvial terrace sites in south Texas, and to evaluate its effectiveness on completion.

Exhibit 1 goes on to say that a "modification of the techniques pioneered at sites along the Wurzbach Parkway [is] mandated for mitigation of 41WB437."

Following a brief summary of the methods used in the Higgins Experiment, assumptions and key elements of the modified techniques used at 41WB437 are discussed below. This is followed by a critical evaluation of the approaches used relative to budgetary constraints, methodological approach validity, and research design issue contribution. A final section offers recommendations and suggestions about how the mix of traditional and alternative methods might be optimized on future projects.

\subsection{THE HIGGINS EXPERIMENT EXCAVATION STRATEGIES}

The Higgins site (41BX184) was a large, intensively utilized area, rich in prehistoric artifacts compressed into shallow, overprinted deposits. It contained large quantities of burned rocks, many burned rock features, a massive burned rock midden, quantities of lithic debitage, and scattered stone tools. The cultural materials appeared to represent roughly 6,000 years of prehistory compressed into 40 to $65 \mathrm{~cm}$ thick clay-dominated Holocene terrace deposits along Panther Springs.

The 1993 excavation, dubbed by Black as the "Higgins Experiment," was "designed to explore site structure through the application of new methodological strategies" (Black et al. 1998:iii) as an alternative to what was viewed by the researchers as "the traditional approach" that "had ceased to produce new insights, aside from particularistic detail." (Black 1995a:3) "The Higgins Experiment was an attempt to point the way toward new strategies for making archeological investigations more productive by showing that viable alternatives to the methodological status quo could be developed within the context of compliance-driven research." (Black and Jolly 1998b:229)

The researchers developed "an explicit series of hypotheses and expectations that we intended to test by targeting classes of information [burned rocks] that are often ignored, using a mix of new and old methods, technologies, and tools." (Black and Jolly 1998b:229) Their premise was that "the Higgins site's basic structure, overprinted though it was, was still intact, and could be seen through the patterning of the many cooking features in the hearth field." (Black and Jolly 1998b:229) The data collection was designed, very purposefully, to provide data they thought would address their hypotheses and, just as purposefully, to exclude data they judged to be extraneous (Black and Jolly 1998b:229).

Their field strategy revolved around 1) the implementation of a broad, open excavation block dug with the aid of a GradallTM, and 2) the use of a TDS and field computers to maximize piece-plotted data (Black et al. 1998:iii). The TDS was used to record the individual pieces of burned rocks and chert artifacts found in situ in lieu of their assignment to an arbitrary $10 \mathrm{~cm}$ vertical level obtained 
during screening from 1 by $1 \mathrm{~m}$ grid units. Black et al. (1998) appear to have assumed that excavators would have discovered nearly every piece of cultural material of any significance and then obtained their provenience with great precision by using a TDS.

\subsubsection{Use of the TDS on the Higgins Experiment}

The Higgins Experiment demonstrated that the TDS can be used to obtain precise provenience, record certain large artifact classes (mostly burned rocks), and define the larger-scale patterning of burned rocks. However, flakes were so numerous that assigning them sequential numbers was stopped because it was too time consuming. In fact, the sampling was totally biased towards large burned rocks, most of which measured greater than $7 \mathrm{~cm}$ in diameter. The TDS data were used for spatial analysis, which Black et al. (1998) believed was now cost effective for the first time. The authors concluded that the TDS technique showed great promise even though it requires a more systematic sampling strategy for small artifacts than was implemented during this experiment (Black et al. 1998). The lack of the smaller flakes was believed not to have affected the main focus of the project, which centered on the patterning of burned rocks.

One of the major problems encountered with the spatial data was the very complex nature of the archaeological record due to the compressed stratigraphy. The TDS plots of burned rocks were believed to provide a very useful data set that could generate accurate statistics as well as realistic graphics that would allow researchers to explore spatial patterning of material remains in many different ways (Black and Jolly 1998b:236).

\subsubsection{Use of the No-screen Strategy}

The no-screen strategy enabled researchers to focus on the horizontal distribution and patterning of large objects comprised mostly of burned rocks with little attention paid to lithic debitage and other small objects in an attempt to understand highly localized patterns of prehistoric use of the landscape by huntergatherers. In justifying this approach, Black and Jolly (1998a:33) characterize the traditional square-hole approach as not-so-scientific, stating that it "masks the true variability by averaging or smearing the data " and "reduces the complexity of the data by greatly simplifying much of its three-dimensionality. They suggest that this simplification is "justifiable when archeologists have in mind the kinds of questions that can be easily addressed by data with relatively coarse resolution." (Black and Jolly 1998a:33) In their opinion, "if one is interested in revealing site structure in all its glorious challenging complexity, then we need to use sophisticated means capable of recording and reflecting three-dimensional reality." (Black and Jolly 1998a:33).

\subsubsection{Acknowledged Problems from the Higgins Experiment}

The investigators admit that, in planning for the data recovery program, they did not take full advantage of the useful data that were recovered from the testing phase and use them in planning the data recovery excavations. Most of their ideas, they further admit, were developed from impressions of the site's data and not on close scrutiny of the testing phase data. Apparently, many burned rock features encountered were believed to be in place and at least partially intact. However, the analyses were unable to make meaningful links between the chipped 
stone artifacts and the cooking features in the hearth field.

Because of the inability to recognize a hearth and its associated living surface during the excavations, the archaeologist abandoned hand screening around individual features. To compensate, samples of fill spaced in a $2 \mathrm{~m}$ grid were fine screened, but these samples proved to be too widely spaced to produce a data set capable of revealing behaviorally significant spatial patterning (Black and Jolly 1998b:231).

On the other hand, we contend that their decision not to pass the excavated dirt through $6.4 \mathrm{~mm}$ screens was not a mistake. If anything, they should have excluded all of the flakes and likely all the non-temporally diagnostic artifacts from TDS plotting (Black and Jolly 1998b:235) because it detracted from their primary goal of assessing large-scale patterning at the site.

Many of the research questions originally proposed that dealt with the social and adaptive aspects of the site investigation were soon abandoned because they could not be adequately addressed (Black 1998:217). The assumption that the hearth field was the focus of family camps could not be verified. Four factors made it difficult to meaningfully evaluate the presence of family groups: 1) many different burned rock features were not well defined and difficult to qualify and interpret, 2) minimal information was offered on lithic debris, 3 ) the lack of various kinds of analyses precluded group size delineation, and 4) considerable overprinting of activities prevented the isolation of occupations.

\subsection{THE LINO SITE EXCAVATION STRATEGIES}

This section first examines and evaluates the assumptions derived from the testing phase that were used to influence the methods mandated in the Lino site excavations. Next, the opportunities and constraints of employing the various excavation strategies utilized on the Lino site are discussed preparatory to the following section, which evaluates the success of those strategies.

\subsubsection{Testing Phase Assumptions}

In regards to the Higgins Experiment, Black et al. (1998) realized that many types of baseline data are required before any major site investigation can be intelligently planned in order to identify and target data suitable for addressing research design issues. The testing phase at 41BX184 had not provided the information necessary to adequately plan the Higgins Experiment. We point out that the testing phase stopped short of being adequate for planning data recovery because its primary goal was simply to evaluate whether or not the site was eligible for nomination to the National Register of Historic Places. They recognized that even with a difficult site, 1) when archaeological problems are clearly stated, 2) the research issues are well defined, and 3) the methods are tightly controlled, new things can be learned from the archaeological record (Black and Jolly 1998b:229). However, the authors imply that the reason they failed to learn more about the archaeological record is the result of non-creative excavation strategies and inappropriate research problems due in part to shortcomings of the testing phase (Black and Jolly 1998b:237).

In contrast to the Wurzbach project, the Lino site (41WB437) appeared, from 1997 testing phase results, to represent the remains of a number of discrete, stratigraphically separated, relatively ephemeral, short-term activity surfaces dating to the Archaic period (Abbott 1997:41). The occupational debris was not thought to be particularly abundant, but each occupation probably contained preserved and buried burned rock features associated with considerable 
charcoal and a large number of dispersed burned sandstone clasts. The presence of isolated burned rocks was thought to indicate that some cultural strata were disrupted and strewn across the point bar surface by high magnitude flooding. The presence of identifiable stratigraphy in the form of alternating beds of massive silts and structured silt loam was thought to provide the potential to correlate spatially discrete, stratigraphically related activity loci with a high degree of precision and confidence (Abbott 1997). Thus, on the basis of site testing information, the Lino site was considered to be an ideal site to address specific behavioral questions and to implement modifications to the field methods pioneered in the Higgins Experiment (Abbott 1997).

The 1997 testing phase at the Lino site was under the direction of Ms. Henderson and consisted of four backhoe trenches and seven formal test units clustered in two areas spaced fewer than $25 \mathrm{~m}$ apart within a site area conservatively estimated at $5,000 \mathrm{~m}^{2}$. Unfortunately, the hand excavations of six 1 by $1 \mathrm{~m}$ units and one 50 by $50 \mathrm{~cm}$ unit focused on three shallowly buried burned rock clusters/features. The testing focused on burned-rock scatters buried within the top $60 \mathrm{~cm}$. None of the seven test pits were hand excavated from the surface to depths exceeding $60 \mathrm{~cm}$. Only three (43 percent) of the seven test units reached a depth of $60 \mathrm{~cm}$ despite the observation of a burned rock, shell fragments, and charcoal in Feature 1 at a depth of $185 \mathrm{cmbs}$ in the profile of a backhoe trench 1 (Abbott 1997:24). Thus, the maximum depth of cultural materials within the terrace is still unknown. The data misled mitigation designers into believing that relatively sterile mud drapes segregated the various occupations that developed within an aggrading terrace.

Thus, the hand excavations during the testing phase failed to clearly define the number of cultural occupations present, the discreteness of their possible vertical separation across different parts of the site, the density of artifacts within the various occupations, or the high and low density areas within the broad site boundaries. The hand excavations also failed to locate any specific area with potentially high-density materials for mitigation investigations.

Despite the recognition of burned rock as one of the most prominent material categories in most hunter-gatherer sites throughout Texas, and the focusing of much of the testing phase investigations on burned rock, this dominant material category was not counted or collected by level during the testing phase. This resulted in significantly skewed artifact-density calculations, hindered the overall understanding of this site, and misled the planning for the mitigation phase.

In summary, then, the burned rock features found during the testing phase were thought be very widely scattered with sparse cultural material between features from an unknown number of occupations separated by culturally sterile mud drapes. The decision to employ mechanical stripping to locate these features seemed to be an appropriate approach. All of the above assumptions about this site and other sites in the region directly influenced decisions concerning the design of the mandated methods used to retrieve the data during mitigation. Obviously, the testing phase had misled the TxDOT archeologists, which reveals the importance of a thorough testing phase prior to initiating mitigation.

As a consequence, the field procedures employed in 1998 for the data recovery program followed the strategies outlined in the testing phase report (Abbott 1997) and mandated in the IFB to conduct data recovery. The target zone of the mitigation excavations was the top 120 $\mathrm{cm}$ of terrace deposits from a single block encompassing about $196 \mathrm{~m}^{2}$, measuring $7 \mathrm{~m}$ 
wide by $28 \mathrm{~m}$ long and containing a volume of $235 \mathrm{~m}^{3}$.

The mandated strategy was described as a threepronged approach: 1) mechanical stripping, 2) hand excavations, and 3) column sampling of fine material, all from a single, large excavation block. A Gradall ${ }^{\mathrm{TM}}$, using a $150 \mathrm{~cm}$ wide bucket was used to strip 2 to $3 \mathrm{~cm}$ thick layers from about $300 \mathrm{~cm}$ wide strips, leaving $80 \mathrm{~cm}$ wide, standing balks between stripped areas. The artifacts revealed during Gradall ${ }^{\mathrm{TM}}$ stripping were to be plotted using a TDS system. When cultural features were identified in the Gradall ${ }^{\mathrm{TM}}$ stripped areas, the feature and a $1 \mathrm{~m}$ radius area around the feature were to be hand excavated with the matrix screened through $6.4 \mathrm{~mm}$ mesh. In situ data in and around the features were to be plotted with the TDS. Following the Gradall ${ }^{\mathrm{TM}}$ stripping down to $120 \mathrm{cmbs}$ in all eight areas, the $80 \mathrm{~cm}$ wide by $7 \mathrm{~m}$ long standing balks were to be hand excavated with the matrix screened through $6.4 \mathrm{~mm}$ mesh screens.

Column samples were to be undertaken in conjunction with the hand excavations at $2 \mathrm{~m}$ intervals across the length of each balk for flotation and fine screen recovery. Each column sample size was 20 by $20 \mathrm{~cm}$ and $10 \mathrm{~cm}$ thick, or about four liters in volume. These matrix columns were designed to recover a spatially representative sample of smaller materials to provide another level of data resolution on materials at the site. Objectives of this three pronged approach were (1) to assess whether the loss in data resolution resulting from the Gradall ${ }^{\mathrm{TM}}$ technique was counterbalanced by an increase in overall data recovery from the considerably larger excavation than just the 40 $\mathrm{m}^{2}\left(48 \mathrm{~m}^{3}\right)$ dug by hand, and (2) to utilize standard methods, including the hand excavation, screening, and matrix columns to provide correlative data at smaller scales of resolution.

\subsubsection{Field Methods: Opportunities and Constraints}

The introduction to this section demonstrates that a major point of disagreement regarding the Higgins Experiment was the optimal mix of traditional and alternative field excavation methods. Although there was general agreement that what is "optimal" depends on site circumstances and the research questions being addressed, there was disagreement on how to determine the most appropriate combination of traditional versus new methods at any given site. Table 15.1 provides a very brief overview of the specific problems and approaches used on the Higgins and Lino sites to help distinguish the differences between the two projects.

From TxDOT's imposition of a "three-pronged approach" at the Lino site, it is clear that they wanted to utilize a more deeply stratified site to test the utility of selected alternative methods while retaining components of what were believed to be the merits of traditional excavation methods. Since a more integrated understanding of the site was a goal, TxDOT sought information on site macro-structure through the mechanical scraping of eight $3 \mathrm{~m}$ wide strips with TDS recording of recognized artifacts. Information concerning the occurrence and distribution of intermediate-sized artifacts was sought from hand excavation and screening of the matrix from balks that measured 80 by $700 \mathrm{~cm}$. Activities around features discovered by the Gradall ${ }^{\mathrm{TM}}$ were sought through hand excavations and screening within a $1 \mathrm{~m}$ radius of each feature. The smallest micro-artifacts were to be sampled through the flotation of matrix from 29 columns dispersed every $2 \mathrm{~m}$ across the balks. 


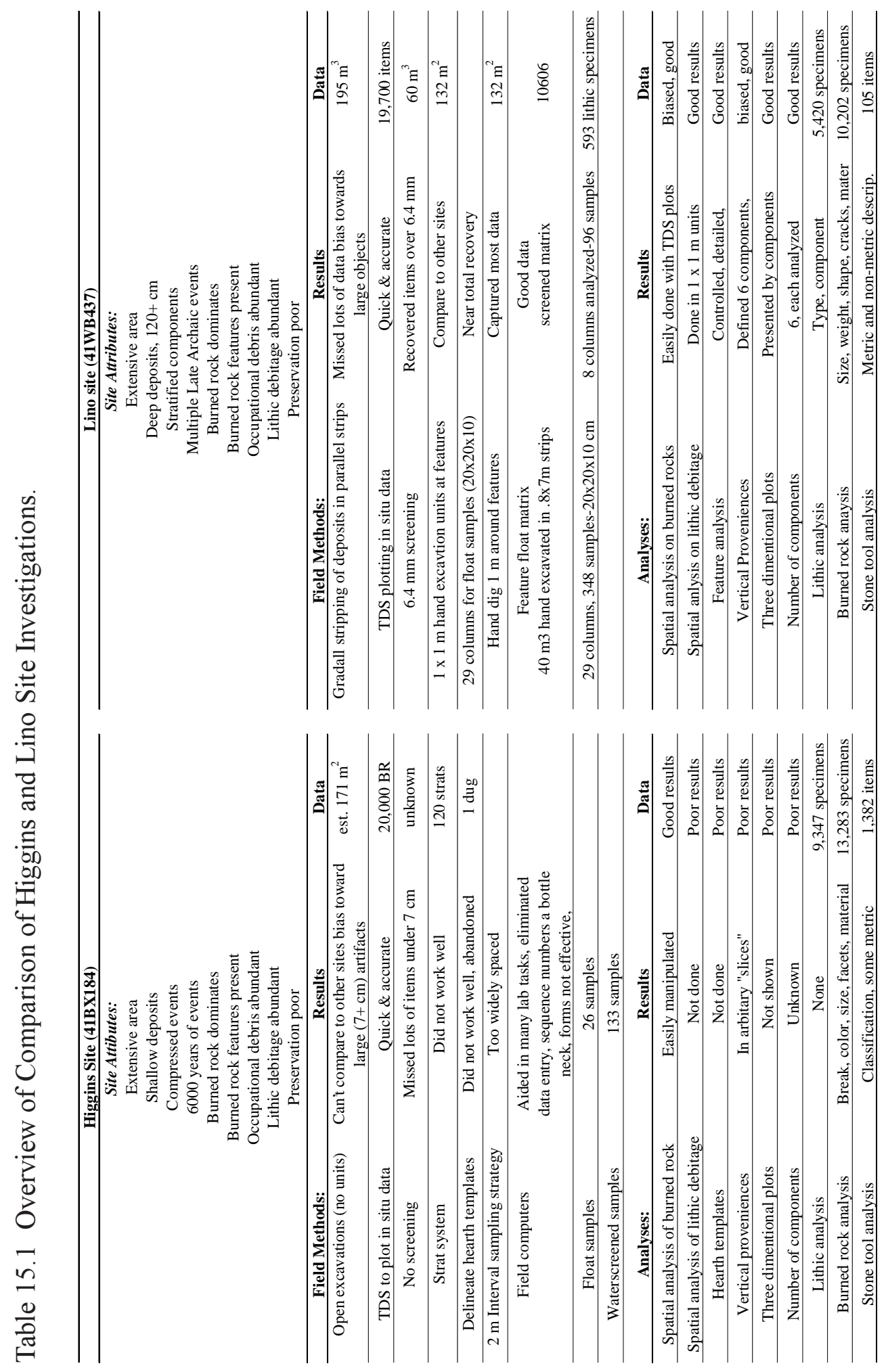


15.3.2.1 New Methods: Gradall ${ }^{\mathrm{TM}}$ Stripping, TDS Plotting, and Field Data Management

Gradall ${ }^{\mathrm{TM}}$ stripping was advocated for economic reasons, since traditional hand excavations are extremely expensive. Rather than hand dig a small, continuous block with the available funds, it was believed that the excavation area could be enlarged to obtain a larger sample of the site occupations if the Gradall ${ }^{\mathrm{TM}}$ was employed to excavate a block roughly $225 \mathrm{~m}^{3}$. This costeffective way of moving earth would enable investigators to find more cultural features and focus hand excavations around them to sample activities, thereby exploring the site's macrostructure (Abbott, Personal Communication 1999). TxDOT acknowledged that the use of a Gradall ${ }^{\mathrm{TM}}$ is not as effective as traditional hand excavations for recovering all forms of archaeological data. Consequently, another goal was to assess whether the amount of data resolution loss resulting from using the Gradall ${ }^{\mathrm{TM}}$ technique was offset by an increase in overall data recovery from a considerably larger excavation area. This issue is addressed below. The Gradall ${ }^{\mathrm{TM}}$ is a very fast and efficient machine that exhibits amazing precision and control in moving dirt in relatively precise 2 to $4 \mathrm{~cm}$ thick scrapes. The Gradall ${ }^{\mathrm{TM}}$ stripping method had a direct bearing on the number of artifacts detected, which was based on the variability of the thickness of each scrape, steadiness of the bucket, bucket speed, and the softness of the sediments. The time required to document the number of items discovered directly affected the overall time needed to complete this task.

Some 1,942 TDS provenience shots were collected on objects discovered during the Gradall $^{\mathrm{TM}}$ stripping across the $196 \mathrm{~m}^{3}\left(155 \mathrm{~m}^{2}\right)$ area at the Lino site. This was in addition to some 6,608 items that were TDS plotted from the $124 \mathrm{~m}^{2}\left(12.4 \mathrm{~m}^{3}\right)$ hand excavation areas around the 24 features identified during the
Gradall ${ }^{\mathrm{TM}}$ stripping effort. The size of an object significantly affected its chance for discovery and documentation (Table 15.2). In general, only some 13 percent of those items plotted by the TDS measured smaller than $3 \mathrm{~cm}$ in size, and some 56 percent of the plotted materials were smaller than $6 \mathrm{~cm}$ in size. Although this seemingly suggests that Gradall ${ }^{\mathrm{TM}}$ stripping effectively recovered relatively small objects, nearly 75 percent of the plotted data were on burned rock, and only 13 percent represented small pieces of lithic debitage. These values indicate either the ratio of burned rocks to flakes or the inability of the monitors to detect small objects, especially if the color hues were in the range of sediments-yellow, brown, or gray. The monitors of the mechanical excavations were effective in noticing white mussel shells, black charcoal, and burned rock pieces.

Some documentation problems could have been overcome by extending the time allowed for completing the stripping operation in conjunction with the TDS recording of artifacts. Budgetary constraints limited the Gradall ${ }^{\mathrm{TM}}$ use to 20 field days. So much cultural material was encountered at the Lino site that, at times, the Gradall $^{\mathrm{TM}}$ had to stop to allow the artifacts to be plotted and bagged and the hand excavations in and around features to be completed. There is a direct relationship between the rate of mechanical excavation (slow bucket speed and thinly scraped layer) and the quantity of material discovered. Since time constraints govern any project, trade-offs will always occur in how the Gradall $^{\mathrm{TM}}$ is used relative to the percent of in situ pieces recovered.

Such trade-offs were encountered at the Lino site. Before the testing-phase assumption that the site contained very limited materials was recognized to be in error, considerable time was consumed when the cultural materials encountered in the upper $50 \mathrm{~cm}$ of deposits were recognized as part of a broad and dense 
Table 15.2 Material Classes Recovered and Plotted by the TDS.

\begin{tabular}{|c|c|c|c|c|c|c|c|c|c|c|c|c|}
\hline \multirow[b]{2}{*}{$\begin{array}{l}\text { Size } \\
\text { (cm) }\end{array}$} & \multicolumn{11}{|c|}{ Class } & \multirow[b]{2}{*}{ Total } \\
\hline & $\begin{array}{c}\text { Burned } \\
\text { Rock }\end{array}$ & Charcoal & $\begin{array}{c}\text { Ground } \\
\text { stone }\end{array}$ & Cores & Debitage & Points & $\begin{array}{c}\text { Other } \\
\text { tools }\end{array}$ & $\begin{array}{c}\text { Mussel } \\
\text { shell }\end{array}$ & $\begin{array}{l}\text { Other } \\
\text { rocks }\end{array}$ & $\begin{array}{l}\text { Snail } \\
\text { shell }\end{array}$ & $\begin{array}{l}\text { Other } \\
\text { items }\end{array}$ & \\
\hline 1 & & 4 & & & 5 & & & & & & & 9 \\
\hline 2 & 4 & 2 & & & 45 & & & 1 & & 1 & & 53 \\
\hline 3 & 69 & 1 & & & 83 & 1 & 5 & 4 & 13 & 1 & & 177 \\
\hline 4 & 134 & & & 1 & 64 & 3 & 4 & 9 & 11 & & & 226 \\
\hline 5 & 224 & 1 & & & 27 & & 4 & 7 & 14 & & & 277 \\
\hline 6 & 275 & & & 7 & 18 & 1 & 4 & 6 & 14 & & & 325 \\
\hline 7 & 218 & 1 & & 4 & 4 & 1 & 5 & 4 & 15 & & & 252 \\
\hline 8 & 167 & & 2 & 3 & 1 & & 1 & 5 & 9 & & & 188 \\
\hline 9 & 108 & & & 7 & 3 & & 1 & & 7 & & & 126 \\
\hline 10 & 88 & 1 & 1 & 4 & & & & 1 & 8 & & & 103 \\
\hline 11 & 41 & & 1 & 1 & & & & 1 & 4 & & & 49 \\
\hline 12 & 39 & & & & & & & 1 & 3 & & & 43 \\
\hline 13 & 28 & & & & & & & & & & & 28 \\
\hline 14 & 16 & & & & & & & & 2 & & & 18 \\
\hline 15 & 7 & & 1 & & & & & & 1 & & & 10 \\
\hline 16 & 7 & & & & & & & & & & & 7 \\
\hline 17 & 3 & & & & & & & & 1 & & & 4 \\
\hline 18 & 2 & & & & & & & & & & & 2 \\
\hline 19 & 1 & & & & & & & & 1 & & & 2 \\
\hline 20 & 2 & & & & & & & & & & & 2 \\
\hline 21 & & & & & & & & & 1 & & & 1 \\
\hline 22 & 1 & & & & & & & & & & & 1 \\
\hline \multicolumn{13}{|l|}{23} \\
\hline$>24$ & 1 & 1 & & & & & & & & & 1 & 4 \\
\hline $\mathbf{0}$ & 14 & 5 & & & 4 & & 4 & & 2 & 4 & 3 & 35 \\
\hline Total & 1,449 & 18 & 5 & 27 & 254 & 6 & 28 & 39 & 106 & 6 & 4 & 1,942 \\
\hline
\end{tabular}

occupation zone. Nine features encompassing $46 \mathrm{~m}^{2}$ of hand excavations across the block were investigated in this uppermost occupation zone. About 95 percent of the artifacts observed in each Gradall ${ }^{\mathrm{TM}}$ strip from Occupation 1 were plotted with the TDS. At times, small artifacts were observed to be sufficiently displaced so as not to merit recordation. Using the mechanical Gradall $^{\mathrm{TM}}$ at very slow speeds and having the monitors sweep aside loose dirt after each scrape would have resulted in the discovery and plotting of more artifacts, but the field time would have increased substantially.

It was anticipated that the mechanical tearing of mesquite tree roots would disrupt intact portions of the occupation surfaces, dislodge in situ material remains, and tear apart the narrow balks. To overcome this problem, a series of $60 \mathrm{~cm}$ deep by $10 \mathrm{~cm}$ wide trenches were dug north- south at $4 \mathrm{~m}$ intervals across the block, using a Ditch Witch ${ }^{\mathrm{TM}}$ to sever the roots. The positioning of the mitigation block in areas containing only a few small trees and bushes also diminished the possibility of root interference. The slow speed of mechanical stripping allowed the crews to cut any root before it could rip through intact matrix.

The width of the excavation block was specifically selected because it was presumed that the Gradall ${ }^{\mathrm{TM}}$ boom could reach across $7 \mathrm{~m}$ without having to be repositioned. Although this is generally true, the machine nevertheless had to be placed inside the edge of the excavation strip to effectively reach the opposite side and maintain good control over the depth of each scrape. After the machine moved the scraped dirt from the far end of the strip, the GradallTM was repositioned to excavated dirt from the near 
side. Consequently, the Gradall ${ }^{\mathrm{TM}}$ had to move often to accommodate the size of the stripped areas.

The extremely unconsolidated, fine sediments and high frequency of burned rock caused some difficulty in maintaining a consistent depth during mechanical scraping. The rate of excavation was slowed to prevent gouging into the underlying deposits. Due to the relatively narrow width $-80 \mathrm{~cm}$ of the fine matrix balks separating the $3 \mathrm{~m}$ wide strips - care had to be taken to avoid damaging the balks with the mechanical bucket. Some fill dirt was left on both sides of the $80 \mathrm{~cm}$ wide balks to prevent accidental damage to the balks and preserve consistent unit widths for the hand excavations. This excess matrix was trimmed from the standardized balk before hand excavation started on the balks.

The uncertain number of components at unspecified depths and the uncertain quantity of materials present within the various occupations precluded planning prior to mechanical stripping. If additional hand excavations had been completed first, then more effective use of mechanical stripping might have been implemented to remove fill between the components. When higher material densities were encountered, the relatively inflexible nature of the predetermined field methods did not permit adequate adjustment in the field tactics to better capture available information.

One final factor that must be considered for future excavations is the availability of GradallTM machines in the region. Although this machine is superior to other mechanical digging devices for executing precise excavation over large horizontal areas, only two rental Gradall ${ }^{\mathrm{TM}}$ machines existed in all of south Texas, and none was immediately available. Even the Laredo District Office of TxDOT did not have access to a Gradall ${ }^{\mathrm{TM}}$. Equipment availability is a significant factor in trying to plan a mitigation program, especially if the project is operating under tight time constraints.

\subsubsection{Manual Excavations}

Clusters and scatters of burned rocks were continuously encountered during Gradall ${ }^{\mathrm{TM}}$ stripping, which indicated that the site contained dense and more or less continuous superimposed horizontal components rather than the widely dispersed, isolated features that were anticipated from the limited site testing results. A consequence of this unexpected cultural material density was that hand excavations at and around discovered features were continuously conducted throughout the 20 days of GradallTM work. Often the GradallTM had to wait until the archaeologists finished an area before the mechanical stripping could proceed.

The TDS plotting of artifacts consumed two people dedicated to using the instrument and the rod. Pre-numbered shot tags were used to ensure that artifacts correlated to TDS shots, but even this effort to simplify the process was not enough to handle the density of artifacts encountered. Pre-numbered shot tags were used as a backup recording system to ensure that the TDS numbers correctly identified the appropriate class of artifacts. Each evening the TDS database was checked against the shot tags to minimize entry errors. This process proved to be quite timeconsuming and cumbersome, but it increased the reliability of the database. Perhaps the simultaneous use of two TDS devices instead of the renumbered tag system would have increased the efficiency of maintaining associated shot correlations.

Since feature numbers were assigned to clusters of materials upon exposing only the tops of only a few rocks, some management problems developed in deploying the distribution of handdug units and guessing which way the feature 
was apt to expand. In some instances, the hand excavations revealed that the cluster of feature rocks represented only a general scatter of rock over an occupation surface. The misapplication of the feature designation caused problems during the electronic sorting of data, since the associations were spurious.

Despite these logistical and management problems, hand excavation was generally regarded as a success. During the Gradall ${ }^{\mathrm{TM}}$ stripping, the crew encountered 24 features scattered across a broad area of the site $\left(156 \mathrm{~m}^{2}\right)$. Hand excavations $\left(124 \mathrm{~m}^{2}, 12.4 \mathrm{~m}^{3}\right)$ were conducted around these features and recovered quantities of cultural debris in nearly every instance. Manual excavations at and around these 24 features yielded some 6,600 artifacts, for an average density of more than 533 items/ $\mathrm{m}^{3}$ (Table 15.3). However, only about 730 of these artifacts (11 percent) were plotted with the TDS; the other 89 percent of the artifacts were recovered from the screen.

The hand excavation of the seven noncontiguous linear balks $\left(48 \mathrm{~m}^{3}\right.$ or $\left.40 \mathrm{~m}^{2}\right)$ was conducted according to plan and yielded a sample of roughly 10,606 artifacts using traditional excavation means. The average density per 10 $\mathrm{cm}$ thick level of about 22 items is quite high, since the testing phase indicated this site contained sparse cultural debris. If the 10,606 items were equally derived from the six different components, then slightly fewer than 1,770 pieces of material came from each component. Because this material came from good context, it can be compared with assemblages from other sites. However, an assemblage of fewer than 2,000 items comprised of nearly 55 percent burned rock and less than 1 percent formal tools is not a very substantial sample.

The hand-excavated balks represent about 20 percent of the targeted excavation block. Although the IFB originally stipulated balk widths to be $40 \mathrm{~cm}$ wide, by agreement between TxDOT, THC, and the contractor they were increased to $80 \mathrm{~cm}$ wide for stability reasons before fieldwork began.

Since the Gradall ${ }^{\mathrm{TM}}$ had already removed the fill from either side of the $80 \mathrm{~cm}$ wide balks, the context of any interesting clusters of materials discovered during the hand excavations could

Table 15.3 Comparison of Classes of Artifacts Recovered by Four Different Recovery Techniques.

\begin{tabular}{|c|c|c|c|c|c|c|}
\hline Methods & $\begin{array}{c}\text { Lithic } \\
\text { Debitage }\end{array}$ & $\begin{array}{c}\text { Burned } \\
\text { Rocks }\end{array}$ & $\begin{array}{c}\text { Mussel } \\
\text { Shell }\end{array}$ & $\begin{array}{c}\text { Charcoal } \\
\text { Specimens }\end{array}$ & Total & $\begin{array}{c}\text { Volume } \\
\left(\mathbf{m}^{3}\right)\end{array}$ \\
\hline Gradall stripping & 252 & 1,446 & 39 & 17 & $1,754 *$ & 175 \\
\hline Density $/ \mathrm{m}^{3}$, projected $/ 235 \mathrm{~m}^{3}$ & 1.35 & 7.73 & 0.21 & 0.09 & 9.38 & \\
\hline Hand excavations - Balks (6.4 mm screens) & 4,475 & 5,915 & 96 & 120 & 10,606 & 48 \\
\hline (balks only) Density $/ \mathrm{m}^{3}$, Projected $/ 235 \mathrm{~m}^{3}$ & 93.23 & 123.23 & 2.00 & 2.50 & 220.96 & \\
\hline Hand excavations -Features ( $6.4 \mathrm{~mm}$ screens) & 1,875 & 4,638 & 19 & 76 & 6,608 & 12.4 \\
\hline Density/m3, Projected $/ 235 \mathrm{~m}^{3}$ & 151.21 & 374.03 & 1.53 & 6.13 & 532.90 & \\
\hline Flotation Columns & 593 & $7,863 \mathrm{~g}$ & - & $82 \mathrm{~g}$ & - & 0.288 \\
\hline Density $/ \mathrm{m}^{3}$, projected $/ 235 \mathrm{~m}^{3}$ & 2059.03 & & & & & \\
\hline Total (without flotation data) & 6,602 & 11,999 & 154 & 213 & 19,156 & 235 \\
\hline
\end{tabular}


not be examined by expanding the excavations into surrounding areas. Interesting patterns detected in these narrow balks usually ended up as just that: isolated, interesting patterns. Even defining the boundaries of burned rock features found in balks was difficult because many burned rocks continued beyond the edges of the 80 by $100 \mathrm{~cm}$ unit. If small post molds or patterns of lithic debitage had been recognized in any unit, it would have been impossible to trace these patterns out. Thus, information was lost. The extent of the lost information is discussed below in section 15.4.

\subsubsection{Fine Screen Recovery from Column} $\underline{\text { Samples }}$

The flotation matrix columns were designed to recover a spatially representative sample of small (fewer than $6.4 \mathrm{~mm}$ ) pieces of material to provide another level of data resolution (Abbott, Personal Communication 1999). Small micro flakes, bone fragments, seeds, snail shells, and other cultural objects were assumed to have considerable potential to be informative about spatial and stratigraphic patterning of activities in a comparable alluvial setting. Furthermore, whereas the larger artifacts were often moved during camp maintenance activities, the smaller micro flakes often remained where they were initially created and thus constituted a better indicator of knapping areas.

Early in the Gradall ${ }^{\mathrm{TM}}$ stripping process it became apparent that extensive bioturbation had occurred throughout the $120 \mathrm{~cm}$ depth of targeted deposits (mostly in the smaller particle sizes) due to termites, ants, and other small insects. This turbation was thought to have had little overall effect on the context of larger artifacts but was significantly detrimental to the context of finer materials recovered by flotation process from the columns of sediment matrices. Consequently, the 16 -liter ( 80 by 20 by $10 \mathrm{~cm}$ ) sample size was reduced to a four-liter ( 20 by
20 by $10 \mathrm{~cm}$ ) sample size. The number and distribution of sample columns remained unchanged across the entire excavation block. All 29 columns encompassing 348 samples were processed and floated, and the heavy and light fractions were retained for analysis. However, the resource managers from TxDOT and the THC agreed to reduce the analytical effort because of the extensive turbation evident in the profiles and overall poor preservation of bone and charred remains. Only eight judgmentally selected columns encompassing 72 samples were analyzed.

The remains from the processing of the flotation samples were sorted into material classes of bone, charcoal, lithic debitage, macrobotanical remains, other rock, and snail shell. Each class of material was counted or weighted (Table 15.4). The results are visually displayed in Figures 15.1, 15.2, and 15.3). In these figures, the left side of a unit provides material class counts from the floated matrix whereas the right side presents counts from the hand excavating and $6.4 \mathrm{~mm}$ screening of the same 80 by $100 \mathrm{~cm}$ unit from which the float sample was taken. This side by side comparison provides a visual representation of the results from the two sampling methods.

Since column samples were collected in arbitrary $10 \mathrm{~cm}$ intervals, they often crosscut the identified occupational zones, which were based on the vertical distribution of larger material remains (Figures 15.1, 15.2, and 15.3). The higher frequencies and greater diversity in the cultural material recovered from the float sample should more closely correspond to the occupation zones. Furthermore, if the smaller pieces of lithic debitage represent in situ knapping activities, then relatively high frequencies of small debris should indicate knapping areas. However, the extensive turbation of the Lino site deposits seems to have obscured the interpretive value of the micro debris distribution. 
Table 15.4 Flotation Results on Eight Columns across the Lino Site.

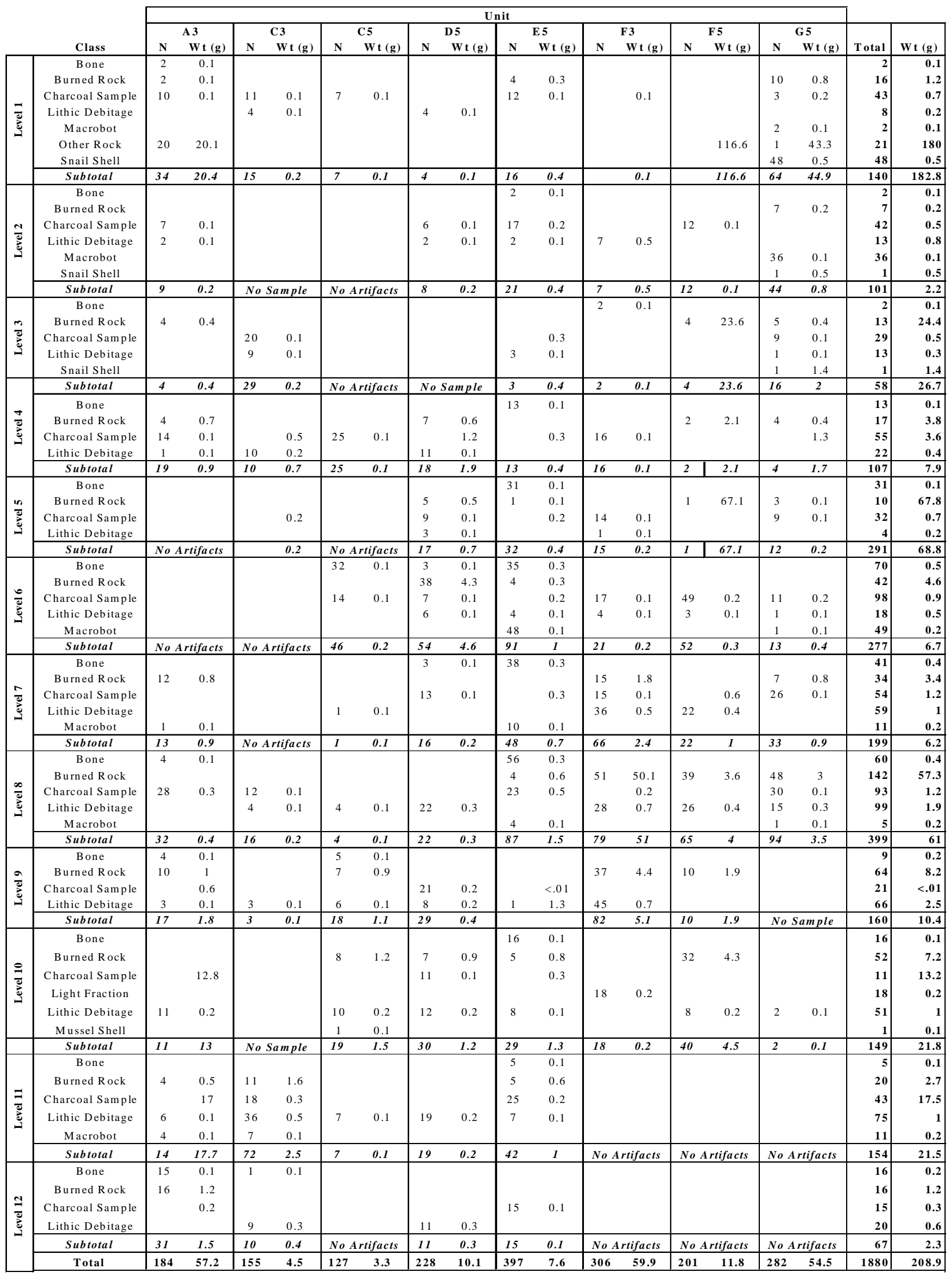



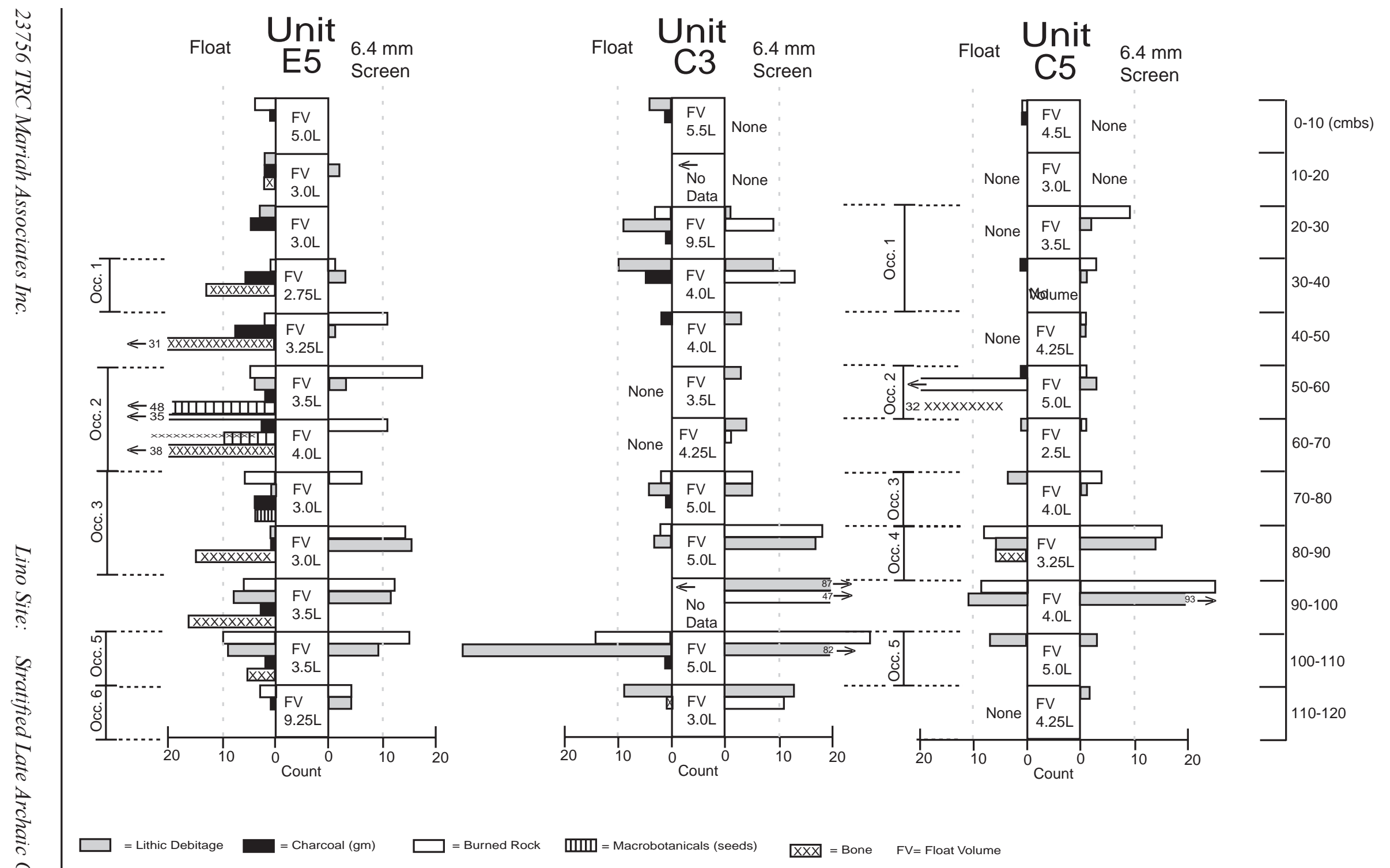

Figure 15.1 Graphic Presentation of Float Data Compared to Corresponding Unit Data in Units E5, C3, and C5. 


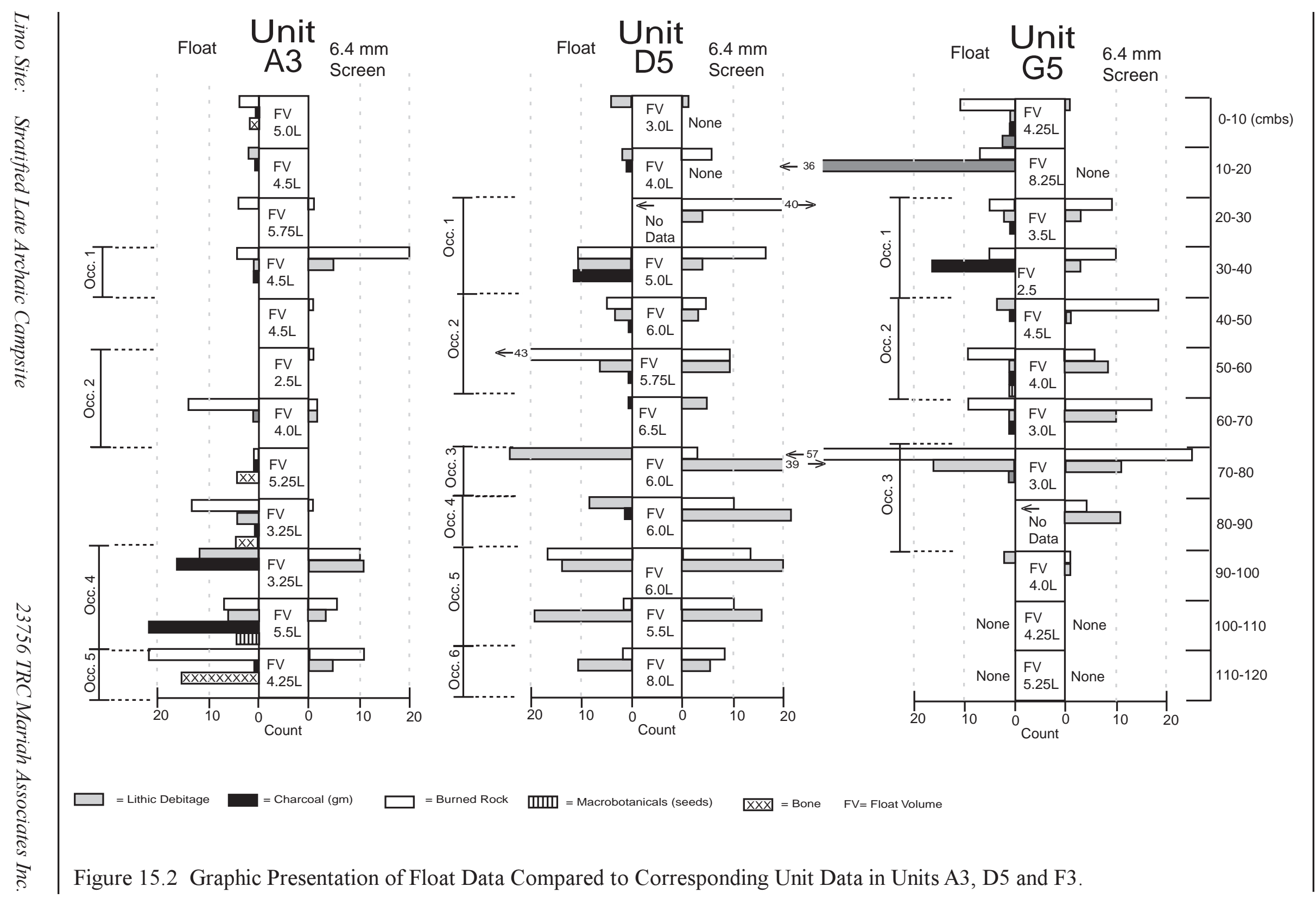



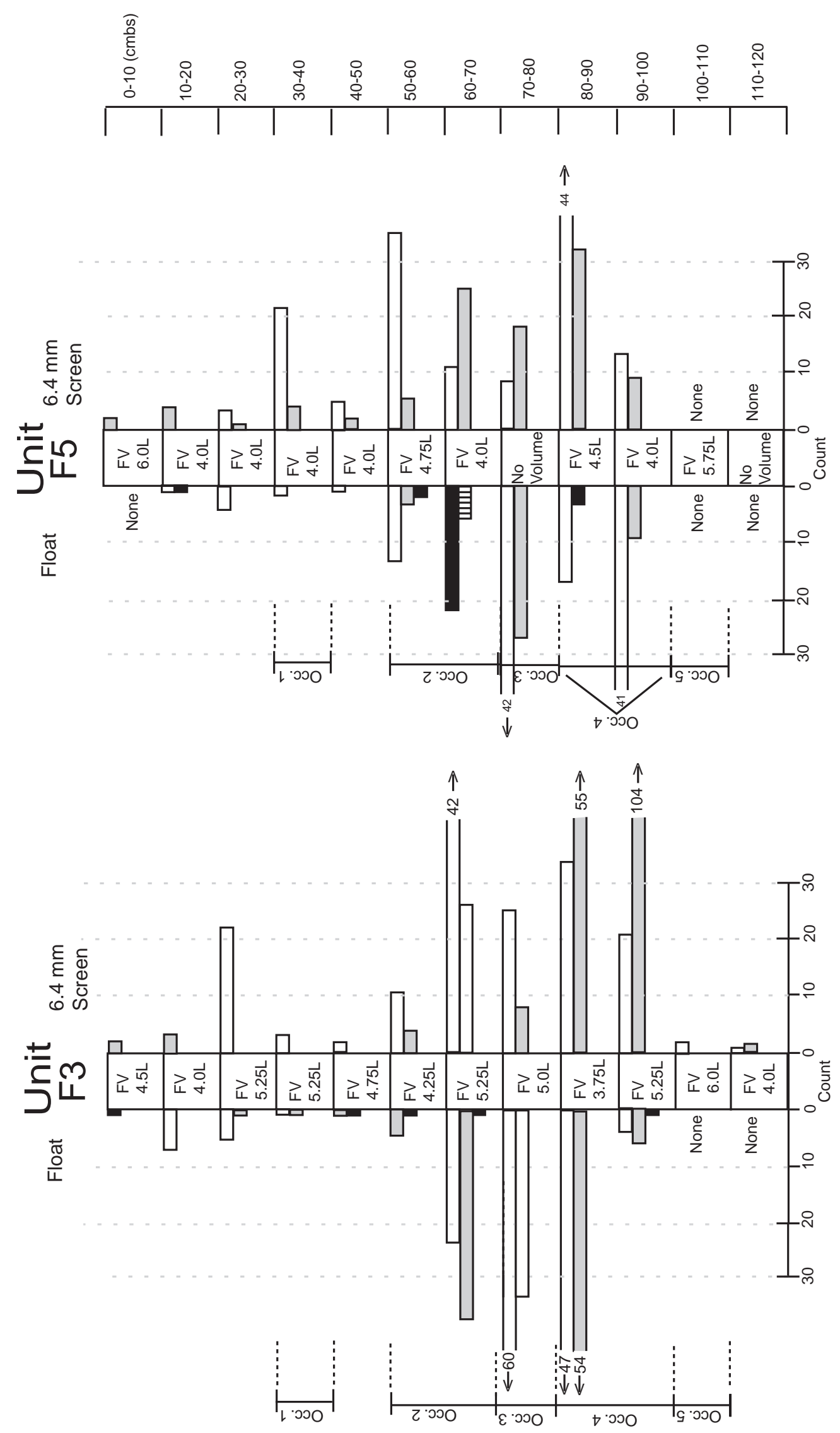

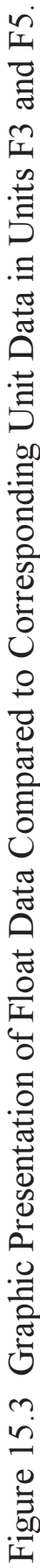


The microdebitage results from unit A3 are examined in some detail to assess their utility in identifying occupations and activity areas. Although no cultural occupation was defined for the upper $30 \mathrm{~cm}$ of deposits based on the paucity of remains from the manual excavations of the whole unit, small quantities of charcoal, tiny bone fragments, possible burned rock crumbs, and a couple of tiny lithic pieces were recovered from the floated matrix from the upper $30 \mathrm{~cm}$ zone. These remains may indicate that some artifacts were slightly displaced upward by postdepositional processes from Occupation 1.

From the layer attributed to Occupation 1 (30 to $40 \mathrm{cmbs}$ ), the floated matrix samples continued to yield small amounts of burned rock fragments, charcoal flecks, and a single flake. Based on this sparse recovery, it is interpreted that no burning, knapping, or cooking activities occurred at this depth in unit A3. The 20 larger burned rocks recovered from the hand excavations at this depth are interpreted as discarded stones. Between 40 to $50 \mathrm{cmbs}$, the lack of cultural materials from both the float column and the coarser hand-dug unit indicates that post-depositional processes did not displace artifacts into the culturally-sterile layer that vertically separates Occupations 1 and 2 .

Occupation 2, which should occur between 50 and $70 \mathrm{cmbs}$, was not well defined in this specific hand-excavated unit. Only a few burned rock pieces and lithic debitage were present. The floated matrix yielded numerous crumbs of burned rock and less than $1 \mathrm{~g}$ of botanical remains. The very sparse material recovery from the float sample indicates no in situ burning or flint knapping at this place in Occupation 2.

The coarse-scale hand excavations did not recover cultural material between 70 to $80 \mathrm{cmbs}$, and only one burned rock was found between 80 to $90 \mathrm{cmbs}$. The floated matrix results from these same levels suggest the presence of at least one occupation. Charcoal and burned rocks were present between 70 to $80 \mathrm{cmbs}$, and numerous burned rock crumbs and four pieces of lithic debitage were recovered between 80 to $90 \mathrm{cmbs}$.

If the occupations were defined solely on results from the hand excavations, then the noncorrespondence in the distribution of micro material from the float samples would appear to have been displaced by post depositional processes. Below $90 \mathrm{cmbs}$, the material recovered from hand excavation methods reflects at least two closely spaced occupations. The floated matrix between 90 to $110 \mathrm{cmbs}$ yielded quantities of charcoal, lithic debitage, less than $1 \mathrm{~g}$ of unburned macrobotanical remains, and burned rock crumbs, which seems to corroborate the results from the coarser hand excavations.

In summary, the floated column matrix samples from unit A3 reflect the presence of multiple occupations in the $120 \mathrm{~cm}$ thick profile, but the number of occupations would be difficult to discern. Different interpretations are possible depending upon the scale of materials used. Since no direct correlation is possible between the hand excavation results and the floated results, it is very difficult to interpret the significance of the float material. Interpreting results from a single vertical column of samples is very problematic due to the small sample size and the effects of bioturbation. The data derived from multiple, closely spaced columns may increase the resolution sufficiently to permit component isolation, but in general, the finescreen materials are difficult to interpret.

\subsection{EVALUATION OF THE SUCCESS OF THE LINO SITE MIXED APPROACHES}

The following discussion evaluates the success of the mixed traditional and experimental excavation strategies. The success of the 
methods is framed by a series of five specific questions related to the effectiveness of the field strategies. Through the examination of each question, data are generated to evaluate specific criteria for measuring the success or failure of the topic. The five basic questions that frame the evaluation are as follows:

1) Was the mechanical excavation of large areas cost effective?

2) How much information was lost using mechanical excavation with a Gradall ${ }^{\mathrm{TM}}$ ?

3) Did the hand excavations of seven narrow balks spaced about $3 \mathrm{~m}$ apart and the $1 \mathrm{~m}$ units around discovered features provide sufficient data to interpret activities and human behaviors?

4) Were micro-debris results from column samples useful for interpreting human behaviors?

5) Did the field approach combining traditional and alternative methods affect the ability to address research design issues?

Each of these topics is explored in separate sections below.

\subsubsection{Was mechanical excavation of large areas cost effective?}

One fundamental assumption of the project involves the cost effectiveness of using a

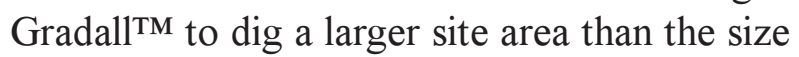
possible using traditional manual excavations. To examine this issue, the cost of using the Gradall $^{\mathrm{TM}}$ strategy is calculated, and then a projection is made of the volume of fill that could have been hand dug had the mechanical funds been allocated to the traditional approach. Finally, an assessment is made of the probability of finding unique pit, hearth, and shell features had the level of effort been reallocated to manual excavations.

The Gradall ${ }^{\mathrm{TM}}$ and operator cost about $\$ 1,200$ / day for each of the 20 days used to mechanically excavate about $187 \mathrm{~m}^{3}$. An additional $\$ 45,000$ was required for crew salaries and other field operating expenses related to monitoring the Gradall ${ }^{\mathrm{TM}}$ stripping, conducting the rapid hand excavations of $12.4 \mathrm{~m}^{3}$ sediments around discovered features, and recording the artifact data using the TDS. This does not include the cost of renting the TDS or the associated computer equipment. Altogether, about $\$ 70,000$ (or about \$374/per cubic meter) was spent on the Gradall ${ }^{\mathrm{TM}}$ phase of field work as compared to $\$ 60,000$ (or approximately $\$ 1,500$ per cubic meter) to hand-excavate the discontinuous balks that encompassed $40 \mathrm{~m}^{2}\left(48 \mathrm{~m}^{3}\right)$.

If the total field effort had been expended on traditional hand excavations, then the amount of artifacts would have substantially increased over the number recovered from the Gradall ${ }^{\mathrm{TM}}$ stripping. Consequently, some of the $\$ 70,000$ from the Gradall ${ }^{\mathrm{TM}}$ would have to be allocated to fund laboratory processing, analysis, and write-up time as well as extra curation costs. If the laboratory budget portion were deducted from the hypothetical $\$ 70,000$ reallocated from the GradallTM work at the same field-tolaboratory ratio as originally proposed, then the remaining portion could be used to supplement the $\$ 60,000$ for hand excavations. Assuming that the "remaining portion" of funds was allocated to the manual excavation of test units at the same cost/cubic meter rate as stipulated for hand-excavation above, then the size of the entire manually excavated block would be about $70 \mathrm{~m}^{2}\left(84 \mathrm{~m}^{3}\right)$. This area/volume could have been dug for the same amount of money as it took to undertake the present project. 
If the hypothetical $70 \mathrm{~m}^{2}\left(84 \mathrm{~m}^{3}\right)$ manually excavated block was configured as a single contiguous block with one axis corresponding to the width of the present Gradall ${ }^{\mathrm{TM}}$-stripped block, then the manually dug area would encompass a 7 by $10 \mathrm{~m}$ rectangular area dug to a depth of $120 \mathrm{cmbs}$. One way of ascertaining whether this smaller manually excavated block would potentially obtain the same range of behaviors as found in the present excavation block is to apply a simulation, or random sampling approach. For analytical purposes, it is assumed that the distribution of different kinds of features represents appropriate proxies for the occurrence of different forms of behavior.

In using the simulation, the hypothetical 7 by $10 \mathrm{~m}$ block is placed over a portion of the 7 by $29 \mathrm{~m} \mathrm{Gradall}^{\mathrm{TM}}$ grid. The smaller grid is shifted along the long axis of larger grid in $1 \mathrm{~m}$ intervals according to randomly selected numbers corresponding to possible positions within the block that range from one to 20 (Figure 15.4). For each randomly selected number, an observation is recorded as to whether or not a particular kind of feature occurred within the smaller block area. A series of such randomly selected observations form the basis for determining how likely certain kinds of features would have been found. Some kinds of features, especially the burned rock dumps, are so common that they and their associated behaviors would have been investigated no matter where the smaller block was placed along the long axis of the larger block. At issue, then, is determining the probability that any or all of the "unique features" (three rock-filled pits, two mussel shell dumps and one hearth feature) would occur within the smaller, hypothetically excavated block. One of the burned rock-filled pits and two mussel shell dumps occur near the western end of the larger block, and two burned rockfilled pits and the hearth occur near the eastern edge of the block. The horizontal distribution of these unique features within the GradallTM stripped area is such that a positive encounter with at least one burned rock-filled pit would occur anywhere the $70 \mathrm{~m}^{2}$ block is placed within the larger block, but shell features would only be found if the smaller block occurred in selected

Randomly Drawn Positions for Center of Block (X1)

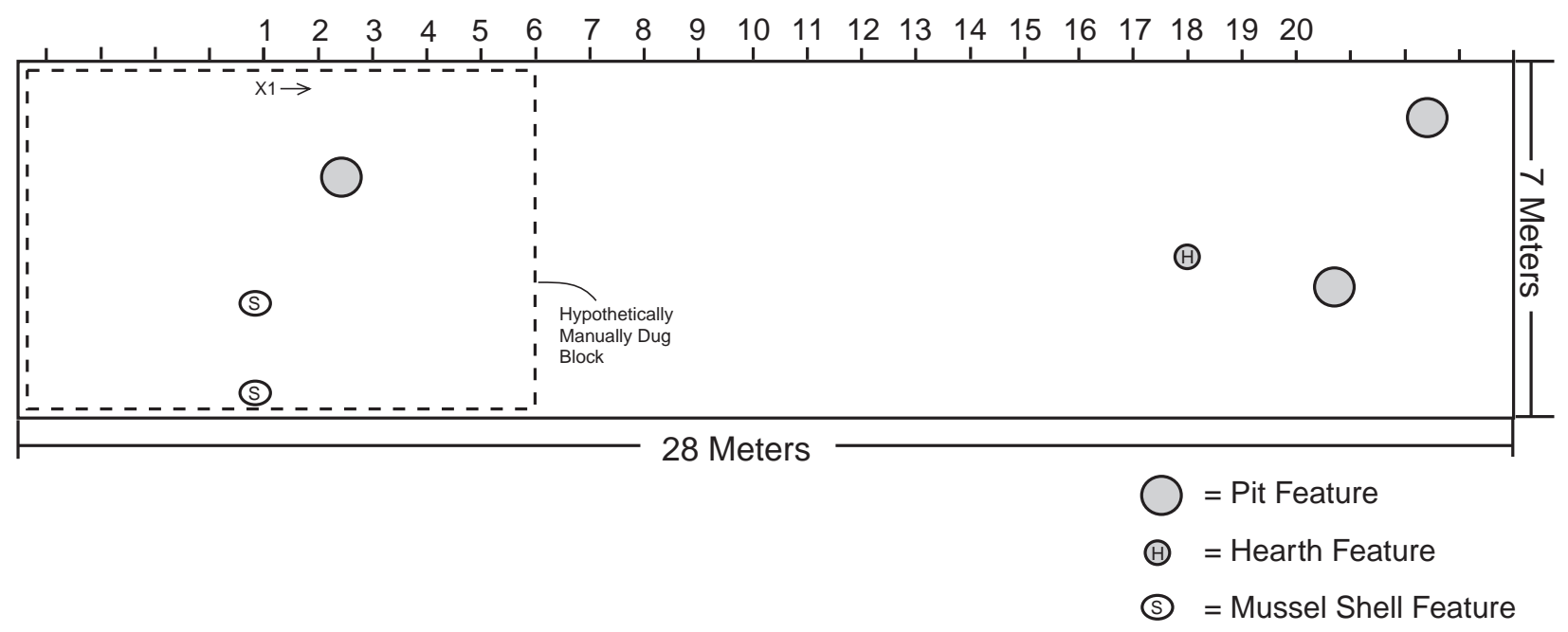

Figure 15.4 A Projected $60 \mathrm{~m}^{2}$ Block Excavation Was Used to Calculate the Possible Encounters with Three Unusual Feature Types at the Lino Site (41WB437). 
positions one through 10 , and the hearth feature would only be exposed in randomly selected positions nine through 20 .

As a heuristic test, one experimental run involving a series of 40 randomly selected potential placements of the smaller block within the Gradall ${ }^{\mathrm{TM}}$-stripped area was preformed. The results ascertained the following statistical chance of finding these unique features: The 70 $\mathrm{m}^{2}$ block would have a 100 percent chance of encountering one or more of the burned rockfilled pits, a 70 percent chance of finding the hearth feature, and only a 40 percent chance of locating the shell dump features. Furthermore, the same percentages would occur of finding a rock filled pit and a hearth (70 percent) or a rockfilled pit and a mussel shell feature in the same block (40 percent). However, there is absolutely no chance for the hearth and shell dump features to occur in the same $70 \mathrm{~m}^{2}$ block. It can be concluded that a single manually excavated block would not have sampled all three kinds of unique feature types, even though better control over context and a higher recovery rate of artifacts would have occurred. Thus, it is acknowledged that the Gradall ${ }^{\mathrm{TM}}$ was cost effective in terms of opening larger areas and finding a wider range of features and associated behaviors than if the traditional hand-dug method were used.

\subsubsection{How much information was lost using mechanical excavation with a Gradall'TM?}

It is generally conceded that Gradall ${ }^{\mathrm{TM}}$ machines are one of the most desirable for use in archaeological excavations because they have a long reach without leaving tread or tire tracks on the work surface, they have sufficient precision to remove thin layers of sediments, and the scrape of the toothless bucket leaves a smooth surface that shows soil color anomalies and other kinds of features. Few studies have examined the limits of the Gradall ${ }^{\mathrm{TM}}$ use.

In order to address this question, a comparison is made of artifact recovery rates from the different methods used at the Lino site. This approach assumes that the average artifact density from the combined six occupations is essentially the same because high densities on one surface may be offset by low densities on other surfaces. Furthermore, the results of the three sampling methods provide a representative measure for comparison.

The frequency of cultural material recovered using the various excavation methods is shown in Table 15.3. Size and durability of materials are principal factors influencing the recovery rates for the different material categories. Since burned rocks are the largest and easiest materials to find, they were readily recorded during all phases of the excavations, but because the sandstone crumbled into many fragments when either hit by the Gradall ${ }^{\mathrm{TM}}$ or saturated during the flotation process, raw counts may be artificially inflated. Weights are more practical than counts in analyzing the quantity of sandstone from the float recovery.

The frequency of flakes recovered by the different recovery methods is also examined. Because lithic debris is generally smaller than 4 $\mathrm{cm}$ in size and is frequently similar in color to the surrounding sediments, flakes were rarely observed in the excavation units and not often plotted with the TDS during any phase of the project. A considerably greater number of flakes was found during the screening process. The floatation of column samples provided the highest frequency of flakes, since nearly every tiny piece was recovered from the fine mesh screens. Obviously, the various techniques yielded different frequencies of lithic debitage and other material types. In general, the 
floatation technique yielded an adjusted density of 2,059 flakes per cubic meter, the $6.4 \mathrm{~mm} \mathrm{(1/}$ 4 inch) mesh screen of the balks yielded adjusted densities of 94 flakes $/ \mathrm{m}^{3}$ ( 4.6 percent), and the Gradall ${ }^{\mathrm{TM}}$ stripping yielded a density of roughly 1.4 flakes $/ \mathrm{m}^{3}$ (0.07 percent) of all potential flakes. Interestingly, the hand excavated units around features in the Gradall ${ }^{\mathrm{TM}}$ stripped areas yielded a density of 151 flakes $/ \mathrm{m}^{3}$ from $6.4 \mathrm{~mm}$ mesh screens. This higher density from the latter area relative to the hand-dug balks undoubtedly reflects the density of materials on the occupational surfaces rather than densities diluted by natural sediments between occupation surfaces. Different rates of recovery were achieved for the different material categories, especially for the burned rocks and charcoal, but the same general trends appear for the various recovery techniques.

If recovery rates from the $6.4 \mathrm{~mm}$ mesh screen of sediments from the $48 \mathrm{~m}^{3}$ hand excavation of the balks are regarded as the standard for recovery, then it appears that nearly 17,434 pieces of lithic debitage should have been recovered from the $187 \mathrm{~m}^{3}$ Gradall ${ }^{\mathrm{TM}}$-stripped area. The 252 pieces of lithic debitage plotted during Gradall ${ }^{\mathrm{TM}}$ stripping represents about 1.4 percent of the total flakes estimated to have been present in the Gradall ${ }^{\mathrm{TM}}$ stripped area. More surprising, if the recovery rate of burned rock from hand excavated balks is used as the standard, then the Gradall ${ }^{\mathrm{TM}}$ technique appears to have missed about 21,598 pieces, or 93.7 percent, of the potentially available burned rocks. These numbers tell the story. Even though nearly 1,900 pieces of nonperishable materials were recovered from the $196 \mathrm{~m}^{3}$ using the GradallTM, some 95 to 98 percent of the flakes and burned rocks were missed.

In summary, it appears that 94 to 99 percent of the artifacts were missed using the mechanical Gradall $^{\mathrm{TM}}$. More importantly, most of the contextual associations among the artifacts on every occupation surface were lost. Although 24 cultural features were discovered with Gradall ${ }^{\mathrm{TM}}$ stripping, the only charcoal stain found during the excavations (Feature 37) occurred during the manual excavations of the balk areas. It is likely that other, comparable features were probably missed by use of the mechanical Gradall ${ }^{\mathrm{TM}}$. Since the stains probably reflect functions different from the burned rock concentrations, an important part of the site structure was lost during Gradall ${ }^{\mathrm{TM}}$ stripping.

\subsubsection{Did the hand excavations of seven narrow balks spaced about $3 \mathrm{~m}$ apart and the $1 \mathrm{~m}$ units around discovered features provide sufficient data to interpret activities and human behaviors?}

Because the width of the balks and areas to be excavated around identified features was stipulated in the IFB, apparently some basis was used to decide on the appropriate size of areas to be investigated around features. Although the basis for deciding the sampling area may have been made purely on economical reasons, we presume that alternative notions entered in the decision-making process. It is possible that TxDOT personnel believed that most of the identified features (especially those with burned rock) would represent primary, in situ hearths forming the focus of activities. Furthermore, it is likely that materials found close to such features represent materials dropped, lost, or discarded near these features and that the recovery of artifacts from these areas relates directly the activities at the features rather than representing materials from different activities overprinted on the same occupation surface.

Thus, it was apparently hoped that excavations of areas within one meter of features encountered during Gradall ${ }^{\mathrm{TM}}$ stripping would relate to activities conducted at the hearths. Furthermore, since the locations of features and other activity areas on the various occupation zones were 
unknown prior to the investigations, it may be argued that the regular spacing of the seven balks was randomly placed relative to the location of the features and their associated activity areas. The excavation approach of dividing each balk into $1 \mathrm{~m}$ segments would facilitate analysis of material distributions as transects through or near features and thus allow discernment of what kinds and quantities of materials occur close to or far from a particular kind of feature. These materials might then be used to identify behavioral activities associated with the features. However, this approach assumes that the area investigated around the feature is sufficiently large to capture associated materials and that all recovered materials relate to the use of the feature.

Unfortunately, there is little theoretical basis for implementing either the excavation of widely spaced discontiguous balks or arbitrarily selecting a $1 \mathrm{~m}$ radius around features as an appropriate size to capture associated materials that will inform on the function and use of specific features. Ethnographic studies of the Inuit, Australian Alyawara, Bushmen, and Tarahumara have been used to develop a model of human activities around hearths, butchering areas, and other features (Binford 1978; 1984 : 144-192). The model defines a series of concentric activity zones surround the warming hearths. The closest area, which extended about $30 \mathrm{~cm}$ from the edge of the warming hearth, is an undesignated area generally devoid of materials and represents a zone too hot for comfortable use. The next zone, from 30 to 100 $\mathrm{cm}$, is the "drop zone" consisting of an area where debris and remains of food cooking or artifact retooling/manufacturing were lost or left by a number of people seated around the fire. Most of the remains in the drop zone tend to be relatively small and of a perishable nature. Beyond the drop zone is an area of unspecified dimensions designated the "toss zone." Most of the items represent larger waste debris intentionally discarded behind seated people or tossed beyond the hearth in front of them. The materials in the toss zone are derived from activity-maintenance behaviors. In general, the range of materials documented in Inuit drop zones and toss zones are bones, wood, and other materials. Burned rocks are generally not regarded as appropriate toss materials. Binford's model does not explicitly deal with hearth maintenance and rock discard activities. In the case of caribou butchering areas, Binford recognizes a walk/work area extending some 2 $\mathrm{m}$ around the carcass, beyond which is a toss zone for disposing unwanted animal parts. Thus the model usually recognizes an area bigger than $1 \mathrm{~m}$ as an appropriate size for study and requires that archaeologists correctly distinguish in situ focal features from discard residues and dumped materials.

At the Lino site, most of the recognized features represent clusters of burned rock (on an occupation surface). These clusters have been interpreted as dumps or discarded materials from stone boiling activities. Most of the artifacts found near these kinds of features are believed to be spurious associations (unrelated to the use of the burned rocks). Nevertheless, other kinds of primary or in situ features have been identified that can be used to assess this question of spatial relevance.

An examination of one charcoal-stained, hearthlike feature (Feature 37 in Occupation 4) is used to assess whether or not the artifacts close to an in situ feature support the concept of a drop zone. The items that were plotted with the TDS along Balk F, which encompasses Feature 37, are depicted in Figure 15.5. With few exceptions, these items were limited to burned rocks greater than $5 \mathrm{~cm}$ in size. By the time that the $30+\mathrm{cm}$ wide charcoal stain was identified in the handdug balk, all of the fill on both sides of Balk F had been removed by the GradallTM. Only a few scattered burned rocks were recorded in the 


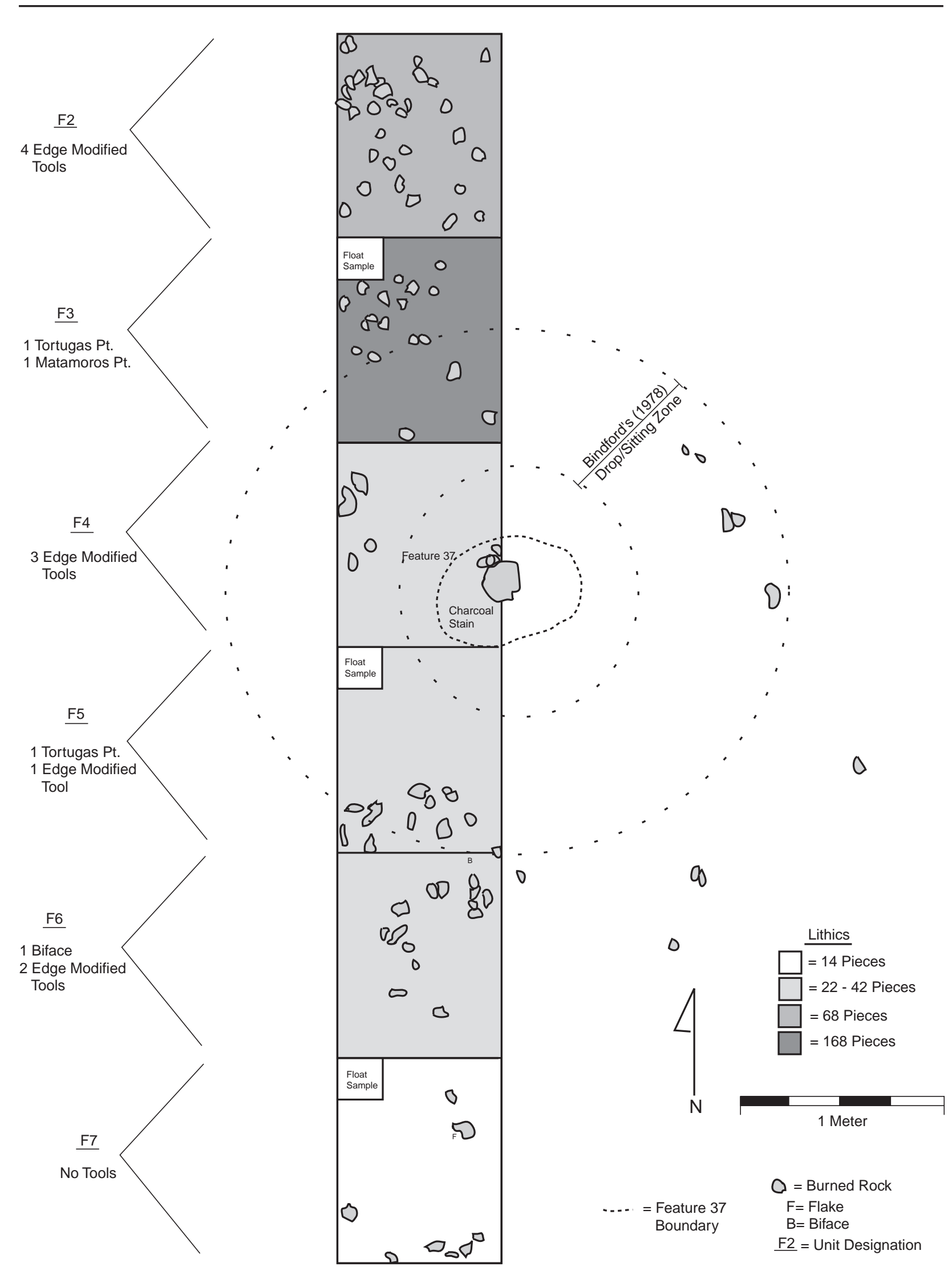

Figure 15.5 Material Distribution around Pit Feature 37, Occupation 4 ( 80 to $90 \mathrm{cmbs}$ ). 
adjoining mechanically stripped area. The handexcavated balk is considered essentially as a random transect through the hearth feature area. Through an examination of materials recovered from units along this transect, Binford's (1978) drop and toss zones model can be examined.

From the $1 \mathrm{~m}$ units comprising Balk F, roughly 45 percent of the smaller recovered items (flakes and stone tools) were not recorded in situ by the TDS. This gap in the available information undoubtedly skews the overall interpretation of the location and kinds of potential activities that occurred near the feature. Figure 15.5 depicts the general density of flakes whereas the larger burned rocks are precisely plotted around the hearth. Burned rocks generally occurred north and south of the hearth, from about $75 \mathrm{~cm}$ to over $200 \mathrm{~cm}$ away from the hearth. The burned rocks occurred primarily beyond the prescribed distance of a drop zone into the toss zone. These materials may be part of a toss zone of materials from the feature, but the small size of the charcoal-stained burned area stands in marked contrast to the volume of rocks surrounding the hearth. Unless multiple discard episodes occurred from the re-use of the hearth feature, it is not possible to heat the rocks in such a confined area. Furthermore, a single large flat rock found on top of the charcoal stain has been interpreted as a cooking griddle. It seems unlikely that the small hearth would accommodate both a griddle as a main cooking element and the heating of large quantities of burned rocks.

The horizontal pattern displayed by the lithic debitage shows that 93 percent of the lithic pieces occurred in the drop and toss zones north of the hearth. However, the highest percentage of debitage (66 percent from units F3, F4, and F5) occur in or along the edge of the presumed drop zone (Figure 15.5). The single examples of Matamoros and Tortugas projectile points came from unit F3 and are associated with 48 percent of the lithic debitage in an area straddling the drop and toss zones. These spatial patterns are generally compatible with the notion of people sitting around the hearth while knapping replacement stone tool tips. The recovery of nine tiny (fewer than $6.4 \mathrm{~mm}$ ) flakes from the finescreen float sample in the northwestern corner of unit F3 indicates that some in situ knapping may have occurred near the suspected drop zone. Four edge-modified flakes were associated with moderate quantities of burned rocks and 68 pieces lithic debitage from unit F2 within the suspected toss zone on the north side of the hearth (Figure 15.5). These expedient tools may have been involved with retooling tasks or a completely different task such as scraping hides.

One Tortugas point and one edge-modified flake were found with 42 pieces of lithic debris from unit F5 within the proposed drop zone south of the hearth. The recovery of only one tiny flake from the float sample does not provide strong support for knapping activities south of the hearth. A biface from the northeastern corner of unit F6 was mixed with burned rocks along the edge of the toss zone. The lithic debitage and burned rock frequencies in unit F6 are relatively consistent with the quantities of burned rock in toss zone units F2 and F3 north of the hearth. Two edge-modified flakes constitute the only tools from unit F6. The decrease in recognized stone tools and flakes in unit F7 might reflect a density fall-off with distance from the hearth.

In summary, the horizontal distributions of nonperishable cultural material from the narrow $80 \mathrm{~cm}$ wide balk passing through hearth Feature 37 provide conflicting results for the drop and toss zone model. The low frequency of tiny flakes in the fine screen float sample from unit F5 and the moderate frequency of tiny flakes in unit F3 do not reflect activities of a postulated drop zone. Most flakes are clustered on the north side of the hearth and are not found symmetrically around the hearth. These mixed 
results may only reflect different recording techniques for the classes of recovered material or the very general application of the material distributions to this model. Although the results provide some interpretative support that Feature 37 was a small warming hearth, the model does not account for the burned rocks. The conflicting interpretations might have been resolved if the distribution of material from the entire area around the hearth was investigated rather than just a narrow transect through the area.

Overall, the hand excavation of the linear balks provided a sample of cultural data amounting to about 1,775 items/component, which can be compared to other sites. However, since six components are represented with an average of fewer than 1,775 pieces/component, the hand excavations yielded relatively small assemblages to provide reliable comparisons. As much as 95 percent of the assemblage was lost due to use of the Gradall ${ }^{\mathrm{TM}}$. Only the lithic debitage, the burned rocks, and perhaps the charcoal categories provide sufficient numbers of materials to provide valid comparisons. The numbers and densities of stone tools per occupation zone are quite low and may not reflect the range of tools present or the internal variations within tool classes that occur in a larger assemblage. The general distribution of materials on an occupation surface that is useful for developing site structure is evident to some degree, but the $3 \mathrm{~m}$ wide void areas between the parallel balks make interpretations of the material distribution patterns tenuous to use at best.

\subsubsection{Were the fine screen results from column samples useful for interpreting human behaviors?}

The fine screen sample columns provide information about the presence or absence of cultural materials, types of materials, and some gross level horizontal and vertical distribution patterns that may be present on the various occupation surfaces. Previous research on recovery methods has determined that mesh size influences interpretations about the composition of faunal assemblages, or about the where knapping activities occurred (e.g., Baker 1975; Butler 1993; Casteel 1972, 1976; DeMarcay and Steele 1986; Shaffer 1992; Shaffer and Sanchez; 1994; Struever 1968; and Watson 1972). Mesh sizes of $3.2 \mathrm{~mm}$ (1/8 inch) screens substantially increased the recovery of bones from mammals weighing between 18 and $340 \mathrm{~g}$ over that from the $6.4 \mathrm{~mm}$ (1/4 inch) screens (Shaffer and Sanchez 1994). The decrease in the mesh size of screens correlates with an increase in the rate of recovery of small animal bones.

The recovery of small animal bones from fine mesh screens creates interpretative problems about the cultural significance of the bones recovered. Many very small animals, including snakes, moles, mice, turtles, fish, and even small bone splinters from larger animals can occur as non-cultural inclusions in natural deposits. It is increasingly difficult to distinguish small animal bones in the natural environment from those culturally introduced unless the remains are burned, butchered, or occur in such unambiguous cultural contexts as pit features.

Recent lithic experiments involving the rates of data recovery have discovered that standard 6.4 $\mathrm{mm}$ (1/4 inch) screens retain only some eight percent, by count, of core and biface knapping debris (Tomka and Fields 1990). It has often been assumed that since larger flakes are subjected to removal from production areas, the recovery of microdebitage may be a good indicator of in situ knapping or tool resharpening activities. Thus, the heavy fraction component of flotation samples should capture nearly all sizes of lithic debitage from an occupation surface, which might be useful in discerning activity areas. However, a number of cultural and natural post-manufacture processes can 
move microdebitage and distort its archaeological distribution pattern. Recent ethnological and archaeological studies have shown that in some areas, stone tool manufacturing activities were conducted on hides or mats and that the full size range of lithic debris was collected and disposed in formal dump areas as part of a site maintenance strategy (Quigg and Peck 1995; Quigg 1997; Clark 1986:24). In addition, flood events, burrowing rodents, and root disturbances horizontally and vertically displace the smaller pieces of lithic debris into other areas. Thus, the presence of tiny flakes at a locality represents an accumulation from a complex range of cultural and natural processes.

Flotation samples are commonly processed to recover microbotanical remains and charcoal from the light fraction component of the sample; the fine screening of the heavy fraction component commonly yields micro flakes, snail shells, mussel shells, burned earth pellets, fire cracked rock, and various sizes of natural gravel and sediments. Often the charred plant remains are the focus of micro screening analysis. Since many of these smaller items are readily subjected to movement from turbation processes, the occurrence of these materials is difficult to interpret. Furthermore, due to the time requirements necessary to collect and process (float, sort, identify) the contents of these samples as well as the analytical, reporting, and curation costs, the use of systematic fine screening must be carefully considered. Thus, it is incumbent upon the archaeologist to control the context of the samples to enhance the interpretative value of distinguishing natural from cultural materials.

Turning to the flotation results from the Lino site, it is apparent that on average, the fine screening materials would have yielded from each cubic meter of sediments processed 2,059 flakes, 2,265 $\mathrm{g}$ of fire cracked rock and $285 \mathrm{~g}$ of charcoal. The placement of the sample columns reflects a very coarse scale of resolution $(3 \mathrm{~m}$ apart east-west by $2 \mathrm{~m}$ apart north-south). A comparable $2 \mathrm{~m}$ systematic sampling interval used on the Higgins Experiment was deemed too widely spaced to produce useful data for revealing behaviorally significant spatial patterning (Black and Jolly 1998b: 231). We would advocate that given the turbation and association problems discussed above, such a rigid system of column samples collected through multiple occupational zones should not be employed without solid justification. Flotation and fine-screening techniques are helpful methods for recovering data that should be primarily used in conjunction with investigating feature associations or other areas with tightly bounded, culturally relevant contexts.

In summary, the flotation and fine screen recovery is a very costly and time-consuming data collection strategy that should be flexibly applied at the discretion of the field archaeologist to address questions directed at specific patterned activity areas on a horizontal occupation. The collection of sediments from stacked samples crosscutting multiple occupations on a broad scale grid for enhanced recovery of small items is not, in our opinion, methodologically or theoretically sound. The extent of turbation and vertical movement of smaller materials, as observed at the Lino site, causes uncertainty in the context and limits interpretation.

Since larger artifacts and burned rocks are less likely to have been substantially moved, these items provide a much better indication of the number and depths of components. If, indeed, cost reduction was a primary consideration for mandating mechanical equipment to learn more about a site, then in retrospect, it would have been cost effective to reduce or do without the fine screen sampling of sediments in regular 
columns. The use of flotation on samples from feature contexts is legitimate and necessary for enhancing the interpretation of activities on site.

\subsubsection{Did the field approach combining traditional and alternative methods affect the ability to address research design issues?}

Due to the general knowledge of the cultural sequence and specific adaptations developed for south Texas, the seven research design domains addressed above in Section 13.0 were very broad. They include contributions to areas of 1 ) subsistence practices, 2) burned rock technology and data content, 3) structure and organization of the sites, 4) chronology and cultural affiliation, 5) site formation processes, 6) lithic resource procurement and technology, and 7) paleoenvironmental studies.

Most of these research design topics are examined using diverse kinds of corroborative information, usually extracted from relatively discrete kinds of objects. If, for example, preservation conditions of bone, pollen, and macrobotanical remains are poor or uninformative, then the subsistence issue is addressed using alternative isotope and lipid residue data extracted from burned rocks as well as use-wear analysis on stone tools. In general, some kinds of data are available to address most of the broad research design issues.

Many of the research issues can be addressed by relatively discrete pieces of material (a datable piece of charcoal, a point type, a series of tools, a cluster of burned rocks, etc.) linked to a definable occupation zone. The use of TDS material plotting across the entire excavation block facilitated the definition of occupation zones and the recognition of materials that can accurately be regarded as culturally contemporaneous. Without such precision in recording material provenience, the confident assignment of disparate kinds of artifacts and samples to the same occupation would have been difficult. The diminished certainty of assigning various materials to a specific component would have weakened the strength of analyzing the site on a component-by-component basis..

Nevertheless, beyond the ascription of a piece of material to a specific occupation, the absolute provenience of an item is generally not critical for addressing most research design issues, including the topics of subsistence practices, burned rock technology, chronology, cultural affiliation, lithic resource procurement and technology, and paleoenvironmental studies. Even the issue of site formation process is concerned with comparisons of materials from the vertical axis of the site, and the various excavation balks provide ample opportunities to pull samples to examine change through time. Thus, the innovative use of Gradall ${ }^{\mathrm{TM}}$ strips and discontinuous excavation balks do not seem to have detrimentally affected these research design issues. The issues would be addressable to some extent even if more than 80 percent of the excavation block was mechanically dug with the Gradall $^{\mathrm{TM}}$. However, since some 95 to 98 percent of the assemblage was missed by the use of the Gradall ${ }^{\mathrm{TM}}$, it is uncertain whether a more robust artifact assemblage would have been recovered had manual excavations been undertaken throughout the duration of the project. Clearly, the average recovery of fewer than 1,700 artifacts from each of the six components is small for comparative purposes.

Only one research issue, site structure/ organization, relied exclusively on discerning the contextual relationships among artifacts, features, and other materials on each occupation zone. Using the TDS within eight GradallTM strips across the $196 \mathrm{~m}^{2}$ block area provided a provenience on the horizontal distribution of burned rocks larger than $5 \mathrm{~cm}$ in size and burned rock and shell features. Indeed, the mechanical 
excavations provided a broader examination of the site than possible when strictly using manual excavations on a contiguous block. Even though the stripping provided some information about the distribution of features with burned rock, it is fairly clear from the sole discovery in the handexcavated balk areas of burned stain Feature 37, which lacked rocks, that some classes of features were not identified from monitoring the mechanically scraped strips. Indeed, a portion of this feature was mechanically removed without being identified.

The hand-excavated balks constituted about onefifth of the excavation block. They essentially constituted a $0.8 \mathrm{~m}$ wide transect across the excavation block at $3.0 \mathrm{~m}$ intervals. Although the IFB called for the spacing of $40 \mathrm{~cm}$ wide balks at $1.5 \mathrm{~m}$ intervals, it is clear that constraints from mechanical excavations would jeopardize the preservation of such thin balks. Thus, even though the original plan called for closer spacing of balks and would have potentially provided a remedy for observing artifact patterns more evenly across the excavation block, the original design did not consider instability of the thinner balks to be a problem. Regardless of the need to modify the original design of the Gradall ${ }^{\mathrm{TM}}$ strips, either layout design would have mechanically removed about 79 percent of the fill.

Despite discussions in sections six through 12 above that concerned spatial patterning of features, burned rock, debris, and tools for the various components, the extent of information loss from the mechanical excavations is unknown. It is possible that significantly different interpretative patterns might have become apparent if more of the excavation block had been hand excavated. Results at the Lino site indicate that the use of a Gradall ${ }^{\mathrm{TM}}$ to excavate through occupation zones was not an appropriate approach for examining site structure under these conditions. At one level, it is apparent that most components had some form of horizontal patterning and that different activities seem to have occurred, but the identification of the patterns, activities, and feature functions is based on overly small samples of associated materials.

If a major research design goal is to discern site structure, then large excavation blocks are needed to increase the confidence in interpreting the horizontal distributions of materials. Examples of data recovery projects that began to discern activity areas and site structure from manual excavations include the Longhorn site (41KT53) with $340 \mathrm{~m}^{2}$ (Boyd et al. 1993), the Mustang Branch site (41HY209-T) with $194 \mathrm{~m}^{2}$ (Ricklis and Collins 1994:238), the Sanders site (41HF128) with two blocks totaling $110 \mathrm{~m}^{2}$ (Quigg 1997), and the Curry site (41CC131) where $204 \mathrm{~m}^{2}$ were dug (Treece et al. 1993). It does not appear that the seven narrow discontiguous balks (each seven meters long) at the Lino site has provided an optimal area for identifying or interpreting prehistoric activity areas.

The fine screen data from the columns of water screen samples provided little useful information for addressing research design issues. Despite the processing of 348 samples and the sorting of 70 samples, no charred macrobotanical plant part except wood charcoal was recovered, and the charcoal flecks were generally too small for wood species identification. All of the useful charred plant remains were found directly associated with features and materials on the occupation surface. For reasons discussed above, the microdebitage, burned rock crumbs, mussel shell fragments, and mussel shell parts were ancillary to materials recovered from manual excavations. Due to interpretative problems associated with the extensive turbation at the site, these materials were not used to address any of the research design issues. 


\subsubsection{Evaluative Summary of the Lino Site Field Tactics}

In summary, it can be concluded that the TDS system was very useful for maintaining proveniences of recognized materials in the field and for discerning the depth and geometry of buried occupation surfaces on the sites.

In contrast, the utility of mechanical Gradall ${ }^{\mathrm{TM}}$ machines to dig through a series of occupation zones is regarded as mixed. The Gradall ${ }^{\mathrm{TM}}$ proved to be somewhat more cost effective than manual excavations. Consequently, a slightly larger area and more diverse features were encountered than would have been otherwise possible from manual excavations. However, overall, the mechanical excavations were not effective because an estimated 95 to 98 percent of the artifacts in the site were lost in using this method over the traditional use of manual excavations. Much of the data loss may not have adversely affected the ability to address most of the research design issues. Mechanical stripping though occupation surfaces and obtaining data from the manual excavation of discontiguous parallel balks separated by $3 \mathrm{~m}$ are clearly not optimal ways of examining the site structure research design issue. The loss of data from mechanical excavation is too great to permit adequate understanding of the activities and organization of behaviors on this Late Archaic site in south Texas and outweighs any cost advantages gained from opening up a slightly larger area for manual excavation, at least for sites having the configuration and artifact density of the Lino site.

\subsection{SUGGESTIONS AND RECOMMENDATIONS FOR FUTURE PROJECTS}

With the advantage of hindsight, the following suggestions are offered to improve upon the mixture of traditional and alternative methods applied to similar excavations in the future. We also confess at the outset that "standard" approaches have incrementally evolved over the years, and a certain amount of tried-and-true testing has accompanied the development of these standard methods. Radical departures from standard field methods generally have a low chance of success, but such experiments must occasionally be performed to ensure that appropriate technological advances are applied to the discipline. Overall, we feel that cost savings are most effectively applied to a judicious application (including the use of sampling) during material analysis in response to research design issues. The loss of critical artifacts and their contextual associations by the application of alternative field methods may not be recovered. This is especially true for areas such as south Texas, where so few large-scale excavations have been conducted that the basic cultural sequences are poorly known. Thus, projects must be well planned from adequate site testing and well executed to maximize information potential. Following are our recommendations for data recovery fieldwork, beginning with the planning stage.

\subsubsection{Planning and Remedial $\underline{\text { Investigations }}$}

The initial testing phase must be intensive, and it must be concerned with more than merely determining whether or not a site meets minimal eligibility criteria for nomination to the National Register of Historic Places. The testing phase should focus on specific questions about the size, number, and depths of components, approximate age or cultural affiliations. The testing phase should include collection of sufficient information about the condition, preservation, and material content to allow the formulation of meaningful research design issues. These kinds of information are even more important if a rigid or systematic recovery plan is to be imposed on a project. The level of testing conducted at the 
Lino site, which manually reached to only half the target depth of the mandated mitigation excavations, is an example of inadequate testing.

If the initial testing phase has not provided sufficient data, then a multi-phase or multistaged data recovery phase should occur to collect sufficient remedial information to more fully understand the nature of the site, its contents, and the context of the material. For sites with shallow deposits, considerable data can be quickly and efficiently collected using a grid of small $(0.5$ by $0.5 \mathrm{~m})$ units to delineate horizontal variability in the site structure. Otherwise, if the cultural deposits are deep and stratified, the remedial data recovery phase should use a series of dispersed backhoe trenches coupled with geomorphic studies and manual excavations of deep pits along the trenches to investigate features exposed in the side walls and ascertain the number and locations of occupation zones. Sufficient time should be allotted after the remedial work to conduct preliminary analyses to plan for the placement of and methods used in opening one or more excavation blocks. Arguments raised by various agencies that time and dollar constraints prevent adequate testing to develop sound data recovery projects appear to ensure the opposite effect and may risk failure to meet regulatory requirements.

Depending upon the size of the site, permanent platforms may be established for one or more TDS stations to facilitate quick and consistent setup throughout the duration of the data recovery phase. After a broader site understanding is reached about the site, a more informative mitigation program can be designed to include research issues and alternate strategies for obtaining specific kinds of data and targeting specific occupation(s). This is exactly what a testing program is supposed to accomplish (McGimsey and Davis 1977:113).

\subsubsection{Data Recovery Investigations}

The formal stage of mitigation occurs after the data needs and recovery strategy plan have been developed and approved. Depending upon the depth of the target occupation zone(s), the main mitigation phase may be initiated by mechanical removal of excessive overburden to a level above the target occupation(s). Additional backhoe trenches may be placed adjacent to the expected edges of the block area prior to overburden removal to understand the geometry of the buried occupation zone and the stratigraphic context.

Aside from the possible removal of overburden and the excavation of trenches for discerning site geometry, we do not advocate the use of heavy machines to excavate through target occupation zones during initial stages of excavations. Block excavations should be conducted by manual excavations through target occupation zone(s) and the systematic screening of removed fill through $6.4 \mathrm{~mm}$ mesh hardware cloth. In many cases, water screening is a faster way to field process sediments even through a $3.2 \mathrm{~mm}(1 / 8$ inch) mesh screen than standard dry screening methods. However, considerable logistical and field preparation work is needed to accommodate the water screen process, and substantial laboratory time may be needed to identify, sort, and quantify the recovered materials.

The goal of the excavation should be to collect and document a representative sample of features and associated cultural materials from tightest contextual zones that have a chance of being contemporaneous. Accordingly, the excavations should never follow pedogenic horizons because the soils have formed after sediment deposition and often have little chance of reflecting brief, contemporaneous periods of time that are needed to document a brief period 
of culture. For similar reasons, we argue that target occupation zones should avoid occupational palimpsests that developed on stable landforms. In ideal situations, target excavation zones should rely on thin, recognizably distinctive natural depositional strata within an aggrading setting to maximize the association of materials and minimize the compression of time. In lieu of the presence of stratigraphically distinctive zones, excavations should maintain tight provenience control using standard squares and relatively thin $(5$ or $10 \mathrm{~cm}$ thick) levels. Obviously some flexibility in the approach is desirable to allow for adjustments to specific situations, and clearly, the grid and level system should not be so mindlessly employed so as to ignore the obvious associations and context of features, including clusters of burned rocks, bone fragments, lithic debris, and soil anomalies such as pits, post molds, and oxidation surfaces/stains. The documentation of features requires slightly different collection and recording strategies to ensure maximum extraction of data sets sufficient to identify and interpret their function.

Alluvial deposits often contain stratified cultural components. The quality and density of information return from stratified components at any given spot in a site will probably be variable and reflect the rate of deposition, length of occupation, and range of activities and materials used. Initially, a relatively small, contiguous block excavated through the cultural bearing deposits should provide sufficient data and assemblage context from the various components before one or more target occupation zones are selected. This staged expansion of the excavations is a cost-effective way of deciding whether areas are returning appropriate information to meet the research needs. For example, at the Mustang Branch site (41HY209-T), a relatively small $\left(25 \mathrm{~m}^{2}\right)$ block was excavated through stratified occupations before a much larger block $\left(115 \mathrm{~m}^{2}\right)$ was opened on a single Toyah occupation (Ricklis and Collins 1994). Thus, in order to extend the utility of available funds for a project, field efforts should briefly examine and document multiple occupations, but work should focus or target on but a few productive components that appear to maximize the data return or contain data to address specific research questions.

We support the continued use of TDS instruments to document in situ materials. As previously discussed, multiple TDS instruments and some other form of log or backup system should be employed to prevent the mis-assignment of provenience shots to a series of artifacts. The traditional approach of hand mapping on paper the relative positions of features in plan and profile should not be abandoned. Furthermore, we agree that the method of recording provenience data using a TDS system is not incompatible with the traditional use of a grid system to control and standardize densities per volume of sediments. Additionally, we would recommend that the TDS be used to record the corner of each unit and the absolute beginning and ending elevations of excavated levels. The use of TDS plotting can facilitate the rapid removal of the overlying sediments, the opening of broad areas to discern site structure, and the expansion in any direction to pursue materials on the target occupation zone.

Due to the potential for electronic glitches and/or missed correlation of provenience observations to specific artifacts, the TDS database should be downloaded and checked against the backup log books or other independently derived system on a daily basis. The costs of using the instrument and the skill level of those individuals using the instrument should not be underestimated. Unfortunately, other hidden costs are associated with using the TDS to collect, check, clean up, and manipulate provenience information; these costs are not easily quantifiable. 
Flexibility in the field is critical to obtaining the appropriate kinds of information from unpredictable buried remains. Since archaeology is a discovery science, it is ill advised to completely shackle the fieldwork with preordained methods. Close cooperation between the funding agency and performing entity through the course of a project is a more satisfactory way to achieve objectives cost effectively.

Flotation and fine screen samples have a very useful place in the archaeologist's repertoire of field tactics. The data derived from these methods does provide a more complete record about the range of materials present as compared to recovery from the $6.4 \mathrm{~mm}$ screening procedures, but the methods should focus on sensible contexts of features, house floors, and activity areas, and not from stacked samples in columns spaced at arbitrary intervals through multiple occupation surfaces. The use of flotation columns only makes sense if comparisons of fine screen materials through time are sought from the general patterns of a few test pits. As a routine tactic, the collection of samples from numerous columns placed at regular widely spaced intervals should probably be avoided. The cost of collecting matrix samples may not be overly expensive in itself, but the cost transporting, floating, sorting, analyzing, identifying, and curating can add significant costs to the total project. Furthermore, much of the data recovered from fine screen processing is difficult to interpret because of material origin ambiguity and turbation factors.

If site structure is a major research issue, then more detail is required from the field to document and record the range of available kinds of data. As demonstrated by the Higgins Experiment, the emphasis of primarily documenting the distribution of burned rocks to the exclusion of other classes of artifacts does not appear to have provided the data necessary to completely understand the breadth of human behavior that occurred at the site. The documentation and plotting of a range of material classes is required to delineate details of the site structure and the corresponding human behaviors. The more restrictive the collection policy to specific classes of material, the less likely that meaningful specific site structure can be delineated.

In some instances, ending manual excavations within an appropriate-sized mitigation may mean that not enough diagnostic features or material from the target occupation(s) are obtained to characterize the assemblage. As long as the geometry of the target occupation(s) is delineated, and it is clear that the relevant materials are isolated from other components, we see no harm in conducting supplemental mechanical stripping. Identified features should be excavated to add to the overall feature diversity and horizontal patterns underlying the site structure. In addition, as long as the target occupation zone can be isolated, the removed fill can be bulk screened to increase the number and range of tools from the assemblage. This approach was successfully conducted at the Jewett mine using specially constructed heavy-duty screens that could accommodate the volume of fill from the bucket of a front-end loader (Fields 1987). This practice should be reserved as a field exit strategy only because the context and association of materials obtained by these methods are not properly controlled. However, as a means of expanding the assemblage size of formal tools for comparative purposes, especially if from sites scheduled to be destroyed, this approach is better than dealing with small samples of tools.

Finally, one appropriate area to reduce costs should occur in the area of analytical design (and not during the field recovery). We do acknowledge that any form of excavation is only selectively recovering a sample of artifacts, but 
the procedures should be relatively rigorous and uniformly applied. The failure to collect available materials precludes all future studies and renders the curated collection biased in unaccountable ways.

In contrast to the rigor of collection, it is possible to focus the level of analysis on materials that address specific issues. Other classes of data perhaps deemed less informative, such as the volume of knapping debris or burned rocks, can be presented in summary form or sub-sampled for detailed analysis. In either case, other archaeologists can use the curated collection to address different problems by conducting indepth analyses. The careful selection of appropriate areas to spend available funds can result in overall cost reduction with optimum information recovery for the project.

We are not advocating the overall dismissal of research design issues or the wholesale reduction of analysis of the entire collection. Instead, we advocate the selective focusing of analyses on appropriate research topics. In the present study, it might have been easy to abandon the subsistence research design issue due to the paucity of recovered animal bones and macrobotanical remains. However, reconsideration of the subsistence issue led to the possibility of using isotope and chemical analyses on organic residues sealed by carbonates inside burned rocks to obtain alternative, useful data. This in turn has opened the possibility of dating porous burned rock features throughout south Texas, which lacks associated charcoal, and has considerably advanced the current knowledge about using convergent lines of evidence to reconstruct resources used by ancient people. Suddenly, burned rock feature sites once regarded as undatable due to the absence of associated charcoal are able to provide insights into past activities. New contributions and advancement can revolutionize the approaches used to reconstruct Texas's heritage. In some cases, then, additional studies in select areas should be undertaken in conjunction with data recovery projects.

In summary, the mixture of traditional and experimental procedures that were mandated for the excavations at the Lino site proved to yield more robust kinds of data than extracted from the Higgins Experiment, which furthers understanding of the prehistory of people in south Texas. In this regard, the Lino site experiment helps delineate the appropriate mixture of methods to be used on future studies.

The assemblage sample obtained from each of the six recognized components is quite limited and heavily skewed by the extensive use of mechanical stripping. The Gradall ${ }^{\mathrm{TM}}$ stripping was successful in locating burned rockdominated features and larger isolated burned rocks, but it missed about 95 percent of the total material from multiple well-defined occupation zones. Only two-thirds of the components yielded diagnostic artifacts and some tools. It also appears that the hand-excavated area of 40 $\mathrm{m}^{3}$ was too small to yield a sizeable assemblage, so comparative studies will be hindered by the assemblages from the Lino site. Therefore, the Gradall ${ }^{\mathrm{TM}}$ stripping yielded a poor overall return that was not counterbalanced by the increase in overall data recovery from the considerably larger excavation area. In light of the present study and the results at similar types of sites, the continued use of Gradall ${ }^{\mathrm{TM}}$ machines as the primary means of site excavation seems inappropriate. However, if the burned rock features are the only probable intact material remaining in a site, then Gradall ${ }^{\mathrm{TM}}$ stripping to discover such features would be an appropriate discovery technique. This would then be followed by hand excavation of any discovered feature. 
The TDS equipment proved to be very helpful in defining the location and geometry of specific occupation surfaces. It can be effectively used as an adjunct to, rather than a replacement of, the traditional grid system.

The fine screening of four-liter sediment samples stacked as columns in a 2 by $3 \mathrm{~m}$ grid across the excavation block did not provide much useful information about past activities on the site. The mandate to use such a strategy might have been developed to make up for the lack of testingphase information about the lower occupations in the excavation block. Fine screening is very useful in augmenting the coarse $(6.4 \mathrm{~mm})$ screen results from feature contexts, but for sampling activities on expansive living surfaces, the proveniences must be carefully selected, or a smaller grid should be used. The confidence of the fine screen results is low because considerable turbations have adversely affected the site sediments. Overall, the wholesale processing of the fine screen matrix samples proved to be too costly to justify the material returns. Fine screen results can provide important adjunct data about a site, but the contexts should be carefully chosen. 
Intentionally Left Blank 


\subsection{REFERENCES CITED}

Abbott, J. T.

1997 Archeological Testing of Sites 41WB437 and 4lWB438, Webb County, Texas. Archeology Studies Program, Environmental Affairs Division, Texas Department of Transportation.

Abbott, J. T., G. L. Ellis, and G. A. Goodfriend 1995 Chronometric and Integrity Analysis Using Land Snails. In NHRP Significance Testing of 57 Prehistoric Archeological Sites on Fort Hood, Texas, edited by J. T. Abbott and W. N. Trierweiler pp. 801-814. United States Army Fort Hood, Archeological Resource Management Series, Research Report No. 34.

Abbott, J. T., G. A. Goodfriend, and G. L. Ellis 1996 Landsnail Investigations. In Archeological Testing at Fort Hood: 19941995, edited by W. N. Trierweiler pp. 619636. United States Army Fort Hood, Archeological Resource Management Series, Research Report No. 35.

Ambrose, S. H.

1991 Effects of Diet, Climate and Physiology on Nitrogen Isotope Abundances in Terrestrial Foodwebs. Journal of Archaeological Science 18:293-317.

Ambrose, S. H. and M. J. DeNiro

1986 The Isotopic Ecology of East African Mammals. Oecologia 69:395-406.

Baker, G.

1975 To Sieve or Not to Sieve. Antiquity 49:61-63.
Barnes, V. G.

1976 Geologic Atlas of Texas, Laredo Sheet. Bureau of Economic Geology, University of Texas-Austin.

Bellomo, R. V.

1991 Identifying Traces of Natural and Humanly Controlled Fire in the Archaeological Record: The Role of Actualistic Studies. Archaeology in Montana 32(2):75-93.

Berglund, B. E. and M. Ralska-Jasiewiczona, editors

1986 Handbook of Holocene Palaeoecolgy and Palaeohydrology. Chichester (West Sussex); New York; Wiley.

Binford, L. R.

1978 Dimensional Analysis of Behavior and Site Structure: Learning from an Eskimo Hunting Stand. American Antiquity 43(3): 330-361.

1984 In Pursuit of the Past: Decoding the Archaeological Record. Thames and Hudson, New York.

\section{Birkeland, P. W.}

1984 Soils and Geomorphology. Oxford University Press, New York.

Birkeland, P. W., M. N. Machette, and K. M. Haller 1991 Soils as a Tool for Applied Quaternary Geology. Utah Geological and Mineral Survey Miscellaneous Publication 91-3. Utah Department of Natural Resources, Salt Lake City. 
Black, S. L.

1989 South Texas Plains. In From the Gulf to the Rio Grande: Human Adaptation in Central, South, and Lower Pecos Texas, edited by T. R. Hester, S. L. Black, D. G. Steels, B. W. Olive, A. A. Fox, K. Reinhard, and L. C. Bement, pp. 39-62. Research Series 33, Arkansas Archeological Survey Research Series No. 33.

1995a Introduction. In Archeology along the Wurzbach Parkway: Module 1: Introduction, Conceptual Framework, and Context of Archeological Investigations in Bexar County, South-Central Texas, by D. R. Potter, S. L. Black, and K. Jolly, pp. 16. Studies in Archeology 17, Texas Archeological Research Laboratory, University of Texas-Austin.

1995b Archeological and Ethnological Background. In Archeological Investigations at the Loma Sandia Site (41LK28): A Prehistoric Cemetery and Campsite in Live Oak County, Texas, by A. J. Taylor and C. L. Highley, pp. 31-45. Volume 1, Studies in Archeology 20, Texas Archeological Research Laboratory, University of Texas-Austin.

1998 Site Structure. In Archeology along the Wurzbach Parkway: Module 3: Investigations and Experimentation at the Higgins Site (41BX184), by S. L. Black, K. Jolly, C. D. Frederick, J. R. Lucas, J. W. Karbula, P. R. Takac., and D. R. Potter, pp. 217-228. Volume 1. Studies in Archeology 27, Texas Archeological Research Laboratory, University of TexasAustin.
Black, S. L., L. W. Ellis, D. G. Creel, and G. T. Goode

1997 Hot Rock Cooking on the Greater Edwards Plateau: Four Burned Rock Midden Sites in West Central Texas. Studies in Archeology 22, Texas Archeological Research Laboratory, University of Texas-Austin. Archeology Studies Program, Report 2, Texas Department of Transportation, Environmental Affairs Department.

Black, S. L. and K. Jolly

1998a The Development of a Nontraditional

Research Strategy. In Archeology along the Wurzbach Parkway: Module 3: Investigations and Experimentation at the Higgins Site (41BX184), by S. L. Black, K. Jolly, C. D. Frederick, J. R. Lucas, J. W. Karbula, P. R. Takac., and D. R. Potter, pp. 31-38. Volume 1. Studies in Archeology 27, Texas Archeological Research Laboratory, University of TexasAustin.

1998b Evaluating the Higgins Experiment. In Archeology along the Wurzbach Parkway: Module 3: Investigations and Experimentation at the Higgins Site (41BX184), by S. L. Black, K. Jolly, C. D. Frederick, J. R. Lucas, J. W. Karbula, P. R. Takac., and D. R. Potter, pp. 229-238. Volume 1. Studies in Archeology 27, Texas Archeological Research Laboratory, University of Texas-Austin.

Black, S. L., K. Jolly, C. D. Frederick, J. R. Lucas, J. W. Karbula, P. R. Takac., and D. R. Potter. 1998 Archeology along the Wurzbach Parkway: Module 3: Investigations and Experimentation at the Higgins Site (41BX184), Volumes 1 and 2. Studies in Archeology 27, Texas Archeological Research Laboratory, University of TexasAustin. 
Blair, W. F.

1950 The Biotic Provinces of Texas. The Texas Journal of Science 2(1):93-117.

Bomar, G. W.

1983 Texas Weather. University of Texas Press, Austin.

Bousman, C. B.

1990 Paleoenvironments and Human Diets.

In Prehistoric Archeological and Paleoenvironments in Hidalgo and Willacy Counties, South Texas: Results of the Phase II Test Excavation, by C. B. Bousman, S. A. Tomka and G. L. Bailey, pp. 91-103. Reports of Investigations Number 76. Prewitt and Associates, Inc. Austin.

1998 Paleoenvironmental Change in Central Texas: The Palynological Evidence. Plains Anthropologist 43(164):201-219.

Boutton, T. W.

1991 Stable Carbon Isotopes and the Study of Prehistoric Human Diet. In Critical Reviews in Food Science and Nutrition 30:373-385.

Boutton, T. W., S. R. Archer, A. J. Midwood, S. F. Zitzer, and R. Bol

$1998 \delta^{13} \mathrm{C}$ Values of Soil Organic Carbon and

Their Use in Documenting Vegetation

Changes in a Subtropical Savanna Ecosystem. Geoderma 82:5-41.

Boutton, T. W., S. F. Zitzer, S. R. Archer, L. A. Cifuentes, and J. P. Angerer

1992 Nitrogen Fixation by Woody Plants in a Subtropical Savanna: Evidence Based on Natural Abundance of Nitrogen-15. La Copita Research Area: 1992 Consolidated Progress Report.
Boyd, D. K., J. Peck, S. A. Tomka, and K.W. Kibler 1993 Data Recovery at Justiceburg Reservoir (Lake Alan Henry), Graza and Kent Counties, Texas: Phase III, Season 2. Reports of Investigations Number 88, Prewitt and Associates, Inc. Austin.

Brink, J., M. Wright, B. Dawe, and D. Glau 1986 Final Report of the 1984 Season at Head-Smashed-In Buffalo Jump, Alberta. Archaeological Survey of Alberta Manuscript Series No. 9. Alberta Culture and Multiculturalism Historical Resources Division, Edmonton.

Brown, K. M., D. R. Potter, G. D. Hall, and S. L. Black

1982 Excavations at 41LK67: A Prehistoric Site in the Choke Canyon Reservoir, South Texas. Choke Canyon Series 7. Center for Archaeological Research, University of Texas-San Antonio.

Bruseth, J. E.

1997 Letter of Concurrence for Testing 41WB437 and 41WB438 from J. E. Bruseth to N. Kenmotsu of the Texas Department of Transportation.

Bryant, M. B. and D. H. Riskind

1980 The Paleoenvironmental Record for Northeastern Mexico: A Review of the Pollen Evidence. In Papers On The Prehistory of Northeastern Mexico and Adjacent Texas, edited by J. F. Epstein, T. R. Hester, and C. Graves, pp. 7-31. Special Report No. 9. Center for Archaeological Research, University of Texas-San Antonio.

\section{Bryant, V. M.}

1966 Pollen Analysis: Its Environmental and Cultural Implications in the Amistad Reservoir. Unpublished M. A. thesis, University of Texas-Austin. 
1969 Late Full Glacial and Post Glacial Pollen Analysis of Texas Sediments. Unpublished Ph.D. dissertation, University of Texas-Austin.

Bryant, V. M. and H. J. Shafer

1977 The Late Quarternary Paleoenvironment of Texas: A Model for the Archeologist. Bulletin of the Texas Archeological Society, 48:1-25.

Bryant, V. M. Jr., and R. G. Holloway

1985 ALate Quaternary Paleoenvironmental Record of Texas: An Overview of the Pollen Evidence. In Pollen Records of Late Quaternary North American Sediments, edited by V. M. Bryant, Jr. and R. G. Holloway, pp. 39-70. American Association of Stratigraphic Palynologists Foundation, Dallas.

Bunker, R. C.

1978 The Geomorphic Framework of Human Occupation in the Frio River Valley, Choke Canyon Dam Reservoir Area, Live Oak and McMullen Counties, Texas. Department of Geological Sciences, University of Texas-Austin

Butler, V. L.

1993 Natural Verses Cultural Salmonid Remains: Origins of the Dalles Roadcut Bones, Columbia River, Oregon, U.S.A. Journal of Archaeological Science 20:124.

Campbell, T. N.

1983 Coahuiltecans and Their Neighbors. In Handbook of North American Indians, Volume 10, W. C. Sturtevant, General Editor, pp. 343-358. Smithsonian Institution, Washington, D. C.
Campbell, T. N. and T. J. Campbell 1981 Historic Indian Groups of the Choke Canyon Reservoir and Surrounding Area, Southern Texas. Choke Canyon Series: Volume I. Center for Archaeological Research, University of Texas-San Antonio.

Caran, S. C.

1998 Quarternary Paleoenvironmental and Paleoclimate Reconstruction: A Discussion and Critique, with Examples from the Southern High Plains. Plains Anthropologist 43(164):111-124.

Cason, J. F.

1952 Report on Archaeological Salvage in Falcon Reservoir, Season of 1952. Bulletin of the Texas Archeological and Paleontological Society 23:218-259.

Casteel, R. W.

1972 Some Biases in the Recovery of Archaeozoological Faunal Remains. Proceeding of the Prehistoric Society 38:328-388.

1976 Comparison of Column and Whole Unit Samples for Recovering Fish Remains. World Archaeology 8:192-198.

Church, F.

1999 A Summary of the Results of a High Power Use-Wear Analysis of a Sample of Chipped Stone Artifacts from Site 41ZP364, Zapata County, Texas. In Data Recovery at 41ZP364: An Upland Campsite at Falcon Reservoir, Zapata County, Texas, by J. M. Quigg and C. Cordova, Technical Report No. 22317, in press. TRC Mariah Associates Inc., Austin. 
Church, T., C. Caraveo, R. Jones, and J. Sirianni 1996 Mountains and Basins: The Lithic

Landscape of the Jornada Mogollon. Archaeological Technical Reports Number 8. Anthropology Research Center, University of Texas-El Paso.

Clark, C.

1987 Subsistence Intensification in Deer Resource Use at the McCutchinMcLaughlin (34LT-11) Site, Latimer County, Oklahoma. M. A. thesis, University of Oklahoma.

Clark, J. E

1986 Another Look at Small Debitage and Microdebitage. Lithic Technology 15(1):21-33.

Collins, M. B.

1991 Thoughts on Future Investigations of Burned Rock Middens. In The Burned Rock Middens of Texas: An Archeological Symposium, edited by T. R. Hester, pp. 124. Studies in Archeology No. 13. Texas Archeological Research Laboratory, University of Texas-Austin.

1994 Chronometric Investigations. In Archaic and Late Prehistoric Human Ecology in the Middle Onion Creek Valley, Hays County, Texas, by R. A. Ricklis and M. B. Collins, pp. 499-505. Studies in Archeology 19, Texas Archeological Research Laboratory, University of TexasAustin.

1998 Forty Years of Archeology in Central Texas. Bulletin of the Texas Archeological Society 66:361-400.

Collins, M. B., C. B. Bousman, and T. K. Perttula 1993 Historic Context: Quaternary Environments and Archeology in
Northeastern Texas. In Archeology in the Eastern Planning Region, Texas: A Planning Document, edited by N. A. Kenmotsu and T. K. Perttula, pp. 49-67. Department of Antiquities Protection, Cultural Resource Management Report 3, Texas Historical Commission, Austin.

Delwiche, C. C., P. J. Zinke, C. M. Johnson, and R. A. Virginia

1979 Nitrogen Isotope Distribution as a Presumptive Indicator of Nitrogen Fixation. Botanical Gazette 140:65-69.

DeMarcay, G. B. and D. G. Steele 1986 The Value of Fine Screening on Inland Based Hunter-Gather Habitation Sites. In Archaeological Investigations at 41LK201, Choke Canyon reservoir, Southern Texas, by C. L. Highley, pp. 250264. Choke Canyon series No. 11, Center for Archaeological Research, University of Texas-San Antonio.

DeNiro M.J.

1987 Stable Isotopes and Archaeology. American Scientist 75:182-191.

DeNiro M. J. and S. Epstein

1978 Influence on the Distribution of Carbon Isotopes in Animals. Geochimica et Cosmochimica Acta 42:495-506.

Dering, J. P.

1999 Carbonized Plant Remains from 41ZP364: Identification and Analysis Using Scanning Electron Microscopy. In Data Recovery at 41ZP364: An Upland Campsite at Falcon Reservoir, Zapata County, Texas. by J. M. Quigg and C. Cordova, Technical Report No. 22317, in press. TRC Mariah Associates Inc., Austin. 
Dibble, S. D. and D. Lorrain

1968 Bonfire Shelter: A Stratified Bison Kill

Site, Val Verde County, Texas. Miscellaneous Papers No. 1.Texas Memorial Museum, University of TexasAustin.

Dreimanis, A.

1962 Quantitative Gasometric Determination of Calcite and Dolomite by Using Chittick Apparatus, Journal of Sedimentary Petrology 32(3)520-529.

Driver, H. E., and W. C. Massey 1957 Comparative Studies of North American Indians. Vol. 47. Transactions of the American Philosophical Society, Philadelphia.

Eickmeier, W. G. and M. M. Bender

1976 Carbon Isotope Ratios of Crassulacean Acid Metabolism Species in Relation to Climate and Phytosociology. Oecologia 25:341-347.

Ellis, G. L., J. T. Abbott, and S. L. Black 1998 TxDOT Review Comments and Response. In Archeology along the Wurzbach Parkway: Module 3: Investigations and Experimentation at the Higgins Site (41BX184), Volume II, by S. L. Black, K. Jolly, C. D. Frederick, J. R. Lucas, J. W. Karbula, P. R. Takac., and D. R. Potter, pp. 413-415. Studies in Archeology 27, Texas Archeological Research Laboratory, University of TexasAustin.
Ellis, G. L., and G. A. Goodfriend

1994 Chronometric and Site-Formation Studies Using Land Snail Shells. Preliminary Results. In Archaeological Investigations on 571 Prehistoric Sites at Fort Hood, Bell, and Coryell Counties, Texas, edited by W. N. Trierweiler, pp. 183-201. United States Army Fort Hood, Archeological Resource Management Series, Research Report No. 31.

Ellis, G. L., G. A. Goodfriend, J. T. Abbott, P. E. Hare, and D. W. Von Endt

1996 Assessment of Integrity and Geochronology of Archaeological Sites Using Amino Acid Racemization in Land Snails Shells: Examples from Central Texas. Geoarchaeology 11(3):189-213.

Ellis, L. W.

1997 Hot Rock Technology. In Hot Rock Cooking on the Greater Edwards Plateau: Four Burned Rock Midden Sites in West Central Texas, by S. L. Black, L. W. Ellis, D. G. Creel, and G. T. Goode, pp. 43-81. Studies in Archeology 22, Texas Archeological Research Laboratory, University of Texas-Austin. Archeology Studies Program, Report 2, Texas Department of Transportation, Environmental Affairs Department.

Evans, G. L.

1962 Notes on Terraces of the Rio Grande, Falcon-Zapata Area. Bulletin of the Texas Archeological Society 32:33-46.

Fenneman, N. M.

1938 Physiography of the Eastern United States. McGraw Hill, New York. 
Fields, R. (Editor)

1987 Excavations at the Alley Road Site (41LN149B) and the Harris Hole Site (41LN30), Jewett Mine Project, Leon County, Texas. Prewitt and Associates Reports of Investigations Number 61, Austin.

Gee, G.W. and J. W. Bauder

1986 Particle-Size Analysis. In Methods of Soil Analysis (Second Edition), edited by A. Klute, American Society of Agronomy, Madison.

Gile, L. H., F. F. Peterson, and R. B. Grossman 1966 Morphological and Genetic Sequences of Carbonate Accumulation in Desert Soils. Soil Science 106:6-15.

Griffiths, H.

1992 Carbon Isotope Discrimination and the Intergration of Carbon Assimilation Pathways in Terrestrial CAM Plants. Plant, Cell, and Environment 15:10511062.

Gustavson, T. C. and M. B. Collins

1998 Geoarcheological Investigations of Rio Grande Terrace and Flood Plain Alluvium rom Amistad Dam To the Gulf of Mexico. Technical Series 49, Texas Archeological Research Laboratory, University of TexasAustin. Archeological Studies Program Report No. 12, Texas Department of Transportation.

Hall, G. D., S. L. Black, and C. Graves

1982 Archeological Investigations at Choke Canyon Reservoir, Southern Texas: Results of Phase I Findings. Choke Canyon Series 5. Center for Archaeological Research, University of Texas-San Antonio.
Hall, G. D., T. R. Hester, and S. L. Black 1986 The Prehistoric Sites at Choke Canyon Reservoir, Southern Texas: Results of Phase II Archaeological Investigations. Choke Canyon Series 10. Center for Archaeological Research, University of Texas-San Antonio.

Hartle, D. D. and R. L. Stephenson

1951 Archaeological Excavations at the Falcon Reservoir, Starr County, Texas. In River Basin Surveys, prepared for the Smithsonian Institution, Washington, D.C.

Heaton, T. E., J. C. Vogel, G. von la Chevallerie, and $\mathrm{G}$. Collett

1986 Climatic Influence on the Isotopic Composition of Bone Collagen. Nature 322:823-824.

Heaton, T. H. E.

1987 The 15N/14N Ratio of Plants in South Africa and Namibia: Relationship to Climate and Coastal/Saline Environments. Oecologia 74:236-246.

Heaton, T. H. E., J. C. Vogel, G. von la Chevallerie and $\mathrm{G}$. Collett

1986 Climate Influence on the Isotope Composition of Bone Nitrogen. Nature 322(28):822-823.

Henderson, $\mathrm{J}$.

1997 Archeological Resources Survey Report. On file with the Environmental Affairs Division, Texas Department of Transportation, Austin.

Hester, T. R.

1971 Archeological Investigations at the La Jita Site, Uvalde County, Texas. Bulletin of the Texas Archeological Society 42:51148. 
1980 Digging Into South Texas Prehistory. Corona, San Antonio.

1981 Tradition and Diversity Among the Prehistoric Hunters and Gathers of Southern Texas. Plains Anthropologist 26(92):119-128.

1995 The Prehistory of South Texas. Bulletin of the Texas Archeological Society 66:427459.

Hester, T., R., S. L. Black, D. G. Steele, B. Olive, A. Fox, K. Reinhard, and L. Bement

1989 From the Gulf to the Rio Grande: Human Adaptation in Central, South and Lower Pecos Texas. Research Series No. 33. Arkansas Archaeological Survey, Fayetteville.

Highley, C. L.

1986 Archaeological Investigations at 41LK210, Choke Canyon Reservoir, Southern Texas. Choke Canyon Series: Volume 11, Center for Archaeological Research, University of Texas-San Antonio.

1995 Lithic Artifacts. In Archaeological Investigations at the Loma Sandia Site (41LK28): A Prehistoric Cemetery and Campsite in Live Oak County, Texas, by A. J. Taylor and C. L. Highley, pp. 405519. Studies in Archeology 20, Texas Archeological Research Laboratory, University of Texas-Austin.

Hillsman, M. J.

1992 Evaluation of Visible and UltravioletExcited Attributes of Some Texas and Macroscopically Similar New Mexico Cherts. Unpublished Master's thesis, Eastern New Mexico University, Portales.
Hodge, F. W.

1907 The Narrative of Alvar Nuez Cabeza de Vaca. Spanish Explorers in the Southern United States, 1528-1543. Barnes and Noble, New York.

Hofman, J. L., L. C. Todd, and M. B. Collins 1991 Identification of Central Texas Edwards Chert at the Folsom and Lindenmeier Sites. Plains Anthropologist 36(137)297308.

House, J. H., and J. W. Smith

1975 Experiments in Replication of FireCracked Rock. In Cache River Archeological Project, pp. 75-80. Research Series No. 8. Arkansas Archeological Survey, Fayetteville.

Inglis, J. M.

1964 A History of Vegetation on the Rio Grande Plain. Texas Parks and Wildlife Bulletin No. 45, Austin.

Jackson, M. A.

1998 The Nature of Fire Cracked Rock: New Insight from Ethnoarchaeological and Laboratory Experiments. Unpublished $\mathrm{M}$. A. thesis, Texas A \& M University, College Station.

Jenson, J. H.

1988 Functional Analysis of Prehistoric Flint Tools by High-Powered Microscopy: A Review of West European Research. Journal of World Prehistory 2:53-88.

Johnson, L.

1995 Past Cultures and Climates at Jonas terrace, 4IME29, Medina County, Texas. Office of the State Archeologist, Report No. 40. Texas Department of Transportation and Texas Historical Commission, Austin. 
Jones, J. G.

1999 Analysis of Phytoliths from Site 41ZP364, Zapata County Texas. In Data Recovery at 41ZP364: An Upland Campsite at Falcon Reservoir, Zapata County, Texas, by J. M. Quigg and C. Cordova. Technical Report No. 22317. TRC Mariah Associates Inc., Austin.

Karlstrom, E. T.

1988 Rates of Soil Formation on Black Mesa, Northeast Arizona: A Chronosequence in Late Quaternary Alluvium. Physical Geography 9:301-327.

Keeley, L. H.

1980 Experimental Determination of Stone Tool Use: A Microwear Analysis. University of Chicago Press, Chicago.

Krieger, A. D. and J. T. Hughes 1950 Archaeological Salvage in the Falcon Reservoir Area. Progress Report No. 1, 38 pages. Prepared for the National Park Service. Manuscript on file at the Texas Archaeological Research Laboratory, University of Texas-Austin.

Krumbein, W. C. and L. L. and Sloss 1963 Stratigraphy and Sedimentation, 2nd ed. W. H. Freeman, San Francisco.

Labadie, J. H. 1988 Archaeological Excavations at the Shrew Site 4lWN73, Wilson County, Southern Texas. Texas State Department of Highways and Public Transportation, Highway Design Division, Contract Reports in Archaeology, Report Number 2, Austin.
Lintz, C.

1989 Experimental Thermal Discoloration and Heat Conductivity Studies of Caliche from Eastern New Mexico. Geoarcheology 4(4): 319-346.

McGimsey, C. R., and H. A. Davis (editors)

1977 The Management of Archeological Resources: The Airlie House Report. Special Publication of the Society for American Archaeology.

\section{McGraw, A. J.}

1983 Arroyo De los Muertos and Other Prehistoric Terrace Sites Along the Rio Grande, Laredo, Texas. Archaeological Survey Report, No. 106. Center for Archaeological Research, University of Texas-San Antonio.

Machette, M. N.

1985 Calcic Soils of the Southwestern United States. In Soils and Quaternary Geology of the Southwestern United States, edited by D. L. Weide. pp. 1-21. Special Paper 203, Geological Society of America, Boulder.

Malainey, M.

1999 Analysis of the Fatty Acid Compositions of Burned Rock Residues from Site 41ZP364, Zapata County, Texas. In Data Recovery at 41ZP364: An Upland Campsite at Falcon Reservoir, Zapata County, Texas. by J. M. Quigg and C. Cordova. Technical Report No. 22317. TRC Mariah Associates Inc., Austin. 
Mercado-Allinger, P. A., N. A. Kenmotsu, and T. E. Perttula

1996 Archeology in the Central and Southern

Planning Region, Texas: A Planning

Document. Office of the State

Archeologist Special Report 35 and the

Divison of Antiquities Protection

Cultural Resources Management Report

7. Texas Historical Commission, Austin.

Monger, H. C.

1993 Soil-Geomorphic and Paleoclimatic

Characteristics of the Fort Bliss Maneuver

Areas, Southern New Mexico and Western

Texas. Historic and Natural Resources

Report No. 10. Cultural Resources

Management Program, Directorate of the

Environment, United States Army Air

Defense Artillery Center, Fort Bliss, Texas.

Nass, J. P. Jr.

1987 Use-Wear Analysis and Household Archaeology: A Study of the Activity Structure of the Incinerator Site, an Anderson Phase Fort Ancient Community in Southwestern Ohio. Ph.D. dissertation, Department of Anthropology, Ohio State University Microfilms, Ann Arbor.

Neck, R.W. and A. L. Metcalf

1988 Freshwater Bivalves of the Lower Rio Grande, Texas. Texas Journal of Science 40(3):259-268.

Nordt, L. C.

1993 Additional Geoarchaeological Investigations at the Fort Hood Military Reservation, Ft. Hood, Texas. Research Report No. 28, Addendum to Research Report No. 25, Archaeological Resource Management Series, United States Army, Fort Hood, Texas.
Nunley, P. and T. R. Hester

1966 Preliminary Archeological Investigations in Dimmit County, Texas. Texas Journal of Science 18(3):233-253.

O'Leary, M. H.

1981 Carbon Isotope Fractionation in Plants. Phytochemistry 20:553-367.

Owen, L. R., G. Unrath, and P. Vaughn

1984 Register of Microwear Analysts and Their Research. Early Man News 7/ 8:3089.

Potter, D. R. and S. L. Black

1995 Archeology along the Wurzbach Parkway: Module 2: Initial Testing and Evaluation of Five Prehistoric Sites in the Upper SaladoWatershed, Bexar County, Texas. Studies in Archeology 18, Texas Archeological Research Laboratory, University of Texas-Austin.

Potter, D. R., S. L. Black, and K. Jolly 1995 Archeology along the Wurzebach Parkway: Module 1: Introduction, Conceptual framework, and Context of Archeological Investigations in Bexar County, South-Central Texas. Studies in Archeology 17, Texas Archeological Research Laboratory, University of TexasAustin.

Prewitt, E. R.

1995 Distribution of Typed Projectile Points in Texas. Bulletin of the Texas Archeological Society 66:83-173.

Prewitt, E. R. and J. G. Paine

1988 The Swan Lake Site (41AS16) on Copano Bay, Aransas County, Texas: Settlement, Subsistence, and Sea Level. Bulletin of the Texas Archeological Society 58:147-168. 
Quigg, J. M.

1997 The Sanders site (41HF 128): A Single Event Late Archaic Camp/Processing Site, Hansford County, Texas. Technical Report No. 19751. TRC Mariah Associates Inc., Austin.

1999 Archeological Monitoring at Sites 41ZP39 and 41ZP176, for TransTexas Gas Well Site USA \#3, Falcon Reservoir, Zapata County, Texas. Technical Report No. 23224. TRC Mariah Associates Inc., Austin.

Quigg, J. M. and C. Cordova 1999a Archeological Investigations at Upland Sites 41ZP39 and 41ZP176, for TransTexas Gas Well Site USA \#3, Falcon Reservoir, Zapata County, Texas. Technical Report No. 22347. TRC Mariah Associates Inc., Austin.

1999b Data Recovery at 41ZP364: An Upland Campsite at Falcon Reservoir, Zapata County, Texas. Technical Report No. 22317, in press. TRC Mariah Associates Inc., Austin.

\section{Quigg, J. M. and G. L. Ellis}

1994 Burned Rock Mound Chronometric Investigations. In Archeological Investigations on 571 Prehistoric Sites at Fort Hood, Bell and Coryell Counties, Texas, edited by W. N. Trierweiler pp. 203274. United States Army Fort Hood, Archeological Resource Management Series, Research Report No. 31.

Quigg, J. M. and J. Peck

1995 The Rush Site (41TG346): A Stratified Late Prehistoric Locale in Tom Green County, Texas. Technical Report No. 816C, TRC Mariah Associates Inc., Austin.
Quigg, J. M., J. Peck, and C. Frederick 1996 Summary and Conclusions. In Early Archaic Use of the Concho River Terraces: Cultural Resource Investigations at 41TG307 and 41TG309, Tom Green County, San Angelo, Texas, by J. M. Quigg, J. Peck, C. Lintz, A. C. Treece, C. D. Frederick, R. Clem, G. L. Ellis, P. Schuchert, and J. T. Abbott, pp. 251-273. TRC Mariah Associates Inc., Technical Report 11058.

Ralph, E. K., N. H. Michael, and M. C. Han 1973 Radiocarbon Dates and Reality. MASCA Newsletter 9(1): 1-20.

Reineck, H. E. and I. B. Singh 1980 Depositional Sedimentary Environments, 2nd ed., Springer-Verlag, Berlin.

Ricklis, R. A. and M. B. Collins 1994 Archaic and Late Prehistoric Human Ecology in the Middle Onion Creek Valley, Hays County, Texas. Studies in Archeology 19, Texas Archeological Research Laboratory, University of TexasAustin.

Ruecking, F., Jr.

1955 The Coahuiltecan Indians of Southern Texas and Northern Mexico. Unpublished M. A. thesis, University of Texas.

Salinas, M. 1990 Indians of the Rio Grande Delta: Their Role in the History of Southern Texas and Northeastern Mexico. University of Texas Press, Austin. 
Sanders, R. R. and W. J. Gabriel

1985 Soil Survey of Webb County, Texas. U.S.

Department of Agriculture, Soil Conservation Service in cooperation with Texas Agricultural Experimental Station. Publishing Company, Houston.

Schoeninger, M. J. and M. J. DeNiro

1984 Nitrogen and Carbon Isotopic Composition of Bone Collagen from Marine and Terrestrial Animals. Geochim. Cosmochim. Acta 48:625-639.

Scott, R. F., IV

1982 Excavations at Sites 41LK31/32 and $41 L K 202$ in the Choke Canyon Reservoir, South Texas, Part 1: Prehistoric Investigations. Choke Canyon Series 8. Center for Archaeological Research. University of Texas-San Antonio.

Sealy, J. C., N. J. van der Merwe, A. L. Thorp, and J. L. Lanham

1987 Nitrogen Isotope Ecology in Southern Africa: Implications for Environmental and Dietary Tracing. Geochimica et Cosmochimica Acta 51:2707-2717.

Shafer, B. S.

1992 Quarter-Inch Screening: Understanding Biases in Recovery of Vertebrate Faunal Remains. American Antiquity 57:129-136.

Shafer, B. S. and J. L. J. Sanchez 1994 Comparison of 1/8"- and 1/4"-Mesh Recovery of Controlled Samples of Smallto-Medium-Size Mammals. American Antiquity 59:525-530.

Shearer, G., R. Kohl, R. Virginia, B. Bryan, J. Skeeters, E. Nielsen, M. Sharifi, P. Rundel.

1983 Estimates of $\mathrm{N}_{2}$-Fixation from Variation in the Natural Abundance of ${ }^{15} \mathrm{~N}$ in the Sonora Desert Ecosystems. Oecologia 56:365-373.
Soil Survey Staff

1962 Soil Survey Manual. Agricultural Handbook No. 18. U. S. Department of Agriculture, Washington, D. C.

1975 Soil Taxonomy. Agricultural Handbook No. 436. U. S. Department of Agriculture. Washington, D. C.

Stafford Jr., T. W.

1984 Quaternary Stratigraphy, Geochronology, and Carbon Isotope Geology of Alluvial Deposits in the Texas Panhandle. Unpublished $\mathrm{Ph}$. D. dissertation, Department of Geosciences, University of Arizona.

Stark, R. T.

1997 Piedras Calientes: Ethnohistory, Experimental Archaeology, and Cooking with Hot Rocks. Unpublished M. A. thesis, University of Texas-Austin.

Stein, J. K.

1984 Organic Matter and Carbonates in Archaeological Sites. Journal of field Archaeology 11:239-246.

Steward, J.

1973 Theory of Culture Change: The Methodology of Multilinear Evolution. University of Chicago Press.

Struever, S.

1968 Floatation Techniques for the Recovery of Small-Scale Archaeological Remains. American Antiquity 33:353-362.

Suhm, D. A., A. D. Krieger, and E. B. Jelks 1954 An Introductory Handbook of Texas Archeology. Bulletin of the Texas Archeological Society 25. 
Takac, P. R.

1999 Archeological Analysis of Archeological and Experimental Rocks from 41ZP364, Zapata County, Texas. In Data Recovery at 41ZP364: An Upland Campsite at Falcon Reservoir, Zapata County, Texas, by J. M. Quigg, Technical Report No. 22317. TRC Mariah Associates Inc., Austin.

Taylor, A. J.

1995 Appendix F: Radiocarbon Assays. In Archeological Investigations at the Loma Linda Site (41LK28): A Prehistoric Cemetery and Campsite in Live Oak County, Texas. Vol. 2, Studies in Archeology 20. Texas Archeological Research Laboratory, University of Texas-Austin.

Taylor, A. J. and C. L. Highley

1995 Archeological Investigations at the Loma Sandia Site (41LK28): A Prehistoric Cemetery and Campsite in Live Oak County, Texas. 2 Vols. Studies in Archeology 20. Texas Archeological Research Laboratory, University of TexasAustin.

Tieszen, L. L.

1994 Stable Isotopes on the Plains: Vegetation Analyses and Diet Determinations. In Skeletal Biology in the Great Plains: Migration, Warfare, Health, and Subsistence, edited by D. W. Owsley and R. L. Jantz, pp. 261-282. Smithsonian Institution Press, Washington, D.C.

Tieszen, L. L. and T. Fagre

1993 Carbon Isotope Variability in Modern Archaeological Maize. Journal of Archaeological Science 20:25-40.
Tomka, S. A. and R. C. Fields

1990 Chipped Stone Artifacts, 41LN29A and 41LN106. In Excavations at the Charles Cox, Lambs Creek Knoll, and Buffalo Branch Sites, Jewett Mine Project, Leon County and Freestone Counties, Texas, edited by R.C. Fields, pp. 141-220. Reports of Investigations, Number 70. Prewitt and Associates, Inc. Austin.

Toomey, R. S. III, M. D. Blum, and S. Valastro Jr. 1993 Late Quarternary Climates and Environments of the Edwards Plateau, Texas. Global and Planetary Change 7:299-320.

Treece, A. C., C. Lintz, W. N. Trierweiler, J. M. Quigg, and K. Miller.

1993 Cultural Resource Investigations in the O. H. Ivie Reservoir, Concho, Coleman and Runnels Counties, Texas. Volume IV: Data Recovery Results of Ceramic Sites. Mariah Associates, Inc. Austin.

Turner, E. S. and T. R. Hester 1993 A Field Guide to Stone Artifacts o Texas Indians. (2nd ed.). Gulf, Houston.

Turpin, A. A., H. H. Eling Jr., and M. V. Moreno 1993 From Marsh Land to Desert: The Late Prehistoric Environment of Boca de Potrerillos, Nuevo Leon, Mexico. North American Archaeologist 14(4):305-323.

1994 The Archaic Environment of Boca de Potrerillos, Nuevo Leon, Mexico. North American Archaeologist 15(4):331-357.

van der Merwe, N. J.

1982 Carbon Isotopes, Photosynthesis, and Archaeology. American Scientist 70:596606. 
Van Devender, T. R.

1990 Late Quarternary Vegetation and Climate of the Chihuahuan Desert, United States and Mexico. In Packrat Middens: The Last 40,000 Years of Biotic Change, edited by J.L. Betancourt, T. R. Van Devender, and P. S. Martin. pp. 104-133. University of Arizona Press, Tucson.

Vierra, B. J., C. B. Bousman, J. R. Cross, J. P. Dering, W. Gose, A. A. Fox, R. G. Howells, J. Hnziker, D. L. Nickels, A. L. Metcalf, B. A. Meissner, and L. C. Nordt

1997 Draft of 41MV120: A Stratified Late Archaic Site in Maverick County, Texas. Archaeological Survey Report No. 251, Center for Archaeological Research, University of Texas-San Antonio.

Virgina, R. A. and C. C. Delwiche 1982 Natural ${ }^{15}$ NAbundance of Presumed $\mathrm{N}_{2}$ Fixing and Non- $\mathrm{N}_{2}$-Fixing Plants from Selected Ecosystems. Oecologia 54:317325 .

Wakefield, W. W.

1968 Archeological Survey of Palmetto Bend and Choke Canyon Reservoir, Texas. Survey Report 5, Texas Archeological Survey, University of Texas-Austin.

Warembourg, F. R.

1993 Nitrogen Fixation in Soil and Plants. In Nitrogen Isotope Techniques, edited by R. Knowles and T. H. Blackburn, pp.127156. Academic Press, New York.
Waters, M. R.

1992 Principles of Geoarchaeology: A North American Perspective. University of Arizona Press, Tucson.

Watson, W. P. N.

1972 Fragmentation Analysis of Animal Bone Samples from Archaeological Sites. Archaeometry 14:221-228.

Yellen, J.

1977 Archaeological Approaches to the Present. Academic Press, New York.

Yerkes, R. W.

1987 Prehistoric Life on the Mississippi Floodplain: Stone Tool Use, Settlement Organization, and Subsistence Practices at the Labras Lake Site, Illinois. University of Chicago Press, Chicago.

1989 Microwear Analysis of Selected Chipped Stone Artifacts from the Spicebrush Swallowtail Site (33Vi222), Vinton County, Ohio. In Phase IV Mitigation: Excavation of 33Vi222, A Late Archaic Lithic Processing Station, Elk Township, Vinton County, Ohio, by F. Church. Report submitted to Bucher, Willis, and Ratliff, Aurora, Illinois. 


\subsection{GLOSSARY}

A/I Ratio The ratio of D-allosioleucine to L-isoleucine (A/I) proteins contained in Rabdotus snail shells. This ratio is a measure of age. All amino acids are initially in the L-form but over time, the $\mathrm{L}$-form converts or racemizes to the $\mathrm{D}$-form. This ratio can be used to measure age unless the shells have been exposed to prolonged heat from a hearth, which will accelerate the chemical change.

AMS See accelerated mass spectrometry.

Allostratigraphic Unit

Depositional unit made up of sediments dating to a coeval period of deposition.

Accelerated Mass Spectrometry (AMS)

Laboratory technique used for radiocarbon dating tiny particles of carbon in organic remains and residues.

Archeomagnetism

The application of paleomagnetic techniques to measure the orientation of magnetic particles in thermally heated archeological samples (burned rocks in the present study) to ascertain information about firing temperatures, degree of sample movement during cooling, and perhaps the number of progressively cooler heating episodes.

Balk A wall of undisturbed dirt left between Gradall-stripped areas that, in the present study, was hand-excavated to increase control over the recovery of archeological specimens.

Bioturbation The churning and mixing of sediments by living organisms, including burrowing rodents, insects, worms, and plant roots.

Burned Rock Dump

A loose cluster of heated rocks that has no patterning, and lacks indications of in situ burning, such as a prepared basin, lenses of charcoal or ash, and the absence of an oxidation rim. Scattered charcoal or other cultural may be present in or around the rocks.

CAD See computer aided drafting.

C3 Plants A photosynthetic pathway that most trees and flowering bushes use to assimilate carbon dioxide into their systems. The average carbon isotope of $\mathrm{C} 3$ matter is $-26.5 \%$ with a range from about $-24.0 \%$ to $-34.0 \%$.

C4 Plants A photosynthetic pathway used by most xeric (arid) grasses and corn to assimilate carbon dioxide into their systems. The average carbon isotope of $\mathrm{C} 4$ matter is $-12.5 \%$ 
with a range of $-6 \%$ o to $-19 \%$. These plants are more resistant to water stress but more susceptible to cold temperatures.

CAM Plants A photosynthetic pathway for assimilating carbon dioxide into plants that can change from C3-like to C4-like plants depending on the diurnal (day/night) cycle. Most succulents such as cactus are CAM plants. The carbon isotope values of most CAM plants are similar to the values in $\mathrm{C} 4$ plants.

CD-ROM This is a compact disk programmed in a "read only" format. On the present project, the disk contains the entire archeological database with a "read-me" users' manual file.

Computer Aided Drafting

A method for drafting maps, features, and stratigraphic sketches using computers.

Cumulic Soil Soil that increases the thickness of its horizon components during part or all of its genesis and formation, which usually occurs by the slow deposition of additional sediments.

Curie Temperature

The temperature at which the magnetic properties of a substance change from ferromagnetic to paramagnetic.

Data Collector The electronic field notebook used with the total data station (TDS) mapping instrument.

Diatom Single-celled plankton or colonial algae, with silica cell walls, found in all bodies of water, damp habitats, and soils. Since different species have particular environmental requirements and tolerances, they are useful in reconstructing past environmental conditions.

\section{Desiccation Cracking}

This is the contraction upon drying of formerly saturated clay-rich sediments, thus causing regularly patterned visible cracks in the sediment.

Ditch Witch ${ }^{\mathrm{TM}}$ A mechanical excavating device that utilizes a rotating bucket system to dig and clear fill from trenches. The bucket widths may vary as may the actual size of the machines.

Douseman Flotation System

This is a top-of-the-line, commercially manufactured flotation device that allows for the separation and capture of heavy-fraction components (sands, flakes, stones etc.) and light-fraction components (roots, seeds, charcoal) of sediment or bulk matrix samples in a water environment agitated by air and/or water currents.

EDM An electronic distance measurement instrument. 
EDXA See ecologically diagnostic xylem analysis.

\section{Ecologically Diagnostic Xylem Analysis}

A method that measures the size and abundance of cells and other anatomical features that are visible in a transverse section of wood and/or wood charcoal. The documentation of differences in mesquite wood charcoal from different occupation periods provids information about varying moisture and temperature conditions.

Fatty Acids The major constituents of fats and oils (lipids) that occur in nature in plants and animals. Fatty acids may be absorbed into porous archaeological materials during cooking, including burned rocks and ceramics, or ground into manos, metates, or mortar holes.

Ferruginous Iron-containing materials. In the present study, the term refers to sandstone that has a ferruginous, or red, color.

Gas Chromatography

This highly technical measuring device separates and measures the amount of elemental components of a specific sample by the measurement of light passed through gas at regulated temperatures, which allows the detection of fatty acids at the nonogram level.

Glauconitic Sandstone

A quartz sandstone or an arkosic sandstone rich in a green mineral, closely related to mica called glauconite.

Gradall ${ }^{\mathrm{TM}} \quad$ A wheeled or tracked mechanical excavating vehicle that has an extending telescopic arm with an approximately $150 \mathrm{~cm}$ wide, straight edge bucket that can be tilted in all directions. The telescopic arm provides excellent control over the tilting bucket, which can precisely remove sediments and leave a smooth surface.

HCL Hydrochloric acid.

IFB Invitation for bids.

Legume A plant that produces a bean or seed pod vessel in various forms consisting of one cell and/or two valves. Common legume plants in South Texas include mesquite, Texas ebony, various acacia, Dalea $\mathrm{sp}$, mimosa, and rattlebush.

Mesic Condition

A relatively moist interval generally used in the context of climatic conditions.

Microwear The high-powered microscopic evidence on a stone tool that was created from longterm use. The wear may appear as striations, tiny nicks, polish, rounding, etc. The 
present study used magnification between $100 x$ and 500x to observe edge modification on each artifact.

Nunamiut A specific band of the Inuit people (formerly known as Eskimos).

Overbank Deposits

The deposition of fine silts and clay particles that are left on terrace tops and banks when water in creeks exceeds the capacity of the channel and drops the suspended sediments load in the lower energy environment. Overbank depositional processes usually cause minimal movement to large objects on the terrace top.

Pedogenesis The dynamic process of soil formation and development, which typically leads to the formation of a darkened, organic-rich A-horizon at or near the surface, and the downward movement of fine clays and/or the formation of carbonate nodules in lower B horizons.

Phytoliths Tiny microscopic silica particles that develop within most plants. Dissolved silica is transported into growing plants through water and then deposited along cell walls as silica particles. Different kinds of plants and different parts of a plant develop phytoliths of various shapes. After the plants die, the silica bodies become part of the mineral component of soils left in the ground.

Site Structure The spatial distribution of features, artifacts, and debris across an archeological site that is used to reconstruct manufacture, maintenance, processing, production, and disposal activities at specific loci, and the spatial ways prehistoric groups organized their space at a site.

Stereonet A two-dimensional, circular graphic representation of a three-dimensional vector of the earth's past magnetic polar position, which is used in the study of the archaeomagnetism of burned rocks. The 360 degrees of the circle represents the longitudinal position of the earth viewed relative to the axial pole with the circumference representing the equator. The relative distance from the center of the circle to the edge represents the latitude position of the paleomagnetic poles, as reflected by magnetic particles in the burned rock.

TDS See total data station.

TRM Thermoremanent magnetization is the remaining orientation of magnetic particles inside rocks that retains the orientation of the ambient (surrounding) magnetic field when the hot rock cooled. Since various forms of magnetic particles have different Curie temperatures (the temperature point where the magnetic properties of a mineral completely aligns to the ambient magnetic field), many rocks heated to low temperatures may retain a partial TRM signature.

Total Data Station 
An electronic mapping device used to collect/record data in three-dimensional space. This data can then be manipulated electronically to identify various aspects of the data.

Turbation Disturbance to the natural matrix deposits generally caused by biological (burrowing rodents, insects, worms, and plant roots) and natural (soil creep, dessication crack displacement, frost heaving, landslides, etc.) processes.

Ultraviolet Light

The wave length of light above that usually detected by the human eye that fluoresces various kinds of minerals and emits distinctive colors. On this project, a multiband light source (UV light 254/366 nm Model UVGl-55) was used to investigate the visual fluorescence of stone tools to identify their source.

Vector Component Diagram

A three-dimensional representation of thermal magnetization in a two-dimensional plane using a Cartesian coordinate system.

Xeric A period of dry or relatively arid condition generally used in conjunction with discussing climatic conditions. 
Intentionally Left Blank 


\section{APPENDIX A}

Radiocarbon Analyses by Beta Analytic Inc. 
Intentionally Left Blank 
BETA ANALYTIC INC.

DR. M.A. TAMERS and MR. D.G. HOOD
UNIVERSITY BRANCH

4985 S.W. 74 COURT

MAMI, FLORIDA, USA 33155

PH: 305/667-5167 FAX: 305/663-0964

E-MAIL: beta@radiocarbon.com

\section{REPORT OF RADIOCARBON DATING ANALYSES}

FOR: Dr. C. Britt Bousman

University of Texas at San Antonio
DATE RECEIVED: Aut $h$. July 16, 1997

DATE REPORTED: JulY 30, 1997

\begin{tabular}{rccc}
\hline Sample Data & $\begin{array}{c}\text { Measured } \\
\text { C14 Age }\end{array}$ & $\begin{array}{c}\text { C13/C12 } \\
\text { Ratio }\end{array}$ & $\begin{array}{c}\text { Conventional } \\
\text { C14 Age (*) }\end{array}$ \\
\hline Beta-106325 & $3220+/-50$ BP & $-23.30 / 00$ & $3240+/-50$ BP
\end{tabular}

SAMPLE \#: 41 WB437 Charcoal Sample 1 (BT1, $180 \mathrm{cmbs}$ )(F1) ANALYSIS: AMS (LLNL)

MATERIAL/PRETREATMENT : (charred material) : acid/alkali/acid

Beta-106327 $2110+/-40$ BP $-23.60 / 00 \quad 2130+/-40$ BP

SAMPLE \#: 41 WB437 Charcoal sample 3 (BT1, $80 \mathrm{cmbs}$ )(F6)

NALYSIS: AMS (LLNL)

TERIAL/PRETREATMENT: (charred material): acid/alkali/acid

NOTE: It is important to read the calendar calibration information and to use the calendar calibrated results (reported separately) when interpreting these results in $A D / B C$ terms.

\begin{tabular}{|c|c|}
\hline Fax Transmittal Memo & 4 of Pages 5 \\
\hline To: Mike Quige & From: JTA \\
\hline Co:i TRe mariant & Co.: TxDOT \\
\hline Dept.: & Phone \# 416-2758 \\
\hline Fax\# $329-8750$ & Fax\# \\
\hline
\end{tabular}

Dates are reported as RCYBP (radiocarbon years before present, "present" = 1950A.D.). By International convention, the modern. reference standard was $95 \%$ of the $C 14$ content of the National Bureau of Standards' Oxalle Acid \& calculated using the Libby C14 half life (5568 years). Quoted errors represent 1 standard deviation statistics ( $68 \%$ probability) \& are based on combined measurements of the sample, background, and modern reference standards.
Measured C13/C12 ratios were calculated relative to the PDB-1 International standard and the RCYBP ages were normalized to -25 per mil. If the ratio and age are accompanied by an ("), then the C13/C12 value was estimated, based on values typical of the materlal type. The quoted results are NOT calibrated to calendar years. Calibration to calendar years should be calculated using the Conventional C14 age. 


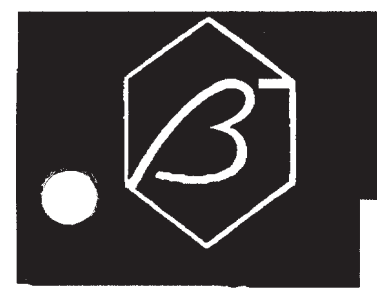

\section{BETA ANALYTIC INC.}

DR. M.A. TAMERS and MR. D.G. HOOD
UNIVERSITY BRANCH

4985 S.W. 74 COURT

MIAMI, FLORIDA, USA 33155

PH: 305/667-5167 FAX: 305/663-0964

E-MAIL: beta@radiocarbon.com

\section{REPORT OF RADIOCARBON DATING ANALYSES}

FOR: Dr. C. Britt Bousman

University of Texas at San Antonio
DATE RECEIVED: June 16, 1997

DATE REPORTED: JU1Y 14, 1997

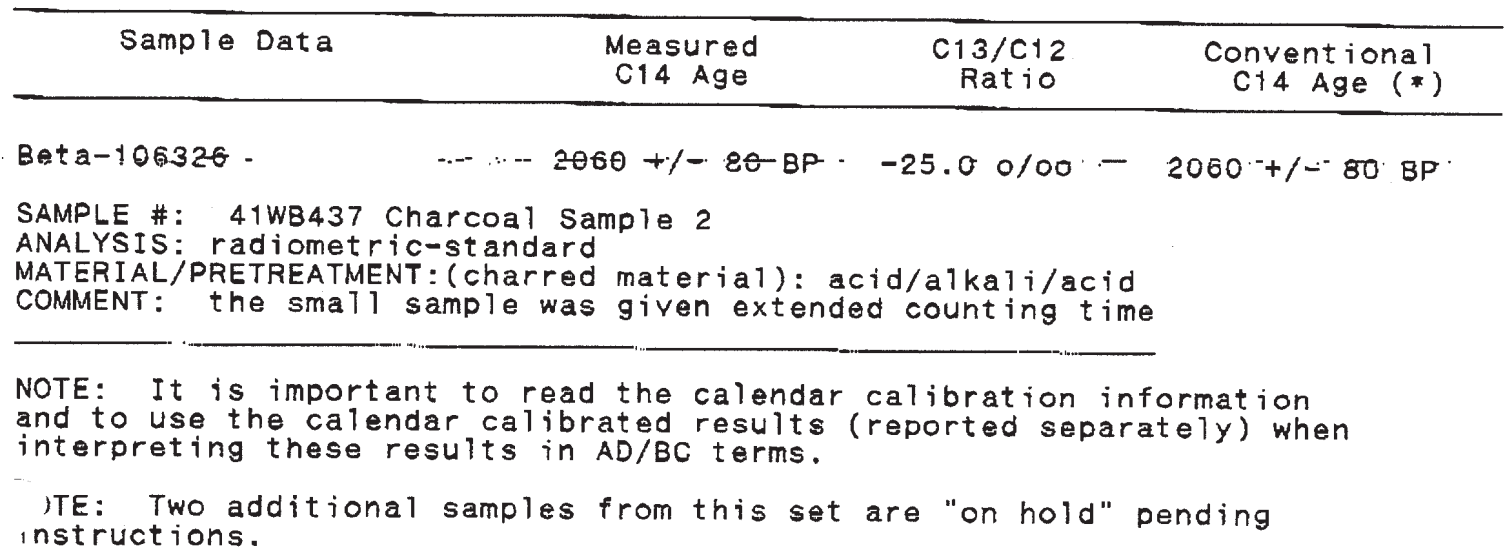

Dates are reported as RCYBP (radiocarbon years before present, "present" = 1950A.D.). By International convention, the modern reference standard was $95 \%$ of the C14 content of the National Bureau of Standards' Oxalic Acid \& calculated using the Libby C14 half life (5588 years). Quoted errors represent 1 standard deviation statistics ( $68 \%$ probability) \& are based on combined measurements of the sample, background, and modern reference standards.
Measured C13/C12 ratios were calculated relative to the PDB-1 international standard and the RCYBP ages were nomalized to -25 per mil. If the ratio and age are accompanied by an $\left({ }^{*}\right)$, then the C13/C12 value was estimated, based on values typical of the material type. The quoted results are NOT calibrated to calendar years. Calibration to calendar years should be calculated using the Conventional C14 age. 


\section{CALIBRATION OF RADIOCARBON AGE TO CALENDAR YEARS}

(Variables:C13/C12=-23.3:lab mult. $=1$ )

Laboratory Number: Beta-106325

\section{Conventional radiocarbon age: $\quad 3240 \pm 50 \mathrm{BP}$}

Calibrated results:

(2 sigma, 95\% probability)

cal BC 1620 to 1410

Intercept data:

Intercept of radiocarbon age with calibration curve:

cal BC 1505

1 sigma calibrated results:

cal BC 1530 to 1435

( $68 \%$ probability)

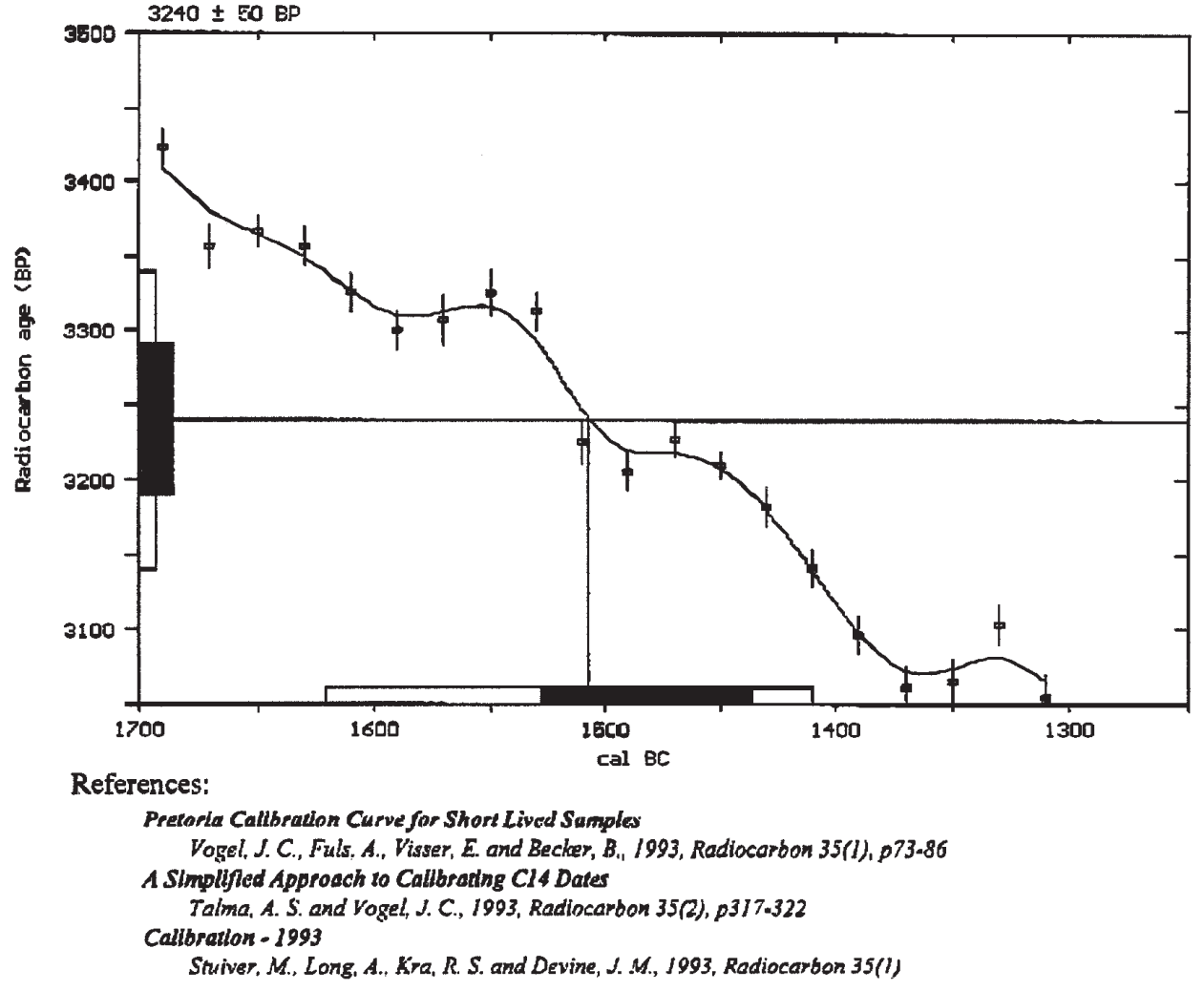

Beta Analytic Radiocarbon Dating Laboratory

4985 S.W.74th Courl, Miami, Florida 33155 = Tel: (305)667-5167. Fax: (305)663-0964 a E-mail: beta@radiocarbon.com 


\section{CALIBRATION OF RADIOCARBON AGE TO CALENDAR YEARS}

(Variables: $\mathrm{C} 13 / \mathrm{Cl2}=-25.0:$ lab. mult $=1$ )

Laboratory Number: Beta-106326

\section{Conventional radiocarbon age: $\quad 2060 \pm 80$ BP}

Calibrated results: Cal BC 350 to 300 and

(2 sigma, $95 \%$ probability) cal BC 215 to cal AD 110

\section{Intercept data:}

Intercept of radiocarbon age with calibration curve:

cal BC 45

1 sigma calibrated results: ( $68 \%$ probability)

cal BC 175 to cal $\mathrm{AD} 45$

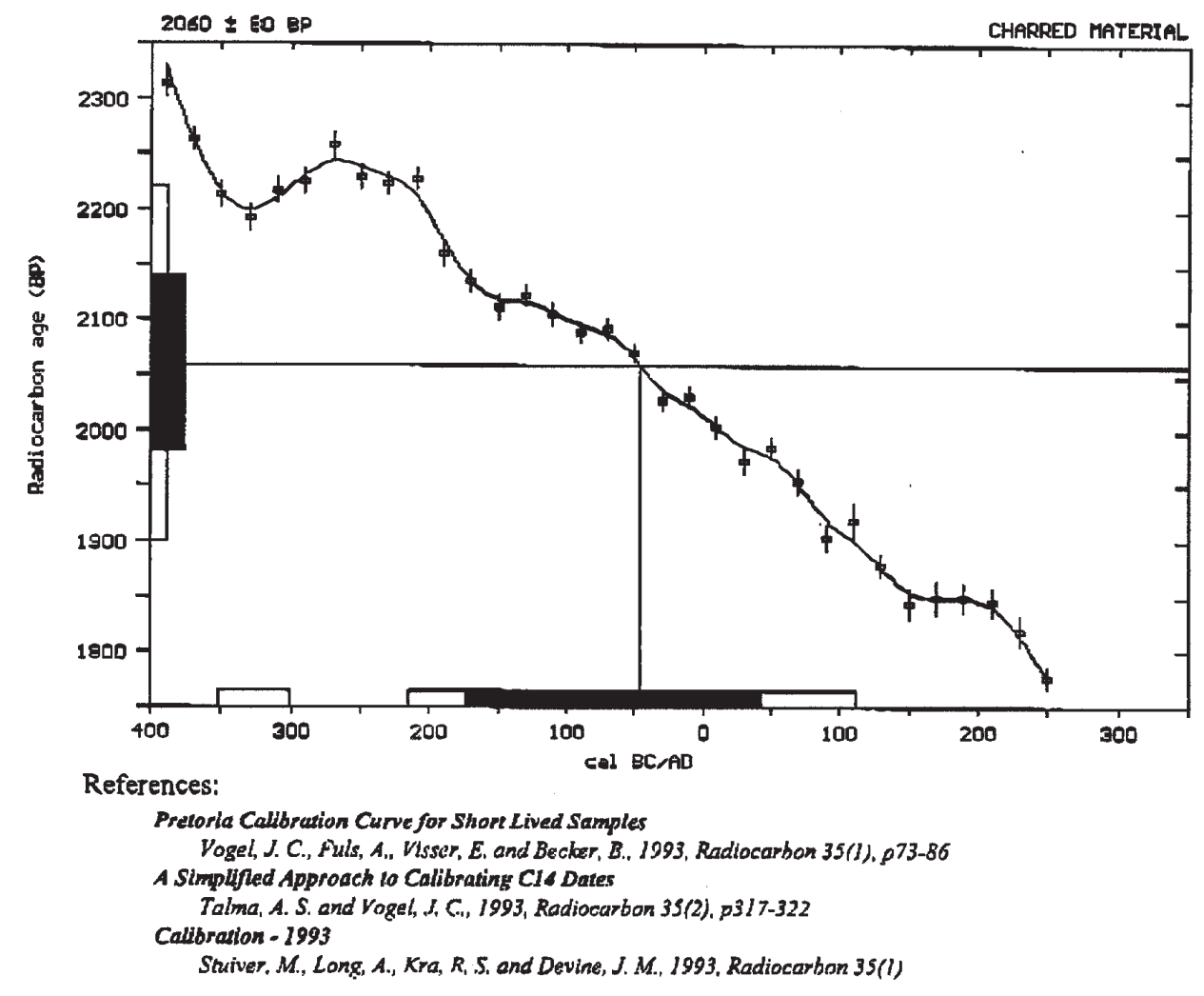

Beta Analytic Radiocarbon Dating Laboratory

4985 S.W. 74th Court, Miami, Florida 33155 . Tel: (305)667-5167 . Fax: (305)663-0964 E E-mail: beta@radiocarbon.com 


\section{CALIBRATION OF RADIOCARBON AGE TO CALENDAR YEARS}

(Variables:C13/C12=-23.6:lab mult. $=1$ )

Laboratory Number: Beta-106327

\section{Conventional radiocarbon age: $\quad 2130 \pm 40 \mathrm{BP}$ \\ Calibrated results: (2 sigma, 95\% probability) \\ cal BC 345 to 310 and cal BC 210 to 40}

Intercept data:

Intercept of radiocarbon age with calibration curve:

cal BC 165

1 sigma calibrated results: ( $68 \%$ probability)

cal BC 190 to 75

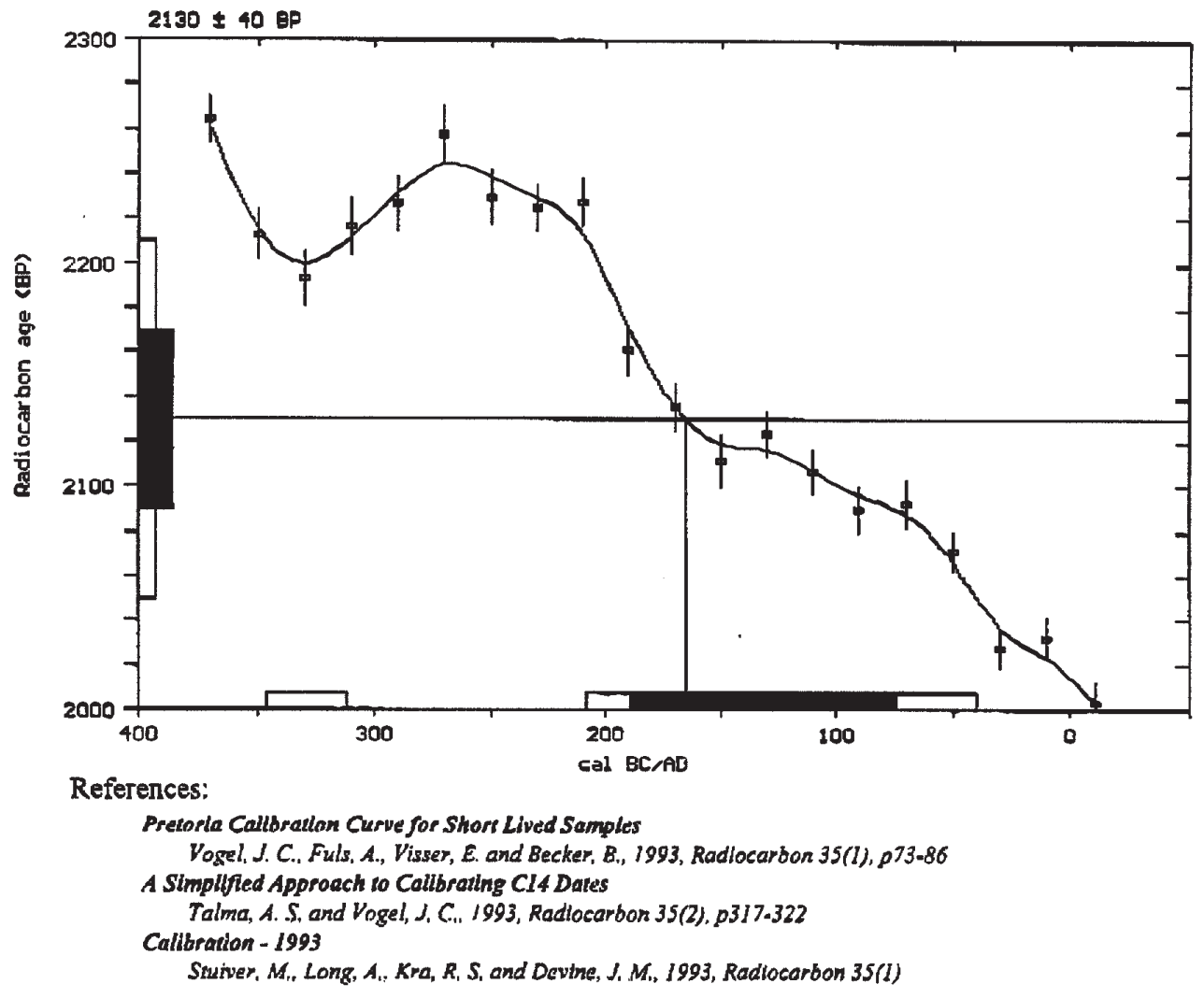

Beta Analytic Radiocarbon Dating Laboratory 4985 S.W. 74th Court, Miami, Florida 33155 . Tel: (305)667-5167 . Fax: (305)663-0964 I E-mail: beta@radiocarbon.com 


\section{BETA ANALYTIC INC.}

DR. M.A. TAMERS and MR. D.G. HOOD
UNIVERSITY BRANCH

4985 S.W. 74 COURT

MIAMI, FLORIDA, USA 33155

PH: 305/667-5167 FAX: 305/663-0964

E-MAIL: beta@radiocarbon.com

\section{REPORT OF RADIOCARBON DATING ANALYSES}

Dr. James Abbott

Texas Dept. of Transportation
August 31,1998

September 23, 1998

\begin{tabular}{rccc}
\hline Sample Data & $\begin{array}{c}\text { Measured } \\
\text { C14 Age }\end{array}$ & $\begin{array}{c}\text { C13/C12 } \\
\text { Ratio }\end{array}$ & $\begin{array}{c}\text { Conventional } \\
\text { C14 Age }(*)\end{array}$ \\
\hline Beta-121727 & $2100+/-40 \mathrm{BP}$ & $-23.60 / 00$ & $2120+/-40 \mathrm{BP}$
\end{tabular}

SAMPLE \#: WB437/586-a

ANALYSIS: Standard-AMS

MATERIAL/PRETREATMENT:(organic material): acid washes

Beta-121728

$2420+/-50$ BE $-21.90 / 00$

$2470+/-50 \mathrm{BP}$

SAMPLE \#: WB437/769-C

ANALYSIS: Standard-AMS

MATERIAL/PRETREATMENT:(organic material): acid washes

Beta-121729

$$
2130+1-40 \text { BP } \quad-25.0 \% / 00
$$

SAMPLE \#: WB437/1781-4

ANALYSIS: Standard-AMS

MATERIAL/PRETREATMENT:(charred material): acid/alkali/acid

Beta -121730

$$
1920+1-50 \mathrm{BP}
$$

$-23.0 \% / 00$

SAMPLE \#: WB437/1847-1

ANALYSIS: Standard-AMS

MATERIAL/PRETREATMENT:(charred material): acid/alkali/acid

NOTE: It is important to read the calendar calibration information and to use the calendar calibrated results (reported separately) when interpreting these results in $\mathrm{AD} / \mathrm{BC}$ terms.

Dates are reported as RCYBP (radiocarbon years betore present, "present" = 1950A.D.). By International convention, the modern reference standard was $95 \%$ of the $\mathrm{C} 14$ content of the National Bureau of Standards' Oxalic Acid \& calculated using the Libby C14 half life (5568 years). Quoted errors represent 1 standard deviation statistics ( $68 \%$ probability) \& are based on combined measurements of the sample, background, and modern reference standards.
Measured $\mathrm{C} 13 / \mathrm{C} 12$ ratios were carculated relative to the PDB-1 international standard and the RCYBP ages were normalized to -25 per mil. If the ratio and age are accompanied by an $\left(^{*}\right)$, then the $\mathrm{C} 13 / \mathrm{C} 12$ value was estimated, based on values typical of the material type. The quoted results are NOT calibrated to calendar years. Calibration to calendar years should be calculated using the Conventional $\mathrm{C} 14$ age. 


\section{CALIBRATION OF RADIOCARBON AGE TO CALENDAR YEARS}

(Variables:C13/C12=-23.6:lab mult. $=1$ )

Laboratory Number: Beta-121727

Conventional radiocarbon age: $\quad 2120 \pm 40 \mathrm{BP}$

Calibrated results: ( 2 sigma, $95 \%$ probability)

cal $B C 330$ to 330 and cal BC 205 to 35

Intercept data:

Intercept of radiocarbon age with calibration curve:

cal BC 150

1 sigma calibrated results: (68\% probability)

cal BC 185 to 60

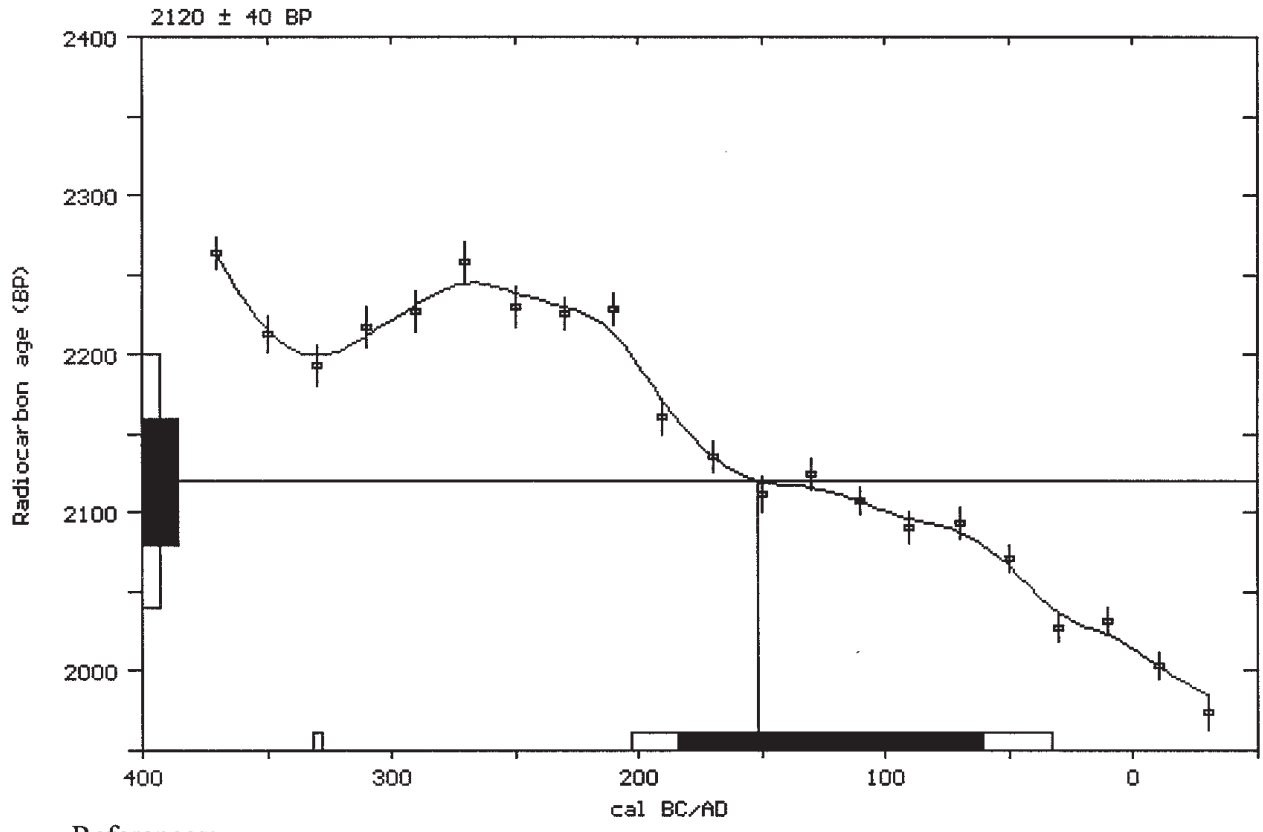

References:

Pretoria Calibration Curve for Short Lived Samples

Vogel, J. C., Fuls, A., Visser, E. and Becker, B., 1993, Radiocarbon 35(1), p73-86

A Simplified Approach to Calibrating C14 Dates.

Talma, A. S. and Vogel, J. C., 1993, Radiocarbon 35(2), p317-322

Calibration - 1993

Stuiver, M., Long, A., Kra, R. S. and Devine, J. M., 1993, Radiocarbon 35(I)

Beta Analytic Radiocarbon Dating Laboratory

4985 S.W. 74th Court, Miami, Florida 33155 m Tel: (305)667-5167 = Fax: (305)663-0964 - E-mail: beta@radiocarbon.com 


\title{
CALIBRATION OF RADIOCARBON AGE TO CALENDAR YEARS
}

\author{
(Variables:C13/C12=-21.9:lab mult. $=1$ ) \\ Laboratory Number: Beta-121728
}

Conventional radiocarbon age: $\quad 2470 \pm 50 \mathrm{BP}$

Calibrated results:

( 2 sigma, $95 \%$ probability)

cal BC 790 to 400

Intercept data:

Intercepts of radiocarbon age with calibration curve:

1 sigma calibrated results: (68\% probability)

cal BC 745 and cal BC 700 and cal BC 530

cal BC 770 to 415

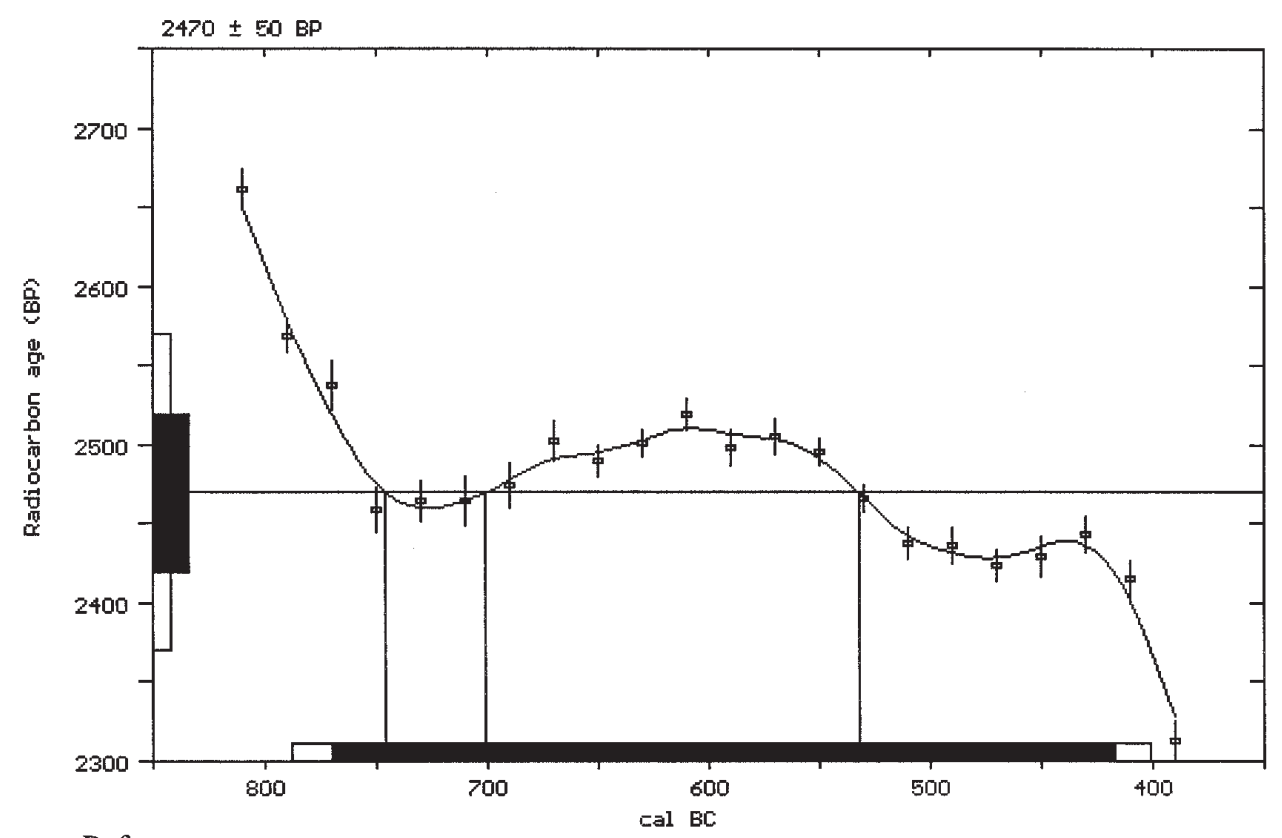

References:

Pretoria Calibration Curve for Short Lived Samples

Vogel, J. C., Fuls, A., Visser, E. and Becker, B., 1993, Radiocarbon 35(1), p73-86

A Simplified Approach to Calibrating C14 Dates

Talma, A. S. and Vogel, J. C., 1993, Radiocarbon 35(2), p317-322

Calibration - 1993

Stuiver, M., Long, A., Kra, R. S. and Devine, J. M., 1993, Radiocarbon 35(1)

\section{Beta Analytic Radiocarbon Dating Laboratory}

4985 S.W. 74th Court, Miami, Florida 33155 — Tel: (305)667-5167 — Fax: (305)663-0964 a E-mail: beta@radiocarbon.com 
CALIBRATION OF RADIOCARBON AGE TO CALENDAR YEARS

(Variables:C13/C12=-25:lab mult. $=1$ )

Laboratory Number: Beta-121729

\section{Conventional radiocarbon age: $\quad 2130 \pm 40 \mathrm{BP}$}

\section{Calibrated results: \\ ( 2 sigma, $95 \%$ probability) \\ cal $B C 345$ to 310 and \\ cal BC 210 to 40}

Intercept data:

Intercept of radiocarbon age

with calibration curve:

cal BC 165

1 sigma calibrated results:

(68\% probability)

cal BC 190 to 75

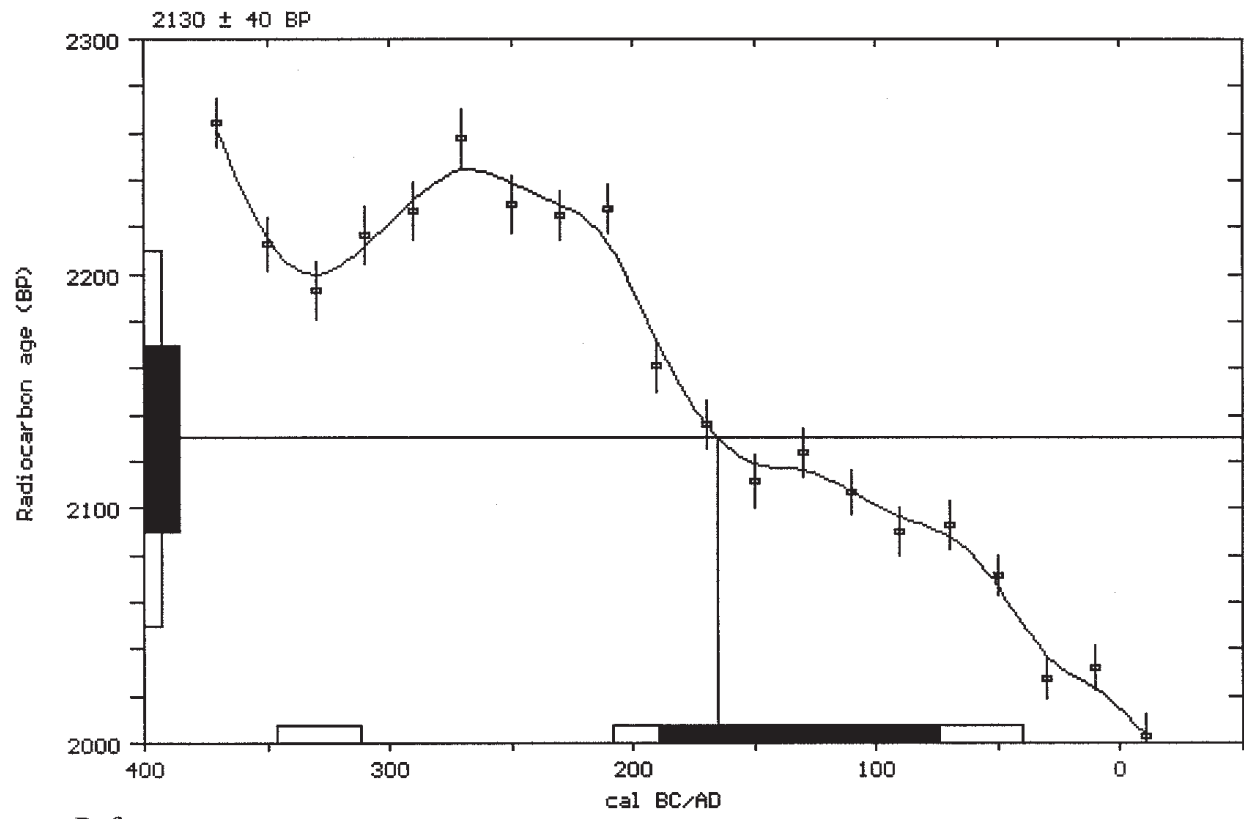

References:

Pretoria Calibration Curve for Short Lived Samples

Vogel, J. C., Fuls, A., Visser, E. and Becker, B., 1993, Radiocarbon 35(1), p73-86

A Simplified Approach to Calibrating C14 Dates

Talma, A. S. and Vogel, J. C., 1993, Radiocarbon 35(2), p317-322

Calibration - 1993

Stuiver, M., Long, A., Kra, R. S. and Devine, J. M., 1993, Radiocarbon 35(1)

\section{Beta Analytic Radiocarbon Dating Laboratory}

4985 S.W. 74th Court, Miami, Florida 33155 . Tel: (305)667-5167 — Fax: (305)663-0964 - E-mail: beta@radiocarbon.com 


\title{
CALIBRATION OF RADIOCARBON AGE TO CALENDAR YEARS
}

\author{
(Variables:C13/C12=-23:lab mult. $=1$ )
}

Laboratory Number: Beta-121730

Conventional radiocarbon age: $\quad 1950 \pm 50 \mathrm{BP}$

Calibrated results:

(2 sigma, 95\% probability)

\author{
cal BC 40 to cal AD 160
}

Intercept data:

Intercept of radiocarbon age with calibration curve:

cal AD 70

1 sigma calibrated results: (68\% probability)

cal AD 15 to 110

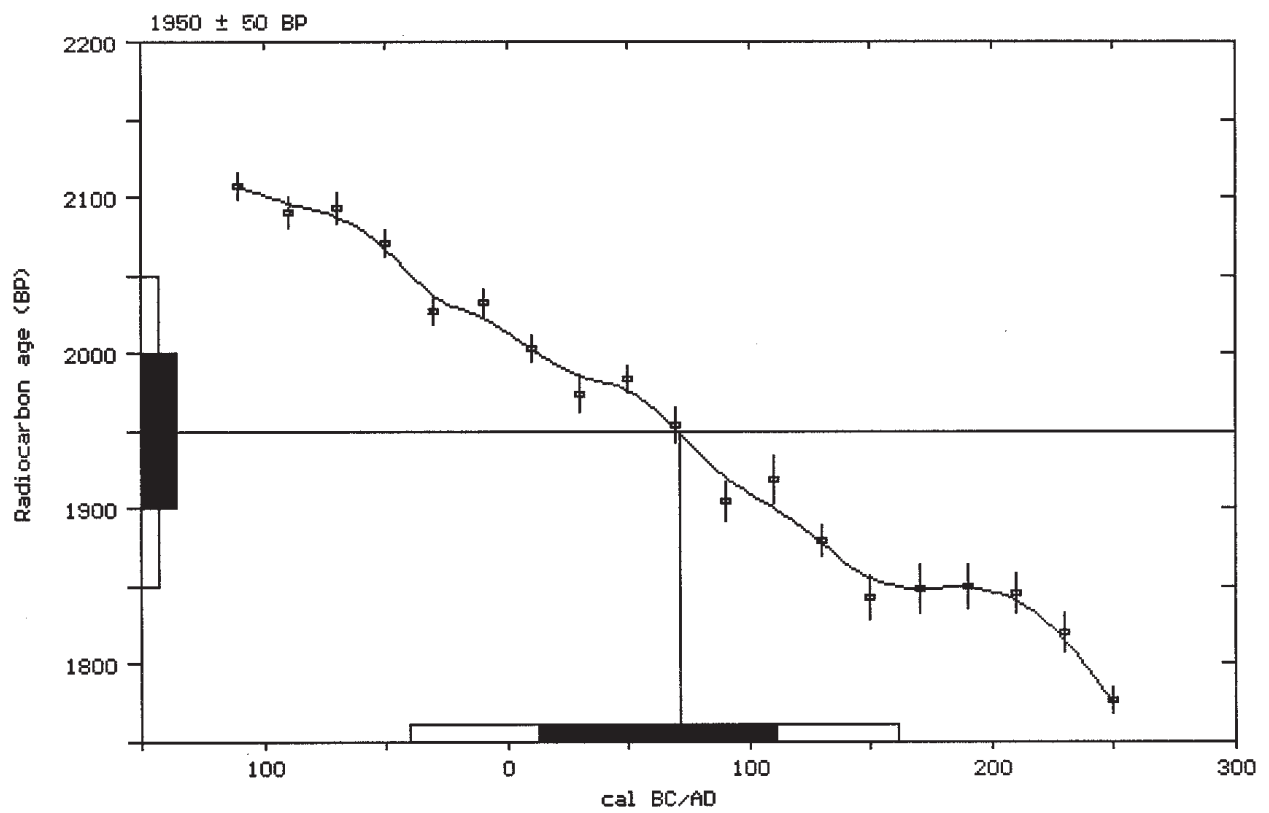

References:

Pretoria Calibration Curve for Short Lived Samples

Vogel, J. C., Fuls, A., Visser, E. and Becker, B., 1993, Radiocarbon 35(1), p73-86

A Simplified Approach to Calibrating C14 Dates

Talma, A. S. and Vogel, J. C., 1993, Radiocarbon 35(2), p317-322

Calibration - 1993

Stuiver, M., Long, A., Kra, R. S. and Devine, J. M., 1993, Radiocarbon 35(l)

\section{Beta Analytic Radiocarbon Dating Laboratory}

4985 S.W. 74th Court, Miami, Florida 33155 - Tel: (305)667-5167 - Fax: (305)663-0964 — E-mail: beta@radiocarbon.com 


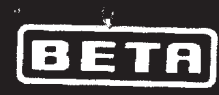 \\ BETA ANALYTIC INC. \\ DR. M.A. TAMERS and MR. D.G. HOOD \\ UNIVERSITY BRANCH \\ 4985 S.W. 74 COURT \\ MIAMI, FLORIDA, USA 33155 \\ PH: 305/667-5167 FAX: 305/663-0964 \\ E-MALL: beta@radiocarbon.com}

\section{REPORT OF RADIOCARBON DATING ANALYSES}

Dr. James Abbott

Texas Dept. of Transportation
September 2, 1998

october 10,1998

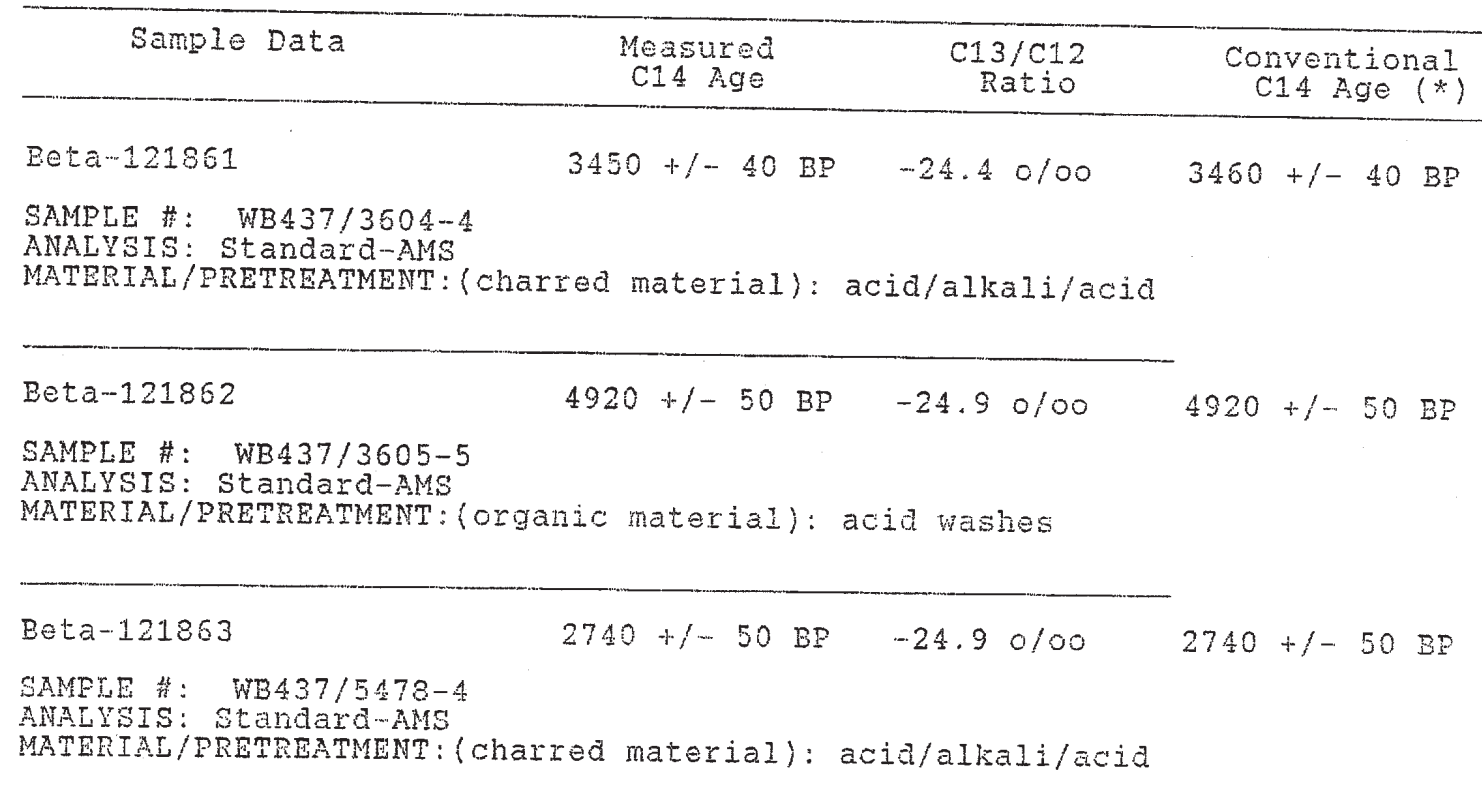

NoT: It is important to read the calendar calibration information and to use the calendar cal ibrated results (reported separately) when interpreting these results in AD/BC terms. Dates are reported as RCYBP (radlocarbon years before present,
"present" = 1950 A.D.). By International convention, the modern
reference standard was $95 \%$ of the C 14 content of the National
Bureau of Standards' Oxalic Acid \& calculated using the Libby C14
half life ( 5568 years). Quoted errors represent 1 standard deviation
statistics ( $68 \%$ probability) \& are based on combined measurements
of the sample, background, and modern reference standards.
Measured $\mathrm{C} 13 / \mathrm{C} 12$ ratios were calculated relative to the PDB-1 international standard and the RCYBP ages were normalized to -25 per mil. If the ratio and age are accompanied by an ("), then the $\mathrm{C} 13 / \mathrm{C}_{12}$ value was estimated, based on values typical of the material type. The quoted results are NOT calibrated to calendar years. Calibration to calendar years should be calculated using the Conventional $\mathrm{C} 14$ age. 


\title{
CALIBRATION OF RADIOCARBON AGE TO CALENDAR YEARS
}

\author{
(Variables: $\mathrm{C} 13 / \mathrm{C} 12=-24.4:$ lab mult. $=1$ ) \\ Laboratory Number: \\ Beta-121861 \\ Conventional radiocarbon age: \\ $3460 \pm 40 \mathrm{BP}$ \\ Calibrated results: \\ (2 sigma, 95\% probability) \\ cal BC 1885 to 1670
}

Intercept data:

Intercept of radiocarbon age with calibration curve:

cal BC 1750

1 sigma calibrated results:

(68\% probability)

cal BC 1860 to 1845 and

cal BC 1775 to 1705

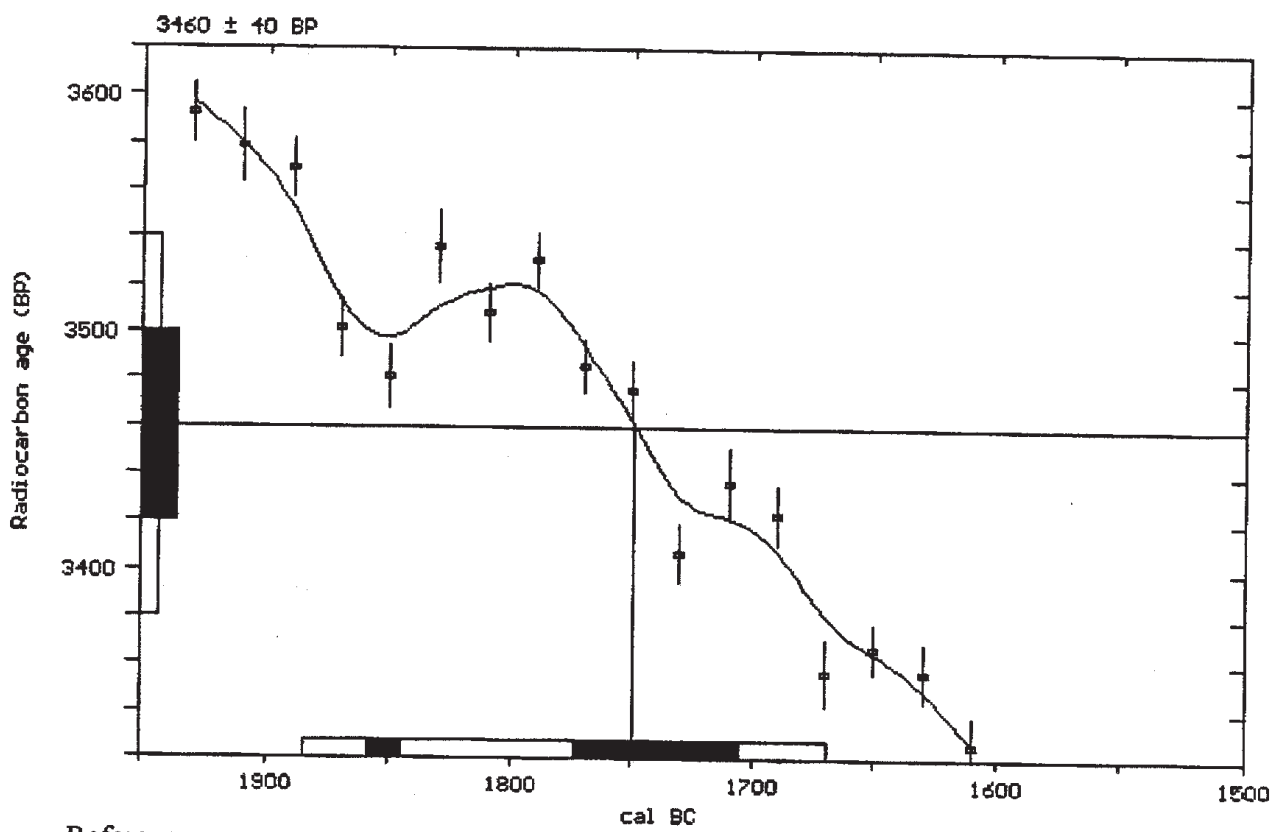

References:

Pretoria Calibration Curve for Short Lived Samples

Vogel, J. C., Fuls, A., Visser, E and Becker, B., 1993, Radiocarbon 35(I), p73-86

A Simplified Approach to Calibrating C14 Dates

Talma, A. S. and Vogel, J. C., 1993, Radiocarbon 35(2), p317-322

Calibration - 1993

Stuiver, M., Long, A, Kra, R S. and Devine, J. M., 1993. Radiocarbon 35(1)

Beta Analytic Radiocarbon Dating Laboratory
4985 S.W. 74 th Court, Miami, Florida $33155 \backsim$ Tel: $(305) 667-5167 \backsim$ Fax: $(305) 663-0964$ E-mail: beta@radiocarbon.com 


\section{CALIBRATION OF RADIOCARBON AGE TO CALENDAR YEARS}

(Variables:C13/C12=-24.9:lab mult. $=1$ )

Laboratory Number: Beta-121862

Conventional radiocarbon age: $4920 \pm 50 \mathrm{BP}$

Calibrated results: (2 sigma, 95\% probability)

cal BC 3790 to 3640

Intercept data:

Intercept of radiocarbon age with calibration curve:

cal BC 3695

1 sigma calibrated results: (68\% probability)

cal BC 3760 to 3655

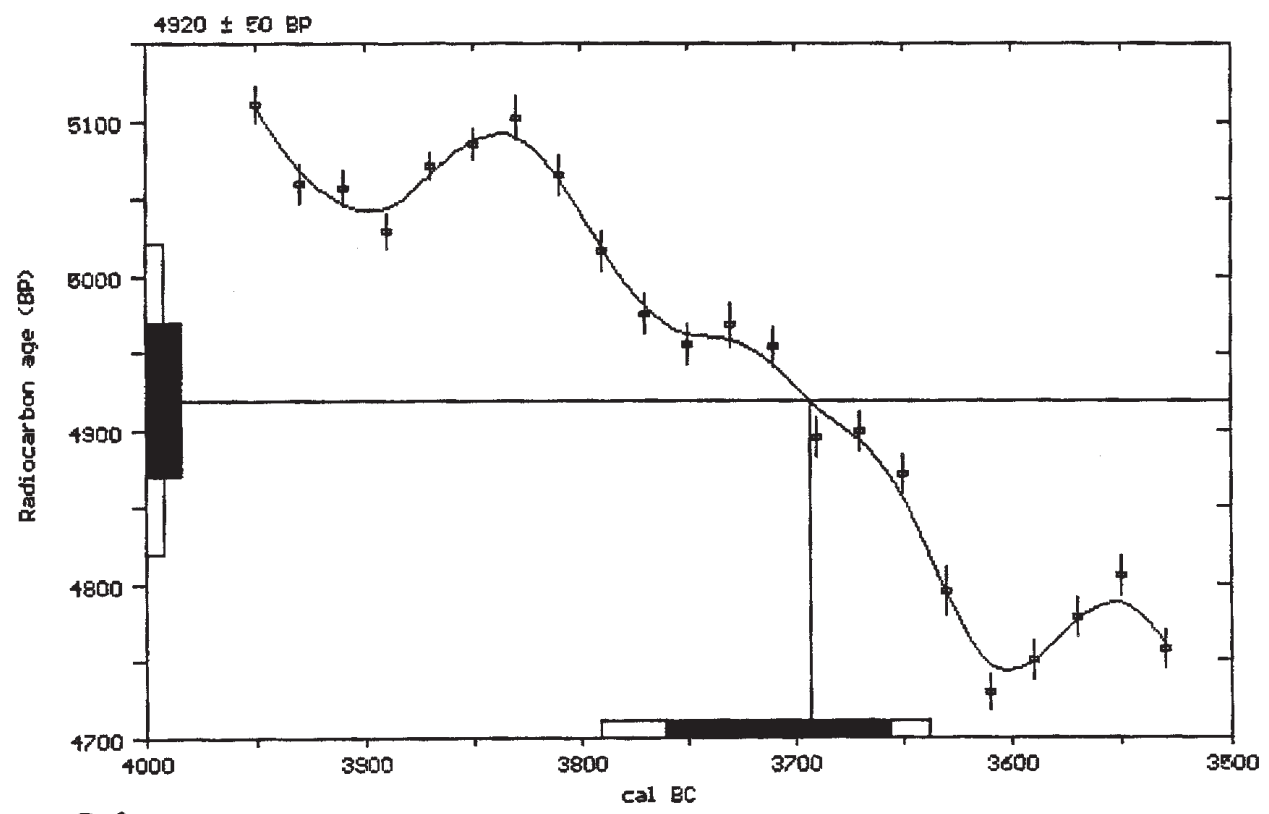

References:

Pretoria Calibration Curve for Short Lived Samples

Vogel, J. C., Fuls, A., Visser, E. and Becker, B., 1993, Radiocarbon 35(1), p73-86

A Simplified Approach to Calibrating C14 Dates

Talma, A. S. and Vogel, J. C., 1993, Radiocarbon 35(2), p317-322

Callbration - 1993

Stuiver, M., Long, A., Kra, R. S. and Devine, J. M., 1993, Radiocarbon 35(I)

\section{Beta Analytic Radiocarbon Dating Laboratory}

4985 S.W. 74th Court, Miami, Florida 33155 . Tel: (305)667-5167 = Fax: (305)663-0964 -E-mail: beta@radiocarbon.com 


\section{CALIBRATION OF RADIOCARBON AGE TO CALENDAR YEARS}

(Variables:C13/C12=-24.9:lab mult. $=1$ )

Laboratory Number: Beta-121863

Conventional radiocarbon age:

Calibrated results:

(2 sigma, 95\% probability)

Intercept data:

Intercept of radiocarbon age with calibration curve:

1 sigma calibrated results: (68\% probability)

$$
2740 \pm 50 \mathrm{BP}
$$

cal BC 990 to 805

cal BC 855

cal BC 915 to 825

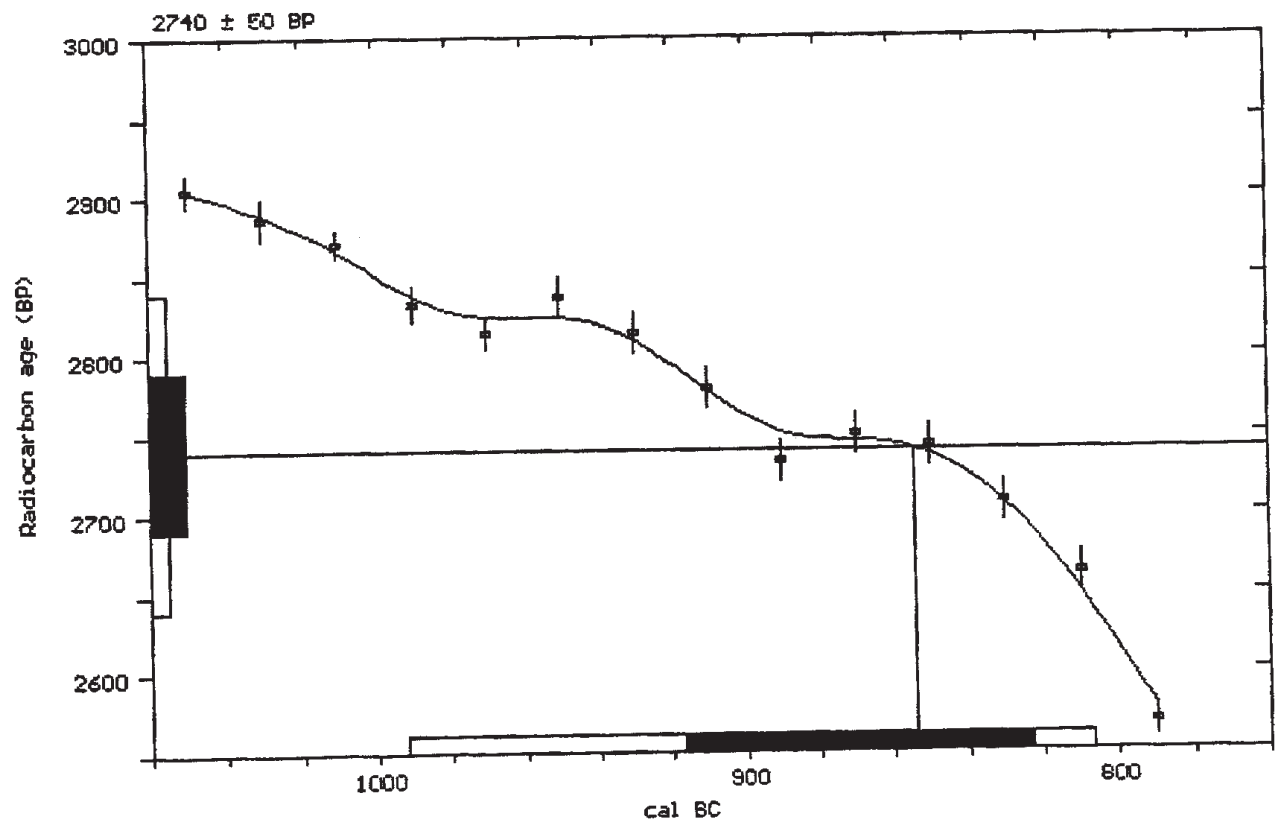

References:

Pretoria Calibration Curve for Short Lived Samples

Vogel, J. C., Fuls, A., Visser, E. and Becker, B., 1993, Radiocarbon 35(1), p73-86

A Simplifted Approach to Calibrating C14 Dates

Talma, A. S. and Vogel, J. C., 1993, Radiocarbon 35(2), p317-322

Calibration - 1993

Stuiver, M., Long, A., Kra, R. S. and Devine, J. M., 1993, Radiocarbon 35(I)

\section{Beta Analytic Radiocarbon Dating Laboratory}

4985 S.W. 74th Court, Miami, Florida $33155 \backsim$ Tel: (305)667-5167 Fax: (305)663-0964 E-mail: beta@radiocarbon.com 


\section{BETA BETA ANALYTIC INC.}

DR. M.A. TAMERS and MR. D.G. HOOD

UNIVERSITY BRANCH

4985 S.W. 74 COURT

MIAMI, FLORIDA, USA 33155

PH: 305/667-5167 FAX: 305/663-0964

E-MAIL: beta@radiocarbon.com

\section{REPORT OF RADIOCARBON DATING ANALYSES}

Dr. James Abbott

September 28, 1998

Texas Dept, of Transportation

October 23,1998

\begin{tabular}{lccc}
\hline \multicolumn{1}{c}{ Sample Data } & $\begin{array}{c}\text { Measured } \\
\text { C14 Age }\end{array}$ & $\begin{array}{c}\text { C13/C12 } \\
\text { Ratio }\end{array}$ & $\begin{array}{c}\text { Conventional } \\
\text { C14 Age (*) }\end{array}$ \\
\hline $\begin{array}{l}\text { Beta-122719 } \\
\text { SAMPLE \#: WB437/5377-2C }\end{array}$ & $1590+/-50 \mathrm{BP}+2.30 / 00$ & $2040+/-50 \mathrm{BP}$ \\
ANALYSIS: Standard-AMS \\
MATERIAL/PRETREATMENT: (shell): none
\end{tabular}

Beta-122720

$1350+/-40$ BP $-1.10 / 00$

$1740+/-40 \mathrm{BP}$

SAMPLE \#: WB437/5377-2d

ANALYSIS: Standard-AMS

MATERIAL/PRETREATMENT:(shell): none

NOTE: It is important to read the calendar calibration information and to use the calendar calibrated results (reported separately) when interpreting these results in $\mathrm{AD} / \mathrm{BC}$ terms.

Dates are reported as RCYBP (radiocarbon years before present, "present" = 1950A.D.). By International convention, the modern reference standard was $95 \%$ of the $\mathrm{C} 14$ content of the National Bureau of Standards' Oxalic Acid \& calculated using the Libby $\mathrm{C} 14$ half life (5568 years). Quoted errors represent 1 standard deviation statistics (68\% probability) \& are based on combined measurements of the sample, background, and modern reference standards.
Measured $\mathrm{C} 13 / \mathrm{C} 12$ ratios were calculated relative to the $\mathrm{PDB}-1$ international standard and the RCYBP ages were normalized to -25 per mil. If the ratlo and age are accompanied by an $\left({ }^{\star}\right)$, then the C13/C12 value was estimated, based on values typical of the material type. The quoted results are NOT calibrated to calendar years. Calibration to calendar years should be calculated using the Conventional C14 age. 


\section{CALIBRATION OF RADIOCARBON AGE TO CALENDAR YEARS}

(Variables:C13/C12=2.3:Delta-R=0 $\pm 0:$ Global res $=-200-500: 1$ ab mult. $=1$ )

Laboratory Number: Beta-122719

\section{Conventional radiocarbon age: $\quad 2040 \pm 50 \mathrm{BP}$ \\ (local reservoir correction not applied)}

\section{Calibrated results: \\ (2 sigma, 95\% probability) \\ cal AD 240 to 465}

Intercept data:

Intercept of radiocarbon age with calibration curve:

cal AD 370

1 sigma calibrated results: ( $68 \%$ probability)

cal AD 290 to 420

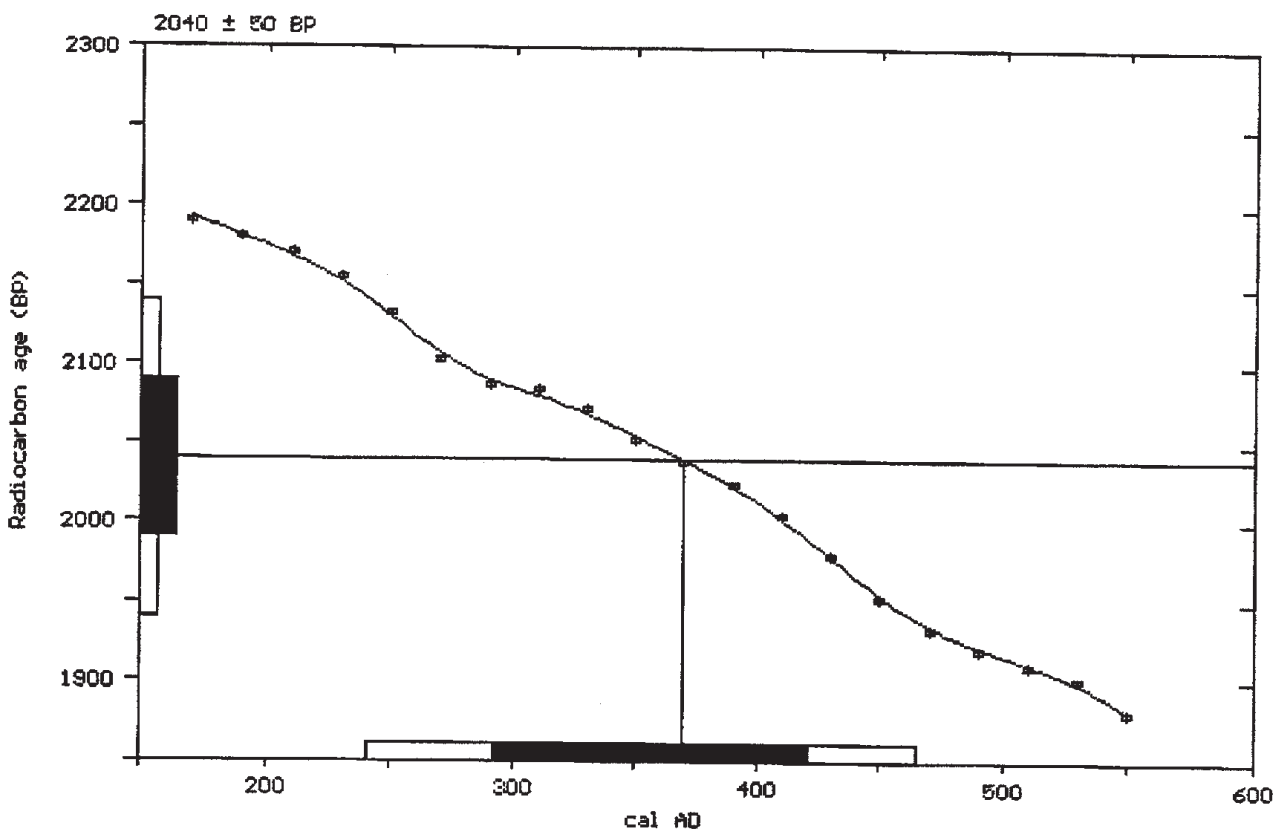

References:

Pretoria Calibration Curve for Short Lived Samples

Vogel, J. C., Fuls, A., Visser, E. and Becker, B., 1993, Radiocarbon 35(1), p73-86

A Simplified Approach to Calibrating C14 Dates

Talma, A. S. and Vogel, J. C., 1993, Radiocarbon 35(2), p317-322

Culibration -1993

Stuiver, M., Long, A., Kra, R. S. and Devine, J. M., 1993, Radiocarbon 35(I)

\section{Beta Analytic Radiocarbon Dating Laboratory}

4985 S.W. 74th Court, Miami, Florida 33155 - Tel: (305)667-5167 a Fax: (305)663-0964 E-mail: beta@radiocarbon.com 


\section{CALIBRATION OF RADIOCARBON AGE TO CALENDAR YEARS}

(Variables:C13/C12=-1.1:Delta-R=0 $\pm 0:$ Global res $=-200-500: 1 \mathrm{ab}$ mult. $=1$ )

Laboratory Number: Beta-122720
Conventional radiocarbon age: $\quad 1740 \pm 40 \mathrm{BP}$
(local reservoir correction not applied)

Calibrated results:

(2 sigma, 95\% probability)

cal AD 615 to 730

Intercept data:

Intercept of radiocarbon age with calibration curve:

cal $\mathrm{AD} 670$

1 sigma calibrated results: ( $68 \%$ probability)

cal AD 650 to 695

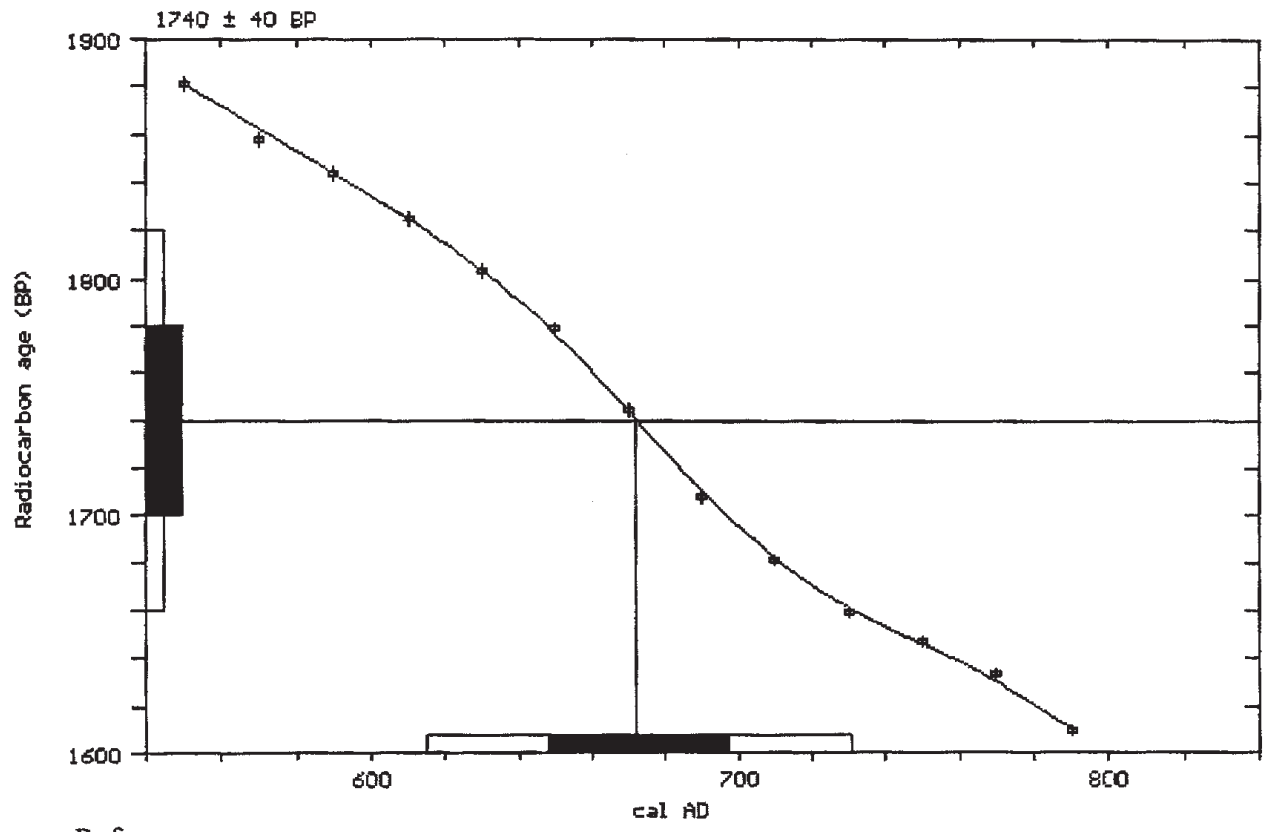

References:

Pretoria Calibration Curve for Short Lived Samples

Vogel, J. C., Fuls, A., Visser, E. and Becker, B., 1993, Radiocarbon 35(1), p73-86

A Simplified Approach to Calibrating C14 Dates

Talma, A. S. and Vogel, J. C., 1993, Radiocarbon 35(2), p317-322

Calibration - 1993

Stuiver, M., Long, A., Kra, R. S. and Devine, J. M., 1993, Radiocarbon 35(1)

\section{Beta Analytic Radiocarbon Dating Laboratory}

4985 S.W. 74th Court, Miami, Florida 33155 - Tel: (305)667-5167 a Fax: (305)663-0964 E-mail: beta@radiocarbon.com 


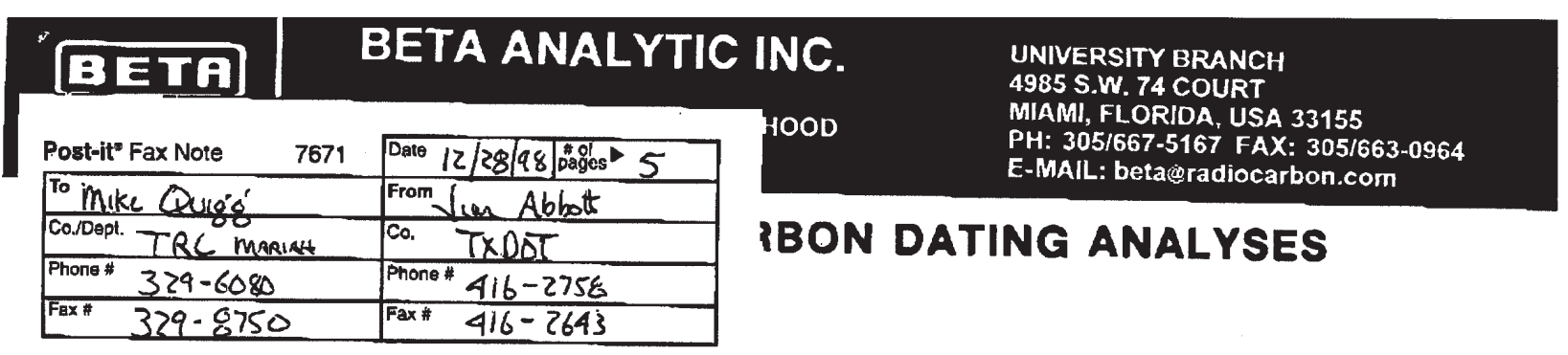

Dr. James Abbott

Texas Dept. of Transportation

Novmeber 13,1998

December 19,1998

\begin{tabular}{lccc}
\hline \multicolumn{1}{c}{ Sample Data } & $\begin{array}{c}\text { Measured } \\
\text { C14 Age }\end{array}$ & $\begin{array}{c}\text { C13/C12 } \\
\text { Ratio }\end{array}$ & $\begin{array}{c}\text { Conventional } \\
\text { C14 Age (*) }\end{array}$ \\
\hline Beta-124388 & $3200+1-50$ BP & $-25.70 / 00$ & $3190+/-50$ BP \\
SAMPLE \#: WB437/703A & & & \\
ANALYSIS: Standard-AMS \\
MATERIAL/PRETREATMENT: (organic material): acid washes
\end{tabular}

Beta-124389 $2220+/-60$ BP $-20.50 / 00 \quad 2290+/-60$ BP

SAMPLE \#: WB437/705A

ANALYSIS: Standard-AMS

MATERIAL/PRETREATMENT: (organic material): acid washes

Beta-124390 $840+/-50 \mathrm{BP} \quad-21.20 / 00 \quad 900+/-50 \mathrm{BP}$

SAMPLE \#: WB437/5455/4a

ANALYSIS: Standard-AMS

MATERIAL/PRETREATMENT: (charred material): acid/alkali/acid

Beta-124391

$3040+1-60$

$-23.70 / 00$

$3060+/-60 \mathrm{BP}$

SAMPLE \#: WB $437 / 5167 / 4$

ANALYSIS: Standard-AMS

MATERIAL/PRETREATMENT: (charred material) : acid/alkali/acid

NOTE: It is important to read the calendar calibration information and to use the calendar calibrated results (reported separately) when interpreting these results in $A D / B C$ terms.

Dates are reported as RCYBP (radiocarbon years before present, "present" = 1950A.D.). By international convention, the modern reference standard was $95 \%$ of the $C_{14}$ content of the National Bureau of Standards' Oxalic Acid \& calculated using the Libby C14 half life ( 5568 years). Quoted errors represent 1 standard deviation statistics ( $68 \%$ probability) \& are based on combined measurements of the sample, background, and modern reference standards.
Measured $\mathrm{C}_{13 / \mathrm{C} 12}$ ratios were calculated relative to the PDB-1 International standard and the RCYBP ages were normalized to -25 per mil. If the ratio and age are accompanied by an ("), then the C13/C12 value was estimated, based on values typical of the material type. The quoted results are NOT calibrated to calendar years. Calibration to calendar years should be calculated using the Conventional $\mathrm{C} 14$ age. 


\section{CALIBRATION OF RADIOCARBON AGE TO CALENDAR YEARS}

(Variables:C13/C12=-25.7:lab mult. $=1$ )

Laboratory Number: Beta-124388

\section{Conventional radiocarbon age: $\quad 3190 \pm 50 \mathrm{BP}$}

Calibrated results: (2 sigma, 95\% probability)

cal BC 1530 to 1385

Intercept data:

Intercept of radiocarbon age with calibration curve:

cal BC 1435

1 sigma calibrated results: (68\% probability)

cal BC 1505 to 1410

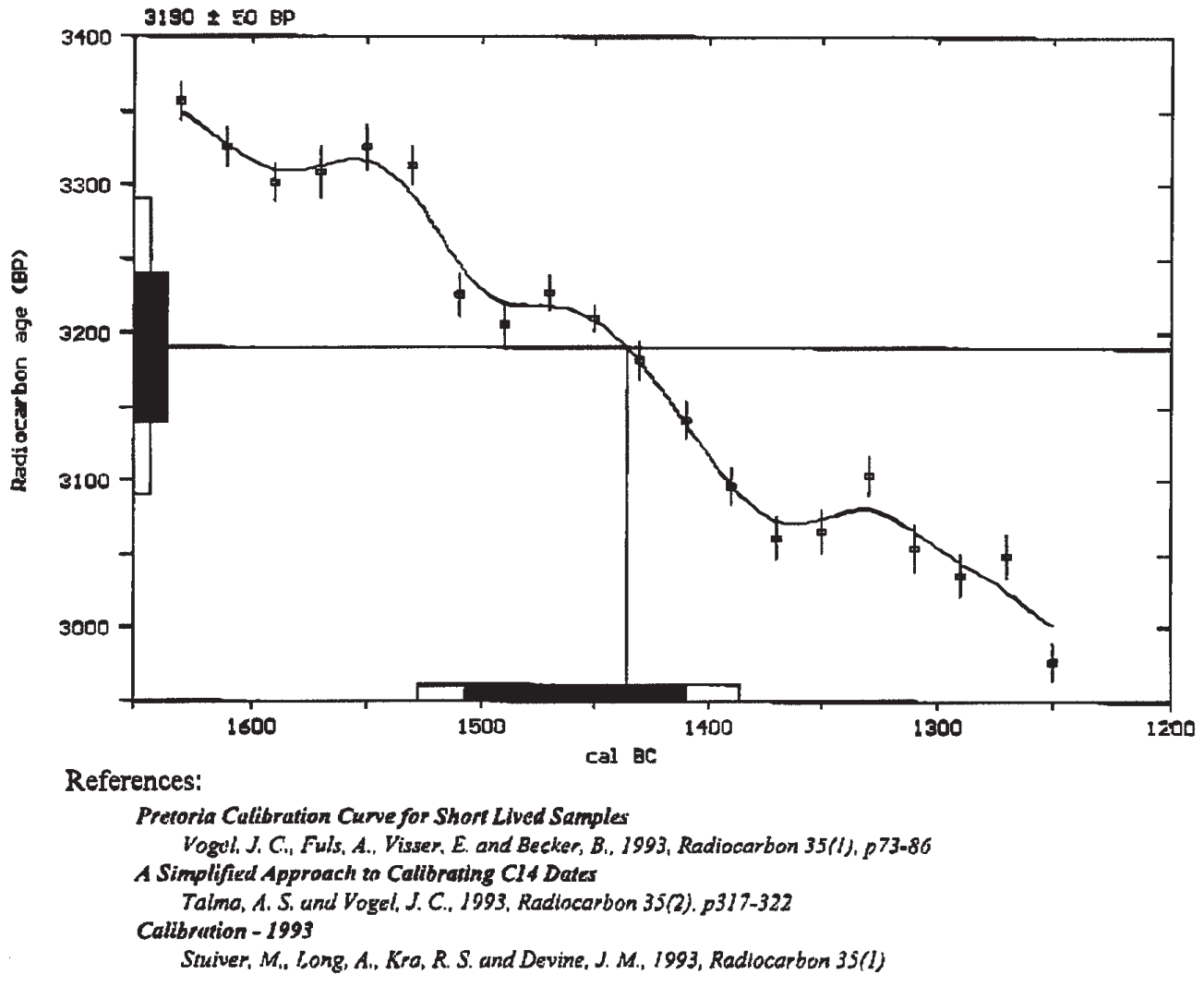

Beta Analytic Radiocarbon Dating Laboratory 4985 S.W. 74th Court, Miami, Florida 33155 a Tel: (305)667-5167 a Fax: (305)663-0964 a E-mail: beta@iadradiocurbon.com 


\section{CALIBRATION OF RADIOCARBON AGE TO CALENDAR YEARS}

\begin{tabular}{cl}
\multicolumn{2}{c}{ (Variables:C13/C12 $=-20.5$ :lab mult.=1) } \\
Laboratory Number: & Beta-124389 \\
Conventional radiocarbon age: & $2290 \pm 60 \mathrm{BP}$ \\
Calibrated results: & cal BC 415 to 190 \\
(2 sigma, 95\% probability) &
\end{tabular}

Intercept data:

Intercept of radiocarbon age with calibration curve:

cal BC 380

1 sigma calibrated results: (68\% probability)

cal BC 395 to 355 and cal BC 290 to 230

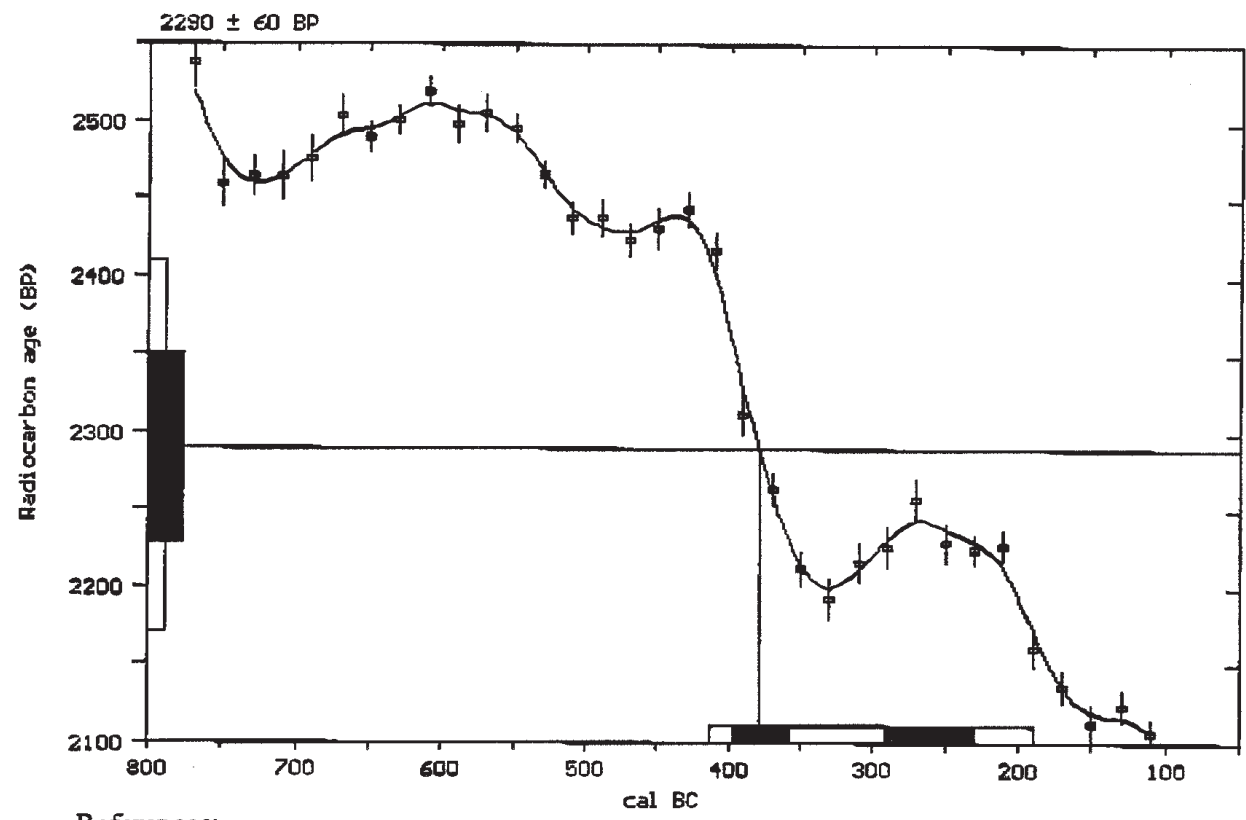

References:

Pretoria Callbration Curve for Shon Lived Samples Vogel, J. C... Fuls, A., Visser. E. and Becker, B., 1993. Radiocarbon 35(1), p73-86 A Slmpllfied Approuch to Calibrating CI4 Datus

Talma, A. S. and Vogel, S. C., 1993. Radiocarbon 35(2), p3I7.322

Calibration -1993

Shiver, M.. Long, A., Kra, R. S, and Devine, J. M., 1993, Radiocarbon 35(l)

\section{Beta Analytic Radiocarbon Dating Laboratory \\ 4985 S.W.74th Court, Miami, Florida 33155 . Tel: (305)667-5167 . Fax: (305)663-0964 a E-mail: beta@radiocarbon.com}




\section{CALIBRATION OF RADIOCARBON AGE TO CALENDAR YEARS}

(Variables: $\mathrm{C} 13 / \mathrm{C} 12=-21.2:$ lab mult. $=1$ )

Laboratory Number: Beta-124390

Conventional radiocarbon age: $\quad 900 \pm 50 \mathrm{BP}$

Calibrated results:

(2 sigma, $95 \%$ probability)

cal $\mathrm{AD} 1020$ to 1250

Intercept data:

Intercept of radiocarbon age with calibration curve:

cal AD 1170

1 sigma calibrated results: (68\% probability)

cal AD 1040 to 1215

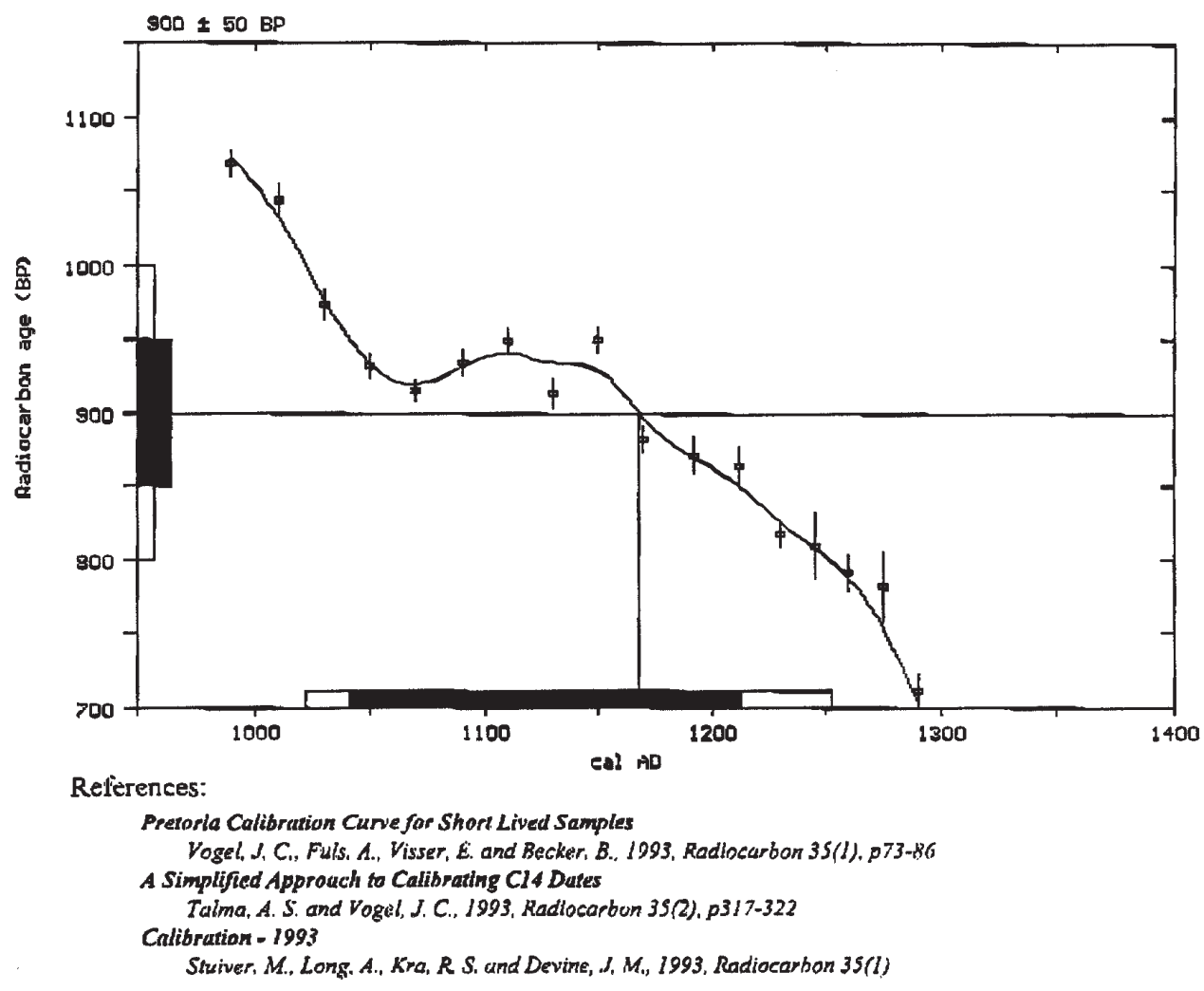

Beta Analytic Radiocarbon Dating Laboratory

4985 S.W. 74th Court, Miami, Florida 33155 . Tel: (305)667.5167 — Fax: (305)663-0964 E-mail: beta@radiocarbon,com 


\section{CALIBRATION OF RADIOCARBON AGE TO CALENDAR YEARS}

(Variables: $\mathrm{C} 13 / \mathrm{C} 12=-23.7: \mathrm{lab}$ mult. $=1$ )

Laboratory Number: Beta-124391

Conventional radiocarbon age: $\quad 3060 \pm 60 \mathrm{BP}$

Calibrated results:

(2 sigma, 95\% probability)

cal BC 1430 to 1130

Intercept data:

Intercept of radiocarbon age with calibration curve:

cal BC 1305

1 sigma calibrated results: (68\% probability)

cal BC 1400 to 1250

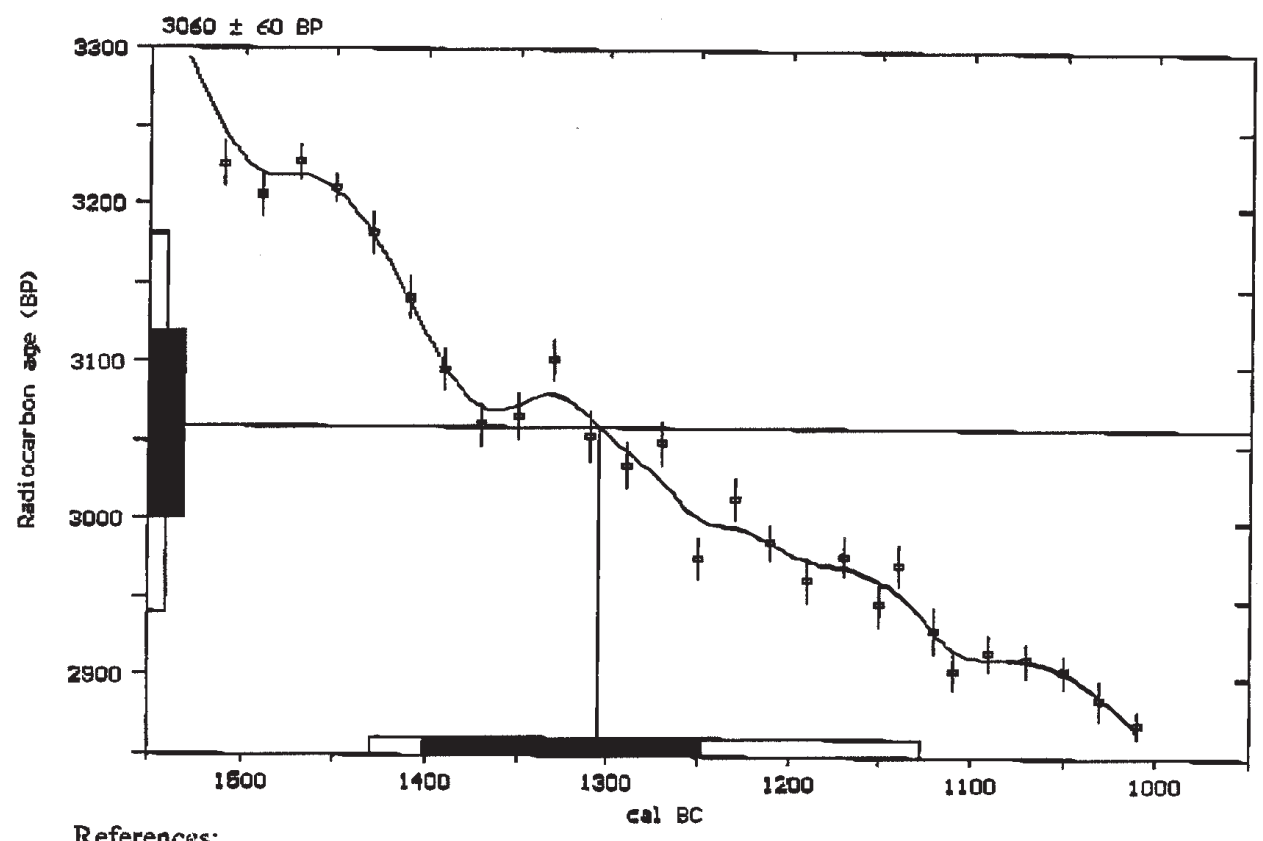

References:

Pretoria Callbration Curve for Short Llved Sampler

Vogel, J. C. Fuls, A., Visser, E. and Becker, B., 1993, Radiocarbon 35(1), p73.86

A Simplified Appronch to Culihrating CI4 Dutes

Tolma, A. S. and Vogel, J. C., 1993, Redlocurbon 39(2), p317.322

Calibration - 1993

Stulver, M., Long. A, Kra, R. S. and Devine, J. M., 1993, Radiocarbon 35(I)

\section{Beta Analytic Radiocarbon Dating Laboratory \\ 49,85 S.W. 74th Courh, Miami, Floride 33155 - Tel: (305)667-5167 . Fax: (305)663-0964 - E-mail: beta@radiocarbon.com}




\section{APPENDIX B}

Macrobotanical Analyses by J. Philip Dering 
Intentionally Left Blank 


\title{
Identification of Carbonized Plant Remains and EDXA Studies of Mesquite Wood from 41WB347 Using Scanning Electron Microscopy
}

\author{
Phil Dering \\ Center for Ecological Archaeology \\ Texas A\&M University \\ College Station, TX 77843-4352
}

February, 1999 


\section{List of Figures}

Figure 1 Transverse Section of Honey Mesquite Charcoal (Sample 3080).

Figure 2 Tangential Section of Honey Mesquite Charcoal (Sample 4125).

Figure 3 Transverse Section of Honey Mesquite Charcoal (Sample 5114-7).

\section{List of Tables}

Table 1. Macroplant Sample Identifications.

Table 2. EDXA Measurements of Charred Mesquite Wood: References Samples and Archaeological Samples from 41WB437 


\section{Identification of Carbonized Plant Remains and EDXA Studies Using Scanning Electron Microscopy from 41 WB347}

Twelve samples of carbonized plant remains were submitted to the Archaeobotany Laboratory of the Center for Ecological Archaeology for identification. The purpose of this analysis is to identify the fuel woods and any plant foods that may be present in the archaeological assemblage. In addition, a large sample of carbonized wood was submitted for characterization with an electron microscope. Scanning electron microscopy is used to characterize the size and density of anatomical characters of the charred wood in order to establish a proxy data base for inferring paleoclimatic conditions. Twenty of these samples were investigated and characterized.

Changing climatic conditions affect the size and character of xylem tissue in certain woods. With a drop in effective moisture, the density of vessel elements increases and the diameter of vessel elements decreases in the wood of certain species. Wood charcoal, therefore, has the potential to become a proxy measure of climatic change. Studies of wood charcoal taxonomic frequencies and anatomical change in South Africa have been able to identify climatic trends over the last 10,000 years (Prior, 1988; Prior and Price-Williams 1985:472; Scholtz 1986).

\section{Methods}

\section{Wood Charcoal Identification}

Each charcoal fragment was fractured after scoring. All specimens were first examined using a Nikon dissecting scope at magnifications varying from $8 \mathrm{X}$ to $45 \mathrm{X}$. Preliminary identifications were assigned to each specimen, primarily on the basis of its transverse anatomy. Specimens that exhibited adequate diagnostic features were selected for further study. Each specimen had to possess both early and/or late-wood pores and parenchyma, and more than one annual growth ring in transverse section.

Each specimen was assigned to a taxonomic category based on anatomical characteristics observed in the transverse, radial, and tangential sections of the carbonized wood. The accuracy and the taxonomic level of each identification is dependent on the size, condition, and abundance of diagnostic characters each specimen possesses. In a small, weathered assemblage, the degree of success in identification is quite variable, as illustrated in Table 1. Many charred wood fragments are not identifiable because they are too small, or the anatomical structure has been destroyed by biological or mechanical degradation. Biological degradation, especially if it is caused by insects or fungi, is often noted in the charred wood of an archaeological assemblage. Wood affected by these processes often lacks structure or diagnostic elements and is placed in a category termed indeterminate.

\section{Ecologically Diagnostic Xylem Analysis (EDXA)}

The density and size of specific anatomical features in wood differ according to conditions of varying moisture, temperature, and elevation (Baas 1982; Carlquist 1977). These principles have been applied to wood charcoal studies at archaeological sites in South Africa by February 
(1994), Scholtz (1986), and Tusenius (1989). They have developed ecologically diagnostic xylem analysis (EDXA), an approach that measures the size and abundance of multiple anatomical features that are visible in a transverse section of wood. The size, abundance, and distribution of several anatomical features of wood have been shown to be related to a plant's ability to withstand water stress (Carlquist 1975, 1977). Several indices have been developed based on measurements of these anatomical features. These indices provide evidence of a plant's tolerance to extreme drought or moisture (Scholtz 1986). The most expedient index, and the one suggested for use in the study region of the Rio Grande Plains, is the vulnerability index developed by Carlquist (1977) and adapted by Sholtz (1986) and Tusenius (1989). It is based on the measurement of xylem vessel diameter and density of xylem vessels in a transverse section of wood. For example, a woody plant species grown under drought conditions contains vessel elements that are comparatively small in diameter, and more densely packed. The same species grown under moister conditions exhibits comparatively large diameter vessel elements and fewer vessels per $\mathrm{mm}^{2}$ in a measured transverse section of the wood (Carlquist 1977; Scholtz 1986).

In order to reduce interspecific variability, mesquite is the only wood type used for these EDXA studies. Mesquite has been chosen because of its broad distribution across southern North America-from East Central Texas and Oklahoma to southern California. In Texas alone, mesquite grows in rainfall regimes from 39 inches $(1016 \mathrm{~mm})$ to eight inches $(203 \mathrm{~mm})$ per year. The broad distribution of mesquite and its ability to adapt to a wide range of rainfall regimes makes it ideally suited for use as a proxy. What is not yet well demonstrated, however, is whether or not mesquite reacts consistently to changes in rainfall.

\section{Electron Microscopy}

The best method for documenting xylem tissue measurements is to photograph wood specimens from different stratigraphic levels of the site using a scanning electron microscope, and then secure vessel diameter and vessel density measurements from the photograph (Scholtz 1986; Tusenius 1989). Ten specimens were selected from each of the two occupation levels at the Lino Site, for a total of 20 specimens. These two levels correspond to two occupation periods, the lower level around 3000 B.P. and the upper level around 2000 B.P. Ideally, specimens from each of the occupational levels should show some differences in the anatomical characteristics of the xylem.

Specimens of sufficient size were fractured along the transverse (cross section), plane. Each specimen was secured to a $1-\mathrm{x}-1 \mathrm{~cm}$ aluminum cylindrical stub using $12 \mathrm{~mm}$ wide carbon conductive tape. All samples were dried in an oven at 55 degrees $C$ for 72 hours, and then sputter-coated with gold-palladium to a thickness of $20 \mathrm{~nm}$ (nanometers). Each specimen was examined in a JEOL T330A scanning electron microscope operating at $15 \mathrm{kv}$, with magnifications varying from $35 \mathrm{X}$ to $100 X$.

A transparent point-plotter grid is then laid over the photograph, and all anatomical elements contacting a point are counted and measured. This facilitates the methodical assessment of the charcoal piece as the measurements begin in the upper left corner and continue across and down to the lower right corner of the photograph. Area of the vessel elements is determined by making tangential and radial measurements at the widest part of the opening, excluding the cell wall (IAWA 
Committee 1989). Then the area of each vessel area is determined by plugging the measurements into the formula for the area of an ellipse.

\section{$\underline{\text { Results and Discussion }}$}

\section{Identification of the Charcoal Assemblage}

Of the nine charred samples submitted to the CEA Archaeobotanical Laboratory, eight possessed recognizable woody structure. Six of the samples $(5507-5,1846,1852-2-4,5144-009$, 5305, and 5506-004) were identified as honey mesquite (Figures 1, 2 and 3). One sample (1842-22), exhibited a radial line of four to eight connected vessel elements and compared favorably to agarita (Berberis trifoliata), a member of the holly family. Some material was identified as Condalia, a common shrub of the southern Texas savanna. The rest of the woody material was not identifiable, primarily because it was smaller than $2 \mathrm{~mm}$ cross-section and poorly preserved, rendering identification impossible. The woody taxa indicate that the species composition of the woody vegetation may not have changed that much during the Holocene. However, that does not mean that the structure of the vegetation did not change. A savanna is a tension zone between woody and grassland vegetation, and climatic or land use changes tend to favor the spread of grasslands or shrubs. Archer (1995) has argued that southern Texas has a history of just such changes. Changes in dominance between grasses and shrubs in a savanna has the potential to alter drastically the resource structure of the region. This would definitely affect forager subsistence practices.

All of the seeds in the sample were modern grass seed belonging to the same genus, Setaria, which is commonly known as bristlegrass. These seeds still contained very delicate, membranous tissues, an indication that they were very recently introduced into the profile, possibly by insect or rodent burrowing activity.

\section{Ecologically Diagnostic Xylem Analysis (EDXA)}

As previously stated, the results of this analysis are preliminary and are intended to contribute to a much larger database assembled in the near future from several sites across the region. Measurements of vessel diameters, vessel density, and the vulnerability index of mesquite samples are presented in Table 2 .

These EDXA results demonstrate that there are clear differences in the anatomy of mesquite collected in its eastern range, as compared to mesquite collected from its western range. In Texas alone mesquite grows in rainfall regimes from 39 inches $(1016 \mathrm{~mm})$ to eight inches $(203 \mathrm{~mm})$. For example, the diameter of xylem vessels is larger, and the density of the xylem vessels is lower in mesquite collected from Brazos County which has average annual rainfall of approximately 39 inches $(1016 \mathrm{~mm})$. This results in a much higher vulnerability index, which indicates that the eastern mesquite has adapted to a moister precipitation regime. Conversely, mesquite from Val Verde County, with an average annual rainfall of 17 inches $(432 \mathrm{~mm})$ has much smaller diameter vessels which occur in a much higher density, generating a lower vulnerability index, indicating a plant much better adapted to drought (Carlquist 1975, 1977; Scholtz 1986). 
Although these are preliminary results, the measurements demonstrate some differences between the 2000 B.P. occupation and the 3000 B.P. occupation. The values for the mean vessel diameter, vessel density, and the vulnerability index all differ somewhat between the two occupation levels. There is, however, some overlap in the data. For example, four samples from the 2000 B.P. level have a lower vulnerability index $(1810.4,1822.5,4229,4233)$ than the highest index value from the 3000 B.P. sample (3612). Sample 3612 has a much more mesic reading than any of the other samples from the 3000 B.P. occupation level. This may be due in part to the position of the tree on the landscape or to movement of archaeological material through the soil profile via rodent or root disturbance.

Despite the overlap, the mean vulnerability index of the 3000 B.P. occupation level is about half of that for the 2000 B.P. occupation level. This suggests that mesquite from the earlier occupation level exhibits characteristics of a plant adapted to drier conditions. The mesquite from the 3000 B.P. level may have lived in a somewhat more mesic environment.

What does this research imply? First, it demonstrates that the anatomy of archaeological mesquite from southern Texas is measurable. Judging from its abundance at archaeological sites in the region, mesquite must have been both a plentiful and preferred fuel source for much of the Holocene. That is, there is enough material from some sites in the region to provide representative sample for analysis. Second, the measurements hold the promise that the data may serve as a proxy for inferring paleoclimates. True, several factors other than evapotranspiration rates and available effective moisture may affect wood anatomy. Three of the most important of these factors include soil type, position on the landscape, and frequency of burning events. However, these may tend to average out allowing the analyst to be able to read the overall anatomical characteristics of the regional population of mesquite from the archaeological record, and to use that record as a proxy for vegetation changes, hence climatic changes, in an area the size of the effective foraging range of an archaeological site.

\section{Summary}

Nine wood charcoal samples from $41 \mathrm{WB} 347$ were identified using conventional light microscopy. Mesquite was the most abundant wood in the sample. Wood resembling that from the holly family, perhaps Berberis trifoliata (agarita), also was identified in the samples.

EDXA studies of 20 wood charcoal samples were conducted with the aid of a scanning electron microscope. These studies were conducted to continue building a database that may potentially serve as a proxy for the study of in the region via the examination of wood charcoal. The work is preliminary, but the analysis of both reference material and archaeological material demonstrates that the method is promising. Reference mesquite samples were collected and examined from Brazos County, an area with 39 inches average annual rainfall, and from Val Verde County, an area with 17 inches average annual rainfall. The vulnerability index was found to be much higher for the material collected from the moister precipitation regime.

Twenty archaeological charcoal samples were analyzed. The results suggest that there is a difference in the wood anatomy of mesquite between the two occupational periods at 41WB437. 
There is, however, some overlap between the two sample populations. These changes may reflect changes in ecological conditions. The vulnerability index of the 2000 B.P. sample is much higher than the 3000 B.P. sample, suggesting that effective moisture was much lower around 3000 B.P. That is, the mesquite wood from the 2000 B.P. sample was adapted to somewhat more mesic conditions.

\section{$\underline{\text { References }}$}

Archer, Steve

1995 Tree-grass Dynamics in a Prosopis-Thornscrub Savanna Parkland: Reconstructing the Past and Predicting the Future. Ecoscience pp.83-99. Vol. 2(1).

Baas, $\mathrm{P}$.

1982 Systematic, Phylogenetic, and Ecological Wood Anatomy-History and Perspectives. In New Perspectives in Wood Anatomy, edited by Baas, P., pp. 23-58. Martinus Nijhoff: The Hague.

Carlquist, S.

1975 Ecological Strategies of Xylem Evolution. University of California Press. Berkeley

1977 Ecological Factors in Wood Evolution: A Floristic Approach. American Journal of Botany 64:887-896.

Meyer, R.E., Morton, H.L., Haas, R.H, Robison, E.D., and T.E. Riley

1974 Morphology and Anatomy of Honey Mesquite. Technical Bulletin No. 1423. Agricultural Research Service, United States Department of Agriculture. Washington, D.C.

Prior, Julia

1988 Methods Used in Charcoal Analysis and the Relationship Between Woods Used in Archaeological Times and the Present Fuelwod Crisis. In, Scanning Electron Microscopy in Archaeology, edited by Sandra L. Olsen, pp. 187-202. BAR International Series 452. Oxford, England.

Prior, Julia and D. Price-Williams

1985 Investigation of Climatic Change in the Holocene Epoch Using Archaeologial Charcoal from Swaziland, Southern Africa. Journal of Archaeological Science 12:457-475

Scholtz, Anton

1986 Palynological and Palaeobotanical Studies in the Southern Cape. Unpublished M.A. Thesis. University of Stellenbosch.

Shackleton, C.M. and F. Prins

1992 Charcoal Analysis and the "Principle of Least Effort." Journal of Archaeological Science 19:631-637. 
Tusenius, Madelon

1989 Charcoal Analytical Studies in the North-Eastern Cape, South Africa. South African Archaeological Society Goodwin Series 6:77-83.

Wheeler, E.A., P. Baas, and P.E. Gasson

1989 IAWA List of Microsocopic Features for Hardwood Identification. International Association of Wood Anatomists at the Rijksherbarium. Leiden, The Netherlands. 
Table B1 Macroplant Sample Identifications.

\begin{tabular}{|c|c|c|c|c|c|}
\hline $\begin{array}{l}\text { Sample } \\
\text { Number }\end{array}$ & $\begin{array}{l}\text { Feature/ } \\
\text { Unit }\end{array}$ & $\begin{array}{l}\text { Occupa- } \\
\text { tion }\end{array}$ & Taxon & Part & Count \\
\hline $1813-4 a$ & F14 & 1 & Acacia & & 1 \\
\hline $1847-1 \mathrm{a}$ & F14 & 1 & Hackberry & & 1 \\
\hline $1820-4 a$ & F15 & 1 & Huisache & & 1 \\
\hline $1839-4 a$ & F19 & 1 & Mesquite & Root & 1 \\
\hline $3080-\mathrm{a}$ & F30 & 5 & Mesquite & Wood & 1 \\
\hline $3613-3 a$ & F30 & 5 & Mesquite & Wood & 1 \\
\hline $5295-6 a$ & F40 & 5 & Indeterminate & Flecks & 1 \\
\hline $3578-5 a$ & F24 & 5 & Indeterminate & Monocot & 1 \\
\hline $1846-2-4 a$ & F13 & 1 & Mesquite & Wood & 1 \\
\hline $3558-3 a$ & F20 & 3 & Mesquite & Wood & 1 \\
\hline $3558-4 a$ & F20 & 3 & Mesquite & Wood & 1 \\
\hline $3558-5 a$ & F20 & 3 & Mesquite & Stern knot from lateral bud & 1 \\
\hline $3594-6 a$ & F27 & 4 & Indeterminate & Hardwood root & 1 \\
\hline $3603-4 a$ & F29 & 5 & Mesquite & Wood & 1 \\
\hline $3604-4 a$ & F29 & 5 & Mesquite & Wood & 1 \\
\hline 4894-a & C3/L12 & 5 & Mesquite & Root & 1 \\
\hline $5057-\mathrm{a}$ & B4/L12 & 6 & Mesquite & Root & 1 \\
\hline $5478-4 a$ & E2/L12 & 6 & Indeterminate & Hardwood & 1 \\
\hline $662-b$ & F14 & 1 & Huisache & Wood & 1 \\
\hline $3578-5 b$ & F24 & 5 & Indeterminate & $\begin{array}{l}\text { Woody twig or rhizome, not } \\
\text { completely carbonized }\end{array}$ & 1 \\
\hline $662-a$ & F14 & 1 & Acacia & & 1 \\
\hline $3594-4 a$ & F27 & 3 & $\begin{array}{l}\text { Agarita (Berberis trifoliata) } \\
\text { or very similar diffuse } \\
\text { porous wood }\end{array}$ & Wood & 1 \\
\hline $3576-5$ & F23 & 3 & Hackberry Celtis sp. & & 1 \\
\hline $3566-4$ & F22 & 4 & Hackberry Celtis sp. & & 1 \\
\hline $1780-4 a$ & F10 & 1 & Huisache & & 1 \\
\hline $5167-4$ & A5 & 5 & Huisache & & 1 \\
\hline $5297-4$ & F34 & 2 & Indeterminate & & 1 \\
\hline $3599-4$ & F28 & 4 & Indeterminate & & 1 \\
\hline $5281-2 a$ & $\mathrm{C} 1$ & 3 & Indeterminate & & 1 \\
\hline $1781-5 a$ & F10 & 1 & Indeterminate & Flecks & 1 \\
\hline $1797-6 a$ & F12 & 1 & Mesquite & Wood & 1 \\
\hline $5554-4 \mathrm{a}$ & $\mathrm{F} 2$ & 4 & Mesquite & Wood & 1 \\
\hline $1834-7$ & F18 & 3 & Mesquite & Wood & 1 \\
\hline $1833-5$ & F17 & Misc & Mesquite & Wood & 1 \\
\hline 2895 & F26 & 4 & Mesquite & Wood & 1 \\
\hline $5553-4 a$ & $\mathrm{~F} 2$ & 3 & Mesquite & Wood & 1 \\
\hline $5455-4 a$ & D7/L11 & 5 & Mesquite & Wood & 1 \\
\hline
\end{tabular}


Table B1 continued.

\begin{tabular}{|l|l|l|l|l|l|}
\hline $\begin{array}{l}\text { Sample } \\
\text { Number }\end{array}$ & $\begin{array}{l}\text { Feature/ } \\
\text { Unit }\end{array}$ & $\begin{array}{l}\text { Occupa- } \\
\text { tion }\end{array}$ & Taxon & Part & Count \\
\hline $1837-5$ & F18 & 3 & Mesquite & Wood & 1 \\
\hline $5438-4$ & D6 & 4 & Mesquite & Wood & 1 \\
\hline $5382-5 a$ & D1 & 3 & Mesquite & Wood & 1 \\
\hline $1811-5 a$ & F14 & 1 & Mesquite & Root & 1 \\
\hline $3590-4$ & F26 & 4 & Mesquite & Root & 1 \\
\hline $1845-2-4$ & F12 & 1 & Mesquite & Wood & 34 \\
\hline $5507-5-1 \mathrm{a}$ & & 1 & Condalia & Wood & 4 \\
\hline $5507-5-1 \mathrm{~b}$ & & 1 & Indeterminate & Wood & 2 \\
\hline $5507-5-2$ & & 1 & Setaria sp. Bristlegrass & Modern seed & 11 \\
\hline $1846 \mathrm{a}$ & F13 & 1 & Mesquite & Wood & 4 \\
\hline $1846 \mathrm{~b}$ & & 1 & Indeterminate & Wood & 2 \\
\hline $1846 \mathrm{c}$ & & 1 & Poaceae (grass gamily) & Stalk/culm & 1 \\
\hline $1842-2-3$ & F9 & 1 & $\begin{array}{l}\text { Holly family, cf. agarita } \\
\text { Berberis trifoliata })\end{array}$ & Wood & 3 \\
\hline $1852-2-4 \mathrm{a}$ & F19 & 1 & Mesquite & Wood & 18 \\
\hline $1852-2-4 \mathrm{~b}$ & & 1 & Indeterminate & Wood $(<2 \mathrm{~mm})$ & 14 \\
\hline $5144-004$ & A-3 & 1 & Mesquite & Wood & \\
\hline 5712 & F36 & 1 & $\begin{array}{l}\text { No identifiable carbonized } \\
\text { remains }\end{array}$ & & 43 \\
\hline $5506-004-4$ & & 1 & Bristlegrass Setaria sp. & Modern seed & Wood \\
\hline $5305-4-3$ & C3 & 1 & Mesquite & Wood $(<2 \mathrm{~mm})$ & 16 \\
\hline & & 1 & Indeterminate & & \\
\hline
\end{tabular}


Table B2 EDXAMeasurements of Charred Mesquite Wood: References Samples and Archaeological Samples from Lino Site 41WB437.

\begin{tabular}{|c|c|c|c|}
\hline $\begin{array}{l}\text { Sample Type, Location, } \\
\text { and Accession Number }\end{array}$ & Mean Vessel Diameter & Vessels $/ \mathbf{m m}^{2}$ & Vulnerability Index \\
\hline Reference, Brazos County & 0.09 & 11.1 & 0.00811 \\
\hline $\begin{array}{l}\text { Reference, Val Verde } \\
\text { County }\end{array}$ & 0.048 & 27 & 0.00178 \\
\hline \multicolumn{4}{|l|}{$2000 \mathrm{BP}$} \\
\hline 41WB437-1810.4 & 0.061 & 26.3 & 0.00232 \\
\hline 41WB437-1810.5 & 0.069 & 25.3 & 0.00273 \\
\hline 41WB437-1822.5 & 0.052 & 22.6 & 0.00230 \\
\hline $41 \mathrm{WB} 437-3552$ & 0.072 & 20.1 & 0.00358 \\
\hline 41WB437-3580 & 0.066 & 19.8 & 0.00333 \\
\hline 41WB437-4229 & 0.057 & 22.3 & 0.00256 \\
\hline 41WB437-4233 & 0.061 & 24.7 & 0.00247 \\
\hline 41WB437-5114.7 & 0.071 & 20.0 & 0.00355 \\
\hline 41WB437-5448 & 0.065 & 19.4 & 0.00335 \\
\hline 41WB437-5482 & 0.074 & 18.5 & 0.00400 \\
\hline Mean & 0.0648 & 21.55 & $\mathbf{0 . 0 0 3 0 7}$ \\
\hline \multicolumn{4}{|l|}{$3000 \mathrm{BP}$} \\
\hline 41WB437-3080 & 0.051 & 26.2 & 0.00195 \\
\hline 41WB437-3573.5 & 0.046 & 24.8 & 0.00185 \\
\hline 41WB437-3573.6 & 0.041 & 27.9 & 0.00147 \\
\hline 41WB437-3603.4 & 0.039 & 28.3 & 0.00138 \\
\hline 41WB437-3604.4 & 0.037 & 23.8 & 0.00155 \\
\hline 41WB437-3606.4 & 0.048 & 24.6 & 0.00195 \\
\hline 41WB437-3611.3 & 0.052 & 28.0 & 0.00186 \\
\hline 41WB437-3612 & 0.058 & 21.9 & 0.00265 \\
\hline 41WB437-4125 & 0.043 & 23.4 & 0.00184 \\
\hline 41WB437-5248 & 0.051 & 26.7 & 0.00191 \\
\hline Mean & 0.0466 & 25.56 & 0.00184 \\
\hline
\end{tabular}




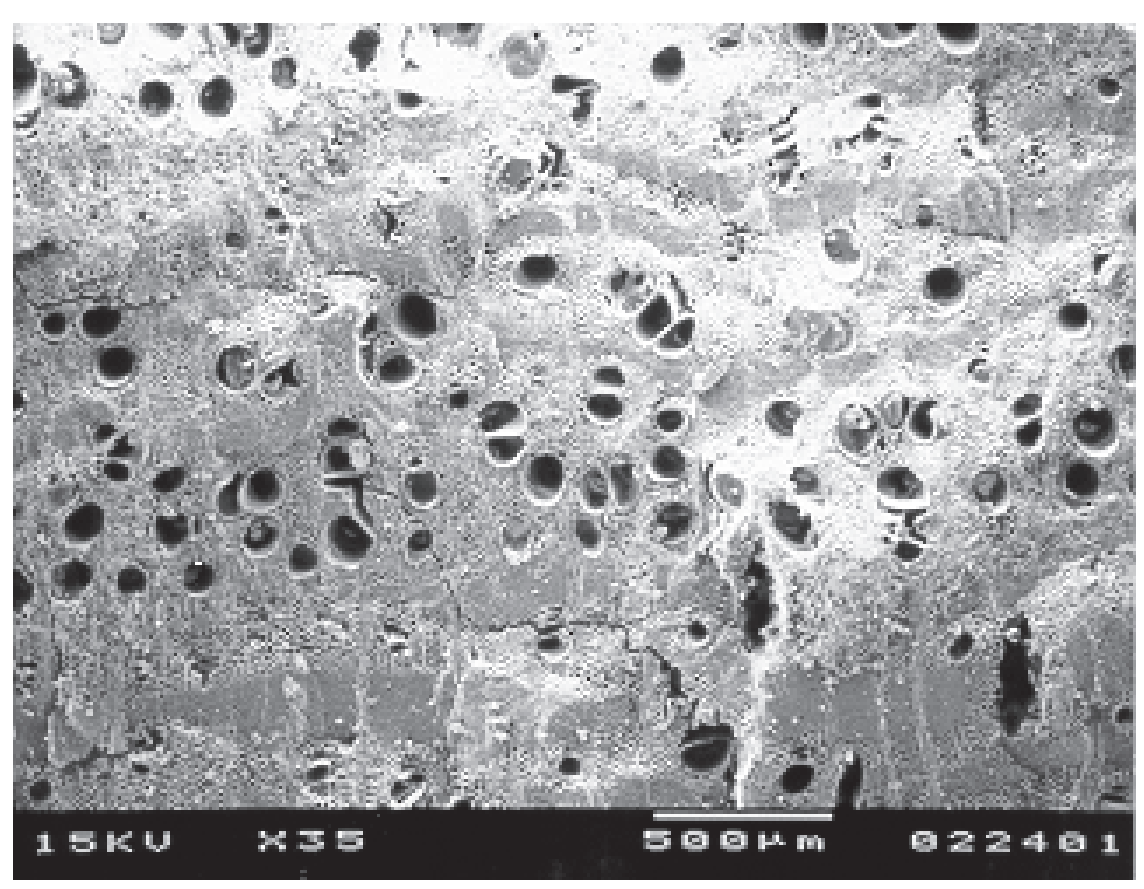

Figure B1 Transverse Section of Honey Mesquite Charcoal (Sample 3080).

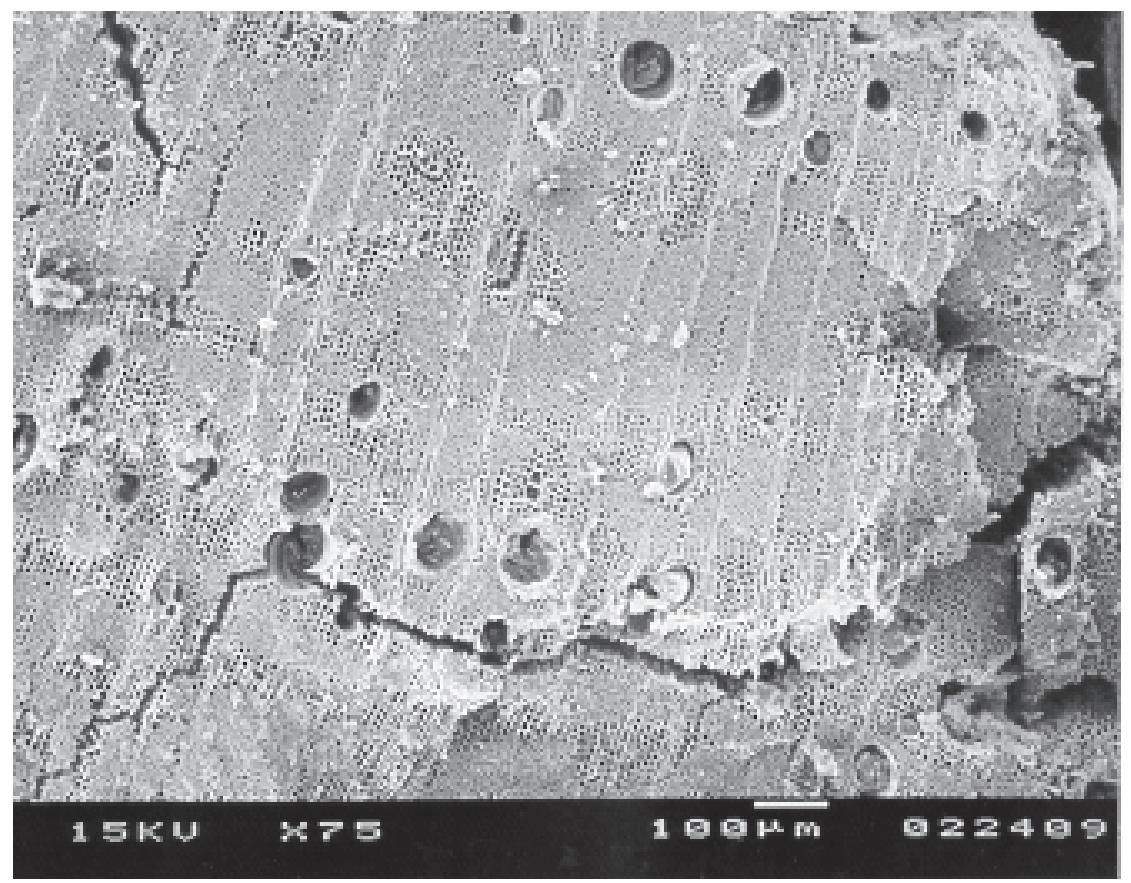

Figure B2 Tangential Section of Honey Mesquite Charcoal (Sample 4125). 


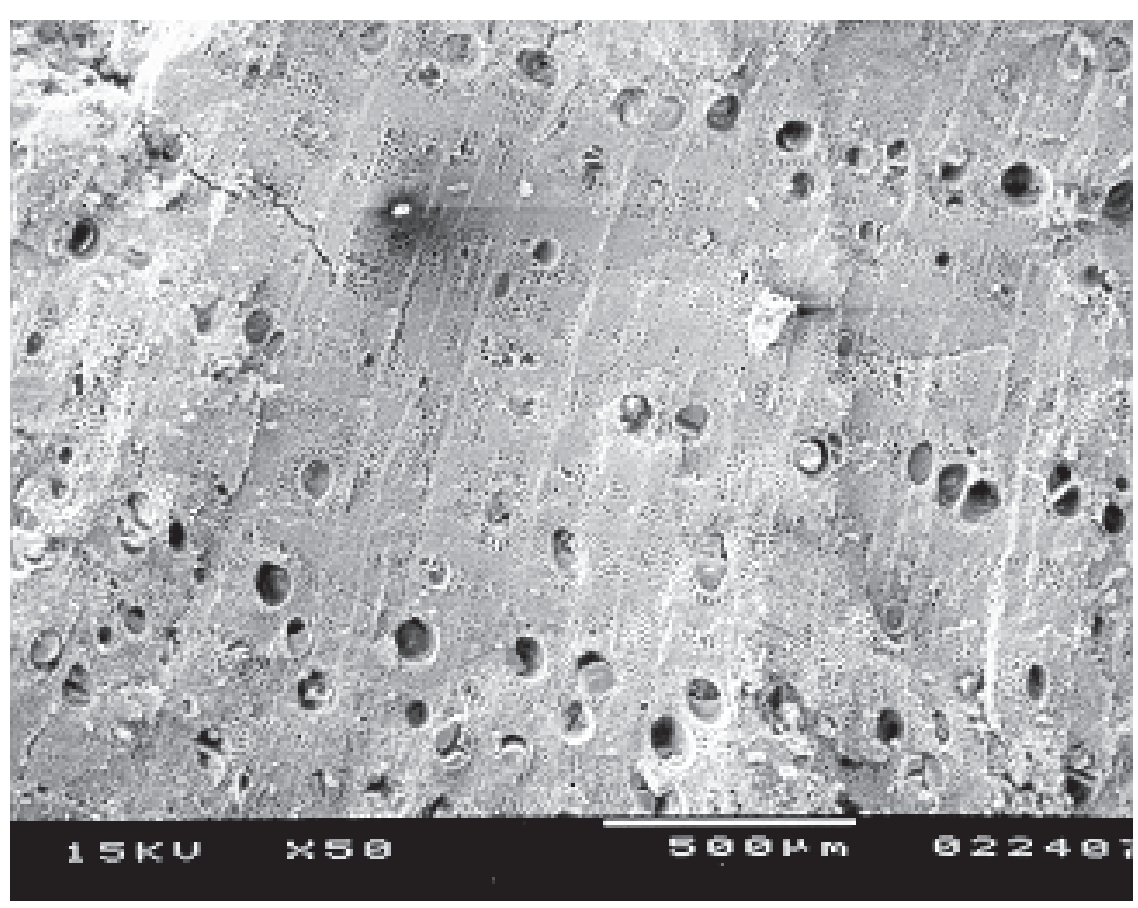

Figure B3 Transverse Section of Honey Mesquite Charcoal (Sample 5114-7). 
Intentionally Left Blank 


\section{APPENDIX C \\ Use Wear Studies by Caryn M. Berg}


Intentionally Left Blank 


\title{
THE LINO SITE (41WB437)
}

\section{USE WEAR ANALYSIS OF FLAKED STONE ARTIFACTS}

\author{
Caryn M. Berg \\ Department of Anthropology \\ University of Colorado \\ Campus Box 233 \\ Boulder, CO 80301 \\ (303) 492-7480
}

January 18, 1999 
Intentionally Left Blank 


\section{INTRODUCTION}

The goal of this analysis was the identification and interpretation of potential use traces on a sample of flaked stone artifacts from the Lino Site (41WB437), a Late Archaic period site in southern Texas. The sample consisted of 104 artifacts, including 17 projectile points, identified primarily as Tortugas and Refugio types, 56 pieces of debitage, and 31 pieces of worked stone. The worked stone category is an inclusive one that encompasses all artifacts intentionally flaked into specific morphological forms. This category includes 23 bifaces, five scrapers, two drills, and one uniface. The high power method of microwear analysis was used to examine these artifacts for potential traces of use.

\section{METHODS}

Microwear analysis is characterized by two approaches. The first involves the use of low magnifications (up to 60x) to study use "damage." Use damage consists of the minute flake removals on tool edges resulting from use rather than manufacture. Using low magnification, it is often difficult to distinguish between use wear and manufacturing damage, and subsequent damage caused by soil movements, the settling of deposits, trampling, or bag wear (Flenniken and Haggarty 1979; Shea and Klenck 1993). Additionally, the low magnification technique does not allow for the identification of different worked materials. The second method of microwear analysis requires higher magnification (100 to 500x) to observe very different kinds of tool use: polishes and striations on the surface of the tools (Keeley 1978, 1980; Vaughan 1985; Moss 1986). The use wear analysis for this project consisted of the high power approach; all analysis for this project was accomplished using an Olympus BHM microscope with magnification capabilities of 50x to 400x using the 'high power' technique described by Keeley (1980:10-14) and Vaughan (1985). There are several steps in the microwear analysis process.

All artifacts were first recorded through drawings. These drawings served as records as well as diagrams on which use wear (and other) details may be recorded.

After the artifacts are drawn, they are cleaned; the cleaning of stone tools prior to analysis is critically important. Normal toothbrush cleaning does not affect the nature of the polish, but chemical cleaning beyond toothbrush cleaning is required to remove any extraneous deposits. Although chemicals can affect the brightness of the polish (Anderson 1980; Keeley 1980), their use seems to be the only workable solution at present. Before examination, the flaked stone artifacts were cleaned in a dilute ammonia solution for ten minutes using an ultrasonic cleaner and immersed in a series of chemical solutions for ten minutes each. The artifacts were first placed in a 10 percent solution of HCL (hydrochloric acid) to remove any inorganic residues. This was followed by a three percent solution of $\mathrm{H}_{2} \mathrm{O}_{2}$ (hydrogen peroxide) to remove organic residues. Acetone was used throughout analysis to remove grease build up on the artifacts as well as the hands of the analyst. At high magnifications, even soils from the skin can obscure observations on the artifact.

After cleaning, artifacts are first scanned at 50x to observe possible edge damage and to scan for bright areas that may indicate the presence of polish. Although low power analysis was not emphasized for this analysis, artifacts were scanned for initial evidence of edge damage using low 
power and traces observed were noted. In addition, traces observed at low power were used to aid in interpretation of use traces observed at high power, when necessary. All margins of the artifact were then scanned at 100x to identify potential use traces and initial evidence of polish, if present. At this point it was possible to determine which edge was likely to have been used.

Any potential microwear is then observed at a magnification of $200 \mathrm{x}$ to make identifications. At this stage, use traces were identified using experimental data as well as published photographs and use wear description (Keeley 1980; Keeley and Newcomer 1975; Semenov 1964; Vaughan 1985). For a more intensive description of microwear techniques used, refer to Keeley (1980) and Vaughan (1985).

Use was inferred by the "texture, intensity, distribution, and other features of polishes, striations, edge damage, edge morphology, and tool morphology" (Unrath et al. 1986: 120). Keeley's (1980) research indicates that materials such as bone, wood, plant, and hide leave distinctive polishes on the stone surface when the duration of use is sufficient for these polishes to form. To identify the use of tools from different geographic regions, microwear analysts often rely on experimental tools as well as on available ethnographic analogs (Keeley 1980; Unrath et al. 1986; Vaughan 1985; Yerkes 1987). In this analysis, experimentally produced polishes as well as existing polish descriptions were used to infer use. The reliability of the inference of use was classified as high, medium, and low. Those artifacts with high degrees of inference were generally either unbroken or contained use traces that could be identified to polish type and/or mode of use. Those artifacts classified with medium degree of reliability were either broken and/or contained traces of use that could not necessarily be identified to a specific polish type or mode of use. Artifacts classified with a low degree of reliability in terms of use inference generally contained traces of use that were weak at best in terms of polish or presence of edge damage.

\section{ANALYSIS}

A total of 104 artifacts were analyzed. It was possible to identify traces of use on only six of these artifacts (Figure 1). Only two of these artifacts bore traces of use that permitted specific identification of material worked; these artifacts were determined to have been used primarily for hide processing. The artifacts will be discussed separately below by morphological category.

\section{Debitage}

Fifty six pieces of debitage were examined for traces of use (Table 1). These artifacts were originally classified as edge modified; however, including those artifacts classified as used, only four of those artifacts could be classified as having been intentionally modified.

$\underline{3726}$

This artifact is a distal fragment of an edge modified flake. The right lateral edge of the ventral face of this flake exhibited retouch and traces of use. The use traces observed are best described as having the presence of a "greasy" polish that is slightly rugged in texture (Figure 2). The polish contains some tiny pits and is consistent with Keeley's (1980) description of fresh hide/ 
meat polish. The polish extends slightly in from the edge of the artifact and along most of the edge, retouch scars cut into the polish, suggesting that the artifact may have been intended for reuse. There are no striae present that may indicate mode of use, however the location of polish extending into the edge and the absence of polish on the opposite face of the artifact suggest that this artifact was used in a scraping motion (see Figure 1).

INTERPRETATION: This artifact was used to scrape fresh hide. RELIABILITY OF INFERENCE: High.

\section{$\underline{5276-5}$}

This artifact is a complete edge modified flake bearing traces of a weak polish on the right lateral edge of the dorsal face of the flake (see Figure 1). At 100x, the polish is evident as bright areas along the edge and at 200x, the bright patches exhibit a greasy luster (Figure 3). This luster is consistent with fresh hide/meat polish and is associated with rounded edges. Rounding is one characteristic that is indicative of hide working and in the absence of wear traces on the opposite face of the artifact, it is possible to suggest that this artifact may have been used in a scraping motion to work fresh hide. In the absence of definitive polish traces, however, this interpretations are tentative at best.

INTERPRETATION: This artifact was used to scrape fresh hide. RELIABILITY OF INFERENCE: Medium to low.

$\underline{5388}$

This artifact is a complete edge modified flake bearing traces of use on the right lateral edge of the dorsal face of the flake (see Figure 1). The polish observed has a dull, matte appearance and is slightly rough in texture (Figure 4). Although the polish is not well developed, it is consistent with experimental and published descriptions of polish associated with dry hide processing (Keeley 1980). Retouch scars cut into the polish; this retouch may have obliterated more developed polish along the edge of the artifact and suggest that this artifact may have been intended for reuse. Two short deep striae running perpendicular to the edge of the artifact suggest that this artifact may have been used in a scraping motion. This inference is strengthened by the lack of use traces on the opposite face of the artifact.

INTERPRETATION: This artifact was used to scrape dry hide. RELIABILITY OF INFERENCE: High.

One other artifact (5728) was determined to have possibly been used, but this inference was indeterminate at best. This artifact is the distal portion of an edge modified flake and retouch on the dorsal face (see Figure 1) appears to be associated with edge rounding on the opposite ventral face. As mentioned earlier, rounding is one characteristic that is indicative of hide working, and it is possible that this artifact may have been used, but the lack of other indicators make such an inference low in reliability. 
Two-thirds of the debitage was classified as unused with a high degree of reliability. No inference of use was made for the remaining debitage because the artifacts were incomplete. Assuming that this sample of debitage is representative of the debitage assemble, the results suggest that flakes were not generally selected for use as tools. While the lack of use wear on debitage indicates that this class of flaked stone was not selected for use, the lack of use wear on worked stone actually suggests that this class of artifact may have been typically selected for use.

\section{Worked Stone}

The worked stone category includes all artifacts intentionally flaked into specific morphological forms. Thirty-one artifacts identified as worked stone including 23 bifaces, five scrapers, two drills, and one uniface were examined for use wear traces (Table 2). Of these, only one was determined to have traces of use.

One artifact identified as a side scraper (4956) bore traces of a weak polish confined to the edge of the artifact (see Figure 1 for location of use traces). This polish appeared to be rough in texture and was associated with slight edge rounding; because these use traces are confined to one face of the artifact, a scraping motion was inferred. However, the area of the polish location is small and the polish and edge rounding are weak. Therefore, the reliability of this inference is medium at best.

The remainder of the artifacts in the worked stone category were determined to be unused (54.8 percent) or inferences were not made about use because the artifacts were incomplete. This is consistent with the interpretation of such artifacts as being the primary source for tools. As is noted by Bamforth (1991:227-228), the general lack of use traces on flaked tools is consistent with the pattern seen in flaked tool stage for this assemblage. The majority of bifaces recovered probably represent unused, discarded production failures or the hafted, or used portion of finished flaked tools. Therefore, the lack of use wear on these artifacts is not surprising. Those artifacts intended for use were likely carried off-site when activities at the site were completed.

\section{Projectile Points}

Seventeen artifacts identified as projectile points were subjected to high power microwear analysis (Table 3). Projectile points have been defined as "a bifacially flaked, symmetrical tool with a point at one end and a base suitable for hafting at the other" (Christenson 1985:68). Typically, these artifacts are recognized through their worked margins, symmetrical shape, pointed tips, and diagnostic basal attributes indicative of hafting. The term projectile point itself implies that such artifacts were used to tip projectiles such as arrows or spears for use as weapons. As early as 1932 however, A.V. Kidder noted that we do not know the exact function of these artifacts, calling into question the functional classification of often intuitively derived morphological types (Kidder 1932). Therefore, a microwear analysis of projectile points is appropriate in order to confirm their morphological classification.

Of the 17 projectile points examined, only one (2641) bore traces of use. This projectile point is complete and has been identified as a Tortugas point. Traces of a bright, rough textured polish are present along a small portion of the lateral edge of the point (see Figure 1). This polish 
is associated with minimal edge rounding and may suggest that the particular artifact might have been used in a manner not suggested by its morphological classification. The polish is not identifiable to a specific material however, and the lack of other use indicators make the reliability of this inference fairly low. The lack of use wear specific use wear on projectile points is not necessarily surprising. These artifacts often do not bear traces of use and this absence of use wear traces may suggest that these artifacts were actually used as projectile points.

Zier (1978:36) has noted that when a projectile point is in use as a projectile, it may hit its target or it may miss. When it does hit its intended target, the point may break on its tip if it strikes bone or it may pass through the fleshy parts of an animal, resulting in little damage to the point. In terms of traces recognizable under high power magnification, it would be possible to recognize wear if a point hit its intended target and the animal continued to run with the point imbedded, therefore causing friction and traces of wear (Douglas Bamforth, personal communication 1997). Again, however traces of wear may still be absent depending on the time duration of such a situation and the placement of the point. If the projectile point misses its intended target, damage may or may not occur depending on the strength of impact when the point strikes the ground or some other object. Therefore, when considering function, it is possible that a projectile point bearing no traces of use may actually have been used as a projectile point (Ahler 1970; Zier 1978).

Given these considerations, is possible to speculate that many of these may have been used as projectiles. It is evident here that all complete artifacts examined do not bear evidence of use wear denoting non-projectile functions, but again, many of the artifacts identified as projectile points are incomplete. This limits the strict interpretation of these artifacts as unused.

\section{SUMMARY}

The lack of use wear traces observed on these flaked stone artifacts from the Lino site is consistent with the interpretation of this site as a short term camp site for hunter-gatherers. While it is evident that used flaked stone tools were discarded at these sites, the discard of such artifacts at these sites is minimal. The general lack of wear traces on debitage indicates that this class of artifact was not considered important as a tool source. Tools such as these would require little effort to manufacture and they are therefore not generally hafted, nor are they generally maintained after they become dull during use. However, if flakes were the primary source for tools at these sites, we would expect to see a greater frequency of discarded used flakes. In general, the interpretation of flakes identified as unused was done so with a high degree of confidence.

The overall absence of wear traces on worked stone suggests that manufacture and rejuvenation of this particular class of artifact may have occurred at this site but that all tools considered usable were carried off site when the site was abandoned. The lack of use wear on projectile points may actually indicate that these artifacts were used as their morphological classification implies.

In summary, the lack of use wear on the flaked stone artifacts indicates that flaked stone artifacts identified as drills, bifaces, unifaces, and scrapers likely represent the primary class of 
tools used by these populations. In contrast, the absence of use wear on debitage indicates that flakes were not considered an important tools source.

\section{REFERENCES CITED}

Ahler, Stanley A.

1970 Projectile Point Form and Function at Rodgers Shelter, Missouri. Missouri Archaeological Society Research Series No.8.

Anderson, Patricia C.

1980 A testimony of prehistoric tasks: diagnostic residues on stone tool working edges. World Archaeology 12: 181-194.

Bamforth, Douglas B.

1991 Prehistoric Land Use: The Flaked Stone Evidence. In Resource Use and Settlement in the Santa Ynez River Valley, edited by Craig F. Woodman, James L. Rudolph, and Teresa P. Rudolph, pp. 185-245. Science Applications International Corporation, Santa Barbara.

Christenson, Andrew L.

1985 Prehistoric Tool Kit. In Prehistoric Stone Technology on Northern Black Mesa, Arizona

by William J. Parry and Andrew L. Christenson, pp. 43-93. Center for Archaeological Investigations Occasional Paper No. 12. Southern Illinois University, Carbondale.

Flenniken, J.J., and J.C. Haggarty

1979 Trampling as an Agency in the Formation of Edge Damage: An Experiment in Lithic Technology. Northwest Anthropological Research Notes 12: 208-214.

Keeley, Lawrence H.

1978 Microwear Polishes on Flint: Some Experimental Results. In Lithics and Subsistence:

The Analysis of Stone Tool Use in Prehistoric Economies, edited by Dave D. Davis, pp. 163-

178. Vanderbilt University Publications in Anthropology No.20, Nashville.

1980 Experimental Determination of Stone Tool Uses. University of Chicago Press. Chicago.

Keeley, L.H. and M.H. Newcomer

1977 Microwear Analysis of Experimental Flint Tools: A Test Case. Journal of Archaeological Science 4: 29-62.

Kidder. A.V.

1932 The Artifacts of Pecos. Phillips Academy and Yale University Press, New Haven.

Moss, Emily H.

1986 What Microwear Analysts Look At. Early Man News 9/10/11: 91-96. 
Odell, George Hamley and Frieda Odell-Vereecken 1980 Verifying the Reliability of Lithic Use-Wear Assessments by 'Blind' Tests: The Low Power Approach. Journal of Field Archaeology 7: 87-120.

Semenov, S.A. 1964 Prehistoric Technology. Cory, Adams and McKay, Ltd. London.

Shea, John J., and Joel D. Klenck 1993 An Experimental Investigation of the Effects of Trampling on the Results of Lithic Microwear Analysis. Journal of Archaeological Science 20: 175-194.

Unrath, Guenther, Linda R. Owen, Annelou van Gijn, Emily H. Moss, Hugues Plisson and Patrick Vaughan

1986 An Evaluation of Use-Wear Studies: A Multi-Analyst Approach. Early Man News 9/10/ 11: 117-176.

Vaughan, Patrick C.

1985 Use-Wear Analysis of Flaked Stone Tools. The University of Arizona Press. Tucson.

Yerkes, Richard W.

1987 Prehistoric Life on the Mississippi Floodplain. University of Chicago Press, Chicago.

Zier, Christian J.

1978 A Functional Analysis of Projectile Points from Yellowjacket, Colorado. Plains Anthropologist 23-79: 31-45. 
Table C1 Summary of Use Wear Analysis for Debitage.

\begin{tabular}{|c|c|c|c|}
\hline Catalog \# & Condition & Observed use wear & Interpretation of use \\
\hline 562 & Distal & No use traces observed & \\
\hline 1702 & Shatter & No use traces observed & Unused \\
\hline 1785-1a & Complete & No use traces observed & Unused \\
\hline $1835-4$ & Complete & No use traces observed & Unused \\
\hline $1836-6$ & Complete & No use traces observed & Unused \\
\hline 1955 & Complete & No use traces observed & Unused \\
\hline 2880 & Complete & No use traces observed & $\begin{array}{l}\text { Indeterminate, heavily } \\
\text { weathered }\end{array}$ \\
\hline 2989 & Complete & No use traces observed & Unused \\
\hline $3583-4$ & Incomplete & No use traces observed & \\
\hline $3624-3$ & Incomplete & No use traces observed & Unused, heat treated \\
\hline 3725 & Complete & No use traces observed & Unused \\
\hline 3726 & Distal & Polish & Scraping fresh hide \\
\hline 3773 & Complete & No use traces observed & Unused \\
\hline 3885 & Proximal & No use traces observed & \\
\hline 3896 & Complete & No use traces observed & Unused \\
\hline 3921 & Complete & No use traces observed & Unused \\
\hline 4379 & Complete & No use traces observed & Unused \\
\hline 4391 & Distal & No use traces observed & Unused \\
\hline 4632 & Distal & No use traces observed & \\
\hline 4753 & Incomplete & No use traces observed & \\
\hline 4796 & Complete & No use traces observed & Unused \\
\hline $5116-6$ & Complete & No use traces observed & Unused \\
\hline $5165-6$ & Complete & No use traces observed & Unused \\
\hline 5216-1a & Heat spall & No use traces observed & Unused \\
\hline $5258-5$ & Complete & No use traces observed & Unused \\
\hline $5269-4$ & Incomplete & No use traces observed & Unused \\
\hline $5276-5$ & Complete & Weak polish, edge rounding & Scraping \\
\hline $5282-5$ & Complete & No use traces observed & Unused \\
\hline $5296-4$ & Complete & No use traces observed & Unused \\
\hline $5305-6$ & Complete & No use traces observed & Unused \\
\hline $5348-5$ & Distal & No use traces observed & \\
\hline $5374-5$ & Complete & No use traces observed & Unused \\
\hline $5377-8$ & Complete & No use traces observed & Unused \\
\hline $5388-7$ & Complete & Polish, striae & Scraping dry hide \\
\hline $5407-5$ & Complete & No use traces observed & Unused \\
\hline $5407-6$ & Complete & No use traces observed & Unused \\
\hline $5412-4$ & Heat spall & No use traces observed & Unused \\
\hline $5454-7$ & Complete & No use traces observed & Unused \\
\hline $5467-5$ & Complete & No use traces observed & Unused \\
\hline $5478-7$ & Complete & No use traces observed & contintudedsed next page \\
\hline
\end{tabular}


Table C1 continued.

\begin{tabular}{|c|c|c|c|}
\hline Catalog \# & Condition & Observed use wear & Interpretation of use \\
\hline $5478-6$ & Complete & No use traces observed & Unused \\
\hline $5509-5$ & Distal & No use traces observed & Unused \\
\hline $5512-4$ & Complete & No use traces observed & \\
\hline $5542-6$ & Proximal & No use traces observed & \\
\hline $5543-6$ & Shatter & No use traces observed & Unused \\
\hline $5552-5$ & Medial & No use traces observed & Unused \\
\hline $5561-4$ & Proximal & No use traces observed & \\
\hline $5565-5$ & Complete & No use traces observed & \\
\hline $5573-3$ & Complete & No use traces observed & \\
\hline $5589-4$ & Distal & No use traces observed & Unused \\
\hline $5653-4$ & Distal & No use traces observed & Unused \\
\hline $5725-1$ & Distal & No use traces observed & Unused \\
\hline $5726-1$ & Complete & No use traces observed & Indeterminate, retouched \\
\hline $5727-1$ & Complete & No use traces observed & Edge rounding \\
\hline $5728-1$ & Incomplete & No use traces observed & \\
\hline $5729-1$ & Complete & & \\
\hline
\end{tabular}


Table C2 Summary of Use Wear Analysis for Worked Stone.

\begin{tabular}{|c|c|c|c|c|}
\hline Catalog \# & Artifact type & Condition & Observed use wear & Interpretation of use \\
\hline 840 & Biface & Complete & No use traces observed & Unused \\
\hline $1837-6$ & Biface & Proximal & No use traces observed & \\
\hline 2387 & Biface & Complete & No use traces observed & Unused \\
\hline 2671 & Biface & Complete & No use traces observed & Unused \\
\hline 2899 & Biface & Complete & No use traces observed & Unused \\
\hline 3475 & Uniface & Complete & No use traces observed & Unused \\
\hline 3553 & Biface & Complete & No use traces observed & Unused \\
\hline $3598-4$ & Scraper & Complete & No use traces observed & Indeterminate, retouched \\
\hline $3605-4$ & Biface & Complete & No use traces observed & Unused \\
\hline $3610-2$ & Biface & Incomplete & No use traces observed & \\
\hline 3949 & Biface & Complete & No use traces observed & Unused \\
\hline 4210 & Biface & Distal & No use traces observed & \\
\hline 4231 & Scraper & Complete & No use traces observed & Unused \\
\hline 4310 & Biface & Complete & No use traces observed & Unused \\
\hline 4541 & Biface & Distal & No use traces observed & \\
\hline 4554 & Biface & Medial & No use traces observed & \\
\hline 4582 & Biface & Complete & No use traces observed & Unused \\
\hline 4614 & Biface & Tip & No use traces observed & \\
\hline 4638 & Biface & Complete & - & Heavily weathered \\
\hline 4817 & Biface & Complete & No use traces observed & \\
\hline 4919 & Biface & Incomplete & No use traces observed & \\
\hline 4956 & Side scraper & Complete & $\begin{array}{l}\text { Weak generic polish/Edge } \\
\text { rounding }\end{array}$ & Scraping? \\
\hline 5329 & Drill & Complete & No use traces observed & Unused \\
\hline $5349-4$ & Biface & Incomplete & No use traces observed & \\
\hline $5377-6$ & Scraper & Complete & No use traces observed & Unused, retouched \\
\hline $5377-7$ & Scraper & Complete & No use traces observed & Unused \\
\hline $5493-5$ & Biface & Complete & No use traces observed & Unused \\
\hline $5495-4$ & Biface & Incomplete & No use traces observed & \\
\hline $5511-6$ & Drill & Complete & No use traces observed & Unused \\
\hline $5532-4$ & Biface & Proximal & No use traces observed & Unused \\
\hline $5575-5$ & Biface & Incomplete & No use traces observed & \\
\hline
\end{tabular}


Table C3 Summary of Use Wear Analysis for Projectile Points.

\begin{tabular}{|c|c|c|c|c|}
\hline Catalog \# & Point Type & Condition & Observed use wear & Interpretation of use \\
\hline 1523 & Refugio & Tip broken & No use traces observed & Tip possibly broken during use \\
\hline $1829-1$ & Refugio & Base & No use traces observed & \\
\hline 2244 & Refugio & Base & No use traces observed & \\
\hline 2641 & Tortugas & Complete & Unidentifiable polish & Indeterminate \\
\hline 2652 & Tortugas & Base & No use traces observed & \\
\hline 2688 & Tortugas & Base & No use traces observed & \\
\hline 2772 & Tortugas & Base & No use traces observed & \\
\hline 3437 & & Base & No use traces observed & \\
\hline 3491 & Tortugas & Complete & No use traces observed & $\begin{array}{c}\text { Unused, calcium carbonate } \\
\text { covered }\end{array}$ \\
\hline 3733 & & Tip broken & No use traces observed & \\
\hline 3783 & Tortugas & Base & No use traces observed & \\
\hline 4478 & & Complete & No use traces observed & Unused \\
\hline 4683 & Refugio & Complete & No use traces observed & Unused \\
\hline 5072 & Tortugas & Tip & No use traces observed & \\
\hline $5327-1$ & Tortugas & Base & No use traces observed & \\
\hline $5474-3$ & Refugio & Tip missing & Impact fracture of tip & \\
\hline $5711-1$ & Tortugas & Complete & No use traces observed & Unused \\
\hline
\end{tabular}



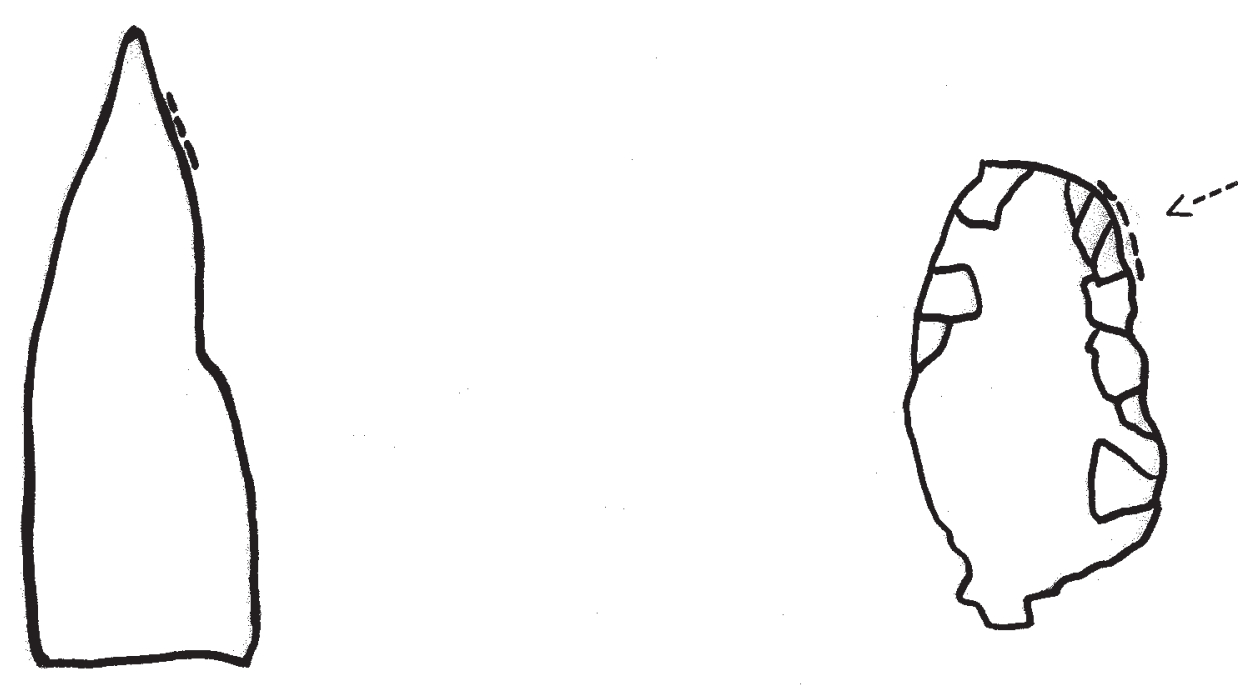

2641
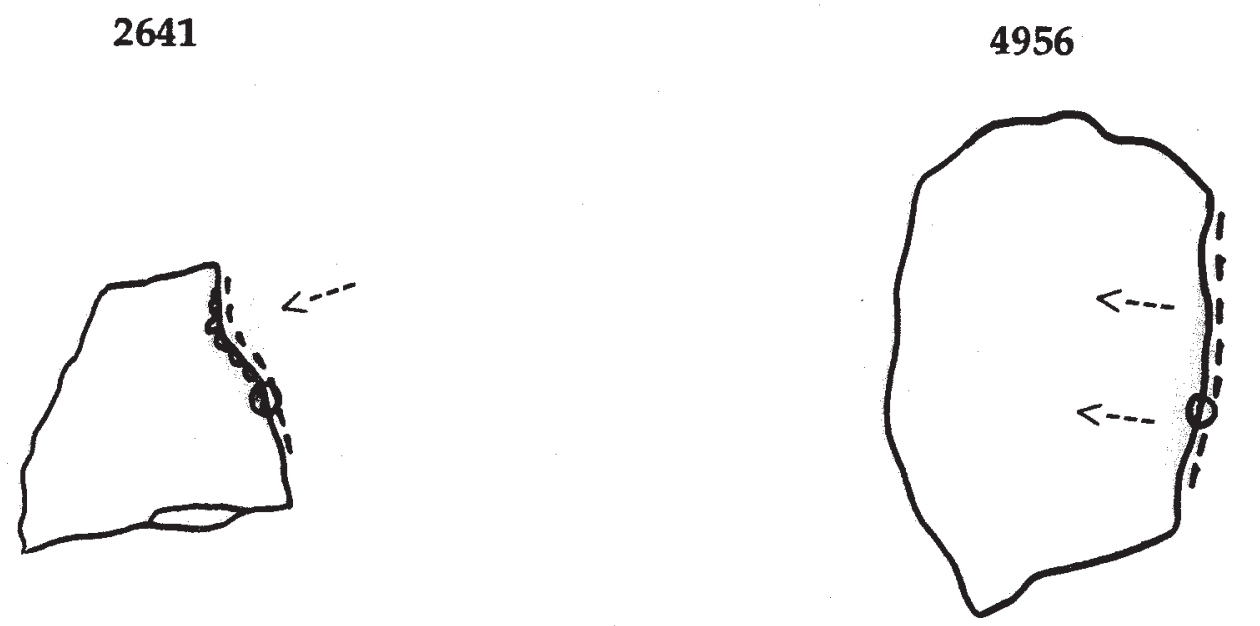

3726
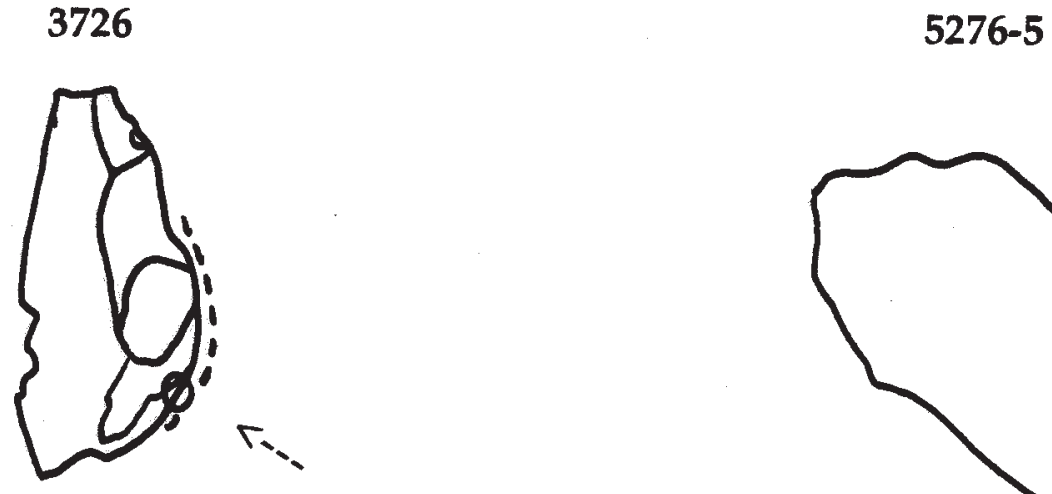

5388

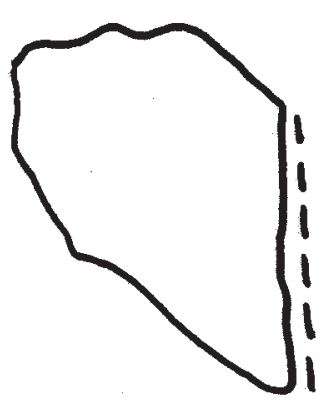

5728

--> Direction of use

-.-- Location of microwear traces Area of photograph

Figure C1 Use Traces Identified on Artifacts from the Lino Site 41WB437. 


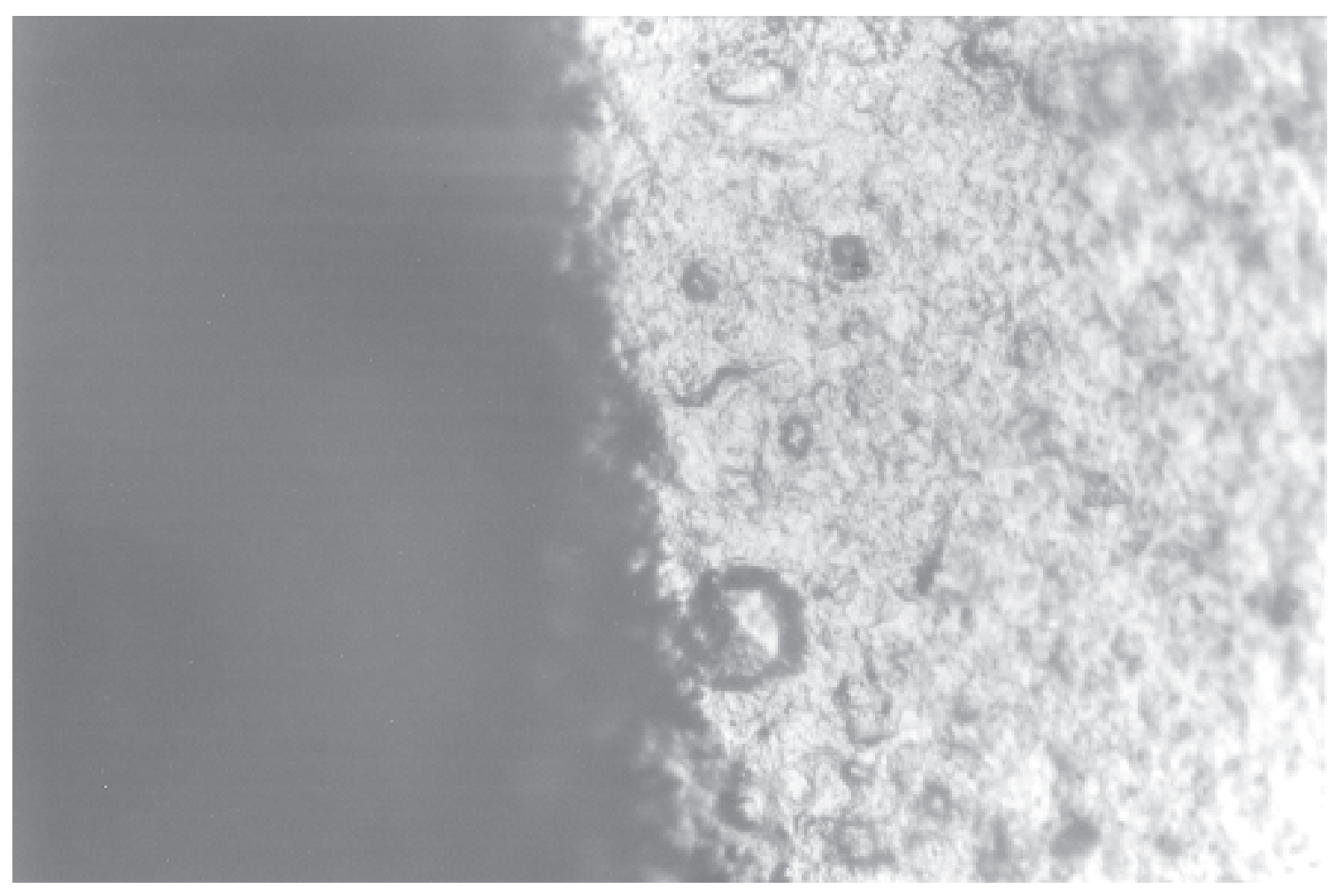

Figure C2 Polish from Processing Fresh Hide/Meat on 3726 (200x).

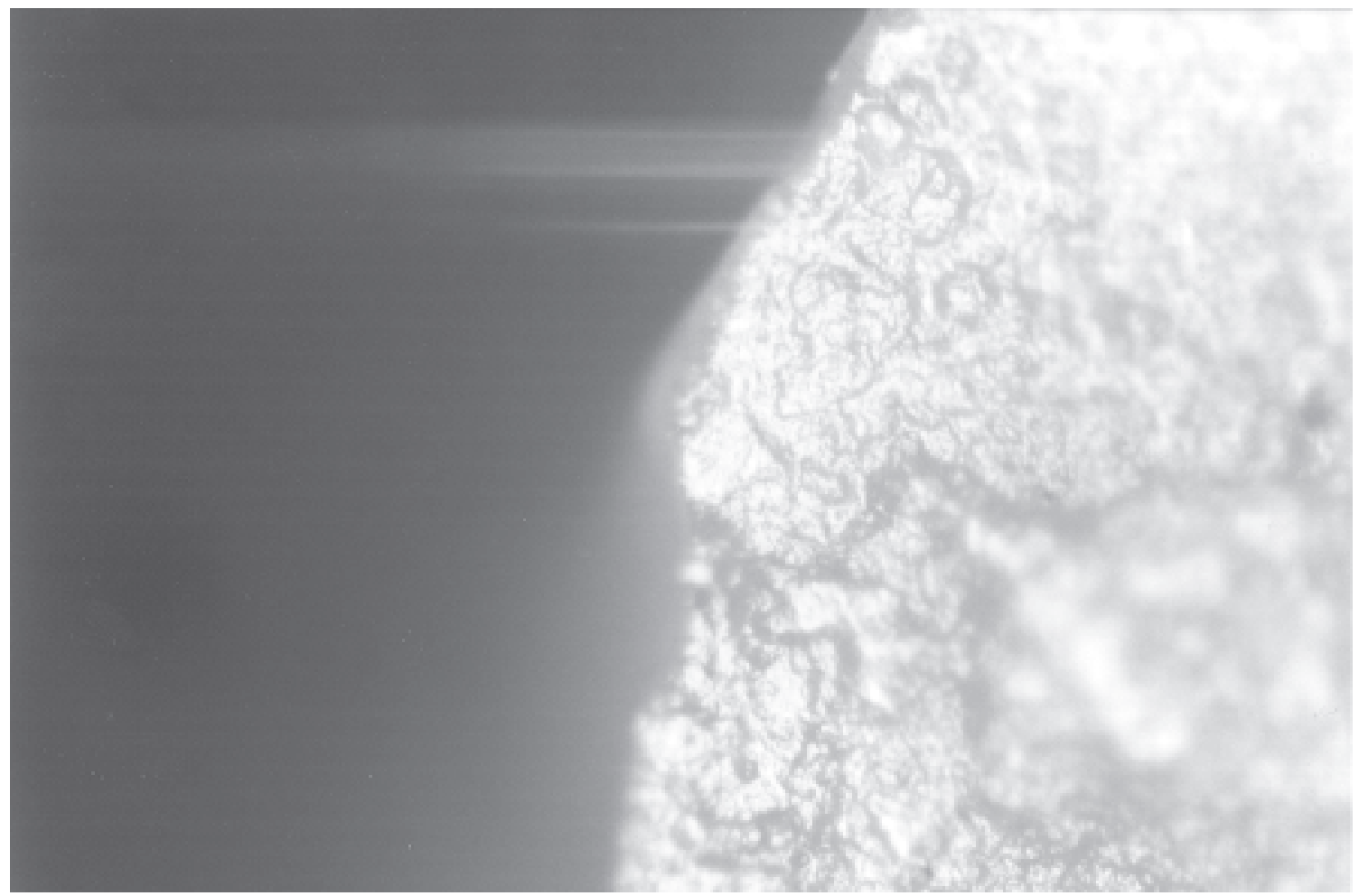

Figure C3 Weak Polish Present on 5276-5 (200x). 


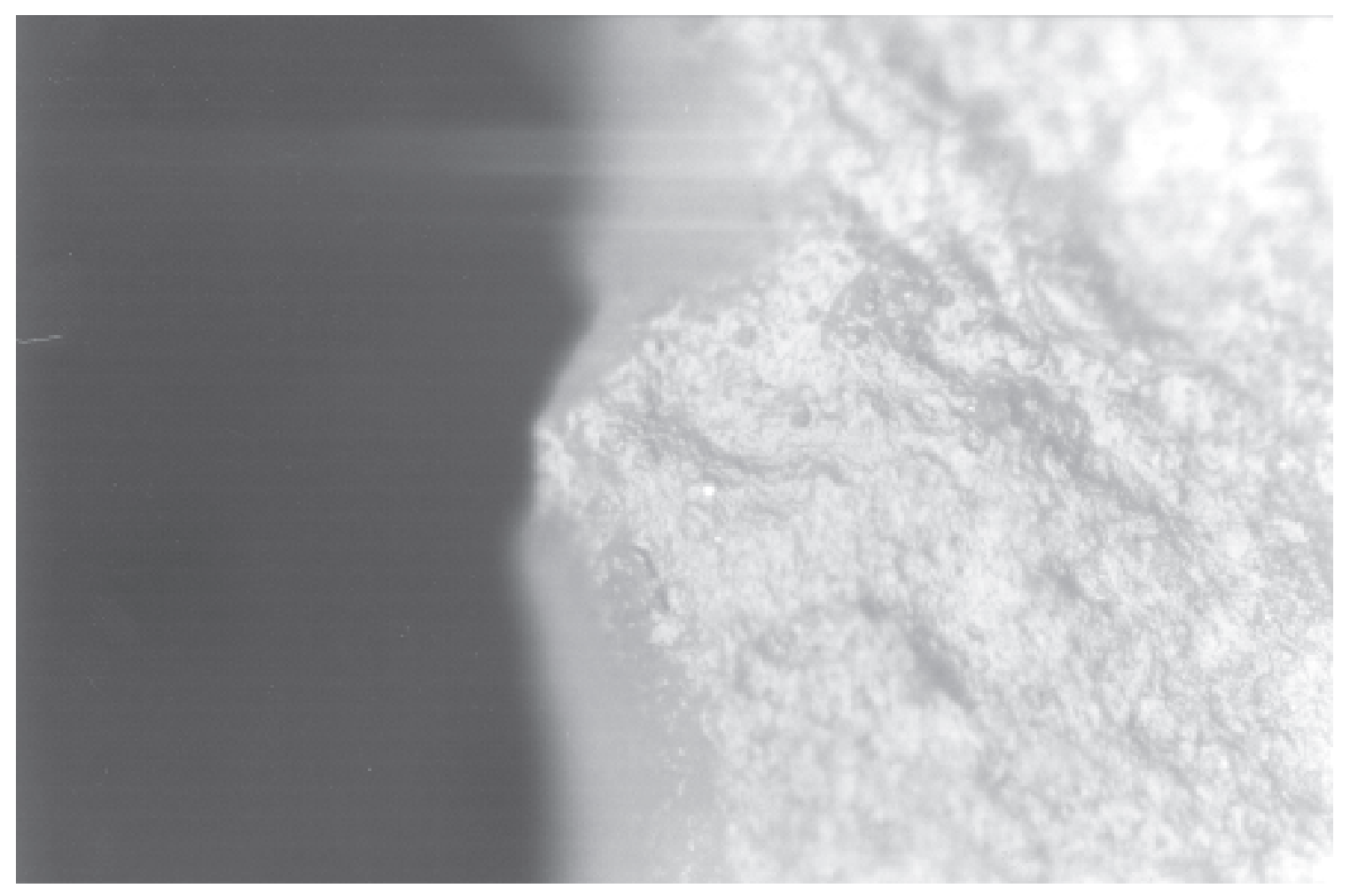

Figure C4 Polish from Processing Dry Hide on 5388 (200x). 


\section{APPENDIX D \\ Carbon and Nitrogen Isotopic Laboratory Results}


Intentionally Left Blank 


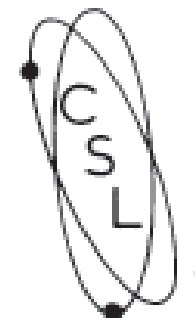

COASTAL

SCIENCE

LABORATORIES, INC.

6000 Mountain Shadows Drive - Austin, Texas 78735 • (512) 288-5533

August 28, 1998

Mr. Mike Quigg

Project Manager

TRC MARIAH ASSOCIATES, INC.

3939 Bee Caves Road, Suite C-100

Austin, Texas 78746

Dear Mike:

We have completed stable isotope analysis of your samples received recently. Carbon data are reported relative to the PDB standard and nitrogen data are reported relative to atmospheric nitrogen. These analyses are believed accurate to \pm 0.2 per mil.

Project No. 23756

\begin{tabular}{ccccccc} 
Site & Catalogue & Feature & TDS Shot & Coastal & $\delta^{13} \mathrm{C}$ & $\delta^{15} \mathbf{N}$ \\
\hline No. & No. & No. & No. & Lab No. & Value & Value \\
\hline 41WB437 & $457 \mathrm{~b}$ & 19 & 1401 & 1 & $-21.3,-21.5$ & $7.8,8.3$ \\
41WB437 & $769 \mathrm{~b}$ & 14 & 1711 & 2 & -20.9 & 9.6 \\
41WB437 & 844b & 13 & 1786 & 3 & -20 & 9.9 \\
41WB437 & $914 \mathrm{~b}$ & 15 & 1855 & 4 & $-19.3,-19.7$ & 9.5 \\
41WB437 & $1155 \mathrm{~b}$ & 12 & 2095 & 5 & $-21.3,-21.3$ & 7.4
\end{tabular}

Yours truly,

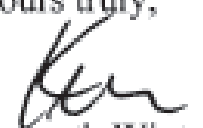

Kenneth Winters

Laboratory Manager

CSL Ref.\#CP51 


\section{Coastal Science Laboratories, Inc.} 6000 Mountain Shadows Dr. Austin, TX 78735 512-288-5533_csl@infinity.ccsi.com

September 29, 1998

\section{METHODS OF ANALYSIS}

\section{Analysis of Carbon Isotope Ratios}

The analysis of the stable carbon isotope ratio of biological tissue or the organic carbon content of sediments and soils is performed at CSL by personnel well trained in the handling of such material. The method of analysis is one generally accepted in the geochemical community similar to the handling of petroleum samples described by Sofer (1979). Approximately $5 \mathrm{mg}$ of biological tissue or $200 \mathrm{mg}$ of sediment is ground in a glass mortar with copper oxide which has been precleaned at $800^{\circ} \mathrm{C}$ for three hours. The sample mixture is transferred to precleaned $\left(590^{\circ} \mathrm{C}\right.$ for two hours ) Pyrex tubes. Tubes are evacuated to 0.1 torr and sealed at the distal end by collapsing at high temperature. As many as sixty tubes per batch are transferred to a stainless steel tube rack in a box furnace and heated to $590^{\circ} \mathrm{C}$ for two hours followed by a slow cool down period to near ambient temperature. Separation of $\mathrm{CO}_{2}$ from other combustion products (mainly $\mathrm{N}_{2}$ and $\mathrm{H}_{2} \mathrm{O}$ ) is performed on a glass vacuum line incorporating diffusion pumps backed by rotary mechanical pumps. Reaction products in the sample tube are passed over a liquid nitrogen cooled trap to collect the $\mathrm{CO}_{2}$ and $\mathrm{H}_{2} \mathrm{O}$. Noncondensable gases are pumped away and $\mathrm{CO}_{2}$ is then distilled away from the water by warming the trap to dry ice temperature. Transfer of the $\mathrm{CO}_{2}$ to a sample bulb is performed by chilling the bulb with liquid nitrogen. The clean $\mathrm{CO}_{2}$ sample is then suitable for isotopic analysis. All materials and equipment for this analysis are currently being used at CSL for analysis of a wide range of sample types.

The analysis of $\mathrm{CO}_{2} d^{13} \mathrm{C}_{\text {PDB }}$ is performed on SIRA Series II Model 10 or 12 isotope ratio mass spectrometers (triple collector) (VG Isogas Ltd., Cheshire, England). These and other instruments are currently operating at CSL under the same conditions.

\section{Analysis of Nitrogen Isotope Ratios in Biological Tissue and Sediments}

Analysis of biological tissue and sediment or soil samples for organic nitrogen is performed in a manner similar to that for carbon. In addition to the copper oxide, however, an aliquot (ca. $100 \mathrm{mg}$ ) of purified copper powder and an aliquot (ca. $50 \mathrm{mg}$ ) of precleaned $\left(800^{\circ} \mathrm{C}\right.$ for two hours) $\mathrm{CaO}$ is added to the sample/CuO mixture. A small wad of reagent grade copper turnings is also placed in the distal end of the sample tube. The extra elemental copper addition to the sample mixture provides enhanced reduction of nitrogen oxides which form in the tube at high temperatures but which convert to $\mathrm{N}_{2}$ and $\mathrm{CuO}$ as the combustion mixture cools. The $\mathrm{CaO}$ addition serves to eliminate some or all of the $\mathrm{CO}_{2}$ forming in the combustion mixture at elevated temperatures and reduces the ambient pressure in the reaction tube allowing enhanced reaction of the nitrogen present. Combustion of the samples is similar to that for carbon except that the furnace temperature is reduced after combustion at a much slower rate to allow for the complete conversion of nitrogen oxides to $\mathrm{N}_{2}$. Extensive work at CSL over several years has shown this to be a superior method for producing isotopically reproducible analysis of nitrogen in organic samples which contain comparatively much more carbon than nitrogen.

Recent advances in the preparation of samples by way of elemental analysers and GC-combustion interfaces involve the direct injection of the sample combustion products into the mass spectrometer. These new continuous flow (CF) techniques can greatly reduce sample preparation time and increase the sensitivity of the measurement. Where it is applicable and can be proven comparable to our standard methods, CSL is now adopting some CF methods for preparation and analysis of difficult sample types. 
Table D1 Stable Carbon and Nitrogen Isotope Values on Prehistoric Residues from Burned Rocks.

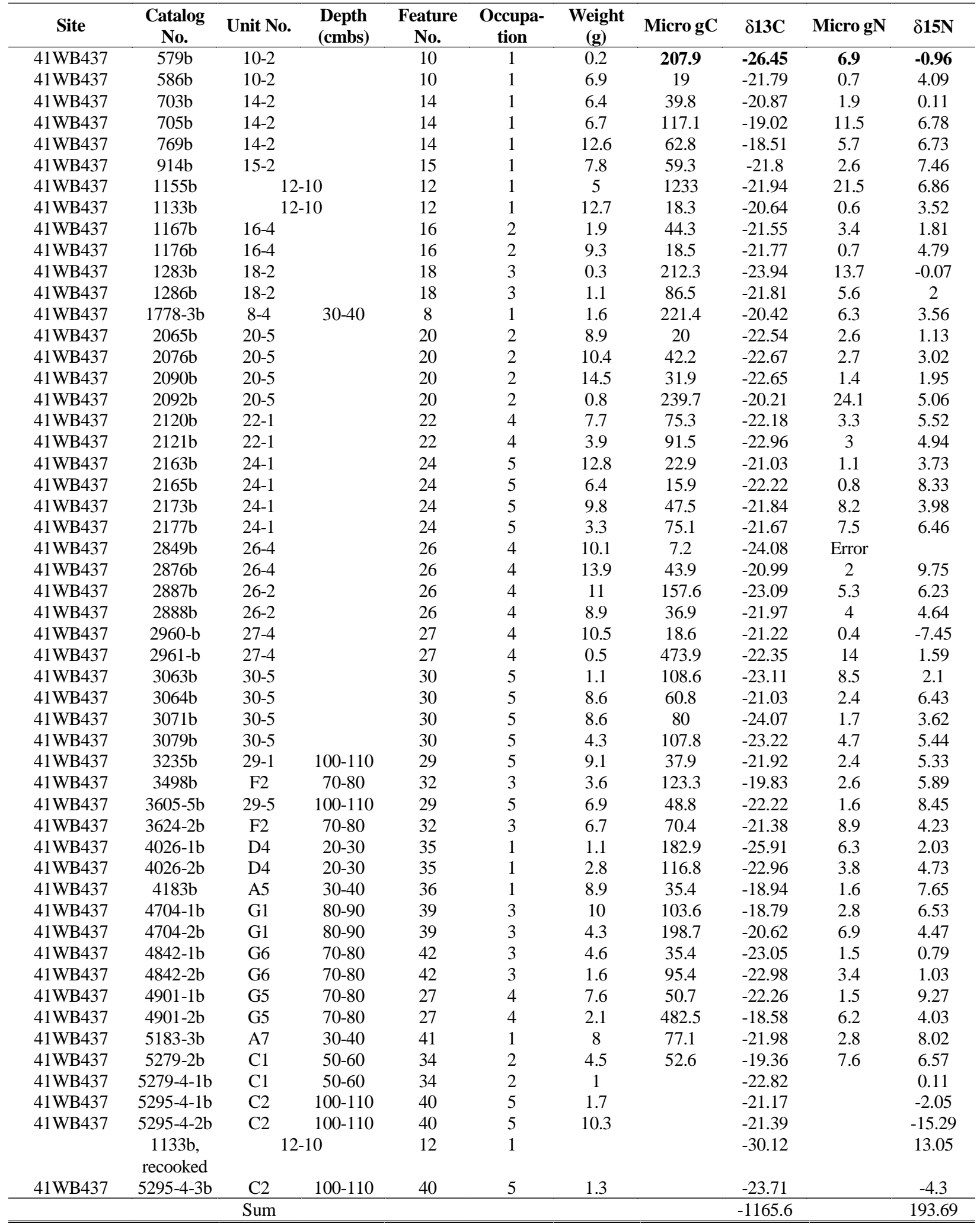


Table D2 Stable Carbon and Nitrogen Isotopes from Modern Plants and Animals.

\begin{tabular}{llccccc}
\hline County & Material & Catalog No. & Age & $\begin{array}{c}\text { Weight } \\
\text { (microg) }\end{array}$ & $\begin{array}{c}\delta \mathbf{1 3 C} \\
\text { values }\end{array}$ & $\begin{array}{c}\delta \mathbf{1 5 N} \\
\text { values }\end{array}$ \\
\hline Webb & Mesquite beans & $6450 \mathrm{~b}$ & Modern & 7.6 & -25.62 & -0.32 \\
Webb & Prickley pear tuna & $6453 \mathrm{~b}$ & Modern & 12.5 & -17.00 & -1.82 \\
Webb & Deer & $6455 \mathrm{~b}$ & Modern & 14 & -24.60 & 2.19 \\
Webb & Buffalo meat & $6456 \mathrm{~b}$ & Modern & 8.3 & -22.36 & 2.82 \\
Webb & Prickly pear & $6457 \mathrm{~b}$ & Modern & 11.5 & -20.27 & 2.44 \\
Webb & & $6458 \mathrm{~b}$ & Modern & 5.8 & -24.16 & 3.73 \\
\hline Zapata & Rabdotus, meat & & Modern & & -25.21 & -2.57 \\
Zapata & Deer, tendons & & Modern & & -21.72 & 10.21 \\
La Salle & Deer, marrow & & Modern & & -30.07 & 10.91 \\
La Salle & Deer, skin & & Modern & & -22.07 & 14.28 \\
Williams & Dear, meat & & Modern & & -22.40 & 14.41 \\
La Salle & Deer, meat & & Modern & & -22.23 & 11.77 \\
Dering & Mesquite flour & & Modern & & -26.13 & 8.06 \\
Zapata & Mesquite beans & & Modern & & -27.32 & 8.03 \\
Zapata & Prickly pear tuna & & Modern & & -12.19 & 6.98 \\
Zapata & Prickly pear pad & & Modern & & -12.05 & 11.67 \\
\hline \hline
\end{tabular}




\section{APPENDIX E}

Demagnetization Analysis by Wulf A. Gose 
Intentionally Left Blank 


\title{
Archeomagnetic Analyses of Rocks from Site 41WB437 in Webb County, Texas
}

\author{
Wulf A. Gose \\ Department of Geological Sciences \\ The University of Texas at Austin
}

\section{Introduction}

Archeomagnetism is the application of paleomagnetic techniques to archeological samples. The most common application makes use of the geomagnetic field's secular variation for dating purposes. Clay-lined hearths are the most popular archeological feature for this research, at least in North America (e.g., Wolfman 1984; Dubois 1989; Sternberg 1989; Eighmy and Sternberg 1990). The magnetic remanence in the clay is measured in the laboratory, and ages are estimated by correlating the mean direction of magnetization with the previously established secular variation curve.

In the archeomagnetic investigation of burned rocks, the magnetic signal of rocks is used in a different way, namely to study human behavior and site formation processes. Like the clay liner, all rocks contain small amounts of magnetic minerals such as magnetite or hematite. During the process of rock formation, these minerals will acquire a remanent magnetization parallel to the ambient magnetic field, usually the geomagnetic field. For a random assemblage of rocks placed in a hypothetical hearth before it is fired, the directions of magnetization will be a random distribution as these rocks retain their original (i.e., geologic) vectors of magnetization. If the same rocks are heated, they will acquire a common thermoremanent magnetization (TRM) parallel to the ambient field at the time of the heating. If the heating temperature does not exceed the Curie temperature (the temperature above which all magnetic alignments are randomized, e.g., 580 degrees $\mathrm{C}$ for magnetite and 680 degrees $\mathrm{C}$ for hematite), then the rocks will acquire a partial TRM. Progressive demagnetization makes it possible to discriminate between these alternatives and yields the maximum temperature of heating. Figure E1 shows the directions of magnetization for rocks from a hypothetical fireplace before and after heating. (Note: the term "fireplace" is used in a generic sense to indicate any feature that was subjected to heating). The stereonet is a two-dimensional representation of a three-dimensional vector. In paleomagnetism, the net combines both hemispheres into one graph. Directions with a positive inclination plot in the lower hemisphere, which lies below the plane of the paper, and are shown by solid symbols. Directions with a negative inclination point upwards and are shown with open symbols.

Before heating, the directions of magnetization scatter (Figure E1a). After heating, the directions cluster if the fireplace is left undisturbed, displaying the common direction that they acquired during cooling. In archeomagnetic studies it is often helpful to plot the direction of the magnetic dipole field $(\mathrm{PD}=$ present dipole) at the sampling site as a reference direction because the expected direction of an undisturbed fireplace should fall within 20 to 30 degrees of that direction (Sternberg 1989; Eighmy and Sternberg 1990).

Twelve rock samples collected by TRC personnel were subjected to archeomagnetic analyses. Unfortunately, the rock samples were not oriented, which limits their interpretive value. 


\section{Experimental results}

From each hand sample, one $2 \mathrm{~cm}$ cube was cut. Because the rocks were poorly cemented, all cubes were coated with sodium silicate (liquid glass) in order to minimize contamination of the magnetic instruments. The magnetic remanence of the samples was measured with a cryogenic magnetometer. All samples were subjected to progressive thermal demagnetization in 50 degrees $\mathrm{C}$ increments, where the sample is heated to the desired temperature, allowed to cool in a zero magnetic field, and remeasured.

The intensities of the natural remanent magnetization are large, with values that range from 8 by $10^{-}$ ${ }^{5} \mathrm{Am} 2 / \mathrm{kg}$ to 2 by $10^{-3} \mathrm{Am} 2 / \mathrm{kg}$ with the exception of rock 705 , which has an intensity of 6 by $10^{-6}$ Am2 $/ \mathrm{kg}$. After most heating steps, the magnetic susceptibility was measured in order to test for major changes in the magnetic mineralogy due to heating. Such changes would indicate that the magnetic mineralogy had been altered and subsequent data would no longer represent the original sample. The susceptibility is a measure of the magnetic mineral content of a sample and depends on the concentration as well as the type of magnetic mineral. The results are displayed in Figure E2. For each rock, the susceptibility remains roughly constant, which indicates that no significant changes were caused by the thermal demagnetization. If the rocks are indeed burned rocks then one would not expect any significant changes because any alteration is likely to have occurred during the "archeological" heating. Only rock 2090 experienced an increase in susceptibility after heating to 500 degrees $\mathrm{C}$. However, this change did not affect the direction or intensity of magnetization.

The results of the thermal demagnetization are shown as a set of vector component diagrams. A vector component diagram is a representation of a three-dimensional quantity - the magnetic vectorin two dimensions employing a Cartesian coordinate system. The graph shows the projection of the magnetic vector onto the north-south-east-west plane as well as the projection onto the up-downhorizontal plane (Figure E3). If a sample contains only one component of magnetization, then there will be a series of points heading towards the origin with increasing levels of demagnetization due to the loss of intensity of magnetization (e.g., sample 4901, Figure E4). The best-fitting vector is calculated using principal component analysis (Kirschvink 1980). For such a sample, the directions for each demagnetization step will plot on a stereonet as a very tight cluster of points.

The value of vector component diagrams and PCA becomes apparent when a sample contains two or more components of magnetization. The synthetic data shown in the vector component diagram depicted in Figure E3 reveal two components of magnetization. Component one is defined by the first four demagnetization steps and component two by steps five through 10. In the case of burned rocks, the first component is usually interpreted as the culturally created magnetization and the high-temperature component as the original geological magnetization. If the sample in Figure E3 was thermally demagnetized, then we interpret the results to indicate that the sample was heated to a temperature between steps four and five. Thus the thermal history of each rock can be reconstructed. However, caution needs to be exerted because the same magnetic behavior would also be observed if the sample were heated above the Curie point, allowed to cool to the intermediate temperature, and moved, intentionally or unintentionally, into a new position wherein it cooled to ambient temperature. This alternate interpretation can generally be resolved if the rock sample was fully oriented and if additional rocks from the same feature are available for magnetic analysis. Sample 
705 is a clean example of a sample that carries two components (Figure E6). While stereonet shows continually changing directions, and no mean direction can be calculated, the vector component diagram clearly defines two components, one of which is revealed by the first seven demagnetization steps (NRM to 350 degrees C) and the second over the range from 450 degrees $\mathrm{C}$ to 625 degrees $\mathrm{C}$.

Samples 4901 and 5295 (Figures E4 and E5) exhibit only one component of magnetization carried by magnetite. Either these two rocks were never heated at all or they were heated above 580 degrees $\mathrm{C}$, the Curie point of magnetite. Oriented samples are required to distinguish between these very different interpretations. Experience with many other burned rocks suggests to me that these rocks were never heated (e.g., Gose, 1990, 1993, 1994; Gose et al. 1994)

Rocks 705, 1133, 2090, 2120, 2168, 2876, and 5183 reveal two components of magnetization upon thermal demagnetization (Figures E6 through E12). Sample 3064 also carries two well-defined components but may also contain a third component (Figure E13). Samples 575 and 4704 are magnetically the most complex samples and contain three and four components, respectively (Figures E14 and E15).

A common feature of all samples is that they lose all or nearly all intensity when heated to 600 degrees $\mathrm{C}$, which implies that the magnetic remanence in these samples is carried by magnetite, which has a Curie point of 580 degrees $\mathrm{C}$.

Table E1 lists the approximate temperature at which the samples exhibited a change in direction upon demagnetization.

\section{Discussion}

The samples submitted for archeomagnetic analyses were not oriented, a fact which severely limits the interpretive value of the data. Eight of the twelve samples carry two components of magnetization. This observation can be interpreted in several ways.

1. The samples were exposed to the temperatures listed in Table E1 and then cooled. In this interpretation, the low-temperature component is the culturally created magnetization, and the high-temperature is the geological magnetization. With the exception of sample 2876, all other samples experienced only very moderate temperatures.

2. The samples were heated above 580 degrees $\mathrm{C}$, cooled to the temperature listed in Table E1, moved, intentionally or unintentionally, and cooled to ambient temperature.

3. The samples were never heated. It is quite common for geological samples to contain multiple components of magnetization, which is precisely why principal component analysis was introduced to paleomagnetic research in 1980. The magnetic data alone cannot discriminate between these alternatives.

Special attention was given to the possibility that some of the rocks may be boiling stones. As a heated rock is submerged in a vessel filled with water (and other ingredients), it cools and will 
acquire a magnetic remanence parallel to the ambient magnetic field. When the food is stirred the rock will be moved into a different position and will acquire a magnetic remanence over the lower temperature range. Repeated stirring will impart a series of partial thermoremanences, each with a different direction of magnetization. What is measured in the laboratory is the sum of all these remanences. Progressive demagnetization sequentially removes one component after the other: first the lowest temperature component followed by the next temperature interval component and so on. Such a behavior was indeed observed on a sample from another archeological site (Roger, 1998). If the rock was in continuous motion during cooling it would acquire a very large number of magnetic components that cannot be separated in a vector component diagram and the sum of all partial TRM's will be close to zero (random walk model).

Among the analyzed samples, only rock 4704 has a magnetic signature that could have resulted from its use as a boiling stone. In order to test whether this rock could survive submersion in water, a small subsample as well as small subsamples from rocks 2120 and 2876 were heated to 650 degrees $\mathrm{C}$ and dropped into room-temperature water that was frequently stirred. Rock 2876 largely disintegrated, leaving only one small fragment intact (26 percent by weight). Rock 2120 lost 4.2 percent of its weight in spillage, and rock 4704 lost 2.5 percent. The intensities of magnetization of all three rocks were similar before and after the experiment, The frequent stirring did not randomize the magnetic components because the small rocks samples (approximately eight grams) cooled very quickly to the temperature of the water, and thus the rocks acquired only one component of magnetization. If the sandstones analyzed here are the only readily available rock type at this site or if preference was given to sandstones, then rock 4704 would be a reasonable candidate for use as a boiling stone. But much of Webb county is covered by the Uvalde gravel, which has an ample supply of "hard" rocks that seem much more suitable as boiling stones, and thus I doubt that any of the analyzed rocks would have been used as a boiling stone in the manner visualized above.

If, on the other hand, the heated rocks were placed in water without subsequent movement until they were cold, then a fundamentally different magnetic signature is to be expected. As the hot rock is transported from the fireplace to the food container it will rapidly cool and acquire a hightemperature thermoremanence. If the rock remained roughly in the same orientation relative to north then the sample will gain one component of magnetization. After submergence in water these sandstones will rapidly cool due to their high porosity and permeability and, in the process, they will acquire a second component of magnetization. Experimental boiling stones from this very sandstone were magnetically analyzed and described by Takac (1999) and some of the experimental rocks indeed fits this pattern. Thus the magnetic data from the archeological rocks could be interpreted as being the result of stone boiling.

At this time, only a few boiling stones, experimental or archeological, have been subjected to detailed magnetic analyses. No definitive magnetic signature has been recognized as yet. It seems that different rock types as well as different usage cause a different magnetic response. An extensive experimental data base is needed before one can proceed from stating that the magnetic data are compatible with the rocks having been used as boiling stones to the magnetic data prove that the rocks were used as boiling stones. 


\section{References}

DuBois, R. L.

1989 Archeomagnetic Results from Southwest United States and Mesoamerica and Comparison with Some Other Areas. Physics of the Earth Planetary Interiors 56: 18-33.

Eighmy, J. L. and R. S. Sternberg (editors)

1990 Archaeomagnetic Dating. University of Arizona Press.

Gose, W. A.

1990 Archeomagnetic properties of burned limestone. In Excavations at the Camp Pearl Wheat site (4IKR243), an early Archaic campsite on Town Creek, Kerr County, Texas, edited by M.B. Collins, B. Ellis, and C. Dodt-Ellis. Studies in Archeology 6, Texas Archeological Research Laboratory, University of Texas-Austin.

Gose, W. A.

1993 Archeomagnetic dating of burned features. In Data recovery at Justisburg Reservoir (Lake Alan Henry), Garza and Kent counties, Texas, Phase III, season 2, edited by D. K. Boted, J. Peck. S. A. Tomka, and K. W. Kibler, pp. 329-337. Reports of Investigations, Number 88, Prewitt and Associates, Austin.

Gose, W. A.

1994 Archeomagnetism. In Archaic and Late Prehistoric Human Ecology in the Middle Onion Creek Valley, Hays County, Texas, edited by R. A. Ricklis and M. B. Collins, pp 507-537. Studies in Archeology 19, Texas Archeological Research Laboratory, University of TexasAustin.

Gose, W. A., K.S. Collins, and M.B. Collins

1994 Paleomagnetic studies from the Moore-Hancock farmstead, Austin, Texas. Jour. Field Archaeology 21: 125-129.

Kirschvink, J. L.

1980 The least square line and plane and the analysis of paleomagnetic data. Geophys. Jour. Royal Astron. Soc. 62: 699-718.

Rogers, R.

1998 Excavation at the Walleye Creek site 41LE57. Espey, Huston and Associates, Austin.

Sternberg, R. S.

1989 Secular variation of archeomagnetic direction in the American Southwest, A.D. 700-1425. Journal of Geophysical Research 94: 527-546.

Takac, P. R.

1999 Archeomagnetic analysis of archeological and experimental rocks from 41ZP364, Zapata County, Texas. TRC Mariah Associates, Austin. 
Wolfman, D.

1984 Geomagnetic dating methods in archaeology. In Advances in Archaeological Method and Theory 7, edited by M. B. Schiffer, pp. 363-458. Academic Press, New York.

\section{Tables}

Table E1 Approximate Temperature at which the Samples Exhibited a Change in Direction upon Thermal Demagnetization.

\begin{tabular}{|c|c|c|c|}
\hline \multirow{2}{*}{ Sample } & \multicolumn{3}{|c|}{$\begin{array}{c}\text { Change in direction } \\
\text { approximate temperature }{ }^{\circ} \mathbf{C}\end{array}$} \\
\hline $4901-2$ & none & & \\
\hline $5295-4$ & none & & \\
\hline 705 & 400 & & \\
\hline 1133 & 150 & & \\
\hline 2090 & 200 & & \\
\hline 2120 & 375 & & \\
\hline 2168 & 250 & & \\
\hline 2876 & 500 & & \\
\hline $5183-3$ & 200 & & 550 \\
\hline 3064 & 350 & $500 ?$ & \\
\hline 575 & 200 & 450 & \\
\hline $4704-2$ & 200 & 400 & \\
\hline
\end{tabular}

Figures
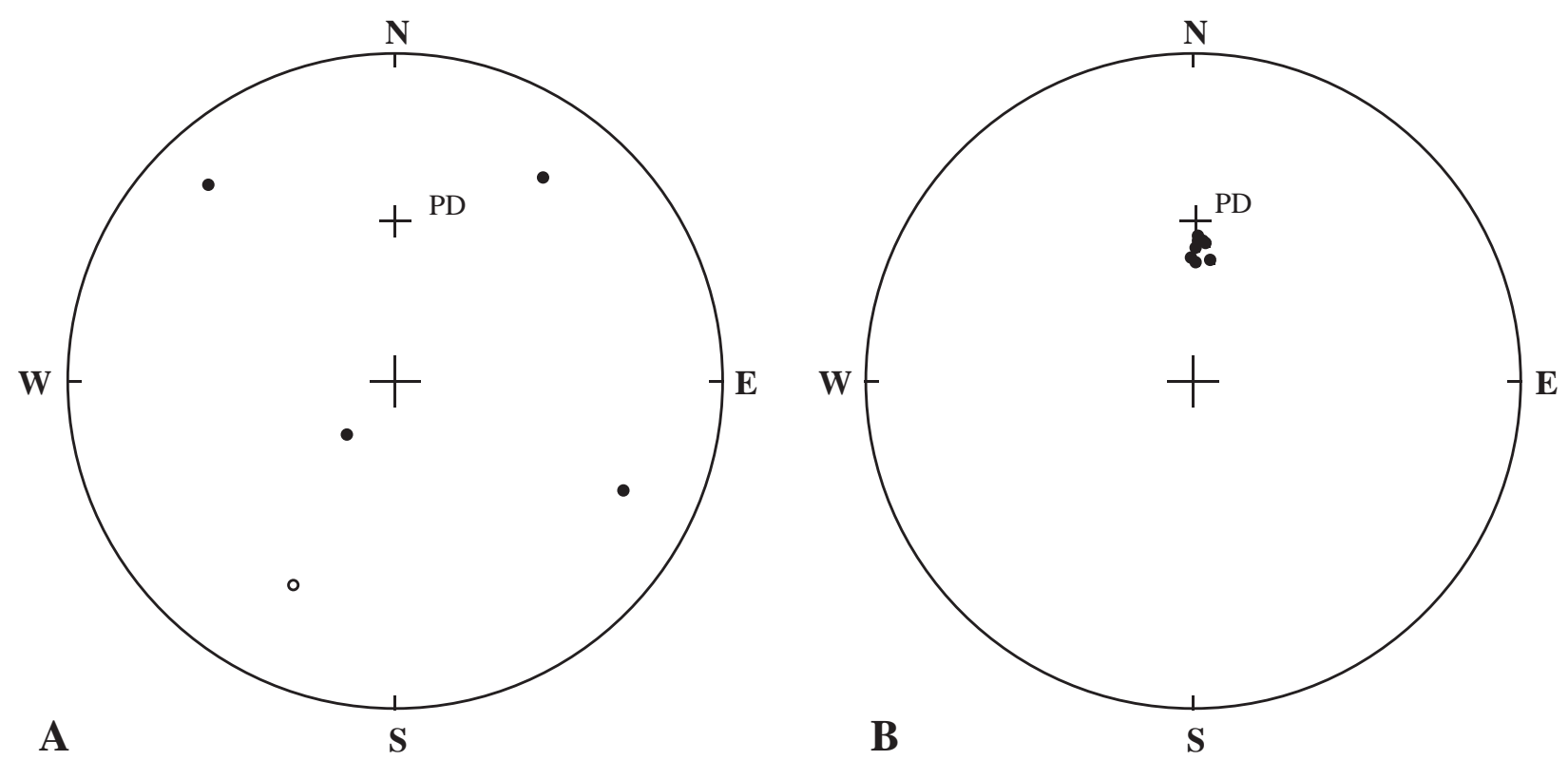

Figure E1 Stereographic Projection of the Directions of Magnetization for Rocks from a Hypothetical Fireplace. A. Before heating, the directions exhibit a random distribution resulting from the geological magnetization of randomly assembled rocks. B. After heating and cooling in place, the rocks acquire a common thermoremanent magnetization parallel to the ambient magnetic field. PD is the direction of the present dipole field at the sampling site. Solid dots indicate directions with positive inclination and lie in the lower hemisphere (below the plane of the paper). Open symbols represent directions in the upper hemisphere. 


\section{WB437}
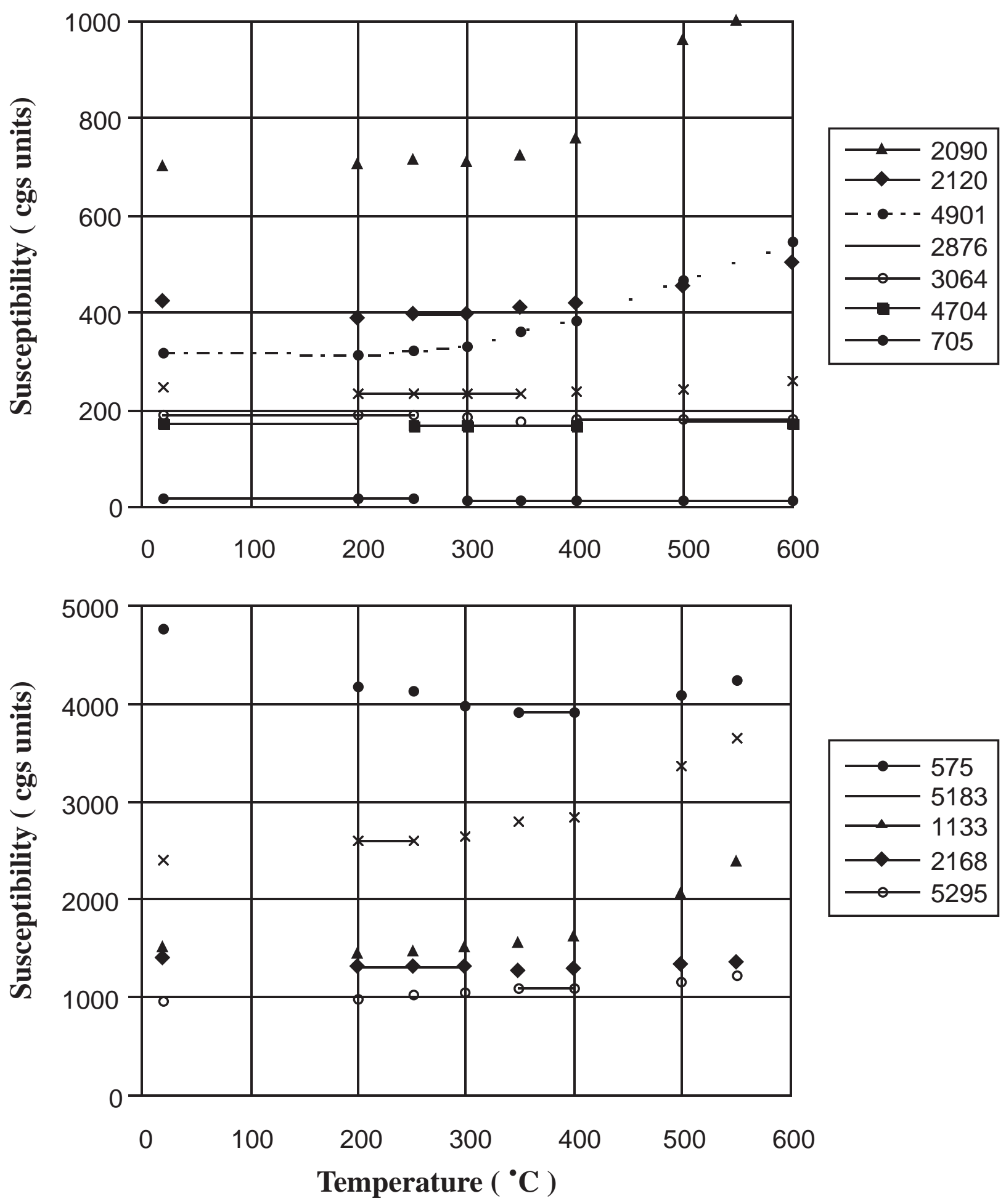

Figure E2 Variations of the Magnetic Susceptibility during Laboratory Heating. The susceptibility was remeasured after most thermal demagnetization steps in order to check for mineralogical changes. Note the different susceptibility scales. 


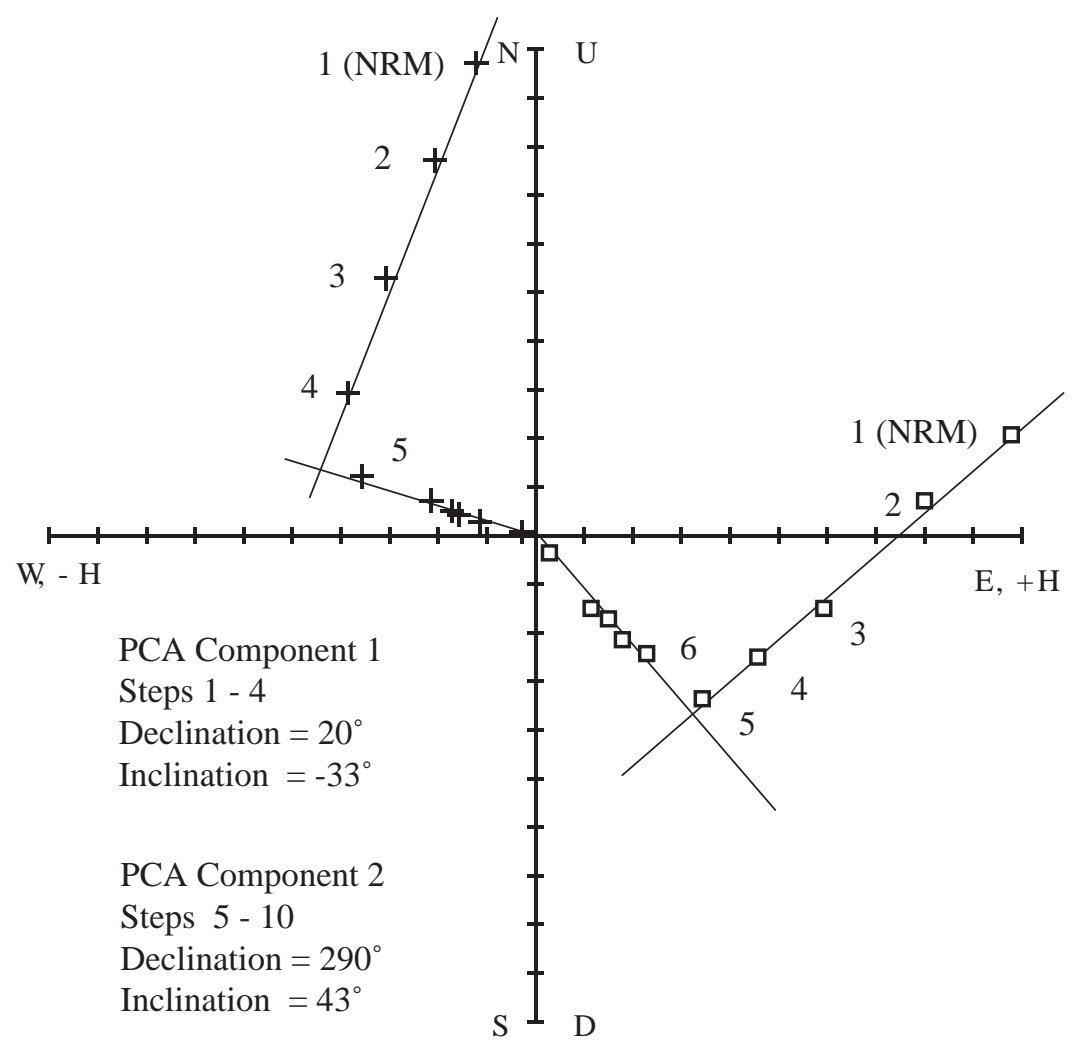

Figure E3 Shematic Vector Component Diagram. The axes are the normalized intensities of magnetization and define two perpendicular planes. Crosses lie in the north-south-east-west plane and open squares in the up-down-horizontal plane. This hypothetical sample contains two components of magnetization. Component 1 is defined by the first four demagnetization steps and component two by steps five through 10. Principal component analysis calculates the bestfitting vectors. 


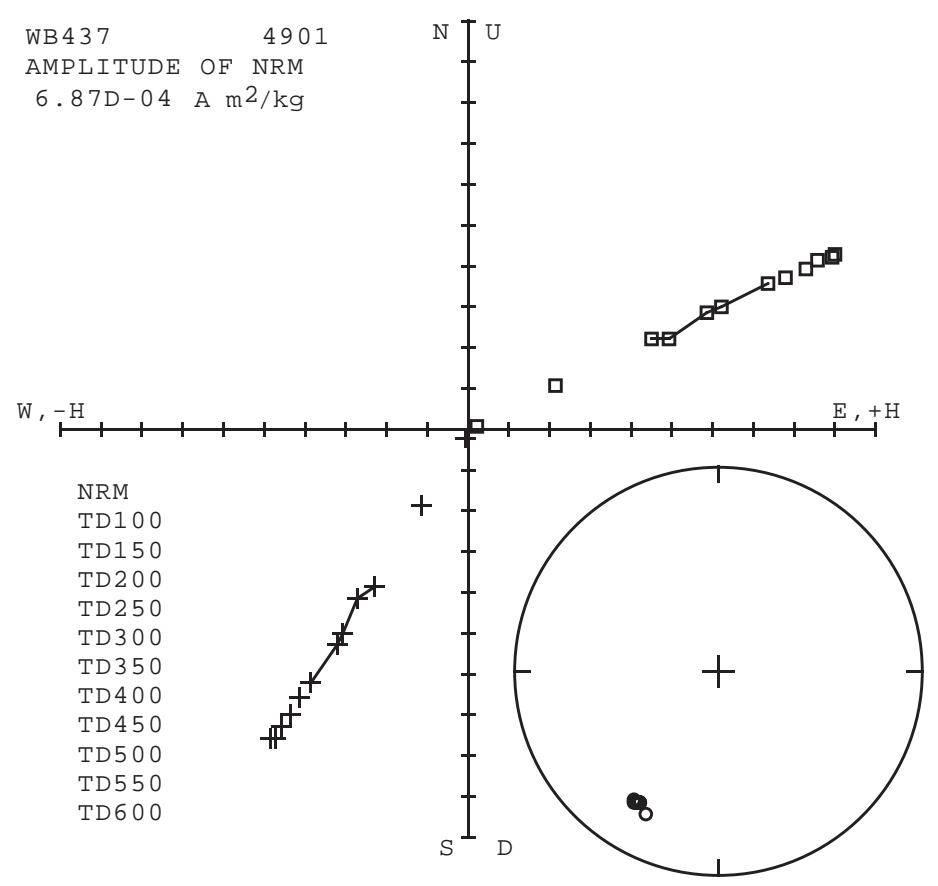

Figure E4 Vector Component Diagram for Sample 4901 from Lino Site 41WB437. Each graph lists the sample number and its intensity of magnetization (length of axes). The thermal demagnetization (TD) steps are given in degrees $\mathrm{C}$. The stereonet shows the directions of magnetization with an arrow indicating the general trend of directional changes if present. Conventions as in Figures E1 and E3. Figures are arranged by complexity of magnetic behavior.

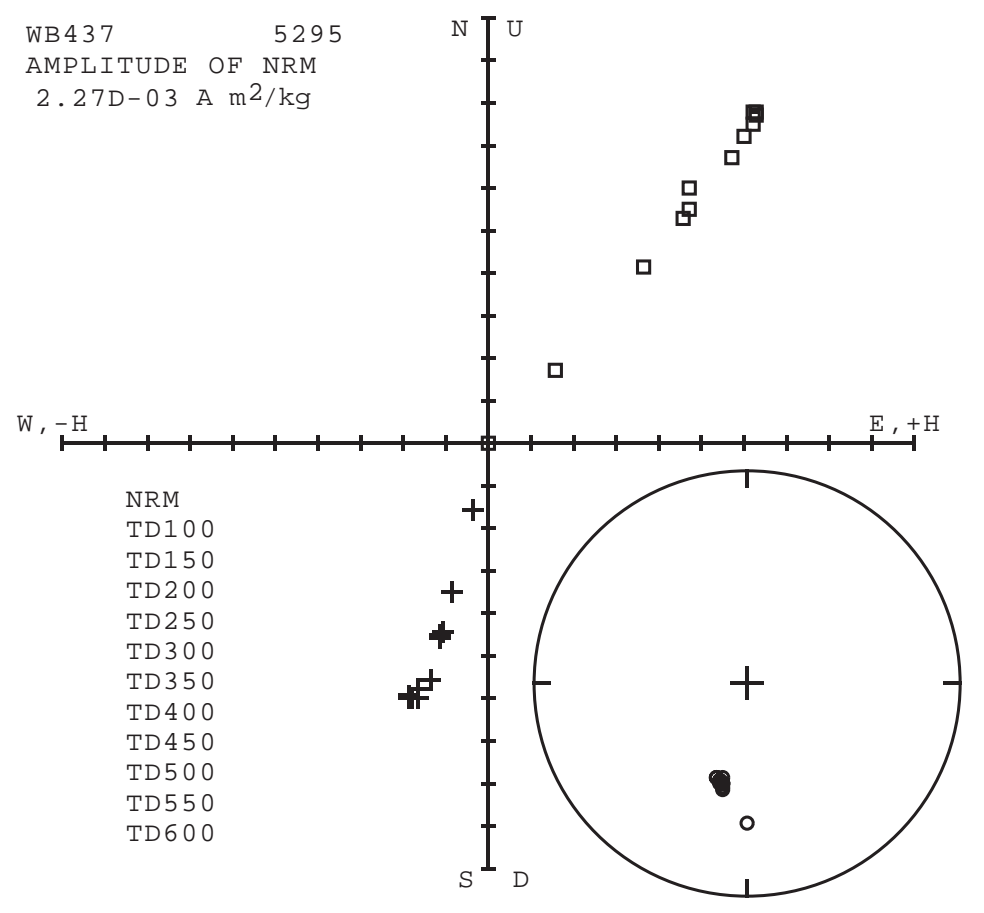

Figure E5 Vector Component Diagram for Sample 5295 from Lino Site 41WB437. Each graph lists the sample number and its intensity of magnetization (length of axes). The thermal demagnetization (TD) steps are given in degrees $\mathrm{C}$. The stereonet shows the directions of magnetization with an arrow indicating the general trend of directional changes if present. Conventions as in Figures E1 and E3. Figures are arranged by complexity of magnetic behavior. 


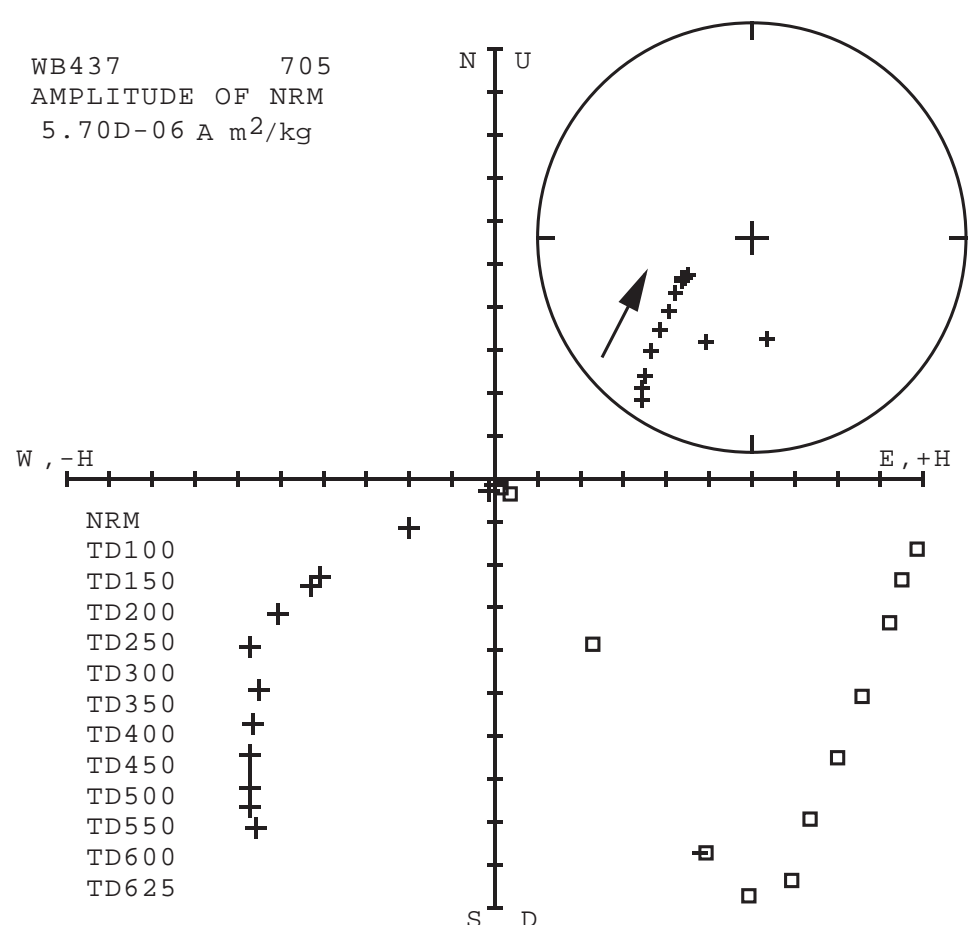

Figure E6 Vector Component Diagram for Sample 705 from Lino Site 41WB437. Each graph lists the sample number and its intensity of magnetization (length of axes). The thermal demagnetization (TD) steps are given in degrees C. The stereonet shows the directions of magnetization with an arrow indicating the general trend of directional changes if present. Conventions as in Figures E1 and E3. Figures are arranged by complexity of magnetic behavior.

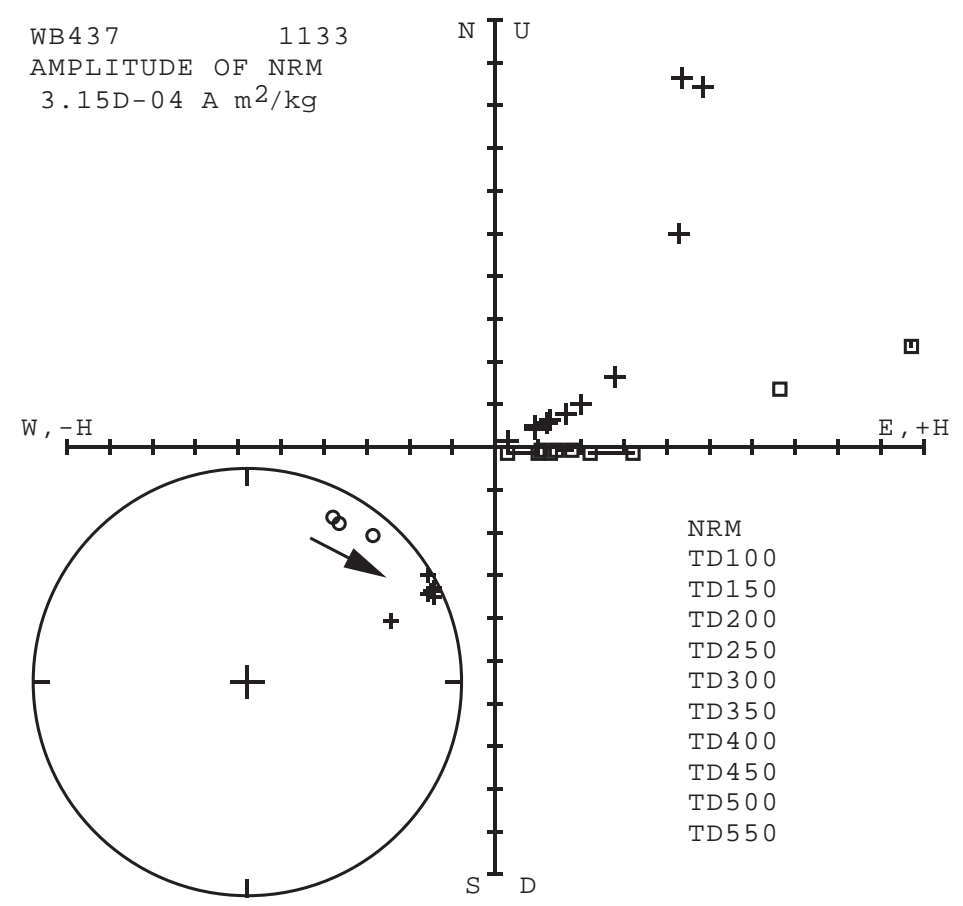

Figure E7 Vector Component Diagram for Sample 1133 from Lino Site 41WB437. Each graph lists the sample number and its intensity of magnetization (length of axes). The thermal demagnetization (TD) steps are given in degrees $\mathrm{C}$. The stereonet shows the directions of magnetization with an arrow indicating the general trend of directional changes if present. Conventions as in Figures E1 and E3. Figures are arranged by complexity of magnetic behavior. 


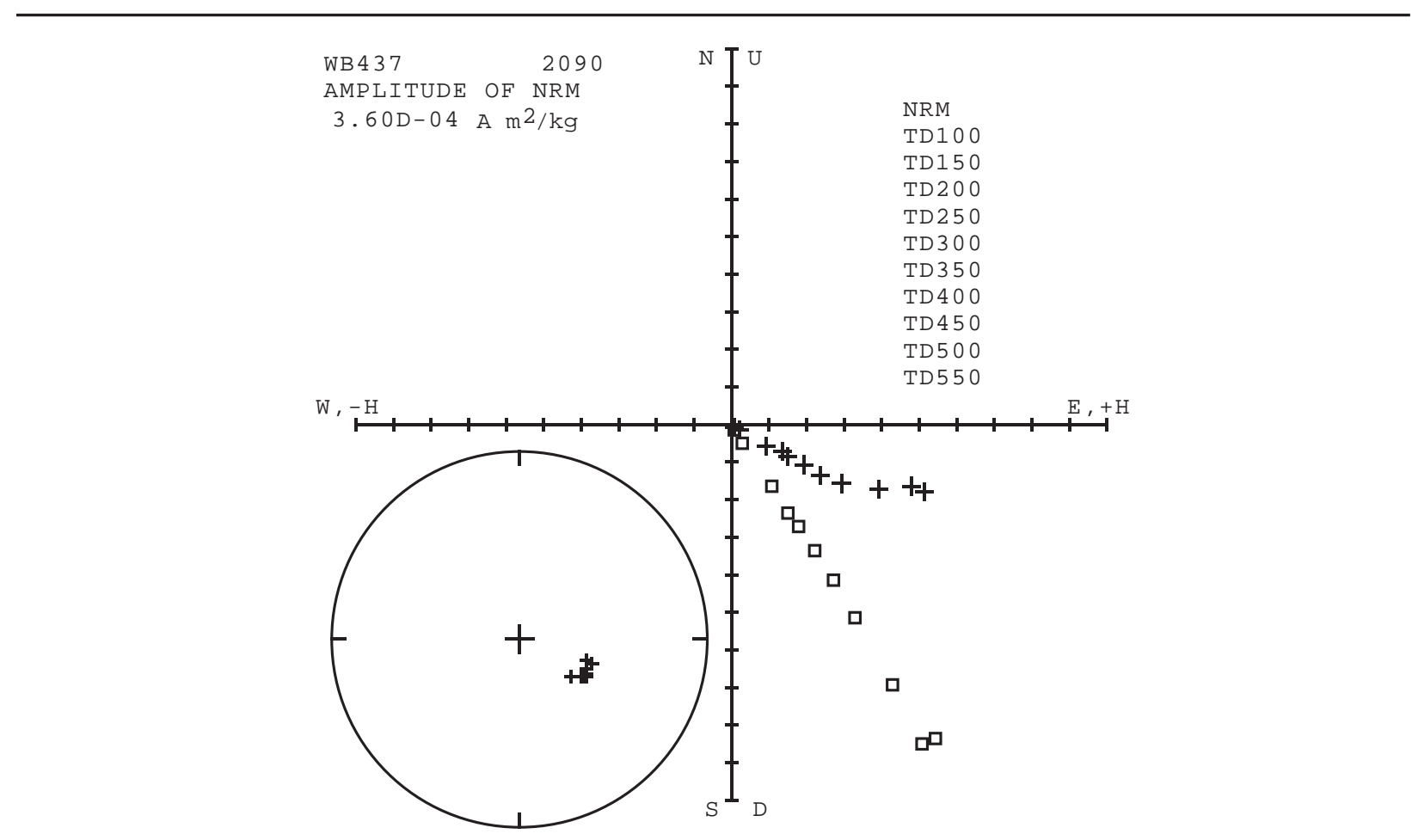

Figure E8 Vector Component Diagram for Sample 2090 from Lino Site 41WB437. Each graph lists the sample number and its intensity of magnetization (length of axes). The thermal demagnetization (TD) steps are given in degrees $\mathrm{C}$. The stereonet shows the directions of magnetization with an arrow indicating the general trend of directional changes if present. Conventions as in Figures E1 and E3. Figures are arranged by complexity of magnetic behavior.

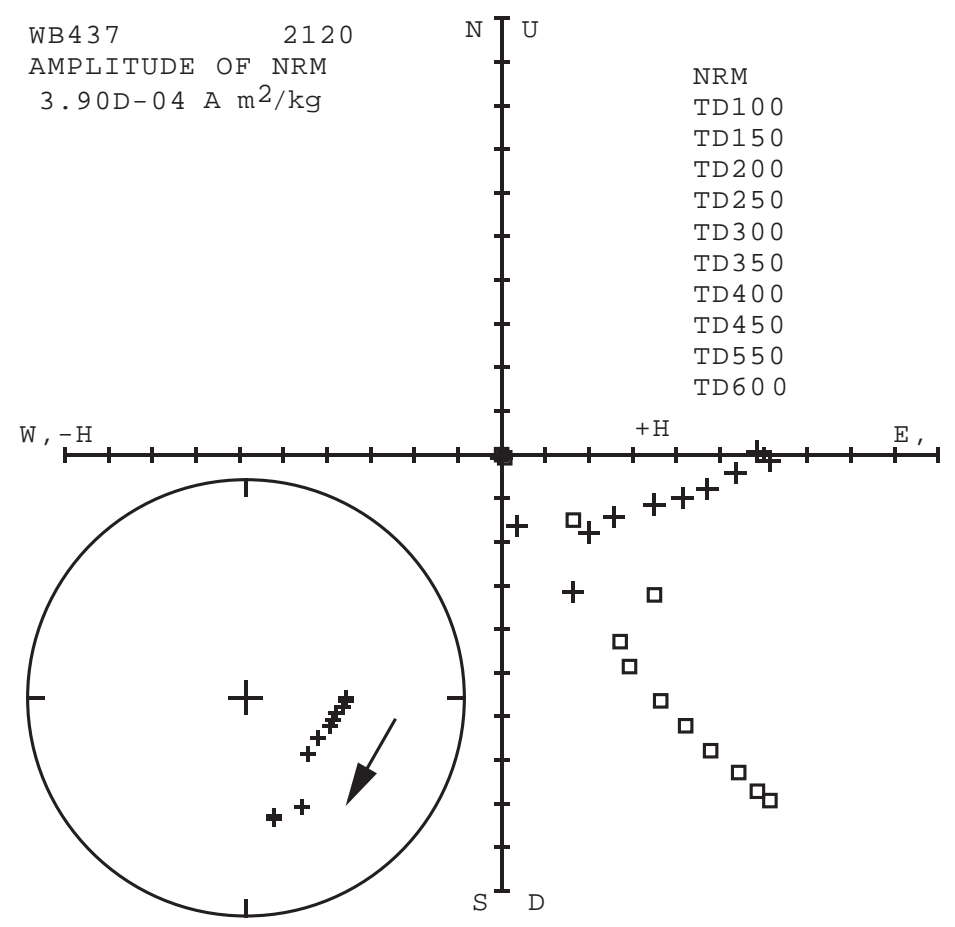

Figure E9 Vector Component Diagram for Sample 2120 from Lino Site 41WB437. Each graph lists the sample number and its intensity of magnetization (length of axes). The thermal demagnetization (TD) steps are given in degrees $\mathrm{C}$. The stereonet shows the directions of magnetization with an arrow indicating the general trend of directional changes if present. Conventions as in Figures E1 and E3. Figures are arranged by complexity of magnetic behavior. 


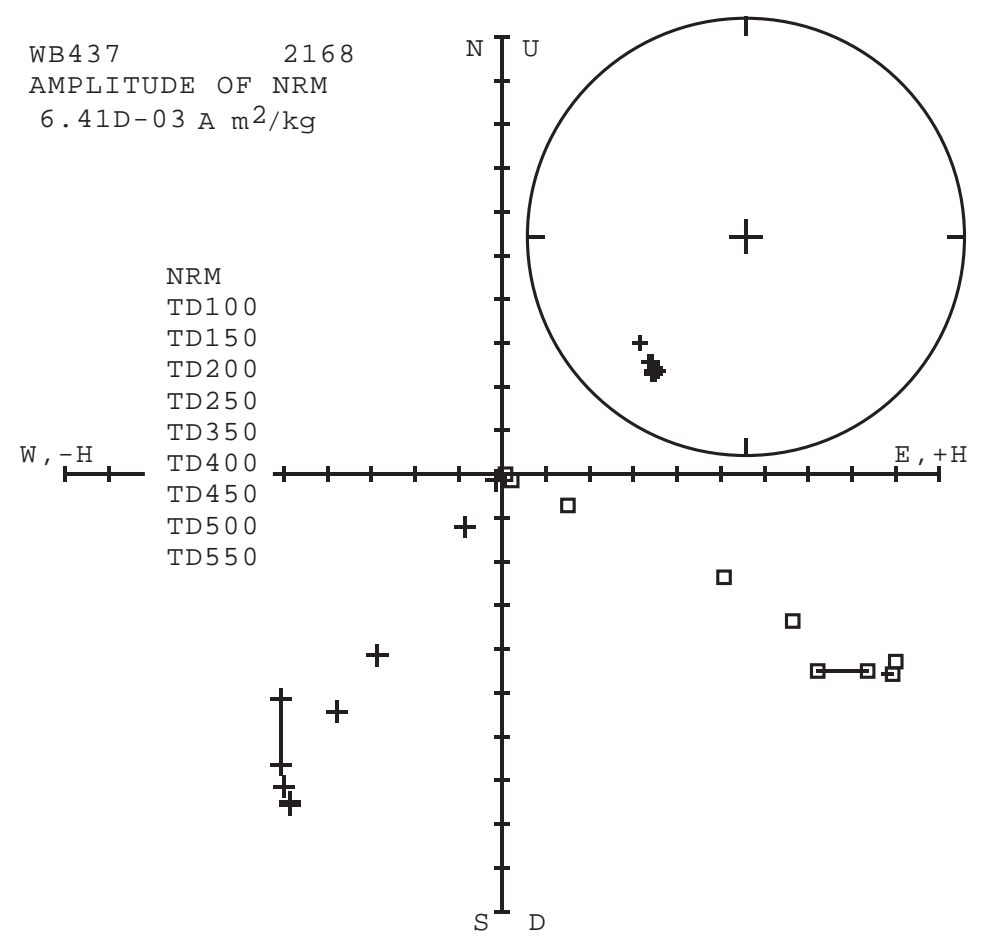

Figure E10 Vector Component Diagram for Sample 2168 from Lino Site 41WB437. Each graph lists the sample number and its intensity of magnetization (length of axes). The thermal demagnetization (TD) steps are given in degrees $\mathrm{C}$. The stereonet shows the directions of magnetization with an arrow indicating the general trend of directional changes if present. Conventions as in Figures E1 and E3. Figures are arranged by complexity of magnetic behavior.

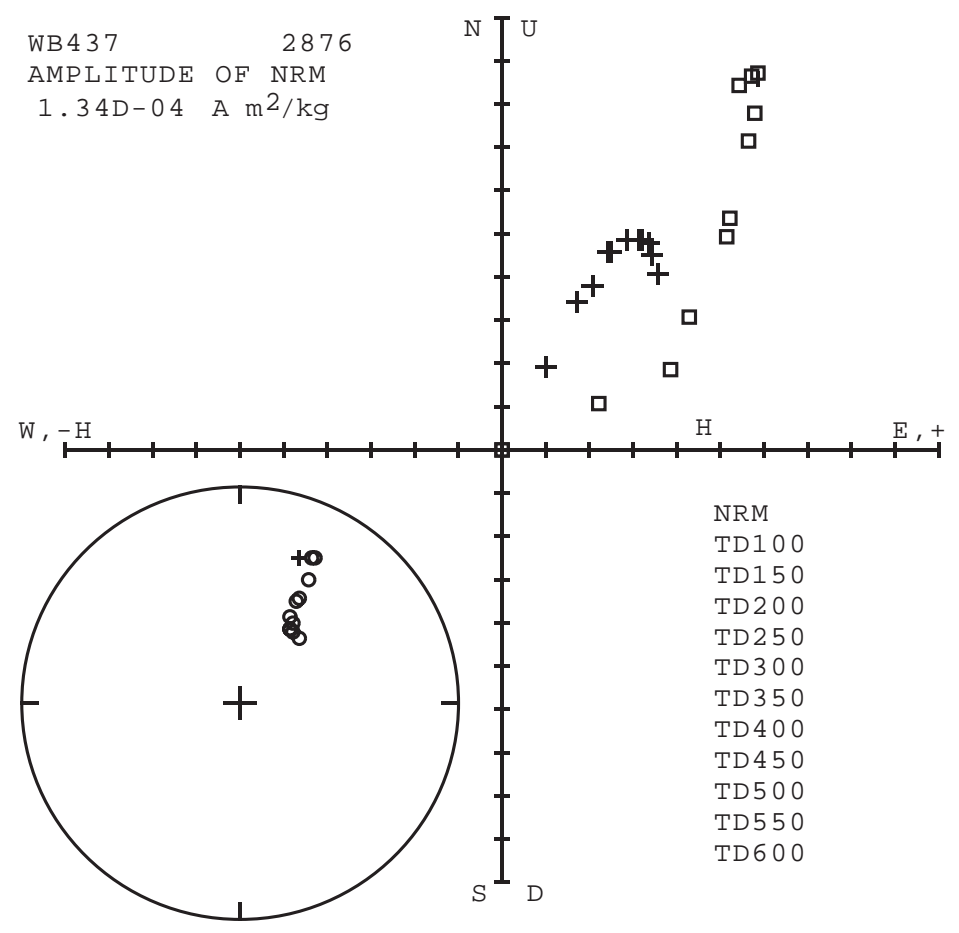

Figure E11 Vector Component Diagram for Sample 2876 from Lino Site 41WB437. Each graph lists the sample number and its intensity of magnetization (length of axes). The thermal demagnetization (TD) steps are given in degrees $\mathrm{C}$. The stereonet shows the directions of magnetization with an arrow indicating the general trend of directional changes if present. Conventions as in Figures E1 and E3. Figures are arranged by complexity of magnetic behavior. 


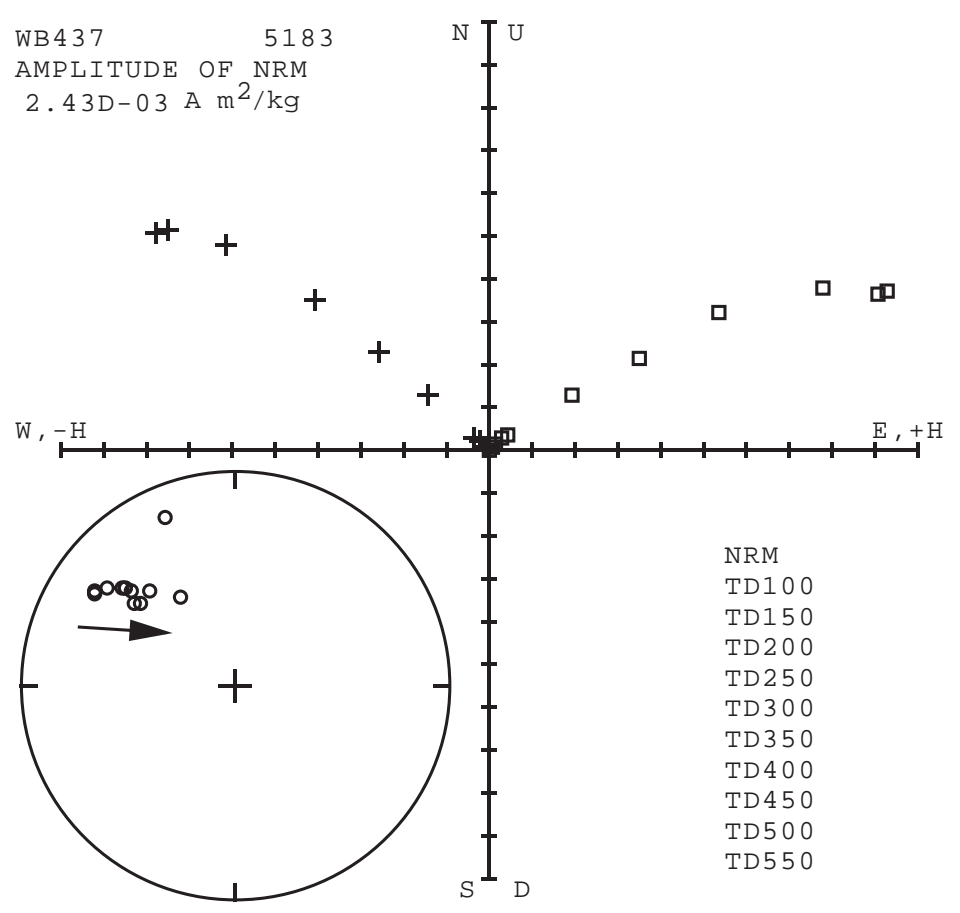

Figure E12 Vector Component Diagram for Sample 5183 from Lino Site 41WB437. Each graph lists the sample number and its intensity of magnetization (length of axes). The thermal demagnetization (TD) steps are given in degrees $\mathrm{C}$. The stereonet shows the directions of magnetization with an arrow indicating the general trend of directional changes if present. Conventions as in Figures E1 and E3. Figures are arranged by complexity of magnetic behavior.

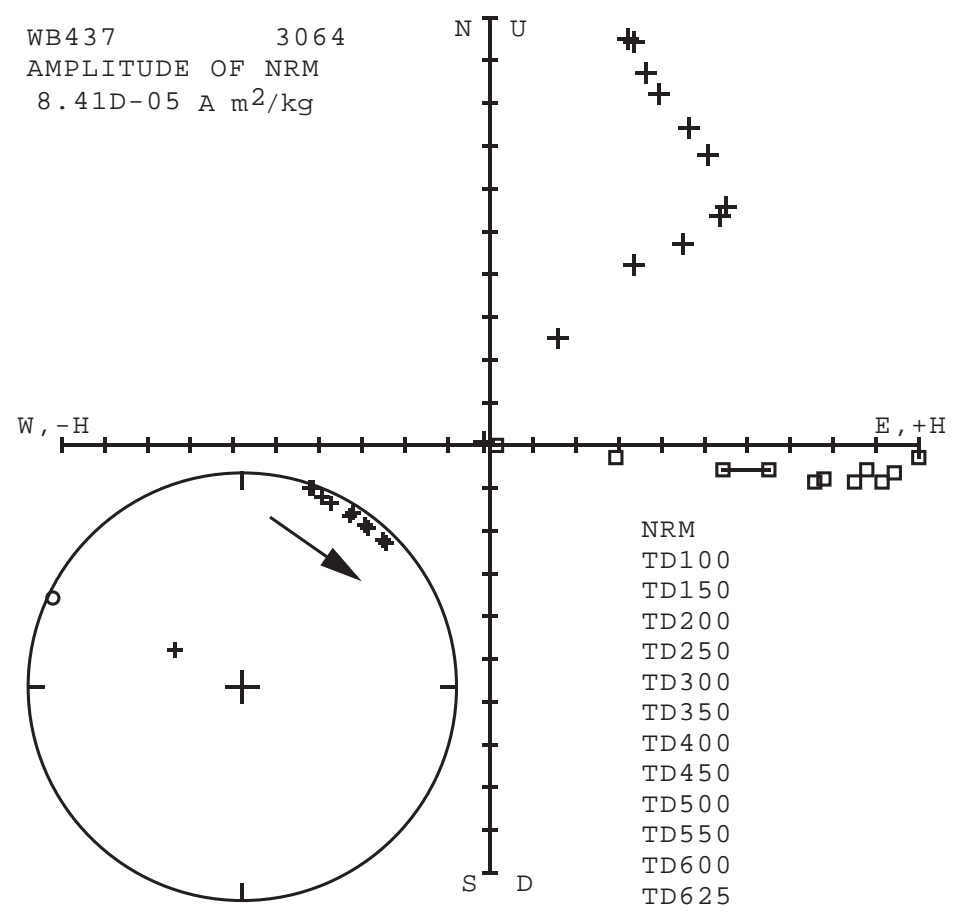

Figure E13 Vector Component Diagram for Sample 3064 from Lino Site 41WB437. Each graph lists the sample number and its intensity of magnetization (length of axes). The thermal demagnetization (TD) steps are given in degrees $\mathrm{C}$. The stereonet shows the directions of magnetization with an arrow indicating the general trend of directional changes if present. Conventions as in Figures E1 and E3. Figures are arranged by complexity of magnetic behavior. 


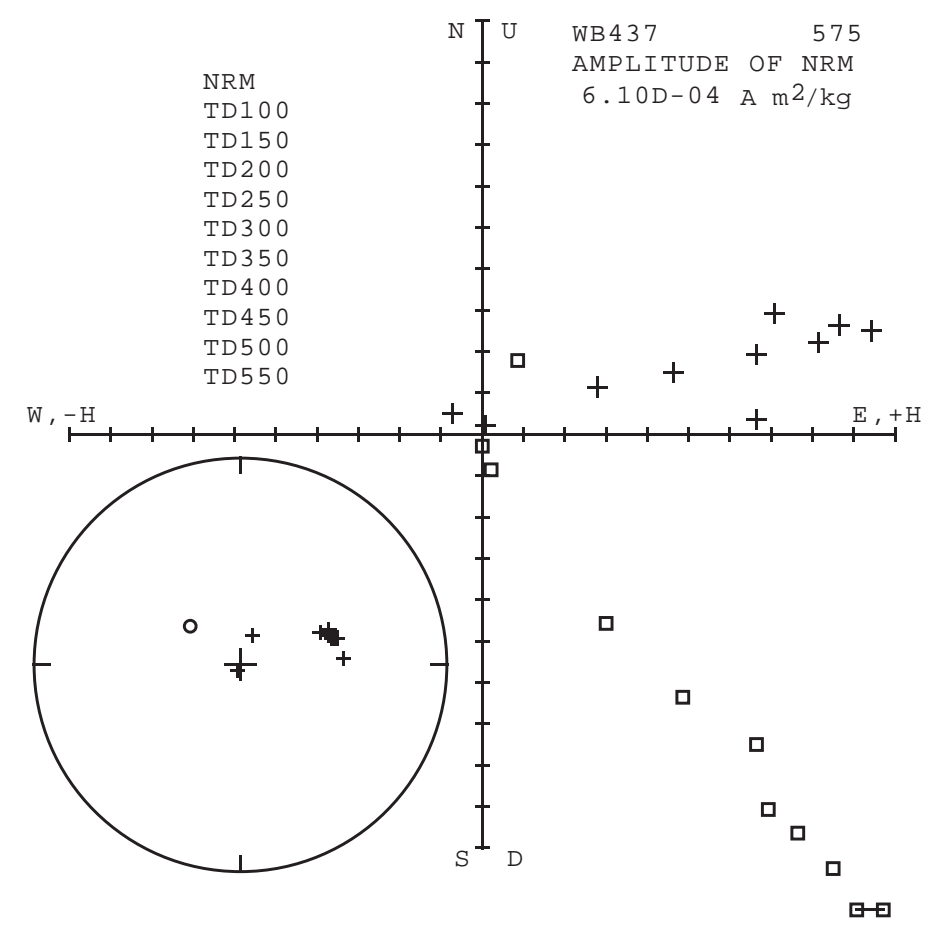

Figure E14 Vector Component Diagram for Sample 575 from Lino Site 41WB437. Each graph lists the sample number and its intensity of magnetization (length of axes). The thermal demagnetization (TD) steps are given in degrees $\mathrm{C}$. The stereonet shows the directions of magnetization with an arrow indicating the general trend of directional changes if present. Conventions as in Figures E1 and E3. Figures are arranged by complexity of magnetic behavior.

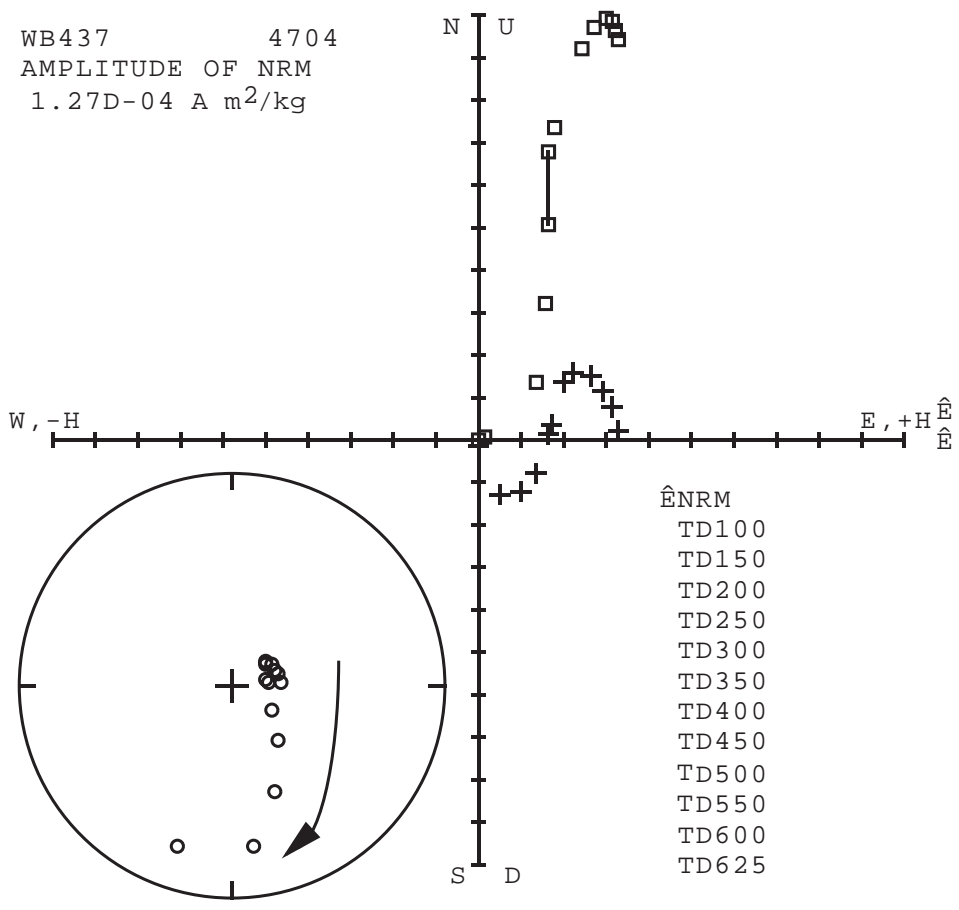

Figure E15 Vector Component Diagram for Sample 4704 from Lino Site 41WB437. Each graph lists the sample number and its intensity of magnetization (length of axes). The thermal demagnetization (TD) steps are given in degrees $\mathrm{C}$. The stereonet shows the directions of magnetization with an arrow indicating the general trend of directional changes if present. Conventions as in Figures E1 and E3. Figures are arranged by complexity of magnetic behavior. 


\section{APPENDIX F}

Rabdotus Shell A/I Ratios by Glenn A. Goodfriend 
Intentionally Left Blank 


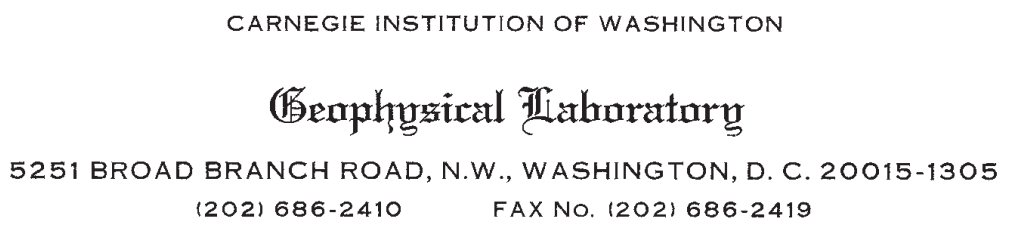

Mr. Mike Quigg

September 8, 1998

TRC-Mariah Associates Inc.

3939 Bee Caves Road, suite C-100

Austin, TX 78746

Fax: (512) 329-8750

Dear Mike,

Here are the amino acid racemization results for the land snail (Rabdotus alternatus) from the Laredo site 41WB437. The analyses were carried out by HPLC (amino acid analyzer). $\mathrm{A} / \mathrm{I}$ is the D-alloisoleucine/L-isoleucine ratio. Samples are calibrated against my standard STD0.30. (See next page.)

There is a very clear bimodal distribution of $A / I$ values in the overall data set. Except for one sample (CF-208), every sample fits into either of two clumps: one averaging 0.107 $( \pm 5.8 \%)$ and the other averaging $0.144( \pm 6.5 \%)$. The range within each of these groups is only very slightly greater than the analytical error $(5 \%)$, indicating a rather tight cluster of ages within each group. However, both age groups occur in each of 3 of the 4 proveniences--only the 4 shells in 5386 fall entirely into the older group. Both test pits (I presume A5 and D1 refer to test pit numbers) show mixing between the two layers sampled, but rather more so for A5 than for D1, which has just one shell (CF-215) that is stratigraphically out of place, of the limited number of specimens analyzed.

Because of this distribution of $\mathrm{A} / \mathrm{I}$ values, it is probably necessary to do only two radiocarbon dates: one for the younger group and one for the older group. Let me know how you would like to proceed with this.

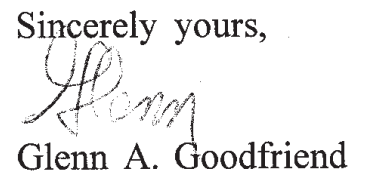

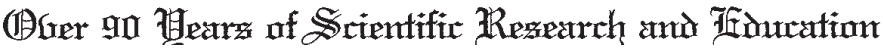


Table F1 Rabdotus Shell A/I Ratios.

Site 41WB437

$\begin{array}{llll}\text { My sample no. } & \text { Your sample no. } & \text { Provenience } & \text { A/I } \\ \text { CF-204 } & 5160-2 \mathrm{a} & \text { A5, 30-40 cm } & 0.096 \\ \text { CF-205 } & 5160-2 b & & 0.112 \\ \text { CF-206 } & 5160-2 \mathrm{c} & & 0.137 \\ \text { CF-207 } & 5160-2 d & \text { A5, } 110-120 \mathrm{~cm} & 0.154 \\ \text { CF-208 } & 5167-2 \mathrm{a} & & 0.172 \\ \mathrm{CF}-209 & 5167-2 \mathrm{~b} & & 0.113 \\ \mathrm{CF}-210 & 5167-2 \mathrm{c} & & 0.105 \\ \mathrm{CF}-211 & 5167-2 \mathrm{c}(\mathrm{sic}) & & 0.115 \\ \mathrm{CF}-212 & 5377-2 \mathrm{a} & & 0.108 \\ \mathrm{CF}-213 & 5377-2 \mathrm{~b} & & 0.103 \\ \mathrm{CF}-214 & 5377-2 \mathrm{c} & & 0.106 \\ \mathrm{CF}-215 & 5377-2 \mathrm{~cm} & 0.144 \\ \mathrm{CF}-216 & 5386-2 \mathrm{a} & \mathrm{D} 1,110-120 \mathrm{~cm} & 0.141 \\ \mathrm{CF}-217 & 5386-2 \mathrm{~b} & & 0.141 \\ \mathrm{CF}-218 & 5386-2 \mathrm{c} & & 0.131 \\ \mathrm{CF}-219 & 5386-2 \mathrm{~d} & & 0.158\end{array}$




\section{APPENDIX G}

Lipid Residue Analyses by Mary Malainey 
Intentionally Left Blank 


\title{
Analysis of the Fatty Acid Compositions of Burned Rock and Ground Stone Tool Residues from the Lino Site, 41WB437, Webb County, Texas
}

\author{
Prepared for \\ TRC Mariah Associates, Inc. \\ 3939 Bee Caves Road, Suite C-100 \\ Austin, Texas U.S.A 78746
}

by

Mary Malainey, Ph.D.

11 Mager Drive West

Winnipeg, Manitoba

Canada R2M 0R9 
Intentionally Left Blank 


\section{Introduction}

The fatty acid component of residues from 43 burned rocks associated with cultural features and five ground stone tools from the Lino site, 41WB437, Webb County, South Texas, were analyzed using gas chromatography. The residues were identified using criteria developed from the decomposition patterns of experimental residues. The first section of this report outlines the development of the identification criteria. Following this, the analytical procedures and results are presented. Five food plants found in the vicinity of the Lino site are evaluated as possible sources of the burned rock residues. The assessment is made on the basis of the fatty acid compositions of the uncooked foods and that of experimental cooking residues prepared from four of these plants.

\section{Identifying Archaeological Residues Using Fatty Acid Composition}

Gas chromatography has been used extensively to analyze the fatty acid component of absorbed archaeological residues since it was first employed by Condamin et al. (1976). Fatty acids are the major constituents of fats and oils (lipids) and occur in nature as triglycerides, consisting of three fatty acids attached to a glycerol molecule by ester-linkages. Their insolubility in water and relative abundance compared to other classes of lipids, such as sterols and waxes, make them suitable for residue analysis. The shorthand designation, $\mathrm{Cx}: \mathbf{y} \omega \mathbf{z}$, refers to a fatty acid with a chain length of $\mathbf{x}$ carbon atoms with $\mathbf{y}$ double bonds (points of unsaturation), with the most distal double bond on the zth carbon atom from the methyl end of the chain. The shorthand designation, C18:109, refers to the most common monounsaturated isomer with a chain length of 18 carbons; its single double bond is located nine carbons from the methyl end of the chain. The shorthand designation, C16:0, refers to a saturated fatty acid with a chain length of 16 carbons.

Unsaturated fatty acids, which are found widely in fish and plants, decompose more readily than saturated fatty acids, sterols or waxes. In the course of decomposition, simple addition reactions may occur at points of unsaturation (Solomons 1980), or peroxidation may lead to the formation of a variety of volatile and non-volatile end products that continue to degrade (Frankel 1991). Peroxidation occurs most readily in fatty acids with more than one point of unsaturation.

Determining the composition of uncooked plants and animals is an important first step in the identification of archaeological residues; but, because of fatty acid decomposition, direct comparisons between uncooked plants and animals and highly degraded archaeological residues are not possible. Marchbanks (1989) suggested that a method able to discriminate samples of uncooked plants, land mammals and fish on the basis of their relative fatty acid composition could also be used to identify the parent materials of archaeological residues. A formula was proposed to identify samples based on the percent of saturated fatty acids $(\% \mathrm{~S})$, where

$$
\% \mathrm{~S}=\frac{\mathrm{C} 12: 0+\mathrm{C} 14: 0}{\mathrm{C} 12: 0+\mathrm{C} 14: 0+\mathrm{C} 18: 2+18: 3 .}
$$

Marchbanks (1989) felt the use of $\mathrm{C} 12: 0$ and $\mathrm{C} 14: 0$ as a measure of saturated fatty acids was more appropriate than $\mathrm{C} 16: 0$ and $\mathrm{C} 18: 0$ because the amounts of the latter fatty acids change with decomposition. Two polyunsaturated fatty acids, C18:2 and C18:3, were included because they are 
common in plants. Marchbanks (1989) demonstrated \%S could be used to discriminate uncooked food samples but did not test the criteria with decomposed cooking residues. This criteria has been used to identify residues from a variety of materials including pottery, stone tools and burned rocks (Marchbanks 1989; Marchbanks and Quigg 1990; Collins et al. 1990).

Skibo (1992:89) could not use Marchbanks' (1989) technique because too many modern food samples did not have $\mathrm{C} 12: 0$ or $\mathrm{C} 14: 0$. Using instead two ratios of fatty acids, $\mathrm{C} 18: 0 / \mathrm{C} 16: 0$ and $\mathrm{C} 18: 1 /$ C16:0, he tried to identify the contents of cooking pots actively used by the Kalinga people of the Philippines (Skibo 1992). He (1992) reported it was possible to link the uncooked foods with residues extracted from cooking pots used to prepare one type of food; however, the ratios could not identify food mixtures. The utility of these ratios did not extend to residues extracted from archaeological potsherds recovered from a Kalinga midden of unknown age, however. Comparisons between archaeological and contemporary cooking vessels were not possible because the ratios of the major fatty acids in the residue had changed with decomposition (Skibo 1992:97).

Loy (1994) was critical of Collins et al. (1990) application of Marchbanks' (1989) criteria to identify residues from the Camp Pearl Wheat site. Loy (1994) suggested that Saturation Index (SI), determined by the ratio:

$$
\mathrm{SI}=1-[(\mathrm{C} 18: 1+\mathrm{C} 18: 2) / \mathrm{C} 12: 0+\mathrm{C} 14: 0+\mathrm{C} 16: 0+\mathrm{C} 18: 0)]
$$

would provide results that are easier to interpret. Loy (1994:618) admitted, however, that poorly understood decompositional changes to the original suite of fatty acids make it difficult to develop a criteria for distinguishing animal and plant fatty acid profiles in archaeological residues.

The major disadvantage of the characterizing ratios proposed by Marchbanks (1989), Skibo (1992) and Loy (1994) is they have never been empirically tested. They are based on criteria that effectively discriminate food classes on the basis of their original fatty acid composition. The resistance of these criteria to the effects of decompositional changes has not been demonstrated. Rather, Skibo (1992) found his fatty acid ratio criteria could not be used to identify highly decomposed archaeological samples.

In order to identify a fatty acid ratio unaffected by degradation processes, Patrick et al. (1985) simulated the long-term decomposition of one sample and monitored the resulting changes. An experimental cooking residue of seal was prepared and degraded in order to identify a ratio of fatty acids not altered by oxidation. Patrick et al. (1985) found that the ratio of two C18:1 isomers, oleic and vaccenic, did not change with decomposition; this fatty acid ratio was then used to identify an archaeological vessel residue as seal. While the fatty acid composition of uncooked foods must be known, Patrick et al. (1985) showed that the effects of cooking and decomposition over long periods of time on the fatty acids must also be understood.

\section{Development of Identification Criteria}

As the first stage in developing the identification criteria used herein, the fatty acid compositions of more than 130 uncooked native food plants and animals from Western Canada were determined 
using gas chromatography (Malainey 1997; Malainey et al. In Press a). When the fatty acid compositions of modern food plants and animals were subject to statistical analyses, the resultant groupings generally corresponded to divisions that exist in nature (Table 1). Clear differences in the fatty acid composition of large mammal fat, large herbivore meat, fish, plant roots, greens and berries/seeds/nuts were detected, but the fatty acid composition of the meat of medium-sized mammals resembles berries/seeds/nuts.

Samples in cluster A, the large mammal and fish cluster, had elevated levels of C16:0 and C18:1. Divisions within this cluster stemmed from the very high level of $\mathrm{C} 18: 1$ isomers in fat, high levels of C18:0 in bison and deer meat, and high levels of very long chain unsaturated fatty acids (VCLU) in fish. Differences in the fatty acid composition of plant roots, greens, and berries/seeds/nuts reflect the amounts of $\mathrm{C} 18: 2$ and $\mathrm{C} 18: 3 \omega 3$ present. The berry, seed, nut, and small-mammal meat samples appearing in cluster B have high to extremely high levels of C18:2. Samples in subclusters VIII, IX and X have high to extremely high levels of C18:1 isomers as well. Modern food samples in cluster $\mathrm{C}$ are mainly plant roots and greens but include some berries. These samples all have higher levels of $\mathrm{C} 18: 2$; except for the berries, all samples have elevated levels of C16:0. Higher levels of $\mathrm{C} 18: 303$ and/or very long chain saturated fatty acids (VLCS) are also common.

Secondly, the effects of cooking and degradation over time on fatty acid compositions were examined. Nineteen residues were prepared by cooking samples of meats, fish, and plants (alone or combined) in replica vessels over an open fire (Malainey 1997; Malainey et al. In Press b). After four days at room temperature, the vessels were broken and a set of sherds analyzed to determine changes after a short term of decomposition. A second set of sherds remained at room temperature for 80 days and then were placed in an oven at 75 degrees $\mathrm{C}$ for a period of thirty days in order to simulate the processes of long-term decomposition. On the basis of changes observed in fatty acid composition of the experimental cooking residues, a method of identifying archaeological vessel residues was proposed (Table 2).

It was found that the levels of medium chain fatty acids (C12:0, C14:0 and C15:0), C18:0 and $\mathrm{C} 18: 1$ isomers in the sample could be used to distinguish the degraded experimental cooking residues (Malainey 1997, Malainey et al. In Press b). Higher levels of medium chain fatty acids indicated the presence of plants such as roots, greens, and most berries. High levels of C18:0 indicated the presence of large herbivore. Moderate levels of C18:1 isomers with low levels of C18:0 indicated the presence of either fish or foods similar in composition to corn. High levels of C18:1 isomers with low levels of C18:0 suggested the presence of beaver or foods of similar fatty acid composition. The criteria for identifying six types of residues were established experimentally; the seventh type, plant with large herbivore, was inferred.

\section{Comparisons with Modern Food Plants from Texas}

Since the initial study, the collection of modern foods has been expanded to include plants from Texas. Two legumes, mesquite beans (Prosopis glandulosa) and Texas ebony seeds (Pithecellobium ebano Berlandier), two cacti products, tasajillo berry (Opuntia leptocaulis) and prickly pear tunas (Opuntia engelmannii), and Spanish dagger pods (Yucca treculeana), a perennial herb in the lily family, were selected because they were likely used as food by the former inhabitants of South 
Texas. The fatty acid compositions of the five plants were determined using gas chromatography (Table 3). The fatty acid compositions of mesquite beans and prickly pear tunas were found to be intermediate in composition between foods in subcluster VII and X. The foods in subcluster VII include four types of seed: corn (Zea mays), sunflower (Helianthus annuus), winter squash (Cucurbita pepo) and bulrush (Scirpus sp.); and three varieties of berries: saskatoon (Amelanchier alnifolia), hawthorn (Crataegus sp.) and pin cherry (Prunus pensylvanica). The foods in subcluster X include three types of berries: juniper (Juniperus sp.), gooseberry (Ribes oxyacanthoides) and blueberries (Vaccinium angustifolium); two types of seed: dock (Rumex sp.) and goosefoot (Chenopodium album); and muskrat (Ondatra zibethicus) meat.

The Texas ebony seeds were intermediate in composition between subclusters VI and V.

Subcluster VI contains acorn (Quercus macrocarpa), knotweed (Polygonum sp.) and dock (Rumex sp.) seeds; two varieties of mushroom (Armillaria sp. and Leccinum sp.); and beaver (Castor canadensis) meat. Subcluster V includes hazelnut (Corylus americana), pincherry, and chokecherry (Prunus pensylvanica and $P$. virginiana). The tasajillo was very similar in composition to the seeds in cluster IX: marsh-elder (Iva sp.) and arrowgrass (Triglochin sp.). Spanish dagger pods were also similar in fatty acid composition to the seeds in cluster IX, but their C18:1 isomer level was about 10 percent higher than the average for this cluster.

\section{Experimental Cooking Residues of Texas Food Plants}

Experimental cooking residues of four of the food plants from Texas have been prepared. Residues for Texas ebony and Spanish dagger were prepared by boiling food stuffs in a large glass beaker lined with a fired clay cylinder. An electric hot plate was used as the heat source; total cooking time was two hours. The fatty acid composition of cooking residues was determined after 50 days at room temperature and simulated long term decomposition ( 75 degrees $\mathrm{C}$ oven for 30 days). J. Michael Quigg cooked mesquite beans and prickly pear pads using a technique known as stone boiling in January 1998. Sandstone pieces collected from bedrock below Holocene sand deposits were heated on a gas stove. The hot rocks were then placed in a container with water and the food. Heat from the rock was sufficient to boil the foods at a temperature of 99 degrees $\mathrm{C}$ for between 50 and 60 minutes. A maximum interior temperature of 204 degrees $\mathrm{C}$ and surface temperature of 412 degrees $\mathrm{C}$ was recorded for the rock used to cook the mesquite. A maximum interior temperature of 239 degrees $\mathrm{C}$ and surface temperature of 538 degrees $\mathrm{C}$ was recorded for the rock used to cook the prickly pear pads. It is hypothesized that the lipids extracted from the archaeological burned rock samples were introduced in a similar manner. Rocks were heated in a hearth, and a pit dug into the soil served as the cooking receptacle. The fatty acid composition of residues absorbed into the rocks used for cooking were analyzed after one year; these rocks were not subjected to simulated long-term decomposition.

The fatty acid compositions of the experimental cooking residues are presented in Table 4. Fresh Texas ebony seeds have an initial C18:2 level of 26 percent and C18:1 isomer levels of about 45 percent. As a result of cooking (thermal degradation) and simulated time (oxidative degradation), the amount of the polyunsaturated fatty acid, C18:2, in the sample drops significantly. While maintaining a percentage composition above 40 percent, the level of $\mathrm{C} 18: 1$ in the sample slowly decreases with respect to the more stable saturated fatty acids, C16:0 and C18:0 (Table 4, Figure 1). 
The relative percentage of saturated fatty acids increases with the decomposition of unsaturated fatty acids. After simulated long term decomposition, the cooking residue from Texas ebony seeds resembles degraded beaver (Figure 2).

A similar pattern is observed with Spanish dagger, which has initial C18:2 levels of 62 percent and C18:1 isomer levels of 24 percent. The level of C18:2 drops rapidly while the level of C18:1 slowly decreases with respect to the saturated fatty acids (Table 4, Figure 3). After simulated long term decomposition, the cooking residue from Spanish dagger is intermediate in composition between degraded beaver and degraded corn (Figure 4).

Tasajillo is similar in composition to Spanish dagger, except that its initial level of C18:1 isomers is only 14 percent. On the basis of its similarity to Spanish dagger, the cooking residues of tasajillo berries should be intermediate in composition between degraded beaver and degraded corn. Many plants that have a very low fat content, such as plant greens, roots, and many berries, do not degrade in the expected manner, however. Instead, the levels of both $\mathrm{C} 18: 2$ and $\mathrm{C} 18: 1$ isomers drops very quickly. This rapid degradation of mono-unsaturated and polyunsaturated fatty acids occurs in chokecherries, a berry with high initial levels of C18:1 isomers and C18:2 (Figure 5). These residues are characterized by levels of medium chain fatty acids greater than 10 percent, together with low levels of C18:0 (less than 27.5 percent) and C18:1 isomers (less than 15 percent). Experimental cooking residues of tasajillo must be prepared in order and subjected to simulated long-term decomposition in order to determine its degradation pattern.

Fresh prickly pear has a C18:2 level of 49 percent and C18:3 13 level of five percent, which makes it quite similar in composition to corn (Figure 4). In Figure 6, the composition of fresh prickly pear tunas is compared to that of the cooking residue of prickly pear pads after one year. Although the graphs are not comparing the compositions of identical parts of the prickly pear plant, the decomposition pattern observed is that expected on the basis of its similarity to corn. The oil content of prickly pear pads is probably significantly lower than that of corn, which may partially account for the high level of degradation of the cooking residue in the absence of simulated longterm decomposition.

Fresh mesquite beans, with a C18:2 level of 45 percent, are also similar in composition to corn; although, their $\mathrm{C} 18: 3 \omega 3$ level of 12 percent is significantly higher than that of corn (three percent). The composition of fresh mesquite beans compared to that of the cooking residue after one year is presented in Figure 7. The difference in C18:3 13 levels between corn and mesquite may account for the maintenance of high levels of $\mathrm{C} 18: 1$ and $\mathrm{C} 18: 2$ in the mesquite cooking residue after one year. In this respect, the one-year-old mesquite cooking residue resembles the cooking residue of beaver after four days (Figure 2). With simulated long-term decomposition, the cooking residue would likely resemble that of corn more closely.

\section{Methodology}

Absorbed residues from forty-three burned rock samples associated with identifiable features (Table 5 ) and absorbed or surface residues from five ground stone tools (Table 6) were extracted and analysed using gas chromatography. The procedure used to extract residues from the burned rocks 
(Lino 1 through Lino 43); one of the manos (Lino 46) and the abraders (Lino 49 and Lino 50) was modified from Evershed et al. (1990). This procedure enabled lipids absorbed into the sample matrix to be extracted from the sample with minimal processing. Surface contaminants were removed by grinding 2 to $3 \mathrm{~mm}$ of the exterior surface off the rock with a Dremel ${ }^{\circledR}$ tool fitted with a silicon carbide grinding stone. Immediately thereafter, the rock sample was crushed with a hammer mortar and pestle then transferred to a 10-dram screw-top glass vial.

Chloroform:methanol $(2: 1 \mathrm{v} / \mathrm{v} ; 10 \mathrm{~mL})$, the solution used in the lipid extraction (Folch 1957), was added and the sample placed in a freezer (-20 degrees $\mathrm{C})$. Lipids were extracted from the crushed rock by ultrasonication ( 2 X $10 \mathrm{~min})$ while in chloroform-methanol $(2 \times 50 \mathrm{~mL})$. Chloroformmethanol $(2: 1 \mathrm{v} / \mathrm{v})$ solvent washes were used to extract residues from one of the two working surfaces of the other manos (Lino 47 and Lino 48). An acid solution had been used to remove a sample for phytolith analysis from the other working surface of these manos. Surface washes were taken from the manos because the hardness of the rock made it difficult to remove a sample for analysis. These manos were never handled in the field or in laboratory settings without gloves so no contamination with modern lipids from fingerprints would be present.

Solids were removed by filtering the solvent mixture into a round-bottomed flask; solvents were removed by rotary evaporation. Any remaining water was removed from the lipids by evaporation with benzene $(2 \mathrm{~mL}) ; 1.5 \mathrm{ml}$ of chloroform:methanol was used to transfer

the dry lipids to a screw-top glass vial with a Teflon ${ }^{\circledR}$-lined cap and the total lipid extract solution was stored under nitrogen at -20 degrees $\mathrm{C}$.

For each sample, $600 \mu \mathrm{L}$ of the total lipid extract solution was placed in a $20 \mathrm{~mL}$ screw-top test tube and dried in a heating block under nitrogen, giving 10-20 mg of lipid. Fatty acid methyl esters (FAMES) were prepared by treating the dry lipid with $6 \mathrm{ml}$ of $0.5 \mathrm{~N}$ anhydrous hydrochloric acid in methanol (65 to 70 degrees C, 60 min). Fatty acids that occur in the sample as di- or triglycerides are detached from the glycerol molecule and converted to methyl esters. After cooling to room temperature, $4 \mathrm{~mL}$ of distilled water was added, and the FAMES were recovered with petroleum ether $(2 \mathrm{X} 3 \mathrm{~mL})$ and transferred to a vial. The solvent was removed under a gentle stream of nitrogen and then the FAMES were transferred to a GC vial with a conical glass insert with $75 \mu \mathrm{L}$ of iso-octane.

Solvents and chemicals were checked for purity by running a sample blank. The entire lipid extraction and methyl esterification process was performed, and FAMES were dissolved in $75 \mu \mathrm{L}$ of isooctane, and $1 \mu \mathrm{L}$ of the solution was injected onto the column. Traces of contamination were discovered and subtracted from the sample chromatograms. The relative percentage compositions were calculated by dividing the integrated peak area of each fatty acid by the total area of fatty acids present in the sample.

\section{Gas Chromatography Analysis Parameters}

The GC analysis was performed on a Hewlett-Packard 5890 gas chromatograph fitted with a flame ionization detector connected to a Hewlett-Packard 3390 computing integrator. Samples were separated using a Supelcowax 10 fused silica capillary column (15 m X 0.32 mm I.D.; Supelco; 
Oakville, Ontario). An autosampler injected a $1 \mu \mathrm{L}$ sample using a split injection system with the ratio set at 1:40. Hydrogen was used as the carrier gas at a linear velocity of $40 \mathrm{~cm} / \mathrm{second}$. Column temperature was programmed from 180 to 210 degrees $\mathrm{C}$ at two degrees $\mathrm{C}$ per minute; lower and upper temperatures were held for four and 12 minutes, respectively. Peaks were identified through comparisons with several external qualitative standards (NuCheck Prep; Elysian, Manitoba). Using this procedure, fatty acids are detectable to the nanogram $\left(1 \mathrm{X} 10^{-9} \mathrm{~g}\right)$ level.

\section{Results}

Results of the analysis of the absorbed residues from the 43 burned rock samples (Lino 1 through Lino 43) and absorbed or surface residues from the five ground stone tools (Lino 46 through Lino 50) are presented in Table 7. The residue of one sample, Lino 27, is contaminated with modern lipids and there is insufficient material to allow for re-analysis. The level of C18:2 is between 10 percent and 20 percent in many samples, indicating that the level of decomposition of the burned rock residues is lower than that typically observed in archeological pottery cooking vessel residues. This finding is consistent with the hypothesised introduction of residues into burned rocks. The thick chunks of porous sandstone used for stone boiling were completely immersed in the broth and able to absorb a relatively large amount of residues at the end of the cooking process while at a relatively low temperature. In comparison, only the interior of the pottery cooking vessels is in contact with its contents; the walls are quite thin, and the exterior is often exposed to high temperatures, which increases the degradation rate of absorbed residues Levels of C18:2 greater than 10 percent are also observed in the absorbed residues from the abrader (Lino 49 and Lino 50).

The high degree of residue preservation exhibited in many of the burned rock samples and the abraders complicates the application of identification criteria which, as mentioned previously, was developed for pottery cooking vessels. The criteria is based on the relative percentage of medium chain saturated fatty acids (C12:0, C14:0 and C15:0), a long chain saturated fatty acid (C18:0), and a mono-unsaturated fatty acid (C18:1) that degrades to a stable level in the cooking residues of many types of foods. Due to high amounts of C18:2 in the residues, the relative percentages of the other fatty acids in the sample are slightly depressed. Five samples identified as Large Herbivore (Lino 3, Lino4, Lino 15, Lino 21, and Lino 23) have C18:0 values between 26.46 percent and 27.28 percent. With further degradation of $\mathrm{C} 18: 2$, the C18:0 would surpass 27.5 percent and fall within the category of Large Herbivore. Similarly, six samples (Lino 5, Lino 7, Lino 9, Lino 18, Lino 19, and Lino 25) are identified as Plant because, with slightly more degradation, levels of C18:2 and C18:1 would decrease and the level of medium chain fatty acids would increase to more than 10 percent. Furthermore, the relatively low levels of C18:0 (25.32 percent or lower) and C18:1 (14.62 percent or lower) in these samples excludes them from any other category.

As shown in Table 8, 12 burned rock residues were identified as Plant. These residues were identified in samples from all occupations at the site; however, the highest occurrences are in Occupations 1, 4 and 5. Ten of the burned rock residues were identified as Large Herbivore. These residues were identified in samples from Occupations 1, 2, 4 and 5; most are associated with Occupations 1 and 2. Three samples, one each from Occupations 2, 3 and 5, were identified as Beaver. One residue from Occupation 2 was identified as Fish/Corn. Single occurrences of residues identified as Large Herbivore with Plant or Bone Marrow and Plant with Large Herbivore are associated with 
Occupation 3. One residue from Occupation 4 fell on the border between the categories of Fish Corn and Plant. One residue from Occupation 5 was identified as Fish/Corn with Plant. Another residue may be from a plant with high levels of $\mathrm{C} 17: 0$; cat tail seeds are known to have high levels of this fatty acid (Malainey et al. In press a). Eleven of the samples submitted for analysis contained insufficient lipid for identification, including three samples each from Occupations 1, 3 and 5 and one sample each from Occupations 2 and 4.

Occurrences of residue identifications within the various features at the site are presented in Table 9. The burned rocks from nine features contained only a single type of residue. Plant is the only identifiable burned rock residue associated with three Features, 15, 29 and 42. The only identifiable burned rock residue occurring in Features 12 and 22 is Large Herbivore. The only residue identified in Features 30 and 34 is Beaver. One burned rock from each of Features 22, 30, 34 and 42 contained insufficient lipids for analysis. The residue sample from Feature 39 was identified as Plant with Large Herbivore. The burned rock residue sample from Feature 41 was identified as Fish/Corn and Plant.

More than one type of residue was identified in eight features. Features 10, 14, 16 and 26, contained burned rocks with residues identified as Large Herbivore and burned rocks with residues identified as Plant. Burned rock residues from Feature 18 included identifications of Large Herbivore with Plant or Bone Marrow and Beaver. Residues identified as Large Herbivore and Fish/Corn were present in the burned rocks associated with Feature 20. The burned rocks from Feature 24 contained residues identified as Plant and Large Herbivore, as well as the residue which may represent an unknown seed with high initial levels of C17:0. Feature 27 contained burned rocks with residues identified as both Plant and borderline Plant and Fish/Corn.

The burned rocks from Features 32, 35, 36, and 41 in Occupation 1 and Feature 40 in Occupation 5 contained insufficient lipids for identification.

Identifiable residues were extracted from four of the five ground stone tools submitted. The surface residue from one mano, Lino 47, and the absorbed residue from one abrader, Lino 49, were both identified as Fish/Corn. The surface residue from another mano, Lino 48, and the absorbed residue from the other abrader, Lino 50, were both identified as Beaver. The absorbed residue from the third mano, Lino 46, contained insufficient lipids for identification.

\section{Conclusions}

Absorbed residues from 42 burned rock rocks and three ground stone tools along with surface residues from two other ground stone tools were extracted and analyzed using gas chromatography. Twelve burned rock residues were identified as Plant, ten were identified as Large Herbivore, and three were identified as Beaver. There were single occurrences of residues identified as Large Herbivore with Plant or Bone Marrow, Plant with Large Herbivore, Fish/Corn, and Fish/Corn and Plant. One residue fell on the border between Plant and Fish/Corn; another residue may represent an unknown seed with high initial levels of C17:0. The residues from one abrader and one mano were identified as Fish/Corn; the residues from the other abrader and a second mano were identified 
as Beaver. Eleven of the burned rocks and one mano contained insufficient fatty acids to make an identification.

Mesquite and prickly pear are the strongest candidates for residues identified as Fish/Corn. These include three residues: Lino 14, Lino 47, and Lino 49. The experimental cooking residue for prickly pear pads degraded very quickly without simulated long-term decomposition. It must be considered as a candidate for samples identified as Fish/Corn and Plant, samples which border the categories of Fish/Corn and Plant, as well as samples identified as Plant with higher levels of C18:1 isomers. These include the following samples: Lino 5, Lino 24, Lino 40, and possibly Lino 19.

Texas ebony seeds are strong candidates for residues identified as Beaver with C18:1 levels greater than 28 to 30 percent. This would include two burned rock residues, Lino 30 and Lino 33, as well as the residue from one abrader, Lino 50. Residues identified as either Beaver with C18:1 slightly above 25 percent, or Fish/Corn with C18:1 levels slightly below 25 percent, may have been the result of cooking Spanish dagger or tasajillo. This would include one burned rock residue, Lino 11, and the residue from one mano, Lino 48.

In general, seeds, nuts and berries with high fat contents are more likely to generate cooking residues that degrade in a predictable manner. Other parts of plants, including greens, roots, and most berries have low fat contents so that the unsaturated fatty acids in the cooking residue degrade very quickly. It is possible that degraded residues produced by cooking tasajillo or prickly pear could be identified as Plant, but this must be confirmed experimentally.

\section{References}

Collins M.B., B. Ellis and C. Dodt-Ellis

1990 Excavations at the Camp Pearl Wheat Site (41KR243): An Early Archaic Campsite on Town Creek, Kerr County, Texas. Studies in Archaeology 6. Texas Archeological Research Laboratory, The University of Texas-Austin.

Condamin, J., F. Formenti, M.O. Metais, M. Michel and P. Blond

1976 The Application of Gas Chromatography to the Tracing of Oil in Ancient Amphorae. Archaeometry 18 (2):195-201.

Evershed, R.P., C. Heron and L.J. Goad

1990 Analysis of Organic Residues of Archaeological Origin by High Temperature Gas Chromatography and Gas Chromatography-Mass Spectroscopy. Analyst 115:1339-1342.

Folch, J., M. Lees, and G.H.S. Stanley

1957 A Simple Method for the Isolation and Purification of Total Lipids from Animal Tissues. Journal of Biological Chemistry 266, 497.

Frankel, Edwin N.

1991 Recent Advances in Lipid Oxidation. Journal of the Science of Food and Agriculture. 54:465511. 
Loy, Thomas

1994 Residue Analysis of Artifacts and Burned Rock from the Mustang Branch and Barton Sites (41HY209 and 41HY202). In Archaic and Late Prehistoric Human Ecology in the Middle Onion Creek Valley, Hays County, Texas. Volume 2: Topical Studies, by R.A. Ricklis and M.B. Collins, pp.607- 627. Studies in Archeology 19, Texas Archaeological Research Laboratory, The University of Texas-Austin.

Malainey, Mary E.

1997 The Reconstruction and Testing of Subsistence and Settlement Strategies for the Plains, Parkland and Southern Boreal Forest. Ph.D. Thesis, University of Manitoba.

Malainey, M.E., R. Przybylski and B.L. Sherriff

In Press a. The Fatty Acid Composition of Native Food Plants and Animals of Western Canada. Manuscript accepted for publication in the Journal of Archaeological Science.

In Press b. The Effects of Thermal and Oxidative Decomposition on the Fatty Acid Composition of Food Plants and Animals of Western Canada: Implications for the Identification of Archeological Vessel Residues. Manuscript accepted for publication in the Journal of Archaeological Science.

Marchbanks, Michael Lee

1989 Lipid Analysis in Archaeology: An Initial Study of Ceramics and Subsistence at the George C. Davis Site. Unpublished M.A. thesis, The University of Texas-Austin.

Marchbanks, M.L. and J.M. Quigg

1990 Appendix G: Organic Residue and Phytolith Analysis. In: Phase II Investigations at Prehistoric and Rock Art Sites, Justiceburg Reservoir, Garza and Kent Counties, Texas, Volume II, pp. 496-519, by D.K. Boyd, J.T. Abbott, W.A.Bryan, C.M. Garvey, S.A. Tomka and R.C. Fields. Reports of Investigations No. 71. Prewitt and Associates, Inc, Austin, Texas.

Patrick, M., A.J. de Konig and A.B. Smith

1985 Gas Liquid Chromatographic Analysis of Fatty Acids in Food Residues from Ceramics Found in the Southwestern Cape, South Africa. Archaeometry 27 (2): 231-236.

Skibo, James M.

1992 Pottery Function: A Use-Alteration Perspective. Plenum Press, New York.

Solomons, T.W. Graham

1980 Organic Chemistry. John Wiley \& Sons, Toronto. 
Table G1 Summary of Average Fatty Acid Compositions of Modern Food Groups Generated by Hierarchical Cluster Analysis.

\begin{tabular}{|c|c|c|c|c|c|c|c|c|c|c|c|c|c|c|c|}
\hline Cluster & \multicolumn{4}{|c|}{$\mathbf{A}$} & \multicolumn{6}{|c|}{ B } & \multicolumn{5}{|c|}{$\mathrm{C}$} \\
\hline $\begin{array}{c}\text { Sub } \\
\text { Cluster }\end{array}$ & I & II & III & IV & V & VI & VII & VIII & IX & $\mathbf{X}$ & XI & XII & XIII & XIV & XV \\
\hline Type & $\begin{array}{c}\text { Mam- } \\
\text { mal } \\
\text { Fat } \\
\text { and } \\
\text { Mar- } \\
\text { row }\end{array}$ & $\begin{array}{c}\text { Large } \\
\text { Herbi- } \\
\text { vore } \\
\text { Meat }\end{array}$ & Fish & Fish & $\begin{array}{c}\text { Berries } \\
\text { and } \\
\text { Nuts }\end{array}$ & Mixed & $\begin{array}{c}\text { Seeds } \\
\text { and } \\
\text { Berries }\end{array}$ & Roots & Seeds & Mixed & Greens & Berries & Roots & Greens & Roots \\
\hline C16:0 & 19.90 & 19.39 & 16.07 & 14.10 & 3.75 & 12.06 & 7.48 & $\begin{array}{l}19.98 \\
\end{array}$ & 7.52 & 10.33 & 18.71 & 3.47 & 22.68 & 24.19 & 18.71 \\
\hline C18:0 & 7.06 & 20.35 & 3.87 & 2.78 & 1.47 & 2.36 & 2.58 & 2.59 & 3.55 & 2.43 & 2.48 & 1.34 & 3.15 & 3.66 & 5.94 \\
\hline C18:1 & 56.77 & 35.79 & $\begin{array}{l}18.28 \\
\end{array}$ & 31.96 & 51.14 & 35.29 & 29.12 & 6.55 & $\begin{array}{l}10.02 \\
\end{array}$ & 15.62 & 5.03 & 14.95 & 12.12 & 4.05 & 3.34 \\
\hline C18:2 & 7.01 & 8.93 & 2.91 & 4.04 & 41.44 & 35.83 & 54.69 & 48.74 & 64.14 & 39.24 & 18.82 & 29.08 & 26.24 & 16.15 & 15.61 \\
\hline C18:3 & 0.68 & 2.61 & 4.39 & 3.83 & 1.05 & 3.66 & 1.51 & 7.24 & 5.49 & 19.77 & 35.08 & 39.75 & 9.64 & $\begin{array}{ll}17.88 \\
\end{array}$ & 3.42 \\
\hline $\begin{array}{l}\text { VLCS } \\
\end{array}$ & 0.16 & 0.32 & 0.23 & 0.15 & 0.76 & 4.46 & 2.98 & 8.50 & 5.19 & 3.73 & 6.77 & 9.10 & 15.32 & 18.68 & 43.36 \\
\hline VLCU & 0.77 & 4.29 & 39.92 & 24.11 & 0.25 & 2.70 & 1.00 & 2.23 & 0.99 & 2.65 & 1.13 & 0.95 & 2.06 & 0.72 & 1.10 \\
\hline
\end{tabular}

Table G2 Criteria for the Identification of Archaeological Residues Based on the Decomposition Patterns of Experimental Cooking Residues Prepared in Pottery Vessels

\begin{tabular}{|l|c|c|c|}
\hline Identification & Medium Chain & C18:0 & C18:1 isomers \\
\hline Large herbivore & $\leq 15 \%$ & $\geq 27.5 \%$ & $\leq 15 \%$ \\
\hline Large herbivore with plant OR bone marrow & low & $\geq 25 \%$ & $15 \% \leq X \leq 25 \%$ \\
\hline Plant with large herbivore & $\geq 15 \%$ & $\geq 25 \%$ & no data \\
\hline Beaver & low & low & $\geq 25 \%$ \\
\hline Fish or corn & low & $\leq 25 \%$ & $15 \% \leq X \leq 27.5 \%$ \\
\hline Fish or corn with plant & $\geq 15 \%$ & $\leq 25 \%$ & $15 \% \leq X \leq 27.5 \%$ \\
\hline Plant (except corn) & $\geq 10 \%$ & $\leq 27.5 \%$ & $\leq 15 \%$ \\
\hline
\end{tabular}


Table G3 Fatty Acid Compositions of Five Food Plants Found in South Texas.

\begin{tabular}{|l|l|l|l|l|l|}
\hline Fatty Acid & $\begin{array}{l}\text { Mesquite } \\
\text { beans }\end{array}$ & $\begin{array}{l}\text { Prickly pear } \\
\text { tunas }\end{array}$ & $\begin{array}{l}\text { Texas ebony } \\
\text { seeds }\end{array}$ & $\begin{array}{l}\text { Spanish dagger } \\
\text { pods }\end{array}$ & $\begin{array}{l}\text { Tasajillo } \\
\text { berries }\end{array}$ \\
\hline C12:0 & 0.06 & 0.65 & 0.00 & 0.10 & 0.65 \\
\hline C14:0 & 0.20 & 0.65 & 0.02 & 0.11 & 0.55 \\
\hline C15:0 & 0.30 & 0.14 & 0.01 & 0.06 & 0.09 \\
\hline C16:0 & 16.25 & 11.45 & 12.82 & 9.86 & 9.10 \\
\hline C16:1 & 1.40 & 0.77 & 0.31 & 0.07 & 0.46 \\
\hline C17:0 & 0.21 & 0.12 & 0.10 & 0.11 & 0.11 \\
\hline C18:0 & 2.59 & 3.42 & 8.62 & 1.83 & 3.35 \\
\hline C18:109 & 17.47 & 19.51 & 43.39 & 22.70 & 9.95 \\
\hline C18:1011 & 1.39 & 3.62 & 1.18 & 1.35 & 3.79 \\
\hline C18:2 & 45.49 & 48.96 & 26.17 & 61.78 & 65.61 \\
\hline C18:3 & 12.12 & 5.02 & 0.06 & 0.67 & 1.58 \\
\hline C20:0 & 0.75 & 1.09 & 3.42 & 0.32 & 0.71 \\
\hline C20:1 & 0.86 & 1.79 & 0.54 & 0.31 & 0.23 \\
\hline C20:2 & 0.00 & 0.26 & 0.00 & 0.00 & 0.00 \\
\hline C22:0 & 0.51 & 1.03 & 1.95 & 0.32 & 1.42 \\
\hline C22:1 & 0.00 & 0.42 & 0.21 & 0.00 & 0.00 \\
\hline C24:0 & 0.38 & 1.12 & 1.20 & IX & 2.38 \\
\hline Subcluster & VII / X & VII / X & & \\
\hline
\end{tabular}

Table G4 Fatty Acid Compositions of Degraded Experimental Cooking Residues of Food Plants Found in South Texas.

\begin{tabular}{|l|l|l|l|l|l|l|}
\hline \multirow{2}{*}{ Fatty acid } & \multicolumn{5}{|c|}{ Relative Percentage Composition } \\
\cline { 2 - 7 } & \multicolumn{2}{|l|}{ Texas ebony seeds } & \multicolumn{2}{c|}{ Spanish dagger pods } & \multicolumn{1}{c|}{$\begin{array}{c}\text { Prickly } \\
\text { pear pads }\end{array}$} & $\begin{array}{c}\text { Mesquite } \\
\text { beans }\end{array}$ \\
\cline { 2 - 7 } & $\mathbf{5 0}$ days & Long term & $\mathbf{5 0}$ days & Long term & $\mathbf{1}$ year & $\mathbf{1}$ year \\
\hline C12:0 & 0.02 & 0.14 & 0.23 & 1.81 & 2.40 & 0.59 \\
\hline C14:0 & 0.22 & 0.37 & 1.41 & 3.67 & 4.75 & 1.13 \\
\hline C15:0 & 0.15 & 0.15 & 0.90 & 1.35 & 2.05 & 0.45 \\
\hline C16:0 & 18.09 & 30.50 & 21.66 & 33.79 & 37.61 & 29.32 \\
\hline C16:1 & 0.48 & 0.71 & 0.00 & 0.87 & 3.90 & 5.37 \\
\hline C17:0 & 0.33 & 0.44 & 1.51 & 1.72 & 1.48 & 0.59 \\
\hline C18:0 & 12.37 & 18.80 & 11.64 & 12.78 & 16.78 & 6.44 \\
\hline C18:1s & 45.33 & 41.45 & 17.69 & 26.86 & 23.35 & 36.71 \\
\hline C18:2 & 23.01 & 7.44 & 44.97 & 17.14 & 7.68 & 19.40 \\
\hline Total & 100 & 100 & 100 & 100 & 100 & 100 \\
\hline
\end{tabular}


Table G5 List of Burned Rock Samples Analyzed from the Lino Site.

\begin{tabular}{|c|c|c|c|c|}
\hline Lab. Ref. No. & $\begin{array}{l}\text { TRC Mariah } \\
\text { Catalog No. }\end{array}$ & Associated Feature & Occupation & $\begin{array}{l}\text { Sample Size } \\
\text { (grams) }\end{array}$ \\
\hline Lino 1 & BR\#586-d & Feature 10 & Occupation 1 & 30.57 \\
\hline Lino 2 & BR\#579-d & Feature 10 & Occupation 1 & 22.21 \\
\hline Lino 3 & BR\#1133-d & Feature 12 & Occupation 1 & 22.93 \\
\hline Lino 4 & BR\#1155-d & Feature 12 & Occupation 1 & 20.14 \\
\hline Lino 5 & BR\#705-d & Feature 14 & Occupation 1 & 22.22 \\
\hline Lino 6 & BR\#703-d & Feature 14 & Occupation 1 & 27.23 \\
\hline Lino 7 & BR\#769-d & Feature 14 & Occupation 1 & 26.42 \\
\hline Lino 8 & BR\#914-d & Feature 15 & Occupation 1 & 28.60 \\
\hline Lino 9 & BR\#1167-d & Feature 16 & Occupation 2 & 21.15 \\
\hline Lino 10 & BR\#1176-d & Feature 16 & Occupation 2 & 30.34 \\
\hline Lino 11 & BR\#1283-d & Feature 18 & Occupation 3 & 29.14 \\
\hline Lino 12 & BR\#1286-d & Feature 18 & Occupation 3 & 24.30 \\
\hline Lino 13 & BR\#2090-d & Feature 20 & Occupation 2 & 28.83 \\
\hline Lino 14 & BR\#2065-d & Feature 20 & Occupation 2 & 21.90 \\
\hline Lino 15 & BR\#2092-d & Feature 20 & Occupation 2 & 27.96 \\
\hline Lino 16 & BR\#2121-d & Feature 22 & Occupation 4 & 27.59 \\
\hline Lino 17 & BR\#2120-d & Feature 22 & Occupation 4 & 23.10 \\
\hline Lino 18 & BR\#2163-d & Feature 24 & Occupation 5 & 27.55 \\
\hline Lino 19 & BR\#2173-d & Feature 24 & Occupation 5 & 24.22 \\
\hline Lino 20 & BR\#2177-d & Feature 24 & Occupation 5 & 20.23 \\
\hline Lino 21 & BR\#2165-d & Feature 24 & Occupation 5 & 19.20 \\
\hline Lino 22 & BR\#2888-d & Feature 26 & Occupation 4 & 28.55 \\
\hline Lino 23 & BR\#2849-d & Feature 26 & Occupation 4 & 34.80 \\
\hline Lino 24 & BR\#4901-2d & Feature 27 & Occupation 4 & 32.00 \\
\hline Lino 25 & BR\#2961-d & Feature 27 & Occupation 4 & 31.56 \\
\hline Lino 26 & BR\#2960-d & Feature 27 & Occupation 4 & 26.12 \\
\hline Lino 27 & BR\#3605-5d & Feature 29 & Occupation 5 & Contaminated in lab \\
\hline Lino 28 & BR\#3235-d & Feature 29 & Occupation 5 & 18.29 \\
\hline Lino 29 & BR\#3063-d & Feature 30 & Occupation 5 & 30.39 \\
\hline Lino 30 & BR\#3071-d & Feature 30 & Occupation 5 & 27.53 \\
\hline Lino 31 & BR\#3624-2d & Feature 32 & Occupation 3 & 21.53 \\
\hline Lino 32 & BR\#3498-d & Feature 32 & Occupation 3 & 30.39 \\
\hline Lino 33 & BR\#5279-4-2d & Feature 34 & Occupation 2 & 31.50 \\
\hline Lino 34 & BR\#5279-4-1d & Feature 34 & Occupation 2 & 26.38 \\
\hline
\end{tabular}

continued on next page 
Table G5 continued.

\begin{tabular}{|l|l|l|l|l|}
\hline Lab. Ref. No. & $\begin{array}{l}\text { TRC Mariah } \\
\text { Catalog No. }\end{array}$ & Associated Feature & Occupation & $\begin{array}{l}\text { Sample Size } \\
\text { (grams) }\end{array}$ \\
\hline Lino 35 & BR\#4026-1d & Feature 35 & Occupation 1 & 30.46 \\
\hline Lino 36 & BR\#4183-d & Feature 36 & Occupation 1 & 23.80 \\
\hline Lino 37 & BR\#4704-2d & Feature 39 & Occupation 4 & 32.59 \\
\hline Lino 38 & BR\#5295-4-1d & Feature 40 & Occupation 5 & 26.06 \\
\hline Lino 39 & BR\#5295-4-3d & Feature 40 & Occupation 5 & 33.22 \\
\hline Lino 40 & BR\#5183-3d & Feature 41 & Occupation 1 & 28.06 \\
\hline Lino 41 & BR\#5295-4-2d & Feature 40 & Occupation 5 & 24.66 \\
\hline Lino 42 & BR\#4842-2d & Feature 42 & Occupation 3 & 28.44 \\
\hline Lino 43 & BR\#4842-1d & Feature 42 & Occupation 3 & 34.70 \\
\hline
\end{tabular}

Table G6 List of Ground Stone Tool Samples Analyzed from the Lino Site.

\begin{tabular}{|l|l|l|l|l|}
\hline Lab. Ref. No. & $\begin{array}{l}\text { TRC Mariah } \\
\text { Catalog No. }\end{array}$ & Tool Type & Provenience & Sample \\
\hline Lino 46 & $\# 1998 \mathrm{~b}$ & mano & Gradall area & $27.09 \mathrm{~g}$ \\
\hline Lino 47 & $\# 4725 \mathrm{~b}$ & mano & F4 $100-110 \mathrm{~cm} \mathrm{bs}$ & surface wash \\
\hline Lino 48 & $\# 4726 \mathrm{~b}$ & mano & F4 $100-110 \mathrm{~cm}$ bs & surface wash \\
\hline Lino 49 & $\# 3717 \mathrm{~b}$ & abrader & C1 $20-30 \mathrm{~cm} \mathrm{bs}$ & $24.51 \mathrm{~g}$ \\
\hline Lino 50 & $\# 5642-46$ & abrader & D3 $100-110 \mathrm{~cm} \mathrm{bs}$ & $36.79 \mathrm{~g}$ \\
\hline
\end{tabular}




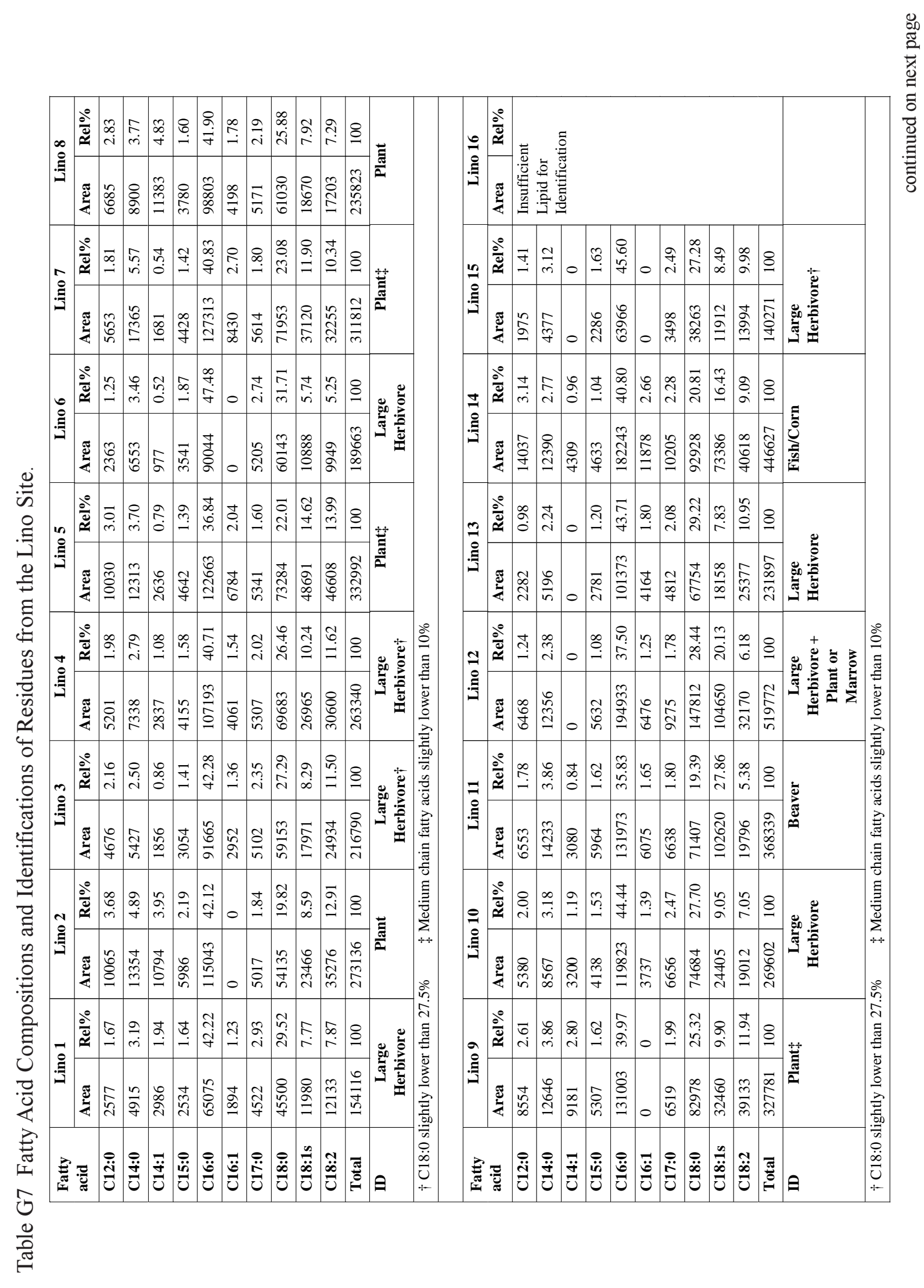




\begin{tabular}{|c|c|c|c|c|c|c|c|c|c|c|c|c|c|c|c|c|}
\hline \multirow{2}{*}{$\begin{array}{l}\text { Fatty } \\
\text { acid }\end{array}$} & \multicolumn{2}{|c|}{ Lino 17} & \multicolumn{2}{|c|}{ Lino 18} & \multicolumn{2}{|c|}{ Lino 19} & \multicolumn{2}{|c|}{ Lino 20} & \multicolumn{2}{|c|}{ Lino 21} & \multicolumn{2}{|c|}{ Lino 22} & \multicolumn{2}{|c|}{ Lino 23} & \multicolumn{2}{|c|}{ Lino 24} \\
\hline & Area & Rel\% & Area & Rel\% & Area & Rel\% & Area & Rel\% & Area & Rel\% & Area & Rel\% & Area & Rel\% & Area & Rel\% \\
\hline C12:0 & 7313 & 2.71 & 7031 & 2.98 & 4471 & 2.12 & 0 & 0 & 8704 & 3.50 & 5610 & 2.93 & 3285 & 1.59 & 5719 & 2.66 \\
\hline C14:0 & 9949 & 3.69 & 8644 & 3.66 & 8157 & 3.87 & 0 & 0 & 10795 & 4.34 & 8379 & 4.37 & 7313 & 3.54 & 12305 & 5.71 \\
\hline C14:1 & 2568 & 0.95 & 2261 & 0.96 & 1075 & 0.51 & 0 & 0 & 0 & 0 & 1331 & 0.69 & 0 & 0 & 1433 & 0.67 \\
\hline C15:0 & 4053 & 1.50 & 4070 & 1.72 & 3182 & 1.51 & 1058 & 1.04 & 3490 & 1.40 & 4514 & 2.35 & 3686 & 1.78 & 5802 & 2.69 \\
\hline C16:0 & 106953 & 39.70 & 94839 & 40.16 & 76766 & 36.45 & 25532 & 25.16 & 99618 & 40.01 & 74684 & 38.95 & 99023 & 47.95 & 84352 & 39.17 \\
\hline C16:1 & 4300 & 1.60 & 6289 & 2.66 & 8072 & 3.83 & 0 & 0 & 5205 & 2.09 & 5085 & 2.65 & 0 & 0 & 0 & 0 \\
\hline C17:0 & 5461 & 2.03 & 4582 & 1.94 & 3746 & 1.78 & 18534 & 18.27 & 4147 & 1.67 & 4078 & 2.13 & 5393 & 2.61 & 4718 & 2.19 \\
\hline C18:0 & 74086 & 27.50 & 58044 & 24.58 & 45534 & 21.62 & 22903 & 22.57 & 67772 & 27.22 & 46148 & 24.07 & 55006 & 26.63 & 38434 & 17.85 \\
\hline C18:1s & 28023 & 10.40 & 24558 & 10.40 & 25821 & 12.26 & 13209 & 13.02 & 26743 & 10.74 & 20616 & 10.75 & 15206 & 7.36 & 43673 & 20.28 \\
\hline C18:2 & 26666 & 9.90 & 25812 & 10.93 & 33757 & 16.03 & 20223 & 19.94 & 22528 & 9.05 & 21281 & 11.10 & 17612 & 8.53 & 18901 & 8.78 \\
\hline Total & 269372 & 100 & 236130 & 100 & 210581 & 100 & 101459 & 100 & 249002 & 100 & 191726 & 100 & 206524 & 100 & 215337 & 100 \\
\hline ID & \multicolumn{2}{|c|}{$\begin{array}{c}\text { Large } \\
\text { Herbivore }\end{array}$} & \multicolumn{2}{|c|}{ Plant } & \multicolumn{2}{|c|}{ Plant } & \multicolumn{2}{|c|}{ Unknown Seed } & \multicolumn{2}{|c|}{$\begin{array}{c}\text { Large } \\
\text { Herbivore } \dagger\end{array}$} & \multicolumn{2}{|c|}{ Plant } & \multicolumn{2}{|c|}{$\begin{array}{c}\text { Large } \\
\text { Herbivore } \dagger\end{array}$} & \multicolumn{2}{|c|}{ Plant-Fish/Corn } \\
\hline
\end{tabular}

\begin{tabular}{|c|c|c|c|c|c|c|c|c|c|c|c|c|c|c|c|c|}
\hline \multirow{2}{*}{$\begin{array}{l}\text { Fatty } \\
\text { acid }\end{array}$} & \multicolumn{2}{|c|}{ Lino 25} & \multicolumn{2}{|c|}{ Lino 26} & \multicolumn{2}{|c|}{ Lino 27} & \multicolumn{2}{|c|}{ Lino 28} & \multicolumn{2}{|c|}{ Lino 29} & \multicolumn{2}{|c|}{ Lino 30} & \multicolumn{2}{|c|}{ Lino 31} & \multicolumn{2}{|c|}{ Lino 32} \\
\hline & Area & Rel\% & Area & Rel\% & Area & $\operatorname{Rel} \%$ & Area & Rel\% & Area & Rel\% & Area & Rel\% & Area & Rel\% & Area & Rel\% \\
\hline C12:0 & 10212 & 1.67 & 8268 & 4.90 & \multirow{12}{*}{\multicolumn{2}{|c|}{$\begin{array}{l}\text { Sample } \\
\text { Contaminated } \\
\text { with Modern } \\
\text { Lipids }\end{array}$}} & 5001 & 4.03 & \multirow{12}{*}{\multicolumn{2}{|c|}{$\begin{array}{l}\text { Insufficient } \\
\text { Lipid for } \\
\text { Identification }\end{array}$}} & 10867 & 4.86 & \multirow{12}{*}{\multicolumn{2}{|c|}{$\begin{array}{l}\text { Insufficient } \\
\text { Lipid for } \\
\text { Identification }\end{array}$}} & \multirow{12}{*}{\multicolumn{2}{|c|}{$\begin{array}{l}\text { Insufficient } \\
\text { Lipid for } \\
\text { Identification }\end{array}$}} \\
\hline C14:0 & 25784 & 4.21 & 14823 & 8.78 & & & 9199 & 7.41 & & & 11981 & 5.36 & & & & \\
\hline C14:1 & 0 & 0 & 0 & 0 & & & 1634 & 1.32 & & & 0 & 0 & & & & \\
\hline C15:0 & 8802 & 1.44 & 5487 & 3.25 & & & 3285 & 2.65 & & & 4088 & 1.83 & & & & \\
\hline C16:0 & 264668 & 43.20 & 65934 & 39.04 & & & 57430 & 46.25 & & & 64114 & 28.70 & & & & \\
\hline C16:1 & 0 & 0 & 0 & 0 & & & 0 & 0 & & & 0 & 0 & & & & \\
\hline C17:0 & 10709 & 1.75 & 4642 & 2.75 & & & 2969 & 2.39 & & & 3047 & 1.36 & & & & \\
\hline C18:0 & 138611 & 22.63 & 44237 & 26.19 & & & 31949 & 25.73 & & & 30839 & 13.80 & & & & \\
\hline C18:1s & 28697 & 4.68 & 9626 & 5.70 & & & 3925 & 3.16 & & & 64581 & 28.90 & & & & \\
\hline C18:2 & 125170 & 20.43 & 15889 & 9.40 & & & 8772 & 7.06 & & & 33911 & 15.18 & & & & \\
\hline Total & 612653 & 100 & 168906 & 100 & & & 124164 & 100 & & & 223428 & 100 & & & & \\
\hline ID & Plant $\neq$ & & Plant & & & & Plant & & & & Beaver & & & & & \\
\hline
\end{tabular}




\begin{tabular}{|c|c|c|c|c|c|c|c|c|c|c|c|c|c|c|c|c|}
\hline \multirow{2}{*}{$\begin{array}{l}\text { Fatty } \\
\text { acid }\end{array}$} & \multicolumn{2}{|c|}{ Lino 33} & \multicolumn{2}{|c|}{ Lino 34} & \multicolumn{2}{|c|}{ Lino 35} & \multicolumn{2}{|c|}{ Lino 36} & \multicolumn{2}{|c|}{ Lino 37} & \multicolumn{2}{|c|}{ Lino 38} & \multicolumn{2}{|c|}{ Lino 39} & \multicolumn{2}{|l|}{ Lino 40} \\
\hline & Area & Rel\% & Area & Rel\% & Area & Rel\% & Area & Rel\% & Area & Rel\% & Area & Rel\% & Area & Rel\% & Area & Rel\% \\
\hline C12:0 & 6024 & 2.65 & \multirow{11}{*}{\multicolumn{2}{|c|}{$\begin{array}{l}\text { Insufficient } \\
\text { Lipid for } \\
\text { Identification }\end{array}$}} & \multirow{11}{*}{\multicolumn{2}{|c|}{$\begin{array}{l}\text { Insufficient } \\
\text { Lipid for } \\
\text { Identification }\end{array}$}} & \multirow{11}{*}{\multicolumn{2}{|c|}{$\begin{array}{l}\text { Insufficient } \\
\text { Lipid for } \\
\text { Identification }\end{array}$}} & 8558 & 7.03 & \multirow{11}{*}{\multicolumn{2}{|c|}{$\begin{array}{l}\text { Insufficient } \\
\text { Lipid for } \\
\text { Identification }\end{array}$}} & \multirow{11}{*}{\multicolumn{2}{|c|}{$\begin{array}{l}\text { Insufficient } \\
\text { Lipid for } \\
\text { Identification }\end{array}$}} & 13909 & 9.88 \\
\hline C14:0 & 6750 & 2.97 & & & & & & & 9703 & 7.97 & & & & & 10752 & 7.64 \\
\hline C14:1 & 1902 & 0.84 & & & & & & & 0 & 0 & & & & & 0 & 0 \\
\hline C15:0 & 1605 & 0.71 & & & & & & & 2518 & 2.07 & & & & & 2074 & 1.47 \\
\hline C16:0 & 60734 & 26.76 & & & & & & & 46737 & 38.38 & & & & & 48776 & 34.64 \\
\hline C16:1 & 9403 & 4.14 & & & & & & & 0 & 0 & & & & & 4864 & 3.45 \\
\hline C17:0 & 3439 & 1.52 & & & & & & & 2441 & 2.00 & & & & & 2373 & 1.69 \\
\hline C18:0 & 19712 & 8.69 & & & & & & & 35516 & 29.17 & & & & & 28074 & 19.94 \\
\hline C18:1s & 101832 & 44.87 & & & & & & & 8414 & 6.91 & & & & & 23467 & 16.66 \\
\hline C18:2 & 15530 & 6.84 & & & & & & & 7884 & 6.47 & & & & & 6536 & 4.64 \\
\hline Total & 226931 & 100 & & & & & & & 121771 & 100 & & & & & 140825 & 100 \\
\hline ID & \multicolumn{2}{|l|}{ Beaver } & & & & & & & \multicolumn{2}{|c|}{$\begin{array}{l}\text { Plant + Large } \\
\text { Herbivore }\end{array}$} & & & & & \multicolumn{2}{|c|}{$\begin{array}{l}\text { Fish/Corn + } \\
\text { Plant }\end{array}$} \\
\hline \multirow{2}{*}{$\begin{array}{l}\text { Fatty } \\
\text { acid }\end{array}$} & \multicolumn{2}{|c|}{ Lino 41} & \multicolumn{2}{|c|}{ Lino 42} & \multicolumn{2}{|c|}{ Lino 43} & \multicolumn{2}{|c|}{ Lino 46} & \multicolumn{2}{|c|}{ Lino 47} & \multicolumn{2}{|c|}{ Lino 48} & \multicolumn{2}{|c|}{ Lino 49} & \multicolumn{2}{|c|}{ Lino 50} \\
\hline & Area & Rel\% & Area & Rel\% & Area & Rel\% & Area & Rel\% & Area & Rel\% & Area & Rel\% & Area & Rel\% & Area & Rel\% \\
\hline C12:0 & \multirow{11}{*}{\multicolumn{2}{|c|}{$\begin{array}{l}\text { Insufficient } \\
\text { Lipid for } \\
\text { Identification }\end{array}$}} & 8474 & 2.91 & Insuffic & & Insuffi & & 6702 & 4.57 & 29248 & 4.61 & 5557 & 1.60 & 8430 & 2.57 \\
\hline C14:0 & & & 26336 & 9.03 & Lipid f & & Lipid & & 12348 & 8.42 & 59085 & 9.32 & 20892 & 6.03 & 18048 & 5.49 \\
\hline C14:1 & & & 0 & 0 & & & & & 0 & 0 & 0 & 0 & 0 & 0 & 0 & 0 \\
\hline C15:0 & & & 17050 & 5.85 & & & & & 2594 & 1.77 & 24628 & 3.89 & 8086 & 2.33 & 8346 & 2.54 \\
\hline C16:0 & & & 123854 & 42.49 & & & & & 48802 & 33.27 & 265364 & 41.86 & 126914 & 36.61 & 109274 & 33.25 \\
\hline C16:1 & & & 7948 & 2.73 & & & & & 0 & 0 & 0 & 0 & 8512 & 2.46 & 0 & 0 \\
\hline C17:0 & & & 5556 & 1.91 & & & & & 1903 & 1.30 & 7578 & 1.20 & 4463 & 1.29 & 3823 & 1.16 \\
\hline C18:0 & & & 70434 & 24.16 & & & & & 35789 & 24.40 & 86186 & 13.60 & 66816 & 19.27 & 50824 & 15.47 \\
\hline C18:1s & & & 18398 & 6.31 & & & & & 26061 & 17.76 & 160142 & 25.26 & 56815 & 16.39 & 94382 & 28.72 \\
\hline C18:2 & & & 13448 & 4.62 & & & & & 12501 & 8.52 & 1638 & 0.26 & 48623 & 14.03 & 35497 & 10.81 \\
\hline Total & & & 291498 & 100 & & & & & 146700 & 100 & 633869 & 100 & 346678 & 100 & 328624 & 100 \\
\hline
\end{tabular}


Table G8 Results of the Residue Analysis Presented for Each Occupation.

\begin{tabular}{|c|c|c|c|c|c|}
\hline \multirow[b]{2}{*}{ Identification } & \multicolumn{5}{|c|}{ Occupation } \\
\hline & $\begin{array}{c}1 \\
\text { ca. } 2000 \text { B.P. }\end{array}$ & 2 & 3 & 4 & $\begin{array}{c}5 \\
\text { ca. } 3200 \text { B.P. }\end{array}$ \\
\hline $\begin{array}{l}\text { Large } \\
\text { Herbivore }\end{array}$ & $\begin{array}{ll}\text { Lino } 1 & \text { F10 } \\
\text { Lino } 3 & \text { F12 } \\
\text { Lino } 4 & \text { F12 } \\
\text { Lino } 6 & \text { F14 }\end{array}$ & Lino $10 \mathrm{~F} 16$ & $\begin{array}{l}\text { Lino } 13 \text { F20 } \\
\text { Lino } 15 \text { F20 }\end{array}$ & $\begin{array}{ll}\text { Lino } 17 & \text { F22 } \\
\text { Lino 23 } & \text { F26 }\end{array}$ & Lino 21 F24 \\
\hline $\begin{array}{l}\text { Large } \\
\text { Herbivore } \\
\text { +Plant or } \\
\text { Marrow }\end{array}$ & - & - & Lino 12 F18 & - & - \\
\hline $\begin{array}{l}\text { Plant + Large } \\
\text { Herbivore }\end{array}$ & - & - & & Lino 37 F39 & - \\
\hline Plant & $\begin{array}{ll}\text { Lino } 2 & \text { F10 } \\
\text { Lino } 5 & \text { F14 } \\
\text { Lino } 7 & \text { F14 } \\
\text { Lino } 8 & \text { F15 }\end{array}$ & Lino 9 F16 & & $\begin{array}{ll}\text { Lino } 22 & \text { F26 } \\
\text { Lino } 25 & \text { F27 } \\
\text { Lino 26 } & \text { F27 } \\
\text { Lino } 42 & \text { F42 }\end{array}$ & $\begin{array}{ll}\text { Lino } 18 & \text { F24 } \\
\text { Lino 19 } & \text { F24 } \\
\text { Lino 28 } & \text { F29 }\end{array}$ \\
\hline $\begin{array}{l}\text { Fish/Corn (ca. } \\
\text { mesquite } \\
\text { beans/prickly } \\
\text { pear) }\end{array}$ & $\begin{array}{l}\text { Lino } 49 \\
\text { Abrader }\end{array}$ & & Lino 14 F20 & - & Lino 47 Mano \\
\hline $\begin{array}{l}\text { Fish/Corn + } \\
\text { Plant }\end{array}$ & Lino $40 \mathrm{~F} 41$ & - & - & - & \\
\hline $\begin{array}{l}\text { Borderline } \\
\text { Fish/Corn or } \\
\text { Plant }\end{array}$ & - & - & - & Lino 24 F27 & \\
\hline $\begin{array}{l}\text { Beaver (ca. } \\
\text { Texas ebony) }\end{array}$ & - & Lino 33 F34 & Lino $11 \mathrm{~F} 18$ & $\begin{array}{l}\text { Lino } 50 \\
\text { Abrader }\end{array}$ & $\begin{array}{c}\text { Lino } 30 \text { F30 } \\
\text { Lino } 48 \text { Mano }\end{array}$ \\
\hline Unknown Seed & & & & & Lino 20 F24 \\
\hline $\begin{array}{l}\text { Insufficient } \\
\text { Lipid }\end{array}$ & $\begin{array}{l}\text { Lino } 35 \text { F35 } \\
\text { Lino } 36 \text { F36 }\end{array}$ & Lino 34 F34 & $\begin{array}{ll}\text { Lino } 31 & \text { F32 } \\
\text { Lino } 32 & \text { F32 }\end{array}$ & $\begin{array}{c}\text { Lino } 16 \text { F22 } \\
\text { Lino } 43 \text { F42 } \\
\text { Lino } 46 \text { Mano }\end{array}$ & $\begin{array}{ll}\text { Lino } 29 & \text { F30 } \\
\text { Lino } 38 & \text { F40 } \\
\text { Lino } 39 & \text { F40 } \\
\text { Lino 41 } & \text { F40 }\end{array}$ \\
\hline Total & 12 & 4 & 7 & 12 & 12 \\
\hline
\end{tabular}

Lino $40=$ sample number, $\quad$ F23 = feature number 
Table G9 Identifications of Burned Rock Residues for Each Feature.

\begin{tabular}{|c|c|c|c|}
\hline Residue Identifications & Feature & Occupation & Samples \\
\hline \multirow[t]{2}{*}{ Large Herbivore only } & 12 & 1 & 2 \\
\hline & 22 & 4 & $1 *$ \\
\hline \multirow[t]{3}{*}{ Plant only } & 15 & 1 & 1 \\
\hline & 29 & 5 & 1 \\
\hline & 42 & 4 & $1 *$ \\
\hline \multirow[t]{4}{*}{ Large Herbivore and Plant Only } & 10 & 1 & 2 \\
\hline & 14 & 1 & 3 \\
\hline & 16 & 2 & 2 \\
\hline & 26 & 4 & 2 \\
\hline \multirow[t]{2}{*}{ Beaver Only } & 30 & 5 & $1 *$ \\
\hline & 34 & 2 & $1 *$ \\
\hline Large Herbivore + Plant or Bone Marrow and Beaver & 18 & 3 & 2 \\
\hline Large Herbivore and Fish/Corn & 20 & 3 & 3 \\
\hline Plant, Large Herbivore and Unknown Seed(?) & 24 & 5 & 4 \\
\hline Plant and Borderline Plant - Fish/Corn & 27 & 4 & 3 \\
\hline Plant with Large Herbivore & 39 & 4 & 1 \\
\hline Fish/Corn and Plant & 41 & 5 & 1 \\
\hline \multirow[t]{5}{*}{ Insufficient Lipids for Identification } & 32 & 3 & 2 \\
\hline & 35 & 1 & 1 \\
\hline & 36 & 1 & 1 \\
\hline & 40 & 5 & 3 \\
\hline & 42 & 4 & 1 \\
\hline
\end{tabular}


Figure G1 Bar graphs comparing the fatty acid composition of uncooked Texas ebony to experimental cooking residues after 50 days and simulated long term decomposition.

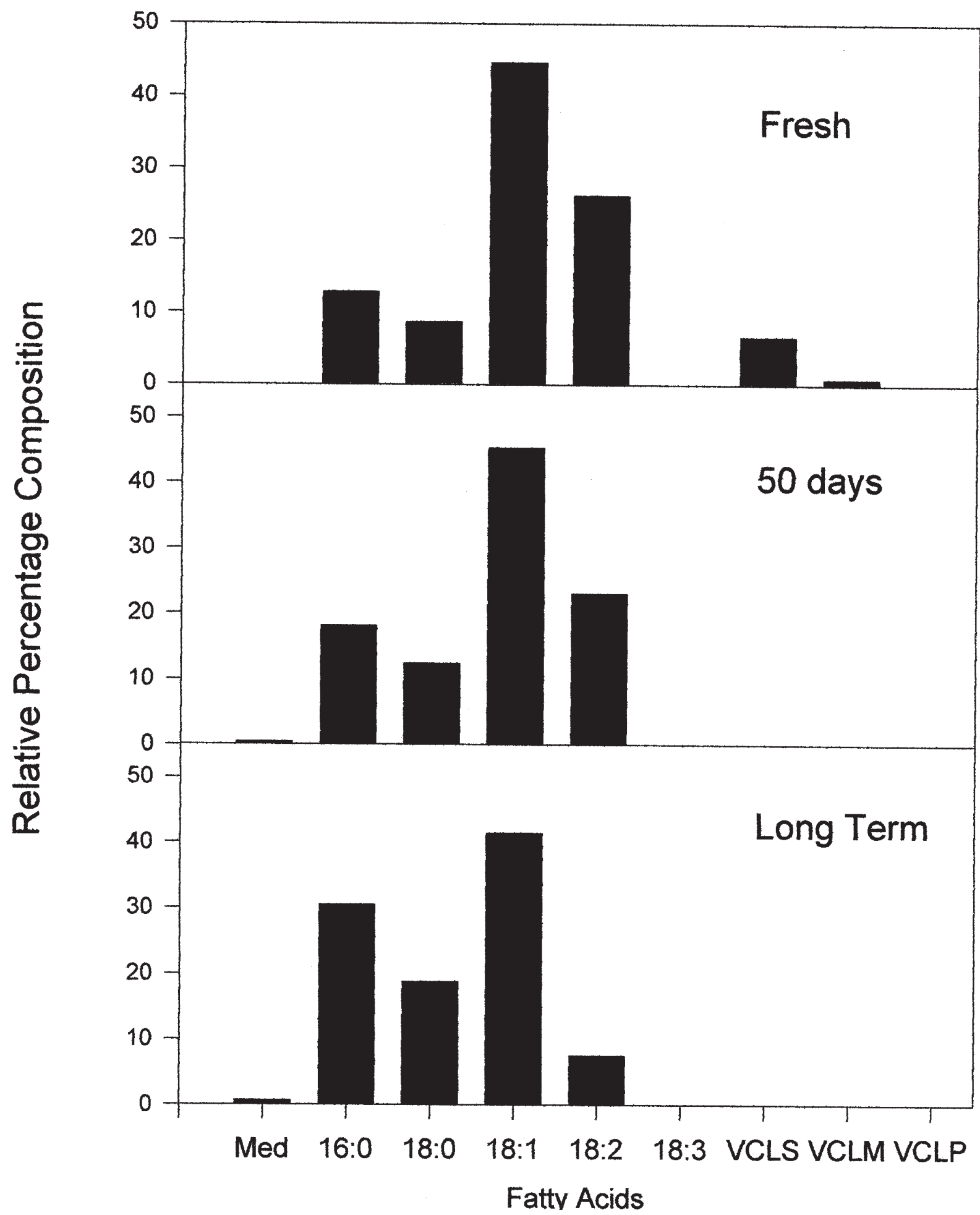


Figure G2 Bar graphs comparing the fatty acid composition of uncooked beaver meat to experimental cooking residues after 4 days and simulated long term decomposition.

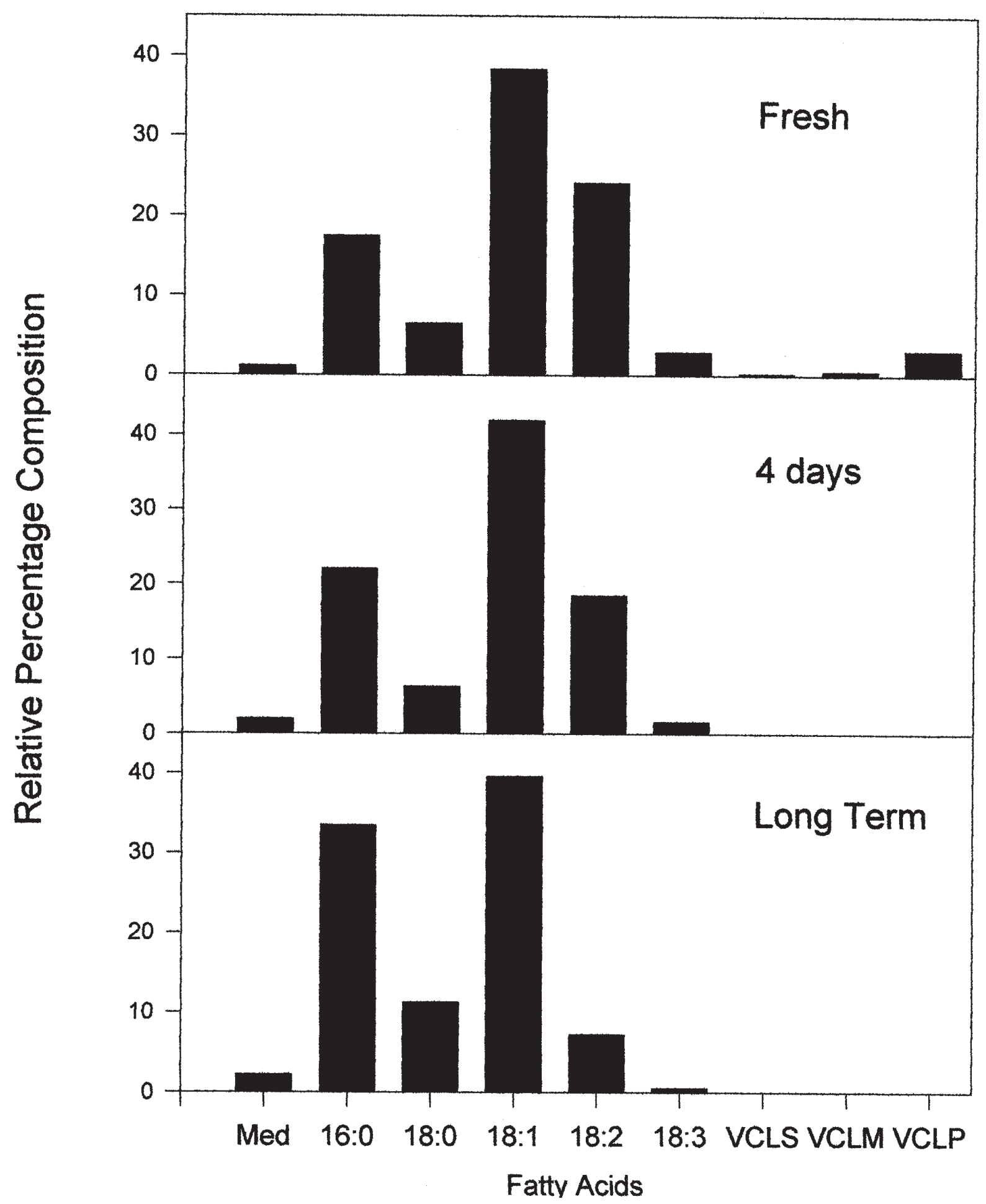


Figure G3 Bar graphs comparing the fatty acid composition of uncooked Spanish digger to experimental cooking residues after 50 days and simulated long term decomposition.

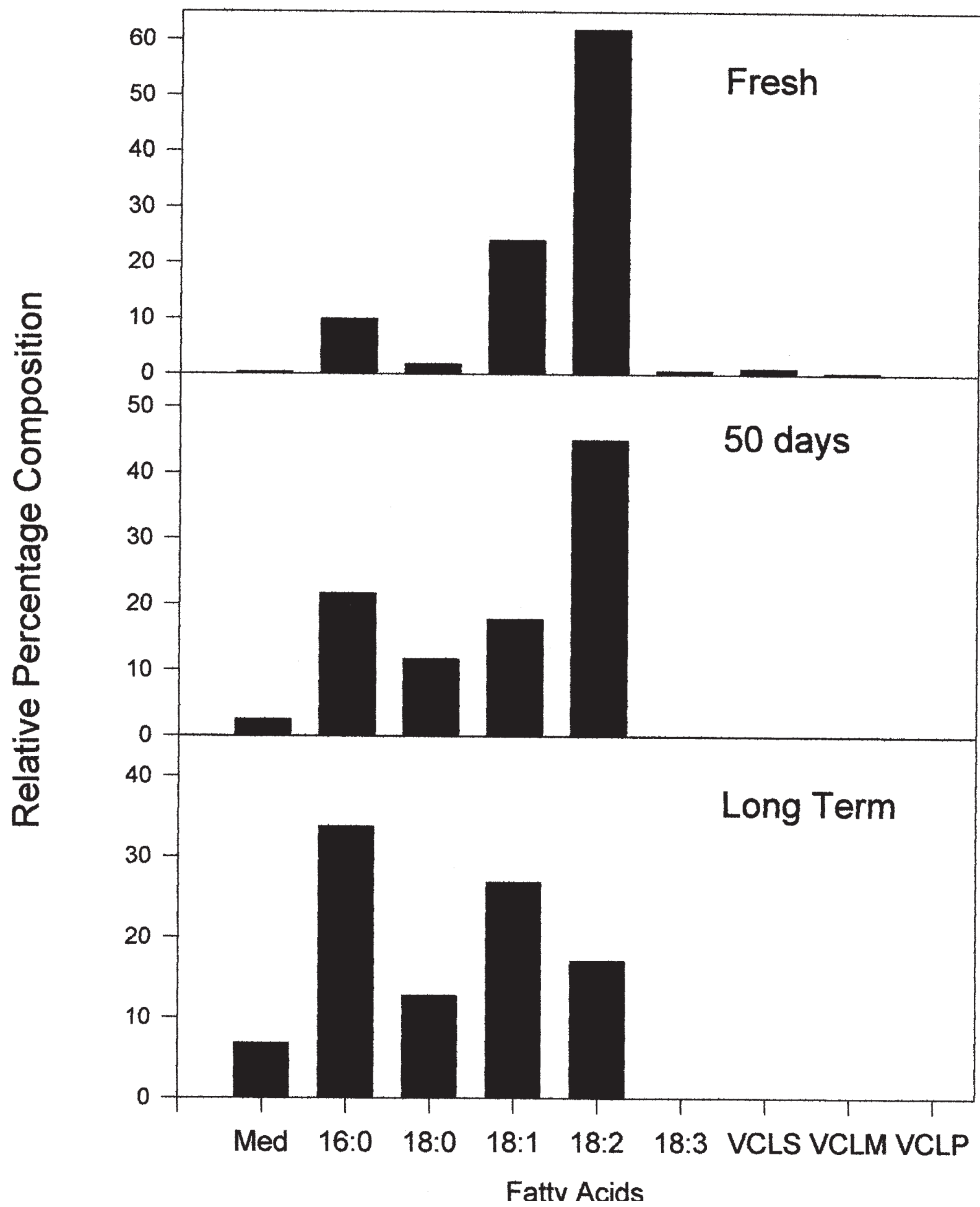


Figure G4 Bar graphs comparing the fatty acid composition of uncooked corn to experimental cooking residues after 4 days and simulated long term decomposition.

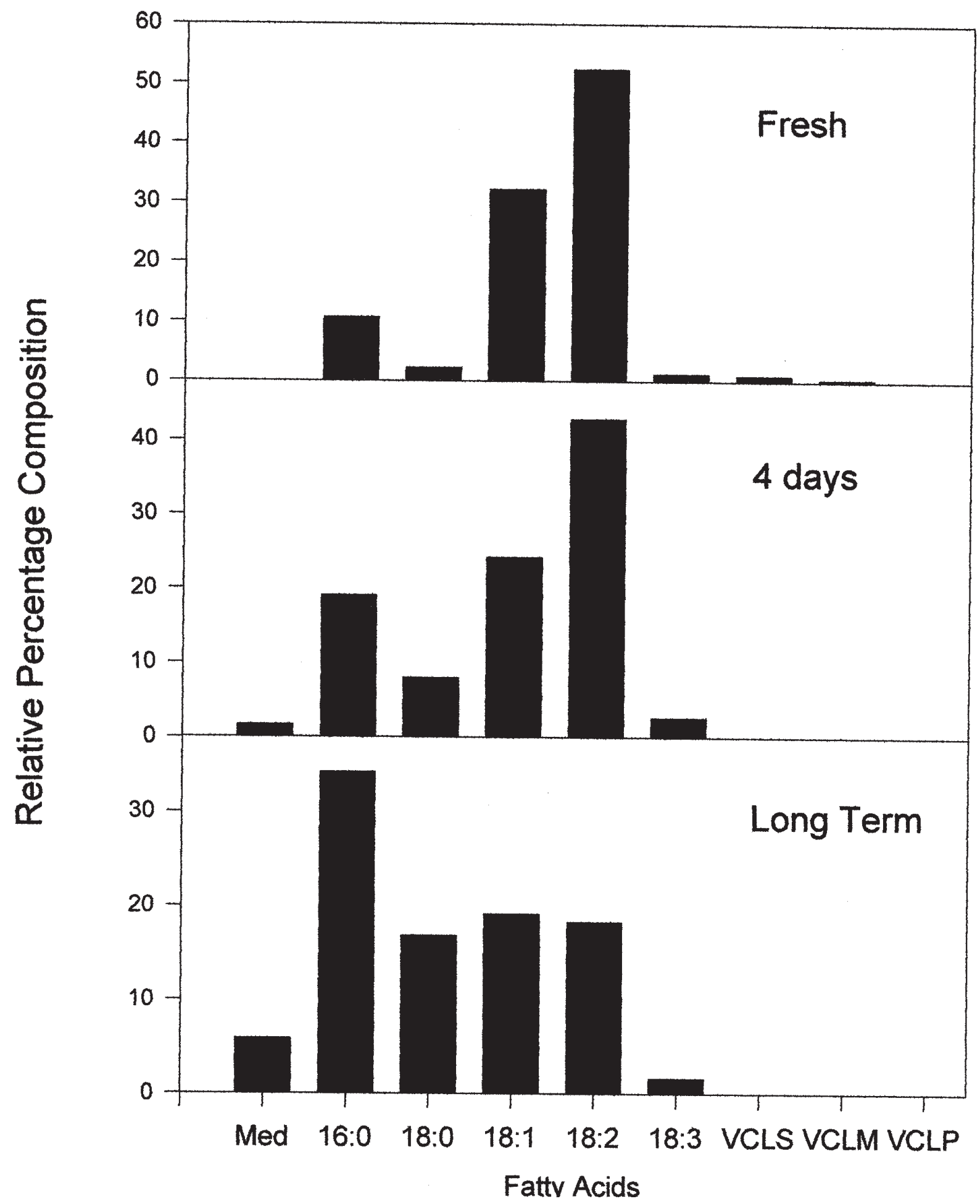


Figure G5 Bar graphs comparing the fatty acid composition ot uncooked chokecherry to experimental cooking residues after 4 days and simulated long term decomposition.

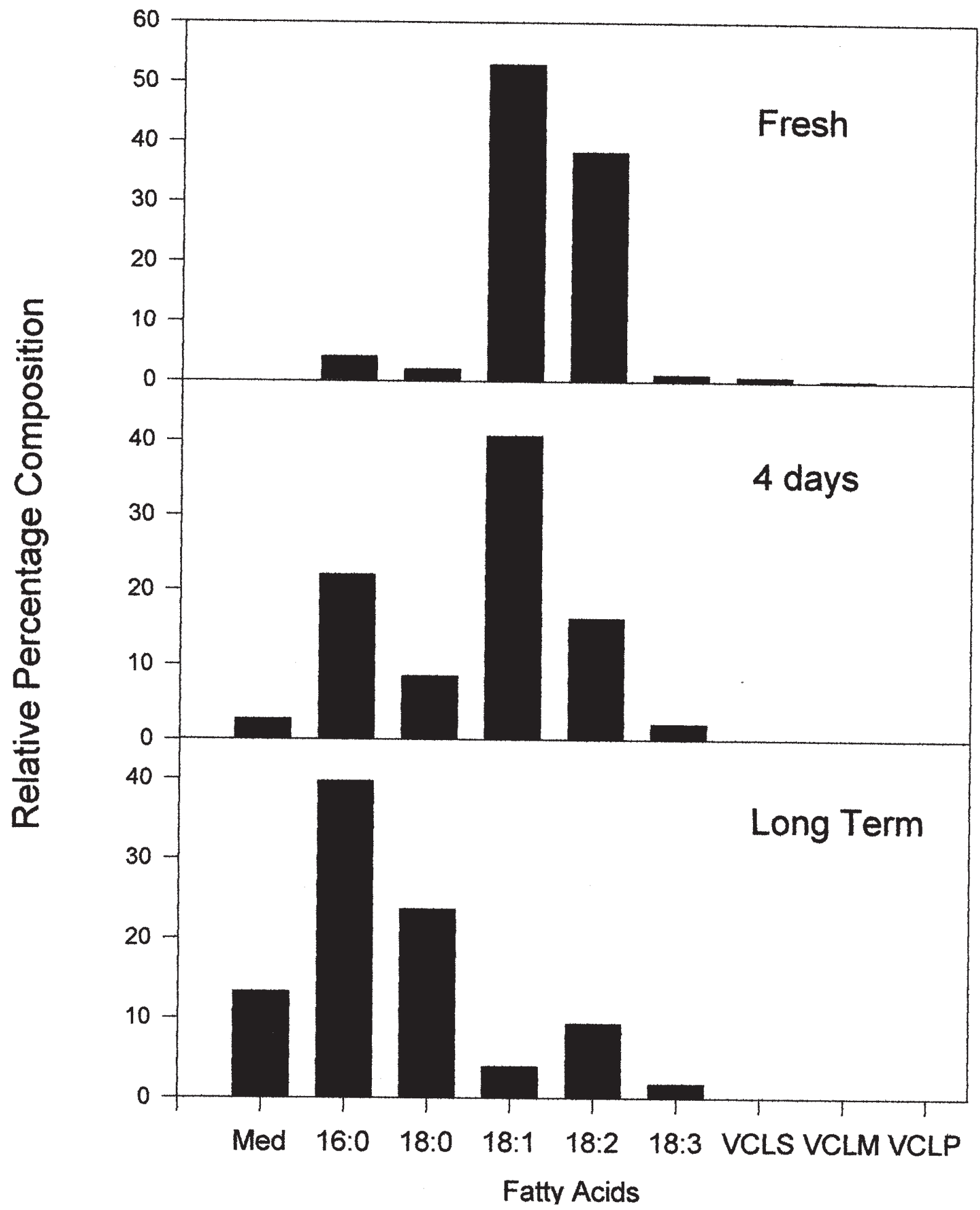


Figure G6 Bar graphs comparing the fatty acid composition of uncooked prickley pear to an experimental cooking residue after one year.

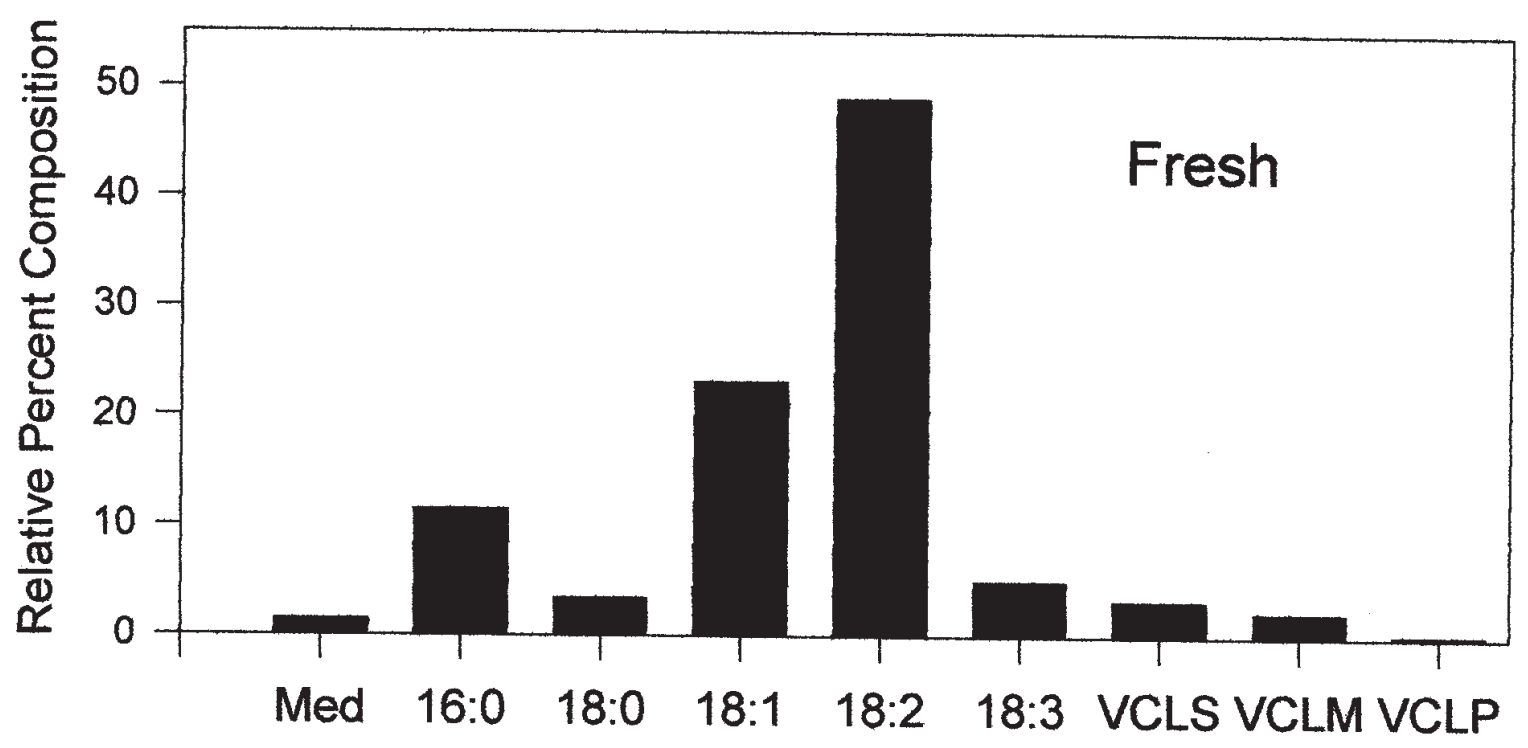

Fatty Acids

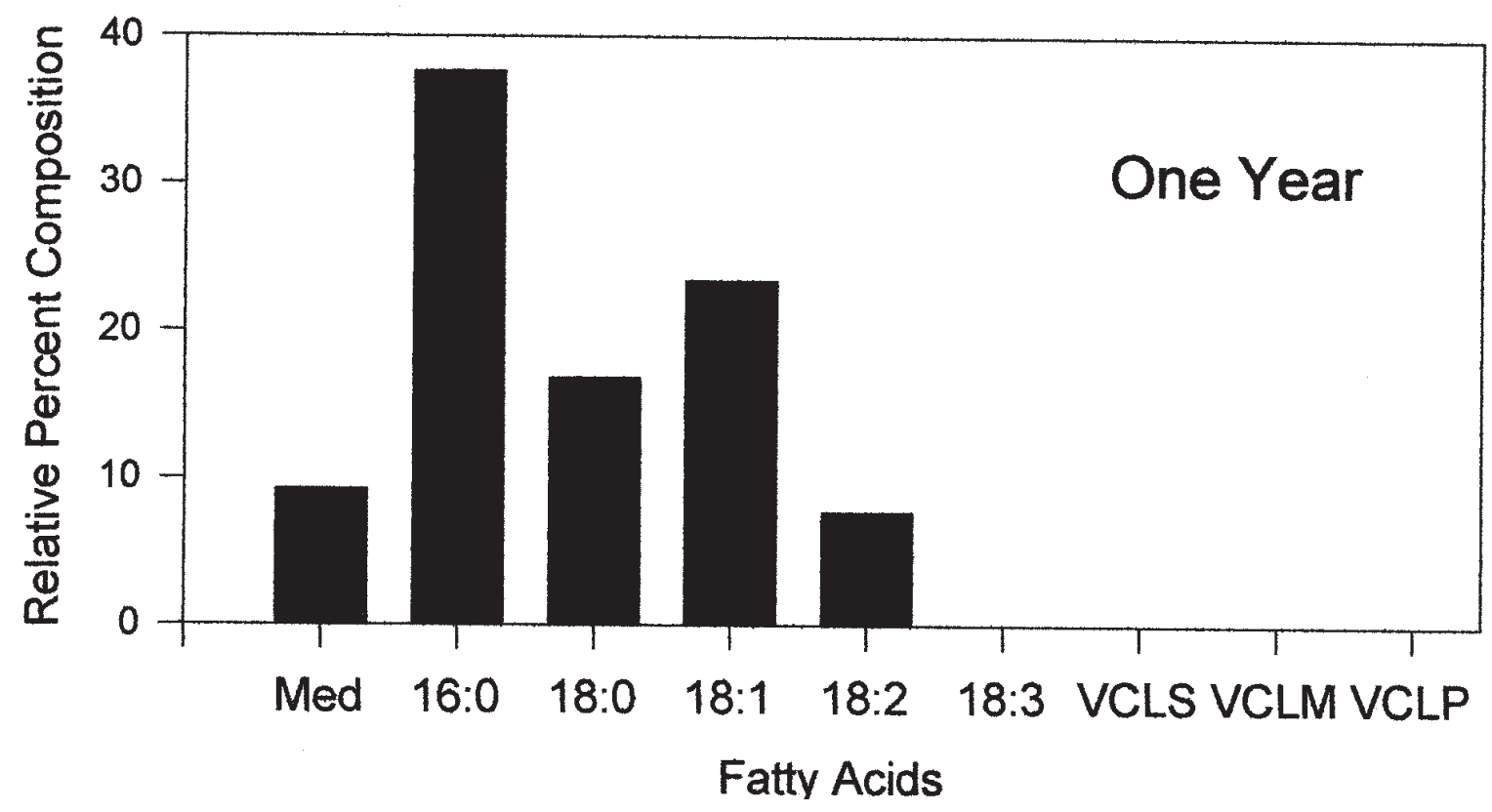


Figure G7 Bar graphs comparing the fatty acid composition of uncooked mesquite to an experimental cooking residue after one year.

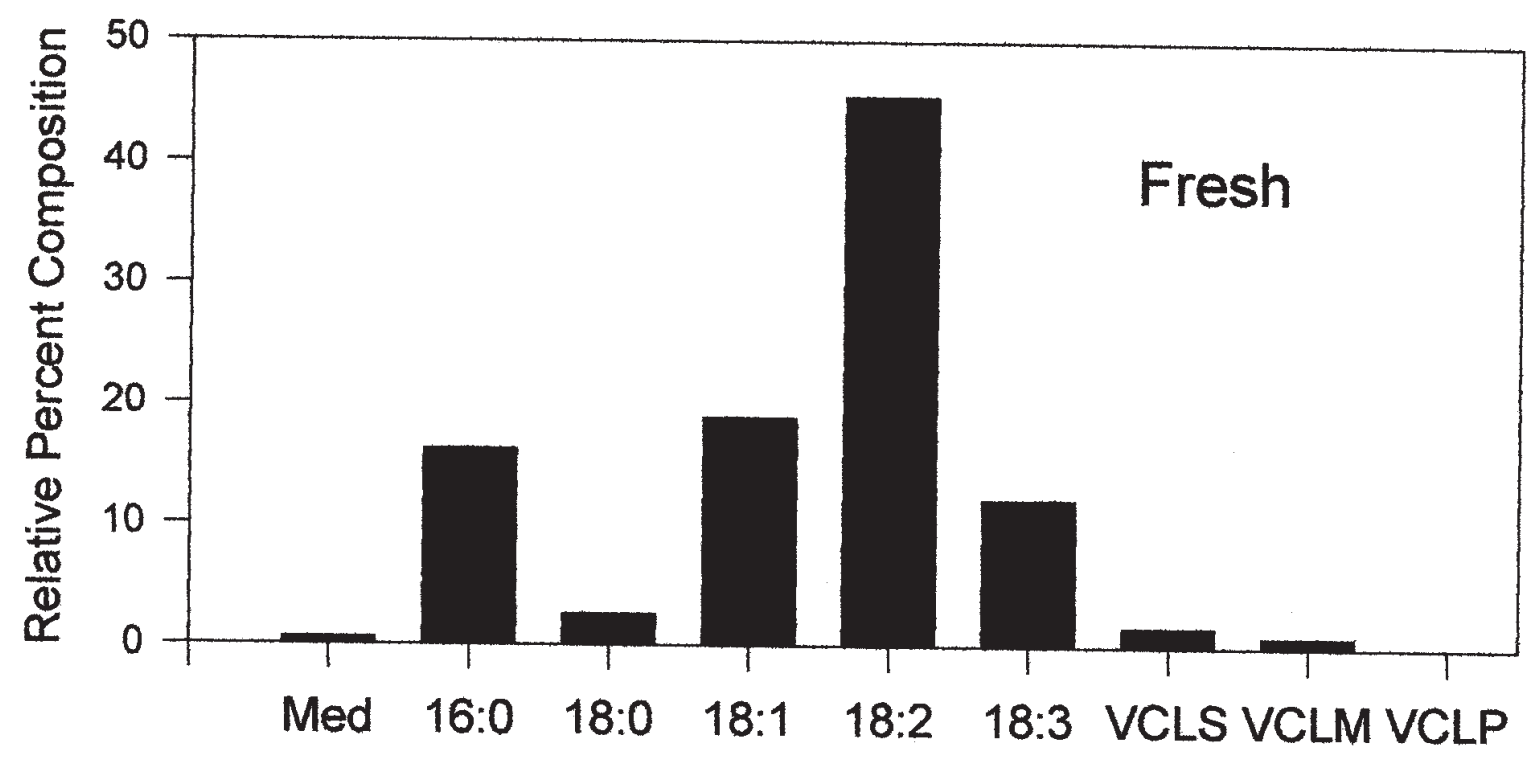

Fatty Acids

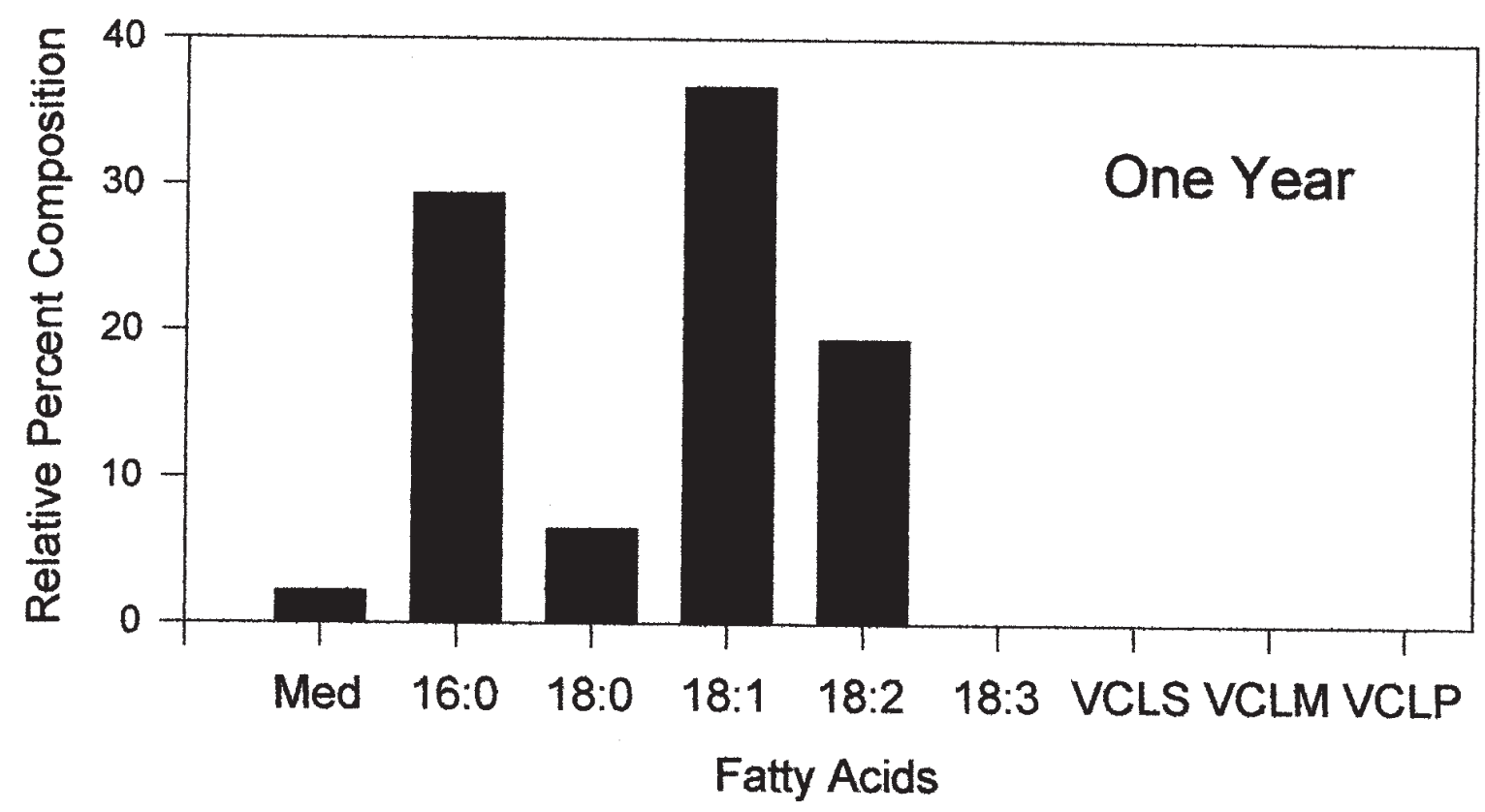




\section{APPENDIX H}

Phytolith Analysis by John G. Jones 
Intentionally Left Blank 


\title{
Analysis of Phytoliths from Site 41WB437
}

\author{
John G. Jones, Ph.D. \\ Associate Director, Palynology Laboratory \\ Texas A\&M University, College Station, TX 77843-4352
}

A total of five phytolith samples were examined from site 41WB437, Webb County, Texas. This site is an Archaic age site situated near the Rio Grande, near Laredo, Texas. It was anticipated that an analysis of the phytoliths in these sediments might provide insights into prehistoric plant use as well as information on the paleoenvironment of this region.

Samples examined were selected both because of their strategic provenience and because they came from a variety of settings (i.e., shallow features, deeply buried features, ground stone) that might demonstrate the full spectrum of preservation conditions. Samples selected for analysis came from Feature 14 (a basin hearth), from a deeply buried $(100 \mathrm{cmbs})$ alluvial sample, from beneath a mussel shell, and from two ground stone artifacts (manos, FS\# 4725 and 4726).

The phytolith samples were processed using techniques developed at the Texas A\&M University Palynology Laboratory. The soil samples were quantified (10 grams) and placed in beakers. In the case of the phytolith washes from ground stone, an 80 square centimeter area was selected on the grinding face of the artifact. Here, the adhering soil was removed with distilled water and collected. The grinding face was then rinsed carefully with hydrochloric acid, and then rinsed again with distilled water. As additional residue testing was to be performed on these artifacts, particular care was taken to not contaminate these artifacts.

Next, carbonates were removed with 10 percent hydrochloric acid. The samples were rinsed, screened through 150 micron mesh, and a series of "short spins" was initiated to remove residual hydrochloric acid and to facilitate the removal of clay particles and the smallest of phytoliths. This step is necessary as phytoliths smaller than 2 to 3 microns are rarely identifiable or valuable. Following this step, the samples were sonicated in a Delta D-5 ultrasonic generator for a period of 30 seconds, and several additional short spins were performed. These steps facilitated the removal of most of the remaining fine clays.

The residues were next transferred to glass $100 \mathrm{ml}$ tubes, and Schulze's solution (42 percent nitric acid and potassium chlorate) was added to the samples. The samples were placed in a boiling water bath for several hours until all organic traces had been removed. Next, the samples were centrifuged and rinsed until neutral. Following this treatment, five percent $\mathrm{KOH}$ was added to the residues to remove any additional humates. After additional rinsing in distilled water, the residue was transferred to a $300 \mathrm{ml}$ glass beaker, and the samples were fractionated in a water column. Here, samples were separated into two size categories: three to 25 micron and 25 to 150 micron ranges. After fractionation, the residues were transferred to $15 \mathrm{ml}$ tubes, and the remaining water was removed in preparation for heavy density separation. At this point, zinc bromide (Sp.G. 2.38) was added to the samples, which were then spun at high speeds for about 10 minutes. The lighter phytolith fraction was collected, and the heavy density separation step was repeated, again collecting the lighter phytoliths. 
The phytolith residues were next rinsed and transferred to absolute ethanol for curation. A single drop containing phytoliths was added to a cover slip, and it was then allowed to dry. A drop of Meltmount adhesive (refractive index 1.539) was added to the cover slip, and a permanent slide was then made for each fraction of each sample.

Slides were examined at high magnification (1000x to $1250 \mathrm{x})$ using oil immersion and differential interference contrast settings on a Jenaval compound stereomicroscope.

The analysis of the phytolith samples from site 41WB437 revealed a total loss of all fossil phytoliths from both the archaeological sediments and ground stone samples. Factors influencing fossil phytolith preservation are not completely understood. It is clear that highly oxidizing conditions, such as cycles of wetting and drying, especially when coupled with a high $\mathrm{pH}$ (i.e., limestone substrate), are very destructive to biogenic silica. Clearly, these are the conditions predominating in the site area. However, abundant phytoliths were recovered from sites in nearby Zapata County. There, oxidizing environmental conditions were similar to site 41WB437, but the substrate was sandstone. I have examined phytolith samples from Val Verde County, west of the site area, and have found that phytoliths are not preserved in open-air sediments in limestone regions. Sediments collected in dry caves, however, frequently display excellent phytolith preservation, even if the sediments have extremely high $\mathrm{pH}$ values. Clearly, the limiting factors for phytolith preservation in South and West Texas are the presence of both oxidizing conditions and high $\mathrm{pH}$ values.

A total of five phytolith samples from a variety of locations at site 41WB437 were examined. Analysis revealed that due to extreme oxidizing conditions, coupled with the high $\mathrm{pH}$ of the region, fossil phytoliths were not preserved. These same oxidizing conditions are known to be destructive to fossil pollen as well. It is unfortunate that fossil phytoliths were not preserved in these sediments, as the paleoenvironment of this region is poorly known.

Despite the poor preservation of phytoliths at this site, it is important to continue testing sediments from archaeological sites in South Texas. As little paleoenvironmental data exists for this region, the potential gains from these studies far outweigh the cost of these types of analyses. 
APPENDIX I

Diatom Assessment by Barbara Winsborough 
Intentionally Left Blank 


\title{
MICROPALEONTOLOGICAL ANALYSES OF SEDIMENTS
}

\section{FROM THE LINO SITE (41WB437)}

(Two Reports: July 28, 1998 and October 8, 1998)

\author{
Barbara Winsborough \\ Winsborough Consulting \\ 5701 Bull Creek Road \\ Austin, Texas 78756 \\ (512) 467-1858 \\ bwinsbor@tpoint.net \\ Prepared For \\ Mike Quigg \\ Project Manager \\ Mariah Associates Inc. \\ 3939 Bee Caves Road \\ Suite C-100 \\ Austin, Texas 78746
}


Intentionally Left Blank 
REPORT 1: July 28, 1998

\section{Introduction and Methodology}

Although a previous diatom analysis of sediment from the Lino Site was not productive in finding diatoms in the sediment, there was other material of micropaleontological interest in the cleaned residue, such as dense concentrations of small spherical bodies about one micrometer in diameter, probably the remains of bacteria. In this study, three additional samples (Table 1) were processed and examined for diatoms and any other material that could be of micropaleontological interest.

About $1 \mathrm{cc}$ of sample material was cleaned by boiling in hydrogen peroxide to which nitric acid was then added. After rinsing the acid from the sample, material was mounted on glass slides with Hyrax resin, which provides a refractive index that contrasts with that of silica. Two slides from each sample were scanned at both low and high magnification and any notable material was recorded. Additionally, material from sample two was mounted on slides without any processing to examine the untreated hairs. Comparative material from a sample of ashy soil from a historic site in San Antonio was examined unprocessed and processed for comparison of the nature of the silica grains.

\section{Results and Discussion}

The results (Table 1) show that these samples contain a variety of materials. There are two types of silica in the samples: rounded grains and sharp flakes. The sharp flakes are similar to volcanic ash and may result from the grinding of grain with a mano and metate made of scoria. The rounded silica grains are typical of those that occur in potash. Sample three contains relatively coarser-sized silica grains than the other two samples.

On each slide there are several fibers or hairs that are long, slender filaments with a central core and growth (?) ridges that ring the surface. The hairs are 10 to 17 micrometers in diameter and over 300 micrometers long. They are long (whole?) in the untreated material and broken into short segments in the processed samples. Included as Figures 1 through 5 are photos of these hairs from both treated and untreated material. It has yet to be determined whether these are animal or plant hairs. 


\section{REPORT 2: October 8, 1998}

Diatoms, when present, provide paleoenvironmental information that can complement the input of other disciplines associated with archaeological investigations and provide additional site-specific information. A sediment sample (\#5719-2, $17 \mathrm{~g}$; A-5; 30-40 cmbs; Feature 36; soil from under mollusk shell) from the Lino Site (41WB437) was submitted to Winsborough Consulting to assess the presence/absence of diatoms. Because the sample is from an alluvial deposit of a small creek, and might include other microorganisms, the presence of any biogenic material is reported.

About $1 \mathrm{cc}$ of sample material was processed by boiling in hydrogen peroxide to which nitric acid was then added. After rinsing the acid from the sample, material was mounted on glass slides with Hyrax resin. Two slides were scanned at both low and high magnification, and all recognizable material was recorded.

The results are that there are no diatoms in the sample at all, but there are some other things worthy of note. There is a large number of small clusters of spheres, each cluster about five micrometers in diameter. Each sphere is about a micron or less in diameter and filled with what appears to be iron. These individual spheres are the correct size for bacteria such as iron reducing bacteria associated with the breakdown of organic material. In addition to organic materials there is a substantial amount of ash in the sample, either volcanic ash or otherwise derived. There are no remains of macrophytes, vascular plants, pollen, spores, sponge spicules, protozoans, algal or cyanobacterial filaments. There must have been some nutrient source, however, to support the dense bacterial growth. 
Table I1 Micropaleontological Components in Samples from the Lino Site (41WB437).

\begin{tabular}{|c|c|c|c|c|c|c|}
\hline Sample & Diatoms & Bacteria & $\begin{array}{c}\text { Fibers or } \\
\text { Hairs } \\
\end{array}$ & Silica & Phytoliths & Other \\
\hline $\begin{array}{c}(1) \\
\text { 41WB437- } \\
\text { 769a, } \\
\text { Feature } 14, \\
\text { shot } 1711, \\
3.7 \mathrm{~g}\end{array}$ & none & absent & common & $\begin{array}{l}\text { some sharp } \\
\text { flakes and } \\
\text { rounded } \\
\text { grains }\end{array}$ & none & $\begin{array}{l}\text { stellate plant } \\
\text { hairs, } \\
\text { amorphous } \\
\text { organic } \\
\text { residue }\end{array}$ \\
\hline $\begin{array}{c}(2) \\
41 \mathrm{WB} 437- \\
844 \mathrm{a}, \\
\text { Feature } 13, \\
\text { shot } 1786, \\
3.2 \mathrm{~g}\end{array}$ & none & absent & common & $\begin{array}{l}\text { many sharp } \\
\text { flakes, some } \\
\text { rounded } \\
\text { grains }\end{array}$ & none & $\begin{array}{c}\text { amorphous } \\
\text { organic } \\
\text { residute }\end{array}$ \\
\hline $\begin{array}{c}(3) \\
\text { 41WB437- } \\
914 \mathrm{a}, \\
\text { Feature } 15, \\
\text { shot } 1855, \\
3.0 \mathrm{~g}\end{array}$ & $\begin{array}{l}\text { one corroded } \\
\text { cell of } \\
\text { Hantzschie } \\
\text { amphioxys, a } \\
\text { common soil } \\
\text { species }\end{array}$ & absent & rare & $\begin{array}{l}\text { many sharp } \\
\text { flakes, some } \\
\text { rounded } \\
\text { grainsd }\end{array}$ & $\begin{array}{c}\text { dumbbells } \\
\text { and other } \\
\text { shapes }\end{array}$ & $\begin{array}{c}\text { amorphous } \\
\text { organic } \\
\text { residue }\end{array}$ \\
\hline
\end{tabular}




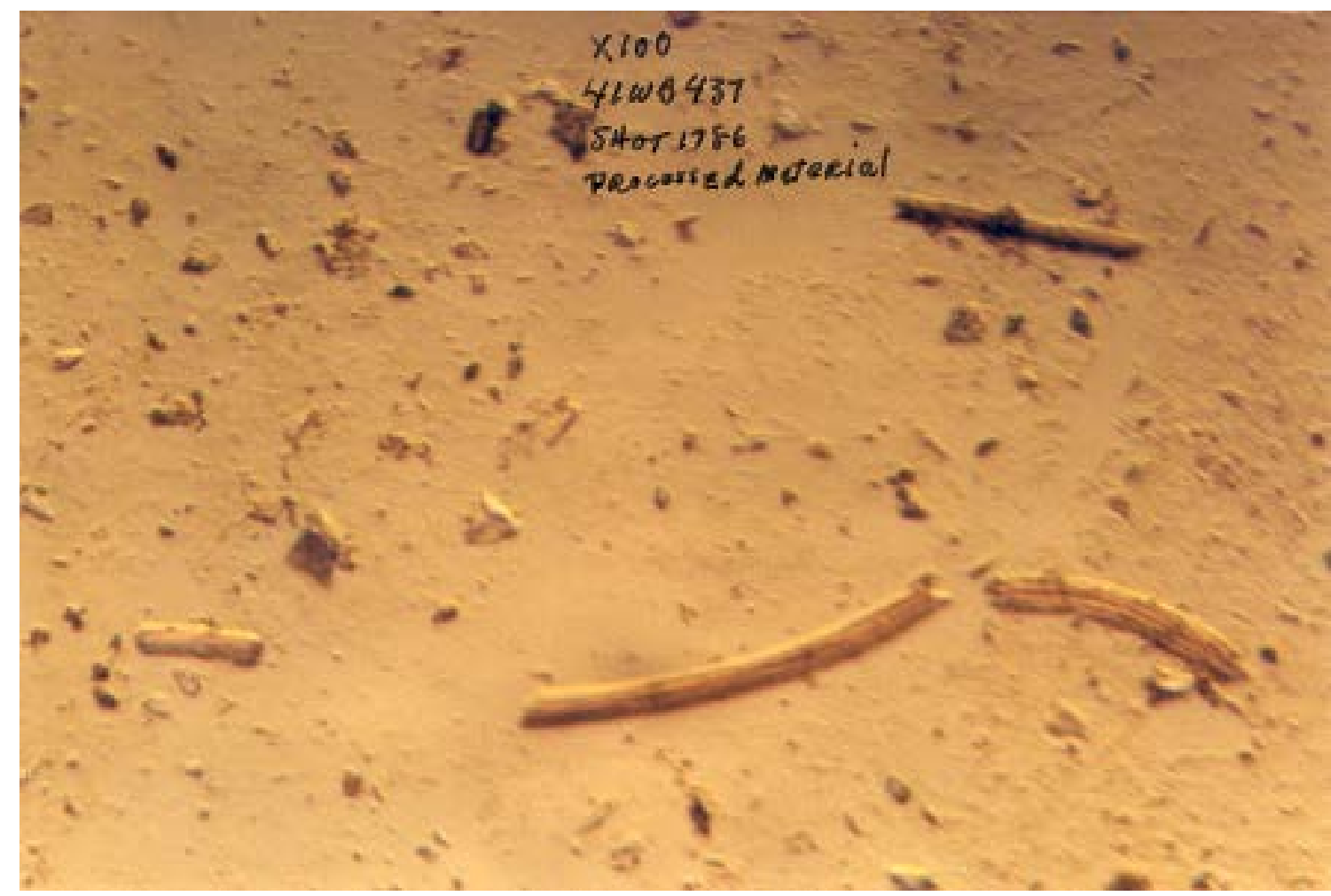

Figure I1 x100 41WB437 Shot 1786 Processed Material.

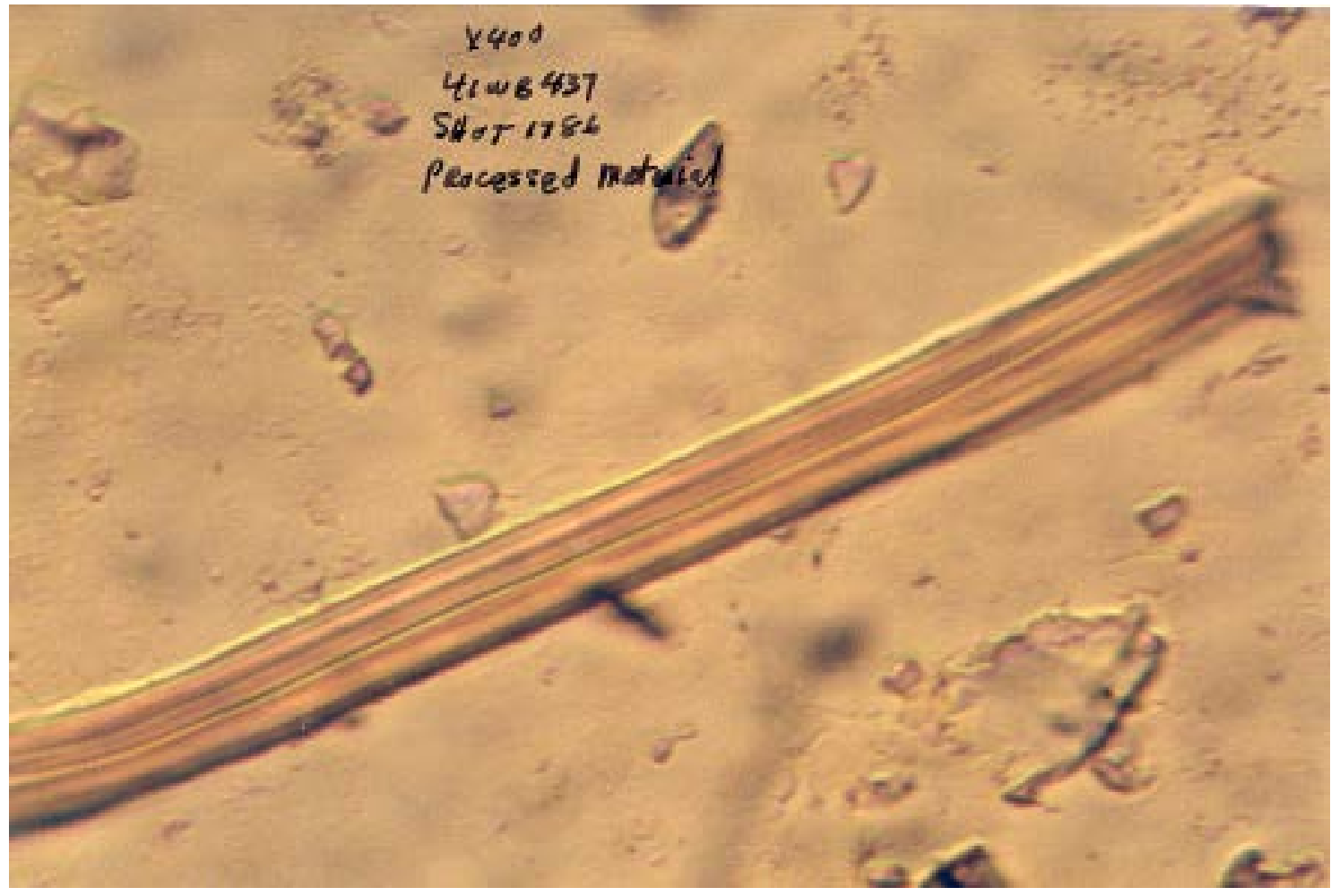

Figure I2 x400 41WB437 Shot 1786 Processed Material. 


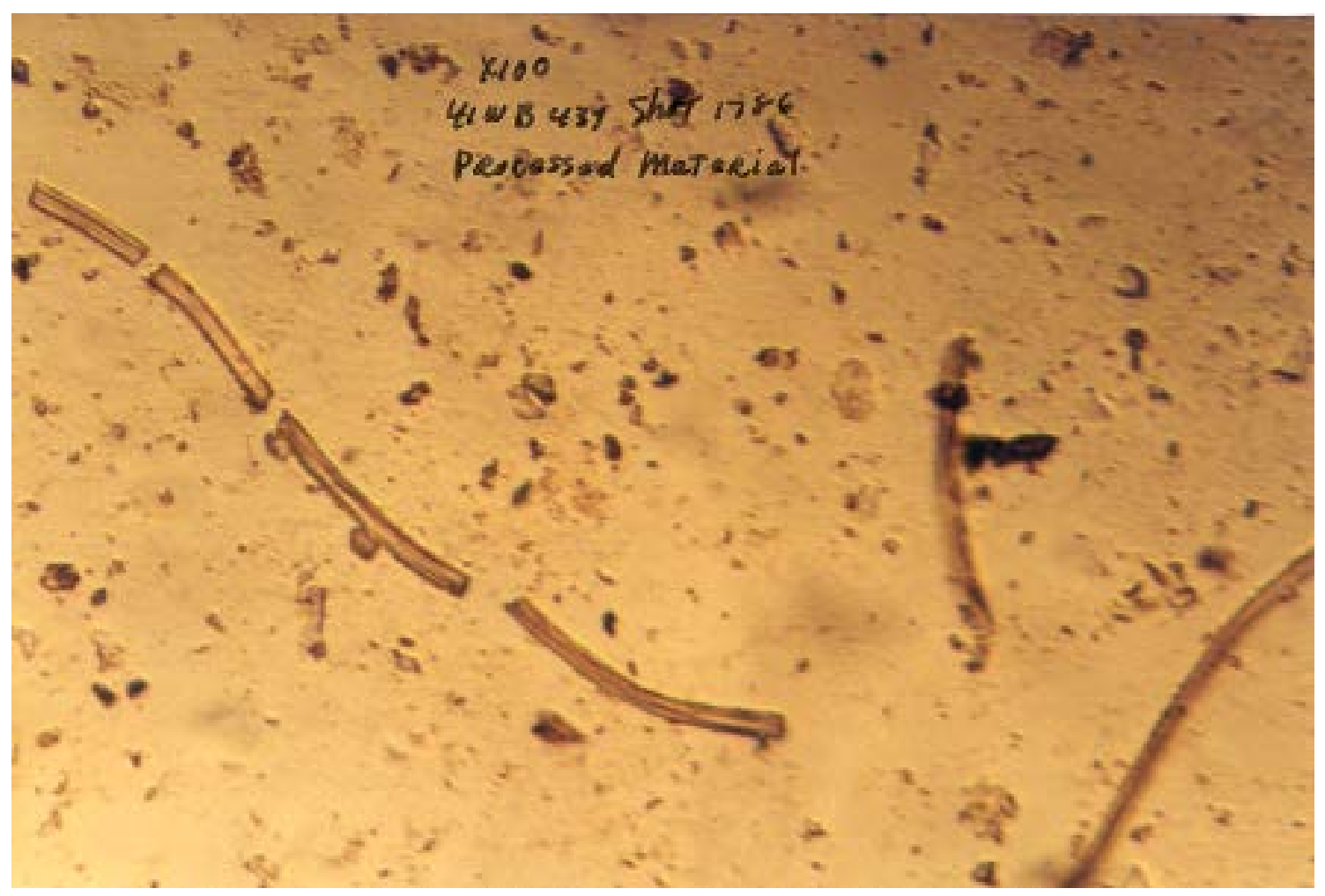

Figure I3 x100 41WB437 Shot 1786 Processed Material.

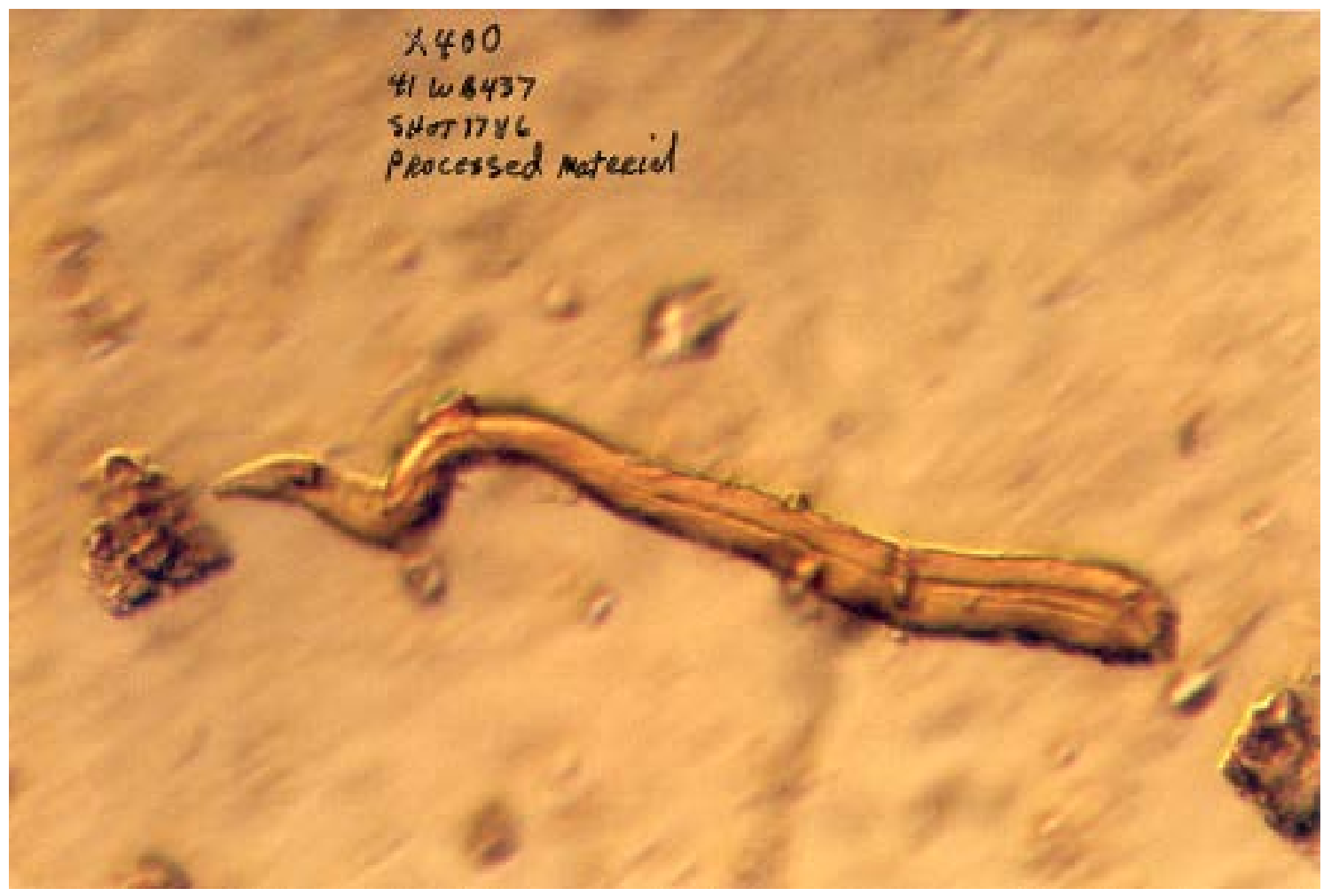

Figure I4 x400 41WB437 Shot 1786 Processed Material. 


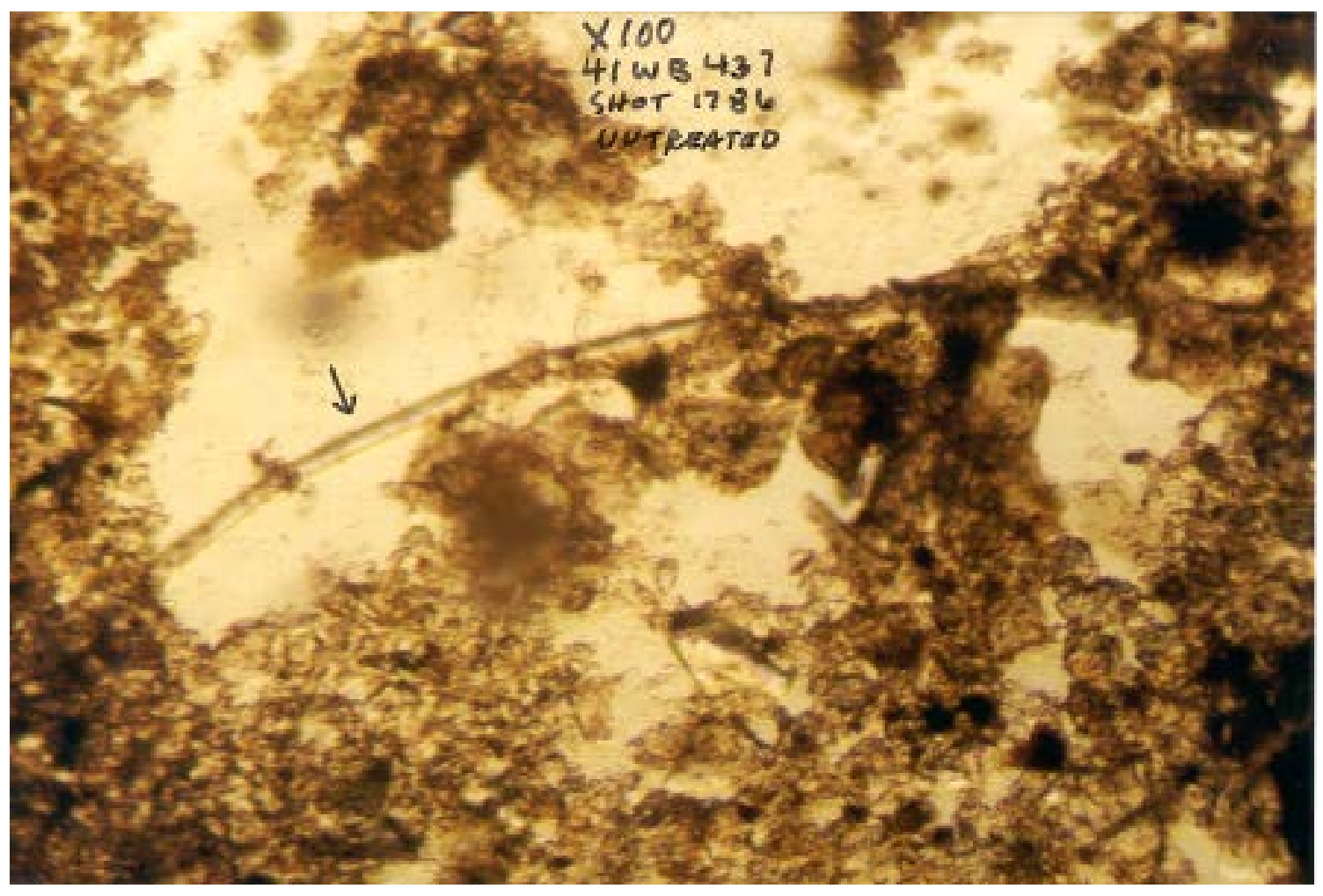

Figure I5 x100 41WB437 Shot 1786 Untreated. 